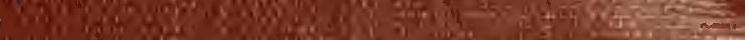

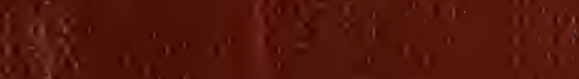
$13 \times x^{2}$
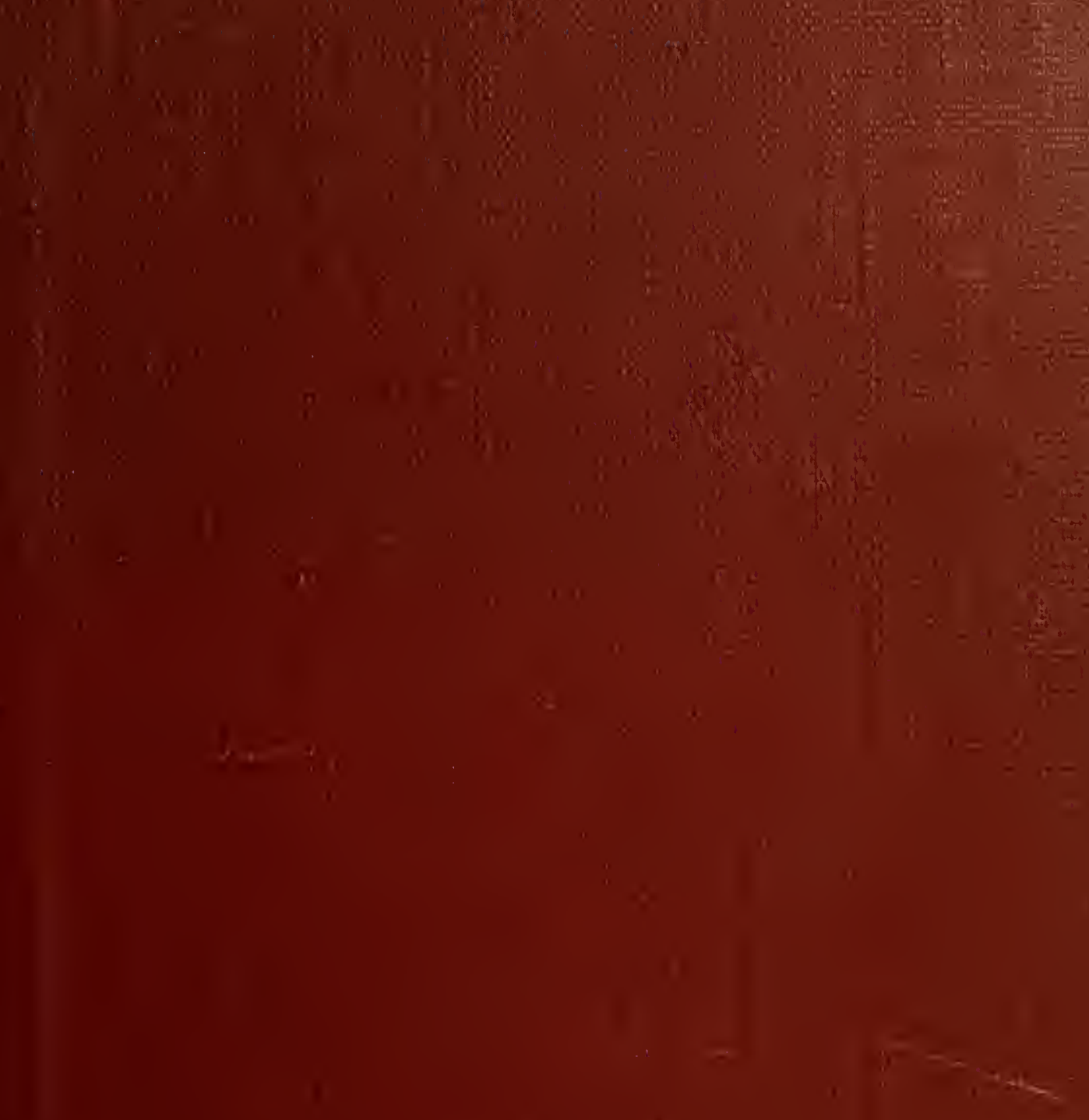

(1.9.

at s.
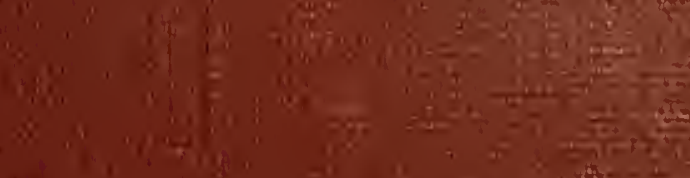


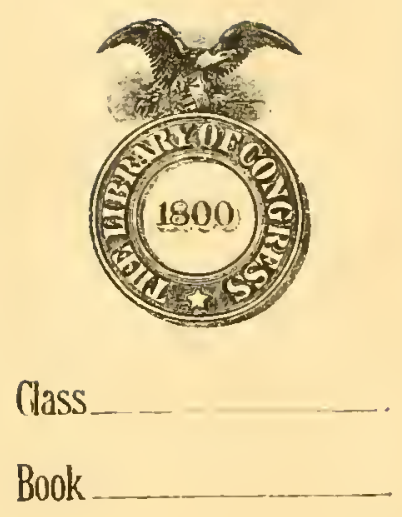

COPYRICHT DEPOSIT 





SPORT WITH GUN AND ROD 



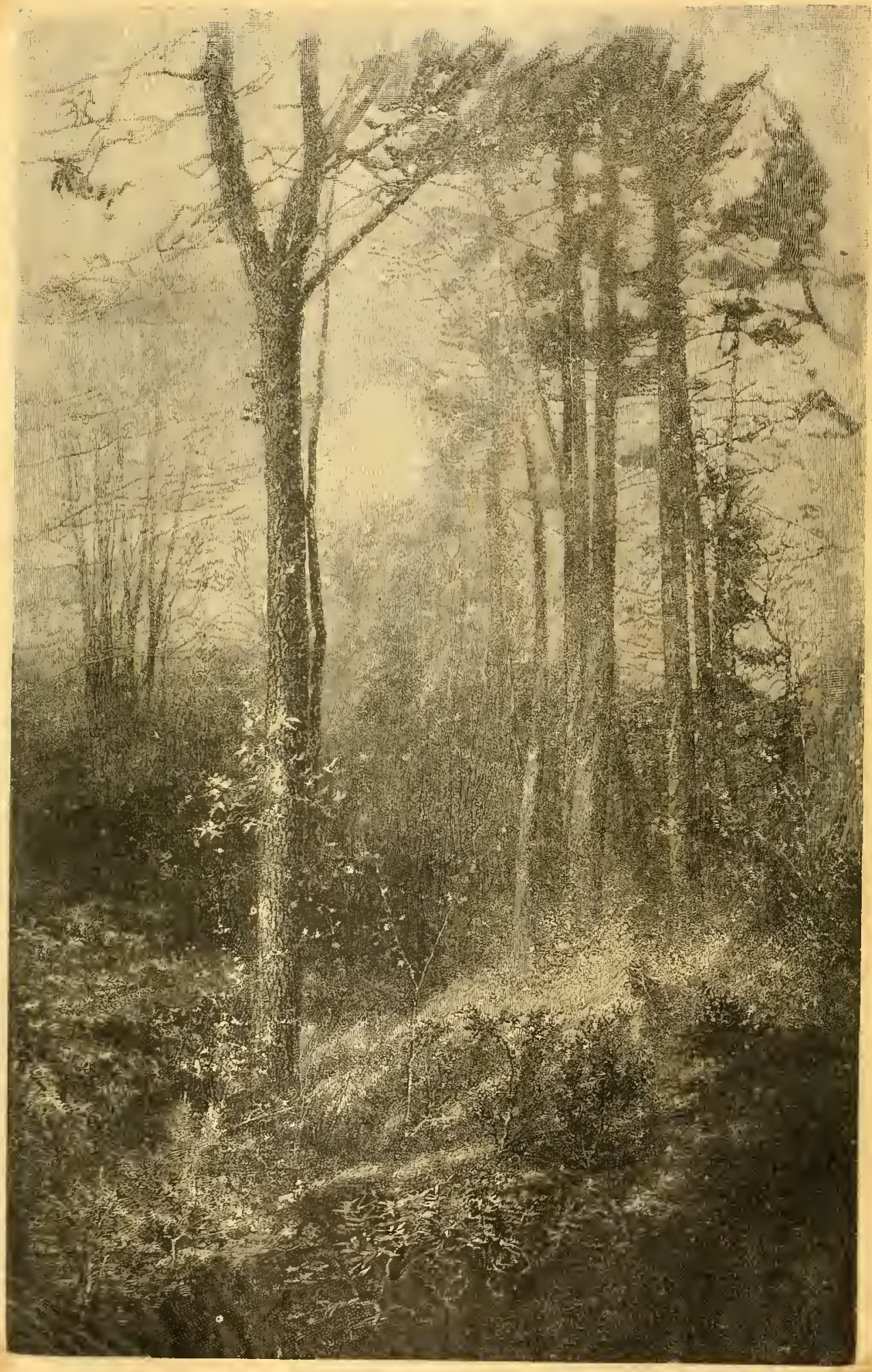




\section{SPORT}

\section{WITH GUN AND ROD}

IN

AMERICAN WOODS AND WATERS

EDITED W

ALFRED M. MAYER

PROFESSOR IN
THE STEYEXS INSTITUTE OF TECHNOLOGY

NEW YORK

THE CENTURY CO 


$$
\begin{aligned}
& =11 \\
& =10
\end{aligned}
$$

Copyright, 1 $1 \tilde{E}_{3}$, wy The Century Co.

$$
-1-2+3: 0
$$

Press of The. L. De Vine \& Co. NEW YORK. 


\section{PREFACE}

T

$\mathrm{HE}$ love of the chase is deeply imbelded in man's nature. During the untold centuries of his sayage condition he followed it of necessity. We now revert to our primitive employment for our pleasure and recreation, pursuing with ardor, sports which often involve much bodily fatigue and always require skill and training. An impulse, often irresistible it seems, leads man away from civilization, from its artificial pleasures and its mechanical life, to the forests, the fields, and the waters, where he may have that frecdom and peace which civilization tenies him. If this be not so, then why is it that the man of alfairs as well as the man of leisure feels again the joy of his youth as he bids farewell to his office or his club, and seeks the solitudes of the woods and the plains? He will meet there some old familiar face in a guide, or fellow-sportsman, and welcome it with the ardor of good-fellowship. He will undergo all sorts of bodily discomforts, - coarse food and rough bed, the wet and the cold, - and yet be happy, because for a little spell he is free; in other words, he has, for the time, lecome a civilized savage. If, with gun and rod, he goes into the recesses of the great woods, and lives there for weeks or months, or mounts his horse and traverses the western plains and mountain passes, relying on his rifle for his subsistence, he is made to realize that there are many things to be learned outside of cities and away from his usual occupations. He will find fool for philosophy in the behavior of his hunting companions: he will see who is manly and unselfish, who endowed with pluck and self-reliance: for three weeks' association with a friend in the wilderness will reveal more of his real character than a clozen years' with him amid the safe retreats and soothing comforts of civilized life. He will learn how few are the real wants of a happy life in the midst of uncivilized nature. His troubles, if he carried any with him, will ranish : time will seem of as little value to him as to the savage. and like all true sportsmen and "honest anglers," he will return to his home with a calmed spirit and a contented mind. 
We shall have attained our object in this book, if the sportsman, as he reads it, feels his lungs expand with the cool, balsam-laden air of the woods; hears the sudrlen whir-r-r of the ruffer grouse on the mountain-side, and feels his nerves grow tense as he agrain stands over his dog and is about to flush the wookcock or snipe; hears the breakers on the rocky coast, as in imagination he makes a long "cast" into the surf; smells the salt marshes, while he hears the cres of the wild fowl and the whistle of the ducks' wings. By its perusal, also, the younger reader may be led to spend his vacations in the enjoyment of sports which are manly and health-giving, which engender selfreliance and good-fellowship, and develop a love for Nature.

Iy connection with this volume was unexpected. Some time ago I suggested to the editor of THE CENTLRY MAGAZINE that the various articles on hunting and angling which had appleared in that periodical should be collected into a book. At the time I made this suggestion, I had no intention or desire to undertake the editing of writings describing the pursuit of game, so varied in habits and haunts that no one person could be expected to have hacl the reyuisite experience, and it was only at the solicitation of the pulishers that I undertook the task. To make the work complete, several papers have been added, some of which are here printed for the first time.

In behalf of the publishers, I wish to acknowledge indebtechess to the courtesy of Kegan Paul \& Co., of London, for the use of the paper on Moose-Hunting in Canada, by the Earl of Dunraven; to Houghton, Mifflin S Co., for the articles contributed by Charles Dudley Wamer and John Burroughs: to Charles Scribner's Sons, for the paper on Bow-shooting by Maurice Thompson, and to James R. Osgood \& Co., for the poem by the same author.

ALFRED M. MAYER.

Maplewuud.

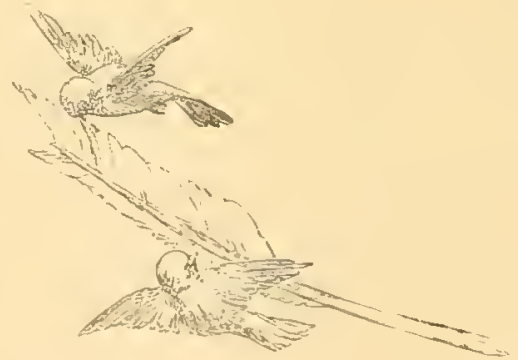




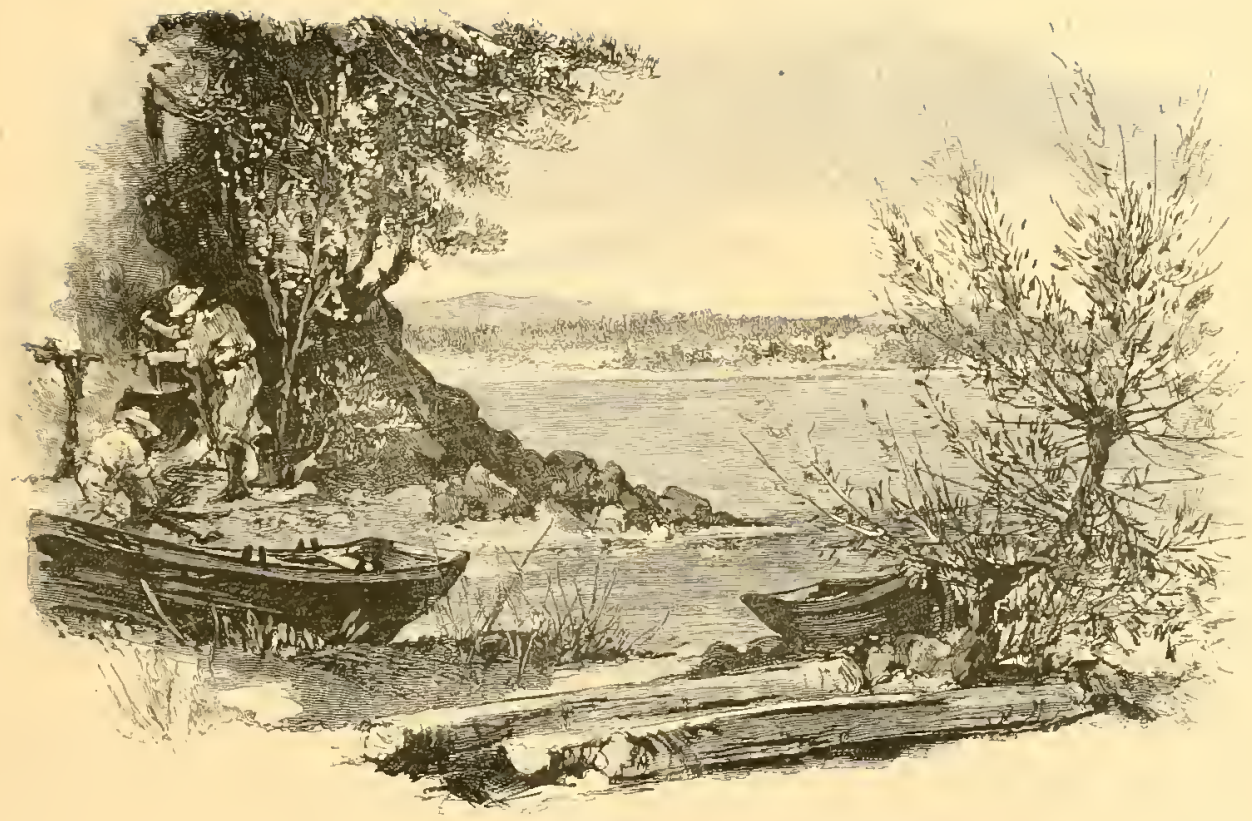




\section{JAPAN PROOFS.}

T1TLES.

IN THE WOOIS

HEAD OF MULE-DEER

HEAD OF FAWN OF ,

MULE-DEER

$\left.\begin{array}{l}\text { Head of Rocky } \\ \text { Mountain Win Sheep }\end{array}\right\}$ James C. Bearl

HEAD OF MUSK-OX

BLACK BASS
BROKE AWAY

'THE MICHIGAN ? GRAYLING

BoT WhITES !
- AT DAWN ?

A Grouse Family

At Sunset

South American ,

Goat-sucker
James C. Beard

Gurcion Trumbull

ARTISTS.

- Engraved direct

I from Nature 1

I. Harrison Mills

II. M. Cary

James C. Beard

James C. Beard

James C. Beard

| Engraved direct |

1 from Nature 1

James C. Beard
ENGRAIERS.

PAGES.

Elbricge Kingsley Frontispiece.

I. Harrison Mills $\begin{gathered}\text { Vignette on } \\ \text { 'litle. }\end{gathered}$

R. A. Müller

Facing $t^{6}$

R. A. Müller

" 280

J. H. E. Whitney

"314

H. Davidson • “ 334

F. S. King

6 494

R. C. Collins

" 612

F. S. King

“6 646

Elbridge Kingsley

.6 $79^{8}$

Frank French

$\cdot \mathrm{S}_{3} \mathrm{C}$ 


\section{FULL-PAGE ILLUSTRATIONS.}

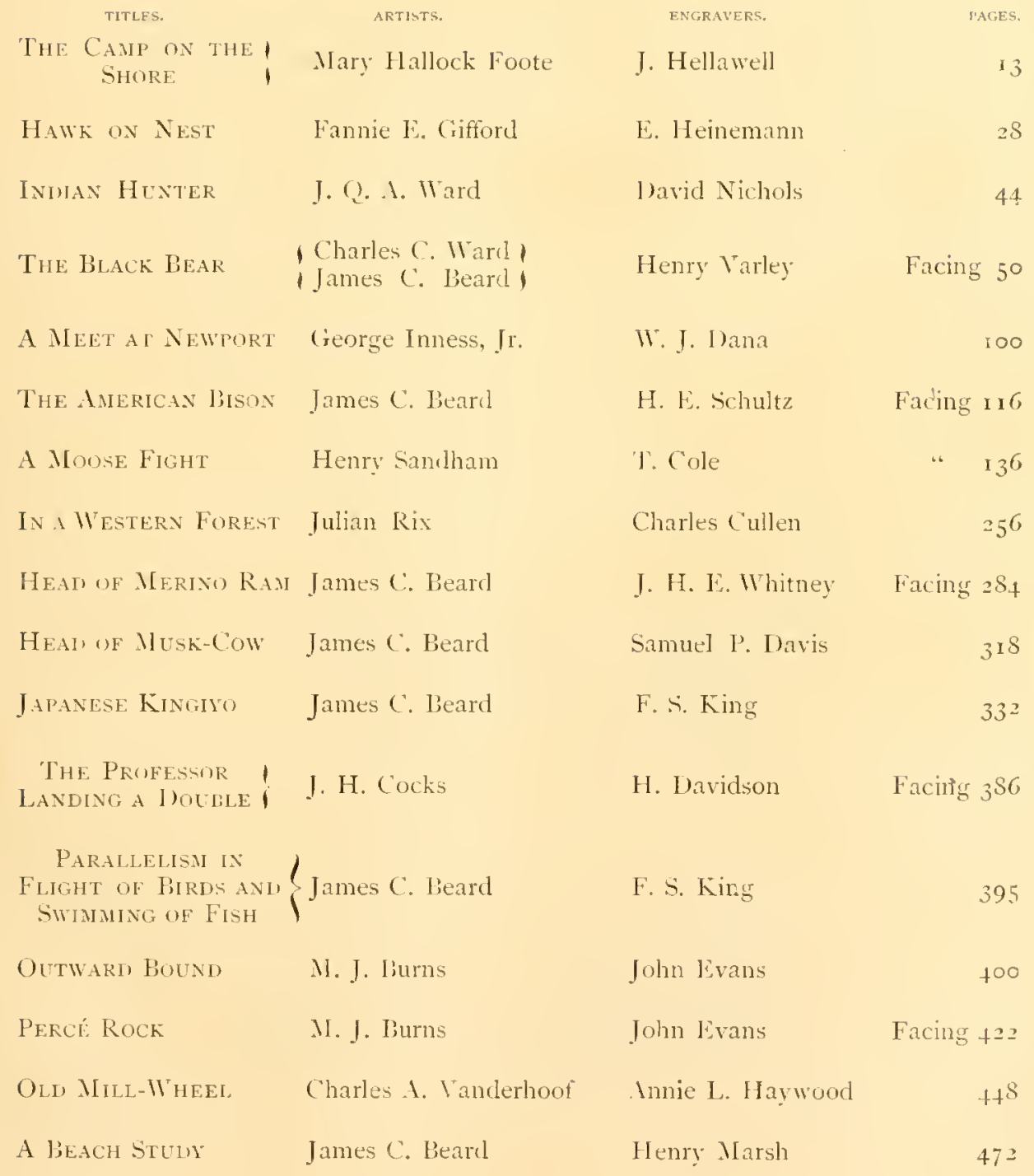


TI LES.

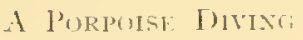

3RT1-1:

| Charles (". Marcil I Dan Beard

Henry Sandham

Stejhen Parrish

Fidelia Bridges

James C. Bearl

EUROPEAX GRAI । PARTRIDGES

Wonacuck and Youni Tames ('. Beard

A Minson's Sime
Fanily

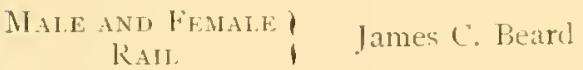

OUT OF DOORS

A BiRT Methey
Roger Riordan

Fidelia Bridges
HWIRIIPER

Elloridge Kingsley

Facin: ${ }^{\prime} S_{2}$

R. C.. Collins

$5+10$

Elbridgre Kingsley

572

F. S. King

610

I. 11. F. Whitney

Facing $66+$

samuel P. I avis

.. 686

Henry Marsh

* 696

J. H. I: Ithitney

.6 $75^{2}$

Henry Marsh

$79^{6}$

F. . . King

SSO

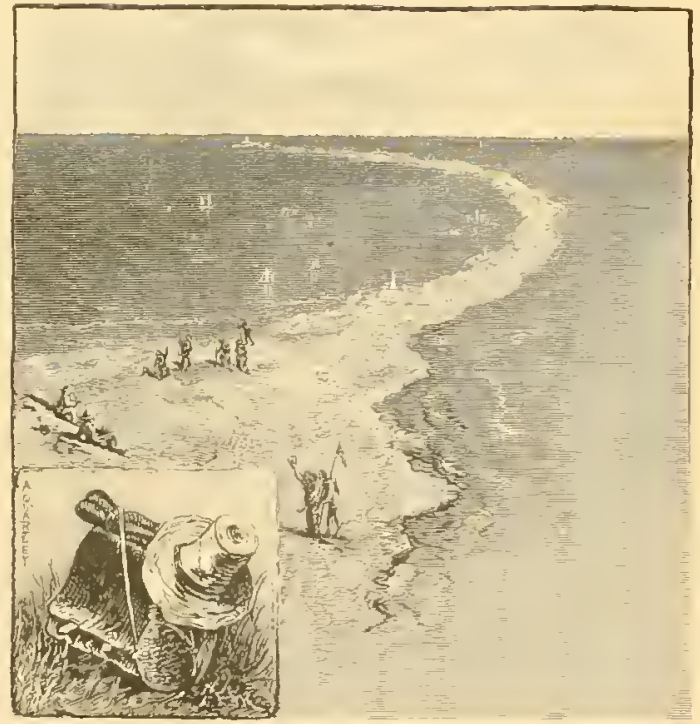




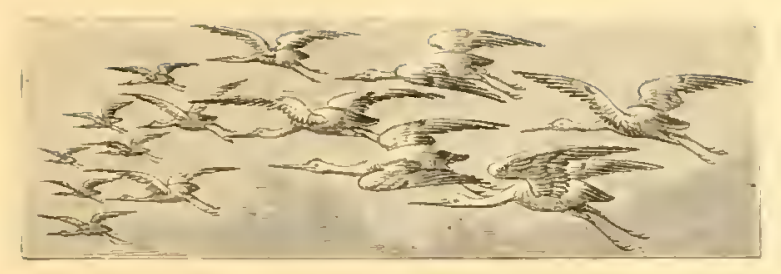

\section{TABLE OF CONTENTS.}

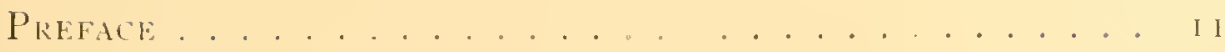

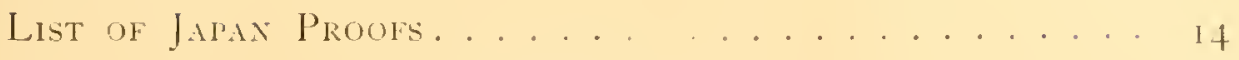

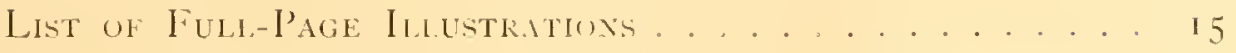

The Prehistoric Huxter......... Alfind M. Mayer. 29 Illustrations: Axe, Spear-head, and Knife of Archæolithic age-Skeleton of the Great Irish Elk-Arrowhearl from Killarney-Spear-head and țrowhead foum? near l'ont-Leroy-Fish-spear, Kents' CavernHarıoon-Point of bone and nephrite - Prehistoric Carving on lvory-Fish-spears, La MadelaineArrowhead from Lake Bienne - Tail-piece.

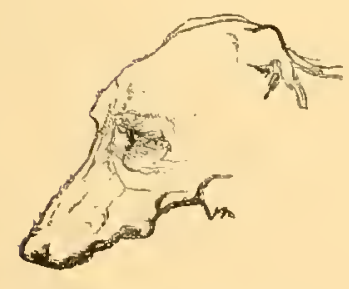

\section{LARGE GAME.}

TIIE BLACK BEAR............. Charles C. Wurd.

Illustrations, from skelches by the author: Head of

Black Bear-Bear and Culs - The Bear Pass. . Jumcs C. Beard. Skull of Black Bear - Fore-paws - Hind-paws - A

Dear-fall Trap . . . . . . . . . . . Charles C. Ward.

The Indian, from a sketch by the author. . . . . . M: Taber.

Sacking a Lumber Camp, from a sketch by the author .

H. P. Share. After Honey - An Aboriginal Hunter - Tail-piece. . . . Dan Bearl. A Feast on a Log. . . . . . . . . . . . . Roger Riondan. 2 
Bear-hunting in the Solth ........ Fames Gordon. 65

Illustrations, from sketches by the author: (1/l Asa Cutting through the Canebrake - Bear Hieroglyphics

- It Bay - The Death - Old Asa in Triumph . . . If: L. Sheppard. In the Forest. . . . . . . . . . . . Granille Perkins. A Flight of Wild Geese (Two engravings). . . . . . James C. Bcarl. A Hunter's Paradise. . . . . . . . . . . Thomas Moran. Tail-piece . . . . . . . . . . . . . S. Church.

Fon-huntixg n New Englaxin... Roziland E. Robinson. Illustrations, from sketches by the author: Headpiece . . . . . . . . . . . . . . Lo Hopkins. "An Honest fox IIust live". . . . . . . . Jormes C. Bectrl. After a Breakfast - "Holed"-_Tantalizing the Dogs . . John $\Pi$ : Bolles. The Dog's Dream - The Start_on the Trail - l'he

Run-way . . . . . . . . . . . . . Alfred Käppes. Calling the Dogs . . . . . . . . . . . Malter Shirlazi. Another Stratagem. . . . . . . . . Pitor Horan. Bearing Home the Brush. . . . . . . . . . . James E. Kelly. A Happy Family-Head of Fox-hound-To Destroy

the Scent . . . . . . . . . . . Ronvland E. Robinson. In November . . . . . . . . . . . . . Jerris NiEnte. Tail-piece. . . . . . . . . . . . . . Henry firver.

A Buffalo-hunt in Northern Mexicu ... . Leze Mallace. io I Illustrations, from sketches by the author: The school of the Lariat-now, Fire:-Tail-piece . . . . . . . . James E. Kelly. The "Мlozo" . . . . . . . . . . . . . II. L. Sheppart. The Patio, from a sketch by the author . . . . . . Tolln II: Bolles. The Start - Our First View of the Herd . . . . . George Inness, Jr. On the Roarl - Juan - Santos - In the Rear Court -

"Ender the Colonnade"-In the Corridor-A Group of Vaqueros - A Maguey Field . . . . . . . Mary Hallock Foote. Head of American Buffalo . . . . . . . . . James C. Beard. The Tangle of Paths. . . . . . . . . . . Lew Hillace.

The Nörti American Cervile. . . George Bird Grinnell. I 29 Illustrations: A Noose Fight. . . . . . . . Fenry Sandham. Barren-ground Caribou. . . . . . . . Charles C. If ard. Head of American Elk-Head of Mule-Inecr. . . . James C. Bearl. Tail-piece. . . . . . . . . . Reger Riordan. 


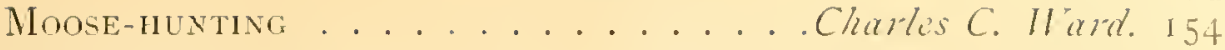

Illustrations, from sketches by the author: Riding clown a

Tree-Moose Family - Mloose-yard--Fire Hunting . . Henry Serndlum.

The Mloose-call . . . . . . . . . . . . . Jomin's E. Kelly.

Moose-Birds . . . . . . . . . . . . . James C. Beart.

Socotoma - Still Hunting-A Moose-hunter's Camp -

The Old Block-House - Stone Medallion . . . Charles C: Marn.

Jay and Cedar Birds. . . . . . . . . . Fütclia Bridges.

The Darkening Pines. Engraved direct from nature. Elbridge Kingsley.

Returning from the Hunt . . . . . . . . . . Hem? Sandham.

Moose-hunting in Cinad. . . . . Earl of Dumrach. I 82

Illustration: Tail-piece. Engraved direct from nature . . Elbridge Kingsley.

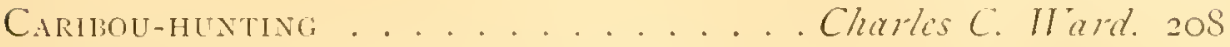

lllustrations, from sketches ly the author: Caribou Barrens - Caribou Crossing a Frozen Lake. . . . . Thomas Moran.

Attacked by a IVolf-Afloat on a Cake of Ice-Bringing in the Caribou-A Good Chance. . . . . . Hemy Samblum.

Woodland Caribou Hoofs - Caribou Migrating - For-

est lirds - Seh-ta-ga-bo- I Shot from Tomah . . . Charles C. Hamt.

Cedar Birds . . . . . . . . . . . Fïdelid Bridges.

Deer-hunting on the de Sabee..... M. Mackay Laffan. 233

Illustrations: $U_{1}$, Saginaw bay-Cam! Lrwin-On

the Au Sable-Deception - Under the Cedars -

Hung Up-A General Surprise-A Torch of the

Au Sable-Sweepers - A Ton and a half of Venison. II. Irackay Laffiry.

A lumber-sled . . . . . . . . . . . . Sol. Eytinge.

Huntisg the Mule-Deer ix Culorado. F. Harrison Mills. 257 lllustrations: from a sketch by the author, "And Tiny"

Said he Thought he Could". . . . . . . . Frederick Diclman. The Fall of the Leader, from a sketch by the author . . George Inness, Ji: Head of the Mule-Deer-"Are you luooking for us?"

- An Attack of Buck Fever-Oslorne and his Dog

- How Tiny Beguiled them-A Pattern in a Net

of Twigs-A Dissolving View . . . . . . . . . Harrison Mills.

On the Grand ................ Thomas Moran.

Tail-piece . . . . . . . . . . . Julian Rix. 
The ITht, Sheep ol the Sierr. . . . . Fohn Murr. 2 So Illustrations, after sketches by the author: Head of Rocky Nountain IVild Sheep - Head of the Merino

Ram (1)omestic) - The Water-ousel . . . . . James C. Fianl. A Feeding-ground . . . . . . . . . . Hurr Fonn. Snow- bound on Mount Shasta - J umping over a Preci-

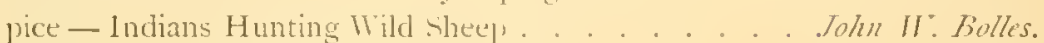
Williamson spuce Tree. . . . . . . . . R. Swain Giffiont. In a sierra Forest. . . . . . . . . Thomas d/uran. Crossing a Canon Stream . . . . . . . George Inness, Jr.

The Antelorl. . . . . . . . George Bird Grinnell. 303 Tail-piece . . . . . . . . . . George Gilison.

A Musk-Ox Hent. ........... Frederick Scha'atha. 313 Illustrations: Head of Musk-0x-llead of Musk-Cow . . James C. Bearl. From sketches by the author: Parseneuk in a Tight

Place-Un the Trail-At Bay . . . . . . . George Inness, Jr. An Esquimo Camp . . . . . . . . . . . II Taber.

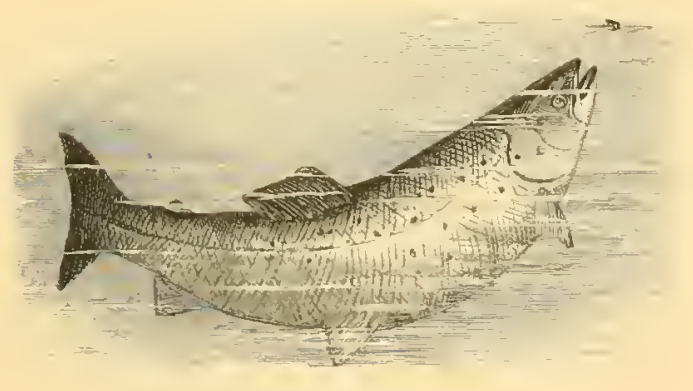

FISH.

The Prinitive Fish-hook ........ Barnet Phillips. 337

Illustrations: Stone Fish-gorge-Bricole (two cuts)-

Double Hook - Prehistoric Forms - Sharpened

Needle used in France-Bronze Fish-hooks-

l loulle Hook, barbed-Alaskan Halibut-hook (two cuts) - Russian Fish-hook-Artificial Stone Shrinp . . . . . . . . . . . Henry II: Troy. An Alaskan Fish-hook . . . . . . . Francis Lathrop. Shell-hooks (five cuts).

Tail-piece . . . . . . . . . . . . . Hopkins. 


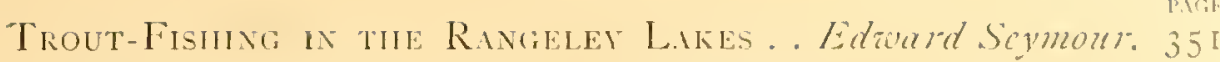

Illustrations: The Junt tion of Rangeley and Kemebago - Allerton Lodge - Stony Batter-Cleft Rock. Camp Kennebago - ['pper l lam .

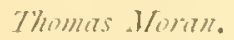
The Interior of the Camp - Telling Fish-stories . . . Charles S. Reinhart. Experiment in Natural Philosophy - Catching a Fivepouncler - Spirit of Mlooselucmaguntic - " Matching" a Seven-pound Trout - lireaking Camp . . . . II: L. Sheptard. Head of l'rout . . . . . . . . . . . F. Runtec. The Dam on Rangeley Stream . . . . . . . . . IT. II. Gibson. The Net Result . . . . . . . . . . . . Foger Rionden. lakes and Heacl Waters of the Androscoggin and Kienneber - Hic Jacet.

Binck Buss Ftshixi........... Fames H. Henshall. 379 Illustrations: Large-mouthed Black Bass - smallmonthed Black Bass. . . . . . . . . . . E. R. Copeland. Near the River. . . . . . . . . . . Thomas Monan. Luke . . . . . . . . . . . . . . . . Josph Pennell. The Professor Landing a louble — In Ideal "Still Fisher". . . . . . . . . . . . H. Cocks.

In tue Hatuts of Breamanis Bass (Poem). Mamrice Thompson. 396

SiLMON-Fisming ................... G. Milkinson. foI

Illustrations: On the Godbout — The Restigouche and Matapediac Rivers - Valley of the liatapediac - in the Harbor of St. John $-A$ Canadian Fishing River - Quebec from the River - A Memory of Quebec - A Half-breed Netting Salmon - River Craft on the St. Lawrence . . . . . . . . . . . Menry Samdham.

Scotch Poacher - Gaffing at lig Salmon Hole- The l'hilosophical Angler - Our English Friend - The Strategic Angler - My First Salmon - The Patient Angler - An Irate Angler - The Countess of Dufferin Pool - Part of the Fun - Equal to the Emergency - A Little o' yer Fly-ile"-Late to Dinner — One Way Fish are Lost. . . . . . . . . . . I: L. Sheppard.

Percé Rock, South of Gaspé Basin - Falls at the Narrows of York River . . . . . . . . Thomas Jloran. Percé Rock ................ . IJ. J. Burns. Misfortune . . . . . . . . . . . Jichacl Il . . . . . . . $2 \mathrm{~A}$ 
The Camp) at Night .

Will H. Lozi.

Sparrows.

Fideliu Bridises.

"Fifty Cents a Hunirerl"

- Tames C. Berard.

The Rise.

\|ilter II. Brackitt.

Canadian Salmon Rivers and ( iaspe Basin.

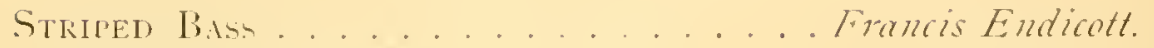

Illustrations: Ciosnoll's lsland, cuttyhunk ......... H. Cocks. The Cluib-house and stands. . . . . Charles At Tanderhoof. On the 1stand. . . . . . . . . . Thomas J/oran. On the Way to the stands - The Light-house at ciay

Head . . . . . . . . . . . . . Tohn II. Bolles.

Fishing from the Stands. . . . . . . . II: Tuther.

Back from the Beach - Tail-piece. . . . . . . . . . S. Church.

Along the ('liff - On the Beach - Along shore. . . R. Sauin Gifford. Indian Head. . . . . . . . . . . . . Aug. IIIIll. The Edge of the Cliffs. . . . . . . Charles S. Reinhart. Crab . . . . . . . . . . . Roger Riordan. Basket Fish. . . . . . . . . . . . . Tancs C. Beard. Montauk Light. . . . . . . . . . . . Malter Minris. Montauk (two cuts) . . . . . . . . F. Mepkinson Smith.

A Good Catch - Striped Bass or kock Fish - Fishing A. I. 1496 .

Porioise-shouting. . . . . . . . . Charles C. Mard.

Ilustrations: Cape Blonidon - Cape split. . . . . Henry Sandham. Sebatis Beaching the Canoe - The Camp at Indian Beach - Trying out Blubber - Spearing a Porpoise - Taking a Porpoise Aboarl - Shooting a Porpoise - Sebatis Idrift.

A Porpoise Diving, from a sketch hy the author. 1\%. I. Burns. On the Wray to the liddies Tail-piece. Dan Bearal. Georse II: Edaurds. R. Sirain Gifford.

Tine Michlgax Grayerixg. Thaddens Norris. Illustrations: The Michigan Grayling. . . . . . . Tames C. Bart. View on the Manistee. . . . . . . . . . Thomas Monan. On the Manistee-sweepers in the Manistee. . M: Mackay Laffan. Tail-piece. Engraved direct from nature. . . . . Elliridge Kingslel. 
Sea-trout Fisming ................ Macdonough. 507

Illustrations: Turning a Rapid - Making a Portage -

The Lake Camp-A pool - The Outlet - Tailpiece . . . . . . . . . . . . . . L. Sheppart.

Long Sault Rapids. . . . . . . . . . . Honry Semdham.

Padilling . . . . . . . . . . . . . . . Itill H. Lone.

Gur Skipper . . . . . . . . . . : IVilliam 11. Chase.

Homeward Bounsl . . . . . . . . . . . R. Stwrin Gifford.

The Custom-house, Guebec . . . . . . F. Hopkinson Smith.

Map of Some Sea-trout Waters - Running the Lachine Rapids-En Route-Clay liank and RapidsCleaning for a ('amp - The Home Camp - Cetting Rearly for Breakfast - Running a Rapisl.

Tie Halcyon in Canala. . . . . . . Fohn Burroughs. $5+1$ 17lustrations: On the St. Lawrence-The Citarlel at

()uebec - A Caleche - A Canadian Interior . . Hcnry Sandham. Hawk and Kinglitd. . . . . . . . . . Fumie E. Giffort. On the Way to the River - Along the Huclson . . Mary Hallock Foote. Lake Memphremagog - In the Thousand Islands.

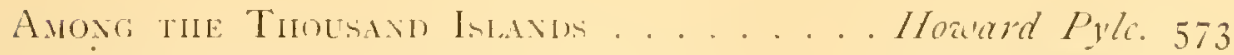

Illustrations: Eagle's Head . . . . . . . . . . Frank B. Hayer. Inlet to the Lake - Head of Creek and lron Sipring . . Thumas Horan. Flowers from lron sturing. . . . . . . . . . . Helema de Kay. The Devil's Oven - llock where the Steamer Pred was IBurned . . . . . . . . . . . . . Henry Farny. General View from Bluff Island - kiver Craft - .1 Fishing Party - Bonnie Castle . . . . . . . . . O. Daridson. Ruins of the Old Fort - Camping Out - Cookings a Camp Dinner - Catching a lluskalonge-Spearing Eels in Eel Bay. . . . . . . . . . . How . . . . . Plille.

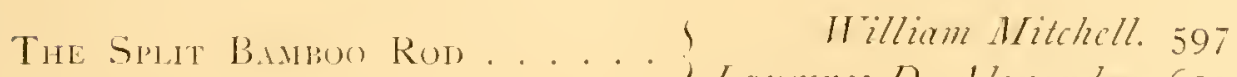
1 Laurence D. Alexander. 601

On the Intention of the Reel. . . . . Alfred M. Hayer. 603

Relation Between the I'eight and Length

of Brook-trout. . . . . . . . . Hodgson Ellis. 605 


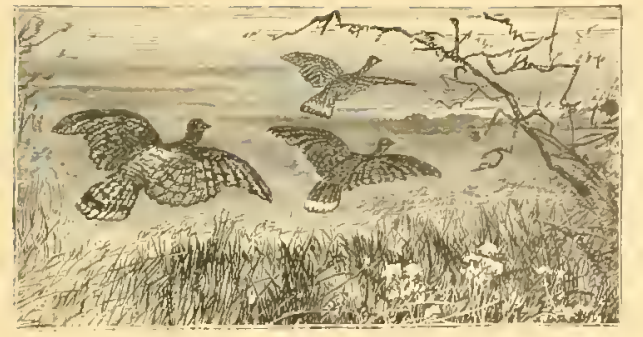

FEATIERED GAME.

Some American Sporting 1)oge

Illustrations: (rreyhound-Leer-houmal

Milliam M. Tilcston. 615 The Neet at the "Harp and lagle"

. Ablotl H. Thaver.

I. Mintswerth Thompson.

Rablut-hunting with Beagles

Jolin II: Bolles.

Fox-hunting in the south

II: L. Sheppard.

Red Irish setter- Blark-and-W'hite setter-fiordon

Setter - Heacl of J'ointer - Black-and-White Pointer

- Liver-and-White Pointer-Cocker Spaniels -

Irish Itater-spaniel. . . . . . . . . . . . . . F. Runge.

Retricving .

Breaking Young I)ogs — I hown (harge. . . . . . . Setmes C. Beard.

Tail-piece . . . . . . . . . . . . . . . Theolore Robinson.

I'ointers of lifty years ago- Eilwarl Laverack -

(iround Plan, liront Elevation, and Side View of

Kennel.

Noktif Americix Cromese. . . . Charles E. Mhitchead. 639 Illustrations: Grouse in Field - Flushing a Covey of

Pinnated Grouse . . . . . . . . . Fidelia Bridises.

The Drumming-log - A Grouse Family - Making

themselves at Home - The lifteenth of August on

the Prairie - (irouse on Nest - Tail-piece. . . . James C. Beard. April-fool . . . . . . . . . Alfied Kappes. A Twitch-u\} - The Coyote Hunting . . . . Jolin W: Bolles. Across the Path . . . . . . . . . . . Sol. Eytinge. $\Lambda$ Prairie Minutet. . . . . . . . H. II: Hcrick. The Gillie Boy . . . . . . . . . . James E. Kelly.

Bob White, the Game Brkn of Auerici. . Alfred M. Mayer. $66_{3}$

Illustrations: European Gray l'artridges_" Bob White!"

- White Bob White-California Valley Partridge or Quail-Bob White and European Quail - Mrs.

Bob White and Family - European Red-legged

Partridges . . . . . . . . . James C. Beard. 
Bob White Egg (from the collection of H. B. Hailey).

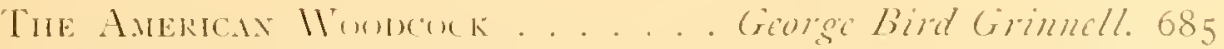
Illustrations: Woodcock and Young . . . . . . . Jetme's C. liculd.

Egg of 1 oodlcock (irom the (ollection of H. li. Bailey).

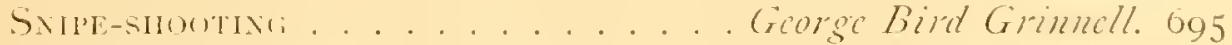

Illustrations: 1 Wilson's snipe Family. . . . . . . .ames C. Berrol.

Egg of Wilson's sinipe from the collection of $\mathrm{H}$. II. Bailey).

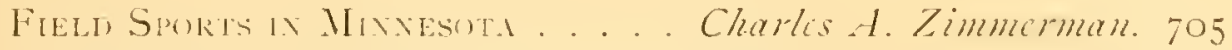
Illustrations, from sketches ly the author: I Close ShotA Side Shot - Bonded Goods in Transit - i " Bond" in Wet Weather -1 Cold IIorning-The Bridge stand-coose-shooting from stubble . . . . . . . . B. Frost.

A Tight Shell-Stopping an Incomer-Wild (reeseWild I)ucks . . . . . . . . . Kobert Blum. Kandyohi P'ass - Canvas-back and Red-Head-Goose

Inecoys . . . . . . . . . Churles A. Zimmerman.

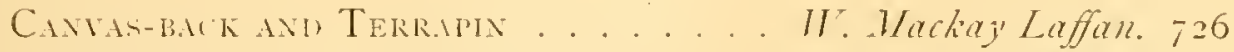
Illustrations: At the Club in Colonial lays. . . . . . . F. B. Mayer. l)iving for Celery (Two ('uts) - The Nefarious Pothunter-Our Quarters--Rowing Down to the Blind - Blind at Biddison's Point-Over the DecoysJoe-Interrupted Pilgrims - A Toll of Ducks Coming In-Dividing the Spoils-In the Larder-Posthumous Migration - 1 Terrapin Ilunter's HomeTerrapin for Three . . . . . . . . M. Mackay Laffan. After a Good Lay's Work . . . . . . . . . . . . . T. Coe.

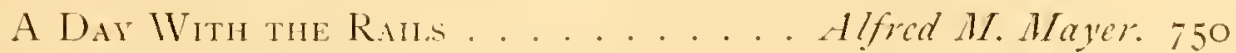
Illustrations: Nale and Female Rail. . . . . . . Jomes C. Biart. A Pusher-Rail-shooting . . . . . . . . . Joseph Pernell. Egg of the Carolina Rail. (From the collection of H. B. Bailey.) 
The Shot-Gux................. Alfred M. Meryer 765

Illustrations: Mechanism of the Match-lock-The

German Wheel-lock-Spanish Flint lock-Manton

Flint-lock - lefaucheux's Breech-loader - Parts of

a Gun-section of Hammerless Breech-action-

Patent Treble Wedge-fast Gun-Parts of an Ordinary liar-lock - Stanton's Rebounding L ock- Hammerless Gun-Breech and Part of the Fore-end of sneider Hammerless ( iun_-sneider's I ouble-grip) Tuplever (im- Three-twist Barrel-Four-twist Barrel - Two spirals Welded logether in the MiddleStamp of London Gunmakers Company-Stamp of the Birmingham Proof-house.

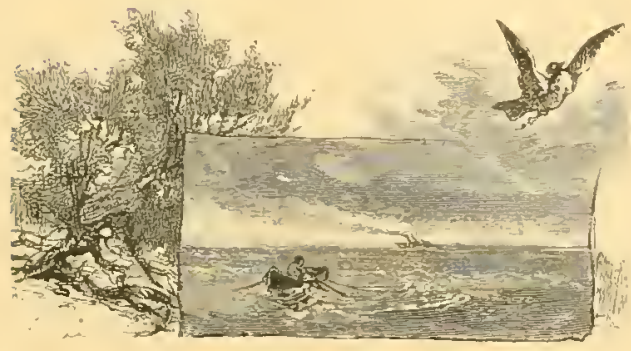

OUT OF DOORS.

Canps ani Tranpe about KTiad . . . . . I rbor ller. Sor

Illustrations: Cross Section of Camp- Fround l'an of Camp-.1 Jumper .

1. L. Holles'.

From sturlies ly F. E. Church: Night View of the

Camp - Ktaaln, from the South Shore - The Trav-

eler-Wood Interior on Mount Turner-A View in

the Great Basin. From studies lyy H. W. Robbins:

The Missing Link-East branch of the Penolscot -

Ktaaln Lake, from the Slide in the Basin . . . . . Thomas Moran.

From a study by l.. We Forest: Ktaain from Creek at

West End of Lake. . . . . . Charles A. Iandcrhoof.

Tail-piece . . . . . . . . . . . . . Elbridge Kingsley.

How I Kilden a Brak....... Charles Dudley Harner. 8zo

A Fignt whet a Trout ...... Charles Dudley Harner. 827 


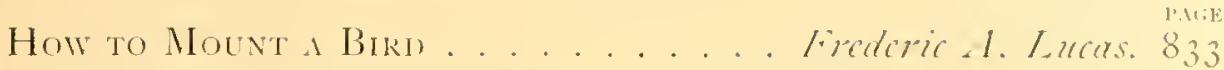

Illustrations: Ready for Work - I Taxiclermist's Sanctum

- South American Croat-suclier-Argus I'heasant -

Great Auk-Scarlet Ibis and Young Crocodile-

Young Waterfowl-Owlet - Heal of Saiga - 1

South American Nonkey-the Bell Bird-Ciolden

Eagle - .1 I ittle Stranger from the Tropics- I

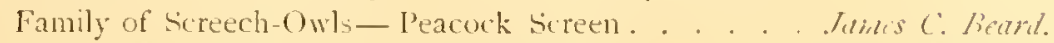

How the Wing is Wired - Bird, Wrapped. . . . . Sirchloric . L. Lucas.

Bow-Shootint ............. Mentice Thompson. 854 Illustrations: Stringing the Bow - I)rawing the bow -

Aiming High . . . . . . . . . . . . . . M: L. Shefperd.

A Good Target . . . . . . . . . . . Finnic E. Gifforl.

What You Aimed At - When the Irrow (sot There-

A Successful Shot - Thunter-Pumper . . . . . . James C. Beard.

Casar. . . . . . . . . . . . Allen C. Redwend.

A Staid Old Farmer . . . . . . . . . Eillridge Kingsley.

Our Camp on Indian River-()n the Edge of the

Woods - Along the Bay - The Haunt of the Heron . . Thomes Aforan.

Waiting for a Shot . . . . . . . . . . Alfird Kappes.

Tail-piece . . . . . . . . . . . . D. Maitland Amstrong.

Bows, Arrows, and Accouterments.

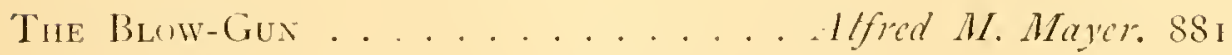

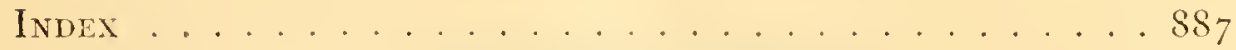

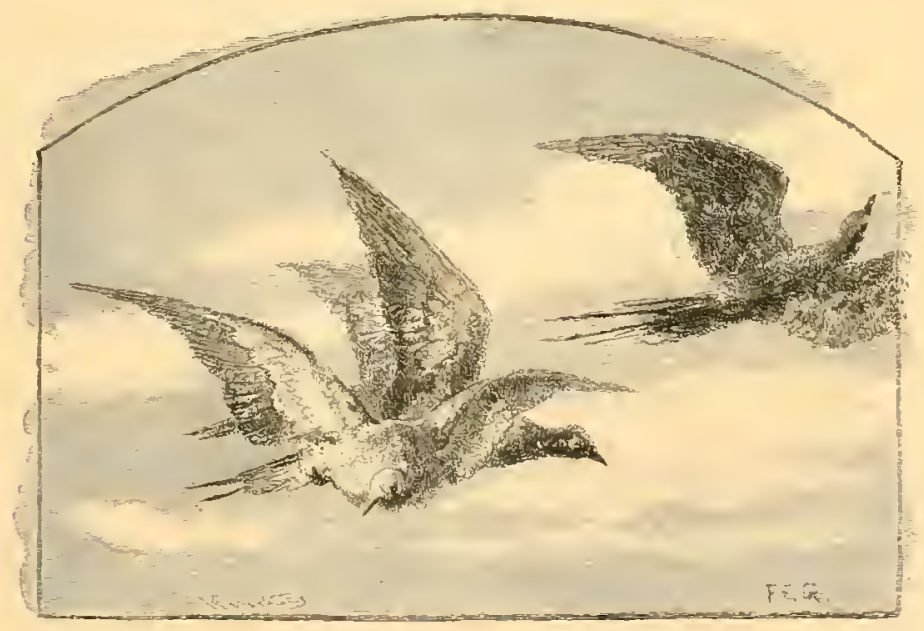




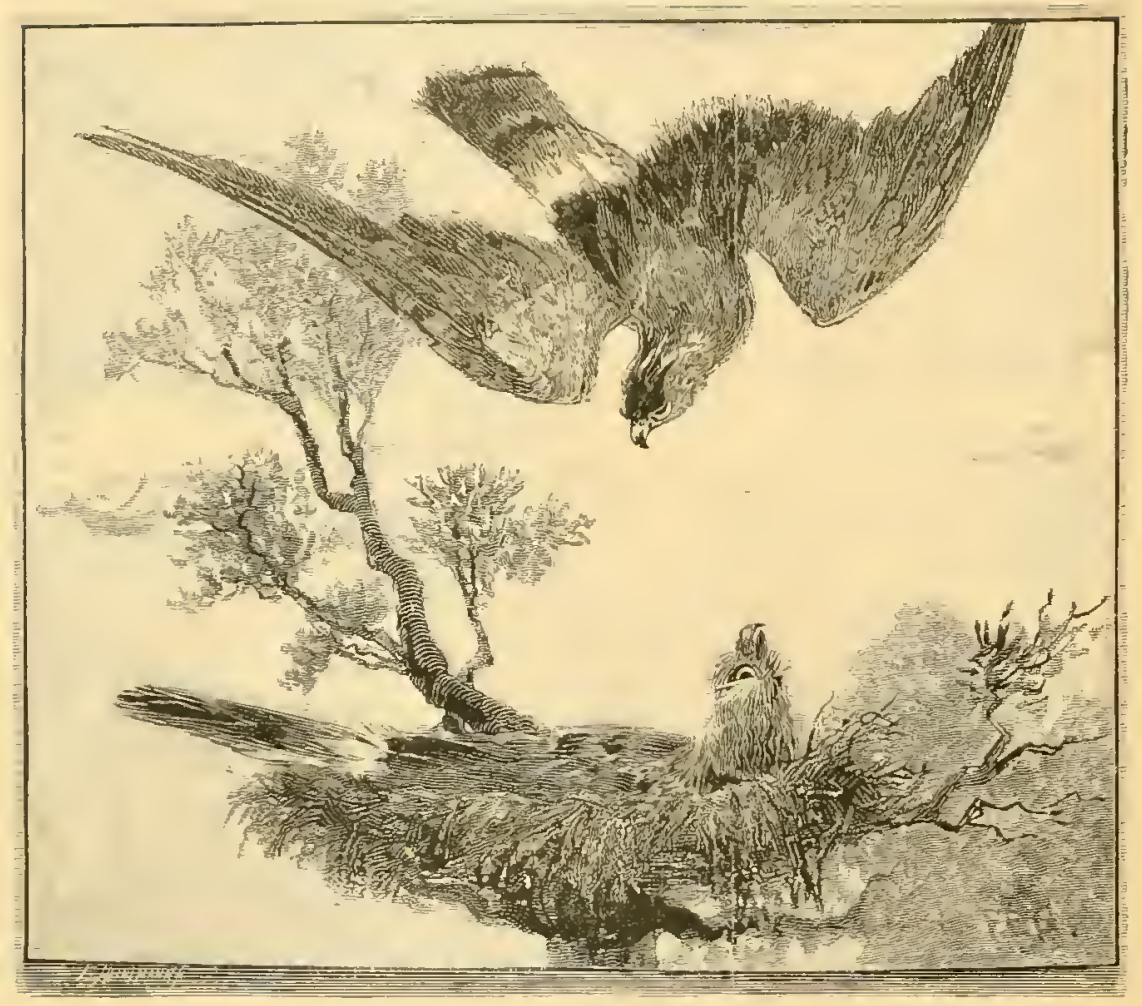




\title{
THE PREHISTORIC HINTER.
}

\author{
BY ALFREI) M. MAYER.
}

$\mathrm{B}$

$Y$ hunting and fishing the prehistoric man obtained his subsistence, and in these pursuits were his greatest pleasures. It may then be of interest to the modern sportsman-who, begging his pardon, is himself a good deal of a savage-to know something of this ancient brother hunter and angler, from whom he has inherited his love of sport and his savage instincts.

Thanks to the wonderful discoveries of quite recent days, we can now give the history of man as a hunter and angler from his first known appearance on earth to the present day. IV e first find him living in the river-valleys of Europe and of this country, his only weapons of the chase being pieces of flint rudely chipped into roughly pointed forms. Thence we track him to the caves in the banks of the rivers, where the fashion of his arms of flint and bone. and his skill in the arts of design and carving, show that he has made a notable step in his progress toward civilization. He is now a fisherman as well as a hunter. Then we see him as a diveller on the shores of the sea and the borders of the fjords, and the dog first appears as man's companion. Thence we trace him to the lakes, where he dwells in wooden houses built on piles. He wears woven fabrics as well as skins, cultivates the soil, and has herds. He fashions stone into elegantly shaped tools and weapons, with highly polished cutting edges. Later, he replaces these with bronze implements cast in stone molds. The dog now shares with man the perils and excitement of the chase and the comforts of his dwelling. The pile-dweller builds canoes or dug-outs, which he paddles over the lake, and he angles with spindles of bone and finely shaped barbed hooks of bronze suspended to lines spun of flax. 
VIe will attempt to give mosaics of these primitive hunters and anglers, formed, it is true, out of rather large stones and of few colors: for the pictures have to he made out of what fragments this prehistoric man has left of his habitations, his feasts, his flint, bone, and bronze implements his sketches and his carvings. Sometimes, however, the arrangement of these fragments will make an almost accurate picture of him. We can clothe him in his garments, adjust his crude ornaments, place in his hands the arms of the chase, and see him as he once pursued the noble gane which everywhere surrounded him.

THE HiNTEK OF THE 1)RIFT.

1)ecp below the surface of the gravel-beds in many river-ralleys in France, England, and various other parts of the world are found stone axes, spear-heads and knives of flint, rudely chipped into shape by races of men who were the first hunters of whom we have any record. The records these inunters have left are these stone implements and their own bones, which are found side by side

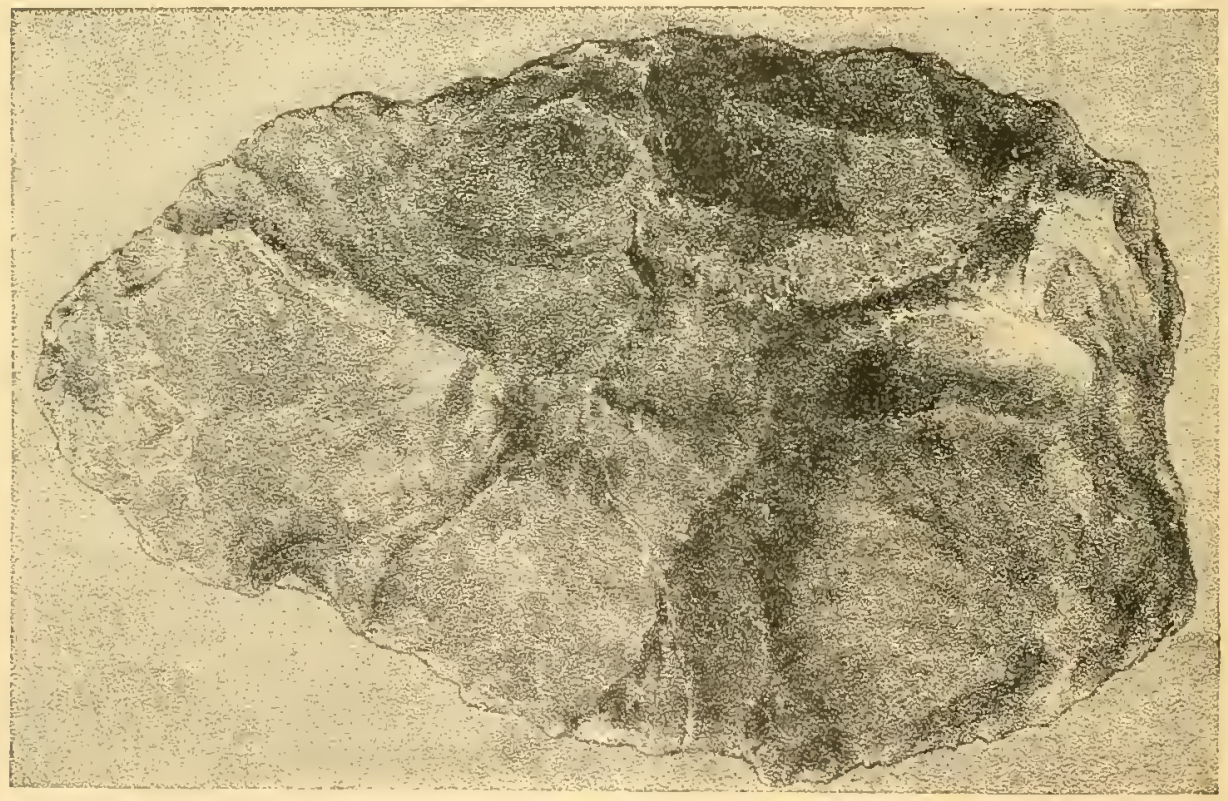

AXE OF ARCHEULITHIC ACE FOTND AT A DEPTH OF TEN FFET IN THE GRAVEL-BEDS OF THE DILUVIUS AT AIULIN-QLIGNON, NEAR ABBEFILIE, VALLEY OF THF SOMMEFROM THE COLLECTIUN OF ALFRED M. MAYER. 


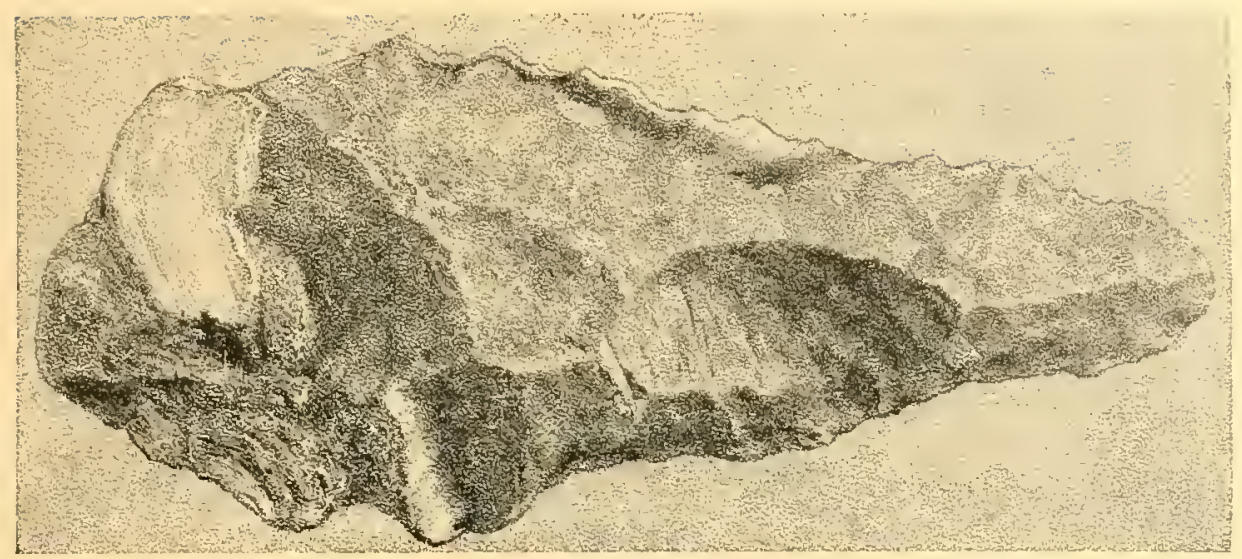

SPEAR-HEAD FOUND AT SAME PLACE AS AXE-FROM COLLECTION OF ALFRED M. MAVER.

with the bones of the animals they slew, and whose flesh was probably their only food.

These gravel-beds, forming what is called river-drift, are of great age. Lyell is of opinion that the chipped-flint implements and the bones found in the drift of the river Somme, in France, are at least one hundred thousand years old; while others hold that two hundred and fifty thousand years have elapsed since these ancient men hunted with their rude arms such extinct animals as the great Irish elk, the mammoth, the urus, and the cave bear. With their stone axes and fint spears they brought down the noble game, and skinned and cut it up with their flint knives.

The gigantic Irish elk, which stood ten feet in height and carried magnificent antlers which spread eleven feet from tip to tip; the urus, which disappeared in historic times, and which was described by" Cesar as "nearly equal to the elephant in bulk, but in color, shape. and kind resembling a bull "; the cave bear, longer than our grizzly: the cave lion; the hyena; a woolly-haired rhinoceros; a hippopotamus; the mammoth; the aurochs, or bison; the musk-ox; the wild horse; these were the animals hunted by these most ancient of prehistoric men. They have all passed away, except the aurochs, which the Russian Government has saved from extermination by strictly guarding them in the forests of Lithuania, and the muskox, which, however, now lives in the arctic regions and is seldom seen below the parallel of sixty-eight. The rest are only known to us from their bones, except the mammoth, which has 


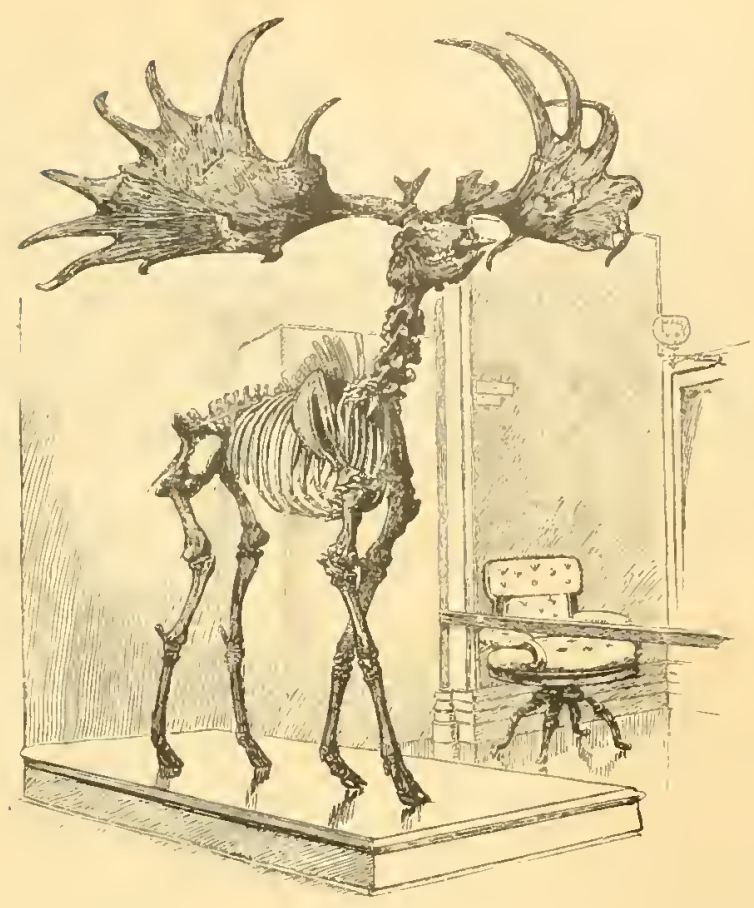

SKFI.ETON OF IIIE GREAT IRISH ELK-IN THE NEW YORK MLSFLL OF NATURAI. HISTORY.

been found in the flesh, imbedded in the arctic ice of siberia, where a few have been preserved by refrigeration during untold ages.

It is not difficult to make a sketch of this ancient hunter. IVe see him clad in skins. He is armed with a stone axe fastened to a long handle, a long-shafted flint-tipped spear, and a sharp flint knife. Thus equipped, the hunter of the drift set out in pursuit of game which in size and numbers exceeled any now existing. IVe can imagrine a company of these men craftily approaching a herd of aurochs, or wild horses, selecting one for their prey, and then, with the stealthy approach of the tiger, drawing near till with sudden spring they felled the animal to the ground with blows of their tomahawks or thrusts of their lances; or we see them speeding over the snow, giving chase to the huge mammoth, the wild urus, or to the swift elk, till these animals, succumbing to the superior endurance of man to fatigue and hunger, allow the hunters to surround them, and the game falls, pierced with flint lances or stunned with the blows of stone axes. 
I here recall the narration of a friend of mine, an honest hunter and trapper of northern Maine. His rifle became useless when far away from his home-camp, and short of food, he came upon the tracks of a large bull-moose. On his snow-shoes he followed these tracks till night, when he slept in the hollow he scooped out

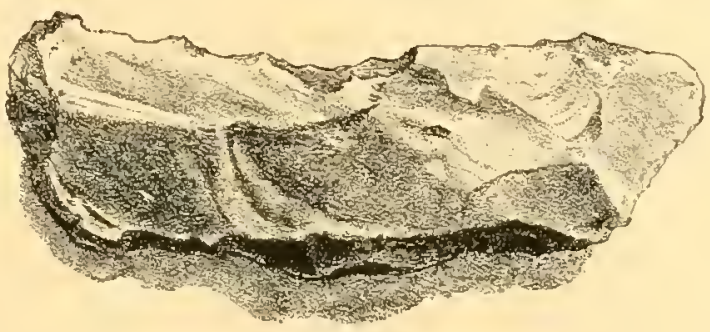

KNIFE FOUNI) IT S.ME I'LACE AS AXE AND SPEAR-HEAD - COLLECTION OF ALFRED M. MAYER.

between two fallen trees. At break of day, he was up and speeding on the snow after his game. In the afternoon, he first caught sight of the moose. He had nothing with which to attack the huge beast but a pocket-knife. With this he cut down a sapling birch and tied the knife to it in such manner that the blade could not close upon the handle. He only stopped a moment in the chase to cut down the sapling, trimming it of its branches and tying to it the knife while he was scudding over the snow. Overtaking the moose and using his extemporized lance, he gave him a severe stab in the throat. The bull at once charged him; but the hunter was prepared for this, and escaped the danger by quickly stepping behind a tree. After several repetitions of this manouvre the moose became exhausted from loss of blood and desperation, and fell at last, a victim to the blade of a pocket-knife in the hands of a man, because he was his superior in endurance.

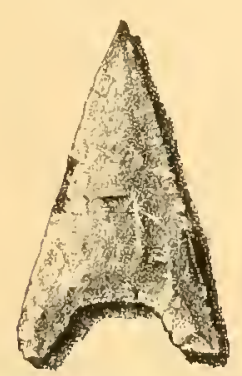

ARROWHEAL FROM KIL I.IRNEY, IREIANDCOLLECTION OF AL FRED M. MAYER.

While he told his story, I pictured to myself the man of the drift armed with a similar weapon in his sharp flint spear, and chasing the great lrish elk over the crust of the snow-clad hills of Europe.

After my friend had slain the moose, he set out in search of a fellow-trapper who would help him carry the meat to camp and share it with him; but before he left the moose he turned him on his back, and with lumps of snow propped up his legs, so that if a storm should occur in his absence the 


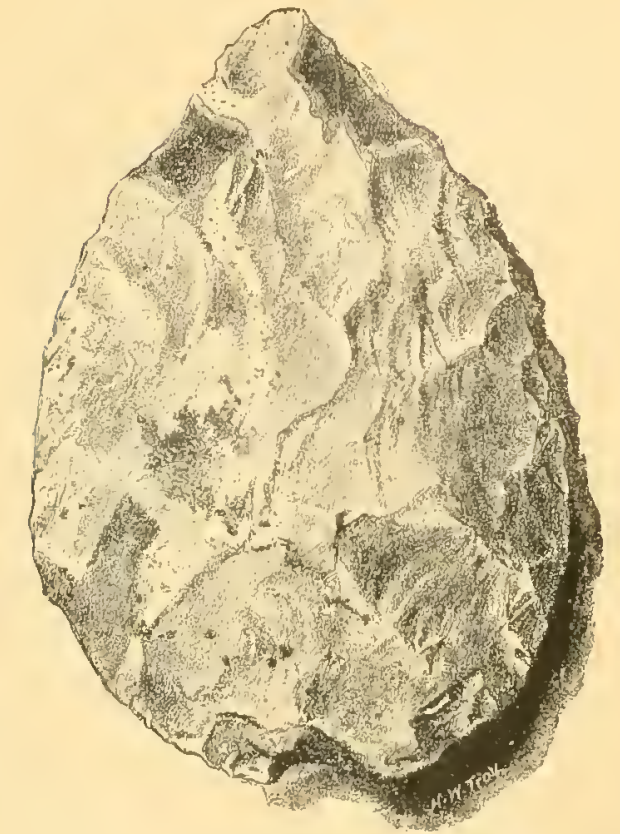

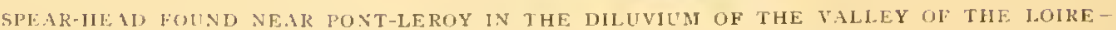
FROM THE COLLECTION OF AIFRED M. MAYER.

moose woukl not be lost to sight in the snow. This is a usual practice with hunters, and it is not improbable that the same plan was practiced by the cave-men; for in one of their sketches of a group of reindeer, three are on their backs. One in particular, with stiffened legs in the air, is not merely a sketch made on the surface of the piece of antler in a reversed position, a fact which is at once evident when we examine the pose of the head, neck, and legs with the drawing turned upside down.

WTe may reasonably suppose that yet another plan of hunting was practiced by these prehistoric men. In the chase of the mammoth or the aurochs, one of these creatures would sometimes be surrounded by the hunters and driven over the brow of a precipice, an experience which would be likely to suggest the use of pitfalls.

Flint axes, spears, and knives were the only arms of the chase used by the men of the drift, for no arrowhead, nor any kind of fishing implement or harpoon, has been found in the drift. On finding the arrowhead, we infer the use of the bow. This invention does not appear till the period of the cave-dwellers - a more recent date, yet far removed in time from ours. How man, armed only with the lance and the

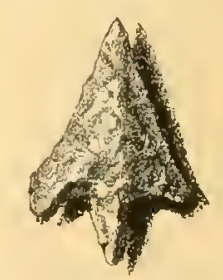

ARROWHEAD FOUND NEAR PONT-LEROY ALFRED M. MAYER. 
stone tomahawk, could approach near enough to kill the swift-footed animals of the drift period, is explained by the fact that wild animals and birds do not naturally regard man as their enemy till he has taught them differently by attacking and wounding them. How often has the sportsman in the recesses of the Maine woods seen the ruffed grouse, only a few feet distant, walking leisurely across his path; while in cultivated sections of our country he is the most wary of birds, often disappointing the sportsman by springing up before him many yards beyond gun-shot. Also the squirrels, and even the deer, in regions where they have never been molested, do not exhibit that extreme fear of man which is usually attributed to them as part of their nature. It is also to be remembered that during the period of the drift, man must have been few in number compared with the game which he pursued, so that it took a long time before the animals over an extended area became aware that he was an enemy more dangerous than his size and appearance had led them at first to infer.

But as the game became aware of this fact, man had to devise weapons which could be projected from the hunter to the now more wary and more distant game, and the necessity for such weapons led to the invention of the bow and arrow, the sling, the bola, the boomerang, and the blow-gun.

Even in our own day's we have seen the change in the range of firearms advance with the increase of wariness in the game of the IVest. This education of animals in the knowledge of man's killing power is also especially notable in the difficulty of now approaching the wild turkey, compared with the manner in which it could be killed during the early period of the history of this country.

\section{The Cale-dwelling Hunter and Fisherman.}

The men of the drift were sueceeded by the men of the caves,so called because they used these natural shelters as dwellings. The flint and bone implements of these men, and the relics of their feasts, are found in the caves of Germany, Switzerland, Belgium, and England; but especially notable are the caves of the valleys of the rivers Dordogne and Vézère, in France. 
In the hardened beds of these cares are found flint and bone implements, and sketches and carrings on bones, which show that the men of the caves were much more advanced than the men of the drift. They hunted the same game, but it appears that the manmoth and great elk had now diminished in numbers, and that the herds of reindeer had so increased that this period in the history of prehistoric man is often called the reincleer period.

To the flint axes, spears, and knives of the drift-men, the cavedweller had added the arrow and bow and fish-harpoons, the heads of which were skillfully and with great labor cut with fint-flakes out of the horn and bone of the reindeer. Some of these harpoons are armed with barbs along their sides; others are formed of lanceshaped pieces of bone, broad and hollow at their bases, showing that these were probably placed on the end of a shaft, and connected therewith by a long cord. On striking the fish the head of the harpoon would separate from the shaft. and the fish could be played and landed by the cord.

Mr. Phillips has shown, in his chapter on "The Primitive Fishhook," that the cave-dwellers probably used a flint-flake, or splinter, in a manner similar to the baited needle used in these days in "sniggling" for eels and pike. A similar angling implement, made of bone, has been found among the relics of the pile-dwellers in the Swiss lakes, and our Indians of Frenchman's Bay, Naine, seem to have used a like angling tool. According to Dr. Keller ("Lakedwellings of Switzerland and other parts of Europe"), the sniggler yet survives in Switzerland, where it is used for catching wild clucks.

The fish-bones and carvings found in the caves show that their inhabitants speared or caught the salmon, trout, pike, and carp.

Though whistles made of the foot-bone of the reindeer, with a hole in one sicke near the bottom of the cavity, have been found in the caves, yet they were not used as dog-calls, for the relics of the caves do not show that they had this animal as assistant in the chase and companion and protector. By blowing into one of these whistles,

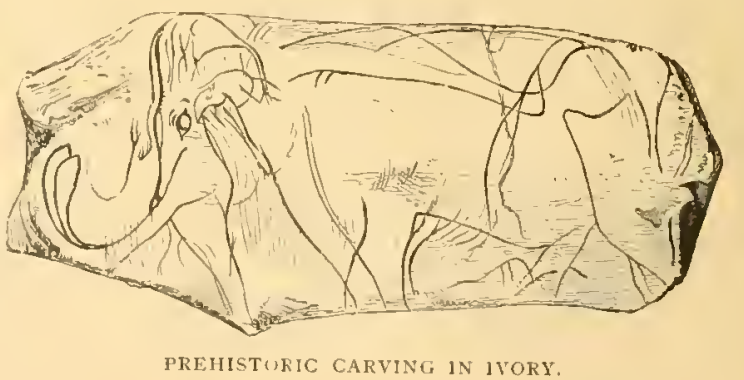


Armed with their bows, and lances and arrows tipped with flint, and carrying at their sides poignards of reindeer horn, with beautifully carved handles, the men of the caves set out in pursuit of the urus, the wild horse, and the reindeer; and if such formidable beasts as the mammoth, the cave-bear, or lion came in their way, they did not hesitate to give them battle. In one of the caves have been found several incisors of the cave-bear and the lion, on which (with flint-flakes) are admirably clepicted various denizens of the forest, the stream, and the sea. These teeth are perforated at their roots, and no doubt were once strung in a necklace to adorn some ancient Nimrod, mighty among those who dwelt in cares.

The bones of the larger animals, like the mammoth and woolly rhinoceros, are rare in the caves. This is easily accounted for. The hunters, after bringing down such large game, would, after the fatigue and excitement of such a great hunt, make a feast on the spot where the huge victim fell, and cutting up the carcass with their flint knives, they would carry what they could to the caves for their wives and little ones. "Vre can picture to ourselves," says Mr. Dawkins ("Early Man in Britain"), "the camp around the carcass, and the fires kindled not merely to cook the flesh, but to keep away the beasts of prey attracted by the scent of blood. The tribe assembled around, and the dark trunks of the oaks or Scotch firs lighted up by the blaze, with hyenas lurking in the background, are worthy of the brush of a future Rembrandt."

\section{The Hunter ani Fishermin of the Sel-shore and the Fjord.}

The arctic climate in which the men of the river-drift and the cave-dwellers lived slowly gave place to a climate more like that of our own age. During this climatic change, the mammoth, the Irish elk, the great bear and cave-lion disappeared, while the reindeer, musk-ox, chamois and ibex either slowly migrated to arctic regions or moved to alpine heights where they could have the cold suited to their natures.

Man changed his habits with the change of climate. He appears now as a dweller on the shores of the sea and an inhabitant of huts built on piles driven into the bottom of lakes. Living near and on the water, he becomes an angler as well as hunter. 
Along the shores of the Danish island of Zealand and the fjords of Jutland are found vast deposits of shells, the remains of feasts. Some of these shell-heaps are a thousand feet long and nearly two hundred feet in width. They are formed of the shells of the oyster, cockle, mussel, and periwinkle. Among these are found the bones of ducks, swans, and geese, of the great penguin, or auk, and of the large grouse known as the capercailzie (Tetrao urogallus.) "This bird, no longer found in Denmark, though still inhabiting the forests of Germany, deserves special mention. In spring it feeds chiefly on the buds of the pine, a kind of tree not growing naturally at present in Denmark, but very common during the stone age, as has been ascertained by the examination of Danish peat bogs. Thus it would seem that the disappearance of the pine from Denmark caused the capercailzie to leave that country." Bones of the sparrow are never found in these shell-heaps. (Happy people!)

The ducks, geese, and swans which these fowlers hunted they may have killed in a manner similar to that described, as follows, by Col. W. H. Gilder in "Among the Esquimos with Schwatka" ("Scribner's Monthly," vol. 22, p. 81 ):

"A most novel and interesting method of bird-catching is practiced during the spring and early summer, while the ducks and geese are molting and unable to fly. The Esquimo puts his frak- that is, his seal-skin canoe-on his head, tike an immense hat, and repairs to the big lake, or the sea-side, where he has seen the helpless birds swimming and feeding in the water. Here he launches his frail bark, and when seated, which is not always accomplished without a ducking, takes his double-bladed oar in his hands, and at once starts in pursuit of the game. Before him, on his $k y a k$, where he can seize it at the propermoment, lies his duck-spear, together with other implements of the chase. Cautiously approaching the featherless flock, he sometimes gets quite near before his presence is observed; but even then, before he is within striking distance, there is a great spluttering in the water, as the band scatters in every direction, vainly beating the water with the curious looking stumps that soon will wear their plumage and once more do duty as wings. Some dive below the surface and come up a great way off, and always just where you are not looking for them; but as the flock takes alarm, the hunter dashes forward, feeling the necessity for speed rather than for caution. $\mathrm{He}$ is soon within fifteen or twenty feet of the struggling mass, and, seizing a curiouslooking spear, with three barbs of unequal length, he poises it for a moment in the air. and then hurls it with unerring aim at the devoted bird, impaling it with a sharpened iron or bone spike in the center of the barbs. The handle of the spear is of wood, and floats on the surface of the water, so that the hunter can recover his weapon and the game at his leisure." 
From the existence in these shell-heaps, or "kitchen-middens," of the bones of the cod, herring, flounder, and eel, we may infer that these fishermen had boats, made like the Esquimo $k y a k$, of sealskins; or, more probably, they used dug-outs, hollowed by the action of fire and the cuts of their stone axes and gouges. In these they ventured on the sea to take these fish. They also hunted the stag, the roe, the wild boar, urus, wolf, fox, lynx, beaver, seal, and otter, for the bones of these animals are found in the kitchen-middens, split lengthwise with flint tools, whose marks are seen on them. They thus extracted the marrow from the bones and the brain from the skulls. The bones of the hare are wanting. Perhaps, like the Laplanders of our day, they had superstitious notions concerning this animal which prevented them from slaying him.

The bones of the animals of the kitchen-middens are gnawed dog-fashion, showing that the dog now first appears as the companion of man. He was also man's victim, for his skull is often found split open so that his brain could be eaten. Let us give these people the credit of supposing that they sacrificed one of their own household only on great ceremonial occasions, as is the case with our Indians.

\section{The Hunter and Angler of the Lakes.}

Far more interesting than the remains in the kitchen-middens are the relics found at the bottom of the lakes of Switzerland, Germany, France, and Italy. During the winter of $18_{54}$, the water in the Swiss lakes sank to a very low level, and gave the dwellers along the shore the opportunity of adding to their lands by building walls along the low water-line. During these constructions at Meilen, on Lake Zurich, stone, bronze, and bone implements and fragments of pottery were brought to light. The tops of piles were also found, and this led to the discovery of the habitations of ancient men. They lived in dwellings built on piles, somewhat after the manner of savages in Venezuela and in some Polynesian and Asiatic Islands. Similar dwellings are inhabited by certain African tribes in Dahomey and in Lake Mohrya. Even in our own country there is a lacustrine village at St. Malo Pass, near Lake Borgne, Louisiana, where dwell Malay fishermen from the Philippine Islands.*

$$
\text { * In "Harper's Weekly," MIarch 3i, I883. }
$$


The houses forming the villages of the European lake-dwellers were constructed of a framework of wood, interwoven with withes and encased in mud. The roofs were thatched, and a hole in the roof let out the smoke, which arose from slabs of stone on which they built their fires. Mlany of these houses, of rectangular and circular forms, were erected on one large platform, of two or three acres in area, supported by the piles. A narrow causeway, often two thousand yards and more in length, led from the village to the shore, arrowheAd from piLe-dwellthus giving them protection from hostile tribes ING IN LARE BIENNE, SWITZER-
ALFRED MOA AYALR. and from the attacks of ferocious beasts.

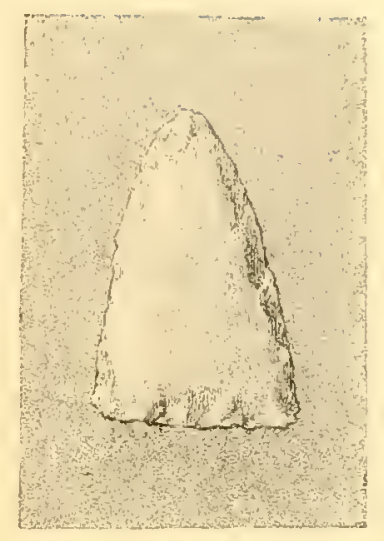

In some of the smaller lakes, mounds were formed of sticks, trunks of trees, stones and loam, with piles driven in their midst to give stability to this foundation. The dwellings on these mounds, with their interwoven withes and encasement of mud, must have appeared like huge beaver-houses. Probably the beaver was their first instructor in lacustrine architecture.

From the relics of these people, we can quite accurately reproduce their life. They clothed themselves in skins and fabrics woven of flax, and were armed with axes-no longer roughly chipped, but now handsomely formed and polished-mounted in sockets of elk horn, which were fastened to wooden handles. They carried bows made of yew, and arrows and spears armed with neatly shaped, sharp flints which were fastened to the shafts with asphalt and firm wrappings of the tendons of the stag. 1t is probable that they were dexterous in the use of the sling. They constructed dug-outs, in which they paddled over the lakes, and angled from them with their bone snigglers, and hooks made of the tusks of the wild boar for the great lake trout and the huge pike. They also fished with nets woven of flax.

During a later period in their history, bronze was introduced, and then their arms became more effective and more elegant in form, although similar to the same weapons previously made of stone and bone. The greatest advance the use of bronze produced was in their angling tools, for their hooks of bronze are nearly as perfect in 
form and proportion as those used by the anglers of our own day, as is seen from an inspection of the bronze hook depicted in Mr. Phillips's chapter on "The Prehistoric Fish-hook."

While the aged men, women, and children were employed in forming weapons, canoes, agricultural tools, pottery, or in weaving cloths and nets, the men set out over the causeway, - some to lead their focks to pasture and guard them from the wolves and bears, while others, taking to the mountains and the dells, hunted the elk, the stag, the urus, the bison, the roe-deer, the wild boar, and the brown bear; while others devoted their time to trapping the fox and the beaver. The hare they did not chase, although they were accompanied by dogrs. Indeed, the dog is now first seen in the history of prehistoric man as a companion, whose friendship, intelligence, and moral qualities were so highly appreciated by these hunters that they would not partake of his flesh. The skull of the dog is found unbroken among the relics at the bottom of the lakes.

"When evening draws near, smoke begins to rise from the huts, where the women are baking and cooking, for the men who have been hunting in the woods will soon return, armed with spear and bow, and loaded with the game killed by them. Those who have spent the day in fishing guide their boats homeward; field laborers, returning from the cultivated patches along the shore, are seen to wend their way toward the bridge, driving before them the lowing cattle which were permitted to graze on the land during day-time, and are now to be stabled for the night among the huts, safe from the attacks of wolf and bear." **

Whence the lake-dwellers came, what language they spoke, and when they first built their lacustrine dwellings, are unanswered questions. We know that men lived on these pile-dwellings many centuries before the discovery of bronze. At some stations, only stone implements are found; at others, bronze and iron arms and tools overlie those of stone, showing that these places were the sites of dwellings during the many ages which must have elapsed from the neolithic, or recent stone age, through the bronze to the iron age.

Among the coins found in the relics of the pile-dwellings at Marin is one of Claudius, which goes to show that in Switzerland the lake-

* "Early Man in Europe," by Charles Rau. A work giving, in the most interesting manner, an account of discoveries relating to prehistoric times. 
dwellers were living in their lacustrine villages as late as the first century after Christ; yet neither Casar nor Pliny mentions these curious dwellings.

The habitations in the eastern lakes seem to belong more to the stone age, while those in the west belong both to the age of stone and of bronze.

Among these bronze implements we find axes, swords, daggers, spear and arrow heads, knives, chisels, sickles, and fish-hooks, which are as well adapted by their forms to their uses as any implements of the period of bronze. With the exception of the cross-bow, which they do not appear to have used, their arms were as effective as any which preceded the period when gunpowder introduced entirely different types of weapons.

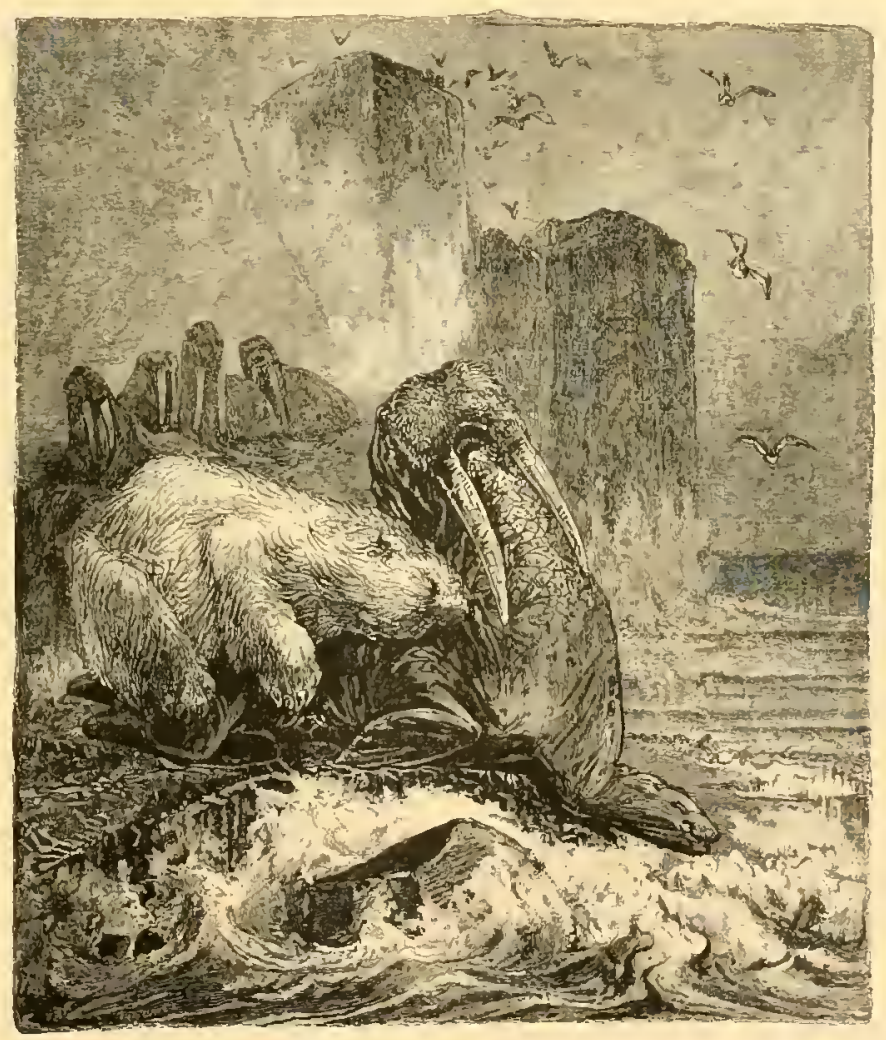




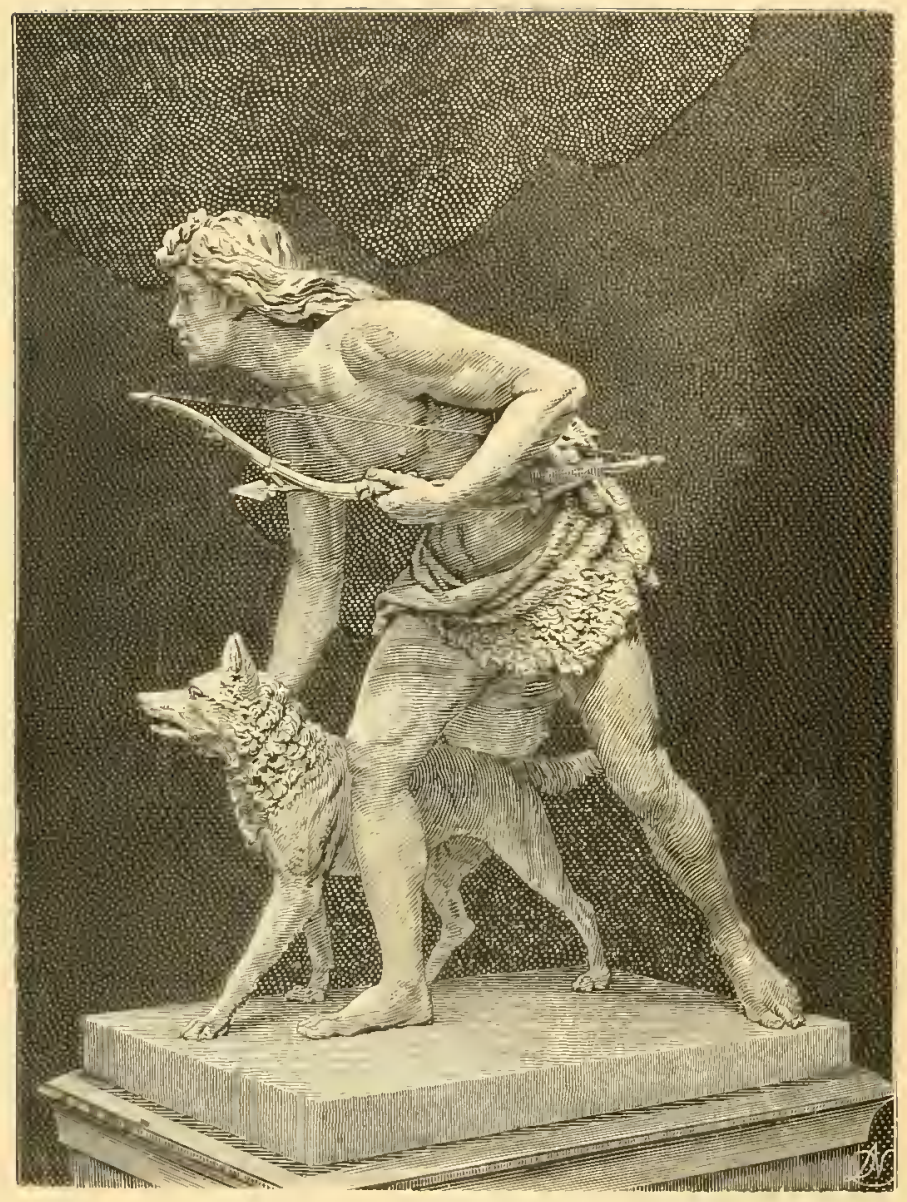


LARGE GAME 
In pastures, masureless as air.

The bison is my noble game;

The bounding clk, whose antli's tear

The branches, falls before my aim.

- Bryant. 


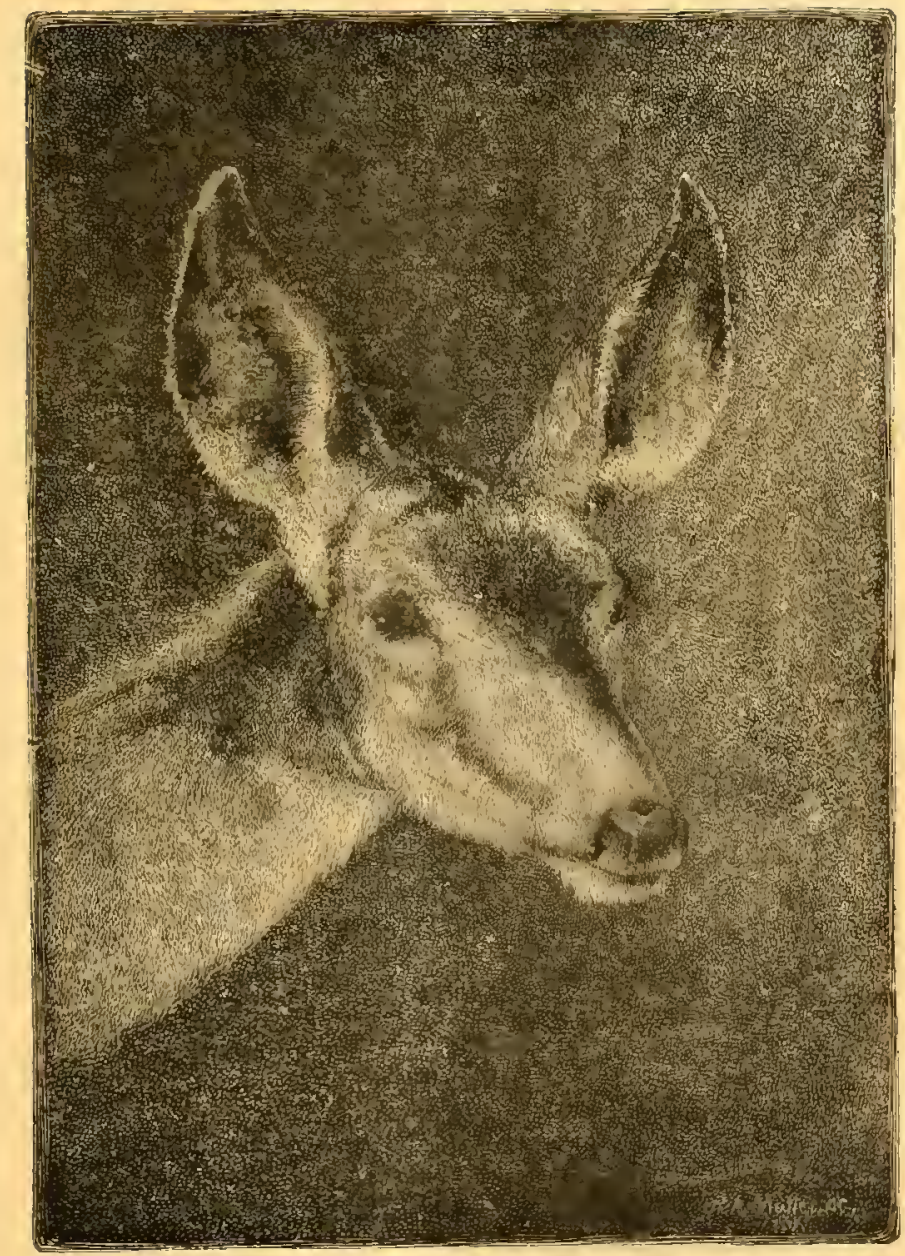





\title{
THE BLACK BEAR.
}

\author{
BY CHARLES C. WARI).
}

T

HE black bear (Ursus Americamus) derives its name from its fur, which is a rich, warm, and extremely glossy jet black, except on the muzzle, where, beginning at the mouth, the hair is a fawn color, which deepens into the dark tan color of the face, and ends in rounded spots over each eye. These color-marks and its peculiarly convex facial outline are the distinguishing marks of the species. The tan color becomes, with age, a brownish gray. The largest black bear I ever saw weighed five hundred and twenty-three pounds, and measured six feet and four inches from the tip of the nose to the root of the tail. One of this species seems to possess the power of transforming himself at will into a variety of shapes. When stretched out at length, he appears very long; when in good condition, short and stout; when upright, tall; and when asleep, he looks like a ball of glossy black fur. The black bear of to-day may be termed omnivorous, inasmuch as fish, flesh, fowl, regetables, fruit, and insects are all eagerly devoured by him. He mates in October, and the period of gestation lasts about one hundred and twenty days. Two to four cubs form a litter. The cubs are always jet black, and not ash color, as some of the older naturalists affirm. If, according to Flourens, the natural life of an animal be five times the period of its growth to maturity, I should think that the black bear's limit was about twenty years. I knew of a cub which increased in size until his fourth year, when he appeared to have arrived at maturity.

Many country people and some experienced hunters have seen, as they believe, another species of the black bear, which they name a ranger, or racer. He is described as being a longer, taller, and 
thinner animal than the black bear proper, extremely savage, and is distinguished by a white star or crescent on his breast. Marvelous tales are related of his ruthless doings, and any act of more than ordinary ferocity and daring, such as the wanton destruction of a large number of sheep, in daylight, in sight of the farm-house, is always attributed to a ranger. It is also said of him that he never hibernates, but prowls about all winter, seeking what he may devour, and keeping the farmers constantly on the alert to protect their stock. 1 have never had sufficient proof to warrant belief in the existence of a ranger bear, but have occasionally met with specimens of the black bear answering in some points to the above description. For instance, I have seen several black bears with white crescents on their breasts. The truth probably is that at times, during mild winters, a stray black bear may be seen prowling about, when, in accordance with all accepted ideas on the subject, he should be fast asleep. This probable fact. and the variation in size and form common to all animals, no doubt account for the popular belief in the existence of the ranger bear.

The time when the black bear selects the den in which his long winter nap is taken depends on the openness or severity of the season. In any season, he is seldom met abroad after the first of December, and he is not seen again until the first warm days of March. He does not seem particular as to the character of his den, provided it shields him from the inclemency of the weather. A retreat dug by his powerful claws under the roots of a windfall, a rocky cave on the hill-side, or a hollow log, if he can find one large enough to admit him, will serve for a winter home. When he is ready to hibernate, he is in fine condition and his fur is at its best. When he comes out in the spring, he is in a sorry condition, and is seldom molested unless he makes himself troublesome to farmers. Numerous, and curious beyond belief, have been the theories and explanations offered by naturalists to account for the suspension of the functions of nature during hibernation. An Indian whom I have found to be trustworthy has often called my attention to fir-trees which had been freshly stripped of their bark, to a distance of five or six feet from the ground, and has told me that it was the work of bears that were after the balsam, large quantities of which, according to the Indian, they eat every autumn before going into their dens. 


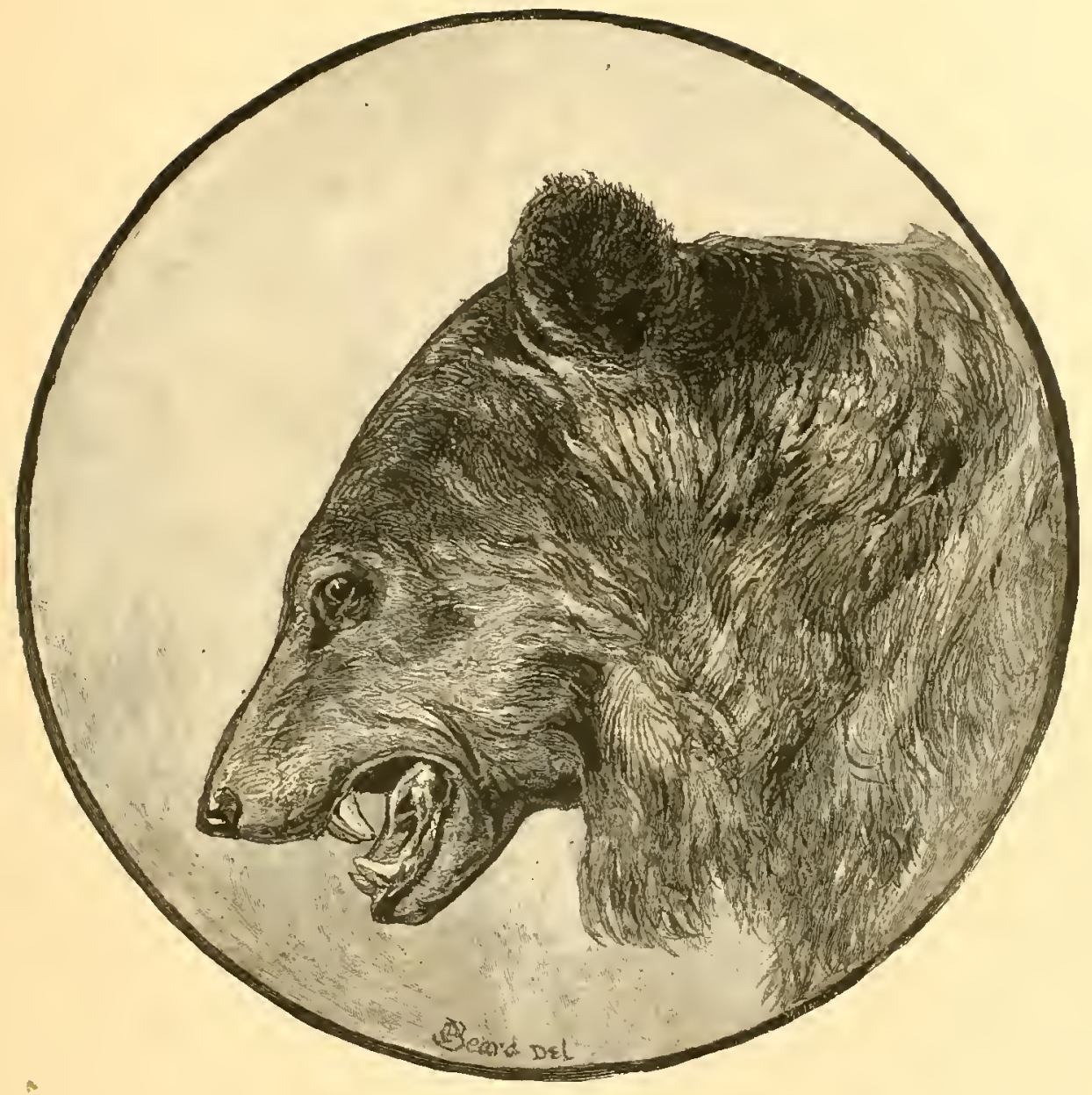

HEAL UF BLACK BEAR (URSUS AMERICANUS).

DRAWN BY JAMES C. BEARD, AFTER A SKETCH BY CHARLES C. WARD. 

It was his theory that the balsam prevented bodily waste, and that when the bears came out in the spring they dug up and ate large quantities of a root which had the effect of restoring bodily functions that had been suspended during the period of hibernation. The den is sometimes revealed by a small opening over the bear's place of concealment, where the snow has been melted by his breath. When efforts are made to dislodge him, by making a fire of boughs and moss at the entrance to his den, he will attempt to trample the fire out, and often succeeds. He has, however, a natural dread of fire, and at the first signs of a forest-fire becomes greatly alarmed, and flies to the open clearings and roadways. 1 once passed on horseback through a forest-fire which was burning on each side of the road, and most of the distance I was accompanied by a large black bear, that was following that avenue of escape.

It would seem improbable that the young of the black bear were liable to fall a prey to the fox and black cat, or fisher, yet such is the fact. This happens, of course, when the cubs are very young and incapable of following their dam in her search for food. The black cat is the most successful cub-slayer. The fox, notwithstanding his proverbial sagacity, is often surprised by the return of the bear, and is killed before he can escape from the den. An Indian hunter, who knew of two litters of cubs which he intended to capture as soon as they were old enough to be taken from their dam, was anticipated in one case by a black cat, and in the other by a fox. The latter paid the penalty of his adventure with his life, and was found in the den literally torn into shreds by the furious bear. The fox had killed one of the cubs, when the old bear surprised and dispatched him, and went off with the two remaining cubs. The Indian overtook and slew her and captured the cubs. Upon another occasion, he was not so fortunate. Stimulated by the large price offered by the officers of a garrison town for a pair of live cubs, he was indefatigable in his endeavors to find a den. One day, when accompanied by his little son, a boy of ten, he discovered unmistakable traces of a bear's den, near the top of a hill strewn with granite bowlders, and almost impassable from the number of fallen pines. One old pine had fallen uphill, and its upreared roots, with the soil clinging to them, formed, with a very large rock, a triangular space into which the snow had drifted to a depth of ten or twelve feet. The Indian was about to 
pass on, when he detected the whining of bear-cubs. By making a ditour, he reached a place on a level with the hottom of the bowlder, and there saw the tracks of an old bear, leading directly into the center of the space between the tree-root and the bowlder. The old bear, in her comings and goings, had tunneled a passage under the snow-drift. Getting down on his hands and knees, the Indian, with his knife held between his teeth, crept, bear fashion, into the tunnel. After entering several feet, he found the usual bear device-a path branching off in two directions. While pondering what to do under such circumstances, a warning cry came from his little son, who was perched on the top of the bowlder, and the next instant the old bear rushed into the tunnel and came into violent contact with the lndian, the shock causing the tunnel to cave in. The Indian, after dealing the bear one blow, lost his knife in the snow, and seized the bear with his hands: but she proved too strong for him, and was the first to struggle out of the drift, when, unfortunately, she met the little Indian boy, who had climbed down to his father's rescue. He received a tremendous blow on the thigh from the bear's paw as she passed, which crippled him for life. Four days afterward the Indian, determined to avenge the injury of his son by slaying the old bear, returned to the den and discovered her lying dead upon the snow in front of the bowlder: his one blow had gone home, and the poor creature had crawled back to her young to die. The Indian dug away the snow and found three cubs that were dead or dying.

The principal strongholds of the black bear at the present day are the great forests of Maine and New Brunswick. My own observation and the reports of farmers lead me to think that Bruin is growing more carnivorous and discontented with a diet of herbs Assuredly, he is growing bolder. He is also developing a propensity to destroy more than he can eat, and it is not improbable that his posterity may cease to be frugi-carnivorous. It is fortunate that an animal of the strength and ferocity which he displays when aroused seldom attacks man. The formation of his powerful jaws and terrible canine teeth are well adapted to seize and hold his prey, and his molars are strong enough to crush the bones of an ox. His great strength, however, lies in his fore-arms and paws. His mode of attacking his prey is not to seize it with his teeth, but to strike terrific blows with his fore-paw. 


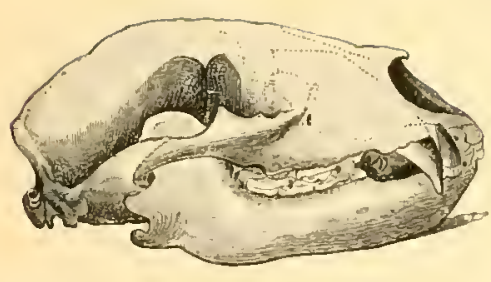

SKULI, OF BLACK BEAR

Bruin's weakness is for pork, and to obtain it he will run any risk. When the farmers, after suffering severe losses at his hands, become unusually alert, he retires to the depths of the forest and solaces himself with a young moose, caribou, or deer. He seldom or never attacks a full-grown moose, but traces of clesperate encounters, in which the cow-moose has battled for her offspring, are frequently met with in the woods. The average value of a bear, including the bounty, is twenty dollars. This being the case, it may appear surprising that larger numbers are not taken. But the black bear combines extreme cunning with great sagacity, and every year he seens to be getting more on his guard, and suspicious of all devices intended for his capture. Large, full-grown animals are seldom killed. A black bear skin, taken at the proper season, is not excelled by any other kind of fur. If properly dressed, it possesses great softness and a gloss peculiar to itself. The fur is highly esteemed in Europe, where it is used for sleigh and carriage robes and coat linings and trimmings. It is also in much request

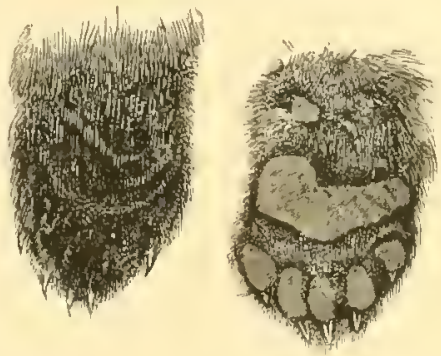

FORE-PAWS in England and other parts of Europe, for the shakos of certain infantry regiments and the housings and trappings of cavalry.

In the autumn of 1879, in the Red Rock district. Province of New Brunswick, eighteen bears were killed, only two of which had arrived at maturity; some of them were only yearlings. Only ten or twelve settlers and their families inhabit the district, and cluring that year seventy-three head of stock, including sheep, hogs, and horned

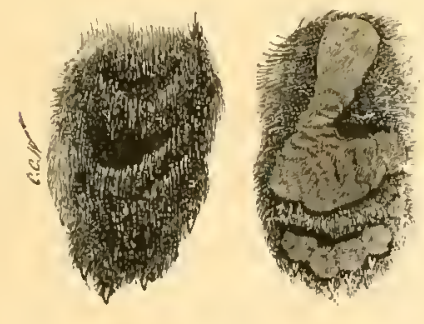

HIND-P.AWS. cattle, were destroyed by bears. This district, situated on the extreme outskirts of civilization, is the bear's paradise. The houses in most cases are built of logs, and the occupants are a stalwart, simple race, whose manners and customs carry you back to the frontier life of half a century ago. They are hospitable to a degree not 
often met with at the present clay. The farms on which they live are clearings in the primeval forests. I) uring a visit to this district, I had the luck, unexpectedly, to see Bruin at home in one of his wildest retreats. North of the settlement a range of rocky hills rises perpendicularly from the shores of a forest lake. The hills are strewn with gigantic bowlders, over which the hunter must pick his way with no little difficulty and danger. I3ut by that expert climber, the black bear, such rugged ground is easily traversed. Our tramp had been a long one, and on our return my Indian guide proposed that we should cross the Red Rock hills, and thus save much time. Great black clouds threatened an autumn storm. After much hard climbing, we reached a place where the whole hill-side seemed riven apart. On every side we were surrounded by precipices and deep gulches, partly filled with great bowlders and sharp fragments of rocks. Nlthough the dangers were not of Alpine magnitude, they might just as well have been, inasmuch as they were greater than we had any means of overcoming. In attempting to find a way out, we clambered along a ledge of rocks that afforded only insecure footing, and gradually diminished in width until all farther progress in that direction became impracticable. Retracing our steps, almost in despair of finding an outlet, we came to a fissure in the cliff just wide enough to admit one at a time. For a distance of twenty feet we were able to walk in an upright position; then the passage narrowed rapidly, and we had to crawl upon our hands and knees in almost perfect darkness. Presently we came to a place where the opening was so low that, if one attempted to straighten up, his back came in contact with a solid wall of rock; thence the passage took a sharp downward pitch, at the bottom of which we found a space sufficiently large to permit us to regain an upright position. The clarkness was now complete. and, not daring to move for fear of getting a fall, 1 thought it prudent to return to the ledge, and imparted my intention to the guide. I received no reply, and called out in a louder voice. To my surprise, the answer came in a muffled tone from a locality apparently directly under me. By this time my eyes had become accustomed to the gloom, and I detected a bluish, glimmering light on the rocky wall overhead, proceeding from a distant corner of the space in which I stood. Creeping to the source of the light, I found a wedge-like opening, decreasing in 


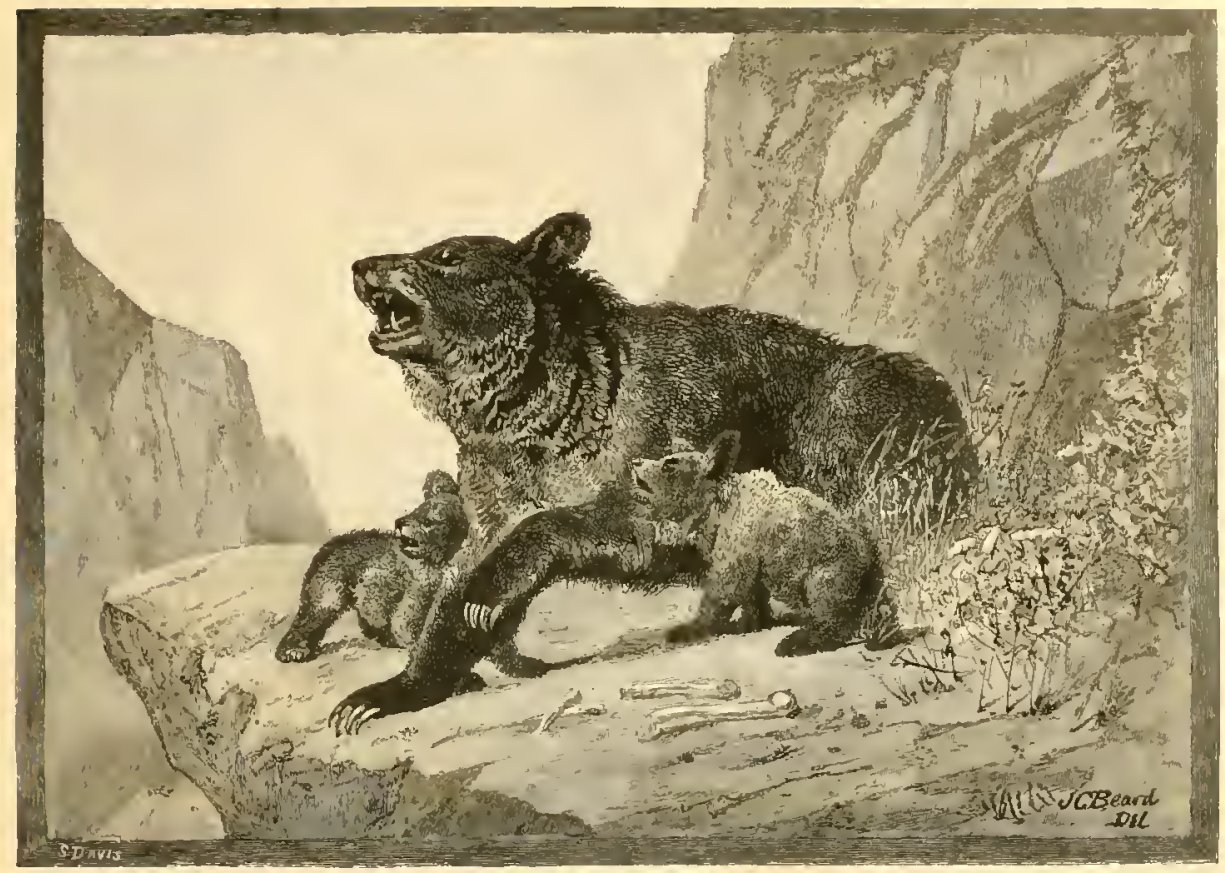

BEAR AND CUBS.

width as it descended. While debating with myself what to do next, the guide's head appeared at the bottom of the opening. He called to me to come down. Entering in a recumbent position, feet foremost, I slipped down and discovered that the passage led into another chamber-like space, with the difference that it was in open daylight, the sky being visible beyond an overhanging ledge of rocks. The rocky platform was strewn with bones, and plentifully sprinkled with porcupine quills. The information of the guide was not needed to convince me that we were in the ante-chamber of a bear's den, and that the room above was the den proper. It seems almost incredible that the black bear should permit such an offensive animal as the porcupine to occupy the same den with him, but there is good reason to believe that he sometimes does so. Although it was too early in the season for Bruin to seek permanent winter quarters. I did not feel at all certain that he might not pay occasional visits to his den, and urged the guicle to get out of the place as soon as possible. As there was likely to be more than one entrance to the den, we looked about us and discovered that, by climbing over a jutting ledge of rock, we should be able to get upon a lower and 


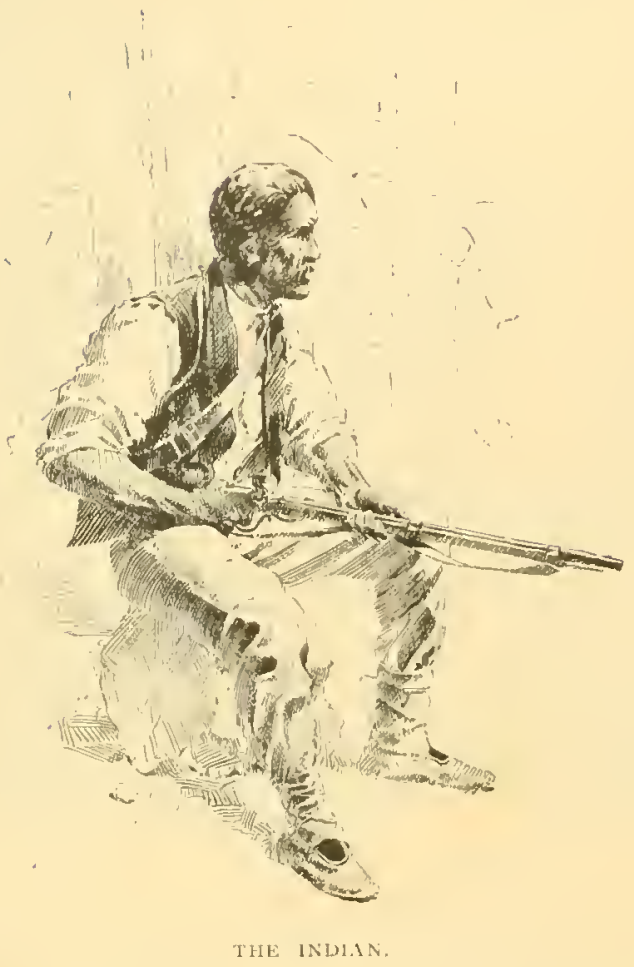

much more extensive plateau of rock immediately under the den. We reached the platform safely, and, selecting a spot where we were sheltered and concealed by bowlders, we called a halt and lighted our pipes. A slight tap on the shoulder caused me to turn around, and, looking in the direction indicated by the guide, I saw a large bear seated on his haunches and looking intently at something. Farther away I saw another bear, crossing a chasm on an old pine$\log$ that bridged it, and which afterward helped us out of our dilemma. Another tap on the shouider, and another surprise in store for me; for, up the hill-side, above the den, sat another bear with his head partly turned to one side, and looking in an inquiring manner at the two bears below him. By this time the one on the log had nearly crossed over, and the one sitting on his haunches growled frightfully. We were not fifty yards from him, and he might at any moment detect our presence; fortunately, we were well to leedrard of him. We had been exploring a stream connecting a string of lakes, to exam- 
ine a very extensive and perfect beaver-dam, and, not expecting to hunt, had left our rifles at the camp. All I had to fight with was a solid sketch-book, while, by some strange fatality, the Indian had in our climb even lost his knife out of its sheath. I was looking

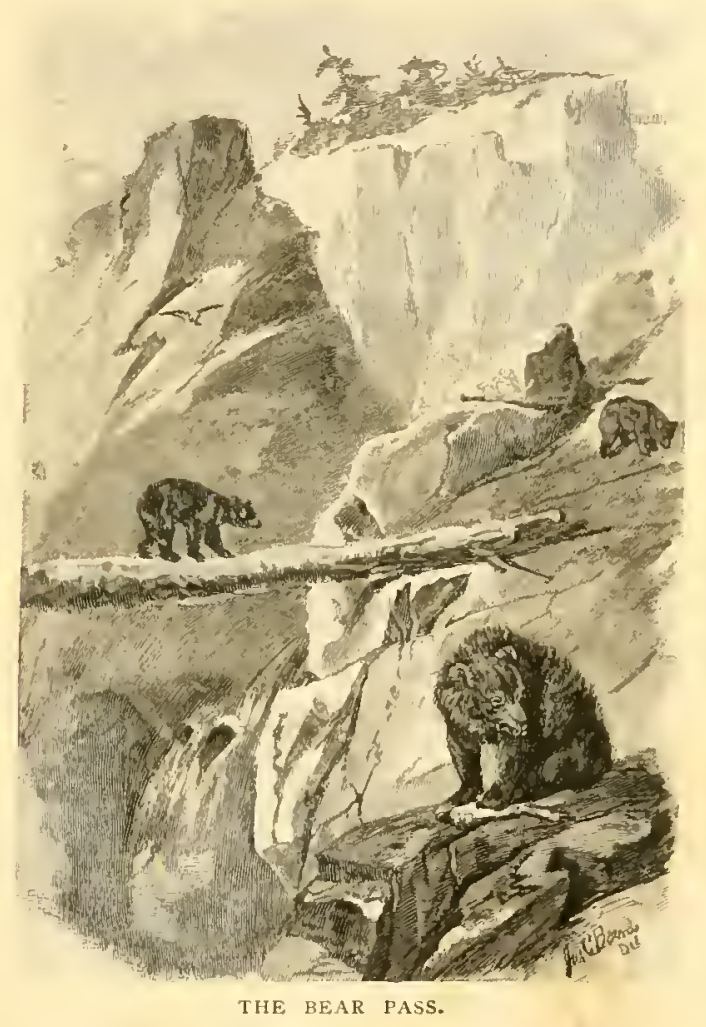

about for some way of escape, when I noticed that the bear on the hill-side had vanished, and the one that crossed over on the log had moved toward the one sitting on his haunches. They sat about ten feet apart, and made the strangest noise I ever heard. Commencing with the sniff peculiar to the bear, the noise was prolonged into a deep, guttural growl, accompanied by a peculiar champing of the jaws. At that moment, a large stone, evidently dislodged by the bear that had vanished from the hill-side, came tumbling down the ravine. It struck on the solid ledge on which we were crouching, and broke into pieces. Instinctively looking up, in apprehension that the fragment might be the advance guard of an avalanche, we lost sight of the two bears, and never saw them again. Alarmed by 


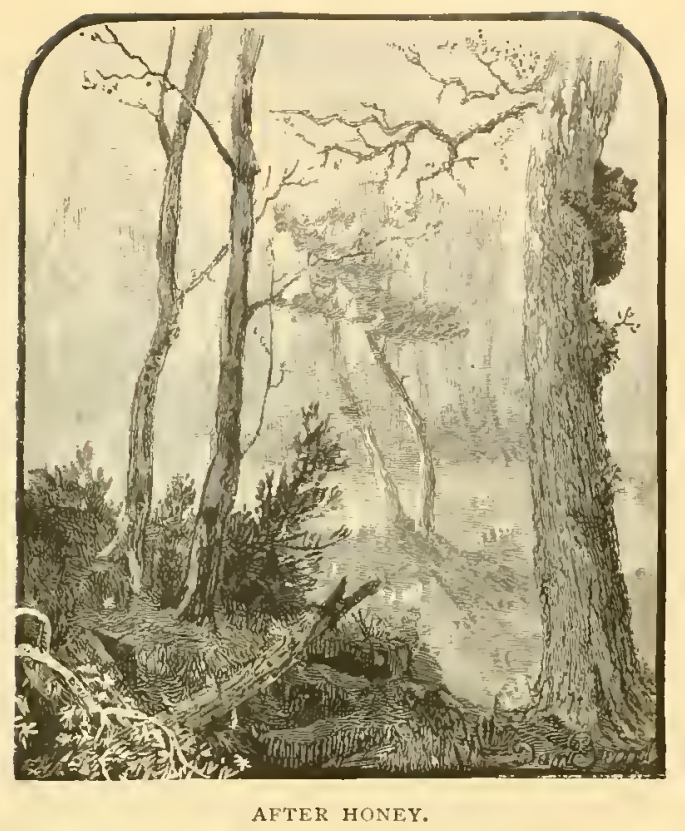

the falling stone, they had swiftly and stealthily gone away. The guide said that the two bears which were on the ledge with us were males, and that, as it was the pairing season, the growling we were treated to was merely the preliminary of a terrible fight. During the pairing season, the males congregate in bands and scour the forest, growling, snarling, and fighting. On such occasions, all prudent hunters avoid an encounter with them. The females are savage when suckling their young, and will fight to the death in their protection. At all other seasons, both males and females avoid a meeting with human beings, but if attacked and wounded, or brought to bay, the black bear is a foe to be dreaded. Their keen scent and acute hearing enable them to detect the approach of an enemy, and to keep out of his way.

Sometimes the black bear is hunted with dogs trained for the purpose. The dogs are not taught to seize the game, but to nip his heels, yelp around him, and retard his progress until the hunters come up and dispatch him with their rifles. Common yelping curs possessed of the requisite pluck are best adapted for the purpose. Large dogs with sufficient courage to seize a bear would have but a small chance with him, for he could disable them with one blow of his powerful paw. Another way of hunting is to track Bruin to his 
winter den, and either smoke or dig him out, when he may be dispatched by a blow on the head with the poll of an ax as he struggles out. Various kinds of traps, set-guns, and dead-falls are also employed against him. A very efficient means of capture is a stee] trap, with double springs so powerful that a lever is necessary in setting it.

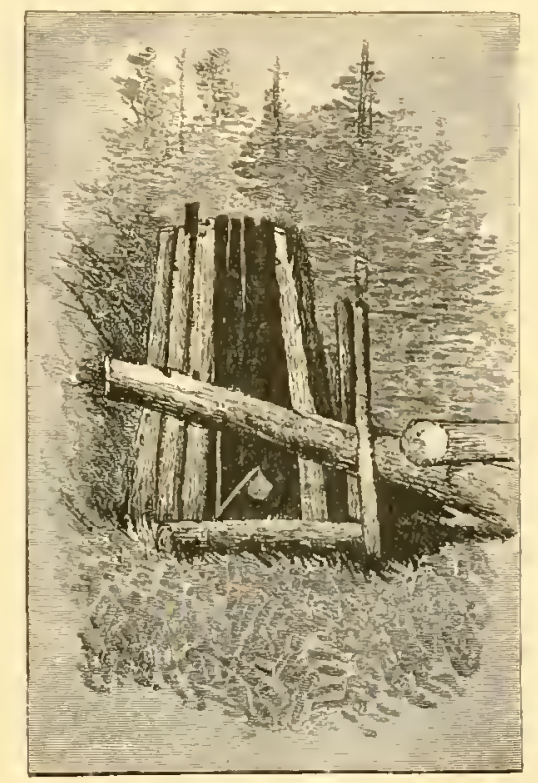

A DEAD-FALL TRAP.

The trap is placed in runs or pathways known to be frequented by bears, and concealed, care being taken not to handle the trap. A stout chain, with a grapnel or a large block of wood attached, is fastened to the trap. Even with this an old bear often manages to escape altogether, his sagacity teaching him to return and liberate the grapnel or block whenever it catches upon anything and checks him. He dies eventually, of course, if unable to free himself from the trap, but in some cases he has been known to gnaw off a part of his paw and leave it in the trap. This mode of capture is open to the charge of cruelty, as the bear is usually caught by a paw, and sometimes by the snout, and the injury not being immediately fatal, the animal may die a lingering death of great agony. The set-gun, if properly arranged, kills the bear instantly. The gun is placed in a horizontal position, about on a level with a bear's height; one end of a cord is fastened to the trigger and brought forward in such a way that when 
the bait is attached to the other end of the cord it hangs over the muzzle of the gun, and the least pull on the bait discharges the gun, which is protected from the weather by a screen of bark. The ordinary dead-fall consists of a number of stout poles driven in the ground in the form of a U. In front of the opening is placed a heavy log. The bait is suspended from a string within the inclosure so that it will be necessary for the bear to place his fore legs over the $\log$ in order to reach it. The string has connection with a piece of wood which props up the dead-fall, consisting of a heavy log of beech or birch timber weighted with other logs. When the bear pulls at the bait, the prop is drawn from uncler the heavy timber, which falls across his back. It sometimes happens that the hunter, to his discomfort, finds that his dead-fall has proved fatal to one of his own or his neighbor's cattle.

In the autumn, bear-hunters take advantage of Bruin's known partiality for raspberries, blackberries, and blueberries, and set traps and dead-falls in the approaches to the patches. He also frequents the beech-forests, and his expertiess as a climber enables him to obtain the rich mast, on which he grows corpulent. In the spring, when he first comes from his winter quarters, he feasis upon the ants and grubs he discovers by industrious digging, or by turning over decayed logs. Later in the season, when the herrings and alewives run up the streams to spawn, Bruin turns fisherman. and captures the fish by intercepting them as they pass over

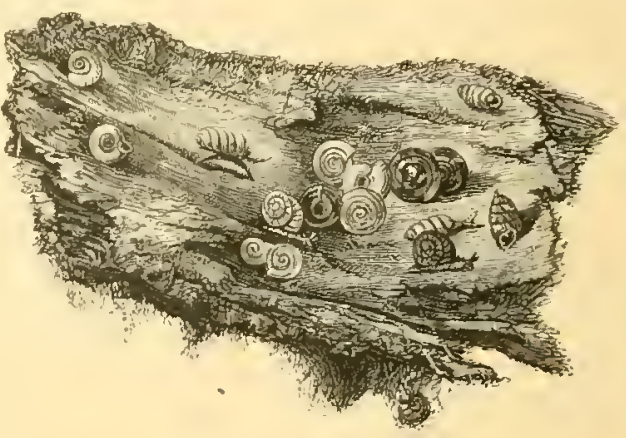
shallow places, and scooping them out with his paws. His taste for pork and molasses and such delicacies often encourages him to visit the camps of lumbermen, where he sometimes makes sad havoc.

If captured when very young and carefully trained, the black bear becomes tame, but 1 doubt if he ought to be trusted as a pet. My own efforts to tame young bears have not always proved successful. It is unpleasant, on returning from a journey, to find your house surrounded by the neighbors armed with old muskets and pitchforks, the windows broken, the gardens trodden down, your family impris- 


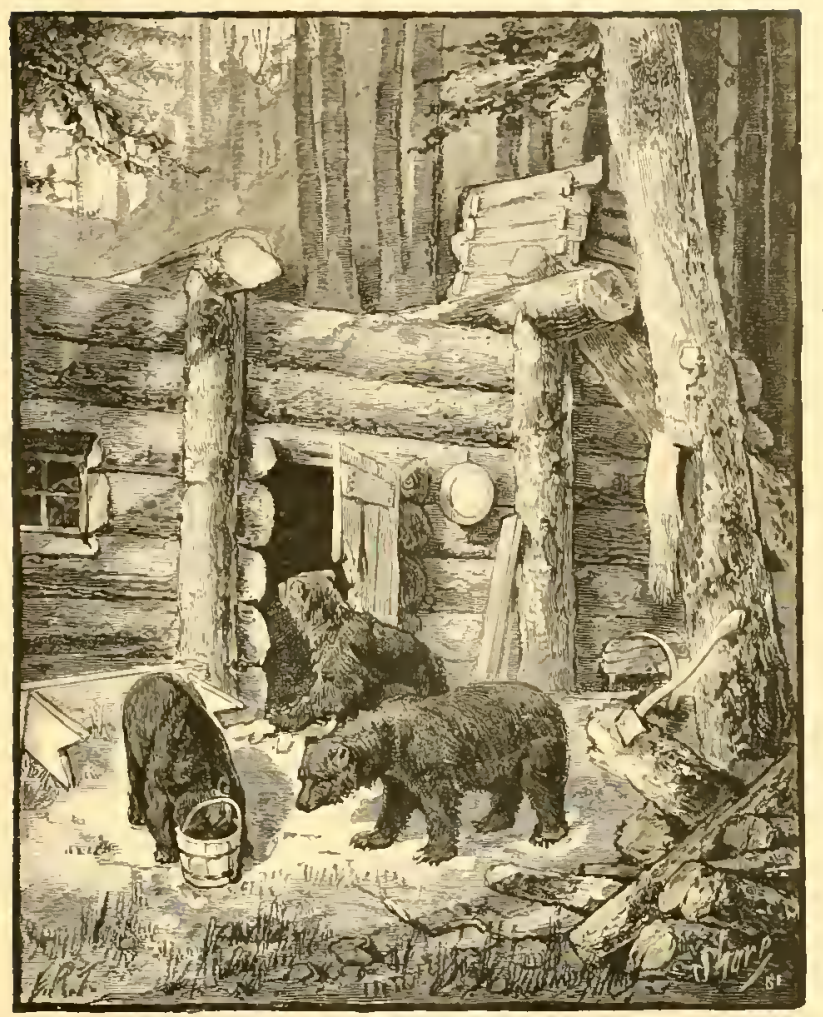

SACKING A LUMBER CAMY.

oned in the dining-room, and to be told by your man-servant, who has prudently kept outside of the house, that the pet bear, in a state of ferocity, is in possession. Nevertheless, if one is willing to endure that sort of thing, a vast amount of amusement can be grot out of a tame bear.

I really think that Bruin possesses the sense of humor; at all events, his actions point that way, and there is no doubt that he is extremely cunning and observing. I once had an English friend visiting me, who played the flute. He was in the habit of marching up and down, while playing, near a tame bear I had at the time. The bear had a piece of stick about two feet long, which he tossed about for amusement. After a time, he came to handle the stick very much as my friend did his flute. This annoyed my sensitive friend, and in revenge he teased the bear with uncouth noises. Bruin sniffed and whined, and waited his opportunity for delivering a 
tremendous blow with his paw at his enemy, whose tall hat was knocked completely over his eyes. He escaped being scalped by dropping flat and rolling out of the reach of the bear. This bear spent much of his time in the tree to which he was chained, and when climbing usually got his chain twisted over and under the branches in a most intricate manner, but never failed to take out every turn as he descended. A friend, who owned a tame bear, told me that, for a long time, he could not account for the mysterious way in which the poultry disappeared. Observing, at different times, a good many feathers around Bruin's pole, he began to suspect that the bear was the culprit. Close watching confirmed his suspicions. When Bruin thought he was unobserved, he would seize any unfortunate hen or'chicken within his reach and devour it; but if any one approached before he could complete the meal, he would sit upon his prey until the danger of discovery had passed. He was betrayed, at last, by the cackling of an old hen that he had failed to silence.

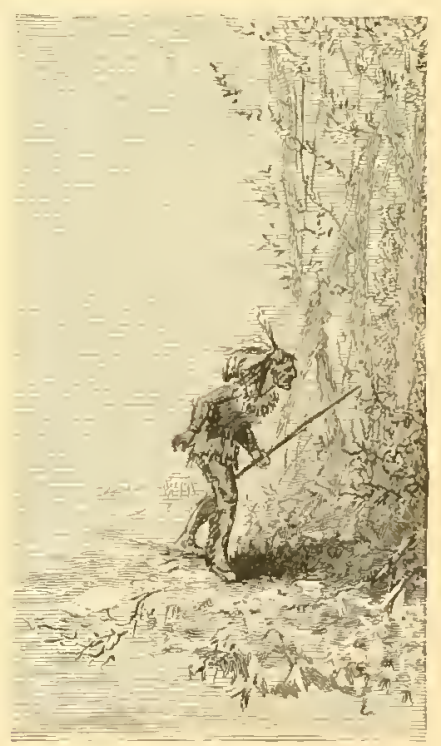




\title{
BEAR-HUNTING IN THE SOUTH.
}

\author{
BY JAMES (
}

F

ROM my youth, bear-hunting has been to me a fascinating sport, and, after an expericnce of more than thirty years in all kinds of Southern sports, during which I have seldom failed to spend a portion of the winter camp-hunting in the Mississippi bottom, I think I may venture to relate one of my bear-hunts, and give the inexperienced sportsman some idea of the characteristics of the bear.

We had pitched our tent on the banks of a beautiful sheet of water, one of the chain of lakes that drains the swamps of Tunica County, Mississippi, when the Father of Maters inundates the valleys. Through these lakes and the bayous leading from them the annual overflows are carried off into the Coldwater. Tallahatchie, and Sunflower rivers, thence into the Yazoo, and back into the Mississippi.

Besides old Hannibal, a negro servant, there were only four of us in camp. One was a professional hunter, two were cotton-pl-nters and experienced hunters - not simply sportsmen who occasionally spent a day of recreation in quail-shooting over a brace of pointers, but hunters who had studied wood-craft until it seemed like instinct to thread their way through the wilderness by day or night, without other compass than the moss on the north side of the trees.

When a novice in wood-craft joins a party of old hunters, he is often subjected to many a practical joke; although, at the same time. old hunters are very generous in imparting information or in rescuing him from danger. On this occasion, the target of our jokes was James Rogers, a fair-haired Northerner from "old L.ong lsland's seagirt shore," an enthusiastic sportsman, a crack shot at pigeons, but 
in our section almost as helpless as a babe,- the opposite, in every respect, of our backwoods hunter, whose pen-portrait I will endearor to give. Living by hunting and trapping from boyhood, an uneducated frontiersman, he was the boan idcal of a hunter-clad in buckskin hunting-shirt and leggins, with an otter-skin cap on his head and a 'coon-skin pouch in which he carried his ammunition swung across his shoulders, and a short rifle in his hand; about five feet ten inches tall, round-bodied, but with no surplus flesh, and with muscies like corded steel. His hair was steel gray and inclined to curl where it fell below the temples. I I is features were regular, and by long exposure to sun, rain, and miasma were wrinkled and bronzed; but, clear and brilliant through a complexion like a tanned alligator-skin, sparkled a pair of merry blue eyes that indicated a soul as gay and free as the wild woods he loved so well. All through the swamps he was known as "Old Asa, the bear-hunter." The two planters were Major Iuncan and myself.

IThen old Asa sounded his horn, about twenty-five dogs of all descriptions gathered around him: like their master they were trained hunters, and many bore the marks of Bruin's claws. If you should ask the pedigree of old Beargrease or Bravo, the two most noted leaders of the pack, I should be compelled to admit that the vilest mongrel strains coursed through their veins. For there is no certainty in breeding them: often the most "or'nary"-looking cur makes the best bear-dog. On my annual expeditions to the swamps, I was accustomed to buy, borrow, and "persuade" to follow, every specimen of the canine race I could pick up; and if out of a dozen I secured one who "took to bear," I was lucky.

A bear-pack requires logs of various sizes. A few rough-haired terriers, active and plucky, that can fight close to Bruin's nose and dodge under the cane when pursued; some medium-sized dogs to fight on all sides, and a few large, active curs to pinch his hindquarters when he charges in front or crosses an opening in the woods. Bear-dogs must fight close, but not attempt to hold a bear ; you want them to hang on but not to hold fast. A well-trained pack will only seize hold at the same time when one of their number is caught: then they boldly charge to the rescue of their comrade, and as soon as he is freed, loose their holds and run. Then gathering around the bear again, they worry him until he climbs a tree, where 
he falls an easy prey to the hunter. 'The hunter never cheers his pack unless he is in trouble and wants their assistance.

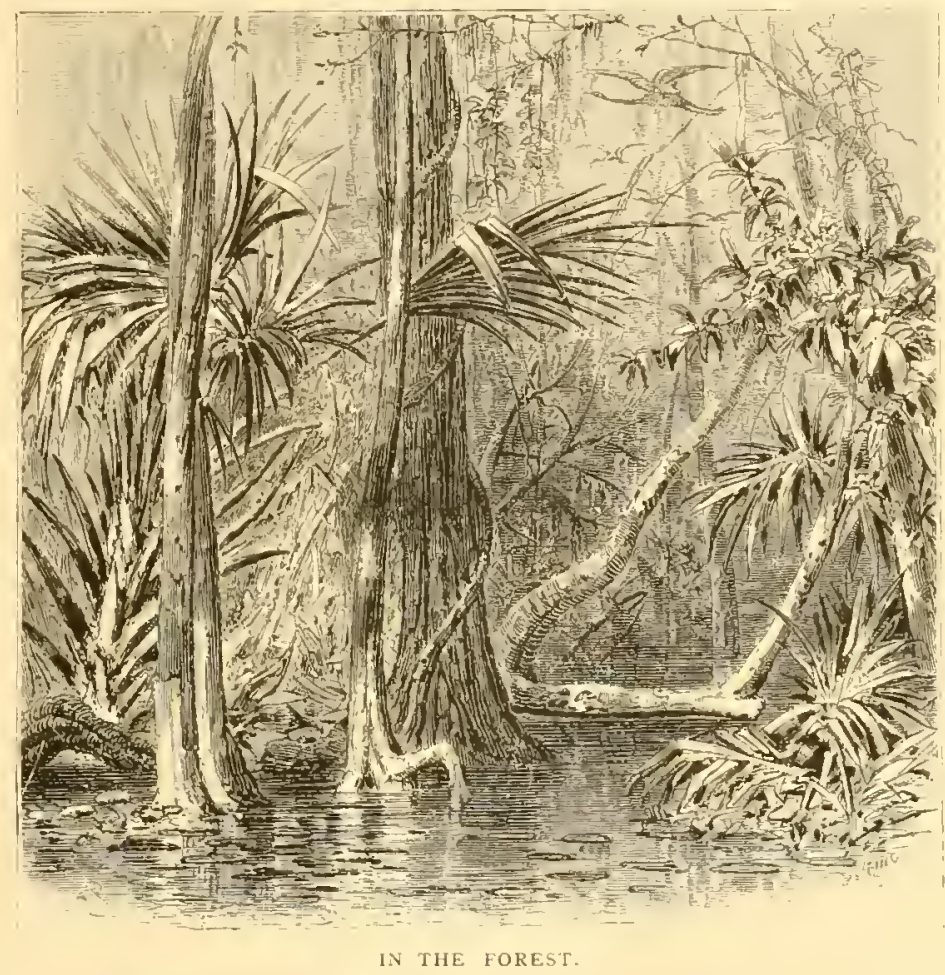

The bear usually makes his bed in the most impenetrable canebrake. He cuts and piles up heaps of cane until he has a comfortable spring mattress. He is very fastidious in his taste, and will not remain in a wet bed; so, after every spell of bad weather, he changes his quarters. In diet he has a wide, almost omniverous taste. In the summer, he is very destructive to the farmer's cornfields, showing a decided relish for green corn or roasting ears, or fat pig or mutton as a side-dish, not refusing a pumpkin by way of dessert. As the fall season approaches, he climbs after the wild grape, the succulent muscadine, the acorn, and the persimmon, and leaves his sign everywhere he travels, in heaps of hulls of pecan and scalybark hickory nuts. This is called the lapping season, as he ensconces himself in a tree-lap and breaks the limbs to pieces, in gathering nuts and fruits. He is also excessively fond of honey, and is utterly regardless of bee-stings while tearing to pieces a nest of wild bees from a hollow tree. 


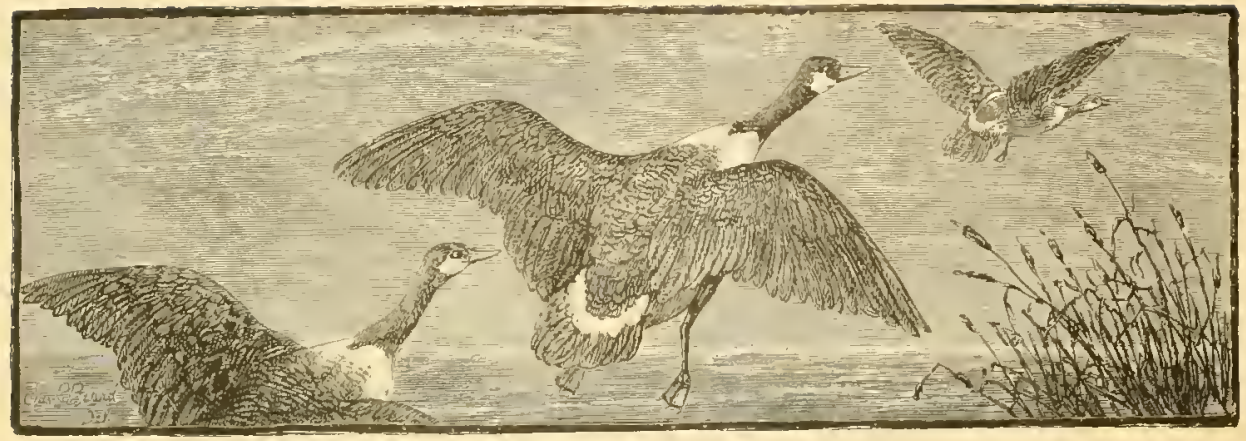

Hunters sometimes entrap him by placing in his path a vessel containing whisky made very sweet with honey. Bruin is easily intoxicated, and very human in his drunken antics. I have seen him killed by negroes while lying helpless upon his back catching at the clouds; but such slaughter is unsportsmanlike, and no true hunter would resort to it.

But old Asa and the dogs are off down the lake-side, and we follow in single file.

Here, indeed, is the hunter's paradise. Flocks of mallard, teal, and wild duck, covering acres of surface, are floating lazily upon the limpid water; on the other side, a dozen swans are gracefully glicling along. A flock of ungainly pelicans, with their huge mandibles scooping after minnows, waddle about the opposite shore. The wild goose is heard overhead, while the sentinel of the flock on the water replies. The white and blue crane, motionless as the sentinels of Pompeii, line the shore. The tall cypresses in the lake, with their fringed foliage, lift their weird knees out of the water and look lonely and desolate; while the oaks and gums upon the shore, draped in clinging vines, festooned with moss, and reflected in the lake, add to the somber picture of the wilderness. The sycamores and cottonwoods are of immense size, some being ten feet in diameter.

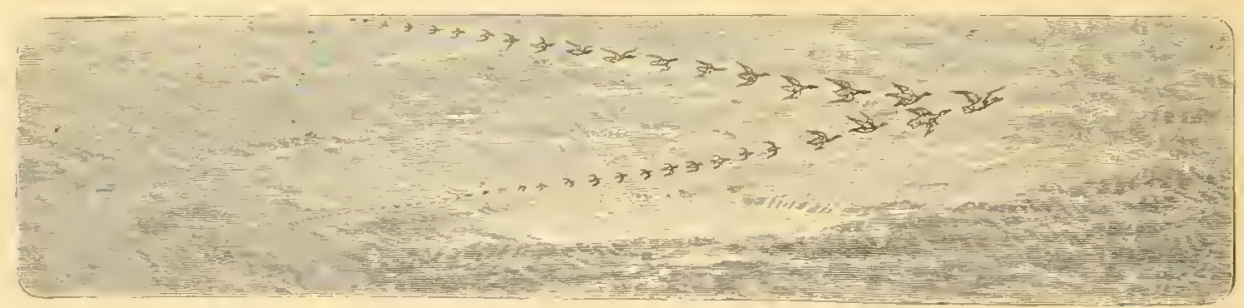


Old Asa turned from the lake and boldly entered a cancbrake, we following. Here the foremost horse has the hardest time, for he must break the way for the rest through cane and bamboo-vines. Old Asa's horse, however, like his master, was a trained hunter, and would wait the stroke of the hunting-knife which cut the vines, to push on through the tangled mass. Going through cane, every one is required to take the cartridge from his gun ; or, if he has a muzzleloader, to take the cap from the tube.

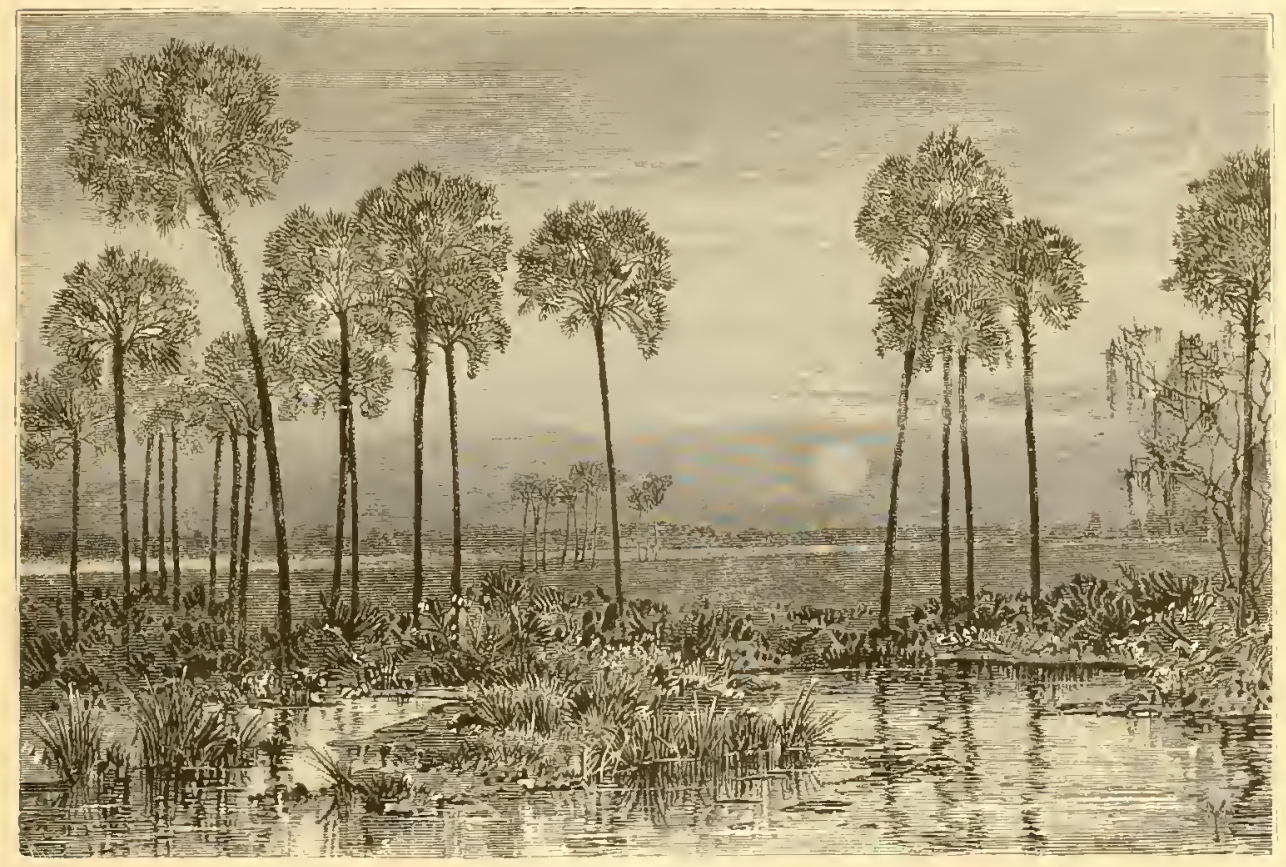

A HUNTER'S PARADISE.

After crossing a canebrake ridge of half a mile, we entered a large, open wood, where we found a quantity of overcup acorn mast, upon which bear and deer feed during the winter months. Under the limb of a pawpaw we saw a fresh buck-scrape. This is made by the male deer, while scratching his antlers amid the branches above; he scrapes the earth with his feet, as a sign for his tawny mate. A little farther on, within easy range, we startled the antlered monarch from his lair; but not a gun was raised to arrest his flight. As the deer lifted his white flag and bounded off, the younger logs pricked up their ears and looked anxiously forward, ready to burst forth in full cry; but a word in a harsh tone from old Asa caused 


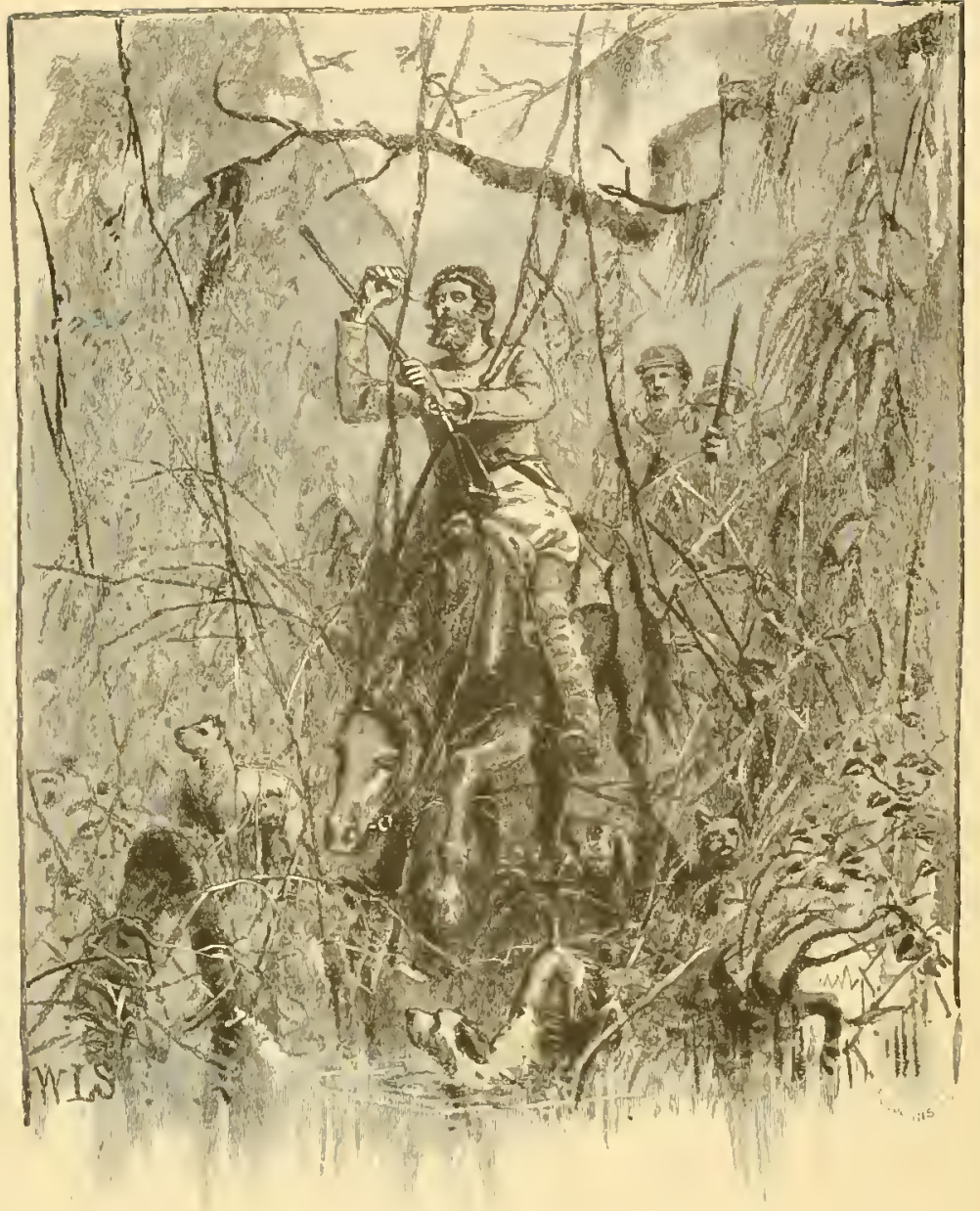

(ILD ASA CUTIING THROUGH THE CANEBRAKE.

them to fall to the rear. "This is a bear-hunt, and these are beardogrs," said Asa, and we understood that no other game must be shot before them. On rainy days, we go out from camp, singly, and "still-hunt" for deer; for then they are easily found, as they avoid the wet cane and feed in the open woods.

"Here's a b'ar sign!" exclaimed Asa, ats he pointed to the foot of a large overcup acorn tree. Just then, a sound that vibrates through the hunter's heart with a thrill of pleasurable emotion fell upon our ears, Of our pack of dogs only the reliable hunters, such as Bravo and Beargrease, are allowed full liberty in ranging the woods. There was the sound again! Bravo had struck a trail! Every dog rushed forward at the well-known signal 
of their leader; but the track was cold, and every nose wals lusy smelling among the leaves, trying to unravel its mystic windings. We rode slowly along; old Beargrease made a circle, and struck the trail farther ahead. The old dog seemed to know he had solved the problem this time, for sitting upon his haunches, he raised his head, and uttered his prolonged cry- which was to us a note of exquisite joy. Bravo, Granger, and twenty more joined in the chorus, and slowly, but surely and steadily, they moved along on the trail. "More sign!" shouted old Asa, presently; "here's his stepping-path," and he pointed to a path made by the bear as he passed to and fro from the cancbrake. Here he explained to Rogers that the path was made by a habit the bear has of always putting his feet in precisely the same tracks; this habit is often taken advantage of, and a trap is set in his path, or a grun is placed so as to kill or mortally wound him. old Asa.

"And this one, I can see by his signs, is a big fat old he," aclded

"Now, look here, old fellow," replied Rogers, "don't test my credulity too far. I would like to know how you can tell a fat bear from a lean bear, or a he bear from a she bear, when you have never seen it."

"Little boy," replied Asa, while a benevolent expression mocked the gay humor in his clear blue eye, "your education has been sadly neglected: book-l'arnin' may be very useful in town, but one grain of common sense is worth a bushel of college diplomas in the swamps. Now listen and l'arn wisdom: I know this is a fat bar, because his hind toe marks do not reach the fore ones: had he been poor, they would well-nigh have overlapped."

"But how do you know it is a he bear, and a big he besides?"

"The Lord pity your ignorance, child! don't you see whar he writ it up on that hackbery?"

"Well," replied Roger, "you will have to interpret it; I can see nothing but meaningless scratches up there on the tree; what do you make of it?"

"Look close," replied Asa, "and you will see the tallest marks are the freshest; a young b'ar, feeling very large all by himself, wrote his name thar first; the way he does it, he places his back ag'in' the tree and, turning his head, bites the bark as high as he can 


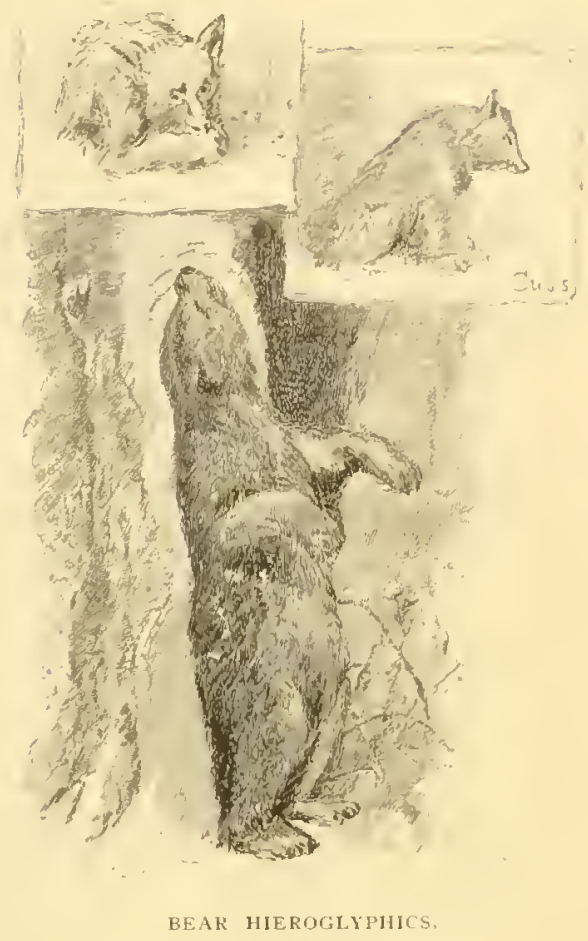

reach, which means, in bar lingo, 'I'm boss of the moods-beware how you trespass on my domains.' The next bar that comes along takes the same position and tries to outreach the first. Now, this old fellow has written in b'ar hiroglyphics 'a foot higher, "Mind your eye, young un, you're a very small potato; l'm the hoss that claims preëmption rights to these pastures.' Another reason for knowing it's a he b'ar is that the she's have young about the third week in January, and it's about that time. We hunt them in February by examining the cypress-trees, where they have left their marks climbing to their dens. The young ones, when first born, are not larger than a rat."

"I have read that the bear was a hibernating animal; how about that?" asked Rogers.

"The bar becomes very fat in winter," said Asa, "and his insides are so covered with fat that he has no room for food; in a cold climate he would jie up, but here he is tempted by the mild winters to keep traveling around."

While old Asa was giving our city friend this bit of natural history, the dogs were busy at work on the trail; the track was 
growing warmer. Suddenly they all dashed into the cane, when, ahew! - with a snort and crash through the cane, as if all the fiends had broken loose from Tartarus, the bear was started from his lair. With a wild yell, we all followed, pell-mell, in pursuit. For a mile or more the bear seemed to gain upon his pursuers; but, like a relentless fate, the ficree pack stuck to his heels, while the hunters were slowly cutting their way through the cane. Old Asa led the way, with that intuition which belongs to the practiced woodsman and aids him in avoiding the heaviest canebrakes.

Reaching a boggy bayou, we paused to listen for the pack. The baying of dogs underneath the heary cane cannot be heard at a great distance; and, as we halted on our horses, we could hear no sound but the melancholy soughing of the winds through the lonely cypress. Old Asa leaped from his horse, and, telling us to keep silent, knelt and placed his ear close to the ground. For a few moments the silence was almost painful. Then springing to his feet, he exclaimed:

"Ail right. boys! The b'ar has turned toward camp; I heard them distinctly; they are fighting very close."

"How will we cross the bayou?" asked Rogers. "It would bog a saddle-blanket here."

"Follow me, young un," said old Asa, "and I'll l'arn you what your school-master never lid-how to cross a boggy bayou."

Then proceeding up the bayout, he selected a spot where the cypress-knees were thickest, and led the way safely across; then pushing rapidly forward, flanking the canebrake and keeping to the open woods, after a detour of a mile we were again in hearing of the pack.

" He has turned back!" shouted old Asa. "Scatter out across the opening and some of us will get a shot!"

We promptly obeyed the order, and soon heard them coming, crashing madly through the canebrake. Presently out jumped the bear near Major Duncan's stand, with the dogs pressing him like a legion of furies. As the major attempted to shoot, his horse wheeled, and before he could turn, the bear had seen him and turned back into the cane, preferring a score of dogs to one hunter; going farther down the cane, he again burst into the opening and crossed close to Rogers, who had dismounted and was standing by 
a fallen tree. As the bear leaped the log, Rogers fired. Although a bear is a large animal, yet when he is running he is not so good a target as one would think. If the reader will attempt to put a ball through the center of a barrel-head while it is in rapid motion he will have some idea of shooting at a running bear. Rogers missed, but the dogs, encouraged by the report of his gun, attacked with renewed vigor. Across the open woods, in plain view, we beheld a grand sight. As the dogs charged at the report of Rogers's gun, Rocket, a large, active fellow (a cross between a mastiff and a greyhound), seeing the way clear, made a dash, and catching one of the bear's hind feet, tripped him so adroitly that he rolled over on his back, and before he could recover was covered with dogs. But a sweep of his huge paws' scattered his foes in every direction. I few leaps and he again reached the canebrake, and soon we heard the dogs at bay. We dismounted, hitched our horses, and proceeded on foot to the scene of action. But it was slow work, for the bear always seeks the heaviest canebrake for his battle-ground. We had to creep and crawl, sometimes prostrate upon the ground, under the tangled mass of cane and vines, often having to use our hunting-knives in disentangling ourselves.

Except old Asa, who carried a rifle, we were all armed with short, double-barrel shot-guns, loaded with buck and ball. This, in my judgment, is the most effective weapon for bears, as they are generally shot in a tree or on the ground at close quarters; and after the labors of a bear-chase the nerves arc apt to be a little shaky for drawing a fine bead with a rifle.

Cutting our way through the mass of cane, we reached the outer circle of dogs and beheld the bear sitting with his back against the trunk of a tree, his fore paws just touching the toes of his hind ones as they projected up in front of him. Thus, with his rear protected, he stood at bay, occasionally making a rush for a dog who had ventured too near, and when he had scattered his foes, returning to his position, pressed again in turn by the dogs he had pursued. It was a splendid picture - the huge beast, shaggy and grim, with the white froth dripping from his red lips and lolling tongue, beset on every side, fighting a host, relying alone upon the strength of his mighty arm to keep his foes at bay. At length, greatly worried, he resolved to do what a large, fat bear greatly dislikes, viz., take a tree. 


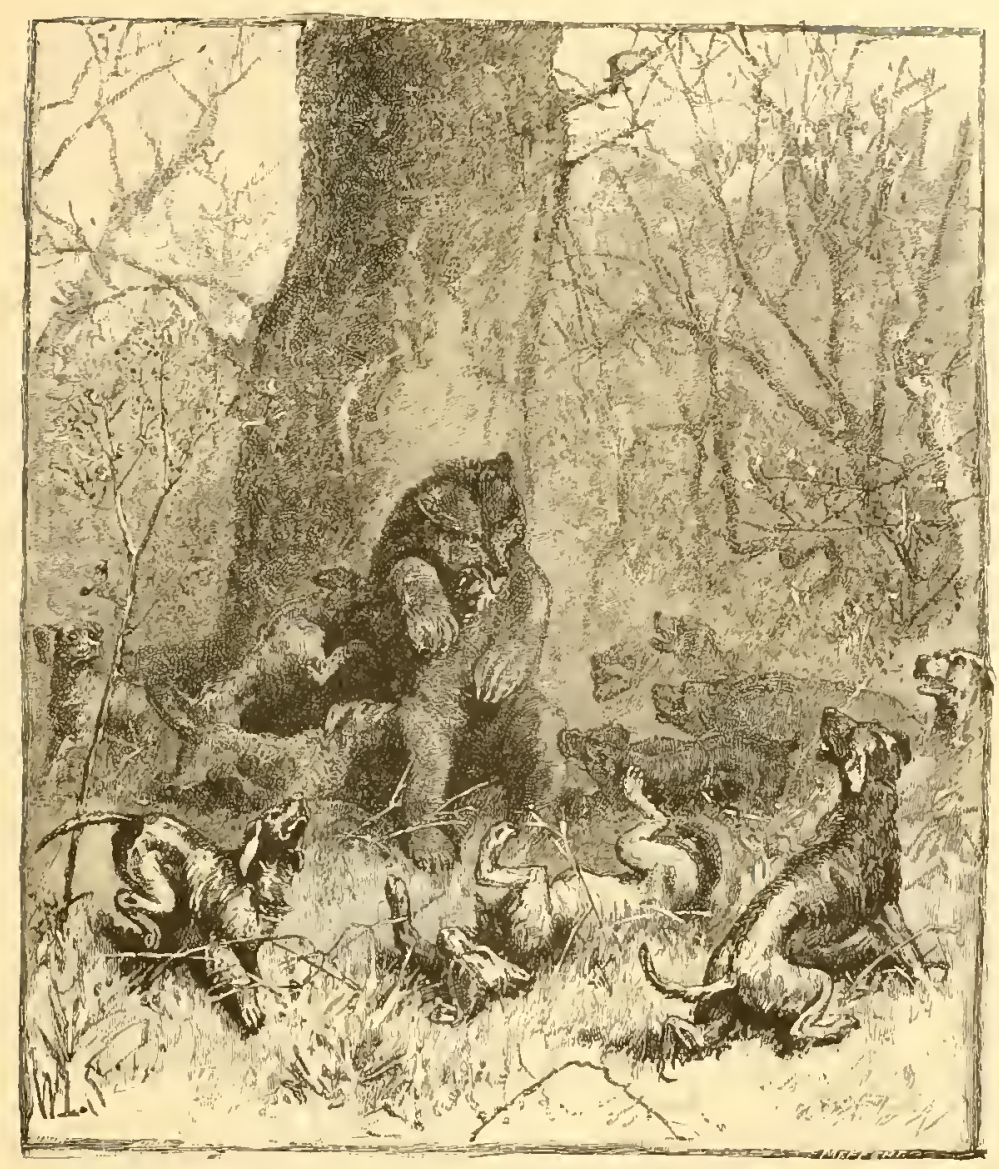

AT BAY.

Making a rush, as a feint to scatter his enemies, he sprang up into an oak and seated himself in a fork about twenty feet from the ground.

By this time my companions had arrived, and it was agreed that Rogers, who had never killed a hear, should have the shot. He took his position in front of the tree and attempted to get a sight at the bear's head; but a bear's head is a had target, as it is in constant motion, and the frontal bones are so sharp and hard that, unless the hunter makes a center shot, the ball will glance and do but little harm: moreover, when wounded, however slightly, the bear is almost sure to abandon the tree. It the report of Rogers's gun, though slightly stunned by the glancing ball. Bruin threw his arms around the tree on the opposite side, and came down, as old Asa said, "like a streak of greased lightning." The pack covered him as he touched 


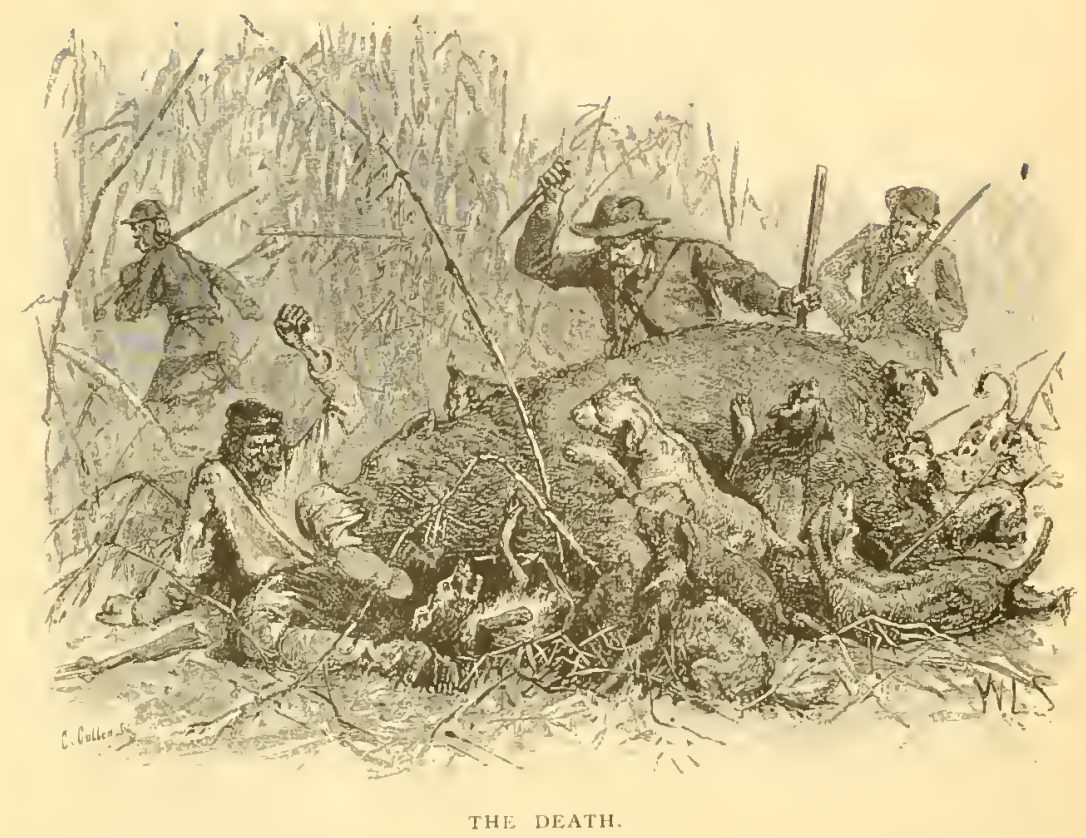

the earth. Major Duncan rushed to the rescue of the dogs, who are almost sure to get hurt if a bear is wounded; but the dogs were so thick the major could not shoot. I saw Bravo caught in Bruin's arms, and saw the major push a couple of dogs aside and fire, but he only succeeded in knocking the brute down and releasing the old dog. At the same moment, a stroke of Bruin's paw sent the major's gun spinning through the air. The bear then rushed away into the canebrake. Around and around, within the space of a few hundred yards, the battle raged fiercely. The hunters were all scattered through the canebrake, when the bear chanced to head directly for Rogers, who fired and, as the bear charged, took to his heels, and but for the courage of the dogs would have been caught.

At the report of the gun, the maddened pack covered the game again, and he had to stop to shake them off. Rearing on his hind feet, he would strike down with his fore paws, his long, sharp claws making the "fur fly" wherever they struck. The bear generally strikes downward, as he is pigeon-toed, and from the conformation of his fore-arm cannot well strike laterally when rampant.

Rogers had gained on the bear by the dogs' renewed attack, but as soon as Bruin had shaken them off, he again pursued his human 
foe, when old Asa, pushing Rogers aside, heroically stepped in front, and dropping on one knee, threw his rifle to his shoulder and fired. The bear, though mortally wounded, sprang upon him. I was close at hand, but could not shoot without the risk of hurting my friend. I shouted to the pack. Regardless of danger, the brave dogrs rushed to the rescue, and again covered the bear, just as he had seized old Asa by the leg. I sprang forward, and reaching the opposite sick struck a well-directed blow and fell back, leaving my knife in the

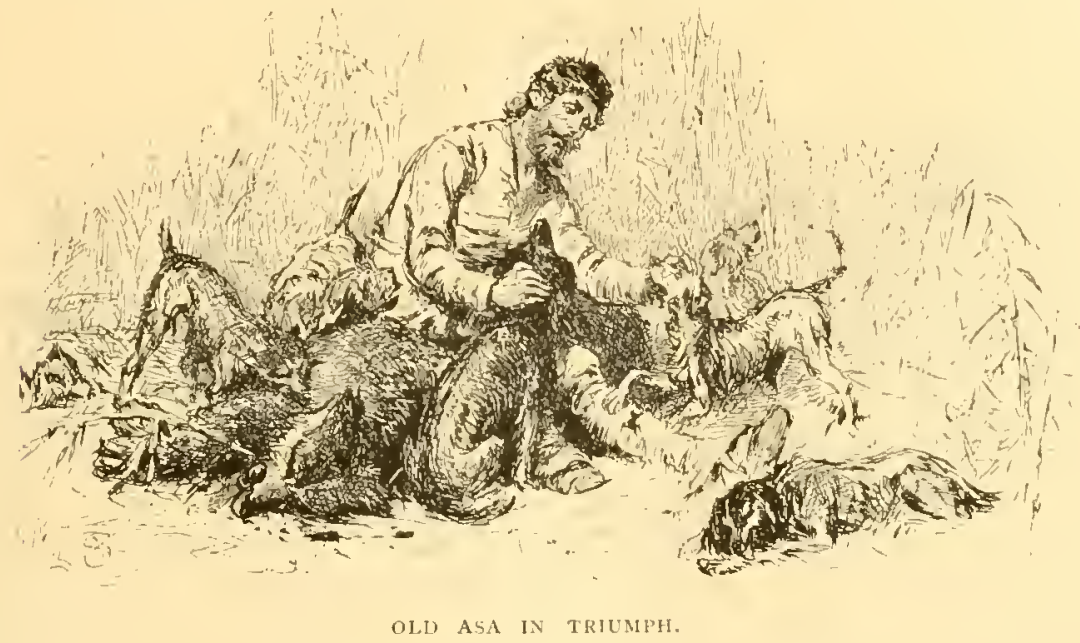

monster's heart. The experienced hunter always strikes a bear from the opposite side to which he stands, as the bear is sure to turn to the side from whence he receives the blow: and woe to the unlucky hunter caught in his death-grasp. As the bear rolled over and expired, old Asa sprang to his feet and exclaimed, as he grasped my hand, "Bully for you, old pard! A leetle more an' I would have been mince-pie for that tarnal critter, tryin' to save Greeny, thar. Hoopee, good dogs!" And, at the voice of affection from their master, they gathered around him, while the old huinter sat on the carcass of the bear and caressed his battle-scarred pets, examining all of their wounds before he looked at his own. It proved to be an ugly, though not dangerous, bite on the calf of the leg.

"Boys," he said, "we are only a mile from camp, and if I can get to the bayou just outside of this cane. I can walk with less pain than 1 can ride through the brake."

Refusing all assistance, the old hunter started for camp alone, 
and, getting into the bayou, waded into the cold water, as he said, to numb the pain. We skinned and cut up the bear, which was no easy task, as a bear's hide does not peel off like a deer's, but is tight on his body, like a hog's, the removal of every inch requiring the assistance of the knife. We reached camp by dark, and found old Asa with his leg poulticed with medicinal herbs, in the virtues of which he was well acquainted. Wounded as he was, the old man was the life of the camp. He smoked his pipe and cracked jokes at everybody. Calling Hannibal, he instructed him in the mysteries of making a "filibuster." He first took the caul-fat, or bear's handkerchief, and spread it out on the inside of the fresh hide; then he cut slices of liver and choice bits of bear-meat, in the selection of which he was' a connoisseur. Between the layers he placed a very thin slice of bacon, all the time rolling it in the caul-fat, occasionally inserting sprigs of fragrant spice-wood, as he said to give it a flavor, until a large meat sandwich was made. Then, sticking a wooden skewer through it, he roasted it before the fire. And a more savory dish never regaled the palate or olfactories of a hungry hunter.

In summing up the casualties of the fight, we found two dogs killed and seven wounded-three severely. Quiet at length settled upon our camp, the hoot of the barred owl alone breaking the stillness of the night. But it did not disturb the peaceful dreams of dogs or hunters, or of Hannibal, snoring to the accompaniment of the kettle, which hummed a lullaby as it prepared the head of Bruin for to-morrow's repast.

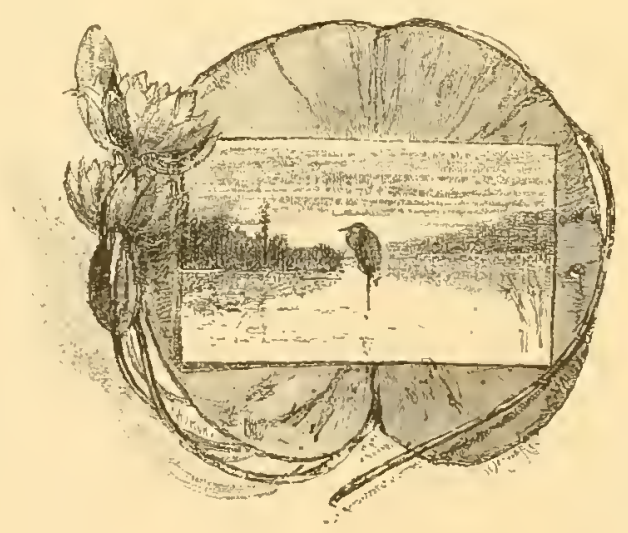




\section{FON-HUNTING IN NEIT ENGLANI).}

V

By ROITLANI) F, RUBINSOX.

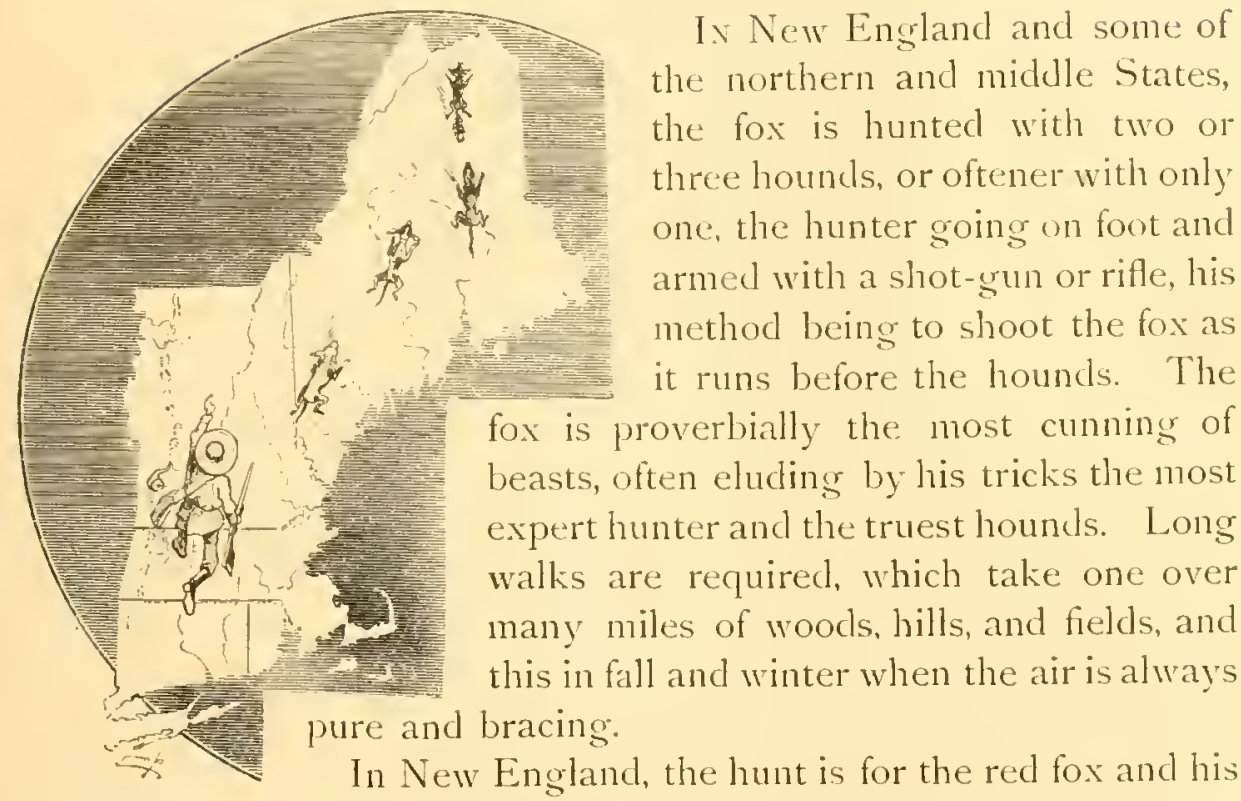
varieties; the silver and cross foxes, the gray fox of the south and west being almost, if not quite, unknown. From the tip of his nose to the root of his tail, the red fox measures about twenty-eight or thirty inches, his tail sixteen to eighteen inches including hair, and his height at the shoulder thirteen inches. His long fur and thick, bushy tail make him look larger and heavier than he is. Of several specimens which I have weighed, the largest tipped the beam at twelve pounds; the least at seven pounds. The general color is yellowish red; the outsides of the ears and the fronts of the legs and

feet are black; the chin and usually the tip of the tail, white; and 
the tail darker than the body, most of its hairs being tipped with black. The eyes are near together and strongly express, as does the whole head, the alert and cunning nature of the animal.

The cross fox, much scarcer than the red, is very beautiful. It is thus described by Thompson: "A blackish stripe passing from the neck down the back and another crossing it at right angles over the

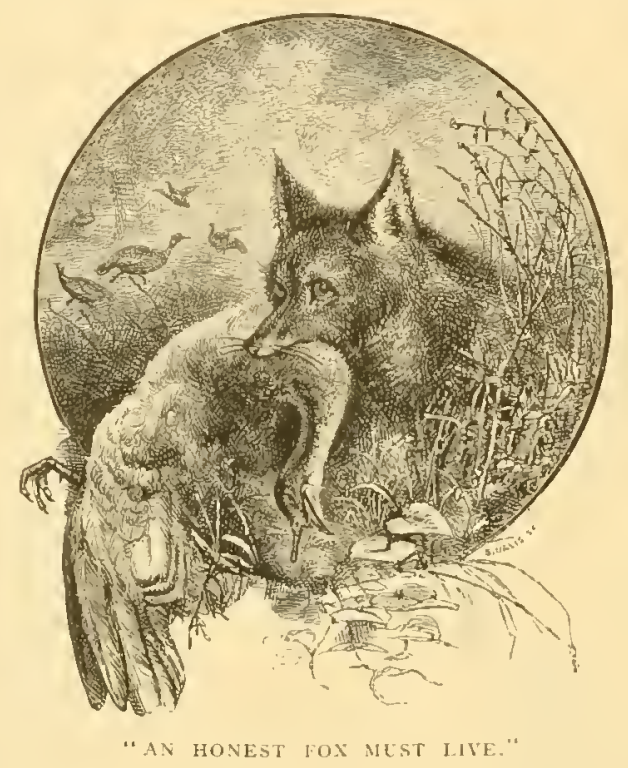

shoulders; sides, ferruginous, running into gray on the back; the chin, legs, and under parts of the body, black, with a few hairs tipped with white; upper side of the tail, gray; under side and parts of the body adjacent, pale yellow; tail tipped with white. The cross upon the shoulders is not always apparent, even in specimens which, from the fineness of the fur, are acknowledged to be cross foxes. Size, the same as the common fox."

The black or silver fox is so rare in New England that to see one is the event of a life-time. The variety is as beautiful and valuable as rare. Its color is sometimes entirely of a shining black, except the white tip of the tail, but oftener of a silvery hue, owing to an intermixture of hairs tipped with white. It has probably always been uncommon here, for it is said to have been held in such estimation by the Inclians of this region, that a silver fox-skin was equal in value to forty beaver-skins, and the gift of one was considered a 
sacred pledge. One often hears of silver foxes being seen, but, like the big fish so often lost by anglers, they almost invariably get away.

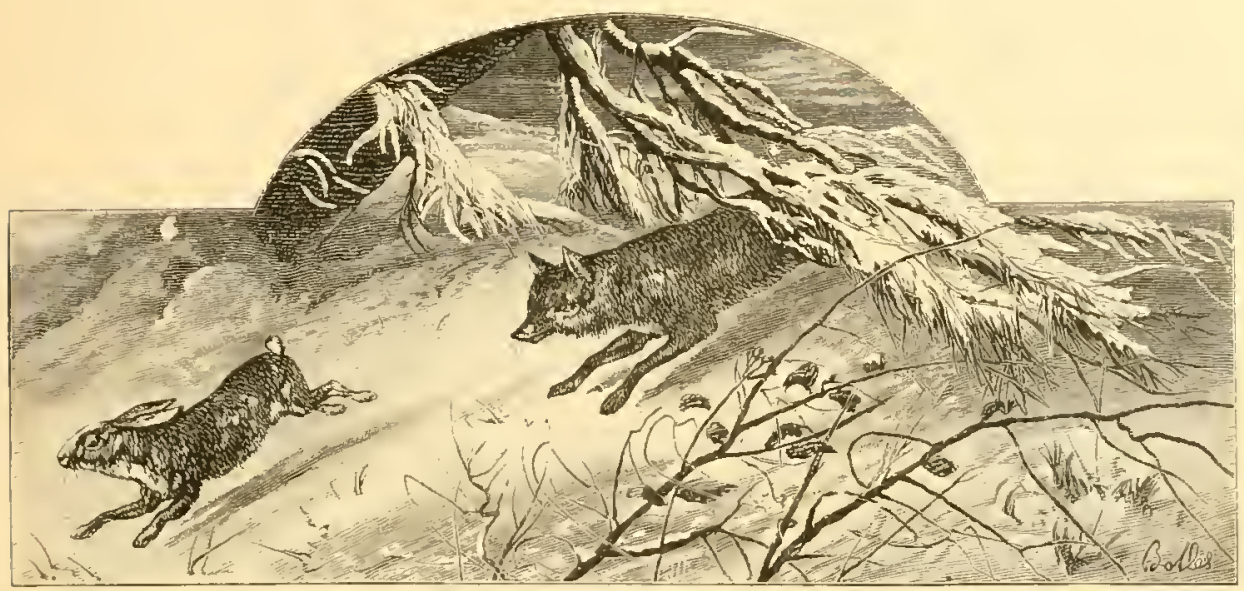

AFTER A BREAKF.1ST.

Foxes are less rare in settled countries and on the borders of civilization than in the wilderness, for, though they find no fewer enemies, they find more abundant food in the open fields than in the forest. The common field-mouse is a favorite in their bill-of-fare; and the farmer's lambs and the grood wife's geese and turkeys never come amiss therein. These are all more easily got than hares or grouse. In justice to Reynard it must be said, however, that when mice are plenty, lambs and poultry are seldom molested. In times of scarcity, he takes kindly to beech-nuts in the fall, and fills himself with grasshoppers and such small deer in the summer. When these fail, - why, what would you? An honest fox must live.

When not running before the hounds, he is seldom seen in daytime, except it may be by some early riser whose sharp eye discerns him in the dim dawn, moving in meadow or pasture, or picking his stealthy way across lots to his home woods. In these roods he spends his days, sleeping or prowling slyly about in quest of some foolish hare or grouse.

It is doubtful if the fox resorts to his burrows much except in great stress of weather and during the breeding season, or when driven to earth by relentless pursuit. For the most part, he takes his hours of ease curled up on some knoll, rock, or stump, his dense fur defying northern blasts and the "nipping and eager air" of the 


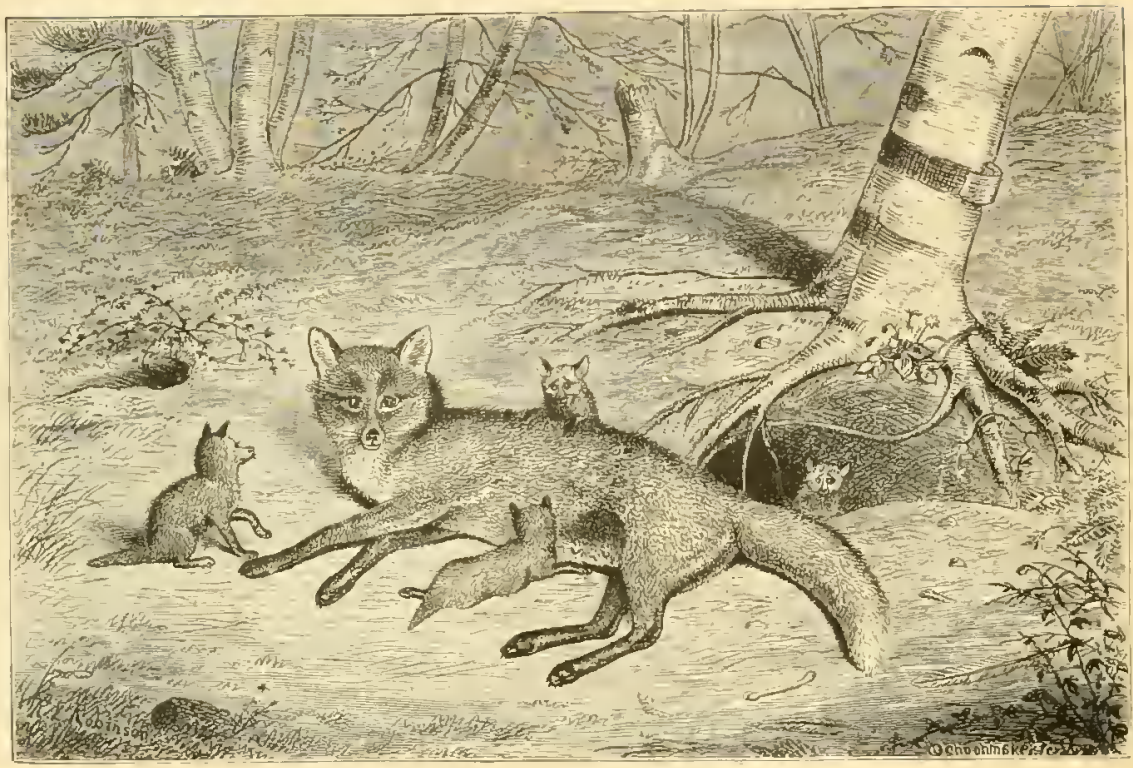

A HAPPY FAMILY

coldest winter night. Shelter from rain or snow-storms he undoubtedly will take, for he is not overfond of being bedraggled, though it is certain he will sometimes take to the water and cross a stream without being driven to it.

Reynard goes wooing in February, and travels far and wide in search of sweethearts, toying with every vixen he meets, but faithful to none, for his love is more fleeting than the tracks he leaves in the drifting snow. In April, the vixen having set her house in order by clearing it of rubbish, brings forth her young,- from three to six or more at a litter. This house is sometimes a burrow in sandy soil with several entrances; sometimes a den in the rocks, and sometimes, in old woods, a hollow log. In four or five weeks the queer little pug-nosed cubs begin to play about the entrance. The mother hunts faithfully to provicle them with food, and may sometimes be seen on her homeward way with a fringe of field-mice hanging from her month. About the entrance to the den may be seen the wings of domestic poultry, wild ducks, and grouse, and the legs of lambs, - the fragments of many a vulpine feast.

It is a curious fact, and one I have never seen mentioned in print, that while the cubs are dependent on the mother, a hound will only follow her for a few minutes. Of the existence of this provision for 
the safety of the young foxes 1 have had ocular proof, confirmed by the statements of persons whom I believe. In June, 1868, an old vixen was making sad havoc with one of my neighbors' lambs, and an old fox-hunter was requested to take the field in their defense. He proceeded with his hounds (tolerably good ones) to the woods where her burrow was known to be, and put the dogs out. They soon started her and ran her out of the woods, but greatly to the surprise of the hunter they returned in a few moments, looking as shamefaced as whipped curs, with the old fox following them. Disgusted with the behavior of his own dogs, he sought the assistance of an old hound of celebrated qualities, belonging to a neighbor. She was put out with the other dogs, with just the same result. The rixen was at last shot, while she was chasing the hounds, who then turned upon her, biting and shaking her as is their wont when a fox is killed before them; but my friend, the hunter, told me they were as sick and distressed as ever louss were after an encounter with a skunk. About the last of Mlay, 1875, I witnessed a like incident. A stanch old hound of my own having accompanied me on a fishing excursion. started a fox in a piece of woods where a litter of young were known to be. Anxious to preserve the litter for sport in the fall, 1 hastened to call in the dog. I found him trotting along with lowered tail, the vixen leisurely trotting not more than five rods in advance, stopping every half minute to bark at him, when he would stop till she again went on. I called him in as easily as if he had been nosing for a mouse, though under ordinary circumstances it would have required a vigorous assertion of authority to have taken him off so hot a scent.

If the life of the vixen is spared and she is not continually harassed by men or dogs during the breeding season, slye will remain in the same locality for years, and rear litter after litter there; perhaps not always inhabiting the same burrow, but one somewhere within the same piece of woods or on the same hill. If she is much disturbed, or if she perceives that her burrow is discovered, she speedily removes her young to another retreat. The young foxes continue to haunt the woods where they were reared for some months after they have ceased to require the care of their mother, and then disperse. The habits above mentioned are common to the cross and silver foxes, as well as the red fox. 


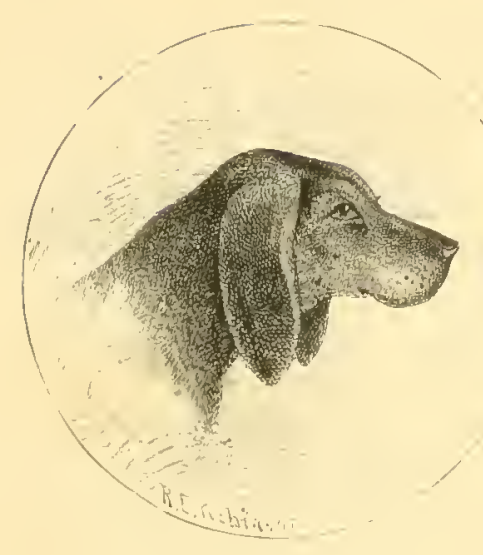

And now for the hunt. From his helpless babyhood in leafless April, Reynard has come, by the middle of the autumn, to months of discretion and to a large and increasing capacity for taking care of himself. The weapons are double-barrel shot-guns, of such weight and caliber as may suit the individual fancy. A very light gun will not do the execution at the long range sometimes required, while on the other hand, a very heavy one will become burdensome in the long tramps that may be necessary; for a man of ordinary strength, an 8-1b. gun will be found quite heavy enough. It should be of a caliber which will properly chamber its full charge of, at least, B B shot,- for I hold that the force of lighter shot will be broken by the thick fur of the fox; indeed, I would suggest still heavier pellets, say B B B, or even A.

Our hounds, not so carefully bred as they should be, cannot be classed in any particular breed. They are more like the old Southern fox-hound than like the modern English, and for our purpose are incomparably superior to the latter. They are not fleet, like him (fleetness here being objectionable, as will be shown), but of great endurance, and unsurpassable scenting powers,- - for they will follow a fox through all his devious windings and endless devices, from dawn till dark, through the night and for another day. Our best dogs are well described by Shakspere in "Nidsummer Night's Dream":

\footnotetext{
"My hounds are bred out of the Spartan kind, So flew'd, so sanded; and their heads are hung With ears that sweep away the morning dew; Crook-kneed, and dew-lapp'd like Thessalian bulls, Slow in pursuit, but matched in mouth like bells, Each under each."
}

Their colors are blue-mottled, with patches of black and tan or yellow, with tan eye-patches; white, flecked with yellow, termed by old-time hunters "punkin-an'-milk"; white and black and black and tan, with variations and admixtures of all these colors. It is an old 
saying, "that a good horse cannot be of a bad color"; and the color of a hound is more a matter of fancy than of excellence. I loud and melodious voice is a most desirable quality, and this many of our native fox-does possess in perfection. A hound with a weak roice is a constant worry, and one with a discordant roice vexes the ear. When the game is
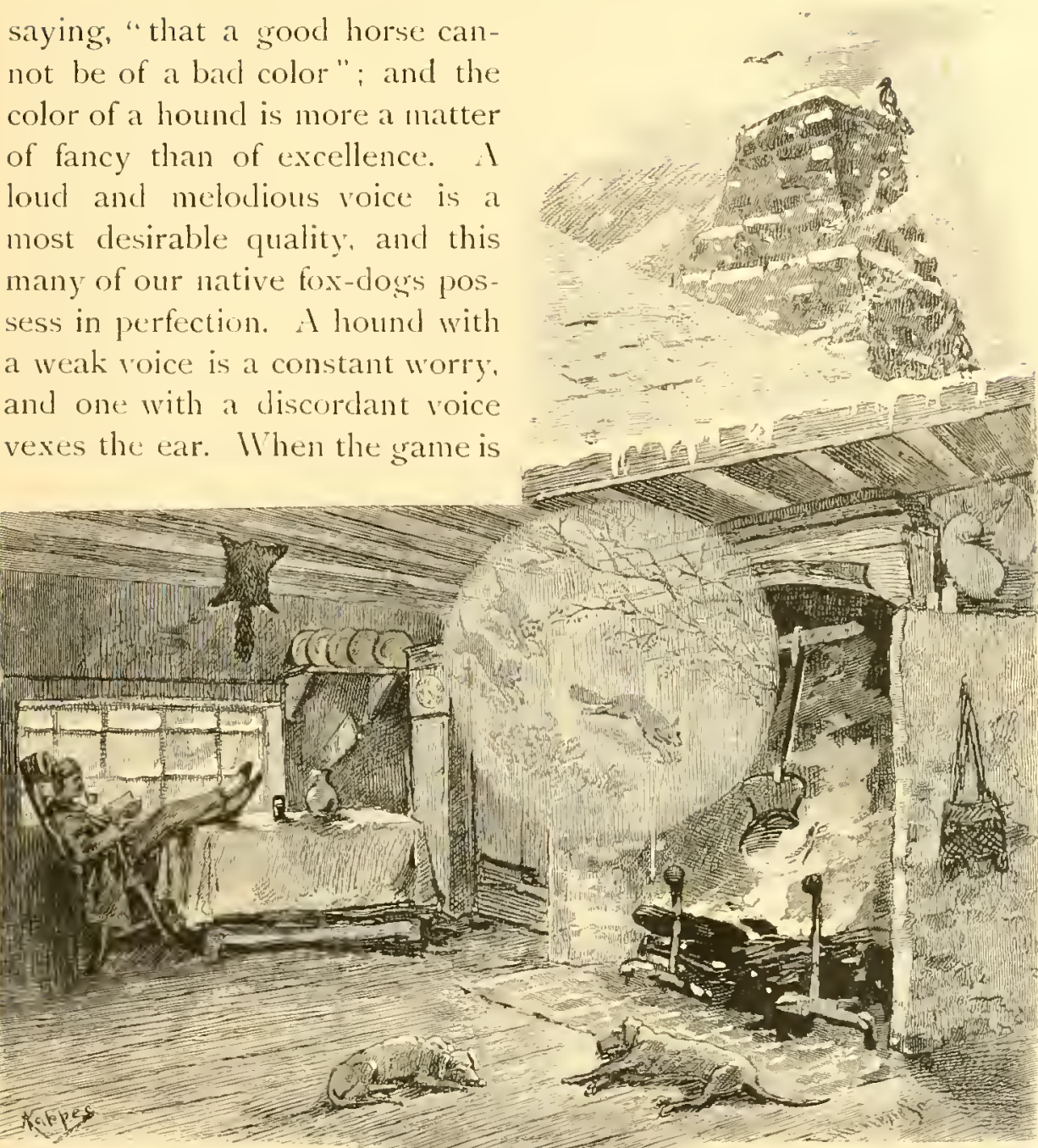

started the dog should tongue, so that you may always know just

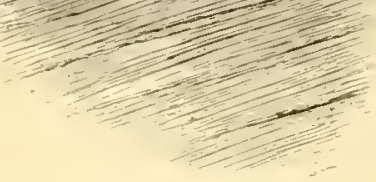

wrinkled brows and continually give (and the fox as well) where he is. The forcheads, and lons pendent ears and flews of many of these dogs, give them an extremely sad and troubled expression. Perhaps (who knows?) this solemn cast of visage comes of much pondering on the knavish tricks of the wily fox, and of schemes for circumventing his many artifices. Their tails are not at all inclined to be bushy, like those of the English fox-hounds of the present day, but are almost as slender and clean as the tail of the pointer. 
It is the early morning of one of the perfect days of late October or early November. In the soft gray light of the growing day, the herbage of the pastures and the aftermath of the meadows are pearly with frost which is thick and white on boards and fence-rails. The air is chill

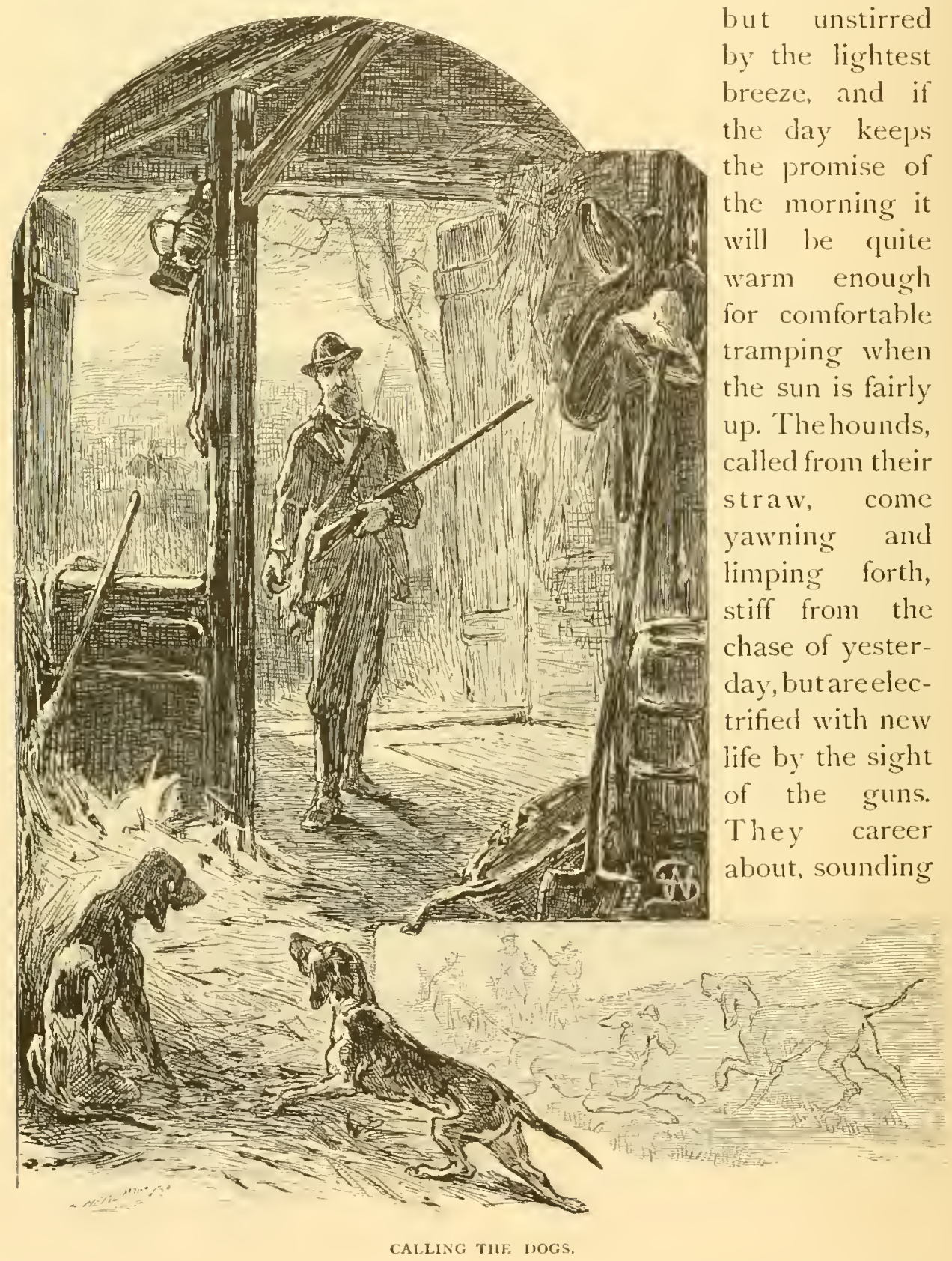




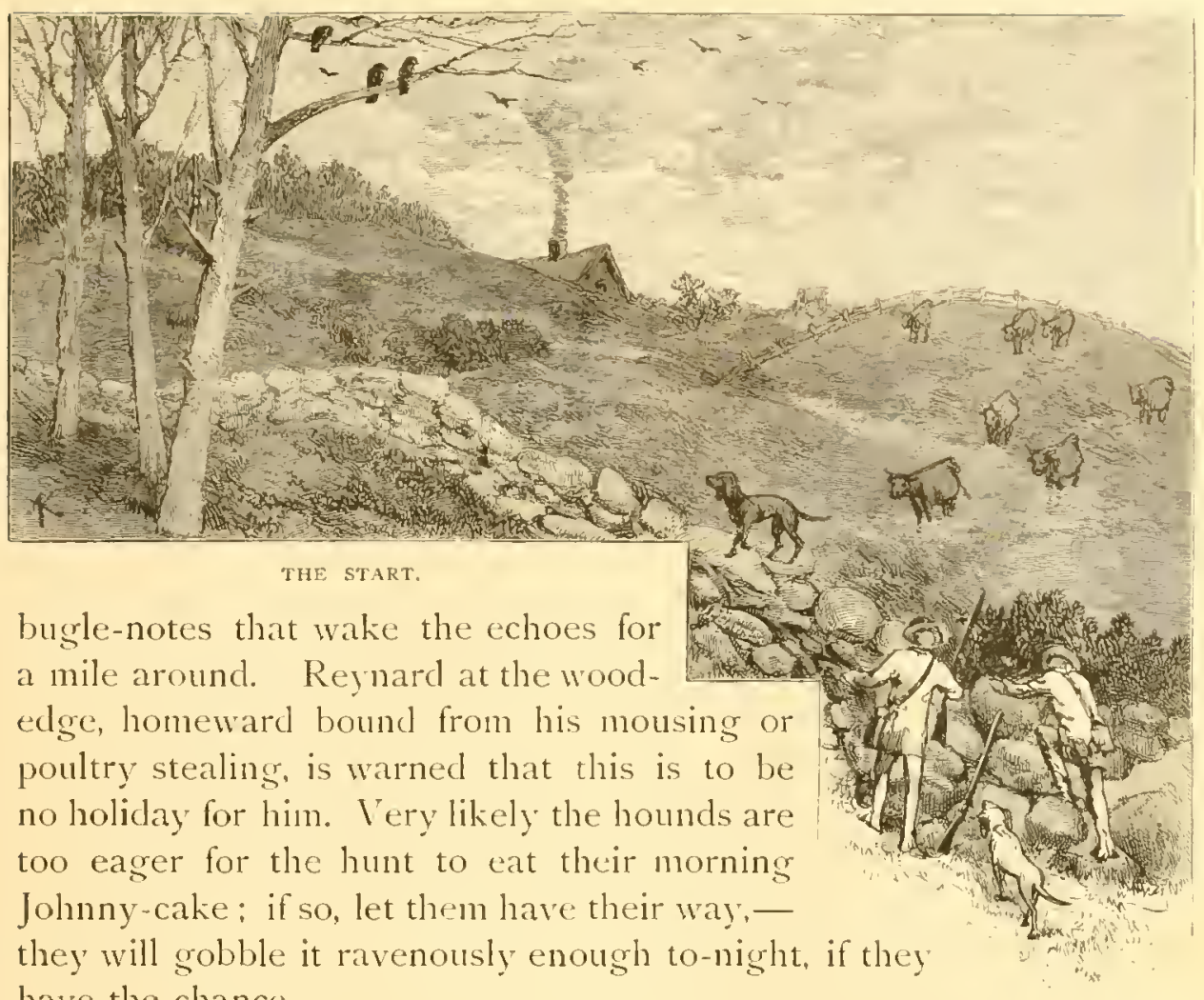
have the chance.

And now, away! across the frosty fields toward yonder low hill, which we dignify with the name of mountain. No song-birds now welcome the coming day; almost the only sound which breaks the gray serenity is the clamor of a flock of crows in the distant woorls, announcing their awakening to another day of southward journeying, or the challenge of a cock in a far-off farm-yard. As you hurry across the home pasture, the cows stop chewing the cud, to stare curiously at hounds and hunters, and then arise, sighing and stretching, from their couches on the dry knolls. A flock of sheep start from their huddled repose and scurry away, halting at a little distance to snort and stamp at the rude disturbers of their early meditations. Almost the only signs of life are these, and the upward crawling smoke of kitchen chimneys, where sluggards are just making their first preparations for breakfast. Yours has been eaten this half hour. The old dog plods along, with serious and business-like air, disdaining and repelling all attempts of his younger companion to 
beguile him into any unseemly gambols; but when you cross the fence which bounds the pasture lying along the foot of the hill, where the rank grass, mixed with last year's growth. is ankle deep, and where grass and innumerable stumps and logs afford harbor for colonies of field-mice, you find "there is life in the old dog yet." He halts for an instant and snuffs the air; draws toward a tuft of grass and noses it carefully; his sensitive nostrils dilate; his staid and sober tail begins, not to

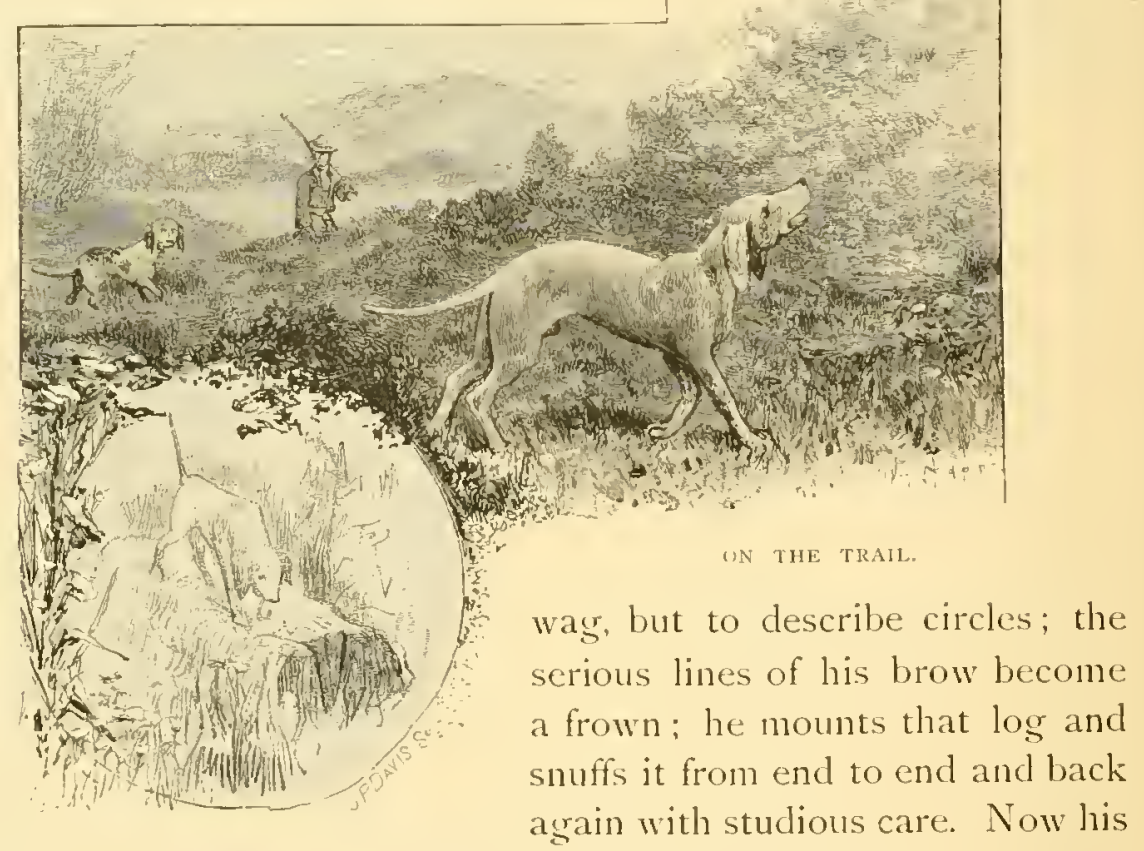

loud, eager snuffing has grown to a suppressed challenge, and every muscle seems strained to its utmost tension, as he leaves the log and makes a few lopes toward the woods, stops for an instant as if turned to stone, raises his good gray muzzle skyward, and awakens all the woods and hills with his deep, sonorous voice! That way has Reynard gone, and that bugle-note has perhaps given him premonition of his doom. This note has recalled the young dog from his wild ranging, and he joins his older and wiser companion, without bringing much aid, however, for, catching the scent, he proclaims his discovery till long after he has overrun it, now and then slightly disconcerting the old truth-teller: but the veteran soon learns to 


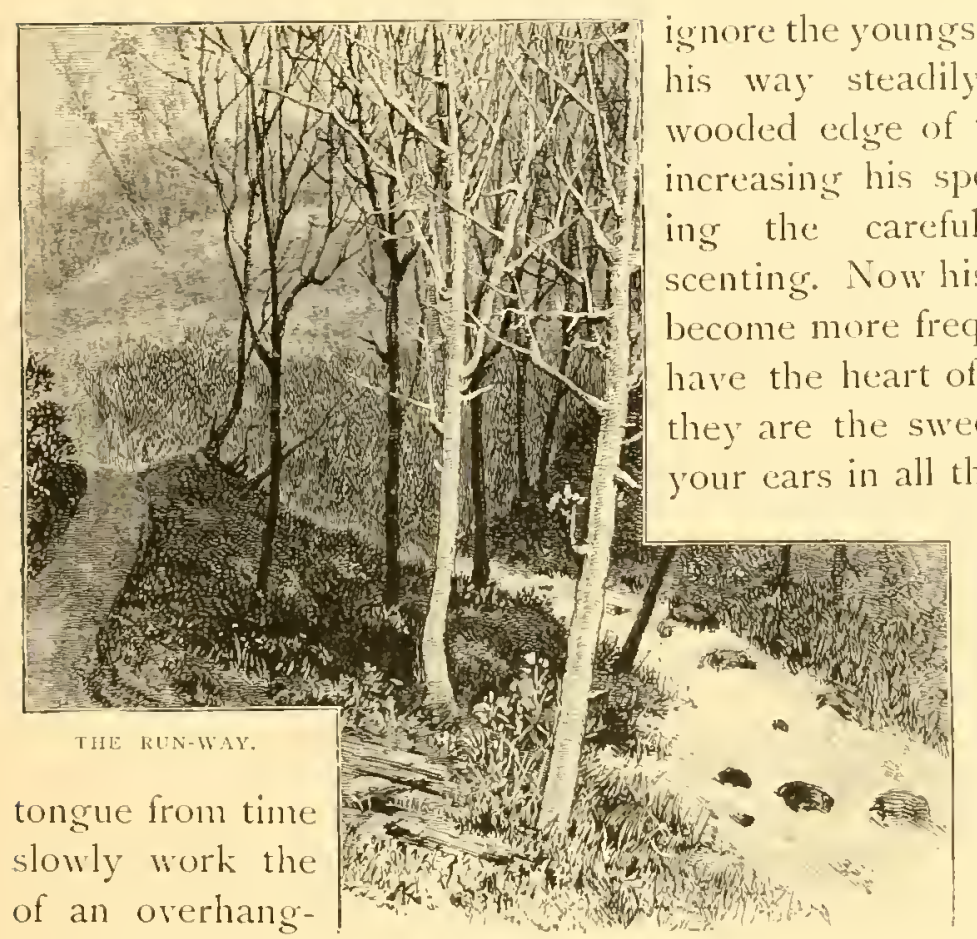

ignore the youngster, and works his way steadily toward the wooded edgre of the hill, never increasing his speed, nor abating the carefulness of his scenting. Now his tuneful notes become more frequent. If you of a fox-hunter, sweetest music to the steep side of the hill he takes his way, the young dog following, and both giving to time. They trail to the top ing ledge, and now there is a hush; but, almost before the echo of their last notes has died away, forth bursts a wild storm of canine music. Reynard is afoot, or, as we Yankees say, "the fox is started," and the reeking scent of his recent footsteps steams hot in the nostrils of his pursuers. The hounds are now out of sight, but you hear every note of their jubilant song as they describe a small circle beyond the ledge, and then go northward along the crest of the hill. Their baying grows fainter and fainter as they bear away to the further side, till at last it is almost drowned by the gurgle of the brook.

Now, get with all speed to "the Notch," which divides the north from the south hill, for this the fox will pretty surely cross when he comes back, if back he comes, after making a turn or two or three at the north end. On this habit of his, of running in circles, and in certain run-ways as he goes from hill to hill, or from wood to wood, is founded our method of hunting him. If he" plays" in small circles, encompassing an acre or so, as he often will for half an hour at a time before a slow dog, you cautiously work up to leeward of him and try your chances for a shot. If he encircles the whole hill, or crosses from hill to hill, there are certain points, which every fox, 


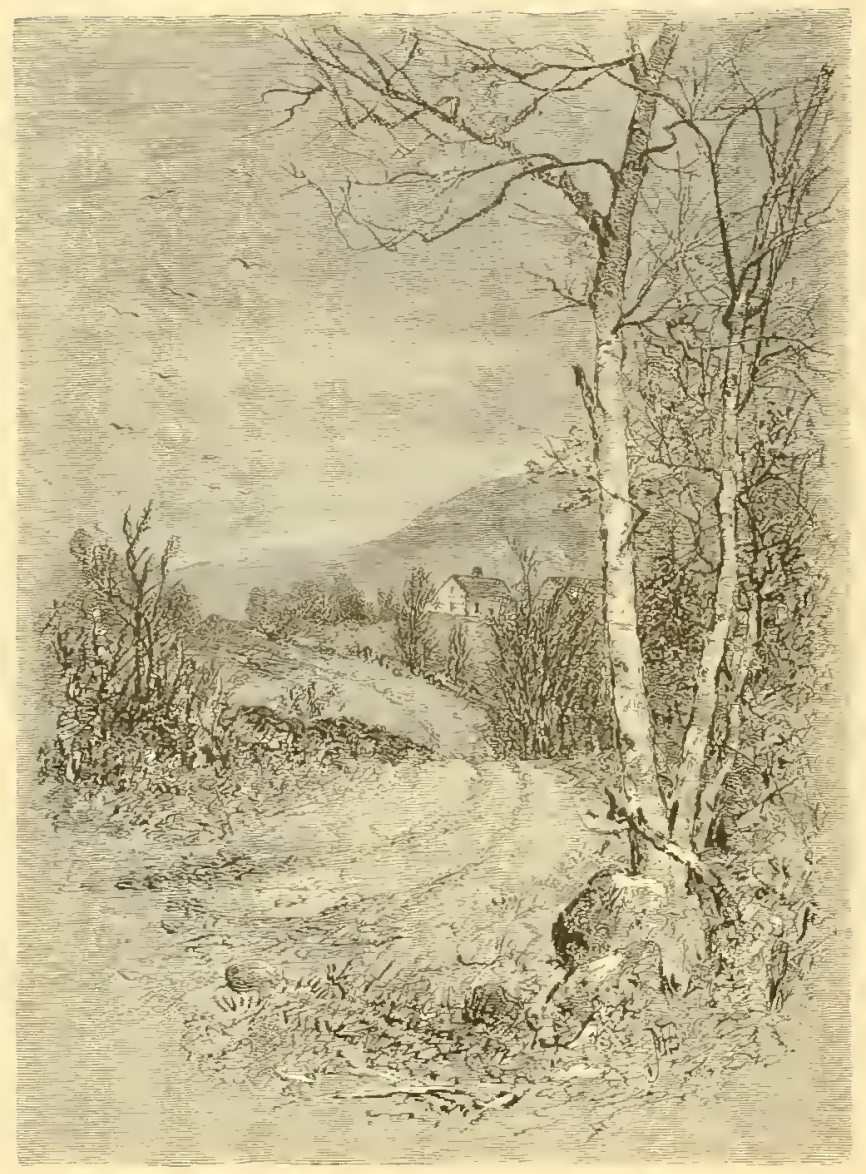

IN NOVEMBER.

whether stranger or to this particular woodland born, is likely to take in his way, but not sure to do so. Having learned these points by hearsay or experience, you take your post at the nearest or likeliest one, and between hope and fear await your opportunity. Such a place is this Notch, toward which with hasty steps and beating heart you take your way. When the for returns, if he crosses to the south hill, he will come down that depression between the ledges which you face; then cross the brook and come straight in front of you, toward the wood-road in which you stand, or else turn off to the right to cross the road and go up that easy slope to the south hill, or turn to the left and cross on the other hand. Standing midway between these points, either is a long gun-shot off. but it is the best place to post yourself; so here take breath and steady your nerves. 
How still the woods are! The hounds are out of hearing a mile away. No breeze sighs through the pines or stirs the fallen leaves. The trickle of the brook, the penny-trumpet of a nut-hatch, the light hammering of a downy woodpecker are the only sounds the strained ear catches. All about rise the gray tree-trunks; overhead, against the blue-gray sky, is spread their net of branches, with here and there a tuft of russet and grolden and scarlet leaves caught in its meshes. At your feet, on every side, lic the fading and faded leares, but bearing still a hundred hues; and through them rise tufts of green fern, brown stems of infant trees and withered plants; frost-blackened beech-drops, spikes of the dull azure berries of the blue cohosh, and milk-white ones, crimson-stemmed, of the white cohosh; scarlet clusters of wild turnip berries; pale asters and slender golden-rod, but all so harmoniously blended that no one object stands forth conspicuously. So kindly does Nature screen her children, that in this pervading sray and russet, beast and bird, blossom and gaudy leaf. may lurk unnoticed almost at your feet. The rising sun begins to glorify the tree-tops. And now, a red squirrel startles you, rustling noisily through the leaves. He scrambles up a tree, and, with nervous twitches of feet and tail, snickers and scolds till you feel almost wicked enough to end his clatter with a charge of shot. A bluejay has spied you and comes to upbraid you with his discordant voice. A party of chickadees draw nigh, flitting close about and pecking the lichened trunks and branches almost within arm's-length, satisfying curiosity and hunger together.

At last, above the voices of these garrulous visitors, your ear discerns the baying of the hounds, faint and far away, swelling, dying, swelling, but surely drawing nearer. Louder rings the "musical confusion of hounds and echo in conjunction," as the dogs break over the hill-top. Now, eyes and ears, look and listen your sharpest. Bring the butt of your gun to your shoulder and be motionless and noiseless as death. for if at two gun-shots off Reynard sees even the movement of a hand or a turn of the head, he will put a tree-trunk between you and him, and vanish altogether and "leave you there lamenting."

Is that the patter of feet in the dry leaves, or did the sleeping air awake enough to stir them? Is that the fox? Pshaw! noonly a red squirrel scurrying along a fallen tree. Is that quick, 
muffled thud the drum of a partridge? No, it never reaches the final roll of his performance. It is only the beating of your own heart. But now you hear the unmistakable nervous rustle of Rey-

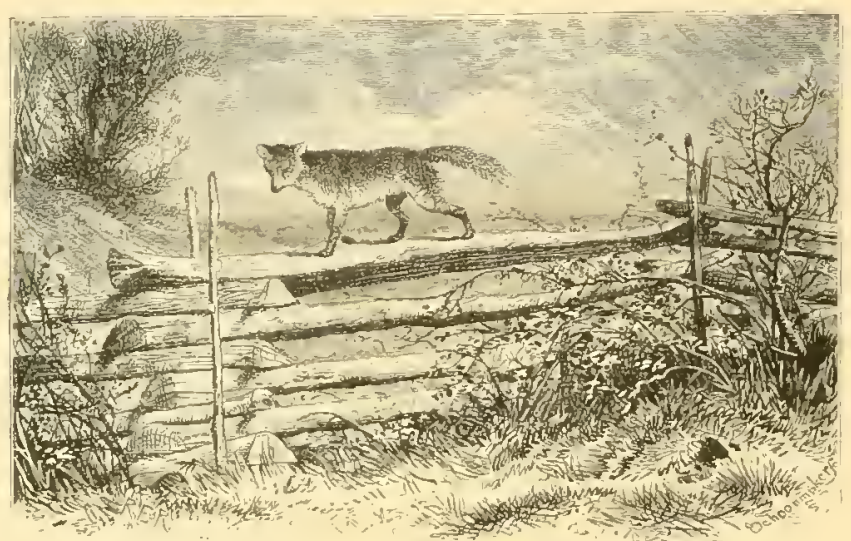

TO DESTROY THE SCENT

nard's footsteps in the leaves; now bounding with long leaps, now picking his way; now unheard for an instant as he halts to listen. A yellow-red spot grows out of the russet leaves, and that is he, coming straight toward you. A gun-shot and a half away, he stops on a knoll and turns half-way round to listen for the dogs. In great suspense you wonder if he will come right on or sheer off and baffle you. But a louder sounding of the charge by his pursuers sends him onward right toward you. His face is a study as he gallops leisurely along, listening and plotting. He picks his way for a few yards along the outcropping stones in the bed of the brook, and then begins to climb the slope diagonally toward you. He is only fifty yards off when you raise the muzzle of your gun, drop your cheek to the stock, and aim a little forward of his nose; your finger presses the trigger, and while the loud report is rebounding from wood to hill, you peer anxiously through the hanging smoke to learn whether you have cause for joy or mortification. Ah! there he lies, done to death, despite his speed and cunning. The old dog follows his every footstep to the spot where he lies, stops for a breath in a half surprise as he comes upon him, then seizes him by the back, shaking him savagely, and biting him from shoulders to hips. Let him mouth his fallen foe to his heart's content, no matter how he rumples the sleek fur; it is his only recompense for the faithful service he has so well performed. And now the young dog comes up and claims his reward, and be 


\section{For-Hunting in New England.}

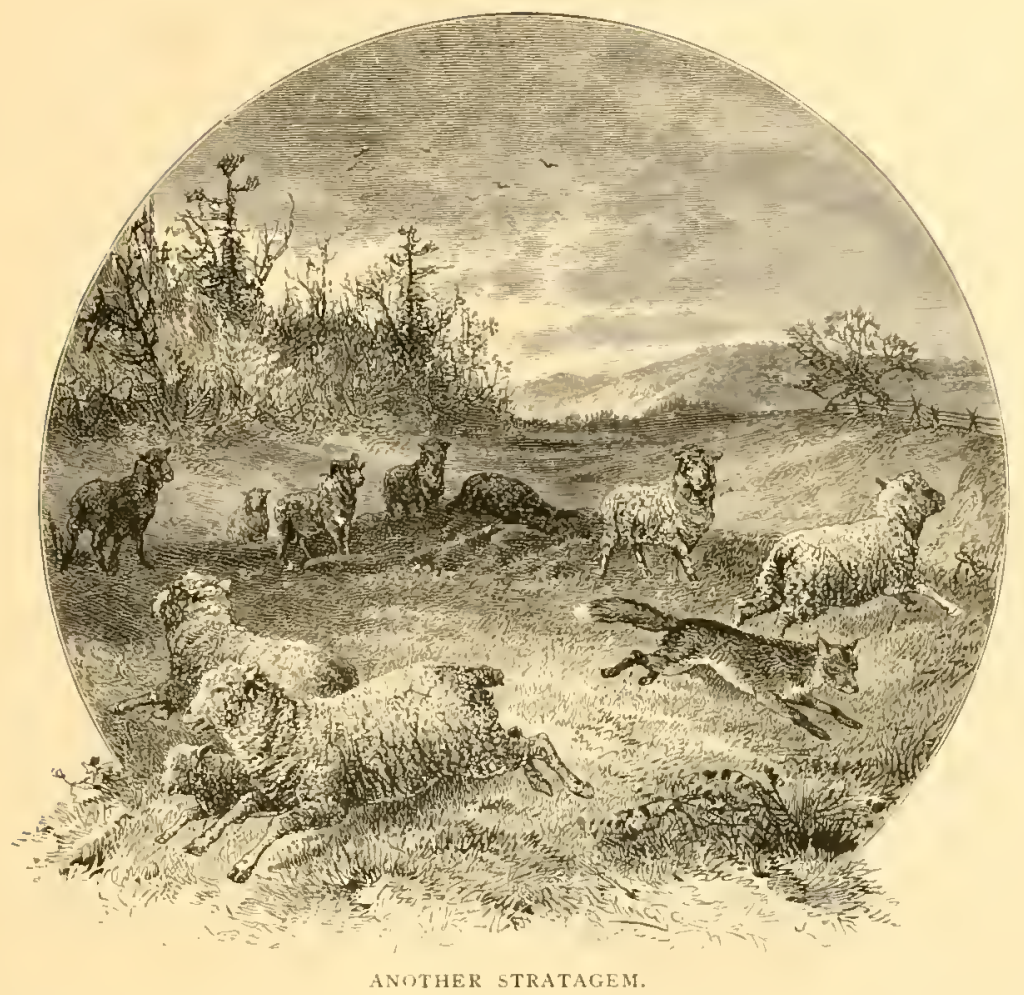

sure this morning's work will go far toward making him as stanch and true as his chase-worn leader.

But think not thus early nor with such successful issue is every chase to close. This was ended before the fox had used any other trick for baffling the hounds, but his simplest one of running in circles. An hour or two later, and old fox, finding the dogs still holding per sistently to all the windings of his trail, would have sped away to another hill or wood a mile or so off, and would have crossed newlyplowed fields, the fresh earth leaving no tell-tale scent; would have taken to traveled highways, where dust and the hoofs of horses and the footsteps of men combine to obliterate the traces of his passage: or have trod gingerly along many lengths of the top rails of a fence and then have sprung off at right angles with it to the ground, ten feet away: and then, perhaps, have run through a flock of sheep, the strong odor of whose feet blots out the scent of his. These artifices quite bewilder and baffle the young dog. but only delay the elder. who knows of old the tricks of foxes. Nothing can be more admirable than the manner of his working, as he comes to the edge of the plowed field. He wastes no time in useless pottering 
among the fresh-turned furrows, but with rapid lopes skirts their swarded border, till, at a far corner, his speed slackens as his keen nose catches the scent again in the damp grass: he snuffs at it an instant to assure himself, then sounds a loud, melodious note, and goes on baying at every lope till the road is reached. Along this he zigzags till he finds where the for has left it. and now comes the puzzling bit of fence. The old log thinks the fox has gone through it: he groes through it himself, but finds no scent there; puzzles

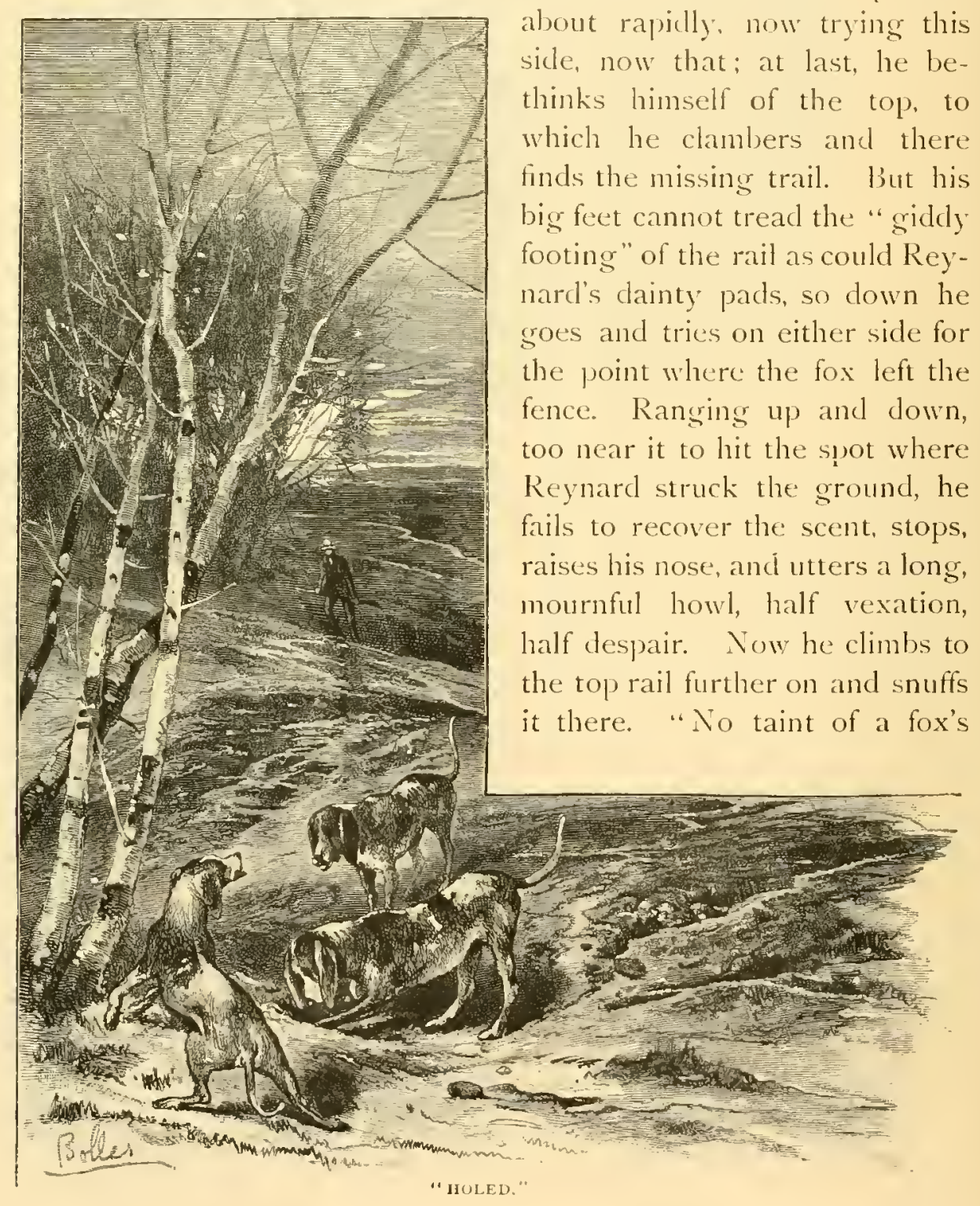


foot is here," so he reasons, "and he must have jumped from the fence between here and the place where I found it," and acting on this logical conclusion, he circles widely till he has picked up the trail onces more, and goes merrily on to the sheep pasture. Here satisfying himself of the character of this trick, he adopts the same plan employed at the plowed field, and after a little finds the trail on the other side and follows it to the hill, but more slowly now, for the fox has been gone some time; the frost has melted, the moisture is exhaling, and the scent growing cold. The fox has long since reached the hill and half encircled it, and now hearing the voices of the hounds so far away and so slowly nearing, has bestowed himself on the mossy cushion of a knoll for rest and cogitation. Here he lies for a half hour or more, but always alert and listening, while the dogs draw slowly on, now almost losing the trail on a dry ledge, now catching it in a moist, propitious hollow, till at last a nearer burst warns poor slyboots that he must again up and away. He may circle about or "play," as we term it, on this hill, till you have reached a run-way on it where you may get a shot; or, when you have toiled painfully up the steep western pitch and have just reached the top, blown, legweary, but expectant, he will probably utterly disappoint and exasperate you by leaving this hill and returning to the one he and you have so lately quitted,-yea, he will even intensify the bitterness of your heart by taking in his way one or two or three points where you were standing half an hour ago! What is to be done? He may run for hours, now on the hill where he was started, or he may be back here again before the hunter can have regained that. To hesitate may be to lose, may be to gain, the coveted shot. One must choose as soon as may be and take his chances. If two persons are hunting in company; one should keep to this hill, the other to that, or while on the same hill, or in the same wood, each to his chosen run-way, thus doubling the chances of a shot.

At last, the hounds may be heard baying continuously in one place, and by this and their peculiar intonation, one may know that the fox, finding his tricks unavailing, has run to earth, or, as we have it, "has holed." Guided to his retreat by the voices of the hounds, you find them there, by turns, baying angrily and impatiently and tearing away, tooth and nail, the obstructing roots and earth. If in a sandy or loamy bank, the fox may, with pick and spade, be dug 
ignominiously forth, but this savors strongly of pot-hunting. If he has taken sanctuary in a rocky den, where pick and spade avail not, there is nothing for it but to call the dogs off and try for another fox to-day, or for this one to-morrow, when he shall have come forth again. This is the manlier part, in either case, for Reynard has fairly baffled you, has run his course and reached his goal in safety.

Sometimes an old fox, when he hears the first note of the hounds on the trail he made when he was mousing under the paling stars, will arise from his bed, and make off at once over dry ledges, plowed fields and sheep pastures, leaving for the dogs nothing but a cold, puzzling scent, which, growing fainter as the day advances and the moisture exhales, they are obliged, unwillingly, to abandon at last, after hours of slow and painstaking work. A wise old hound will often, in such cases, give over trying to work up the uncertain trail, and guessing at the direction the fox has taken, push on, running mute, at the top of his speed, to the likeliest piece of woodland, a mile away perhaps, and there, with loud rejoicings, pick up the trail. W'hen after a whole day's chase, during which hope and disappointment have often and rapidly succeeded each other in the hunter's breast, having followed the fox with untiring zeal through all the crooks and turns of his devious course, and unraveled with faultless nose and the sagacity born of thought and experience his every trick, - the good dogs bring him at the last moment of the gloaming within range, and by the shot, taken darkling. Reynard is tumbled dead among the brown leaves, great is the exultation of hunter and hound, and great the happiness that fills their hearts. After tramping since early morning over miles of the likeliest "starting-places" without finding any trail, but cold and scentless ones made in the early night, and so old that the dogs cannot work them out. as the hunter takes his way in the afternoon through some piece of woodland, his hounds as discouragred as he, with drooping tails and increased sorrow in their sad faces, plodding, dejected at heel, or ranging languidly, - it is a happy surprise to have them halt, and with raised muzzles and half-closed eyes, snuff the air, then draw slowly up wind with elevated noses, till they are lost to sight behind gray trunks and mossy logs and withered brakes, and then, with a crashing flourish of trumpets, announce that at last a fox has been found, traced to his lair by a breeze-borne aroma so subtle that the 


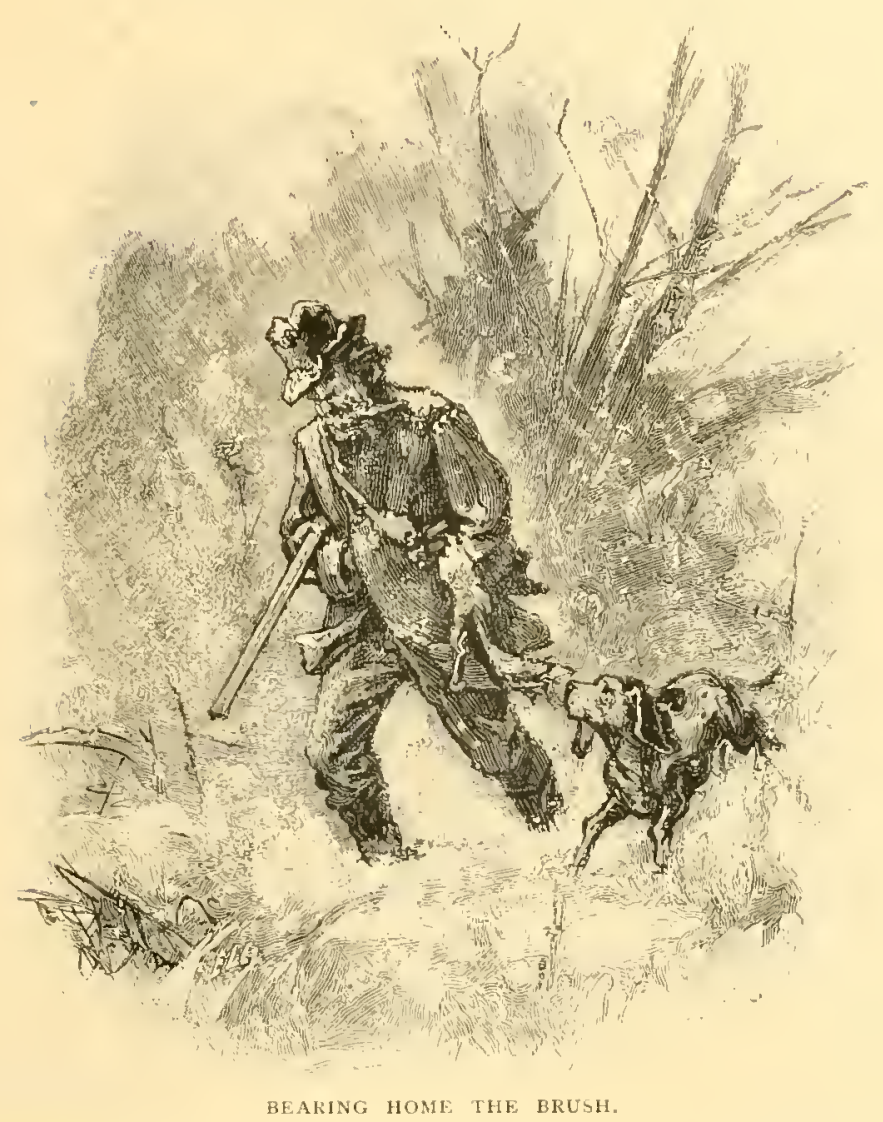

sense which detects it is a constant marvel. A fox started so late in the day seems loath to leave his wood, and is apt to play there till a shot gives to the hunter and hounds their reward.

When one sees in the snow the intricate windings and crossings and recrossings of the trail of a mousing fox, he can but wonder how any dog by his nose alone can untangle such a knotted thread till it shall lead him to the place where the fox has laid up for the day; yet this a good hound will unerringly do, if the scent has not become too cold. To see him do this, and to follow all his careful, sagacious work, are in nowise the least of the pleasures of this sport.

It is a favorite season for fox-hunting when the first snows have fallen, for though the walking is not so good, and hounds are often much inclined to follow the track by sight as well as by smell, the telltale foot-prints show pretty plainly which way the fox has gone, how 
long he has been gone, and whether it is worth your while to allow the dogs to follow his trail ; and you are enabled to help the hounds in puzzling places, though a dog of wisdom and experience seldom needs

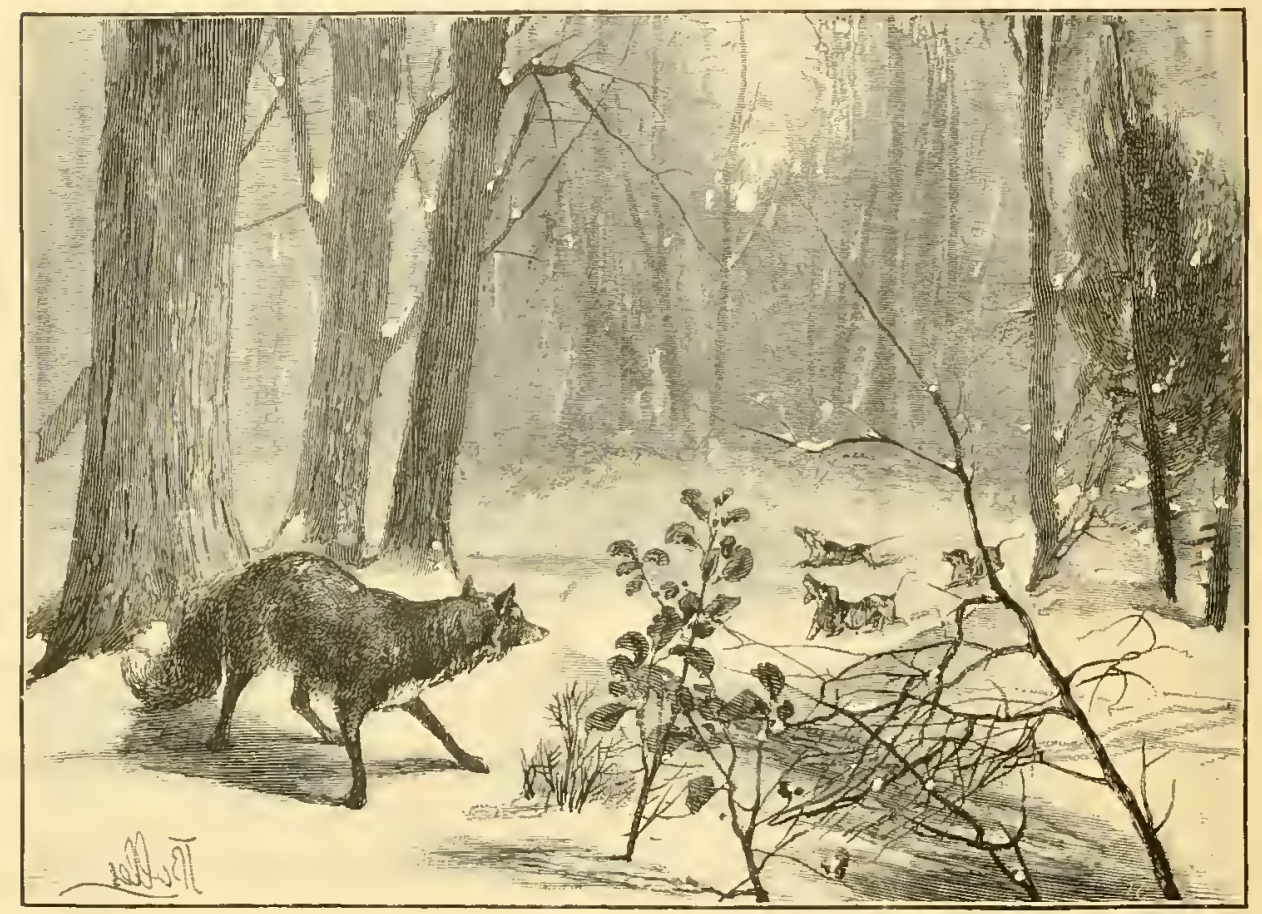

TANTALIZING THE DUGS.

help, except for the saving of time. A calm day is always best, and if warm enough for the snow to pack without being at all "sposhy," so much the better. Though it is difficult to "start" a fox during a heavy snow-fall, if you do start him, he is pretty certain to "play" beautifully, seeming to reckon much on the obliteration of his track by the falling snow. At such times he will often circle an hour in the compass of two or three acres. Glare ice holds scent scarcely more than water. This, no one knows better than the fox, and you may be sure he will now profit by this knowledge if naked ice can be found. He will also run in the paths of the hare, pick his way carefully along rocky ridges swept bare of snow by the wind, leaving no visible trace of his passage, and, at times, take to traveled highways. If the snow is deep and light so that he sinks into it, he will soon, through fatigue or fear of being caught, take refuge in den or 
burrow. If the snow has a crust which bears him, but through which the heavier hounds break at every step, he laughs them to scorn as he trips leisurely along at a tantalizingly short distance before them. Hunting in such seasons is weary work, and more desirable then is the solace of book and pipe by the cozy fireside, where the hounds lie sleeping and dreaming of grlorious days of sport, already past or soon to come.

In winter as in autumn, the sport is invigorating and exciting, and Nature has now, as ever, her endless beauties and secrets for him who hath eyes to behold them. To such they are manifold in all seasons, and he is feasted full, whether from the bald hill-top he looks forth over a wide expanse of gorgeous woods and fields, still green under October skies, or sees them brown and sere through the dim November haze, or spread white and far with December snows. The truest sportsman is not a mere skillful butcher, who is quite unsatisfied if he returns from the chase without blood upon his garments, but he who bears home from field and forest something better than game and peltry and the triumph of a slayer, and who counts the day not lost nor ill spent though he can show no trophy of his skill. The beautiful things seen, the ways of beasts and birds noted, are what he treasures far longer than the number of successful shots.

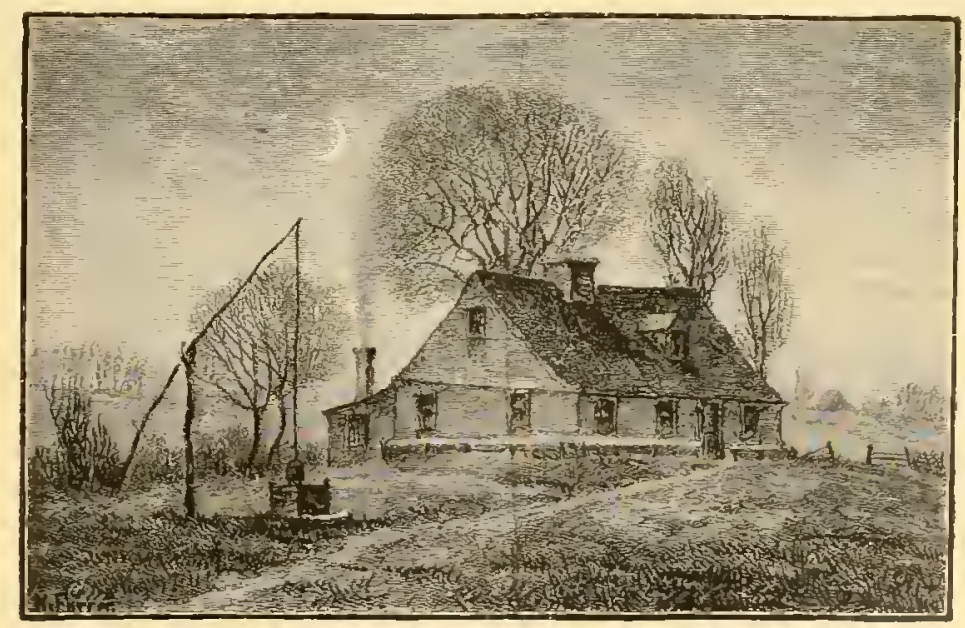




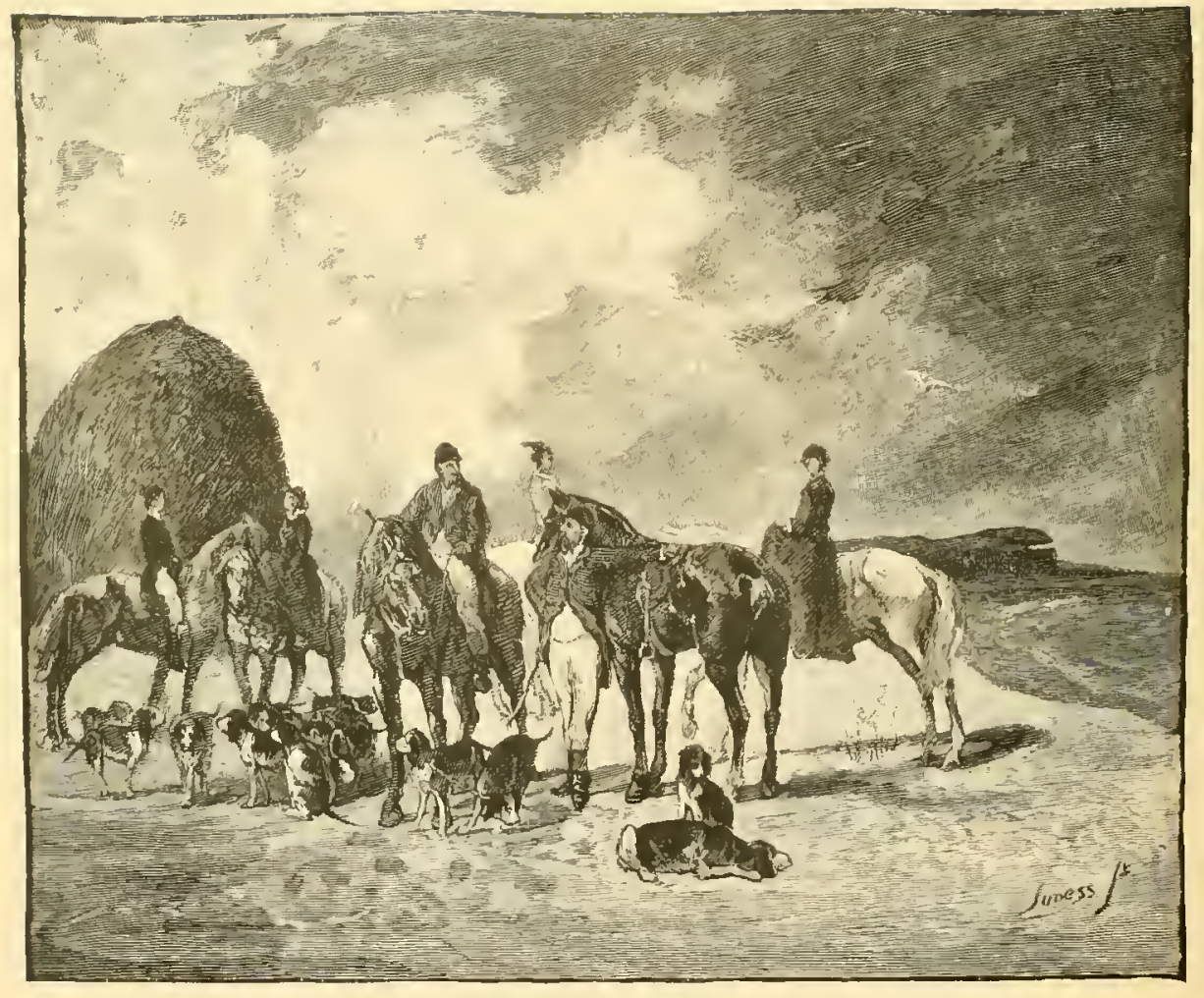

A MEET AT NEWPORT. 


\section{A BUFFALO HUNT IN NORTHERN MENICO. \\ IY GEN. LEW. WALLACE.}

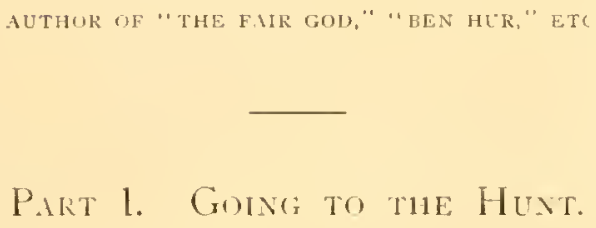

0

NE traveling to the far city of Chihuahua by way of Monterey and Saltillo must cross what the Mexicans call El Desierto, which is not to be understood as a region of shifting sand and mud-gray mountains, like the deserts of the Bedawee. It is only a rainless belt - rainless in the summer and fall and part of the winter. More fertile land, speaking of the land itself, is not on the globe. The results of irrigation by the sufficient water-courses are incredible to strangers, while the plateaus and long swates between mountains, and frequently the mountains clear to their crests, are covered with rank grasses which, grown in the brief season of rain, are peculiar in that they cure themselves in the standing stalk. Such are the pasturas of Durango and Chihuahua, vast enough and rich enough to feed and fatten all the herds of whatever kind owned by men.

The resting-places on the way to the desert are Parras, celebrated for its sweet red wines and the wonderful beauty of its site and surroundings; Alamos, most rural of Mexican towns, dominating the great Laguna district, once so coveted by the dead president of the Latter Day Saints; and Mapimi, whence, off the road right or left, lo, the dreaded wilderness!

The towns named are two and three days apart, with certain ranchos between them, but for which the wayfarer would be compelled to bivouac where the night found him, on the open plain or 
under some great rock, and I am not certain but the plain or the rock would furnish preferable lodging. The peon, however, to whom the sunburnt and perishing habitations have fallen, is of simple soul, full of easy content. He and Nature live close neighbors, and what with much borrowing from her, he has few needs ungratified, and no experience of better things to dog him with vain wishes. Of these places of torment - I speak as somewhat used to civilized ways there rise vividly to mind Seguein, Bocarilla. Tierra Leon, and Salitre. Should my reader be of the class sometimes smitten with a longing for a home in a desert, let me recommend to him a day and night in Salitre. Besides the solitude of the waste place it is squatted in, the flavor of muscal, in constant distillation, hangs round it all the year. Superb specimen of a low-down rancho, nothing need be said of it as a hotel.

But these midway stops are not all Bocarillas and Salitres. The hacienda of Patos was the residence of the administrator of the great Carlos Sanchez, who, in Maximilian's day, was monarch of over seven thousand peons, settled on his estate of $8,131,242$ acres. With such possessions it is not wonderful that Carlos was overcharmed by the prospect of an empire; and when he accepted the office of Grand Chamberlain to the short-lived emperor, it is not more strange that Juarez, the Lincoln of his country, followed him with a decree by which Patos became the property of the nation, subject to purchase. A more beautiful place will scarcely be found in Mexico. He who has seen the patio of the Casa Grande, and rested in the coolness of its broad colonnade, may not soon forget Patos, which he comes upon from the hill-country between Saltillo and Parras, an unexpected Paradise on a grim, purgatorial road.

Then Hornos will not out of mind. First heard of at Alamos, it is finally overtaken at the end of a long day's journey. Its externals are nothing, - four dead faces of cream-white stone, originally softer than the coquina of Florida, - no windows, one door with two mighty valves which look as if they might have once hung in the Joppa gates of Jerusalem.

A hospitable Spaniard told me the story of the house. Señor Don Leonardo Zuloaga was a European by birth and education. He owned a great estate on the edge of the unexplored Bolson, extending quite to Alamos on the south. The fortune was ducal. There 


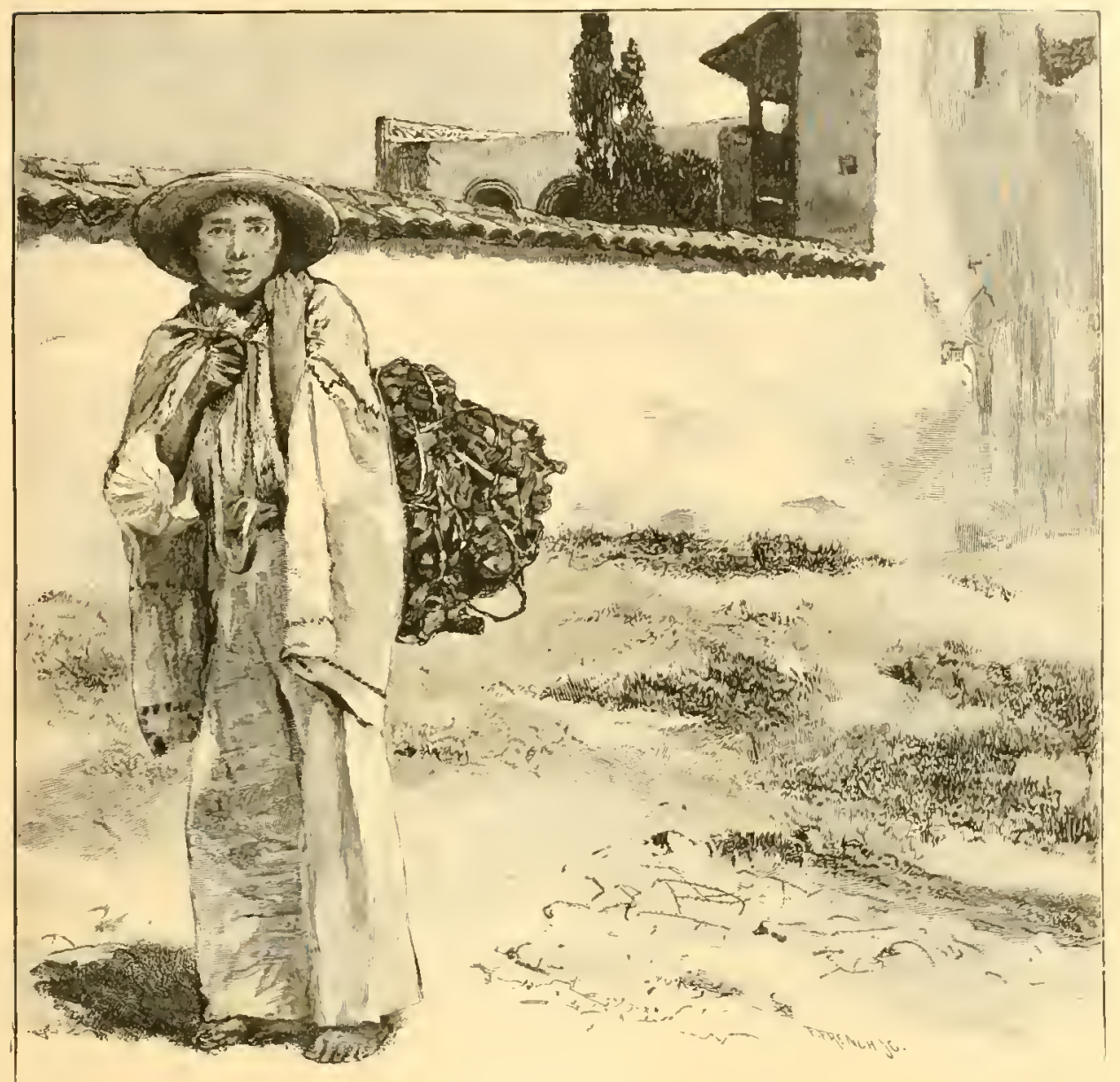

ON THE ROAD

was in his tastes a streak of savagery, and to indulge it he wandered out so far in the desert and built this fortalice. Then he brought pictures, books, wines, guns, dogs, horses; friends followed in swarms, his hospitality was semi-regal; when his guests palled of feasting, drinking, gambling, and hunting deer and wolves, not seldom he led them in long pursuit of the Comanche, or Lipan, or Apache, all quite as untamable as wolves. The Lagunieros were of his tenantry - fierce, idle, independent republicans, upon whom not even the French could make an impression, though they plied them with fire and sword. One day, they came up and demanded that he rent them certain lands upon their terms. He refused; war ensued, and regular battles. Zuloaga was driven off, and finally died of sheer 
mortification, a disease with all over-proud souls. Gonzales Herrera, a brutal ranchero, assumed the estate by right of conquest, and supplanted the unquestioning hospitality of the proprietor with an out-

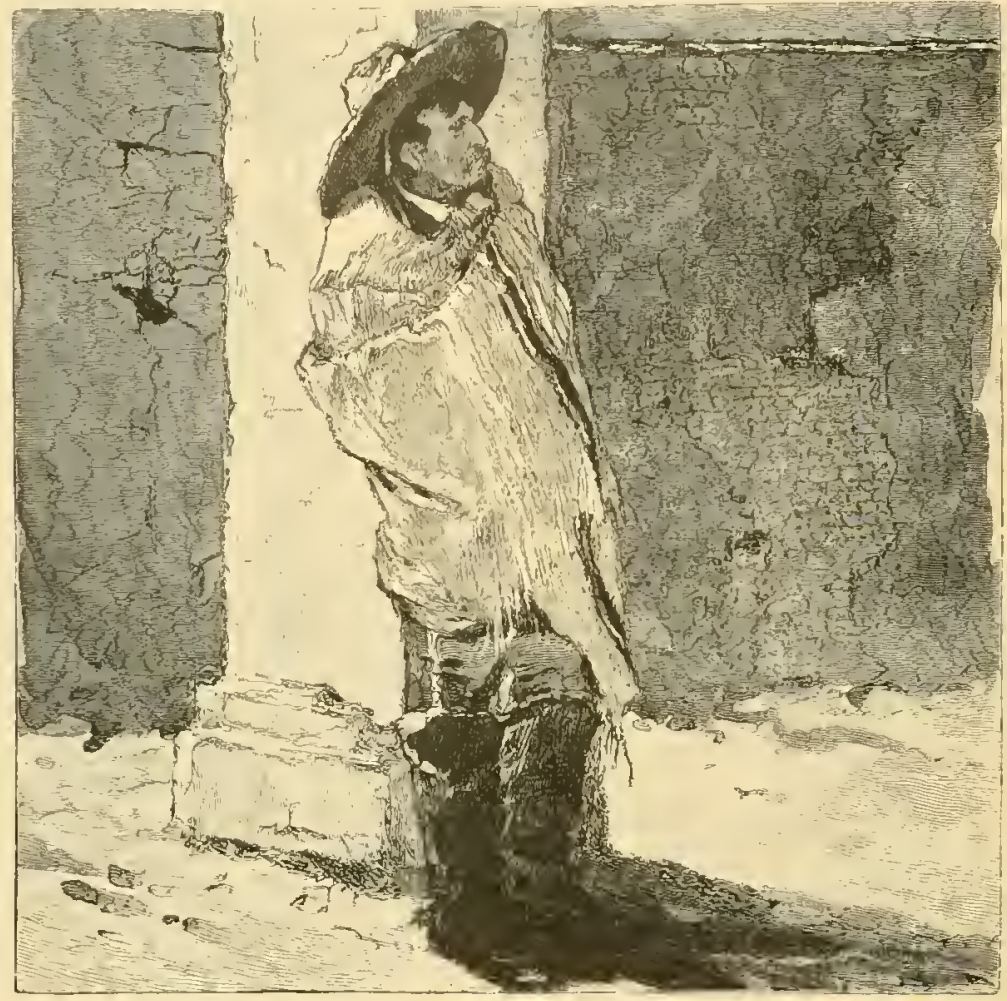

JUAN.

lawry strong enough to defy the state, backed by the national government.

To the door of this sadly haunted dwelling in the wilderness we drove, the evening of an October day in the year 1867 . The party consisted of Colonel C—an American; Mr. Roth, a German; myself, and three mozos, - that is to say, three native Mexicans, chattels of his excellency Don Andreas Viesca, governor of the State of Coahuila-brave men, true, honest, affectionate, at home on the highways of the desert, and brimful of experience derived from lifelong pilotage to and fro on all the beaten marches of Northern Mexico. Juan, Teodora, and Santos, - only their baptismals are given, as in the sister republic nobody troubles about the surname of a peon. Of the trio, the first was our coachman, and the second our 


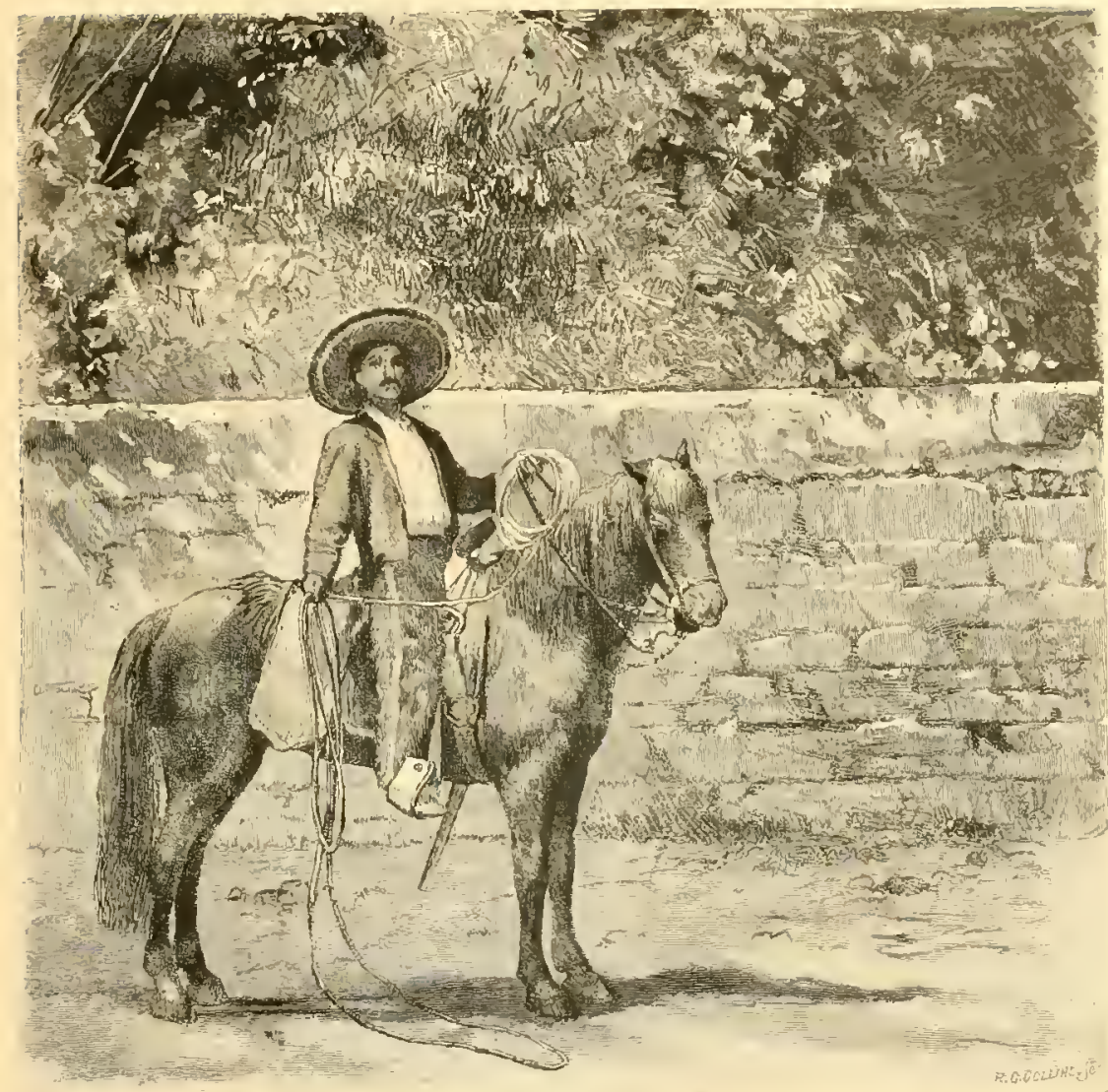

SANTOS

rear guard: while the third went always before to spy out the land for which he had eyes of the far reach of an eagle's, good for the unusual in any form, - dust in the valley, smoke on the mountain, or what not. This half-military order of travel, be it remarked, was not affected by the party as a choice or an eccentricity; it was merely a precaution against the enterprise of ladrones in general, and just then a necessity, as the journey carried across the line of a raid for scalps and plunder, in vigorous execution by a band of Apaches from the region of the Conchas river, of whom more anon.

To the very door we drove without seeing a soul. I pleased myself thinking how different in the day of the romantic Don Leonardo. Then swarthy retainers held the portal in swarms, and, seeing us afar, they would have run to meet us, the effusion of their welcome being but notice in advance of the politer reception in store for us by 
the generous master himself. Then the great house, so tomb-like in its present silence, would have been noisy as a populous khan in an Orient desert. As it was, we halted outside, while Santos rode in

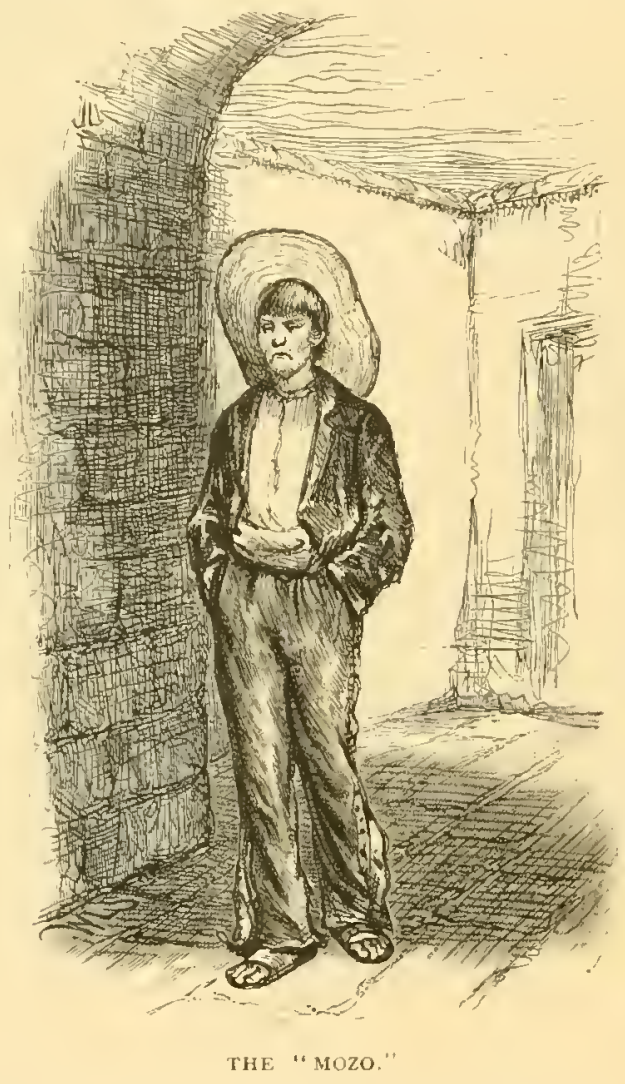

through the half-opened entrance unchallenged, unsaluted. We heard the hoofs of his horse ring the echoes of the arched, but dirty, passage to the patio. IVas there no warder-no steward? Did the castle keep itself? Our mozo at length appeared with answer-a sleepy-looking wretch in jacket and breeches of rusty leather, under a great sombrero of the genuine old style, and withal a swagger so easy-going, yet so perfect as an emphasized insolence, that only the pencil can do it justice.

The man announced himself master of the house, and gave us permission to pass the night within. We would have to find our own beds; his only contribution to our supper would be a mess of warm frijoles; he had fodder for our cattle. Ay dc mi, Zuloaga! 


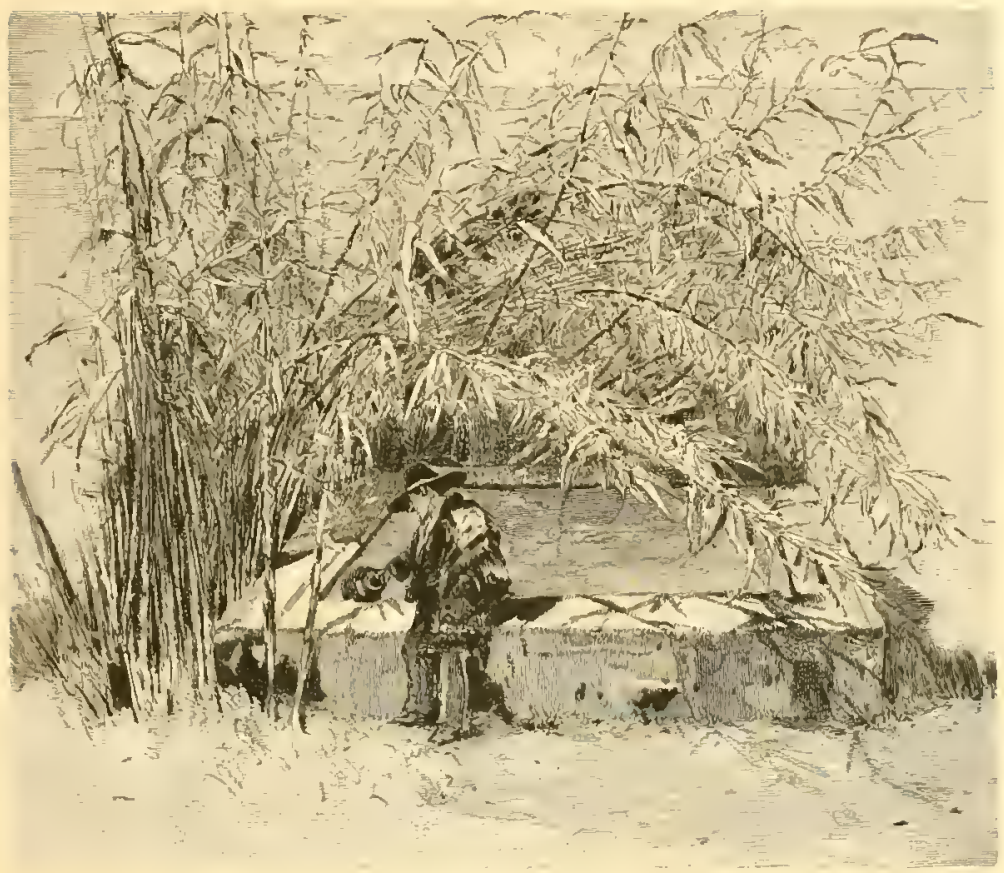

IN THE IEEAR COURT.

To be sure, there was no barbican defending the entrance, nor portcullis a-swing on creaking chains, nor overshadowed grass-grown ditch; yet, as we rolled in. I thought of Branksome tower; of the stag-hounds, weary of the chase, and asleep upon a rushy floor; of the kinsmen of the bold Buccleuch - the nine and twenty knights of fame, of whom the matchless master sang:

"They carved at the meal

With gloves of steel,

And they drank the red wine through the helmet barr'd."

A very martial vision, by the troth of a paladin! But instead, some nomadic children of the desert, going, they knew not where nor for what, were in full possession of the patio, resting happily from their travel of the day.

We alighted from the carriage in a square court-yard,一patio, in the Spanish,_paved and quite spacious. On the four sides doorways without doors yawned darkly at us. The purposes the chambers served in the golden time I knew not; when we found them they were stables; out of some, the long-horned cattle of the nomads looked, bellowing for food: into others, our mules were taken. 


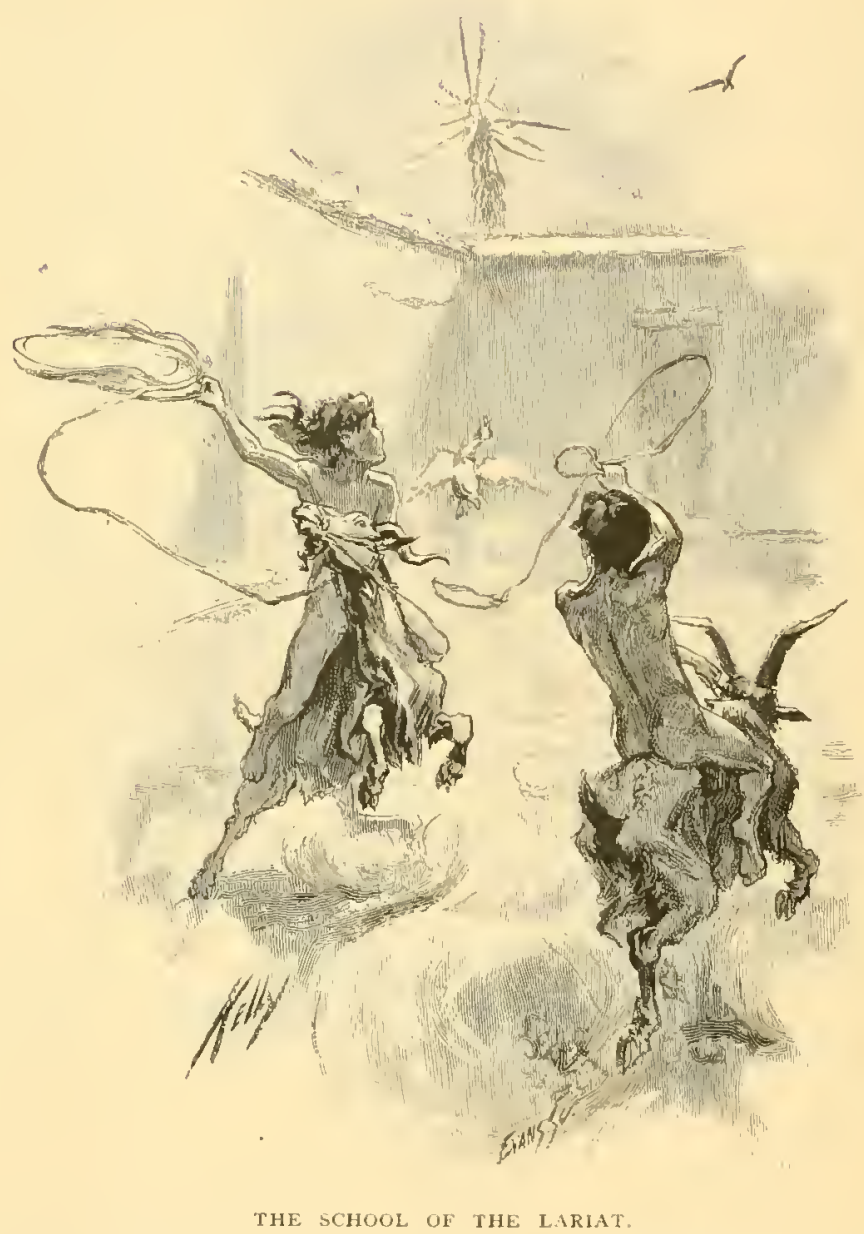

"There is plenty of room; take your choice," he of the mild manner said, when we spoke of disposing of ourselves for the night. We set out forthwith to find the cleanest and best aired unoccupied room.

Through another arched passage, into another square court; and company, nice-looking people, who actually arose and touched their hats to us, though at the moment of our appearance they were laughing with great gusto. Two children-brown-skinned, naked little fellows - had opened a school of the lariat, for the entertainment of the strangers. Gaunt goats, exceedingly tall and strong, served them as steeds; a gander answered for game. They rode with the skill of monkeys and the grace of cupids. The 


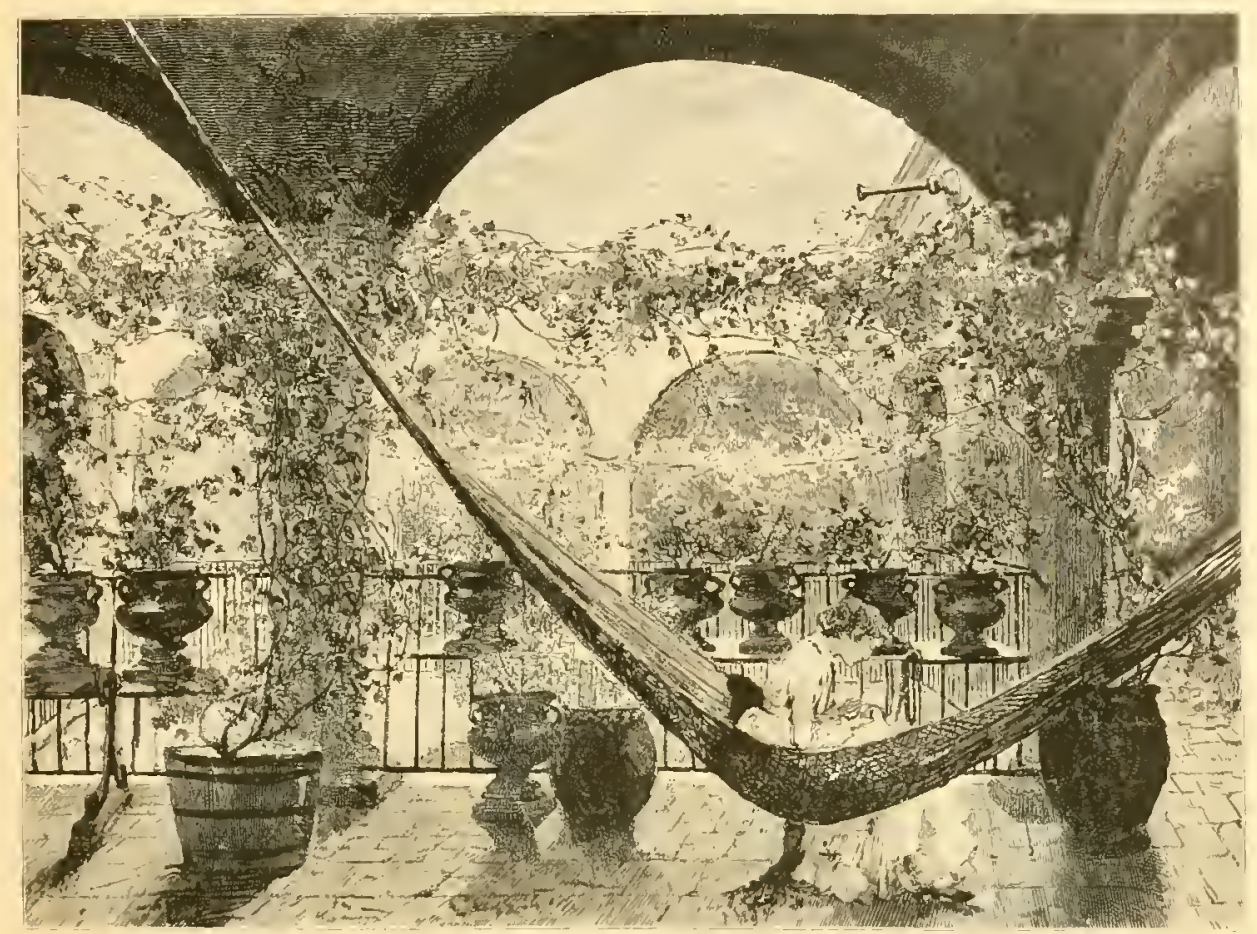

"UNDER THE COLONNADE."

victim fled, hissing and cackling, on wings of fear. When at length the loop hitched around his neck, the exhibition was at an end, and, paying our contribution, we went our way. Next day, we found the polite gentry were travelers like ourselves, only they were going to Parras from Parral, their place of residence.

On into the heart of the castle, another passage and another court, - this latter marked by lingering remains of magnificence,in the center a ruined fountain, and on all sides a continuous colonnade with fluted pillars and chiseled capitals. There were reminders also of a garden, such as sunken beds thinly garnished with flowerless shrubs, and old rose-trees sickly and untended, and other trees, amongst which I recognized a languishing orange and some stunted figs. Half a dozen bananas, their leaves unfurled broad and bright as new banners, arose out of the basin of the fountain in undiminished vigor, relieving the desolation of the place, and filling it with the glory of flame. Here, before the fatal heart-break struck him, Zuloaga and his guests tasted their much pleasance. Under the colonnade yonder it was easy to imagine the hammocks yet swinging, 
I IO A Buffalo Hunt in Northern Mexico.

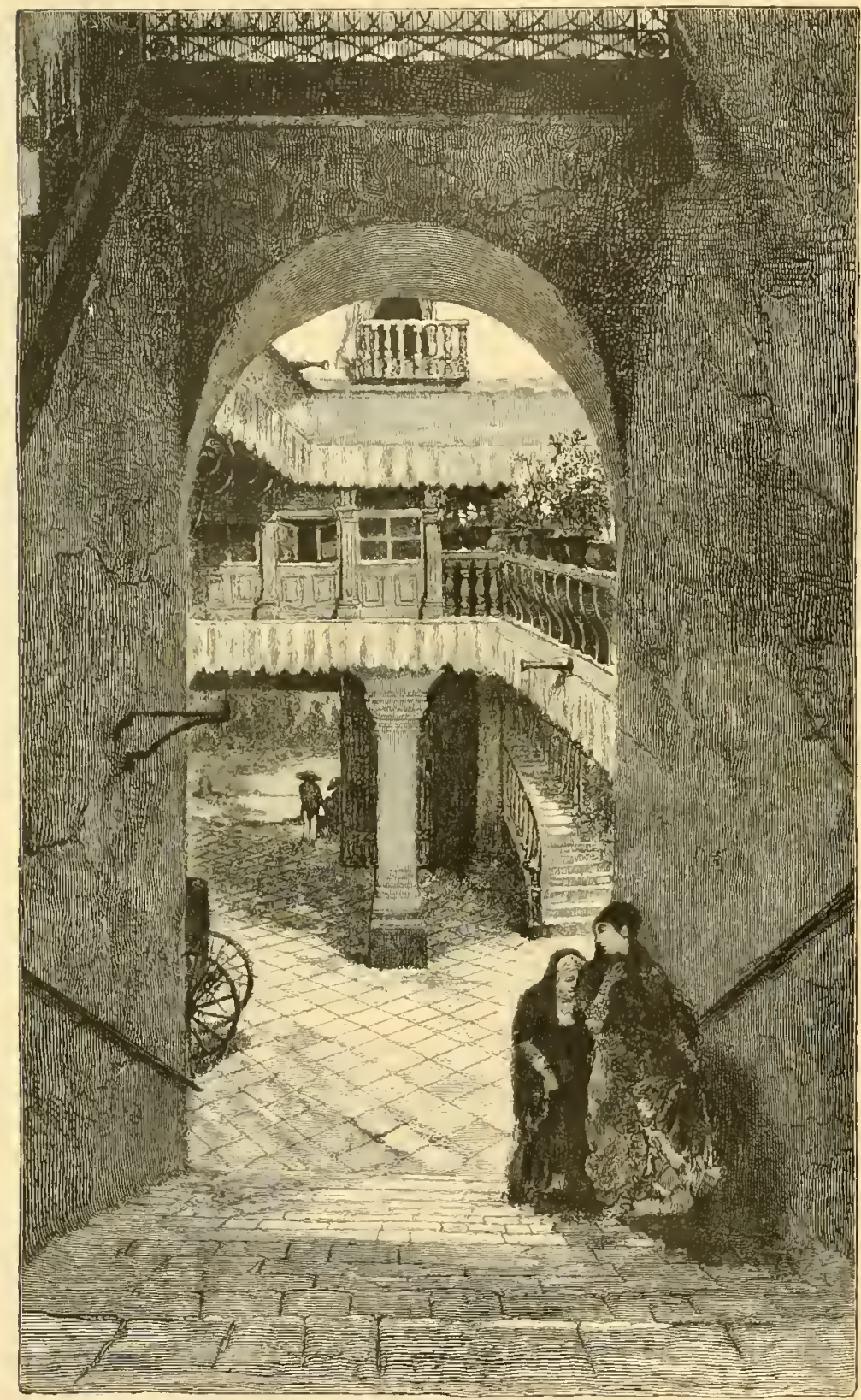

IN TIIE CORRIDOR.

while the gentlefolk smoked, read, or dozed about them; meanwhile, the largesse of Aowers and the cantata of falling waters. There, at the basin, by a table, in the shade of the flaring bananas, the prodigal master used to stand laughing, as, dice-box in hand and high 
overhead, he rattled the white tessare careless of fortune, so soon and so utterly to turn against him. From that room, marked by the carven door, music flowed stream-like out into the moonlit court, voices of women leading, beautiful women taught by the maestros of I urango, may be by the maestros of the capital. Well. into that room we went - in honor of the shade of the departed, I took off my hat; there, too, were traces of the glory's time-tessellated floor, frescoed ceiling, on the walls frane-marks of pictures and

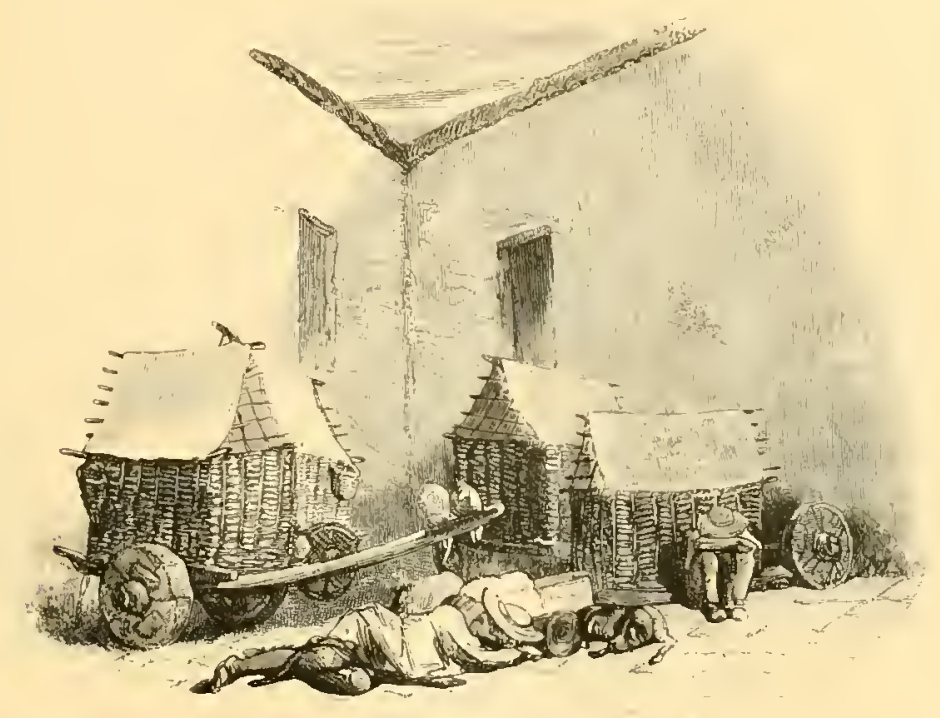

THE PATIO.

mirrors. Ay de mi. Zuloaga! Evil the hour War came in grimvisaged and cruel, and dispersed the waltzers, the singers, and the smokers, and, of all the dainty furniture, left us but one long table on which to spread our pallets in rest of our weary bones. Needless to say, we adopted the table; it was hard, but it lifted us above the range of fleas, and then-ah, if the gallant Spaniard should wake from his sleep and come to us in dreans! Viva!

We returned then to the first patio in search of our mozos, and were greatly astonished there. The house, apparently so deserted, had in our absence given up an unexpected tenantry; men, women, and children-so many! where did they all come from? - were crowded around a delicate-looking shepherd lad 
who sat on a tough little jenny telling a story, to which we also gave instant ear.

About noon, he said, while with his flock in the desert, he had seen away across the pasture a black mass come slowly toward him, spreading as it came. Indians it was not; he rode toward it, andMadre de Dios! it was a herd of buffaloes. And thereupon every one in the patio listening took fire, and cried Madie de Dios! One of the gentlemen bound down the road to Parras, cooler than the rest, pushed through the excited throng and put to the lad a series of questions.

"Buffaloes, did you say?"

"Y'es, sir."

How far out were they?"

"From here?"

"Yes."

"About three leagues."

"In what direction were they moving?"

"From the sun."

The lad meant to say northward.

"Was it a big herd?"

"Very big, sir. I could not count them."

"A thousand?"

"Oh, many more, sir."

We were satisfied, my friends and I, and walked away, leaving the patio all calcitrant with excitement. Soon the strangers followed us. One of them introduced himself as Don Miguel de - (the last of the name has slipped my memory), a merchant of Santa Rosalia, going to Parras for a supply of manta-coarse cotton stuff.

"We have about concluded," he said, " to lie over to-morrow and go hunting. It has been many years since buffalo came so far south; in fact, we cannot any of us remember to have heard of such a visitation in these parts. The opportunity is too rare and good to be lost. Will you go with us, gentlemen? We shall be delighted with your company."

My friend, the colonel, had been a soldier from beginning to end of the great war, and earned his title; now, cn passant, his name is a familiar one in Brazil and in the far up-country Bolivia, whose landlock he is about to break. They know him, too, in the tight little 


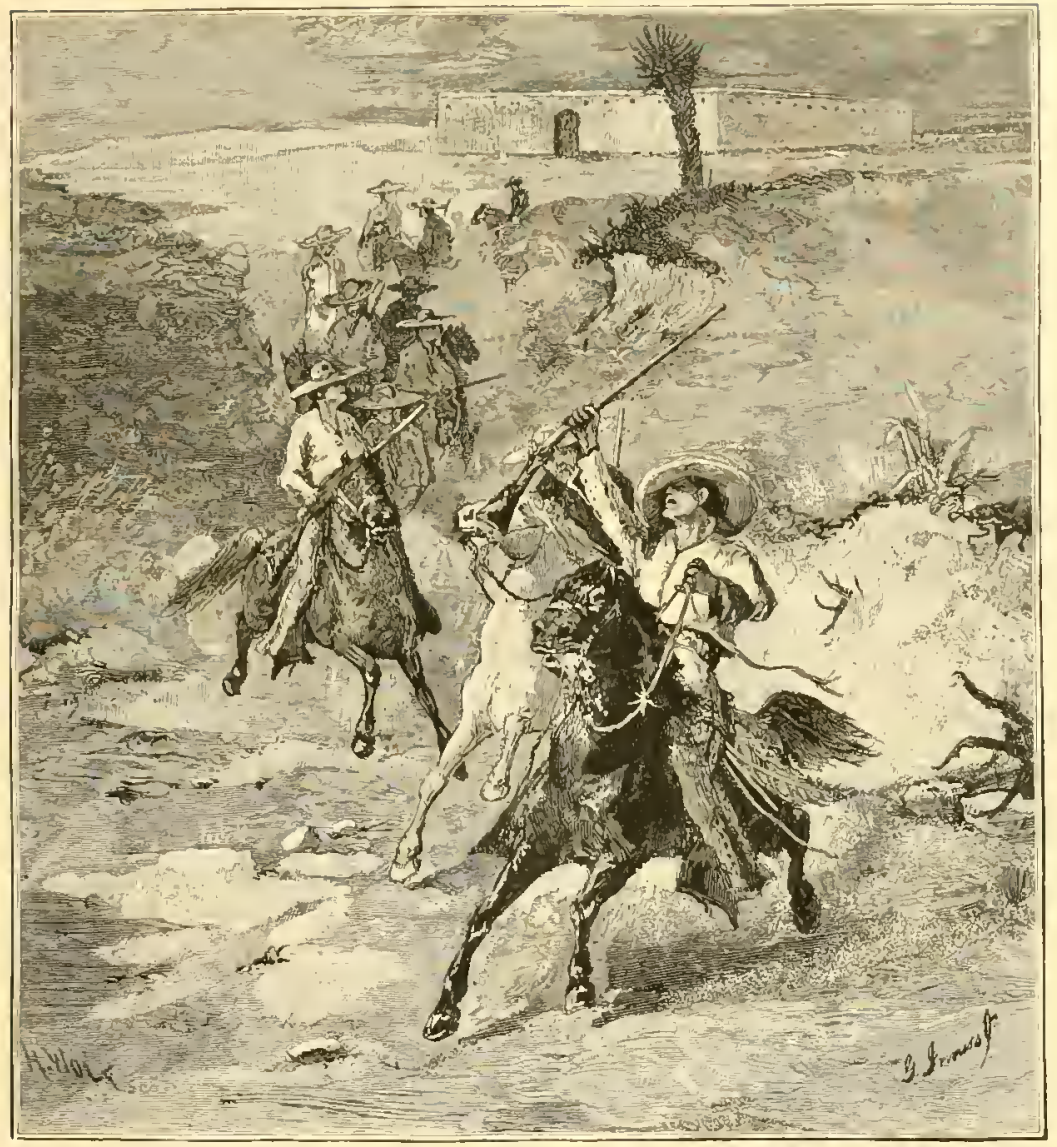

THE STAR'T.

isle where to be known argues a merit out of the common. His spirit arose at the suggestion of the courteous Mexican; he spoke to me, then replied that nothing would make us happier, only we had no horses.

Don Miguel smiled.

"You cannot have been long in these parts," he said. "Horses here are to be had for the asking. We will see you supplied."

The offer was accepted, and the party was to start at five o'clock next morning, under guidance of the shepherd.

\section{Pakt Il. Tile Hunt.}

We did not get started till day, though we breakfasted by candle-light. The sally from the patio in which, midst the confu sion and the seethe and boil of several tempests in an unclean tea- 


\section{II4 A Buffalo Hunt in Northem Mexico.}

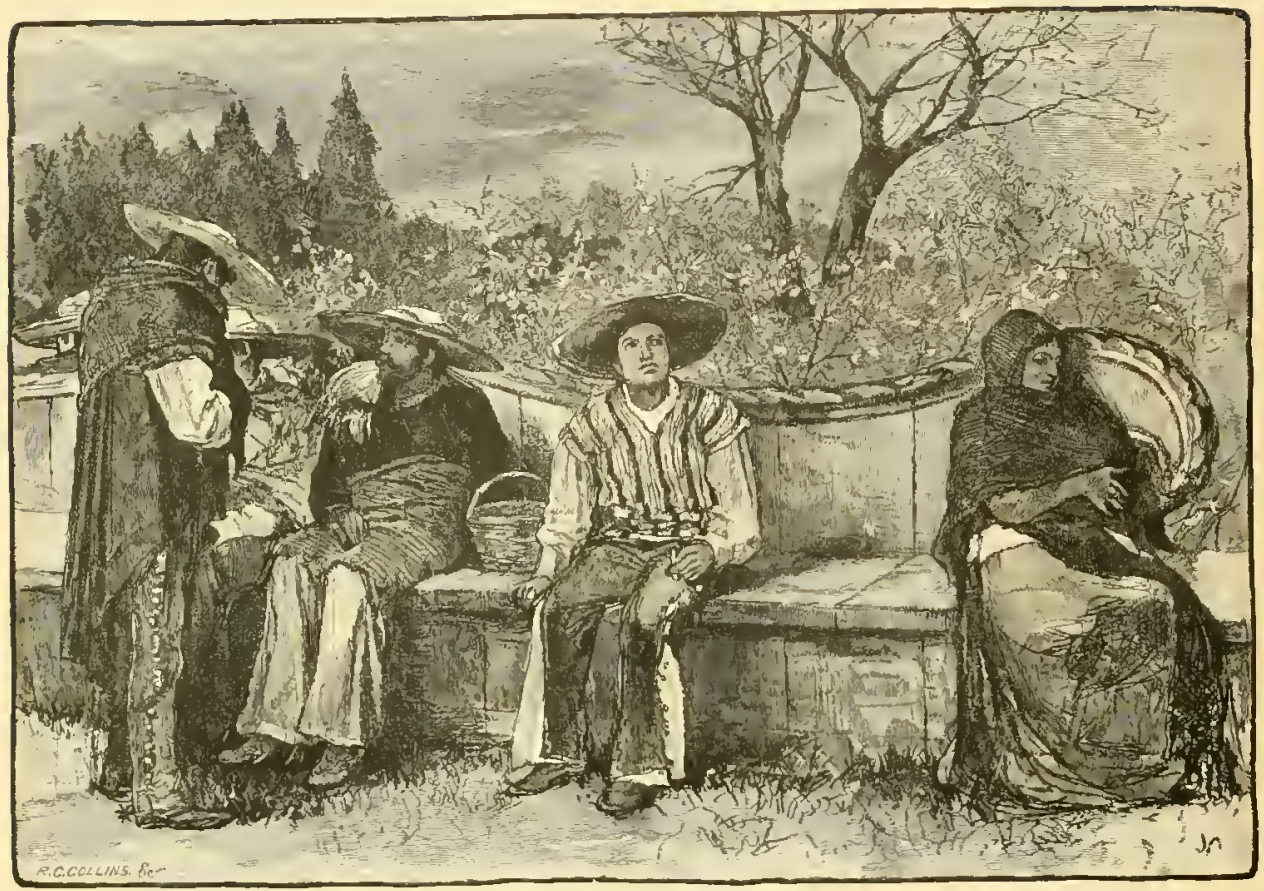

A GROUP OF VAQUUROS.

pot, the final preparations were made was like a charge of untrained cavalry; nor might one have said which were most excited, the horses or the men. For a mile-or more, after the exit, there was furious racing through a dense clond of dust. When at last we drew together and halted to let the guide front, we found the party, about twenty in number, all Nexicans but the colonel and myself. Mr. Roth had declined the sport.

"Who are these people?" I asked.

Don Niguel glanced over the motley crowd.

"Quien sabe, señor?" ("Who knows, sir?")

I called Santos and asked him the question. The good fellow immediately rode here and there amongst them, and returned with this answer:

"Hay rancheros - todos." ("They are all rancheros.")

A ranchero is an independent son of the Mexican soil, generally a renter of lands, always owner of a horse, on which he may be said to live and have his being. To-day a cattle-herder (ádquero), tomorrow a soldier, this week a gambler, next week a robber: with all his sins, and they are as his hairs in number, he has one supreme 
excellence-you may not match him the world over as a rider, not though you set against him the most peerless of the turbaned knights of the jereed. Once it was my fortune to see a thousand rancheros, in holiday garb and mounted, sweep down at a run to meet President Juarez, then cu routc to begin his final campaign against the hapless Hapsburger. They literally glistened with silver-silver on saddle and bridle, silver on jacket and trowsers, silver on hats, silver on heels; and, as with aivas long and shrilly intoned, and stabs of rowel merciless and maddening, they drove their mustangs - the choicest of the wild herds-headlong forward, the spectacle was stirring enough to have made the oldest hetman of the Cossacks young again. No wonder Kleber never ceased admiration of the Mlamelukes who charged his squares over the yellow sands under the Pyramids. These, my compañcros of the hunt, were not in holiday attire. Their clothes were plain tan-colored leather, yet they rode like the thousand, and when l looked in their faces there was no mistaking the tribal relation. The ranchuros of the desert of I)urango are lineally akin to the ranchcros of Tamaulipas and their brothers of Sonora.

My friend and I were well mounted,-Don Miguel had dealt fairly by us,- - yet we could not ride like the Mexicans. Their system is essentially different from ours; whereas we use the rein for every movement of the horse,--forward, right, left, backward, check,they will ride all day keeping it loose over the little finger; a pressure of the knee, an inclination of the body, a wave of the bridle hand, in extreme cases a plunge of the spur, are their resorts. A pull on one of their bits, one pull such as our jockeys are accustomed to at the end of a race, would drive the beasts mad, if it did not make fine splinters of their jaws.

In connection with the excellences of my comrades, it may be well to add that their arms were of every variety, from a Sharpe's repeater to an cscopcta, some of the latter being identical with the bell-mouthed blunderbusses of good Queen Bess. I noticed one which had on it a stamp of the Tower; it was smit with a devouring leprosy of rust, and looked as if Raleigh or one of the later buccaneers had taken it from the old arsenal and dropped it overboard, as he sailed and sailed. Verily, I had rather been a buffalo fired at with such a piece, than the hunter at the other end to do the firing. 
We moved rapidly along a plain road; after a league or more, the road faded into a din path; another league, and we were in the mid-desert. Moved by the novelty of the situation, I let the party pass me, that I might be alone.

Nira! A world of grass, each blade brown or yellowing on the stalk, not dying so much as curing itself,-just far enough gone to rustle at the touches of the winnowing winds; a world of grass without a flower, nor even a wee anemone. The trees are few in number and variety. Off yonder is a solitary cabbage-palm, tall, shaggy, crowned with a shock of green bayonets; it stands motionless, the image of a listening watchman. Here and there groves thinly fleck the broad brown face on which they endure, in the distance wearing the air of neglected apple-orchards. They are mesquite trees, for which I confess partiality, not for their beauty, but for their courage. The idea and the word, as applied, may startle the reader; yet I sometimes please myself thinking that in the kingdom of plants there is a degree of the royal quality. The lichen, up in the realm of the reindeer, and the willow, which survives long burial by the snows everlastingly whitening the echoless shores of Lincoln Sea, must be braver than the palm on the Nile or the redwood on the Amazon. So with the mesquite of the desert. Al, here is one of them close by,-knotted, gnarled, dwarfed, brittle, black of bark, vaster of root than top, yet with a certain grace derived from its small, emerald green leaves, so delicately set on trembling fronds. I have only to look at it once to recognize a hero, not of many tilts with storms, but of an endless battle with drought and burning sun, living sometimes years on nothing but faintest dews. Is it wonderful that it grew branching from the ground so low as to be trunkless? Or that its limbs separated in the beginning, and did their feeble climbing wider and wider apart each day of life, as hateful of each other and the humble stem which generated them ? Or that at last, when full grown, yet comparatively a shrub of low degree, thin and wan of foliage, its shade ill suffices to cool the gophers nestling down deep amongst its sprawling roots, or the crickets, panting as they sing in the gray mosses of uncertain life, stitched like prickly patches on its weather side?

Nevertheless, the tree was disposed to serve me. As I looked at it, thinking of its struggle for life, I was conscious of a warning,what if I should get lost? 


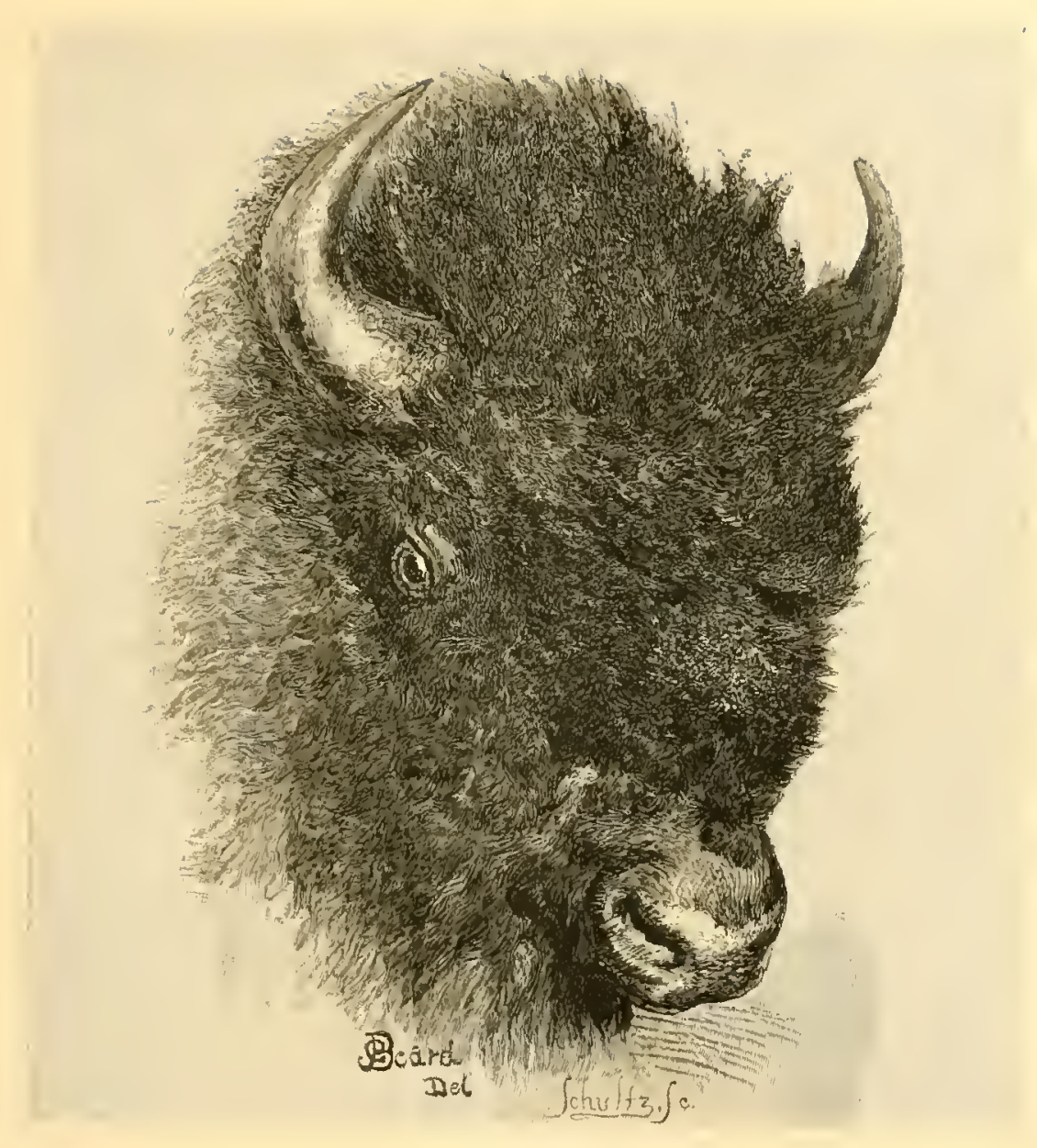

MEAD OF AMERICIN BUFFALO (DISON AMERICANUS).

DRAWN BY JAMES C. BEARD,

SA 

I glanced at the sun, that first compass of the first hunters, and rose in my stirrups essaying to single out the clirection to the house of Zuloaga. To point the locality of the Spaniard's Fountain of Youth had been as easy. Oh, you say, the path of coming was plain! Yes, but-as 1 found before the day was done-that path was one of millions winding in and out, never a skein of silk so hopelessly tangled, in and out as impossible of straightening by a novice like me as some sad lives we all have known; paths worn by wolves galloping in howling packs through the South moonlight; deer paths; and paths known only to the unlovely red children of Uncle

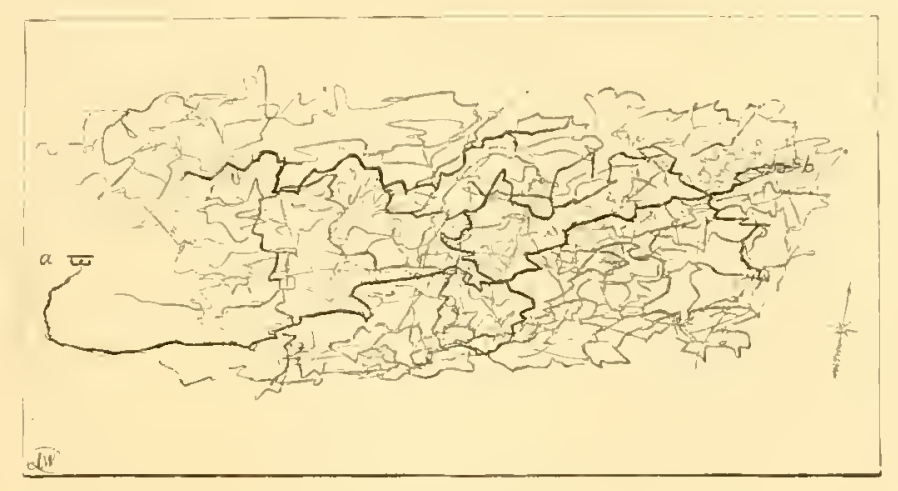

THE TANGLE OF PATHS.

a.- House of Zuloaga, b.- Estanque.

Sam, who perennially tear down that way for scalps of women and children and the loot of undefended ranchos; paths now along the prairie, now through the chaparral, devious and past following and past finding when once lost as the flight of swallows. Oh, if I did know the right one amongst the multiplied zigzag many, and could keep it in shade and shine-keep it truly against the tempting promises of this and that other so friendly and familiar-looking, then doubtless I could make the house. Not caring to make the trial, or to be put to the necessity of making it. I snatched the rein and gave spur to my willing horse.

The gallop was over a great pastura, one of the sheep-ranges of our little guide. I did not like the life of the lad.-following the flock as he does day after day, without other companionship except of his dog and donkey, must be lonesome,-yet it is not altogether void of charm. The glories of the enchanter Distance are about him everywhere. If from grasses crinkling under foot, and dwarfed 


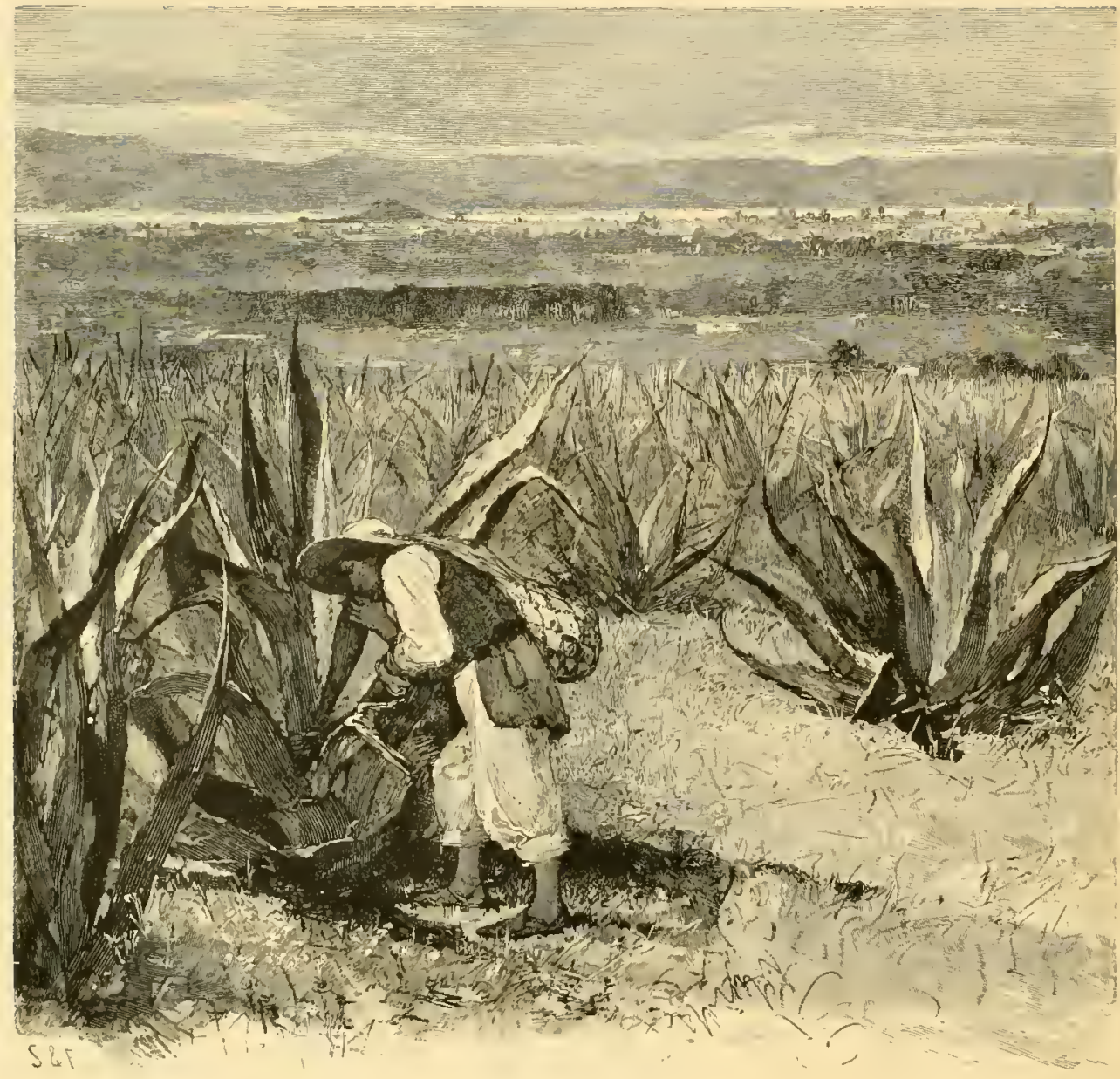

A MAGUEY FIELD.

trees scarce vigorous enough to cover their nakedness with the suggrestion of foliage, he gazes off over them all, who ever saw a horizon with a span so very, very wide? If he looks higher to the sky, nay into it, how the blue inverted bowl widens and deepens as the clear eye shears on, on, through depths to other depths immeasurable! And looking, lo! out of them, by some deft magic, - out of the remove of horizon or the added depths of sky, illusions most likely of atmosphere absolutely purified, or out of them all, it may be, - the Enchanter evolves for me all the effects of space. Did it the same for him? And did he feel them as I did?

We came at length to a body of water, in the Mexican, an estanque; in English, a pond. Off a little way a herd of sheep and goats, 
thousands in number, having slaked their thirst, were wending slowly to fresh feeding grounds. A man, joint keeper with on1 guide, sat by the shore preparing his humble breakfast. Then I knew how the pond made life possible out so far in the afflicted land. The radius of the migration of herd and herdsmen might be wide enough to take in the mountain showing off to our right, like a dab of purple pigment. Whatever its boundary, however, this was its center - this rippling sheet, clear and bright enough to live in my memory another Diamond of the Desert.

While the horses drank, and some of the more careful ranchoros refilled the water-grourds they habitually carried at their saddle-bows, Don Miguel and the colonel interviewed the herdsmen, whose replies were very satisfactory. Our game had spent the night in the vicinity: the water the other side of the pond was muddy with their wading; he had even made fires to drive them away, and they left about sunup, going toward the mountains.

"You see the trees yonder?" he said; "well, two bulls were there not an hour ago, fighting; they may be there now. Quicu sabe, señores?"

"It is but a minute's ride-shall we go?" said Don Niguel to the colonel. The latter called to me; next moment we were off, leaving the party to follow as they severally made ready.

I remember yet the excitement of that ride, the eagerness and expectancy with which we neared the knot of trees, our dash through, pistol in hand. In quiet hours I hear the shout with which the colonel brought us together. In an opening scarce twenty yards square lay a dying bull. He was of prodigious girth, and covered head and shoulders with a coat of sunburnt hair to shame a lion. Long, tangled locks, matted with mud and burs, swathed his forelegs down to the hoofs. The ponderous head of the brute rested helplessly upon the rotting trunk of a palm-tree; the tongue hung from his bloody lips; his eyes were dim, and his breath came and went in mighty gasps. The death-wound was in his flank, a horrible sickening rent. The earth all about bore witness to the fury of the duel. Long time he confronted his foe, and held him with locked horns; at last, he slipped his guard - that broad forehead with its crown of Jove-like curls - and was lost. Who could doubt that the victor was worth pursuit? 
We helped the unfortunate to a speedier death, and lingered to observe him. His travels had been far, beginning doubtless up

"In the land of the llakotah,"

whence winter drove him with all his herd down the murky Missouri. On the Platte somewhere he passed the second summer; then, from the hunting of the Sioux and their fierce kinsmen, he escaped into Colorado; after a year of rest, in search of better pastures, he pushed southward again. lingering in the fields about the head-waters of the Arkansas; there the bold riders of the Comanche found him; breaking from them, he disappeared for a time in the bleak wilderness called The Staked Plains; thence to the Rio Grande, and across into Chihuahua, the pursuer still at his heels; and now there was an end of travel and persecution. As we returned from the chase, I saw him again, lying where we found him, a banquet for the whimpering wolves. Already he was despoiled of his tongue.

The incident, as may be thought, whetted the ardor of the party to the sharpest edge. A wide interval stretched between us and the mountain toward which the game had disappeared; in some of the long swales ahead we knew they were feeding; possibly we might strike them before noon; nobody felt tired. Santos rode forward at a canter; we followed in a body, saying little, but never so observant. Two more miles were put behind. Suddenly, as the mozo was making the ascent of a long up-grade, he stopped, and, turning in his saddle and pointing forward, shouted: "Ola, los bufalos!"

Not a man but felt a great heart-beat and a thrill which shocked him from head to foot. As at command, we raised the guns, lying across the saddles before us. As at command, too, we all broke into a gallop. Santos, like a sensible fellow, came back to meet us.

"Where are they?" everybody asked in a breath.

"Just over the hill," he answered, suppressing his excitement.

"Are there many of them?" I asked.

"Caramba, scinor! We cannot kill them all before night."

We gained the top of the grade, and there they were- not a quarter of a mile away, grazing slowly onward-los demonios del Nortc.

To the left, under a well-grown tree, I caught sight of one, solemn, sedate, magnificent in proportion, magnificently draped in 


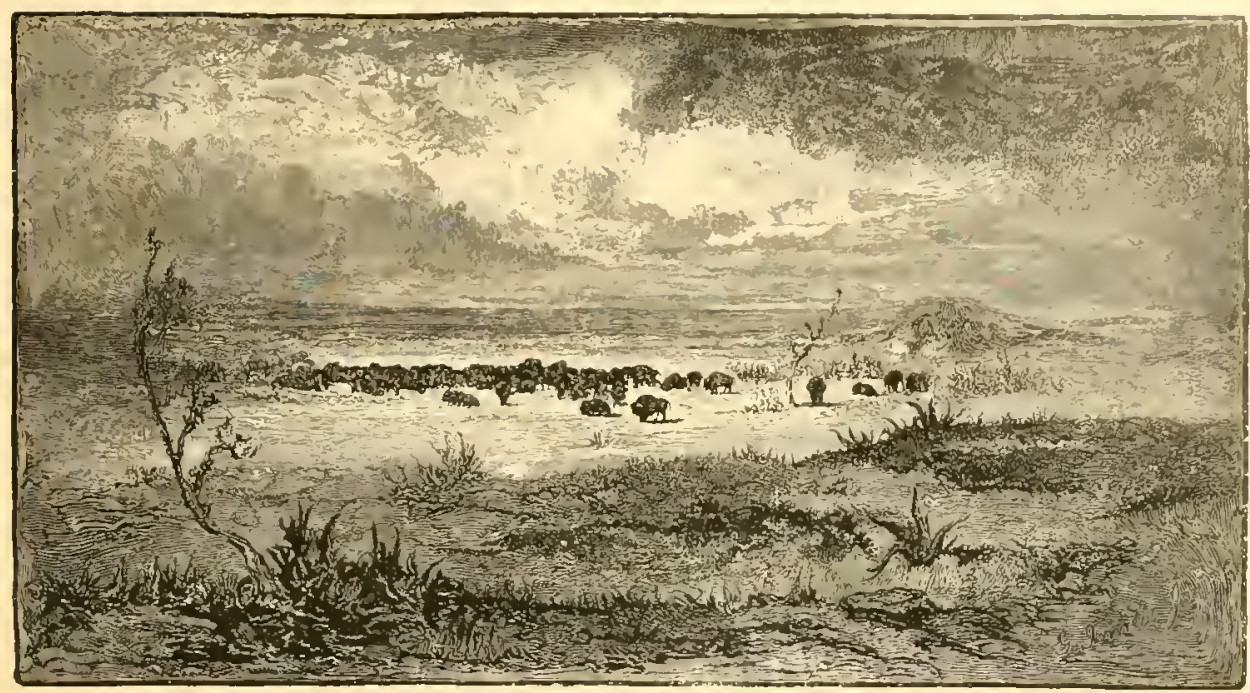

OUR FIRST VIEW OE THE HERD.

flying fur. He alone kept his place motionless and with full front toward us, the perfect picture of confidence, self-collection, and power of toughened thews in wakeful repose. In every flock of living things there is a sentinel who watches, a philosopher who thinks, a lawmaker who ordains, a king who governs; and there they were all in one-and more, he was the victor of the morning's duel. I knew it all with the certainty of intuition.

The exceeding peacefulness of the scene was not lost on me, and the monitor of the low voice did some whispering; but-my blood was running races. The heart was beating in my throat, and the hot parch of the hunter's fever was on my tongue. Pity there is no gauge for the measurement of a man's excitement of spirit; something of the kind should be our next great gift from the wiseacres; and then, if the invention should happily be simple of reference and easy of portage like a pencil or a knife, we could have with us always a doctor to save us from apoplexies, and a guardian to say stop at that point in our pleasures where conscience is in the habit of obtruding, like the ghost at the banquet.

We had no thought of strategy-scattering, flanking, heading off had no places in our heads, and without an inquiry from us the wind continued to blow as it listed. A common impulse seized every man and communicated to every horse. A shout, some fierce gouging with rowels, and away we dashed pell-mell, guns in hand, 
Don Niguel in the lead. The startled herd, executing a volt to the rear, stood a moment at bay. The king under the tree shook his crowned head, and viewed us askance. Ha! ha! was he scared? Or, like a veteran general, was he coolly counting the odds before resolving on battle? If, at a signal, his army had closed cn masse and charged us horns down, what a hurry-scurrying rearward there would have been on our part! But no-he had heard the whoop of assault before, and knew all its significance. The pause was from curiosity, as natural to his kind as to a high-bred lady. We heard his bellow, ragged as the mot of a Nexican trumpet; then he went right-about; whereat there was a general stampede-a blind saure qui pout, which, interpreted literally, means, may the devil take the hindmost. Away they went, all alike, the king forgetful of his dignity, and all the queens for once at least self-dependent.

Now, if the reader will resolve a buffalo into a machine and make study of his locomotive capacities, it will be seen he was not made for speed. He is too weak in the hind-quarters, too ponderous in the fore; and as if the fatted hump on his shoulder were not a sufficient handicap of the poor brute, Nature fashioned his head after the model of a pork-barrel, and hung it so low as to be directly in the way of his forefeet-the very reverse of a horse or a decr. A fortiori, as the lawyers are so fond of saying, he does not leap when in flight, but rolls and plunges, like a porpoise at play. In short, there would have been shame everlasting in the house of Zuloaga if our mustangs, outfliers of the desert winds, had failed to overtake the lumbering fugitives in less than a half mile.

I do not know what my companions did-a quick concentrating of self seized me, insomuch that 1 became to the world else the merest husk of a purpose; the circumstances of the charge, those the eye catches and those the ear hears, looks, actions, words, yell; even the stirring rataplan of the horses drumming hoofs and the deep bass earth-rumble of the game in multitudinous flight - all failed my perception; for as we drew near the chase one straggler claimed my attention - a heifer, clean built and clean of hide. She was running freely, and could have made better speed but for the slower hulks in her way. I had a thought that she might make better meat than the bigger specimens, and yet another, she might be more easily killed; and to kill her I bent every faculty. 


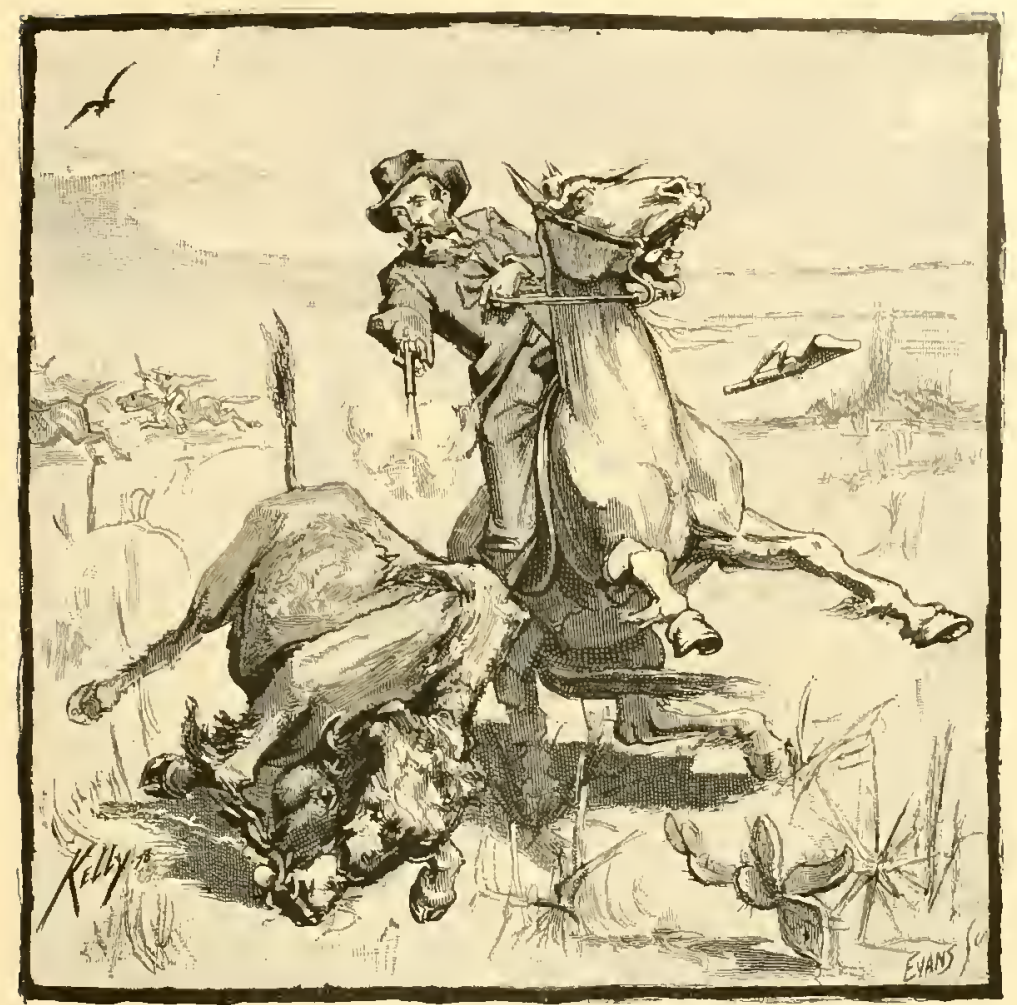

NOW, FIRE!

The mustang caught the spur; forward-close-closer-by bending in the saddle I could have laid hand on my prey; then, fully conscious that she was singled out, how she struggled to get away! How the muscles of her flanks swelled and knotted in desperate exertion! The time came to use my $\mathbf{W}$ inchester. I selected the place to shoot at, just behind the shoulder, and brought the rifle down. Goodness! I was left of the game, when, being righthanded, I should have gone to the right. Three times I tried to get aim, but in vain. I laid the gun across the saddle, and drew my pistol-a Smith \& Wesson, the best of revolvers then, yet not near so good as now; for that I was in place. Forward again, and closer in-closer-now, fire! The bullet lodged in the shoulder. Again, and in the heart; hurrah! $M_{y}$ horse shied; the rifle fell to the ground; I barely escaped tumbling after; the victim moaned, staggered, stumbled, fell. Aye, count me one; and, better yet, count me the FIRST ONE! 
Upon coming to,-observe all the words imply, - I was dismounted, and in the act of picking up my gun. The conduct of man was never more purely instinctive than mine had been throughout. I make the confession without shame, for I am not of those who believe thought must govern and direct what all we do, otherwise there is no credit. In cases of peril bullet-swift, to wait on reflection is to die. Instinct moves us; we obey, and live. Thought implies conditions, and a final judgment upon them; instinct implies instant action - something dull men are incapable of.

Let me pass the pride and happiness of that triumphant moment. The fisherman who has landed the traditional trout of a famous brook, or a ten-pound golden salmon from the golden beds of the Kankakee, can tell you my feelings; and to enable a hunter to interpret for me, it is only required that he should have bagged a wild goose, flying full-quilled from the Arctics.

The mustang was at last reduced to quiet; then I looked about. The huntsmen and the herd were out of sight in a trough of the land ahead; yells and frequent shots signaled their whereabouts. Not another carcass was to be seen; I had made the first capture; what if it should be the only one? While so thinking, - the faintest semblance of a selfish wish lurking under the reflection,- suddenly the noise ceased. Strange! Something had certainly occurred. I swung into the saddle; then up from the hollow rode a ranchero, coming to speak to me, I supposed; he went by like a ricochetting shot. Others appeared; the same haste possessed them, only they shouted: "Prićsa, scñor! Los Indios, los Indios!" ("Make haste, sir! Indians, Indians!")

Ah, the cursed Apaches!

The interruption was not an agreeable one; in fact, the effect was decidedly chilling; yet I managed to control myself, and ride forward. The last of the rancheros passed in flight; only the colonel, Don Miguel, his friends, and Santos and Teodora, remained.

"What's up now?"

The colonel answered coolly:

"The fellows say they came upon Indians in the grass down yonder. I think they are lying."

Don Miguel shrugged his shoulders nearly to the top of his head, and fairly hissed: 
"It is nothing, sir," with an expression of contempt without an equivalent in English.

Santos touched his hat, indicating a wish to speak.

"What is it?" I asked him.

"There are no Indians there."

"No?"

"I stopped one of the men long enough to have him show me where the ambush was, and _ " he laughed heartily.

"Well ?" I said, impatiently.

"And the buffaloes had run right over the place."

We looked at each other curiously. Don Niguel suggested we go see for ourselves, and the colonel supported him with a round declaration that they had taken eight or ten good fat cows, and he didn't like to run away from them to accommodate anybody, much less a thieving Apache. A reconnoissance was determined upon.

We rode into the hollow and up it, cautiously following the trail of the herd.

"Hist!" cried Santos, a little in advance. "Look there!"

We looked, and were startled. Not twenty yards away stood a sorrel pony rudely housed in Indian style. At sight of us it raised its head and whinnied piteously. Santos went to it, and stooped to catch the lariat about its neck.

"Fesu Christo!" he yelled as if shot. I thought he would roll out of his saddle.

"For love of God, gentlemen, come and see," he next exclaimed.

We stood not upon the order of going.

"Caramba!" said Don Niguel, reining back.

Then the colonel blew a long whistle of disgust, as well he might. An Indian warrior was lying face downward in the grass at the forefeet of the pony-dead! The stampede of the rancheros was explained.

A worn knife, butcher's pattern; a hatchet, such as plasterers use; a redwood bow, short but broad, and variously painted on the back; a quiver of arrows; a lance, of the Nexican sort; a dirty clay-pipe, in a dirty bag of raw tobacco-were the assets of the dead man.

In the division of spoils, my friend the colonel took two feathers found in the scalp-lock, indicative, as he was pleased to believe, of 
the high rank of the deceased. A pair of moccasins, taken from the saddle, fell to me; they were unworn, and soft as a castor glove. I have them yet, and keep them because they were beaded by the warrior's love, the daughter of an arrow-maker who lives in a painted tepee off over the Sierras, by the lout-singing, but lonely, Gila. A visitor now and then comes and casts a doubt upon the tale of the moccasins; but he always leaves me in disfavor.

We agreed to attribute the end of the savage to ugliness, complicated with original sin. When the shepherds were told about him, they turned pale and crossed themselves. They knew why he was in wait where death found him, mercifully for them.

It remains to say the discovery finished the hunt.

The Indian's pony, seven superb buffalo hides, and any amount of meat, were our trophies. The bivouac by the cstanque that night was savory with the smell of roasting joints, and next day, when we bade adieu to Don Miguel and his friends at the door of the house of Zuloaga, all the patios were beautiful with festoonery, which, at the end of a week, was taken down, weighed, and divided. No one ever tasted better came scca.

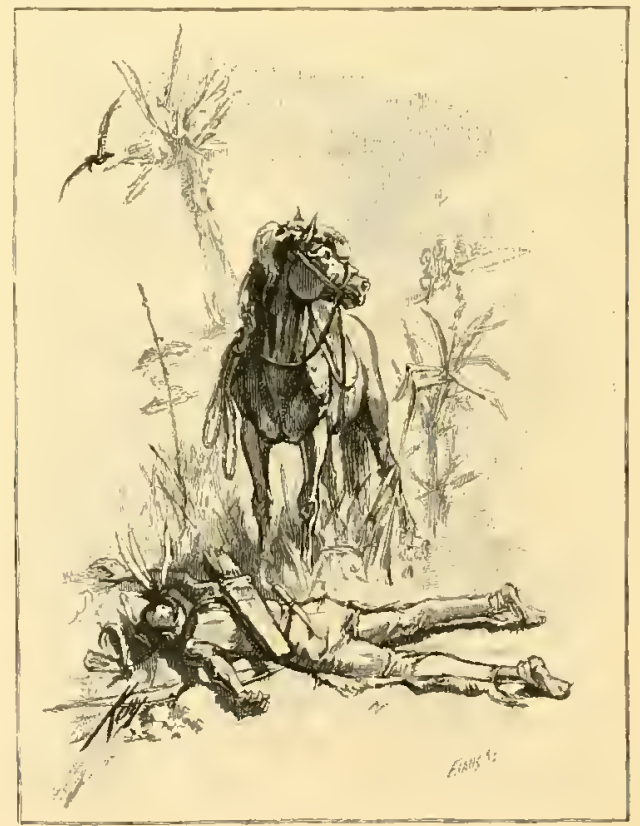




\title{
THE NORTH AMERICAN CERVIIAE.
}

\author{
(iEURGF BHRD GRINNELI, PH. D.
}

T

HE deer family includes the most important of our large game animals. Deer, of one species or another, are found throughout the whole of North America, from within the Arctic circle south to Mexico. They are most numerous in the northern United States, where the Arctic forms and those inhabiting more temperate regions overlap, and here two of the most magnificent representatives of the family-the moose and the elk-are found. The value of the deer to the aborigines of this continent can scarcely be over-estimated. In many sections of country, the natives formerly depended for animal food almost wholly upon the deer at certain seasons; and at the present day the Esquimaux rely, for several months of the year, entirely upon the reindeer for subsistence. Until some time after the settlement of this country by the whites, the clothing of the natives was manufactured chiefly from deer-skins. Shirts, leggings, and moccasins were and are made from the dressed skins of the red, the mule, and the black-tail deer; while the coarser and heavier hides of the moose and elk were used for covering lodges, for robes and blankets, and for moccasins, as well as in the manufacture of ropes and lines and for a variety of other purposes. At present, blankets and cheap cotton cloths have, to a considerable extent taken the place of buckskin in the manufacture of Indian garments. But to-day, the clothing of the Innuit is made almost entirely from the skins of the reindeer, dressed with the hair on, the garments worn next to the skin being made from the summer hides, on which the hair is short and fine, and the outer ones from skins taken later in the season, and therefore coarser. 
Six unquestioned species of deer inhabit North America. These are the moose (Alce Amoricana-Jard.), the barren ground caribou (RangiforGrulandicus-Baird), the elk (Cornes Canadensis-Erxleben), the mule deer (Cariacus macrotis (Say) Gray), the black-tail deer (Cariacus Columbianus (Rich.) Gray), and the Virginia deer (Cariacus lirginianus (Bodd.) Gray). Beside these, there are several geographical races or varieties, the zoölogical status of some of which is, however, doubtful. The woodland caribou is a distinct race of the Arctic reindeer, and the California form of the mule deer appears also to be a good variety. In the several supposed races of Cariacus Irirginianus, such as macmurus, loucurus, Mcxicanus, and Coucsi, size appears to be the distinguishing varietal characteristic. In the six species already mentioned, we have every variety of size and form, from the gigantic moose, which is taller than the largest horse, down to the little dwarf deer of Arizona, which at the withers measures scarcely thirty-two inches in height. Not less is the difference in grace and beauty of form between the various North American members of this family. On the one hand stands the Virginia deer, whose very name is symbolical of elegance and beauty of motion; on the other, the moose, huge, ungainly, and, in most of its movements, awkward. With a head more hideous than that of a mule, a neck so short that it cannot reach the ground, legs of immense length, and huge horns shaped like coal shovels, it is as far as possible from being graceful or attractive. But regard it with the hunter's eye, as, when startled, it dashes along with swinging trot, crashing through the forest and making the dead sticks snap and fly in its impetuous career, taking in its stride without any apparent effort the great fallen logs that lie in its course, and in a moment disappearing shadow-like among the bare tree trunks in the distance, and it will be acknowledged that, if not a graceful, it is at least a grand animal. Most of the North American deer, however, are beautiful and graceful.

Before speaking in detail of the various species of Corvida found in North America, it is desirable to explain just what a deer is.

Roughly speaking, all hoofed animals are contained in the order Ungulata. This division of the Mammalia includes, therefore, the formerly accepted orders Pachydermata, Ruminantia, and Solidungula, which have been discarded by modern naturalists. The group is a very large one, its families being the horses, tapirs, rhinoceroses, 
hippopotami, hogs, camels, musk-deer, deer, giraffe, and the Boride, in which stand the cattle, sheep, and antelopes. The order is divided into Perrissodactyla and Artiodactyla, or odd and even toed ungulates. The distinction between the living representatives of these two groups is well marked, and the division is a convenient one; but it is probable that the future discovery of fossil forms of ungulates will show that the artiodactyles and perrissodactyles grade into one another, so that it will be impossible accurately to define the terms. Although these groups are loosely called odd-toed and even-toed ungulates, the fundamental difference between them does not consist in the number of digits on the foot, but in the fact that in the perrissodactyles the development of the foot takes place in the line of the middle toe, which is usually symmetrical in itself, whereas in the artiodactyles the third and fourth digits share equally in this development, and together form a symmetrical pair.

To make this clear, it is perhaps necessary to go a little further, and, by explaining the manner of progression of two of the more familiar forms of the order, to give an idea of the construction of these two types of ungulate foot. The horse is a perrissodactyle, having a single visible toe, which is symmetrical in itself. He walks upon the extremity of this toe, the hoof corresponding to the nail of the third or middle finger in man. Comparing it with the human hand and arm, it will be seen that the fore leg of the horse, from the hoof to the fetlock joint, corresponds to the middle finger, and the portion between the fetlock and what is ssually termed the knee, to the middle metacarpal - the bone which lies between the knuckle of the third finger and the wrist. Following the leg up toward the body, it appears that the "knee" of the horse is really its wrist; that the elbow is high up close to the body, while the humerus - the bone between the elbow and the shoulder-lies within the body, and out of sight. In the hind leg a similar sequence will be found. The animal walks on the toe corresponding to the third digit in the human foot, the hock is the ankle, while the true knee is close to the body. The horse, therefore, supports his weight on the third digit of each foot. His thumb and little finger, and the first and fifth digits of the foot, have been wholly lost; but in the fore and hind foot the metacarpals and metatarsals of the second and fourth digits still persist in the form of the slender, sharp-pointed bones. called by horse- 
men side-bones or splints, which lie hidden beneath the skin, close to the large third digit, metacarpal or metatarsal.

Now the ox is an artiodactyle. His weight is supported on the tips of two toes, which represent the third and fourth digits of the human hand, or foot, as the case may be. The first has been wholly lost, but the second and fifth are represented by the two little supplementary hooflets behind and above the main hoofs. The functional hoofs are symmetrical in pairs, the third and fourth digits being equally developed, and taking an equal part in the constitution of the foot and in performing its work. The metacarpals and metatarsals of the third and fourth digits are equally developed, but are anchylosed togrether, so that they appear like a single bone, with, however, two distinct articular surfaces at their lower ends to support the phalanges of the digits. The Corida belong to the Artiodactyla, and their feet are constructed upon the same plan as those of the ox. They are also ruminants, and belong in a subdivision of the Artiodactyla styled Pccora, to which belong the Camelopardide (giraffes) and Boride (cattle, sheep, and antelopes).

All the Corida have horns, and these alone are enough to distinguish this family from any other. The horns of the Boitide are permanent osseous outgrowths from the frontal bone of the skull, and are enclosed in a horny epidermic sheath, which is usually persistent, a single species - our prong-horn antelope - being the only exception to the rule. These bony outgrowths, which form the core of the horn, are usually permeated by large air sinuses, and from this fact the group have been called Cavicomia (hollow-horned). In the deer family, however, the horns are constructed on quite a different plan. They are still outgrowths of bone from the frontals, but the outer epidernic sheath encloses them for a short time only, and, as soon as their growth is completed, is shed. The perfect horn is now mere dead bone. It remains firmly attached to the skull for a few months, and then drops off, to be renewed again the following year. These horns are, in fact, true bones, and in their constitution do not differ materially from the other bones of the body.

Their method of growth is as follows: From each of the frontal bones there arises a short, stout process, growing outward and upward, forming what is called the pedicel. This pedicel is covered 
with ordinary hairy skin, except upon the upper flat circular surface of its extremity, on which the horn of the preceding year was supported. Here the skin is naked and black. In the spring, usually about May 1 , the time varying somewhat in the different species, and even in different individuals of the same species, this flat surface becomes convex, gradually swells outward, becomes longer, and soon takes the shape of a short spike. At first, it is straight and swollen and is shaped somewhat like a cucumber. It is now little more than a mass of coagulated blood inclosed in a sack of thin skin, which is covered by a coat of fine brown hair called "velvet," and during the first part of its growth there is but little trace of bony structure apparent in it. The horn is soft to the touch, and may be somewhat compressed in the hand or bent a little in any direction. It is hot and feverish, too, and the pulsation of the arteries which supply it with blood may be felt. It is also extremely sensitive and tender, and the deer is extremely careful to avoid striking it against the trees or undergrowth near which he may pass.

When the point is reached at which the first tine is to be put off, the extremity of the growing horn becomes somewhat flattened from side to side and then divicles, the tine at first being quite small, and increasing in length much more gradually than the beam. The same thing takes place with each of the succeeding branches, so that the beam and all the tines attain their full length at the same time. During the whole period of their growth, the horns are abundantly supplied with blood-ressels, three distinct sets of arteries, according to Caton, passing up through and without the pedicel. The horns grow with very great rapidity, usually attaining their full size in about three months. Huxley, in speaking of this marvelously rapid growth, refers to a pair of antlers, weighing seventy-two pounds, which were produced in ten weeks. As might be imagined, the production of such a mass of osseous tissue in so short a time is a severe drain upon the animal's system, and in most species the males at this time become very thin and weak. During the growth of the horn a circular notched and jagged ridge makes its appearance at the base of the horn just above the pedicel. This "burr" serves in a measure to protect the blood-ressels which pass along beneath the skin of the pedicel, and these take their way through it and between its projections, and thence along the channels in the surface of the 
horn beneath the periosteum - the membrane which incases the living bone.

The horns reach their full size in August, and, from being at first very soft and afterward spongy, have at length become quite hard. They are, however, still covered with the "velvet," and beneath this the blood continues to circulate, but now more slowly than at any time since the horn began to grow. The time at which the horn becomes fit for use as a weapon of offense or defense varies slightly in the different species of our deer, but is usually about September 1. The animal's head now appears to trouble him, and to be irritated like a healing wound, and he rubs his horns violently in the bushes or against the branches and trunks of trees. The tender "velvet" is thus torn off and hangs in bleeding strips about his horns and head, but he continues to rub for several days, until at length the antlers are quite free from skin, their tips white and polished, and the inequalities about the burr filled with finely crushed fragments of bark. He is then ready for the rutting season, which immediately ensues.

The horn is now dead, and at its connection with the skull-the extremity of the pedicel-absorption begins to take place, and in the course of four or five months the attachment to the frontal is so weakened that the horn drops off of its own weight. The end of the pedicel bleeds a little at first, but almost at once heals over, and until the following spring is covered with the black skin already mentioned.

As a rule, these weapons are borne only by the male deer; but the female caribou always has small horns, and in very rare instances the female Virginia deer has been killed with a single spike, or a pair of straight, short, and scarcely branched horns. The horns of all our North American deer become fit for service in September, and they are shed at various times from December to March.

From what has already been said, it will be seen that a deer is an artiodactyle ruminating ungulate, with solid, deciduous horns.

The arrangement of the teeth in this family is as follows: Incisors, $\frac{0}{8}$; canines, $\frac{1-1}{0-0}$, or wanting; molars, $\frac{\frac{f}{6}-\frac{6}{6}}{6}$. Canines are said to be always wanting in the female, but this is by no means true of all species, for they are usually present in the female of Corius Canadensis, and I have also detected small ones occasionally in Cariacus Columbianus. 
The keenness of the deer's olfactories has become proverbial, and the experienced hunter, when starting out, always first satisfics himself as to the direction of the wind; for a deer, when its nose has tolk it that a man is in the neighborhood, waits for no more Jefinite information on the subject, does not seek to learn just where he is, nor how far off, but makes the best of its way from the spot. All deer are alike in possessing this keen power of scent and in the readiness with which they take to flight when warned by this sense.

From the very nature of the case, the eyes are less to be relied on to warn the animal of danger. We are accustomed to hear men say that the deer's vision is defective, and even so good an authority as Judge Caton makes this statement in his excellent work on this group. There seems to be no sufficient reason for supposing this to be the case. It is true that deer will pass close by a man sitting in the woods without seeing him, provided only he remains perfectly motionless; but this does not necessarily imply any imperfection of vision. Other mammals and birds will do precisely the same thing. The deer would not walk up to a man standing or sitting in the middle of a meadow, and where there were no surrounding objects. A man, if motionless, in the woods, when clothed in hunter's garb, very closely resembles a stump or a stick. The deer is not especially familiar with the human form and does not recognize in it anything alarming, nor, since it is without motion, does it distinguish it from any of the many other quiescent objects over which its eye passes, and which it has no especial reason for closely examining. Its experience has taught it that these quiescent objects are not dangerous, and it therefore pays no attention to them unless they are markedly different in appearance from those to which its eye is accustomed. A white tent or a red shirt will, however, at once catch a deer's eye, because these are unusual objects. Anything that moves is observed at once, and, unless it is recognized as something commonly seen and not dangerous, is avoided. The deer has no friends; the hand of man and of the larger animals is against him ; and the fact that an object moves, and hence has life, is to him prima facic evidence that it is an enemy, and so, on the slightest hint of danger. he takes to his heels. Like other wild creatures, the deer seems to recognize danger only in life, and life only in motion. 
The Moose (Alce Americana, Jard.).

The moose is by far the largest of the Cerida, and considerably exceeds a horse in height, often measuring six feet or more at the withers. This great height is, in a measure, due to the extreme length of the legs; but the long mane-like hairs of the neck, which are naturally slightly raised, also tend to make the animal appear taller than it really is. When the moose is at his best,- - that is, in the autumn, - he is black, with tan legs and muzzle, and grayish belly and flanks, but later in the season the coat fades to a dark grizzled gray. The tips of the hairs are black, becoming pale gray about half-way toward the roots, and then changing to dull white. The young, when first born, are bright bay, sometimes with faint indications of spots on the sides. These markings are soon lost, however, and by September the color of the body is brownish gray, the head and legs being reddish.

The horns of the moose are broadly palmate, being sometimes sixteen inches across their widest part, and their spread is often five feet or more. The yearling bull has only a short spike; the horns of a two-year-old, now before me, are ten inches long, and a brow antler four inches in length springs from the beam six inches above the burr. The third year a small palm is developed, and for several seasons thereafter the horns increase in size. The head of this species is a marvel of ugliness, the great rounded nose, or mouffle, and the overhanging square-cut upper lip maling it appear indescribably heavy and coarse. The neck is very short, and this fact, in connection with the very long legs, renders it difficult, if not impossible, for the moose to graze on level ground. The young are brought forth in May, and are usually two in number. A calf moose is a most grotesque and, at the same time, a most interesting little animal. Years ago, in the valley of the Upper Yellowstone, a tame one, which had been captured by the sons of a settler there, came under my notice. Late in the month of August it was as large as a good-sized calf, and was strong and fat. It was quite as much at home about the ranche as one of the dogs, and manifested not the slightest fear. The greater part of its time was spent among the willow brush down by the river-bank; but at the whistle, if it hap- 


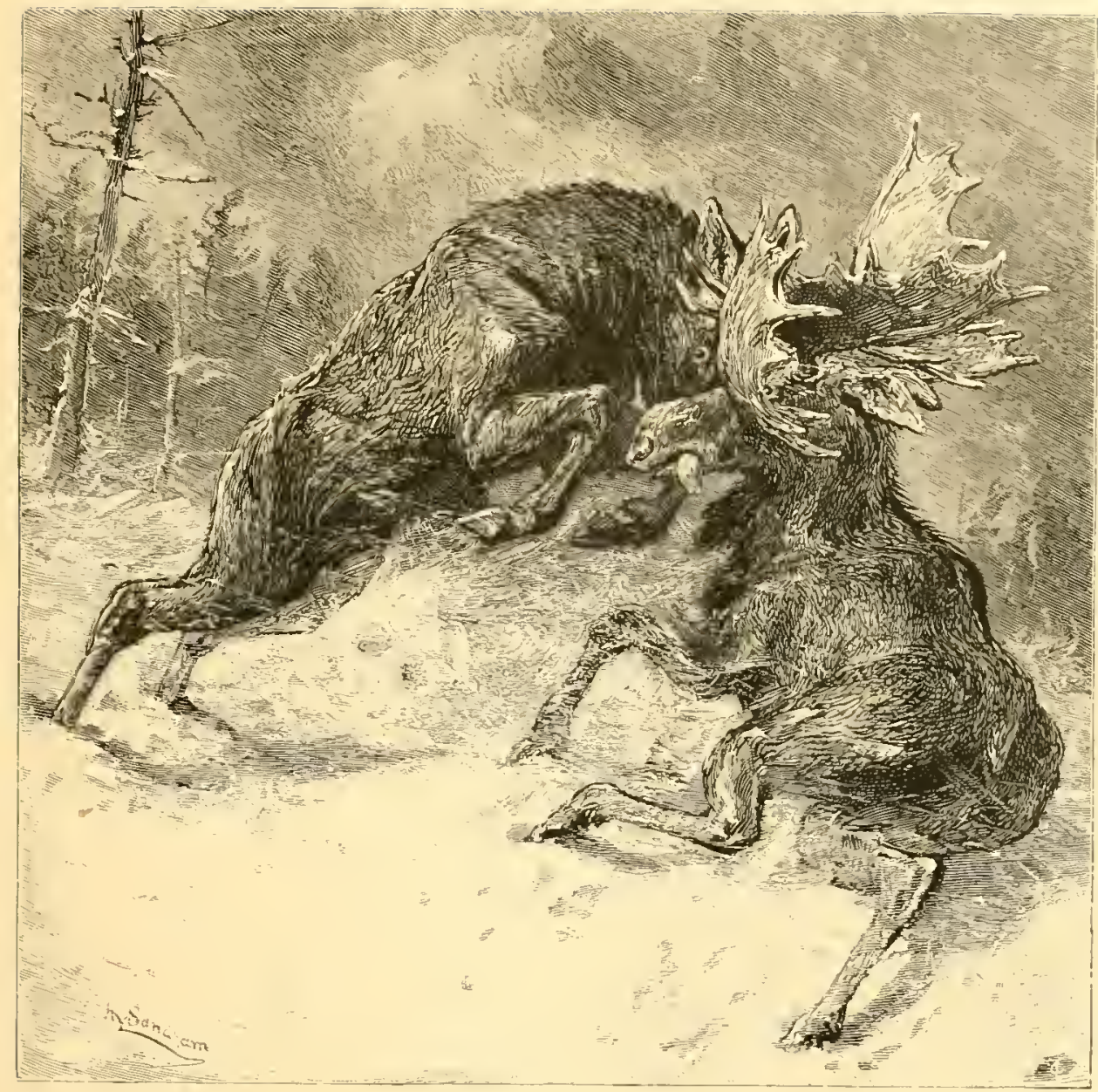

A HOOSE FIGHT. 

pened to be hungry, it would come trotting swiftly up, to the house. The boys who owned it rather complained because it would only obey the summons when it wanted a drink of milk, and said that at other times they were obliged to go down to the willows, and drive it up before them. It had been caught only two months before, and so, although it browsed to some extent on the undergrowth near the water, it still depended for subsistence mainly on cow's milk. It'hen the pail containing this was placed on the ground, the moose had a hard struggle to reach it. He would straddle the pail with his fore legs, and thus bring his mouth to the level of the liquid. As this sunk lower, his feet would gradually spread farther and farther apart, until sometimes 1 would feel anxious lest he should split in two, and it was always a question whether he would be able to recover his upright position without accident, but he never seemed to find the slightest difficulty in doing this by means of an awkward bound, which brought his feet close together again.

In the United States, moose are still found in small numbers in northern Maine, but are apparently extinct in the Idirondack region of New York, where they were once of frequent occurrence. In Michigan and $W$ isconsin, a few probably still exist; and they are more numerous in the tamarack swamps of Minnesota. Proceeding westward, no country adapted to this species is found until the main range of the Rocky Mountains is reached. In western Montana, northern Wyoming and Idaho, Washington, and portions of Oregon they are moderately abundant, though less so than the other species of Cervide found in this region. They are often killed, however; but the character of the country which they most affect is so difficult that the hunter is likely to neglect the moose, preferring the less laborious task of stalking the elk or the mule-deer, or even the leg-tiring climb after mountain sheep. But, as the Western country settles up, the fate of the moose there will be what it has been in New York and other Eastern States, and this superb creature will be known only in history. Its one hope of preservation from extinction lies in the proper policing of the Yellowstone National Park and the protection of its game, and here, if proper steps are taken, it may be preserved for all time.

Since it is difficult or impossible for the moose to crop the grass on level ground, a large portion of its food is arboreous. In the 
spring, it feeds on the young and tender shoots of the birch, the maples, poplar, and mountain ash, as well as those of some coniferous trees; during the summer, the willows and the water-lilies and other aquatic plants form a considerable portion of its food; and in winter, with its sharp incisors it nips the twigs and strips off the bark from different shrubs and trees.

The horns of the moose start in April and become hard early in September. The rutting season at once follows, lasting until November. At the beginning of this season the bulls are at their best, and then is the time to hunt them. Later, the flesh becomes somewhat strong, and, before the rut is over, the animals have become thin, and are scarcely fit for food.

It seems a pity that the moose cannot be domesticated. Experience has shown that they are readily tamed, and that they can be broken to harness without much difficulty. The elk of Europe was formerly used to draw sledges in Sweden, and in America the moose has occasionally been used as a draught animal, and has shown itself strong and tireless. It has not been practicable, however, to use it during the rutting season.

In winter, when the snows lie deep, and traveling becomes difficult, the moose "yard up," as it is called; that is, they collect in localities where food is abundant, and remain there until spring, or until they are driven off by hunters. This species is less gregarious than most deer, and it is somewhat unusual to see more than four or five together, and these are usually a single family of old and young.

\section{The Caribou (Rangifer Gronlandicus, Baird).}

The older naturalists described the two forms of American caribou under different specific names, and regarded both as different from the reindeer of the Old World. At present, however, the best authorities consider the woodland caribou (R. Gromlandicus tarandus), which is the common Southern form, as a fairly good geographical race of the barren ground species, and look upon the circumpolar forms as identical.

The head of the caribou, while less coarse than that of the moose, is far from presenting the delicate and graceful outlines seen in the 
genera Corzus and Cariacus. It is blunt and rather heavy, shaped, in fact, somewhat like that of a cow, though less wide across the forehead. The form is much heavier and stouter than that of most deer. During the summer, this species is dark brown on the body and legs, becoming paler, and almost white on the belly and rump. The head and neck are white at all seasons, and in winter a long beard or mane depends from the latter. Late in the autumn, the hair throughout becomes longer, and the color of the animal changes to a paler cast, so that it is a faded gray or soiled white, somewhat shaded with brownish on the legs and flanks. The young are at first spotted, but less pronouncedly so than is the case with most of our deer. The arctic form is much the smaller of the two, an adult male weighing, after having been eviscerated, only from ninety to one hundred and thirty pounds. This would give a live weight of from one hundred and forty to two hundred pounds. The woodland form, on the other hand, is, with the exception of the moose and elk, the largest of the North American deer. A good-sized male will stand four feet high at the withers, and may weigh from four hundred to five hundred and fifty pounds.

The horns of the caribou are remarkably large and heavy for the size of the animal, and this grenus is the only one in which both sexes commonly produce these outgrowths. Those of the female are usually small, slender, and but slightly palmate, and bear two or three small tines. In the male, however, they are long, branching and irregular, most of the tines being widely expanded from above downward toward their extremities, and the palmate portion terminating at its margin in half a dozen short points. The antlers vary widely in the size and shape of their branchings, and do not seem to have any common form. Those of the arctic reindeer are nearly twice the actual size of the woodland race, while the aninal which carries them is only about half as large.

The caribou's foot is broad and spreading, and the supplementary hooflets, or dew-claws, are large, the whole being admirably adapted for supporting the animal in its passage through marshes or over the snow. The thin, horny shell which forms the border of the hoof also serves it well when traveling on the ice. The representatives of the second and fourth digits contribute something to the support of the animal's weight, and are always more or less worn and abraded 


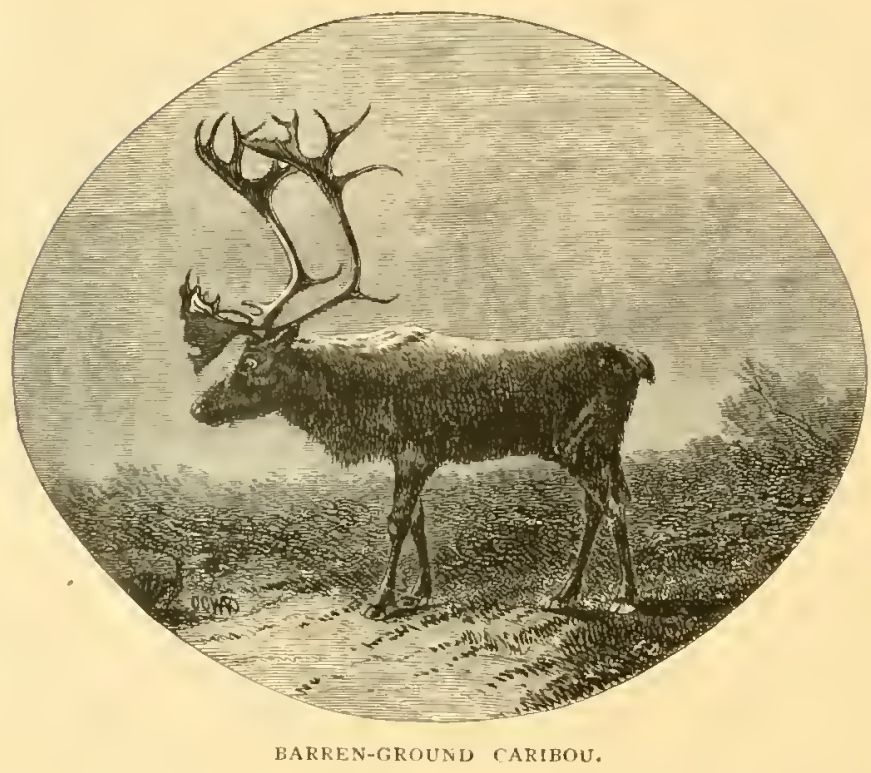

on their inferior surfaces. When the animal trots swiftly, these dewclaws strike against one another with a loud, clattering noise.

The food of this species consists principally of the so-called reindeer moss (Cladonia rangiforina). which, in winter, they reach by scraping away the snow with their hoofs; but they also eat other mosses and lichens which grow upon the trees or on the barrens which they frequent. During the summer they feed on grasses and the tender shoots of shrubs, but do not appear at any season to strip the saplings of their bark as do the moose. The young are brought forth in May.

As to the habits of the barren-ground caribou we are not well informed, for the species is known only to arctic explorers and to the servants of the Hudson Bay Company, in British America. Richardson's accounts of it are, however, quite full, and from these it appears that this form does not differ materially from its woodland relative, except in the range of country which it inhabits, and in the greater extent and regularity of its migrations. The woodland caribou is much more southern in habitat, and frequents especially the forests of British America, occurring regularly in Maine and perhaps in the Rocky Mountain region of the United States along the border. The barren-ground deer, on the other hand, occupies the wide treeless plains about the Arctic Sea, where 
the only other large ruminant is the musk-shecp, only retiring southward to the forest belt in winter.

The migration of the caribou is a notable feature in its habits, and the journeys which it performs are longer and more regular than those of any other species of North American Cerida. Others, as the elk (Cor'us Canadousis) and the mule-deer (Cariacus mucrotis), change from one feeding ground to another at the approach of winter and again in spring; but such changes do not usually involve journeys of much more than seventy-five or a hundred miles, while those of the caribou are far more extended. In the woodland caribou, the migration seems to be little more than a mere restlessness, a desire to keep moving, or a natural change from a winter feeding ground to a summer one and back again: but, in the barren-ground form, the journeys take place with so much regularity and are on such a large scale that they have attracted the attention of all travelers who have had opportunities of observing them. The last-named deer spend the winter along the borders of the low forests near the arctic circle, and at the approach of spring begin to travel northward toward the shores of the Arctic sea, which they reach early in May, the females preceding the males. Here the young are born, and the summer is spent. The rutting season is in September, and soon afterward the herds retrace their steps southward. In the island of Newfoundland, however, where the woodland form is the only one found, a general movement of these deer takes place in April, at which time they leave the lowlands on which they have passed the winter, and where food is at that season more easily obtained, and travel in a northwesterly direction toward the higher mountainous country. Here they remain during the summer, and at the approach of cold weather a retrograde movement ensues.

Caribou are notorious for being great travelers and almost constantly on the move. Their powers of scent are very keen, and when much hunted they are extrenely wary and difficult of approach, and if once started it is impossible to come up with them, for they do not cease their flight until they have put a long distance between themselves and the danger which threatened. The gait of the caribou is a long. swift trot. It never gallops, though when first frightened, it may make a few startled bounds. This tireless trot, it is said, can be kept up for many hours. 


\section{The ElK (Cerous Canadensis, Erxleben).}

The elk, or, as it is sometimes called, the wapiti, is a near relative of the red deer of Europe, but is a much larger animal. At the withers it measures about five feet in height, being thus about as tall as a horse. The females are somewhat smaller. The shape of the elk is much like that of the common deer, being graceful, and having none of the coarseness and awkwardness of the moose and caribou. The head is small and finely formed, the legrs slender and delicate, and the whole shape strong, yet elegant. During the greater portion of the year the color of the elk is a yellowish brown, of a somewhat varying shade, the head, neck, legs, and belly being a dark wood brown. I have sometimes killed specimens in autumn so pale that they might fairly be called yellow, and have seen others in the same band which were almost brown. At the approach of winter, the coat becomes darker throughout. On the rump, extending up on the back above the tail, and also down on the inner side of the legs, is a patch of yellowish white, bordered by a stripe of dark brown or black. The tail is extremely short, and is clothed with hair only upon the upper surface and sides. The hair upon the neck is always much longer and coarser than that on the body, and in winter increases in length so as to become really a mane. The elk is provided with quite a heavy coat of short. close wool, which is, however, concealed by the hair, and is only to be observed in spring, when the pelage is shed. The horns of this species, which are only borne by the males, are long, cylindrical, and branching, and are much more nearly straight in the beam than those of any other North American deer. They are usually very symmetrical - though abnormal forms are sometimes seen - and bear on each beam five or more tines, directed forward, inward, and upward. The antler of the bull elk in his second year is a straight spike from ten to eighteen inches long, which is usually bifurcated.

The elk was formerly distributed over the whole of temperate North America, its range having been even more extended than that of the buffalo, and almost as wide as the Virginia deer's. The advance of the settlements has, however, caused its extinction throughout 


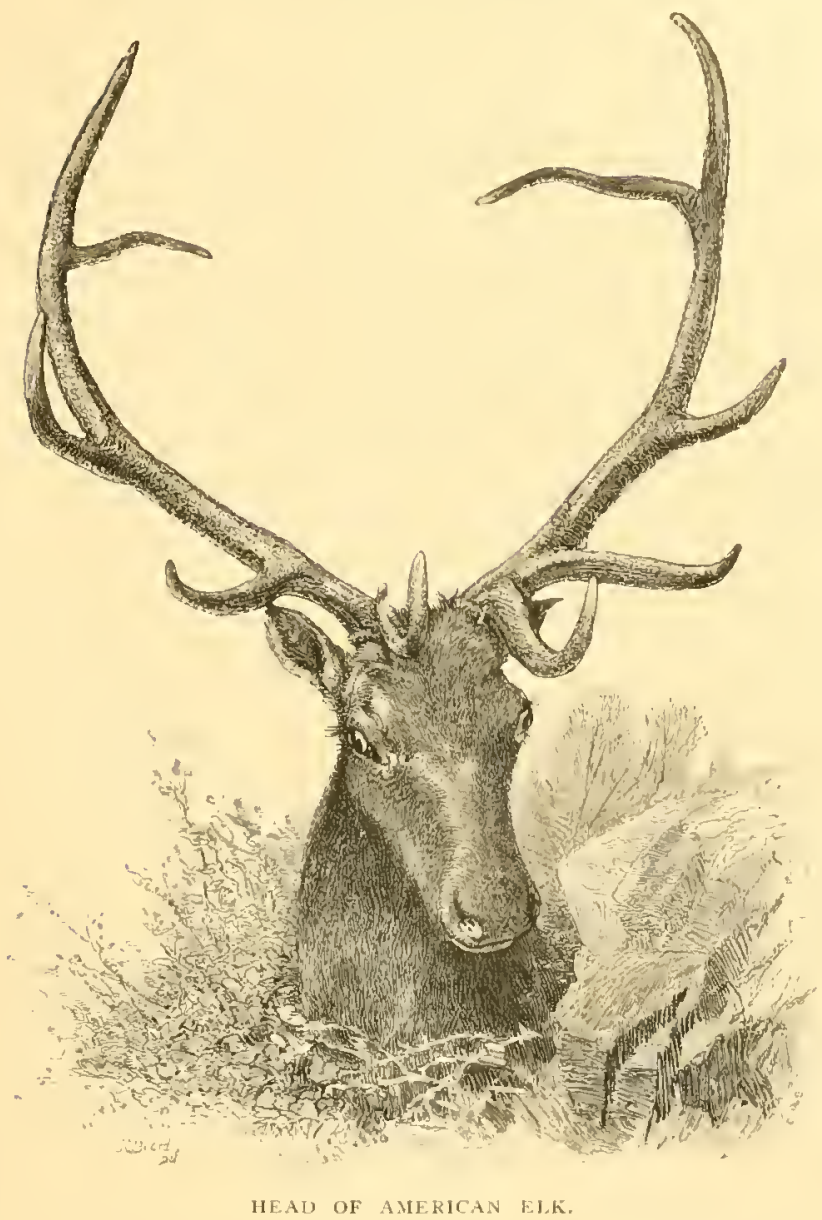

the greater portion of its former habitat, and to-clay there is probably only one very circumscribed locality east of the Mississippi River where it is to be found in the feral state. In the dense forests of the lower peninsula of Michigan it is said that a few still exist, but their numbers are becoming less each year, and before long they will all have disappeared. West of the Missouri River, and in the Rocky Mountains, there are regions in which this species is even yet moderately abundant; but it is now impossible to find them anywhere in such numbers as formerly. Less than ten years ago, there were many secluded localities in Colorado, Wyoming, and Montana, where, in the late autumn and winter, these animals would collect in bands numbering thousands of individuals; but at the present day it is unusual to see one hundred together. The hide of the elk has a 
commercial value, which makes it sought after by those butchers of the plains called "skin hunters": and the size and beauty of the animal causes it to be ruthlessly pursued by so-called sportsmen, who are eacrer to kill, so that, on their return to civilization, they may boast of the slaughter they have made among these graceful denizens of plain and mountain. The same wanton butchery, which has over the greater portion of our country exterminated the buffalo and the moose, is causing the elk in like manner to disappear.

The young are born in May and June, and are at first bright bay in color, profusely spotted with white, after the manner of the common red cleer. At the time of the birth of the calves, the females are scattered and the bulls keep by themselves in small companies of two, three, or half a dozen. If in a mountain country, they frequent the highest hills, usually close to the snow line, and do not move about much; while, if on the plains, they spend their time among the thick willow brush along streams. About the first of August, the elk begin to "band up," as the hunters phrase it, and at this time they are to be found in scattering companies, which remain together until the rutting season begins in September. Each male now collects as many cows as possible, and keeps them together, jealously guardingr them and driving away any other bulls which may approach. This lasts for a month or more, and during this time the bulls are constantly moving about, looking after the cows that are under their charge, and fighting. Many little groups of bulls, however, will be found without any cows.

After the rut is over, the elk collect in large bands, and at the approach of winter shift from place to place, gradually working toward their winter feeding grounds. These are usually bald bills, which the winds keep swept clear of snow, so that the grass is always exposed. In such situations they spend the winter.

The usual gait of the elk is a long, swift trot, which it can keep up for a great length of time without manifesting fatigue. When greatly frightened they sometimes run, but this pace, while perhaps somewhat faster than the trot, soon tires the animal. This species is killed almost exclusively by still-hunting, though, on the plains, it is not unusual to run them down on horseback. This requires a very good horse and an open, favorable country. 
The Mule-Deer (Cariacus macrotis (Say) Ciray).

This species equals the common Virginia deer in height, but is more stoutly built, has somewhat shorter legrs, and is in all respects a heavier, less graceful animal. The ears are the most striking characteristic of this deer, and from them it has received the name "mule," or the Spanish equivalent buro, deer. They are extremely large, being nearly twice as long and wicle as those of our common species, and when seen thrown forward, as the animal stands gazing curiously at one, or flapping backivard and forward as it runs away, are sure to attract attention. The tail, from which it takes its more common, but incorrectly applied, name, "black tail," is quite unlike that of any other species of our Corida. It is short, round, naked beneath, clothed on its upper surface with very short, white hairs, and terminates in a thick brush of longer jet black ones. In summer, the coat of the mule-deer is red, the hairs being short, and so sparsely distributed that the black skin is easily seen through them. There is a triangular patch of white upon the rump, crossing it at, or a little above, the root of the tail. Early in the month of September, the close, thick, winter dress begins to grow, and the summer hairs fall out. The tips of the hairs of this winter pelage are black; and when it first starts, the animal for a short time appears almost black. Later, as the hairs grow longer, the color becomes steel-gray; and toward the end of the winter, when they are longest. and each one shows a greater proportion of white, the coat becomes still paler in cast.

The horns do not bend forward so much as do those of Cariacus Virginianus, and each beam of the pair is forked at least once, and the division is so equal that it is difficult to decide whether the anterior branch is the main beam and the posterior a tine, or the reverse. This forking may sometimes occur twice or three times in the same horn.

The mule-deer is found throughout the greater part of the Missouri River region, and thence westward on the plains, in the Rocky Mountains, and in the Sierra Nevaclas. It is an inhabitant of rough, broken country, and on the plains is usually only to be found about high buttes, in the bad lands, or where the country is diversified with 


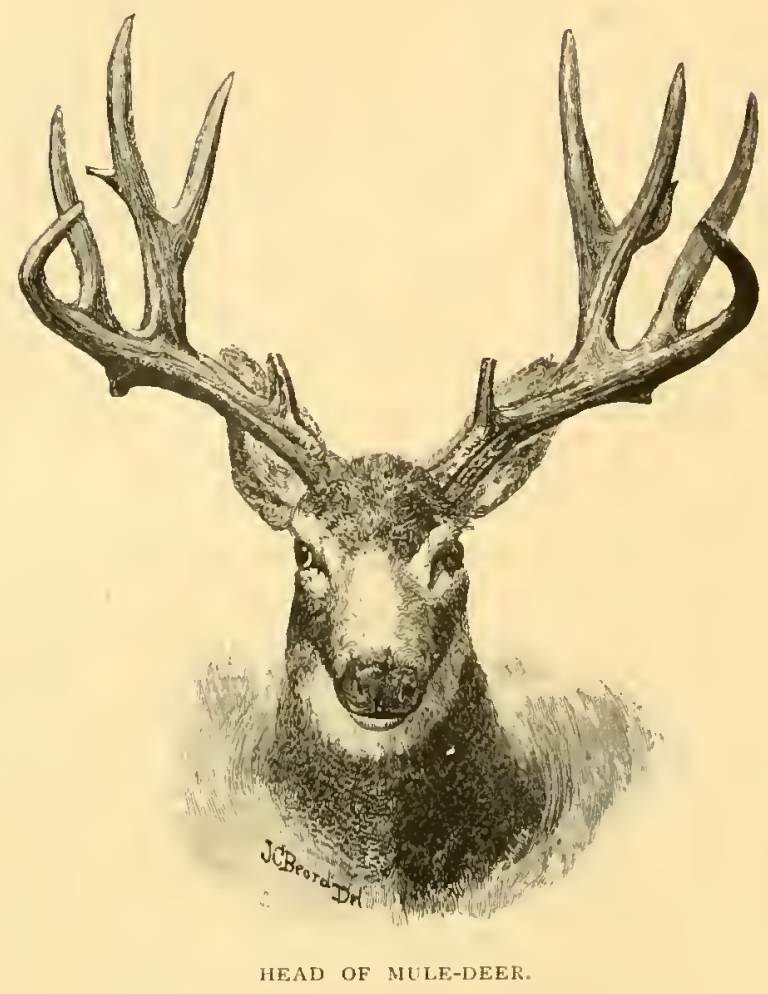

rocky ridges dotted here and there with scattering pines or junipers. Its favorite resorts are the coulies, gulches, and cañons which so often break up the high table-lands of the central plateau of this continent; but it is as often to be found among the green timber high up on the mountain-side, or, in summer, among the low trees that grow just below the snow-line. It is to such localities as the last named that the bucks resort during the summer, when they are "growing their horns," and when their thin coat of hair affords them little or no protection against the flies.

The young of the mule-deer are born the last of May or early in June. They are two in number, and are prettily spotted like the calf elk, the spots being lost in September, when the summer coat is shed. Just previous to this date, the mother begins to wean her fawns, and hides from them, not permitting them to suckle her. They are, therefore, quite thin in the early autumn, but soon learn to forage for themselves, and by the time that cold weather sets in are fat and in good condition. 
The rutting season is in September and October, the "velvet" having been shed from the antlers during the early part of the former month. At the begimning of the rut the bucks are enormously fat, and the flesh at this time is superior to that of any deer with which I am acquainted.

Caton's variety of the mule-deer (C. macrotis Califormicus) ( $\mathrm{Am}$. Vat., X.. 464, August, 1876) is distirguished from the ordinary. form by a more reddish cast of pelage, and by the presence of a dark line extending down the upper surface of the tail and uniting with the black brush at the tip.

\section{Black-Tal Deek (Cariacus Columbianus (Rich) Gray).}

The true black-tail deer is intermediate in size between the mule and the common deer. In form and build it more nearly resembles the former, while weighing about as much as the latter. The horns curve forward more decidedly than in Cariacus macrotis, but in the forking of the beam it resembles that species. The tail, on the other hand, is more like that of $C$. Firginiunus, being broad and flat, though not so long as in that species, and covered throughout with hair. It is white below and black above and on the sides.

In color, the black-tail resembles our common red deer, beingr bright bay in summer and changing to gray in the winter. The under surface of the head and the belly are white. The changes in the pelage, as regards time and character, are similar to those which take place in the mule-deer.

The range of this species is the most circumscribed of any of our Cirida. It appears to be confined to a comparatively narrow strip of territory - the mountain ranges of the Pacific coast. There is no record of its capture east of the Sierra Nevada mountains, although a hunter of reliability has informed me that, in an experience of ten years in the Central Rocky Mountain region, he believes that he has killed three deer of this species. Something more definite than a doubtful statement of this kind is required, however, before we can extend the limits of this species beyond those given above. In the Sierra Nevadas, and in the mountains of the Coast Range, the blacktail is abundant, sharing its range to the south with Caton's mule- 
deer, and to the north with the caribou and the elk. Its northern limits do not appear to be very definitely known. I have myself met with it as far north on the Pacific coast as latiturle $5 \mathrm{I}^{\circ}$, and it may be assumed that it is found many degrees farther to the northward.

The young of this species are usually born in May, and are spotted, and this ornamentation is decidedly more vivid than in the young of the mule-deer and the elk. The spots are more numerous, more regularly arranged in lines, and more sharply defined, than in those species, and thus approach the markings on the young of the common deer.

The black-tail deer is an inhabitant of the dense coniferous forests of the Pacific coast, and appears to delight especially in such tangled solitudes as their dark and damp recesses afford. They are seldom found far from the timber, or from some dense cover into which they can retreat if alarmed. Along the sea-coast, especially to the northward, where they have been but little hunted, they come down frequently to the salt water, for the purpose of feeding upon a species of sea-weed cast up by the waves, and the trails made in their passage up and down the sides of the mountains are often worn a foot or two deep, showing a great amount of travel over them. The Indians of British Columbia kill great numbers of these deer a!ong the water's edge, stealing up within shot in their light canoes, which they paddle noiselessly along, close to the shore. Still hunting in the forest is practiced with success in many localities. Deer are very abundant on the islands and among the mountains of this coast, and as they are not often disturbed they are very unsuspicious, and will frequently permit the hunter to approach very close without taking the alarm. There are, however, great areas of territory where, owing to the thick and tangled character of the undergrowth, stalking is out of the question, because of the impossibility of noiseless progress through the thickets. Hounds are therefore often used to drive the deer to certain well-known runways, or into lakes, rivers, or arms of the sea, where the hunter has no difficulty in paddling or rowing up to the swimming quarry and dispatching it. Like the common deer, the black-tail is a rapid swimmer, and I have seen the strength and skill of two practiced paddlers severely taxed to bring a light canoe up to a deer swimming across a lake. 


\section{VIRGiNe DEER (Cariacus I Tirginianus (Bodd.) (iray').}

The red deer is so well known that an extended description of its physical characteristics seems scarcely necessary. The summer coat is bright bay; the throat and under surface of the tail being white at all seasons. In the autumn, the coat becomes grayer and the animal is then said to be "in the blue." There is usually a reddish or brownish cast over the deer's coat, even in winter. The upper surface of the tail is dark brown. The shape of the Virginia deer is the most graceful of any of our species. The head is slim and delicate, the ears fine and pointed, and the legs long and slender. The conspicuous feature of this species, when frightened, is the tail, which is carried high and shows the white under-surface.

This has the widest distribution of any of our deer, extending from ocean to ocean, and from about the fifty-fourth paralle] of north latitude south into Mexico, and, perhaps, Central America. Unlike the elk and the mule-deer, it does not retreat before the advance of civilization, but when driven from its home, disappears for a short time only, and soon returns. To-day, there are probably not more than one or two States in the Union in which wild deer do not exist, and a high authority recently wrote, "It may be found to-day in every State and Territory of the United States."

There is a very wide variation in the size of individuals of this species in different and even in the same sections of country. On these differences, as distinguishing characters, a number of supposed varieties of C. Virginianus (loucurus, macrurus, Mcricanus, and Coucsi) have been based, most of which appear to be of doubtful validity. There are big deer and little deer, just as there are tall and short men; and until some characters more tangible and constant than size can be given, it is scarcely worth while to dignify small specimens of the Virginia deer with varietal names. In the year is 74 , during the first expedition of the late General Custer into the Black Hills of Dakota, deer were found there in great numbers, and most of them were of this species. It was a common thing to kill, on the same day, adult bucks, which one man could without difficulty lift and put on a horse, and others, two or three times as large, which required the united strength of two men to put in the same position. 
The Virginia deer seems equally at home among the mountains, in the forest, or on the prairie. It delights in dense cover in which to rest, and in a prairie country conceals itself during the greater portion of the day in the willowy thicket along the streams or among the high grass of sloughs.

From its wide distribution and the consequent variety of the locations in which it makes its home, it is hunted in a number of different ways. Still hunting is the most legitimate as it is the most difficult method. Hunting with hounds, as usually practiced in the South, has much to recommend it. The dogs are put on the track of the deer, and the hunters, armed with shot-guns, follow on horseback, keeping as near the hounds as possible, and endeavoring. by cutting across corners'and riding chords of circles, to get within shot of the fleeing animal. To successfully follow the chase through forest, swamp, and canebrake, or along the rough mountain-sides, requires courage, nerve, and a firm seat in the saddle, and no better school of horsemanship could be devised than this method of deer hunting. 1ts excellence was well shown during the early part of the war, when the irregular Confederate cavalry, armed with doublebarreled shot-guns, were very troublesome to the Union forces. Hounds are also employed to drive the deer to runways or to water. It requires no very great degree of skill to shoot a deer as he runs by within thirty or forty yards, and even less to kill one when swimming in the water but a few feet from the boat. The latter method is therefore in high favor with the average summer tourist, who cares nothing as to how his game is secured, provided only he can truthfully boast that he has killed a deer. Jacking is a very pernicious method often employed in summer or when deer are abundant. A lantern or fire of some kind is carried, which discloses the position of the deer, while the glare of the light dazzles it, and it stands gazing for a longer or shorter period, giving the hunter an opportunity to shoot. "Breasting" is employed where the deer make their home among very high grass, such as is to be found on some of the prairies of the South-west or in the great beds of the dry lakes which are to be found in northern and western Nebraska. Here the thick cane-grass stands seven or eight feet high, and the head of a mounted man is only just visible above the tops. Several horsemen. armed with shot-guns, form a line on the leeward side of the space to be hunted 
over and ride through it, a little more than a gun-shot apart. The deer that lie in their course are started from the grass, and bound off ahead of the hunters, every now and then showing their backs above the tops of the grass. The horsemen have to shoot from the saddle, and very quickly, to secure their game.

Fossil deer occur in the tertiary deposits of North America. In the Miocene of the lVest are found remains of deer-like animals, Leptomery'x: and from the lower Pliocene a genus of true deer, Cosony, has been described, of which there are several species. These all have very small antlers, which are divided into two tines. In their osteological characters these deer differed from existing species in many respects. The orbit was not closed behind, and the metapodial (splint) bones were entire, though those of the second and fifth digits were very slender.

In the Post-pliocene deposits, species of deer, closely allied to our elk, moose, and caribou, have been found, the latter having been met with far south of its present range.

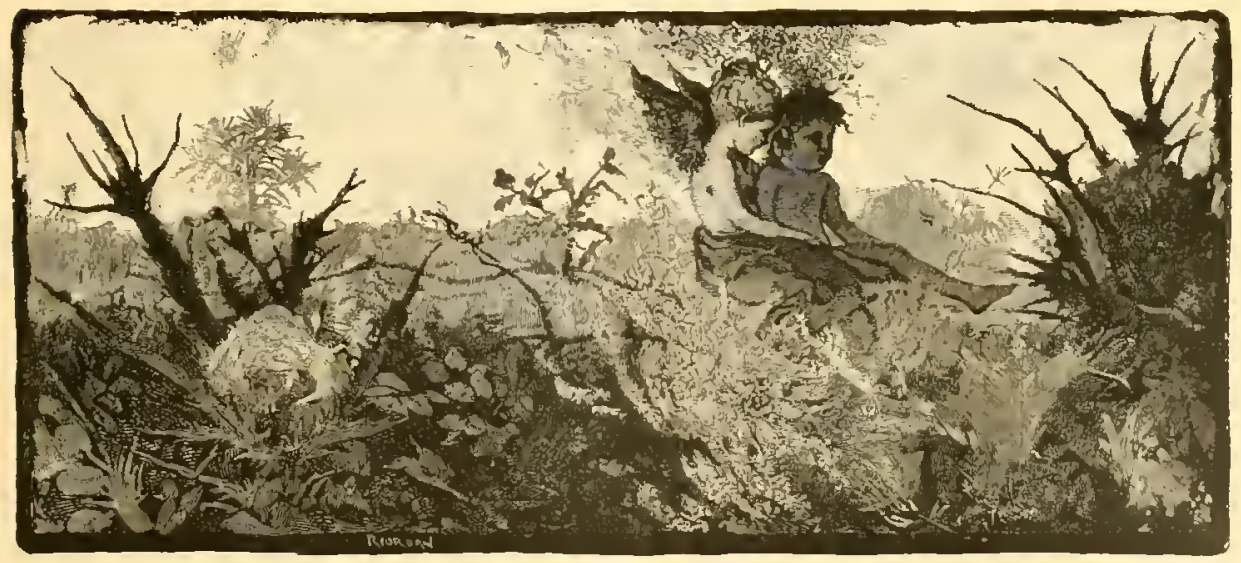




\title{
MOOSE-HUNTING.
}

\author{
BY CHARLES C. WARD.
}

T

is much to be regretted that a mammal of so much dignity and importance as the American moose (Cornts Alces - Linn. : Hee 4 mericanus - Jardine) is fast clisappearing from our forests. Tardy legislation is loing something, it is true, for his protection, and may probably prevent a repetition of such a scene as happened on the Tobique River in the province of New Brunswick, several years ago, when several hundred of these noble animals were slaughtered for the sake of their hides, and their carcasses left to rot in the forest.

To the early settlers in the States of Maine, Vermont, and New Hampshire, and the provinces of Nova Scotia and New Brunswick, the flesh of the moose was the main-stay, and his hide furnished them with serviceable clothing. At the present time, with the exception of Maine, the moose are almost extinct in the Eastern States, and they are becoming scarce in Nova Scotia. In New Brunswick, they are seldom found on the rivers emptying into the Bay of Fundy, where in former days they existed in vast numbers. They can yet be found, however, in consiclerable numbers on the head-waters of the Restigouche and Miramichi rivers and their branches; in the provinces of Quebec and Ontario south of the St. Lawrence; in the central parts of the county of Rimouski, and thence southward along the borders of Maine, and all through the country south of the city of Quebec to New Hampshire. In the county of Gaspé they are extinct, having been exterminated by ruthless hunters for the sake of their hides. North of the Ottawa and St. Lawrence rivers, the moose ranges from Lake Wanapitiping nearly to the Saguenay. Their northern limit is now somewhere near the watershed of Hudson Bay; it was formerly beyond it. The western limit is about the longitude of Lake Huron. None are now found north 
of Lake Superior, although they have existed in this region as far north as the Albany River. In the North-west territories, they are found as far as the Mackenzie River. A friend gave me the measurements of a moose killed in Rupert's Land, which, if correct, would go far to verify some of the old-time stories of the wondrous size of the moose. In the United States, moose are still found in sufficient numbers to warrant the belief that, by judicions protection, the species might be perpetuated. They are quite abundant in Oregon, Washington Territory, and the whole northern border of the United States as far as the Lake of the $\mathbb{W}$ roods. They are still met with occasionally in the northern part of Michigan, along the shores of Lake Superior, and very rarely in northern Vermont and the Arlirondack region. They also inhabit the wooded region of the great lakes and that lying thence westward to the Rocky Mountains. The southernmost point at which they have been found in the West is in ldaho, on the forks of the Snake River near the Three Tetons, where several were seen and killed by members of the United States Geological and Geographical Survey of the Territories. The present southern limits of the moose on the Atlantic coast are the provinces of New Brunswick and Nova Scotia, in the Bay of Fundy. These provinces are still his favorite haunts, and here in the present day he is most accessible to the hunter. This is perhaps owing to the infinite number of lakes and the prevalence of swampy: low-lying woods and bogs, in which he loves to dwell.*

The color of the American moose when in his prime is almost jet black, becoming more or less streaked with brownish gray as the animal advances in years. The head is so large as to appear out of harmony with the other proportions of the body. The ears are upward of one foot long, yellowish brown in color, and bordered with a narrow strip of a deeper shade, the inside lined with yellow hairs. Surrounding the orbit of the eye the skin is destitute of hair, and is of a pale flesh color; the eye is a velvety brown, and soft in expression, except when the animal is wounded or brought to bay, when it assumes a lurid hue and a twinkling, savage expression. The flanks

* I beg to acknowledge the kindness of Professor Paird, of the Smithsonian Institution, Dr. Elliott Coues, U.S. A., and Professor Bell, of the Geological Survey of Canada, in furnishing me with the latest information with regard to the geographical distribution of the moose. 
are a yellowish white, and the legs brown, and of extraordinary length. White, of Selborne, writing of a moose which he had seen, quaintly remarks upon "the strange length of its legrs, on which it was tilted up much in the manner of the birds of the gralle order." A curious muscular development of the upper lip, termed the moufle, is common to both sexes, and a pendulous gland hangs from the neck of the males. The neck and withers are surmounted by a voluminous mane of a light gray color. This hair is dyed various brilliant colors by the Indians, and is used to embroider designs upon birch bark, velvet, and other materials.

The largest moose that I ever saw measured six feet and nearly five inches at the withers, a trifle less at the buttock, and four feet and five inches from the withers to the buttock, and from withers to the top of the skull, twenty-seven inches. The head measured two feet and five inches from the moufle to a point between the ears, and nine inches between the eyes. The horns weighed forty-five pounds, and measured four feet and three inches from tine to tine at their widest part, and at their greatest width the palmated parts measured thirteen inches. The horn, at its junction with the skull, was eight inches in circumference. The whole carcass, before gralloching; must have weighed close upon twelve hundred pounds. I have heard of cases where the specimen exceeded these measurements, but the reports lacked confirmation. The moose is commonly represented very much higher at the withers than at the buttock, which is undoubtedly a mistake, as in no instance (and I have measured many animals) have I found any great difference in favor of height at the withers, although the mane gives a casual observer a contrary impression. The great length of its legrs and prehensile lip are of much benefit to the moose, and wonderfully adapted to his mode of feeding, which consists in peeling the bark from, and browsing upon, the branches and tender shoots of deciduous trees. When the branches or tops of trees are beyond his reach, he resorts to the process termed by hunters "riding down the tree," by getting astride of it and bearing it down by the weight of his body until the coveted branches are within his reach.

The senses of smelling and hearing are very acute; his long ears are ever moving to and fro, intent to catch the slightest sound, and his wonderfully constructed nose carries the signal of danger to his 


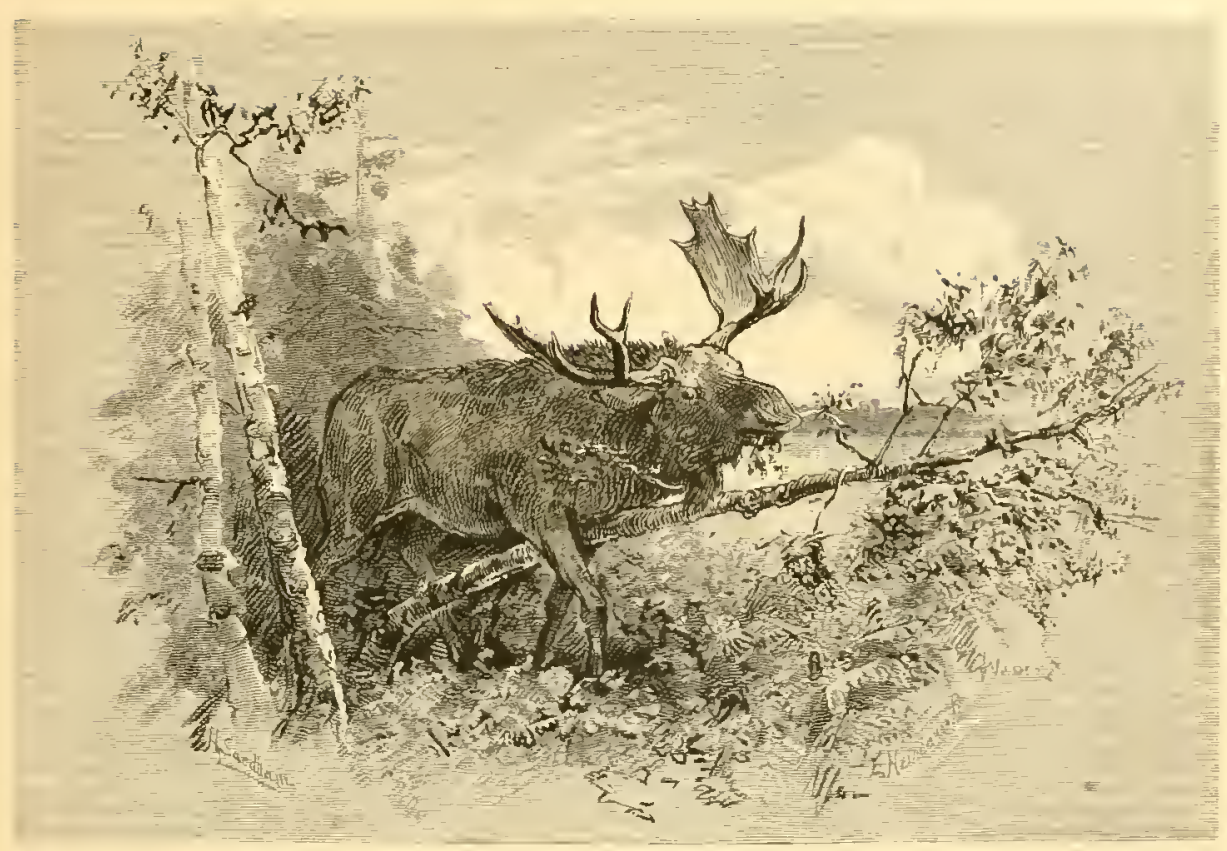

RIDING DOWN A TREE.

brain long before the unwary hunter has the slightest idea that his presence is suspected. When alarmed, this ponderous animal moves away with the silence of death, carefully avoiding all obstructions, and selecting the moss-carpeted bogs and swales, through which he threads his way with a persistence that often sets at defiance all the arts and endurance of even the practiced Indian hunter.

Nuch has been said and written of the ungainly appearance of the moose. Probably very few persons have seen the moose in his wild state, - perhaps only after he has passed through the hands of some unskilled taxidermist, whence he emerges, in most instances, an animal fearfully and wonderfully made. No person who has seen this noble animal in his native forests could fail to be impressed with the majesty and grandeur of his appearance. A few years ago, I was painting some tree studies near one of the numerous lakes in Charlotte County, New Brunswick, and for a long time I sat working in utter silence, until my attention was attracted by a movement in the branches, and presently a magnificent moose came out into the open. and walked quietly down to a pond almost directly in front of me, with his head erect and his broad antlers thrown back almost to his 
withers; his jet black skin, spotted white by the checkered sunlight, shone as glossy as satin. For a moment he stood silent, as if listening, then moved away, all unconscious that he had had a spectator.

A full-grown moose sheds his horns in the month of January; and they are not again fully restored until the end of August. By this time the velvet has been worn off and the horns are a rich fawn color, shaded or marked with dark brown, and polished by having been rubbed on the stems of the poplar and larch. The animal is now in the perfection of his strength and condition, and emerging from the swamps and bogs where he has spent the summer, feeding on the yellow pond-lilies, and evading the moose-fly and similar pests by frequently standing neck deep in some forest lake, he abandons the long silence maintained while his horns were in the velvet, and enters upon the rutting season - a noisy, aggressive, and pugnacious character. The fights which now occur between the old males are terrific. Greek has met Greek, and the combat is often prolonged until their horns become inextricably interlaced, and both animals die a miserable death. I once saw, in the month of October, two pairs of horns firmly locked together, with parts of the skulls attached, sticking out of a swamp, but as we were on the trail of a moose and had no time to spare, I failed to secure them; I could never find the spot again.

Early in May, the cow-moose brings forth two, and sometimes three calves, of a dark fawn color and slightly dappled. It has been affirmed that the cow-moose retires to some sequestered spot in order to protect her young from the attacks of bears and also of the bullmoose, but 1 an of opinion that the latter is not at any time very distant from the cow and her calves.

On one occasion, in the early summer, 1 saw an old cow-moose, with two calves, come out from an island in a lake and disport in the water. Presently a very large bull-moose came out of the forest at a little distance from them, and began to eat the roots of the yellow pond-lily; which he procured by diving for them and bringing them to the surface of the water in his teeth. While he was still feeding, the cow and her calves retired.

On the approach of winter, the moose form into small herds of five or six animals, often containing a bull, a cow, and the young of two seasons, and establish themselves in what is termed a mooseyard. The yard is situated in some part of the country where there 


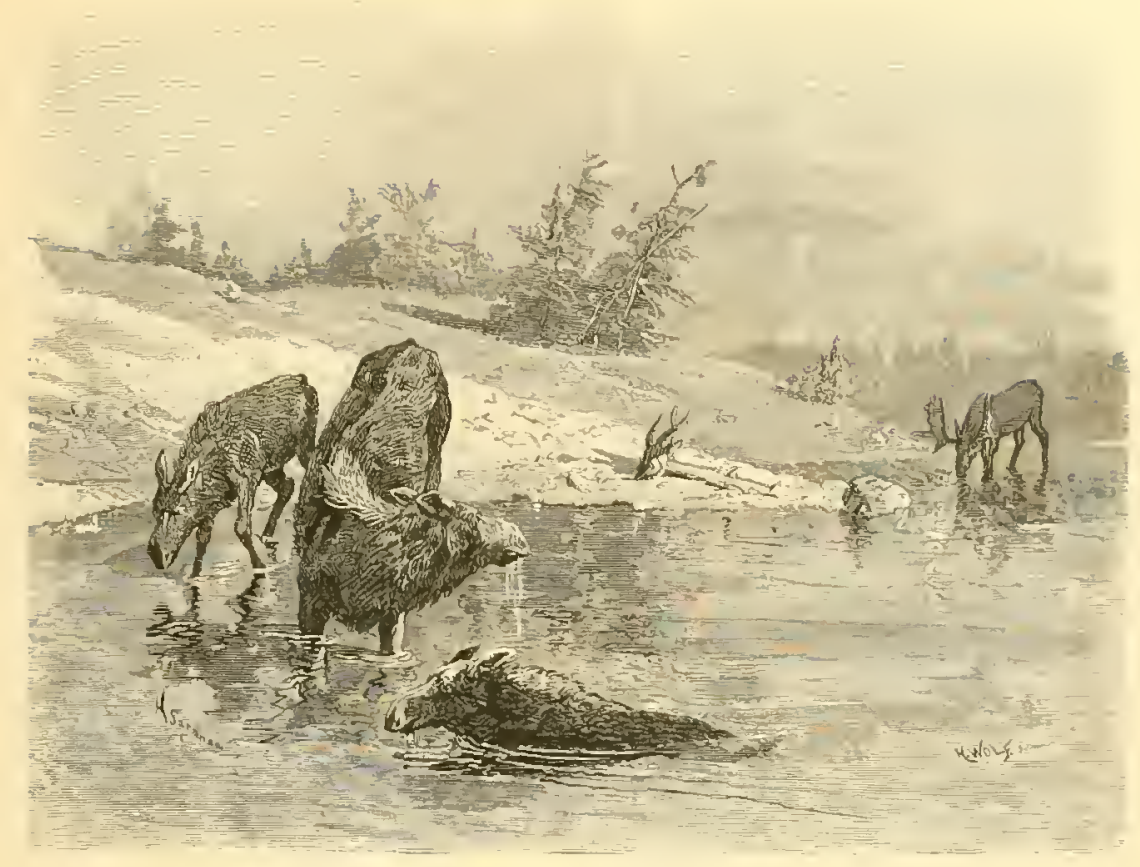

A MOOSE FAMILY.

is an abundant growth of young deciduous trees, such as the white birch, poplar, maples, and mountain ash; these, together with a few of the coniferous trees, the balsam fir and juniper, form the staple diet of the moose. Some writers maintain that the bull-moose never yards with the females and young, but this is disproved by my own experience as a moose-hunter, extending over a period of many years, and in company with one of the most intelligent and accomplished Indian guides. I have on many occasions found and killed males occupying the same yard with old and young females. A few years ago, when out on a hunt with my friend, Colonel $\mathrm{W}-$ and some Indian guides, we discovered a moose-yard, occupied by a very large bull, two cows, and younger animals. After a long and desperate hunt, we killed the bull and captured one of the young moose alive. I admit that very old bulls, grizzled with age, their horns almost bleached white, affect solitary habits, and yard alone.

The maximum age attained by the moose is difficult to determine; some hunters profess to judge hy the number of tines on the horns, but that method is not to be relied upon. The Indians say' that the horns do not attain their full size until the sixth year, and 


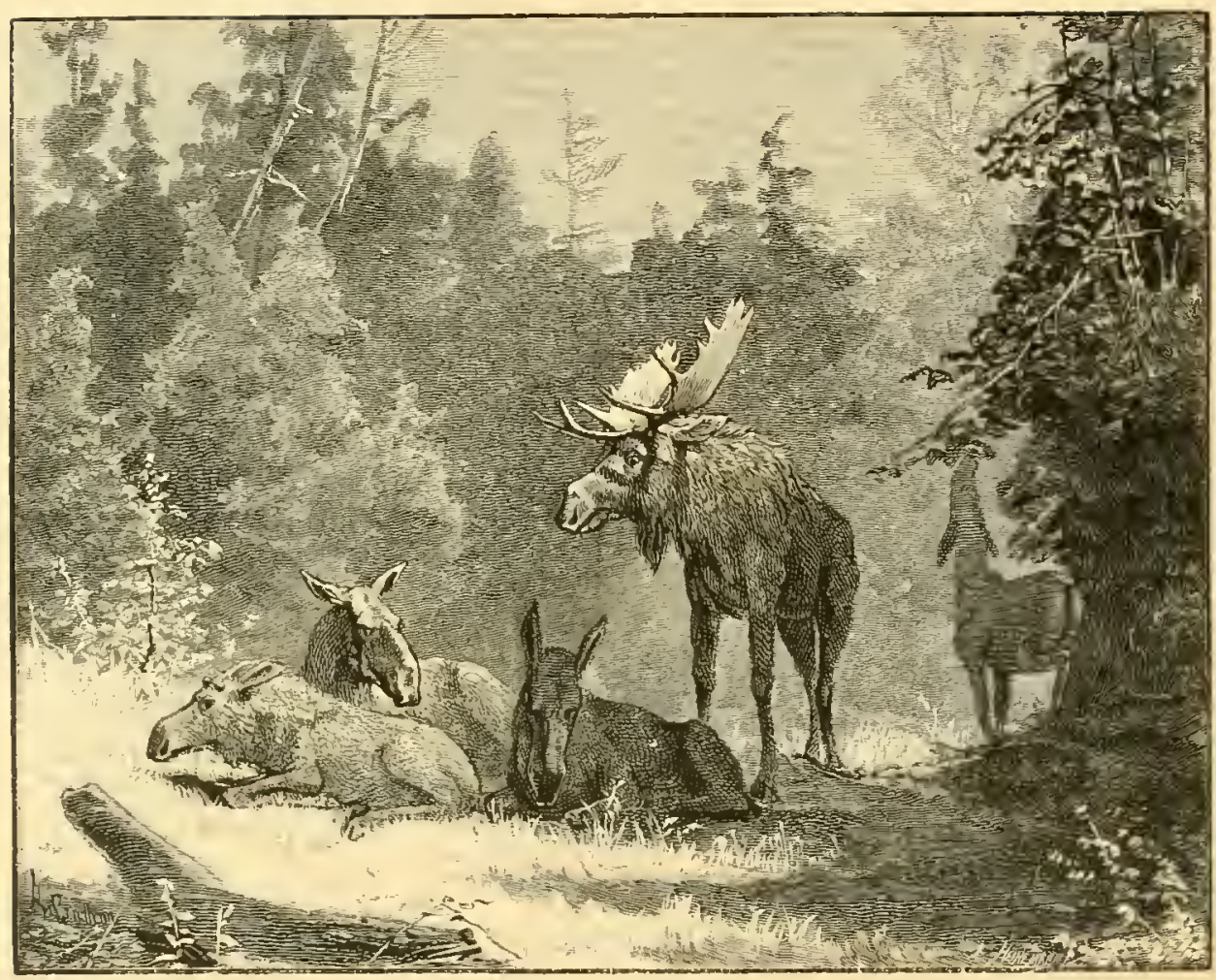

1 MOUSE-YARD.

that then the tines and palmation are perfect; and further, that the duration of life is probably about twenty years.

There are three modes of hunting the moose, termed still hunting, fire hunting, and calling. There was another mode, which, I an happy to say, legislation has in a great measure suppressed. I refer to the wholesale slaughter of the unfortunate animals when the deeplying snows of a protracted winter had imprisoned them in their yards and renclered them only a too easy prey to the unprincipled butchers who stew them for the sake of their skins.

To be successful in still hunting, or creeping upon the moose, necessitates the aid of a skillful Indian gruide. Very few, if any, white men ever attain the marvelous precision with which an Indian, to whom the pathless forest is an open book which he reads as he runs, will track to its death an animal so exceedingly sensitive to the approach of man. This gift, or instinct, seems born with the Indian, and is practiced from his early childhood. It is not uncommon to 
find little Indian boys in the forest, several miles from the wigwam. armed with a bow and arrows, the latter having an old knife-blade inserted in the heads. One little fellow named Socotoma was a very expert shot, and woe betide mit-chi-css, the grouse, and mat-cy-gmis, the hare, if they happened in the way of little Socotoma when he

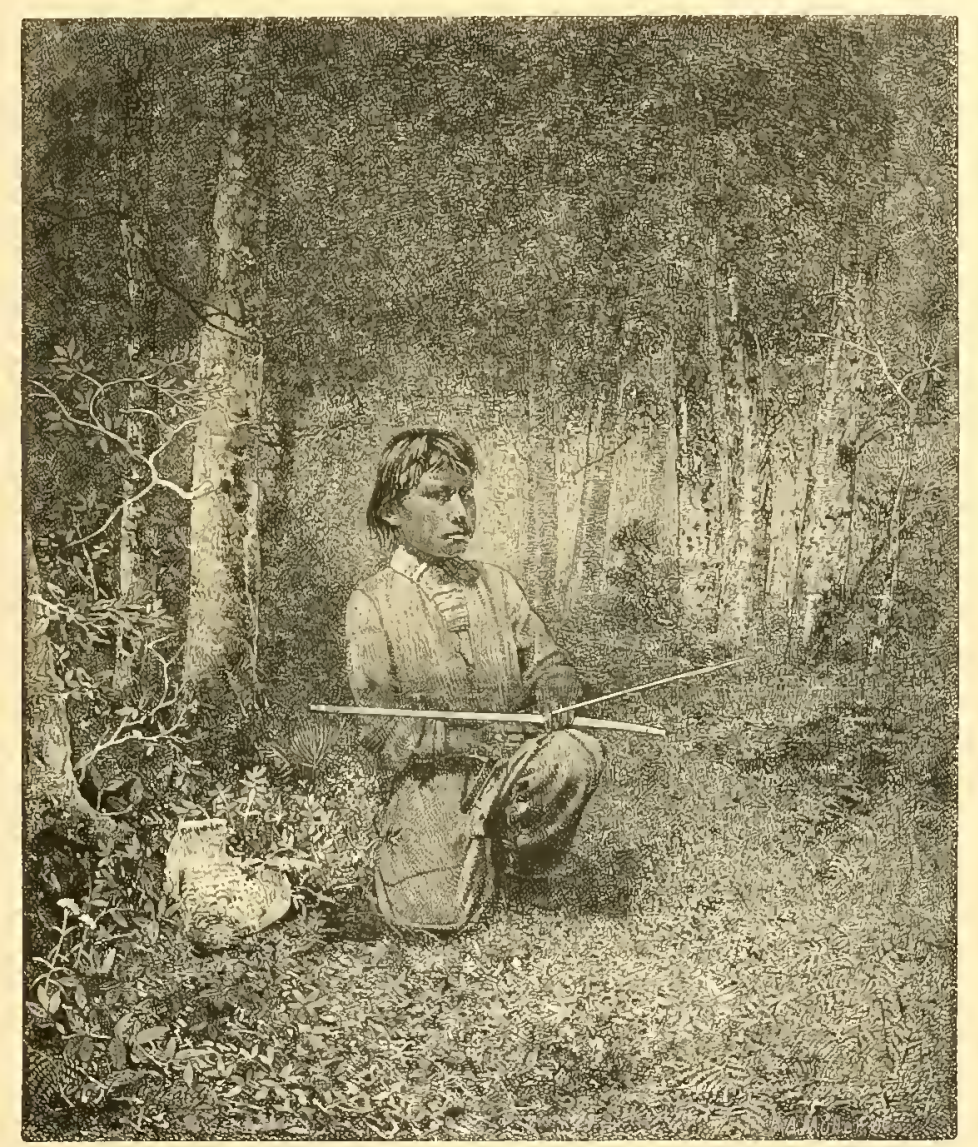

sucotuma.

was on the war-path; and although he could not thus be killed, even moo-in, the bear, would be likely to feel the "stinging arrow."

The finely modulated voice of the Indian is especially adapted to imitate the different calls and cries of the denizens of the forest, and with a trumpet of birch bark he will imitate to the life the plaintive low of the cow-moose and the responsive bellow of the bull. Early morning, twilight, or moonlight are all favorable to this manner of hunting. The Indian, having selected a favorable position for his 


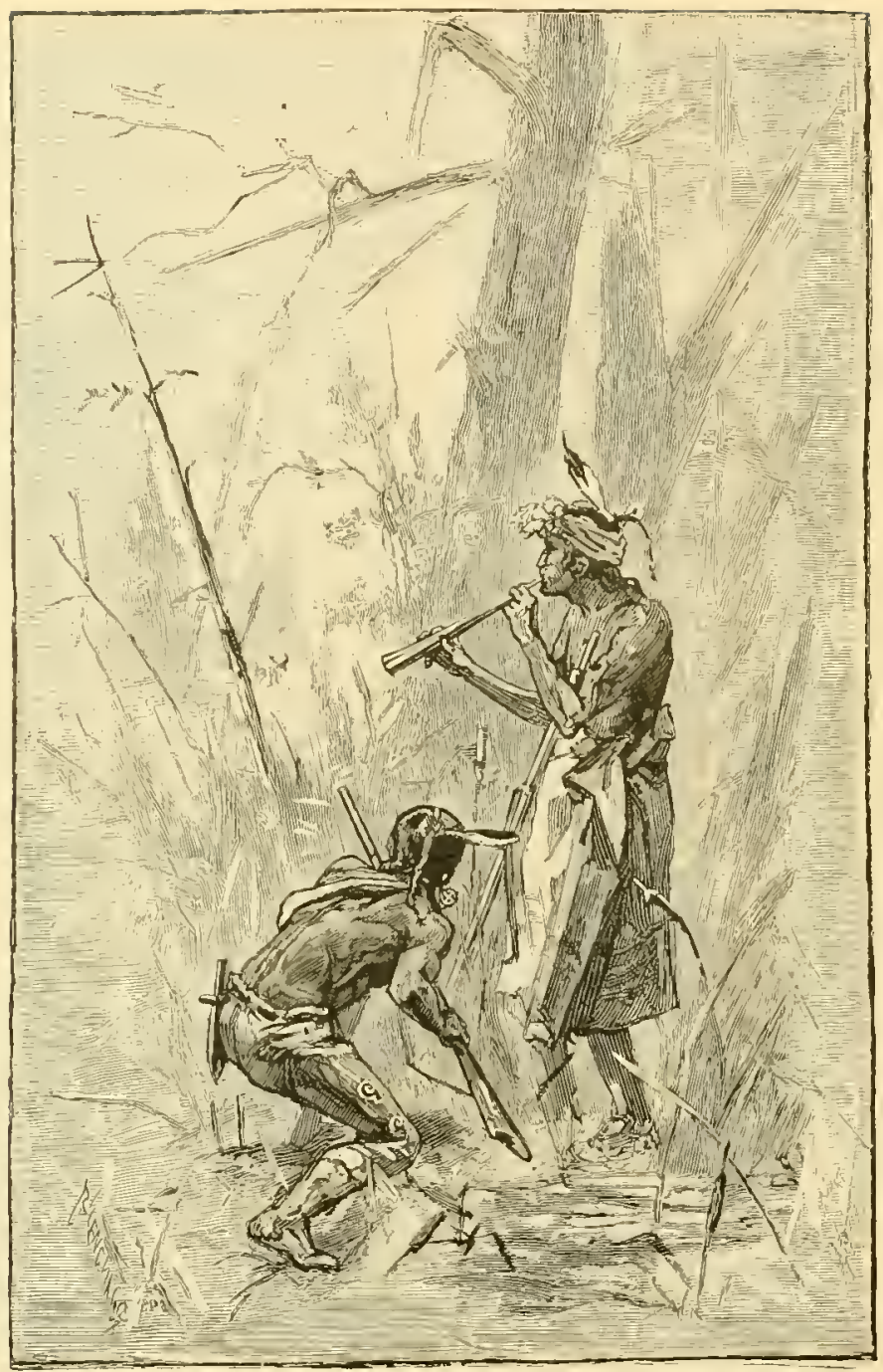

THE MOOSE-CALL.

purpose, generally on the margin of a lake, heath, or bog, where he can readily conceal himself, puts his birchen trumpet to his mouth, and gives the call of the cow-moose in a manner so startling and truthful that only the educated ear of an Indian could detect the counterfeit. If the call is successful, presently the responsive bullmoose is heard crashing through the forest, uttering his blood-curdling bellow or roar, and rattling his horns against the trees in challenge to all rivals, as he comes to the death which awaits him. Should the imitation be poor, the bull will either not respond at all, 
or approach in a stealthy manner and retire on discovery of the cheat. Moose-calling is seldom attempted by white men, the gift of calling with success being rare even among the Indians.

Fire hunting, or hunting by torch-light, is practiced by exhibit ing a bright light, formed by burning bunches of birch hark in places known to be frequented by moose. The brilliant light seems to fas cinate the animal, and he will readily approach within range of the rifle. The torch placed in the bow of a canoe is also used as a lure on a lake or river, but is attended with considerable danger, as a wounded or enraged moose will not unfrequently upset the canoe.

The mode of hunting which generally prevails is that of still hunting, or creeping upon the moose, which is undoubteclly the most sportsmanlike way, and affords the greatest pleasure. Still hunting can be practiced in September, and all through the early winter months, until the snow becomes so deep that it would be a sin to molest the poor animals. The months of September and October are charming months for camping out, and the moose are then in fine condition, and great skill and endurance are called for on the part of the hunter. The moose possesses a vast amount of pluck, and when once started on his long, swinging trot, his legs seem tireless, and he will stride over bowlders and windfalls at a pace which soon distances his pursuers, and, but for the sagacity of the Indian guide in picking out the trail, would almost always escape.

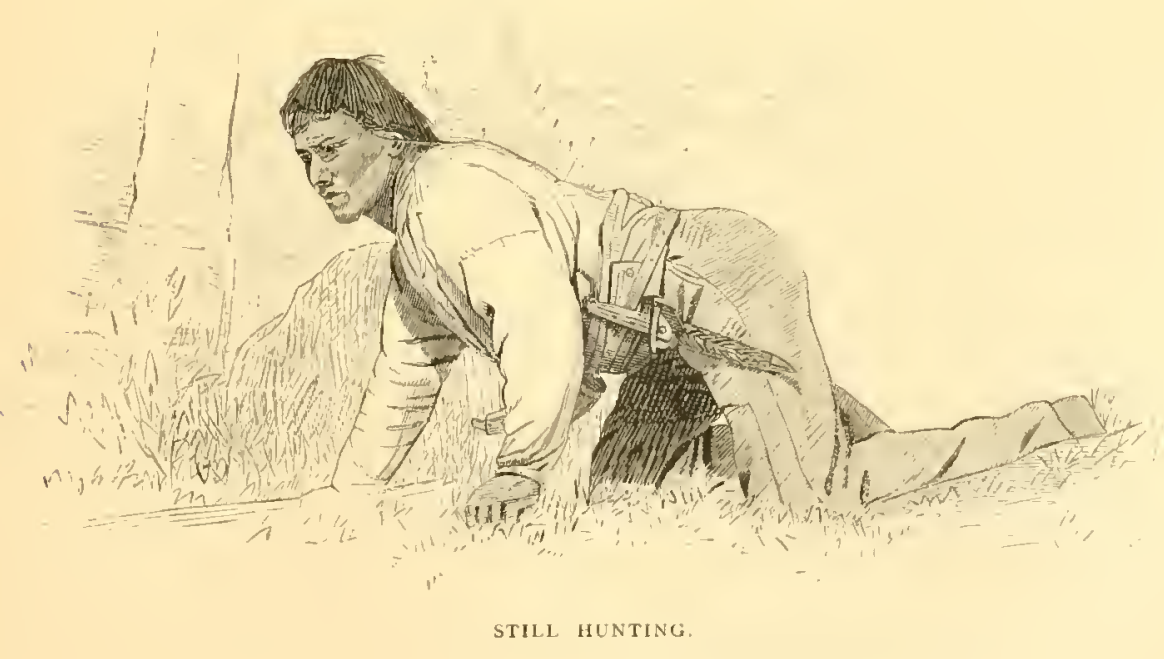




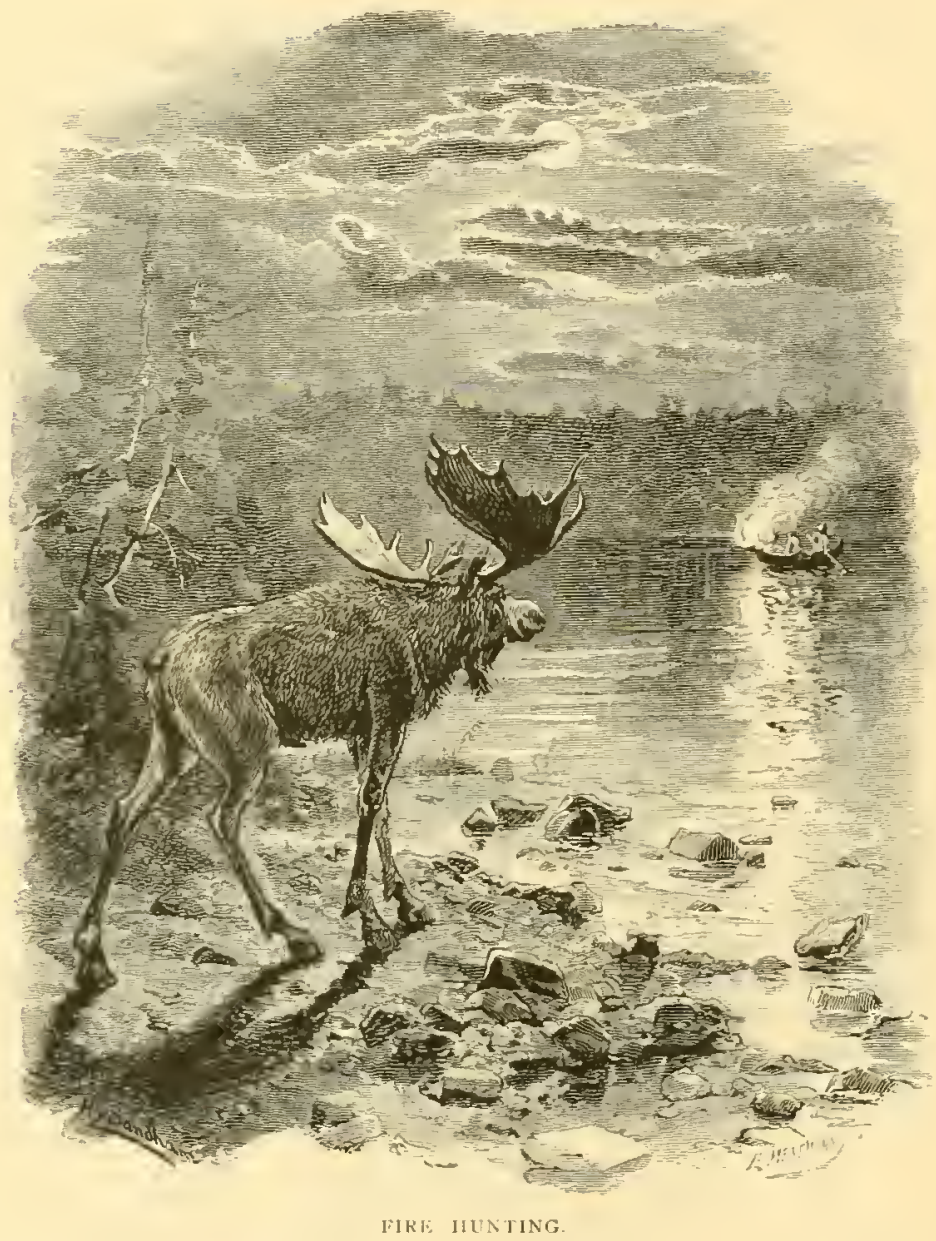

If the sportsman combines the tastes of a naturalist with his love of out-door life, his camping-out holiday will prove all the more enjoyable. One often hears the remark, "How strange it is that animals, birds, life of any kind, is so seldom met with in an American forest!" My own experience, and 1 doubt not that of many other lovers of nature, has been very different, for whatever your name may be, you will seldom gain the confines of the forest without being greeted as "Sweet Willie," by ki-ha-nars, the smaller red-polled linnet, and you will not have traveled far before the little chickadee, hanging head down as is his wont, will welcome you to the forest. The Indian name for little black-cap, kich-i-ge-gelas, is surprisingly like his note of greeting. And before you fairly get your lunch out, that ubiqui- 
tous rascal with the long string of jaw-breaking names, Corrus Cancdensis, Perisoreus Comadensis, Canada jay, mp-kemu-sis, whisky-jack, or moose-bird, will perch on the toe of your boot, or some other point of vantage, and dispute every mouthful with you; while me-kok, the little red squirrel, is sure to be on hand, chattering querulously for his share of the crumbs. Presently, the tall ferns in front of you wave slightly, and mat-a-gmis, the hare, bounds off; and if you watch quietly you will probably see quak-sis, the fox, follow quickly on his trail, - and all this while you are eating your lunch. That over, you start on the business of the day, fishing or shooting, and at almost every step you are surrounded by the denizens of the forest. "There is that old hen-grouse again, with the broken wing, which is not broken at all; she is only fooling you while her brood of little chicks are scampering off out of your way. That bunch of tumbled brakes, not yet recovered from the pressure of some heavy body, tells you that moo-in, the bear, has been roused from his mid-day nap, and is beating a hasty retreat on your approach. I foot-print in the wet moss, not unlike that of a large dog, hints to you that mo-al-sin, the wolf, is at his old tricks again, chasing the deer. If you are bent on fishing, and are careful as you approach the stream, you may detect that industrious individual, quc -bcct, the beaver, repairing a leak in his dam. Ind in particular, rest assured, if you succeed in catching some trout, that the daring thief, che-ok-kis, the mink, will be apt to steal them from under your very nose; and in the gloaming your ears will be charmed by a chorus of many songsters. led by that melodious vocalist the hermit thrush. And yet there are people who say there is no life in an American forest!

In moose-hunting, the services of a trustworthy Indian guide are indispensable, not only to insure success, but for the sake of comfort. These Indians are masters of wood-craft, and can start a fire in the heaviest rain or snow storm ; they are also expert ax-men, and furnish an abundant supply of dry fire-wood, and keep up such a roaring fire in front of the comfortable bark-covered camp, that the cold is seldom felt, even when camping out in winter on the snow. The writer has been fortunate in having had on his hunting expeditions the services of Sebatis, a member of the tribe of Passamaquoddy Indians, who, unlike their savage brethren of the plains, are a peaceful and interesting people, and live quietly on their reservations at 
Pleasant l'oint, near Eastport, Maine. The Passamaquoddies receive subsidy from the Inited States and Canadian governments, and they and the I'enobscot lndians have each a representative of their own race in the Maine legislature.

My tried friend and companion of many a hunt, Sebatis, is a thoroughiored Indian of Mohawk descent, and an accomplished hunter. Ilis wonderful knowledge of the woods, and of the habits of animals and birds, sained in a life-long experience, is seldom

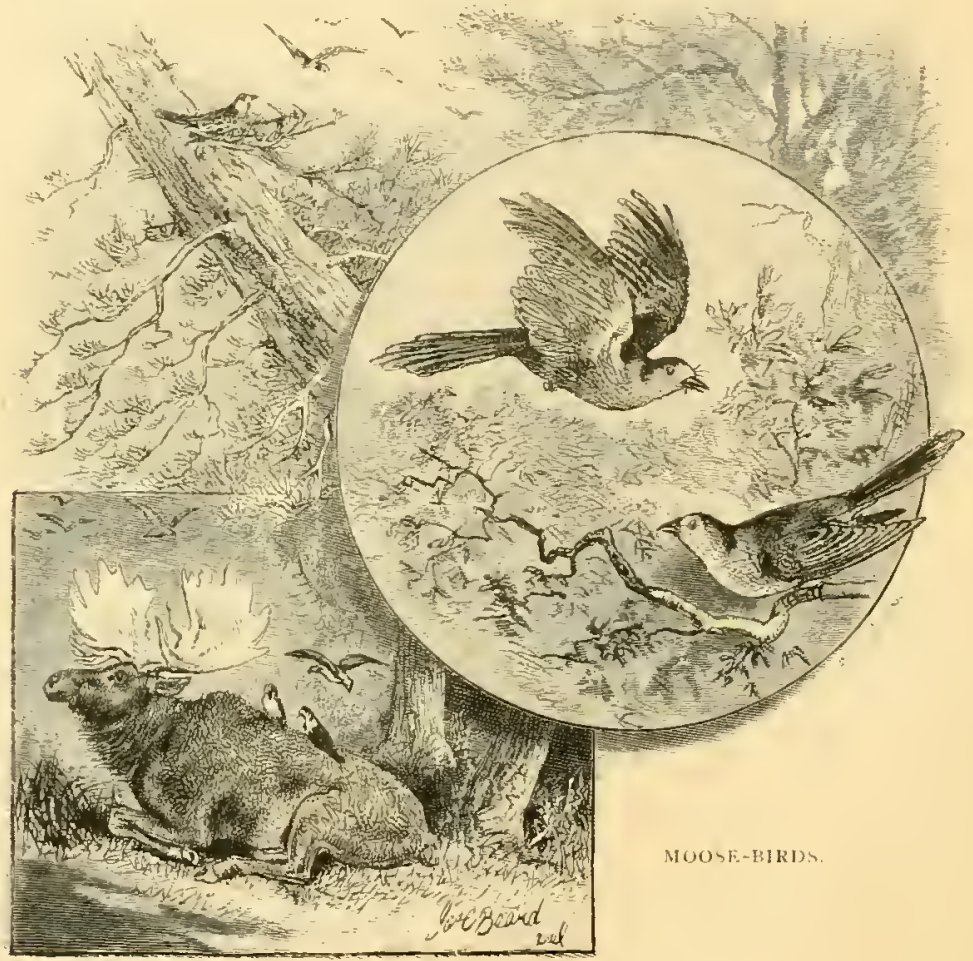

equaled, and he delights to impart his knowledge, and can readily give the Inclian names for, and relate the habits of, any animal or bird inquired about. He is also an excellent story-teller, and as he is a model of sobriety, one never apprehends that his interesting yarns and hair-breadth 'scapes are merely the voluble flow of "after dinner talk."

He has frequently drawn my attention to the curious fact that we invariably met large numbers of moose-birds when we happened to be in a moose country. The moose is infested by a tick, which his 


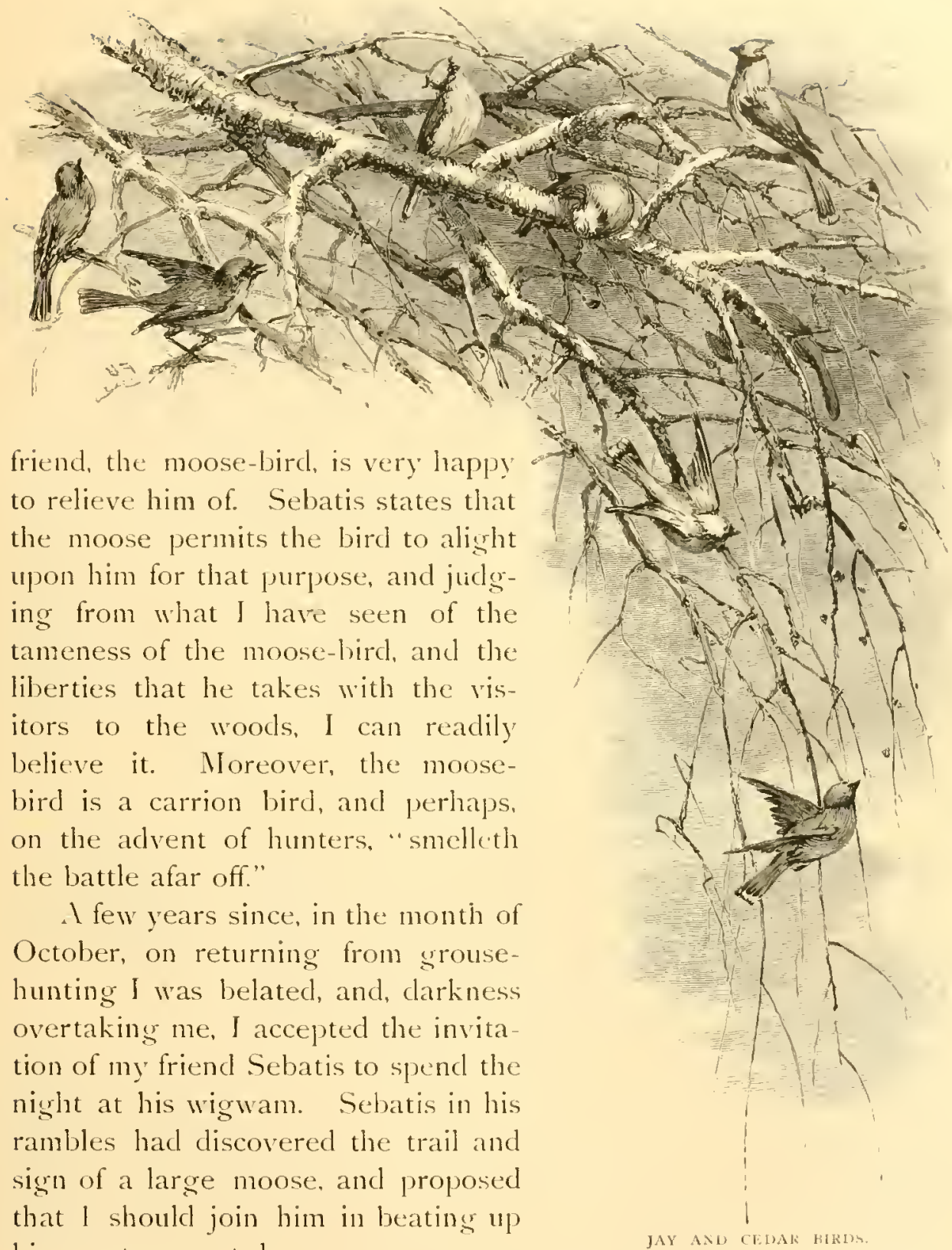
his quarters next day.

In the morning. I sent into the village for my rifle and a supply of provisions, on the receipt of which we enlisted the services of Swarsin, a brother of Sebatis, and boarded the latter's canoe in the lake where he had left it the previous evening. We paddled three 


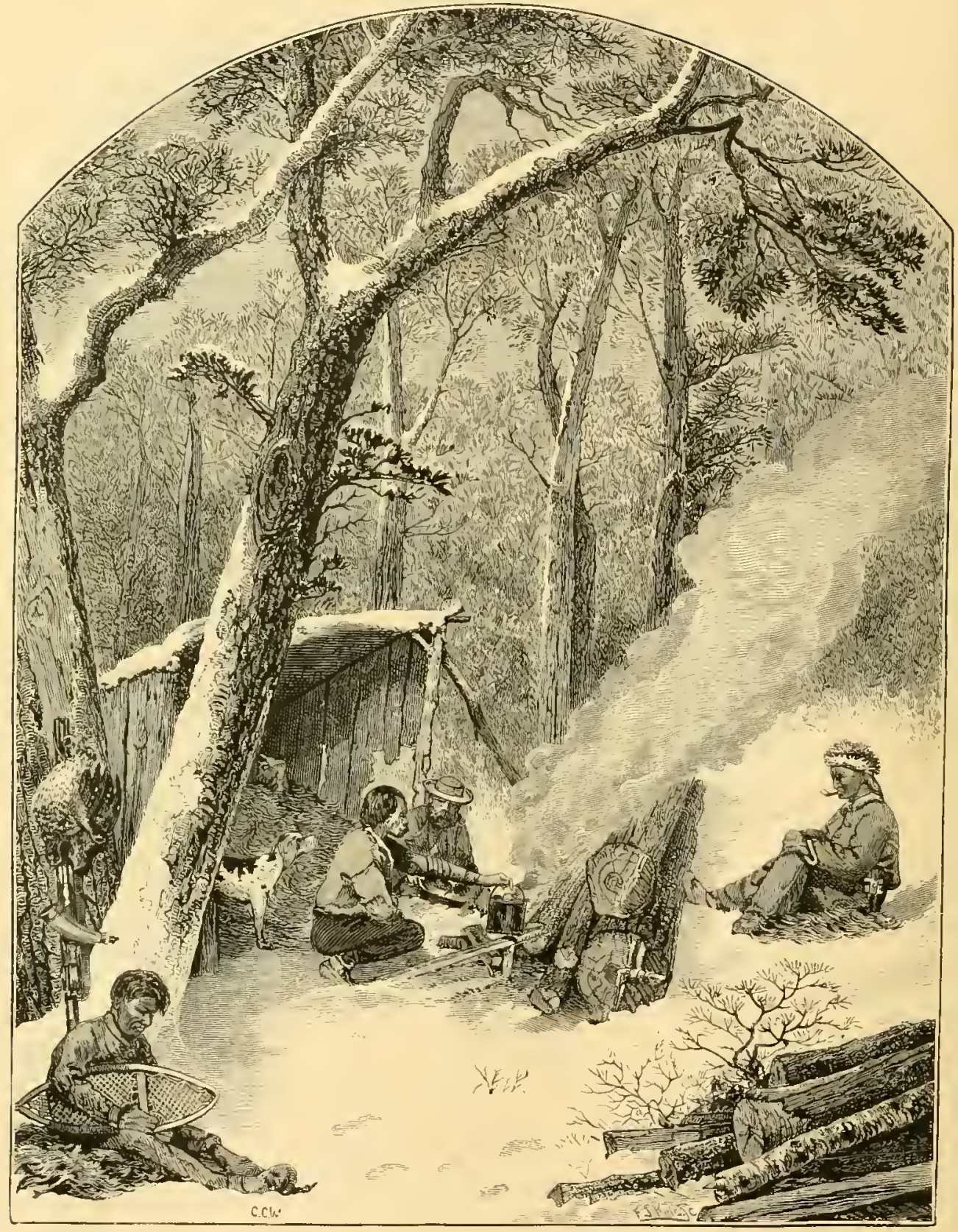

A MUISE-HUNTER'S C.MMP.

miles up the western side of the lake, then portaged two miles to another lake, where we intended to establish our head-quarters. On our way, we started several coveys of ruffed grouse, and twice had a 


\section{Moose-Hunting.}

chance to shoot decr, but Sebatis forbacle molesting them, for fear we might thereby alarm the moose.

The next day we were early astir, and Sebatis started off alone to reconnoiter. In about an hour he returned and told me, in a mysterious manner, that he had found signs of two moose, one of which was a very large one, - and that he knew him very well. Upon my asking for an explanation of such a strange statement. Sebatis said:

"More'n two years ago I hunt these mount"ins with Lola-find sign very big moose. You see I can tell must be pretty big moose, 'cause he peel bark so high on trees; never all my life see moose peel 'em bark so high."

"Well, Sebatis," I said, "I suppose the sooner we gret on his trail the better?"

"Sartin, start now, take two days' provisions; big moose very strong, may be travel long ways before we kill 'em."

"Not come camp again to-night?" inquired Swarsin, who looked after his comfort.

"No," replied Sebatis; "may be never see camp again. I think big moose devil."

Swarsin was lazy and very superstitious, consequently the allusion to his satanic majesty did not hasten matters in pracking for the hunt. and I imagine that he did not relish the prospect of a two-days tramp after an animal with such a questionable reputation, for he was longer than usual in getting the things together.

"Sivarsin just like old woman, so slow," said Sebatis. "Best leave 'im take care camp, shoot 'em chipmunks an' rabbits."

This hastened Swarsin, and in a few moments we were off.

Sebatis led the way, which was anything but a pleasant one, for at the start we had to cross a wicle bog, and great care was required in placing one's feet, as a misstep let one into the waist in the oozy mire. On the farther side of the bog a rapid brook flowed at the foot of a hard-wood ridge. By jumping from bowlder to bowlder we all, as I supposed, reached the other side in safety; but on looking back I saw Swarsin hesitating on the last jump, which was a pretty stiffish one. In such a case to hesitate is to precipitate a disaster, which proved true in poor Swarsin's case, as he jumped short of the bank, and in an instant the quick water swirled him past. In a few moments he rejoined us, much crest-fallen. 
"I make mistake this mornin' when I call Sivarsin ole woman: Swarsin musquash [muskrat], like'm water pretty well," said Sebatis.

Being in close proximity to the moose-sign discovered by Sebatis in the morning, we had to proceed with extreme caution so as not to make the slightest noise, and at the same time keep to the leeward of the moose. II e had just grained the cover of a maple forest when Sebatis halted abruptly, and, pointing to a newly peeled maple. said:

"Fresh sign; moose peel 'cm this mornin'."

And then commenced one of those wonderful exhibitions of skill on the part of the lndians, which is ever a matter of surprise and admiration to the white hunter: this sure and confident tracking of an unseen animal, through pathless forests, swamps and bogs, now stopping to examine a broken twig or a half obliterated foot-print in the yielding moss, or to note something utterly beyond the ken of a white man, such as the disturbance of the water in some blackish pool, or the displacement of objects which would escape the observation of any one but an Indian.

After tramping on in silence for nearly an hour, I ventured to ask Sebatis how much start the moose had.

"Moose little more in hour ahead, walking pretty fast; may be lay down by-em-by, then we find "im."

The country through which we were passing was covered with an unbroken forest of deciduous trees, among which the maple predominated. The brisk October air was just tempered enough to render walking enjoyable, and the hazy sun of a late Indian summer lighted up the forest with a peculiar, dreamy, golden glow.

As we penetrated deeper into the forest, the trees took on larger forms, and here and there giant pines in sroups of two and three darkened our way.

"You keep 'im same course; Sivarsin an' me go hunt fresh sign somewhere," said Sebatis, rousing me out of a reverie, and stalking off in ghostly silence, Swarsin following him like his shadow, and as noiseless.

As directed, I kept my course and tramped onward, the forest increasing in density and gloom as 1 advanced. I had probably traveled a mile or more, when 1 approached a dack group of pines, in the center of which rose something gray and weather-stained, having the appearance of an abandoned habitation. As I stood looking 


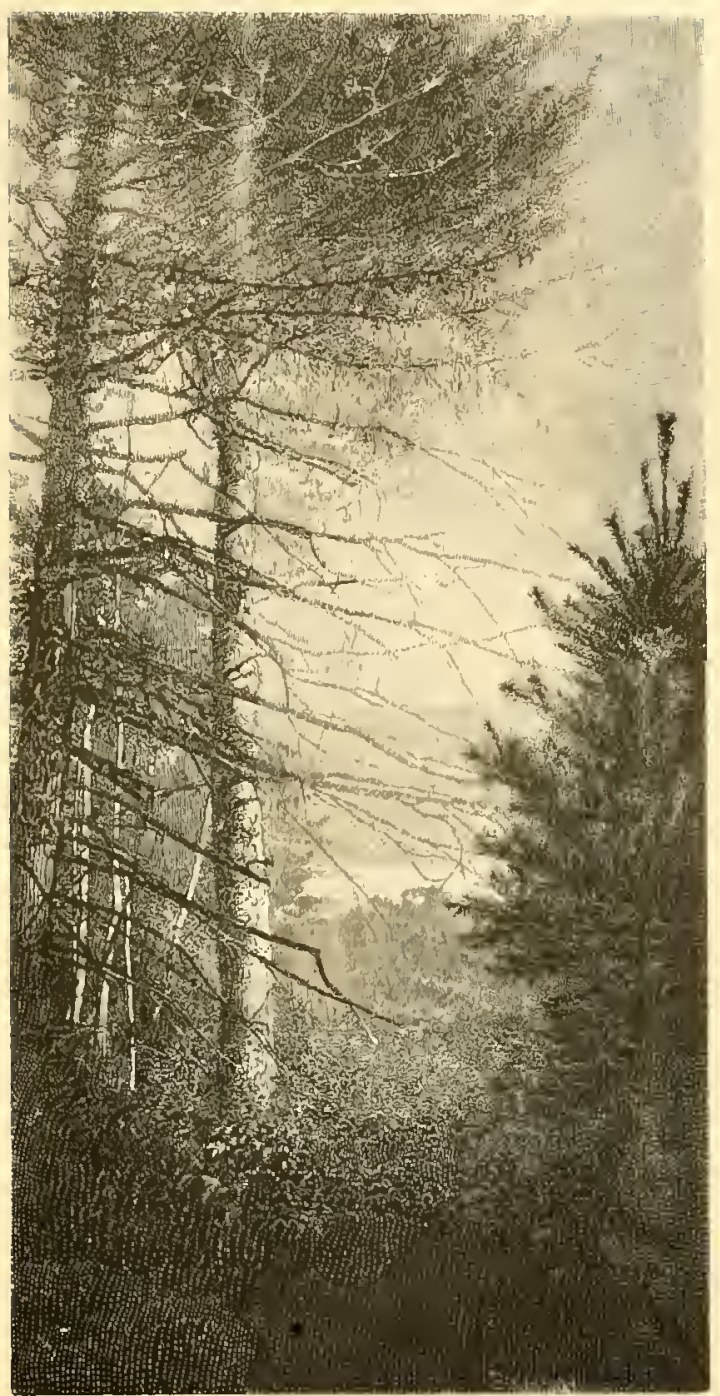

THE DARKENING PINES,

on in surprise, I made it out to be the old and long-deserted works of some lumberers, or, mayhap, a block-house of the olden tine. The walls, built of huge logs, had originally risen to a height of two stories, but the roof had been crushed in by a tree which had fallen across it, and many of the logs had droppeel out of place. Out of the middle, several good-sized trees were growing, proving that it was a structure of some antiquity. All the surroundings were mossgrown, and a peculiar gray light pervaded the place, - an air of un- 
substantiality which produced a curious, bewildering effect. In fact, the whole affair had such an uncanny look, that I should not have been surprised to detect the sinister face of "Le Renard Subtil " peering at me from behind a cover; and as I turned to resume my way, I had quite made up my mind to encounter the grim visage of "Le Gros Serpent," and was agreeably surprised to find my trusty Sebatis watching me intently.

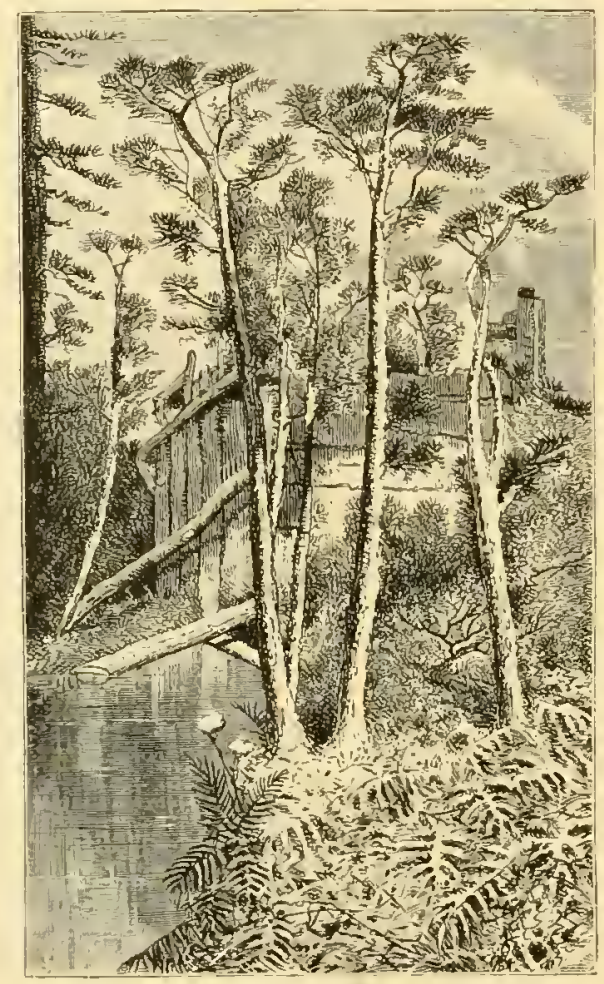

THE OLD BLOCK-HUUSE.

"What you call 'im?"

"I think that it is a deserted lumberers' camp, or perhaps an old block-house."

"You watch 'im little while, then all gone, can't see not'in' 't all; plenty ghosts here; best come away."

"Did you ever see it before?"

"No, never see 'im 't all, only just now; bad luck top here; ghosts come by-em-by."

Yielding to his importunities, we walked away. Sebatis, in conmon with all of his race, was very superstitious, and all attempts 
to convince him of the folly of cntertaining such thoughts were unavailing. He still held that it had no existence in fact, and was merely a derice of the evil one. It really seemed as if he wished to avoid discussion, so I let the subject drop.

We were now rejoined by Swarsin, who had followed the moose track to the edge of a swamp.

When sojourning in the woods, you have only to express a wish for a nice cool spring, and your fidus tchates, if he be an Indian. seldom fails to find one. In the present instance there was one at hand, as usual. We halted long enough to lunch and to smoke a pipe, and then were off again on the trail of the moose.

We now changed our tactics. Sebatis, having appointed a rendezvous at the outlet of a small lake, went off alone, while Swarsin and 1 tramped over to the swamp to try our luck there. Deftly picking up the sign. Swarsin led me through the treacherous bog, where I sometimes broke in to my knees, and considered myself lucky even in gretting off so fortunately as that. After half an hour of this, I was overjoyed to find that the moose had taken to the forest again. Howcver, my joy was short-lived, for soon we were again on descending ground interspersed with swamps and bogs, - a most detestable country to travel in, but fortunately, at this time of year, clear of those torments, black-flies and mosquitoes.

"Two moose track here," said Swarsin. "What best du now?"

"Keep on till we meet Sebatis."

"I see "im Sebatis track little ways back. One moose turn back; Sebatis follow that one."

" Well, I suppose we had better keep on after the other moose."

"No: Sebatis break branches he want us follow same way."

"How do you know he broke the branches? Perhaps the moose was browsing on them."

"I can tell pretty quick. Sebatis break "im; always moose bite 'im."

Submitting to his superior wood-craft, I told him to lead the way.

This time the moose led us over bowlder-strewn hills, with here and there a windfall thrown in. Now, in a country like this, the moose has much the advantage of the hunter, his long legrs enabling him to clear obstacles which cause the hunters to pause now and then to regain their wind. 
We were just clambering over a ledge of rocks on the hill-side when Swarsin said:

"Best get gun ready; moose only little ways 'head now!"

The words were hardly spoken, when the booming report of Sebatis's smooth-bore echoed through the woods, and the blue smoke from the discharge, floating up through the trees, pointed our way.

Sebatis did not seem elated with his success, though the animal he had killed was a full-grown cow-moose.

"Lost big moose ayain," he said. "I follow this one, think big moose all time."

"How did you get mistaken?"

"I don't gret staken 't all,- - find plenty sign two moose,-— follow track bigges' one, - by-em-by lost track - don't see not'in'."

"Where did you lose the track?"

" Jus' little ways this side big barren, small lake handy, I think go on water - hide somewhere. You see, always moose like water pretty well; in summer time, when flies bad, moose get right under water jus' like porp'us, jus' leave nose out, then nobody can't see 'im 't all."

"How did you happen on the track of the cow-moose?"

" Well, you see, when I los' sign bull-moose, I go hunt "in somewhere, then I find sign cow-moose."

"Do you think the big bull was in company with the cow-moose? Isn't the season almost too late?"

"No, not too late yet. I think jus' what you think, - may be bull come again by-em-by, then good chance call 'im to-night."

"What goin' to do with moose, Sebatis?" said Swarsin.

"Butcher 'im, then put 'im in camp. - camp handy, 'bout half mile."

The Indians, with a dexterity acquired by long practice, skinned the moose, cut up the carcass, and packed it into camp.

"Now," said Sebatis, "I go hunt chance call bull-moose to-night: Swarsin, he stay camp an' get wood an' make fire, by-em-by we have pretty good supper."

Sebatis was not long absent; on his return, he sat down in a taciturn mood to the supper which Swarsin had cooked.

Much as I have been in the society of Indians, I have never got 
accustomed to their abrupt way of speaking; the tone is neither harsh nor loud, but the utterance is so curt and sententious, that onc is always startled and taken unawares, and this is more especially the case when on the trail. Around the camp-fire, their fincly modulated voices are very musical and capable of wonderful expression. Is we lay off enjoying our pipes after supper, I asked Sebatis to tell me what he knew of the bull-moose.

" Ii ell," he said, "I tell you all 'bout it. You see, more 'n two years ago, me an' Lola hunt moose these mount'ins. One day we find sign very large moose; hunt 'im all day, moose travel so fast we can't come up with him 't all; by-em-by night come, then camp somewhere: nex' day we follow track till 'bout sundown, then I find sign close on brook, then sign lost, can't find 'im anywhere, just same I lost 'im to-day. Then Lola an' me walk in brook, try find where moose take land again Well, Lola, he follow brook up-stream. I go down, don't find sign anywhere; by-em-by come on lake, then I see moose swimmin' 'most cross lake, only see little piece horn stickin' up, swim so deep, you see, try hide; then I go 'round lake, creep jus' like wildcat, don't make no noise 't all, try cut 'im off, you see. W'ell, by-em-by get pretty tired creepin', then lift up my head look somewhere, an' by tunders! I see moose layin' down handy; then I say I got old bull-moose this time. Jus' when I put on cap my gun I hear moose jump, then I fire; well, s'pose you don't 'lieve me, when I come on place, no moose there, then scared pretty bad; sartin I think mus' be devil. Well, you see, I don't like give 'im up that way, so I load gun an' go hunt 'im sign again somewhere. By-em-by I find sign again jus' on other side big windfall ; well. I stan' there lookin' roun', an' by tunders! I hear a gun fire, an' then I see Lola stan' there 'longside young t'ree-year-old bull-moose. I ask Lola where he start that moose. Well, you see, when I leave Lola on brook he go up-stream, then by-em-by see moose sign, then he go hunt 'im, you see, an' kill 'im jus' when I meet 'im. By tunder! that's very' crur'us; I can't 'stand it 't all. Then Lola an' me look everywhere, don't find no sign that big bull-moose; so we have give im up an' go home. By tunders! I never know anythin' so crur'us all my life."

"Don't you suppose that you got confused in some way, and that the bull-moose you saw in the lake did not take ground again, and 
fooled you, and that the young bull shot by Lola was the one that you saw and fired at?"

"Sartin I don't get 'fused 't all, that not same one. I tell you why; you see. I don't make no 'stake, 'cause I see that big moose layin' down jus' plain I see you now: 'sides I see horns, bigges' horns I ever see all my life."

"I guess Sebatis pretty tired that time, fall 'sleep, then dreamin'. you see, don't see no moose 't all," said Swarsin.

"Don't mind what that Swarsin say, he don't know nothin', no more 'n woodchuck; what I tell you all true, every word."

"Well," said I. "Sebatis, if the big moose we hunted to-day is. as you suppose, the same one that you have just been telling about, and we are lucky in calling to-night, and manage to bag him, I suppose your mind will be at rest?"

"Sartin, you can't put 'im that moose in bag, too big: but 'spose we kill 'im, then I know 'taint devil 't all, only mighty cunnin' ole bull-moose, that's all."

"Sebatis pretty good hand tell story," said Swarsin. "S'pose he tell all "bout bear-hunt, when he get his arm "most tore off."

"Sartin that's true, get my arm 'most tore off sure enough," said Sebatis, as be rolled up his coat-sleeve, and exhibited several frightful scars on his left arm.

"How did that happen, Sebatis?" I inquired.

"Well, you see. happen grood many years ago, used to be old times, Injins campin' out all winter, hunt, trap, everythin'. One winter two or three camps on McI)ougal Lake, so you see I start one mornin' look at my traps. Well, I jus' walkin' 'long, don't have no gun, no knife, not'in' but small little kind of hatchet, that's all; by-em-by I see pretty big old she-bear walkin' on snow, comin' right up to me: I little scared first, you see don' have no gun, no knife, not'in' but that small little kind of hatchet, so I think pretty poor chance kill bear. Well, not much time thinkin', for old bear come walkin' 'long pretty' quick, when he got 'most up where I stan'in' then get right up on his hin' legs jus' like man an' look at me, then I don't move 't all, jus' look at bear, that's all; by-em-by that bear get down again an' go 'way walkin' very slow, then you see, I think best try kill 'im, so I chase 'm; then you see that bear stop again an' jus' gettin' up on his hin' legs, when I strike 'm all my might right on his 


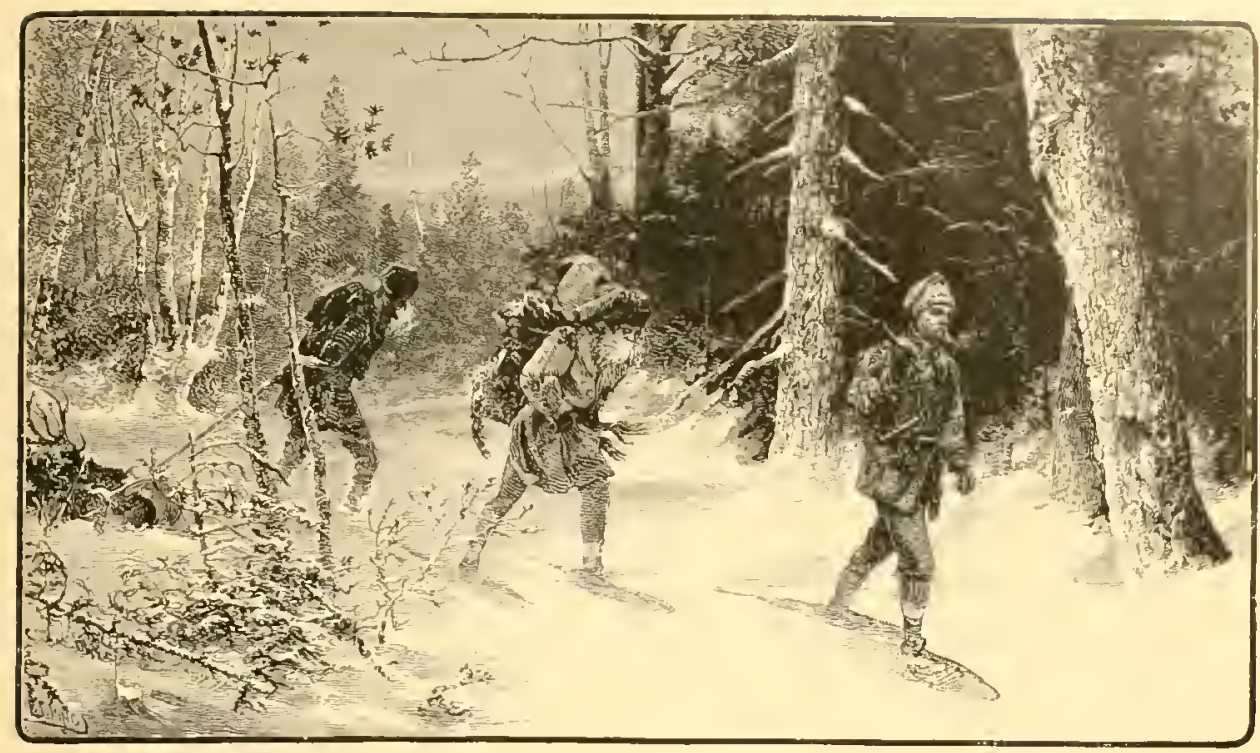

RETURNING FROM THE HUNT.

head with that small little kind of hatchet, s'pose hit 'in fair, sartin kill 'im; but, you see, bear very quick. When he see me try strike 'im, he jus' dodge little bit, an' on'y handle strike 'im an' broke short off. and that small little kind of hatchet fall off on snow somewhere. Then I feel pretty bad, you see, bear gettin' cross an' take right hold my arm an' bite savage; then, you see, I get pretty cross, too, so I take bear right on his t'roat both my han's an' choke 'im bad; then, you see, he don't like it 't all, begin to cry, an' I see tears come on his face, then I choke 'im all my might, you see; then he bite so savage I 'most drop. Well, I don't know what goin' happen next; when he stop bitin' so hard, then I stop choke 'im jus' a little. you see; then by-em-by he let go my arm altoget'er, then I let go his t'roat, an' he drop right on snow again an' walk off slow, then I walk off slow nother way, you see. Well, by tunders! my arm pain pretty bad, blood soaked all on my coat everywhere; then I go on camp pretty quick. Well, you see, nobody on that camp cn'y myself, all 'lone, so I fix my arm best way I can, an' put on balsam. Nex' mornin', I take my gun an' knife, an start get that bear. By-em-by, I strike sign an' follow 'bout mile, then I fin' den. When I look in I can't see not'in' 't all, then light match an' see two little cubs, very' small, jus' like small little dog; then I think best go hunt old bear, an' come back an' get cubs. Nell, little 
ways off 1 fin' sign old bear gone off somewhere's again, so I follow pretty quick, an' by-em-by see old bear walkin' on snow, an' I gro up pretty close, an' jus' when he rise up again on hind legs I fire, kill 'im dead first shot, then my arm feel 'most well again, then I go get cubs; well, you see, when I fin' den again cubs all gone, on'y some little bits fur an' blood, that's all."

"What killed the cubs?" I inquired.

"Well, you see, nobody don't kill 'em 't all, po-kumpk been there eat 'em all up."

"Who on earth is po-kumple?"

"Po-kumpk!' that's black cat, you know; some people call 'em fishers."

"That's a very good story, Sebatis," I remarked, by way of compliment.

"No, that's not good story 't all, that's true. My arm don't get well again most six months."

The moon was now visible, and I asked Sebatis when he would try to call the moose.

"Pretty soon," he replied. "I go somewhere now try find birch bark make moose-call; you an' Swarsin take guns, an' go down on barren handy on lake, by-em-by 1 come."

Obeying the directions of Sebatis, Swarsin and I tramped down to the edge of the barren and took up a position in the dense shadow of some tall ferns. There was not a breath of air stirring, and the moon was partially obscured by watery-looking clouds that threatened ere long to treat us to a wetting. As we sat waiting for Sebatis, the silence was oppressive; presently, the monotony was relieved by the occasional hooting of an owl, that after a time became almost continuous.

"That owl keeps up an awful row," I said to Swarsin.

"That aint owl 't all, that Sebatis; may be he wants us come somewhere."

"Wont we make too much noise, groping our way in the clark?"

"Hist! that's cow-moose," he said, as a wailing cry floated through the air.

I shrewdly suspected the cow-moose to be none other than our friend Sebatis, with his trumpet of birch bark, and in a few moments was convinced of the fact, for from far away in the distance came the answering call of a bull-moose. 
"Now, then," said Swarsin, "we try find Sebatis; you follow me creepin', then we don't make no noise 't all."

Just then the hoot of the owl was repeated, and Swarsin crept on with hastened speed. I followed as best I could, and was getting pretty tired of my bargain, when the call of a bull-moose-this time much nearer-echoed through the woods. now."

"Bull-moose come by-em-by," said Swarsin; "we best keep still

"How about Sebatis? Isn't he waiting for us ?"

"Sebatis here," replied that worthy, who had joined us so silently as to escape my notice.

"What is the matter with the moose?" I whispered to Sebatis. "Isn't he coming very slowly?"

"Well, I tell you," said Sebatis: "you see, that moose either devil, else he know so much we can't cheat 'im easy. When I first try 'im he answer kind of frightened, don't smash 'round 't all an' make big noise. Mos' bull-moose, when he hear cow, get kind of jealous, you see, an' begin roar an' smash 'roun', an' knock his horns on trees, try make big noise, you see, an' scare off some other bull may be. Now I try "im again."

And once more the marvelous imitation of the cry of the cowmoose, in plaintive and gentle cadence, floated through the air.

I should have been extremely disappointed if this last masterly performance of Sebatis's had failed to elicit a response. For a time, I thought that it had failed, when I was startled by hearing the angry challenge of a bull, close at hand.

"Sartin I cheat bull-moose that time," chuckled Sebatis! "He's comin' now, best have gun ready."

For a few moments we listened intently, with our ears on the alert for the slightest sound.

"Sebatis," I whispered, "I'm afraid he wont come."

"You jus keep quiet little while, you see I know all 'bout it; that very wise ole bull, he been fooled good many times, you see; that make 'im pretty scarey-by-em-by-s'pose all quiet, I try 'im 'gain."

"Has he gone back from us since you called the last time?"

“No, he's comin' all time: but, you see, he try 'roun' every way first, try an' get our wind; s'pose he don't get on lee side, we have 'im sure." 
"How is it we don't hear him?"

"Always moose when scared come slow; very careful, you see, don't step on branches, not'in', make no noise 't all, and keep listenin' all time, you see; that take 'im long time gettin' here."

Again the counterfeit presentment, this time louder than before, echoed through the forest. As it died away, our ears detected a slight crash in the woods, instantly followed by a soft note from a bull-moose, to which Sebatis replied, then all was silent.

"Look," said Sebatis in a low tone, "bull-moose comin', you see big black somethin' on barren this side lake, that's him. Now, when you see "im clear, make good shot."

Although l strained my eyes in trying to discern the moose, it was some time before I could make lim out, and then not in a way to insure a satisfactory shot. Reaching out my hand, I touched Sebatis, who took the hint, and in a low, modulated tone again gave the call.

This time, without replying, the bull-moose moved cautiously forward, evidently very uneasy and anxious. His great body was now plainly visible in full relief against the shimmering lake, and as it was not likely that 1 would get a better chance I fired. There was a crash, and as the smoke cleared away l saw the moose struggling to his feet again, when Sebatis put in a well directed shot and ended the scene.

"By tunders!" exclaimed Sebatis, as he gazed on the huge proportions of the fallen moose, "that loigges' moose I ever see all my life; no wonder I t’ink devil, so cunnin', you see. One time to-night I t'ink not much cluance kill that moose."

"You still think that it is the moose that fooled you so often?"

"Sartin, that same moose: I know 'im, you see, 'cause lorns so broad, 'most five feet 'cross on top."

The measurenents and weight of this noble specimen have been stated in another part of this paper, and the magnificent antlers are now in the possession of the writer.

Charlotte County, New Brunswick, the scene of our hunt, was at one time a place much frequented by Indians, and various interesting relics of their former occupation of the country have been from time to time discovered. On the portage road at St. George, stone pipes, chisels, tomahawks, etc., etc., have frequently been turned up, and a 
few years since an object of much ethnological interest was found, in the shape of a stone medallion having the full-sized head of an lndian sculptured upon it. This stone is now in the collection of the Vatural History Society at St. John, New Brunswick. On one of the mountains on Lake Utopia there was at one time a curious structure resembling an altar, and built with large slabs of granite. Recently some vandals, in order to gratify an idiotic whim, tumbled the largest block down the hill-side and into the lake.

The glory of the noble forest where we hunted the devil-moose has departed, and all is now blackened stumps and ashes where once the green canopy seemed boundless. Sometimes a heavy gale, such as the Saxby in 1869 , prostrates the trees, or the insatiable lumbermen cut them down, and then in summer-time, when everything is as dry as tinder, a party of hunters or anglers are careless of their fire, and soon the country is in a blaze for miles. This drives the moose and caribou away from their ancient haunts, and they seldom return. With a little precaution, all of this might be prevented, and the trouble of restocking our rivers with salmon, trying to re-introduce the game, and all the rest of it, might be avoided.

Nowadays, when I take a holiday with Sebatis, we occasionally make a long hunt in search of moose or caribon, but in general have to content ourselves with a deer, the ruffed grouse, ducks, and hares of the country, and the glorious brook-trout which fill the innumerable lakes in Charlotte County, - single specimens often reaching the weight of seven pounds.

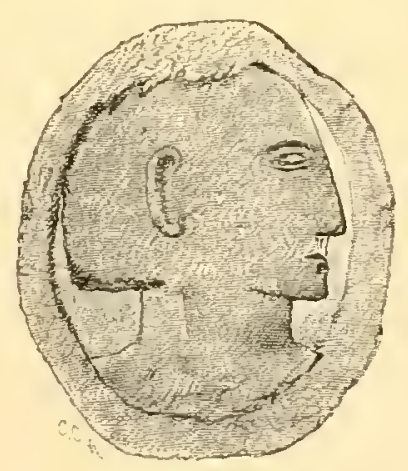




\title{
MOOSE-HUNTING IN CANADA.*
}

\author{
PI THE EARL OF DUNRAVEN.
}

M

OOSE-HUNTING, if it has no other advantages, at least leads a man to solitude and the woods, and life in the woods tends to develop maisy excellent qualities which are not invariably produced by what we are pleased to call our civilization. It makes a man patient and able to bear constant disappointments; it enables him to endure hardships with indifference, and it produces a feeling of self-reliance which is both pleasant and serviceable. True luxury, to my mind, is only to be found in such a life. No man who has not experienced it knows what an exhilarating feeling it is to be entirely independent of weather, comparatively indifferent to hunger, thirst, cold, and heat, and to feel himself capable, not only of supporting, but of enjoying life thoroughly, and that by the mere exercise of his own faculties. Happiness consists in having few wants and being able to satisfy them, and there is more real comfort to be found in a birch-bark camp than in the most luxuriously furnished and carefully appointed dwelling.

Such a home I have often helped to make. It does not belong to any recognized order of architecture, although it may fairly claim an ancient origin. To erect it requires no great exercise of skill, and calls for no training in art schools. I will briefly describe it.

A birch-bark camp is made in many ways. The best plan is to build it in the form of a square, varying in size according to the number of inhabitants that you propose to accommodate. Having selected a suitable level spot and cleared away the shrubs and rub-

* Reprinted, by permission. from "The Nineteenth Century." 
bish, you proceed to make four low walls composed of two or three small suitable-sized pine logs laid one on the other, and on these little low walls so constructed you raise the frame-work of the camp. This consists of light thin poles, the lower ends being stuck into the upper surface of the pine trees which form the walls, and the upper ends leaning against and supporting each other. The next operation is to strip large sheets of bark off the birch trees, and thatch these poles with them to within a foot or two of the top, leaving a sufficient aperture for the smoke to escape. Other poles are then laid upon the sheets of birch-bark to keep them in their places. A small door-way is left in one side, and a door is constructed out of slabs of wood, or out of the skin of some animal. The uppermost $\log$ is hewn through with an ax, so that the wall shall not be inconveniently high to step over, and the hut is finished. Such a camp is perfectly impervious to wind or weather, or, rather, can be made so by filling up the joints and cracks between the sheets of birch-bark and the interstices between the pine logs with moss and dry leaves. You next level off the ground inside, and on three sides of the square strew it thickly with the small tops of the sapin, or Canada balsam fir, for a breadth of about four feet; then take some long pliant ash saplings or withy rods, and peg them down along the edge of the pine tops to keep your bed or carpet in its place, leaving a bare space in the center of the hut, where you make your fire. Two or three rough slabs of pine, to act as shelves, must then be fixed into the wall, a couple of portage-straps, or tump-lines stretched across, on which to hang your clothes, and the habitation is complete.

I ought, perhaps, to explain what a "portage-strap" and a "portage" are. Nany French and Spanish words have become incorporated with the English language in America. The Western cattle-man, or farmer, speaks of his farm or house as his "ranche," calls the inclosure into which he drives his stock a "corral," fastens his horse with a "lariat," digs an "acequia" to irrigate his land, gets lost in the "chapparal," instead of the bush, and uses commonly many other Spanish words and expressions. No hunter or trapper talks of hiding anything; he "caches" it, and he calls the place where he has stowed away a little store of powder, flour, or some of the other necessaries of life, a "cache." The French word "prairie," as everybody knows, has become part and parcel of the English lan- 
gruage. Indians and half-breeds, who never heard French spoken in their lives, greet each other at meeting and parting with the salutation "bo jour" and "adieu." And so the word "portage" has come to be generally used to denote the piece of dry land separating two rivers or lakes over which it is necessary to carry canoes and baggage when traveling through the country in summer. Sometimes it is literally translated and called a "carry." Another French word, "traverse," is frequently used in canoeing, to signify a large unsheltered piece of water which it is necessary to cross. A deeply laden birch-bark canoe will not stand a great deal of sea, and quite a heavy sea gets up very rapidly on large fresh-water lakes, so that a long "traverse" is a somewhat formidable matter. You may want to cross a lake, say five or six miles in width, but of such a size that it would take you a couple of days to coast all round. That open stretch of five or six miles would be called a "traverse."

The number and length of the portages on any canoe route, and the kind of trail that leads over them, are important matters to consider in canoe traveling. A man, in giving information about any journey, will enter into most minute particulars about them. He will say, "You go up such-and-such a river," and he will tell you all about it - where there are strong rapids, where it is very shallow, where there are deep still reaches in which the paddle can be used, and where you must pole, and so forth. Then he will tell you how you come to some violent rapid or fall that necessitates a "portage," and explain exactly how to strike into the eddy, and shove your canoe into the bank at a certain place, and take her out there, and how long the "portage" is; whether there is a good trail, or a bad trail, or no trail at all: and so on with every "portage" on the route. Carrying canoes and bagrgage across the "portage" is arduous work. A birch-bark canoe must be treated delicately, for it is a very fragile creature. You allow it to ground very carefully, step out into the water, take out all the bales, boxes, pots, pans, bedding, rifles, etc., lift up the canoe bodily, and turn her upside down for a few minutes to drain the water out. The Indian then turns her over, grasps the middle thwart with both hands, and with a sudden twist of the wrists heaves her up in the air, and deposits her upside down on his shoulders, and walks off with his burden. An ordinary-sized MicMac or Melicite canoe, such as one man can easily carry, weighs 
about seventy or eighty pounds, and will take two men and about six hundred or seven hundred pounds.

The impedimcnta are carried in this manner: A blanket, cloubled to a suitable size, is laid upon the ground; you take your portigestrap, or tump-line, as it is sometimes called, which is composed of strips of webbing or some such material, and is about twelve feet long, a length of about two feet in the center being made of a piece of broad, soft leather; you lay your line on the blanket so that the leather part projects, and fold the edges of the blanket over either portion of the strap. You then pile up the articles to be carried in the center, double the blanket over them, and by hauling upon the two parts of the strap bring the blanket together at either side, so that nothing can fall out. You then cut a skewer of wood, stick it through the blanket in the center, securely knot the strap at either end, and your pack is made. You have a compact bundle, with the leather portion of the portase-strap projecting like a loop, which is passed over the head and shoulders, and the pack is carried on the back by means of the loop which passes across the chest. If the pack is very heavy, and the distance long, it is usual to make an additional band out of a handkerchief or something of that kind, to attach it to the bundle, and pass it across the forehead, so as to take some of the pressure off the chest. The regular weight of a Hudson's Bay Company's package is eighty pounds; but any Indian or half-breed will carry double this weight for a considerable distance without distress. A tump-line, therefore, forms an essential part of the royageur's outfit when traveling, and it comes in handy, also, in camp as a clothes-line on which to hang one's socks and moccasins to dry.

A camp such as that I have attempted to describe is the best that can be built. An ordinary camp is constructed in the same way, but with this difference, that instead of being in the form of a square, it is in the shape of a circle, and the poles on which the bark is laid are stuck into the ground instead of into low walls. There is not half so much room in such a camp as in the former, although the amount of material employed is in both cases the same. It may be objected that the sleeping arrangements cannot be very luxurious in camp. A good bed is certainly an excellent thing, but it is very hard to find a better bed than Nature has provided in the wilderness. It would 
appear as if Providence had specially designed the Canada balsam fir for the purpose of making a soft couch for tired hunters. It is the only one, so far as I am aware, of the coniferous trees of North America in which the leaves or spicula lie perfectly flat. The consequence of that excellent arrangement is, that a bed made of the short, tender tips of the Canada balsam, spread evenly to the depth of about a foot, is one of the softest, most elastic, and most pleasant couches that can be imagined; and as the scent of the sap of the Canada balsam is absolutely delicious, it is always sweet and refreshing - which is more than can be said for many becls of civilization.

Hunger is a good sauce. A man coming in tired and hungry will find more enjoyment in a piece of moose meat and a cup of tea than in the most luxurious of banquets. Moreover, it must be remembered that some of the wild meats of North America cannot be excelled in flavor and delicacy; nothing, for instance, can be better than moose or caribou, mountain sheep or antelope. The "moufle," or nose of the moose, and his marrow-bones are dainties which would be highly appreciated by accomplished epicures. The meat is grood, and no better method of cooking it has yet been discovered than the simple one of roasting it before a wood fire on a pointed stick. Simplicity is a great source of comfort, and makes up for many luxuries; and nothing can be more simple, and at the same time more comfortable, than life in such a birch-bark camp as I have attempted to describe. In summer-time, and in the fall, until the weather begins to get a little cold, a tent affords all the shelter that the sportsman or the tourist can require. But when the leaves are all fallen, when the lakes begin to freeze up, and snow covers the earth, or may be looked for at any moment, the nights become too cold to render dwelling in tents any longer desirable. A tent can be used in winter, and 1 have dwelt in one in extreme cold, when the thermometer went down as low as $32^{\circ}$ below zero. It was rendered habitable by a little stove, which made it at the same time exceedingly disagreeable. A stove sufficiently small to be portable only contained wood enough to burn for an hour and a half or so; consequently, some one had to sit up all night to replenish it. Now, nobody could keep awake, and the result was that we had to pass through the unpleasant ordeal of alternately freezing and roasting cluring the whole night. The stove was of necessity composed of very thin sheet-iron, as light- 
ness was an important object, and consequently when it was filled with good birch-wood and well under way, it became red-hot, and rendered the atmosphere in the tent insupportable. In about half an hour or so it would cool down a little, and one would drop off to sleep, only to wake in about an hour's time shivering, to fint everything frozen solid in the tent, and the fire nearly out. Such a method of passing the night is little calculated to insure sound sleep. In the depth of winter it is quite impossible to warm a tent from the ontside, however large the fire may bc. It must be built at such a distance that the canvas cannot possibly catch fire, and hence all heat is dispersed long before it can reach and warm the interior of the tent. It is far better to make a "lean-to" of the canvas, build a large fire, and sleep out in the open. $\wedge$ "lean-to" is easily made and scarcely needs description. The name explains itself. You strike two poles, having a fork at the upper end, into the ground, slanting back slightly; lay another fir pole horizontally between the two, and resting in the crutch: then place numcrous poles and branches leaning against the horizontal pole, and thus form a frame-work which you cover in as well as you can with birch-bark, pine boughs, pieces of canvas, skins, or whatever material is most handy. You build an enormous fire in the front, and the camp is complete. A "lean-to" must always be constructed with reference to the direction of the wind; it serves to keep off the wind and a certain amount of snow and rain. In other respects it is, as the Irishman said of the sedanchair with the bottom out, more for the honor and glory of the thing than anything else. For all practical purposes, you are decidedly out of doors.

Although the scenery of the greater part of Canada cannot justly be described as grand or magnificent, yet there is a weird, melancholy, desolate beauty about her barrens, a soft loveliness in her lakes and forest glades in summer, a gorgeousness of color in her autumn woods, and a stern, sad stateliness when winter has draped them all with snow, that cannot be surpassed in any land. I remember, as distinctly as if I had left it but yesterday, the beauty of the camp from which I made my first successful expedition after moose last calling season. I had been out several times unsuccessfully, sonetimes getting no answer at all; at others, calling a bull close up, but failing to induce him to show himself; sometimes failing on account 
of a breeze springing up, or of the night becoming too much overcast and cloudy to enable me to see him. My companions had been equally unfortunate. We had spent the best fortnight of the season in this way, and had shifted our ground and tried everything in vain. At last, we decided on one more attempt, broke camp, loaded our canoes, and started. We made a journey of two days, traversing many lovely lakes, carrying over several portages, and arrived at our destination about three oclock in the afternoon. We drew up our canoes at one of the prettiest spots for a camp I have ever seen. It lay beside a little sheltered, secluded bay at the head of a lovely lake, some three or four miles in length. The shores near us were covered with "hard-wood" trees-birch, maple, and beech, in their glorious autumn colors; while the more distant coasts were clothed with a somber, dark mass of firs and spruce. Above the ordinary level of the forest rose at intervals the ragged, gaunt form of some ancient and gigantic pine that had escaped the notice of the lumberman or had proved unworthy of his ax. In front of us, and to the right, acting as a breakwater to our harbor, lay a small island covered with hemlock and tamarack trees, the latter leaning over in various and most graceful angles, overhanging the water to such an extent as sometimes to be almost horizontal with it. Slightly to the left was a shallow spot in the lake marked by a growth of rushes, vividly green at the top, while the lower halves were of a most brilliant scarlet, affording the precise amount of warmth and bright coloring that the picture required. It is extraordinary how everything seems to turn to brilliant colors in the autumn in these northern latitudes. The evening was perfectly still; the surface of the lake, unbroken by the smallest ripple, shone like a mirror and reflected the coast-line and trees so accurately, that it was impossible to tell where water ended and land began.

The love of money and the love of sport are the passions that lead men into such scenes as these. The lumberman, the salmonfisher, and the hunter in pursuit of large game, monopolize the beauties of nature in these Canadian wilds. The moose (Cerrus Alces) and caribou (Corius rangifor) are the principal large game to be found in Canada. The moose is by far the biggest of all existing deer. He attains to a height of quite eighteen hands, and weighs about twelve hundred pounds or more. The moose of 
America is almost, if not quite, identical with the elk of Europe, but it attains a greater size. The horns especially are much finer than those to be found on the elk in Russia, P'russia, or the Scandinavian countries.

The moose has many advantages over other deer, but it suffers also from some terrible disadvantages, which make it an easy prey to its great and principal destroyer, man. Whereas among most, if not all, the members of the deer tribe, the female has but one fawn at a birth, the cow-moose generally drops two calves - which is much in favor of the race. The moose is blessed with an intensely acute sense of smell, with an almost equally acute sense of hearing, and it is exceedingly wary and difficult of approach. On the other hand, it is but little fitted to move in deep snow, owing to its great weighth. Unlike the caribou, which has hoofs specially adapted for deep snow, the moose's feet are small, compared with the great bulk of the animal. If, therefore, it is once found and started when the snow lies deep upon the ground, its destruction is a matter of certainty; it breaks through the snow to solid earth at every step, becomes speedily exhausted, and falls an easy prey to men and doys. Again, a large tract of land is necessary to supply food for even one moose. In summer, it feeds a good deal upon the stems and roots of waterlilies, but its staple food consists of the tender shoots of the moosewood, ground-maple, alder, birch, poplar, and other deciduous trees. It is fond of ground-hemlock, and will also occasionally browse upon the supin, or Canada balsam fir, and even upon spruce, though that is very rare, and I have known them when hard pressed to gnaw bark off the trees. Nova Scotia and New Brunswick are nearly " settled up." Nore and more land is cleared and brought under cultivation every day; more and more forest cut down year by year; and the moose-supporting portion of the country is becoming very limited in extent. On the other hand, the moose is an animal which could easily be preserved if only reasonable laws could be enforced. It adapts itself wonderfully to civilization. A young moose will become as tame as a domestic cow in a short time. Noose become accustomed to the ordinary noises of a settled country with such facility, that they may sometimes be found feeding within a few hundred yards of a road. A railway does not appear to disturb them at all. I have shot moose within sound of the barking of dogs and the cack- 
ling of geese of a farm-house, in places where the animals must have been constantly hearing men shouting, dogs barking, and all the noises of a settlement. Their sense of hearing is developed in a wonderful degree, and they appear to be possessed of some marvelous power of discriminating between innocent sounds and noises which indicate danger. On a windy day, when the forest is full of noises, - trees cracking, branches snapping, and twigs breaking,the moose will take no notice of all these natural sounds; but if a man breaks a twig, or, treading on a dry stick, snaps it on the ground, the moose will distinguish that sound from the hundred voices of the storm, and be off in a second.

Why it is that the moose has developed no peculiarity with regard to his feet, adapting him especially to the country in which he dwells, while the caribou that shares the woods and barrens with him has done so in a remarkable degree, I will leave philosophers to decide. In the caribou, the hoofs are very broad and round, and split up very high, so that, when the animal treads upon the soft surface of the snow, the hoofs spreading out form a natural kind of snow-shoe and prevent its sinking deep. The frog becomes absorbed toward winter, so that the whole weight of the animal rests upon the hoof, the edges of which are as sharp as a knife, and give the animals so secure a foothold that they can run without fear or danger on the slippery surface of smooth glare ice. Now the moose, on the contrary, is about as awkward on the ice as a shod horse, and will not venture out on the frozen surface of a lake if he can help it. His feet are rather small and pointed, and allow him to sink and flounder helplessly in the deep snows of midwinter and early spring.

There are several ways in which the moose is hunted; some legitimate and some decidedly illegitimate. First of all there is moose-calling, which to my mind is the most interesting of all woorlland sports. It commences about the beginning of September, and lasts for about six weeks, and consists in imitating the cry of the female moose, and thereby calling up the male. This may sound easy enough to do, especially as the bull at this season of the year loses all his caution, or the greater part of it. But the pastime is surrounded by so many difficulties, that it is really the most precarious of all the methods of pursuing or endeavoring to outwit the moose; and it is at the same time the most exciting. I will endeavor 
to describe the method by riving a slight sketch of the death of a moose in New Brunswick woods last year.

It was early in October. We had pitched our tents - for at that season of the year the hunter dwells in tents - upon a beautiful hard-wood ridge, bright with the painted foliage of birch and maple. The weather had been bad for calling, and no one had sone out, though we knew there were moose in the neighborhood. We had cut a great store of firewood, gathered bushels of cranberries, dug a well in the swamp close by, and attended to the thousand and one little comforts that experience teaches one to provide in the woods, and had absolutely nothing to do. The day was intensely hot and sultry; and if any one had approached the camp about noon he would have deemed it deserted. All hands had hung their blankets over the tents, by way of protection from the sun, and had gone to sleep. About one o'clock 1 awoke, and sauntered out of the tent to stretch my limbs and take a look at the sky. I was particularly anxious about the weather, for 1 was tired of idleness, and had determined to go out if the evening offered a tolerably fair promise of a fine night. To get a better view of the heavens, I climbed to my accustomed look-out in a comfortable fork near the summit of a neighboring pine, and noted with disgust certain little black shreds of cloud rising slowly above the horizon. To aid my indecision I consulted my dear old friend, John Williams, the Indian, who, after the manner of his kind, stoutly refused to give any definite opinion on the subject. All that I could get out of him was, "W'ell, dunno; mebbe fine, mebbe wind get up; guess pretty calm, perhaps, in morning. Suppose we go and try, or, p'raps, mebbe wait till tomorrow." Finally I decided to go out; for although, if there is the slightest wind, it is impossible to call, yet any wise and prudent man, unless there are unmistakable signs of a storm brewing, will take the chance: for the calling season is short and soon over.

I have said that an absolutely calm night is required for calling, and for this reason: the moose is so wary, that, in coming up to the call, he will invariably make a circle down wind in order to get scent of the animal which is calling him. Therefore, if there is a breath of wind astir, the moose will gret scent of the man before the man has a chance of seeing the moose. A calm night is the first thing necessary. Secondly, you must have a moonlight night. No moose will 
come up in the day-time. You can begin to call about an hour before sunset, and moose will answer up to say two hours after sunrise. There is very little time, therefore, unless there is bright moonlight. In the third place, I need scarcely observe that to call moose successfully you must find a place near camp where there are moose to call, and where there are not only moose, but bull moose; not only bull moose, but bulls that have not already provided themselves with consorts; for if a real cow begins calling, the rough imitation in the shape of a man has a rery poor chance of success, and may as well give it up as a bad job. Fourthly, you must find a spot that is convenient for calling, that is to say, a piece of dry ground, for no human being can lie out all night in the wet, particularly in the month of October, when it freezes hard toward morning. You must have dry ground, well sheltered with trees or shrubs of some kind, and a tolerably open space around it for some distance; open enough for you to see the bull coming up when he is yet at a little distance, but not a large extent of open ground, for no moose will venture out far on an entirely bare exposed plain. He is disinclined to leave the friendly shelter of the trees. A perfect spot, therefore, is not easily found. Such are some of the difficulties which attend moose-calling and render it a most precarious pastime. Four conditions are necessary, and all four must be combined at one and the same time.

Having once determined to go out, preparations do not take long. You have only to roll up a blanket and overcoat, take some tea, sugar, salt, and biscuit, a kettle, two tin pannikins, and a small ax, with, I need scarcely say, rifle and ammunition. The outfit is simple; but the hunter should look to everything himself, for an Indian would leave his head behind if it were loose. A gooul thick blanket is very necessary, for moose-calling involves more hardship and more suffering from cold than any other branch of the noble science of hunting with which I am acquainted. It is true that the weather is not especially cold at that time of year, but there are sharp frosts occasionally at night, and the moose-caller cannot make a fire by which to warm himself, for the smell of smoke is carried a long way by the slightest current of air. Neither dare he run about to warm his feet, or flap his hands against his sides, or keep up the circulation by taking exercise of any kind, for fear of making a noise. He is sure to have got wet through with perspiration on 
his way to the calling place, which of course makes him more sensitive to cold.

So 1 and the Indian shouldered our packs, and started for the barren, following an old logging road. Perhaps 1 ought to explain a little what is meant by a "logging road" and a "barren." A $\log$ ging road is a path cut through the forest in winter, when the snow is on the ground and the lakes are frozen, along which the trunks of trees or logs are hauled by horses or oxen to the water. A logging road is a most pernicious thing. Never follow one if you are lost in the woods, for one end is sure to lead to a lake or a river, which is decidedly inconvenient until the ice has formed: and in the other direction it will seduce you deep into the inner recesses of the forest, and then come to a sudden termination at some moss-covered, decayed pine stump, which is discouraging. A "barren," as the term indicates, is a piece of waste land; but, as all hunting grounds are waste, that definition would scarcely be sufficient to describe what a "barren" is. It means, in Nova Scotia and New Brunswick, an open marshy space in the forest, sometimes so soft as to be almost impassable; at other times composed of good solid hard peat. The surface is occasionally rough and tussocky, like a great deal of country in Scotland.

In Newfoundland, there are barrens of many miles in extent, high, and, comparatively speaking, dry plateaus: but the barrens in the provinces I am speaking of vary from a little open space of a few acres to a plain of five or six miles in length or breadth. There has been a good deal of discussion as to the origin of these "barrens." It appears to me that they must have been originally lakes, which have become dry by the gradual elevation of the land, and through the natural processes by which shallow waters become choked up and filled with vegetable débris. They have all the appearance of dry lakes. They are about the size of the numerous sheets of water that are so frequent in the country. The forest surrounds them completely, precisely in the same way as it does a lake, following all the lines and curvatures of the bays and indentations of its shores; and every elevated spot of dry, solid ground is covered with trees exactly as are the little islands that so thickly stud the surface of the Nova Scotian lakes. Most of the lakes in the country are shallow, and in many of them the process by which they become 
filled up can be seen at work. The ground rises considerably in the center of these barrens, which is, I believe, the case with all bogs and peat mosses. 1 have never measured any of their areas, neither have 1 attempted to estimate the extent of the curvature of the surface; but on a barren where I hunted last year, of about two miles across, the ground rose so much in the center that when standing at one elge we could see the upper half of the pine trees which grew at the other. The rise appeared to be quite gradual, and the effect was as if one stood on an exceedingly small globe, the natural curvature of which hid the opposite trees.

To return to our calling. We got out upon the barren, or, rather, upon a deep bay or indentation of a large barren, about four o'clock in the afternoon, and made our way to a little wooded island, which afforded us shelter and dry ground, and which was within easy shot of one side of the bay, and so situated with regard to the other that a moose coming from that direction would not hesitate to approach it. The first thing to be done is to make a lair for oneself-a little bed. You pick out a nice sheltered soft spot, chop down a few sapin branches with your knife, gather a quantity of dry grass or bracken, and make as comfortable a bed as the circumstances of the case will permit.

Having made these little preparations. I sat down and smoked my pipe while the Indian climbed up a neighboring pine-tree to "call." The only object of ascending a tree is that the sound may be carried further into the recesses of the forest. The instrument wherewith the caller endeavors to imitate the cry of the cow consists of a cone-shaped tube made out of a sheet of birch-bark rolled up. This horn is about eighteen inches in length and three or four in diameter at the broadest end, the narrow end being just large enough to fit the mouth. The "caller" uses it like a speakingtrumpet, groaning and roaring through it, imitating as well as he can the cry of the cow-moose. Few white men can call really well, but some Indians, by long practice, can imitate the animal with wonderful success. Fortunately, however, no two moose appear to have precisely the same voice, but make all kinds of strange and diabolical noises, so that even a novice in the art may not despair of himself calling up a bull. The real difficulty - the time when you require a perfect mastery of the art-is when the bull is close by, suspicious, and 
listening with every fiber of its intensely accurate ear to detect any sound that may reveal the true nature of the animal he is approaching. The smallest hoarseness, the slightest wrong vibration, the least unnatural sound, will then prove fatal. The Indian will kneel on the ground, putting the broad end of the horn close to the earth, so as to deaclen the sound, and, with an agonized expression of countenance, will imitate with such marvelous fidelity the wailing, anxious, supplicating cry of the cow, that the bull, unable to resist, rushes out from the friendly cover of the trees, and exposes himself to death. Or it may be that the most accomplished caller fails to induce the suspicious animal to show himself; the more ignoble passion of jealousy must then be aroused. The Indian will grunt like an enraged bull, break dead branches from the trees, thrash his birch-bark horn against the bushes, thus making a noise exactly like a moose fighting the bushes with his antlers. The bull cannot bear the idea of a rival, and, casting his prudence to the winds, not unfrequently falls a victim to jealousy and rage.

The hunter calls through his horn, first gently, in case there should be a bull very near. He then waits a quarter of an hour or so, and, if he gets no answer, calls again a little louder, waiting at least a quarter of an hour-or half an hour some Indians say is best - after each attempt.

The cry of the cow is a long-drawn-out melancholy sound, impossible to describe by words. The answer of the bull-moose, on the contrary, is a rather short guttural grunt, and resembles at a great distance the sound made by an ax chopping wood, or that which a man makes when pulling hard at a refractory clay-pipe. You continue calling at intervals until you hear an answer, when your tactics depend upon the way in which the animal acts. Great acuteness of the sense of hearing is necessary, because the bull will occasionally come up without answering at all; and the first indication of his presence consists of the slight noise he makes in advancing. Sometimes a bull will come up with the most extreme caution; at others, he will come tearing up through the woods, as hard as he can go, making a noise like a steam-engine, and rushing through the forest apparently without the slightest fear.

On the particular occasion which 1 am recalling, it was a most lovely evening. It wanted but about half an hour to sundown, and 
all was perfectly still. There was not the slightest sound of anything moving in the forest, except that of the unfrequent flight of a moose-bird close by. And so 1 sat watching that most glorious transformation scene - the change of day into night; saw the great sun sink slowly down behind the pine trees: saw the few clouds that hovered motionless above me blaze into the color of bright burnished gold; saw the whole atmosphere become glorious with a soft yellow light, gradually dying out as the night crept on, till only in the western sky there lingered a faint glow, fading into a pale cold apple-green, against which the pines stood out as black as midnight, and as sharply defined as though cut out of steel. As the darkness deepened, a young crescent moon shone out pale and clear, with a glittering star a little below the lower horn, and above her another star of lesser magnitude. It looked as though a supernatural jewel - a heavenly pendant, two great diamond solitaires, and a diamond crescent-were hanging in the western sky. After awhile, the moon, too, sank behind the trees, and darkness fell upon the earth.

I know of nothing more enchanting than a perfectly calın and silent autumnal sunset in the woods, unless it be the sunrise, which, to my mind, is more lovely still. Sunset is beautiful, but sad; sunrise is equally beautiful, and full of life, happiness, and hope. 1 love to watch the stars begin to fade, to see the first faint white light clear up the darkness of the eastern sky, and gradually deepen into the glorious coloring that heralds the approaching sun. I love to see Nature awake shuddering, as she always does, and arouse herself into active, busy life; to note the insects, birds, and beasts shake off slumber and set about their daily tasks.

Still, the sunset is inexpressibly lovely, and 1 do not envy the condition and frame of mind of a man who cannot be as nearly happy as man can be, when he is lying comfortably on a luxurious and soft couch, gazing in perfect peace on the glorious scene around him, rejoicing all his senses, and saturating himself with the wonderful beauties of a northern sunset.

So I sat quietly below, while the lndian called from the tree-top. Not a sound answered to the three or four long-drawn-out notes with which he hoped to lure the bull. After a long interval he called again, but the same perfect, utter silence reigned in the woods, a silence broken only by the melancholy hooting of an owl, or the imaginary 
noises that filled my head. It is extraordinary how small noises become magnified when the ear is kept at a great tension for any length of time, and how the head becomes filted with all kinds of fictitious sounds; and it is very remarkable also how utterly impossible it is to distinguish between a loud noise uttered at a distance and a scarcely audible sound close by. After listening very intently amidst the profound silence of a quiet night in the forest for an hour or so, the head becomes so surcharged with blood, owing. I presume, to all the faculties being concentrated on a single sense, that one seems to hear distant voices, the ringing of bells, and all kinds of strange and impossible noises. A man becomes so nervously alive to the slightest disturbance of the almost awful silence of a still night in the woods, that the faintest sound-the cracking of a minute twig, or the fall of a leaf, even at a great distance-will make him almost jump out of his skin. He is also apt to make the most ludicrous mistakes. Toward morning, about day-break, I have frequently mistaken the first faint buzz of some minute fly, within a foot or so of my ear, for the call of moose two or three miles off.

About ten o'clock, the Indian gave it up in despair and came down the tree; we rolled ourselves up in our rugs, pulled the hoods of our blanket coats over our heads, and went to sleep. 1 awoke literally shaking with cold. It was still the dead of night, and the stars were shining with intense brilliancy, to my great disappointment, for I was in hopes of seeing the first streaks of dawn. It was freezing very hard, far too hard for me to think of going to sleep again. So I roused the Indian, and suggested that he should try another call or two.

Accordingly, we stole down to the edge of the little point of wood in which we had ensconced ourselves, and in a few minutes the forest was reëchoing the plaintive notes of the moose. Not an answer, not a sound-utter silence, as if all the world were dead! broken suddenly and horribly by a yelt that made the blood curdle in one's veins. It was the long, quavering, human, but unearthly scream of a loon on the distant lake. After what seemed to be many hours, but what was in reality but a short time, the first indications of dawn revealed themselves in the rising of the morning star, and the slightest possible paling of the eastern sky. The cold grew almost unbearable. 
That curious shiver that runs through nature - the first icy current of air that precedes the day-chilled us to the bones. I rolled myself up in my blanket and lighted a pipe, trying to retain what little caloric remained in my body, while the Inclian again ascended the tree. By the time he had called twice it was gray dawn. Birds were beginning to move about and busy squirrels to look out for their breakfast of pine-buds. I sat listening intently, and watching the blank, emotionless face of the Indian as he gazed around him, when suddenly 1 saw his countenance blaze up with vivid excitement. His eyes seemed to start from his head, his muscles twitched, his face glowed, he seemed transformed in a moment into a different being. At the same time he began, with the utmost celerity, but with extreme caution, to descend to the ground. He motioned to me not to make any noise, and whispered that a moose was coming across the barren and must be close by. Grasping my rifle, we crawled carefully through the grass, crisp and noisy with frost, down to the edge of our island of woods. and there, after peering cautiously around some stunted juniper bushes, I saw standing, about sixty yards off, a bull-moose. He looked gigantic in the thin morning mist which was beginning to drift up from the surface of the barren. Great volumes of steam issued from his nostrils, and his whole aspect, looming in the fog, was vast and almost terrific. He stood there, perfectly motionless, staring at the spot from which he had heard the cry of the supposed cow, irresolute whether to come on or not. The Indian was anxious to bring him a little closer, but I did not wish to run the risk of scaring him; and so, taking aim as fairly as 1 could, considering I was shaking all over with cold, I fired and struck him behind the shoulder. He plunged forward on his knees, jumped up, rushed forward for about two hundred yards, and then fell dead at the edge of the heavy timber on the far side of the barren.

We went to work then and there to skin and clean him, an operation which probably took us an hour or more; and having rested ourselves a few minutes, we started off to take a little cruise round the edge of the barren and see if there were any caribou on it. I should explain that "cruising" is, in the provinces, performed on land as well as at sea. A man says he has spent all summer "cruising" the woods in search of pine timber, and if your Indian wants" 
you to go out for a walk, he will say, "1,et us take a cruisc around somewhere." Accordingly, we trudged off over the soft, yielding surface of the bog, and, taking advantage of some stunted lushes. crossed to the opposite side, so as to be well down wind in case any animal should be on it. The Indian then ascended to the top of the highest pine-tree he could find, taking my glasses with him, and had a good look all over the barren. There was not a thing to be seen. We then passed through a small strip of wood, and came out upon another plain, and there, on ascending a tree to look round, the Indian espied two caribou feeding toward the timber. W'e had to wait some little time till they got behind an island of trees, and then, running as fast as the soft nature of the ground would permit, we contrived to get close up to them just as they entered the thick woods, and, after an exciting stalk of about half an hour, 1 managed to kill both.

Having performed the obsequies of the chase upon the two caribou, we returned to our calling-place. By this time it was about noon; the sun was blazing down with almost tropical heat. We had been awake the greater part of the night, and had done a hard morning's work, and felt a decided need for refreshment. In a few minutes we had lighted a little fire, put the kettle on to boil, and set the moose kidneys, impaled on sharp sticks, to roast by the fire; and with fresh kidneys, gook strong tea, plenty of sugar and salt, and some hard biscuit, I made one of the most sumptuous breakfasts it has been my lot to assist at.

Breakfast over, I told the Indian to go down to camp and bring up the other men to assist in cutting up and smoking the meat. As soon as he had departed, I laid myself out for a rest. I shifted my bed - that is to say, my heap of dried bracken and pine-tops - under the shadow of a pine, spread my blanket out. and lay down to smoke the pipe of peace in the most contented frame of mind that a man can ever hope to enjoy in this uneasy and troublesome world. I had suffered from cold and from hunger-1 was now warm and well fed. I was tired after a hard day's work and long night's vigil, and was thoroughly capable of enjoying that greatest of all luxuriessweet repose after severe exercise. The day was so warm that the shade of the trees fell cool and grateful, and I lay flat on my back, smoking my pipe, and gazing up through the branches into a per- 
fectly clear, blue sky, with occasionally a little white cloud like a bit of swan's-down floating across it, and felt, as I had often felt before, that no luxury of civilization can at all compare with the comfort a man can obtain in the wilderness. I lay smoking till I dropped off to sleep, and slept soundly until the men, coming up from camp, awoke me.

Such is a pretty fair sample of a good day's sport. It was not a very exciting day, and 1 have alluded to it chiefly because the incidents are fresh in my mind. The great interest of moose-calling comes in when a bull answers early in the evening, and will not come up boldly, and you and the bull spend the whole night trying to outwit each other. Sometimes, just when you think you have succeeded in deceiving him, a little air of wind will spring up; he will get scent of you, and be off in a second. Sometimes a bull will answer at intervals for several hours, will come up to the edge of the open ground, and there stop and cease speaking. You wait, anxiously watching for him all night, and in the morning, when you examine the ground, you find that something had scared him, and that he had silently made off, so silently that his cleparture was unnoticed. It is marvelous how so great and heavy a creature can move through the woods without making the smallest sound; but he can do so, and does, to the great confusion of the hunter.

Sometimes another bull appears upon the scene, and a frightful battle ensues; or a cow will commence calling, and rob you of your prey; or you may get an answer or two in the evening, and then hear nothing for several hours, and go to sleep and awake in the morning to find that the bull had walked calmly up to within ten yards of you. Very frequently you may leave camp on a perfectly clear, fine afternoon, when suddenly a change will come on, and you may have to pass a long, dreary night on some bare and naked spot of ground, exposed to the pitiless pelting of the storm. One such night I well remember, last fall. It rained and thundered and blew the whole time, from about eight o'clock, until daylight at last gave us a chance of dragging our chilled and benumbed bodies back to camp. Fortunately such exposure, though unpleasant, never does any one any harm in the wilderness.

Occasionally, a moose will answer, but nothing will induce him to come up, and in the morning, if there is a little wind, you can resort 
to the only other legitimate way of hunting the moose, namely; "creeping," or "still hunting," as it would be termed in the States, which is, as nearly as possible, equivalent to ordinary deer-stalking.

After the rutting season the moose begin to "yard," as it is termed. I have seen pictures of a moose-yard, in which numbers of animals are represented inside and surrounded by a barrier of snow, on the outside of which baffled packs of wolves are clamorously howling; and I have seen a moose-yard so described in print as to make it appear that a number of moose herd together and keep tramping and tramping in the snow to such an extent that by midwinter they find themselves in what is literally a yard-a hollow, bare place, surrounded by deep snow. Of course, such a definition is utterly absurd. A moose does not travel straight on when he is in search of food, but selects a particular locality, and remains there as long as the supply of provisions holds out: and that place is called a yard.

Sometimes a solitary moose "yards" alone, sometimes two or three together. Occasionally, as many as half a dozen may be found congregated in one place. When a man says he has found a "moose-yard," he means that he has come across a place where it is evident, from the tracks crossing and recrossing and intersecting each other in all directions, and from the signs of browsing on the trees, that one or more moose have settled down to feed for the winter. Having once selected a place or "yard," the moose will remain there till the following summer, if the food holds out and they are not disturbed by man. If forced to leave their "yard," they will travel a long distance-twenty or thirty miles-before choosing another feeding-ground. After the rutting season, moose wander about in an uneasy state of mind for three weeks or so, and are not all settled down till the beginning of November.

In "creeping," therefore, or stalking moose, the first thing to be done is to find a moose-yard. You set out early in the morning. in any direction you may think advisable, according to the way the wind blows, examining carefully all the tracks that you come across. When you hit upon a track, you follow it a little way, examining it and the ground and trees, to see if the animal is traveling or not. If you find that the moose has "yarded," that is to say, fed, and you can come across evidences of his presence not more than a couple of 
days or so old, you make up jour mind to hunt that particular moose.

The utmost caution and skill are necessary. The moose invariably travels down-wind some little distance before beginning to feed, and then works his way up, browsing about at will in various directions. He also makes a circle down-wind before lying down, so that, if you hit on a fresh track and then follow it, you are perfectly certain to start the animal without seeing him. You may follow a moose track a whole day, as I have done before now, and finally come across the place where you started him, and then discover that you had passed within fifty yards of that spot early in the morning, the animal having made a large circuit and lain down close to his tracks. The principle, therefore, that the hunter has to go upon is to keep making small semicircles down-wind, so as to constantly cut the tracks and yet keep the animal always to windward of him. Having come across a track and made up your mind whether it is pretty fresh, whether the beast is a large one worth following, and whether it is settled down and feeding quietly, you will not follow the track, but go down-wind and then gradually work up-wind again till you cut the tracks a second time. Then you must make out whether the tracks are fresher or older than the former: whether they are tracks of the same moose or those of another, and leave them again and work up, and cut them a third time; and so you go on gradually, always trimming down-wind and edging up-wind again, until, finally, you have quartered the whole ground.

Perhaps the moose is feeding upon a hard-wood ridge of beech and maples of, say, two or three miles in length and a quarter of a mile in width. Every square yard you must make good, in the way I have endeavored to describe, before you proceed to go up to the moose. At length, by dint of great perseverance and caution, you will have so far covered the ground that you will know the animal must be in some particular spot. Then comes the difficult moment. I may say at once that it is mere waste of time trying to creep except on a windy day, even with moccasins on; and it is of no use at any time trying to creep a moose unless you are provided with soft leather moccasins. No human being can get within shot of a moose on a still day; the best time is when windy weather succeeds a heavy fall of rain. Then the ground is soft, the little twigs strewed about bend instead 
of breaking, and the noise of the wind in the trees deadens the sound of your footsteps. If the ground is dry, and there is not much wind, it is impossible to get near the game. When you have determined that the moose is somewhere handy,-when you come across perfectly fresh indications of his presence,-you proceed inch by inch ; you must not make the smallest noise; the least crack of a dead branch or of a stick under foot will start the animal. Especially careful must you be that nothing taps against your gun-stock, or that you do not strike the barrel against a tree, for, naturally, any such unusual sound is far worse than the cracking of a stick. If, however, you succeed in imitating the noiseless movements and footsteps of your Indian, you will probably be rewarded by seeing him presently make a "point" like a pointer dog. Every quivering fiber in his body proves his excitement. He will point out something dark to you among the trees. That clark mass is a moose, and you must fire at it. without being too careful what part of the animal you are going to hit, for probably the moose has heard you, and is only waiting a second before making up his mind to be off.

Generally speaking, the second man sees the moose first. The leader is too much occupied in looking at the tracks-in seeing where he is going to put his foot down. The second man has only to tread carefully in the footsteps of the man preceding him, and is able to concentrate his attention more on looking about. The moment you spy or hear the animal, you should imitate the call of a moose,- first, to attract the attention of the animal, which, if it has not smelt you, will probably stop a second to make sure what it is that has frightened him; secondly, to let the Indian in front know that the game is on foot. Moose-creeping is an exceedingly diffcult and exciting pastime. It requires all a man's patience, for, of course, you may travel day after day in this way without finding any traces of deer. To the novice it is not interesting, for, apparently, the Indian wanders aimlessly about the woods without any particular object. When you come to understand the motive for every twist and turn he makes, and appreciate the science he is clisplaying, it becomes one of the most fascinating pursuits in which the sportsman can indulge. Sometimes one may be in good luck and come across a moose in some glade or " interval," the result of the labors of former generations of beavers. An "interval " is the 
local term for natural meadows, which are frequently found along the margins of streams. Beavers have done great and useful work in all these countries. The evidences of their labors have far outlived the work of aboriginal man. They dam up little streams and form shallow lakes and ponds. Trees fall in and decay; the ponds get choked with vegetation, fill up, and are turned into natural meadows of great value to the settler. Beavers have played an important part in rendering these savage countries fit for the habitation of civilized man.

The moose may also be run down in winter-time on snow-shoes. This may be called partly a legitimate, and partly an illegitimate, mode of killing the animal. If the snow is not very deep, the moose can travel, and to come up with him requires immense endurance on the part of a man, but no skill except that involved in the art of running on snow-shoes. You simply start the animal and follow after him for a day, or sometimes two or three days, when you come up with him and walk as close as you like and shoot him.

If the snow lies very deep in early spring, moose may be slaughtered with ease. The sun thaws the surface, which freezes up again at night and forms an icy crust strong enough to support a man on snow-shoes, or a dog, but not nearly strong enough to support a moose. Then they can be run down without trouble. You find your moose and start a dog after him. The unfortunate moose flounders helplessly in the snow, cutting his legs to pieces, and in a very short time becomes exhausted, and you can walk up to him, knock him on the head with an ax, or stick him with a knife, as you think best. Hundreds and hundreds of moose have been slaughtered in this scandalous manner for their hides alone. The settlers also dig pits for them and snare them, both of which practices, I need hardly say, are most nefarious. There is nothing sportsmanlike about them, and they involve waste of good meat, because, unless a man looks to the snare every day (which these men never do), he runs the chance of catching a moose and finding the carcass unfit for food when he revisits the place. I shall not describe the method of snaring a moose, for fear some reader who has followed me thus far might be tempted to practice it, or lest it might be supposed for a moment that I had ever done such a wicked thing myself. 
Many men prefer caribou-hunting to moose-hunting, and 1 am not sure that they are not right. The American caribou is, I believe, identical with the reindeer of Europe, though the American animal grows to a much larger size and the males carry far finer horns. The does have small horns also. I believe the caribou is the only species of deer marked by that peculiarity. Caribou are very fond of getting out on the lakes as soon as the ice will bear, and feeding round the shores. They feed entirely on moss and lichens, principally on the long gray moss, locally known as "old men's beards," which hangs in graceful festoons from the branches of the pines, and on the beautiful purple and cream-colored caribou moss that covers the barrens. They are not very shy animals, and will venture close to lumber camps to feed on the moss which grows most luxuriantly on the tops of the pines which the ax-men have felled. Caribou cannot be run down, and the settlers rarely go after them. They must be stalked on the barrens and lakes, or crept up to in the woods, precisely in the same manner as the moose.

Such is a brief outline of some Canadian sports. Life in the woods need not be devoted entirely to hunting, but can be varied to a great extent by fishing and trapping. The streams and lakes teem with trout, and the finest salmon-fishing in the world is to be found in New Brunswick and on the north shore of the gulf. In Lower Canada there is still a good deal of fur to be found. In New Brunswick and Nova Scotia beavers are almost extinct, and marten, mink, lynx, otter, and other valuable fur-bearing animals are comparatively scarce. It would be hard, I think, for a man to spend a holiday more pleasantly and beneficially than in the Canadian woods. Hunting leads him into beautiful scenery; his method of life induces a due contemplation of nature and tends to wholesome thought. He has not much opportunity for improving his mind with literature, but he can read out of the great book of nature, and find "books in the running brooks, sermons in stones, and grood in everything." If he has his eyes and ears open, he cannot fail to take notice of many interesting circumstances and phenomena ; and if he has any knowledge of natural history, every moment of the day must be suggesting something new and interesting to him. A strange scene, for example, which came within my observation last year, completely 
puzzled me at the time and has done so ever since. I was in Nova Scotia in the fall, when one day my Indian told me that in a lake close by all the rocks were moving out of the water, a circumstance which I thought not a little strange. However, I went to look at the unheard-of spectacle, and sure enough there were the rocks apparently all moving out of the water on to dry land. The lake is of considerable extent, but shallow, and full of great masses of rock. Nany of these masses appear to have traveled right out of the lake, and are now high and dry some fifteen yards above the margin of the water. They have plowed deep and regularly defined channels for thenselves. You may see them of all sizes, from blocks of, say, roughly speaking, six or eight feet in diameter, down to stones which a man could lift. Moreover, you find them in various stages of progress: some a hunclred yards or more from shore, and apparently just beginning to move; others half way to their destination, and others, again, as I have said, high and dry above the water. In all cases there is a distinct groove or furrow which the rock has clearly plowed for itself. I noticed one particularly good specimen, an enormous block, which lay some yards above highwater mark. The earth and stones were heaped up in front of it to a height of three or four feet. There was a deep furrow, the exact breadth of the block, leading down directly from it into the lake, and extending till it was hidden from my sight by the depth of the water. Loose stones and pebbles were piled up on each side of this groove in a regular clearly defined line. I thought at first that, from some cause or other, the smaller stones, pebbles, and sand had been dragged down from above, and consequently had piled themselves up in front of all the large rocks too heavy to be moved, and had left a vacant space or furrow behind the rocks. But if that had been the case, the drift of moving material would of course have joined together again in the space of a few yards behind the fixed rocks. On the contrary, these grooves or furrows remained the same width throughout their entire length, and have, 1 think, undoubtedly been caused by the rock forcing its way up through the loose shingle and stones which compose the bed of the lake. What power has set these rocks in motion it is difficult to decide. The action of ice is the only thing that might explain it; but how ice could exert itself in that special manner, and why, if ice is the cause 
of it, it does not manifest that tendency in every lake in every part of the world, I do not pretend to comprehend.

My attention having been once directed to this, I noticed it in various other lakes. Unfortunately, my Indian only mentioned it to me a day or two before I left the woods. I had not time, therefore, to make any investigation into the subject. Possibly some of my readers may be able to account for this, to me, extraordinary phenomenon.

Even from the point of view of a traveler who cares not for field sports, Nova Scotia and New Brunswick, and, in fact, all Canada, is a country full of interest. It is interesting for many reasons which I have not space to enter into now, but especially so as showing the development of what, in future, will be a great nation. For whether in connection with this country, or as independent, or as joined to the United States, or any portion of them, that vast region which is now called British North America will assuredly some day support the strongest, most powerful, and most masterful population on the continent of America.

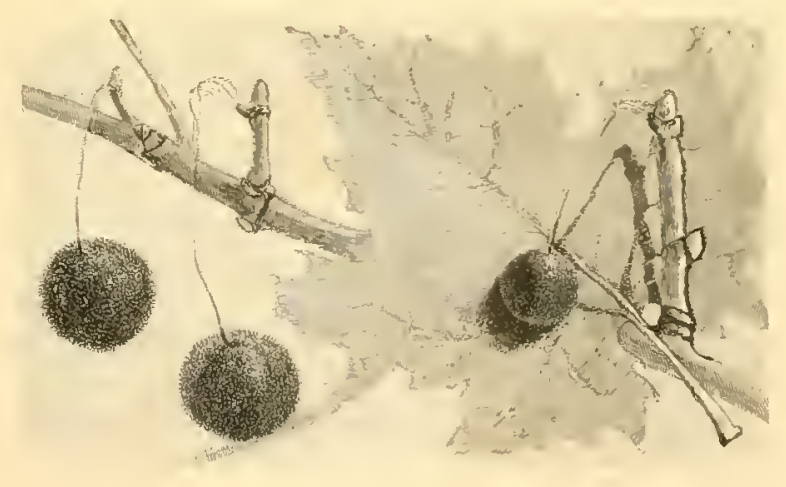




\section{CARIBOU-HUNTING. \\ $\sqrt{11}$ \\ BY CHARLES C. WARD.}

T

O determine accurately the geographical distribution of an animal of such wandering habits as the caribou, or American reindeer (Corus tarandus-Linn.; Rangifer Caribou-Audubon and Bachman), is extremely difficult. Every few years make a change. One year finds the species receding from haunts previously occupied and encroaching upon grounds hitherto unfrequented; and in some districts, from various causes, we find them exterminated.

I may say, however, that the caribou largely inhabits Labrador and Newfoundland, still exists in considerable numbers in the province of New Brunswick, in the wilderness regions of the Restigouche, in the country watered by the upper south-west branch of the Miramichi, also on Cairns River - another branch of the Miramichi. He is also abundant at the head-waters of Green River, in the county of Madawaska. In Queens County, he is found at head of Grand Lake, Salmon River. In Kent County, he is again met with on the Kishanaguak and Kishanaguaksis, also frequently on the Bathurst road, between Bathurst and Chatham. A few years ago, the animals were quite numerous in Charlotte County, and are still occasionally met with. In the adjoining province of Nova Scotia their numbers are gradually decreasing, their strongholds at present being confined to the Cobequid Nountains and the uplands of Cape Breton. Going westward and south of the St. Lawrence, the caribou is again met with in Rimouski, his haunts extending southward along the borders of the State of Maine and the country south of the city of Quebec to New Hampshire. The moose is found with him all through this 


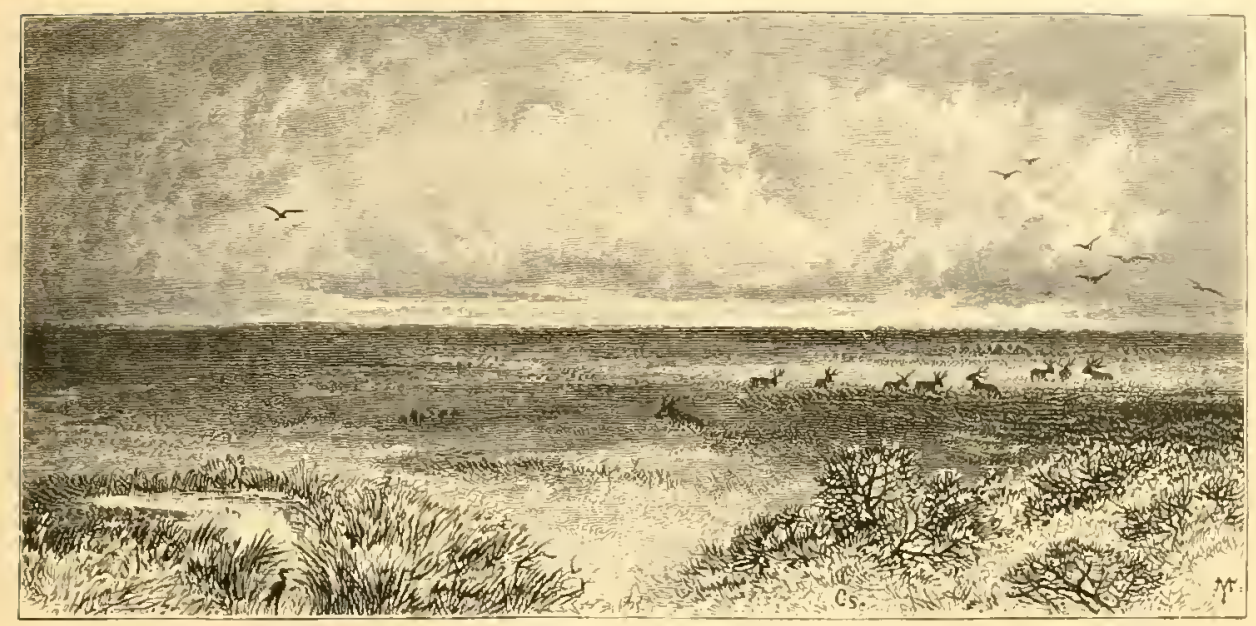

CARIBOU BARRENS.

district, and also the Virginia deer in its southern part. North of the Ottawa and St. Lawrence, the caribou ranges all through the vast forest regions as far as the southern limits of Hudson's Bay, and is abundant in the north-west territories, as far as the McKenzie River, and is also found inhabiting the high lands of British Columbia.

In the State of Naine they are met with in tolerable abundance, and if the existing game-laws are strictly enforced, we may hope that their numbers will not be diminished. In the wilderness tracts of that State there are vast stretches of barrens, amply provided with the reindeer lichen and interspersed with innumerable lakes and uplands, constituting a country admirably adapted to the habits of the caribou. It has been said that the caribou extends along the border west of Lake Superior to the Pacific; but, as late as 1874 , none were found along the border of Dakota and Montana. If the species reaches the wooded region at and west of the Rocky Mountains, its presence does not seem to be well attested. It is, however, said to occur in Washington Territory, but I may add that a competent authority doubts the existence of the caribou in the United States west of the Red River of the North. Within the last year, the presence of the caribou in Minnesota and Wisconsin has been authenticated.

The prevailing color of the caribou is a dark fawn inclining to gray, darkest at the tips of the hairs, on the sides, ears, face, and 
outside of the legs, and fading to almost pure white on the neck and throat. The under part of the body and tail is white, and a ring of white encircles the legs just above the hoof. Some specimens have a light spot on the shoulders and a black patch on the mouth. It is not uncommon to find aged and full-grown animals adorned with a flowing mane, which adds greatly to the grace and beauty of their appearance. In midwinter I have noticed departures from the above description, the coats of some animals inclining more to light gray; and in others, one half of the body was very light gray, and the other half much darker. In particular, I remember having killed a doe of extraordinary size and beauty of form, whose general color was an exceedingly rich dark brown, and entirely different from that of any other caribou in the herd.

The heads and antlers of the caribou present much diversity of form, and seldom are any two found alike. In the same herd, I have seen heads very like that of a two-year-old colt; then, again, others had pronounced Roman noses, the whole head appearing much longer. In some instances, the palmation extends throughout the horns; while in others, such as the Labrador caribou, it is often confined to the tines at the top of the horn, the main stem being nearly round. Again, we find in the caribou inhabiting Newfoundland horns of very great size, perfect in palmation, and in many cases having both brow antlers developed.

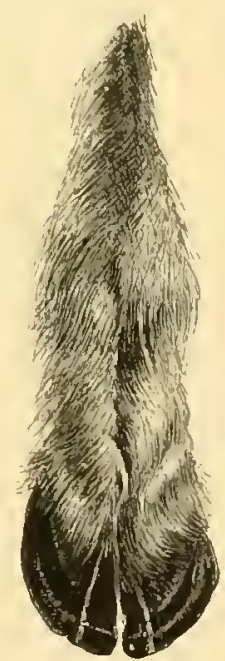

WOODLAND CARIBOU HOUFS.

The construction of the caribou's hoof differs from that of any other animal of the deer tribe, and is wonderfully adapted to the services it is required to perform, and enables the animal to travel in deep snows, over frozen lakes and icy crusts, when the moose and deer are confined to their yards and at the mercy of their foes. Toward the end of the season, the frog begins to be absorbed, and in the month of December is entirely so; at the same time, the hoof expands and becomes concave, with sharp and very hard, shell-like edges. 
The hoof figured in this paper is drawn from nature, and measures fourteen inches in circumference, five inches in diancter, and has a lateral spread of ten inches. A full-grown cariloou stands nearly five feet at the shoulder, and weighs from four hundred to four hundred and fifty pounds.

The animal is very compact in form, possessed of great speed and endurance, and is a very Ishmaelite in its wandering habits; changing, as the pest of flies draws near, from the low-lying swamps and woods where its principal article of diet, the Cladonia rangiforina, or reindeer lichen, abounds, to the highest mountain fastnesses; then again, when the cold nights give warning of the changing season, descending to the plains.

The rutting season begins early in the month of September: the antlers then have attained their full growth, and the animals engage in fierce conflicts, similar to those indulged in by the moose, and frequently with as tragic an ending. The does bring forth one, and sometimes two fawns in the month of May; and bucks, does, and the young herd together in numbers varying from nine or ten inclividuals to several hundreds.

Horns are common to both sexes, but the horns of the bucks are seldom carried later than the month of December. while the does carry theirs all winter, and use them to defend the fawns against the attacks of the bucks. Both sexes use their hoofs to clear away the snow in searching for mosses on the barrens. In their biennial migrations, they form well-defined tracks or paths, along which the herds travel in Indian file. I have often studied their habits on the extensive caribou barrens between New River and the head of Lake Utopia, in Charlotte County, New Brunswick. These barrens are about sixteen miles in extent, and marked with well-defined trails, over which the aninals were constantly passing and repassing, here and there spending a day where the lichens afforded good living. then away again on their never-ending wanderings.

A friend of mine, who visited Newfoundland on an exploring expedition, informs me that there the caribou holds almost exclusive domain over an unbroken wilderness of nearly thirty thousand square miles, in a country wonderfully adapted to his habits, and bountifully supplied with his favorite food - the reindeer lichen.

The caribou is possessed of much curiosity, and does not readily 


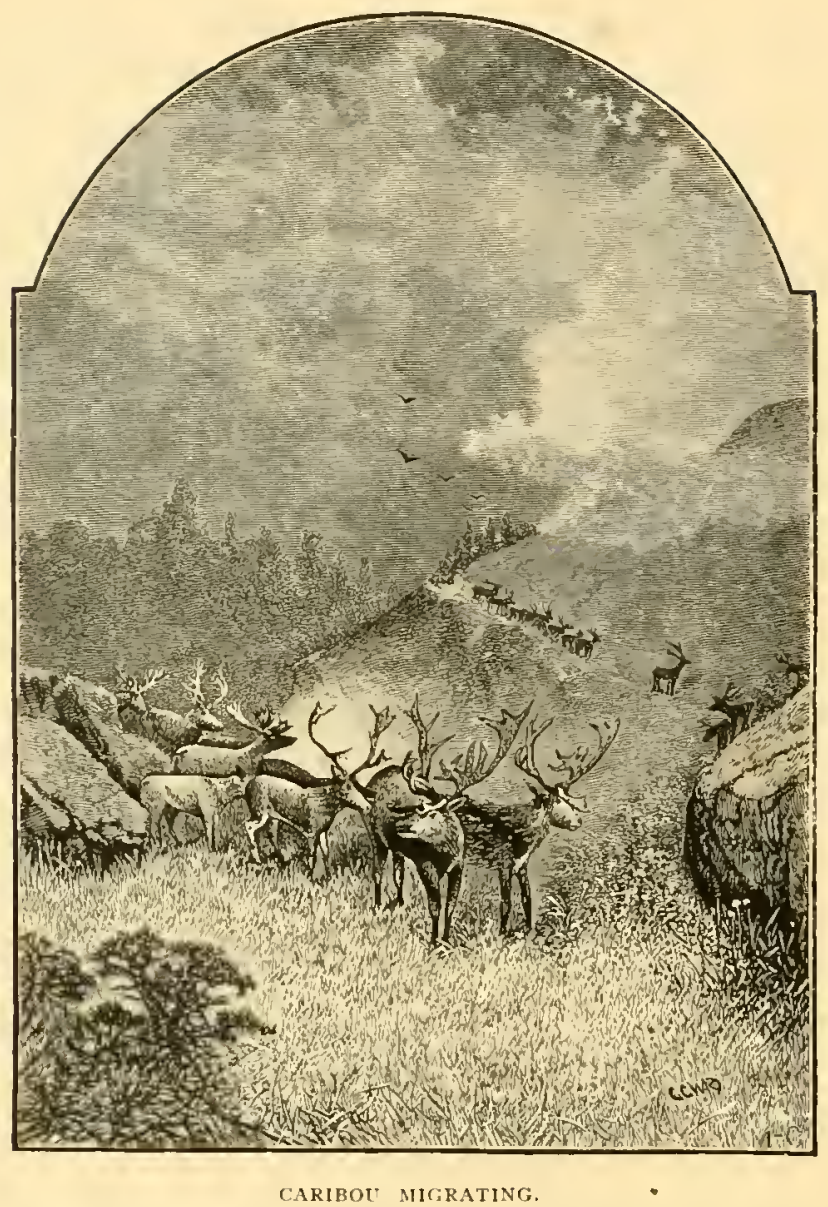

take alarm at what he sees. Where his haunts have been unmolested, he will unconcernedly trot up within range of the rifle. I am inclined to believe that a great deal of this apparent fearlessness is due to defective vision. If this is so, he is compensated by having a marvelous gift of scent, quite equal, if not superior, to that of the moose. And well for the caribou that he is thus gifted. The wolf follows the herds throughout all their wanderings. On the plains or on the hills, where the poor caribou retire to rear their young, he is constantly lurking near, ready to pounce on any straggler, or-if in sufficient numbers - to boldly attack the herd.

The woodland caribou is very swift, and cunning in devices to escape his pursuers. His gait is a long, swinging trot, which he performs with his head erect and scut up; and there is no animal of the 


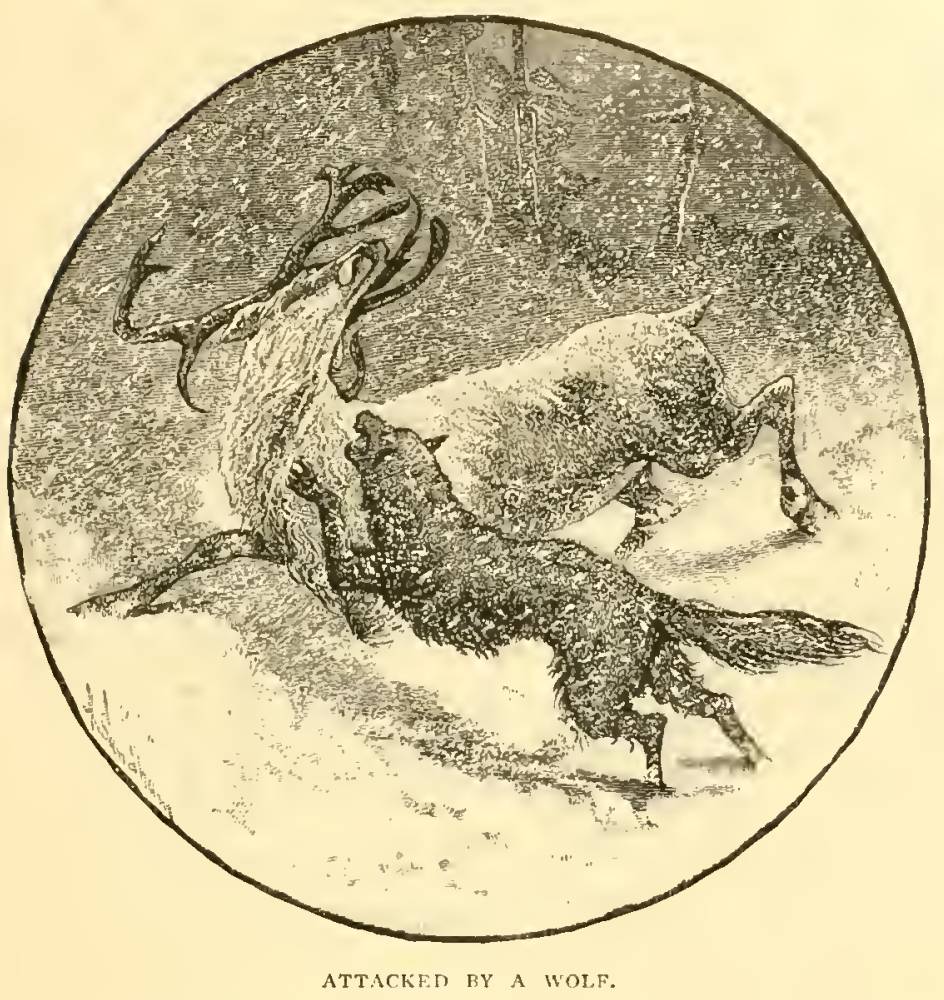

deer tribe that affords better sport or more delicious food when captured. The wandering habits of the caribou make it very uncertain where one will fall in with him, even in his accustomed and wellknown haunts. When once started, the chase is sure to be a long one and its results doubtful; in fact, so much so that an old hunter seldom follows up a retreating herd, but resorts to strategy and tries to head them off, or at once proceeds by the shortest way to some other barren in hopes of finding them there.

It seems to be a mooted question whether the barren-ground caribou (R. Grexulandicus) found inhabiting the Arctic regions and shores of Hudson's Bay is another species, or only a variety of the woodland caribou. The barren-ground caribou is a much smatler animal, and seldom exceeds one hundred and fifty pounds weight, while large specimens of the woodland caribou weigh nearly five hundred pounds.

The caribou is very fond of the water, is a capital swimmer, and in jumping he is more than the equal of any other deer. His advent$14 \mathrm{~A}$ 


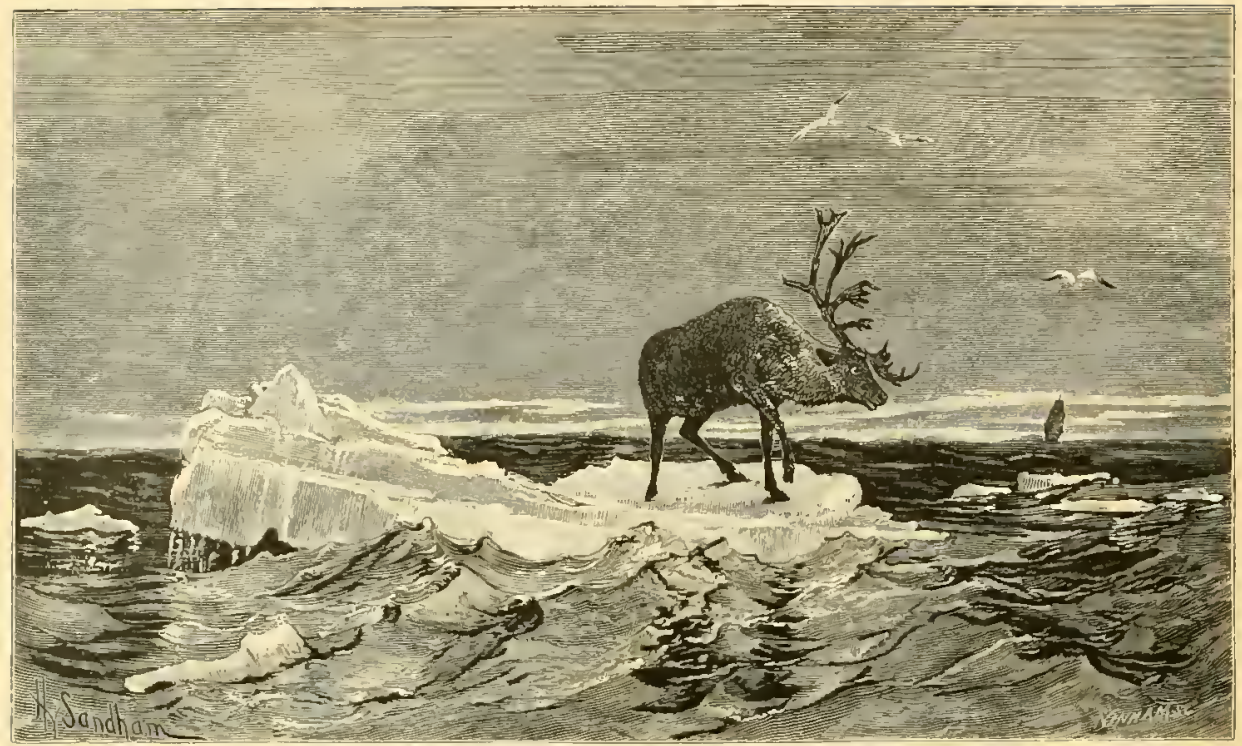

AFLOAT ON A CAKE OF ICE

urous disposition, no doubt, in some degree influences the geographical distribution of the species. In the month of December, 1877 . a caribou was discovered floating out to sea on a cake of ice near Dahousie, on the Restigouche River in New Brunswick, and was captured alive by some men who put off to him in a boat.

It is said that, in very severe seasons, large numbers of caribou cross from Labrador to Newfoundland on the ice. His admirably constructed hoof, with its sharp, shell-like, cutting edges, enables him to cross the icy floes: when traveling in deep snow, its lateral expansion prevents him from sinking.

At one time the Indians were as great adepts at calling the woodland caribou as they are in the present day in deluding the moose. My Indian friend Sebatis is the only lndian 1 know who can imitate the calls of the caribou, and he has for a long time given up this manner of hunting. He informs me that, from being so much hunted and molested in their haunts, the caribou have become much more timid and wary even during the rutting season, and also seem to be much more critical of the sounds produced by the birch-bark call, and consequently very seldom respond thereto.

The quiet gray color of the caribou is well adapted to conceal his presence from the hunter, and it requires an educated eye to pick out his form on the heathy barren, where everything assimilates to him 
in color; and, were it not for occasional effects of light disclosing his position, the hunter might frequently pass within easy shot without seeing him. The Indians are so well aware of this that they always approach a barren with extreme caution, always traveling lown wind, and never disconcerted if game is not sighted at once. Nor is the case improved when one comes to hunt for them in the forest; there, the gray tree-trunks and tangled undergrowth make it cxtremely difficult to see them.

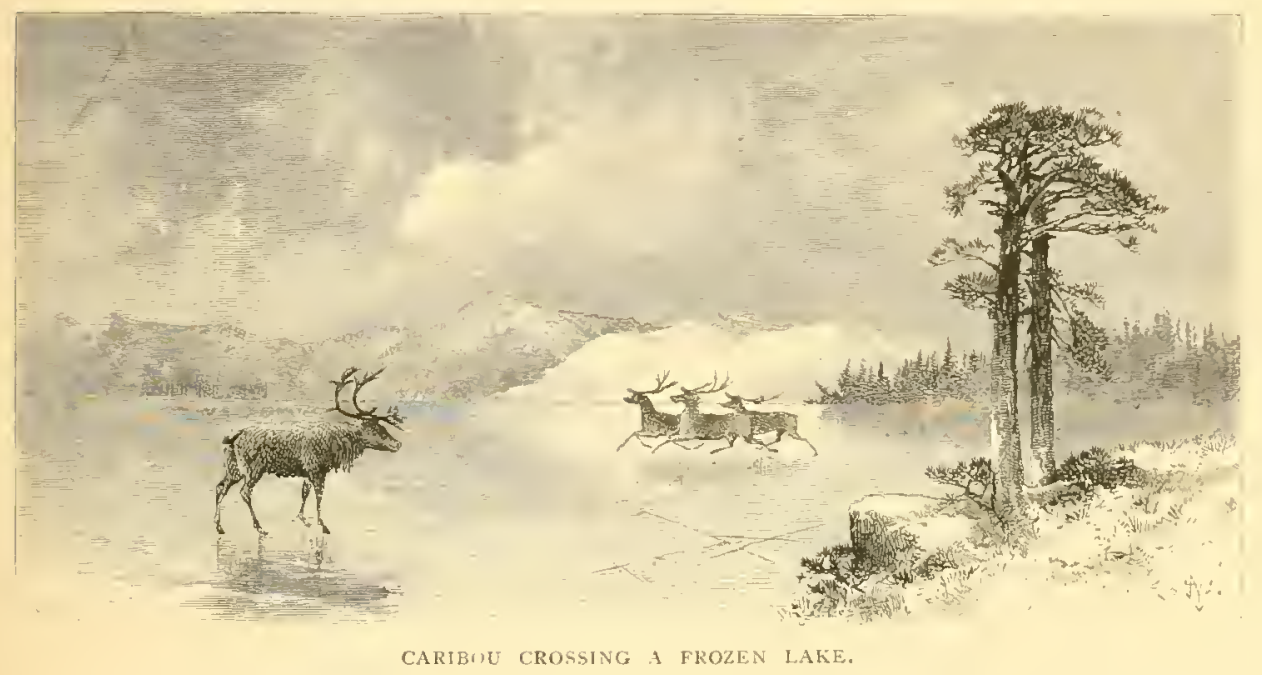

The caribou, whatever may be his need for haste, seldom bounds or gallops, except for a few jumps when first he spies his enemy, but drops into his accustomed trot, which carries him over the ground with great rapidity, and then, no matter how old a hand the hinter may be, nothing but the admirable skill in venery of his Indian guide will afford him the slightest chance of coming up with the game again.

The indifference or curiosity with regard to the noise of fire-arms exhibited by the caribou often stands the hunter in good stead and affords him a chance for a second shot, should his first prove ineffectual; for it is not uncommon for a herd to stand stock-still on hearing the report of a gun, even when one of their number has fallen a victim thereto. The pause is but for an instant, and the hunter must be quick to take advantage of it, or his chance will be gone before he is aware of it; for, recovering quickly from the shock, or alarm, or whatever it may be, the herd will dash off at a rattling pace. 
A caribou, if not mortally wounded, will endeavor to keep up with the herd, and will travel a long way without giving out. If near the sea-coast, the wounded animal seeks it to die, and so is often found by the hunter. In such cases the skill of the Indian again comes in play, and he will follow the track of the wounded animal, readily picking it out from all the others, and seldom failing to run it down. The Indians say that the caribou likes to feed on sea-weed, and goes to the coast in the spring and fall of the year for that purpose.

Once upon a time, not so long ago as when "little birds built their nests in old men's beards," but quite long enough to make one regret the days when caribou were plenty on all the barrens in Charlotte County, New Brunswick, the writer, in company with his Indian friend Sebatis and an old Indian named Tomah, traveled all day in pursuit of a herd of caribou, and after losing much time lying in ambush, behind a big bowlder, were suddenly overtaken by nightfall, which, in the short November days, shuts down without warning.

"How far to camp, Sebatis?" I inquired.

"Well, s'pose daylight, about five miles; but so dark now, you see, makes it good deal further."

"Can you find the camp?"

"Find 'im camp? Sartin: but take good while, so dark, can't see nothin' 't all; tumble down good deal, you see, so many win'falls; then may be get in swamp besides."

Had daylight given us the opportunity of selecting a campingplace, we could not have found a spot better suited to our purpose than the grove of grand old firs and hemlocks that hemmed us in on every side and sheltered us with broad, spreading branches. In front we had a forest lake; on the outskirts of our stronghold a plentiful supply of hard wood stood ready for the axe which Tomah was just releasing from its cover of leather.

The darkness and silence of these old woods were appalling, and as I stood leaning on the old tree against which we had stacked our rifles, I gladly welcomed the quick strokes of 'Tomah's axe, that was already dealing death-blows to the birches and maples.

Sebatis had gone off in search of dry wood to start the fire. I had not heard him return, and was watching a curious object moving about in the gloom with something like the actions of a bear. Pres- 
ently it stopped. and seemed to be squatting on its haunches; then there came a curious, crackling sound, like the crunching of bones; then a faint light, gradually increasing in brightness and volume until the surroundings began to take form, and long shadows crept stealthily past me, and the object which 1 had mistaken for a bear arose upon his legs, and quietly observed:

"Pretty good fire by-em-by, when Tomah fetch dry hard wood;" then tramped off to assist Tomah in carrying in the fire-wood.

"Now, then, best cook supper first," said Sebatis; "then make "im bough bend; too hungry now."

"All right, Sebatis; but how are you groing to boil the water for the tea?"

"Well, sartin, we don't have no kettle; have boil 'im water in birch bark; make kin' of box, you see."

"I don't believe you can do it."

"You don't 'lieve it? Well, by t'unders, I show you pretty quick, when Tomah fetch bark."

And show me he dicl; and better tea 1 never tasted than that brewed by Sebatis in his kettle of birch bark, and served in little cups of the same material, deftly fashioned by Tomah.

The frosts of winter had not y'et sealed the forest lakes, and the night was unusually mild, - so much so, indeed, that Sebatis predicted a sudden change ere long.

During the lulls in the talk, 1 fancied that I heard the notes of a bird, but did not allude to it, as the sound might have been caused by steam escaping from one of the huge logs piled on the fire.

"Just so I told you," remarked Sebatis, as he arose to get a light for his pipe, "big snow-storm comin'."

"Why do you think so, Sebatis?"

"I hear 'im wa-be-pe singin' just now: that always sign storm comin'."

"Is wa-be-pe a bird?"

"Yes; wa-be-pe little bird ; got kin' of small little spots all over."

"Does it sing at night?"

"Always; sings best when moonlight; then he sing once every hour all night; s'pose he sing dark night, sign storm comin'."

"Is he like any of the birds that were about the camp yesterday?" 
"No, he don't 'long here 't all, only summer time; this time year most always gone away warm country somewheres; s'pose he don't go pretty quick, sartin get froze."

"S'pose all han's stop talkin', may be chance hear wa-be-pe again," said Tomah.

Taking up a position far enough away to get rid of the noise made by the fire, I waited patiently for wa-be-pe. After listening intently for a few moments, I heard four inexpressibly mournful, bell-like notes, uttered with marked distinctness, and surprisingly like the first four notes of "Auld Lang Syne." On reflection, I became impressed with the idea that the notes of this bird were exactly like the first notes of the song of the white-throated finch; and after consultation with Sebatis, ! was convinced that 1 had placed the nocturnal songster correctly. At the first dawn of clay, after tightening our belts a hole or two, by way of breakfast, as the Indians facetiously remarked, we started to pick up the trail of the caribou. During the night, several inches of light snow had fallen, and the storm still continued.

"Which way, Sebatis?"

"Try back on big barren; then, s'pose we don't find 'im fresh track, go right camp 'fore snow gets too deep; you see we don'c have no snow-shoes, make it pretty hard walkin' by-em-by."

The storm was increasing every moment, and the light snow drifting rapidly before the rising wind, as, tramping in lnclian file, we approached the confines of the big barren. The drift was so heavy on the barren that it was hard work to make headway against it, and I had just turned to regain my wind when I heard Tomah ejaculate in Indian:

"Megahlip! Chin-e-ga-bo!" (Caribou-be careful.)

The words were hardly spoken, when down the wind came a herd of caribou, trotting at a terrinc pace, with head and scut up, and sending the snow in clouds on every side. I tried to get a shot, but was not quick enough. "Bang!" to right of me - "Bang!" to left of me, from the smooth-bores of Sebatis and Tomah, and all is smoke and drifting snow, out of which I get a glimpse of a head or horns, then the full figure of a fast trotting caribou, and last a noble buck wildly plunging in the flying poudre-a victim to the fire of the Indians.

"Come, Tomah, be quick! help butcher caribou. No time lose 


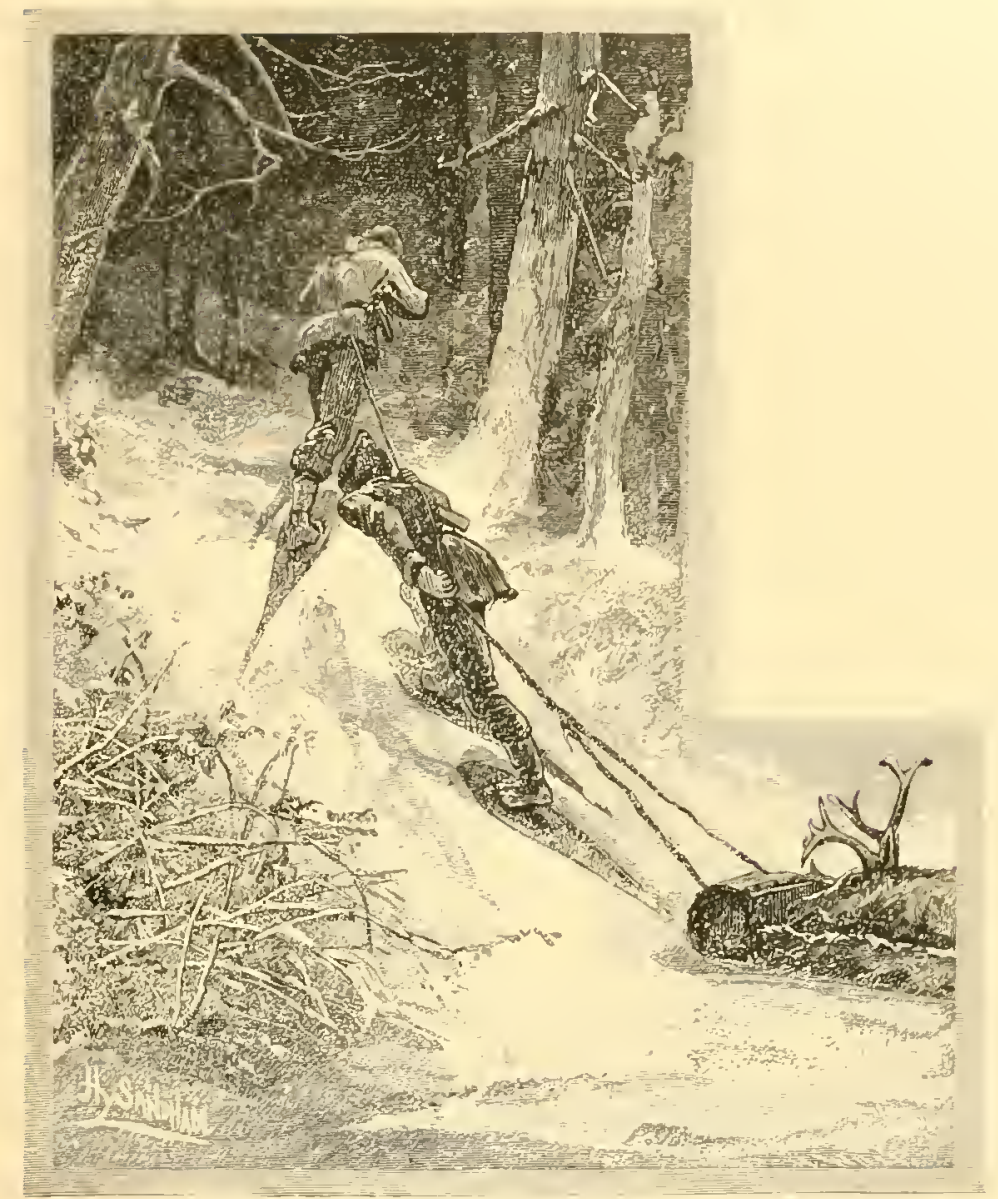

BRINGING IN THE CARIBUU.

gettin' camp; by-em-by pretty hard chance get there, storm so heary, you see," said Sebatis, as he stripped off the hide of the caribou.

In a few moments, the renison intended for the camp was cut, apportioned into loads, and the rest of the animal securely cached, to be brought in when wanted. Then we hastened to get off the barren and into the shelter of the wools, where we could draw a free breath unoppressed by the terrible drift.

As the storm promised to be very heary, we lost no time in gaining the protection of our camp.

"Now then," said Sebatis, as he dropped his load on arriving at camp, "all han's get fire-wood ready, stan' big snow-storms; by t'unders, pretty lucky we get 'im that carihou." 
"Who kill "im that caribou?" inquired Tomah: " two shots fired."

I had been dreading this for some time, but Sebatis cleverly evaded the question, and prevented the endless discussion sure to follow, by facetiously replying :

"Well, l guess bullet kill "in, sartin."

Fortunately, in the hurry of skinning the caribou and cutting up the venison, they either forgot, or had not time to examine whether there was more than one bullet-hole in the skin: and as the latter, probably, would not be recovered until we were on the home-trail, I flattered myself that the discussion would not be revived. However, in this I was mistaken, as will be seen in the sequel.

In appearance, no two men could differ more widely than my two henchmen. Sebatis stood six feet and two inches in his moccasins, had clear-cut features, and was possessed of infinite patience and good humor. Under severe provocation, his temper was apt to be short, but it was over quickly, and he never sulked. Tomah was very short in stature, bow-legged, and had a countenance terrible to look upon, the fierce expression of his restless eyes indicating unmistakably his savage ancestry; and yet, withal, he was not an ill-tempered man; and the deep, tragic tones in which he spoke, even when saying the most commonplace things, made some of his utterances irresistibly comical. His friendship for Sebatis was of long standing, and they got on very well together, except when a dispute arose about the shooting of a moose or caribou. At such times my ingenuity was taxed to prevent a fight. Soon their united efforts as axe-men, with my aid in carrying in, accumulated such a goodly pile of hard wood as enabled us to laugh at the howling storm.

"Sartin I think, no chance hunt 'im caribou to-morrow; always bad snow-shoein' when snow so light," said Sebatis, as he shook off the snow from his clothes and prepared to cook our dinner of fat caribou steaks.

"Sebatis, where are our little friends, the birds? I haven't seen one since our return to camp."

"You see, hicle somewhere when storm so heavy. S'pose sunshine, you see 'im comin': ah-mon-a-tuk (cross-bill), kich-e-ge-gelas (chickadee), ump-kanusis (moose-bird), an'ki-ha-neas(red-poll linnet)."

Early next morning Tomah was absent, and I asked Sebatis where he was. 
"Gone away somewhere 'bout daylight," he replied: "try find im sign caribou, may be."

At noon, Tomah marched into camp, bringing with him, to my horror, the head and skin of the caribou slain the previous day.

"Who kill "im this caribou? Only one ball-hole in skin!" he said, defiantly, and in his leepest bass, as he deposited his spoils on the snow.

"I fire right on his head," said Sebatis, springing to his feet.

" Well, you miss him, sartin. Bullet strike 'im on ribs jus' where J fire," rejoined Tomah.

"Sartin, you tell "im big lie. I don't miss "im 't all," returned Sebatis, fiercely, as he unrolled the skin to examine for himself. H is search disclosed but one bullet-hole, and that was on the side, just as Tomah stated.

After carefully examining the skin, I turned my attention to the head, and was about to give up in despair when I observed that one of the tines had been completely carried away close to the main stem.

"Here's where your ball struck," I said to Sebatis, pointing out the recent fracture on the horn.

"Sartin, that's true," said Sebatis. "I know l didn't miss in 't all."

"Always Sebatis come out pretty well. S'pose nobody else fire, sartin no caribou-steak breakfast this mornin'," growled Tomah.

In the afternoon, the sun shone out bright and warm, and our pert little friends, the birds, shyly renewed our acquaintance. The tameness of these forest birds is ever a source of delight to me. It is quite common to see cross-bills, pine-finches, chickadees, and redpolls all picking up crumbs together at one's feet; and often after a few days' acquaintance they become so familiar that they will accept food from the hand,-bread-crumbs, bits of raw meat; and even salt pork is readily accepted. In fact, nothing seems to come amiss to the little beauties, and they evidently enjoy the change from the dry cones and buds which form the staple of their winter diet.

lt seems ungrateful to single out any one bird where all are so tame, but 1 think that I must give the palm in this respect to my favorite-little black-cap. The naturalists give this little bircl a dreadful character, and say of him that he smashes in the skulls of 
other little birds and eats their brains. I shall always consider it a vile slander, Audubon and all the rest of them to the contrary notwithstanding. These charming little birds are seldom seen except in the depths of the forests; at rare intervals, they come out to the clearings, but their homes are in the forest. In order to give an idea of the tameness of these birds, I may mention that at this moment, as 1 write, a cedar-bird is begging to be taken on my finger and held up to my face so that he may indulge in his pet occupation of preening my mustache, and a red-poll linnet is industriously strewing the floor with my pencils and paper, and if scolded flies away uttering his plaintive call, "Sweet-Willie!"
At night, as we sat over the camp-fire smok-

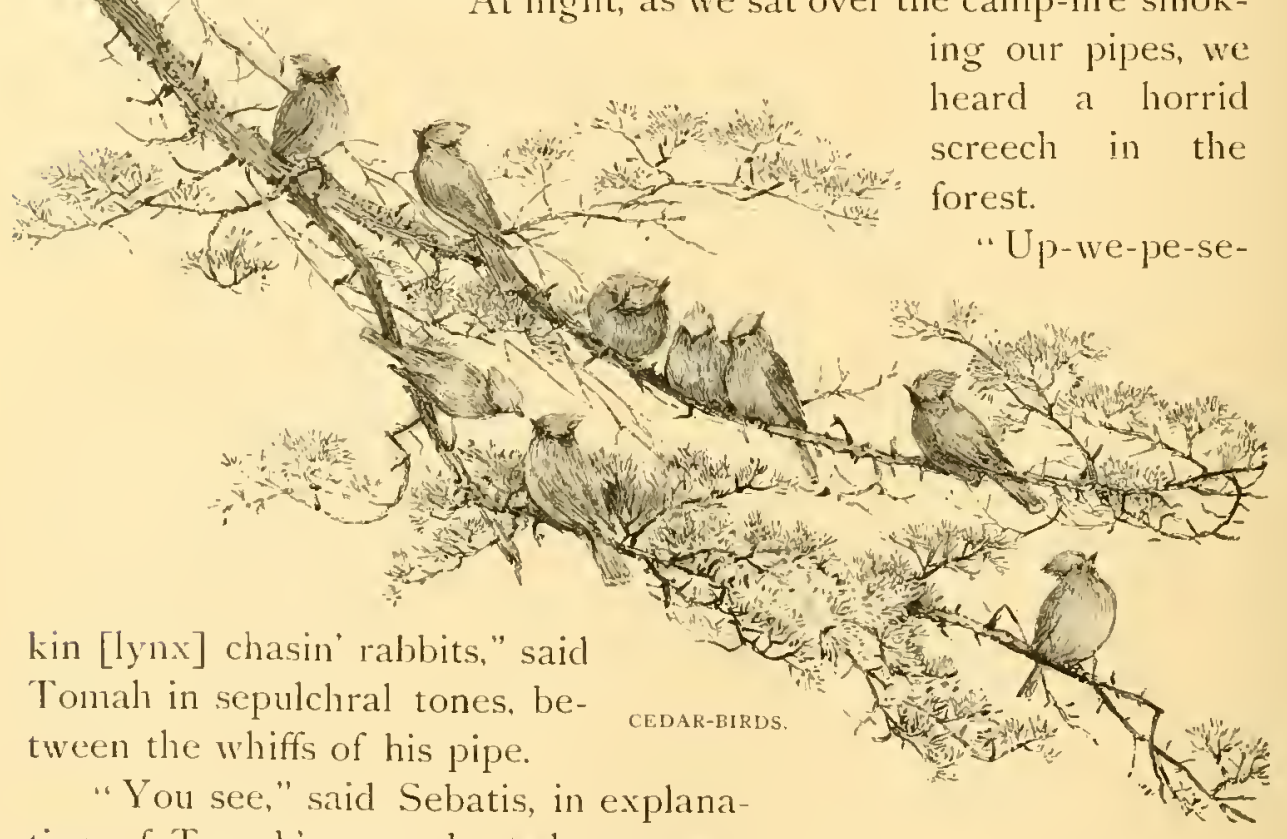
tion of Tomah"s remark, "when up-we-

pe-se-kin make noise like that, scar' 'im rabbit so bad he jump right out sight in deep snow, then you see up-we-pe-se-kin dig him out an' have pretty good supper."

Just as I was turning out next morning, Sebatis walked into camp, and saicl:

"Sartin, caribou very hungry this mornin'; 1 find plenty places where he eat 'im off old men's beards, close up."

This is the long, trailing moss which hangs from the trees and bushes, and is a favorite food of the caribou. 
"What kind of snow-shoeing to-day, Sebatis?"

"Just right; sun pack "im down snow good deal; very goud clance snow-shoein' now."

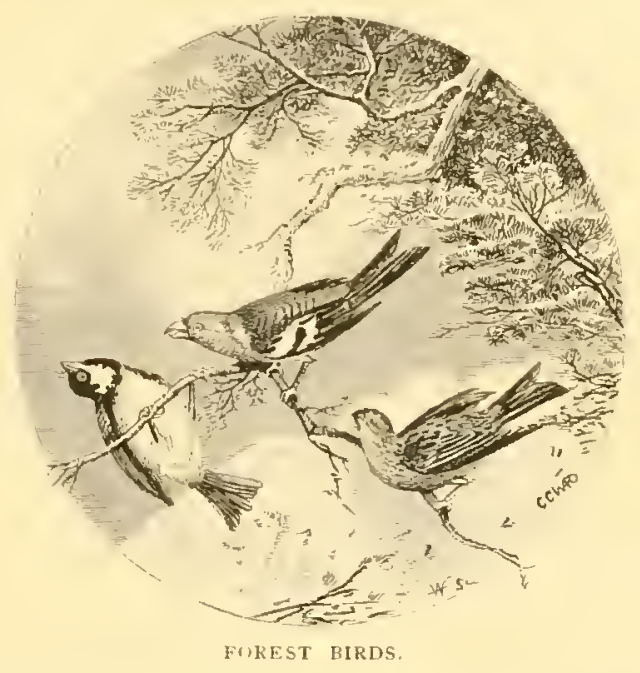

Tomah had breakfast ready, and in a few moments moccasins and snow-shoes were the order of the day.

"Which way, Sebatis?"

"Try "im big barren again."

"Sartin, best go little barren first," said Tomah: "s'pose we don't find 'im caribou, then try "im big barren."

"May be Tomah right," said Sebatis; "little barren nearest,only 'bout two miles, - an' very good ground to fin' caribou."

Just enough snow had fallen to make good snow-shoeing; in fact, we could have got on without snow-shoes but for the drifts and swampy parts of the barrens, over which the broad snow-shoes bore us safely. Fortunately for our comfort, the high wind that prevailed prevented the snow lodging in the spreading boughs of the coniferous trees, and we escaped the smothering often experienced from avalanches of snow immediately after a snow-storm. These avalanches are one of the most disagreeable things encountered in the forest in winter. Sometimes, as the hunter tries to force his way under the pendent boughs of a large fir-tree, the accumulated snow will be discharged upon his head, getting down his neck if his hood is not up, wetting the locks and barrels of his gun, and piling up on 
his snow-shoes in such a manner as to hold him prisoner for the time; and often, in trying to work clear, he gets his snow-shoes tangled and takes a header into the snow, and his misery is complete. Moreover, the chances are ten to one that, while he is helplessly floundering in the snow, he hears the sharp crack of his companion's rifle, who has stolen a march on him and is up with the game; and then good-bye to any sport that day, for even if he could get his gun dry and serviceable again, his nerves are so unstrung that he could not hit the sicle of a house, much less the swift caribou.

On our way to the barren we saw several fresh tracks of caribou, but had not discovered their beds, as the Indians term the depressions in the snow made by the caribou when lying down to rest. After inspecting indications of that kind, the Indian can form a correct opinion of the time elapsed since the beds were occupied, and is guided thereby in his decision as to whether it is wise to follow up the tracks leading therefrom.

Silent as mutes, we tramped along in Indian file; but if the Indians did not use their tongues, their eyes were not idle, and the slightest caribou sign was instantly discovered and examined. We had nearly reached the barren without finding any fresh tracks, and I was getting a little impatient, and sorry that we had not gone to the big barren, as first suggested by Sebatis, as it was in that direction he saw the places where the caribou had cropped off the "old men's beards."

"Little barren handy now," said Sebatis, with his usual abruptness.

"Where is Tomah?" I inquired, having just discovered the absence of that worthy.

"Where's Tomah, sure enough?" echoed Sebatis. "I don't miss him myself only just now."

He had vanished like a "spirit of eld," and as where he had gone, or on what errand, was past finding out, we made our way quietly to the edge of the barren without him.

Long and earnestly Sebatis scanned the barren with his searching gaze, then ventured out a few paces, stopped suddenly, and beckoned me to him.

"Hist! don't make noise," he whispered. "Caribou somewhere on this barren; you see 'im track just 'longside big rock, then little 
ways 'head you see im tracks go everywheres; must be nine, may be ten caribou go that way."

"Are they fresh tracks?"

"We look by-em-by; find out which way wind first. By t'unders, we got wrong end barren."

"What do you mean?"

"Wind blow straight down barren: s'pose we try hunt 'im caribou, sartin he smell us."

"Well, what had we better do?"

"Best hide "im somewheres on barren."

"There 's a clump of firs nearly in the middle of the barren; I should think that a grood place."

"We go try 'im. You see caribou movin' all time; may be by-em-by comin' back on his tracks, then very good chance."

The barren was about three miles long and over one mile wide. sprinkled with groups of fir-trees, and the usual supply of alders, bowlders, and old dead tree-trunks. Lurking about in our place of concealment was tedious in the extreme, and I was about to beguile the time with a smoke, but I remembered in time the terrible rating old Tomah got from Sebatis when smoking, for we were in ambush behind the big bowlder.

Just then we heard the boom of a gun.

"By t'unders, that old Tomah. sartin; so cunnin', you see, just like fox; he find out wind wrong way, then he go round on woods an' come out other end barren."

"Do you think he has turned the caribou back this way?"

"Sartin, that just reason he go round woods; so cunnin', you see, that old Tomal."

We now moved out of our shelter a little so as to command a better view of the barren.

"Do you see any caribou, Sebatis?"

"No, don't see nothin' 't all."

I was looking intently, and fancied that I saw the form of a caribou disappearing behind a bunch of alders. Sebatis saw him at the same moment, and several others that I failed to detect.

"By t'unders!" he whispered, "you see "im. one, two, five caribou, just goin' behin' bushes up there; good chance now, s'pose don't make "im noise." 


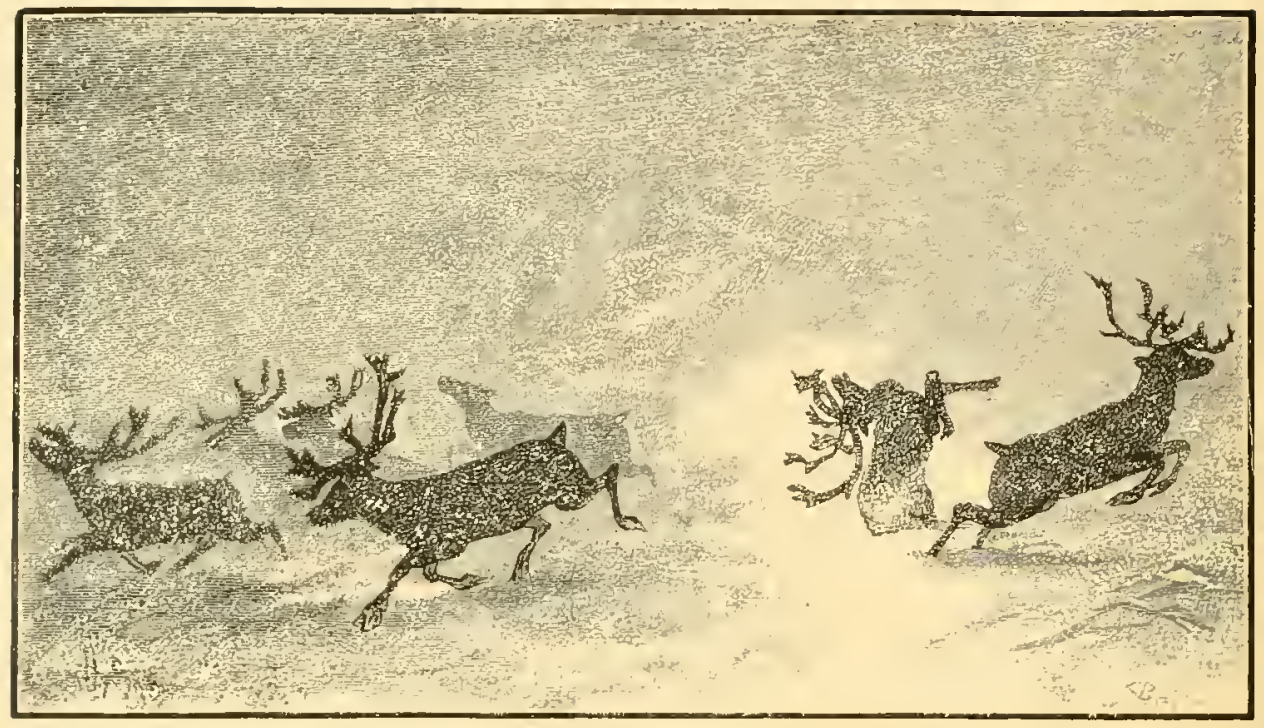

A GOOD CHANCE.

The grood chance was so long in coming that $I$ was well-nigh in despair. Sebatis had crossed to another clump of bushes, and, being rid of him, I was just about to resort to my pipe, when 1 heard the peculiar and unmistakable castanet sound caused by the split hoof of the caribou striking together as he recovered in his stride. and looking out on the barren I saw five caribou, trotting full speed, almost abreast of me, and not over forty yards clistant. They raised such clouds of snow that I could only see their heads and occasionally their shoulders, but as it was my only chance I fired at the second caribou in the herd, and unfortunately only wounded him. He tried to keep up with the herd, but they soon distanced him, and I was hurrying on in pursuit, when "bang!" goes Sebatis's gun from behind some bushes, and down groes my caribou.

"I wounded that caribou, Sebatis; there were four others ahead of him."

"Sartin that's too bad. I don't see 'im 't all, only this one. You see I been look other side bushes, and when I hear gun I run this way; then I see caribou kin' of limpin', you see, an' I chink may be get away, so best shoot 'im more."

"Who kill "im that caribou? Two guns fire, on'y one caribou dead," said a voice over my shoulder, in tones that could be none other than those of Tomah. 
"Two bullets kill "im that caribou sartin this tine," said Sebatis, pointing to two bullet-holes in the boly of the poor caribou.

"Where have you been, Tomah? We thought you were lost."

"No, not lost. When I fin' out wind wrong way, then I go in woods an' cone out head barren ; turn 'in caribou."

"Did you get a shot at them?"

"Sartin, I kill "in caribou."

"How many did you see?"

"Bout tirteen. Five come this way, rest gone away somewhere, may be big barren. Sartin plenty caribou big barren to-morrow."

" Why do you say to-morrow?"

"'Cause caribou all travelin' to-day. I see 'im tracks go everywhere, an' plenty sign bite 'in moss, besides."

We cachat the caribou killed by Sebatis and 1, then tramped to the head of the barren and performed a like office for the one killed by Tomah, - a two-year-old buck, - then to camp, as it was too late in the day to try the big barren.

"Now," said Sebatis, after dinner and the invariable pipes, "Tomah an' me go hunt 'im wood an' bark, make 'im tobaugan, then we haul 'im caribou camp. Keep 'im safe, you see."

During the night there was a fall of snow, which made the snowshoeing heavy. However, we determined to try the big barren; and a weary day we had of it, tramping over the soft snow, which accumulated on the front of the snow-shoe and required quite an effort to throw it off. All traces of the old tracks were obliterated, and we did not see a fresh track that day, although we searched the greater part of the barren, being careful to disturb the snow as little as possible, as a show-shoe trail is almost certain to frighten off a herd of caribou.

After patient watching and manifold observations obtained by climbing trees, the Indians at length, in despair, gave up hunting and took to their pipes. Although as much disappointed as they were, I well knew that it would be futile to urge them on to hunt until they recovered their spirits. Like two graven images, they sat puffing away at their pipes, and to all appearance might have continued so doing until the crack of doom, but for an opportune crash, as of breaking branches, followed by a resounding fall that came from the forest, a little to the right of our position; and although 
they were well aware of the cause of the noise, - a lodged tree suddenly released by the branches giving way and letting it fall to the ground, - it had the effect of waking them up and loosening their tongues.

"Sundown come pretty quick now ; best go camp," said Sebatis.

"Best gro camp," echoed Tomah.

And go to camp we did, in double-quick time, arriving just as darkness was closing in.

There were several changes of weather during the night, first a drizzling rain, then a sharp frost, followed by more snow.

"lietter luck to-day," said Sebatis. "I dreamin' last night, see "im plenty caribou."

"John very good han' dreamin'; I like see 'im fin' caribou first. then I "lieve him," said Tomah.

"Why does Tomah call you John?" I asked Sebatis.

"Well, you see, I got t'ree-four-names, John Baptist Joseph, that's my name."

"I)reamin' so hard he forgot his name," said Tomah; "he got nother name 'sides, Saint John Baptist Joseph, that's his name."

"Sartin, that 's true," said Sebatis; "now, I "member, I tell you all 'bout it-used to be my name just same Tomah tell; well, you see, that pretty long name, then make "im shorter, call 'im Saint Baptist; then make 'im shorter 'gain, call 'im Sebatis; s'pose, make 'im any shorter, by-em-by, name all gone."

"Then, your surname-I mean your family name-is Joseph?"

"Sartin, my father, all my brothers, got same name, Joseph."

"Now, Sebatis got fix "im his name 'gain, s'pose he show us where find 'im caribou," said Tomah.

"Sartin, snow most over, we go big barren 'gain."

The snow was greatly in our favor, as just enough had fallen to enable us to walk noiselessly on the crust.

$A$ very strange sensation is often experienced by the hunter as he walks unconcernedly on his way, after the formation of a crust ; at first he hears a peculiar creaking sound, and fancies that the snow is moving under him, then the creaking becomes louder, and is accompanied by a muffled, rumbling noise, and suddenly the snow under and around him sinks, and he fears that he is about to fall into an abyss. The snow in reality seldom settles over one foot or 
eighteen inches, and no matter how familiar one may be with it, every fresh experience excites the same apprehension.

I had just been let down in that way, when my attention was attracted by Sebatis, and he beckoned me to where he and Tomah were examining something.

"Eight caribou all sleep here last night," he said, pointing to a number of depressions in the snow.

"How long since they started, Sebatis?"

"Start only little while, you see tracks so fresh. Nlways good time hunt 'im when first started, 'cause bite 'im moss an' feedin', then he don't go fast 't all."

"Best take "im off snow-shoes an' walk in caribou tracks," said Tomah.

"Sartin that best, then don't make no noise," said Sebatis.

This mode of traveling is anything but agreeable, but as the snow was not very deep, it was greatly preferable to what I have often experienced on other occasions, when one would sink half-way to the knees at every step, and woe betide him if he made a false step!

"Caribou stop here feedin' little while," saicl Sebatis, pointing to some newly cropped "old men's beard."

"Caribou go two ways," said Tomah, who was a little in advance.

The herd had separated, three caribou going toward the big barren and five off in another direction. Is it promised a better chance for game, I imitated the tactics of the caribou, and divided our party, taking Sebatis with me on the track of the five, and sending Tomah off after the others.

Plodding along in the foot-holes of the caribou was very legtiring, but Sebatis kept on at a trot until brought to a stand by some very fresh sign.

"Caribou bite 'im moss here only 'bout t'ree minutes ago; must be handy somewhere; best put 'im on snow-shoes again, may be have run pretty quick by-em-by."

After putting on his snow-shoes, Sebatis struck out in a direction nearly parallel to the caribou trail, and we set off at a very much quicker gait.

We were just descending a slight declivity, when Sebatis waved his hand to me, exclaiming at the same time: 


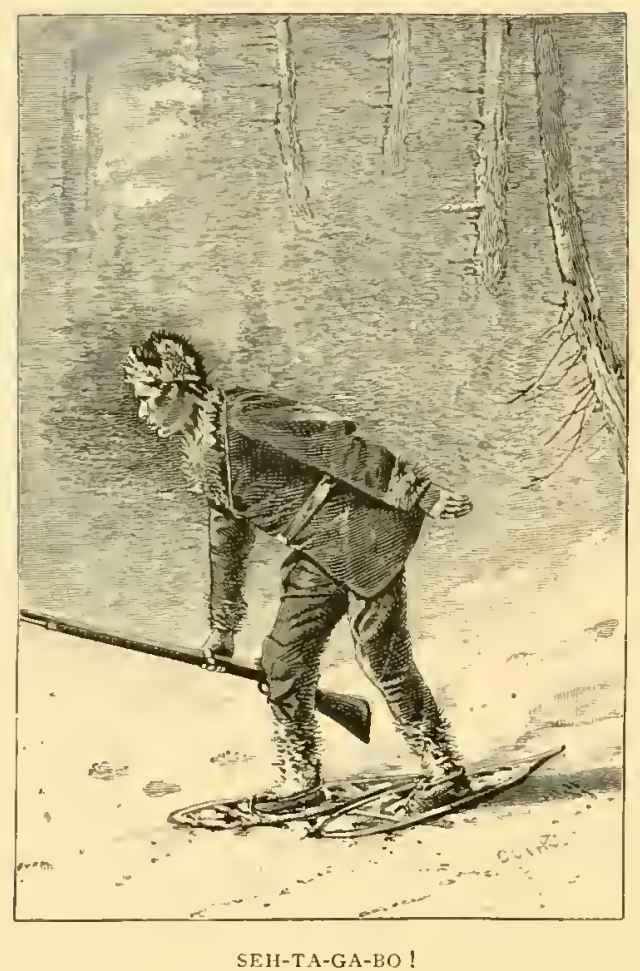

"Seh-ta-ga-bo!" (Keep back.)

At the word 1 dropped in my tracks and awaited further orders. Twice he raised his gun as if to fire, then lowered the muzzle and beckoned me to him.

"What is it all about? Do you see the caribou?" I whispered.

"Sartin, see 'im all five walkin' in woods just little ways 'head. You look same way I point, by-em-by you see "im."

We had just entered a glade of fir-trees, and between the treetrunks I caught a glimpse of what I supposed to be a lake, but did not discover any caribou.

"Hist! there goes caribou, there goes nother one-two-t'ree more : you see 'im? Quick, fire!"

Bang! goes my rifle at an indistinct form moving past the treetrunks some thirty yards distant.

"You kill 'im, sartin," Sebatis whispered. "I see 'im give big jump, then he don't move 't all.

"Are the others gone?" 
"No, scared pretty bad; stan' listenin' somewheres. By t'unders! - look, you see "im caribou move on small bushes right on lakefire!"

"Blaze away, Sebatis. I clon't see them, and they will be off sure if you wait for me."

Bang! goes his smooth-bore with a roar that made me as deaf as an adder for the moment.

"Did you kill him?"

"May be so. Not sure, you see, so much smoke."

We hastened to the spot and found my caribou-a large buck -lying dead in his tracks. A little further on, Sebatis found a bloody trail leading down to the lake, and about one hundred yards from the shore we saw the other caribou - a fine doe-vainly struggling to regain her feet on our approach.

At the sight, I vowed that I would break my gun and never hunt again, until

"Here, Sebatis, take my rifle and finish your work quickly:"

"How far is it to the camp?"

"Little mor'n four miles. I go get tobaugan, an' bring some dinner. Spose you stop here?"

"Yes. Be as quick as you can."

"Sartin, I go pretty quick. You see snowin' again. By-em-by" heavy storm, may be."

True to his promise, Sebatis returned inside of a couple of hours. With appetites born of the woods, we dispatched our lunch. Then to work to get our game to camp. The angry gusts of wind soughing through the lofty branches of the fir-trees, and driving the fastfalling snow into clouds of impalpable powder, warned us to hasten our packing.

"Ready, now, no time spare. By-em-by storm so heavy, hard chance find "im camp," said Sebatis. He had fastened one end of a serviceable rope of withes to the tobaugan, passed part of it over his shoulder and gave me the other end to pass over mine, and away we tramped.

These sudden winter storms possess the magic power of investing the hunter with an indefinable terror. In a very short time all landniarks are obliterated and the air filled with a blinding powder. Now and then the snow settles under him with a crash, and he feels 
as if there was nothing real or substantial around him. The bewildering, drifting powder is everywhere, and he is blinded and buffeted by it in such a manner as calls for the instant exertion of all his courage to carry him safely through.

"By t'unders! Never so glad get camp all my life. So tired, you see storm so lieavy," said Sebatis, as we rested before the camp-fire after our fearful four-mile tramp from the lake.

The click of approaching snow-shoes announced the return of Tomah.

"Who kill "im that cari

Just then he saw that there were two dead caribou, and, without another syllable, he shook the snow from his clothes and sat down by the fire.

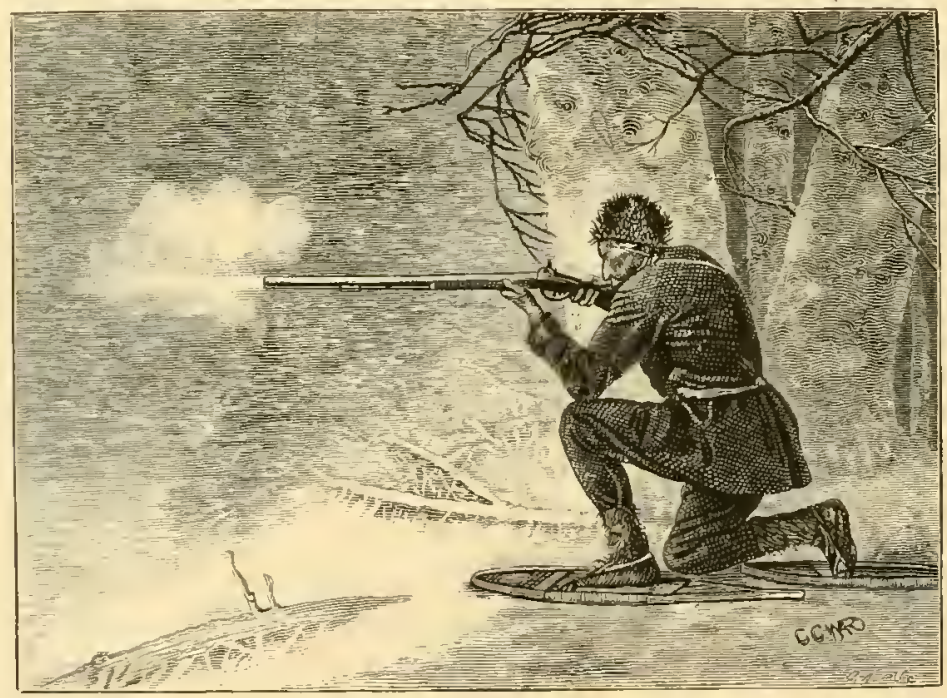

A SHOT FROM TOMAH, 


\title{
DEER-HUNTING ON THE AU SABLE.
}

\author{
BY II. MACKAY IAFFIN.
}

$A^{N}$

invitation to a few weeks deer-shooting in the wilds of Michigan was not to be foregone. There had been occasional rumors heard in the East of the winter sports of the Michigan backwoods; rumors that had lost none of their attractiveness by their journey from the IV est, and which served to make the opportunity, when it dict arrive, wholly irresistible. I was to join a party of gentlemen, who for several years have hunted upon the Au Sable River in northern Michigan, upon one of their annual trips; and we were all to meet upon an appointed day at Bay City, which is at the head, if head it can be called, of Saginaw Bay. Our route thence was by steamer to Tawas, and from Tawas by teams to the huntinggrounds in the Michigan backwoods.

The steam-boat wharf at Bay (ity was full of bustle and activity. There were piles of bagrgage and numbers of anxious owners. Conspicuous among the parcels were the gun-cases, some made of new pig leather or water-proofing, and eviclently out for the first time, and others of weatherworn aspect, telling of many a campaign and of much serious usage. Every object upon the wharf and about the freight office to which a dog could be tied had a clog tied to it. and all these dogs were rearing, and phunging, and tugging at their chains, and griving vent to occasional sharp yells, in a conctition of great excitement - a feeling more or less shared by the numerous higher animals who were present. The crowd was composed of hunting parties bound for the backwoods by way of the various settlements on the Lake Huron side of the Michigan peninsula : of lumbermen going to the camps; of farmers going home, and of the usual 
variety of more or less accentuated Western types. There was a good deal of confusion about it, and among it all our party met, and, after a few moments of spasmodic and pleasant welcome and the interchange of hearty greetings, we got on board the steamer. Our dogs, twelve in number, were safely bestowed between decks, and as remotely from the dogs of other people as possible: all our baggage was put away, nothing missing or forgotten, and we moved off from the wharf with that sense of entire comfort that is incident only to well-ordered and properly premeditated excursions.

We had a delightful run up Saginaw Bay on a beautiful October evening, on which the sun went down with one of those gorgeous displays of color which England's most eminent art critic has told us are seen but very seldom in a life-time. It was an impressive and singularly beautiful spectacle, but one of which our West is prodigal, and which is not consistent with insular conditions of fog and moisture. A note of admiration sounded within the captain's hearing had the effect of eliciting his practical valuation of it. "Humph!" he said, "rain like blazes all day to-morrow." It was a matter of common regret that the barometric impressions of this worthy navigator were invariably correct. We made some stoppages at points upon the shore, where seemingly unaccountable wharves projected from the outskirts of desolation. At these we took off people who might have been fugitives from some new Siberia, and debarked people who might have been exiles going thither. But at half-past eight o'clock we reached East Tawas, where, as the boat came alongside, we were cheerily hailed out of the darkness by a mighty hunter of the wilderness named Curtis, who had come down with his stout team to meet us and help to carry our multifarious traps. We disembarked amid a dreadful howling of the dogs, who charged about in every direction, dragging their masters, in the darkness, over all manner of calamitous obstructions, regardless of kicks, cuffs, or vigorous exhortations. In half an hour we were comfortably ensconced in an inn with an enormous landlord, whose mighty girth shook with unctuous premonitions of an excellent supper. He produced half of a deer slain that very day, and gave us an earnest of our coming sport in the shape of a vast quantity of broiled venison, all of which we dutifully ate.

Our captain - for we had a captain, as every well-constituted 


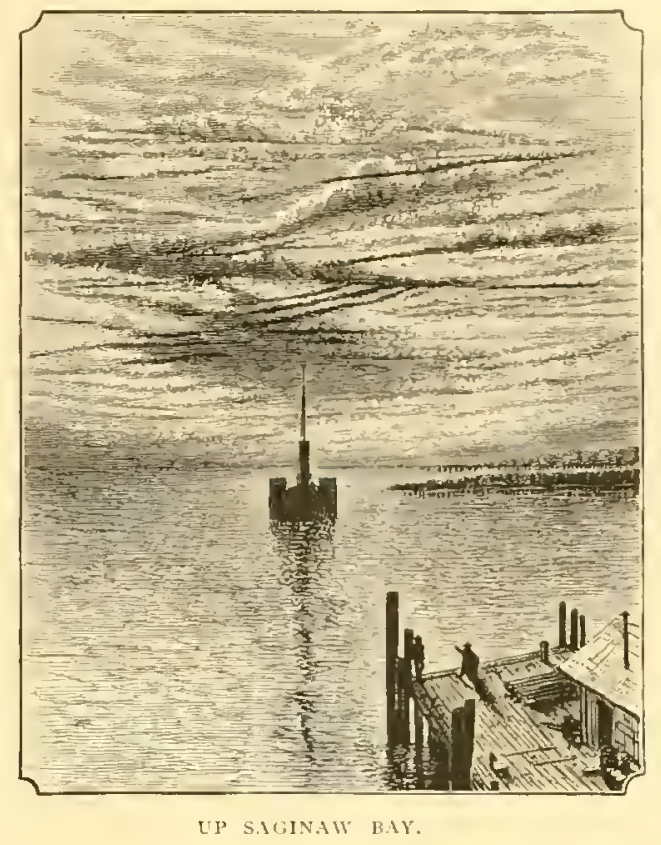

hunting-party should - was Mr. John Erwin, of Cleveland, a gentleman at whose door lies the death of a grievous quantity of game of all kinds, and whose seventy years seem to have imparted vigor and activity to a yet stalwart and symmetrical frame. Hale, hearty, capable of enduring all manner of fatigue, unerring with his rifle, full of the craft of the woods and an inexhaustible fund of kindly humor, he was the soul of our party. We were under his orders the next day, and so remained until our hunt was over. He was implicitly obeyed; none of his orders were unpleasant; they simply implied the necessary discipline of the party. We left Tawas in the early morning. We had two wagons, one of which carried nine of us; the other, Curtis's, had the heavier baggage in it, and was accompanied by the remaining three on foot. They had the option of getting into the wagon by turns, if tired; but they were all good walkers. We had twenty-five miles to make to "Thompson's," where we were to halt for the night, and on the following day proceed leisurely to Camp Erwin, six miles further. As we left Tawas it rained, according to our nautical prophet of the previous evening, and it continued to rain during the entire day. There is nothing particularly exhilarating in driving in a drenching rain, even when it is done under particularly 
favorable auspices. There was some novelty for one, to be sure, in the great wastes of scrub-oak, the groups of stout Norway pines, the white birch, the maples, the spruce-pines, and the beeches, glistening in the impenetrable jungles of tangled undergrowth, and in the iteration and reiteration of landscapes with no landmark or peculiarity whereby one might distinguish one from the other. All this was in one sense a novely, inasmuch as one might never have seen anything like it before; but the enjoyment of it, were it really susceptible of being enjoyed, was marred by the steadiness with which the cold rain beat in our faces ; extinguishing cigars and making pipes a doubtful blessing; drenching everything exposed to it, and imparting that peculiar chill to which mind and body are alike liable under such conditions. One of our party, a veritable Mark Tapley, who was sure to "come out strong" under the most discouraging conditions, whistled fugitive airs in a resolute way ; but they got damp and degenerated into funereal measures, suggesting that possibly the Dead March in "Saul" was originally conceived in a spirit of inferior vivacity or sprightly insincerity, and becoming wet had been recognized as a thing of merit, and had therefore been permanently saturated for use on occasions of public grief. Another dispiriting element was the road, of which a large part was what is known as "corduroy," from some obscure resemblance, which does not exist, between its structure and a certain well-known fabric affected by" horsey" gentlemen. The jolting we got over this was painful to a degree which it is disagreeable to recall. It jarred every bone in one's body, and embittered the whole aspect of life. It alternated with a series of diabolical mud-holes, into which we dived, and rocked, and swayed, and splashed interminably. Bunyan's Slougl of Despond is all very well in its way, but the possibilities of figurative description of that kind are as a closed book to one who has never ridden on a corduroy road in a wagon with inferior springs. At last, we emerged on a higher plateau of sand, and left the marsh behind us for goocl. The rain had become a milder and tolerable evil, compared to the swamp road. All was sand, but the wet made it "pack" beneath the horses' feet and the wheels, and we went over it at an excellent pace. Around us was the Michigan forest in all its wonderful variety of growth and richness, and in all its drear monotony and desolation. Grass there was in tufts, and thin and poor. Thick gray lichens and 
starving mosses strove to cover up the thankless sand, but nothing seemed to prosper in it but the trees, for which it held mysterious sustenance where their deep roots could reach it. liut aven they made an unlovely forest. The great fires that sweep across this resion leave hideous scars behind them. One sees for miles and miles the sandy plain covered with the charred trunks of the fallen forest. Great lofty pines, whose stems are blackened from the root as high as the fire has reached, - huge, distorted, and disfigured, - stand gloomily ahove their moklering brethren, their white skeletons extending their dead and broken arms, in mute testimony of lost grace and beauty. Nothing could be more desolate than these "burnings," as they are called. They present an aspect of such utter, hopeless dreariness, and such complete and painful solitude, as one might imagine to exist only within the frozen circle of the Arctic.

The rain continued and wet us until we began to get on good terms with it, as if we were Mlaskans or Aleuts, and rather liked it. Besicles, we got stirred up over the deer-tracks in the sand. They were very numerous and fresh, and one or two rifles were loaded in hopes of a shot at one "on the wing." None came in sight. however, and the undergrowth and scrub-oaks effectually kept them from our view.

At half-past one o'clock, after a few premonitory symptoms in the shape of fences, of which the purpose was obscure, since they hedged in nothing, and looked as if they had only been put up for fun or practice, we came suddenly to the edge of a basin or depression in the plateau over which we had been driving, and there, beneath us, lay Thompson's. Here in the midst of the wilelerness was a prosperous, healthy-looking farm, actually yielding regetables and cereals, and having about it all manner of horses, cows, piuss, hay-stacks, barns, dogs to bark, pumpkins, and all the other established characteristics of a well-regulated farm. We rattled down the declivity to the house and met with a hearty welcome, most of the party having known Thompson for years. He is a bluff, hearty backwoodsman, whom years of uninterrupted prosperity have made rich. He owns thousands of acres of timber-land, and his house is known far and wide as the best hotel in Michigan. Mrs. Thompson is not exactly a backwoodswoman; indeed, she is quite as much of a surprise to one as is the place itself. She is an excellent lady. 
and her refining influence has been felt in a very marked degree in that wild region. She can shoot, though. Indeed, she handles a rifle with the greatest coolness and skill,-thinks nothing of knocking over a deer, and confesses to aspirations in the direction of bear. Mr. Thompson's welcome in the course of an hour took a practical form, when we all sat down to a magnificent roast of venison, broiled chickens, and the most delicious of vegetables; for it seems that when one does get a bit of Michigan land which will consent to be cultivated, it turns out to be remarkably good land indeed. There were great glass pitchers of excellent milk upon the table, similar pitchers of real cream, and everything was neatly served. The table-cloth was fine and of snowy whiteness, the napkins (this in the heart of a Michigan wilderness!) ditto, and everything just as it should be, and just as one would least have expected to find it.

Thompson's hands came in the evening,-Canadians, for the most part, and talking an inexplicable jargon called French. Reënforced by a few lumbermen and trappers, they filled the big, dimly lighted room which would ordinarily be called the bar-room, but which, having no bar, owing to Mrs. Thompson's way of inculcating temperance principles, cannot so be called. They were noisy, wellbehaved, and good-humored, and they crowded around the stove, and bedewed it pleasantly and copiously with infusion of Virginia plug. There was a great deal of talk about lumber; how many feet such-and-such an one expected to "get out"; where such-and-such camps were about to be located; the prospect of sufficient snow to move the heavy lumber-sleighs, and a variety of topics that had more or less sawdust in their composition. They spoke with loud, individual self-assertion, and there was a curious touch of defiance in every sentence that involved a direct proposition. This quality of their speech, coupled with a degree of profanity which was simply startling in its originality, its redundancy, and its obscurity of purpose, made a stranger feel as if a fight might occur at any moment. But there is no danger of anything of the kind. They live in this atmosphere of exploitation and brag, with entire amicability and good nature, and only fight when the camps break up and the men are paid off. Then they congregate at the lake settlements and elsewhere, and get frightfully drunk for weeks, and shoot and stab with a liberality and self-abnegation that suggest that they ought 
to have a literature built for them like that which a lind and artistic hand has so deftly erected for the farored miner of the Pacific slope.

A curious effect which this native windiness produces upon the stranger who comes to hunt is, that after a week of it he fincls himself impelled to the conclusion that he has shot the only small deer

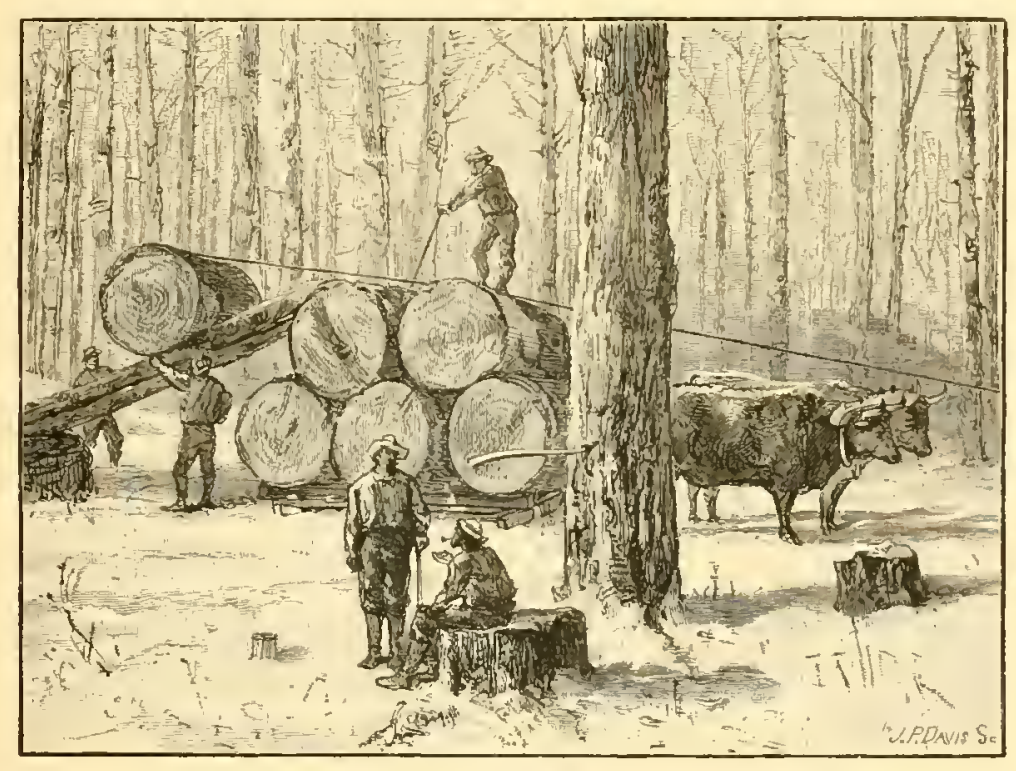

A LUMBER-SI.ED.

there are in the State. We could not meet a man in the country all about that had ever seen a small deer. The word fawn, from desuetude, will be dropped from their language. It was always "the blankest biggest buck! blank me!" or " the blank, blankest blank of a blank of a blank doe! running like blank and blankation for the blank river!" That was all we could ever get : and when perchance one of these identical, peculiarly qualified animals happened to be shot, the speaker stood wholly unabashed and unconscious in the presence of his refutation.

We left Thompson's hospitable place the next morning after an early breakfast. Curtis and his team carried all our traps, and after a tramp of two hours or so orer the wet sand and through the desolate "burnings," we arrived at Camp Erwin. It is a deserted logring camp. The building on the left, in the little sketch I have made, is 


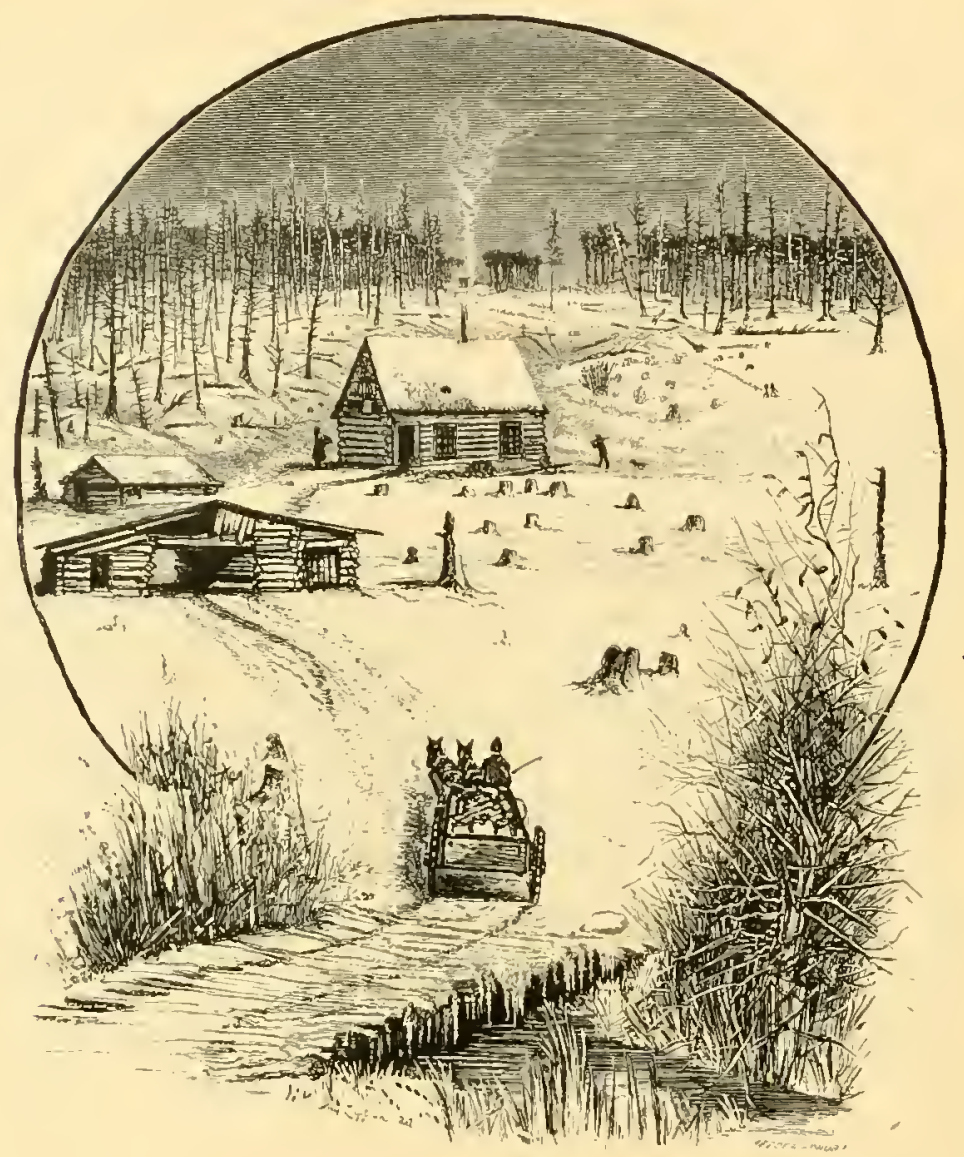

CAMP ERWIN

a rickety old barn; that behind it is a blacksmith's shop, and the remaining house is that in which we had our quarters. It contains, on the upper floor, one large and finely ventilated apartment; and below, the kitchen, dining, and "living" room and two small bedrooms. One of these was occupied by Mr. and Mrs. William Bamfield, the latter of whom had engaged to cook for our party, while the former, a stalwart and extraordinarily powerful backwoodsman. chopper, and blacksmith, " assisted," and made himself indispensable by his general handiness and utility, his readiness to do anything and everything, his good humor, and his entire novelty. Recurring to my sketch again: the stream in the foreground flows a mile away into the Au Sable (pronounced up here Sawble, the Au, too, being generally (tropped), and around the house, as far as one may see, is 
the everlasting "burning." In summer, all is dry, yellow sand; in winter, a mantle of snow sometimes covers it charitably and conccals some of the blackness and deformity of the dead pines.

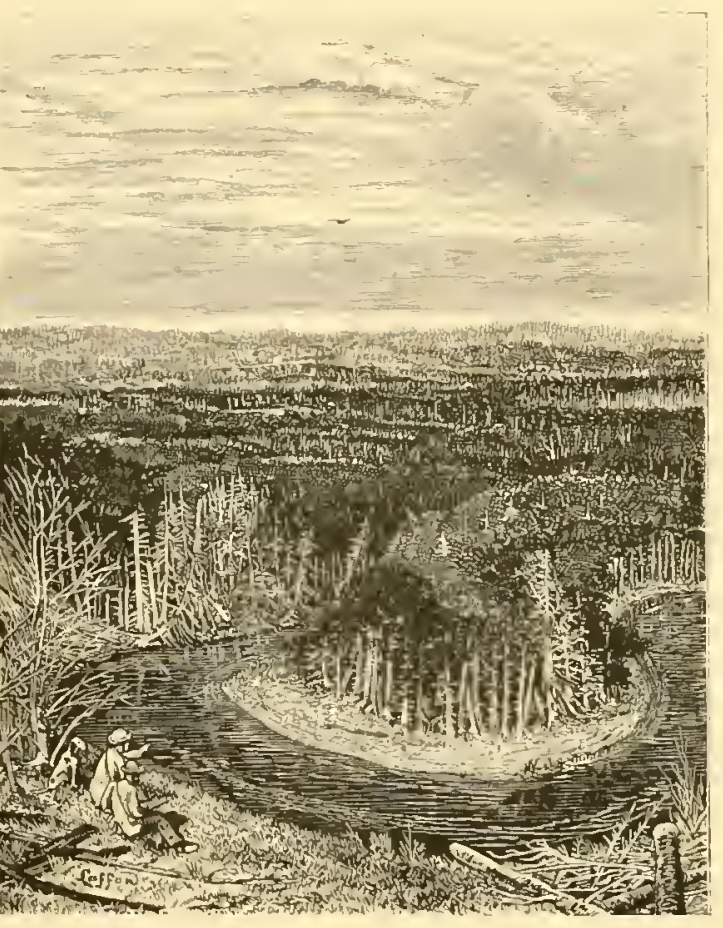

ON THE AU SABLE.

The first day in camp was devoted to unpacking our traps and provisions, filling our ticks with straw, disposing handily of our various knickknacks, overhauling the rifles, and wasting ammunition under excuse of getting one's hand in. My share being accomplished at noon, some of us started down to take a look at the Au Sable River. After a walk of fifteen minutes or so, we came out of the forest abruptly on the edge of a high sand-bluff, and there it lay about one hundred and fifty feet below us. It came around a short bend above; it swept around another in front of us, and below us it wound around a third. Its waters were the color of dark-brown sherry, and its current was silent, swift, and powerful. Beyond, the bank was low, and the forest stretched back over successions of slightly rising plateaus to the horizon. Here and there one could see the scars of the fires, and a sinuous track of the darkest foliage 
revealed the tortuous course of the Au Sable. This description would seem to apply well enough to the sketch I have made, but it was taken from a higher bluff some few miles further down the river. From any similar elevation upon its banks the scene would be the same. Save that the river gains in volume as it travels, its scenery throughout almost its entire length does not vary. It is a succession of interminable twists and turns past high or low bluffs of sand, long reaches of "cedar-swamp," and "sweepers" innumerable. This singular river is one that knows neither droughts nor freshets, which is always cold, but never freezes, and which will always preserve its wildness and its desolation, since, in the future, the wilderness through which it flows will be even wilder and more desolate than it is now.

The first evening in camp, around the council lamp, was spent in discussing the prospects of the morrow, in shooting over again all the deer that had been shot upon previous occasions, in comparing the target shooting of the day, and in the assignment by the captain of each man to his position on the river. Curtis and two of our party were to "put out the dogs," and the rest were to be stationed at the different run-ways. This explains the method of hunting. The river for a certain number of miles was divided into run-ways or points, at which deer, when hard pressed by the dogs, would probably take to the water and afford a chance for a shot. The dogs, twelve in number, were divided among those who were to have charge of them for the day, and they took them in various directions into the forest. When a fresh and promising track was discovered, a dog was let loose upon it, or perhaps two dogs, and the deer, after a run of greater or less duration, took to the river in order to elude pursuit. If it went in at a guarded run-way, it stood an excellent chance of being shot; but, of course, a large majority of deer driven in entered the river above or below, or crossed it shortly after reaching it.

A tick filled with straw and laid upon the floor makes an excellent bed, and sportsmen's consciences are always good, for they sleep with exceeding soundness. The ventilation of the apartment was generous in the extreme. The roof was tight, but all around were the open chinks between the logs, and through these the stars could be seen by anybody that had nothing better to do than look at them. Up through the middle of the floor and out through a big hole at the ridge-pole went the stove-pipe, always hot enough to worry an 
insurance man, and an excellent spot to hang wet clothes. Elsewhere it was as cold as charity, and I supplemented my blankets with my heavy frieze ulster, and went to sleep to dream of griant bucks and a rifle that wouldn't go off.

The Michigan forests abound in a variety of game, but the animals that are valued for their fur have been thinned out by trappers, who, in turn, have disappeared to newer hunting-fields. One still finds the beaver, marten, fisher, lynx, and others. Bears are quite numerous, and there are plenty of wolves. Rabbits and Arctic hares and ruffed grouse exist in great numbers. The elk has almost wholly disappeared from the peninsula, but I heard that some were occasionally found in the extreme northern portion, and I saw a magnificent pair of antlers, having a spread of nearly six feet, which a half-breed had found imbedded in the trunk of a cedar-tree. The skin of the head and the greater portion of the skull were attached, the remainder having been torn away and scattered by wolves. The deer of the region is the Corius Virginianus, or common deer of America, which is distributed over such a large area of our continent. It probably attains its greatest weight in Michigan. I learned, from credible sources, of bucks which weighed over two hundred and fifty pounds. Judge John Dean Caton, in his admirable work on the deer and antelope of America, speaks of having killed a buck in Wisconsin that was estimated to weigh two hundred and fifty pounds, and adds that the largest common deer of which he had any authentic account was killed in Michigan and weighed. undressed, two hundred and forty-six pounds. Of the deer killed by our party, there were no less than three that weighed over two hundred and twentyfive pounds. It is the most beautiful of the corida, and in its graceful carriage, its exquisite agility, and the delicacy and symmetry of its form, no other animal approaches it. It varies somewhat, of course: but the buck, with the shorter legs, the rounded and compact body, the tapering nose and the well-erected, open antlers is the proudest and handsomest animal of the forest. The eye of the deer is large and has the softest and most tender of expressions. The marked convexity of the ball, the deep, calm, and gentle radiance of the iris, and the length of the shadow-line from the larmier to the posterior angle of the lids make up the more obvious anatomy of this amiability. In the rutting season, which occurs 
during the earlier part of the winter, the bucks discard their gentleness in a great measure and fight in the fiercest way. It is doubtful if they ever kill or seriously injure each other, formidable as their antlers are when they have sharpened and polished them by persistent rubbing against the bark of young trees. They charge at each other, head down, and meet with a crash, and then stand or walk round and round in a circle, with interlocked antlers, swaying to and fro, and moodily watching each other's every movement. They continue at this sort of thing for hours, and superior prowess is more a matter of endurance and pertinacity than anything else. It would seem that the buck that holds out the longer completely wears out and exhausts his antagonist, who then withdraws and leaves him victor, - whereby the stronger and more favored males carry off the females and beget offspring possessed, by heredity and otherwise, of the same characteristics. The argument finds a strong illustration in the case of the deer, and backwoodsmen say that the younger and weaker males go unmated and are constantly being pursued and driven about by the stronger and older bucks. Some of these combats between the bucks result in mutual disaster when the antlers interlock and they are unable to withdraw from each other. They prohably could if they made the effort at once, but they butt and push at each other, and each so studiously avoids giving the other an opening, that both are too exhausted to make the effort at separation, and there they remain until the wolves arrive on the scene and close the drama. Our backwoodsman had recently found two bleached skulls with antlers fast in each other's embrace, mutely telling a dark tale of love, jealousy, and a wedding unavoidably postponed. The fawns, betraying by their spots a former characteristic of their species, are timid, pretty little things. They do not seem to have the instinct which leads the adult animal to the water when pursued, and consequently when a dog gets on the scent of a fawn, he will hunt it bootlessly for hours, to the great annoyance of his master. A young fawn, just born, knows no fear of man. If picked up, fondled a few minutes, and carried a little distance, it will, when put down, follow a man just as it would its mother.

A tremendous uproar awoke me at the moment when for the hundredth time my rifle had exasperated me. It was Mr. B., shouting, "Breakfast! breakfast! Turn out for breakfast! The captain's 
up and waiting!" It was half-past four, and everybody woke up at the summons, as was indeed unavoidable. There was a scratching of matches and a discordant chorus of those sounds which people make when they are forcibly awakened and made to get up in the cold, unusual norning. Down-stairs there was a prodigious sizzling and sputtering going on, and the light through the chinks in the floor betrayed Mrs. Bamfield and her frying-pans and coffee-pot, all in full blast. Somebody projected his head through an immature window into the outer air and brought it in again to remark that it rained. A second observation made it rain and snow, and rain and snow it was, - a light, steady fall of both. We were all down-stairs in a few minutes and outside, making a rudimentary toilet with icewater and a bar of soap. Breakfast was ready,-plenty of rashers of bacon, fried and boiled potatoes, fried onions, bread and butter, and coffee, hot and strong. These were speedily disposed of. Coats were buttoned up, rubber blankets and ammunition belts slung over shoulders, cartridge magazines filled, hatchets stuck into belts, rifles shouldered, and out we sallied into the darkness, through which the faintest glimmer of gray was just showing in the east. Half an hour or so later, by the time we had gotten to our run-ways, the dogs would be put out. Off we trudged over the wet, packed sand of the tote-road, the gray dawn breaking dismally through the wilderness. Leaving the road, we struck into the pines, and a walk of a mile through the thick sweet-fern, which drenched one to the waist, brought us to the edge of the cedar swamp by the river. The narrow belt of low bottom-land on each side of the river is called Cedar Swamp. It is a jungle through which it is extremely difficult to progress, and in which one may very readily lose one's bearings. Great cedars grow in it up to the water's edge, and as thickly as they can well stand. Among them lie fallen trees in every stage of decay. heaped one upon another in inextricable and hopeless ruin and confusion. There are leaning cedars that have partly toppled over and rested against their stouter fellows, and there are cedars that seem to have fallen and only partly risen again. Their trunks run for several feet along the ground and then stretch up toward the light, in a vain effort to become erect once more. These trunks and all the fallen giants are covered with a thick carpet of the softest moss; everything, in fact, is covered with it, and here and there it opens, I $6 \mathrm{~A}$ 
and down in the rich mold is a glimpse of a bright little winecolored, trickling stream stealing in and out among the cedar roots and losing itself in miniature tunnels and caverns on its way to the river outside. One's footfall is noiseless, except when a branch beneath the moss breaks, and the sunlight struggles but feebly down

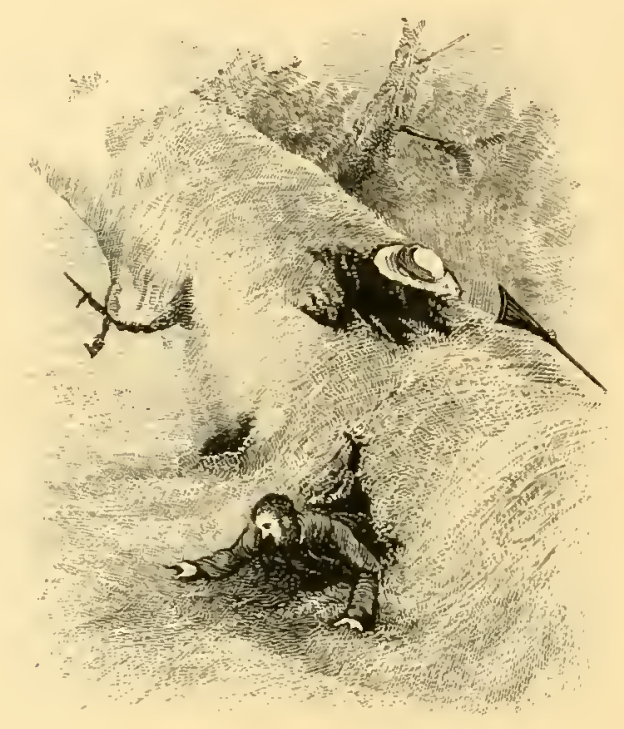

through the trunks and dense foliage above. Sometimes the walking is treacherous, and the giant forms that lie about are hollow mockeries and deceptions beneath their pretty wrapping of green. Standing upon one of these, and doubtful whether to attempt a leap or more circumspectly climb to my next vantage-point, I executed a sudden disappearance, much after the fashion of a harlequin in a pantomime. A hole opened beneath my feet, and I shot through that hollow shell into the swamp beneath, leaving my broad-brimmed hat to cover the aperture by which I made my exit.

After a couple of hundred yards of climb, crawl, and tumble through one of these swamps, my companion took his place under the shelter of the cedars, and indicated mine at a little distance up the river. It was one of the best of our run-ways,-a long stretch of open bank, where the cedar swamp did not reach the river's edge. I got there, took my stand, and indulged in expectation. The exertion of getting through the swamp had warmed me uncomfortably, 
but I soon ceased to regard that as an objection. The place was exposed; there was no shelter; the cold wind and the driving snow and rain had it all their own way with me. My hands became numb, and the metal of my rifle
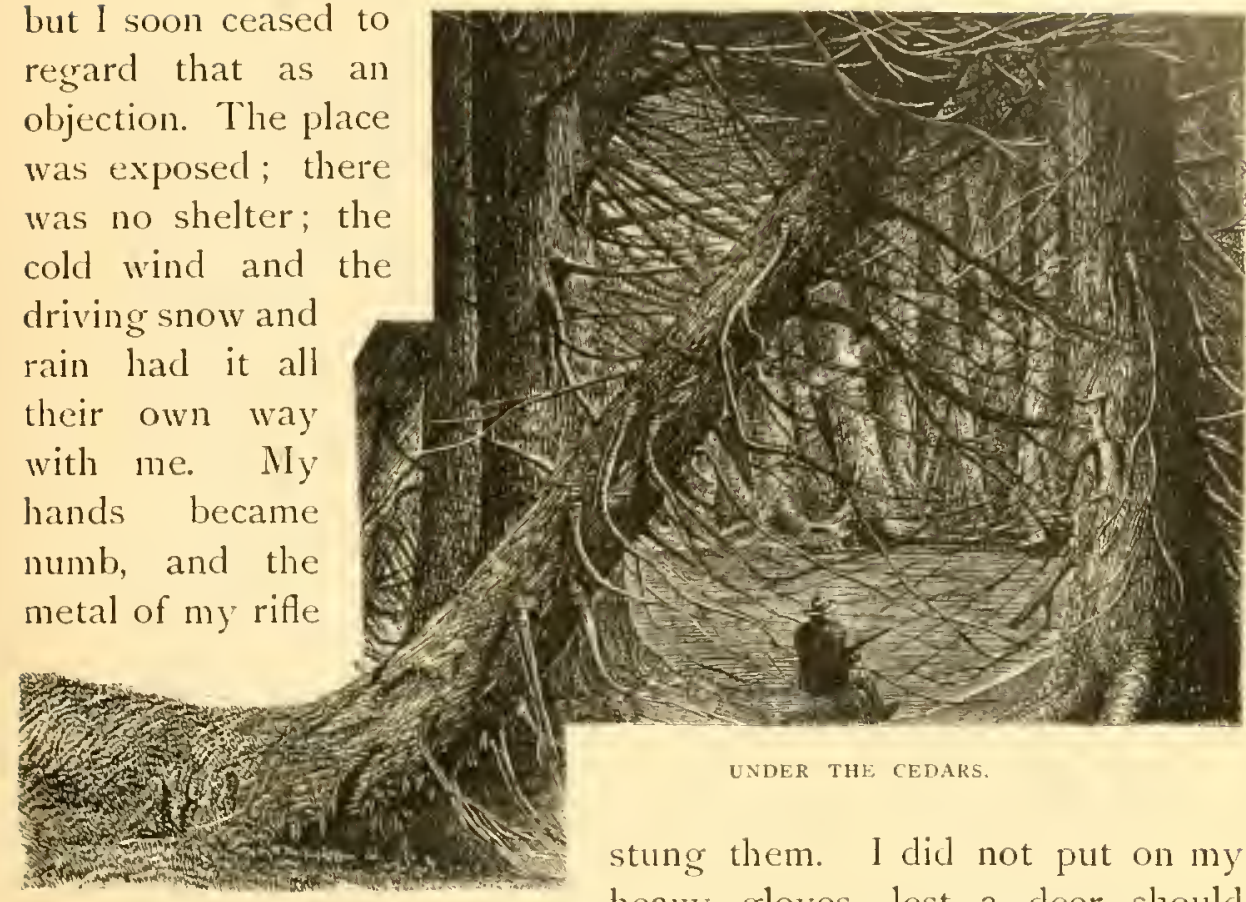

UNDER THE CEDARS.

stung them. I did not put on my heavy gloves, lest a deer should come and they should prove an awkward impediment. I stood my rifle against a tree, stuck them in my pockets, and watched the river, while my teeth chattered like miniature castanets. The wind howled down through the trees, and clouds of yellow and russet leaves came sailing into the river and hurried away upon its surface. I was undeniably, miserably cold. But hark! I seized my rifle. Yes, there it was, sure enough, the bay of a dog in the distance! I forgot to be cold. Nearer it came, and nearer and nearer, and each moment I thought would bring the deer crashing through the thickets into the river. Nearer and nearer the dogs came, until their deep bays resounded and echoed through the forest as if they were in a great hall. But no deer appeared, and the dogs held their course, on, down, parallel with the river. "Better luck next time," I said to myself, somewhat disconsolately; but 1 was disappointed. Presently the sharp, ringing crack of a rifle rang out and reverberated across the forest; another and another followed; and as I began to get cold again, I tried to console myself by meditating on the luck of other people. I stamped my feet; I did the London cabman's exercise with my hands and arms; I drew beads 


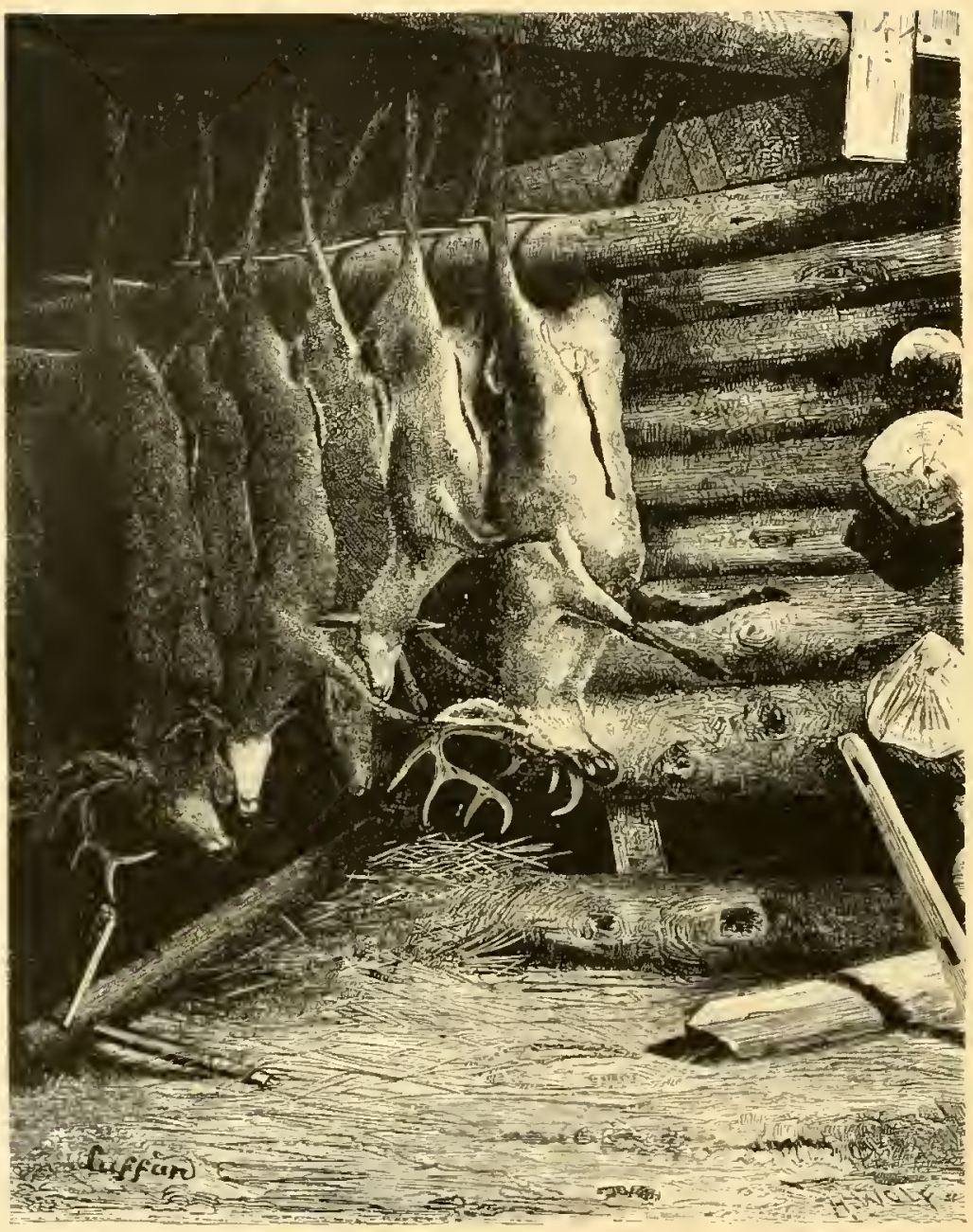

HUNG UP.

on all manner of objects; but steadfastly I watched the river, and steadfastly 1 listened for the dogs. The snow and rain abated, and the hours went by; and stiff and chilled was I when, at half-past twelve, young Curtis's canoe came poling up the river to pick up deer if any had been shot above, and had lodged in the drift-wood, instead of floating down to his watching-place, three miles below. The dogs were all in, he said, and the doctor had shot a big buck and a fawn.

At camp, the doctor was the center of an animated circle. He was most unreasonably composed, as I thought, and told us, with 
his German equanimity, how Jack and Pedro had run in a large buck, which immediately swam down the middle of the river. He fired from his place on the side of a bluff and missed. At the second shot, he succeeded in hitting the deer in the neck just below the mastoid something or other. As if this were not sufficient, there presently appeared and crossed the river a very pretty fawn, whose young hopes were promptly blighted. They said it was not always that the first day yielded even one deer, and it was an excellent augury. During the afternoon, Curtis brought both deer up to camp and dressed them. The buck was finely antlered and was estimated to weigh over two hundred pounds.

The next day $I$ was appointed to the same run-way, and l took my stand, and, acting on the advice of the others, built a brave little fire. Deer being driven into the river or swimming down it pay no attention to a small fire, and the making of it and the keeping it alive furnish excellent occupation. Indeed, there is something quite fascinating about building a fire in the woods, and it is quite inexplicable what a deep concern all the little details of its combustion create in even really thoughtful minds. $11 y$ fire burned cheerily and blew lots of sharp smoke into my eyes, with the aid of the fitful wind; but I was not called upon to shoot any deer. I did not eren hear the dogs, and at two oclock 1 went home to camp, persuaded that I had not yet learned to appreciate our style of hunting. Our captain had a handsome young buck and was in a wholly comfortable frame of mind.

We had a larded saddle of venison cluring the afternoon for dinner. It was flanked by a dish of steaming bacon and cabbage and quantities of mealy potatoes and fried onions. The fragrance that filled the air of the cabin surpassed the most delicate of vapors that ever escaped from one of Delmonico's covers, and we fell upon the table with appetites like that of the gifted ostrich. The air of the Sable would be worth any amount of money in New York.

The next day 1 passed in a meditative fashion on my run-way. I was not disturbed by any deer, but Mr. M. and Mr. B. each scored one. The next evening, one of the dogs, foot-sore and worn out, remained in the woods. His master and one other sallied out into the inky darkness to look for him at points near which they deemed it probable he would have lain down. They took a iantern, without 


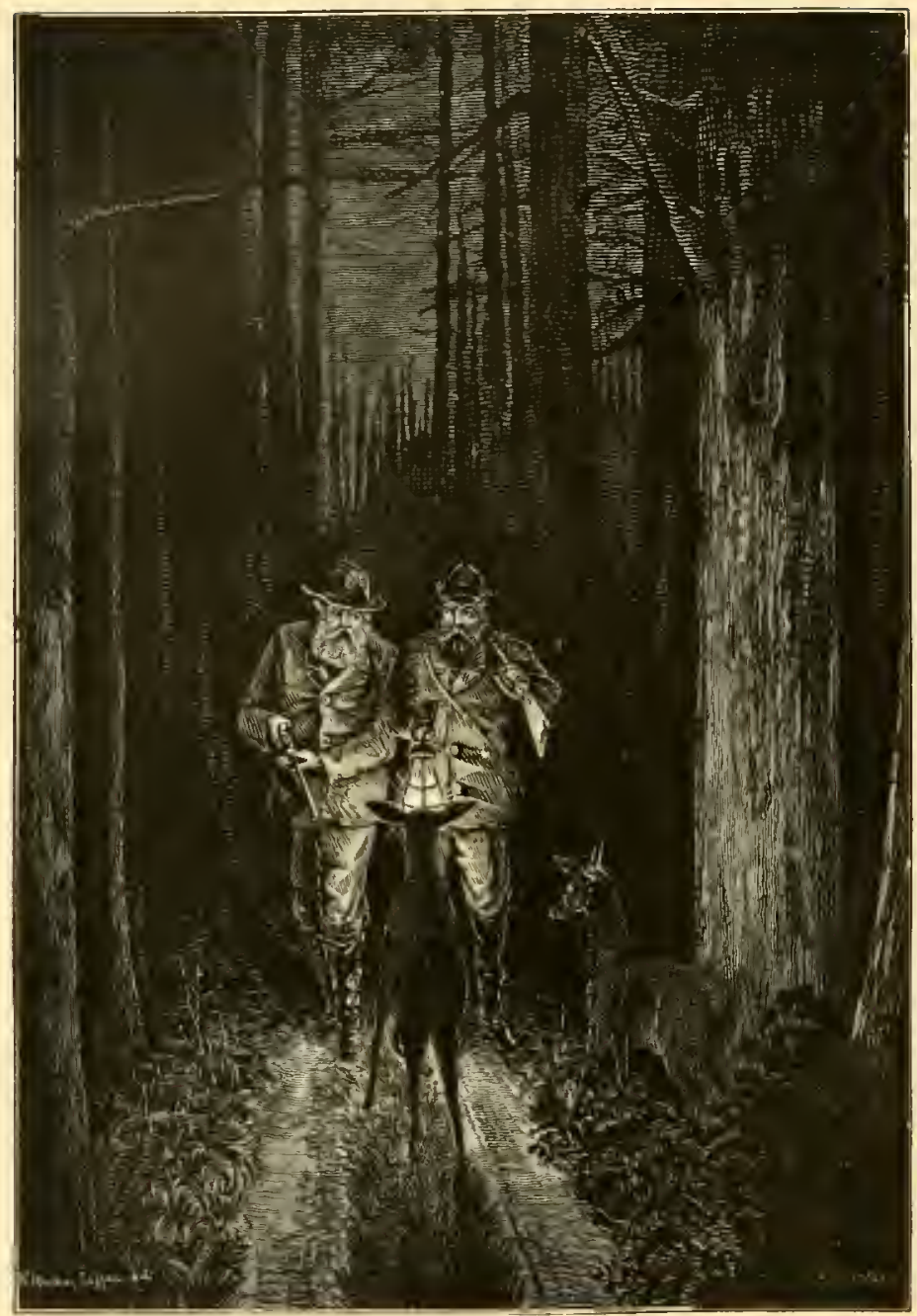

A GENERAL SURPRISE.

which it would have been impossible to walk, and after a fruitless search, extending to a distance of three miles or so, turned back. Suddenly they heard light footfalls in the tote-road, and with two or three beautiful bounds a young doe alighted within the circle illuminated by the lantern, approached it in wide-eyed wonder, and almost touched it with her nose. A young spike-horn buck followed her, and both stared at the light, their nostrils dilated and quivering, and every limb trembling with mingled excitement and fear. There was an exclamation that could not be suppressed, a vain effort to shoot, and the deer were gone like a flash into the darkness. It was 
curious to hear both gentlemen, on returning to camp, protesting that to have shot deer under such circumstances would have been wholly unsportsmanlike.

It was upon my sixth day, when a dozen deer were hanging in the barn, and I, quite guiltless of the death of even one of them, had gone to the river. The hours passed tediously up to noon, when I heard a splash, and saw a deer take the water three hundred yards or so above me. She was a large doe and came down the middle of the river, swimming rapidly and looking anxiously from side to side. I felt unutterable things, and just as she got abreast of me I brought up my Winchester and fired. She sank, coming up again some little distance down, and floated quietly away out of my sight around the bend. This performance produced a sense of pleasant inflation. All my fears vere dispelled, and I felt a keen desire for the presence of others to whom to impart the agreeable fact. It was one of those things about which one always feels as if he could not, unaided, sufficiently gloat upon it. At half-past twelve, the canoe came around the bend, and I prepared to be indifferent, as should become a person who could shoot deer every day if only he were so minded. Strange, I thought, that the legs do not project over the side of the canoe, and how is it that _ At this moment the canoe gave a lurch, and I saw young Curtis's coat with painfu] distinctness lying in the bottom of it, - nothing else. I immediately inferred that he had missed the deer among some drift-logs as he came up. He protested he had not, but agreed to go back and search. I went with him, and just a few yards around the bend we found in the oozy bank tracks which indicated that the animal had fallen to its knees in leaving the water, and up the bank to the top a trail marked with blood. The remarks of Mr. Curtis, though fluent and vigorous, were inadequate to the occasion. I was in a condition of unbounded exasperation. For a little distance through the grass and the bushes the marks could be seen plainly enough, but there they disappeared, and that was the last I saw of my deer. The captain put two dogs out on the trail that afternoon, but the wounded animal had probably died in some dense thicket, for they soon returned without having run any great distance. Four fine deer were killed the next day, without any participation upon my part, and in the evening some of us, with lanterns, went down to the river to 


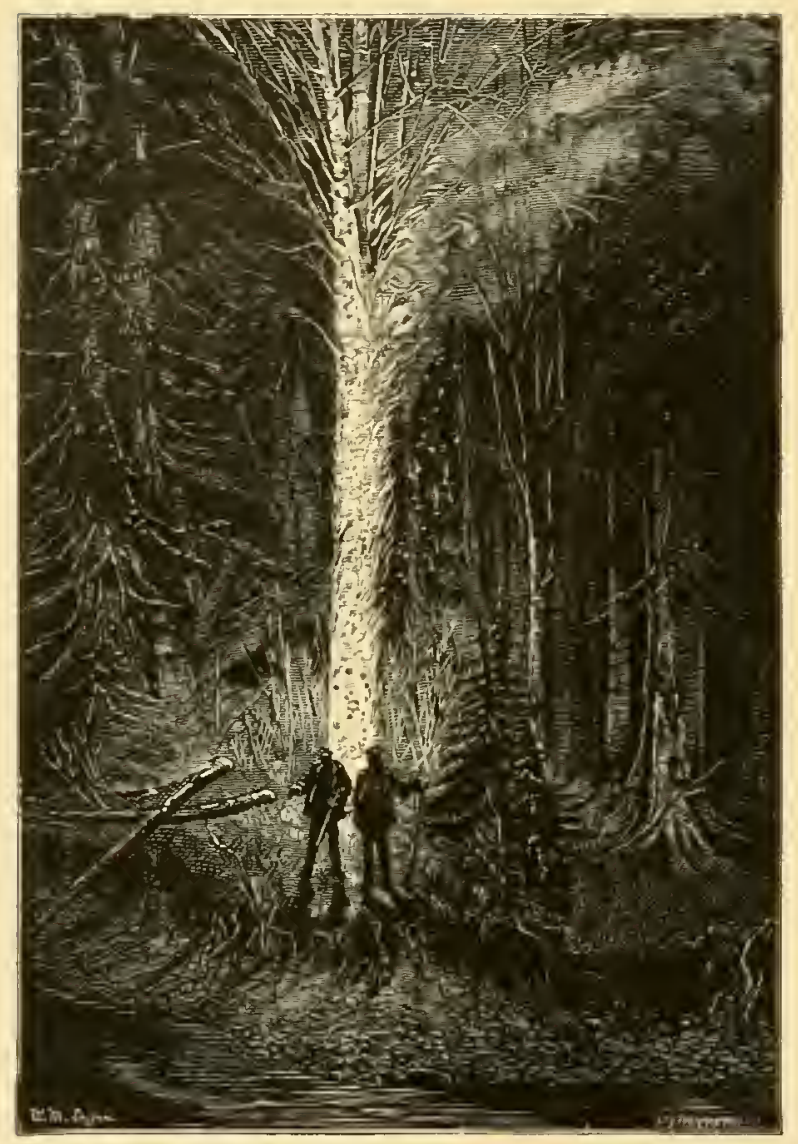

A TURCH OF THE AU SABLE.

secure one that had lodged somewhere in the drift-wood. We found it, by the light of the birch-bark. As we made our way along the bank, our backwoodsman would pick out here and there a large white birch, and apply a match to the curling ringlets of bark at the foot of its trunk. In a minute the whole stem of the tree was in a roaring blaze, that lit up the river-bank all round about and made the great cedars look like gigantic skeletons. Each birch was a brilliant spectacle, while it burned in a crackling, sparkling column of flame, sending showers of sparks through the forest, and then dying out in an angry red and a cloud of murky smoke. Our deer was found, dressed, and hung up on a dead cedar, out of the reach of predatory animals; and we went home to camp by the light of our lanterns. 
Next morning I was at my place, still unsubdued and hopeful. I heard a shot fired on the river below me; 1 heard the baying of the dogs, and listened to it as it died away in the direction of some other run-way. But 1 watched steadily; and as 1 watched, I saw the brush about some cedar roots open, and out there sprang into the shallow water a noble buck. He was a stalwart, thick-set fellow; his legs were short and compact, his fur was dark in its winter hue, and his antlers glistened above his head. He bore himself proudly as he stood in the water and turned to listen for the bay of the dogs he had outrun. I hesitated a moment, doubtful if I should let him get into the stream and swim down, or shoot at him as he stood. I chose the latter, aimed quietly and confidently, and fired. He pitched forward, the current seized him, and he floated down with it and past me, dead. In eight minutes, by my watch, Mr. MI_-'s Jack came to the bank, at the spot where the luuck had come in, and howled grievously over the lost scent. He was worn out and battered, and he came to me gladly when I called him. I had brought some luncheon down with me that morning, and 1 must confess that I was weak enough to give Jack every bit of it.

That afternoon, when I reached camp, I found that I was the last to come in. and that my buck had already been seen and his size noted. I was received with acclamations, and a proposition to gird me, as a measure of affected precaution, with the hoops of a flourbarrel was made and partly carried into execution. There were sung, moreover, sundry snatches of the forester's chorus from "As You Like It":

"What shall he have that killed the deer?"

Of the Au Sable as a navigable river, I am pained to state that I cannot speak in a way calculated to allure people thither for the purpose of sailing upon it. Three of us were induced by our backwoodsman to embark upon a raft and make a run of fifteen miles to Thompson's. We did so, and failed to acquire upon the journey any marked prejudice in favor of that particular form of navigation. Cedars growing at the water's edge have their roots more or less undermined, and some of them fall gradually outward over the river, their branches hanging in the current and becoming denuded of their foliage, or dying. The trunk or stem of the tree is in some cases parallel 
with the water's surface, and in others it dips below it or inclines gradually upward from it. These trees have been named, with a nice sense of the fitness of terms, "sweepers." We found them such.

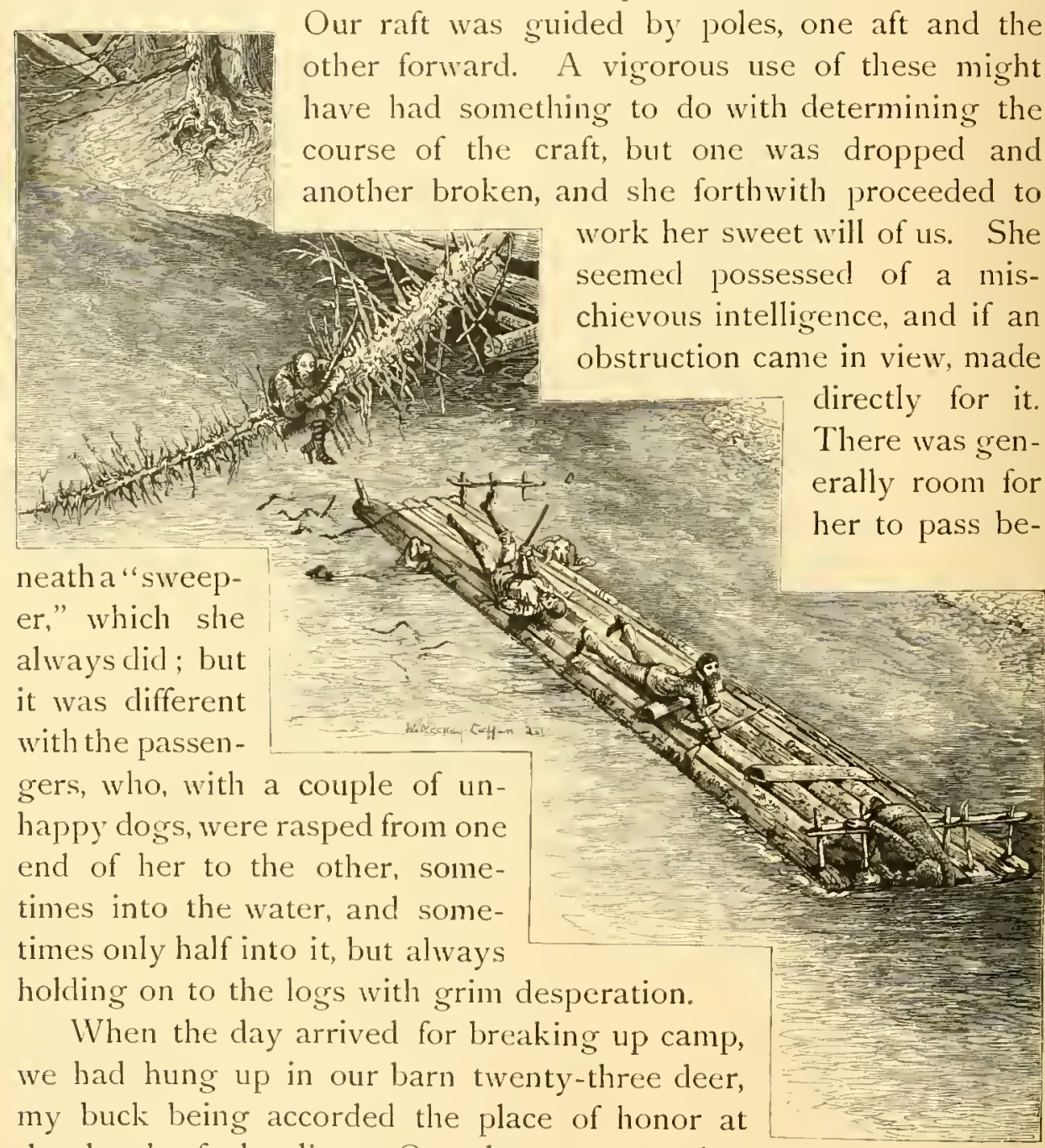
the head of the line. Our dogs were rather the worse for wear, but all were there, which is something unusual at the end of a hunt in this part of the country. The fact is, the natives discourage hunting with dogs, if not, indeed, all hunting in which they themselves do not participate. They place meat which contains strychnine on the deer-paths, and also, when occasion offers, shoot the dogs. A party of gentlemen from Bay City came into our neighborhood a few days later than we 
did. They contemplated a three weeks' hunt, but during the first three days had two dogs shot and three poisoned. Some years ago, a party of Ohio people lost their dogs in the same way, and, unluckily for the active toxicologist, they found out who he was. When I passed that way he had rebuilt his barns and various outbuildings, and it was thought that, until the region commanded the services of a reliable insurance company, he would abstain from the use of strychnine. The immunity our party enjoyed had been gained somewhat as an ancient proprietary right, they having hunted there for so many years. Besides, they had in various ways rendered themselves popular with the natives; no visitor ever left the camp hungry or thirsty; and the Herr Doctor's periodicity was a matter of importance to a widely spread, if not numerous, community. They saved up fractures of six months' standing for him, and events of a more strictly domestic nature seemed to happen adventitiously during his hunting sojourn.

We brought out our venison safely and in good condition, - a ton and a half of it or thereabouts. At Detroit, we went our ways, ending an expedition which had in it, luckily, no mishap to mar it, but plenty of wholesome recreation to make one's recollection of it wholly pleasant.

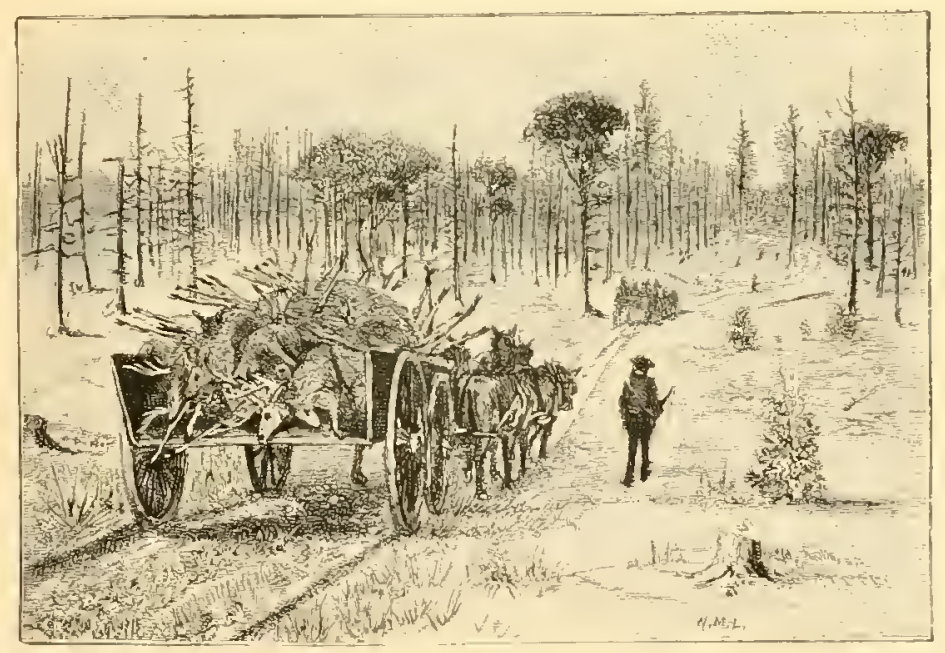

A TON AND A HALF OF VENISON. 


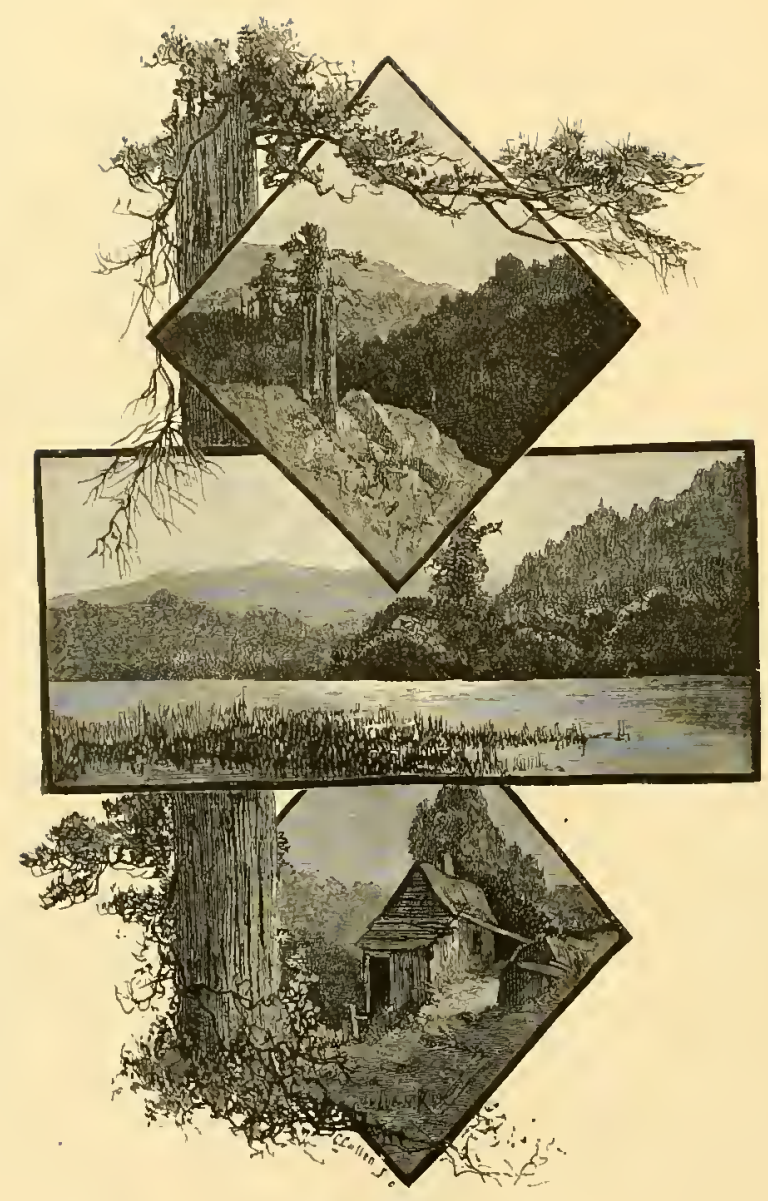




\section{HUNTING THE MULE-DEER IN COLORAI)(}

S

AYS a well-known sportsman,* in a work recently issued for the use of the fraternity, " Good hunting is at present scarcely. to be found east of the Missouri River. W'est of that stream. however, there is a wide extent of territory in many parts of which game may still be found in considerable abundance by those who are sufficiently acquainted with the country to know where to look for it. * * As things stand at present, the country where game most abounds is that which is now, or lately has been, infested by the Indians. * * * The Indians are the only real game preservers in the IVest."

That portion of the new State of Colorado lying west of the main range and north of the San Juan miningr region is perhaps one of the very best of these localities; certainly the most accessible and practicable at a moderate expenditure of money and time. Here in four lays, by rail from New Jork City, one may mount a welltrained animal and plunge at once into the primeval wilds. Here are the gate-ways of the great parks, in and surrounding which are thousands of square miles suited by nature to the purpose of a stronghold from which the game can never be wholly driven. Just within its farther limit is the Ute reservation, and its bulk is almost debatable ground, - the Indians hunting here, and loath to yield to the whites entire possession of their richest grounds and their great medicine waters, the Hot Springs of Niddle Park. Legislation has been pending for a few years past, which will probably limit these

* Charles Hallock, of "Forest and Stream," in "The Sportsman's Gazeteer," pages $7 \mathrm{I}$ and 7.4 . 
friendly savages to a more remote point, and then the most timid of pilgrims may revel in the plenty of a region where 1 have seen five thousand elk in view at once, - the number estimated by men of lifelong experience as herders, - and where I have known one man to kill forty bulls at a single stand. Mlay a merciful Providence impel our legislators to invent some means of controlling the waste of this wealth! But, as I have said, total extermination is impossible. This is demonstrated in the case of the animal I am about to describe, which persists in using even those foot-hill regions of Boulder County, where mining, milling, grazing, and agriculture make together one of the thriftiest localities of the new IVest. Year after year he continues to startle the plowman or the herders by his sudden appearance, and a fortunate pistol-shot sometimes secures him for the larder: but of hunting, properly, there is little done now in the regrions of the great tellurium discoveries, that have converted into swarming camps the hills over which, during my novitiate, I ranged with Hank Green, the Tourtillots, "Bign" Osborne, and old Levi Van Rensselaer. If any of the Boulder boys wish to enjoy a good old-fashioned hunt to-day they go up to St. Irains, Big Thompson, or the Cache La Poudre, or over the range into North or Middle Park. From this region west and south is the heart of the hunting, particularly in that portion reached by the Gunnison and its tributaries. Here roam all the varieties of game animals known to this latitude in America, with, I believe, one exception: the red. or Virginia, deer has never been found west of the range, except as a mongrel. If clesirable, the element of danger may be sought in pursuit of the range and cinmamon, - the first a cousin of the true Ursus horribilis, somewhat stunted by change of habitat, but none the less ugly, - or the less ferocious brown and black bears, or the puma (of whom beware!), or the other cats and lynxes, or the sluggish but courageous wolverine.

The mule-deer does not bear an undisputed name. 1 knew him at first as the black-tail, as he is almost universally called here. A recent issue of the "Rocky Mountain News" contains an indignant protest from one of our hunters against the liberty "eastern " naturalists have taken in rechristening, as he supposes, this animal. The fact is, however, that whether the difference claimed between this variety and that of the Pacific coast* really exists or not, the

* Cariacus Columbianus, or black-tail deer. 


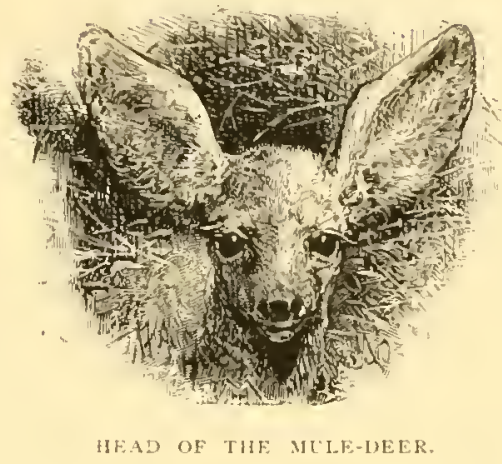

name mule-deer was recorded by Captains Lewis and Clark in their reports of the expeditions of 1804 and 1806 , in which this animal, with the black-tail and Virginia deer, are fully described, with their mixtures and variations and respective limits of habitat. Probably the two, with the bumo* deer of Arizona, may prove to be merely variations of the same animal, as new admixtures indicating the blood of C. virginiams are sometimes found of late, and I have myself noted, among some hundreds of deer killed within a radius of a hundred miles from Denver, marked variations from any of the descriptions given by naturalists. The prominent marks of this variety are those which give the name,-immensely developed ears, a thin, switchy, and brush-tipped tail, a gray and black color, and a general air of sagacity and knowingness not belied by his behavior in the field. Here is his inventory: A pair of immense antlers, main beams well back, prongs straight up. Full length of beam in a well-grown pair measured by myself, fifty-five inches from extreme point to its opposite. Aggregate of growth in this instance, beams and prongs, nine feet and three inches. Sixteen well-developed points not unusual, though ten seems the normal limit, the excess of this number being usually irregular in position and ill balanced. Ears, eight to nine inches in lencth, in almost constant motion. Large, prominent, and beautiful eyes. Heisht, five and a half to six feet to antlers' tips; about four at the haunches. Bocly round and plump, legs slender and graceful, and small feet, seeming utterly inadequate to propel the two to three hundred pounds weight in such wonderful leaps over formidable obstructions, through regions of

* Burro, Spanish name for the ass kind. 
fallen timber and rock, almost impassable to man. His coat is a rich, warm gray or drab, shot with black shadows in the dorsal region, where the hairs are heavy and erect, and each has a tip of yellow and deacl black. A gray to white space, from a downward angle between the eyes, extends to the nose, from under the eyes to the ears, and softening away at the sides of the neck, stops at an exact line a hand's breadth beneath the jaw. The chin, with some irregular touches along the inner portion of the ear usually, the flanks and inside of thighs, are a pure white; and an acorn-shaped patch of the same surrounds the tail, which itself is thin and "switchy," entirely" bare beneath, white above, and having a black, pointed brush at the tip of hairs two to three inches in length. The short, glossy coat of the legs is of the same tawny color that gradually; during the summer, covers the entire animal, till the new "blue" coat shows itself in September. Otherwise this description applies in November, when the deer, in local phrase, begin to "run,"-i. c., to rut. Of course, both sexes are then at their best. The females bring forth their young some time in June; during which month the males, having shed their horns, seclude themselves as if ashamed, "tarrying at Jericho," in fact, till the excrescence that distinguishes them be again grown.

While in the velvet, the horns are very tender. They are warm. Wound them and they bleed. Their gelatinous substance in July is a dainty tidbit to the fortunate coyotes. If you would save them, you must hang them out of reach of your dogs. Gradually, lime is deposited, the tips harden, the blood ceases to circulate, the velvety covering splits open and peels off, the animal hastening the process and the sharpening and brightening of the points by industriously rubbing them upon the bushes and trees, until, in the biight late October days, armed and exulting in his strength and sleekness, he is all ready to go a-courting; and the does, as if aware, and owning too the soft influence of the season, forsake their fawns and hide away in brake and dell. Then may be heard from hill to hill the challenge and the acceptance, and fierce battle be witnessed, in which the eager contestants heed not whomsoever may approach, till the victors retire to cool shadows and the rewards of valor, the vanquished to fight another day; or, if hopeless and superannuated, to begin a life of sulky solitude. 
The novice who is ambitious to slay one of these noble and sagacious animals needs-of the very best-guide, gun, camp outfit, route, range, and luck. If the weather had not its admirable reputation for unfailing reliability in Colorado, during the shooting season, from mid-Augtist till January, he would need also to pray for that.

If you have plenty of time and little money, buy a good pony and saddle, sun and ammunition, blankets, including a light rubber cloth or overcoat, a side of bacon, and a frying-pan,-though you will, when in permanent camp, probably, prefer to broil venison and fish on the coals, - a little salt, a sack of hard-tack, another of dried fruit, a few yards of good line, and two dozen gray hackles with brown bodies, a change of underclothing, a picket-rope, and a light hatchet, a skinning-knife, with belt and sheath, and a stout seamless sack big enough to carry your perishables; tie the lot together and set out on foot.* You can take a little rest now and then, when the road is good, on the top of all this, if balanced nicely on each side of the saddle, or you may mount to ford a river. Of course, it is supposed that you outfit at some valley town, probably Denver. At first, of a certainty, your progress will be slow. Take your time. I have enumerated the smallest possible list of impedimenta for a tyro. If you stay with us for good, you may some time in the future be able to set out on a trip through a few hundred miles of primitive wilderness in a buckskin suit of your own stitching, and carrying, for equipment and subsistence, your gun, three cartridges, a pinch of salt and a jackknife, like Len Pollard; or to detest salt, like Old Hill; or to make a good blanket of snow, like I)oc. Porter. But, for a first experience, you will find these things very handy, and your pampered stomach will probably welcome the additions to your bill of fare procurable at ranches by the way. By the time you lave reached Big Thompson, the Gunnison or the Grand, or the Upper Arkansas, or any of the smaller tributaries of the Platte, your education will be weil under way.

* The pony will cost twenty to eighty dollars; saddle, bridle, etco, ten to twentyfive; a Sharp's "business" rifle. single trigger, with necessary implements, thirty to fifty; hankets, ten to fifteen; and other necessaries at about home prices, with the advantage of selection from approved stock alpropriate to the precise needs of the purchaser, and guaranteed to suit.

$17 \mathrm{~A}$ 


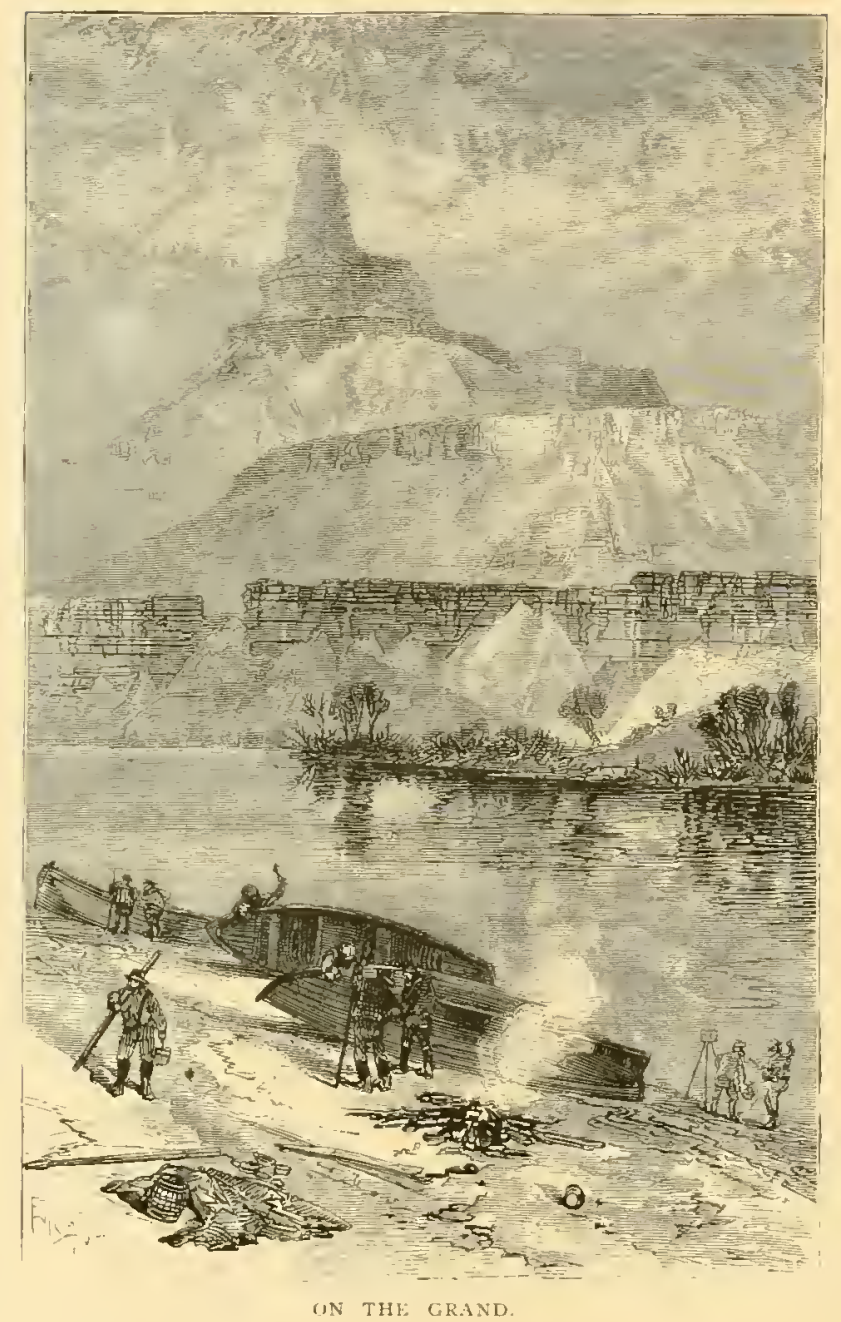

Although you will manage so as to be always within reach of supplies and a post-office, the farther you get from traveled roads and recently hunted ground the better. Go till you are sure there is game about you; then settle down and take things coolly. If you find a camp of genuine and experienced hunters in the neighborhood, they may, at first, look coldly upon you, as one likely to drive the game off the accessible ranges without getting any ; at any rate, driving it away from them. If you are wise, you will acknowledge yourself a novice, and remembering that their sole living may be in this, as yours in quite another and probably more lucrative kind of hunt back across the Mississippi somewhere, perhaps you will do 
well to offer a fair equivalent - say five dollars - to the man who will take you with him and let you shoot a buck of his finding. Go with him, do just as he tells you, and you will get your first deer cheap; then, if you are keen and observant, probably, you will have learned more than a whole season of painful work by yourself would have amounted to, and your second deer will be yours without tribute.

My own first experience in still hunting in Colorado may be taken as an instance of self-confident failure. I would not take a gruide. No, indeed! Had I not been a mighty hunter from my boyhood up!

So I waited for the first snow. I had passed the summer in the foot-hills with a sketching kit on my back and a rifle in my hands, and had been about equally occtipied with the grand scenery and with the dusky grouse and rabbits. Once I had surprised a band of mountain sheep at a lick, by pure accident, and caused a fine old buck to ascend some hundreds of feet of steep rocks with great agility, the ball from my 36 -caliber "rim-fire" only drawing a few drops of blood. Anathematizing that gun as only a tyro can, I took the first opportunity to exchange for a 50 -caliber military rifle, with which I expected to fill the next opening to better purpose.

By and by the deer began to come down from the high feedinggrounds, and over the passes from the parks, and gradually to work south, "banded," and led by the old bucks, and making their way to the warm and sheltered wintering-places south of Pike's Peal. This migratory habit is observed wherever the high and rough nature of the country affords a secure summer retreat, but is too barren and storm-exposed for a winter habitat. Sometimes the hunters would break up and scatter one of these bands, and in twos and threes they would remain and infest the rough country for a time, until joined to a new leadership, and thus, timid and on the alert, they were much oftener seen than secured; the region back of Boulder being peculiarly hard hunting-ground, hilly and broken, and giving the keeneyed and keen-nosed animals a great advantage. One November morning, at three o'clock, bound to be early, and, if hard and conscientious work might avail, to carry a trophy into camp that day, I was trudging cheerfully up Boulder Cañon through the new-fallen snow. Before the dawn began to follow up the morning star, I had climbed a slide in a crevice, some hundreds of feet, and shivered for 
an hour under the pines, waiting for light enough to see to shoot. My method of approach to the foot of the long, shallow, wooded gulch in which I now stood had been well chosen. I had avoided a tedious circuit among logrs, and sticks that would snap, and stones that would roll, and a peculiarly exasperating large-leaved plant, that in its dry condition rattles when touched like castanets. I knew that the deer "used" in this vicinity, for I had frequently seen sign here; I had calculated the direction of the wind, the lay of the land, my course from the light of the rising sun, so that 1 might see better than be seen, hear better than be heard, and, if my nose could not help me, at least to aroid offense to any keener sense of smell than my own. I thought myself very sagacious. Well, in due time I decided that there was light enough for my purpose. Cautiously up the left sicle of the gulch I worked from tree to tree, peering among the shadows, scanning the earth as closely as possible to see whether anything had brushed the feathery flakes that barely covered it. I took a long time, and it grew light too fast, I thought. By and by, high up at the head of a grassy swale that wound down the center, I saw three imprints of round, plump bodies. The snow was deeper here; there were trees close behind, up the gulch, but evidently there had been no desire for shelter. They had all lain so as to see down the slope, their slender legs curled under for warmth, which had melted the bed a little and pressed it closely and firm. I put my hand on the half transparent matrix: it was not frozen yet; the little white pellets of snow-dust that came with the wind, slanting and rolling along the ground, had hardly begun to accumulate in the depressions made by the knees and feet. Evidently, my quarry had lain here in full view of my slow approach; what moment had they cunningly chosen to rise and slip away like shadows? They must still be near. See, the tracks are close together and rambling. No sudden fear, or they would be in pairs and far apart. Strange, they go down the gulch, on the side opposite. Cautiously again I begin to follow the little tell-tale tokens. Very cautious before, I am preternaturally so now. Not a footfall of my own, not a breath do I permit myself to startle my own ears with. I am an hour, perhaps, following these tiny, meandering foot-prints down to a point where they turn sharply and lead straight up the side of the gulch to the ridge at its edge. A new light-the sun is up now, but it isn't that-breaks upon me. It is 


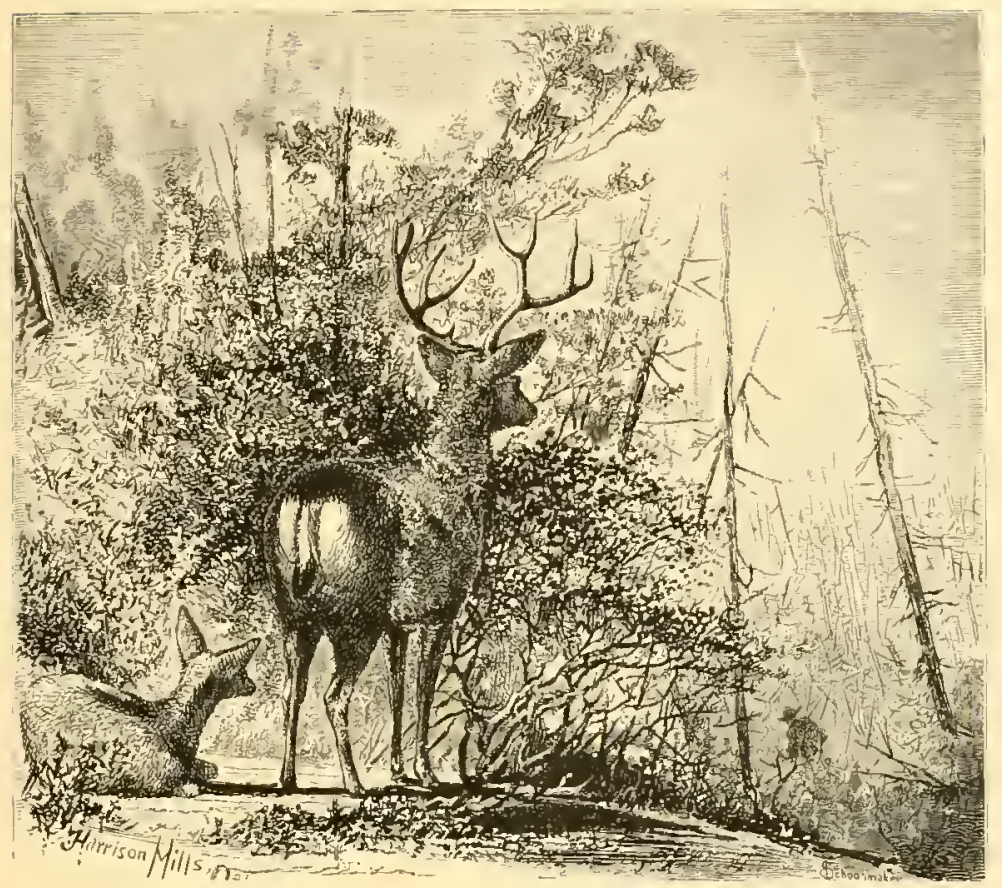

ARE YOU LOUKING FOR US?

hard to believe, but evidently those deer saw me as I began to look for them, and came down through the trees here to inspect me, - to see what I was about, in fact, - and they stood right here and watched me as I passed by on the other sicle, not a hundred yards away. And then they follow; yes, here run the tracks, right along the ridge. The rascals have even stopped when 1 did, measuring their progress with mine. And now I see that the trail has doubled. half the imprints pointing this way, and I begin to suspect still more of their tantalizing cunning. Yes, it is even so. Here they stood and saw my careful inspection of their sleeping apartment, still within easy shooting distance, but partly screened by netted boughs and twigs, and here they turned again and accompanied me down again, retracing their steps; and just at the point where 1 began to climb out, they evidently suspected that I was really in earnest, and that they had better go. The direction of their departure was indicated by three separate lines of double exclamation points in the snow, beginning about eighteen feet from where the light broke upon me as described, and leading due west. 


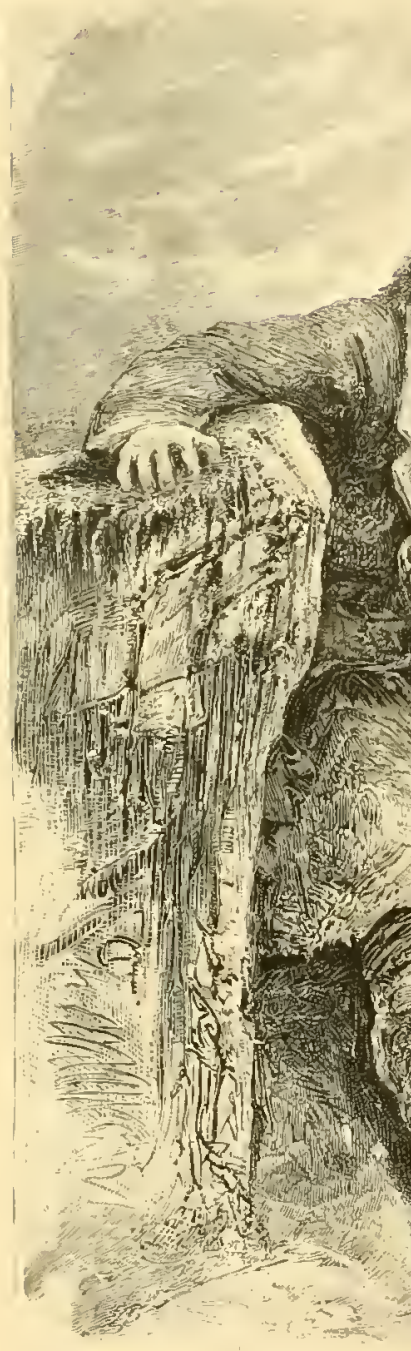

l shouldered my gun and sadly prepared to cross to the next undisturbed range.

That night, as I sat silently by the fire reviewing the day's experience and disappointments, - for I had tramped perseveringly and seen nothing to shoot, -I had to take some goodnatured rallying from the older Nimrods of the camp, who suspected that I had that day met some saddening disappointment.

"The boy aint nigh so chirk an' chipper tonight ez he

is usually," remarked Old Levi. "He's bin to school to-day. I 'xpect some ole buck up in the hills ez been playin' it fine on him."

My next failure was but a day or two later. Again I had risen with the star, having passed a bitter cold night in a deserted
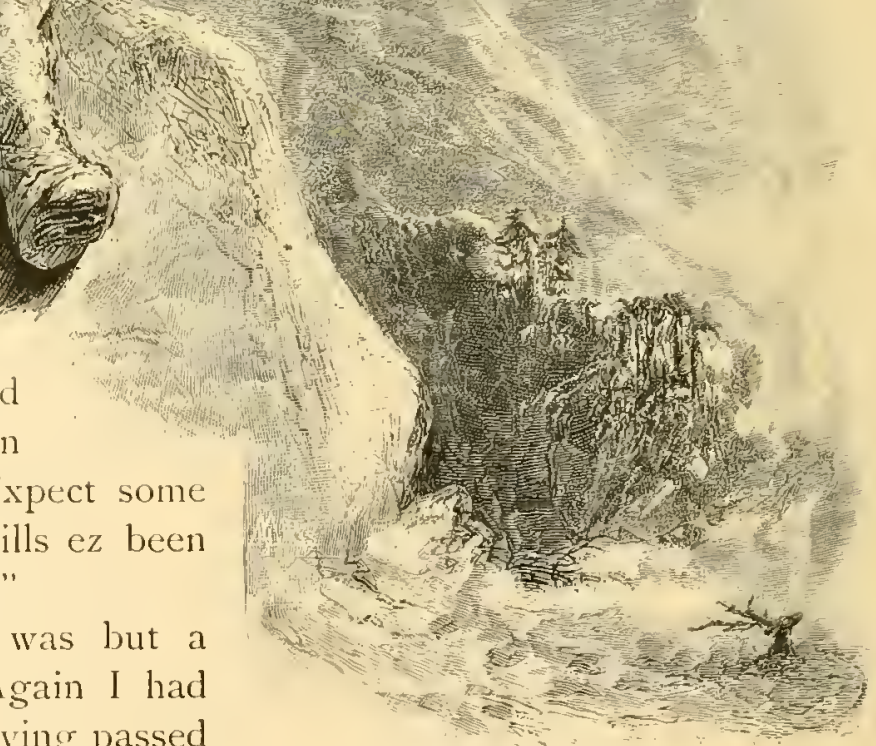

AN ATTACK OF "BUCK FEVER." 
cabin. This time I was successful thus far: I found sign and worked the ground carefully and correctly, my ambition spurred by what Old Levi had told me about a fabulously large buck that for four winters had used this ground, and, though frequently seen and shot at, had thus far escaped unscathed. I knew that Levi and Hank were at that moment less than a mile away, working toward the spot, and I dreamed a little of the delight of having them find me there when they arrived, with the coveted prize at my feet; but when my buck finally broke cover from among the rocks, - at my very fect, incleed,- he was such a beautiful sight, his polished antlers lying back almost upon his round, massive shoulders, his progress - flight, it truly seened - through that too brief vista of griant rocks, through which my way had cost such labor, was something so wonderful to see that I actually forgot I carried a gun till the brute with the charmed life was a mile away. Was it "buck fever"? Well, that was the way it took me; but I never had it afterward. The others soon came up. They had seen nothing. Again that day I was so fortunate as to find, so unfortunate as to fail. IVe had separated, they going toward Gold Hill, I working in the direction of Sugar Loaf Mountain. At the edge of a ravine, I saw a movenent in the thick growth below, faintly against the snowy bottom. I was indulgring in a smoke. In my haste to remove my pipe, I dropped it. Out then came a large doe, and, still uncertain as to the exact point of danger, in short, high jumps went half way up the rise to my left. A prettier shot never offered than when she stopjed, not a hundred yards away, to look at me for a moment. I had a blanket rolled and slung across my shoulder, and in my haste and flurry I forgot it; it got in the way as I brought my rifle up; I stopped to drop $j$, and when I fired, it was at a moving object instead of at a stationary one. I saw the dirt and snow fly a little too high and just ahead of her.

That night after sunset I was building a fire against a huge rock, in the snuggest nook I could find on the east foot of Sugar Loaf, when a tall, good-looking man in an army coat, with a huge muzzleloader under one arm and a little yellow dog on the other, approached my bivouac.

"Hullo! Good-evening! What are you doing here such a night as this?" 
The snow was drifting, and it did promise to be an ugly sort of night. However, I proceeded to explain, as a matter of course, that $I$ was heating this rock to make my bed against; that when it and

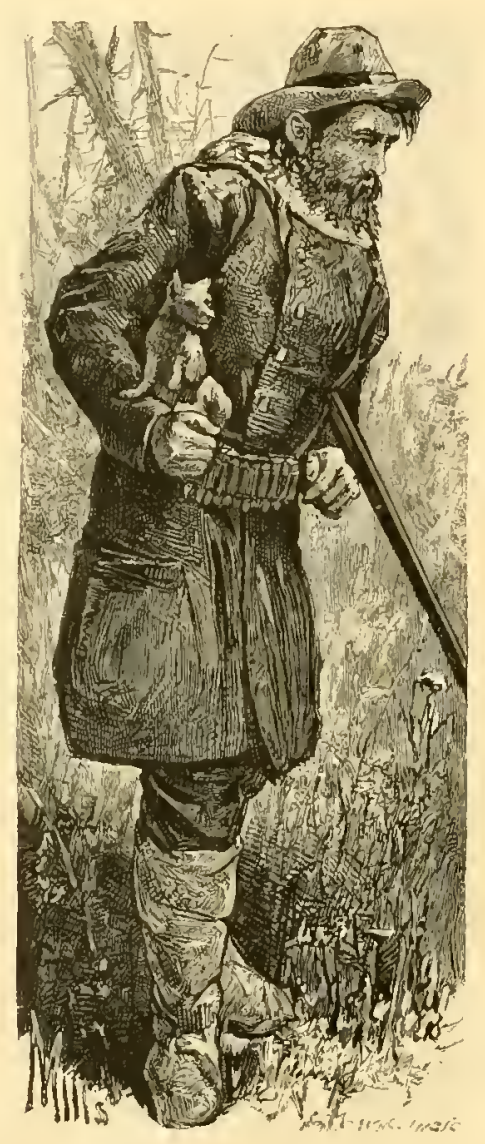

OSBORNE AND HIS DOG.

the ground were sufficiently warmed, I proposed to move the fire out a couple of yards, replenish it, and then and there to roll up in my blankets and sleep the sleep of the just.

"Didn't you see a cabin as you came down the gulch up there?" inquired the tall man, with a puzzled or quizzical smile-I suspected a little of both.

"Y'es," I replied.

"Well, what kind of people do you take us for, anyhow, to think we'd let anybody lie out such a night as this is goin' to be? Just 
pick up those traps of yourn and come along with me, an' don't you ever do that again in this vie-cinity. You'd 'a' been in a nice fix here before morning."

I was on my mettle in those days, and inclined to be proud of my powers of endurance. I had quite enjoyed the prosprect of practicing this kind of bed-warming, which 1 had heard the old fellows tell us of as something to make the pilgrim wonder, and I hardly relished the half-apparent amusement of this big mountaineer, who wasn't in the least impressed by my show of resignation and resources. One look at the black sky, that seemed to be rapidly settling earthward, decided me, however, and with a grateful acknowledgment and a half sense of relief, I followed my entertainer to his mountain home. Ah, those steaks, cut from the rump of that three-hundrect-pound buck hanging in the back room! There were three inches of fat on

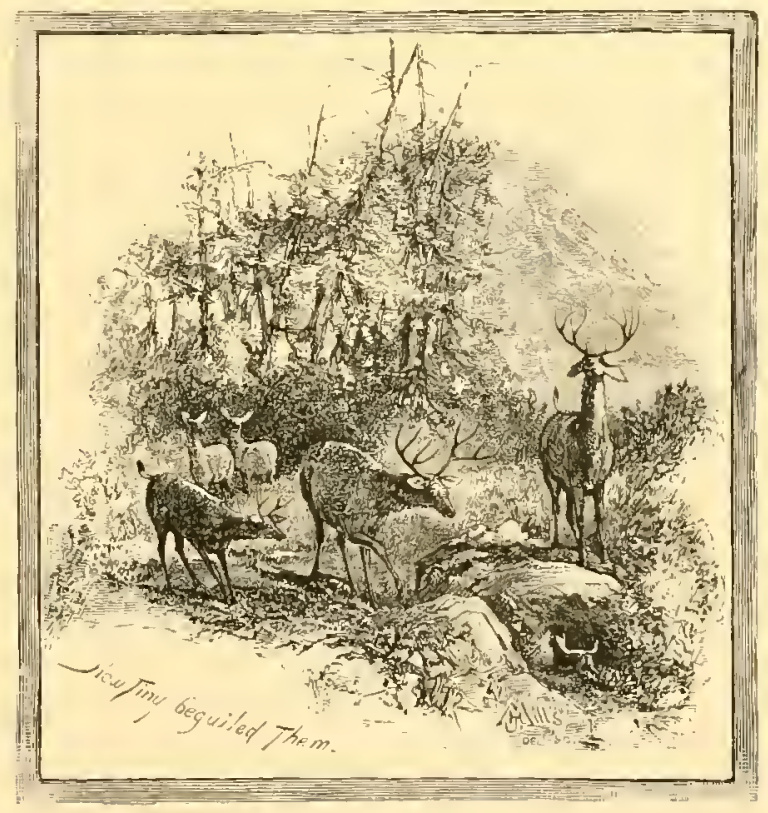

the edges of them, and my handsome hostess blushed before the fire, as she turned them to a beautiful brown, while the little dog looked on with an air of quiet approval and anticipation.

"That's my huntin' dog," said Big Osborne, laughing at my stare of surprise, not to say incredulity. "Yes, sir; and that's the kind of 


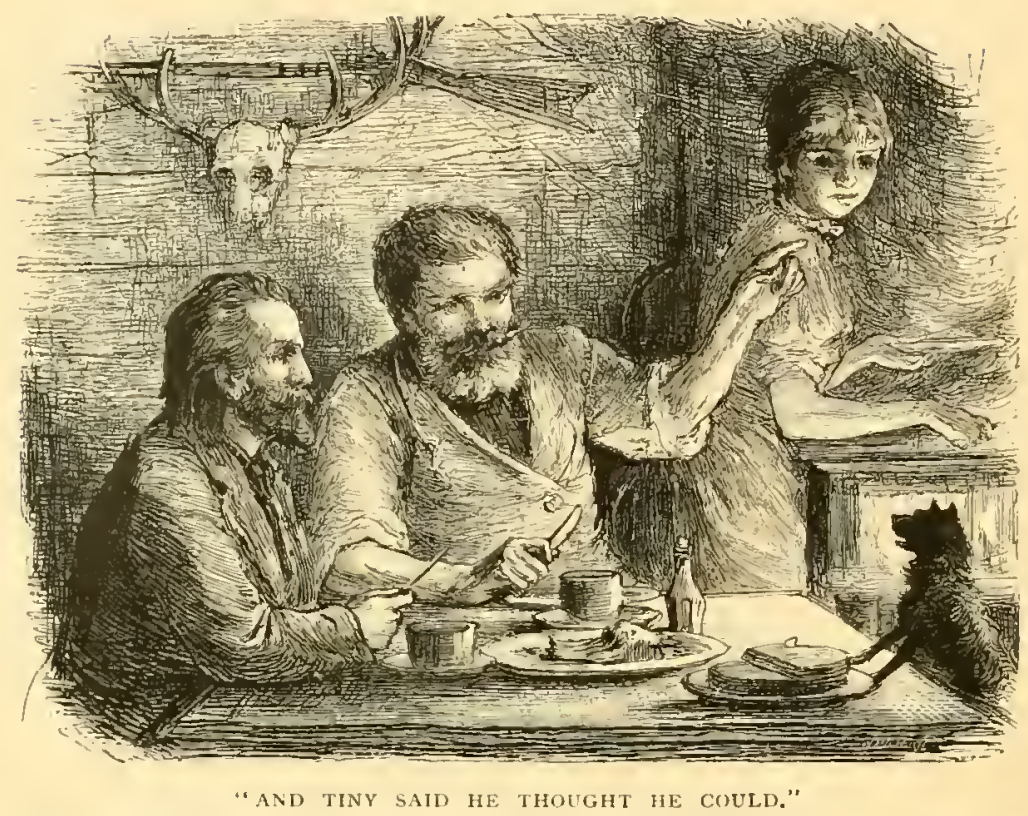

dog for these hills. IOn't scare the deer away, and always fetches 'em. I can take twenty-five dollars for that dog any day; but money can't buy him. You see, he knows as well as I do just what to do. When I get to see a band, I just put him down, and he groes right for 'em and begins to bark. Well, you see, the big ones wont run for him, and after stamping awhile they take after him. He runs a little ways, and then they stop, and he begins to bark again ; and so he keeps leading 'em right toward me, or l keep working up to 'em; and they're so worried and mad and interested, that sometimes I get in two or three shots before they get wind of me at all. That's the way I got that big buck, and I reckon he'd 'a' been too cunning for me: but Tiny fetched him, and he can do it every time. Can't you, Tiny?"

And Tiny said he thought he could.

Next morning, I resumed my hunt; but, although I saw frequent indications of their recent movements - probably during the nightin large bodies, I saw no more deer, and again I returned emptyhanded, this time consoled by the fact that the others had no better luck: in fact, they had not seen a deer at all.

But through faikures like these is the way to uttimate success. I saw my blunders, and thought I might profit by them. I saw that I 
lad yet to learn how to look. There is something in knowing a deer when you sec him. A friend tried long and faithfully to show a deer, standing in full view, to an eager but untrained sportsman, and then had to shoot it before he could see it. He saw it when it fell down, kicking. You look among bowlders and logs, and all are perhaps alike to you; but by and by a bowlder surprises you by jumping, without warning, twenty feet into the air, over another very large one, perhaps, and almost always up-hill; and, while your heart bumps your mouth open, the bowlder disappears, and you say, "Oh! why didn't I shoot him?" Sure enough, why?

It is a most surprising thing to see a deer get up on its legs, - at home, I mean, and when he would prefer to be alone. Watch a cow at the same operation. Laborious elevation of one end, then of the other: then a great yawn, and a cracking of joints, and a lazy twist of the tail and a mighty snort of bovine satisfaction, and she is ready to go to pail or pasture. But she don't budge, mind, without the regular formula. How does a buck start for pasture when you drive him up in the morning? Why, he lies with his four feet under him, and when he is ready to go it is like Jack getting out of the box. The tremendous extensor muscles contract with all the power and facility rest and warmth have given them, and the plump body, like a well-inflated rubber ball propelled by a vigorous kick. flies lightly into the air. The simile is borne out as it seems about to descend; light as thistle-down it nears the earth; another giant impulse from an unseen power-crash-and again it describes its light parabola: crack--bump-thud-thud-thud-each time fainter than the last, and your surprise is all that remains.

The time, patience, effort, and study I spent cluring that winter and the summer and winter following in learning how to outwit that subtlest of all harmless creatures would have mastered a much more exact science. I realized a degree of success, however; and when I stood over my first buck, not chance slain, but really outdone in craft, shot through the heart as he sprang to his feet and turned to see me not twenty steps away, - seeing me and suspecting danger only at the instant of his death, while I had followed him for hours, unsuspected, patiently, perseveringly, - I felt that the achievement was worth all it had cost. Meantime, I had risen with the morning star for days together, crept through miles upon miles of all sorts of 
growth and over all sorts of ground; had seen scores of deer, wounded a few, to my great regret, but, as a rule, had been sparing of ammuntion, unwilling to miss or only to maim. And so 1 came to know them well, and I an glad to say that I was never tempted to harm an inexperienced and careless fawn, or the doe cumbered with maternal cares, although opportunities were frequent for making sure work with these.

1 think the man that can kill a "papoose"-unless impelled by the hunger that knows no law - is no better than an Indian. He is a grade worse. Here, in Colorado, the game-law lets a man kill a deer out of season if he is hungry or if his fanily needs the meat. It ought to imprison the man who will kill a fawn for any other reason, or even then, if he can get jack-rabbits instead. I once heard Len Pollard tell about killing a doe in the bad lands when he was almost starving, on one of his wild journeys. It was July. She was very poor, but Len was hungry. As he stooped to bleed her, something touched the hand that was drawing his knife. It was a little fawn, and right behind it in the bushes was its $t w i n$. Both came and smelt the body, and then licked the hunter's hands. Len is made of good stuff, and he couldn't stand that. He mounted his horse, but the little things followed, and finally he turned and mercifully killed both of them rather than leave them to starve. But he recalls it rather in the light of a tragedy.

Leaving camp early, but not until after a good breakfast, with a brace of invalids whose Colorado appetites are beginning to clamor for relief from the monotony of fresh trout, caught from the stream beside which is our rest, and which the Indians call Yampah, - with light enough to show a moving object a mile away, or a fresh track from the saddle, I will suppose myself, one September morning, five years after the day of disappointment just described, riding at a leisurely pace up a long hollow in a hill-side with an east and south exposure. I have never hunted here until now, but I see groves of quaking asp succeed each other for miles away to the right: and, through occasional vistas to the left, the black pine-tops show, rising from the river by west and north slopes to meet me on the rounded crest bared by last year's fires. There the ground will surely show if any of the kind I seek have lately passed, and those groves are the haunts they love. Skirting their upper edges, with now and then 


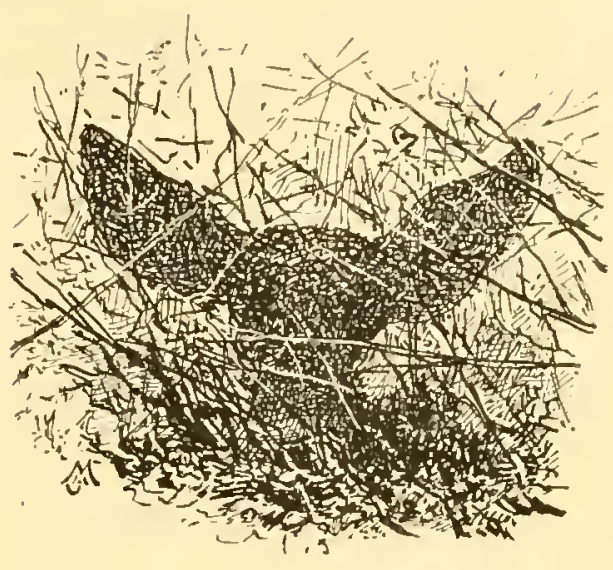

A PATTERN IN A NET OF TWIES.

an incursion, I ride for miles. Not a sign. I ride now with haste, for not until I see sign will I begin to hunt. Suddenly, a fresh tracktwo of them-leisurely winding downward. In a moment, alert. I am on the ground, taking the rein over my pony's head as, rifle in hand, I dismount, so that if I let him go he will put his foot in it presently and hold himself there. (A lariat looped at the saddlefork, or held coiled in the left hand ready to drop, Inclian fashion, is also good.) I intend to leave him here to feed while I prowl around to watch and listen, but presently I make out a peculiar pattern in the net-work of low branches and little sprouts of trees. It is very significant to me; I know there can be no mistake about it, and I immediately send a ball just under the center portion. The pattern disappears without noise, and I reload, catch my pony, that has merely stepped aside at the flash and report of my $4+$-caliber Creedmoor, and lead him about sixty yards into the thicket, and there lies a fine fat doe.

After some dexterous use of the knife, a noose of the lariat hack of her shoulders, a turn forward about the "horn" of the saddle, a few tugs and hitches, and the limp one hundred and fifty pounds is secured by the hooks in the cinch, - for this case made and provided; my patient old Cub, meantime, pretending a vicious attack upon my buckskin breeches, but standing stanchly while I lift and make all fast and secure. Then my gun slung across my shoulder, the sunset in our faces, Cub and I jog lazily toward camp. The sage-hen rises noisily and unwillingly, with much cackle, from our very feet; noise- 
less prowlers, long and lithe, slip from shadow to shadow; the coyote yelps complainingly in the distance, and a camp-fire is twinkling away down by the dim river.

So long as he knows he is unobserved-and your old buck is as shrewd as a man in judging of this, - he stands and eyes the hunter with the coolest curiosity. The moment the approach is direct, changing from oblique, or the hunter conceals himself, or halts and crouches, that moment "old smarty" runs away. The gun should be at the shoulder when the hunter halts to shoot, or there is no time. Often he will lie and lazily watch the approaching enemy, as, gun in hand, he labors along through fallen wood and rocks, and after perhaps a half hour's enjoyment of the game of hide-and-seek, the search getting a little too warm, he will at one jump from his lair, clear a huge rock or log and disappear, his feet leaving the exact imprints in which they have rested perhaps for hours. Frequently, the only evidence the hunter has of his vicinity is the break-neck clatter and crash, sudden as an avalanche, in which the alarmed animal seeks safety and at the same time warns all of his fellows. The best plan then is for the hunter to take another tack, in doing which he may possibly find his game doubling upon him, particularly if he strike for higher ground.

Don't continually try your gun at a mark. It scares the hunters and the game. "What a nice spot to shoot at!" or, "See if I can't hit that tree 'way over there," says Tenderfoot, and presently some startled mountaineer yells out, "Here! who the future condition of misery are you a-shootin'?" which is an awkward query when propounded by an ugly-looking man with a navy armament in his belt. You might hit him after honestly missing a deer or a bear, and he wouldn't blame you so much; but he detests this aimless fusilade which only drives away the game. He suspects, too, that this waster of ammunition will have poor success; for a "dead shot," even, at a target may be a muff in the game country.

Try to be cool enough to mark whether your ball strikes over or under when you miss a shot with a hill-side background. After awhile you will instinctively measure distances and elevate accordingly. Whatever theoretical sportsmen may say, you can just as well estimate a scale to elevate to as the distance of your object, and 
can judge of the perpendicular from bead to notch just as well without the upright bar, or "elevated sight," to waste time in adjusting.

This is the practice of all the old hunters of my acquaintance: Draw on your object fine, as if close by; then, keeping the bead on him, lower the breech carefully till you can see such full elevation of sight, or portion of barrel below it, as in your judgment, guided by experience, is equivalent to the distance, and cut loose. If your rifle is of small caliber, say $\frac{40}{100}$, and uses the long ball, with a heavy charge of powder, making a low trajectory, you will rarely, in these mountains, need to draw coarser than the whole height of the "front sight." or up to, say, twice its height for three hundred yards or a little over. Of this you must know by experiment, however, the amount and strength of powder, weight and density of ball, etc., varying in many cases, as well as the height of sights and distance between them.*

At first, you had better take only such chances as offer within sure range. Take the body rather than the head, and well forward, - just at the point of the shoulder is best. Pull as though you had
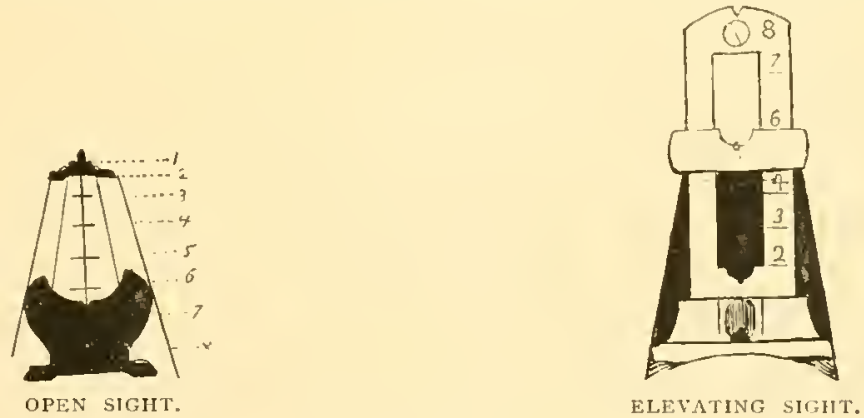

got all day to do it in, even if you use double triggers, which are an abomination.

* In showing the hunter's method of "elevating," I have also illustrated a device of my own, which, upon careful trial, will be found to serve as a ready and faithful substitute for the bar and slide. Let your gunsmith sink a line from behind the bead straight toward the notch of the "buck-horn" sight. At intervals, to mark the degree of elevation for $150,200,300,400$, or 500 yards, these intervals determined by experiment, or by looking through a "peep" sight placed, as usual, back of the breech. cut cross-lines wide and deep enough to be distinctly seen. Of course, the perpendicular line from the bead must, in sighting, fill the notch center, and the cross-line for the distance required may seem to rest upon the top of the buck-horn. The novice in "off-hand" shooting will find this a great help to his progress. 
Morning and evening are best to hunt in. In the bright of the moon, deer feed at night, resting while the sun is high. If not much hunted, they lie in the shade, not far from water; if often alarmed, they "roost high" and keep a good lookout, or perhaps leave for a quieter range. Fires and smoke they detest, and they soon learn to associate the report of fire-arms with the presence and scent of human beings. Still, by judicious method, they may be "herded," till you have all the meat you can take care of.

If a mountain man tells you that he don't know where the game is, believe him. It has become so unsettled by constant and careless hunting (which does not deserve the name- "driving" would better express it) that one must be in constant experience to know its present accessible haunt. It may be plentiful here to-day and gone to-morrow. The incursions of coyotes and foxes among the fawns, and the approach of a mountain lion, or of a man that shoots incessantly, are marching orders to them. Also, to repeat, fire and smoke they particularly abhor. At almost any season, a conflagration may occur, originating in the criminal carelessness or ignorance of some one who has failed to put out his camp-fire, or in the detestable policy of the Indians, or some malcontents among them, at least, who set these fires to destroy the timber that might be of use to the whites and to drive away the game into their own country, it being their policy to disturb their own "cattle," as they term them, as little as possible.

Remember that to see your game before it sees or smells you is the greatest advantage. It sometimes happens that when already in motion, not thoroughly startled, but suspicious, it may be induced to stop and turn by a shrill whistle or a stone thrown in advance. If approaching you and unaware of you, the first will nearly always prove the best thing to do. In the instance illustrated in the picture entitled "The Fall of the Leader," a small band of males is in full flight from the course of a sudden storm. The leader, some yards in advance, stops suddenly, with ears and eyes alert to find the source and cause of an unfamiliar sound more startling than the roar of the winds behind, and, smitten in the same instant, clears at one leap the last intervening logs and yields his life in the dry path of the coming flood.

Always picket or hobble your animals at night, or at least picket one of them - the leader, if they acknowledge one. Neglect of this will cost time and money and vexation. 


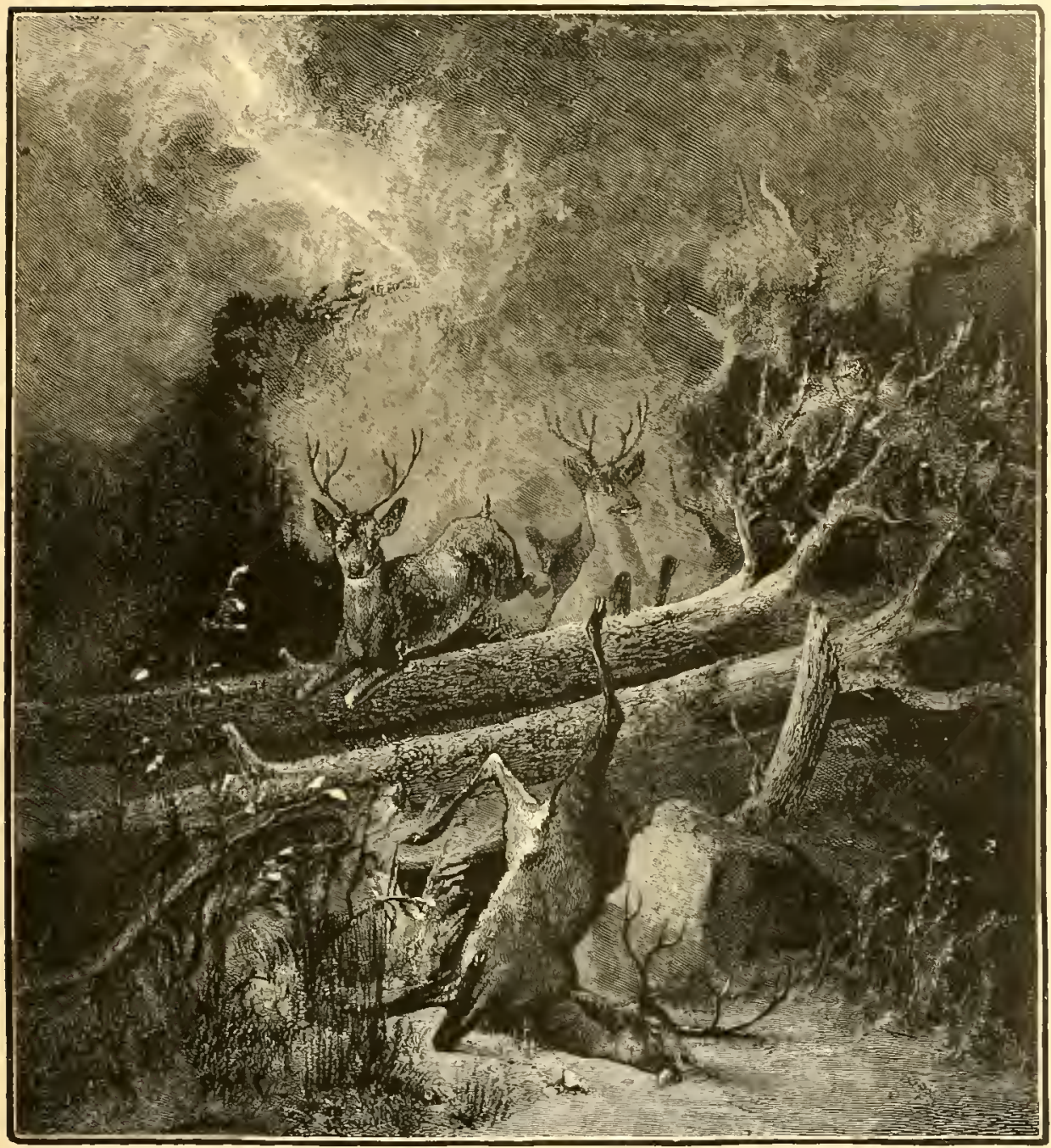

THE FALI, OF THE, LEADER.

If you gret lost, stay where you are till somebody finds you or you find yourself; $i$. $c$. discover some landmark to guide you back. If you have familiarized yourself with the countenances of the high peaks and their bearings, direction of water-courses, etc., and have been careful to take a good look back now and then, you can hardly fail to retrace your steps.

In following a trail, if it suddenly disappears, carefully note the spot where your uncertainty begins, so that you may, at least, find that again. Usually this will occur where pack animals stray or straggle aside to feed, and the riders leave the trail to drive them in, I 8 A 


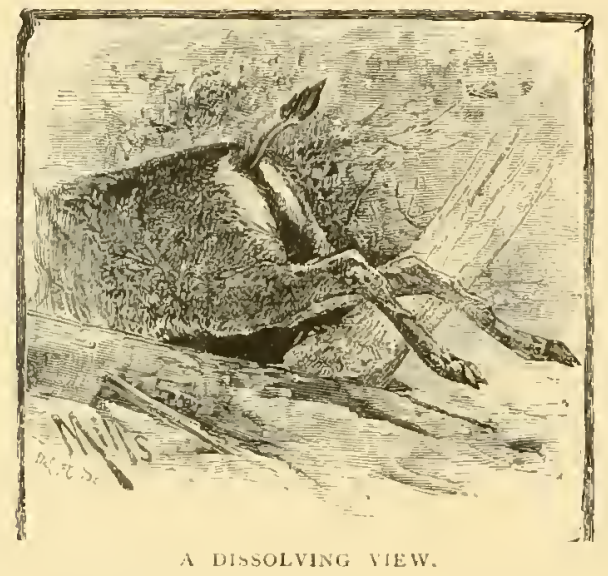

or on difficult crossings of swampy bottoms, where slow progress makes it necessary for a party to widen out, each picking his own way. By careful scrutiny of the far sicle of the open space, morass, or intervening growth, you may usually see, or at least see indications, of the trail you seek.

To save meat for future use, cut it in thin strips, with the grain, and string them on a lariat in the sun. After a few hours of exposure, which may be at successive camps if necessary, it will be thoroughly "jerked." Salt is not indispensable.

Always have matches about you, in some water-proof receptacle.

Let a bear cub alone. Fool with an old bear if you must, but be sure there is no small family about.

In fording a river, look out for "quicks." These, I believe, are never found in swift water. The "riffles"- a term probably peculiar to the Vest, where the stream widens, or below a bend, particularly if there be islands or bars - indicate the places where you may attempt to ford.

Choose rocky or clayey ground, if possible, or clear sand, to build your fire upon: if on a muck of pine-needles, it will burrow, and water will not quench it all. Then, in a day or two, the whole country is burning over and the game driven away, to say nothing of the possible peril to others, and the destruction of the forests.

This is not the whole art of woodcraft, but it will do to begin with, and may suffice. Is a closing word, 1 advise you to be tem- 
perate, and, while doing your share, not to attempt too much. Find a good place and go into camp, instead of trying to do the whole West in a season, and you will probably count among your pleasantest recollections your deer-hunts and hunting-camps in Colorado.

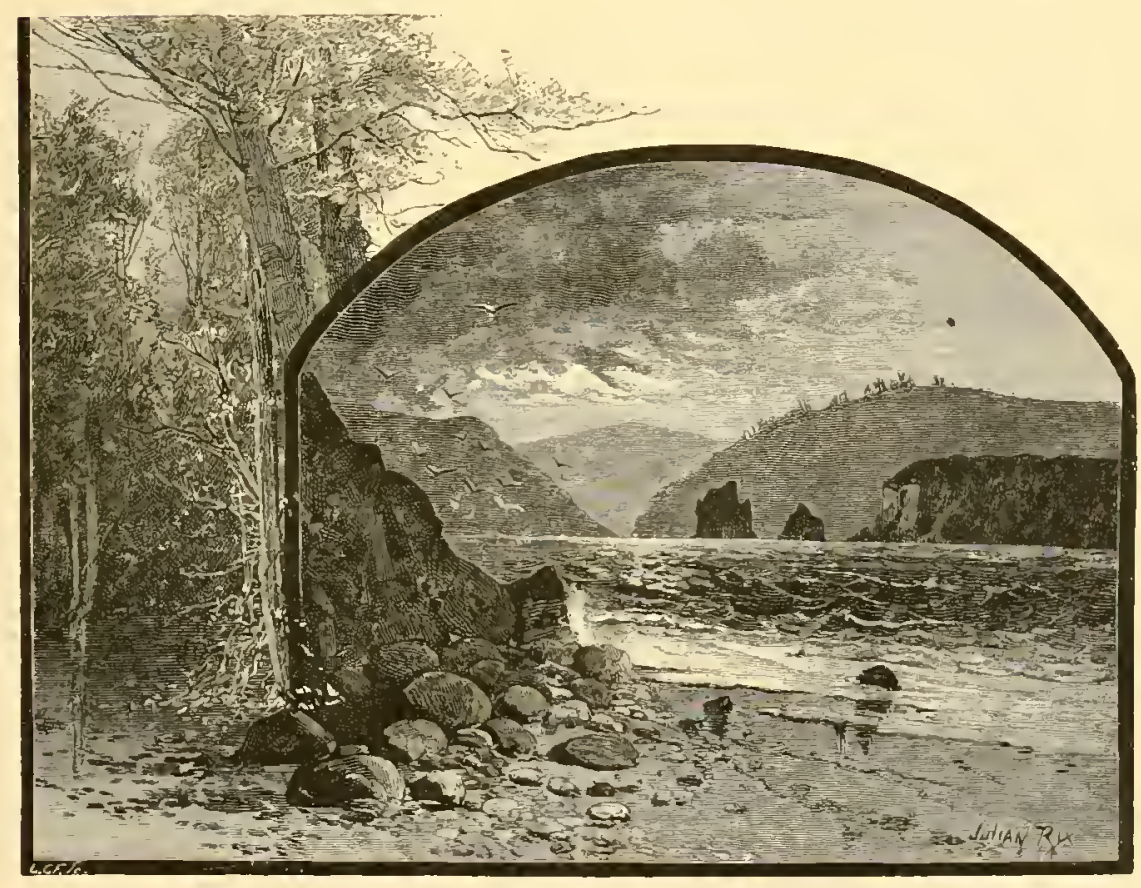




\section{THE WILD SHEEP OF THE SIERRA. \\ BV IUHN MUIR.}

T

HE wild sheep ranks highest among the animal mountaineers of the Sierra. l'ossessed of keen sight and scent, immovable nerve, and strong limbs, he dwells secure amid the loftiest summits of the Alps, from one extremity of the range to the other; leaping unscathed from crag to crag, up and down the fronts of gidly precipices, crossing foaming torrents and slopes of frozen snow, exposed to the wildest storms, yet maintaining a brave, warm life, and developing from generation to generation in perfect strength and beauty.

Nearly all the lofty mountain chains of the globe are inhabited by wild sheep, which, by the best naturalists, are classified under five distinct species. These are the argali (Oils ammon, Linn.), found throughout all the principal ranges of Asia; the burrhal (Oirs burhel), of the upper Himalayas; the Corsican moufflon (Oris musimon, Pal.); the African wild sheep (Ovis tragclephus, Cuv.); and the American big horn, or Rocky Mountain sheep (Ovis Montana, Cuv.). To this last-named species belongs the wild sheep of the Sierra Nevada. Its range, according to Professor Baird, of the Smithsonian Institution, extends "from the region of the upper Missouri and Yellowstone to the Rocky Mountains and the high grounds adjacent to them on the eastern slope, and as far south as the Rio Grande. Westward it extends to the coast ranges of Washington Territory, Oregon, and California, and follows the highlands some distance into Mexico." * "Throughout the vast region bounded on the east and west by the Wasatch Mountains and the Sierra Nevada, there are more than a hundred independent ranges and

* Pacific Railroad Survey, vol. viii., page 678 . 


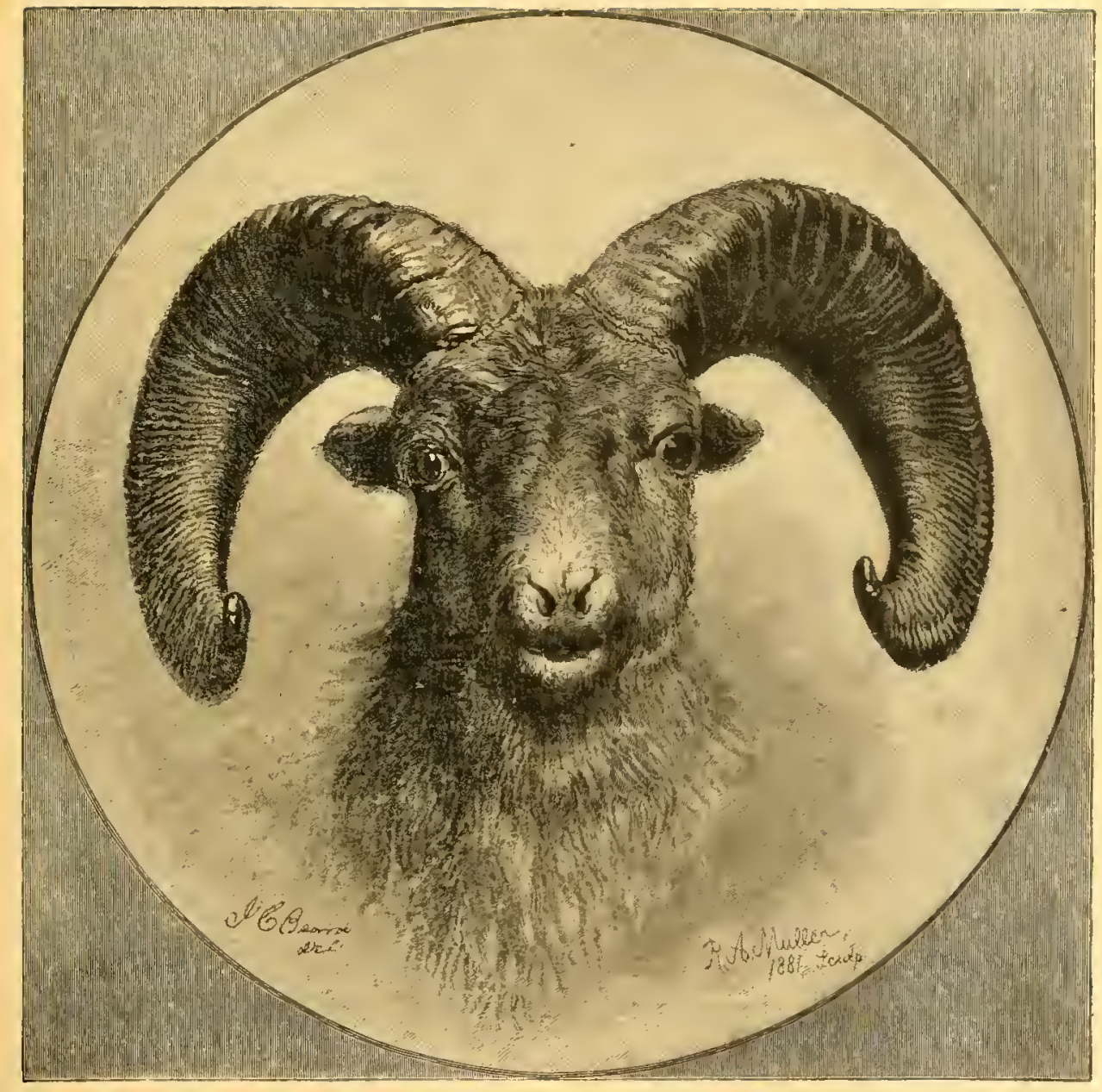



mountain groups, trending north and south in close succession, range beyond range, with summits rising from eight to twelve thousand feet above the level of the sea, every one of which, according to my own obseryations, is, or has been, inhabited by this species of sheep.

Compared with the argali, which, considering its size and the vast extent of its range, is probably the most important of all the wild sheep, our species is, perhaps, a little larger, and the horns are more regularly curved and less divergent. The more important characteristics are, however, essentially the same, some of the best naturalists maintaining that the two are only varied forms of one species. In accordance with this view, Cuvier conjectures that the argali may have been distributed over this continent from Asia by crossing Behring Straits on ice.

On account of the extreme variability of the sheep under culture, it is generally supposed that the innumerable domestic breeds have all been derivect from the few witd species; but the whole question is involved in obscurity. According to Darwin, sheep have been domesticated from a very ancient period, the remains of a small breed, differing from any now known, having been found in the famous Swiss lake dwellings.

Compared with the best-known domestic breeds, we find that our wild species is more than twice as large; and, instead of an all-wool garment, the wild wears a thick overcoat of hair like that of the deer, and an under-covering of fine wool. The hair, though rather coarse, is comfortably soft and spongy, and lies smooth, as if carefully tended with comb and brush. The predominant color during most of the year is brownish-gray, varying to bluish-gray in the autumn; the belly and a large, conspicuous patch on the buttocks are white; and the tail, which is very short, like that of a deer, is black, with a yellowish border. The wool is always white, and grows in beautiful spirals down out of sight among the straight, shining hair, like delicate climbing vines among stalks of corn.

The horns of the male are of immense size, measuring in their greater diameter from five to six and a half inches, and from two and a half to three feet in length around the curve. They are yellowishwhite in color, and ridged transversely, like those of the domestic ram. Their cross-section near the base is somewhat triangular in outline and flattened over toward the tip. In rising from the head, 
they curve gently backward and outward, then forward and outward, until about three-fourths of a circle is described, and until the flattened, blunt tips are about two feet apart. Those of the female are flattened throughout their entire length, less curved than those of the male, and much smaller, measuring less than a foot along the curve.

1 ram and ewe that 1 obtained near the Modoc lava-beds, to the north-east of Mount Shasta, measured as follows :

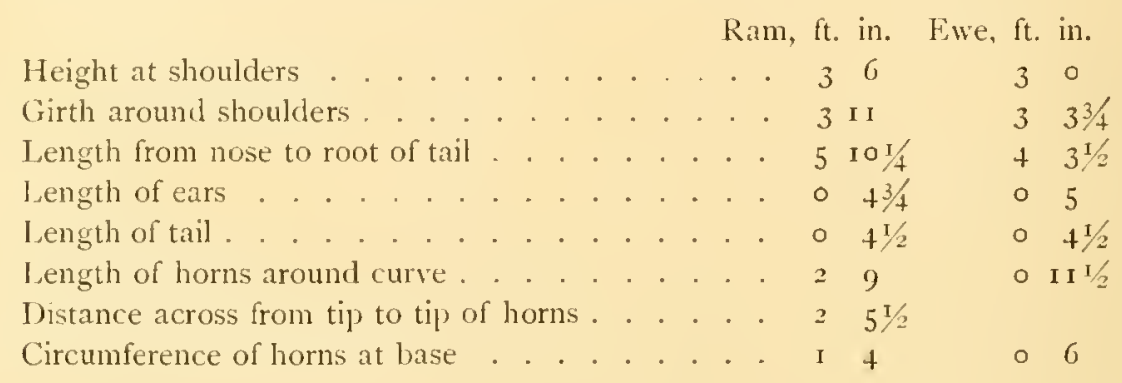

The measurements of a male obtained in the Rocky Mountains by Audubon vary but little as compared with the above.

The weight of his specimen was three hundred and forty-four pounds, ${ }^{*}$ which is, perhaps, about an average for full-grown males. The females are about a third lighter.

Besides these differences in size, color, clothing, etc, as noted above, we may observe that the domestic sheep, in a general way, is expressionless, like a dull bundle of something only half alive, while the wild is as elegant and graceful as a deer, and every movement tells the strength and grandeur of his character. The tame is timid; the wild is bold. The tame is always more or less ruffled and dirty; while the wild is as smooth and clean as the flowers of his mountain pastures.

The earliest mention that 1 have been able to find of the wild sheep in America is by Father Picolo, a Catholic missionary at Monterey, in the year 5797 , who, after describing it, oddly enough, as "a kind of deer with a sheep-like head, and about as large as a calf one or two years old," naturally hurries on to remark: "I have eaten of these beasts; their flesh is very tender and delicious." Mackenzie, in his northern travels, heard the species spoken of by

* Audubon and Bachman's "Quadrupeds of North America." 


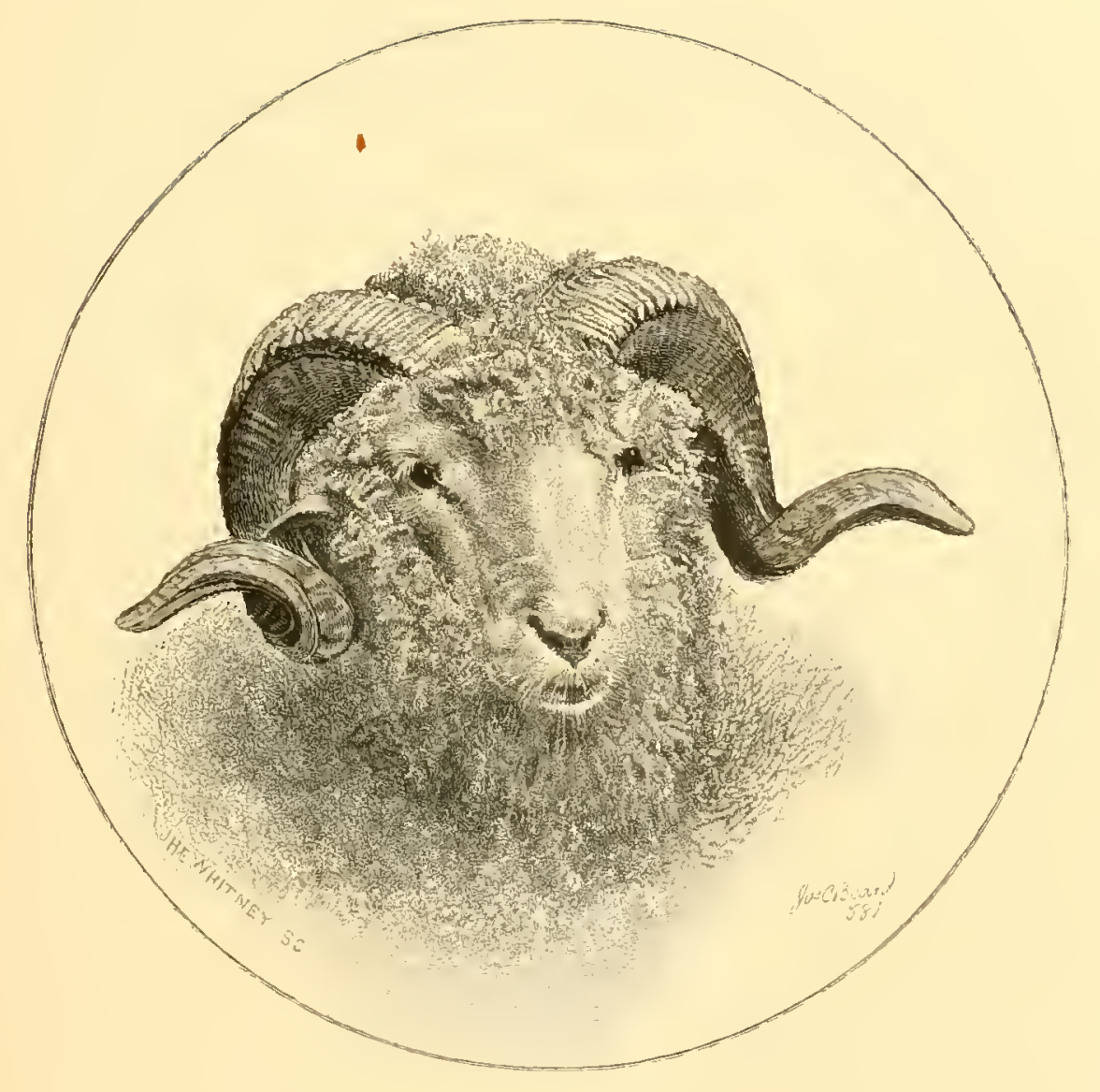

HLAU OF THE MERINO RAM (DOMESTIC).

DRAWN BY JAMES C. HEARD 

the Indians as "white buffaloes." And Lewis and Clark tell us that, in a time of great scarcity on the head-waters of the Missouri, in their journeys they saw plenty of wild sheep, but they were "too shy to be shot."

A few of the more energetic of the Pah Ute Indians hunt the wild sheep every season among the more accessible of the California Alps, in the neighborhood of passes, where, from having been pursued, they have at length become extremely wary; but in the rugged wilderness of peaks and cañons, where the foaming tributaries of the San Joaquin and King's rivers take their rise, they fear no hunter save the wolf, and are more guileless and approachable than their tame kindred.

I have been greatly interested in studying their habits during the last ten years, while engaged in the work of exploring those high regions where they delight to roam. In the months of November and December, and probably during a considerable portion of midwinter, they all flock together, male and female, old and young. I once found a complete band of this kind numbering upward of fifty, which, on being alarmed, went bounding away across a jagged lavabed at admirable speed, led by a majestic old ram, with the lambs safe in the middle of the flock.

In spring and summer, the full-grown rams form separate bands of from three to twenty, and are usually found feeding along the edges of glacier meadows, or resting among the castle-like crags of the high summits; and whether quietly feeding or scaling the wild cliffs for pleasure, their noble forms and the power and beauty of their movements never fail to strike the beholder with lively admiration.

Their resting-place seems to be chosen with reference to sun shine and a wide outlook, and most of all to safety from the attacks of wolves. Their feeding-grounds are among the most beautiful of the wild gardens, bright with daisies, and gentians, and mats of purple bryanthus, lying hidden away on rocky headlands and cañon sides, where sunshine is abundant, or down in shady glacier valleys, along the banks of the streams and lakes, where the plushy sod is greenest. Here they feast all summer, the happy wanderers, perhaps relishing the beauty as well as the taste of the lovely flora on which they feed, however slow tame men may be to guess their capacity beyond grass. 


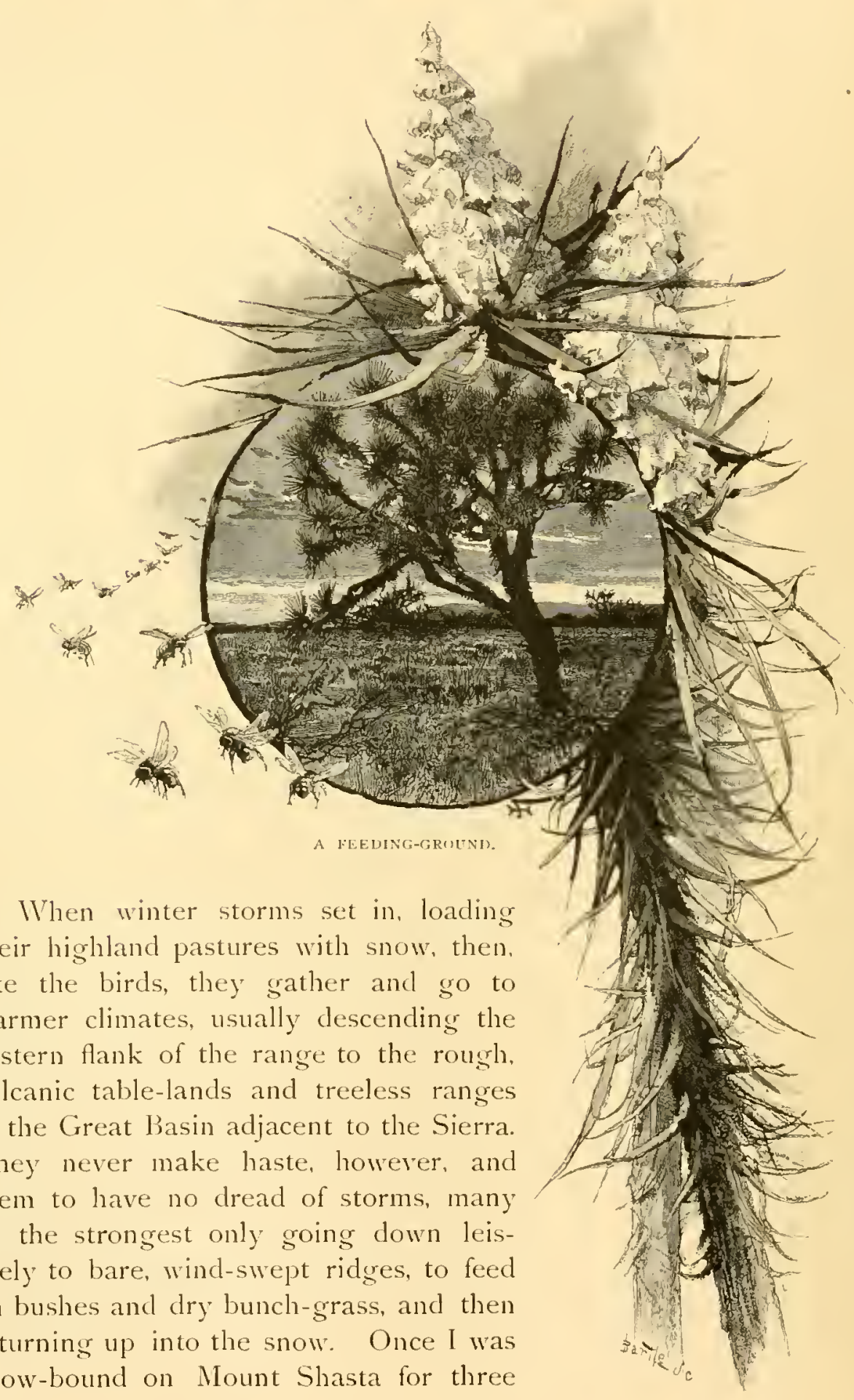




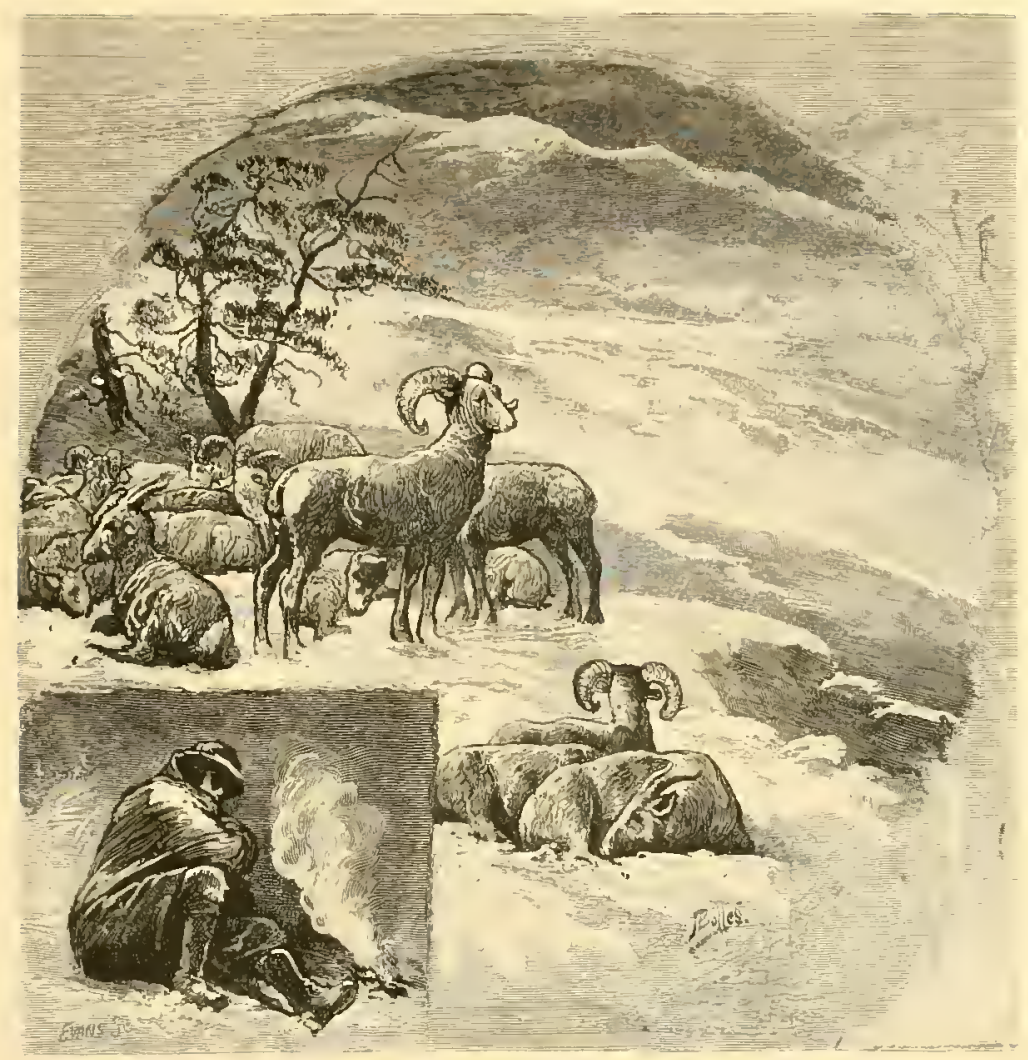

days, a little below the timber-line. It was a dark and stormy time, well calculated to test the skill and endurance of mountaineers. The snow-laden gale drove on, night and day, in hissing, blinding floods, and when at length it began to abate, I found that a small band of wild sheep had weathered the storm in the lee of a clump of dwarf pines a few yards above my storm-nest, where the snow was eight or ten feet deep. I was warm back of a rock, with blankets, bread, and fire. My brave companions lay in the snow, without food, and with only the partial shetter of the short trees, yet made no sign of suffering or faint-heartechess.

In the months of Mlay and June, they bring forth their young, in the most solitary and inaccessible crags, far above the nesting-rocks of the earle. I have frequently come upon the beds of the ewes and lambs at an elevation of from twelve to thirteen thousand feet above sea-level. These beds are simply oval-shaped hollows, pawed out 
among loose, disintegrating rock-chips and sand, upon some sunny spot commanding a good outlook and partially sheltered from the winds that sweep those lofty peaks almost without intermission. Such is the cradle of the little mountaineer, aloft in the very sky; rocked in storms, curtained in clouds, sleeping in thin, icy air; but, wrapped in his hairy coat, and nourished by a strong, warm mother, defended from the talons of the eagle and teeth of the sly coyote, the bonnie lamb grows apace. He soon learns to nibble the tufted rock-grasses and leaves of the white spiræa; his horns begin to shoot, and before summer is done he is strong and agile, and goes forth with the flock, watched by the same divine love that tends the more helpless human lamb in its warm cradle by the fireside.

Nothing is more commonly remarked by noisy, dusty trailtravelers in the high Sierra than the want of animal life-no birds, no deer, no squirrels. But if such could only go away quietly into the wilderness, sauntering afoot with natural deliberation, they would soon learn that these mountain mansions are not without inhabitants, many of whom, confiding and gentle, would not try to shun their acquaintance.

In the fall of 1873 , I was tracing the South Fork of the San Joaquin up its wild cañon to its farthest glacier fountains. It was the season of Alpine Indian summer. The sun beamed lovingly; the squirrels were nutting in the pine-trees, butterflies hovered about the last of the golden-rods, willow and maple thickets were yellow, the meadows were brown, and the whole sunny, mellow landscape glowed like a countenance with the deepest and sweetest repose. On my way over the shining, glacier-polished rocks along the foaming river, I came to an expancled portion of the cañon, about two miles long and half a mile wide, inclosed with picturesque granite walls, like those of Yosemite Valley, the river pouring its crystal floods through garden, meadow, and grove in many a sun-spangled curve.

This hidden Yosemite was full of wild life. Deer, with their supple, well-grown fawns, bounded from thicket to thicket as I advanced. Grouse kept rising from the brown grass with a great whirring of wings, and, alighting on low branches of pine or poplar, allowed a near approach, as if pleased to be observed. Farther on, 


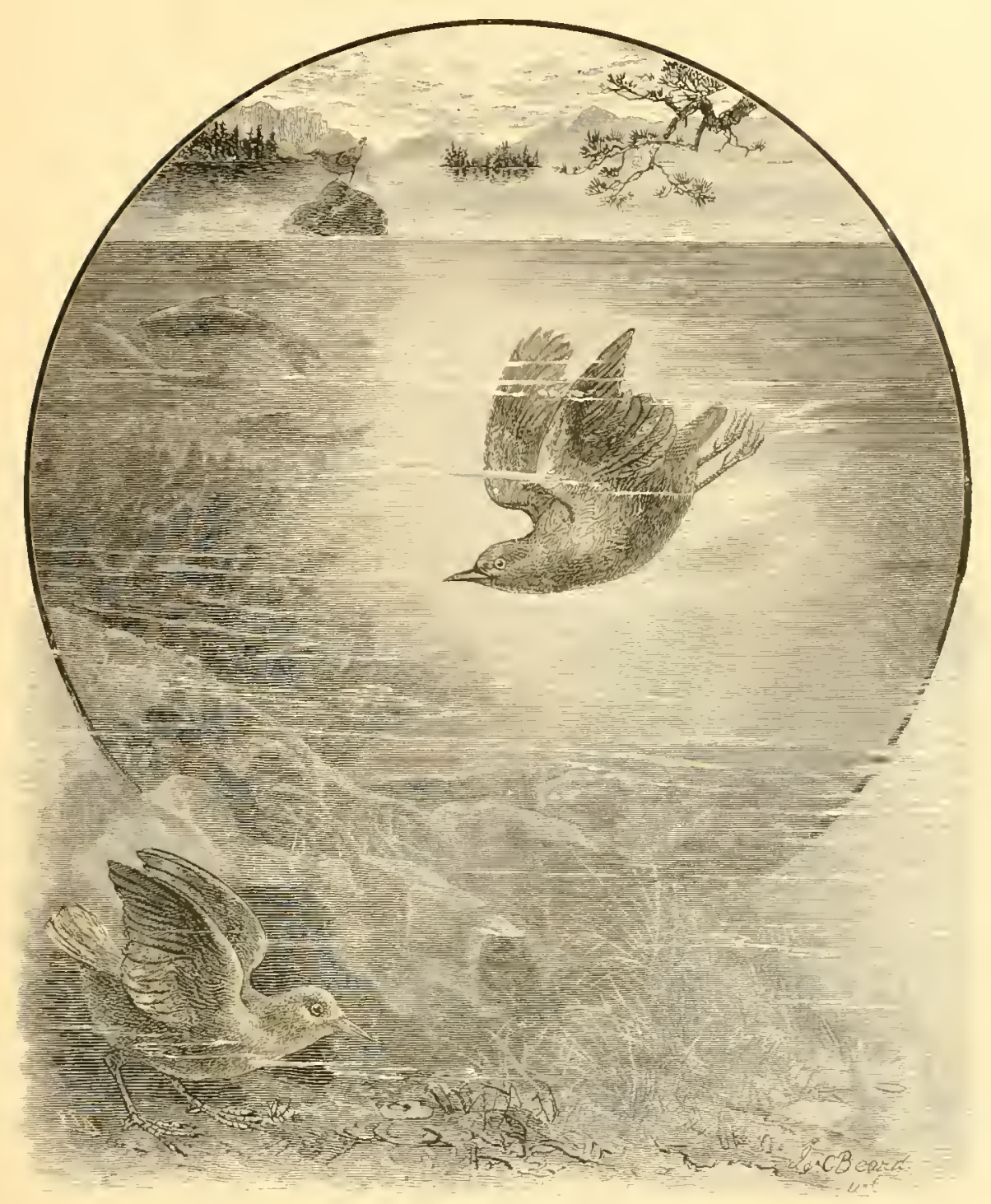

THE WATER-OUSEL.

a broad-shouldered wild-cat showed himself, coming out of a grove, and crossing the river on a flood-jamb of logs, halting for a moment to look back. The bird-like tamias frisked about my feet everywhere among the pine-needles and seedy grass-tufts. Cranes wated the shallows of the river-bends, the kingfisher rattled from perch to perch, and the blessed ousel sang anid the spray of every cascade. Where may lonely wanderer find a more beautiful family of mount- 


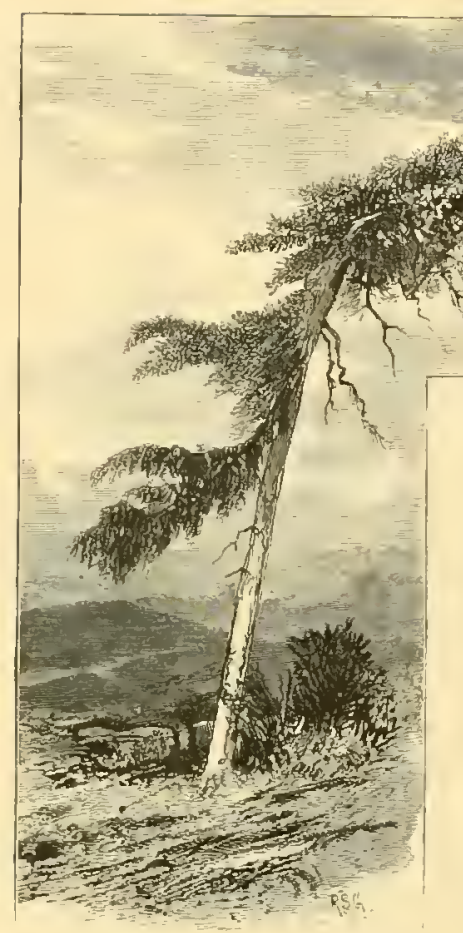

WILLIAMSUN SPRUCE TREE

ain-dwellers, earthborn companions, and fellow-mortals? It was afternoon when I joined them, and the glorious landscape faded in the gloaming before I awoke from their enchantment. Then I sought a camp-ground on the river-bank, made a cupful of tea, and lay down to sleep on a smooth place among the yellow leaves of an aspen grove. Next day, I discovered yet grander landscapes and grander life. Following the curves of the river, over huge, swelling rock-bosses, and past innumerable cascades, the scenery in general became gradually more Alpine. The sugar-pine and silver-fir gave place to the hardier cedar and Williamson spruce.

The cañon walls became more rugged and bare, and gentians and Arctic daisies became more abundant in the gardens and strips of meadow along the streams. Toward the middle of the afternoon I came to another valley, strikingly wild and original in all its features, and perhaps never before touched by human foot. As regards area of level bottom-land, it is one of the very smallest of the San Joaquin Yosemites, but its walls are sublime in height, rising at a bound into the thin sky two to four thousand feet above the river. At the head of the valley the main canon forks, as is found to be the case in all Yosemites. The formation of this one is due to the action of two vast ice-rivers, whose fountains lay to the eastward, on the flanks of Nounts Humphrey and Emerson, and a cluster of nameless peaks farther south. On the slow recession of those rock-grinding glaciers, at the close of the Glacial Period, this valley basin came to light: first a lake, then a sedgy meadow, then, after being filled in with flood and avalanche bowlders, and planted with trees and grasses, it became the Yosemite of to-day - a range for wild sheep and wild men. 
The gray bowlder-chafed river was singing loudly through the valley, but above its massy roar 1 heard the deep booming of a water-fall, which drew me eagerly on. Emerging from the tangled

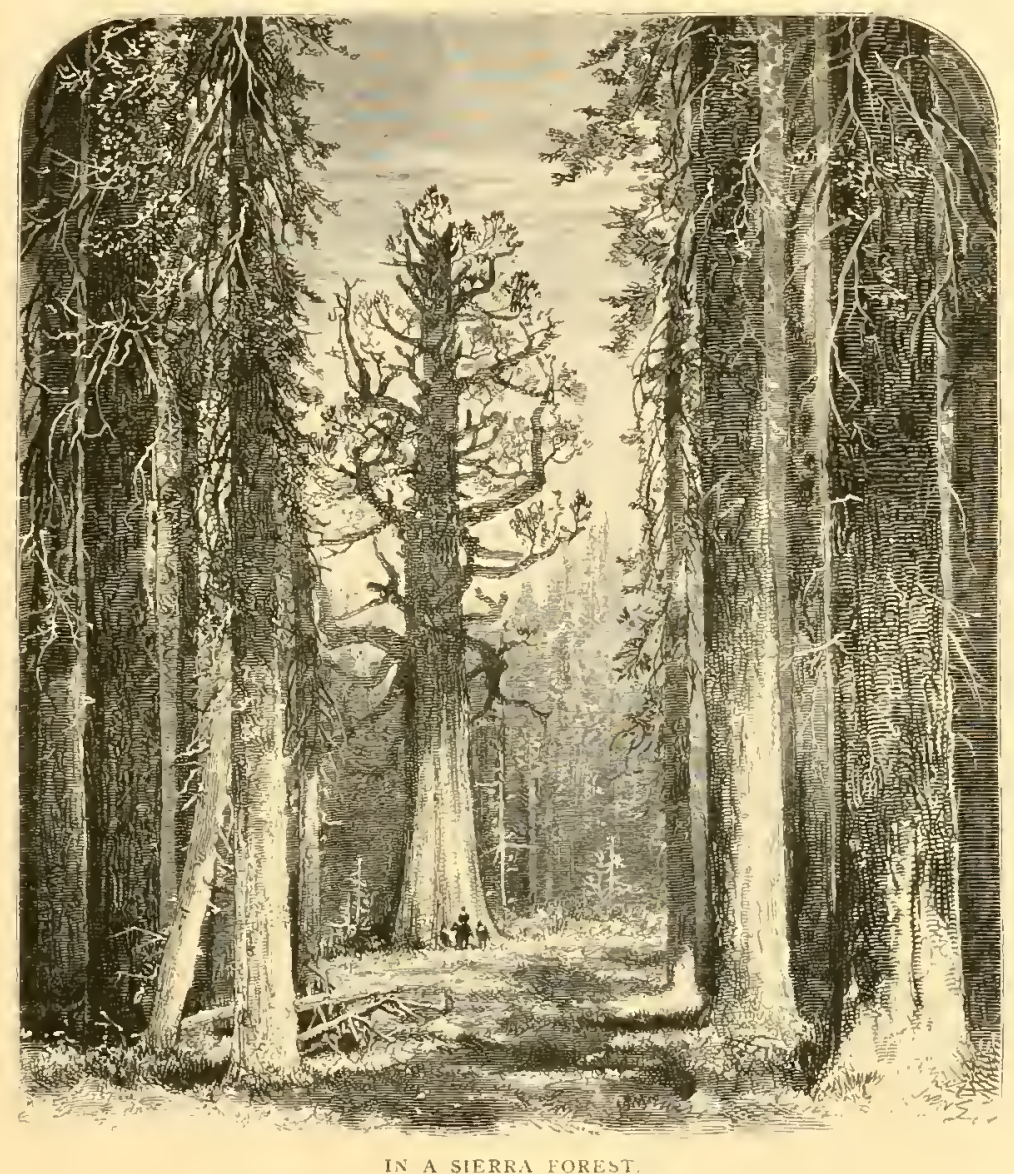

avalanche of groves and briers at the head of the valley, there, in full view, appeared the young San Joaquin fresh from its glacier fountains, falling white and free in a glorious cascade, between granite walls two thousand feet high. The steep incline down which the glad waters thundered seemed to bar all farther progress. It was not long, however, before I discovered a crooked seam in the rock, by which I was enabled to climb to the edge of a terrace that crosses the cañon and divides the cataract nearly in the middle. Here I sat down to take breath and make some entries in my notebook, taking advantage, at the same time, of my elevated position 
above the trees to gaze back over the valley into the heart of the noble landscape, little knowing the while what neighbors were near.

After spending a few irregular minutes in this way, I chanced to look across the fall, and there stood three sheep quietly observing me. Never did the sudden appearance of a mountain, or water-fall, or human friend, so forcibly seize and rivet my attention. Anxiety to observe accurately on so rare an occasion checked boisterous enthusiasm. Eagerly I marked the flowing undulations of their firm, braided muscles, their strong legrs, ears, eyes, heads, their graceful, rounded necks, the color of their hair, and the bold, upsweeping, cycloidal curve of their noble horns. When they moved, I devoured every gesture, while they, in nowise disconcerted either by my attention or by the tumultuous roar of the falling water, advanced deliberately alongside the rapids between the two divisions of the cataract, turning now and then to look at me. Presently they came to a steep, ice-burnished acclivity, which they ascended by a quick succession of short, stiff-legged leaps, reaching the top without a struggle. This was the most startling feat of mountaineering I had ever witnessed, and, considering only the mechanics of the thing, one's astonishment could hardly have been greater had they displayed wings and taken to flight. "Sure-footed mules" on such ground would have fallen and rolled like loosened bowlders. Many a time, where the slopes were far lower. I have been compelled to take off my shoes and stockings, tie them to my belt, and creep barefoot with the utmost caution. No wonder, then, that I watched the progress of these animal mountaineers with keen sympathy, and exulted in the boundless sufficiency of wild nature displayed in their invention, construction, and keeping. But judge the measure of my good fortune when, a few minutes later, I caught sight of a dozen more in one band, near the foot of the upper fall. They were standing on the same side of the river with me, distant only twenty-five or thirty yards, and looking as unworn and perfect as if created on the spot. It appeared by their tracks, which I had seen on the meadow, and by their present position, that when I came up the cañon they were all feeding together down in the valley, and in their haste to reach high ground, where they could look about them to ascertain the nature of the strange disturbance, they were divided, three ascending on one side the river, the rest on the 


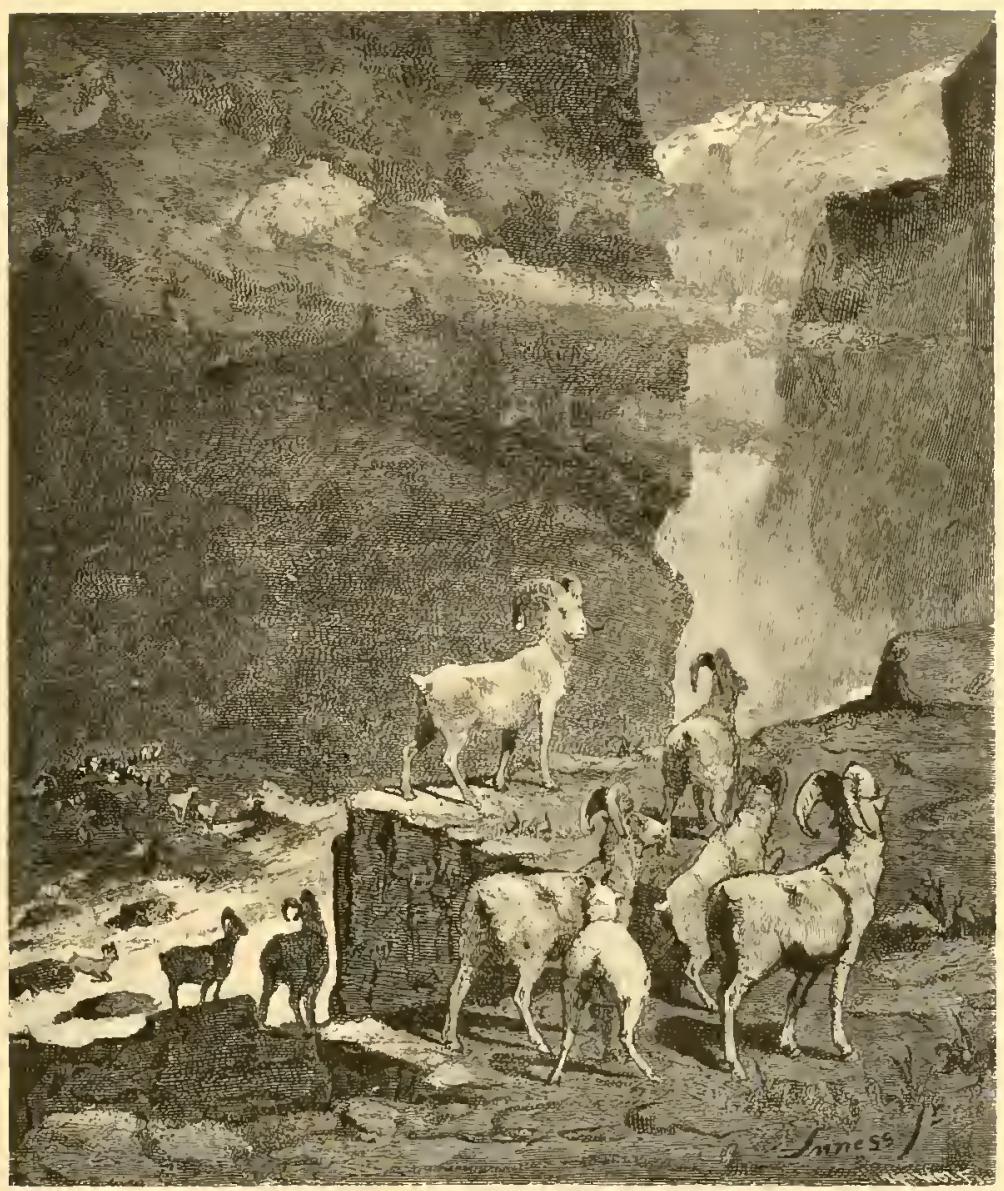

CROSSINC, A A ANON STKEAM.

other. The main band, headed by an experienced chicf, now began to cross the rapicls. This was another exciting feat ; for, among all the varied experiences of mountaineers, the crossing of boisterous, rock-dashed torrents is found to be the most trying to the nerves. Yet these finc, brave fellows walked fearlessly to the brink, and jumped from bowlder to bowlder, holding themselves in perfect poise above the whirling, confusing current, as if they were doing nothing extraordinary.

The immediate foreground of this rare picture was glossy, iceburnished granite, traversed by a few bold lines in which grew rockferns and tufts of healthy bryanthus, with the gray cañon walls on the sides nobly sculptured and adorned with brown cedars and 
pines. In the distance were lofty peaks dipping into the azure, and in the middle-ground was the snowy fall, the voice and soul of the landscape; fringing bushes beating time to its thunder-tones, the brave sheep in front of it; their gray forms slightly obscured in the spray, yet standing out in good heavy relief against the close white water, - their huge horns rising and curving in the midst like the upturned roots of dead pine-trees, while the evening sunbeams streaming up the cañon gilded and glorified all. After crossing the river, the dauntless climbers, led on by their chief, at once began to scale the cañon wall, turning now right, now left, in long, single file, keeping well apart out of one another's way, and leaping in regular succession from crag to crag, now ascending slippery domecurves, now walking leisurely along the edges of precipices, stopping, at times, to gaze down at me from some flat-topped rock, with heads held aslant, as if curious to learn what I thought about it, or whether I was likely to follow them. After reaching the top of the wall, which, at this place, is somewhere between one thousand five hundred and two thousand feet high, they were still visible against the sky as they lingered, looking down in groups of two or three, giving rare animation to the wilderness.

Throughout the entire ascent they did not make a single awkward step, or an unsuccessful effort of any kind. I have frequently seen tame sheep in mountains jump upon a sloping rock-surface, hold on tremulously a few seconds, and fall back baffled and irresolute. But in the most trying situations, where the slightest want or inaccuracy would have resulted in destruction, these always seemed to move in comfortable reliance on their strength and skill, the limits of which they never appeared to know. Moreover, each one of the flock, while following the guidance of the most experienced, yet climbed with intelligent independence as a perfect individual, capable of separate existence whenever it should wish or be compelled to withdraw from the little clan. The domestic sheep, on the contrary, is only a faction of an animal, a whole flock being required to form an individual, just as numerous florets are required to make one complete sunflower.

Those shepherds who, in summer, drive their flocks to the mountain pastures, and, while watching them night and day, have seen them torn to pieces by bears, disintegrated by storms, and scattered 
diverse like wind-driven chaff, will, in some measure, be able to appreciate the self-reliance and strength and noble individuality of nature's sheep.

Like the Alp-climbing ibex of Europe, our mountaineer is said to plunge headlong down the faces of sheer precipices and alight on his big horns. I know only two hunters who claim to have actually witnessed this feat. I never was so fortunate. They describe the act as a diving head-foremost. The horns are so large at the base that they cover all the upper portion of the head down nearly to a level with the eyes, and the skull is exceedingly strong. I struck an old, bleached specimen on Mount Ritter a dozen blows with my ice-axe without breaking it. Such skulls would not fracture very readily by the wildest rock-diving, but other bones could hardly be expected to hold together in such a performance: and the mechanical difficulties in the way of controlling their movements, after striking upon an irregular surface, are, in themselves, sufficient to show this bowlderlike method of progression to be impossible, even in the absence of all other evidence on the subject; moreover, the ewes follow wherever the rams may lead, and their horns are mere spikes. I have found many pairs of horns considerably battered - a result, most likely, of fighting, though, when a great leap is made, they may possibly seek to lighten the shock by striking their heads against anything that may chance to be favorably situated for the purpose, just as men mountaineers do with their hands. I have been interested in the question, after witnessing the performances of the San Joaquin band upon the glaciated rocks at the foot of the falls, and as soon as I procured specimens and examined their feet, all the mystery disappeared. The secret, considered in connection with exceptionally strong muscles, is simply this: the wide posterior portion of the bottom of the foot, instead of wearing down and becoming flat and hard, like the feet of tame sheep and horses, bulges out in a soft, rubber-like pad or cushion, which not only grips and holds well on smooth rocks, but fits in small cavities, and down upon or against slight protuberances. Even the hardest portions of the edge of the hoof are comparatively soft and elastic: furthermore, the toes admit of an extraordinary amount of both lateral and vertical motion, allowing the foot to accommodate itself still more perfectly to the irregularities of rock surfaces, and at the same time increasing the gripping power. 


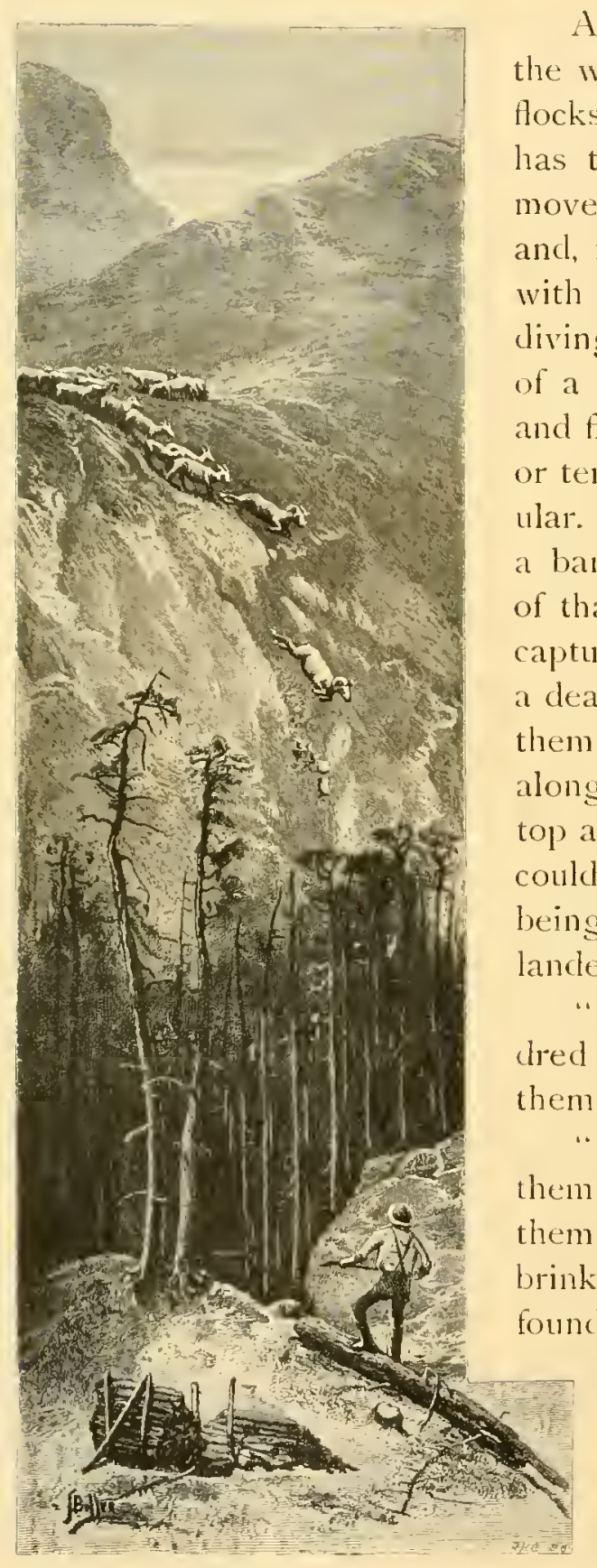

JUMIING OVER A PRECIPICE

At the base of Sheep Rock, one of the winter strongholds of the Shasta flocks, there lives a stock-raiser who has the advantage of observing the movements of wild sheep every winter; and, in the course of a conversation with him on the subject of their living habits, he pointed to the front of a lava headland about a hundred and fifty feet high which is only eight or ten degrees out of the perpendicular. "There," said he, "I followed a band of them fellows to the back of that rock yonder, and expected to capture them all, for I thought I had a dead thing on them. I got behind them on a narrow bench that runs along the face of the wall near the top and comes to an end where they couldn't get away without falling and being killed; but they jumped off and anded all right.

"What!" saic 1, " jumped a hunlred and fifty feet! Did you see them do it?"

"No," he replied. "I didn't see them going down, for I was behind them; but 1 saw them gro off over the brink, and then I went below and found their tracks where they struck on the loose débris at the bottom. They sailed right off. and landed on their feet right side up. That's the kind of animal they' is-beats anything else that goes on four legs."

On another occasion, a flock that was pursued by hunters retreated to another portion of this same cliff where it is still higher, 
and, on being followed, they were seen jumping down in perfect order, one behind another, by two men who happened to be chopping where they had a fair view of them and could watch their prosress from top to bottom. Both ewes and rams made the frightful descent without evincing any extraordinary concern, hugrging close to the rock, and controlling the velocity of their half falling, half leaping movements by striking at short intervals and holding back with their cushioned, rubber feet upon small ledges and roughened inclines until near the bottom, when they "sailed off" into the free air and alighted on their feet, but with their bodies so nearly in a vertical position that they appeared to be diving.

It appears, therefore, that the methods of this wild mountaineering become clearly comprehensible as soon as we make ourselves acquainted with the rocks, and the kind of feet and muscles brought to bear upon them.

The Modoc and Pah Ute Indians are, or, rather, have been, the most successful hunters of the wild sheep. Great numbers of heads and horns belonging to animals killed by them are found accumulated in the caves of the lava-beds and Mount Shasta, and in the upper cañons of the Alps opposite Owens Valley, while the heavy obsidian arrowheads found on some of the highest peaks show that this warfare has long been going on.

In the more accessible ranges that stretch across the desert regions of western Utah and Nevada, considerable numbers of Indians used to hunt in company like packs of wolves, and being perfectly acquainted with the topography of their lnunting-grounds, and with the habits and instincts of the game, they were pretty successful. On the tops of nearly every one of the Nevada mountains that I have visited, I found small, nest-like inclosures built of stones, in which, as I afterward learned, one or more Indians lay in wait while their companions scoured the ridges below, knowing that the alarmed sheep would surely run to the summit, and when they could be made to approach with the wind they were shot and killed at short range.

Still larger bands of Indians used to make grand hunts upon some dominant mountain much frequented by the sheep, such as Mount Grant, on the Wassuck Range to the west of IValker Lake. On some particular spot favorably situated with reference to the 


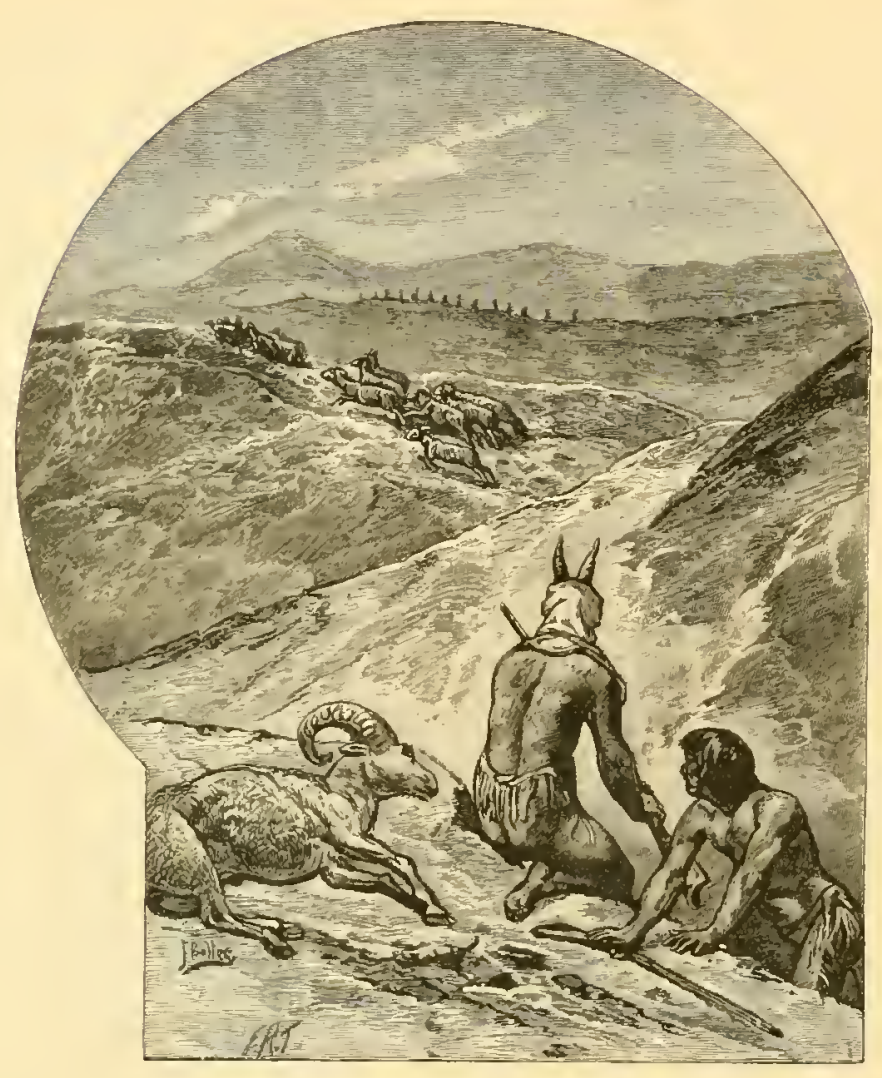

INDIANS HUNTING WILD SHEEP.

well-known trails of the sheep, they built a high-walled corral, with long guiding wings, diverging from the gate-way; and into this inclosure they sometimes succeeded in driving the noble game. Great numbers of Indians were, of course, required-more, indeed, than they could usually muster, counting in squaws, children and all; they were compelled, therefore, to build rows of dummy hunters out of stones, along the ridge-tops they wished to prevent the sheep from crossing. And, without bringing any discredit upon the sagacity of the game, these clummies are found effective; for, with a few live Indians moving about excitedly among them, they can hardly be distinguished at a little distance from men, by any one not in the secret. The whole ridge-top then seems to be alive with hunters.

The only animal that may fairly be regarded as a companion of our sheep is the so-called Rocky Mountain goat (Aplocerus Mon- 
tana, Rich.), which, as its name indicates, is more antelope than goat. He, too, is a brave and hardy climber, fearlessly accompanying the sheep on the wildest summits, and braving with him the severest storms; but smaller and much less dignified in demeanor. His jet-black horns are only about five or six inches in length, and the long white hair with which he is covered must obscure the expression of his limbs. I have never yet seen a living specimen of this American chamois, although a lew bands, it is said, have been found in the Sierra. In some portions of the Rocky and Cascade mountains it occurs in flocks of considerable size, where it is eagerly pursued by the Indians, who make use of its skin in various ways as clothing, that of the head with the horns attached being sometimes worn as a cap.

Three species of deer are found in California-the black-tailed, white-tailed, and mule-deer. The first mentioned (Cerus Columbi(amus) is by far the most abundant, and occasionally meets the sheep during the summer on high grlacier meadows and along the edge of the timber-line; but, being a forest animal, seeking shelter and rearing its young in dense thickets, it seldom visits the wild sheep in its higher homes. The antelope, though not a mountaineer, is occasionally met in winter by the sheep while feeding along the edgres of the sage-plains and bare volcanic hills to the east of the Sierra. So also is the mule-deer, which is almost restricted in its range to this eastern region. The white-tailed species belongs to the coastranges.

Perhaps no wild animal in the world is without enemies, but highlanders, as a class, have fewer than lowlanders. The wily panther, slipping and crouching among long grass and bushes, pounces upon the antelope and deer, but seldom crosses the bald, craggy thresholds of the sheep. Neither can the bears be regarded as enemies; for though they seek to vary their every-day diet of nuts and berries by an occasional meal of mutton, they prefer to hunt tame and helpless flocks. Eagles and coyotes, no doubt, capture an unprotected lamb at times, or some unfortunate beset in deep, soft snow, but these cases are little more than accidents. So also a few perish in long-continued snow-storms, though in all my mountaineering 1 have not found more than five or six that seemed to have met their fate in this way. A little band of three were discovered 
snow-bound in Bloody Cañon a few years ago, and were killed with an axe by some travelers who chanced to be crossing the range in winter.

Man, being the most powerful, is the most dangerous enemy of all, but even from him our brave mountain dweller has little to fear in the remote solitudes of the Alps. The golden plains of the Sacramento and San Joaquin were lately thronged with bands of elk and antelope, but, being fertile and accessible, they were required for human pastures. So also are the magnificent feeding-grounds of the deer-hill, valley, forest, and meadow; but it will be long ere man will care to take the highland castles of the sheep. And when we consider here how rapidly entire species of noble animals, such as the elk, moose, and buffalo, are being pushed to the very verge of extinction, all lovers of wildness will rejoice with me in the rocky security of Oris Montana, the bravest inhabitant of the California Alps.

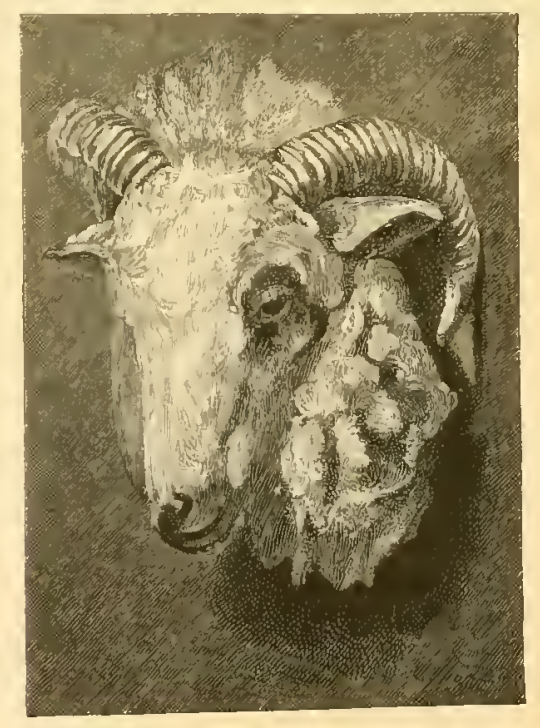




\title{
THE ANTELOPE.
}

\author{
BY GEORGE BIRU GRINALL, PH. I).
}

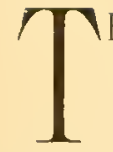

HE prong-horn antelope is the fleetest of North American mammals. Its every movement is full of a lightness and ease which compel admiration, and even when at rest it is beautifully and gracefully statuesque. It is a goodly sight to watch an old buck as he stands outlined against the horizon on the top of some bigh bluff. His legs are slim and delicate, while his round, short body tells of strength and endurance. The proudly arched neck supports a fine pointed head, and the smoothly curving black horns stand out silhouette-like against the blue of the unclouded sky. Nearer at hand are some tiny kids, not very far from their gravely sedate mothers. They walk lightly about over the prairie and daintily pluck the grass or sometimes run sportive races with each other. Their little hoofs scarcely touch the ground, and when they move hither and thither, they seem to float over the earth rather than to tread upon it. They are the very embodiment of lightness and grace, and are withal so playful and merry-hearted that it seems like murder to take their lives. Yet they are quick to catch the alarm, and if the old buck on the hill above should sound his call of warning, the little company would dart away with the speed of the wind - soon to be far from the threatened danger.

The prong-horn antelope occupies a unique position among the horned ruminants. Belonging to that subdivision of the group styled Cavicomia, * it yet sheds its horns annually. As has been

* For some remarks on this subdivision of the ruminants, see the chapter on The North American Ceride in this volume. 
already explained, the horns of North American ruminants are of two kinds: solid, like those of the deer, and hollow, like those of the ox. To this latter class belong those of the antelope, but with this modification, that the horny epidermic sheath which incloses them is not, as is the case with all other hollow-horned ruminants, a permanent covering. The zoölogist knows that scales, feathers, hair, claws, hoofs, and horns are but modifications of the epidermis, and grade into one another in such a way that it is often impossible to decicle at what point one form of covering ends and another begrins. The sheath of the antelope's horn is one form of dermal outgrowth. Chemically, there is scarcely any clifference between it and the hair, and to all intents and purposes $i t$ is composed of hairs agglutinated together. Herein lies the fundamental difference between the shedding of the deer's antlers and that of the antelope's horns. The deer loses a bony outgrowth - a portion of the skeleton: while the antelope parts with a clemal outgrowth - a portion of the integument.

When the antelope sheds its horns, therefore, they do not drop off close to the skull, leaving the head bare like a deer's under the same circumstances, but the sheath falls off from the core, which is now tipped with a new horn, and clothed elsewhere with a thick hairy skin, which before long becomes hard black horn. The adult male antelope is therefore never entirely without horns. The sheath is lost in November or December after the rutting season is over.

Another remarkable characteristic of the antelope is the absence of the supplementary hoofs, or "dew-claws," which represent the second and fifth digits of the foot. These are present $i n$ all the other Pecora except the giraffes.

From the combination of anomalous characters found in this species, it has been considered with great interest by naturalists, and a very high authority has separated it from the true antelopes and placed it in a family (Antilocapride) by itself, thus making the single genus and species (Antilocapra Amoricana Ord) the equivalent in zoölogical rank of so important a family as the Borida.

The prong-horn antelope stands nearly three feet high at the withers, and is from four and one-half to five feet in length. Its body is short and stout, head long and slim, neck rather short and 
usually arched, and legs slender. The eye is very large and set high up on the head, immediately beneath the base of the horn. The antelope is reddish-yellow above and white below. The face up to the horns, an irregularly oval patch at the angle of the jaw, and a line down the back of the neck are l, lackish-brown. The sides and lower portion of the head, several irregular crossbars on the front of the neck, the lower flanks, a large triangular white patch on the rump, and the entire under parts and legs, are white. The hoofs and horns are always black. The latter vary somewhat in form. Near the base they are long oval in cross section, the diameter from before backward being two or three times greater than that from side to sicle. They rise from just above the eye slightly forwarl and outward, and are sometimes sixtcen inches long, though usually less than twelve. The shaft is scimeter shaped, the tip curving sharply so that it is usually directed somewhat downward, but the continuity of the anterior outline is broken by the "prong," which springs from a point about half way between the base and the tip, as a triangular stub, with its point directed inward, forward, and upward. The tips are usually directed backward, or else turn inward so as nearly to meet. Occasionally, a specimen is seen in which one tip is directed in and one backward, and in a pair of horns now in my possession both tips are twisted so as to point forward and lownward. While the horns usually rise straight from the head, only spreading very slightly; they are sometimes directed almost away from each other, like the horns of an ox, and on rare occasions a buck may be seen with one horn growing down over his face, in the style of "the cow with the crumpled horn." Twice 1 have killed bucks with four horns, the extra ones being three or four inches long and attached loosely to the skin behind the normal horns. The female antelope is usually hornless, but a certain proportion of the does have small cylindrical horns, from one to three inches long, and without the prong.

The hair of the antelope is peculiar, being coarse, spongy, and brittle, and so loosely attached to the skin that it is easily pulled off in handling. There is also an under-coat of fine wool, which is especially noticeable in spring when the coat is being shed. This species is provided with a number of glands in the skin, and these exhale a strong and disagreeable odor, which pervades the whole 
skin and hair. From this odor the antelope was formerly called "goat," cabree, and cabrit; but these names are obsolete. Pronghorn is its book name.

The antelope was formerly found all over the plains and among the mountains of the west, wherever the country was adapted to it, from latitude $53 \mathrm{~N}$. south into Mexico, and from about the meridian of 95 west longitude to the Pacific Ocean. There is no evidence to show that it ever ranged east of the Mississippi River. All through the great region indicated it was once abundant, and was equally at home on the flat prairies of the Platte River bottom, the broken bad lands of Dakota and Montana, or among the rugged foot-hills, sage-brush plateaus, and bald mountain slopes of the main range. $1 \mathrm{t}$ is essentially a dweller in the open country and is never found far back in the forests. What it requires, above all things, is a place from which it can overlook all its surroundings; for, although the antelope's powers of scent are very keen, it depends chiefly upon its eyes for warning of impending danger. Still, it is not true, as has been asserted by most writers on this species, that it has a great terror of forests and is never found among them. In the Rocky Mountains. I have frequently seen antelope feeding among the timber in open pine forests, as well as where there was undergrowth, and in North Park, Colorado, where a few years ago this species was to be found in great abundance, I have seen them by hundreds feeding in the bottom of Michigan Creek among thick willows, which were there from twenty to thirty feet high. In such situations they may be easily approached. It has been my experience, however, that if they are once alarmed, it is impossible to drive antelope into the timber. During the summer they are fond of feeding high up in the mountains in the little grassy, park-like valleys which open into one another and become constantly smaller toward the higher ground, being thus often nearly or quite surrounded by thick forest. I have sometimes, on entering such a little park by the only opening into it, come upon a band of antelope, and seen them rush across the open, and then, as they approached the timber, turn and run around the whole circumference of the meadow. and at length, as if in desperation, turn again and run toward and by me, and out of the little opening, so close that I could have thrown a rope over any one of the band. 
The rutting season of the antelope begins in September and lasts nearly to the end of October. They are not always found in pairs at this scason, though usually only a few are secn together, and these companies are likely to consist of individuals of the same sex. Just before and during the rutting season the bucks fight with considerable energy, though I have never seen anything quite like the description of their battles given by Audubon and Bachman. When two males meet, they come together head on and push vigorously, but no great amount of damage seems to result from such contests. On the other hand, an attack is often macle by one buck on another without any warning. Such an assault I once witnessed late in September. Two bucks were following three or four does and kids, and walking quite near together, when suddenly the smaller of the two charged the other, striking him a terrible blow in the flank with his horns, and almost knocking him down. The large buck at once lowered his head and darted at his assailant, which, without any attempt at defense, took to his heels and ran like the wind for at least a mile, the other pursuing for half the distance. Both then slowly returned to the neighborhood of the females, and after a little while, when the small buck found another good opportunity, he repeated the attack, exactly in the same manner, and was again chased away. By the time that the two had again returned to the does, the band had passed over some high bluffs and out of my sight. The larger bucks frequently chase the smaller ones away; but this does little good, as they immediately return again. Soon after the close of the rutting season, a partial migration takes place. The antelope which, during the summer, have inhabited the higher mountain valleys now move down to the lower lands, and there is in all localities more or less shifting about at the approach of severe weather. During the winter they collect in great bands, sometimes numbering several thousand individuals. It the approach of spring, these large herds break up into smatl companies, and scatter over their summer grazing grounds.

Toward the last of Nay, the does are found singly upon the prairie. The kids are born in June and are two in number. For a week or more they are not at all disposed to trust to their legs for safety, but hide in the low grass or among the sage brush, and at this time can be approached and caught in the hands without diffi- 
culty, although a little later they can run fast and far. When captured they become tame at once and are easily reared on cow's milk. They are interesting, but rather inconvenient, pets; for they are so much at home about a house as to be rather in the way. At birth, the hair is crimped, almost curly, and they are brownish-gray in color, with very little white upon them, and are chiefly remarkable for the excessive length of their legs, on which they seem to have some difficulty in balancing themselves. Their color soon changes to that of the adults, but is everywhere of a paler cast.

The cry of the antelope is a bleat, shorter than that of a goat and not so sharp: but this sound is scarcely ever heard by the hunter. When curious and somewhat suspicious they utter a sharp snort, pitched in a higher key than that of a deer; and when suddenly frightened, the bucks often communicate the alarm to their companions by a sharp nasal call, best represented by the syllables bock-bockbock, rapidly repeated.

After man, the worst enemy of the antelope is the wolf. The gray wolf, no doubt, kills a great many: but the coyote is the most destructive. The latter captures the young fawns soon after birth. his keen nose enabling him to detect them in their hiding-places. This discovered, he soon makes a meal of the tender morsel, provided the mother be not near by. If she is at hand, and the coyote is alone, she will beat him off. Most of the antelope which the prairie wolves secure, however, are run down. Three or four coyotes will start one, a single wolf pressing it hard and forcing the pace as much as possible, while the others lope along on either side of the line of flight, choosing the easiest ground, and saving themselves as much as possible by taking short cuts, when the chase circles. As soon as the immediate pursuer becones tired, his place is taken by another which is comparatively fresh; and so the pursuit is kept up, the wolves relieving each other from time to time, until the poor antelope is overtaken, pulled down. and torn to pieces. Sometimes, however, they escape out of the very jaws of their pursuers, for I have occasionally killed individuals which had, several days before, been more or less torn about the legs and flanks by the teeth of the savage brutes. The golden eagle kills many wounded antelope and some kids, but is sometimes beaten off by the latter, as shown by an account of a battle witnessed by my friend, Mr. WV. 
H. Reed, in October, 1SS2, near Como, Wyoming Territory, and communicated to the "Forest and Stream." He says:

"Thurslay. the 26 th of this month, 1 saw a strange battle between two kid antelope and an eagle. The antelope, when first seen by myself and Mr. Carlin, were rumning in our direction, and above them, about one hundred feet, was a large golden eagle, which made a swoop down at the antelope. When the bird dir] this, one of the kids stopped, turned roumd and reared on its hind legs and beat the air with its forefeet, and the bircl of prey rose high in air, only to make another clash, with the same result. This was repeated at least a clozen times, when the eagle, seeming to become tired, flew away and settled himself on a rock, and the antelope trotted away to join a large band on a near hill-side."

Civilized man has proved himself the antelope's worst enemy, and in those districts where hunters are numerous, this species soon disappears. The traveler kills it for food, the skin-hunter for the few cents its hide will bring, the sportsman for its head, the cow-boy to try his six-shooter, and everybody for "fun." Not one man in a hundred can resist the temptation to shoot at the beautiful and graceful animal which chance or its curiosity brings within range of his rifle. That his wagon is already loaded with meat, that he cannot possibly utilize what he kills, makes no difference to him. He must try to slaughter as long as there is game in sight.

To become a successful antelope hunter, it is more necessary that one should understand the habits of his game than that he should be a good shot. During the middle of the day, the antelope are usually lying down in places where they can have a wide outlook, and they are then most difficult to approach. For these resting-places, they select either a knoll in the midst of a broad valley or else the top of a bluff, or, perhaps, the middle slope of a wide, smooth hill-side, so that their gaze can cover all the country about them. The best time for hunting them is in the morning or evening, when they are scattered about on the hill-sides and in the little valleys, feeding. At such times they are most easily approached, and the hunter takes advantage of the inequalities of the ground to discover their presence in time to successfully stalk then. The essential point is that he should see the antelope before they descry him, for if their suspicions are once aroused, it is almost hopeless to attempt to gret within shot of them. As soon as one of these wary creatures sees an object about which he feels doubtful, he takes a long, patient stare at it, and unless sat- 
isfied that it is something usual and harmless. runs to the top of the nearest hill, and from that point again scrutinizes it. If now the object passes out of sight behind any cover, the antelope at once shifts his position to the top of another hill. But in localities where they have been much hunted, the sight of a mounted man, even at a great distance, is enough to set the antelope in motion, and they run off at once without waiting to inspect him. The sight of one running band alarms all those in the neighborhood, and they all move off to points from which they can obtain a good outlook.

In hunting large game, of whatever kind, caution and patience are prime requisites for success; and in the pursuit of no species are these more necessary than with the antelope. It is so constantly on the alert, and its eyesight is so keen, that all the hunter's care is needed to enable him to beat it with its own weapons and on its own ground. When hunting antelope, therefore, it is important to go slowly, and to look over the ground in front of you very carefully before showing yourself. When you approach the crest of a hill, do not ricle your horse quite up to the top of it, but stop him before reaching the summit, dismount, and drop the lariat; or, if he is broken in the usual plains fashion, throw the bridle-rein over his head, and walk carefully to the top. As you approach it, move slowly. Do not raise your head and shoulders at once to look over the ridge, for there may be a band of antelope within a few yards of you. Take off your hat, for its crown is several inches above your eyes, and can therefore be secn before you yourself can see. Raise your head very gradually, and as it rises keep the eyes moving from side to side, so as to take in all the ground on either side of, and beyond, as well as immediately in front of you. If you should see the game, do not duck down your head at once, unless you are positive that the animals have not observed you, but lower it with the same slow motion. A sudden movement is very likely to attract attention. while a slow one will be almost sure to escape notice. If your game is within range, you will of course take your shot as soon as you please, but it may be at some distance, and in such a situation that by taking advantage of some ravine, or hill, or depression in the prairie, you can creep up close enough to shoot. To do this you may have to make a long detour before reaching the desired point. In such a case, notice carefully the lay of the land and 
the position of the wame, for from a different point of view the bluffs and landmarks may look so differently that you may have to look a long time for the animals, and while doing so may expose yourself to their view. Remember to watch the wind, for the antelope's nose is a good one and will tell him of your presence if you come between him and the breeze. Perhaps the band may he at a distance, and there may appear no way of approaching it. In this case, it will be worth your while to sit down and wait a little, to see if they will not feed up nearer to you, and so give you a shot. I)o not be too anxious to know just what they are doing. Every time you raise your head above the bluff, some one of the animals will be likely to see it, and, unless they are frightened by you, they are not likely to make any sudden movement. Do not be too impatient to get your shot. Deliberation will serve you well. IThen you shoot, aim close behind the fore shoulder and just about where the white and the red meet; for the antelope's heart lies low, and, if you hold true, you will have meat in camp that night.

In hunting antelope, it is best always to travel upon the higher ground, since the game is much less likely to see an object above than below or on the same level with it. Keep to the ridges, therefore, and as you surmount each one, scan all the ground with care before you show yourself. There may be an antelope lying down behind some little rise of ground very near you; or perhaps a red back or the black tips of a pair of horns may be just visible over the edge of some ravine, and may at first escape your eye, if you are in a hurry.

Although, where antelope have been much hunted, the sight of a man, even if a long way off, will cause them to run, there are other localities where they are so tame as to permit one to ride within three or four hundred yards without manifesting much uneasiness. In such cases, the animals are curious rather than timid, and will sometimes run toward the bunter; and if he throws himself flat on the ground, they may approach within one hundred yards, or even nearer. This only takes place when they have been but little hunted. In a buffalo country, or where there are cattle, they are sometimes very unsuspicious. The old bucks ordinarily manifest more curiosity than the does, but with it is mingled an astonishing amount of shrewdness, and many instances of their cunning might be 
related. The yearling bucks are possessed of this same spirit of investigation, but are wholly without the wisdom of their seniors. and thus often fall an easy prey to the hunter, frequently walking up to within shooting distance, and standing there stamping and snorting, until a rifle-ball satisfies their curiosity.

Antelope are often hunted with greyhounds, and this is a most noble sport. To practice it successfully, dogs of unusual power and endurance are required, as well as horses of great speed, for the pleasure of the chase is lost unless the hunter keeps the grame in view. When I have seen them used, the Scotch staghounds have not proved fleet enough to overtake the antelope, and the most successful dogs have been large, smooth greyhounds.

Within the past ten years, the antelope have been exterminated in many localities where they were once abundant. The West is now filling up more rapidly than ever before, and with the advance of the settlements comes, in one district after another, the extinction of the antelope. Already along the line of the Union Pacific Railroad they have been driven from the Missouri River to the borders of Wyoming Territory; and, as the farmer breaks up the prairie, the stockman scatters his cattle, and the shepherd leads his flocks into regions hitherto unoccupied, the antelope must retreat before their advance, and seek for himself some feeding-ground where man has not yet penetrated. Such a feeding-ground he will seek in vain. The shrill whistle of the locomotive, quivering over the wide prairie or waking the echoes of the once silent mountain valleys, has sounded the death-knell of large game in the West.

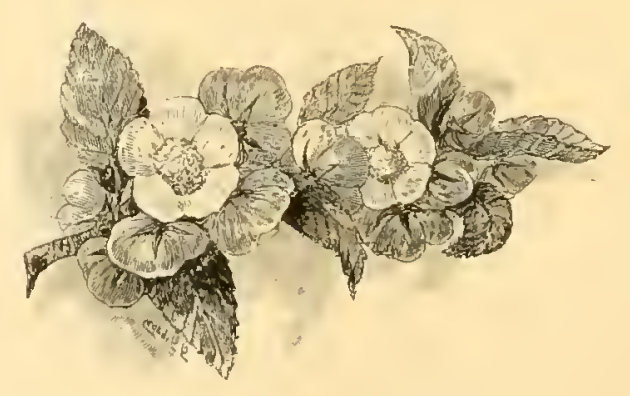




\title{
A MUSK-ON HUNT.
}

\author{
BY FRHIDEICK SCHWATK
}

F

OR about twelve months, during 1879 and 'So, I was traveling by sledge in the arctic regrions with a party of twenty persons. During that time, we depended for our food, as well as for that of our forty-two dogs, upon the game of the country, twice traversed by us, stretching from the waters of North Hudson's Bay to the Arctic Ocean. The design of subsisting for so long a time upon the game of those bleak, dreary regions entailed a great variety of hunting adventures. And to describe one of the incidents of a hunt after musk-oxen, or musk-sheep as they are sometimes called, is the object of this article.

Our route led us from the northermmost point of Hudson's Bay directly to the nearest available point on Back's Great Ii ish River, which empties into the Arctic Ocean just south of the large island known as King William's Land, on which island and adjacent mainland Sir John Franklin's party of over a hundred British seamen perished in $1 S_{4} 8-49$, and whose sad fate it was the object of this expedition, as far as possible, to determine. This route lay directly across country. The bulk of authorities on aretic sledging, both white and native, bore against long overland sledge journeys, an opinion to which they often gave practical illustration by unnecessary detours to follow salt-water ice or sinuous water-courses. Our course, therefore, had never been traveled by either white men or natives, and the latter, who formed an important element of the expedition, advised against it. The Indians of the north, as I found them, are loath to enter a totally unknown country. They knew almost nothing of the game of the region, so thev said, but believed 
that musk-oxen would be found, and if they proved to be plentiful they were willing to undertake the journey. Accordingly, a preliminary reconnaissance as far as Wager River was made by me in January, 1879, and although no musk-oxen were actually seen, we found abundant traces of them. These facts overcame the objections of the natives, who now readily assented to accompany us. Our party was well armed with the finest breech-loaders and magazine guns, and carried an ample supply of fixed ammunition. The hunting force of the party consisted of four full-grown Eskimo men, and three Eskimo hoys, ranging from twelve to eighteen, and the four white men.

We left North Hudson's Bay on the first day of April, 1879 , and, by the Sth of the month, were, according to our natives, in what they termed the musk-ox country, the locality in which they had been accustomed to hunt these huge monsters during winter trips from the sea-coast, where the natives live the greater part of the year. But the musk-cattle of the Arctic are so sparsely distributed that they form only a small part of the game necessary to furnish these northern nomads with their yearly supplies, and they place very little reliance upon them. The annual musk-ox hunt, however, is looked forward to with much interest, and is long in advance the burden of their conversation, while housed in their little snow huts. It is in the sport and excitement of the chase that they find the greatest reward, and not in the meat secured, nor in the half-worthless robes that are thus obtained. These robes are almost of no value to then unless they be near some trading station or whaleships wintering in the ice. 'To' us, however, their huge carcasses were, as food for our three teams of dogs, of great importance compared with that of the reindeer or any other game that we would be likely to fall in with.

On April gth; we came upon a large trail of musk-cattle. The sign was tolerably old, some six or seven days at least; but one of the peculiarities of the animals is that they will travel very slowly when undisturbed and in good grazing country, and this same lierd, so the Eskimo believed, was not far off. They tried to persuade me with all the vehemence of savage logic to remain a day or two in the vicinity and hunt them, but the larder was still too full to warrant any such delay, and we pushed on. 


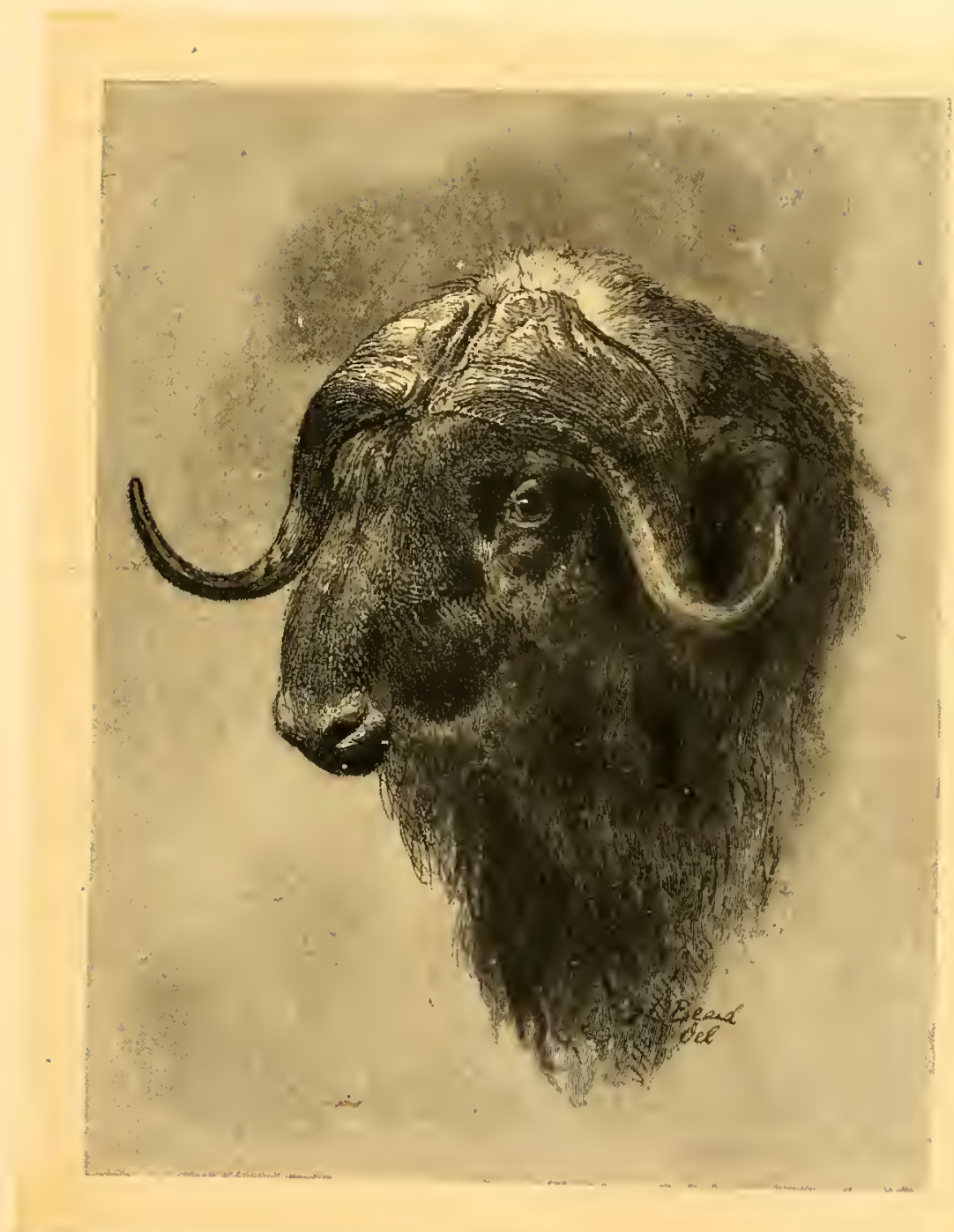



Again, on the $13^{\text {th }}$, we came upon the fresh trail of a large herd of these cattle, and 1 had the hardest work imaginable persuading these natives to pass on without following it up. The Eskimos have far more excitability in the presence of game or its sign than any other race of people I have encountered, not even excepting the various Indian tribes of our great western plains.

Before we had fairly gone into camp, on the 22d, - and by going into camp on an arctic stedge journey is meant the building of peculiarily constructed domes of snow, or snow-houses, the unharnessing of the dogs, et cetera, - a most furious gale of wind arose, which raged so terribly for five days that even the natives found it prudent not to stay out of the snow-huts for any considerable time; and this enforced idleness reduced our commissary to an alarming minimum. We managed, however, to get away by the 28 th, the storm even then only slightly abating; and, after traveling nineteen miles in a northnorth-west direction, we went into camp, the weather somewhat better, but the larder in a reduced condition. Shortly after camping, Ik-queé-sik, my Netschilluk Eskimo guide, who had absented himself while the $i g l o o s$, or snow-houses, were being built, came running excitedly in to the village from a distant high hill, the perspiration in huge drops streaming lown his brown and dirty face, and with my army signal telescope, full drawn, under one arm. While gasping for breath. he reported that he had seen a herd of eight or ten muskoxen about four or five miles to the northward, slowly grazing along to the west, and evidently unaware of danger. Everything was put aside, and every Eskimo, man, woman and child, was soon at the top of a high hill near by, and a dozen dirty and eager natives were clamoring to look through the telescope. We were not long in coming to the decision that the next day should be devoted to securing as many as possible of the long-haired monsters, Ik-queé-sik's discovery having been made too late to risk an attack so near night-fall.

Our dogs, that had been loosened from their harnesses, were now secured to the overturned sledges and to other heavy materials, to prevent their scampering after the game should they scent them in the night, as their ravenous appetites would undoubtedly prompt them to do; while around each animal's nose was closely wound a muzzle of seal or walrus line thongs, to prevent the usual concert of prolonged howls. 
The following morning, a heavy drifting fog threatened to spoil our sport and lose us our coveted meat, but we managed to get away soon after eight o'clock, having a party of eleven rifles, with two Eslimo women, two light sledges, and all the dogs. At that hour the great thick clouds seemed to be lifting, but shortly after starting the fog settled down upon us again. After some two or three hours of wandering around in the drifting mist, guiding our movements as much as possible by the direction of the wind, which we had previously determined, we came plump upon the trail, apparently not over ten minutes old, of some six or seven of the animals. Great fears were entertained by the experienced hunters that the muskoxen had heard our approach, and were now probably "doing their level best" to escape. The sledges were immediately stopped, and the dogs rapilly unhitched from them, from one to three or four being given to each of the eleven men and boys, white or native, that were present, who, taking their harnesses in their left hands or tying them in slip-nooses around their waists, started without delay upon the trail, leaving the two sledges and a few of the poorer dogs in charge of the Innuit women, who had come along for that purpose, and who would follow on the trail with the empty sledges as soon as firing was heard. The dogs, many of them old musk-ox hunters, and with appetites doubly sharpened by hard work and a constantly diminishing ration, tugged like mad at their seal-skin harness lines, as they half buried their eager noses in the tumbled snow of the trail, and hurried their attached human being along at a flying rate that threatened a broken limb or neck at each of the rough gorges and jutting precipices of the broken, stony hill-land where the exciting chase was going on. The rapidity with which an agile native hunter can run when thus attached to two or three excited dogs is astonishing. Whenever a steep valley was encountered, the Eskimos would slide down on their feet, in a sitting posture, throwing the loose snow to their sides like escaping steam from a hissing locomotive, until the bottom was reached, when, quick as thought, they would throw themselves at full length upon the snow, and the wild, excited brutes would drag them up the other side, where, regaining their feet, they would run on at a constantly accelerating gait, their guns in the meantime being held in the right hand or tightly lashed upon the back. 


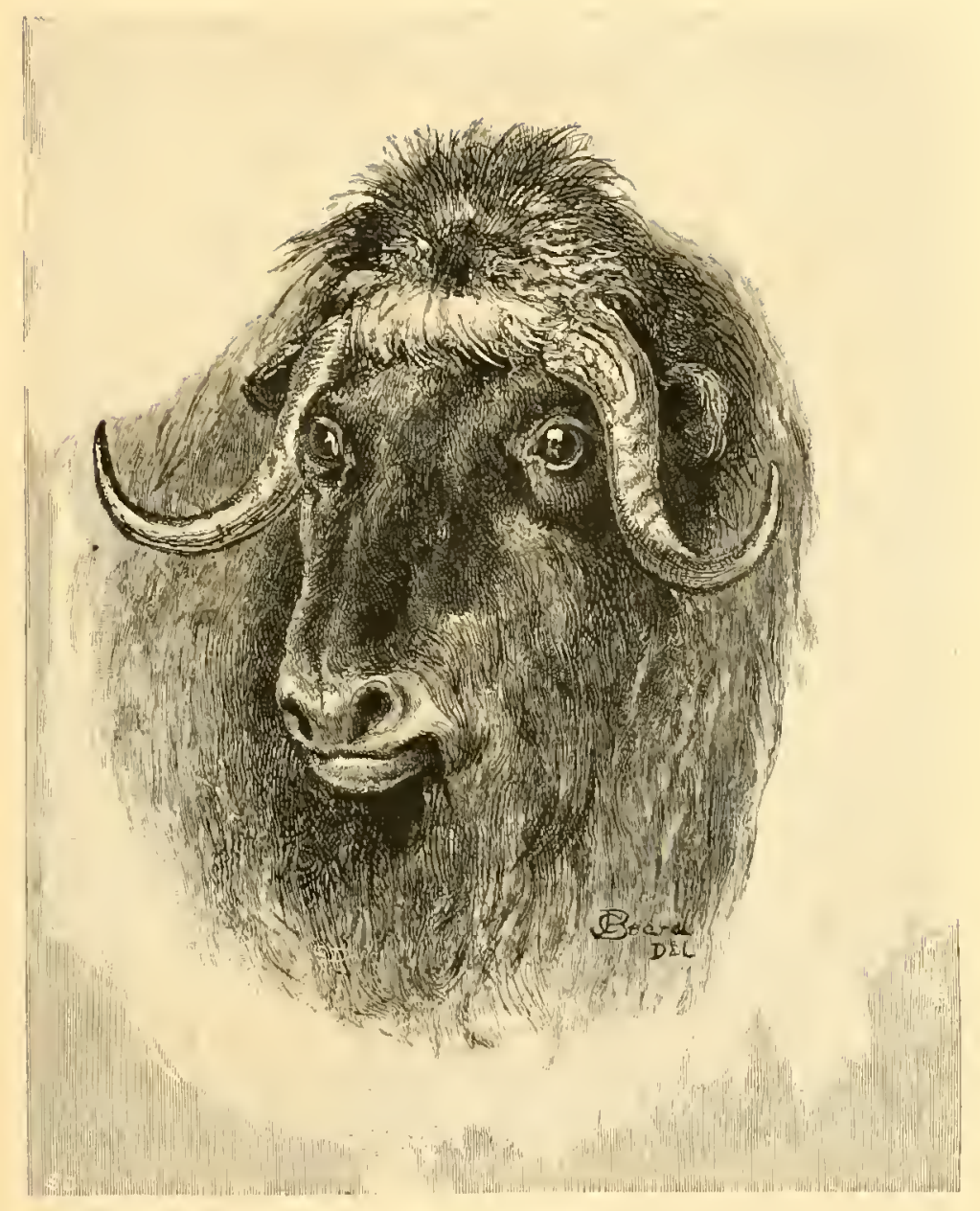

HEAT OF MUSK-COW.

DRAWN BY JAMES C. BEARD. 

We had hardly gone a mile in this harum-scarum chase before it became evident that the musk-oxen were but a short distance ahead, on the keen run, and the foremost hunters began loosening their dogs to bring the oxen to bay as soon as possible; and then, for the first time, these intelligent creatures gave tongue in deep, long laying, as they shot forward like arrows and disappeared over the crests of the hills, amidst a perfect bewilderment of flying snow and fluttering harness traces. The discord of shouts and howlings told us plainly that sume of the animals had been brought to bay not far clistant, and we soon heard a rapid series of sharp reports from the breech-loaders and magazine guns of the advanced hunters. We white men arrived just in time to see the final struggle. The oxen presented a most formidable-looking appearance, with their rumps firmly wedged together, a complete circle of swaying horns presented to the front. with great blood-shot eyeballs glaring like red-hot shot anidst the escaping steam from their panting nostrils, and pawing and plunging at the circle of furious dogs that encompassed them. The rapid blazing of magazine gruns right in their faces - so close. often, as to burn their long. shaggy hair-added to the striking scene. Woe to the overzealous dog that was unlucky enough to get his harness-line under the hoofs of a charging and infuriated musk-ox: for they will follow up a leash along the ground with a rapidity and certainty that would do credit to a tight-rope performer, and either paw the poor creature to death or fling him high in the air with their horns.

Although we tired and panting white men rested where the first victims fell, Too-loó-ah, my best hunter,-an agile, wiry young Iwillik Eskimo of about twenty-six, with the pluck and endurance of a blooded horse, - and half the dogs, pressed onward after the scattered remnants of the herd, and succeeded in killing two more after a hard run for three miles. The last one he would probably not have overtaken if the swiftest dog, Parseneuk, had not chased him to the edge of a steep precipice. Here a second's hesitation gave the dog a chance to fasten on the ox's heels, and the next moment Parseneuk was making an involuntary aerial ascent, which was hardly finished before Too-loó-ah had put three shots from his Winchester carbine into the brute's neck and head, whereupon the two animals came to earth together, - Parseneuk on the soft snow at the bottom of the twenty- 


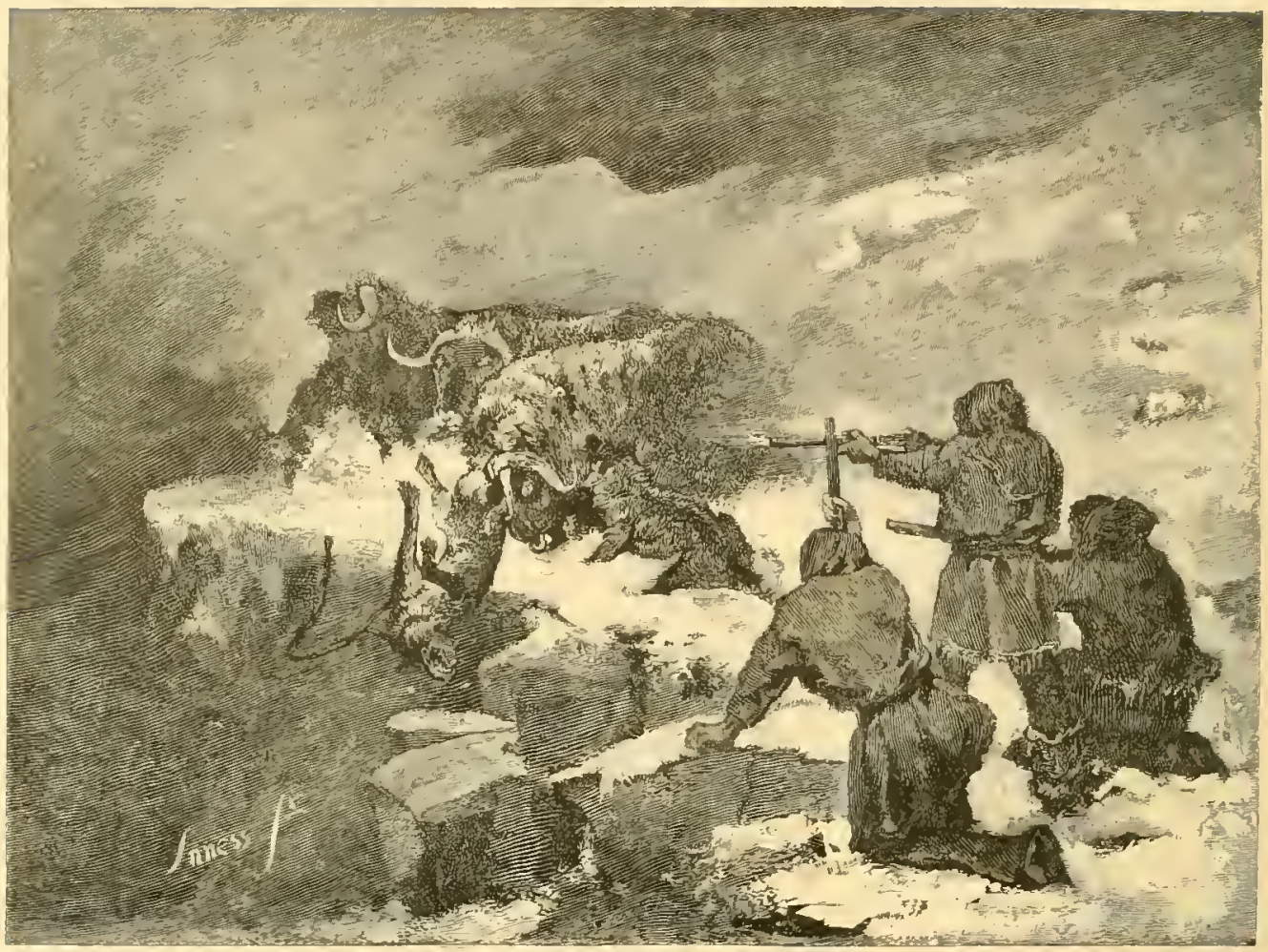

PARSENEUK IN A TIGHT PLACE.

foot precipice, fortunately unhurt. Parseneuk was a trim-built animal that I had secured from the Kinnepetoo Eskimo, who inhabit the shores of Chesterfield Inlet, being one of the very few tribes of the great Eskimo family, from the Straits of Belle Isle to those of Behring Sea, who live away from the sea-coasts. They subsist principally upon the flesh of the reindeer, and their dogs are adepts in hunting these fleet animals, Parseneuk being particularly swift and intelligent as a hunter. He had been the favorite in the Kinnepetoo family from whom he was purchased, and I had to appease several of them with presents, as indirect damages to their affections. He had a beautiful head, with sleek muzzle and fox-like nose, while his pointed ears peered cunningly forth in strange contrast with the many other dogs that 1 have met, whose broken and mutilated ears (usually restored in illustrations of arctic scenes) showed plainly the fights and quarrels in which they had figured. Parseneuk, as a favorite, had been raised and fed in the 
igloo, under the fostering protection of the old squaw, and being saved the necessity of combating for his daily bread, thus preserved his ears.

The chase finished, the half-famished doys receired all they could eat, - their first full feast in over three weeks, - and after loading the two sledges with the remaining meat and a few of the finer robes as mementos and trophies, we returned to our morning's camp, a distance of five or six miles, which we traveled slowly enough, our over-fed dogs hardly noticing the most vigorous applications of the well-applied whip.

The Eskimos with whom I was brought in contact never lunt the musk-oxen without a plentiful supply of well-trained clogs, for with their help the hunters are almost certain of securing the whole herd, unless the animals are apprised of the approach, as they were in our encounter with them. When the flying herd has been brought to bay in their circle of defense by the dogs, the Eskimo hunters approach within five or six feet and make sure of every shot that is fired, as a wounded animal is somewhat dangerous and extremely liable to stampede the herd. A band of these brutes, when once stampeded, are much harder to bring to bay the second time; but it may be well to mention that, if the hunt is properly managed, such stampedes are extremely rare. When the circle of cattle is first approached, the hunters take care to dispatch first the active and aggressive bulls, conformably to a general hunting maxim followed in all parts of the world. As their members fall, one at a time, the musk-oxen persist in their singular mode of defense, presenting their ugly-looking horns toward as many points of the compass as their remaining numbers will allow. When but two only are left, these, with rumps together, will continue the unequal battle, and even the last "forlorn hope" will back up against the largest pile of his deacl comrades, or against a large rock or snow-bank, and defy his pursuers, dogs and hunters, until his death. While the calves are too young and feeble to take their places in ranks, which, in general, is about the first eight or nine months of their existence, they occupy the interior space formed by the defensive circle: but when their elders have perished in their defense, with an instinct born of the species they will form in the same order and show fight. 


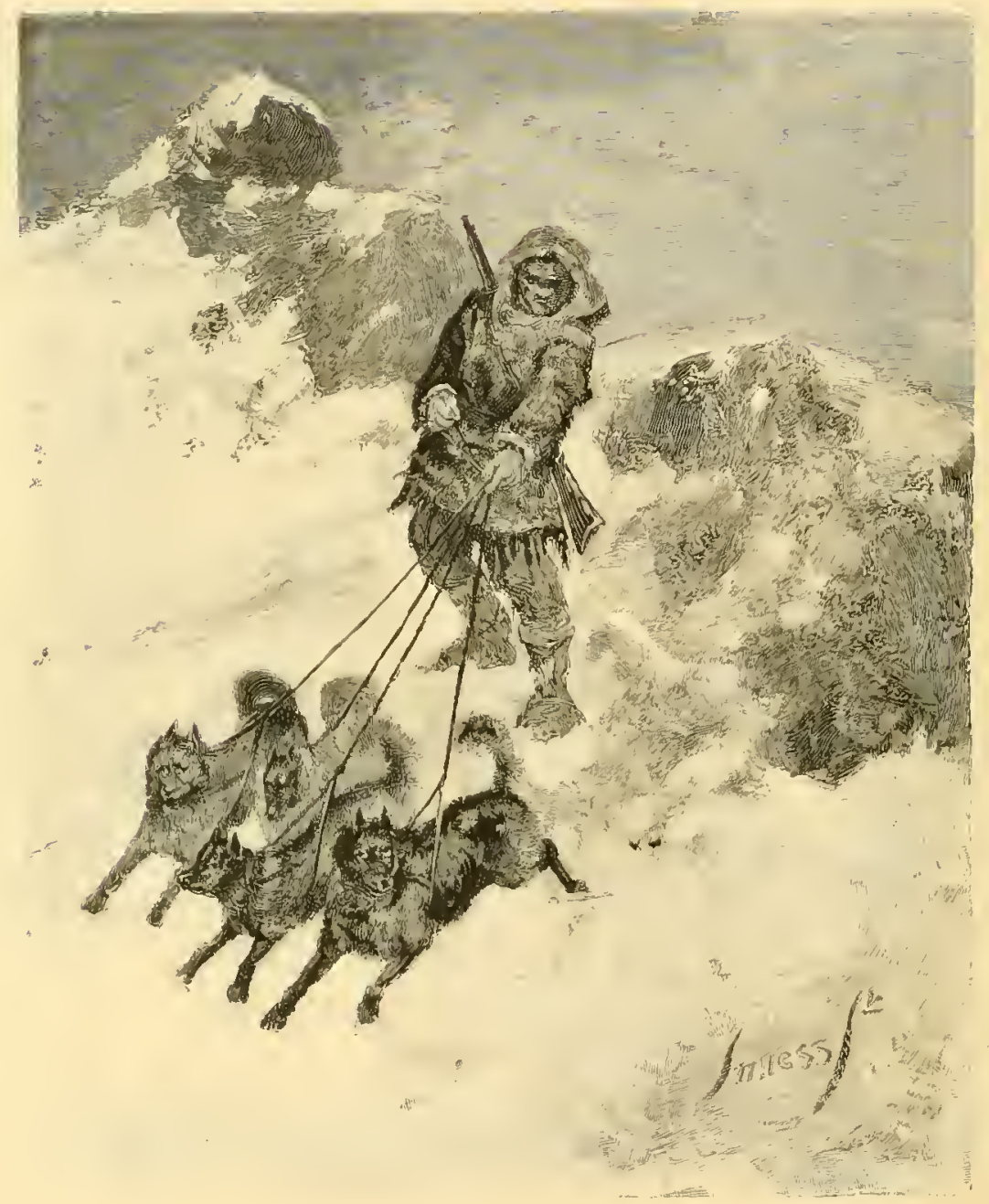

ON THE TRAIL.

The calves are born about the month of May, in this portion of the country, and have the same dirty-brown, awkward, ugly-looking appearance as the buffalo calves of the plains. They can be readily captured alive by the Eskimo dogs, if the hunters are near enough to prevent their being immediately killed by these ravenous animals; but in these inhospitable regions, it is impossible to furnish them with proper nourishment to sustain life until they can be transferred to a vessel, which, moreover, can only escape from here during the autumn months; consequently, there are no cases on record, I believe, where these most curious animals have been exhibited in the 
temperate zones. The natives told me they had kept calves alive for a few day's, but they sank so rapidly they killed them for food.

Before the Eskimo hunters were provided with the fire-arms of civilization, procured in trade with the Hudson's Bay Company or American whale-ships, they used the bow and arrow or the lance. dashing fearlessly past the brutes as they buried the sharpened bone lance-head deep in som vital part. In the olden times, one of their tests of manly courage was for the hunter to pass within the circle of animals and return, backward and forward, hilling one of the oxen at each passage. Of such feats, the old gray-haired men of the tribes still boast.

One old Iwillik Innuit - so 1 was told by his tribe, and they are not given to vain boasting, - while traveling with dogs and sledge from one village to another, during his younger days, came suddenly and unexpectedly upon a couple of musk-oxen that had strayed far from their usual haunts. Unhitching his dogs from the sledge, he soon brought the oxen to bay. His only weapon was a "snowknife," a kind of long-bladed butcher-knife which they use to cut the blocks of snow in constructing heir houses of that material. Nothing daunted, however, he courageously attacked them, and in a few minutes had secured both.

The danger from these formidable and ferocious-looking brutes is undoubtedly more apparent than real, judging from the few accidents that occur. The dogs are frequently killed by being tossed in the air or pawed to death as already described. The musk-bulls are prevented from following up a dog's trailing harness-line by attaching a toggle noose where the trace joins the harness at the root of the dog's tail when the traces are separated from the dogs before they are slipped for the chase; also, a sure way is to fold the trace into a "bundle noose" until it rests on the dog's back. The trained Eskimo dog never barks in the presence of game until liberated from his master's hands.

The musk-ox of the Arctic is only about two-thirds the size of the bison, or American buffalo, but in appearance he is nearly as large, owing to his immense heavy coat of long hair that covers him down below the knees, as if he were carrying a load of black brush. As his generic name (Oibos moschatus) imports, he seems to form a connection between the ox and the sheep. His peculiar covering 211 


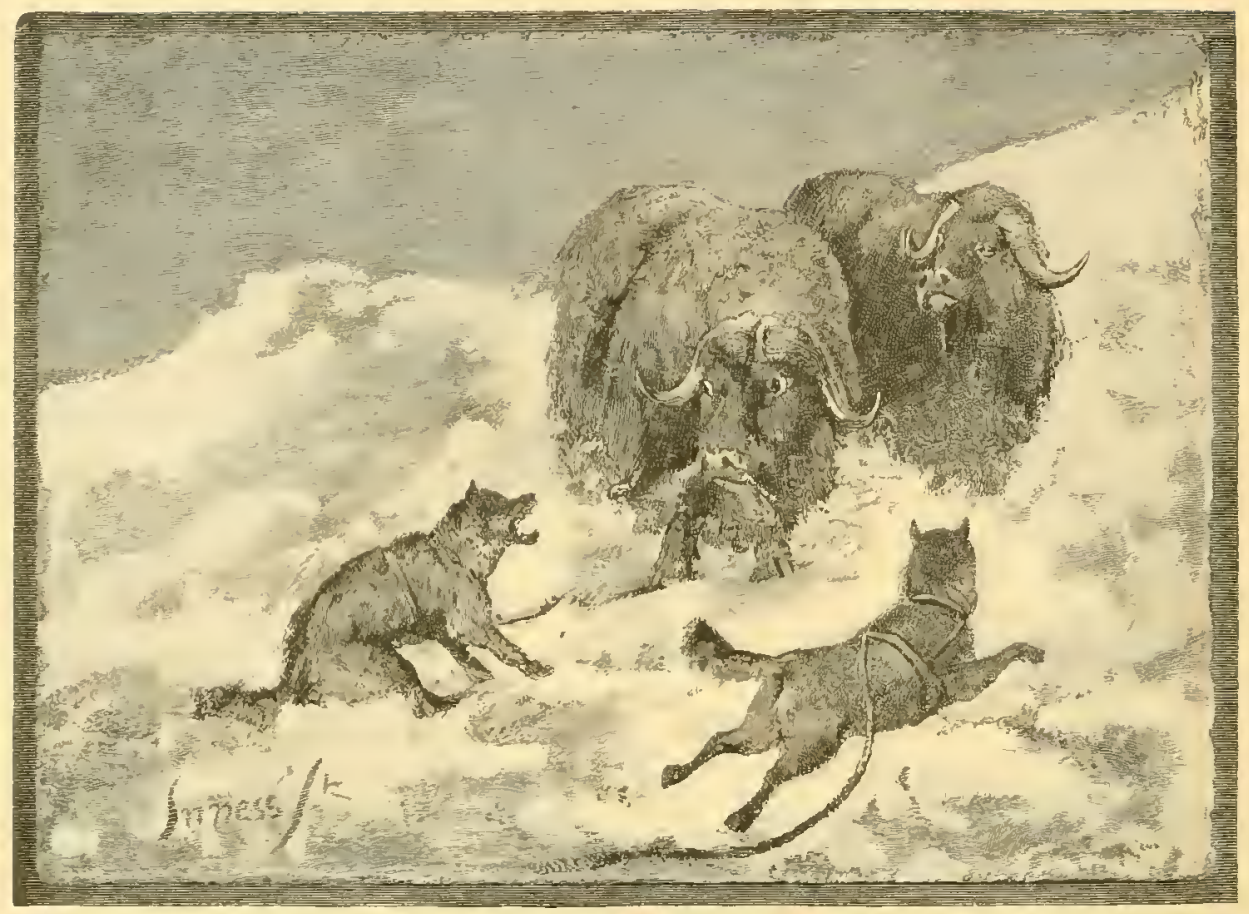

AT BAY.

makes him look like a huge ram, to which his horns add much of similarity. In fact, this covering partakes of the character of both wool and hair. First, there is a dense coat of blackish-brown hair like that on the hump, shoulders, and fore-legs of the buffalo, which extends over the whole body and is, I believe, never shed. Below this there is an undercoating of soft, light brown wool, which is shed annually, and which is invisible through the outer coat, unless parted by the hands. This seems to be a true wool and of the finest texture. A Mr. Pennant, an English gentleman, gives an instance of a man of his, by the name of Jeremy, having woven from this inner fleece of the musk-ox a pair of stockings which were as fine as any of the best silk stockings.

During the summer months, just after this fleece is shed, it is still found, matted into the long black hair, and is only prevented from falling to the ground by this interweaving process. The short hair on their foreheads is very often found matted into little balls or small lumps with ordinary dirt, showing unmistakably that they use their heads and horns in tearing up the earth. This they have been 
seen to do when closely pressed and brought to bay; but they are so seldom hunted that we may suppose their head and horns are used in removing the snow from the mossy patches where they graze in the winter-time. Their horns, from their peculiar shape, would certainly make excellent snow shovels.

The shape of these weapons of defense is certainly most peculiar. Starting from the median line of the forehead, at which point the horns are joined base to base, they present a thick, flat plate, or shield, of corrugrated horn almost a foot in width. As these flat shields circle around the eyes, about four inches from them, the outer edges are gradually incurvated until, about half way between the eyes and nostrils, a perfect horn is formed. From here it tapers, curling upward near its extremity with a jauntiness worthy of a Limerick hook. To the natives of the north, these horns afford many implements of the chase and household utensils. They thoroughly understand the well-known principle of steaming the horn in order to render it soft while it is being worked.

The native bow is usually made of two or three sections of musk-ox horn, tipped with the shorter horn of the reindeer, the whole being firmly lashed with braid made from the sinew on the superficial dorsal muscles of the reindeer, a cluster of these braids about as thick as a man's middle finger running the length of the back of the bow to give it strength and elasticity. I found the Eskimos of King Milliam's Land and vicinity using copper stripped from Sir John Franklin's ships to rivet their bows together. The Eskimo bow is not in any way equal to the Indian bow: seldom being effective at over forty or fifty yards with such game as the reindeer. Except as children's playthings, bows have entirely disappeared, wherever intercourse with the Hudson's Bay Company or American whalers has placed fire-arms in the hands of the natives, and this includes the whole of the great Eskimo family (or Innuits, as they should be properly called), except those stretched along the shores of the Arctic Ocean from about King IVilliam's Land on the east to the farthest point reached by American whalers from the Pacific on the west.

A camp is always picked near a lake which the Eskimos know, by certain signs, has not yet frozen to the bottom. This fact is ascertained by placing their pug noses in close proximity to the 
upper surface, when the peculiar hues indicate the presence or absence of water. While the most of the party are building their little huts of snow for the night's encampment, some cne takes the ice-scoop and chisel and fares out on the lake and selects a place for his operations. He then digs a hole with the chisel about a foot in cliameter, and nearly the same depth, by repeated vertical strokes, and when the chopped ice or débris thus formed commences choking this instrument, it is removed with the icescoop, and this alternation of cutting and removal is kept up until the water is reached, at from four to eight or ten feet below. This digging requires far more dexterity than one would at first glance suppose. The amateur finds it impossible to keep it from rapidly narrowing to a point long before the water is reached. Moreover, if the débris be too freely chopped it becomes reduced to a sort of ice-dust, which will pack in so firmly toward the finishing of the water-hole that the edge of the scoop cannot be wedged under it, with its limited play of action. The children and old women of the village may draw many a meal of goodlysized salmon through this avenue, and this necessitates that the hole should be of fair size throughout. One of the most annoying events of my sledge journey was, after a long and unsuccessful attempt to catch something at one of these water-holes, to find myself suddenly at one, and a big salmon at the other, end of a strong fish-line, separated by an ice-hole through which neither could pass.

The range of musk-cattle is quite extensive. They occupy the extreme northern shores of Greenland on both the east and west coasts as far as they have been explored, and these two ranges are probably connected around the northernmost point of this great polar continent. They occur on both sides of Smith Sound, and in general frequent arctic America from latitude $60^{\circ}$ to $79^{\circ}$ north, and from longitude $67^{\circ} 30^{\prime}$ west, almost to the Pacific coast. It is, however, in the great stretch of hilly country lying between North Hudson's Bay and its estuaries on the south and east, and the Arctic Ocean with its intricate channels on the north and west, that these animals are found in the largest herds and greatest numbers. Captain Hall, in his sledge journey from Repulse Bay to King William's Land, in I 869 , killed 79 musk-oxen, whose hides alone weighed $\delta_{73}$ pounds. 
Dr. Rae, the celebrated Scotch explorer of this region of the Arctic, also secured large numbers of them. The musk-ox occurs fossilized at Escholtz Bay on the north-west coast, and fossil oxen found in clifferent sections of the United States, and which closely resemble the musk-ox, have been described by 1)r. Leidy in the Smithsonian Institution's reports. These were clothed in a long fleece, and roamed through the Mississippi V'alley just before the great drift period. Fossil musk-oxen exist in Siberia and northern Europe; but their living descendants, of which one species is known, are now strictly confined to the arctic region of the Western continent.

The musk-ox derives its name from the peculiar odor which it emits, and which to a greater or less extent also pervades the meat of the animal. The younger animals, however, are much milder, and with the calves I have never been able to discern it at all. Nuch of this odor can be obviated by dressing the animal as soon as killed, especially if it is cold weather, and this rule may be said to be more or less general with all animals and birds having disagreeable odors peculiar to their kind.

I have said the robes are almost worthless to the natives except for purposes of traffic. They are sometimes used to spread on the snow-bed, as the first layer of skins, in order to protect the snow from the heat of the body; but even here they are not nearly so serviceable as the robe of the reindeer, owing to the facility with which the snow can be removed from the latter by a few strokes of a stick. The Ookjoolik, or Ooqueesik-Salik Eskimos of Hayes River, who are not armed, and consequently can procure but few reindeer (whose hicle is the universal arctic clothing), often make long boot-leggings and gloves of musk-ox fur, and this gives them a peculiarly wild and savage appearance that contrasts strangely with other natives. The almost total absence of wood in their country - the little they get being obtained by barter with distant and more fortunate tribesforces them to use the skin of the musk-ox for sledgring in their country. The ears and fore-legs of the skin being lashed almost together, a sledge-like front is obtained, and the articles to be transported are loaded on the trailing body behind. Over lakes, rivers, and flat plains, it is equal to wood, but in very uneven ground its pliability is dangerous to fragile loads. 
When closely pressed, the musk-oxen do not hesitate to throw themselves from the steepest and deepest precipices, and the natives speak of occasions where they have secured them in this manner without wasting powder or lead, finding them dead at the foot of the descent. Sir James Clarke Ross had a personal observation of this kind $i$ one of his arctic expeditions.

McClintock once saw a cow on Melville lsland, in the Parry archipelago, which was of a pure white color, an albino sort of deviation that is known to occur among the buffalo of the plains at rare intervals. She was, however, accompanied by a black calf. This Melville lsland is abundantly peopled with these oxen, not less than one hundred and fourteen being shot within a year by the crews of two ships wintering there. When inhabiting islands, they do not seen to cross from one to another, as the reindecr constantly do when the channel is frozen over, and even confine their annual migrations to very limited areas. Different writers disagree as to whether they can be called migratory in the strict sense of the word. If white men are hunting them without logs, they may station themselves about a herd, close in to seventy or eighty yards, and then, by picking off the restless ones first, so bewilder the remainder that, with fair luck, they may secure them all. There are several instances of such methods being tolerably successful. When the temperature reaches the extremes of the bitter winter weather, as from $-60^{\circ}$ to $-70^{\circ}$ Fahrenheit, the musk-oxen and reindeer herds can be located, at from six to seven miles distance, by the cloud of moisture which hangs over them, formed by their condensing breath, and from favorable heights at even fifteen to twenty miles. Even at these extreme distances, the native hunters claim that they can discern the difference between musk-oxen and reindeer by some varying peculiarities of their vapors.

I remember being one of a party of six - five Innuits besides myself - that chased on a fresh trail of a small herd of musk-oxen from about nine o'clock in the morning until night-fall, which was four in the afternoon. We went at a gait which would be called a good round "dog-trot" for the whole time (except one small rest of five minutes). This is much easier than one would imagine, with a couple of dogs harnessed to you to tow you along; yet I confess I was completely fagged out, after this little run of not less than forty or 
fifty miles, and in a fine condition to believe many stories of endurance while on hunting chases that I had hearct them tell. The thermometer at camp registered $65^{\circ}$ lelow zero, yet there was no suffering from the still cold during such exercise, and, in fact, at times, 1 felt uncomfortably warm.

One of their peculiarities which I have noticed is that when slightly wounded, if they have been knocked over upon their sides, they seem perfectly powerless to rise, eirher from fear or the peculiar formation of their legs. Two of the animals we shot on the 2oth of April received each a broken shoulder and were knocked on their sides. The native men, women, and boys sat upon their heaving sides, evidently enjoying the cruel sport, and all the white men participated for a mere second, rather to please their savage allies, until I requested them to dispatch the brutes, which they ciid by a well-directed heart thrust with a snow-knife. My natives spoke of this occurrence as a rather common incident of the musk-ox battlefield.

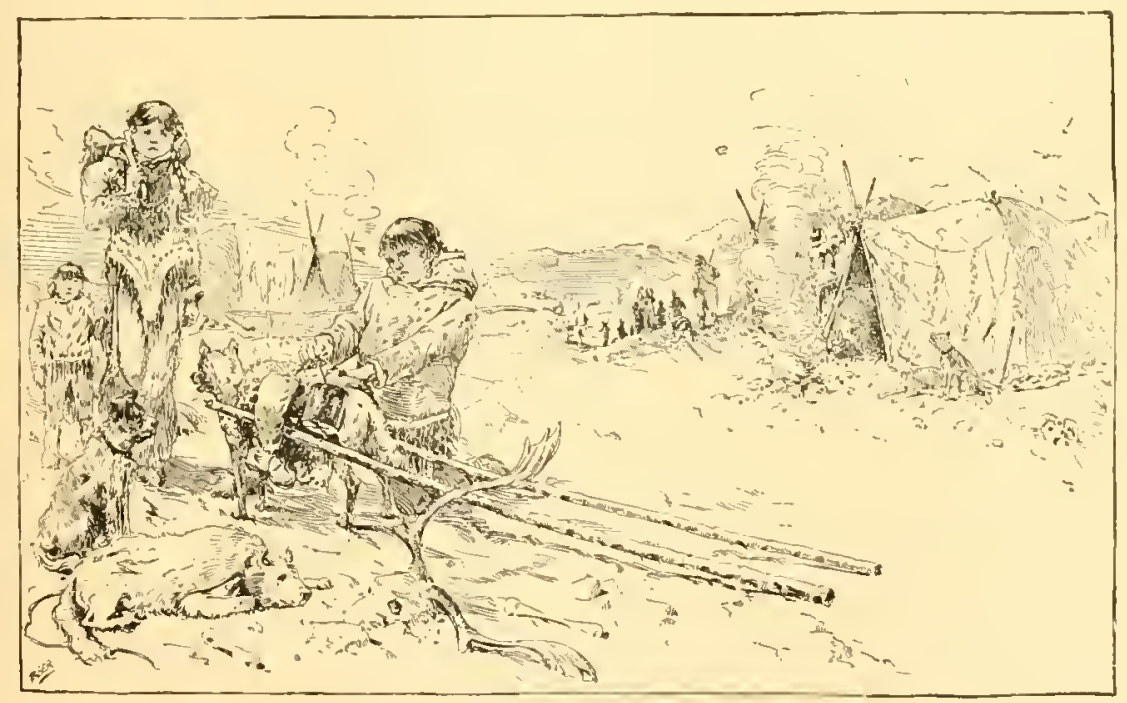

AN ESKIMO CAMP. 


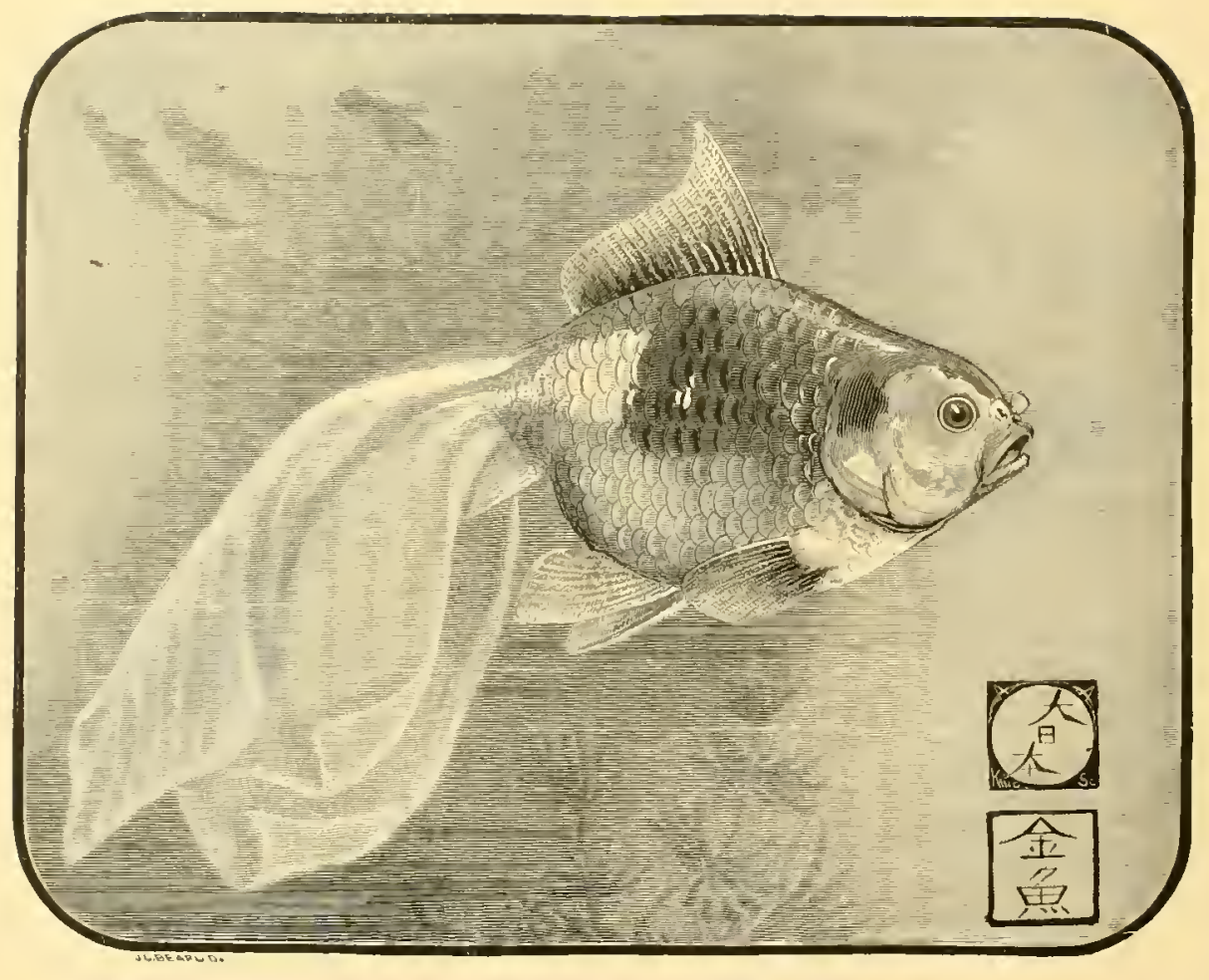


FISH 
I shall stay him no longer than to wish him a rainy inning to rat this following discourse: ant that, if he be an honest angler. the cast wind may never blow whin hi goes a fishing.

- Izaak Hilton. 


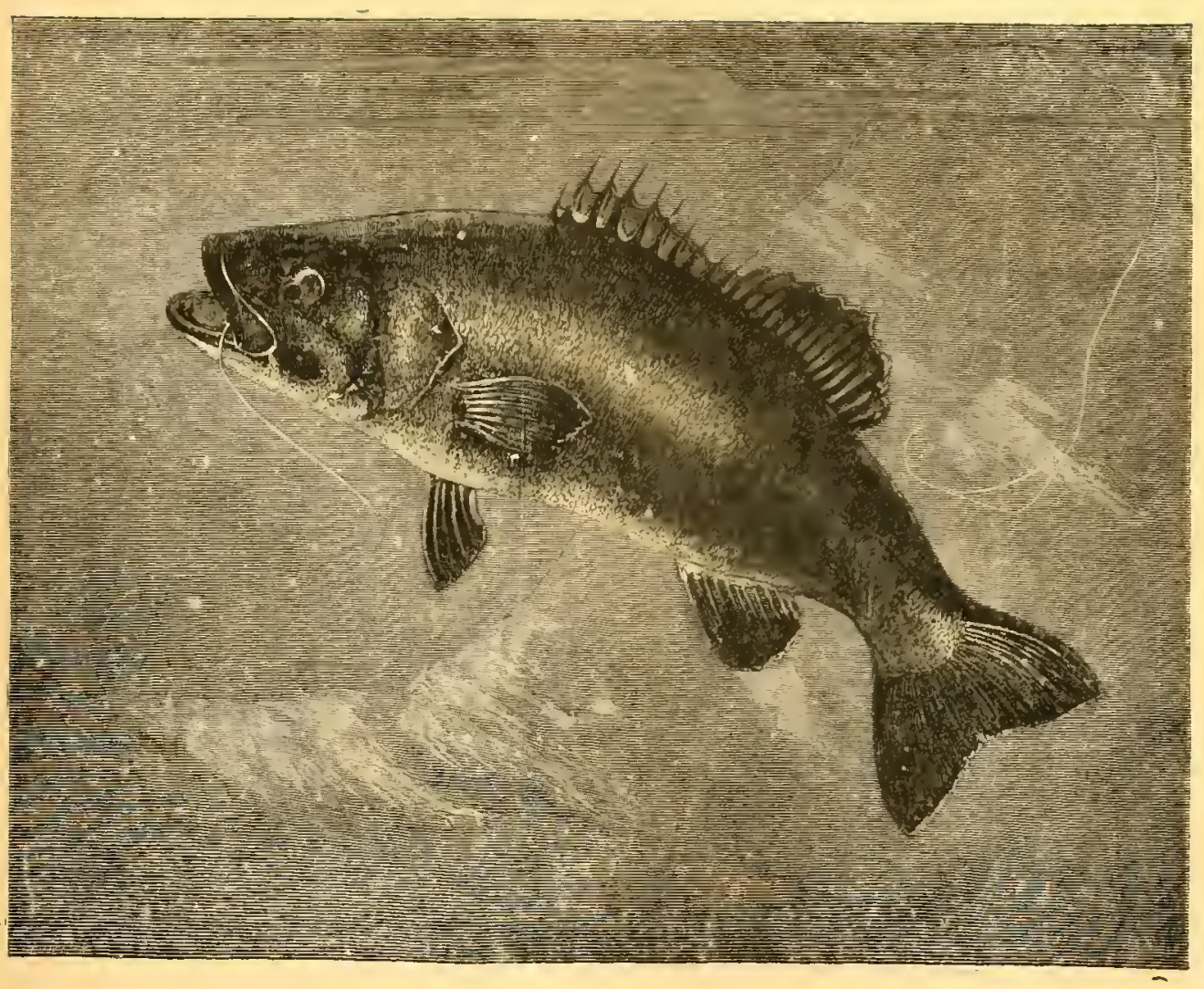





\title{
THE PRIMITIVE FISII-HOOK.
}

\author{
BY B.IRNET PHILLIPS. \\ SECRETARY WF THE AMERICAN FISH CULTURAL ASSICITTION
}

I

H.AVE before me an illustrated catalogue of modern fish-hooks and angling implements, and in looking over its pages 1 find an cmbarras de choix. I have no need for rods, for mine, like wellkept violins, have rather improved by age. A lashing may be frayed, or a ferrule loose, but fifteen minutes' pleasant work will make my rods all right again. Lines are sound, for I have carefully stretched them after use. But my hooks! They are certainly the worse for wear. I began my season's fishing with a meager stock. Firiends borrowed from me, and in replenishing my fly-book in an out-of-the-way place, the purchase was unsatisfactory. As I lost more than one fish from badly tempered or worse fashioned hooks, I recalled a deliglitful paper by Mr. Froude. Rod in hand, he was whipping some pleasant trout stream, near an historic site, the home of the Russells, and, breaking his hooks, commenced from that very moment to indulge in the gloomiest forebodings as to the future of England.

Fairly familiar with the general character of fishing-gear, either for business or amusement, I see in my book, Kirby, Limerick, Dublin, O'Shaughnessy, Kinsey, Carlisle, Harrison, Central Draught, as somewhat distant families of hooks, used for sea or river fishing, and from these main stocks there grow many varieties, with all conceivable twists, quirls, and crookednesses. I discard all trap-hooks, infernal machines working with springs, as only adapted for the capture of land animals. Somehow 1 remember an aggressive book, given to me at an early age, which, containing more than one 
depressing passage, had one of extraordinary malevolence. This was couched nearly as follows: "Suppose you were translated only some seven hundred years back, then, pray, what would you be good for? Could you make gunpowder? You have, perhaps, a vague idea that sulphur, saltpeter, and charcoal are the component parts, but do you know where or how they are procured?" I forget whether this dispiriting author was not equally harrowing in regard to the youthful reader's turning off a spectroscope at a minute's notice, or wound up with the modest request that you should try your hand among the Crusaders with an aneroid barometer of your own special manufacture.

Still this question arises: Suppose you were famishing, though fish were plenty in a stream, and you had neither line nor hook, What would you do? Now, has a condition of this kind ever occurred? Yes, it has, and certainly thousands of times. Not so many years ago, the early surveyors of the Panama route suffered terrible privations from the want of fishing implements. The rains had rendered their powder worthless; they could not use their guns. Had they only been provided with hooks and lines, they could have subsisted on fish. Then there are circumstances under which it would be really necessary for a man to be somewhat of a Jack-of-alltrades, and to be able to fashion the implements he might require, and so this crabbed old book might, after all, act in the guise of a useful reminder. There was certainly a period, when every man was in a condition of comparative helplessness, when his existence depended on his proficiency in making such implements as would catch fish or kill animals. He must fashion hooks or something else to take fish with, or die.

Probably man, in the first stage of his existence, took much of his food from the water, although whether he did or not might depend upon locality. If on certain portions of the earth's surface there were stretches of land intersected by rivers, dotted by lakes, or bordering on the seas, the presence of shell-fish, the invertebrates or the vertebrates, cetaceans and fish, to the exclusion of land animals, might have rendered primitive man icthyophagous, or dependent for subsistence upon the art of fishing. But herein we grapple at once with that most abstruse of all problems, the procession of life. Still, it is natural to suppose, so far as the study of man goes, when con- 
sidered in relation to his pursuits, that in the early dawn of humanity, mammals, birds, and fish must have been synchronous.

After brute instinct, which is imitativeness, then came shiftiness and adaptiveness. The rapid stride of civilization, considered in its material sense, is due solely to the use of such implements as are specially adapted for a particular kind of work. With primitive man, this could never have been the case. Tools of the Paleolithic or Neolithic age (which terms indicate stages of civilization, but are not chronological), whether they were ases, hammers, or arrows, must have served river-drift or cave-men for more than a single purpose. People with few tools do manage by skill alone to adapt these to a variety of ends. The Fijian and the Russian peasant, one with a stone adze, the other with a hatchet, bring to their trades the minimum of tools. The Kafir, with his assegai, fights his battles, kills cattle, carves his spoons, and shaves himself. It was only as man advanced that he devised special tools for different purposes.

According to our present acquaintance with primitive habits, if man existed in the later Miocene age, and used a lance or spear for the killing of land animals, he probably employed the same weapons for the destruction of the creatures - possibly of gigantic form inhabiting the seas, lakes, and rivers. The presence of harpoons made of bone, found in so many localities, belonging to a later period, may not in all cases point to the existence of animals, but to the presence of large fish.

Following, then, closely the advance of man, when his fishing implements are particularly considered, we are inclined to believe that he first used the spear for taking fish; next, the hook and line; and, lastly, the net. There might have been an intermediate stage between the spear and the hook, when the bow and arrow were used.

Interesting as is the whole subject of primitive fishing, we are, however, to occupy ourselves principally with the form of the primitive fish-hook. To-day there are some careful archeologists who are not willing to accept that particular form which is presented below. 1 believe, from the many reasons which can be advanced, that this simple form was the first device used by man in taking fish with a line. The argument I shall use is in some respects a novel one.

These illustrations, exactly copied as to size, represent a small 
piece of dark, polished stone. It was found in the valley of the Somme, in France, and was dug out of a peat-bed twenty-two feet below the surface. 'The age of this peat-bed has been variously estimated. M. Boucher de Perthes thought
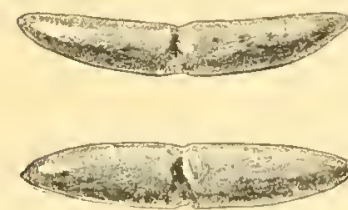

STONE HISH-GOKGE, FRON THE VALLEY OF THE SOMME

(AEW YORK MUSELAI OF NATURAL. IISTORY.)

Neolithic period." thousand years is. C.

Wonderful changes have come to pass since this bit of polished stone was lost in what must have been a lake. Examining this piece of worked stone, which once belonged to a prehistoric man living in that valley, we find it fairly well polished, though the action of countless years has slightly "weathered" or disintegrated its once smooth surface. In the center, a groove has been cut, and the ends of the stone rise slightly from the middle. It is rather crescent-shaped. It must have been tied to a line, and this stone gorge was covered with a bait; the fish swallowed it, and, the gorge coming crosswise with the gullet, the fish was captured.

The evolution of any present form of implement from an older one is often more cleverly specious than logically conclusive; nevertheless, I believe that, in this case, starting with the crude fish-gorge, I can show, step by step, the complete sequence of the fish-hook, until it ends with the perfected hook of to-day. It can be insisted upon even that there is persistence of form in the descendants of this fish-gorge, for, as Professor Mitchell writes in his " Past in the Present," "an old art may long refuse to disappear wholly, even in the midst of conditions which seem to be necessarily fatal to its continued existence."

In the Swiss lakes are found the remains of the Lacustrine dwellers. Among the many implements discovered are fish-gorges made of bronze wire. Then these forms are studied, the fact must be recognized at once that they follow, in shape and principle of construction, the stone gorges of the Neolithic period. Now, it is perfectly well known that the early bronze-worker invariably followed the stone 
patterns. The Lacustrine gorges have had the name of bricole given them. This is a faithful copy of a bronze bricole found in the lake of Neuichatel. It is macie of bronze wire, and is bent in the simplest way, with an open curve allowing the line to be fastened to it. The ends of the gorge are very slightly bent, but they were probably sharpened when first made.

This bricole varies from the rather straight one found in the Lake of Neufchatel, and belongs to a later period. It is possible to imagine that the lake-dweller, according to his pleasure.

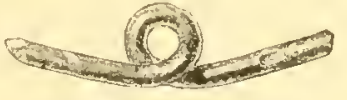

BRICOLE OF A LATER PERIOD. made one or the other of these two forms of fishing implements. Is the double hook required more bronze, and bronze at first was very precious, he might not have had material enough in the early period to make it. This device is, however, a clever one, for a fisherman of to-day who had lost his hook micht imitate it with a bit of wire. Had any member of the hungry Isthmus party before mentioned

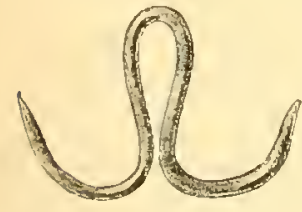

DOUBLE HOOK, FROM THE I.AKE OF NEUFCHATEL. (IN THE COL LECTIKN OF PROF. A M. MAYER.) known of this form of Lacustrine hook, he might have twisted some part of a suspender buckle, providing there were no thorny plants at hand, and have caught fish.

When we compare the four forms, showing only their outlines, the evolution of the fish-hook can be better appreciated. Returning to the stone fish-gorge, the work of the Neolithic period, it is evident that the man of that time followed the shape handed down to him by his ancestors; and as this fashioned stone from the valley of the Somme is of a most remote period, how much older must have been the Paleolithic fish-gorge of rough stone. It might have been with a splinter of fint attached to some tendril, in lieu of a line, that the first fish was taken.

It is very curious to learn that in France a modi-
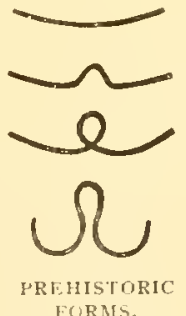

FCRMS. fication of this gorge-hook is in use to-day for catching eels. A needle is sharpened at its eye-end, a slight groove is made in the middle of it, and around this some shreds of flax are attached. A worm is spitted, a little of the line being covered with the bait. 


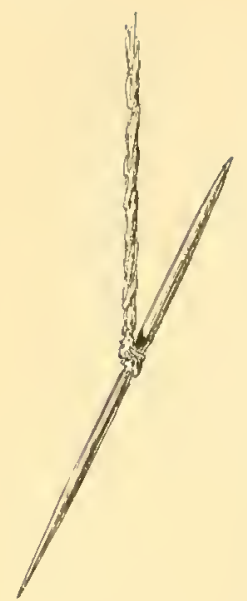

SHARPENED NEEDLE USED FOR CATCHING FISI
IN FRANCE.

Not cels alone are taken with this needle, for $M$. de la Blanchere informs us that many kinds of fish are caught with it in France.

Any doubts as to the use of the Neolithic form of fish-gorge must be removed when it can be insisted upon that precisely this form of implement was in use by our Indians not more than forty years ago. In I 878 , when studying this question of the primitive hook, I was fortunate enough to receive direct testimony on the subject. My informant, who in his younger days had lived among the lndians at the head-waters of lake Superior, said that in 1846 the Indians used a gorge made of bone to catch their fish. My authority, who had never seen a prehistoric fishgorge, save the drawing of one, said that the Indian form was precisely like the early shape, and that the Chippewas fished some with the hook of civilization, others with bone gorges of a primitive period.

In tracing the history of the fish-hook, it should be borne in mind that an overlapping of periods must have taken place. By this is meant, that at one and the same time an individual employed tools or weapons of various periods. To-day, the WVestern hunter lights his fire with a match. This splinter of wood, tipped with phosphorus, the chlorates, sulphur, or paraffine, represents the progress made in chemistry from the time of the alchemists. But this trapper is sure to have stowed away in his pouch, ready for an emergency, his flint and steel. 'The Esquimau, the Alaskan, shoots his seal with an American repeating rifle, and, in lieu of a knife, flays the creature with a flint splinter. The net of the Norseman is to-day sunk with stones or buoyed with wood,-certainly the same devices as were used by the earliest Scandinavian, - while the net, so far as the making of the thread goes, is due to the best modern mechanical appliances. Survival of forms require some consideration apart from that of material, the first having much the stronger reasons for persistence. It is, then, very curious to note that hooks not made of iron and steel, but of bronze, or alloys of copper, are still in use on the coast of Finland, as I have quite recently obtained brass hooks from Northern Europe such as are commonly in use by fishermen there. 
The origin of the double hook having been, 1 believe, satisfactorily explained, to make the barb on it was readily suggested to primitive man, as he had used the same device on fish-spears and harpoons.

This double-barbed hook from the Swiss lakes is quite common. Then, from the double to the single hook the transition was rapid. Single bronze hooks of the Lacustrine period sometimes have no barb. Such differences as exist are due to the various methods of attaching the line.

In Professor A. M. Nayer's collection there

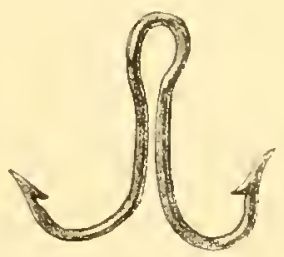

DOUBLE HOOK, BARBED. FROM SWISS LAKES.

is a Lacustrine bronze hook, the shank of which is bent over parallel with the stem of the hook. This hook is a large one, and must have been used for big fish-probably the trout of the Swiss lakes.

Hooks made of stone are exceedingly rare, and though it is barely possible that they might have been used for fish, I think this has not been conclusively shown. Wilson gives, in his work, drawings of two stone hooks which were found in Scandinavia. Though the theory that these stone objects were fashioned for fishing is supported by so good an authority as Mr. Charles Rau, the archaologist of the United States National Museum at Wash-

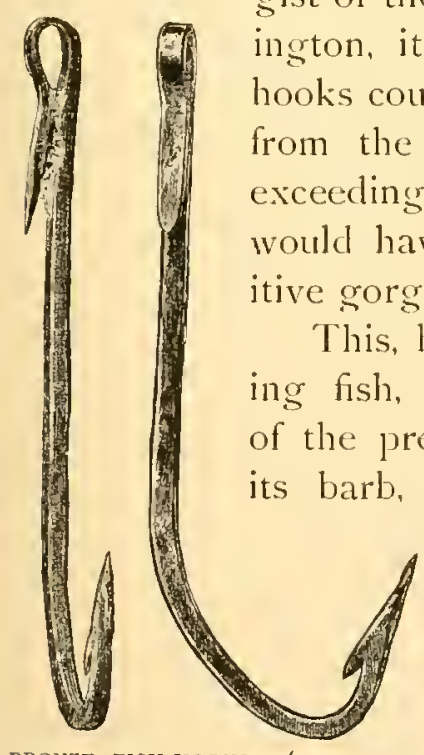

BRONZE FISH-HOOKS. (FROM THE COLLECTIONOF PROF. A. M. MAYER.) loes not seem to me possible that these hooks could have been made for fishing. Such forms, from the nature of the material, would have been exceedingly difficult to fashion, and, even if made, would have presented few advantages over the primitive gorge.

This, however, must be borne in mind: in catching fish, primitive man could have had no inkling of the present curved form of fish-hook, which, with its barb, secures the fish by penetration. A large proportion of sea-fish, and many riverfish, swallow the hook, and are caught, not by the hook entering the jaws of the fish, but because it is fastened in their stomachs. In the Gloucester fisherman's language of to-day, a fish so captured is 


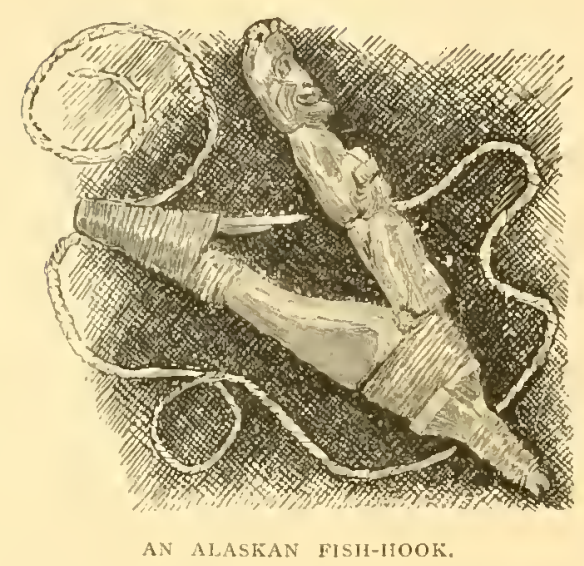

called "poke-hooked"; and accordingly; when the representative of the Neolithic period fished in that lake in the valley of the Somme, all the fish he took must have been poke-hooked. A bone hook, excellent in form, has been found near the remains of a huge species of pike (Esor ). Hooks made of the tusks of the wild boar have aisso been discovered with Lacustrine remains.

In commenting on the large size of the bone hook figured in Wilson's work, its proximity to the remains of large fish was noticed. When the endless varieties of hooks belonging to savage races are subjects of discussion, the kind of fish they serve for catching should always be cited. In the examples of hooks which illustrate works of travel, a grood many errors arise from the simple fact that the writers are not fishermen. Although the outline of a hook be accurately given, the method of securing it to the line is often incorrectly drawn.

In the engraving at the top of this page, an Alaskan halibuthook is represented. The form is a common one, and is used by all the savage races of the Pacific; but the main interest lay in the manner of tying the line to this hook. Since the fish to be caught was the halibut, the form was the best adapted to the taking of the Hipposlossus Americamus; but had the line been attached in any other way than exactly as represented, this big fish could hardly have been caught with such a hook.

In the drawing, the halibut-hook hangs but slightly inclining toward the sea-bottom, the weight of the bait having a tendency to lower it. In this position it can be readily taken by the fish; but 


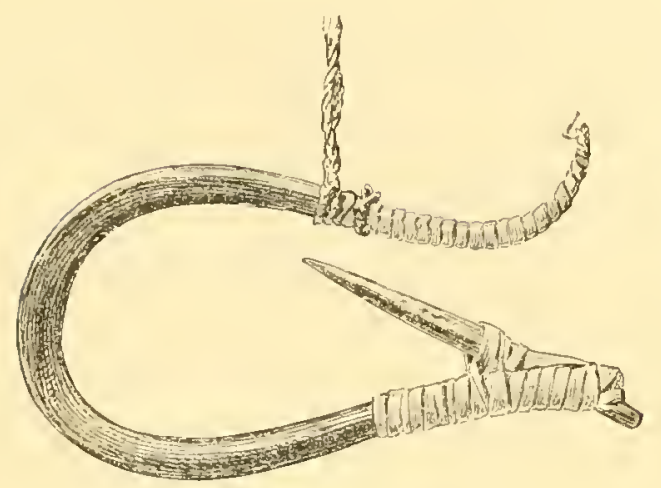

AIASKAN IIALBTT-11OOK. (JROM THE (ULIECTION OF FRUL, I M. MAYFR.)

should it be suspended in a different way, it must be at once seen how difficult it would be for the fish to swallow it. In this Alaskan hook must be recognized the very first idea of what we call to-day the center-draught hook. A clrawing is also griven of a steel hook of a peculiar form coming from Northern Russia. The resemblance between the Alaskan and this Russian hook is at first apparently slight, but they both are, nevertheless, constructed on the same principle. When this Russian hook is seized by the fish, and force is applied to the line by the fisherman, the point of the barb and the line are almost in one and the same direction. Almost the same may be said of the Alaskan hook. Desirous of testing the capabilities of this hook, I lad a gross made after the Russian model, and sent

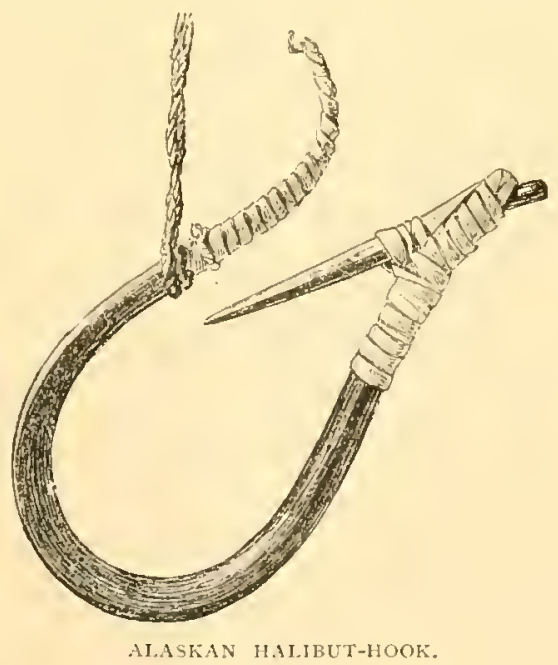


them to Captain J. W. Collins, of the United States Fish Commission, stationed at Gloucester, requesting him to distribute them among the fishermen. While writing this article, I am in receipt of a letter from Captain Collins, informing me that these hooks are excellent, the captains of fishing-smacks reporting that a great many deep-sea fish were taken with them.

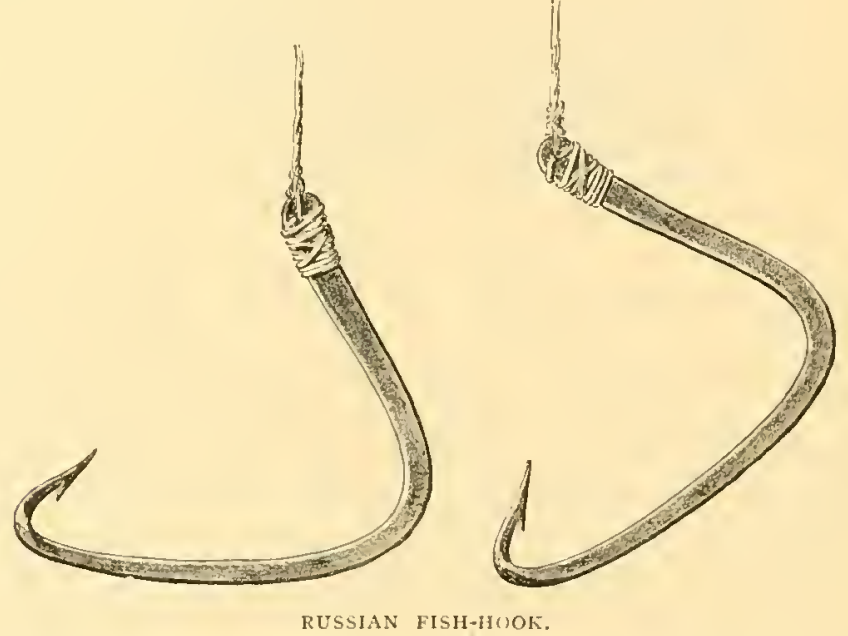

A study of these hooks - the Alaskan and Russian-with reference to the method of attaching the line, explains, I think, the peculiarity of certain shell-hooks of great antiquity found in California which have puzzled archæologists. These hooks, the originals of which are to be found in the National Museum at Washington, are shown in the following engravings. The notch cut in one of the hooks seems to show that the line was attached at that place. Hang the hooks in any other position and they would catch no fish, for one could hardly suppose that the blunt barb could penetrate the mouth of the fish.

If there be some doubt entertained by American archæologists as to the use of these shell-hooks, there can be none in regard to their having barbs. The barbs turn outward, in which respect they differ from all the primitive European hooks I have seen. In confirmation of the idea advanced as to the proper place of attaching the line, Professors C. C. Abbott and F. IV. Putnam, in a chapter entitled "Implements and Weapons made of Bone and Wood," in the United States Geographical Survey, west of the hun- 


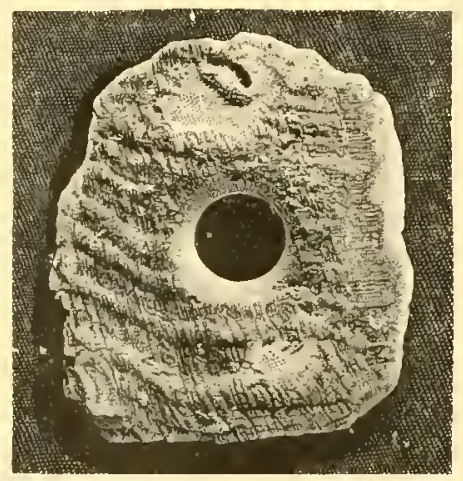

THE BEGINNING OF A SHELL HOOK. (IN THE COLLECTION OF DR. WEST.)

dredth meridian, write, referring to these hooks: "These hooks are flattened and are longer than wide. *** The barbs in these specimens are judged by fishermen of to-day to be on the wrong side of a good fish-hook, and the point is too near the shank. By having the line so fastened that the point of tension is at the notch at the base of the shank, instead of at the extreme end of the stem, the defect of the design of the hook would be somewhat remedied, as the barb would be forced down, so that it might possibly catch itself in the lower jaw of the fish that had taken the hook." The summing up of this is, I think, that in an imperfect way the maker of this Santa Barbara hook had some idea of the efficiency of a center-draught hook. As the first step in manufacturing this hook, a hole was drilled in the shell, and the hook finished up afterward by rounding the outside. Dr. West, of Brooklyn, has a series of such primitive work in his collection.

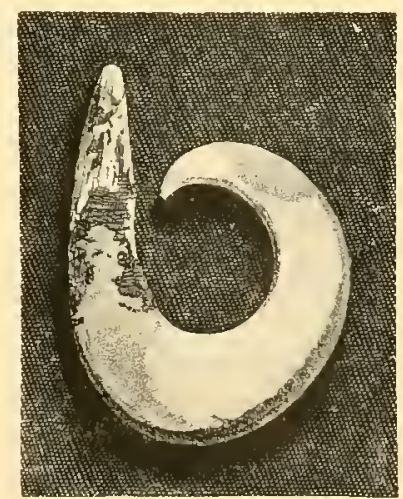

SHELI, HOOK, (NATTUNAL MUSEUM, WASHINGTON.) 


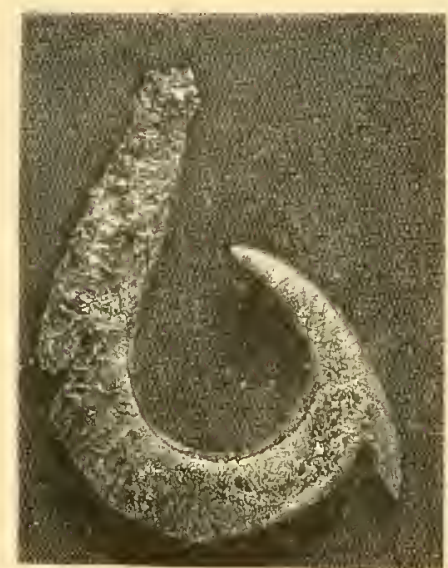

SHELL HOOK. (NATIUNAL. MUSEUM, WASHINGTON,

To advance the idea that in all cases hooks have been improved by slightly increased culture among semi-civilized races would be a source of error. It is quite possible that in many instances there has been retrogression from the better forms of fishing implements once in use. This relapse might have been brought about, not so much by a decrease of intelligence, as changes due to fortuitous causes. A fishing race might have been driven away from a shore or a river-bank and replaced by an inland people.

Some primitive races still use a hook made from a thorn, and in this practice we find to-day a most wonderful survival. On the coast of France, hooks made of thorns are still used to catch fish, the fishermen representing that they possess the great advantage of costing nothing and of not fouling on the sea-bottom. The Piutes take the

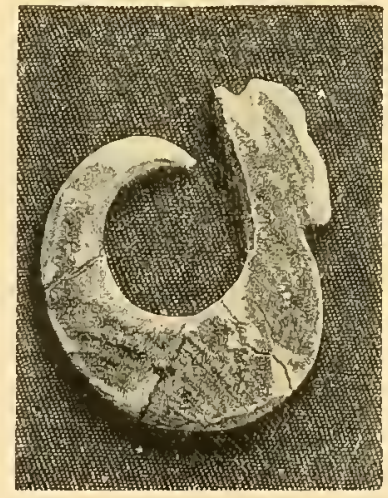

SHELL HOOK FROM SANTA BARBAKA. (NATIINAL MUSECM, WASHINGTON,) 
spine of a cactus, bending it to suit their purpose, and very simple barbless hooks of this kind may be seen in the collections of the National Museum at W'ashington.

Undoubtedly, in primitive times, hooks of a compound character were used. Just as men tipped a deer's antler with a flint, they combined more than one material in the making of their hooks, lash-

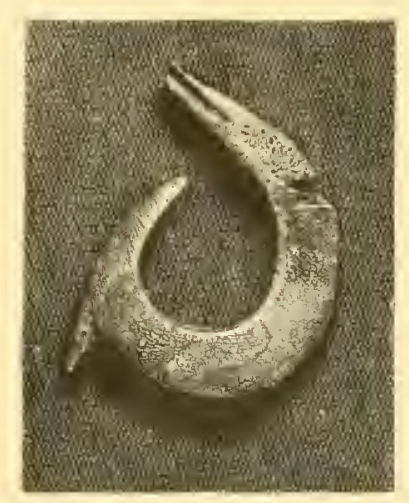

SHFLL HOOK FROM SINTA RARHIRA. (NITIONAI, MUSEUM, BOSTON.)

ing together a shank of bone or wood with a bronze barb. It would be almost impossible in a single article to follow all the varieties of hooks used and the ingenuity displayed in their manufacture. Occasionally, a savage will construct a lure for fish which rivals the daintiest fly ever made by the most fasticlious of anglers. In Professor Mayer's collection there is an exceedingly clever hook, coming from the North-western coast, which shows very fine lapidary work. A small red quartoze pebble of great hardness has been rouncled, polished, and joined to a piece of bone. The piece is small, not more than an inch and three-quarters in length, and might weigh an ounce and a half. In the shank of bone a small hook is hidden. It somewhat imitates a shrimp. The parts are joined together by lashings of tendon, and these are laid in grooves cut into the stone. It must have tak:en much toil to perfect this clever artificial bait, and, as it is to-day, it might be used with success by a clever striped-bass fisherman at Newport.

In this necessarity brief study of primitive fishing, I have endeavored to show the genesis of the fish-hook, from the stone gorge to the more perfected implement of to-day. Simple as 
it may seem, it is a subject on which a good deal of research is still requisite. "It is not an acquaintance with a single series of things which can throw light on any subject, but a thorough comprehension of the whole of them." If in the Swiss lakes there are found bronze hooks of a very large size, out of proportion to the fish which swim there to-day, it is but just to suppose that, many thousands of years ago, long before history had its dawn, the aquatic fauna were then of greater bulk than in 1883 . Considerations on the primitive form of the fish-hook must even comprehend examination of prior geological conditions, differences of land and water, or such geographical changes as may have taken place. Then ichthyology becomes an important factor, for by the char-

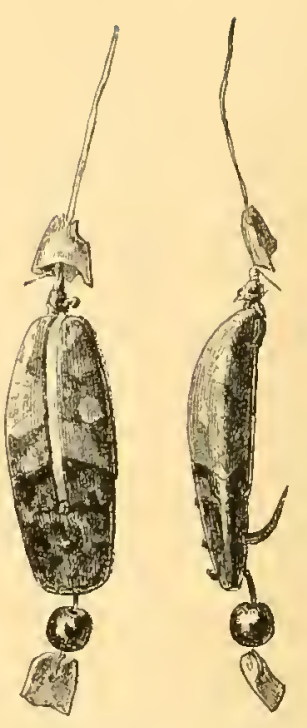

ARTJFICIAL STONE SHRIMP. (FROM THE CULLECTION OF PRUF. A. M. MAYER.) acter of the hook, the kind of fish taken, in some instances, may be understood. We are fast coming to this conclusion: that, putting asicle what can only be the merest speculations as to the condition of man when he is said to have first diverged from the brute, he was soon endowed with a wonderful degree of intelligence. And, if I am not mistaken, primitive man did not confine himself in his fishing to the rivers and lakes alone, but went out boldly. to sea after the cod.

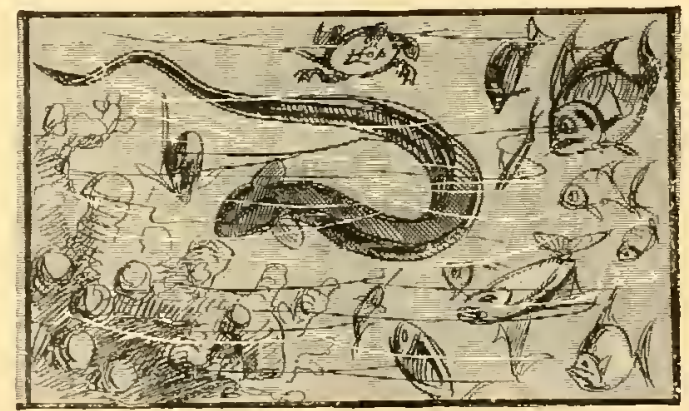




\section{TROUT-FISHING IN THE RANGELEY LAKES. \\ BI EDWARD SEYMOUR.}

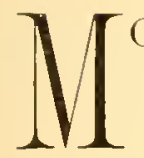

OOSELUCMAGUNTIC, Molechunkemunk, Welokenebacook, Cupsuptuc, and Rangeley are the names carried by the individual members of a group of lakes which are yet destined to be as familiar in the literature of the American sportsman as the salmon rivers of Canada or the trout streams of the Adirondacks. These lakes lie in the western part of Naine, near the New Hampshire boundary line. The White Mountains are some thirty miles distant, a little to the west of south, and Moosehead Lake is about sixty or seventy miles to the north-east. It may be absolute incredulity as to the fish stories which are told of these lakes, - it is hard for one who has not seen a speckled trout weighing ten, eight, or even six pounds to have faith in the existence of a fish of this size and species, - or it may be despair of defining his destination when the sportsman reads the unpronounceable names which these lakes bear; but whatever the cause, the number of visitors to this region has thus far been comparatively small. Thoreau, to be sure, described it in a general way years ago, and so did Theodore Winthrop; but their accounts made it appear like a terra incognita, full of difficulties when it was once reached.

Maine is so profusely dotted over with lakes as to suggest the thought that the State has not yet been well drained, or that a slight tilting of the continent might depress the general level of this region so as to submerge it in the Atlantic. But the fact is that the lakes which have just been named are between fourteen and fifteen hundred feet above the sea-level, and are embosomed in mountains, some of which reach a height of two, three, and even four thousand 
feet. Approaching from the south-east ly way of Farmington and Phillips, you first strike Rangeley Lake at its extreme eastern end; and here the entire group is generally spoken of as the Rangeley Lakes. Coming from the other direction, by way of Andover, Welokenebacook is first reached; and in this region one hears the group spoken of as the Richardson Lakes, although this name is properly applicable only to W'elokenebacook and Molechunkemunk.

Leaving Portland a little after one o'clock, you arrive at Farmington about six. A supper at the Forest House fortifies you for an eighteen-mile ride to Phillips; and this is materially shortened by "Uncle John's" famous "bear story" and other characteristic narratives. Stopping overnight, you take an early start the next morning, and after a stage ride of twenty miles reach Kimball's Hotel, at the head of Rangeley Lake, by noon. Taking dinner here, and after it one of the little steamers which have recently invaded the sanctity of these lakes, you are in an hour and a half landed at the foot of Rangeley.

In comparison with the unpronounceable Indian names which the contiguous lakes bear, that of Rangeley appears singularly com-

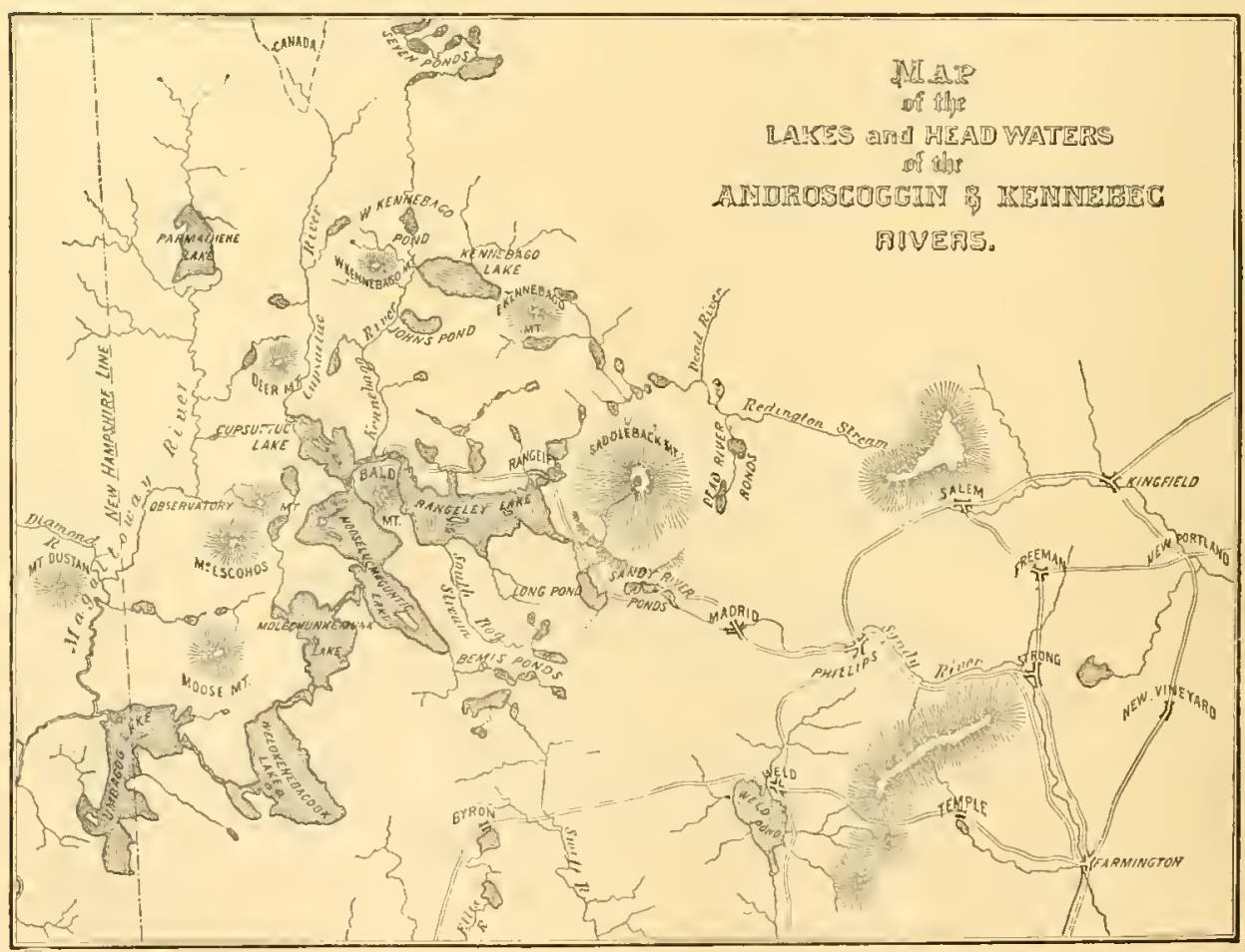




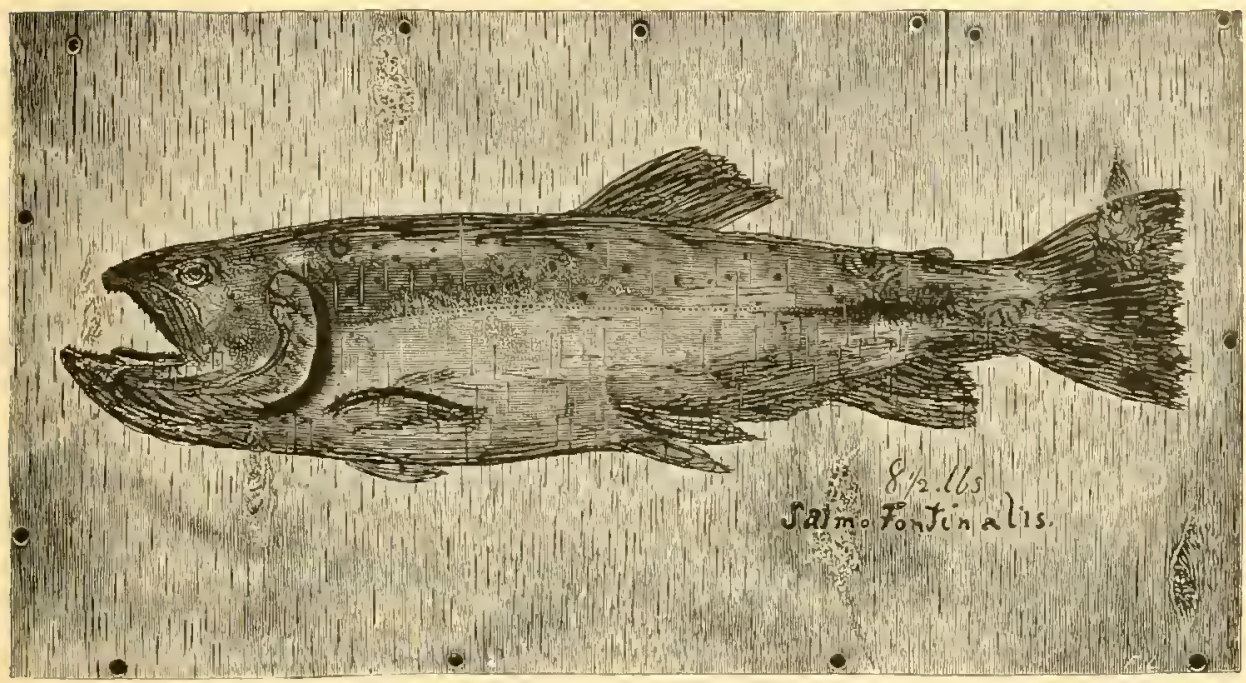

HIC JACET.

monplace and civilized, but formerly it was quite as well off as its neighbors. Originally, it was known as Oquossoc Lake, but about fifty years ago a wealthy English squire, Rangeley by name, having wearied of the civilized tameness of his Virginia estate, decided to settle in this northern wilderness. He cleared a broad traet at the outlet of Rangeley Lake, built a dam across the stream, erected extensive saw and grist mills, and expended large sums of money in other improvements. His supplies of all kinds were transported from Phillips or Farmington, a distance of thirty to fifty miles,

- and he was compelled to haul his lumber a hundred miles to find a market. For twenty years Squire Rangeley lived here, pushing his business enterprises with great energy and more or less success, and enjoying the field sports, of which he was passionately fond. Moose, caribou, deer, bears, and wolves were his constant neighbors; ducks, geese, partridge, and smaller game were so abundant that shooting them could hardly be called sport; and brook-trout weighing from six to nine pounds could be taken by the score from the stream which ran past his front door. When Squire Rangeley gave up the enterprise which he had pushed for a time with so much energy, his mills and buildings were all abandoned, and the clearings which he had made were rapidly seeded down by the hand of nature: pines, spruces, juniper, and fir springing up everywhere in place of the ancient monarchs of the primeval forest which he had cleared away at the cost of so 
much labor. 'Twenty years ago, the frame and roof of the massive old mill were still standing, but in I 866 these were pulled down, and the solid pine timbers of the structure were incorporated in the new dam which was then built for the purpose of floating logs through the outlet in the early spring. Of the old homestead, which occupied a commanding site on a beautiful knoll, only the decayed foundation timbers remain. Enough of the "potash" building still stands to give a passable shelter to the benighted angler. With these exceptions, Squire Rangeley's "improvements" have all disappeared. The township which he once owned, however, still bears his name. Nearly all of the lake lies within its limits. The town of Rangeley -or the "city," as the natives call it - is half a mile back from the extreme eastern end of the lake. Niost of the male inhabitants of the village devote themselves to "guiding" throughout the entire fishing season, and spruce-gum in its native state is one of its chief exports. Apart from these "inclustries," there is little that is noteworthy about the town, and the sportsman misses nothing which he has cause to regret in the fact that his route does not take him to the "city."

Learing the steamer "Molly-chunk-e-munk," - the name of which has thus gallantly been metamorphosed and Anglicized from the Indian appellation of Lake Mole-chunk-e-munk, - members of the Oquossoc Angling Association and visitors to their camp crossed a two-mile carry from the foot of Rangeley Lake to the junction of Kennebago Stream with Rangeley Stream, where is Camp Kennebago. A wagon took the baggage, while the sportsmen themselves walked across through an excellent wood road, which, however, was marshy enough in spots to make very careful stepping or very thick boots indispensable. Indian Rock - a locality famous even in the aboriginal annals of Maine, as its name indicates - is on the left bank of the stream, directly facing Camp Kennebago. Tradition relates that this spot was a favorite haunt of the Indian long before the white man ventured so far into the forest, and that as late as 1855 they made visits here from Canada each season.

The lakes of the Rangeley group are so located with respect to one another that it is extremely difficult for the visitor to get a clear idea of their relative positions. Nothing does this so effectively as an ascent of Bald Mountain, which is one of the most prominent 


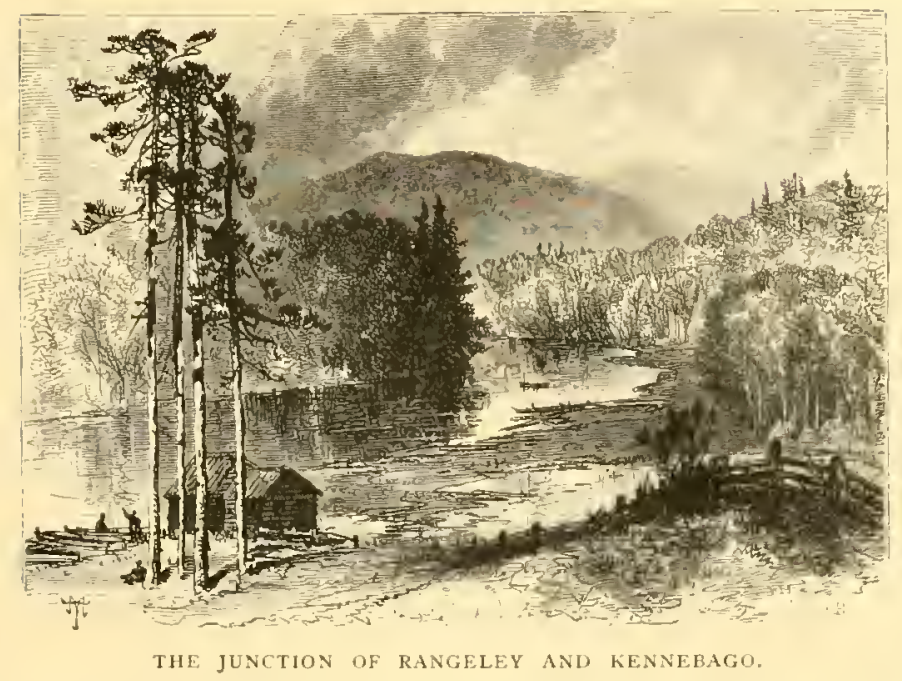

objects in this whole landscape, since it rises seventeen hundred feet above the level of the lake. The ascent may be made with comparative ease by any one at all accustomed to mountain climbing, as there are several paths to the summit. Bald Mountain is in reality a peninsula. Its base is washed by Rangeley Lake, Rangeley Stream, Cupsuptuc Lake, and Mooselucmaguntic. A narrow strip of land on the south connects it with the main-land. Once on the summit, looking eastward, you see the Rangeley, its graceful form deeply outlined and every indentation plainly marked. Old Saddleback, rock-ribbed and bare, and rising four thousand feet, faces you. Still further east are the twin Bigelows, Mount Abraham, and the East and West Kennebago Mountains. That thread of silver in the immediate foreground is the wide and rapid Rangeley outlet, which falls twenty-five feet in the two miles intervening between the point where it leaves the lake and its junction with the calmer and deeper waters of the Kennebago. At this point can be clearly distinguished the grounds and buildings of Camp Kennebago, with the stars and stripes waving from the tall flag-staff. Something more than words is necessary to do full justice to the exquisitely varied panorama of lake and mountain, the beauty of which could be hardly more than indicated by the catalogue of names necessary to identify them. Few finer views can be found in the English lakes, among the Trossachs, or even in Sivitzerland, than this from the summit of Bald Mountain. 


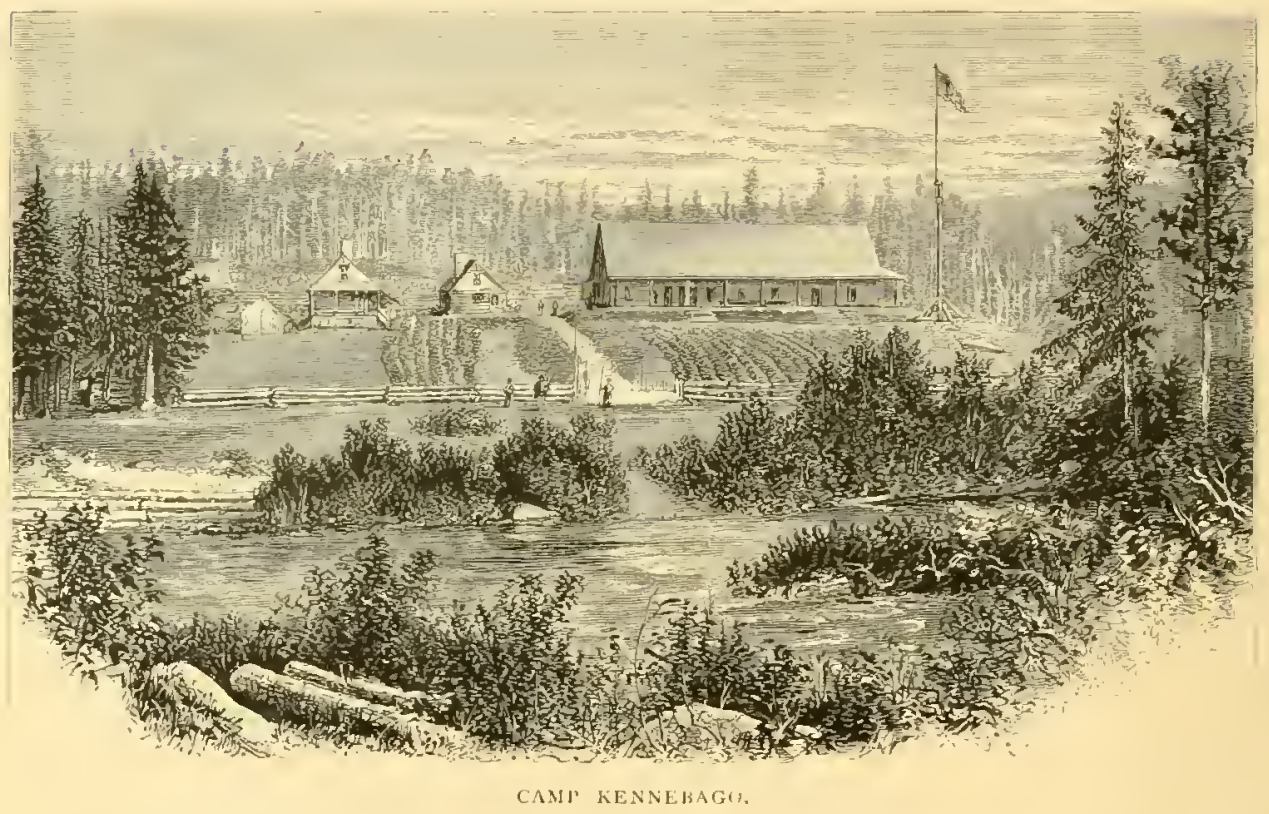

Before describing Camp Kennebago in detail, it may be as well to give in brief a sketch of the history of the Oquossoc Angling Association, of which organization this camp is the head-quarters. So long as thirty years agro, a sportsman now and then worked his way through the wilderness to these lakes, but it is only within the last twenty years that the Rangeley, Kennebago, and Cupsuptuc Lakes, with the upper end of Mooselucmaguntic, have become at all well known to anglers. The Richardson Lakes - Welokenebacook and Molechunkemunk, with Umbagog, forming the lower lakes in the great chain whence the Androscoggin River derives its mighty power-have for the last thirty or forty years been frequented by a score or more of Boston and New York gentlemen. These sportsmen were invariably found at "Rich's," "Niddle Dam," Mosquito Brook, or the "Upper Dam." Hundreds of spotted beauties, weighing from two to eight pounds, were captured by these anglers year after year, but they wisely kept their own counsel, and if an item occasionally found its way into the New York or Boston papers chronicling the arrival of a six or eight pound speckled trout, those who claimed to be best informed dismissed the paragraph with a sneer at the ignorance of editors who did not know the difference between brook-trout and "lakers." In 1860, Henry O. Stanley, 
of Dixfield, now one of the efficient commissioners of fisheries for the State of Maine, organized an expedition to penetrate to the lakes from the upper end. Twenty years before, Mr. Stanley's father had made the survey of much of the lake country, and, discovering the extraordinary size of the trout, had frequently repeated his visits.

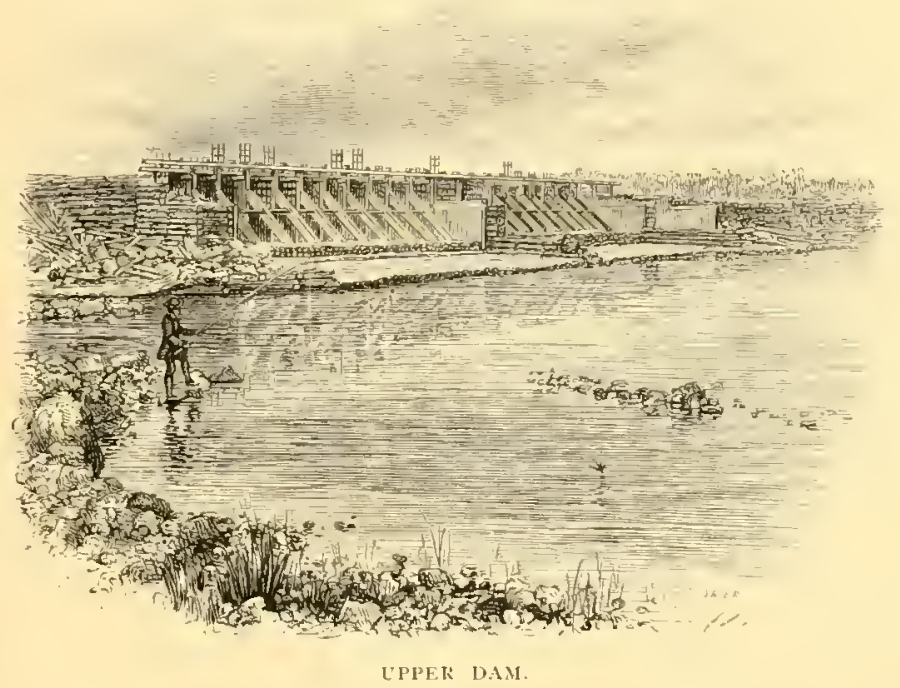

The son now and then accompanied his father on these trips, and with such a preceptor in the gentle art, and with such opportunties for its practice, it is not strange that Mr. Stanley should have achieved the distinction of being the champion fly-fisher of the world. His record of brook-trout weighing from three to nine and a half pounds, all taken with the fly, reaches many hundred. The party which Mr. Stanley headed on the occasion alluded to made its way to the lake, aria Dixfield. Carthage, W'eld, Phillips, and Madrid, striking first the upper end of Rangeley. One of its members, Mr. George Shepard Page, of New York City, was so delighted with his experience upon this trip that in 1863 he made a second journey by the same route. He returned from this trip, bringing with him eight brook-trout weighing respectively $83 \frac{3}{8}, 81 \frac{1}{4}, 7 \frac{1}{4}, 6 \frac{1}{2}, 6,5 \frac{1}{2}$, 5, 5 -total, 51 ig lbs., or an average of nearly $6 / 2$ lbs. each. William Cullen Bryant, Henry J. Raymond, and George Wilkes were pre$23 \mathrm{~A}$ 
sented with the three largest, and made acknowledgments duly in the "Evening Post," the "New York Times," and the "Spirit of the Times." Then there broke out an excitement among anglers altogether without precedent. Scores of letters were sent to the papers which had presumed to call these brook-trout,-some of them interrogative, others denunciatory; others theoretical, and others flatly contradictory. The Aclirondacks had never yielded a brook-trout which weighed more than five pounds, and that, therefore, must be the standard of brook-trout the world over. But Mr. Pagre had foreseen the violent skepticism which was sure to manifest itself, and had sent a seven-pounder to Professor Agassiz, who speedily replied that these monster trout were genuine specimens of the speckled or brook trout family, and that they were only found in large numbers in the lakes and streams at the head waters of the Androscoggin River, in North-western Maine. In 1864, several New York gentlemen visited Rangeley, among the number Messrs. Lewis B. Reed, R. G. Allerton, and L. T. Lazell. Upon their return, they fully corroborated the report made by Mr. Page the year previous, and brought back with them several trout which weighed from three to eight pounds. In 186\%. Mr. Page again visited Rangeley in company with Mr. Stanley, and ten days' fishing by these two grentlemen and Mlr. Fields, of Gorham, N. H., showed these extraordinary results:

\begin{tabular}{|c|c|c|c|c|c|c|c|c|c|c|}
\hline $\begin{array}{l}\text { No. of } \\
\text { Trout }\end{array}$ & & $\begin{array}{l}\text { Weight of } \\
\text { each in lbs. }\end{array}$ & & $\begin{array}{c}\text { Total weight. } \\
\text { lbs. }\end{array}$ & $\begin{array}{l}\text { No. of } \\
\text { Trout }\end{array}$ & & & $\begin{array}{l}\text { Weight of } \\
\text { each in lbs. }\end{array}$ & & $\begin{array}{l}\text { Total weight } \\
\text { lbs. }\end{array}$ \\
\hline 3 & - & 2 & . & 6 & 2 & - & . & $53 / 4$ & . & . III/2 \\
\hline I & . . & $21 / 4$ & . & $21 / 4$ & 5 & . . & . & 6 & . & . 30 \\
\hline 3 & . . & $21 / 2$ & 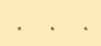 & $7^{1} \frac{1}{2}$ & 2 & 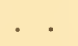 & . & $61 / 4$ & . & . $12 \mathrm{I} / 2$ \\
\hline 2 & . . & $23 / 4$ & . & $5^{1 / 2}$ & I & . & & $61 / 2$ & & $61 / 2$ \\
\hline 5 & . . & . . & . & . 15 & I & . . & . & 7 & . & 7 \\
\hline 5 & . $\cdot$ & $3 \pi / 4$ & 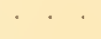 & - $\quad \mathrm{I} 6 \mathrm{~T} / 4$ & 3 & . . & . & $71 / 4$ & 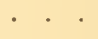 & $213 / 4$ \\
\hline 3 & $\cdot \cdot$ & $3^{\mathrm{I}}=$ & . & $\cdot \quad 10 / 2$ & 3 & . & . & $7^{1 / 2} \cdot$ & . & - $221 / 2$ \\
\hline 2 & . . & $3^{3 / 4}$ & . & $71 / 2$ & $=$ & . & ${ }^{\circ}$ & $73 / 4$ & . . & . $151 / 2$ \\
\hline I & . & . . & . & 4 & 2 & . & . & 8 & . & - I 6 \\
\hline 2 & . . & $4^{1}=$ & . & 9 & I & 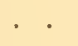 & . & $81 / 4$ & - & . $\quad 81 / 4$ \\
\hline I. & . . & $43 / 4$ & . & $43 / 4$ & I & . & . & $81 / 2$. & 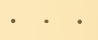 & $81 / 2$ \\
\hline 3 & . . & . . & . & 15 & I & & & $83 / 4$. & $\cdot$ & $83 / 4$ \\
\hline 1 & . & $5^{1 / 4}$ & & $51 / 4$ & I & . & & 9.2. & . & $9^{1 / 2}$ \\
\hline 1 & . & $5^{I / 2}$ & . . & $5^{I / 2}$ & I & 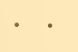 & & 10 & & IO \\
\hline Ave & rage, & nearly 5 lbs. & & & 59 & & & & & 293 \\
\hline
\end{tabular}




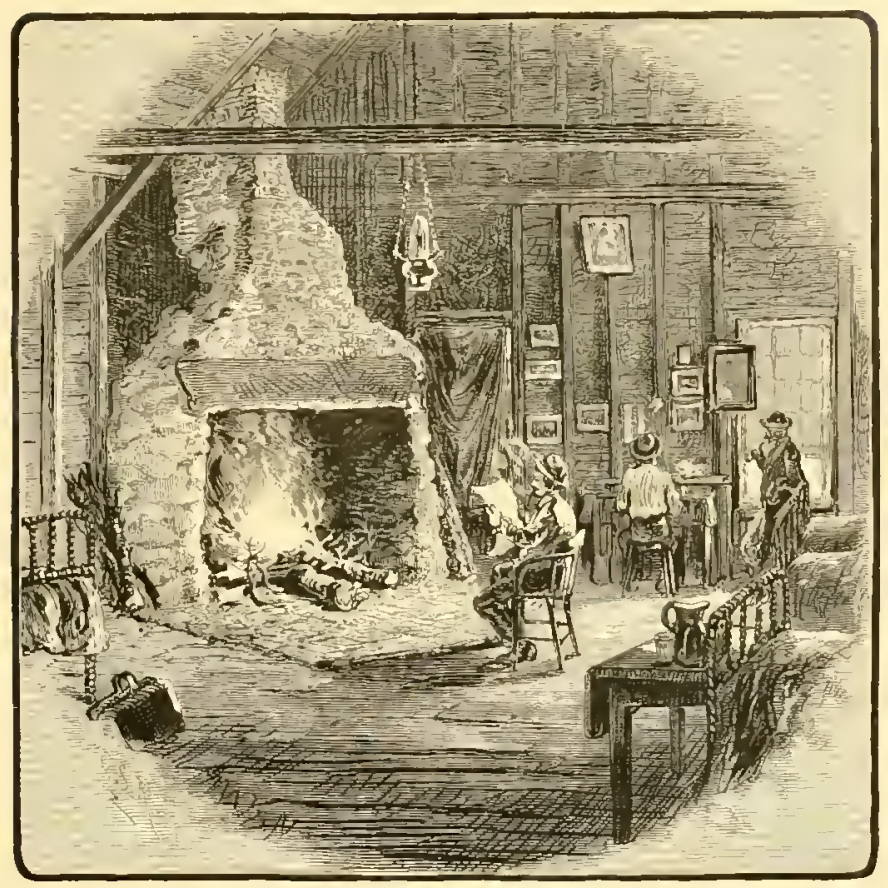

THE INTERIOR OF THE CAMP.

In I 868 , the number of anglers visiting the lakes had so rapidly increased that it was decided to organize an association for the purpose of leasing ground, erecting buildings, and purchasing boats. Messrs. Bowles, of Springfield, Mass., Lazell and Reed, of Brooklyn, N. Y., George Shepard Page and R. G. Allerton, of New York, Hon. W. P. Frye of Lewiston, Me., W. S. Badger, of Augusta, Me., and T. L. Page, of New Orleans, who were all in adjacent camps at the outlet of Rangeley Lake, formally organized the Oquossoc Angling Association by the election of Mr. C. S. Page as president and Mr. L. B. Reed, secretary. In the year following (1869), the association purchased the buildings, improvements, and boats belonging to $\mathrm{C}$. T. Richardson at the junction of the Rangeley and Kennebago, and immediately began the erection of Camp Kennebago. Meantime, the membership rapidly increased, and in 1870 , the association was formally incorporated under the laws of the State of Maine. The membership of the association is limited to seventy-five. Shares are $\$ 200$ each, and the capital stock is \$ro, yoo, which is invested in camp buildings, furniture, 
boats, etc., etc. The annual dues are $\$ 25$. The camp chargres are $\$ 2$ per day for board, $\$ 1$ for board of guide, and fifty cents per day for use of boats. The best guides receive $\$ 2$ per day, making the total cost per day while in camp $\$ 5.50$, unless two persons choose to fish from the same boat, when, of course, the expense of guide, board for guide, and hire of boat may be shared. The fishing season extends from about May 25 to October 1, when the law prohibits the capture of trout save by written permission of the fish commissioner for scientific purposes. 1)uring the first month and the last three weeks of the fishing season, guests are only admitted upon the invitation of members, since the camp accommodations are then likely to he overtaxed; but between June 20 and September 10 the camp is open to all visitors upon the same terms as to members. Ladies and children are also admitted between the dates named. A roomy building with separate apartments is specially reserved for them, and as two or three female servants are constantly employed in the camp, they are sure to be quite as comfortable as in ordinary country hotels.

There are some peculiar features in the arrangement of the camp buildings which will be of interest to those who are not familiar with such structures. The main camp is a substantial board structure, Ioo feet long by $z$ o feet wide. At its extreme westerly end is a wellequipped kitchen, and adjoining it is a dining-room. Then comes the main apartment, which is occupied as a sleeping and sitting room. This room takes the full width of the main building ( 30 feet), is about 60 feet in length, and from the floor to the gable is 30 feet in the clear, giving it a most spacious appearance and securing thorough ventilation. There are no partitions in this apartment, but twentyfive or thirty beds are ranged along its sides, and at its extreme easterly end is a large open fire-place, around which the weary anglers gather after their day's sport, and entertain each other with the rehearsal of their experiences and exploits. As one huge log after another blazes up,-- for the nights are seldom so warm that a fire is oppressive,-- story after story passes around. It rarely happens that some one of the circle has not captured a six or eight pound trout during the day, and the one who has been so fortunate is, of course, the hero of the hour. With what kind of fly the fish was captured, how long it took to land him, the narrow escape which the 


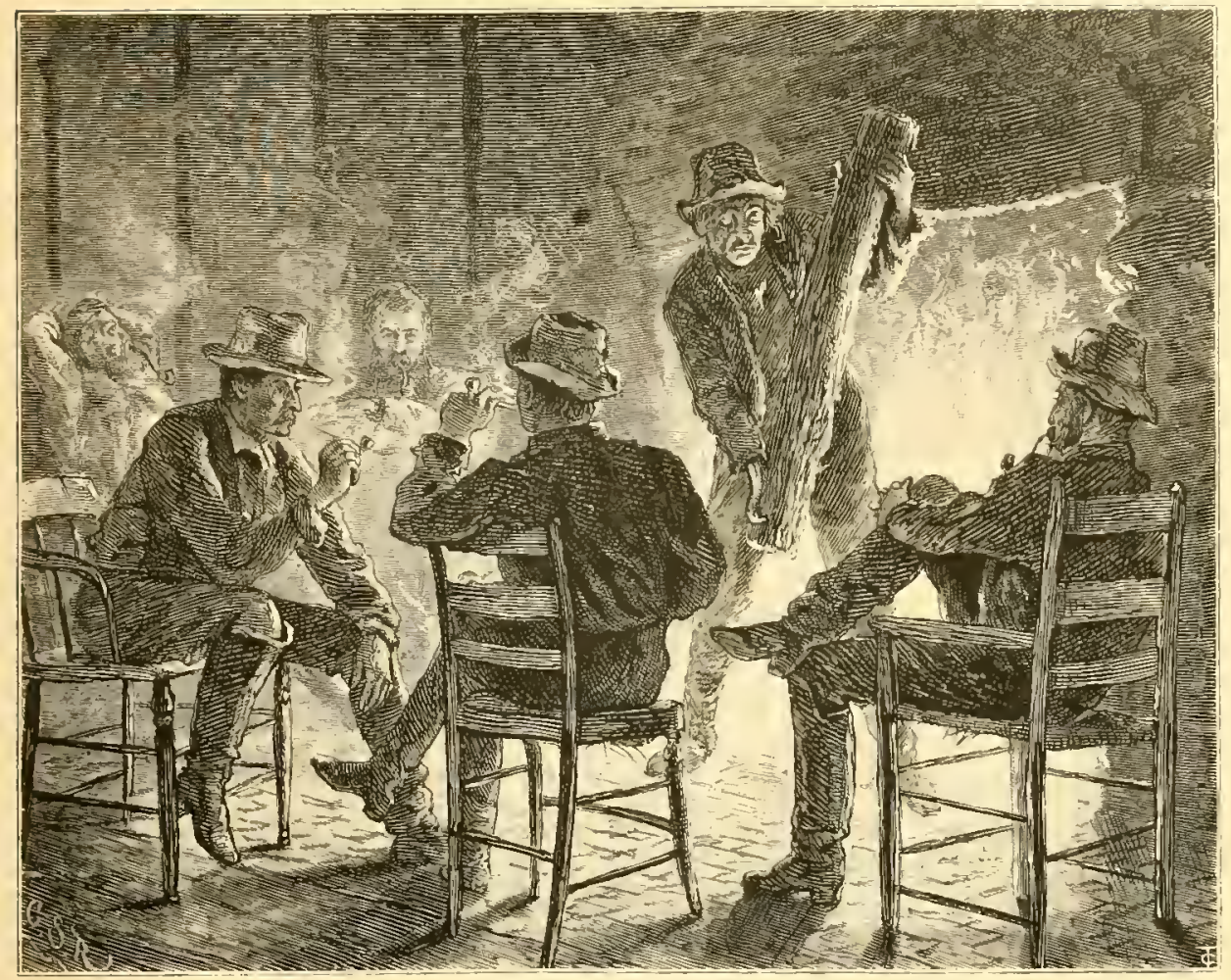

TELLING FISH-STORIES.

lucky angler had from losing his prize just as the guide was netting him, are points which must be rehearsed over and over again. Could one-tenth of the fish-stories which have thus been rehearsed around this famous old fire-place in Camp Kennebago be put on record they would make a book which would throw far into the shade any volume of piscatorial experience that has ever yet seen the light. lefore eleven o'clock, the weary anglers are all in their beds, and the camp sinks into a silence which is undisturbed save by some obstreperous snorer, at least until daylight the next morning, when some fisherman who has had poor luck the previous day starts out with a desperate determination to retrieve his fortunes by testing the virtue of early fishing.

A tour around the upper end of Lake Mooselucmaguntic discovers a number of snugly constructed buildings, some owned by private parties and others by members of the Angling Association, who spend several weeks consecutively at the lake during the fishing season. 


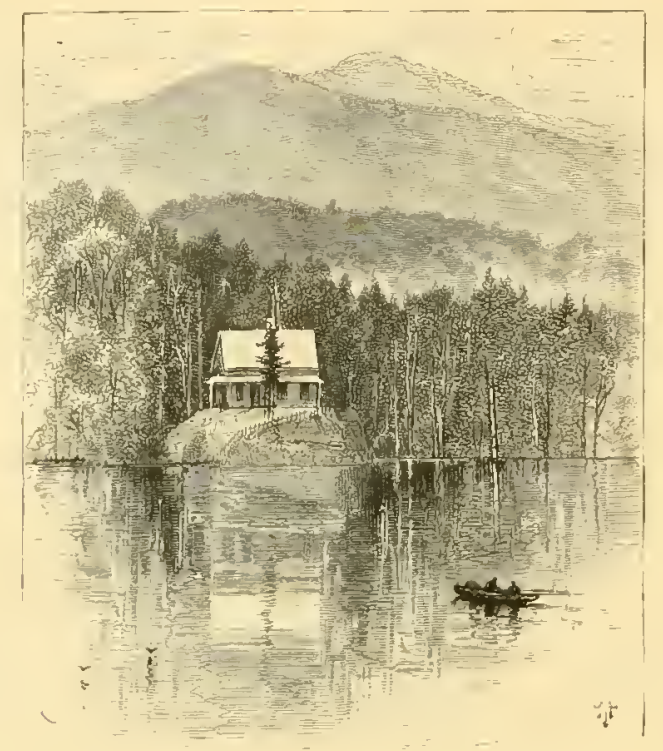

ALLERTUN LODGE

Prominent among the latter are those of Hon. W. P. Frye at the Narrows, and that of R. G. Allerton at Bugle Cove, just at the foot of Bald Mountain. Allerton Lodge is a thoroughly built house, fully equipped with all the comforts of civilization. It is located upon a rocky bluff twenty feet or more above the level of the lake, and commands a magnificent view. Since Bugle Cove is one of the best fishing-grounds on the lake, its proprietor, who is one of the most enthusiastic and persevering of anglers, never fails to make up such a score during his visits in June as to excite the emulation of all other visitors during the rest of the season.

But it need not be imagined that it is only the practiced anglers who are successful in the Rangeley Lakes. There is in Camp Kennebago a record-book in which each visitor is expected to set down his score when he finishes his stay. This exhibits some catches nearly as remarkable as that which has been set down before. In 1869, eleven members of the association in six days' fishing, besides a large number of smaller fish, captured thirty trout weighing as follows: three of $4 \mathrm{lbs}$. each; one $41 / 4 \mathrm{lbs}$; two $4 \frac{3}{4} \mathrm{lbs}$. each; three $5 \mathrm{lbs}$. each; one $5^{1 / 4}$ lbs. ; four $5^{1 / 2} \mathrm{lbs}$. each; two $6 \mathrm{lbs}$. each; two $61 / 4 \mathrm{lbs}$. each; two $63 / 4 \mathrm{lbs}$. each; two $7 \mathrm{lbs}$. each; one $71 / 4 \mathrm{lbs}$; one $71 / 2$ lbs.; three 8 lbs. each; one $81 / 2$ lbs.; one 9 lbs.; - total, 
I $\$ 13 / 4$ Ibs., averaging over 6 1bs. each. Then the ladies find the locality a wonderful one for great "catches" - of trout. Mrs. Theodore Page has taken several weighing between 6 and 9 lbs. each, and even the young folks are fortunate. Masters Harry and Allie Pagre, aged respectively $5 \frac{1}{2}$ and $3^{\frac{1}{2}}$ years, it appears from this record, during one visit caught 57 trout weighing 37 lbs. Ten averaged 1 lb. each, and one weighed two lbs. lest these large catches should provoke remonstrance against such wholesale slaughter of this beautiful fish, it should be stated that it is the almost invariable rule to return to the water all uninjured trout weighing less than half a pound. Those hooked so deeply that they cannot live are kept for consumption at the camp. The larger fish, as soon as caught, are deposited in the car which each boat always has with it. (Tpon the return to camp at night, the living trout are carefully transferred to a larger car, - which in this case is the name given to an ordinary drygoods box with slats on the bottom and sides, admitting free passage through of the water, - and at the end of his stay each angler, if he desires to take a box of trout home with him, selects the largest and releases all the others, which speedily find their way to the deep waters of the lake again. Thus the actual destruction of fish is by no means so extensive as it would at first appear that it might be.

In general, the early spring fishing and the late fall fishing are decidedly the best and most enjoyable. The pestiferous black flies do not appear until June so, but their attentions can be warded off by a liberal application to all exposed parts of the neck, face, and hands of a mixture of tar and sweet oil in equal parts. Oil of pennyroyal, in sufficient quantity to make its odor plainly perceptible, is thought by many to render this preparation more effective. By September, with exemplary regularity, the black flies disappear, and with them goes the only hinderance to complete enjoyment of outdoor life.

As regards methods of fishing, it need only be said that the high-toned angler will not tempt his intended victim with anything but a fly at any season. The best fly fishing is to be had in the streams in the spring and in the lake in the fall. Those who go to the lakes in the spring and early summer determined to catch the biggest fish at all hazards must seek them with live minnows for bait, by still fishing, or by trolling in deep water. In either case, the 
law rules out all gang-hooks. The "single baited hook" only is permitted, and any one infringing upon this wise restriction exposes himself to severe penalties. A larger hook, with a heavier leader than is used in ordinary brook-trout fishing, is called for in these waters; but upon such points and with reference to the varieties of flies which are best for the purpose, advice may be had at any of the fishing-tackle stores. In general, however, give preference in making your selection to the more subdued colors, and do not permit yourself to be stocked up with an immense variety. Five or six kinds, well selected, will be more than enough to give the fish ample range for choice.

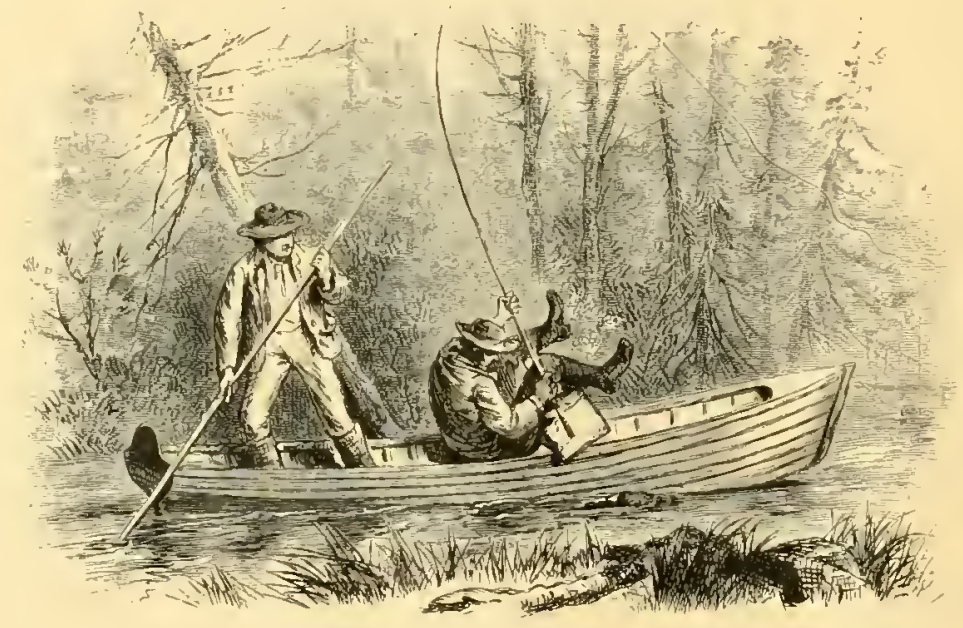

AN LXPERIMENT IN NATURAL PHLUSOPHY.

As I have already stated, these big trout are caught either in the lake or in the streams which feed it, according to the season; and each kind of fishing has its peculiar incidents and surprises. Both Kennebago and Rangeley streams are too deep and swift to be waded in the orthodox style, although at certain seasons they are so shallow in places as to make their navigation even by boats of the lightest draft an undertaking of no little difficulty. Rangeley Stream, between the famous dam at the outlet of Rangeley Lake and Indian Rock, a distance of perhaps a mile and a half, abounds in pools which the big trout love to frequent. It is not unusual for the more enterprising fishermen to work their way up Kennebago Stream four, five, or even six miles. This trip involves 


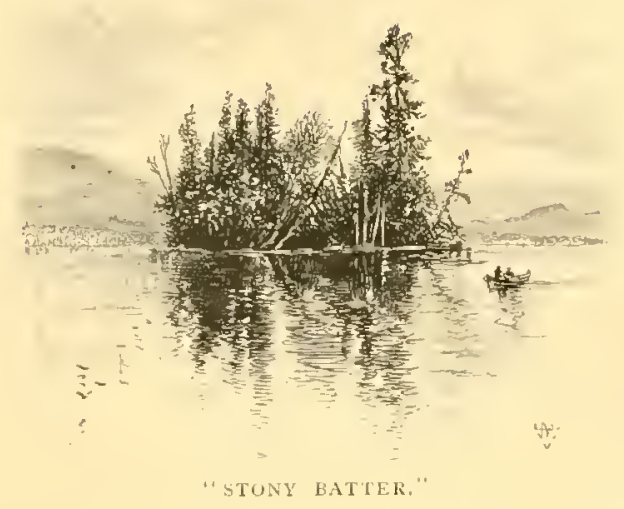

hard labor by the guide in poling or in pulling the boat over the frequent shallows, and great caution is necessary to guard against such a mishap as the pencil of that enthusiastic and scientific sportsman, Dr. F. N. Otis, has reproduced on the opposite page, where an unexpected push by the guide's pole or the sudden striking of the boat's bow upon the pelbbly bottom sends the surprised fisherman, heels over head. into the bottom of his boat, while his leader and flies are sure to become securely hooked in the loftiest overhanging branch within reach. Still, the discomforts of these excursions up the Kennebago or Cupsuptuc streams are sure to be rewarded with some rare sport.

Nor is the fishing in the open lake without its occasional surprises. I very well remember an incident which happened upon the occasion of my first visit to Camp Kennebago, when I was a tyro in trout-fishing, and had not been fully initiated in the use of the fly. My boat was at anchor some distance below "Stony" Batter," and with humiliation I confess that I was angling with a minnow. For a half hour or more there had been no sign of a trout in my vicinity, and I had carelessly laid my pole across the boat, with the butt under the thwart. Suddenly there was a "strike." Before I could seize my pole, the trout had carried the line directly under the boat with such a rush as to snap the rod which I ought to say, in justice to the professional makers, was a cheap store rod-into two or three pieces. The trout escaped, as he deserved to do, and for once I could not help confessing myself outgeneraled. This mishap, of course, put an end to my fishing for the day; but fortunately it occurred quite late in the 
afternoon, and thus left me at leisure to enjoy a scene which was in itself singularly beautiful, and which was an appropriate setting for a striking incident. As the sun was sinking behind the hills, close under which we were fishing, it threw their long shadows far out on the lake, while the waters on the eastern shore were still bright with the golden light of the gentle June evening. In the distance, we descried three specks upon the water, which gradually grew in size as they steadily approached us, until we made out three batteaux laden with the "river-drivers," who were returning from their perilous and tedious journey down the Androscoggin with the great $\log$-rafts,- the results of the previous winter's lumbering. The first sound which disturbed the Sabbath-like stillness of the lake, as the batteaux cane nearer, was the steady thump, thump, thump of the sweeps in the rowlocks. Then we heard the sound of voices, but at first too indistinctly to determine whether it was the echo of boisterous talk, or some river-driver's song, with which the oarsmen were keeping time. But soon the sounds, as they became linked together, grew into that grand old tune, "Coronation," and the words,

"All hail the power of Jesus' name!"

came to us over the peaceful waters, sung with all the strength, steadiness, and fervor which might be expected in a congregation of religious worshipers. Nothing could have been in more perfect harmony with the scene, and yet nothing could have been a greater surprise than to hear this tune, and the words with which it is so inseparably connected, coming with such zest from the throats of men who have gained an undeserved reputation for roughness, not to say profanity, of speech.

During the extremely warm weather, the trout naturally run deep in the lake, since there only can they find the cold water in which they thrive; but even then the streams afford good sport; so that the angler cannot spend a week at the lake during the fishing season without certainty of getting better sport, and more of it, than can be found in any other resort in the country. Another fact that adds greatly to the pleasure of fishing in the Rangeley Lakes is, that with the exception of the land-locked salmon 


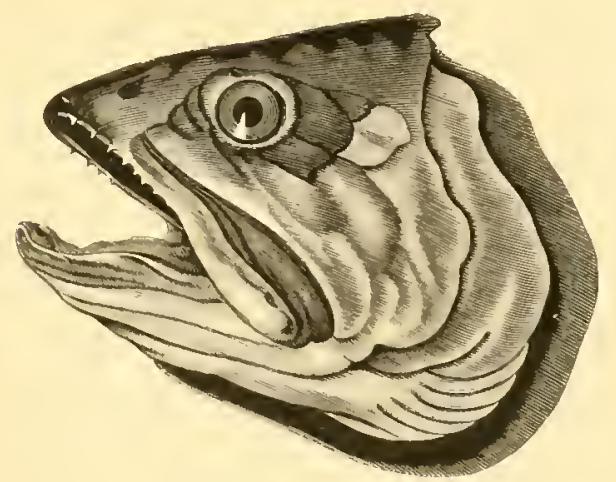

HEAD UF TROUT.

lately introduced, they contain no other fish besides the trout and the smaller fish upon which he feeds. Of the latter, there are three varieties, - the chub, the sucker, and the minnow, or "red-fin," as they are locally termed. All these exist in countless numbers in the streams and at the outlets of these streams into the lake. There is still a fourth variety, called by the natives the "blue-back" trout, the Salmo Oquossa (so named because it is peculiar to these waters), which is also generally supposed to furnish food to the monarchs of the lake. They come in an immense army, actually filling the streams here and there with a dense, struggling mass, which the natives capture by the bushel and by the barrel in nets, buckets, and pails; even scooping them out by hand and throwing them on the bank. They are salted down and preserved in the same way as mackerel are cured. These blue-back trout have never been found more than nine inches in length, nor less than six inches. In flavor, they are quite as rich and delicate when cooked as the brook-trout. After spawning, they return to the lake just as suddenly as they appeared; and, notwithstanding the numbers in which they are captured during their brief stay in the stream, they do not diminish in multitude year after year. It is inferred that their regular haunts must be in the deepest waters of the lake, since their capture by the enticements and appliances which prove irresistible to the speckled trout is almost unknown.

Numerous experiments and continued observations, made under the auspices of some of the practical pisciculturists belonging to the association, have developed results full of interest and of much prac- 
tical value. For instance, in reply to queries as to the probable age of the mammoth trout found in the Rangeley Lakes, Professor Agassiz emphatically declared that "no man living knew whether these six and cight pounders were ten or two hundred years old." To gret some light upon this question, Mr. Page conceived an ingenious device, which he at once proceeded to put in exccution. Platinum wire was obtained, cut into one and a half inch lengths, flattened at one end, and various numbers were stamped on the surface, from $1 / 2$ to 4 , also the numbers $70,71,72$, to denote the year. As trout were captured they were weiglied, one of these tags was passed through the skin just under the adipose fin and securely twisted, and then the fish was liberated. In the course of the two or three years named a large number of these trout were thus labeled. Of course, the chances that any of them would be caught seemed infinitesimally small, yet in 1873 one of them reported. 1 ln June of that year, Mr. Thomas Moran, the artist, captured a fine, vigorous trout weighing $2 \mathrm{x} / 4$ lbs. Upon taking him from the landing-net, the platinum tag flashed in the sunlight. Upon examination, the mark, " $1 / 2-7 I$," was discovered, thus establishing the curious fact that this particular fish had gained $1 / 4$ lbs. in two years.

The entire influence of the association has uniformly been thrown in favor of a rigorous enactment of the laws protecting the trout in the spawning season and regulating the mode of capture. More than this, it has taken the most active measures in the direction of increasing the supply of fish in the waters to which it has access. Land-locked salmon have been introduced (this is one of the very few species which co-exist with the trout), and a large number of the young of the sea salmon (Salmo salar) have also been put into the lakes. Last season, several land-locked salmon two years of age, and weighing half a pound, were captured. This year those of this same growth will probably have reached a pound, and in the course of two or three years these fish, which some anglers regard as even more "gamey" than the trout, must become very abundant.

Some of the earliest and most successful efforts in trout culture are connected with the annals of Rangeley. In October, 1867. Mr. Page transported two live trout-one a male weighing ten pounds, the other a female weighing eight and a half - from Rangeley to his home in Stanley, N. J., a distance of nearly five hundred miles. An 


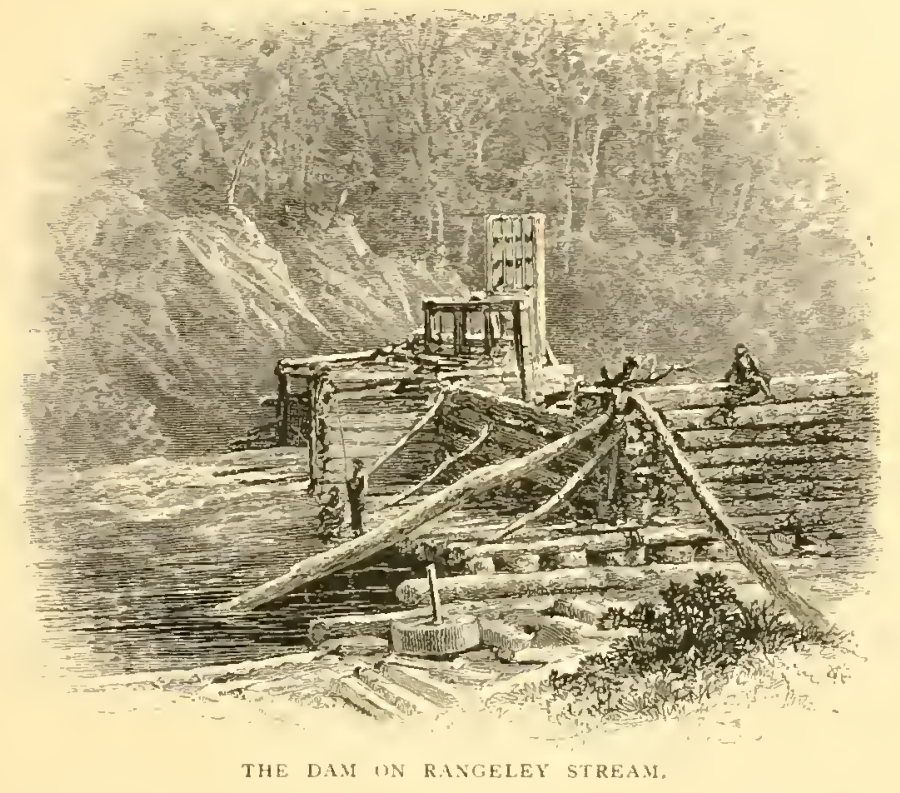

oblong box of forty gallons capacity, lined with sponge which was covered with muslin, and having an air-pump attached, so as to make constant renewal of the air easy, had been carefully prepared. This box was carried from the head of Rangeley on a spring wagon to Farmington, a distance of thirty-five miles, and thence by railroad to its destination in New Jersey. Three days were occupied in the journey, but by unremitting care night and day the magnificent fish were deposited alive in the pond at Stanley. Unfortunately, the weather was unusually warm for the season of the year. The temperature of the pond could not be reduced below $65^{\circ}$, and the larger of the two trout lived only eight hours. The female survived six days longer. Thus the attempt to propagate Rangeley trout in New Jersey by natural means failed. The larger of these trout was, unfortunately, not weighed when first captured, but, when dead, balanced the steelyards at precisely ten pounds. It is a wellknown fact that all fish lose in weight after capture, and Professor Spencer F. Baird and Professor Agassiz both gave it as their opinion that when taken this trout weighed at least eleven and a half pounds. He measured thirty inches in length and eighteen inches in circumference. His tail spread eight inches and his jaws six and a half inches. He was mounted by one of the most skillful taxidermists in the country, Mr. I)ickinson, of Chatham, N. J. 
About this time ( $1 S 67$ ), Mr. Seth Green's attempts to propagate trout artificially had begun to attract attention, and, anticipating the possibility of failure in transporting the live trout so great a distance, Mr. Page, to make assurance doubly sure, had secured 30,000 trout eggs which had been impregnated by the milt of the male in the method now so well understood. These had been carefully packed between layers of moss, and immediately upon their arrival at Stanley were deposited in the hatching-houses. After the usual interval of six weeks, Mr. Page had the gratification of secing the newly hatched trout. In due time they were fed, and when they had attained a suitable size were liberated to stock the stream below the hatching-houses. Thus we have the history of one of the earliest and perhaps the first attempt in this country to take eggs from wild fish, transport them five hundred miles, and successfully hatch them.

The determination of the members of the Oquossoc Angling Association fully to maintain the superiority of their fishing-grounds is conclusively manifested by the arrangements for artificial propagation which were made on Bema Stream, at the extreme southeastern extremity of Lake Mooselucmaguntic, under the direction of Messrs. Page and L. L. Crounse. Three miles up Bema Stream, at the foot of a bold mountain, there bursts out from a rocky bed a series of remarkable springs, which in the spring and fall furnish much of the water that flows down the rapid stream to the lake. The water of these springs rarely falls below $45^{\circ}$, or rises above $49^{\circ}$, and is therefore peculiarly adapted to the propagation of trout. The smaller trout from the lake, weighing two pounds and under, make these springs and the stream in the vicinity their spawning-grounds, and in the month of October they crowd the waters in great numbers. Mr. Stanley, while securing fish for spawn, has actually dipped up as many as six trout of an average weight of a pound each at one scoop of his dip-net. As is their habit, the males always come up in advance and clear off the beds, and in a few days the female follows. So strong is the instinct which leads them to the spawning-beds that the trout, like the salmon, will force themselves over shallows in the stream where there is not depth enough to permit them to swim. Just at the spawningbeds, and over the little branch which carries the water of the springs to the main stream, the gentlemen above named erected a hatching- 


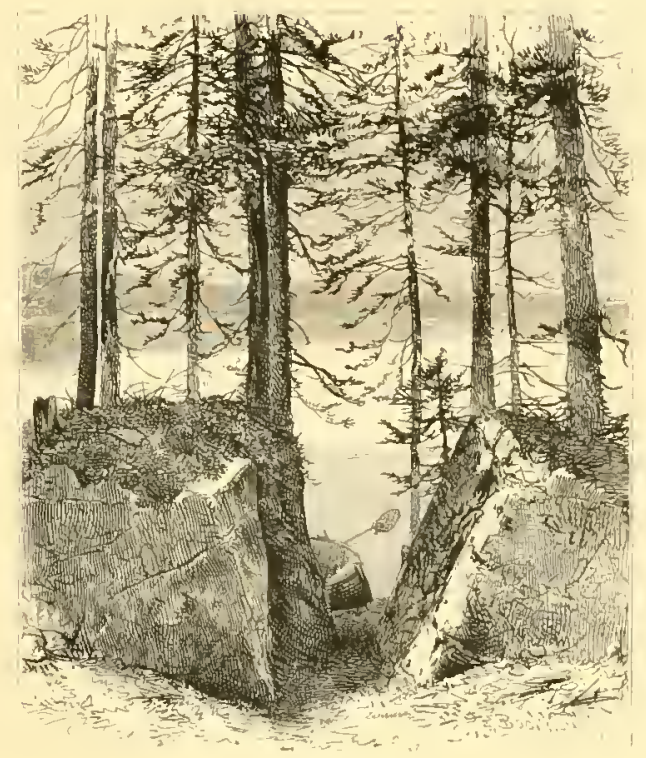

CIEFT ROCK.

house. In return for this privilege, they agreed to place in the waters each season from 50,000 to 100,000 young fiy, recompensing themselves for their trouble, if they could, by taking out spawn for use in other waters. In the seasons of 1873 and 1874 , they were able to deposit in the streams more than the maximum of spawn agreed on. In 1875 and $1876,11 \%$. Stanley's duties as fish commissioner prevented his giving this matter the necessary attention; but the young fry were so successfully hatched the first two seasons that a sudden increase of small trout has been noted in the stream itself and as far up as the Bema l'onds, four miles above the hatchinghouses. Some of the spawn were successfully transferred to other waters, - the eggs had to be carried out in December. on the backs of men, nine miles through the woods, - and Mr. B. B. Porter, the pisciculturist of Crystal Springs, New Jersey, can now show Rangeley trout double the size of any other variety of trout of the same age.

The method of capturing trout for their spawn was either to dip them up near the springs with an ordinary net, as they came up to deposit the spawn, or to take large trout in the lake, chiefly with the fly, in advance of their ripening, and to "car" them until they were stripped, when they were restored to the lake. At one time in the fall of 1874 , Messrs. Stanley and Hayford who were in charge of 


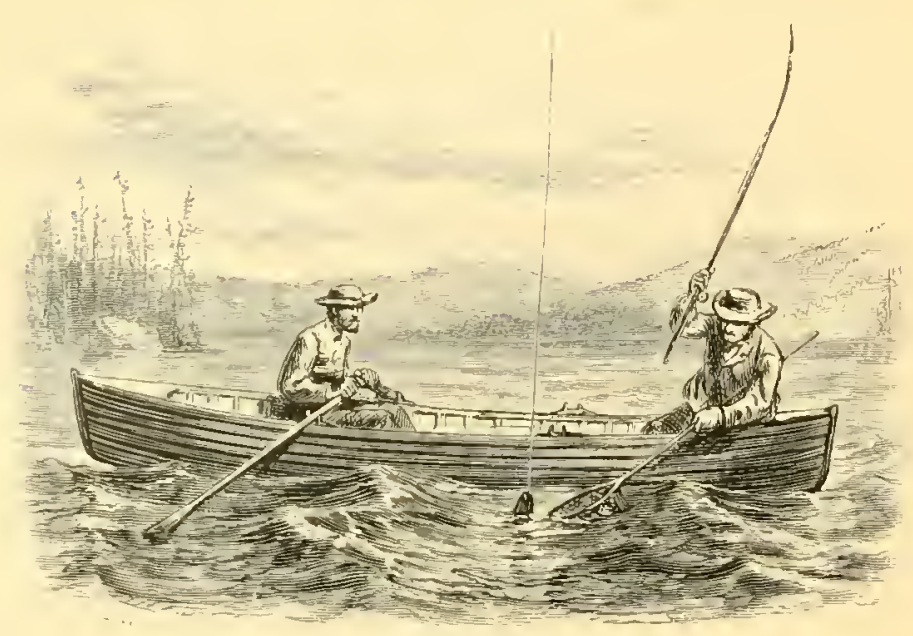

CATCHING A FIVE-POUNDER.

the operation, had in a large car at the mouth of Bema Stream over two hundred of these famous trout weighing from one pound to six pounds each, - a sight which could not be paralleled in any other waters in the world.

The camps at Bema look out over the broad expanse of the bay which opens toward the north-west, and are very prettily situated. The very remoteness of the camp secures its freedom from the visits of miscellaneous tourists, while the beauty of its location and the excellent fishing to be found in its immediate neighborhood amply justify the wisclom shown in its selection by the gentlemen who control it. They and their immediate friends here enjoy a coveted seclusion and keep clear of intruders by a lease of three miles of the shore which covers the entire southern end of Bema Bay. Its position, however, exposes the bay in its front to the north-west gales which prevail to a greater or less extent through the whole season. Those who are accustomed to wait for the traditional "fly breeze" will receive with incredulity the statement that the largest trout have been taken in these waters when a north-west gale was driving the spray from the white-capped waves, and when the persevering angler found a seat in the bottom of his boat the most comfortable position from which to cast his fly, if, incleed, the fly can be said to be "cast" when the wind carries the line so straight from the rod that it is difficult to keep the fly on the surface of the water. Yet the keen-eyed trout, at this very time, rushes the most unwarily 
upon his imaginary prey. A sudden splash from which the spray flies in the face of the wind betrays the presence of one of these mammoth trout. If he misses the fly, a second cast almost invariably provokes the fated fish to a more eager rush. Rising through the topmost curl of the wave. his side, brilliant in purple and gold,

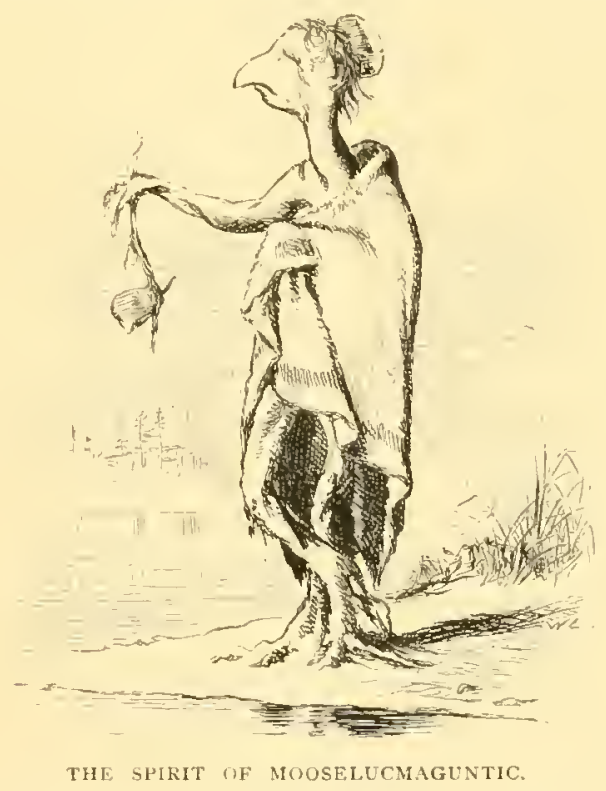

gleams in the sunlight for an instant. But this time he is fast, and there is a thud as if a locomotive, under full headway, had been hooked. With a mad rush, he strikes for the depths of the lake, but the light rod yields like a thing of life. Whether the trout weigh one pound or eight, the lance-wood or split bamboo is faithful to the trust placed in it. With a pertinacity almost human it clings to the frantic fish, steadily drawing him to the surface until, after a contest which may have lasted only ten minutes or which may have been prolonged through two hours, the landing-net of the skillful guide deposits him in the boat.

Apart from the risk of losing your trout because of the difficulty of landing him while the boat is tossing on the waves, this fishing in rough water has its perils, which add to its excitement if they do not increase its pleasures. One bracing September morning, I was industriously casting my fly from my boat, which was anchored three or four hundred yards from the sand-spit at the mouth of Bema 
Stream. The "Spirit of Mooselucmaguntic" (an effigy which the ingenuity of some of the campers had constructed from the gnarled roots which the waves had cast up on the beach and worn into incredibly fantastic shapes) looked upon the scene with a grin which forehoded some dire disaster. Ny guide, in despair at the determination which persisted in casting a fly in such a gale, was fishing from the bow of the boat with a drop line. A sudden exclamation from him, a start and a sharp twitch, indicated that he had hooked a large fish. I turned to see him pull a beautiful three-pounder over the thwart, which he had depressed to the level of the water to save the trouble of using the landing-net. But our triumph was of short duration. No sooner had the victim been deposited in the boat than we both, in an instant, found ourselves pitched out of it and struggling in the water of the lake. Unnoticed by either of us in the excitement of the moment, our boat had swung around into the trough of the sea, and a huge wave had dashed in, completely filling it, and tipping it so nearly over that as the water came in we went out. Confident in my own swimming powers, I called to my guide, as soon as 1 came to the surface and grasped hold of the boat, that 1 could take care of myself, and not to be alarmed on my account. But a desperate series of flounderings on his part indicated to me what I had never before suspected, that, notwithstanding the fact that he had been a guide upon these waters for thirty years, he could not saim a stroke. His frantic efforts to insure his own safety quickly tipped the boat bottom-side up, and again sent us both under. When I came to the surface, he was seated astride of the bow in comparative safety, while the second submersion had so water-logged my hear $y$ winter clothing that I found it impossible to do more than hang on to whatever part of the slippery bottom of the boat I could best clutch. Then it began to look as if our strait was desperate. The anchor-rope held our boat with the same firmness upon which we had before congratulated ourselves, and I fear that it would never have occurred to either of us to cut it and let the boat drift ashore. Fortunately, however, another boat happened just at this crisis to be starting out upon the lake. I3y his vigorous yells, my guide attracted the attention of those in the other boat, and in a few moments it was alongside. My guide easily stepped from his place of refuge into the rescuing boat, nearly upset- 
ting that in his precipitancy, and then it came to my relief. But 1 could neither lift myself over its side, nor could those who were in it pull me in without imminent risk of capsizing. There was no other way but to tow me ashore ingloriously. As soon as my feet struck bottom, I waded to the beach, and then for the first time realized how completely my strength was exhausted, and for how short a time, in all probability, 1 could have sustained myself in the perilous position from which I had so happily escaped. A blazing camp-fire and a dry suit of clothes quickly restored my equanimity; which was, however, completely destroyed again by the reflection, which in an instant burst upon me, that my three rods, including a new split bamboo, together with a carefully prepared box of fishing-tackle, which contained my fly-books, were at the bottom of the lake and in water at least twelve feet deep. It first, it seemed as if my sport for that trip at least had been completely and disastrously terminated. One of our guides, who was an expert swimmer, comforted me by the assurance that he could easily recover the more important articles by diving for them, and for a time it appeared as if this would be the only chance, until it occurred to us that one of the most enterprising and ingenious of our party had a day or two before constructed a square box with a pane of glass in the end, with which, after the manner of the sponge and pearl divers, he had been studying the botton of the lake to cliscover, if possible, the localities which the trout were the most likely to frequent. Taking this out with us the next day, we found that the contrivance worked to a charm. Thrusting below the ripple the end of the box which contained the glass, and excluding the light as far as possible from the other end, every object on the bottom of the lake, at a depth of even fifteen or twenty feet, could be clearly discerned. A little patient labor with this and a large landing-net with a handle of sufficient length was finally rewarded with the recovery of every article of any value. The fly-books, however, were both destroyed, and part of their contents were seriously damaged; still, these were trifling offsets to my own fortunate escape and that of my guide.

An incident in strong contrast with this unfortunate beginning terminated this same eventful fishing trip. Mr. Page, although the most expert and enthusiastic fisherman of our number, had devoted 


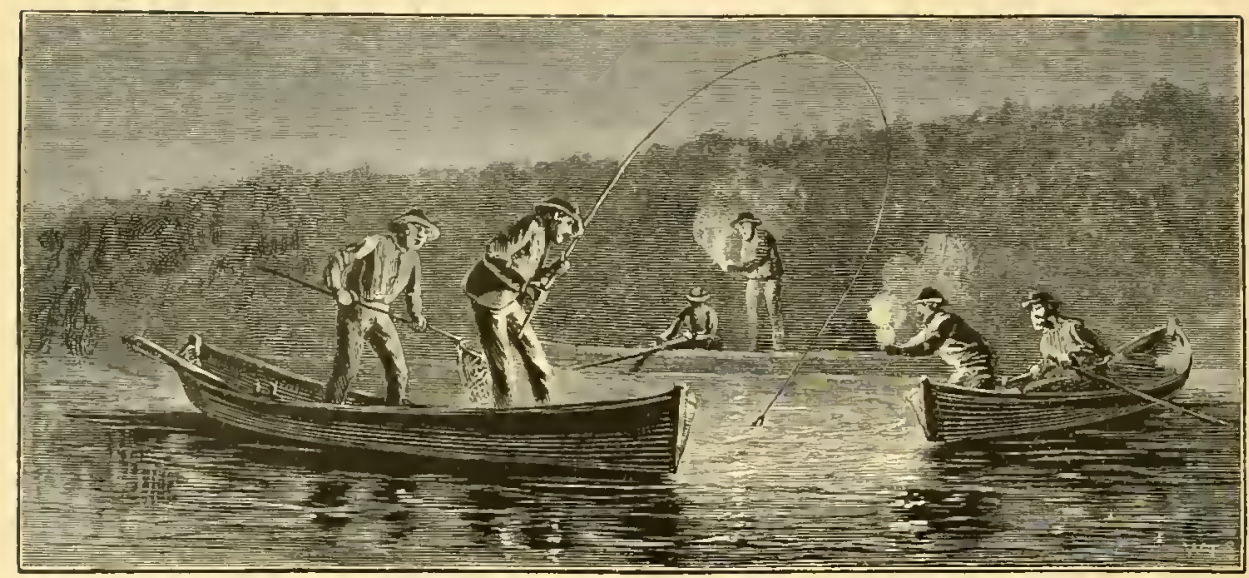

"MATCHING" A SEVEn-POUND TRUUT.

himself so assiduously to caring for the comfort of his guests that his own chances at catching the big trout had been seriously lessened. It was our last afternoon together, and as the hours waned toward sunset, the surface of the lake became as smooth and as brilliant as burnished steel. Our three boats were anchored within a short distance of each other, and we were condoling with our friend upon his lack of luck, when suddenly, a few rods away, there was a quick swirl and splash which told of the presence of a big fish. "That's my trout!" exclaimed Mr. Page, as he ordered his guide to haul anchor and scull him quietly over the spot where the fish had appeared. Two or three casts of the fly, and in an instant, with a ferocious rush, the trout had hooked himself so firmly that his final capture became only a question of time,- but of what a time! After two or three desperate struggles, during which he was met at every turn with the skill of a practiced fisherman, he settled sulkily at the bottom of the lake. Meanwhile, a gentle east wind had sprung up with the setting sun, and Mr. Page's boat began to drift with it gently to the westward. Fifteen minutes, half an hour, three-quarters of an hour passed, and from our anchorage we could see that the trout showed no signs of yielding,-nor did Mr. Page. As it gradually grew too dark to "cast" with satisfaction, my companion in the other boat and myself decided to haul up anchor and "go to see the fun," which, at our distance from the scene of conflict, seemed to be growing decidedly monotonous. By this time Mr. Page had drifted fully half a mile to the westward, 
and not once had the trout given any sign of yielding. When we came up with Mr. l'age it was quite dark, and the contest, which did not seem so very unequal after all,- for it it was yet doubtful which would get the best of it, - had stretched out to a full hour and a quarter. Then, at last. the trout showed signs of exhaustion, and, yelding to the inevitable pressure of the elastic rod, was once brought near the surface, but not close enough to net. Settling again to the bottom, he had apparently made up his mind to stay there: but the gentle, steady persuasion of the faithful seven-ounce Muphy split bamboo fly-rod again proved too much for him, and, straining his tackle to the utmost, Mr. Page brought his victim gradually toward the surface. The three boats had now come so close together that the fish was shut in on all sides. But it had become so dark that it was difficult to discern objects with any distinctness, and to shed all the light we could upon the puzzling

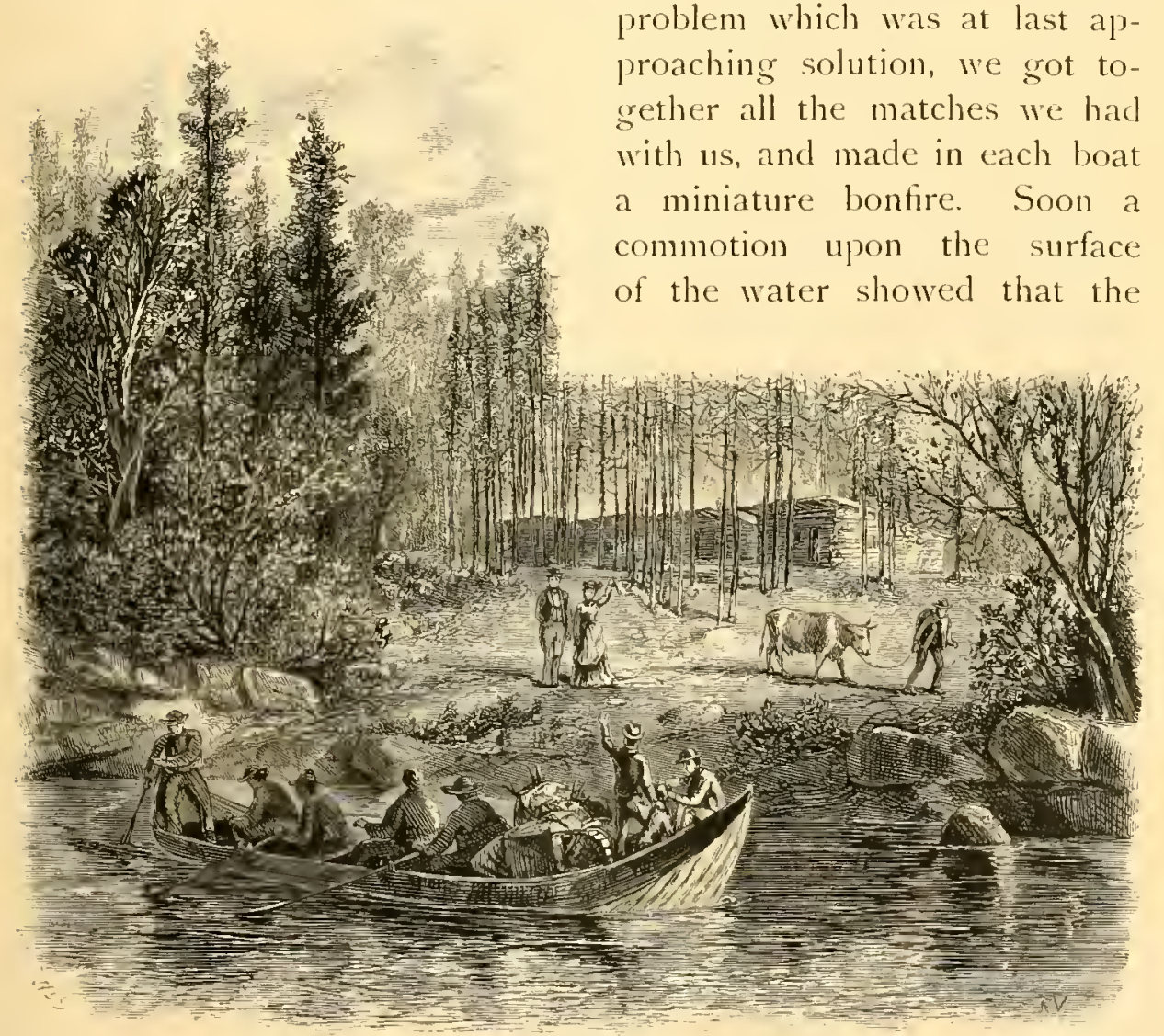

BREAKING CAMP. 
critical moment had arrived. There, with his back fin as erect as ever, was a magnificent trout, which was soon in the landingnet, and in a moment after in the boat, after precisely an hour and a half of as steady and persistent a fight as a fish ever made for life. But his capture was a full reward for all the time and trouble it had cost, since he weighed by the scale full seven pounds.

This trout and one weighing eight pounds which had been taken by Mr. Crounse were among the magnificent trophies which were carried away from Bema when we broke camp a day or two afterward. And the scene upon that memorable morning was one to which it is difficult to do justice with pen or pencil. There was the batteau laden with all the camp paraphernalia, including the pet dog Prince. As passengers, there were the two leaders of the party, Messrs. Page and Crounse, each with his two boys, while the guides pulled the oars. "Dan" Quimby, the faithful cook and profound philosopher, whose "corn-dodgers" had been in steady demand and in unfailing supply during the whole time of our stay in camp, was starting off for a ten-mile tramp overland to Madrid, leading the cow which he had brought in with him by the same route a month before, and the "spirit of Mooselucmaguntic," stripped of its blanket, seemed to be dancing in wild glee at the prospect of being left in undisturbed possession of his wild domain. Two or three of us remained behind to catch a few more trout, and in the hope of a less boisterous passage to the main camp. After a day or two we followed, taking with us delightful memories of the camp at Bema, and trout enough to excite the envy of the less successful anglers at the other end of the lake.

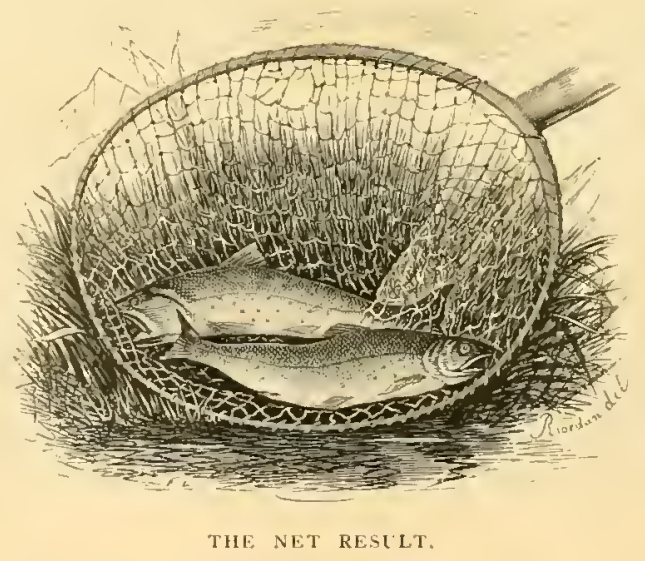




\section{BLACK BASS FISHING. \\ B JAMES I. HENSHALL.}

AUTHOR OF "BOOK W THE BLACK BASS" I.TC.

A

Gl.ORIOUS morning for fishing!" said the l'rofessor, as he stepped down from the broad veranda of a stately Kentucky mansion, and out upon the lawn, dashing the dew-drops from the newly sprung blue-grass, as he leisurely strode along in his heavy wading boots.

Professor Silvanus was a man yet in the prime of life, with a full beard, dark gray eyes, and a tall, powerful frame. A wellinformed naturalist, a capital shot, and an artistic angler, he had wooed nature in her various moods, in all seasons, and in many lands. Facing the east, he now stood, clad in a quiet fishing suit of gray tweed, surmounted by a broad-brimmed hat of drab felt, the smoke from his briar-root pipe wreathing gracefully above his head like a halo before it was borne away on the early morning air.

Meanwhile, Ignatius, his companion and disciple, was busily engaged in bringing out to the veranda the rods, creels, tacklecases, landing-nets, Junch-basket, and other necessaries for a day's fishing.

"Luke is coming with the wagon, Professor," said he, as a wellgroomed span of bays to a light wagonette came dashing around the corner of the house.

After depositing the various articles in the wagon. Ignatius took the reins, the Professor climbed up beside him with the rod-cases, while the colored man Luke, with a sigh, gave up the ribbons and took a back seat. 
The sun was just topping the maples when the impatient team went lashing through the road-gate.

"The bass should rise well to-clay," said the Professor.

"They are well through spawning, and if the water is right, everything else is propitious," replied Ignatius.

"Mighty perfishus for chan'l cats, too," put in Luke; "'sides yaller bass an' green bass, an' black bass, too; any kind o' bass."

"Professor. how many kinds of black bass are there?" inquired Ignatius, as he lightly touched up the flank of the off horse.

"There are but two species of black bass, and they are as much alike as that span of horses; but from the many different names used to designate them in different parts of the country one would be led to think there were many species."

"Local fishermen say there are three kinds here,-black, yellow, and green bass," asserted lgnatius.

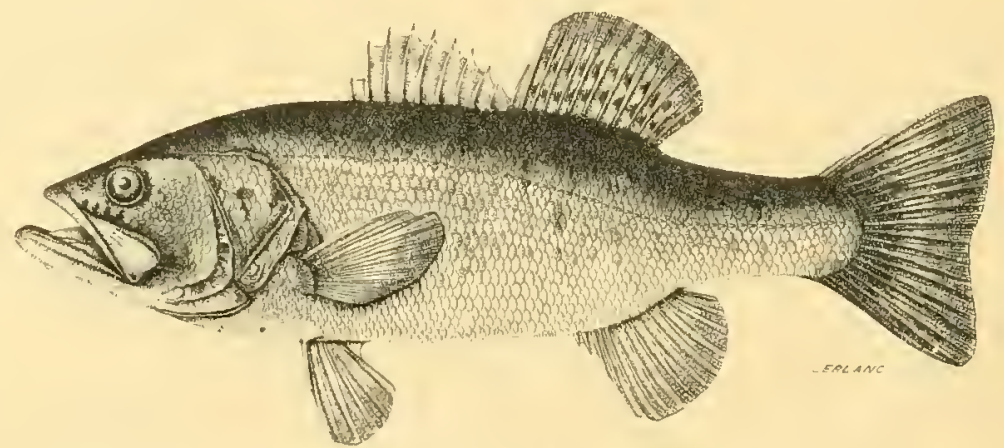

LARGE-MUTTHED BLACK BASS-MICROPTERUS SALMOIDES. (LACÉPEDE.) [AFTER A DRAWHNG FROM NATCRF BY DR. E. R. COPELAND.]

"There are but two well-defined species, the large-mouthed bass and the small-mouthed bass," continued the Professor, settling himself for a lecture. "There has been more confusion and uncertainty attending the scientific classification and nomenclature of the black bass than usually falls to the lot of fishes. some dozen generic appellations and nearly fifty specific titles having been bestowed upon the two species by naturalists since their first scientific descriptions by Count Lacépède in ISO2. Nor has this polyonomous feature been confined to their scientific terminology, for their vernacular names have been as numerous and varied: thus they are known in different sections of our country as bass, perch, trout, chub, or salmon, with or without various qualifying adjectives descriptive of color or habits." 


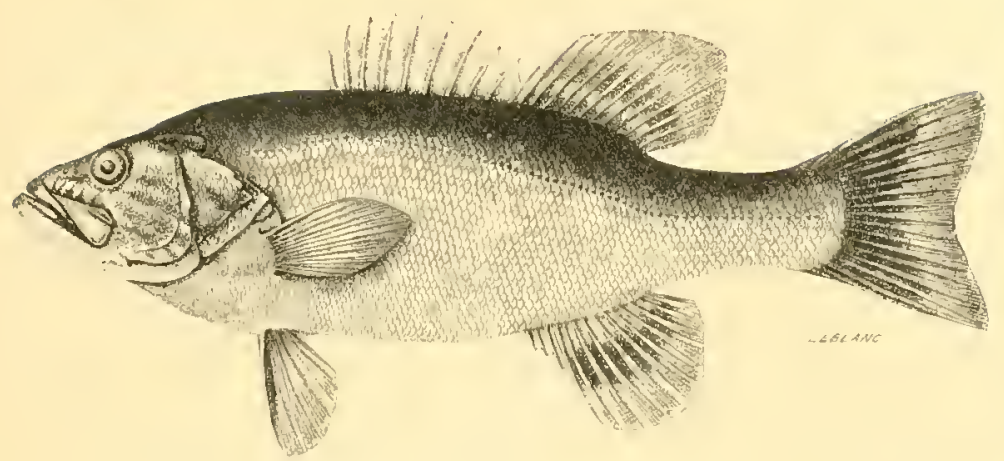

SMALL-MOUTHED BLACK BASS-MICROPTERUS DOLOMIEU. (LACÉPEDDE.) [AFTER A HRAWING FROM NATURE BY DR. E. R. CUPEL.IND.]

"Yes," assented Ignatius, "I have heard them called black perch, yellow perch, and jumping perch up the Rockcastle and Cumberland rivers, and white and black trout in Tennessee."

"Exactly," returned the Professor. "Nuch of the confusion attending the common names of the black bass arises from the coloration of the species, which varies greatly, even in the same waters; thus they are known as black, green, yellow, and spotted bass. Then they have received names somewhat descriptive of their habitat, as, lake, river, marsh, pond, slough, bayou, moss, grass, and Oswego bass. Other names have been conferred on account of their pugnacity or voracity, as tiger, bull, sow, and buck bass. In the Southern States they are universally known as 'trout.' In portions of Virginia they are called chub, southern chub, or Roanoke chub. In North and South Carolina they are variously known as trout, trout-perch, or Welshman; indeed, the large-mouthed bass received its first scientific specific name from a drawing and description of a Carolina bass sent to Lacépède, under the local name of trout, or trout-perch, who accordingly named it salmoides, meaning trout-like, or salmon-like."

"How do you account for the ridiculous practice of applying such names as trout and salmon to a spiny-finned fish of the order of perches?" asked Ignatius.

"They were first given, I think, by the early English settlers of Virginia and the Carolinas, who, finding the bass a game fish of high degree, naturally gave it the names of those game fishes par cxcellence of England, when they found that neither the salmon nor the trout inhabited southern waters. In the same way the mis- 
nomers of quail, partridge, pheasant, and rabbit have been applied, there being no true species of any of these indigenous to America."

"Then, I should say the names are a virtual acknowledgment that they considered the black bass the peer of either the trout or salmon as a game fish," said Ignatius.

"As an old salmon and trout fisher," replied the Professor, "I consider the black bass, all things being equal, the gamiest fish that swims. Of course, I mean as compared to fish of equal weight, and when fished for with the same tackle, for it would be folly to compare a three-pound bass to a twenty-pound salmon."

"The long list of local names applied to the black bass," resumed the Professor, " is owing chiefly to its remarkably wide geographical range; for while it is peculiarly an American fish, the original habitat of one or other of its forms embraces the hydrographic basins of the great lakes, the St. Lawrence, Mississippi, and Rio Grande rivers, and the entire water-shed of the South Atlantic States from Virginia to Florida; or, in other words, portions of Canada and Mexico, and the whole United States east of the Rocky Mountains, except New England and the sea-board of the Middle States. Of late years, it has been introduced into these latter States, into the Pacific slope, England, and Germany."

Reaching the summit of a hill after a long but gentle ascent, the river was disclosed to the view of the expectant anglers. At the foot of the descent was an old covered bridge which spanned al somewhat narrow but beautiful stream. winding in graceful curves among green hills and broad meadows. The ripples, or "riffles," sparkled and flashed as they reffected the rays of the bright morning sun, while the blue and white and gray of the sky and clouds were revealed in the still reaches and quiet pools as in a mirror. Driving through the time-worn and old-fashioned bridge with its quaint echoes, our friends left the turnpike and proceeded down a narrow road, following the course of the river to a small grove of gigantic elms, beeches. and sycamores, where a merry little creck mingled its limpid waters with the larger, but more pellucid, stream.

While Luke unharnessed the horses and haltered them to the low limb of a beech, the Professor and Ignatius went up the creek, with the minnow-seine and bucket, and soon secured a supply of chubs and shiners for bait. The Professor then took from its case 


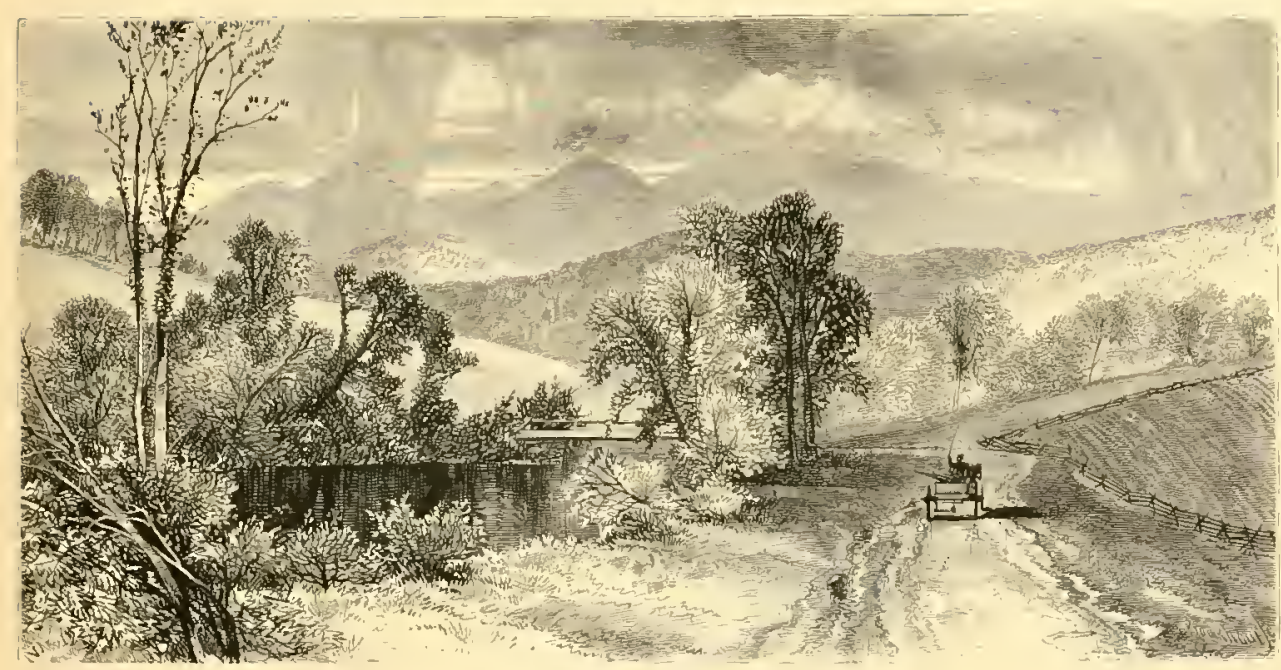

NEAR THE RIVEK.

and put together a willowy and well-made split bamboo fly-rod, eleven feet long, and weighing just eight ounces. Adjusting a light, German-silver click reel, holding thirty yards of waterproofed and polished fly-line of braided silk, to the reel-seat at the extreme butt of the rod, he rove the line through the guide-rings, and made fast to it a silkworm-gut leader six feet in length, to the end of which he looped, for a stretcher or tail fly; what is known, technically, as the "polka," with scarlet body, red hackle, brown and white tail, and wings of the spotted feathers of the gruinea-fowl; three feet above this, he looped on for dropper or bob fly, a "Lord Baltimore," with orange body, black wings, hackle and tail, and upper wings of jungle-cock, both very killing fies, and a cast admirably suited to the state of the water and atmosphere.

Meanwhile, Ignatius, who was a bait-fisher, jointed up an ash and lance-wood rod of the same weight as the P'rofessor's, but only eight and a quarter feet in length, and withal somewhat stiffer and more springy. He then affixed a fine multiplying reel, holding fifty yards of the smallest braided silk line, to which, after reeving through the rod-guides, he attached a sproat hook, No. I 1/2, with a gut snell eight inches long, but without swivel or sinker, for he intended fishing the "riffles," which is surface fishing principally.

Slinging their creels and landing-nets, they were about to depart, when Luke spoke up: 


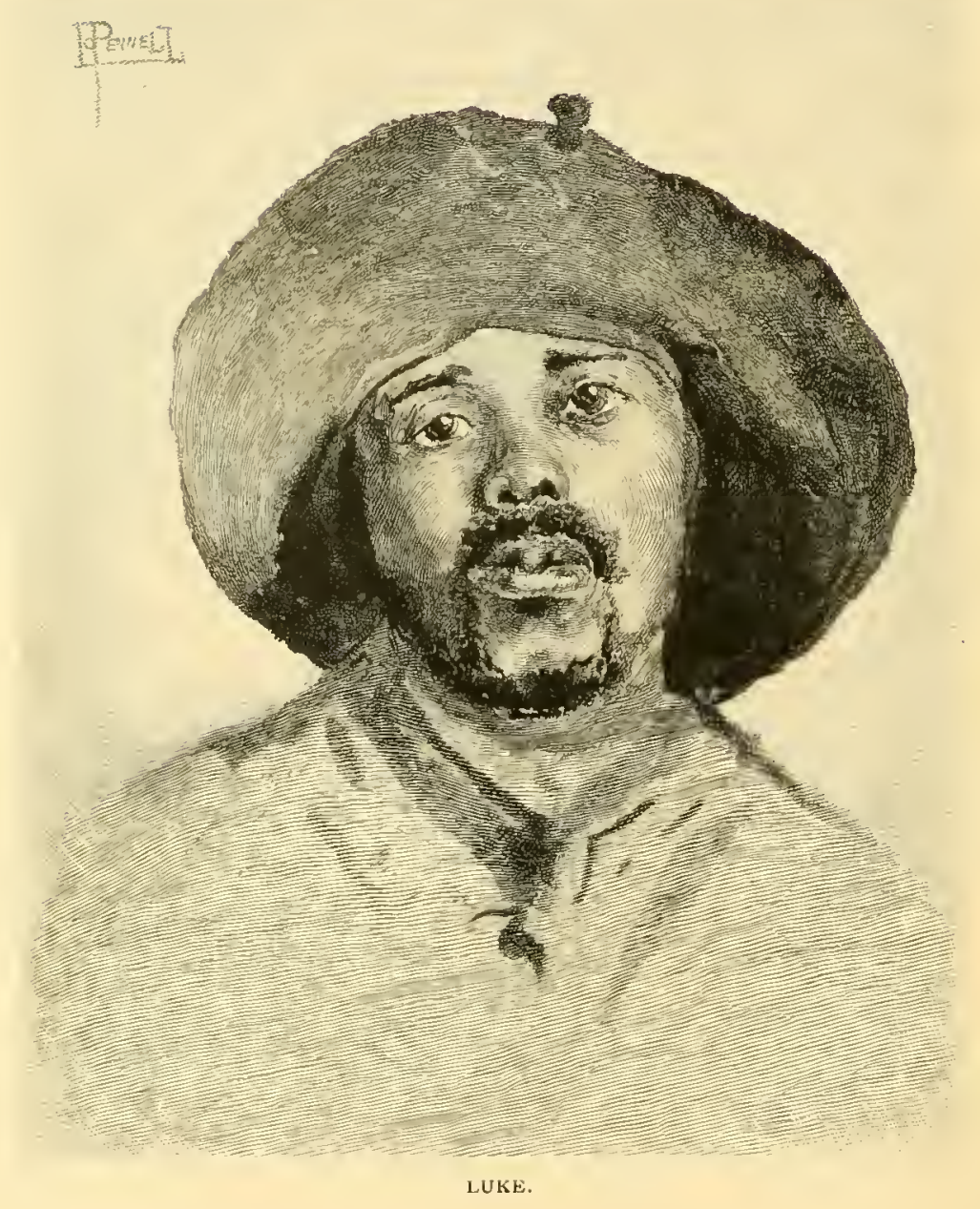

“ Nars' Nash, will you please, sah, gil, me one ob dem sproach hooks I heerd you all talkin' 'bout las' night; mebbe so I'll hang a big chan'l cat w'ile you're gone."

Ignatius, who was fastening the strap of a small, oblong, fourquart minnow-bucket to his belt, gave him several large-sized sproat hooks, saying:

"There, Luke, you will not fail to hook him with one of these, and the Professor will guarantee it to hold any fish in the river."

"Right," affirmed he: "the sproat is the hook beyond compare, the ne plus ultru, the perfection of fish-hooks in shank, bend, barb, and point." 
While the Professor and Ignatius proceeded down the river, Luke rigged up a stout line the length of his big cane pole, a large red and green float, a heavy sinker, and one of the No. 3-o sproat hooks. He then turned orer the stones in the creek until he obtained a dozen large craw-fish, which were ahout to shed their outer cases, or shells, and which for this reason are called "shedders," or "peelers."

"Now, den," said he, "we'll see who'll ketch de mos' fish. Umph! I wunder wat de 'Fessor do if he hang a big chan'l cat wid dat little pole!"

He then baited his hook with a "soft craw," seated himself on a log at the edge of a deep pool, or "cat-hole," and began fishing.

The Professor and Ignatius took their way down-stream a short distance to where a submerged ledge of rocks ran nearly across the river, some two feet below the surface and about ten feet in width. The line of rock was shelving, or hollow underneath on the up-river side, the water being some six feet deep just under and above it, but shoaling gradually up-stream. The ledge was surmounted on its lower edge by a line of loose rocks which cropped up nearly to the surface, producing a rapid, or riffle. On the opposite side of the stream the bank was quite high and steep, forming a rocky, wooded cliff, where the snowy dogwood blossoms and the pink tassels of the redbud lit up the dark mass of foliage which was yet in shadow; for the sun was just peeping curiously over the top. of the cliff, and shining full in their faces-for prudent anglers always fish toward the sun, so that their shadows are cast behind them.

"Now," said the Professor, as he waded out into the stream some fifty feet above the rocky ledge, "the bass have left the cool depths beside the rock and are on the riffle, or just below it, enjoying the welcome rays of the sun while waiting for a stray minnow or craw-fish for breakfast. l'll drop them a line."

So saying, he began casting, lengthening his line at each cast, -the line, leader, and flies following the impulse of the flexible rod in graceful curves, now projected forward, now unfolding behind him,- - until the flies, almost touching the water full seventy feet in his rear, were, by a slight turn of the wrist and fore-arm and apparently without an effort, cast a like distance in front, where they dropped gently and without the least splash just on the lower edge of the rift. Immediately the swirl of a bass was seen near 
the dropper-fly; the Professor struck lightly, but missed it, for he was taken somewhat unawares and failed to strike quickly enough. Throwing his line behind him, he made another cast, the flies dropping, if possible, more lightly than before, and with a somewhat straighter and tighter line.

"I have him!" he exclaimed, as a bass rose and snapped the stretcher-fly before it fully settled on the water. "He hooked himself that time, the line being perfectly taut. He's not a large one, though he gives good play," he continued, as he took the rord in his left hand and applied his right to the reel, the bass, in the meantime, having headed up-stream to the deeper water beside the rock.

"No, no, my fine fellow, that will never do," said he, as he brought the full strain of the fish on the rod by turning the latter over his shoulder and advancing the butt toward the struggling bass, which had made a desperate and quick dash to get under the rock when he found himself in deep water. This "giving the butt," as it is technically termed, brought him to the surface again, when he instantly changed his tactics by springing two feet into the air, shaking his head violently in the endeavor to dislodge the hook, and as he fell back with a loud splash he dropped upon the line, by which maneuver he would have succeeded in tearing out the hook had the line still been taut; but the l'rofessor was perfectly familiar with this trick, and had slackened the line by lowering the tip of the rod as the bass fell back, but instantly resumed its tension by again raising the tip when the fish regained his element. As the Professor slowly reeled the line, the bass dashed hither and yon at the end of his tether, but all the time working up-stream and toward the rod. Then he was suddenly seized by an impulse to make for the bottom, to hide under a rock, or mayhap dislodge the barb or foul the line by nosing against a stone or snag-but not to sulk; for be it known a black bass never sulks, as the salmon does, by settling motionless and stubbornly on the bottom when he finds his efforts to escape are foiled. The bass resists and struggles to the last gasp, unless he can wedge himself beneath a rock or among the weeds, where he will work the hook out at his leisure. The Professor, keeping the line constantly taut and the rod well up, thereby maintaining 


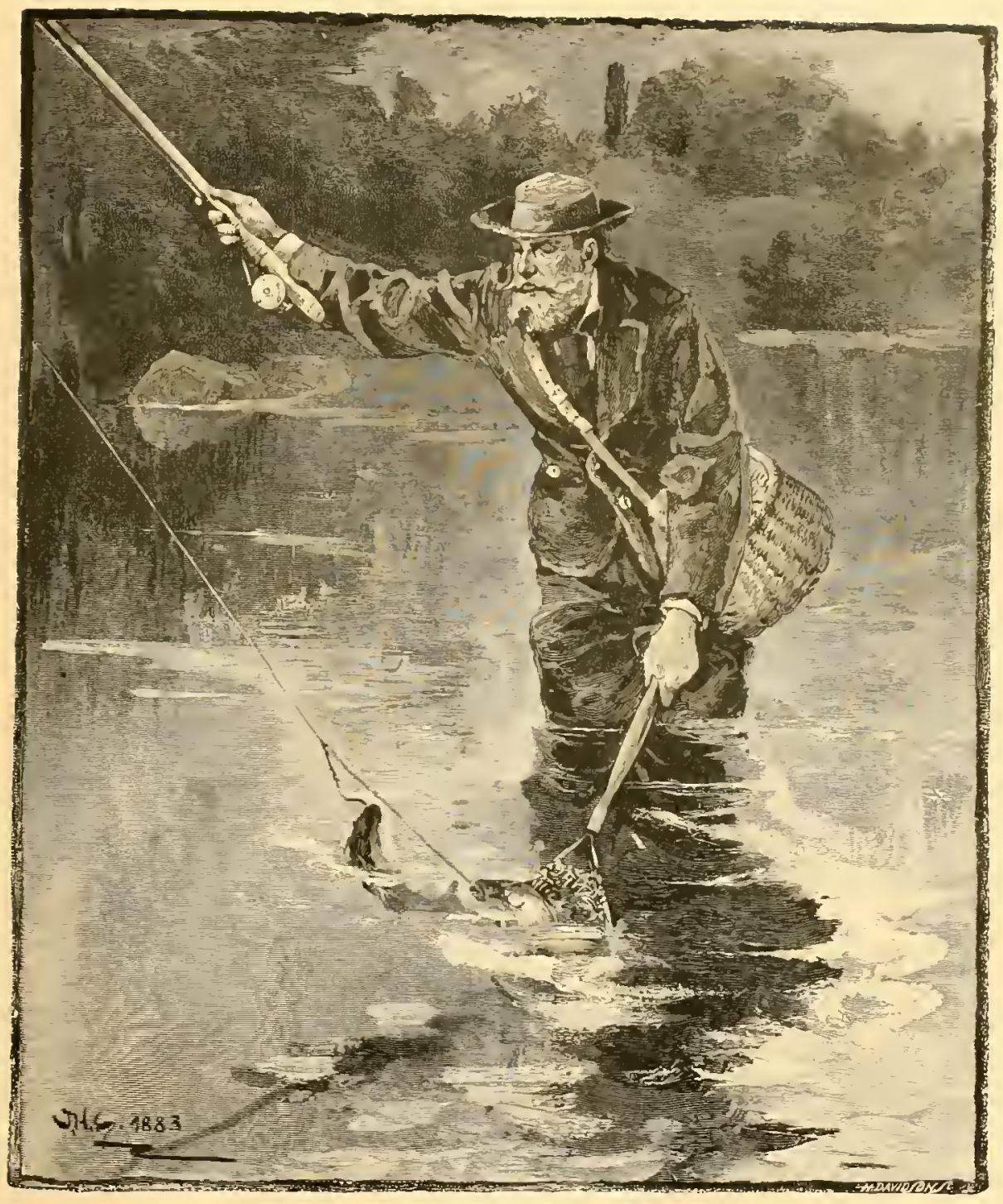

THE PROFESSOR LANDING A DOUBLE.

(DRAWN BY J. H. COCKS.) 

a springy arch, soon reeled the bass within a few feet, when he put the landing-net under him. Then addressing I grnatius, he said:

"The humane angler always kills his fish as soon as caught by severing the spinal cord at the neck with a sharp-pointed knife, by breaking the neck, or by a smart blow on the head. Then raising the gill-cover, he bleech the fish by puncturing a large venous sinus, which shows as a dark space nearly opposite the pectoral fin. Killing and bleeding a fish is not only a merciful act, but it enhances its value for the table, rendering the flesh firmer, sweeter, and of better color."

Ignatius was capable of admiring the Professor's humanity, but he was most attracted by his wonderful skill. His grace and deliberation, though natural and inborn to a certain degree, were chiefly the result of many years devotion to the rod and gun and the practical study of the habits of fish and game. There is more symmetry of form and natural grace of motion among the aboricrinal races of the world, trained to the pursuit of animals on land and water from childhood, than among the civilized and enlightened; our brains are developed and fostered at the expense of our bodies; therefore, the nervous, jerky, impatient, and impetuous man will never make a truly successful angler nor a really good shot, though he may attain to a certain mediocrity in both sports.

At the next cast the Professor fastened a two-pound bass to the "polka," and while giving him play another bass of the same weight took the "Lord Baltimore." As these fish kept down-stream, the full force of the current was an additional factor of resistance to the rod, which seemed to Ignatius to bend nearly double, and caused him to say:

"You will have a hard time to land them both. Professor!"

"Not necessarily, for although the weight is greater, they, together, will not play much longer than a single fish, if so long: for they are pulling against each other. It only remains for me to hold them by the spring of the rod and let them fight it out."

His method of landing them was unique: Holding the net a few inches beneath the surface, he first drew in the bass on the stretcherfly; then, as he turned up the lower or down-river half of the net-rim to the surface, he let the bass on the bob-fly drop back with the current into it, and lifted out both. 
lgnatius proceeded farther out into the stream. but parallel with the shelving rock. Then selecting a minnow four inches long, he passed the hook through the lower lip and out at the nostril. Reeling up his line to the snell of the hook, and with his thumb on the spool of the reel, he turned his left side to the riffe below; then swinging his rod to the right, the minnow nearly touching the water, he macte a sweeping cast from right to left and from below upward, starting the minnow on its flight just before the tip of the rod reached its greatest elevation, by relaxing somewhat the pressure of his thumb on the spool, but still maintaining a certain light and uniform pressure to prevent the reel from back-lashing and the line from overrunning; the minnow was neatly cast, in this way, some seventyfive feet, and just beyond the riffle. Then he reeled slowly, keeping the minnow near the surface (there being no sinker), and just as it was passing through the broken water of the riffe, a bass seized it on the run and continued his rush up-stream toward deep water. Ignatius reeled his line rapidly until he felt the weight of the fish, which then gave a short tug or two, when he was allowed to take a few feet of line, though srudgingly and sparingly, so as to keep it taut. lgnatius then, feeling the bass pull steadily and strongly, drove in the steel by a simple turning over of the rod-hand, while drawing firmly on the line: this set the hook.

The bass continued his race by swimming rapidly between lgnatius and the shore and then up the river, describing a half circle, the line being the radius. The bass, finding his progress thus stayed, sprang clear of the water several times in quick succession ; but Ignatius, instead of slackening the line, skillfully turned the bass over in the air by a slightly increased tension as it left the water, thus preventing, by another method, his falling across the taut line. This latter mode requires more adroitness than the plan used by the Professor, of lowering the tip of the rod to slacken the line as the fish falls back, but it can be more successfully and safely accomplished with the shorter and stiffer minnow-rod than with the fly-rod. The bass was sooner exhausted and brought to creel than if he had been down-stream, not having the strength of the current to aid him.

"That is the best fish yet taken, Isnatius," said the Professor; "he will scale fully three pounds, and you landed him in two minutes."

"One should hold hard and kill quick." 


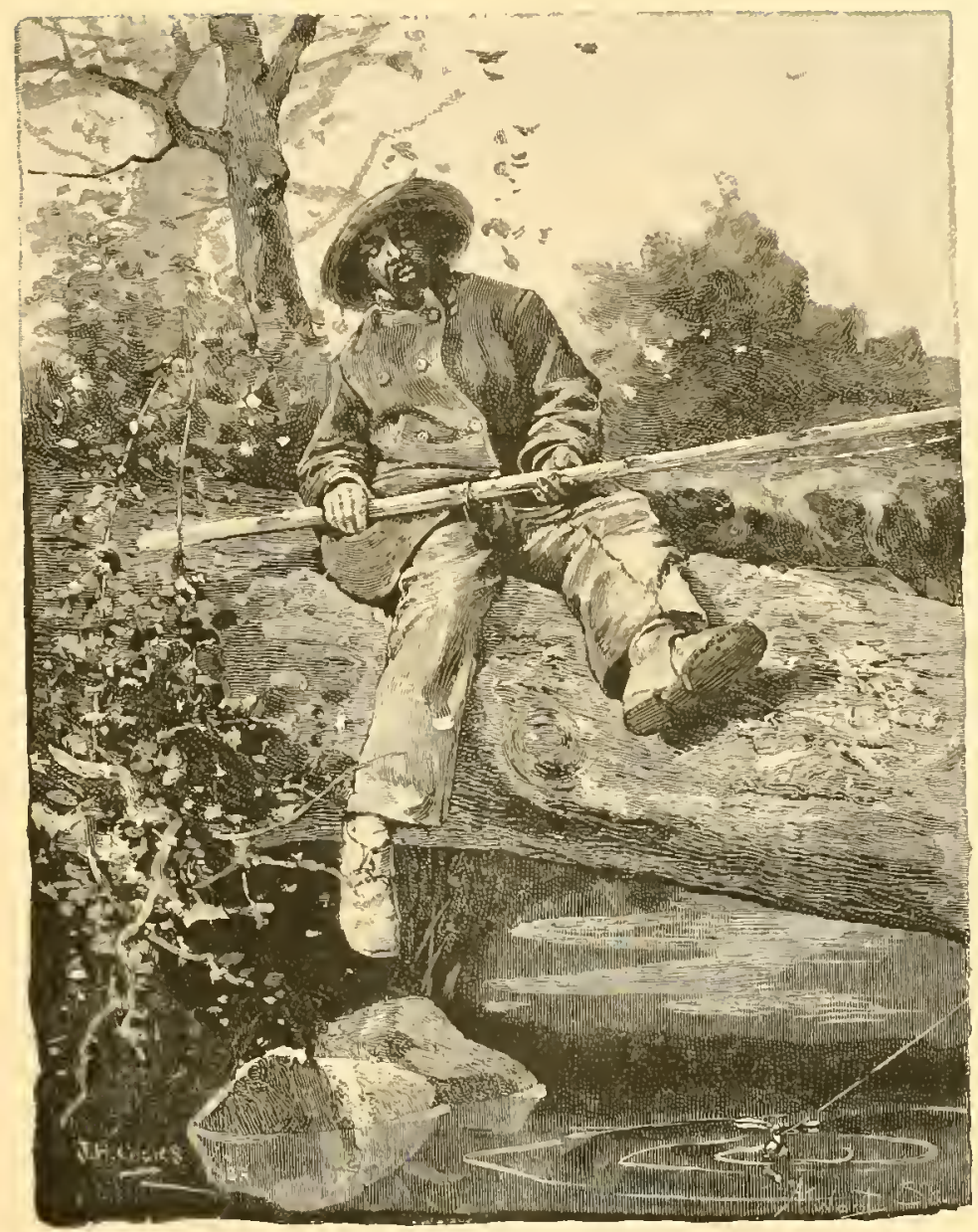

AN IDEAL " STILL, FISHER."

"With a qualification as to the rod, that is the true principle," returned the Professor. "With a properly made, light, and flexible rod, yes; with a bean-pole, no. With a well balanced, supple rod of eight ounces, a pound bass, even in swilt water, can be easily killed in a minute, and one of five pounds in five minutes."

The Professor and Ignatius, having each taken a dozen bass, reeled up their lines and retraced their steps toward the wagon for luncheon. Turning a bend in the river, they came in sight of Luke, still sitting on the log with a firm hold on the rod, but sound asleep.

"Behold the ideal still-fisher!" observed the Professor. 
Suddenly the float disappeared, the point of the rod was violently pulled into the water, and Luke, awakening, took in the situation, and with a savage jerk, struck a large fish which threatened to pull him from his perch. Indeed, he was forced to follow it into the water to save his tackle.

Luke, seeing them approaching, cried out appealingly:

"Wat I grwine to do wid dis fish?"

"Keep your pole up, and lead him out to the shallow water."

Finally, after a few minutes more of great effort, and much floundering of the fish, he succeeded in getting the fish into shallow water, and drew it out on the shore, a channel cat-fish, weighing fully ten pounds.

"I got de boss green bass, too, Mars' Nash," said he, as he drew his fish-string out of the water and displayed a large-mouthed bass of four pounds.

"And the only large-mouthed bass caught this morning." said the Professor. "Now, Ignatius," he continued, "lay it side by side with your heaviest small-mouthed bass, and you will readily see the principal points of difference. In the first place, Luke's fish is more robust, or 'chunkier,' yours being more shapely and lengthy. Then Luke's bass has much the larger mouth, its angle reaching considerably beyond or behind the eye, while in yours it scarcely reaches the middle of the eye; thus it is they are called large and smallmouthed bass. Then the scales of Luke's fish are much larger than those of yours, for if you count them along the lateral line you will find only about sixty-five scales from the head to the minute scales at the base of the caudal fin, while there are about seventy-five on either of your small-mouthed bass. You also observe that the scales on the cheeks of Luke's fish are not much smaller than those on its sides, while on your fish the cheek scales are quite minute as compared with those on its body.

"As for Luke's big-mouthed bass," continued the Professor, "l've taken them in Florida weighing about fourteen pounds. I used a ten-ounce rod for those big fellows; I could have killed them with this little rod by taking more time and muscle, and uselessly prolonging the struggles of the fish, but 1 deem that unsportsinanlike."

"I've heard," said Ignatius, "that most of the Florida bass are taken with the hand-line and trolling-spoon." 
"That is the way most Northern tourists usually take them, be cause they don't know how to handle a rod; and then, the necessary tackle for hand-trolling can be carried in the pocket. It is the simplest mode of angling, if it can be dignified by that name, for it is more suggestive of meat, or 'pot,' than sport. The pseudo-angler sits in the stern of a boat with a stout line, nearly the size of an ordinary lead-pencil and about seventy-five yards long, to the end of which is attached a spoon-bait or trolling-spoon, with one or two small swivels. When the boatman rows the boat slowly and quietly along the trolling-spoon. revolving swiftly beneath the surface at the end of fifty yards of line, glittering and flashing in the sunlight, is eagerly seized by the bass as it passes near his lair, when one or more of the hooks attached to the spoon are fixed in his jaws. While there is a certain amount of excitement in hauling in the struggling bass by 'main strength and stupidity,' as the mule pulls, there is not the faintest resemblance to sport, for there is no skill required in the manipulation of the line or bait or in handling the fish when hooked."

"Do they troll with the hand-line, too?" asked lgnatius.

"Not many of them; they use a long rod or pole for stillfishing, skittering, and bobbing."

"What are skittering and bobbing?"

"Bobbing has been practiced in Florida for more than a century. and is a very simple but remarkably 'killing' method of fishing. The tackle consists of a long cane or wooden rod, two or three feet of stout line, and the 'bob,' which is formed by tying three hooks together, back to back, and covering their shanks with a portion of a deer's tail, somewhat on the order of a colossal hacklefly; strips of red flannel or red feathers are sometimes added; all together forming a kind of tassel, with the points of the hooks projecting at equal distances. The man using the bob is seated in the bow of a boat, which the boatman poles or paddles silently and slowly along the borders of the stream or lake, when the fisher, holding the long rod in front of him, so that the bob is a few inches above the surface, allows it to dip or 'bob' at frequent intervals in the water, among the lily-pads, deer-tongue, and other aquatic plants that grow so luxuriantly in that sub-tropical region. The bass frequently jumps clear of the water to grab the bob, but 
usually takes it when it is dipped or trailed on the surface. Deer hair is very buoyant. and the queer-looking bob seems like a huge, grotesque insect. flying or skimming along the clear, still waters.

"Skittering," continued the Professor, "is practiced with a strong line about the length of the rod, to which is affixed a small trolling-spoon, a minnow, or a piece of pork-rind cut in the rude semblance of a small fish. The boat is poled along, as in 'bobbing,' but farther out in the stream, when the angler, standing in the bow. 'skitters' or skips the spoon or bait over the surface just at the edge of the weeds. Skittering is a more legitimate method of angling than bobbing. for with the longer line the bass gives considerable play before he can be taken into the boat; and as this manner of fishing is usually done in shallow waters abounding in moss, grass, and weeds, the fish must be kept on the surface and landed quickly.

"Ignatius, you should become a fly-fisher," added the Professor. "Your style of bait-fishing is admirably suited to the Northern lakes and the deep rivers, where, indeed, it is the favorite method with the best anglers, though a small swivel or sinker is necessary to keep the minnow beneath the surface. But on such a charming, rapid, and romantic river as this, the artificial fly alone should be ased. This afternoon, when the sun is low in the west, bass will again rise to the fly, and if you like we will try them again."

And now, while the Professor and Ignatius are talking of other matters over their pipes, we will conclude by wishing "good luck" to the entire fraternity of anglers, from him of the asthetic fly to him of the humble worm, but with a mental reservation as to him of the hand-line and spoon.

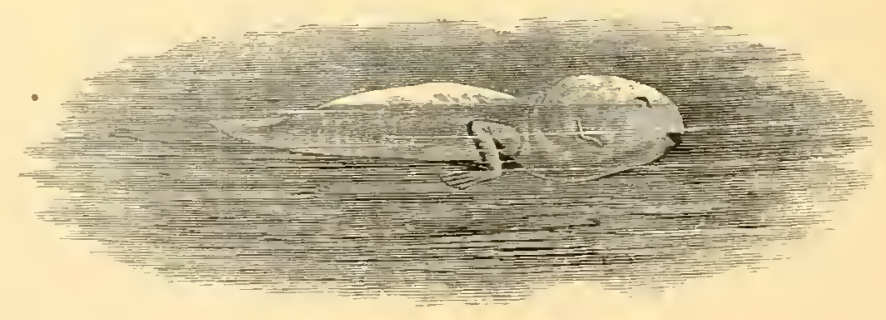




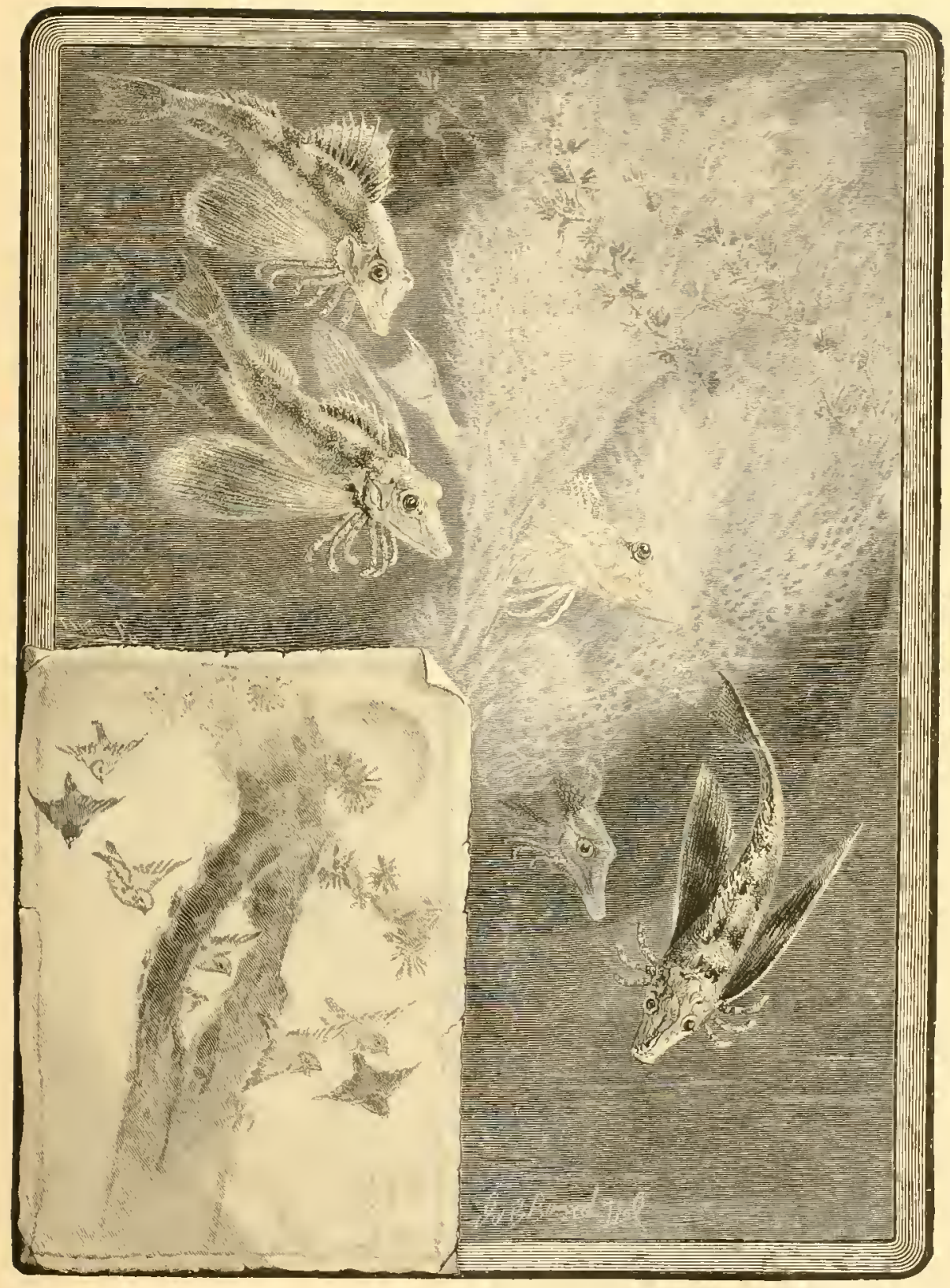




\section{IN THE HAUNTS OF BREAM AND BASS.}

BI MAURICE THOMPSON.

\section{I.}

D)

REAMS come true and everything

Is fresh and lusty in the spring.

In groves, that smell like ambergris,

Wind-songs, bird-songs never cease.

Go with me down by the stream,

Haunt of bass and purple bream;

Feel the pleasure, keen and sweet,

When the cool waves lap your feet:

Catch the breath of moss and mold,

Hear the grosbeak's whistle bold;

See the heron all alone

Mid-stream on a slippery stone,

Or, on some decaying log,

Spearing snail or water-frog,

Whilst the sprawling turtles swim

In the eddies cool and dim!

II.

The busy nut-hatch climbs his tree,

Around the great bole spirally,

Peeping into wrinkles gray,

Under ruffled lichens gay, 
In the Haunts of Bream and Bass.

Lazily piping one sharp note

From his silver-mailed throat,

And down the wind the cat-bird's song

A slender medley trails along.

Here a grackle chirping low,

There a crested vireo ;

Every tongue of Nature sings,

The air is palpitant with wings!

Halcyon prophesies come to pass

In the haunts of bream and bass.

III.

Bubble, bubble flows the stream,

Like an old tune through a dream.

Now I cast my silken line;

See the gay lure spin and shine-

While, with delicate touch, I feel

The gentle pulses of the reel.

Halcyon laughs and cuckoo cries,

Through its leaves the plane-tree sighs.

Bubble, bubble flows the stream,

Here a glow and there a gleam,

Coolness all about me creeping,

Fragrance all my senses steeping,

Spice-wood, sweet-gum, sassafras,

Calamus and water-grass,

Giving up their pungent smells

Draw'n from Nature's secret wells;

On the cool breath of the morn

Fragrance of the cockspur thorn.

IV.

I see the morning-glory's curl,

The curious star-flower's pointed whorl. 
Hear the woodpecker, rap-a-tap!

See him with his cardinal's cap!

And the querulous, leering jay,

How he clamors for a fray!

Patiently I draw and cast,

Keenly expectant, till, at last.

Comes a flash, down in the stream,

Never made by perch or bream.

Then a mighty weight 1 feel,

Sings the line and whirs the reel!

Out of a griant tulip-tree.

A great gay blossom falls on me;

Old gold and fire its petals are, It flashes like a falling star.

A big blue heron flying by Looks at me with a greedy eye.

I see a stripéd squirrel shoot Into a hollow maple-root:

A bumble-bee, with mail all rust, His thighs puffed out with anther-dust,

Clasps a shrinking bloom about, And draws her amber sweetness out.

Bubble, bubble flows the stream, Like an old tune through a dream!

A white-faced hornet hurtles by, Lags a turquoise butterfly,

One intent on prey and treasure, One afloat on tides of pleasure!

Sunshine arrows, swift and keen, Pierce the maple's helmet green. 
VI.

I follow where my victim leads,

Througl tangles of rank water-weeds,

O'er stone and root and knotty log,

And faithless bits of reedy bogr.

I wonder will he ever stop?

The reel hums like a humming-top!

A thin sandpiper, wild with fright,

Goes into ecstasies of flight,

Whilst I, all flushed and breathless, tear

Through lady-fern and maiden's-hair,

And in my straining fingers feel

The throbbing of the rod and reel!

Bubble, bubble flows the stream,

Like an old tune through a dream!

VII.

At last he tires, I reel him in ;

I see the glint of scale and fin.

I raise the rod-I shorten line

And safely land him; he is mine!

The belted halcyon laughs, the wren

Cones twittering from its brushy den

The turtle sprawls upon his log,

I hear the booming of a frog.

Liquid amber's keen perfume,

Sweet-punk, calamus, tulip-bloom,

Gimpses of a cloudless sky

Soothe me as I resting lie.

Bubble, bubble flows the stream,

Like low music through a dream. 


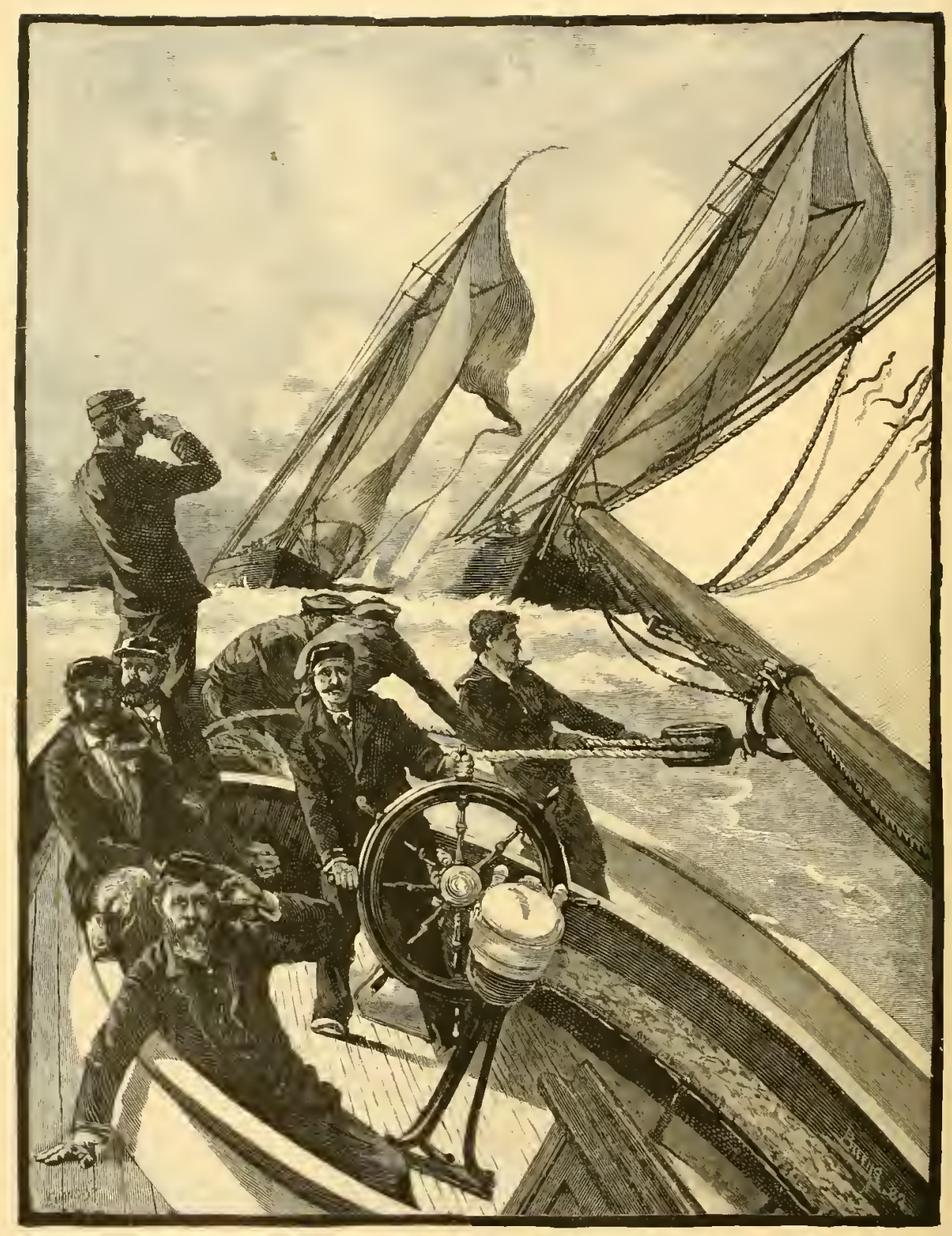




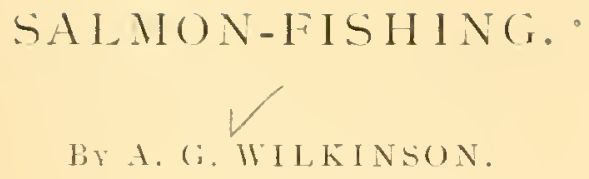

LTHOUGH the salmon is the acknowledged king of fishes, and the taking of it the most royal of sports, yet compara1 tively few indulge in the pastime. There are certainly many, and those too among the foremost men of our country, who concede fully the benefits to be derived, not only from open-air life and exercise, but from having some pursuit or specialty outside of business and profession, - call it hobby, if you will, - which, while it gives rest to certain faculties of the mind, equally exercises and strengthens others. They realize truly that life is better than fame, and sound lungs and good digestion than a fat purse; but the difficulties in the way of taking salmon turn most of these in a different direction for their recreation.

The three principal hinderances to salmon-fishing in this country are: the great trouble in obtaining either a lease of a stream or a permit for the best part of the season; the great distances to be traveled, and consequent loss of valuable time: and the large expense as compared with other sorts of outdoor amusements.

The region where salmon can at the present day be taken, in sufficient numbers to reward one for the attendant trouble and expense, is a circumscribed one. Beginning at Quebec, and following down the river St. Lawrence, the salmon-streams are very numerous upon the northern shore, and extend far away to the Labraclor coast. Among them are the well-known Laval, Godbout, Trinity, St. Margaret, Moisic, St. John's, Magpie, Mingan, Great and Little Romaine Rivers. 
The range of mountains on the north shore runs within a few miles of the St. Lawrence, and hence the rivers upon that side are very short and rapicl, giving but few good pools, and are, as a general thing, very difficult to fish. Only a few good streams are found on the south shore, among which are the Rimouski, Grande Nletis, and Natane. Passing down the Gulf of St. Lawrence, we come to the Basin of Gaspé, into which flow three admirable streams; and farther on, upon the north shore of the Bay of Chaleurs, and at its western end, are some of the best, including the famous Restigouche,

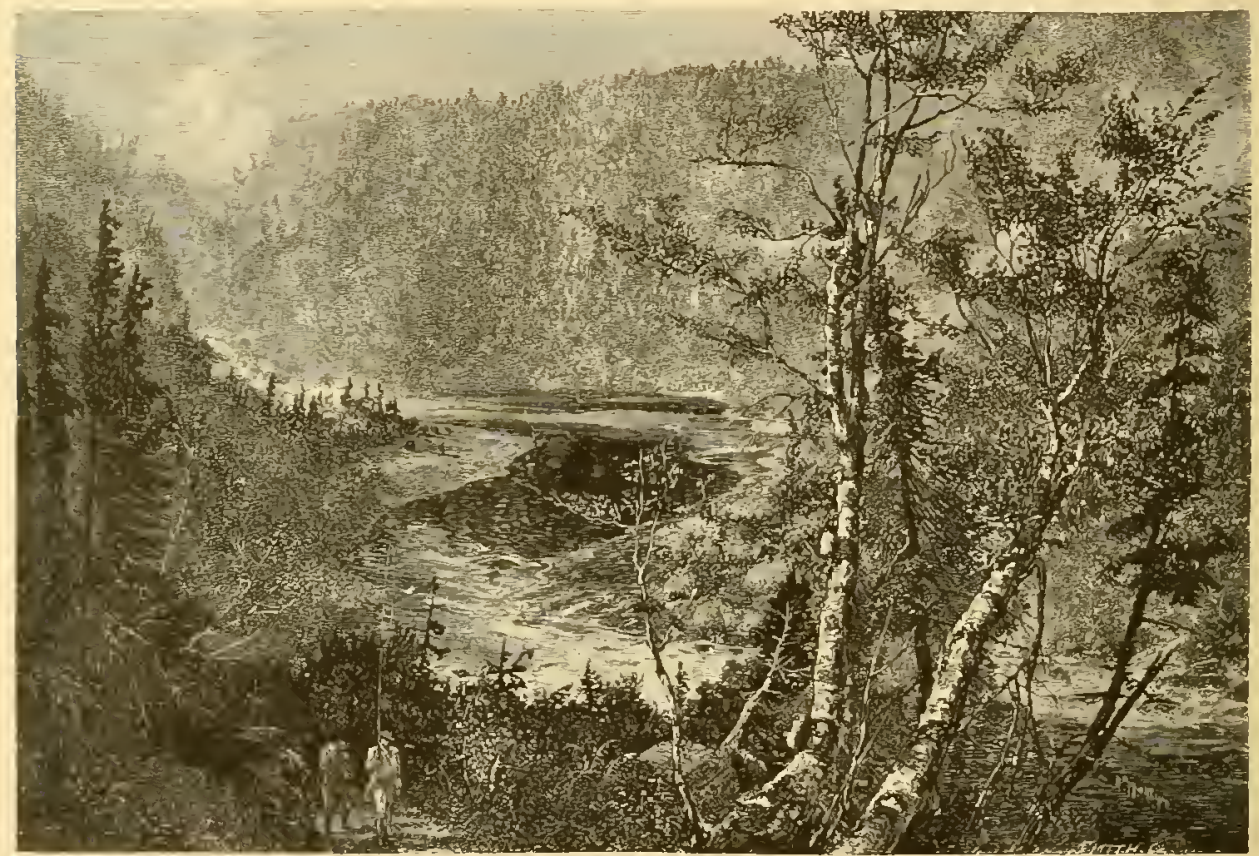

ON THE GODBOUT.

fished yearly by Englishmen who cross the Atlantic for that express purpose; also the Cascapedia, made more noted through Mr. Dawson's charming letters from there, where, at a good ripe age, he took his first salmon. The Nipisiguit on the south shore of the Bay of Chaleurs and the Miramichi on the eastern coast of New Brunswick are the last salmon-streams of any account until we come to Nova Scotia, where there are a few upon its south-east coast below Halifax.

In Cape Breton there is a single good river, the Margarie. Here and there small streams are found in other parts of New Brunswick 


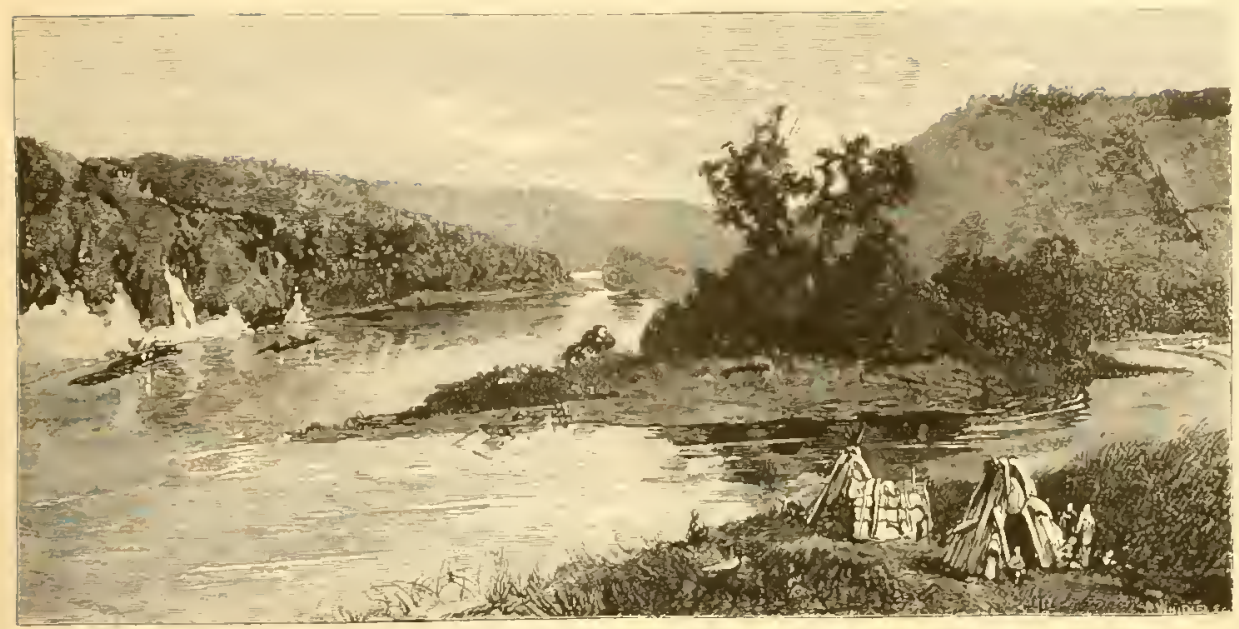

JLNCTIUN OF THE RESTIGOUCHE AND MATAPEDIAC RIVERS.

and in the Island of Anticosti, but practically salmon-angling is confined to the rivers of Canada East and those of the northern part of New Brunswick, which includes the Miramichi.

But few of the rivers we have mentioned debouch near a steamer landing, and all others are difficult of access. To reach these latier the angler must manage in some way to get transportation for many miles over a rough country, where it is difficult to find horses, wagons, or roads; or he must charter a small sailing-ressel and run along a most dangerous coast, carrying with him both canoes and men. The Restigouche and Matapediac are reached with comparative ease from 1)alhousie, a landing-place of the Gulf Port steamers. This line of steamers also touches at Gaspé Basin, leaving passengers just at the mouths of the three streams flowing into it. These are the York, St. John, and Dartmouth, called by the natives the South-ivest, Douglastown, and North-west. These rivers are among the best stocked in Canada. The scenery about them is most varied, and in this respect unlike most uther parts of Canada, where one tires of the monotony of mere grandeur and longs for the picturesque. They flow chiefly through deep gorges, or cañons, and between mountains, which occasionally rise to the height of at thousand or fifteen hundred feet. Beautiful lakes, filied to repletion with brook-trout, are found on the high land between the rivers, which for quite a distance flow within a few miles of one another. These streams are very rapid, and in early spring are almost torrents, and yet they have very few falls 


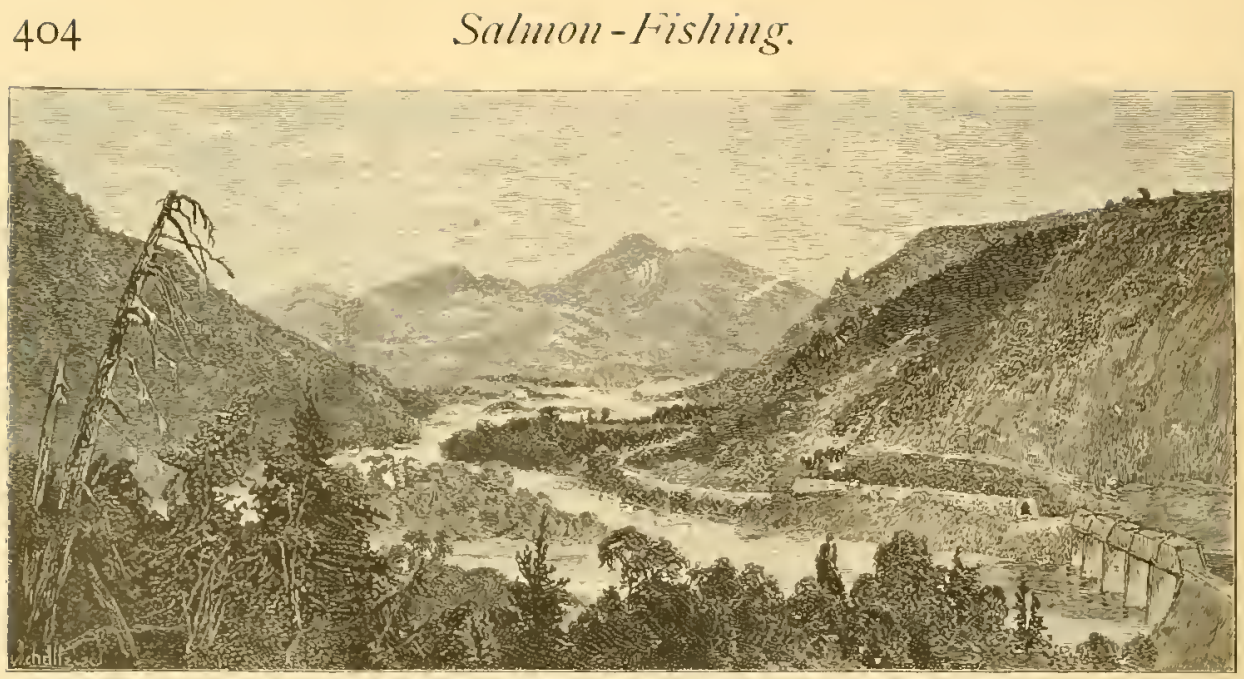

THE VALLEY UF THE MATAPEDIAC.

around which a "carry" must be made. Comfortable houses have been erected at some trouble and expense every ten or twelve miles on those parts of the Jork and St. John which abound in good pools.

The Canadian Government exercises complete control of the principal salmon-streams, both in their tidal and fluvial parts. Leases are commonly given for several years, but occasionally a schedule of vacant rivers is published, giving "upset" or minimum prices at which season permits will be granted. These vary from $\$ 20$ to $\$ 500$ in gold. The very fact that such advertisement is made indicates of itself that the rivers are not, for some reason, very desirable. The best rivers are leased for eight or ten years, and upon the likelihood of a vacancy, numerous applicants bring influences to bear to secure the chance at once.

It is understood that as a general thing leases of the better class of streams are not to be given to the "States" people, as they call us of the United States. Our political anglers often remark that it is more difficult to lease a good salmon-stream than to secure an election to Congress. A thousand dollars has been paid for the use of the fluvial part only of a first-class stream for a single season, this including, of course, all the fittings and canoes, etc. Add to the cost of a "permit" the traveling and camping expenses, and the price of good salmon tackle, which is always of the most expensive sort, and you swell the sum-total of a summer trip to quite an amount. 
While the Canadians are so tenacious of their leases, and naturally desirous of keeping the best streams for themselves, yet they are most generous and kind to their "States" friends. Often, one is not only accorded a permit to fish, but receives an invitation to make, for the time being, all the accessories and fittings of the stream his own, including houses, canoes, and cooking-utensils. My invitation, some years agro.

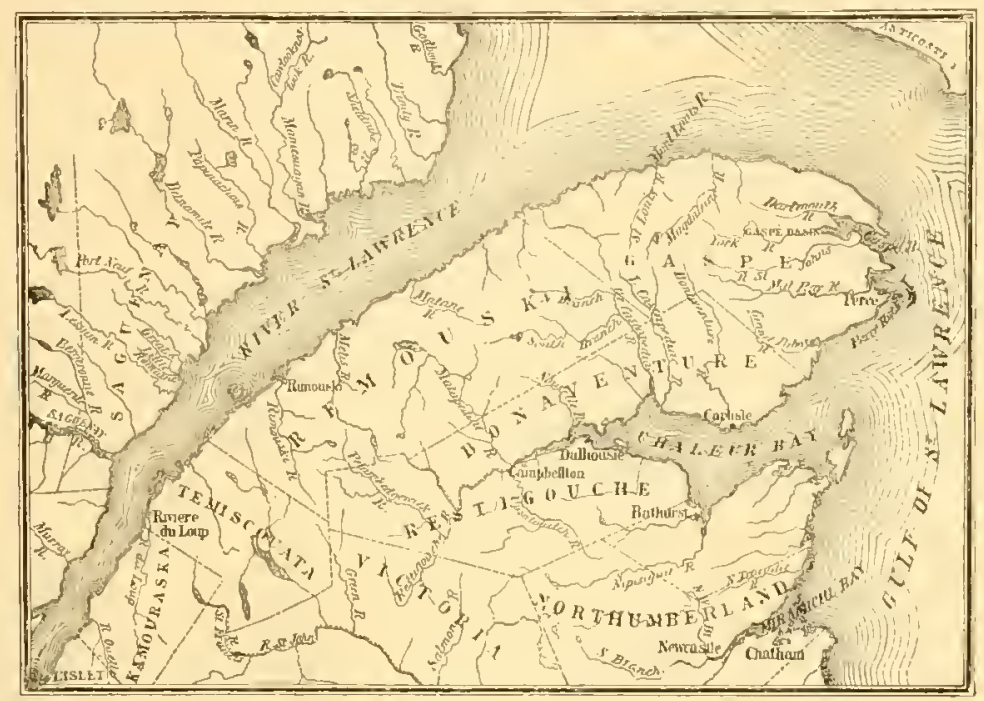

CANADIAN SAIMION RIVERS AND GASPÉ BASIN.

from that genial sportsman, Mr. Reynolds, of Ottawa, was to make the York river my own, paying simply for my men and provisions. His guests kill every year many salmon to his one, and he enjoys their success far better than his own. An Indian would wish him, in the happy hunting-grounds, the exclusive right of the best stream. We can only express our heartfelt wish that for a score of years to come he may continue yearly to take his 47 -pound salmon in his favorite stream.

To the cost of stream and tackle must be added the great uncer. tainty of getting fish. One may secure the best stream, purchase the best tackle, and travel a thousand miles to no purpose, for Salmo salar is a very uncertain fish, and the worst sort of a conundrum. Sometimes he comes early and sometimes late: sometimes he goes leisurely up the rivers, lingering accommodatingly at the pools, and seemingly in good mood for sporting with flies; and sometimes, when kept back by the ice of a late spring, he goes for the headwaters at once, only stoppingr when compelled by fatigue, and then $26 \mathrm{~A}$ 
having no time to waste upon flies. Last year, with scores of salmon, by actual count, in the different pools. often not more than one in a pool could be tempted to rise to our flies. All these combined causes make the number of salmon-anglers small.

A stream being secured, the selection of tackle is an easy matter. A water-proofed American-made silk line of about three hundred feet, tapering gradually at each end, so that it may, when worn, be changed end for end, is the one generally used in this country. A simple reel with click is the best, and it may be of hard rubber or metal, as preferred. If of metal, it is usually nickel or silver plated. In olden times, the Scotch salmon-angler strapped around his waist a roughly made wooden reel of large size, called a pirn. It was entirely unconnected with the rod, along which the line was carried by rings, beginning quite a distance above the hand. In the old Scotch works upon angling, we read of the gaffer singing out to his laird, "Pirn in! pirn in! you'll be drooned and coot" (drowned and cut), by which he meant, "Reel in, or your line will bag and be cut off by getting around the sharp edges of the rocks."

The Scotch poaching angler suspends by straps under his outer garments a capacious bag of coarse linen for concealing his salmon, while quite innocently he carries in his hand a string of trout. Lord Scrope once caught a poacher with a salmon in his bag, and demanded how it got there. The reply was, "How the beast got there I dinna ken. He must ha' louped intil ma pocket as I war wading."

The leader, of nine to twelve feet nearest the hook, is of the best

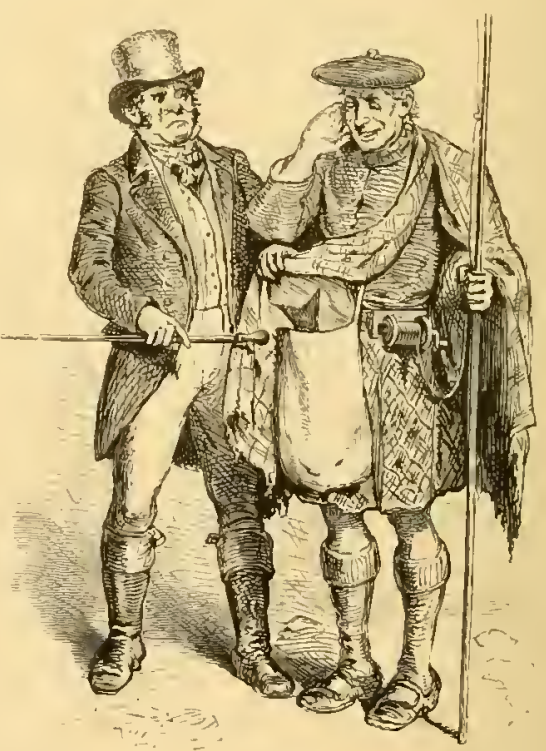
selected silk-worm gut, which should stand a test of four or five pounds strain. This gut is made by taking the silk-worm just before it begins to spin its cocoon, and soaking it in vinegar some hours. The secreting glands of the worm are at that time filled with the mass of glutinous matter from which the silk of the cocoon is to 
be spun. One end of the worm, after it is thus soaked, is pinned to a board, and the other stretched out some eight or ten inches and secured. When this is hardened, it becomes the beautiful white, round gut of commerce, which, when stained water-color, and dropped lightly in the pool, will not be noticed by the fish.

In the matter of rods, the conserrative man still clings to a wellmade wooden one of greenheart or other approved wood, of which the taper and strength are so accurately proportioned that the addition of but a few ounces at the end of the line carries the main bend or arch nearer the butt end. Those who are not so conservative, and who are fond of lessening in every practicable way the somewhat tedious labor of casting the fly, choose a rod of split bamboo, which weighs about two pounds. My own weighs but twenty-seven ounces, although nearly sixteen feet long. No one will risk himself upon a stream without extra rod, reels, and lines, and if he takes a greenheart and split bamboo, he has two as good rods as are made. One who has long used a heavy wooden rod has at first a feeling of insecurity and a distrust of the slender bamboo, which can, if necessary, be wielded by a single strong arm. It is said an old Scotchman, handling one of these rods for the first time, exclaimed: "Do ye ca' that a tule to kie a samont wi? I wad na gie it to my bairnies to kie a gilsie wi." It should be explained that a grilse is a young salmon just returned from a first trip to the sea. After its second trip, it returns a salmon proper, with all the characteristic markings. It often happens that a grilse (called by the Scotch " gilsie," or salmon-peel) is larger than a salmon one or two years older, the varieties differ so in size. The young of the salmon are first called parrs, and have peculiar spots and dark bars, or "finger-marks," as they are called. At eighteen months, they are some six inches long. and the following spring silver scales grow over the bars and spots, when they are called smolt, retaining that name until they go to sea. For a long time the parr was held to be a species of trout, and entirely distinct from salmon. Lord Scrope, the author of "Days and Nights of Salmon-Fishing," a work now extremely rare, held long and animated discussions with James Hogg, the "Ettrick-Shepherd," upon this subject, which was settled practically by a Mr. Shaw, of Drumlanrig, who tagged a parr and identified it again as a full grown salmon in 1836 . 


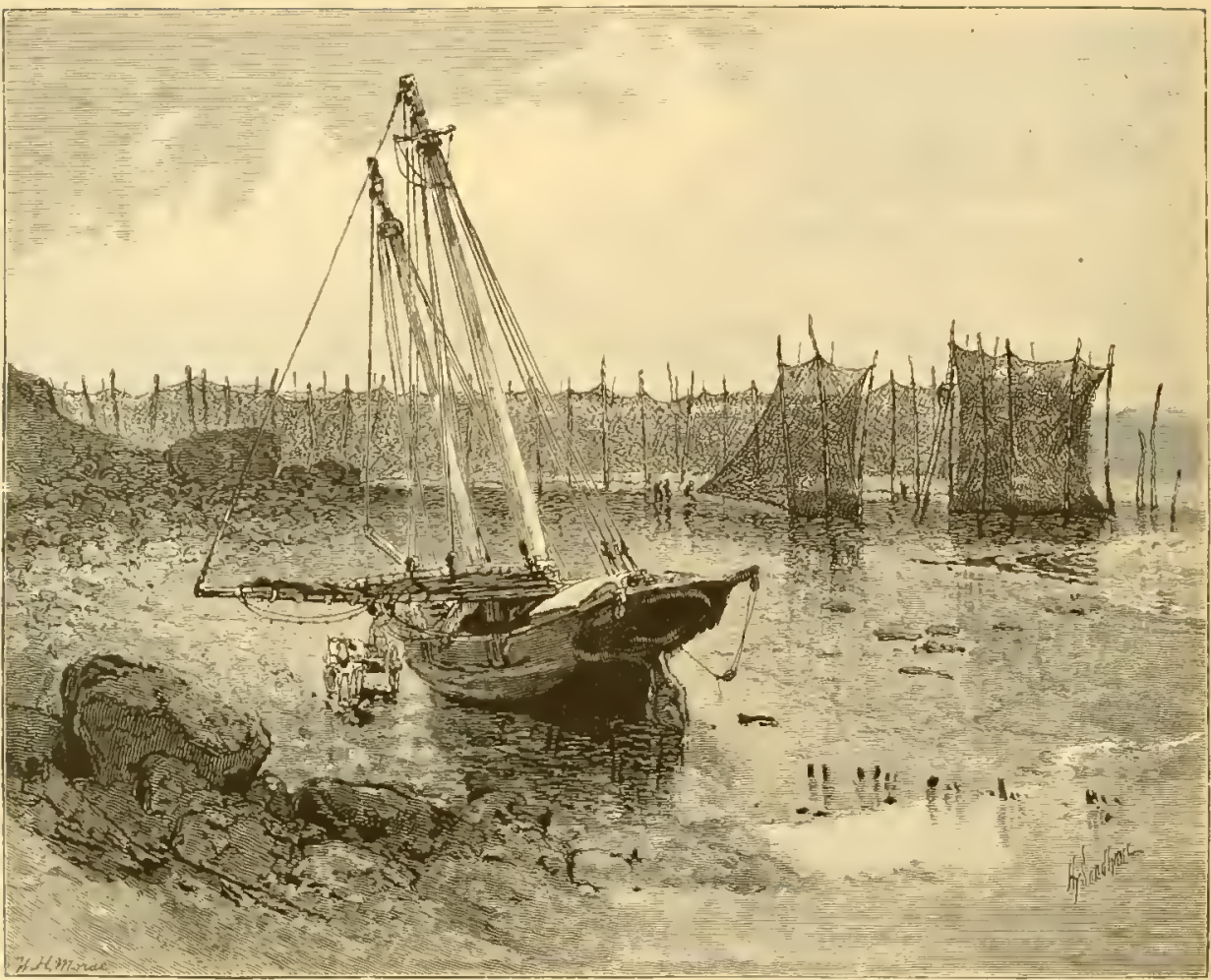

IN THE HAKBOR OF ST, JOHN

The manufacture of a fine rod of split bamboo is a work requiring great skill and judgment, not unlike that required to make the far-famed Cremona violin. The rods are made usually from Calcutta bamboo, as it has a larger proportion of enamel with tough fiber and long growth between joints. In the Japanese bamboo, the fibers follow the joints too closely, and so must be cut into in straightening the pieces. Our American cane is lighter, and the enamel is very hard and elastic, but the inner woody fiber is soft as well as brittle. Sometimes several invoices of Calcutta cane will not contain one suitable piece for rod-making. The canes mildew on the passage, and this injures the fibers. Sometimes they are injured in being straightened over a fire, and often a single worm-hole ruins the entire piece. Just as our forest trees have the thickest and roughest bark on the north side, so the bamboo has thicker and harder enamel upon whichever side was exposed to storms. In making fine rods not only the best cane is selected, but the best side of this selected cane is preferred. 
The split bamboo rod is an instance in which nature is successfully improved. The cane in its natural growth has great strength as a hollow cylincler, but it lacks the required elasticity. The outer surface or enamel is the hardest of vegetable growth, and is made up largely of silica. The rod-maker, by using all of the enamel possible, and by his peculiar construction avoiding the central open space, secures great strength with lightness, and nearly the elasticity of steel itself.

In making a rod, some ten or twelve feet of the butt of the cane is sawed off and split into thin pieces or strands. These pieces are then beveled on each side, so that when fitted together they form a solid rod of about half the diameter or less of the original hollow cane. This beveling is done with a saw, or a plane if preferred, but more expeditiously by having two rotary saws or cutters set at an angle of $60^{\circ}$ to each other, in case the rod is to be of six strands. The strip is fed to the cutters by means of a pattern which, as the small end of the strip approaches, raises it into the apex of the angle formed by the cutters. This preserves a uniform bevel, and still narrows each strand toward its tip end so as to produce the regular decrease in size of the rod as it approaches the extreme end. These strips can also, if desired, be filed to a bevel by placing them in triangular grooves of varying depths in a block of lignum-ritx. The pieces are then filed down to the level of the block, which is held in a vise during the operation.

The six or twelve strips as required, being worked out, and each part carefully tested throughout its entire length by a gauge, are ready for grluing together, a process requiring great care and skill. The parts should be so selected and joined that the knots of the cane "break joints." The parts being tied together in position at two or three points, the ends are opened out and hot glue well rubbed in among the pieces for a short distance with a stiff brush. A stout cord is then wound around the strands from the end glued toward the other portions, which are opened and grlued in turn, say eight or ten inches at a time. A short length only is glued at one time so that slight crooks in the pieces can be straightened, and this is done by bending the rod and sliding the pieces past each other. During the gluing all inequalities and want of symmetry must be corrected or not at all, and so the calipers are constantly applied to every side 


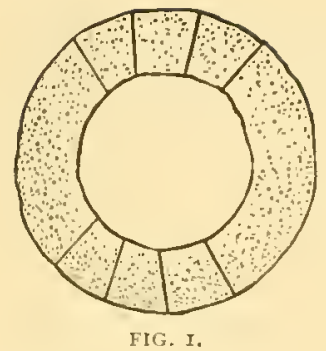

at short intervals, and any excess of thickness corrected by pressing the parts together in a vise. Figure 1 shows a section of a length of bamboo cane from which the strips indicated by spaces marked off are to be sawed. Figure 2 is an end view of the six strands properly beveled and glued together. This length or joint of the rod is made up of six sectors of a circle whose diameter is greater than that of the rod, and hence it is necessarily what in common parlance might be called six-cornered. Figure 3 is an end view, natural size, of a six-stranded salmon-rod tip at its larger end; and Figure + is a longitudinal view of a piece of a Leonard trout-rod tip of trelec strands now gives the size as accurately mine it, and shows what vast and untiring industry is been describing.

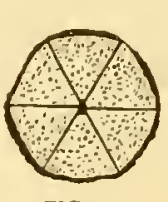
lying before me. This figure as the calipers can deteramount of skill, patience, required in the art we have

The ferrules are water-tight and expose no wood in either the socket or the tenon part. Bamboo is so filled with capillary tubes that water would be carried through the lengths and unglue them, if it could once reach the ends where the joints of the rod are coupled together; hence the necessity of careful ${ }^{\text {rig. } 3 .}$ protection at this place. The entire rod when finished is covered FIG. 4. with the best copal coach varnish. By taking care to renew the varnish from time to time, no water need ever get to the seams.

In spite of the prejudice against what has been called a gentleman's parlor rod, they have steadily gained in favor. Twentyfive years ago, a London firm made split-bamboo rods, putting the enamel inside.* Naturally enough, with the soft part of the cane exposed to wear and weather, and nearly all the enamel sacrificed, they did not find favor in the eyes of thoughtful or scientific anglers, at least. Mr. Phillippi, living at Easton, Pa., conceived the idea, in I866, of putting the enamel upon the outside, where it would do tho most good. Next, Mr. Green and Mr. Murphy put their heads together, and made rods of this sort of four strands,

* See "The Split Bamboo Rod-Its History, etc.," by Mr. William Mitchell, in this book. 
and finally the old well-known firm of A. Clerk \& Co., New York, introduced into the market the Leonard rod of six and twelve strands, and have

since been supplying Europeans with all they get of this article.*

I have taken not a little pains to get, as far as possible, a correct history of this somewhat remarkable inven tion. My own rod of this kind has been used in both rain and shine for several seasons, and is now in pertests, I have never

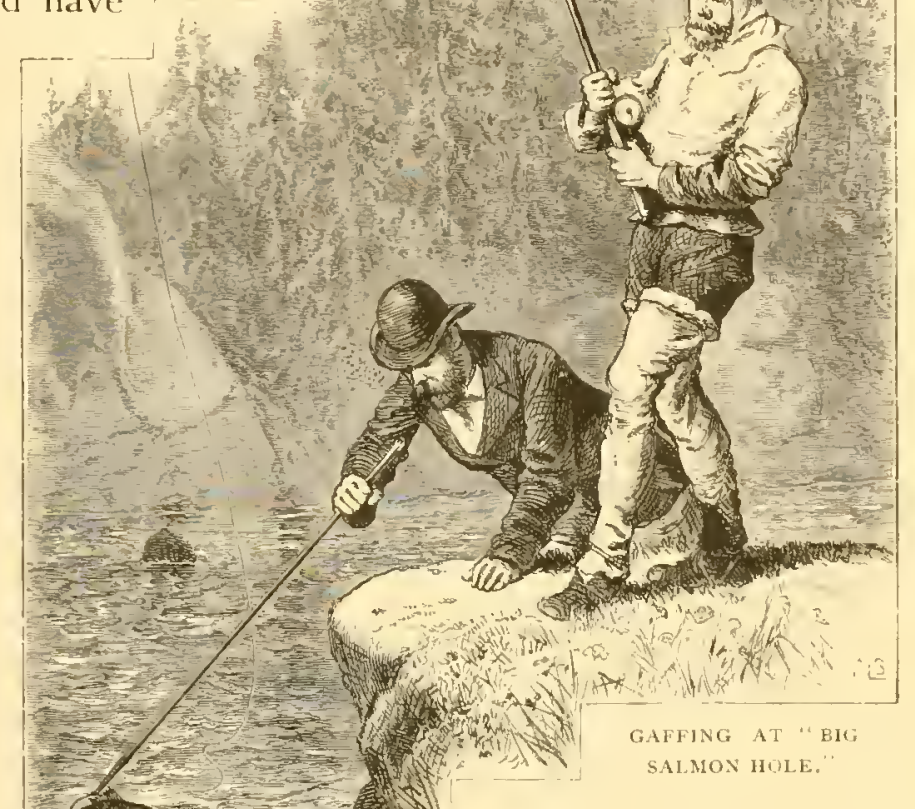

fect order. In careful yet seen a rod of its weight, or of its length and any weight, that could throw a fly quite as far; and, light as it is, it brought last year to gaff in twenty minutes a thirty-five pound fish, which my friend Curtis gaffed for me, off the high rock at the "Big Salmon Hole" of the York. Any rod with which one has killed many" and large fish is, naturally, held to be perfection upon the stream: but the rod we have been describing is beautiful as an objet de icrtu, and in the library becomes a source of joy to every admirer of skilled workmanship, though he be not familiar with its use.

This illustration shows the angler who has kept just strain

* [I have seen a split bamboo rod made. according to the suggestions of that distinguished angler, the late James Stevens, of Hoboken, by Blacker, of London. This rod is of three sections, with the enamel on the outside, and was made in 1852 while Mr. Stevens was in London. This date has been accurately determined for me by his son, Mr. Frank Stevens.-EIITor.] 
enough on the rod to prevent the hook from dropping out of the moutli of the fish, - which measured forty-eight inches in length, - while his friend, after having shillfully hooked him with a prodigiously long gaff, is drawing him forward so as to use both hands in lifting him upon the rock. Is some of our skillful surgeons perform even the delicate operation for a cataract equally well with either hand, so must the successful salmon-angler become ambidextrous. In casting he nust be able, of course, to use either hand forward at will, and when one arm has become lamed by holding the rod, as it rests against the waist in playing a fish, and takes nearly all the strain while the other manipulates the reel, he must be able to change the position of the reel upon the rod, and work it with his left hand while his right manages the rod. This.left-handed arrangement is shown in the figure with the reel on top in its proper position, and the right hand taking all the strain.

The scientific angler, as soon as the fish is hooked, turns his rod over and brings his line uppermost, so that it hugs and strains the rod equally at every inch of its length, leaving to the rings their proper function of simply guiding the line.

Having, through Mr. Curtis's kindness, received an invitation from Mr. Reynolds, as already mentioned, to fish his river, the York, accompanied by any friend whom I might select, I provided myself with a Norris greenheart and a Leonard bamboo in the way of rods, and with an assortment of proper flies.

It is, however, in the selection of friends to accompany us that we find the greatest difficulty connected with a projected excursion for salmon. One may have plenty of friends who would make camp-life delightful, and whose presence at the festive board "would make a feast of a red herring"; but they cannot be ordered for a trip, like tackle. Your choice must, as a matter of course, be very much restricted. You will never trust yourself in camp with your best friend unless you have seen him under fire; that is to say, unless you know how he will stand the thousand and one annoyances incident to long journeys with poor conveyances and still poorer hotels; with black flies, sand-flies, mosquitoes, fleas, and worse. The best companion of the library, the drawing-room, and the watering-place, although possessed of the most kindly attributes, oftentimes becomes absolutely unendurable when quartered for a day or two on the banks of a Can- 


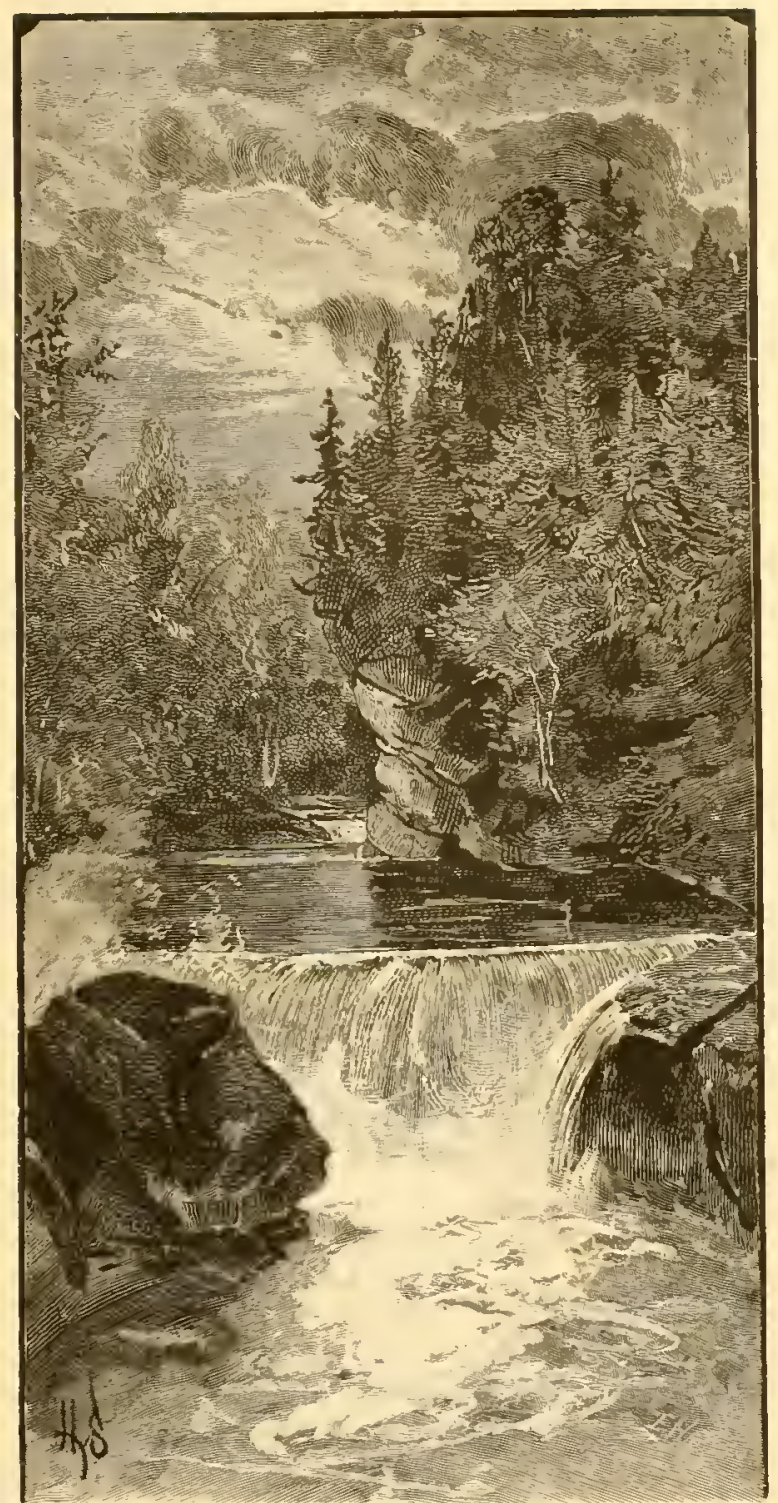

A CANADIAN FISHING RIVER.

adian river, with limited cuisine, unlimited numbers of insects, and poor luck at angling. Never go with one who is painfully precise, and who wishes to have everything his own way and at once. Such a man might as well stay away from Gaspé, where the natives always have their own way, and never, under any circumstances, hurry. Never go with one who is over-excitable or enthusiastic, for it isn't 
just the thing to have a man standing on his head in a birch-bark canoe every time he grets " a rise," or the canoe takes a little water running down rapids. The experienced angler chooses a friend who is deliberate, and takes all ills philosophically, and, if possible, one with that fortunate disposition which permits him to keep both his head and his temper under all circumstances. Other things being equal, he selects an admirer and follower of Brillat-. Savarin, for he has ever remarked that one who fully enjoys and appreciates the best of dinners is just the one to endure with equanimity the worst, if no better is attainable.

To be eighteen miles from the main camp when fish are rising as fast as they can be killed, and to have but three pieces of pilot-bread for the angler and his two men, and to be forced to go without supper and breakfast, or else give up the sport and return, will bring the bad out of any man if it is in him.

Your companionable angler need not always take things quite as coolly as did a well-known editor who, once upon a time, while engaged in pulling in a blue-fish, after sawing his fingers with a hundred or more feet of line, was seized with hunger and fatigue, and, taking a hitch about a cleat, satisfied his inner man with sardines and crackers. To the surprise of all his companions, after finishing his lunch and resting his fingers, he pulled in the fish, which had swallowed the hook so far down that it had to be cut out. Of course, the first few feet of the line which he used was wired so that it could not be bitten off.

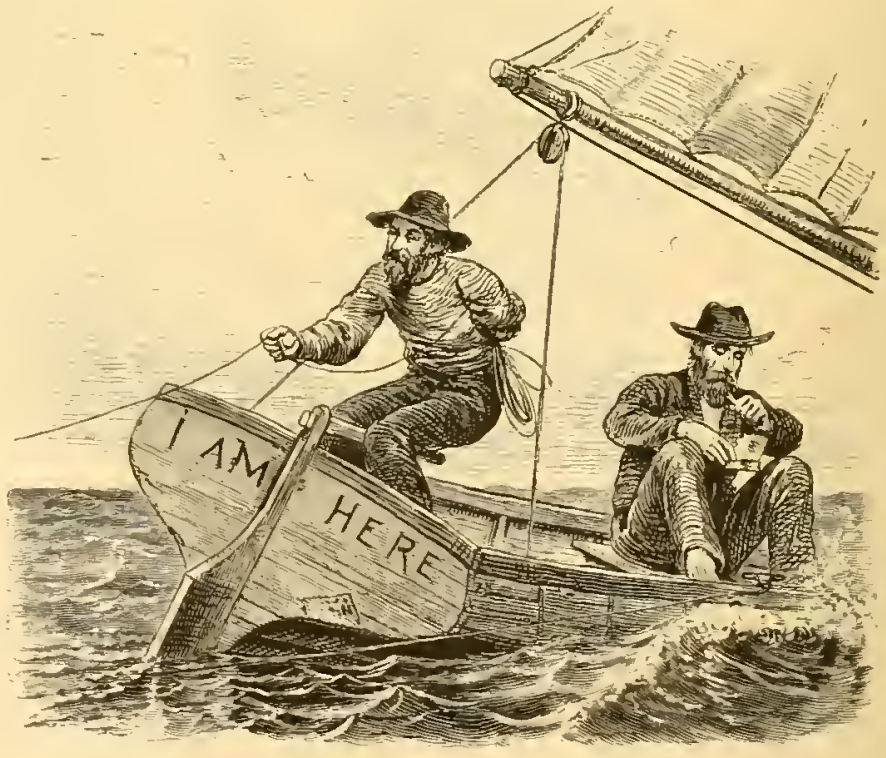

THE PHILOSOPHICAL ANGLER. 


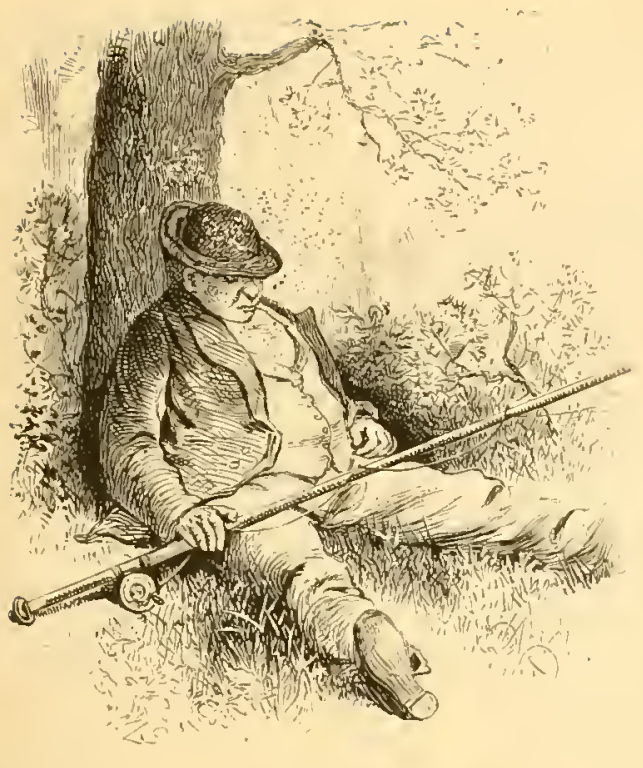

OUR ENGLISH FRIEND.

Here is a sketch from life of a jolly English gentleman, who gets thoroughly disgusted every time he loses a fish. He then, without saying a word, quits the business, puts his back against a smooth tree, and takes a short nap, leaving others to thrash the pools. It is worthy of note that one need never fear meeting snobs, swells, or disagreeable people fishing for salmon. The air of a first-class stream seems fatal to all such.

The last of June, 1874, found Mr. Lazell and the writer tired out with close attention to duties, and with barely frame-work enough left "to veneer a decent man upon," rendezrousing at the office of Fred. Curtis, Esq., in Boston, preparatory to setting out for Gaspé Basin, Canada East. An idler cannot appreciate fully the enjoyment we felt in anticipation of several weeks entire freedom from business of any sort. To gret so far from civilization that no irascible inventor can find you and argue his case until your head seems ready to burst; no client can bore you for hours without giving a single important fact in his case; and where you will hear of no impecunious creditor's paper going to protest, - is worth a large amount of preliminary toil.

After having, as Lazell asserted, taken an outfit sufficient for a whaling voyage, we devoted still a day to getting little odds and ends which Curtis's experience had taught him to provide - things which seemed superfluous, and in fact almost absurd, and yet worth their weight in gold when one is thirty miles from a settlement. Lazell finally, getting a little out of patience, sarcastically insisted upon our taking a crutch, in case any one should lose a leg. Six weeks later, when my unfortunate friend, after cooling off too suddenly from a twelve-mile walk on a hot day, found himself unable to use one leg, and hence was deprived of his turn at the distant best pool, we turned back the laugh by suggesting the crutch which we had 


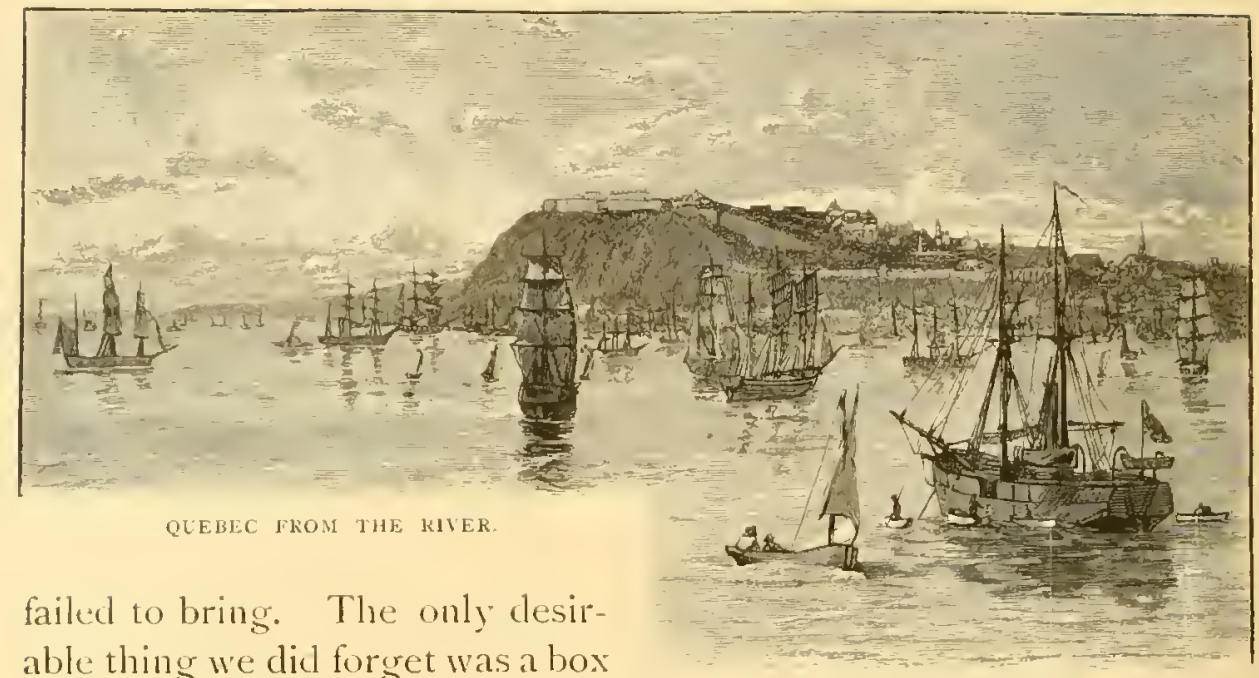
of Bermuda onions. These could not be procured in Canada, and were ordered thither from Boston by telegraph. They only reached us ten days after our arrival upon the stream; and if a tippler longs for his drams as we did for the onions, after a diet of fish and salt meats, we pity him.

To one about to make a trip to Canada East, we would say: Start in all cases from New York, even though you live in Boston. Take express trains direct from New York to Montreal without change, and then the Grand Trunk Railway or night steamer to Quebec. We started twice from Boston, going once by Portland and the Grand Trunk, and once by the Passumpsic Railroad. One can on these routes endure waiting from six or seven P. x. until ten '. M., and then, after two hours' additional travel, waiting from midnight until three $\mathrm{A}$. mond, or Island Pond; and at Richmond being crammed in a small room packed with French-Canadian laborers who never heard of a bath-I say one $c a n$, but he doesn't wish a second experience of the same sort. The Frenchman's remark, that all roads are good which lead to victory, didn't console us when we arrived in Quebec on time.

A day in the quiet, quaint old city of Quebec is not without pleasure and profit. One goes away feeling that, after all, heavy taxes with progress and improvement are not such objectionable things. The quiet of Quebec is broken but once each day - upon the departure of the steamer for Montreal. 
In Quebec, salmon-anglers gret their supplies usually from Waters of John street, Upper City, who from long experience needs only to be told the size of your party, the time of your stay, and approximately, the limit as to expense. When you go aboard your steamer, everything will be found there admirably packed, with not an article wanting, - not even extra corks

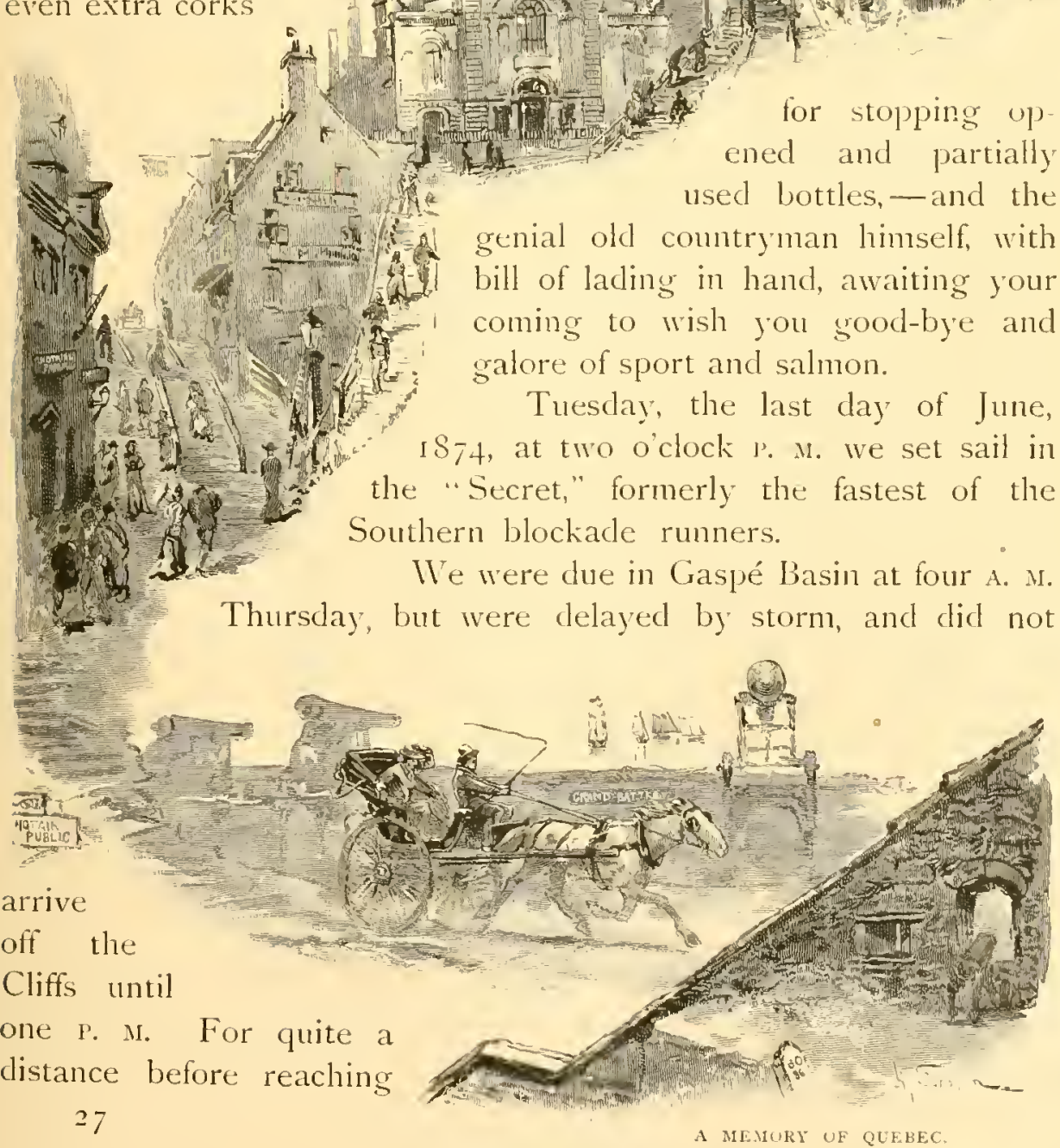


Gaspé Head, which is at the immediate entrance of the Bay, we sailed past long lines of small boats anchored at intervals of a few hundred feet. Into these boats we could see with a glass the cod-fish pulled at rapid rates.

The last few miles of sea-coast is a rugged, nearly perpendicular cliff, in some places over eight hundred feet in height, and resembling somewhat the Dover Cliffs, but more remarkable in appearance. As we turned Gaspé Head, the sun shone out warm and bright, the water became more quiet, and our lady passengers were able to get on deck, and to enjoy themselves for the first time since leaving Quebec.

So well had our kind friend Reynolds arranged matters, that all our men, with horses for taking us with our luggage up the stream, were awaiting us at the wharf.

We delayed a little to receive the honest welcomes of a score or more of the inhabitants, who, having learned that friends of Mr. Curtis had arrived, lost no time in paying their respects. Our friend Curtis has a way of going around the world, dispensing favors right and left, and but few prominent persons in Gaspé had not at some time received the much coveted permit for a day's fishing, accompanied with flies and leaders, or something else equally desired. IVe were now to reap the reward of his thoughtfulness about little matters.

One can be made uncomfortable by a thousand little annoyances, and he will be, if in any way he gets the ill-will of the people near his stream. If he acquires a reputation for bargaining and paying smáll prices for services rendered, he had better at once give up his stream and seek another as far from it as possible. Accompanied with the honest hand-shake of some of the hardy fishermen was their assurance that they should as usual expect all our worn-out flies and frayed leaders upon our return from the river, and also any spare fish we thought not worth sending home. Their universal "so long" in place of good-bye amused us not a little, but why they use it or whence it is derived we could not conjecture.

Half a mile from the landing we stopped upon high ground near the residence of Mr. Holt (then our efficient Consul at Gaspé), to enjoy our surroundings.

At our feet was the Bay, by common consent scarcely less beautiful than the Bay of Naples, which it resembles when seen from a 


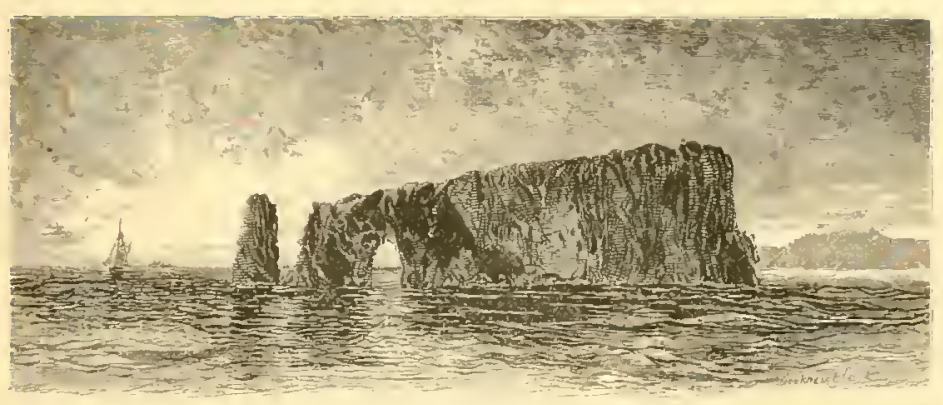

PERCE ROCK, SOUTH OF GASPE BASIN

certain point. In the hazy distance was the indistinct line of the Gaspé Cliffs, and our steamer rapidly making her way to the Gulf. The sun lighted up most beautifully the intense green of the forests, which were broken here and there by neat white cottages and their surrounding patches of still brighter green. Although the very last of $j$ une, the foliage was not yet burned by the summer's sun, and the grass was but just greening.

Six miles from the settlement the road became a mere path, and we took to our saddles, which the thoughtful George had stowed in our two-horse wagon. Two miles farther and we were at the first pool of the river called the High Bank Pool. We determined at once to try it and throw our virgin fly for salmon. Setting up our rods, we scrambled down the steep gravel bank with the enthusiasm of school-boys. lnsects of various sorts were there long before us, and soon we were compelled to send Coffin up the bank for our veils. The veils used are of the thinnest silk barége, in form of a bolster-case open at both ends, which are gathered upon rubber cords. One cord goes around the hat-crown and the other around the neck under the collar. These veils perfectly protect the face from insects, but do not allow smoking, and interfere slightly with the vision; 1 therefore discarded them, and now use a brown linen hood with cape buttoning under the chin. The pests were so persistent that we were glad to put on linen mitts, which tie around the elbow and leave only the finger-tips exposed. Finally, the little brutes drove us to anointing our finger-tips with tar and sweet-oil, a bottle of which usually hangs by a cord from a button of the angler's coat. A philosophical friend once insisted that it only required the exercise of strong will to endure the pests, and that protection was 
effeminate. The second day, he looked much the worse for wear, his handsome face disfigured with swellings, and his eyes almost closed from the poison of the bites.

We now worked away in comparative comfort until I saw Lazell, who was a few hundred feet distant, sucldenly dash off his hat and commence slapping his head with both hands as if determined to beat out his brains. I con-

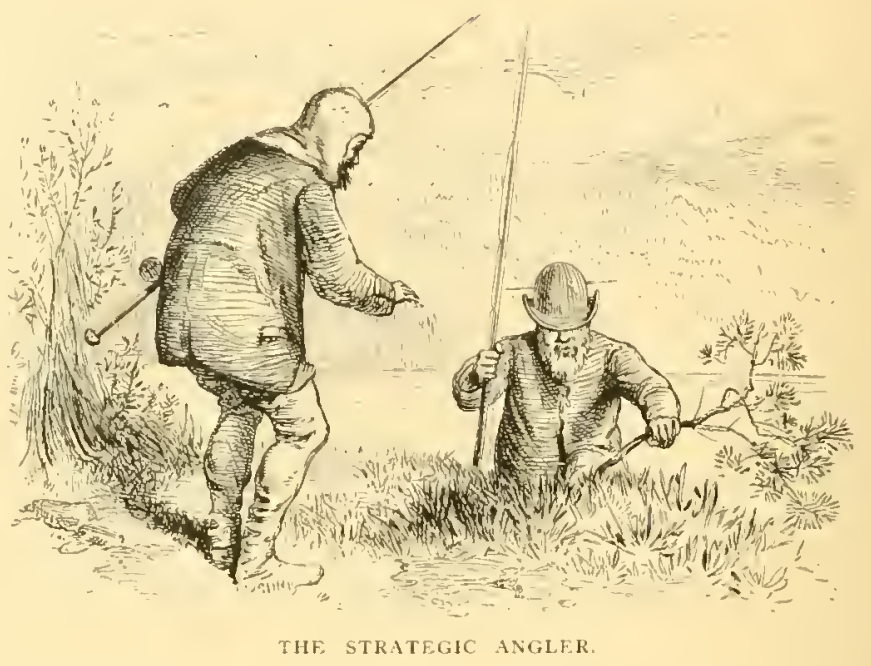
cluded that he must have had a rise, and that, contrary to his custom, he had become excited. Going to him, I found that the black flies, baffled at all other points, had found the ventilating eyelet-hole upon each side of his hat-crown, and had poured in through them in hordes upon the top of his unprotected head. Getting no rise, I climbed up the bank to await my more persevering friend. (It may be noted, in passing, that we learned a few days later that we had not cast within several hundred feet of that part of this pool where salmon usually lie.) Soon my friend's head appeared over the bank with apparently a good stout stick thrust completely through it, hat and all, as if some stray Micmac had shot him with a roughly made arrow. The solution of this was that Lazell had plugged up the holes in his hat with a broken rod, and thus cut off the flies from their favorite foraging grounds.

It is a fact not generally known that the farther north you go, the larger and more venomous are the mosquitoes. According to the late lamented Captain Hall, of Arctic fame, one knows little of the annoyance of these insects who has not been in Greenland during the summer months. After a summer upon the Gaspé streams, a person of even large inquisitiveness doesn't long for any more information upon that branch of natural history. They are so trouble- 
some there that, to fish comfortably, it is necessary to protect the face and neck, and cover the finger-tips with a mixture of tar, sweet-oil, and pennyroyal. Gaspé insects seem fond of newcomers, and our blood afforded them a favorite tipple. Seriously, however, we were not much inconvenienced, as we took every known precaution against them, and not only had our rooms thoroughly smoked with smudges, but kept large smoldering fires around the houses the greater part of the time. When ladies fish, a smudge is kept burning upon a flat stone in the canoe.

We reached our comfortable quarters at House No. 1 at nine P. M. while it was still light. We found that our house was clapboarded, and contained two comfortable rooms; one with berths like a steamer's, which were furnished with hair mattresses and mosquito-bars; the other served as sitting and dining room. A large log house adjoined and was furnished with a good cookingstove, while a tent was already pitched to serve as quarters for our men-five in number. Stoves and furniture are permanent fixtures of the houses at the different stations, as are the heavier cookingutensils, so that in moving up the stream one has merely to carry crockery, provisions, blankets, and mosquito-bars, - which latter are of strong thin jute canvas. Above the first house, the men make your beds of piles of little twigs of the fragrant fir-balsam, whose beauties have been recorded by every writer upon angling. Near each house is a snow-house, dug into the hill-side and thickly covered with firboughs and planks. The snow is packed in them in winter by the men who go up for that purpose and to hunt the caribou that frequent the hills adjoining the river. The snow lasts through the season, and is more convenient than ice. If one drinks champagne, he has but to open a basket upon his arrival and imbed the bottles in the snow, and he has at any moment a frappé equal to Delmonico's best. The fish as soon as killed are packed in the snow, as are the butter, milk, and eggs when brought up every two or three days by the courier, who remains at the Basin ready to start for you at any moment that letters or telegrams arrive. Our courier delighted in surprises for us such as baskets of native strawberries and cream for our dessert. Ten 
cents at Gaspé buys quite a large basket of this exquisitely flavored wild berry.

I have been thus minute in describing our surroundings, because I believe more comfortable and complete arrangements are found on no other stream. It is all very well to camp out under an open "lean-to" or tent, and exceedingly healthful and enjoyable, but we rather enjoyed this comfortable way of living. Standing for six hours or more daily, while throwing a fly or killing a fish, is hard work for one of sedentary habits, and gives enough exercise and oxygen to make one wish for good living and quarters; and with this open-air life one may indulge his appetite with impunity if he can get the food, for his digestion and assimilation are at their best.

The difference between the temperature at midday and midnight in the mountainous regions along the Gaspé salnon-streams is notable. One day last season, the air at nine A. M. was $74^{\circ}$, at two P. M. $84^{\circ}$, and at half-past seven P. M. $51^{\circ}$. We were anxious to get approxinately the temperature of the water of these northern streams to compare with the water of streams farther south, which had been stocked with young salmon by Professor Baird, United States Fish Commissioner, and so made the best observations possible with a couple of ordinary thermometers. At the botton of one pool in the York, near the mouth of the Mississippi. Creek, which is a roaring little branch of the York coming down from the snow of the neighboring mountains, the water at midday was but $401 / 2 \circ$ Fahrenheit, while the air was $78^{\circ}$. In other pools on this river we found the temperature at noon to be $44^{\circ}$ at the bottom and $44^{1 / 2}{ }^{\circ}$ at the surface, with the air at $60^{\circ}$. This was well up among the mountains, thirty-five miles above the mouth of the river. Lower down the stream, $48^{\circ}$ bottom, $4 S 1 / 2^{\circ}$ surface; and sometimes after a very warm day, $471^{\circ}$ to $481 / 2^{\circ}$ at eight o'clock P. 11 . Ten or fifteen miles distant, upon the Dartmouth, which flows through a less mountainous country and has longer and more quiet pools and less shaded banks, we found the pools varying from $55^{\circ}$ to $59^{\circ}$ when the air was $60^{\circ}$ to $70^{\circ}$.

Upon the first morning of our arrival, we did not get up at three A. M., when the day was just dawning, and order up our men to get breakfast. We had been in northern latitudes before, and took the precaution to hang our rubber overcoats over the windows to darken 


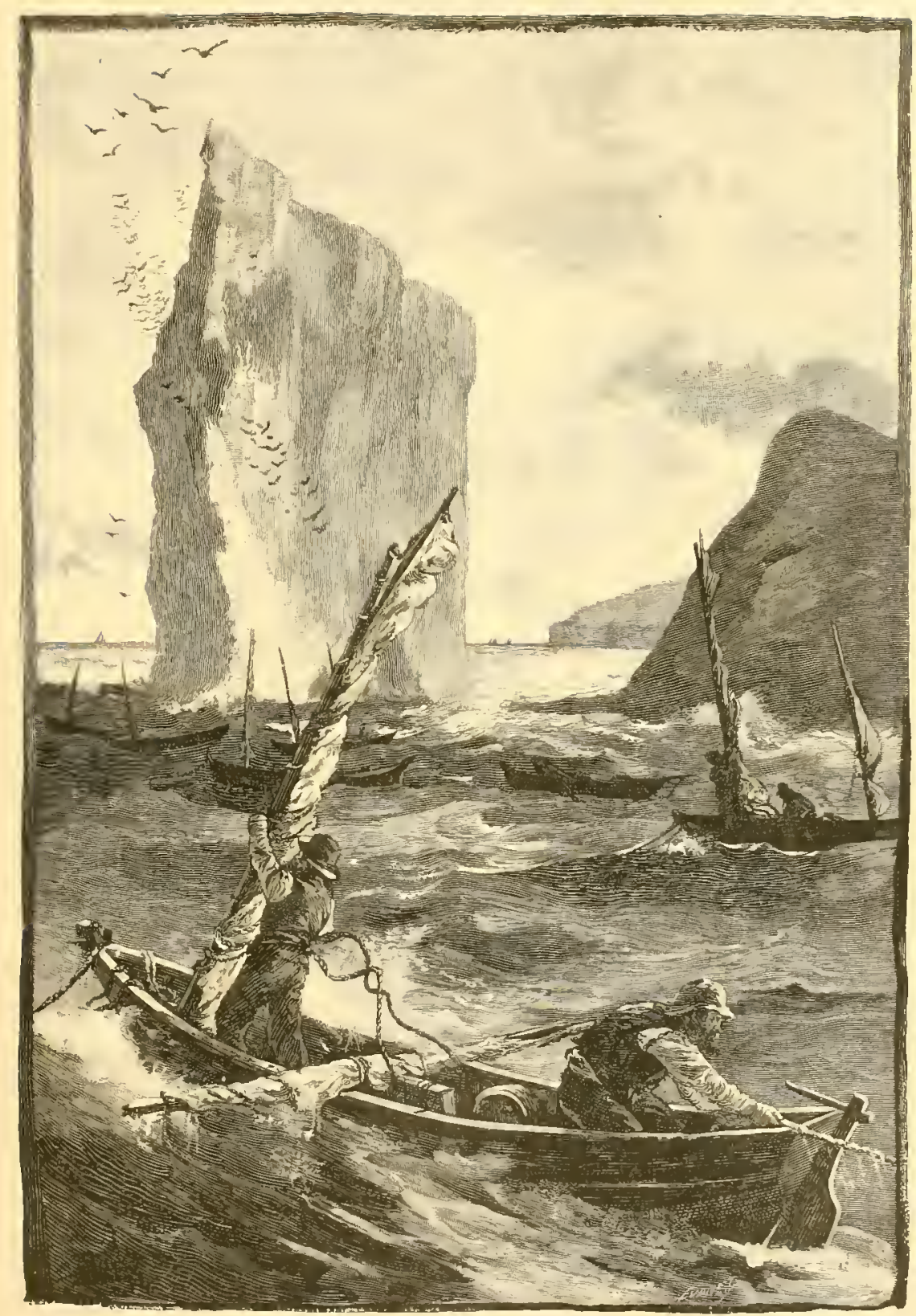

PERCÉ ROCK. 

them, thus keeping out the early morning light and securing a long night's sleep. Our first day opened with a drizzling rain which forbade fishing. After coming a thousand miles, and with but six days' "permit" upon our stream, a rainy day seemed like a misfortune. About ten o'clock, the sun came out, and I

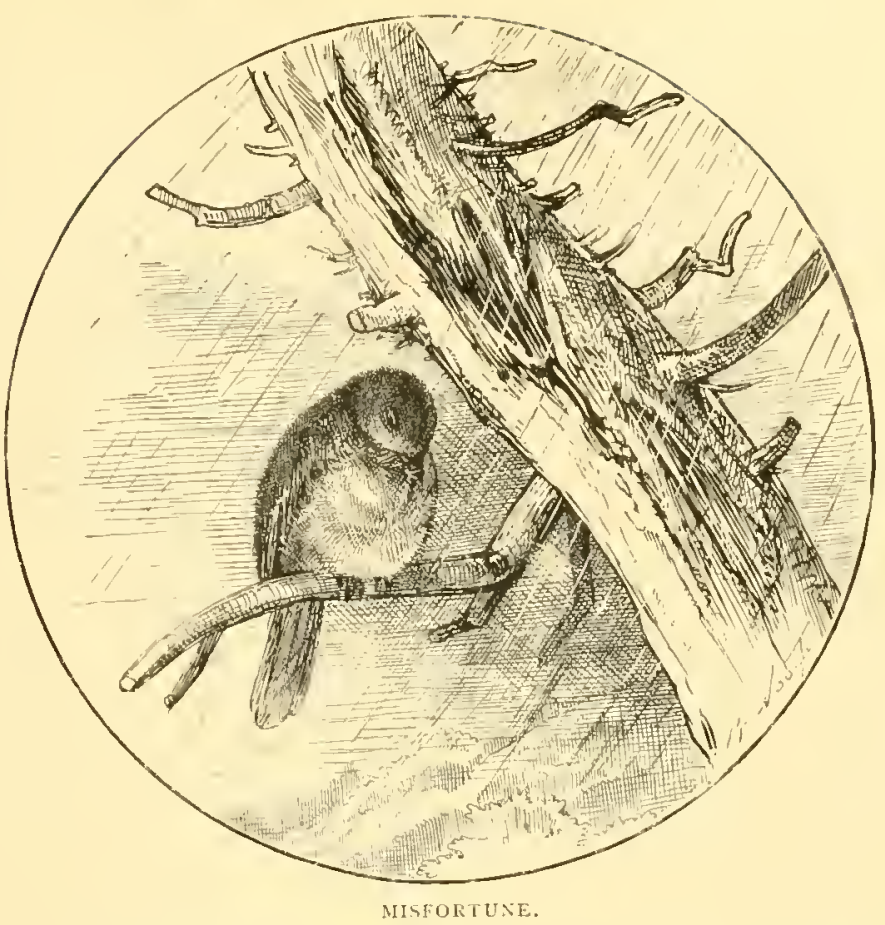
went to the pool directly in front of the house, to practice casting with both hands as well as get used to standing in a cranky canoe. Soon a fish rose and hooked himself, only making it known by spinning off a few feet of line as he dropped back to position at bottom of pool. A fish will thus hook himself nine times in ten if the fly comes slowly over him with a taut or at least straight line behind it. Nore fish are lost by too quick striking them than by other bad management. The steel-like tip of the rod upon the slighest pull at the fly springs forcibly back and fixes the hook at once. I had resolutely determined never to strike, and have never done so. I may have lost a fish by it, but am sure more would have been lost by striking. Of course, a strong, quick pull is given after the fish is hooked and has started the reel, in order to imbed the hook more firmly. Soon my reel was furiously whirling. I had read about the "music of the reel" and all that sort of thing ad nauscum, as I had often expressed it: but somehow, after hearing a salmon in his first fierce run upon a reel with a stiff click, the wonder was that people had not written more about it. 


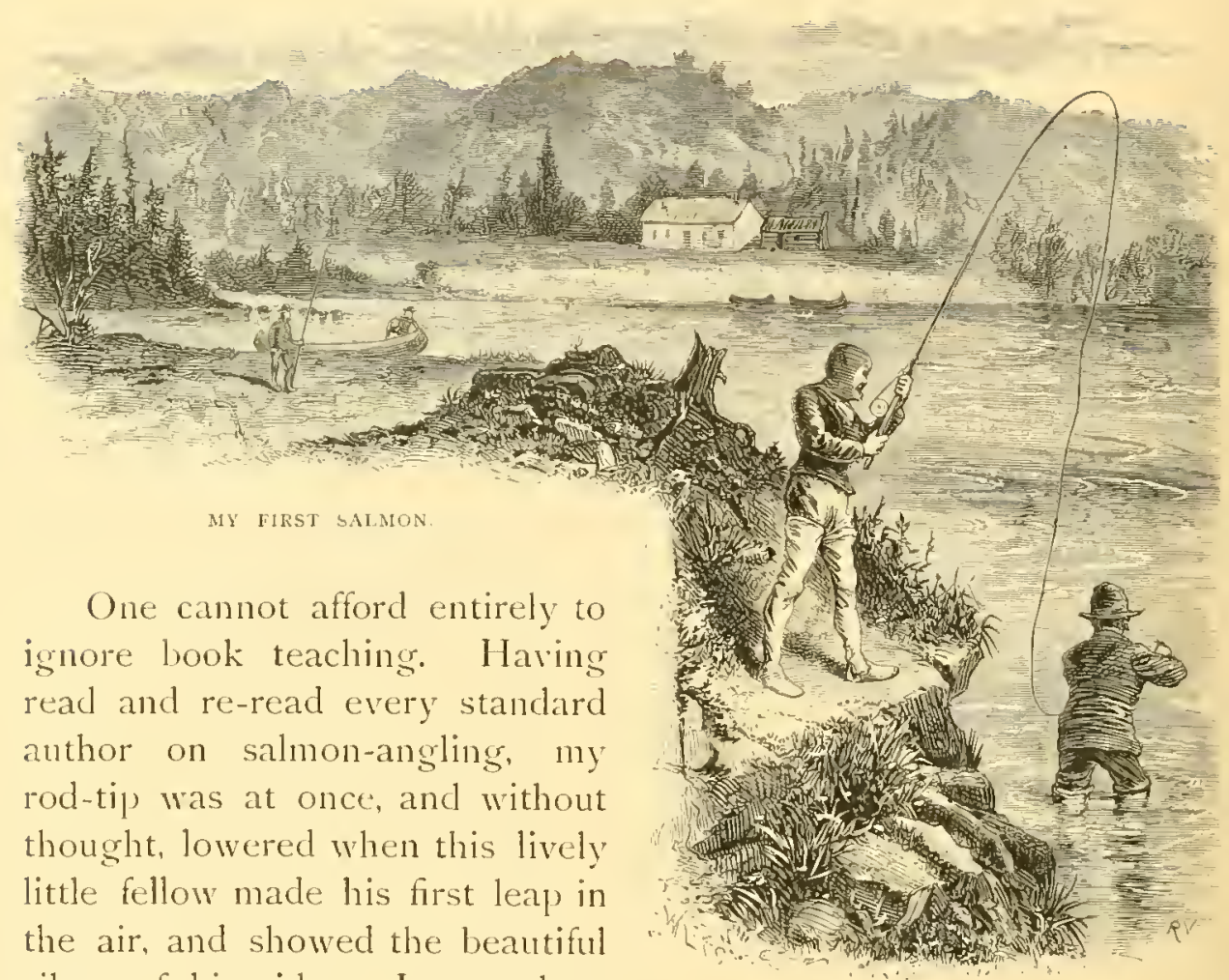
silver of his sides. It was done just as the fingers strike the proper key upon a musical instrument, when the player's mind is too far away perhaps to name the tune he has unconsciously run into. Of course, if you do not lower your rod-tip, the fish, falling upon a taut line, will break himself loose. This fish showed no disposition to leave the pool for the rapids below, but went first to one side, and then to the other, sweeping around by the farther shore, and jumping clean from the water each time he turned. It was impossible to keep below him, so rapidly did he change place. In spite of all the strain which could be safely put upon him, he would now and then get a hundred feet below the rod and rest there in comparative ease, with the force of the current balancing my strain upon him in an opposite direction. When you can keep abreast of your fish, or a little below him, the current, weight of line, and your strain of two or three pounds all in the same direction will soon tire him out.

Most anglers greatly miscalculate the force exerted by the rod, and will speak of using many pounds' strain. An actual test with a 
spring balance upon various rods showed that rarely is a strain of three pounds put upon the fish, and, in fact, few rods can raise a fourpound weight at the end of a line.

As my fish became tired and slowly passed the gaffer, he tried to gaff and missed. This goaded the fish to more desperate running and plunging in the direction of a projecting tree-trunk lying upon the water. If he could have reached it, he would have run under and then jumped back over it, leaving the line fast while he broke himself free. Soon his runs were shorter and his jumps less frequent, and finally, from very weakness, he would turn upon his side. I swung him gently toward the gaffer, who in his eagerness had waded nearly waist-deep into the pool. In an instant the fish was struggling at the end of the cruel gaff, making hard work for the man's brawny arms, and in a moment more he was laid upon the shore, where old William Patterson gave him the coup de grace with a stout short stick carried for that purpose in every canoe. Just at the moment of gaffing many fish are lost; for if more strain is exerted than usual, the hook breaks out of the well-worn hole in the jaw, and if the strain is relaxed a moment before the gaff is in, the slack line lets the hook drop out of the enlarged opening.

My trip and trouble had not been in vain, as my first salmon had been hooked and played to gaff without the slightest assistance. Before putting hin in the snow, I lighted my pipe and sat quietly down to admire and talk to him. It seemed wonderful that the little thread of silk-worm gut could have conquered so brave a fish.

Finding but few fish in the lower pools, we broke camp on Monday, and set out for House No. 2, at what is called the ligig Salmon Hole. The men assured us that it would be impossible to pole the canoes with ourselves and provisions over the shoal rapids, and that in several places they would have to unload and make a "carry." In order, then, to favor our men, Mr. Lazell and I set out to walk the distance, with the cook to show the way and carry our tackle. We could risk the wetting of our extra clothing and provisions, but did not care to have our rods floated down the stream, in case of an overturn. Of itself, a twelve-mile walk is not objectionable, but when one must climb over a dozen fallen trees at every hundred yards, it becomes monotonous. Six miles from camp we came to the North Fork, a roaring brook of perhaps eighteen inches 


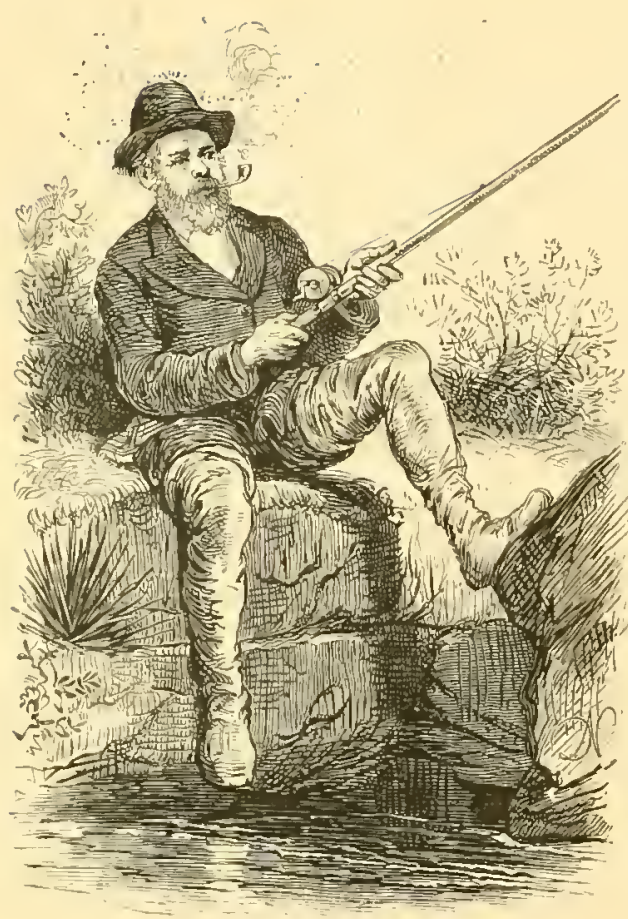

THE PATIENT ANGLER.

in depth. Lazell, with his wading-boots, stalked triumphantly across, while the cook and I went down a quarter of a mile to cross upon a tree which, some years ago, had fallen and formed a natural bridge. There was no path along this wind-swept gorge, and trees were piled upon trees, making many windfalls to be gotten over. At the end of a long half hour we came back to where Lazell was awaiting us. Could we have met the man who said there was a "pleasure in the pathless woods," he would have fared badly. The truth was that the dead-wood of the bridge had broken under our weight, and we were wetter than if we had waded the branch. Often upon this trip we touched, with our rodcases or gaff, the partridges which unconcernedly flew up and lighted on the lower branches of the trees. We reached the pool, and killed a fish before the canoes arrived. The next morning, Annette, Lazell's gaffer, came tumbling down from a tree where he had been sent to point out where the salmon were lying, and ran to the house yelling as if crazy, "Nr. Lazell has got his first fish, and he's a whopper!" Sure enough he had on a fish, and it commenced sulking at once. He had lighted his pipe and taken his seat just where one of Mr. Reynolds's friends, in 1873 , took his breakfast while holding his sulking fish with one hand. Having gone to the pool with my light bamboo, to which he was unaccustomed, he was unprepared for heavy fighting, as he felt insecure and had a dread of breaking it. Now and then, by rapping on the metal butt of the rod with a stone, the vibrations of the line would start the fish into making a short run and lazy jump. The men all put the fish at thirty-five pounds, and they are rarely more than a pound or two out of the way. Soon the fish began quietly working for the deepest part of the pool, and in 
spite of all the strain my friend was willing to put on him, finally got there under the edge of a sharp ledge. The salmon commenced sawing upon the line whenever a strain was brought to bear, and this necessitated giving line at once. After working for one hour and forty minutes, the leader parted.

IVithout a word, Lazell took his own greenheart rod, and in a few minutes was busily casting at the very upper encl of the pool, above where he had hooked the first fish. As good fortune would have it, he soon hooked a large one which came down the pool and tried the same game, but he managed to stop him and slowly swing him away from the center of the pool each time. Quite soon the fish ran and jumped enough to weaken himself, and was brought up to the gaffer. This was my friend's first salmon, and it weighed thirty-three pounds.

The skill of our men in gaffing struck us as remarkable, for during the season they missed for us but a single fish. Not the same romance attaches to them as to Indians, and they do not present that statuesque appearance while gaffing, but they are a thousand times more reliable, and always know better where

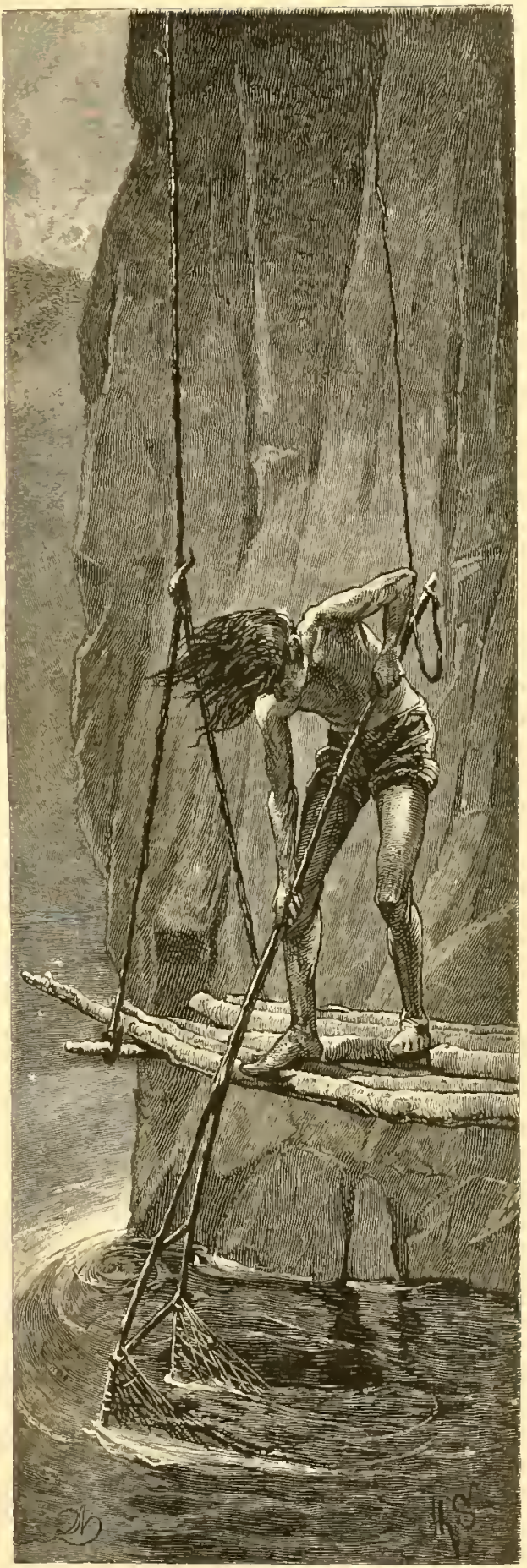

A HALF-Breed NetTING SALMON. 
the fish lie, and how quickest to aid you to circumvent and kill them. The Gaspé men can give even the best of anglers a valuable hint occasionally, which it is quite safe to follow, as it often saves a fish. They come from that good old stock. Scotch-English, and are as true as steel. Money and jewelry were safer in our camps than at home in the way of our servants. They never touch a drop of liquor, and work faithfully from morning till night. Even after long and tedious hours of poling up rapid streams, under a hot sun, they are ready to anticipate your slightest wish. All the men ask for, beside fish, is pork, hard bread, sugar, and black tea. Without the latter they are good for nothing. They make the tea in the teakettle itself, and drink several large tincupfuls at a sitting. Following this by a five minutes' pull at a pipeful of navy plug tobacco, they are ready for work.

In favorable seasons, the Big Salmon Hole of the York is good for two or three fish daily; and as Lazell was unable to walk by reason of cooling too rapidly after our twelve-mile walk, it seemed best to leave to him the exclusive use of this and the other pools near House No. 2. On Wednesday, therefore, I set out for the Narrows, near which are the last and best pools of the river, leaving two men to come with the canoe and luggage, and taking one with me. We arrived before noon, and, after lunch, carefully inspected the pools. By crawling quietly to the edge of low cliffs, or climbing trees, we could count the fish by scores, lying quietly behind small stones or just at the edge of the current, with heads up-stream. At first, one unaccustomed to it only sees large numbers of lark, smooth stones, as he expresses it; but soon a little wavy motion of the lower end of the object is seen, and you find that they are all salmon. only the dark backs being visible as you look down upon them. They rest in these pools for several days, to gain strength for leaping the falls just above. Often one hundred and fifty have been counted in the lower or long pool at the Narrows, and frequently not more than a single one will take the fly.

The matter of taking a fly seems to be one of sheer sport. It is a well established fact that salmon eat nothing during the several months they remain in the rivers. Before entering the Gaspé streams they gorge themselves with capelin, a small fish resembling our smelt. Quite often fish which we killed at the lowest pools had undigested 
parts of capelin in their stomachs. As their digestion is known to be very rapid, this indicates a high rate of speed against a swift current up fierce rapids and over falls. A bit of dried leaf seems to amuse

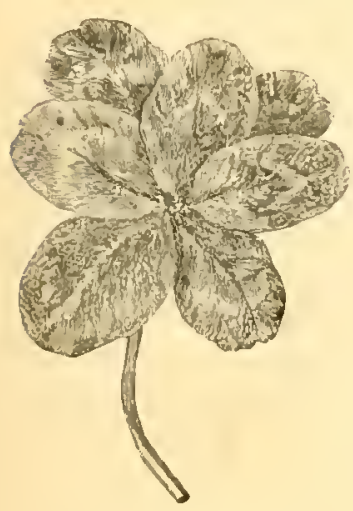
them as much as an artificial fly. Dropping a leaf quietly off a tree into a pool, we could see a salmon rise and take it, and after getting to the bottom open his mouth and let it float up to the surface again, when other fish would take it, one after the other, apparently enjoying the sport like kittens at play: So distinctly could we see the salmon that we easily traced the scars of the nets, which are found on large numbers. Nany we take have an eye entirely blincled from the wound made by the twine. At one time, just under the upper falls, I was for some fifteen minutes so near a salmon that 1 could have touched him with the end of my rod. The water was shallow and clear, and gave a good opportunity of closely watching the king of fishes as he majestically sailed around, probably wondering whether he would succeed in his leap over the falls. Dozens of his fellows were coming up at intervals to look at the falls, but not one could be tempted to take the slightest notice of any fly in our books, although we were out of their sight and threw our flies within a few inches of their noses.

We had with us rods, reels, gaffs, and, unfortunately, a new and untested package of leaders. The run of the first fish hooked parted a leader. A second leader shared the same fate; and a third was taken by a salmon who determined to leave the pool and go down the rapids below. Testing our leaders with the spring balance, we broke them at a pound or pound and a half strain, although they had previously received a thorough soaking. We were in a bad predicament; salmon everywhere; pools full of them, and seeming eager to rise, and no suitable leaders with which to take them. We made the best of it, and with what patience we could, awaited the canoe with our large fly-books containing new gut. From this we afterward tied leaders which stood a strain of five pounds, and were soon engaged in trying to overcome a strong, lively fish.

Presently our head man sung out, "You must lose your fish or get a drenching." A small dark cloud came over the near mountain, trav- 
eled rapidly down the gorge, and before one of the men could bring a rubber coat from the house, a few hundred yards distant, the rain was pouring upon us. The rapidity with which heavy showers follow down the gorges and course of the streams at Gaspé is somewhat startling to a new-comer. Of course, the fish must at all hazards be killed; and, of course, this particular fish was not in half the hurry to come in out of the water that we were, but tried our patience in many ways, sometimes taking us in the canoe where we couldn't wade, and sometimes through quite deep water where we did not wish to take the canoe and disturb the pool. It was thirty-five minutes before faithful old William had him quiet at the bottom of the canoe. He, as well as all our men, preferred to get us into a canoe before gaffing, when practicable, for they then felt much more sure of the fish. The Gaspé-built canoes are very long, and if the angler passes one of the men and steps to the extreme end, he can with perfect ease swing the fish to the gaffer at the other end, always taking great care not to reel in his line beyond its junction with the leader. If he does this and the gaffer misses, or the tired fish gets up life enough for a short spurt, then the knot sticks in the tip ring, and good-bye to fish and tip. It is with some reluctance that we differ with so good an authority as Norris, in his "American Anglers' Book," but we prefer canoe gaffing. We were all thoroughly soaked with rain, and I was additionally uncomfortable from having gone over the tops of my rubber wading stockings in water, which at two P. 11. was only $+2^{\circ}$ Fahrenheit. As there were but three hours more of this the last day of our permit, we could not afford to lose a moment. As soon as the sun came out, I hooked a second fish, and worked away busily until in the three pools I had killed five, when I stopped, wearied as well as satisfied with salmon-fishing, resisting our man's most urgent entreaties to "kill another, and make it a half dozen." I have never made a large score or killed a very large fish, but this work of three hours and a half was quite satisfactory, and is here given:

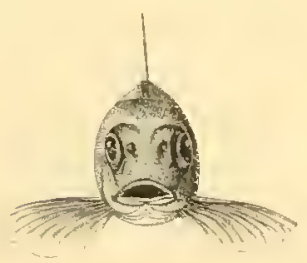

$$
\begin{aligned}
& \text { i Fish of } 22 \text { lbs., Fairy Fly. }
\end{aligned}
$$

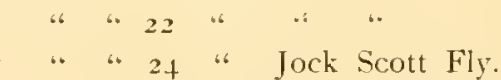

$$
\begin{aligned}
& \text { 1 " " } 211 / 2 \text { " Silver Doctor Fly. } \\
& \text { " " } 23 \text { " Silver Gray } \\
& 5 \quad \overline{1121 / 2} \text {. Average, } 221 / 2 \mathrm{lbs} \text {. }
\end{aligned}
$$


The healthful excitement as well as open air exercise enabled us without ill effects to endure this three and a half hours' wetting.

At half-past four A. w. next day, the canoe went down with the fish, and I walked to Middle House, where I found Lazell in good spirits over one thirty-three pound fish and other smaller ones.

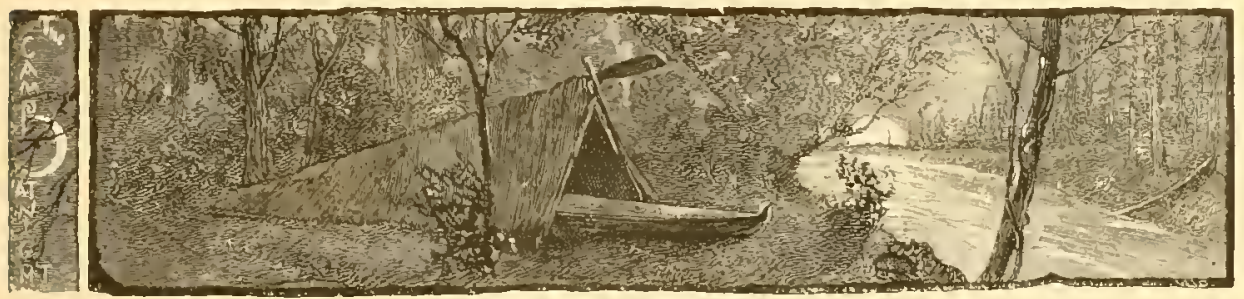

Hastily packing, we set out in uur canoes for House No. 1, where we took in additional fish and luggage. Running down the rapids between sharp rocks, both out of the water and uncler its surface, where all your safety depends upon the accuracy of your men's knowledge, their nerve, and the strength of rather slender spruce setting-poles, is quite exciting to a novice. At the word "check her" from old William at the stern, young James throws his entire weight suddenly upon his pole in the bow. Several times the pole broke, and necessitated quick work in dropping the pieces and grasping a second one, which is always kept within reach in running rapids. Upon breaking a second one, in all likelihood we would have got an extremely unlucky dipping.

We reached Gaspé the same day; having made thirty-five miles since half-past four $\mathrm{A}$. ..., and were in time to have our fish packed in snow and forwarded by the afternoon steamer for Quebec. For transportation, the fish are first "drawn" through the gills, then filled with snow and packed two in a box. The snow is then rammed solid around them until it resembles in consistency a cake of ice, and the box is placed inside of a much larger one. The space between the two boxes is now filled with sawdust. It Quebec, the boxes are examined and refilled, if necessary, before forwarding by rail. Our fish left Gaspé 'Thursday, were in Boston in good condition the Tuesciay following, and were served at the Somerset Club just a week after they were killed. With ice in place of snow, the packing is usually a failure.

Finding a letter at Gaspé inviting us to fish the Dartmouth, we went over to that river on July Ioth, taking horses to a place called by 28 
the habitants Lancy Cozzens, which we presumed to be a corruption of Linse aut cousins. From this point we proceeded by an invention of our own. One of the three canoes had a small sail, and holding another canoc by our hands upon each side of it,

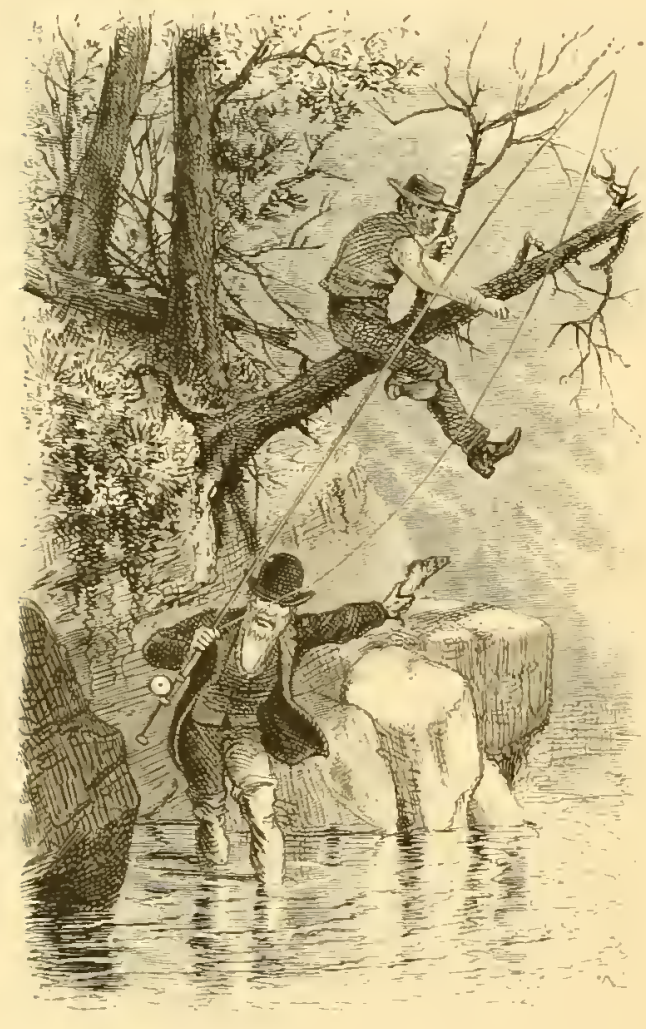

AX IRATE ANGLER we voyaged very independently until we tried to tack under a very stiff breeze-a performance which didn't take place exactly to suit us. Reaching the narrower part of the stream, we took our setting-poles in orthodox fashion, and soon reached camp, where we found a commodious wall-tent ready pitched, and all needed cooking-utensils, as well as a salmon for supper, left in the house by some departing friends.

The sea-trout had just commenced running up the river. and gave us most serious annoyance. The sea-trout is anadromous, and follows up the salmon some weeks later. An old trout-angler believes you not quite sane, and much less serious and truthful, when you positively assure him that oftentimes before you can reach a salmon you must play to gaff a half-dozen or more sea-trout, varying in weight from one to five pounds. That a five-pound trout can be an annoyance, and a serious one at that, isn't readily comprehended. You can't hurry a large trout, but must play and tire him out. Occasionally your man from a tree-top will tell you just where a fine salmon is lying, and, perhaps, that he started for the fly and missed it at your last cast. The next cast, a sea-trout, which is quicker than a salmon, snatches your fly the moment it strikes the water, and in the next few minutes flounders all over the pool, putting an effectual stop to salmon-fishing. Now is the time for self-control-for quietly 
lighting a cigar and strolling back to camp. Sometimes an irascible angler seizes the trout the moment he is off the hook and lurls him vindictively against the cliff.

This same abused sea-trout, however, when broiled before the fire in an open wire broiler, with a bit of salt pork clamped upon him. or rolled in buttered and wetted papers, and roasted uncler the embers, is preferable to salmon, and is more often eaten by the Gaspé anglers. The sea-trout and the common brook-trout. Salmo fontinalis, are taken side by sicle in the same pools; and so great is the apparent dissimilarity, that it seems impossible that they are one and the same species, the sea-trout merely being changed by his trip to sea, as some naturalists assert. The spots on the brook-trout are much more clearly defined, and have the light color upon their edges. while the markings of the sea-trout seem not to be distinct spots so much as irregular markings akin to those of the mackerel. This is as it appears to us who are not naturalists.

It is notable that although the three Gaspé rivers flow into the same bay, and for long distances within a few miles of each other, yet the fish are so different as to be readily distinguished one from another by the natives. The fish run up earliest in the York, and those taken even in the lowest pools are of larger size than those of the other streams. Of course, those that are strong enough to get to the upper pools early in the season before the river has run down are extremely large. The last runs of fish in the York are perhaps a trifle smaller than the general average of the St. John, where the early and late runs are of more nearly the same averaye size. So the fish of the Tay, in Scotland, are a month earlier than those of the Tweed, and presumably in this case because the snow grets out of the former much the sooner. The fish of the St. John are slightly shorter and fuller than those of the lork. resembling more nearly the Salmo quinmat of California. A few seasons since, the St. John was so jammed with the logs of a broken-up lumber raft that the fish were blocked out of it, and that year its peculiar fish were taken in the York. The next year, the St. John was clear, and its fish went back to it. I few seasons later grilse and young salmon were taken in the York which slightly resembled the St. John fish. The parent fish returned to their own stream. Their offspring, which were hatched in the York, remained in that river. 


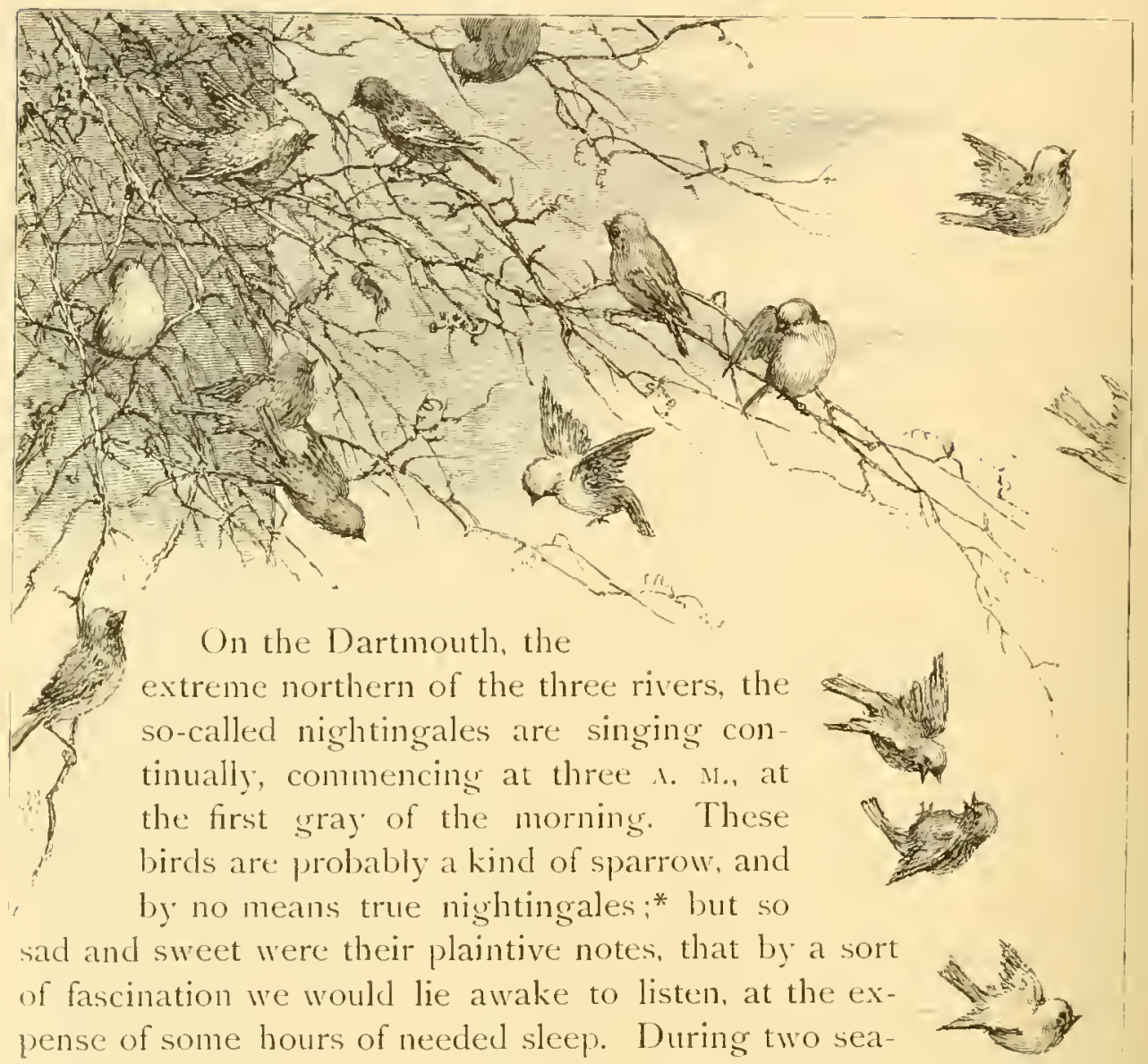
sons upon the other two rivers, only a few miles distant, not one was heard. After some practice in imitating them, we thought the following musical notation gave a very good idea of the song, which varied slightly with different birds, and at different times with the same bird. Between each double bar is a single song. Numbers $\mathrm{I}$ and 2 are different songs of one bird, and Numbers 3 and 4 are songs of another bird.
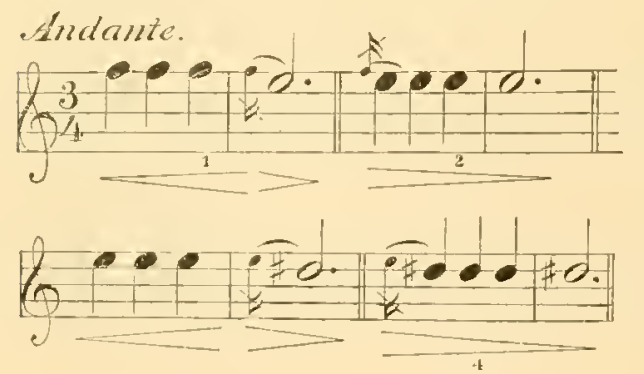

* [The white-throated sparrow (Frimsilla albicollis, Wilson). During springlike days in December, while hunting Bob White in the South, I have often heard the soft, melancholy whistle of this little songster, recalling to me, with "a feeling of sadness and longing," the blessed solitudes and the summer scents of the Northern woods.] - EDIToR. 
The terms of lease of a Canada salmon-stream require the lessee to maintain a guardian upon the river at his own expense. A comfortable log-house of a single room is usually built just below the first pools, and the guardian occupies it during the few months of the angling and spawning season. This expense is quite light, sometimes only a hundred dollars in grold. In addition, the Government appoints and pays overseers, who are assigned to special districts. and are expected rigidly to enforce the law regulating the net fishing in the tidal part of the rivers, and particularly to see that the nets are taken up over Sunday: The Gaspé rivers flow through so wild and inaccessible a country that it impossible for poachers to reach the pools and carry away fish in large quantities except in cannes, which must pass the guardian's house.

If the Government would offer a bounty for every sheldrake killed, it would greatly aid in keeping the streams better stocked. In the stomach of a young sheldrake will be found sometimes six or more parr as the young of salmon are called. When we consider the numbers of broods raised each year on a stream, and that both young and old are gormandizing parr all day long, we see that thousands upon thousands of fish are yearly lost in this way alone. These little parr, by the way, often bite at the fly, which is so large for them that they can only grasp some of its feathers, and hang on so well that you throw them several yards as you withdraw to make a fresh cast. The finger-marks or bars identify them at a glance.

One evening, while on the 1)artmouth, we were surprised by a visit from the guardian and the overseer, who came to dine and spend the night with us. They bragged a little of a big fish the overseer had captured in an unaccountably short time. Upon examining the tackle, we found that the line practically ended at the reel, where it joined a worthless cord, and that even this apology for a line had not been wetted. The rod was a shaky affair, that couldn't possibly kill a lively five-pound trout. The hook was covered thickly with rust. In their canoe we found a fish of over thirty pounds. One eye was covered with an opaque substance which had grown over it on the line of an old net scar. The other eye had across it a recent cut, which had totally destroyed its sight. The fish was then totally blind, and in all likelihood had broken out of a net a few nights before. These cunning jokers had made a sharp and well-defined $28 \mathrm{~A}$ 


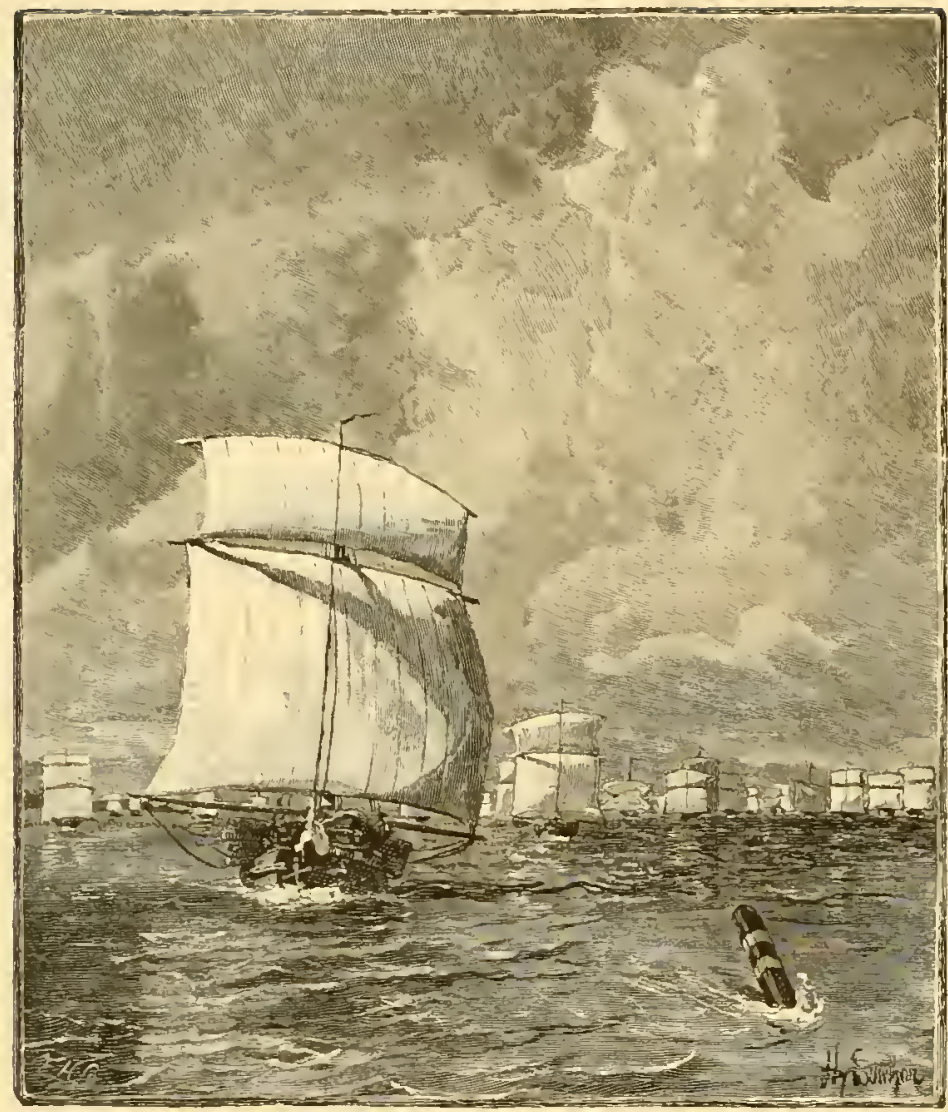

RIVER CRAFT ON THE ST, LAWRENCE.

cut in the jaw where fish are usually hookech, and they had gaffed him as he lay unable to see the approach of the canoe. Ne were glad that they had thus saved the fish from a lingering death, sooner or later, by starration; but raising a blind fish to a fly, and killing him with a rickery bait rod and worthless line, was too much for our credulity. IVe never informed them that we had seen through their little fishstory, and presume that they had many a laugh at having made "States" men believe that blind salmon could be taken with a fly.

IVednesday, July I 5 th, found the usually quiet and sleepy little settlement of Gaspé in great commotion. Some people were out on the house-tops with spy-glasses, and others rushing down to the wharf, where a goodly number had already collecied. Going to the upper rooms of the Gaspé Hotel, to which we had just come from the Dartmouth, we saw a beautiful yacht coming rapidly 
up the Basin under full sail. Soon she was abreast the wharf. giving all a view of her exquisite proportions, and, passing slowly up where the York merges itself in the waters of the Bay. gracefully swung into position and dropped anchor. She was the "Palmer," well known in both this country and Europe for her victory over the "Cambria," and famous as well for being the winner of numerous other races. Soon we received a call from her owner, Mr. Rutherfurd Stuyvesant, who was to have the York the rest of the season. A little later we net the rest of his party, and were invited to pass the evening on board the yacht. The ladies had braved a ten days' voyage from New York, and part of it in very rough weather, off what sailors call the "nastiest of coasts," and were to brave the mosquitoes and black flies as well,-hoping to rival the Countess Dufferin, who had a few weeks before thrown a fly, hooked and played to gaff a large fish upon the St. John.

We returned home by the "Secret," leisurely stopping at various points, as ourfancy dictated. While at a certain place, the steamer

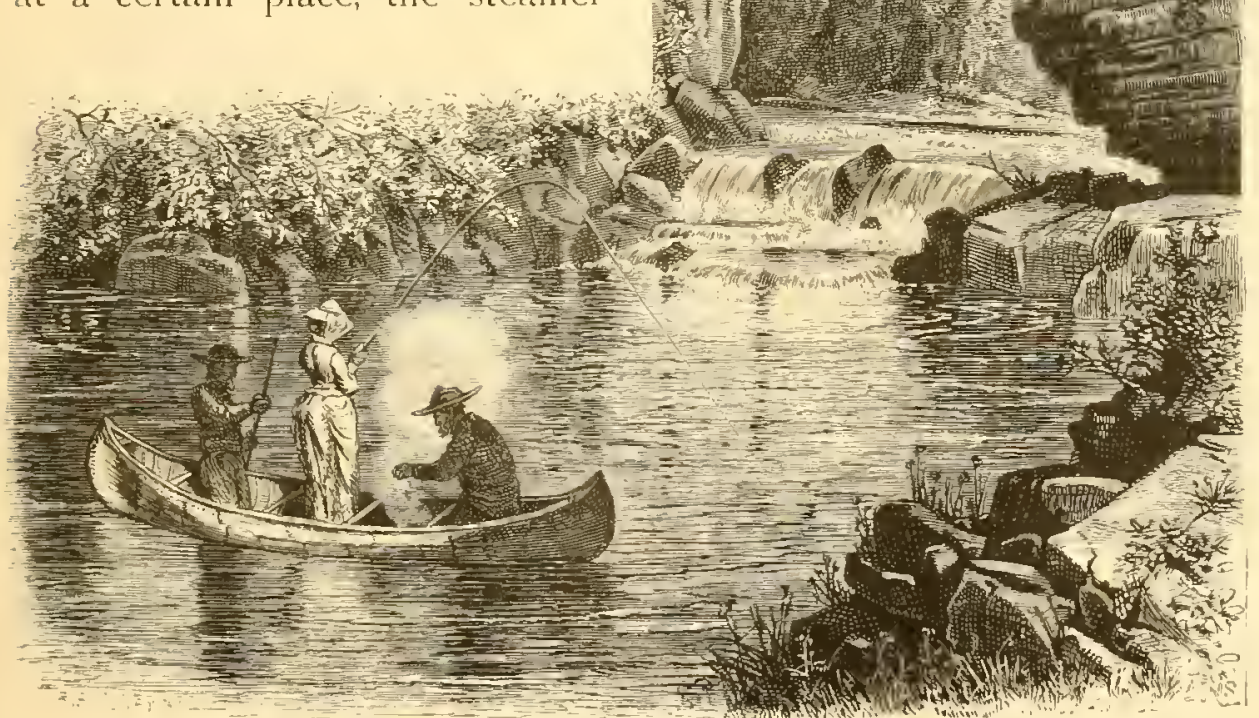

THE COUNTESS OF DUFERIN PUOL, ST, JUHN RIVER. 
touched with the mail, and was to remain two hours. Could the mail be opened at once, and we receive our letters, we might wish to hurry, on by that very steamer. We therefore brought all our forces to bear upon the obdurate postmaster, to induce him to open the small pouch with mail for his office, and give us our letters at once while the steamer was still at the landing. His constant reply was: "It cawnt be done. Government business cawnt be hurried. The mail is ton lawge, too lawge."

When the steamer arrived, he was the first to board her. He chatted consequentially with the officers for more than an hour. They were all on our side, and tried apparently to shake him off. Finally, with the little pouch (which he wouldn't intrust to his clerk -also on our sicle) under his arm, he slowly and with the firm, determined tread of a militia captain on training-day, moved off toward the post-office. Fifteen minutes would have sufficed to distribute the mail; but not until the steamer's last whistle blew dicl he put the letters into the boxes. He reckoned without his host, however; for a friend was quietly watching, and in an instant took our letters and started for the steamer at full run, yelling at the top of his voice. Crood old Captain Davison just then remembered that he had forgotten something, and took time enough with the steamer's agent to enable us to glance inastily over our letters, and ascertain that we could go by that steaner.

In 1874 . Mr. Curtis exchanged his old river, the $\mathrm{St}$. John, for the l)artmouth, in orcler that the former might be set aside for the Governor General. Earl I)ufferin having been called to England in the summer of 1875, it fell to Mr. Curtis's lot to have the use of both streams, and I accompanied him for a few weeks' recreation.

To reach our stream from Gaspé. we were obliged to take

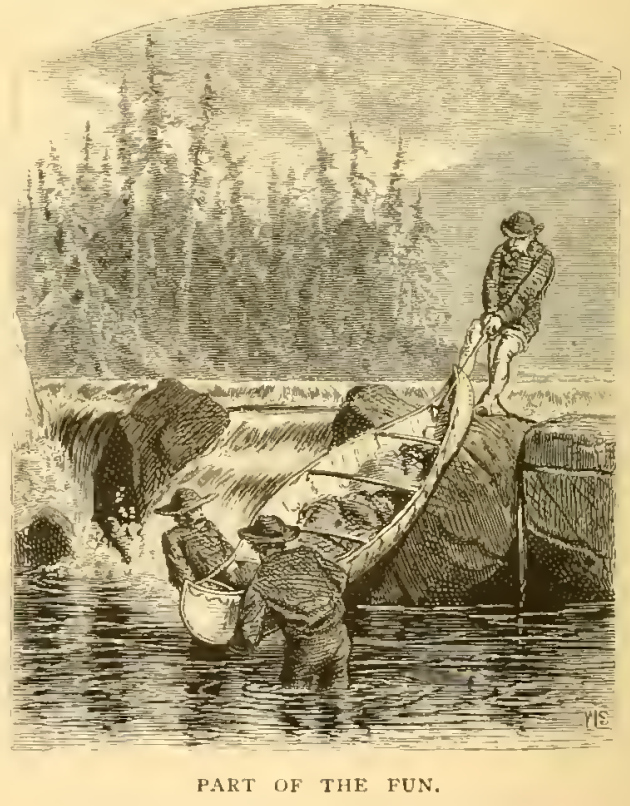


ourselves and all our luggage across the swollen York by repeated trips in a small clug-out, at a place some six miles from its mouth. After crossing, our provisions and luggage were taken in large boxes mounted upon stout timber sled-runners, this being the only conveyance that would stand a nine-mile trip over a slightly widened forest trail. We took saddle-horses, but yet found the trip most tedious by reason of the "windfalls" which had to be cut away by our canoe-men, who carried axes for the purpose, and by the swamp mud through which we frequently had to wade our horses.

The fishing of $1 \$ 75$ was comparatively a failure. less than twenty being killed by three of us during a week on the St. John. A friend of mine, Douglass, one day hooked an ugly fish, which played him all known pranks, and seemed, in addlition, to extemporize a few for the occasion. The fish leaped out of water enough to make it exciting, but not enough to tire himself out. He tried pulling constantly backward and forward in quick, short jerks, which is the worst thing a fish ever does. This makes the coolest angler nervous and anxious, for unless line is upon the instant given, the hook is pulled out, or the gut broken. The fish

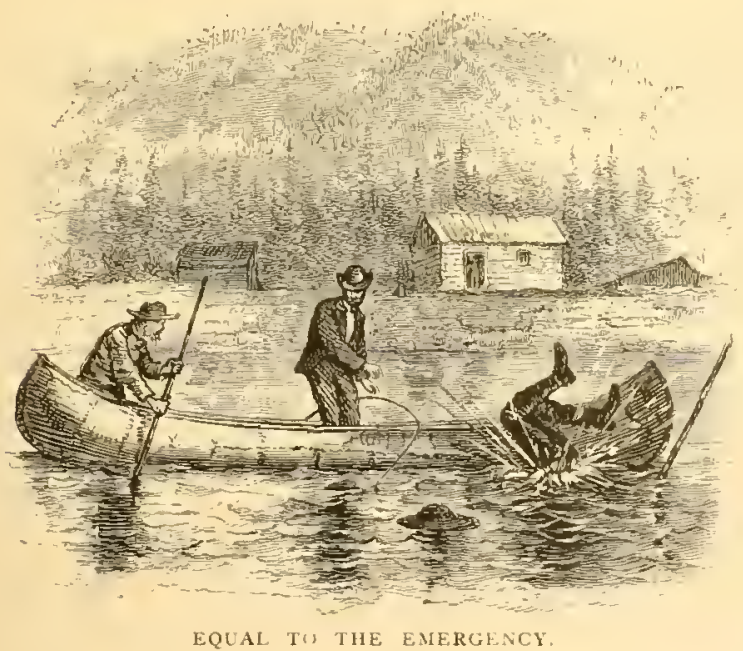
came down in view of the house, when, comparing the pluck and strategy of the fish with the skill of our friend, we counted the fish a trifle ahead. Of course, when near either bank, the men took care to keep on the shore side of the fish, so that when he suddenly rushed for deep water he would not pass under the canoe and break loose. In spite, however, of all precautions, the fish made a dash to run under, and one of the men gave a quick, powerful push on his setting-pole, which unfortunately rested upon a flat, slippery rock. The next instant our view was cut off by an immense pair of caribou hide boots, which seemed suspended in mid-air. 
The fish was just at the canoe, and the greenheart was taking the last possible ounce of strain. The line could not run out fast enough to relieve the rod, and we awaited its snapping. Equal to the emergency, I)ouglass, remembering an old trick of Curtis's, threw the rod behind him, and with reel end in the water and the tip ring resting on the edge of the canoe, the line ran safely and swiftly out. Douglass then tired and killed his fish, which weiglued fifteen pounds - about the average of the St. John fish.

The non-angling reader by this time surmises that the only way to bring a salmon to the gaff is to tire him, by keeping a constant steady strain upon him, with the shortest practicable line. The greatest dexterity and skill of the angler and his men are required to keep the canoe aliways in such a relation to the fish as to make this possible. Half your score depends upon the quickness of

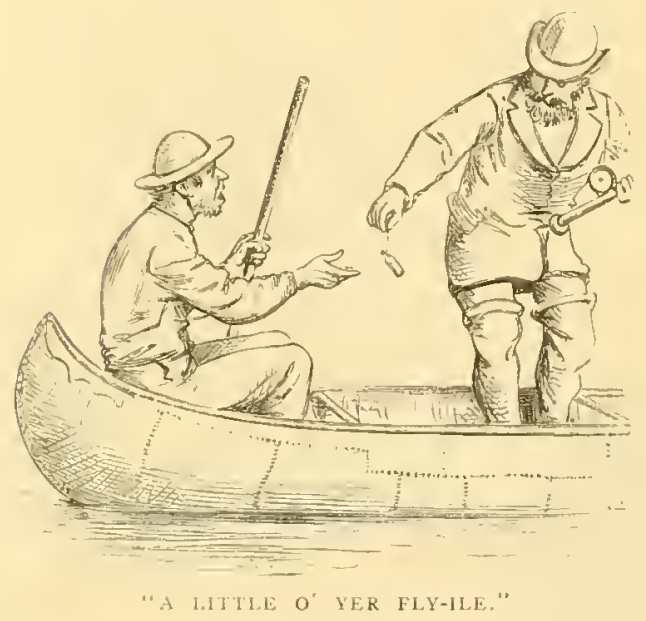
the men, who must, if you are on shore, be so near you with the canoe that if the fish starts down a rapid, they can take you in upon the instant, and follow him. How patiently would our faithful fellows sit on the crossbar of the canoe, and only now and then, when the flies and mosquitoes were unusually troublesome, break silence with "I don't care if I clo take a little o' yer fly-ile."

To give the general reader an idea of the way in which anglers make up their scores for distribution among their friends, we give an old one, which still stands among the best made in America:

F. Curtis's Score of Salmon-Fishing, York River. Lower Canada, for one evening and the following day, $187 x$.

TWO HOURS, THLRSDAY EVENING, JULY 6.

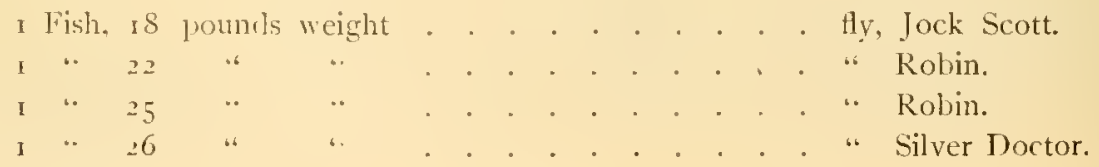




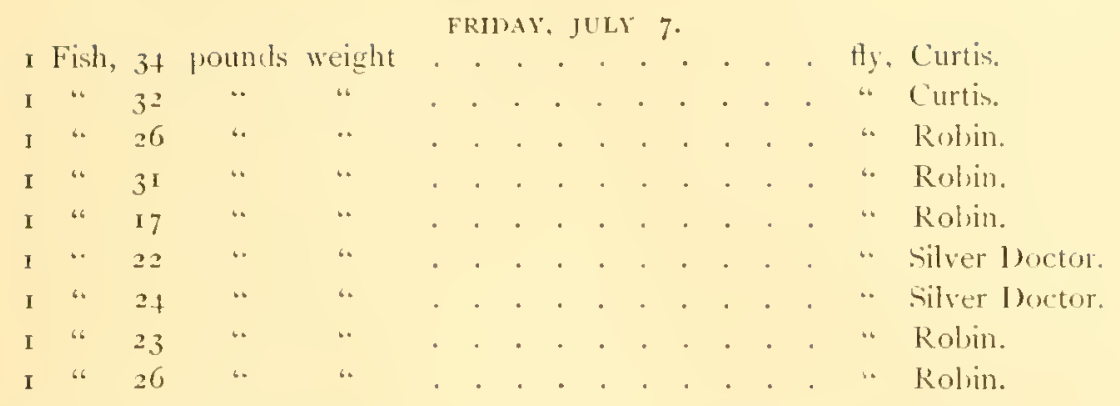

Total weight for both days, 326 pounds. 'Thursday's average, $223-4$ potinds. Friday's average, 26 I 9 pounds earh, and gross weight 235 pounds. Whole average, 25 I-I 3 pounds.

Sunday is the only day in camp when all are sure to be at home for an early dinner and in condition to enjoy and appreciate a good one. On week-days, the cook, who never leaves camp, does not serve dinner until half-past seven 1 . $M$., so as to give all time to return from the pools, which are often a few miles distant. If one gets a sulking fish late in the afternoon, he may be detained until long after the dinner-hour, and it is by no means a very rare occurrence to have a fish gaffed by the light of a birch-bark torch.

Canada fishing-laws forbid throwing a fly Saturday evening after six o'clock, but of course must allow killing a fish previously hooked. On Sunday, all are somewhat rested, and appetites are always keener after the day's rest which follows excessively hard work out-of-cloors.

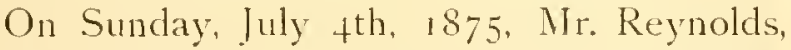
sent word that with three friends he would come over and take dinner with us on our glorious Fourth. As his name is a synonym for hospitality, we were quite anxious to show no shortcomings ourselves in that direction. Our six men and the cook were assisted by Curtis himself. who undertook the unheard-of thing of making a loaf of cake on a salmon-stream. How he succeeded is best told by his own letter to his sister, who had given him the cake recipe:

"I used every available dish in campspilled the flour all over my clothes and the

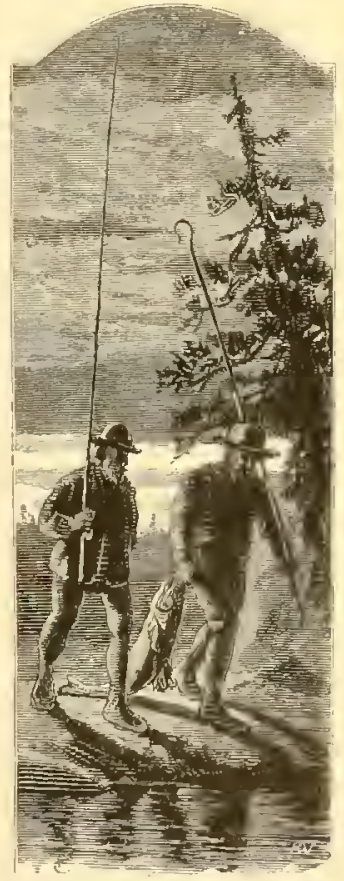

L.ATI TO DINVER. 
floor, and then rubbed it well in with butter, of which latter I melted one mess too much and the other too little. Took a vote, and found a majority of one for stirring it with the sun. Think, after all, I stirred it the wrong way: and ccrtainly put in too much egg-shell to make it settle well, for all the plums, currants, citron, etc, nearly settled through the bottom of the small wash-bowl in which 1 baked it. while some large lumps of sugar failed to get crushed at all. The cake was, however, quite passable. To be sure, I forgot to butter the dish, and had to dig the cake out in small pieces and glue them together: but that was a mere trifle, and my success was greater than could be reasonably expected from so doughty a matter. The cow which I had driven up from the settlement and put in our old and now unused snow-house, so as to kccp hcr; came to grief by breaking her leg on her way down the steep rocky river-bank to get water."

Our admirable courier came up from the Basin early in the morning with a clean pocket-handkerchief full of lettuce leaves, the size of a silver dollar, which he had procured from the minister's wife, who had raised under a cold frame the only lettuce in the settlement. Coffin complained bitterly of the imposition of the lobster-dealer, who, learning that his purchase was for "States" men, charged him ten cents each for lobsters of about five pounds weight, while he sold them commonly to the packer opposite Gaspé for fifty cents a hundred, large and small as they run. So plentiful are lobsters around Gaspé Basin that a few moments suffice to get a basketful hooked up with a peculiar sort of gaff made expressly for the purpose.

A heavy shower overtook our friends between the two rivers. They had, in honor of the special occasion of a Fourth of July dinner with their American friends, dressed themselves in gorgeous apparel of white flannel. What with the rain which had soaked them and beautifully distributed the usual face dressing of tar and sweet oil over large geographical surfaces, the stains of tree-drippings and the wadings through the marsh at the end of the lake, they presented a sorry appearance. Nothing could induce them to remain and dine in such plight, and so after a little rest and a modest lunch of crackers and cheese, they left us. Our bill of fare, which in accordance with camp custom we had written on bark, was quite elaborate.

On Thursday, we received from our friend Reynolds a kind invitation to occupy the York River for a week. Curtis and 
1 accepted, Douglass going off by steamer to take a fortnight upon the Matapediac. We packed luggage in long rubber army-bags, and slung them across the back of an apology for a horse sent up from Gaspé, and went directly over the mountains to House No. I, where we found canoes and extra men awaiting us, and then pushed directly for the Narrows.

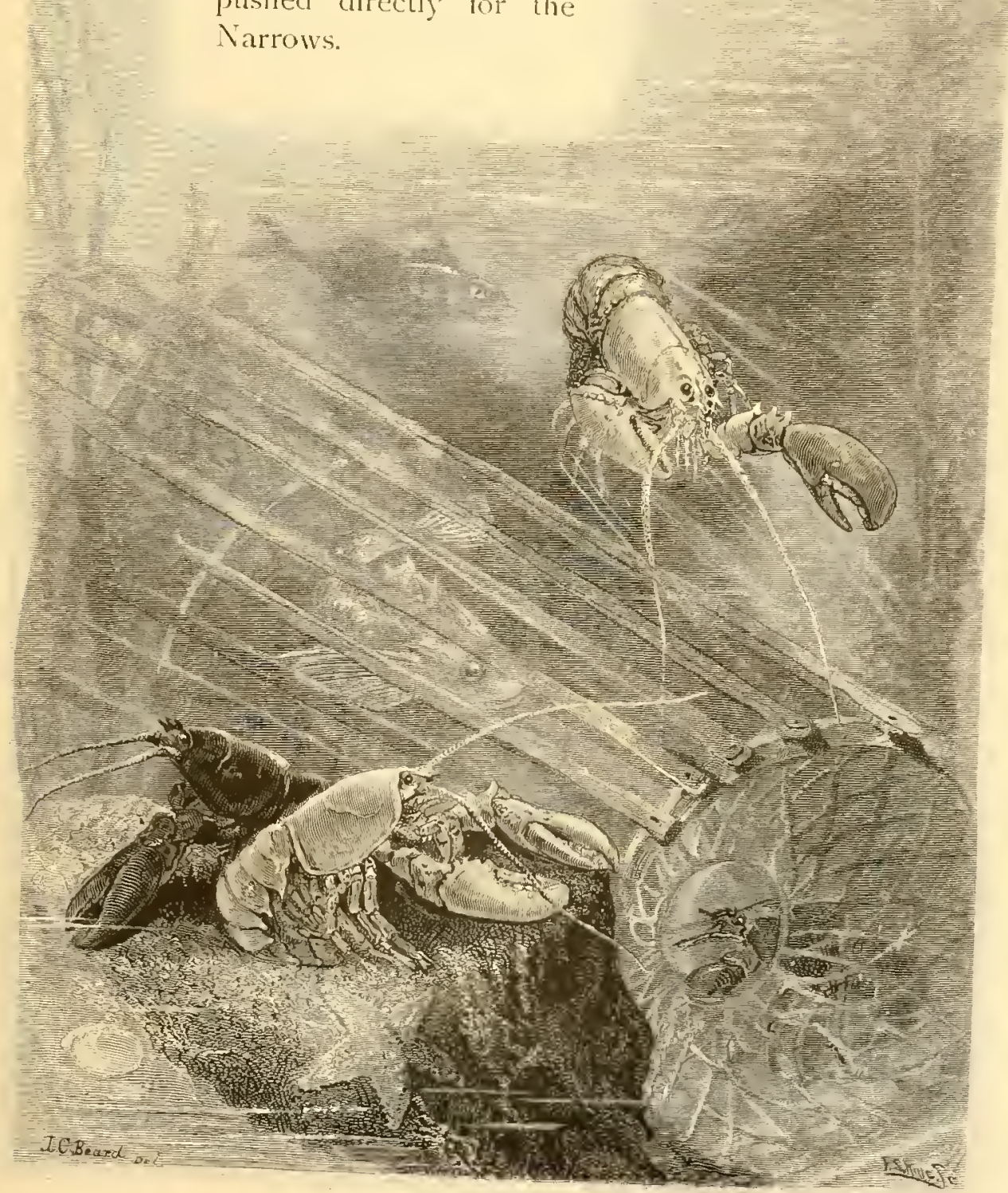

"HFTY CENTS A HUNDRFD," 
In lifting one of our canoes over a slight fall, we swung her around and half filled her with water, suaking our blankets, boxes of bread and crackers, as well as swectening the men's black tea with brown sugar $m$ masse.

Just below the Narrows canoes cannot be used, but the fishing must be clone while standing and wading in from one to two and a half feet of water. Rubber wading-stock-

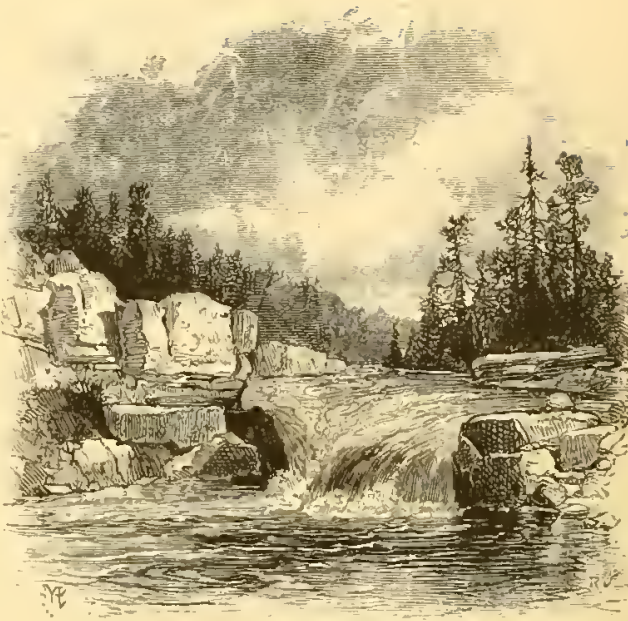

FALLS AT THE NARRUWS WF YORK RIVER. ings are worn, with very large canvas shoes over them, the soles being studded with soft metal nails to prevent slipping upon the rocks. In a moment of excitement, while following a fish, one frequently grets in over the tops of his stockings, and the subsequent carrying of a few gallons of water in these for-the-time rubberbottles is neither comfortable nor easy. Curtis improves upon the stockings by a pair of boots and trowsers, such as are used by the Baptist clergy, and which permit wading above the waist. Another of his improvements is a vertically adjustable piano-stool arrangement in his canne, which, while voyaging, lets one down

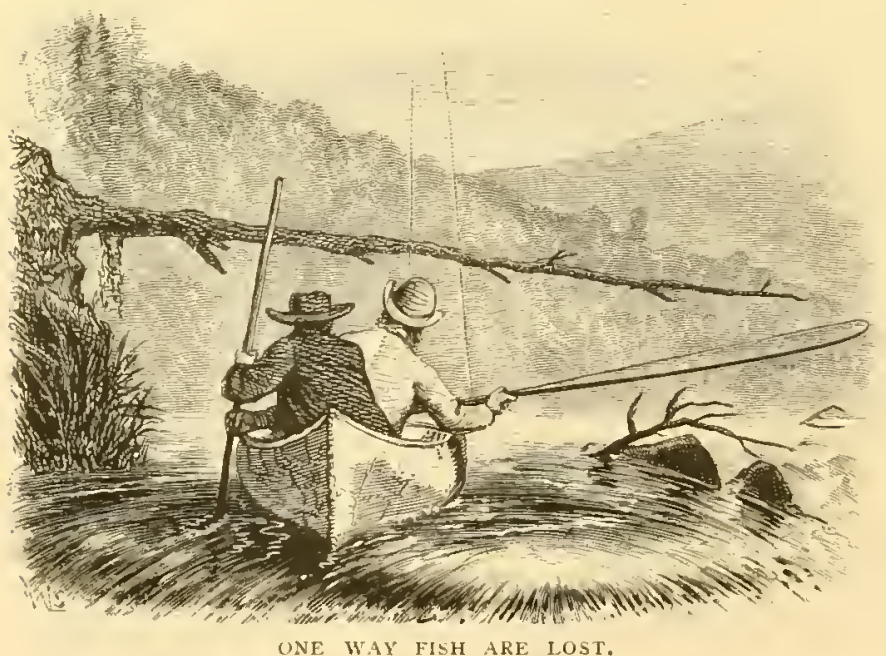

near the bottom to keep the center of gravity low and prevent capsizing, and which when casting can be turned up for a high seat. This, of course, is only to be used as last indicated when one is lame or very much inclined to laziness. 
At the pools, some distance below the Narows, are found numbers of fallen trees, projecting nearly at right angles to the low riverbanks. These trees are the occasion, to nearly all anglers, of the loss of a few fish. P'oling rapidly under them, while intent upon a rumning fish, they find their elevated rod within a few inches of the obstruction. On the instant, the rod is thrown forward, and this gives slack line to the fish and enables him to free himself. I second and too late thought tells him, what every one of course knows, that a line from a given point before him on the water to the top of his rod, when held upright, is precisely the same as from the same griven point to the top of his rod when it is dropped horizontally in the same vertical plane. Nine times out of ten an inexperienced angler forgets this, and does not quickly throw his rod to the center of the river, as shown in the sketch, and thus preserve his rod and keep a uniform strain upon his fish.

The old log-house at the Narrows is replete with pleasant reminiscences. On the pine doors, cupboards, and window-casings are scores and sketches illustrating amusing incidents of life upon a salmon-stream. Sadly we note the names of one or two who, alas! can never gladden us again with their presence.

Higgs's well-known copy of Bagster"s first edition of "lzaak Vaton " is bound in wood from the door of Cotton's fishing-house, "takin off by $\mathrm{H} r$. Higes, near the lock, where he aws sure Old Izadk must hai't touched it." Following out somewhat this conceit, we made our sketches and notes upon the soft bark of some of the old birches that overlooked our quarters.

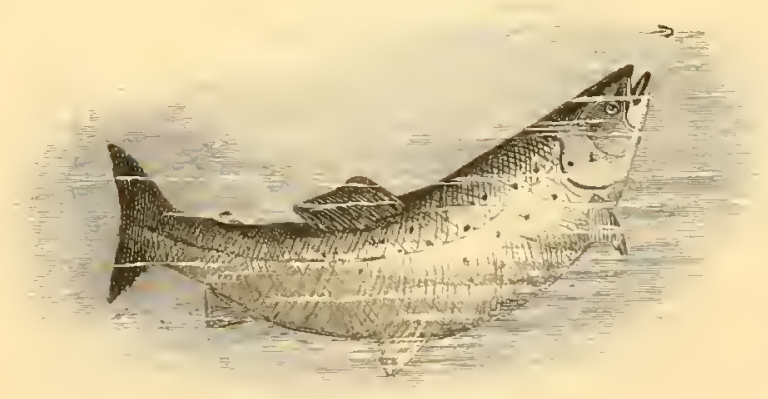




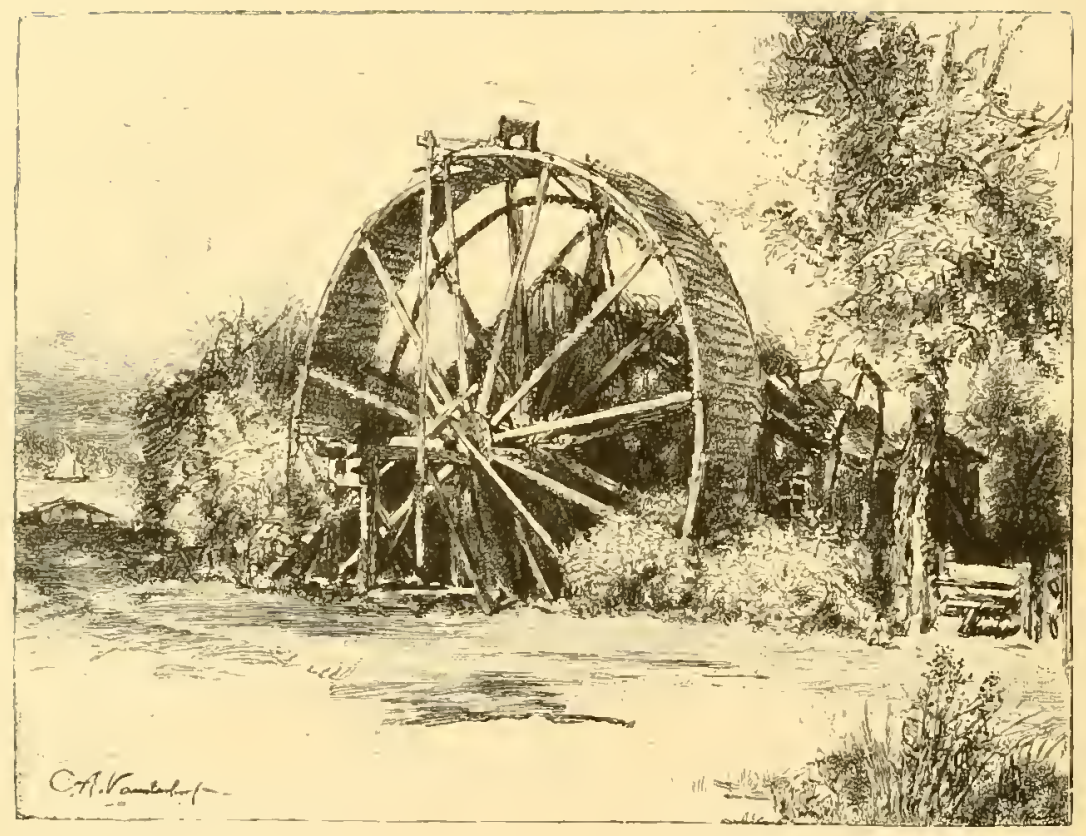




\section{STRIPEI) BASS. \\ BY IRANCIS FNDICOTT.}

T

O the lover of rod and reel, the striped bass, or rock-fish, as he is called south of Philadelphia, is the most important of all our sea fish. His habitat is so extencled and his stay with us so constant; he is so eagerly sought for by anglers of all classes and conditions of life; he affords such sport in the various stages of his growth, from the puny half-pounder found almost everywhere on our Atlantic coast, to the enormous "green-head" who makes his home in the break of the surf; he brings into play such a variety of tackle, from the pin-hook of the urchin fishing from the city docks, to the rods and reels of the crack bass-fisherman, - that he well merits the title which is sometimes bestowed on him of the game fish par cuccllence of the sea.

A bright August morning found the writer, in company with a member of the Cuttyhun Club, steaming down the bay from New Bedford, bound for a trip to the Elizabeth Islands and Martha's Vineyard, and for a bout with the large bass which frequent the rocky shores of those favored regions.

Arriving at the mouth of the harbor, as our little craft steams around Clark's Point and enters Buzzard's Bay, the whole range of the Elizabeth Islands comes into full view, and we find ourselves trying to repeat the old verse by which our ancestors remembered their uncouth Indian names:

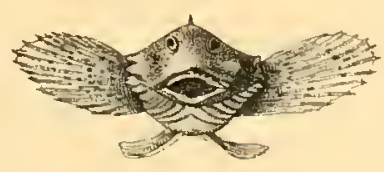

29
"Naushon, Nonamesset, Uncatema and Wepecket, Nashawena, Pasquinese, Cuttyhunk and Penikese." 
There is a mysterious influence at work in these regions which seems to gather the sea-fogs and hold them suspended around the islands, shutting them in completely, while all about, the atmosphere is clear. As we approach the land we observe this phenomenon, and are soon lost in its dense vapors. We steam along slowly, our fogwhistle shrieking at intervals, and every eye strained forward for rocks or vessels which may be in the way, until presently we hear a distant fog-horn answering us, and following it we find ourselves among a fleet of sword-fishermen anchored for the night in Cuttyhunk Bay. There is more music by the steam-whistle with an

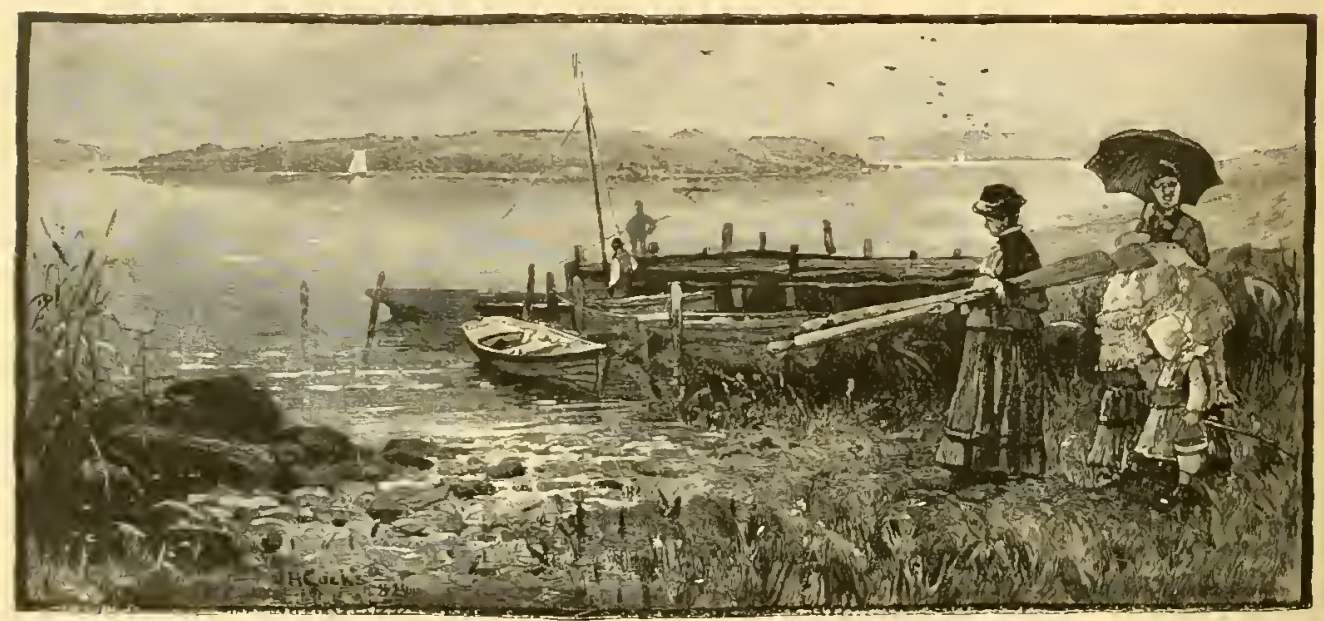

GOSNOLD'S ISLAND, CUTTYHUNK.

answering shout from the shore, and in a few moments the stroke of oars is heard upon the water. A skiff gropes its way toward us through the fog, we gather our baggage together, and are landed on the shingly beach, where, after a short walk, we find ourselves safe under the comfortable roof of the chub-house.

As the tide does not serve until late, we breakfast at the usual hour, and, having tested our line and seen that everything is in order, with a good supply of spare hooks, we start for a brisk walk over the hills, preceded by Perry, our "chummer," bearing a basket full of lobsters and menhaden for bait.

Bleak and uninteresting as these hills appear when seen from the water, every now and then we come unexpectedly on some little gem of picturesque beauty, which is none the less charming from the exceeding plainness of its setting. We hear, too, the abrupt notes 
of the upland plover, wildest of all game-birds, as he rises at a safe distance and speeds his flight to far-off hills. A little later in the season, large flocks of golcten plover will stop on their way south and make it lively for the grasshoppers, which now rise before us in clouds at every step and scatter away in uncertain flight before the wind.

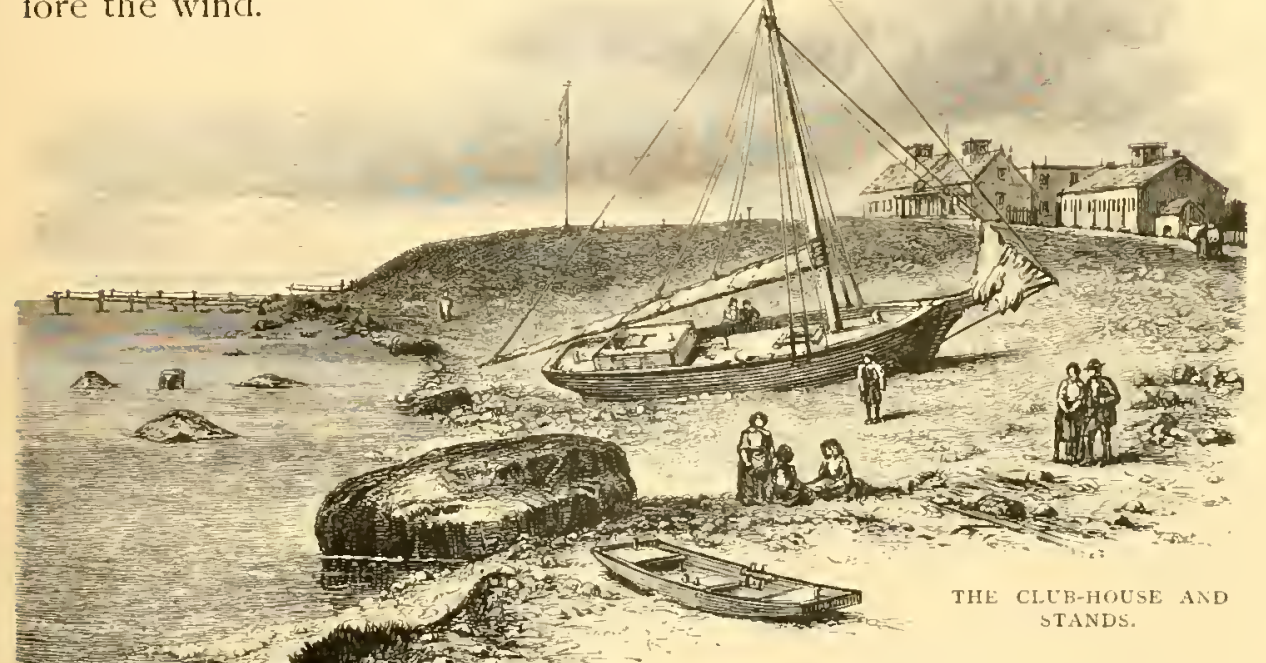

Our brisk walk soon brings us to the edge of a little fresh-water lake, sevarated from the sea by a narrow shingle beach, where we take a skiff and row over water as clear as crystal itself to the landing at the other end. The bottom of this lake is covered with a growth of aquatic vegetation, which seems as though it might harbor sufficient insect life to feed millions of fish: while in the shallows water-lilies grow in profusion, their dark-green leaves crowding each other on the surface, leaving scant room for the snowy petals to shoot up and unfold themselves. Some years ago, the club placed several thousand young trout in the lake, but they did not appear to thrive. or, rather, they disappeared mysteriously; whether they escaped through some under-ground outlet to the sea, or whether they furnished food to the enormous eels which inhabit these waters, is a question difficult of solution. The lake is now stocked with black bass, and the experiment bids fair to succeed. 
Arrived at our destination,-a large granite bowlder, known as Bass Rock, which stands out some distance from the shore and is connected with it by a narrow planking supported on iron rods, - we occupy the seat at the end of the jetty while our chummer, standing behind us, baits the hook with a lobster-tail, and we cast out toward two or three rocks where the waters are swirling with the incoming and receding waves.

The chummer is an important man in his way. He is generally a native of the island, and has done much fishing in his life-time and seen much more. His office is no sinecure; besides keeping four or five baits peeled ready for use, he breaks up the bodies and claws of the lobsters, and chops the head and shoulders of the menhaden into small bits, and throws them out upon the water with an odd-looking wood-and-tin ladle called a "chum-spoon." Without the chum you might catch an occasional straggler, but there is nothing to attract the attention of the fish, and it is only by accident, as it were, that they happen upon the solitary bait with which you are fishing.

But stop! that fellow takes hold as though he meant it, and is laying his course straight for Newport; we must try and stop him short of that. The line whizzes out from the reel, and our thumb would be blistered in a moment were it not for the double worsted thumb-stall which protects it. Perry says he's a twenty-pounder, at least, and he feels like it, for the rod is bent to the curve so beautiful in the eyes of an angler, and the line is strained to the utmost tension. There! he stops and breaks on the surface. How broad his tail looks as he lashes the water in impotent wrath! The worst of his run is over; reel him in carefully, keeping the killing strain on him all the time. He will make two or three more short dashes, and then you may lead him as gentle as a kitten to where Perry stands, with his gaff-hook, ready to reach down and take him in out of the wet. It is a pity to strike the cruel steel into his silvery sides, but it would be dangerous to attempt to land him among the rocks in-shore.

It is true that chumming attracts other less desirable fish. Your blue-fish has an insatiable appetite and a keen nose for a free lunch. We say this ruefully, as we reel in and put on a fresh hook to replace the one just carried away. Egad! that fellow struck like a fortypound bass, and cut the line as clean as though he had carried a pair of scissors! What a game fish he is! He fights to the very last, 
and only comes in when he fears that the struggle is becoming monotonous.

What's that-another blue-fish? No, his pull is too steady ; it's a bass, surely! This one strikes off in another direction; he lays his course as though he were bound for Pasque lsland. There, he has taken the line around that rock; better to give him slack and risk his unhooking himself than have

the line frayed and perhaps parted against the sharp granite edges. Now he's off again; handle lim tenderly: there's no knowing what damage that rub may have done to the slender line-phew! how cold the water is! That wave struck flat against the rock which supports the seat, and drenched us.

There is no royal road to this heavy surf-fishing; with all the appliances for comfort which experience can suggest, there is a certain amount of hard work to be done and exposure to be borne as a part of the price of success. Father Neptune is no respecter of persons, and spatters his royal favors so lavishly and so impartially on the just and the unjust that, unless you are a believer in the 'longshore theory that "salt water never hurts nobody," and can take a thorough soaking philosophically and as a matter of course, you had better give up all thought of being a bass-fisherman. It is somewhat trying to the nerves to have a barrel of salt water dashed unexpectedly in your face, sousing you in an instant from head to foot, and at times, when there is a heavy sea running, it is dangerous. 
Cases are upon record where anglers have been washed from the rocks, and have narrowly escaped with their lives. Even on these stands it is not always safe, although they are supposed to be above high-water mark. Sometimes, during the spring-tides, when the wind has lashed the sea into a fury, or a distant storm is lending additional force to the breakers, the fisherman will sit securely on his

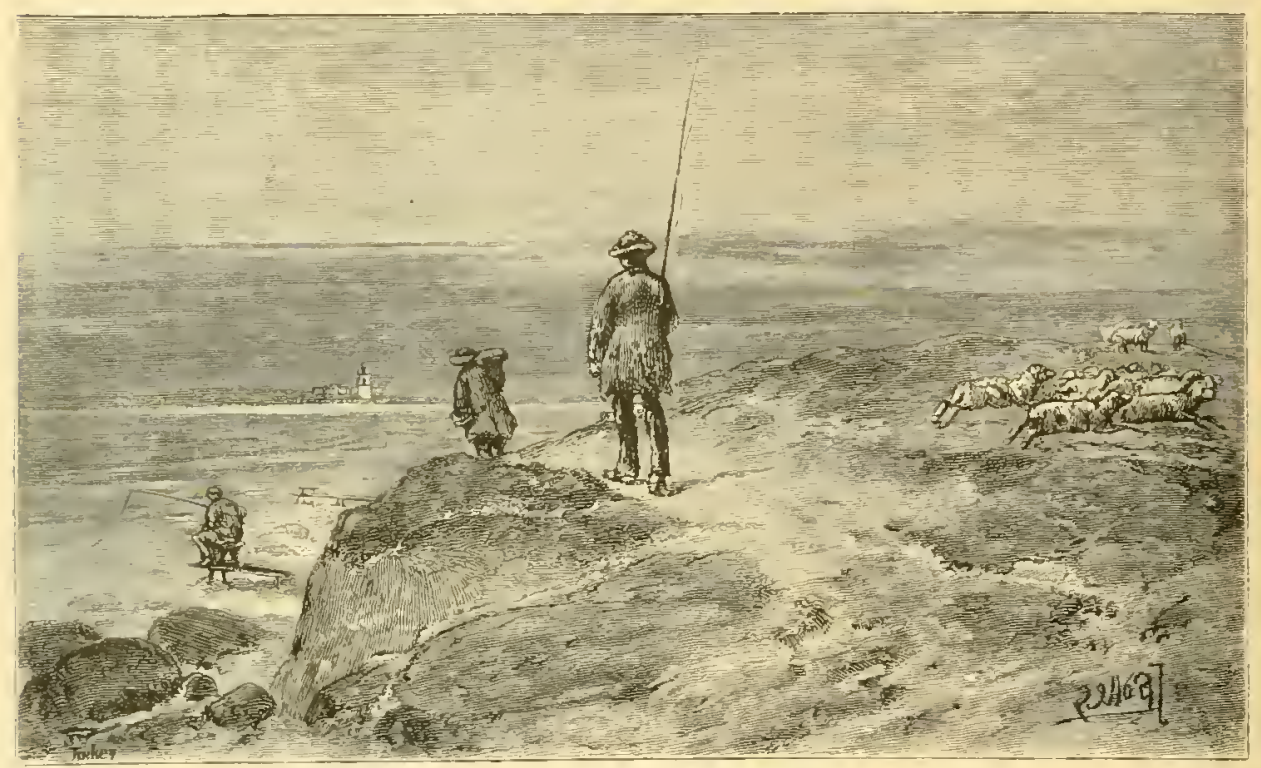

ON THF, WAY TO THE STANDS.

perch and see the white waters breaking angrily among the rocks under his feet. The tide rises higher, but he gives little heed to it, as in such perturbed waters he expects to meet with his greatest success,-perhaps catch the fish which shall make him "high-hook" for the year. The caps of the higher waves sweep over the sag of the narrow plank which connects him with the shore, while the crests of one or two bolder than the rest have lapped his feet with their icy tongues; still he continues to cast, encouraged by the taking of one or two fish, or by the strike of some fish of unknown size, until he is wet to the knees, though the tide cannot be more than threequarters high. An exclamation from his chummer causes him to look up, and a sight meets his eye which, for a moment, appalls him - an enormous, unbroken roller, stretching the length of the coast, and coming on at race-horse speed, followed by two others equally 


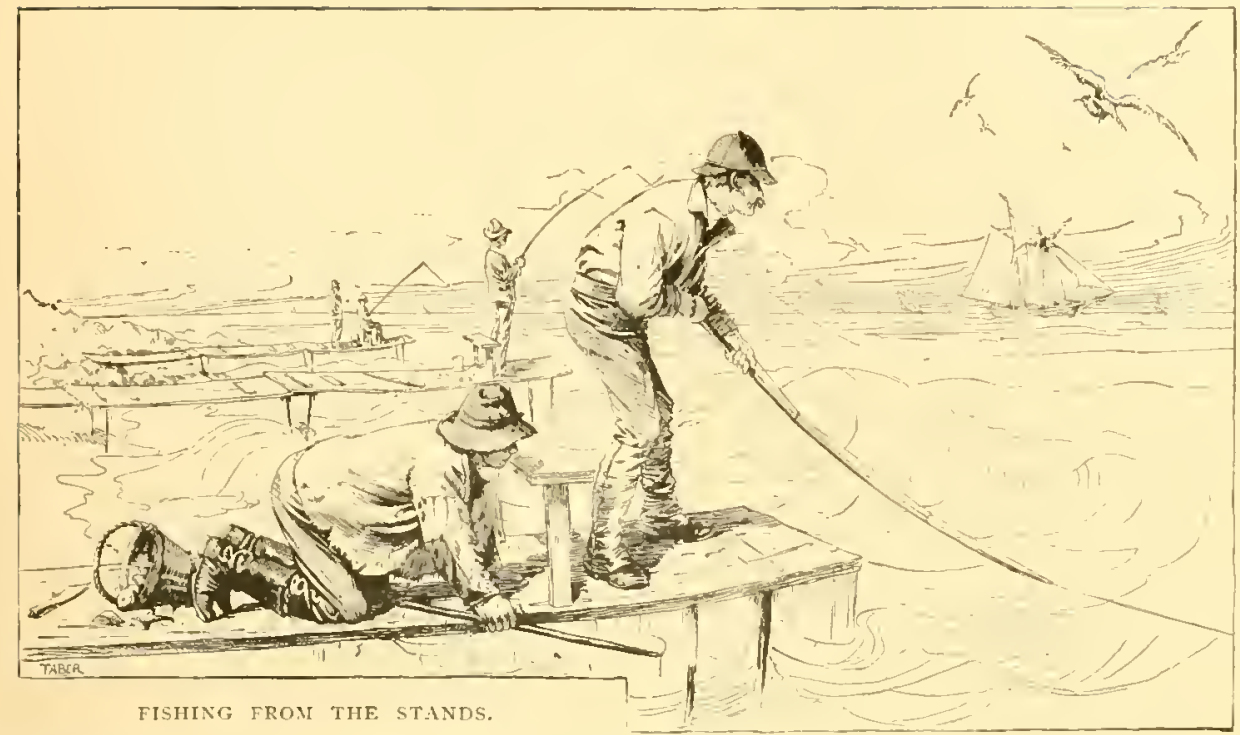

formidable, - for your big fellows generally travel in threes. Escape is impossible, and his only recourse is to hold on tight and take his ducking with what equanimity he can command, when, if he be sensible, he will watch his opportunity and make for the shore, a wetter and a wiser man. Seth Green got caught in this way, on this very rock from which we are now fishing, and retired drenched to the skin, but only for a time; the bass were biting freely, and the "great father of fishes," procuring a rope, lashed himself to the seat, and, in spite of the warnings and remonstrances of his friends, continued his sport, with the waves occasionally making a break clear over his head. Perry tells us this story in the intervals between chopping and chumming, and we notice that the pluck of the old man elicits from him an admiration which no amount of piscicultural skill could have commanded.

Another strike! This fellow betrays himself at the very start, for we see the cloven hoof, or rather the forked tail, which denotes that pirate of the deep, blue sea - the bluefish, and we bring him to gaff as soon as possible, using him rather roughly, for he is seldom alone, and his companions in iniquity are apt to cut him loose by striking at any bit of bait that may have run up on the line, or even at the line itself as it cuts rapidly through the water.

Perry opens this fish and brings us his paunch to examine; in it, besides many pieces of chum, are three hooks-one of them, with 
the bait still on and a bit of the line attached, we identify as our property, which he feloniously purloined and converted to his own use this morning; the others, of strange make and corroded by the strong gastric juices, are evidently much older acquisitions.

But the bass have ceased biting; our stock of bait is reduced to a few shreds and patches, and the inner man calls loudly for repairs, so our chummer starts on ahead with the heavy load of fish, while we linger for a few minutes at the light-house, built on the rising ground between the lake and the sea, to have a chat with the keeper.

Truly, this is classic ground. Lying almost within a stone'sthrow of us, snugly nestled in the bosom of the black-bass pond, is the little island called after Bartholomew Gosnold, that mighty navigator whose name has come down to us in a blaze of posthumous glory as the cliscoverer of Cape Cod.

In the year 1602, eighteen years before the founding of the Plymouth colony, Gosnold built a store-house and began a fort on this islet and did some trading with the Indians. That he had but little faith in their friendliness is evidenced by his building his stronghold on this island within an island, and in fact history gives the aboriginal natives of Cuttyhunk but a sorry character as neighbors. Dr. Belknap visited the island in 1797 , and discovered what he supposed to be the remains of the cellar of Gosnold's store-house, whereupon a later historian breaks forth in this wise: "It is a vestige of the first work performed by Europeans on the New England shores. Here they first penetrated the earth; here the first edifice was erected. Only two centuries have passed away, and from this humble beginning have arisen cities, numerous, large, and fair, in which are enjoyed all the refined delights of civilization."

The first duty of your chummer, on returning from the stand, is to see that the bass are weighed on a pair of scales hanging at the corner of the piazza. This is done in the presence of two members of the club, to avoid-mistakes, the result being entered on a blank slip, which is retained $u$ itil evening, when the score of each member for the whole day is duly entered opposite his name on the records. Our score for the morning's work shows three bass, weighing eighteen and one-half, sixteen and one-half, and nine pounds. Glancing over the leaves of the record-book, we find some interesting items, which we copy-premising that the season in each year 


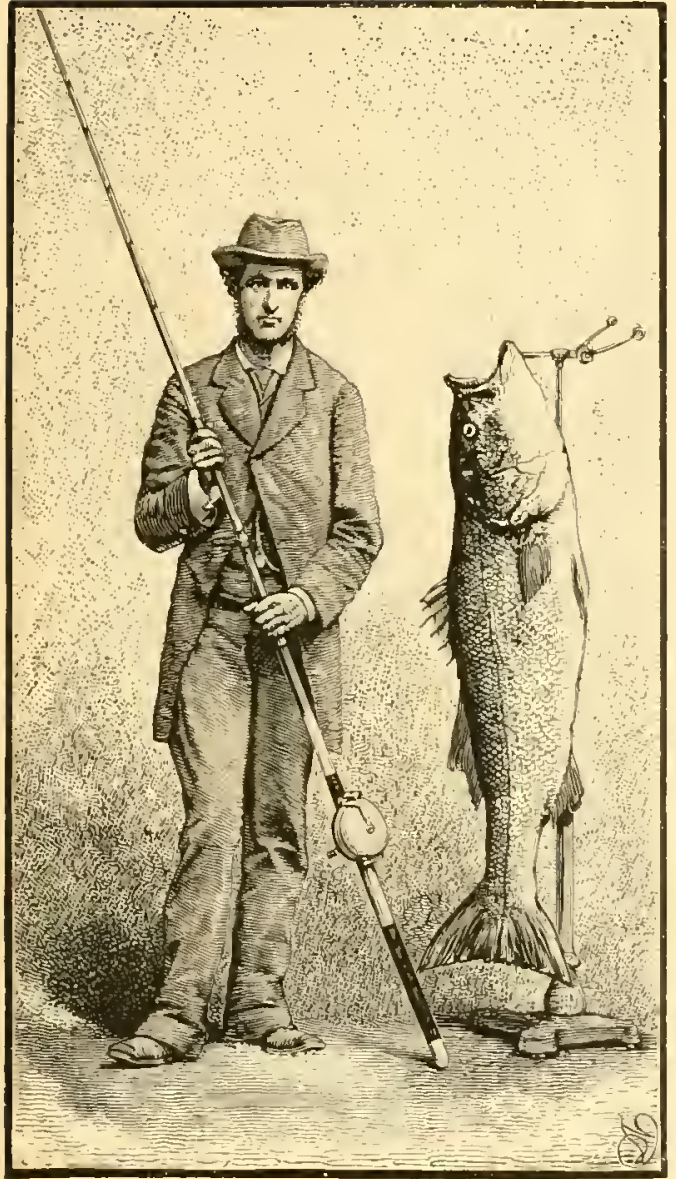

A GOOD CATCH.

lasts but four months, extending from the middle of June to the middle of October. The honorary title of "highhook" is conferred on the member taking the largest fish of the season.

On the opening day of the club in June a great deal of sport is sometimes occasioned by the anxiety of the nembers to wear this coveted honor; and as the member catching the first fish, even if it weigh but four or five pounds, is "high-hook" and entitled to wear the diamond-mounted badge in shape of a bass hook which accompanies the title until a larger fish is taken, it frequently happens that the title and badge will change hands three or four times during the day.

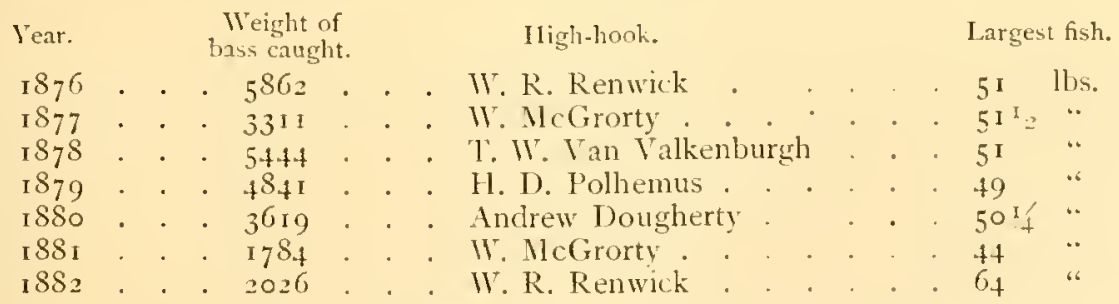

On the following morning we leave our hospitable friends, our destination being Gay Head. We can see its many-colored cliffs from the club-house, across the Vineyard Sound, only eight miles away; but the wind is contrary and the water too rough for the small boat at our disposal, so we conclude to return to New Bedford by the more tranquil waters of Buzzard's Bay, and take the steamer thence 
to Martha's Vineyard. We make an early start, and, as the weather is fair, get a good view of the island of Pune, or Penikese, and its elegant buildings (the Anderson School of Natural History, formerly superintended by Professor Agassiz), which the fog had hidden from sight when we arrived. Skirting along the coast of Nashawena,

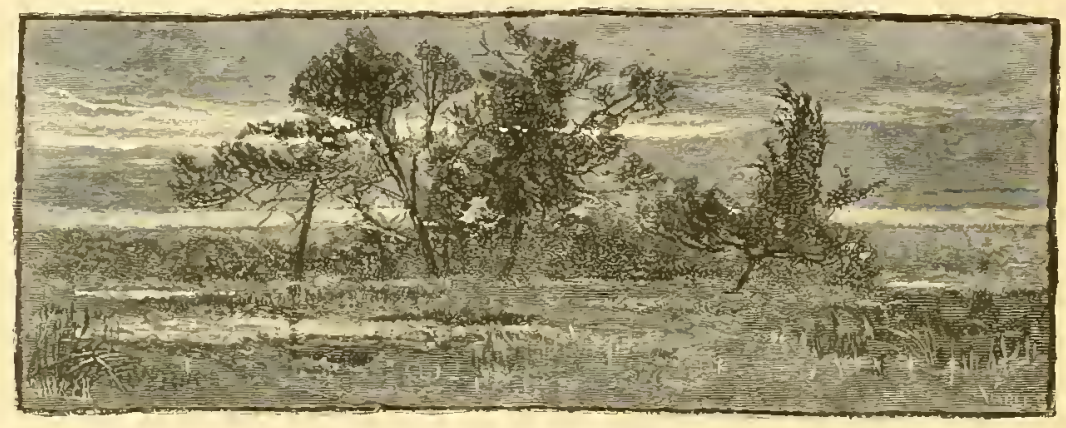

BACK FROM THE BEACH.

and giving Quick's Hole a wide berth on account of its strong currents, we came to the island of Pasque, or Pesk, as the natives call it, and, rounding its easterly point into Robinson's Hole, we drop anchor in front of the Pasque Island club-house. Some of the members of this club are old friends, and we avail ourselves of a longstanding invitation to drop in upon them and see what they are doing with the bass.

Pasque Island does not differ in its general features from Cuttyhunk. Here there are the same bleak-looking hills, bare of trees, with the exception of a little clump of locusts, named, after the aboriginal owner of the island, "Wamsutta's Grove." Early accounts, which represent these islands as covered with a growth of beech and cedars, would be incredible, in view of their present cheerless aspect, were it not that stumps of those trees are occasionally unearthed at the present day. Besides the club-houses, there is but one building on the island, and this dates so far back in the dim past that the accounts of its origin are but legendary. We should like to pin our faith to the story that it was erected by some straggler from Gosnold's band, which would make it the oldest building in New England; but we fear that this claim rests on the same airy basis, and must be placed in the same category, as that which carries the old mill at Newport back to the time of the Norsemen. The club 
owns the whole island, consisting of about one thousand acres, and has in its possession the original deed, dated 1667 , from the Indian sachem Tsowoarum, better known as IVamsutta, conveying Pascachanest, and another island whose name is illegible-probably a little one thrown into the bargain as a make-weight-islands were cheap in those days - "to Daniel Wilcocks, of the town of Dartmouth, in the jurisdiction of New Plymouth," for the sum of twelve pounds.

Before bidding our friends adieu and continuing our journey, we gather the following statistics from the club records:

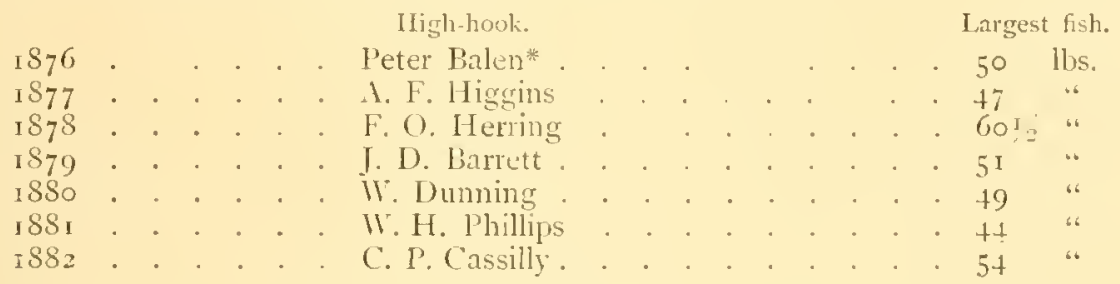

In the early accounts of the settlement of New England, the striped bass is frequently mentioned, and it seems at times to have formed the main food-supply of the forefathers when other sources had failed them. $\dagger$

"Thomas Morton, of Clifford's Inn, gent.," gives a glowing description of their abundance in "New English Canaan, or New Canaan: an abstract of New England, composed in three bookes. The Natural Indowments of the Countrie, and What Staple Commodities it Yeeldeth. Printed by Charles Green, 1632." He writes:

"The Basse is an excellent Fish, both fresh $\&$ salt, one hundred whereof, salted at market, have yielded five 1). They are so large the head of one will give a good eater a dinner, and for daintinesse of diet they excell the Marybones of beefe. There are such multitudes that I have seene stopped into the river close adjoining to my howse, with a sand at one tide. so many as will loade a ship of one hundred tonnes."

A pretty good fish story; it reacls like the prospectus of a land association - as it probably was. Here is another, antedating it by two years, from "New England's Plantation; or, A Short and True

* Clarum et venerabile nomen.

tIn "A Key into the Language of America; or. an Help to the Language of the Natives in that part of America called New England. London: by Roger Williams, $16+3$, " the Indian name of the fish is given thus: "Missuckeke"- bass. 
Description of the Commodities and Discommodities of that Countrey. Written by a Reuerend Divine (Mr. Higginson), now there resident. London, $\mathrm{t}_{6} 30$ ":

"Of these fish (the lasse) our fishers take many hundreds together, which I have seen lying on the shore to my admiration; yea, their nets ordinarily take more than they are able to hale to land, and for want of Boats and men they are constrained to let a many goe after they have taken them, and yet sometimes they fill two boates at a time with them."

The famous Captain John Smith, " sometime Governor of Virginia \& Admiral of New England," wrote in a little book entitled "Advertisements for the Inexperienced Planters of New England, or Anywhere; or, The Pathway to Experience to Erect a Plantation. London, 1631 :"

"The seven and thirty passengers, miscarrying twice upon the coast of England, came so ill provided they only relyed upon the poore company they found, that had lived two yeares by their naked industry and what the country naturally afforded. It is true, al first there hath beene taken a thousand Bayses at a draught, and more than twelve hogsheads of Herrings in a night."

Sturdy John Josselyn, gent., who never hesitated to use a word because of its strength, writes, in his "Account of Two Voyages to New England in 1675 ":

"The Basse is a salt-water fish, too, but most an end (sic) taken in Rivers, where they spawn; there hath been three thousand Basse taken at a set. One writes that the fat in the bone of a Basse's head is his brains, which is a lye."

In a curious poetical description of the colony, entitled "Good News from Nevv England, with an exact relation of the First Planting that Countrey," printed in London, 1648 , these lines occur :

"At end of March begins the Spring by Sol's new elivation,

Stealing away the Earth's white robe dropping with sweat's vexation,

The Codfish, Holybut, and Basse do sport the rivers in,

And Allwifes with their crowding sholes in every creek do swim."

Truly, our ancestors must have had glorious opportunities for sport, though it may be considered doubtful whether those sternvisaged men, whose features had grown grim in facing the hard realities of their pioneer life,-sickness, starvation, and an ever- 
present and treacherous foe,- - found time to "go a-angling," except as a means of warding off famine from their wives and little ones. There is something very pathetic in the accounts of their fishing

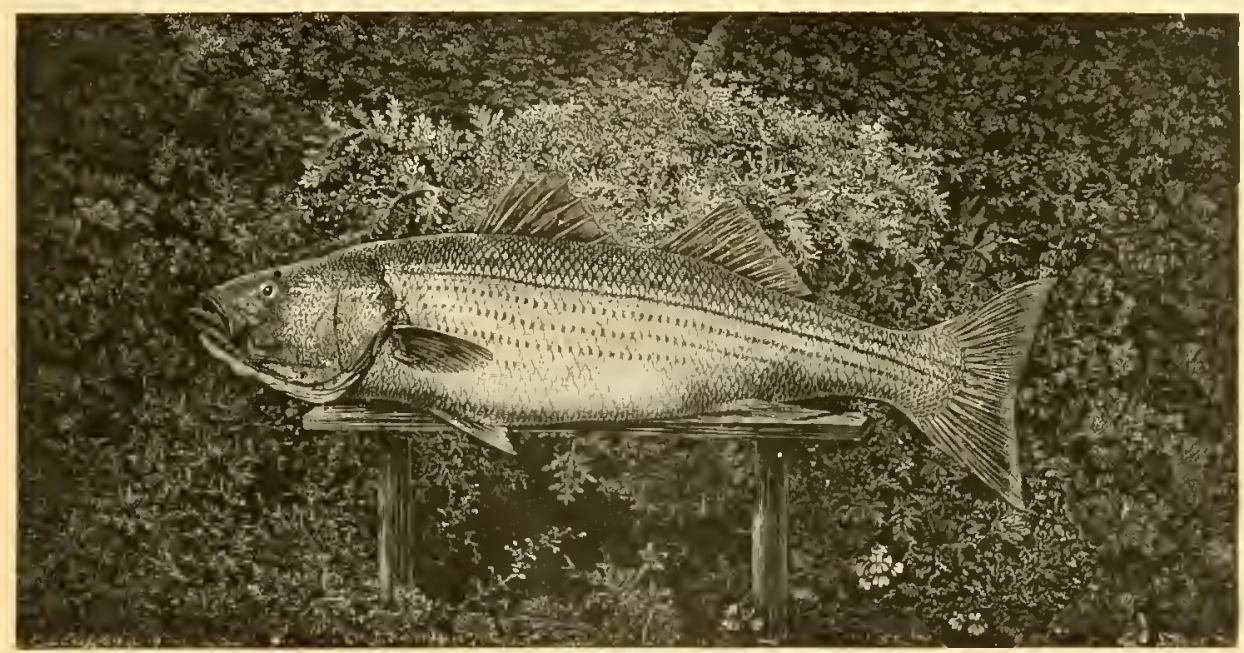

STRIPED BASS OR RUCK FISH. (LABRAX LINEATUS.)

trips as given in Bradford's " History of Plymouth Plantation." It presents the reverse of the rose-colored pictures of Morton and Higrginson:

" They haveing but one boat left, and she not well fitted, they were clivided into severall small companies, six or seven to a gangg or company, and so wente out with a nett they had bought to take bass \& such like fish, by course, every company knowirg their turne. No sooner was ye boate discharged of what she lrought, but ye next company tooke her and wente out with her. Neither did they returne till they had caught something, though it were five or six days before, for they knew there was nothing at home, and to goe home emptie would be a great discouragemente to ye rest."

At New Bedford, we take the steamer for Oak Bluffs, and sail down across Buzzard's Bay and through the narrow strait called Wood's Hole, whose troubled waters bear a close resemblance to those of Hell Gate. Rare bass-fishing there must be in these circling eddies, and we half mature a plan to stop on the way home and have a day at them. Emerging from the Holes into the Vineyard Sound, we steam away for the headlands of Martha's Vineyard, visible in the distance, and in due time haul up at the wharf of that marvelous city of cottages, and take the stage to commence a tedious 

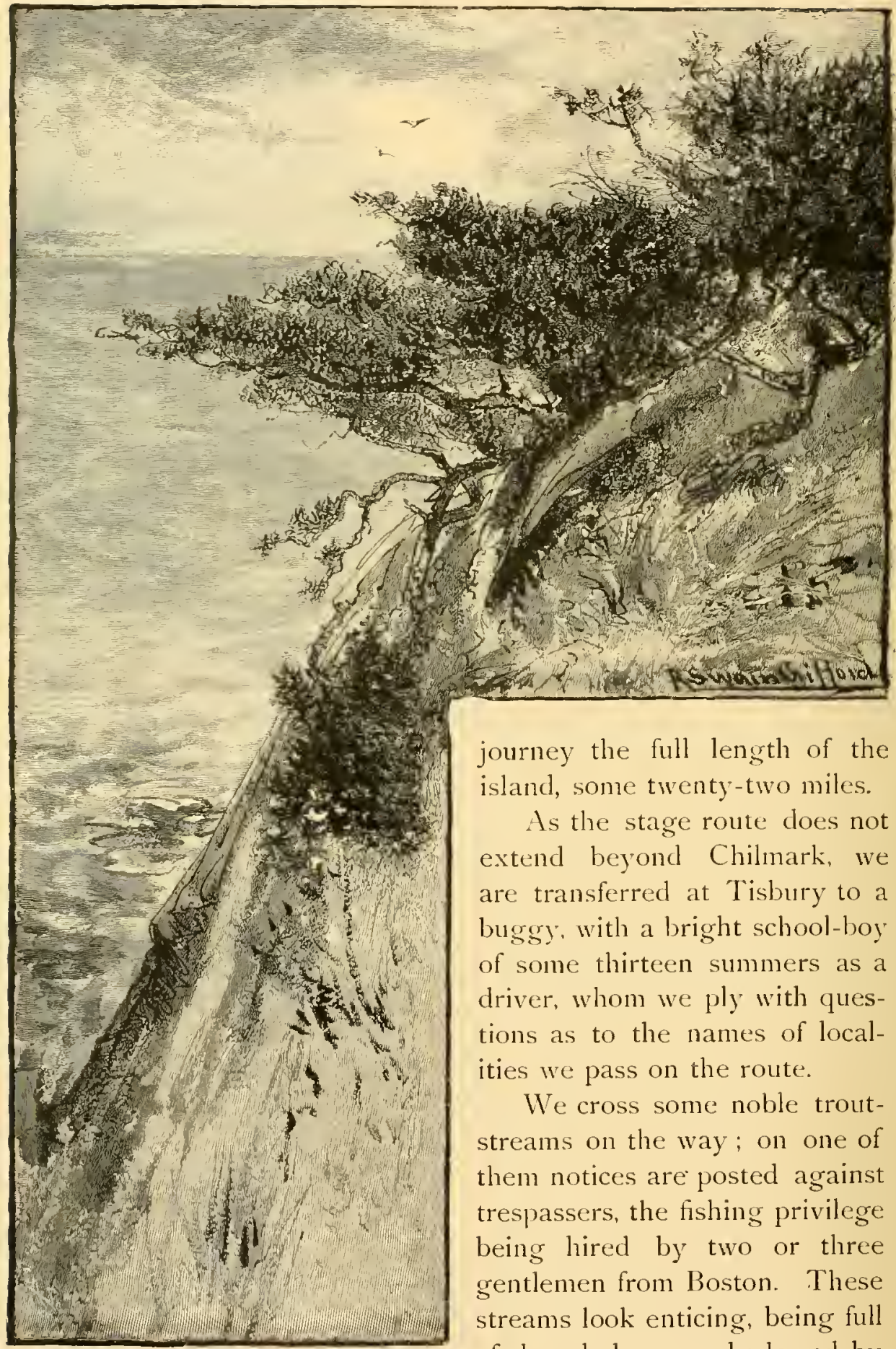

journey the full length of the island, some twenty-two miles.

As the stage route does not extend beyond Chilmark, we are transferred at Tisbury to a buggy, with a bright school-boy of some thirteen summers as a driver, whom we ply with questions as to the names of localities we pass on the route.

We cross some noble troutstreams on the way; on one of them notices are posted against trespassers, the fishing privilege being hired by two or three gentlemen from Boston. These streams look enticing, being full of deep holes overshadowed by 
scrubby alders-the lurking-place of many a large trout, if we may believe our young guide. The trout should be full of game and fine-flavored in these streams-pink-fleshed, vigorous fellows, such as we find in the tide-water creeks of Long lsland

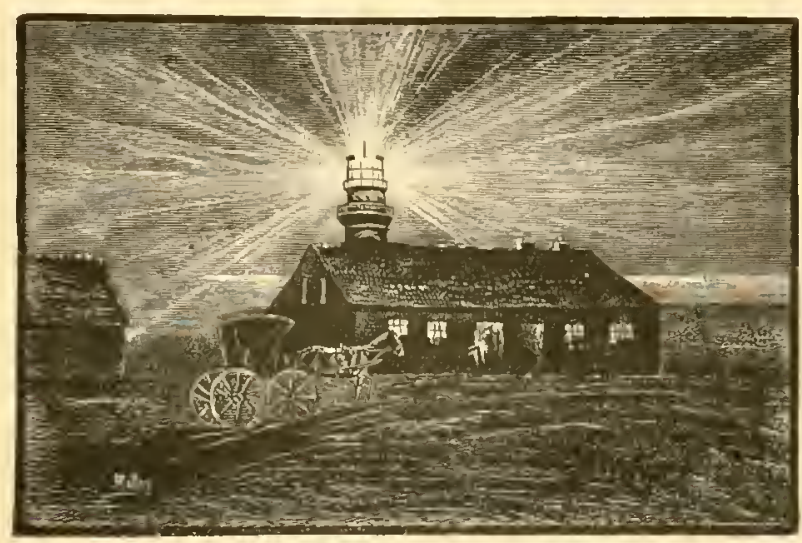

THE L.KGHT-HOUSE AT G.AY HE.AD.

and Cape Cod, who take the fly with a rush that sends the heart jumping into the throat.

As we approach Menemsha Bight, the roads are heavy with recent rains, and the wheels sink deep in the sandy soil. A queer little popping sound, apparently coming from under the wagon, excites our curiosity; we lean over to ascertain the cause, and find the yround covered with myriads of small toads, any one of which could sit comfortably on a dime with room to spare. Some of these, getting caught in the deep rut of the road, struggle feebly to leap over the barrier, and failing in the attempt, the wheels pass over them, each one exploding under the weight with a faint pop, and flattening out into a grotesque exaggeration of his former self, that reminds us of one of the pantomime tricks of the Ravel family.

It is dark when we reach Gay Head, and as we drive up to the door of the keeper's house, which adjoins the light-house, a voice from some unknown region cheerily invites us to enter. We look around for the owner, but see no one to whom the roice could belong. Orerhead, long, slanting bars of white-and-red light flash through the powerful Fresnel lenses in every direction, looking like bands of bright ribbon, cut bias against the larkness of the sky beyond, while 
millions of insects dance in the broad rays, holding high carnival in the almost midday glare. The mysterious voice repeats the invitation, and without more ado we gather our baggage together and enter a cozy sitting-room, where we proceed to make ourselves very much at home. Here we find Mr. Pease, the keeper of the light, who has descended from his lantern, and a gentleman from New Bedford, who gives but poor encouragement in regard to the fishing. He has been here for a week past, and has not caught a solitary bass in all that time; but he tells us such soul-stirring yarns of fish caught cn previous visits, and all told with a modesty which attests their truth, that our spirits are restored at once.

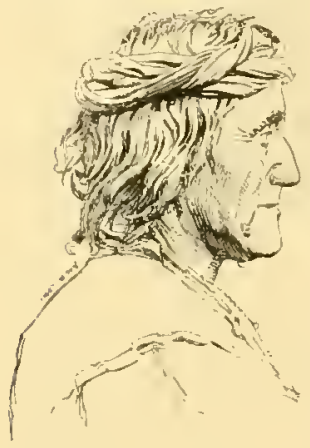

The inhabitants of the town of Gay Head, with the exception of the light-keeper's family; are of somewhat mixed blood. They are called Gay Head Indians, but their features betoken a liberal intercourse with a darker complexioned race; there is a flatness of the nose and an inclination to curliness in the hair which denote anything but an uninterrupted descent from the warlike tribe that Bartholomew Gosnold found in possession of these islands. The last one among them who could build a wigwam died some years ago, and with him died this invaluable secret.

Here there is room for the moralist to make some wise reflections on the vanity and evanescence of all human greatness, and to draw the parallel between this people's present peaceful occupations of farming and berry-picking (we even saw a young squaw who was engaged in a family as seamstress), and the Puritan-roasting, scalpraising, and other cheerful and innocent diversions which obtained among their ancestors. But we confess we would rather go fishing than point morals, any day, and our acquaintance with this people is confined to the young brave of some twelve summers whom we engaged in the morning as our henchman, to procure and cut up bait.

The cliffs at Gay Head are interesting alike to the artist and the geologist, and possess still another interest for the angler, who has to carry fifty pounds of striped bass up their steep and slippery incline. They are of clay formation, broken and striated by the washings of centuries, and when lighted up by the sun present a brilliantly 
variegated appearance, which undoubtedly gave the promontory its name. Black, red, yellow, blue, and white are the colors represented, all strongly defined, and on a clear day, discernible at a great distance. 1) own their steep sides, our feet sticking and sliding in the clay, moist with the tricklings of hidden springs, we pick our way slowly, bearing our rod and gaff-hook; while our little Indian staggers under a basket load of chicken-lobsters, purchased of the neighboring fishermen at the extravagant rate of one dollar and fifty cents per hundred.

It the bottom of the cliffs we skirt along the beach, stopping now and then to pick up bunches of Irish moss, with which the shore is plentifully lined, until we come to three or four large granite bowlders lying at the edgre of the water, and offering such attractions as a resting-place that we stop and survey the field to select our fishing-ground.

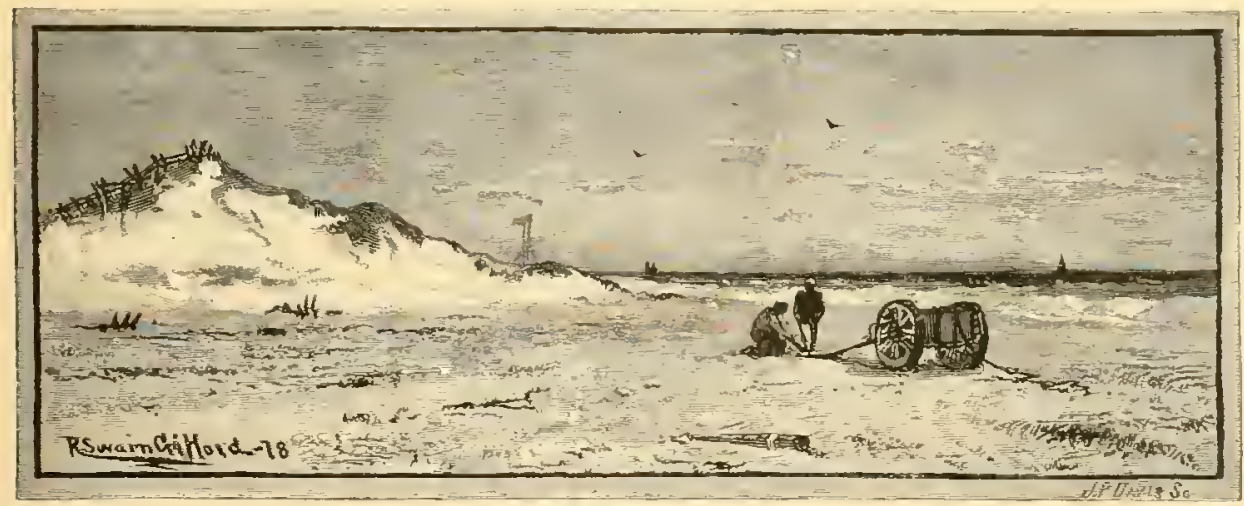

ON THE BEACH.

Across the Vineyard Sound, about eight miles away, and stretch ing out far to the eastward, are Cuttyhunk, Nashawena, and Pasque Islands; and about the same distance to the south-westward, the little island of No Man's Land is plainly visible in the clear atmosphere - even to the fishermen's huts with which it is studded. It is a 
notable place for large bass, and wonderful stories are told of the catches made there - how, on one occasion, when the fish were in a particularly good humor, three rods caught twelve hundred and seventy-five pounds of striped bass in a day and a half.

Looking out seaward some thirty or forty yards, we see three rocks heavily fringed with sea-weed, which rises and spreads out like tentacles with the swell of the incoming tide, and clings to the parent rocks like a wet bathing-lress as the water recedes and leaves them bare. We like the appearance of this spot-it looks as though it misht be the prowling-ground of large fish: and we adjust our tackle rapidly and commence the assault.

lnto the triangle formed by these rocks we cast our bait again and again, while our attendant crushes the bodies and claws of the lobsters into a pulp beneath his heel, and throws handfuls of the mess out as far as his strength will allow. He appears to have inherited some of the taciturnity of his red ancestors, for not a superfluous word do we get out of him all lay long; all efforts to lead him into conversation are met by monosyllabic answers, so that, after many discouraging attempts, we imitate his reticence and are surprised to find with how few words we can get along. A nod of the head toward the sea brings him into immediate action, and he commences to throw out chum rigorously, like a skillfully made automaton: a nod of another significance, and he brings three or four fresh baits and deposits them silently on the rock at our feet.

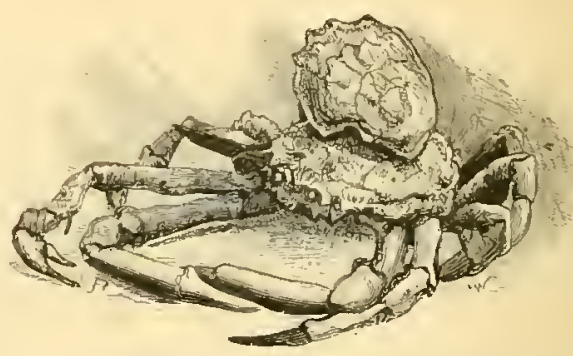

Thus we fish faithfully all the morning, buoyed up by the hope which "springs eternal" in the breast of the angler, but without other encouragement of any kind. Many nibblers visit our bait and pick it into shreds, requiring constant attention to keep the hook covered, while rock-crabs cling to it viciously as we reel in, and drop off just as we are about to lay violent hands on them.

The flood-tide, which had commenced to make when we arrived, is now running fast, and has risen so as to cover the rocks on our fishing-ground, leaving visible the dark masses of sea-weed which float to the surface by its air-cells, and wave mysteriously to and 


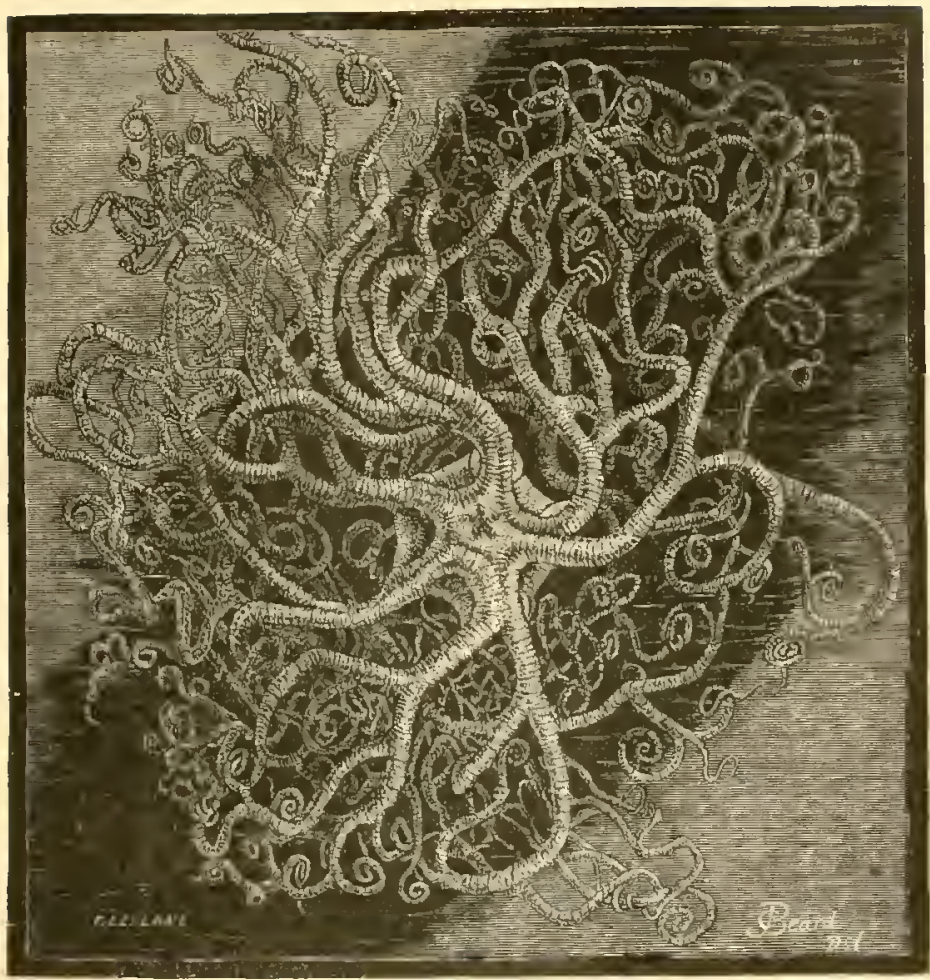

FROM THE DEPTHS (BASKET FISH-ASTRUPHYT(N)),

fro. The surf has risen with the tide, the water is somewhat turbid and filled with small floating particles of kelp or sea-salad, which attach themselves to the line and cause it to look, when straightened out, like a miniature clotlies-line. Occasionally, a wave will dash up against the shelving rock on which we stand, and, breaking into fine spray, sprinkle us liberally, and as salt water dries but slowly, we are gradually, but none the less surely, drenched to the skin.

Suddenly, without the slightest indication of the presence of game-nish, our line straightens out, we strike quick and hard to fix the hook well in, the reel revolves with fearful rapidity and the taut line cuts through the waves like a knife, as a large bass dashes away in his first mad run, fear and rage lending him a strength apparently much beyond his weight. Of course, under the circumstances, the strain on the fish is graduated, but the weight of line alone which he has to draw through the water would be enough to exhaust even a fifty-pounder, and he sonn tires sufficiently to enable us to turn his head toward land. As we pilot him nearer to the 
shore, he acts like a wayward child, making for every rock which happens in the way, and as there are many of them, it requires no little care to guide him past the danger. Presently, however, the steady strain tells on him, his struggles grow weaker, his efforts to escape beconie convulsive and aimless, and we lead him into the undertow, where he rests for a moment until a wave catches him and rolls him up, apparently dead, on the shelving sand. As he lies stranded by the receding water, the hook, which has worked loose in his lip, springs back to our feet. Our little Indian sees the danger and rushes forward to gaff him, with a whoop suggestive of war-paint and feathers; but we push him aside hurriedly - no steel shall mar the round and perfect beauty of the glittering sicles - and, rushing down upon him, regardless of the wetting, we thrust a hand into the fish's mouth and thus bear him safely from the returning waves; then we sit down on the rock for a minute, breathless with the exertion, our prize lying gasping at our feet, our nerves still quivering with excitement, but filled with such a glow of exulting pride as we verily believe" no one but the successful angler ever experiences, and he only in the first flush of his hard-won victory.

But there is no time to yloat over our prey-bass must be taken while they are in the humor, and our chummer is already in the field, throwing out large handfuls of the uninviting-looking mixture; so we adjust a fresh bait and commence casting again, as though nothing had happened to disturb our serenity, only once in awhile allowing our eyes to wander to the little hillock of sea-weed and moss under which our twenty-five pound beauty lies sheltered from the sun and wind.

Another strike, another game strugrgle, and we land a mere minnow of fifteen pounds. And this is all that we catch; the succeeding two hours fail to bring us any encouragement, so we reel in, and painfully make our way up the cliffs, bearing our prizes with us.

We are eager for another day at the bass, but a difficulty presents itself; fish are perishable in warm weather, the bass in a less degree than many others, but still perishable, and we have no ice, nor is any to be purchased nearer than Vineyard Haven - which for our purpose might as well be in the Arctic regions. But we bethink us that we have friends at the Squibnocket Club, some five or six miles away, on the south-west corner of the island, and in the afternoon we persuade Mr. Pease to drive us over there. 
The comfortable little club-house is built facing and adjacent to the water, and after supper, as we sit chatting over a cigar on the piazza, we look out upon the wildest water we have as yet seen. The shore is exposed to the direct action of the ocean, without any intervening land to break the force of the sea, and the white breakers fol-

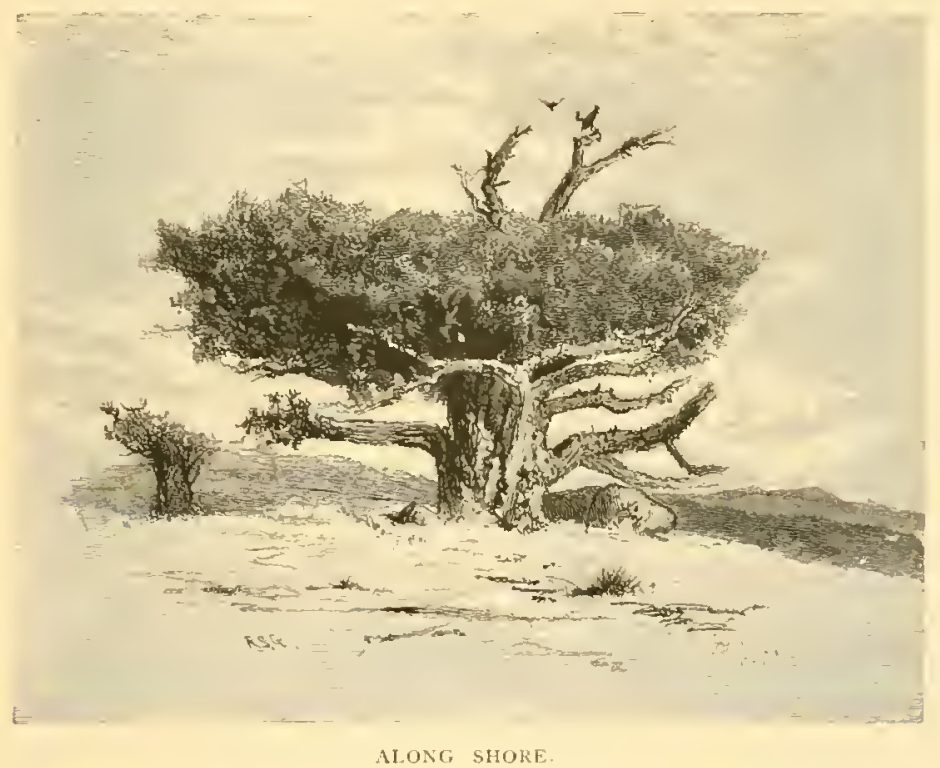

low each other in rapid succession, lashing themselves against the rocks into a foamy suds, which looks as though it might be the chosen home of large bass - as, indeed, they say it is.

The following day is almost a repetition of the first - a long, profitless morning spent in fruitless casting, a sudden strike when we least expect it, and then the catching of three fish within an hour and a half. This capricious habit of the bass is very striking at times. Sometimes, day after day, they will bite at a certain hour, without reference to the height of the ticle, and at no other time. Whether it is that they have set times to visit different localities, and only arrive at the fishing-ground at the appointed hour, or, whether they are there all the time and only come to their appetites as the sun indicates lunch-time, we cannot say.

Our trip is over, and we pack our things to return home. Stored in a box, carefully packed with broken ice, are five bass,- we take no account of two blue-fish of eight and ten pounds, - which weigh respectively twenty-five, fifteen, twenty-eight, twenty-one, ten pounds. 


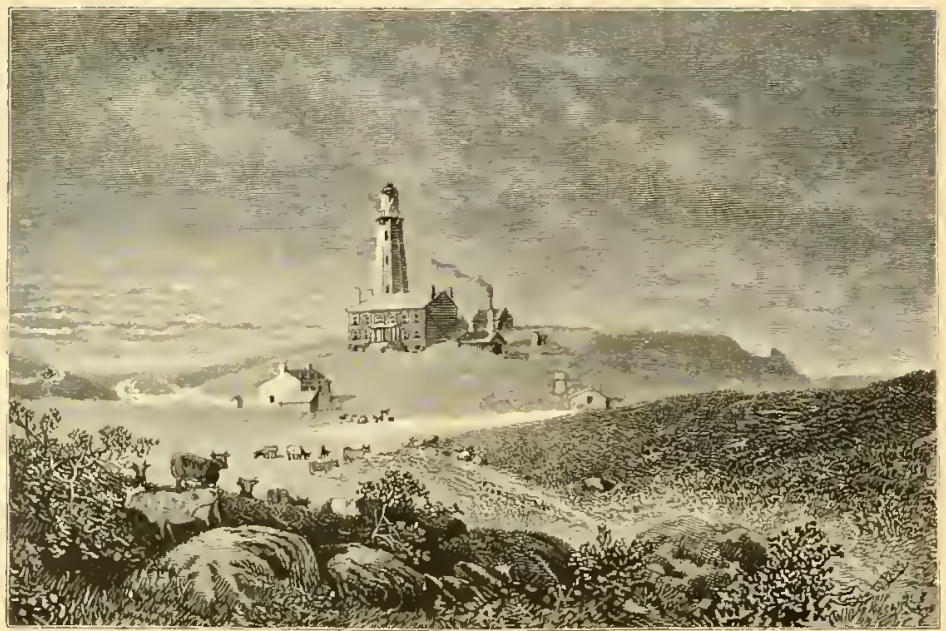

MUNTAUK LIGHT.

If the reader should wish to enjoy this noble sport, the better plan by far is to purchase a share in one of the great bassing clubs, as at their comfortable quarters you can always be certain of bait, skillful chummers, and ice to preserve the fish when caught; and, moreover,

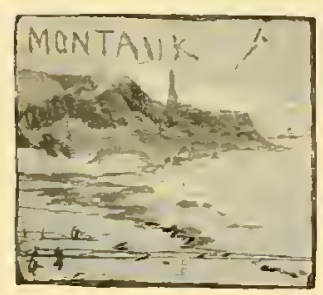
a good meal and a comfortable bed after a hard day's work, or play, as you choose to call it, are desiclerata not always to be obtained at the country tavern where your lines may be cast. But should the intention be to fish only occasionally, then equally good sport may be had in the summer and early autumn months at Montauk Point, Point Judith, Newport, Cohasset Narrows, and many places along shore.

A seventy-two-pounder, caught by a gentleman of New York, is probably the heaviest bass that has yet been landed with rod and reel; and when it is considered that the line used would not sustain much more than one-third that amount of dead weight, and that every ounce of that sev-

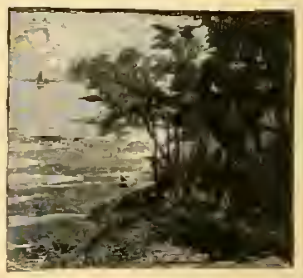
enty-two pounds was "fighting weight," some conception may be formed of the skill and patience required in its capture.

Verily there is nothing new under the sun. As I pen these lines regarding the capture of large fish with light tackle, there comes to mind the memory of a screed written in the long, long ago, and I step to the book-shelf, take down the volume, and transcribe for your 
delectation, $\mathrm{O}$ reader, the quaint advice given by that sainted patroness of the angle, Dame Juliana Berners, nearly four hundred years ago. There is a flavor of mold about the fine old English, but it contains the sum and essence of all scientific angling. Here it is, crisp and fresh as when it was first written, though the hand that penned it has long since crumbled into dust, and the generation for whose "dysporte" it was "empryntyd" by Wynkyn de Worde have been casting their flies from the further bank of the Styx this many a long year:

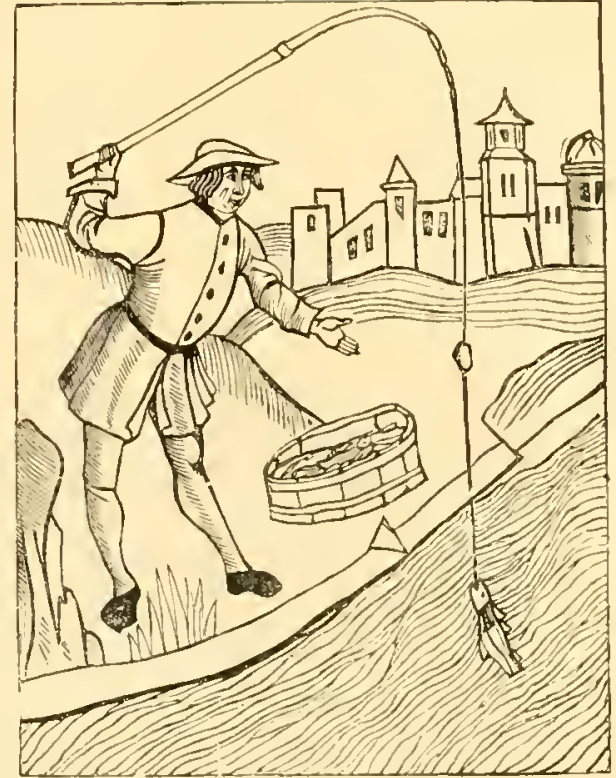

FISHING A. D. I.496. (FROM "wALTUN's COMPLETE ANGLER.")

"Ano of it fortulue pou to smpt a gret fish with a small barmans, theme ne must lroe byut in the water and labour hym there tyll be be orompo and obercome; themte take bum as well as pe can or mave, and ster be waar that pe holde not oure the strengthe of nour lyur, amo as moebe as ve man

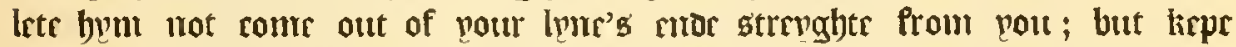
bum sure under the rodor, and ruermore holde bym strenghte, so that pour

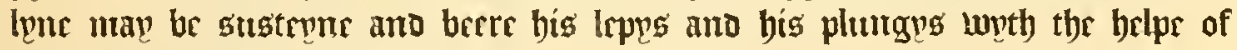
vout cropp and of nout honde."

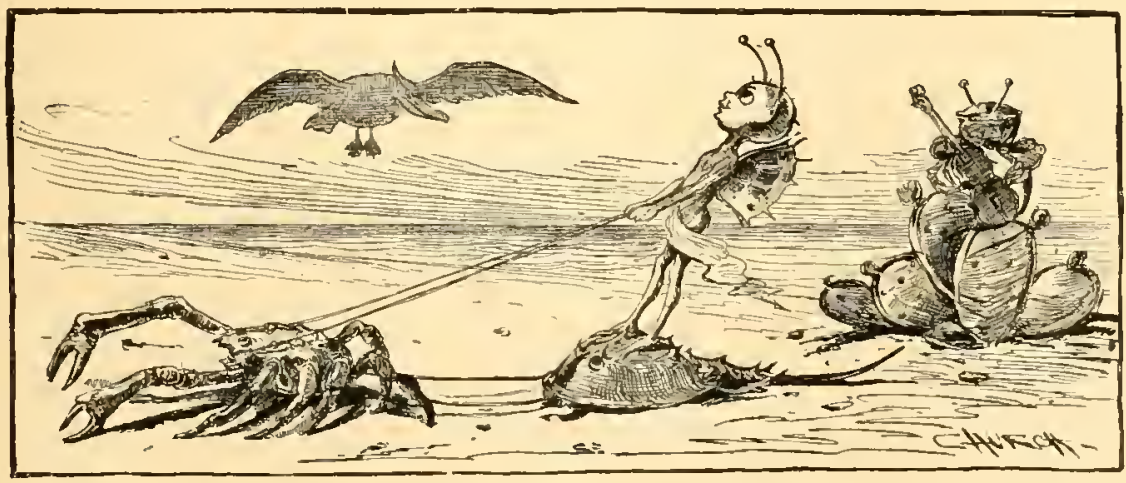




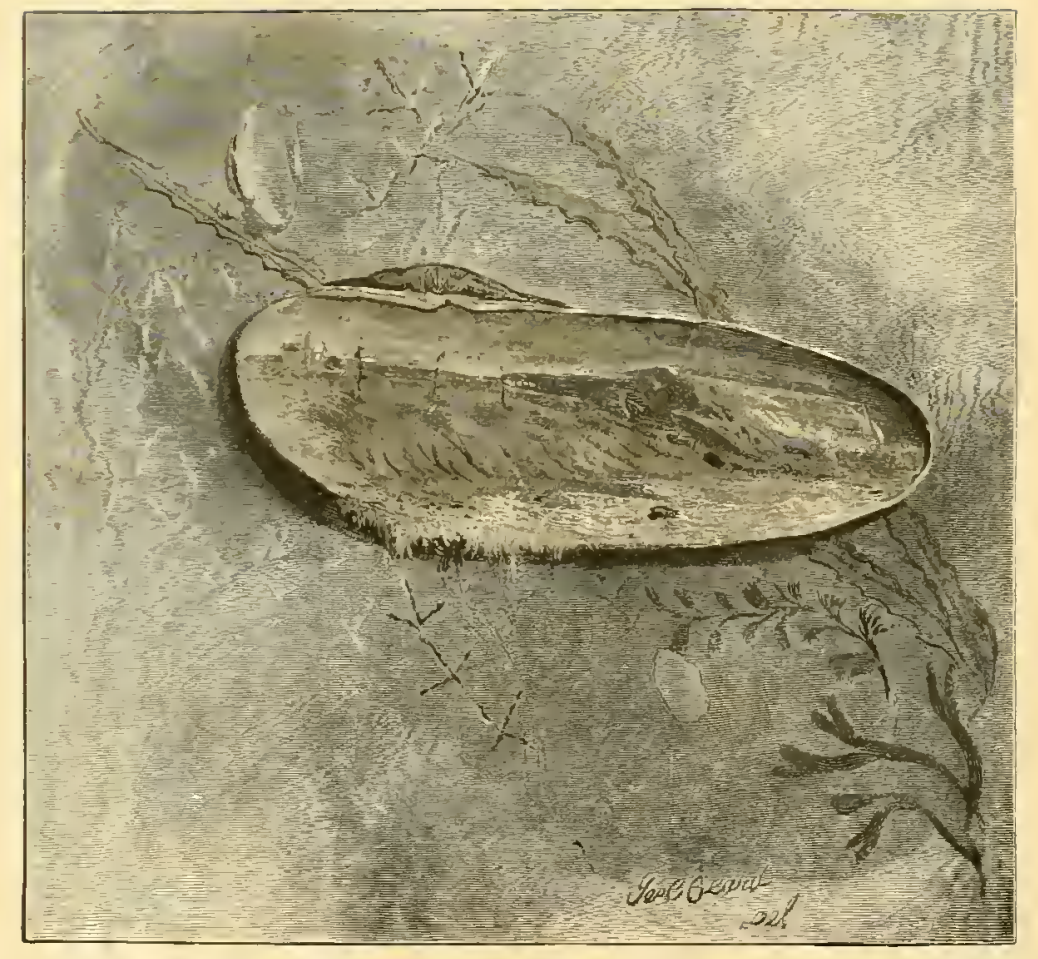




\section{PORPOISE-SHOOTING. \\ HY CHARLFL}

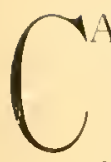

ANOE ahoy-oy-oy !"

"Ahoy-oy-oy!"

"Where are you bound?"

"Indian Beach, Grand Menan."

"You can't fetch it, in this wind and sea; better come aboard the schooner."

The hail came from an outward bound pilot-boat, running down the Bay of Fundy, close-reefed, in a strong breeze, and was addressed to the writer and his Indian friend Sebatis, who were crossing the bay in a canoe bound to Indian Beach, Grand Menan, on a porpoiseshooting expedition.

"Sebatis, the men in the schooner want to take us aboard; they say that there is too much wind and sea to fetch Indian Beach with the canoe."

"No danger: canoe best; we fetch "in Indian Beach all safespose we go on pilot-boat, sartin very sea-sick."

On hearing Sebatis's remark, a hearty laugh and a cheer came from the crew of the pilot-boat; thanking them for their kind intentions, we bore away for our destination.

To one unaccustomed to the sea-worthy qualities of a birch canoe properly handled, the situation would have scemed a perilous one. for the sea was running high, and the breeze stiffening.

"Look out, Sebatis!" I exclaimed, involuntarily, as I was drenched by the spray from a sea breaking almost aboard of us.

"All right! no danger "tall ; only little wet."

"l'm afraid we'll be swamped, Sebatis." 
"No chance swamp "im; I watch canoe so close, you see, water can't come 'board 'tall."

I began to think that our situation very much resembled that of the old Indian who, for lack of a sail, put up a big bush in the bow of his canoe:-all went well with him until the wind increased to a gale and he could not get forward to reef his bush. So he sat like a statue, steering with his paddle, and repeating, in a mournful monotone:

"Too much bush, too much bush, for little canoe."

With this in my mind, I said to Sebatis:

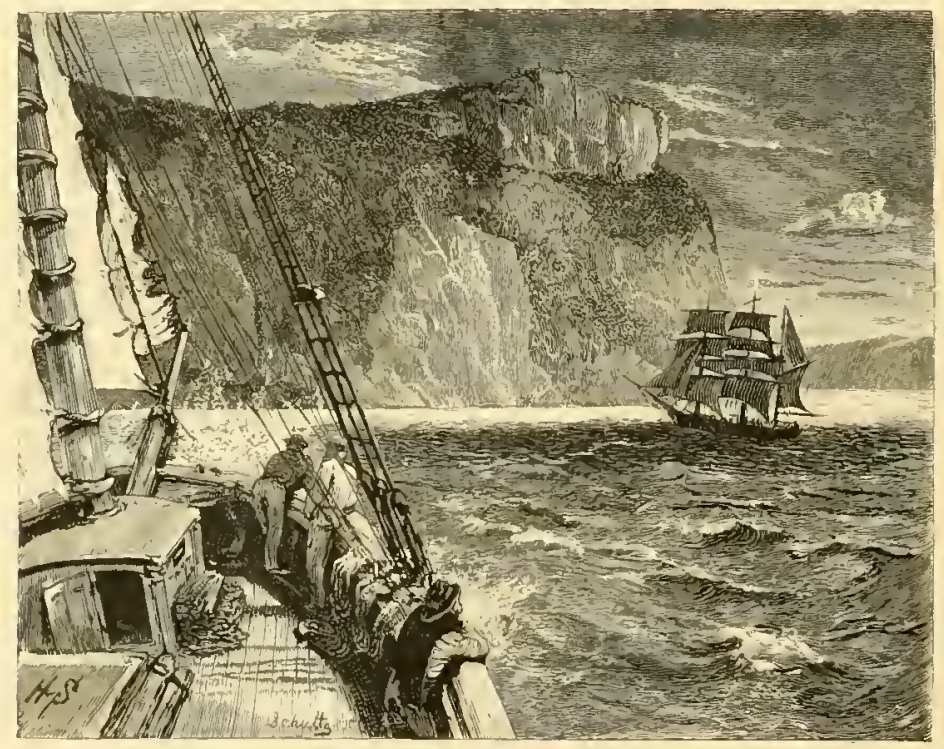

CAPE, BLOMIDON, BAY OF FUNDY.

"Don't you think that we are carrying too much sail? A heavy squall might upset us."

"Well, you see," he replied, "no chance reef "im now, wind so heavy; but I take care, got sheet in my hand, s'pose squall, then I let go pretty quick."

He had the sheet in his hand, as he said, and was steering with the paddle in the other, whale-boat fashion. So I took heart of grace and troubled myself no more about the matter.

"You hear "im wolves?" said Sebatis, pointing to a low-lying group of rocky islands that have crushed many a noble ship with their ugly fangs; "make good deal noise" (alluding to the surf); "wind shift now - fair all way Indian Beach." 


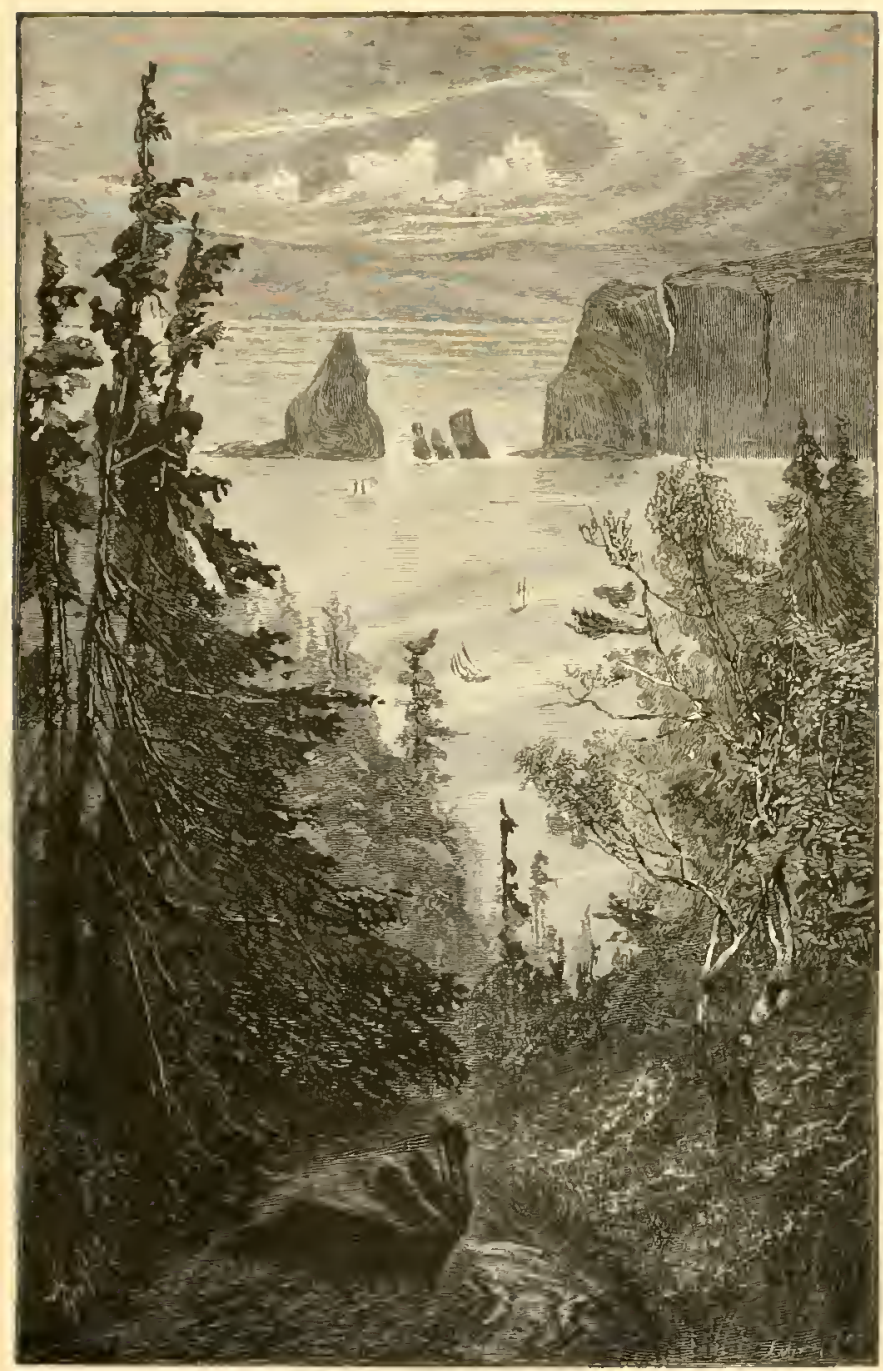

CAPE SPLIT, BAY OF FUNDY.

And away we bounded, the canoe riding the waves like a duck, and so buoyantly that at times six feet of her length were out of water.

After we had sailed for another hour:

"Only a little ways now," said Sebatis. "Just 'round big headland, then no wind, only sea pretty heavy."

In a few moments, we doubled the headland safely, and Sebatis. unstepping the mast and stowing the sail in the bottom of the canoe, resumed his paddle. 
On viewing our prospect for landing, 1 must confess to more anxiety than I had hitherto experienced. True, we were out of the wind, but the night was shutting down apace, and a transient gleam from the storm-rent clouds disclosed the sea rolling in on the beach in such a manner as to make our landing, in the treacherous light of the departing day, a dangerous one.

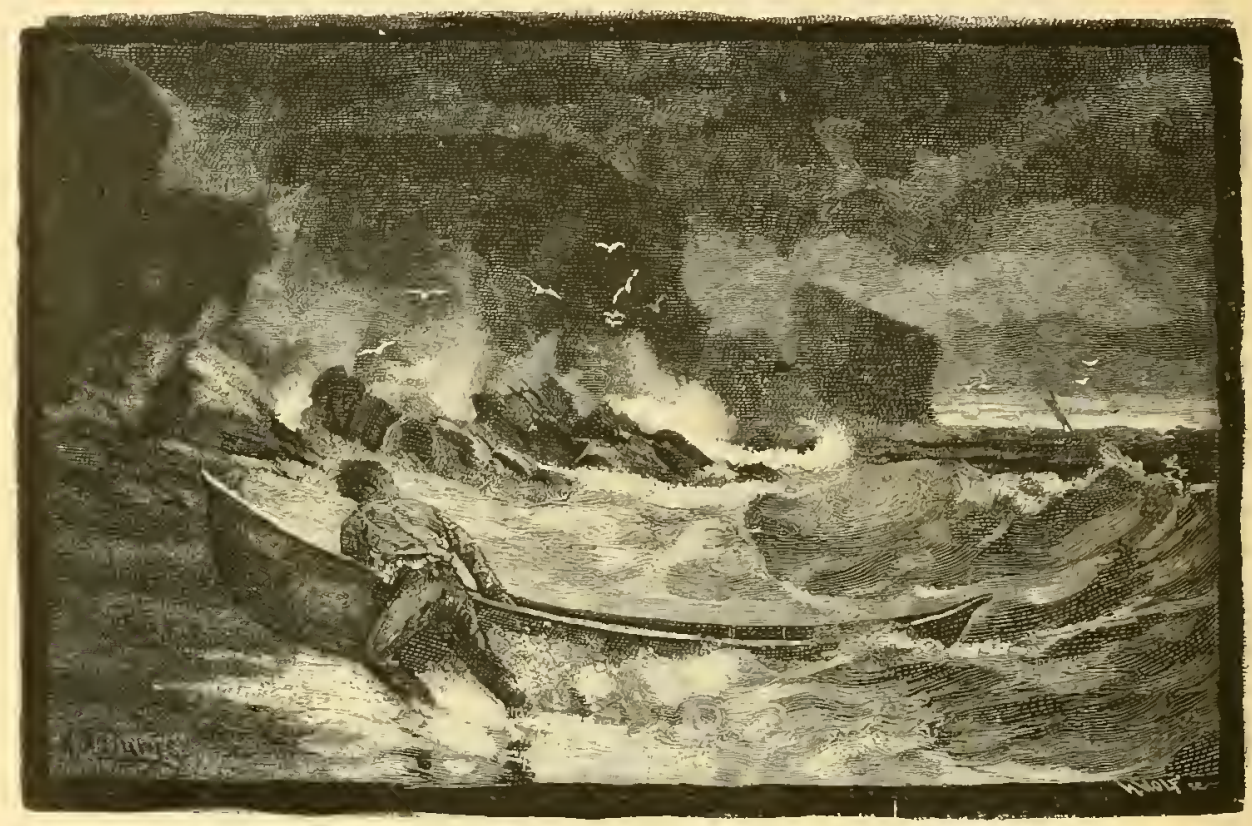

SEBATIS BEACHING THE CANOE.

"Now, then," exclaimed Sebatis, "s'pose you jump overboard, and run right up the beach, when I give the word. I'll beach the canoe all 'lone myself."

He was paddling with might and main, and we were successfully riding the waves within one hundred yards of the beach.

"Now then, jump quick, and run!" he cried, as a receding wave left us in a swashing undertow.

I was overboard in an instant, and struggled out of the reach of the sea. After holding the canoe steady while I jumped, Sebatis followed, and, partly dragging and partly carrying the canoe, beached her high and dry.

We were now on Indian Beach, where the Indians camp for the summer and autumn porpoise-shooting. The beach extends for about half a mile, between two projecting headlands, and the camps, 


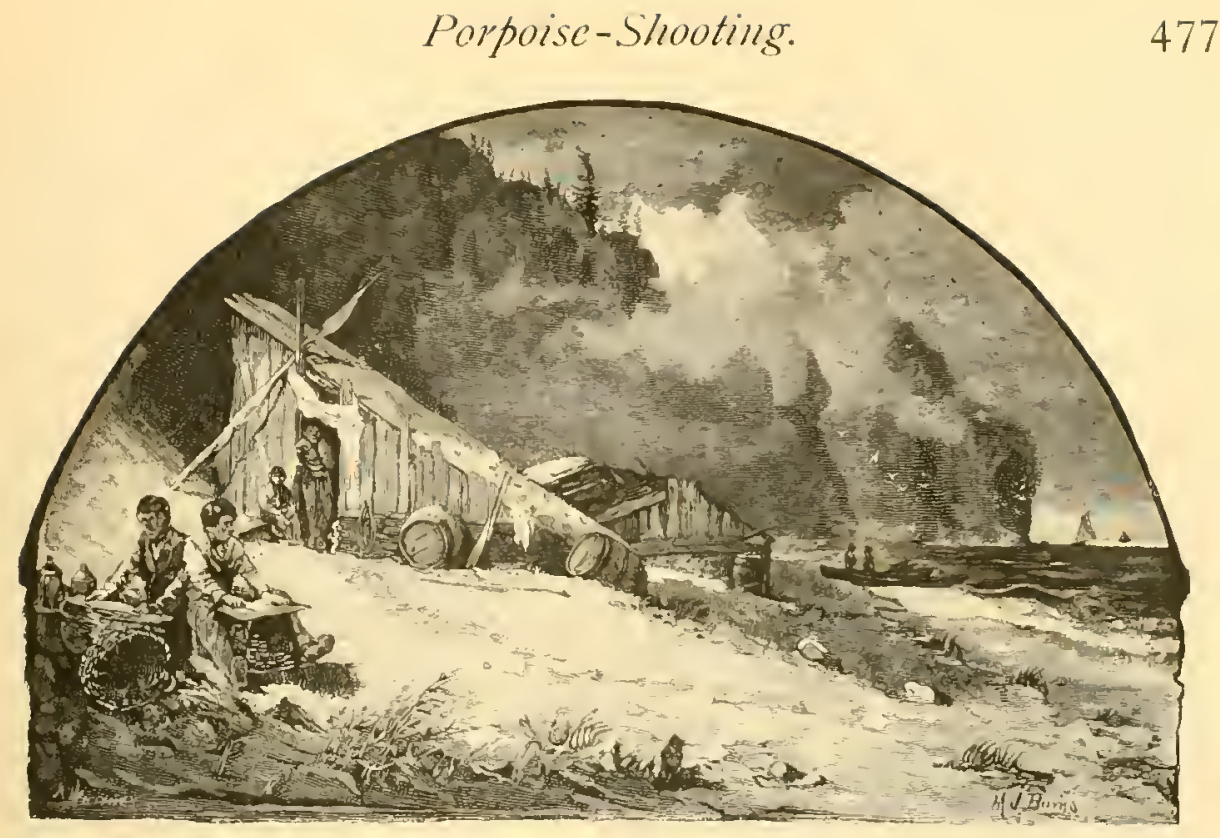

THE CAMP AT INDIAN BEACII.

constructed of drift-wood, are placed just above high-water mark, and under the shelter of the overhanging cliffs.

Drenched with salt water, and as hungry as wolves, we unpacked the canoe and carried our " possibles " to Sebatis's camp.

Porpoise-shooting affords to the Indians of the Passamaquoddy tribe their principal means of support. It is practiced at all seasons of the year, but the fish killed in the winter are the fattest and give the largest quantities of oil. The largest-sized porpoises measure about seven feet in length, about the girth five feet, weigh three hundred pounds and upward, and yield from six to seven gallons of oil. The blubber is about one and one-half inches thick in summer, and two inches thick in winter, at which time the creature is in its best condition. The blubber from a large porpoise weighs about one hundred pounds. The Indians try out the oil in a very primitive manner, and with rude but picturesque appliances. The blubber is stripped off, then cut into small pieces, which are placed in huge iron pots and melted over a fire. All along the beach were placed. at intervals, curious structures, consisting of two upright pieces of wood surmounted by a cross-piece, from which the pots were hung by chains. Under this cross-piece large stones were piled in a semicircle, inside of which a fire was made that was allowed to burn fiercely until the stones were at a white heat. The fire was then 
scattered, and the pots containing the blubber were placed over the stones and just enough fire kept under them to insure the melting of the blubber. When melted, the oil was skimmed off into other receptacles, then poured into tin cans of about five gallons capacity, and the process was complete. If the oil is pure, it readily brings ninety cents per gallon, but if adulterated with seal, or any other inferior oil, its value is reduced to sixty-five cents per gallon. A very superior oil is obtained from the jaw of the porpoise. The jaws

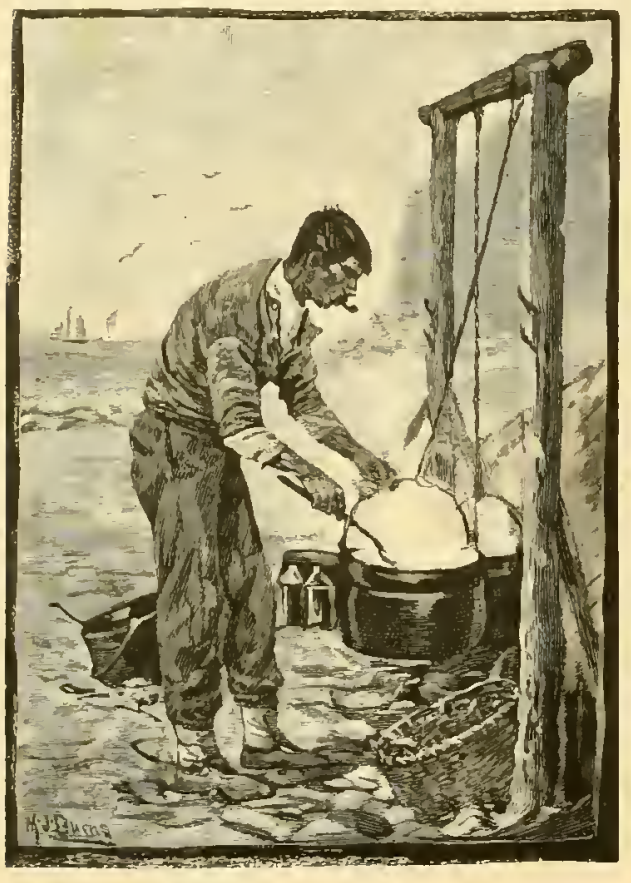

TRYING OUT BLUBBER. are hung up in the sun, and the oil, as it drips, is caught in cans placed for that purpose. The quantity of oil thus procured is small, being only about half of a pint from each jaw, but a large price is paid for it by watchmakers and others requiring a fine lubricator. The oil from the blubber gives a very good light, and was for a long time used in all the light-houses on the coast. It is also a capital oil for lubricating machinery, as it never gets sticky, and is unaffected by cold weather. When pure, it has no offensive smell, and I know of no oil equal to it for those who are compelled to use their eyes at night. The light is very soft, and, when used in a German student's lamp, one can work by it almost as comfortably as by daylight.

If industrious, and favored with ordinary success, an Indian can kill from one hundred and fifty to two hundred porpoises in a year, and each porpoise will probably average three gallons of oil, which is always in demand. But, unfortunately, the poor Indians are not inclustrious, or only so by fits and starts, or as necessity compels them. When they accumulate fifteen or twenty gallons of oil, they take it to Eastport. Maine, to market; and so, much time is lost in loitering about the towns, and in going to and returning from the 


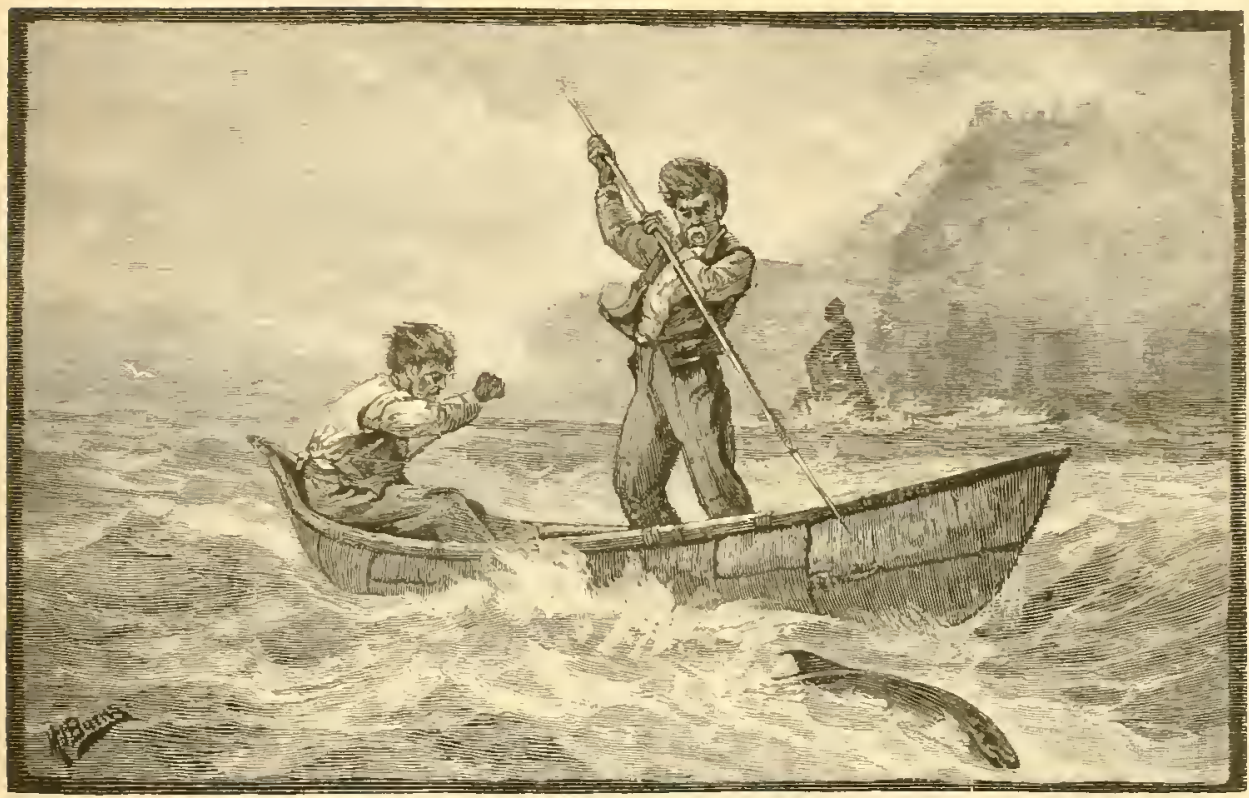

SPEARING A PORPOISE.

hunting-grounds. Noreover, there are always two Indians to each canoe, and the proceeds of the hunt have to be divided. The flesh of the porpoise, when cooked, tastes like fresh pork, and at one time was much used. The Indians still eat it, and it is also in request by the fishermen on the coast, who readily exchange fresl: fish for "porpus" meat with the Indians.

Almost unknown to the outside work, here is an industry followed by these poor Indians, year after year, calling in its pursuit for more bravery, skill, and endurance than perhaps any other occupation. 1 could not help feeling a melancholy interest in them and their pursuits as I sat on the beach at sunrise, watching them embark on their perilous work. For these poor creatures, "porpusin' " possessed an all-absorbing interest, and the chances of success, state of weather, and price obtainable for the oil were matters of every-day discussion.

In the morning, all the women and children turned out to see the canoes go off, and if cluring the lay a storm came up, or the canoes were unusually late in returning, many anxious eyes would be turned seaward. They were always pleasant and good-natured with one another, and generally returned from the hunt about three o'clock in the afternoon. After dinner, one would have thought that, tired 
out with their exertions, they would have sought repose; but they did not seem to need it, and the rest of the day until sundown would be spent in friendly games upon the beach.

To make a successful porpoise-hunter requires five or six years of constant practice. Boys, ten or twelve years of age, are taken out in the canoes by the men, and thus early trained in the pursuit of that which is to form their main support in after years. Porpoise-shooting is followed at all seasons and in all kinds of weather - in the summer sea, in the boisterous autumn gales, and in the dreadful icy seas of midwinter. In a calm summer day, the porpoise can be heard blowing for a long distance. The Indians, guided by the sound long before they can see the game, paddle rapidly in the direction from which the sound comes, and rarely fail to secure the fish. They use long smooth-bored guns, loaded with a handful of powder, and a heavy charge of double $B$ shot. As soon as the porpoise is shot, they paddle rapidly up to him and kill him with a spear, to prevent his flopping about, and upsetting the canoe after they have taken him aboard. The manner of taking the porpoise aboard is to insert two fingers of the right hand into the blow-hole, take hold of the pectoral fin with the left hand, and lift the fish up until at least one-half of his length is above the gunwale of the canoe, and then drag him aboard.

This is comparatively easy to accomplish in smooth water, but when the feat is performed in a heary sea, one can realize the skill and daring required. In rough weather, with a high sea running, the Indian is compelled to stand up in his canoe when he fires, otherwise he could not see his game. In such work as this. one would suppose that upsets would be unavoidable; but, strange to say, they seldom happen,-and only under circumstances where the Indian's skill or foresight is unavailing. When an Indian stands up in his canoe, in rough water, he suits himself to every motion of his frail craft, and is ever ready to sway his body and keep her on an even keel. In this he is ably seconded by his comrade who manages the paddle, and with marvelous dexterity urges the canoe forward, checks her, backs her, whirls her completely around, or holds her steady as a rock, as the emergency may require.

Although an old and experienced canoeist, in the matter of shooting porpoises from a canoe in a heavy sea, and taking them aboard, 


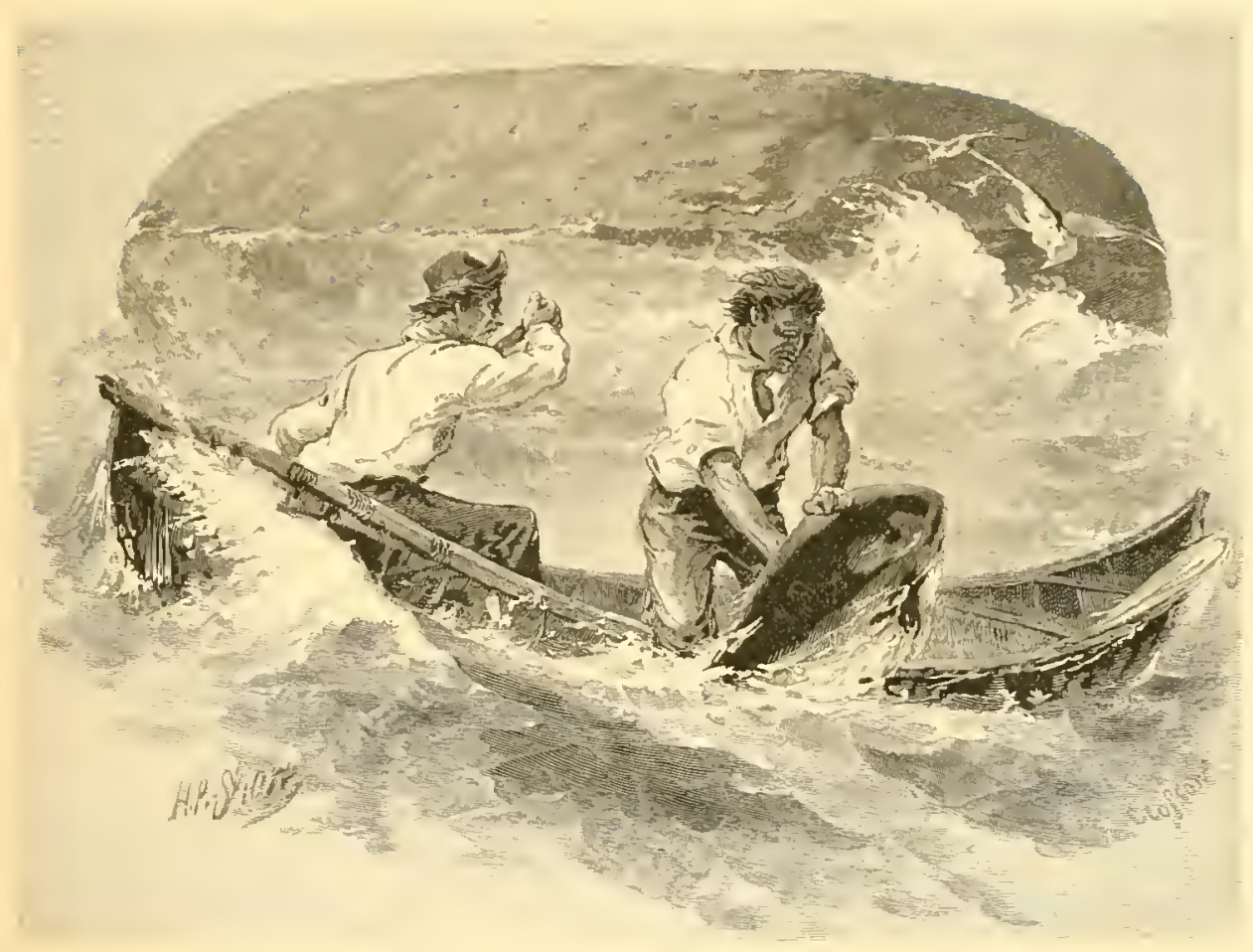

TAKING A PORPUISE ABOARD.

I often feel inclined to side with my friend Colonel IV-, who once arranged a porpoise-shooting expedition on shares with an Indian named Paul. It was the Colonel's first and, I may ald, last experience in this kind of shooting, for the Indian, having shot a very large porpoise, paddled rapidly up to him, speared him, and was in the act of hauling him aboard, when the Colonel recovered his power of speech, and excitedly exchaimed:

"Hold on, Paul! hold on! How much is that porpoise worth?"

"How much worth? May be five dollars."

"Well, Paul, I'll pay you half, and we wont take the porpoise in."

"No," replied Paul, "I pay y'on half; sartin, we take in "im porpus."

The Colonel's appeal was of no avail, as they were surrounded by other canoes similarly occupied, and it was a point of honor with Paul to take the porpoise aboard, otherwise he might have been suspected of cowardice.

Not unfrequently, as the Indian hastily paddles up to dispatch a wounded porpoise with his spear, he sees the terrible dorsal-fin of a 
shark appear, as the monster, attracted by the scent of blood, rushes to dispute possession of the prey.

Mlthough there are well-authenticated cases of a shark's having actually cut the porpoise in two just as the Indian was lhauling it aboard of his canoe, 1 have never heard of any harm resulting to the Indians from attacks of this nature; nor do they in the least fear the sharks, but, on the contrary, boldly attack and drive them off with their lons spears.

One evening, after I had passed several days on the Indian Beach, sketching and making studies, Sebatis returned from visiting one of the camps, and said:

"S'pose you like to try 'im porpusin', I find very grood hand go with us."

"Who is he, Sebatis?"

"You never see "im 'tall; his name's Pieltoma."

"When do we start?"

"May be about daylight, spose no fog."

Judging by my experience during the few days that I had been on the island, Sebatis's proviso about the fog seemed likely to indefinitely postpone our expedition. Whence the fog came, or whither it went, seemed one of those things that no person could find out. At times, when the sun was shining brightly, the distant cliffs would suddenly become obscured as if a vail had been dropped over them, then nearer objects would become indistinct, and while one was wondering at the rapid change, everything animate and inanimate would vanish as if by magic. For a time, silence reigned supreme, then a din as of the infernal regions began. First, a big steamwhistle on the land half a mile away sent out its melancholy boooo-oo in warning to passing mariners; then from the sea came the answering whistle of some passing steamer; then the fishermen at anchor in the bay blew their tin fog-horns and their conch-shell foghorns, until at last one became thoroughly convinced that every conceivable and inconceivable form of "American devil," as the English term our steam-whistle, was faithfully represented in the uproar. Now and then, during an interlude, a sound that might have been uttered by a mountain gnome echoed through the void. This was the dismal "kong, kong" of the raven, seated away up on some projecting crag. Here the raven is a regal bird and attains 


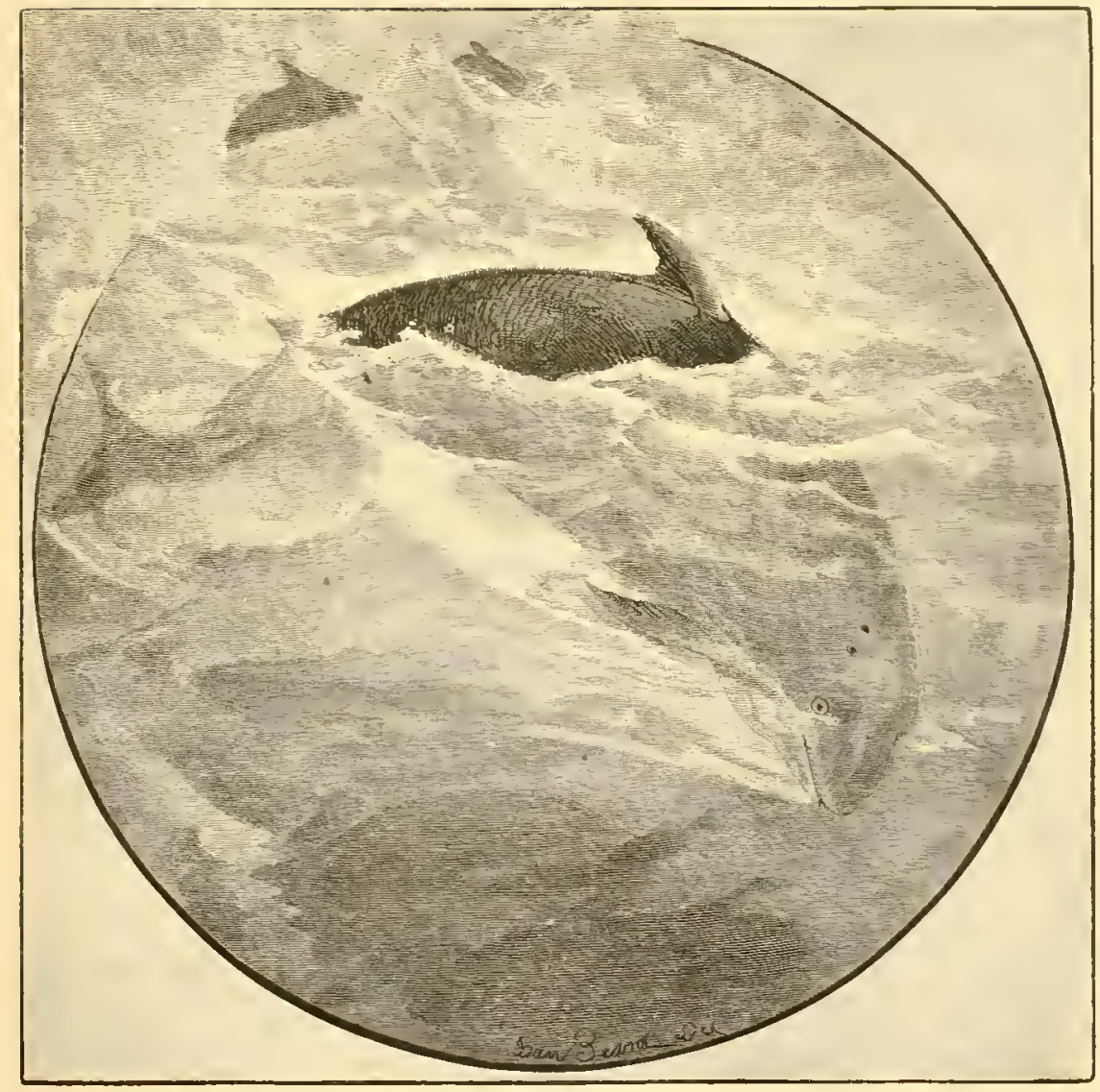

A PORPOISE DIYING.

DRAWN BY DAN. BEARD, AETER A SKETCH BY CHARLES C. WARD. 

his greatest size and most majestic form. The transformation came as quickly, and almost in a twinkling the vail would be lifted from the hill, and the sun would shine out again, bright and warm. Some of the effects of light and shade produced by these sudden transitions are grand beyond all power of description.

Just about daylight next morning, Sebatis aroused me. There was no fog, and it was quite calm on the water, and, as Sebatis remarked:

"A very good day for porpusin."

Pieltoma, a fine-looking young Indian, joined us at breakfast, and, that over, we embarked in Sebatis's canoe and paddled off in quest of porpoises.

"How far out are you going, Sebatis?"

"Can't tell yet; you see, by-em-by; may be we hear "im porpusis blowin' somewheres."

"I hear 'im porpus blowin' just now," said Pieltoma. 'tall."

"Sartin, Pieltona got pretty good ears; I don't hear "inn nothin"

"I hear 'im, sartin," reiterated Pieltoma.

"Which way ?" asked Sebatis.

"Away up on rips, this side Eel Brook. Hark! you hear im now ?" he continued.

"Sartin," said Sebatis. "We go now pretty quick."

Simultaneously their paddles struck the water, and away we went with redoubled speed. I was listening intently; but, so far, my uneducated ears failed to detect the sound.

"There goes porpus!" said Sebatis, dropping his paddle and taking up his gun.

Just then a deafening roar came from the stern, where Pieltoma sat, and the canoe tilted slightly over.

"By tunders!" cried Sebatis, in a chiding tone. "You miss "im porpus sartin, and most upset canoe beside; some time you bust "im gun, s'pose, you put in so much powder."

This custom of overloading their guns frequently results in serious accidents to the Indians, and 1 know two Indians, one with a broken jaw and one with a broken shoulder, the result of this habit. In this, however, they are not singular, as the fishermen of Newfoundland, who use old muskets for cluck and seal shooting, overload 


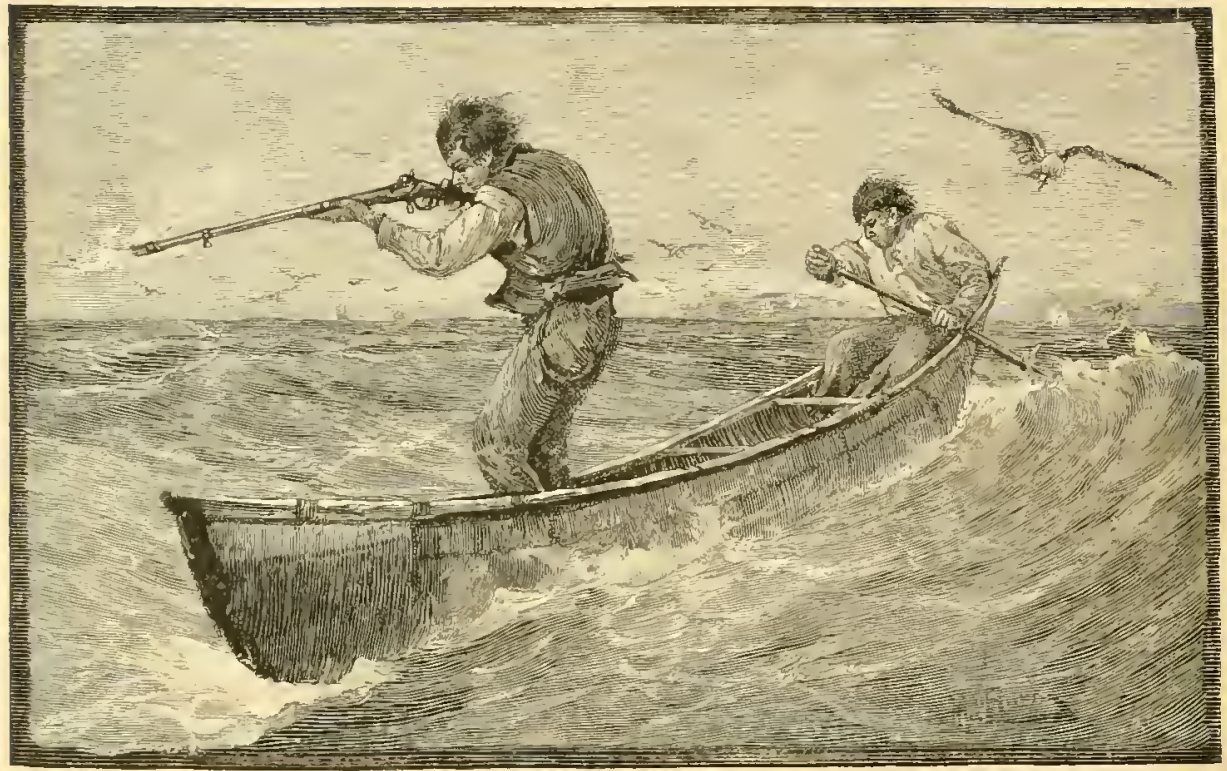

SIOOTING A PORPOISE.

in the same way, and broken shoulders and broken noses are said to be quite common among them.

Poor Pieltoma secmed quite disconsolate at this misadventure, and without remark of any kind resumed his paddle, and we continued on our way.

"What do the porpoises feed on, Sebatis?"

"He eat "im mackerel, herrin's, and most all kinds of small little fishes. By-em-by we come on feedin'-grounds, then see 'im more porpusis."

"1 hear "im porpus again," remarked l'ieltoma.

lnstantly, Sebatis was on his feet, gun in hand, and I just caught a glimpse of a dark body rolling over in the water some fifty yards away, when Sebatis fired, then dropped his grun, and picked up the long spear which lay ready to his hand in the bow of the canoe.

Pieltoma paddled quickly up to the porpoise, and Sebatis stabbed the dying fish repeatedly, and then dragrged him aboard of the canoe. He was a medium-sized fish, and weighed about two bundred pounds.

"Now, then, fill my pipe first, then we go hunt 'im somewhere else; may be find "im more porpusis," said Sebatis.

"It will be Pieltoma's turn to shoot the next porpoise." 
"No; Pieltoma best paddle canoe. I shoot im porpusis."

It afterward transpired that Pieltoma was not an expert in porpoise-shooting. I had thought that all Indians were good porpoisehunters; but it seems that there are several grades of excellence, and that some of the Indians never attain the requisite skill. P'oor Pieltoma was one of the latter class, and in future would have to stick to the paddle, in the management of which he excelled.

After paddling along for some time in silence, he said:

"Sebatis, s'pose we try 'im farther out; porpus may" be chase "im mackerel somewheres. I see "im plenty gulls outside."

"Sartin, that's a very grood plan," replied Sebatis. "We'll go about two miles out."

"Storm coming, Sebatis; wind and sea both rising."

"No, not any storm; only little breezy, that's all. By-em-by you see 'im plenty porpusis. Nways when breezy, then porpusis kind playin', you see-jump round everywheres."

"Do the porpoises go in large schools?"

"Always good many together; sometimes I see "im forty or fifty porpusis all jumpin' 'round at the same time."

"There goes three porpusis!" said Pieltoma.

"Which way?" asked Sebatis.

"There they are. Sebatis," I said, as several black objects appeared, rolling over in the waves.

"I see 'im now. 'Nost too far off shoot 'im. Paddle little ways closer, Pieltoma."

Presently, bang goes his gun, and we are paddling rapidly up to the fish, which is blowing and thrashing the water into foam.

"Pretty big porpus; go over three hundred," said Sebatis, as he savagely speared the porpoise.

" "Mlost too big take im in. Sebatis," said Pieltoma.

"No, not too big; s'pose you come help me to lift 'im up."

Pieltoma came forward, and I passed aft and took the paddle to steady the canoe. As they struggled to get the fish aboard over the gunwale, my knees began to shake - there was quite a swell on, and I feared that we might go over. However, they got it safely aboard at last.

“By tunders! that's pretty good luck, gettin' so big porpus; about six gallons oil, sartin!" exclaimed Sebatis, exultingly. 
"Almost upset the canoe that time, Sebatis."

"Oh, no; no danger to handle a porpus when two men in the canoe. Spose only one man, then pretty risky. About a year ago I got upset myself, takin' in a big porpus all 'lone. Fisherman see me, and send small boat take me off, and tow canoe alongside schooner. Not so bad, you see; save porpus, canoe, paddle, and spear;- lose my gun, that's all."

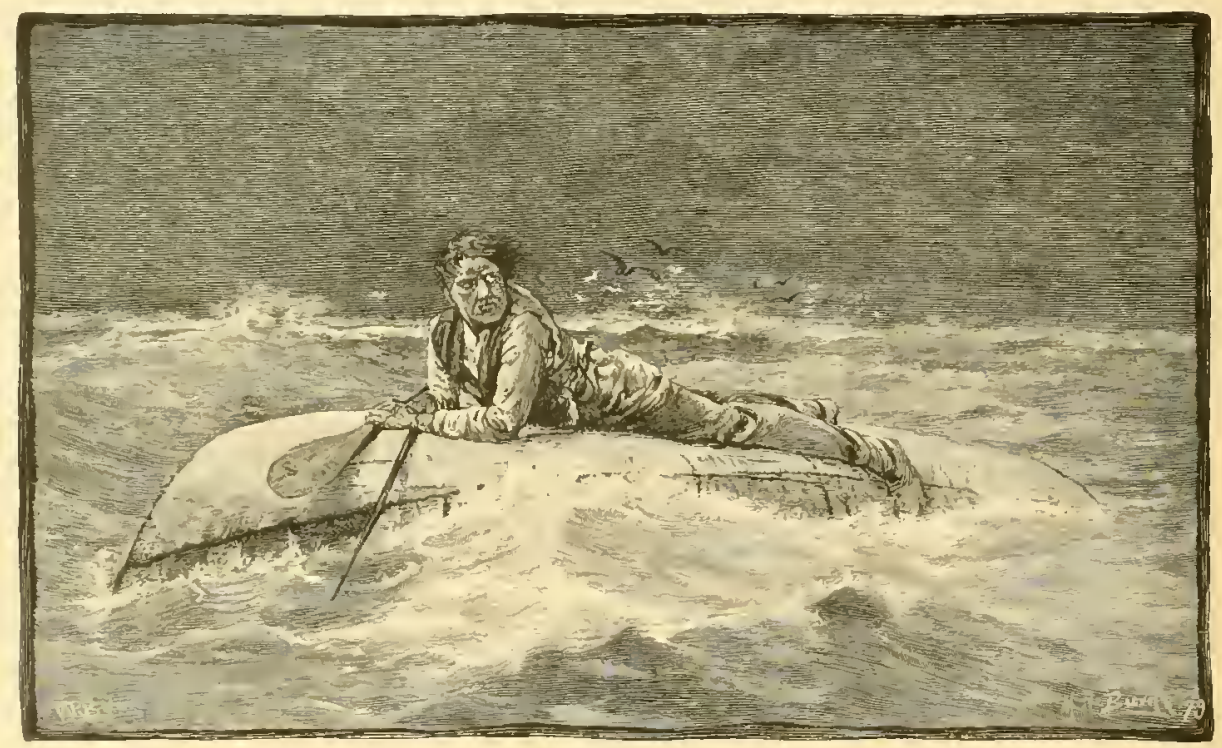

SEBATIS ADRIFT.

"You bad a very narrow escape that time."

"Well, you see, almost don't 'scape 'tall, wind and sea so heavy. By tunders! when I get ashore, and tell all about it, good many lngins come and listen."

"Go on, Sebatis."

" Vell. s'pose I got to tell "im anyhow; best land somewheres, and put 'im out porpuses, and get dinner first; then I tell 'im story, — too hungry now."

After dinner, Pieltoma washed out and dried the canoe, and once more we set out in pursuit of the porpoises.

"Where are we going now, Sebatis?"

"Goin' away long eddy, off northern head."

"Is that a good place for porpoises?"

"Sartin; always on rips very good place: you see, plenty mack- 
erels, herrin's, and all kinds fishes in eddies and rips; very grood feedin'-ground for porpusis, you see."

The eddies, or rips, alluded to by Sebatis, were caused by the obstruction offered by projecting headlands to the ebb and flow of the tide, which on this coast rises some forty feet.

"Pretty late when we gret back, spose we go all way to long rips," said Pieltoma.

" Well," replied Sebatis, "s'pose dark, then we'll camp somewhere all night. I fetch "im provisions and cooking tools; sartin, canoe and sail make very good camp."

Talking did not interfere with their paddling, and we were going at a rapid rate for the place where they hoped to find the porpoises. Presently we entered rough water, with much such a sea as is caused by wind against tide, and the canoe began to jump about in a very lively manner.

"There groes porpus, Sebatis," said Pieltoma.

"I see "im," said Sebatis, standing up in the canoe, gun in hand. Just then we got into some very rough water, and it was a study to see the admirable way in which Sebatis poised himself for a shot.

Pieltoma was holding the canoe well in hand when quite a large wave smashed over the bow of the canoe, and some water came aboard.

"Best sit down, Sebatis, take 'im paddle, may be upset," said Pieltoma.

Sebatis turned a withering glance upon him, and then, as we mounted a wave, fired at some object that 1 did not see.

" Was that a porpoise, Sebatis?"

"Sartin. Four, five porpusis all rollin' over together."

"Did you kill him?"

"No; miss 'im clean; all gone down. You see, Pieltoma scared so bad make me miss "im porpus," he replied, ironically.

Retaining his upright position in the canoe, he reloaded his gun, and stood ready for another shot.

"Quick, Sebatis! Very big porpus on this side canoe," said Pieltoma, whirling the canoe around so as to afford Sebatis a chance for a shot. The next moment we were in the trough of the sea, and I saw a flash of silver on an approaching wave; a belch of fire and a roar from Sebatis's gun instantly followed, and Pieltoma paddled as 


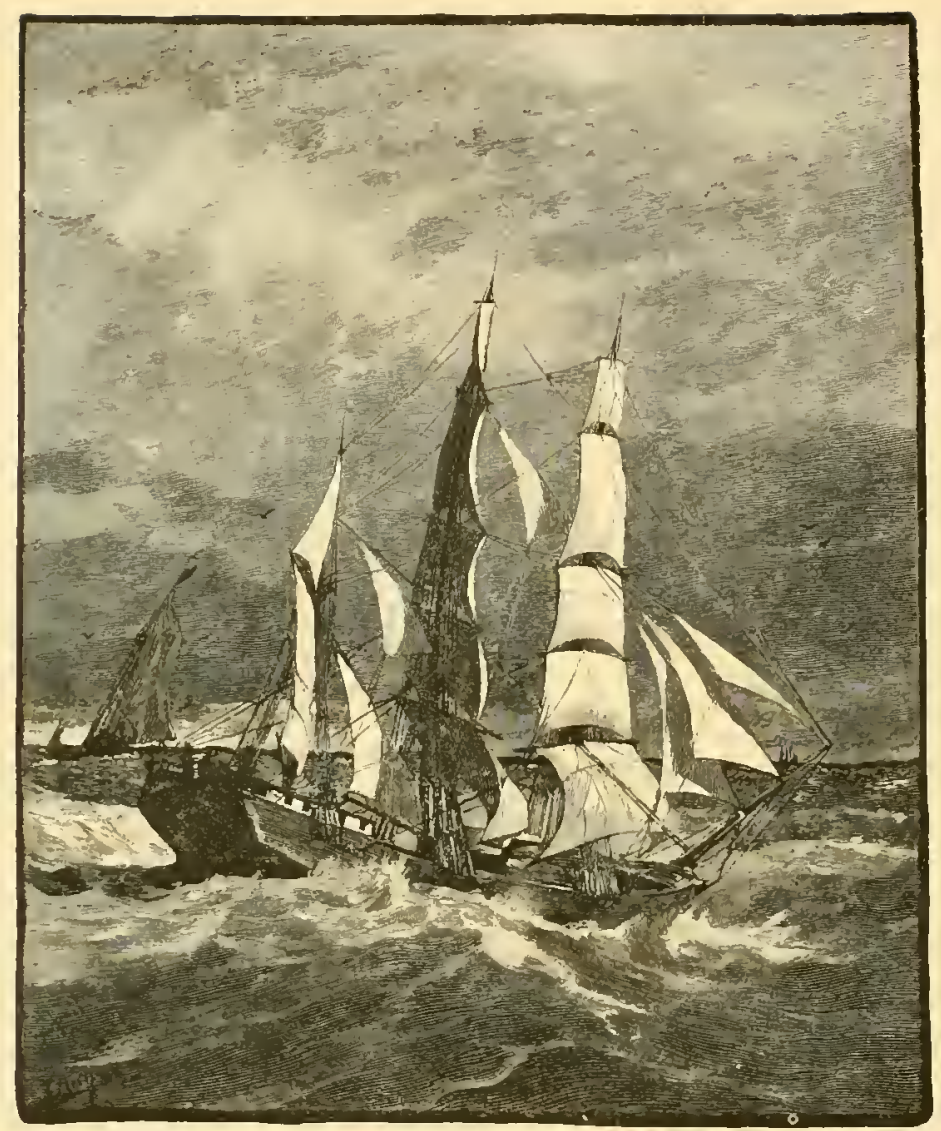

ON THE WAY TO THE EDDIES.

if for life, while Sebatis dropped his gun and picked up his long spear. In the excitement, his usually calm face looked savage, and he plunged his cruel spear relentlessly again and again into a huge fish that we had now come alongside of.

I certainly thought that we should be upset this time, for the canoe was jumping and rocking in a manner to try the steadiest nerves, and the Indians were acting like two demons, and were tugging at the huge fish, in vain efforts to get him aboard. On my hands and knees I crept aft, so as to give them more room. The canoe was drifting aimlessly, now on top of a wave and the next moment in the trough, and I feared that some of the heaviest seas would board us and end the whole matter. At last, their joint efforts succeeded in getting the fish high enough to puth him over the gunwale. 
"How you like "in porpusin'-pretty" good fun?" Sáid Sebatis, as he grasped his paddle and regained control of his canoe.

"If you call this fun, l hope that you will put me ashore before you begin in earnest," I replied.

Presently I heard from seaward the distant booming of guns, as of some ship of war at practice.

"What guns are those, Sebatis?"

"Guns? Oh, that's Injuns shootin' porpusis. Nake good deal noise on salt water."

"I see "im five canoes," said Pieltoma, as we rode on the crest of a wave.

"Sartin, must be bies school porpusis in rips to-clay. look quick; you see "im canoe?" said Sebatis.

"No, I don't see any canoe."

"You watch "im, by-em-by you see "im."

As we ylided into the trough again, I saw a canoe riding a wave, with an Indian standing up in the bow, and another sitting in the stern, paddling. Then, in a short time, we seemed to be surrounded by canoes, and they were constantly popping up, now on one side, then on the other, and at short intervals their guns flashed in the approaching darkness.

"Hadn't we better get ashore somewhere. Sebatis?"

"Yes, we go pretty soon ; kill "im one more porpus first."

"I don't see where you can put him; that one you killed last was an immense one."

"Sartin, that very big porpus, but plenty room one more, spose we find 'im."

Just then there were a flash and a roar, and a canoe passed rapidly to leeward to secure their prey.

"My turn next," said Sebatis, standing up in his canoe again.

"Look out, Sebatis - look out! Big wave comin'!" cried Pieltoma.

I thought that our time had come, but the canoe, dexterously handled by the Indians, rode the wave like an ocean bird.

"If we have many seas like this, Sebatis, we may come to grief in one of them."

"No danger 'tall: only got to be careful, that's all. You see, tide just turned now and we got too far in eddy; move out little way, then good deal smoother." 
"Dark comin' now pretty quick, Sebatis: by-em-by pretty hard chance landin'," said Pieltoma.

Bang! goes Sebatis's gun in answer.

"What was that. Sebatis?"

"Only a small little porpus, — too small count "im, most."

In a few moments they had the porpoise aboard and paddled rapidly for our proposed landing-place at Eel Brook, where we were to camp for the night. The Indians carried the canoe over the beach to the foot of a hill, where some tall fir-trees gave us shelter. They then turned the canoe partly on its side and propped it up with pieces of wood, then spread the sail on poles placed across the canoe, and our habitation was complete.

Sound, indeed, was our slumber that night,-

"While from its rocky caverns the deep-voiced neighboring ocean speaks. and, in accents disconsolate, answers the wail of the forest."

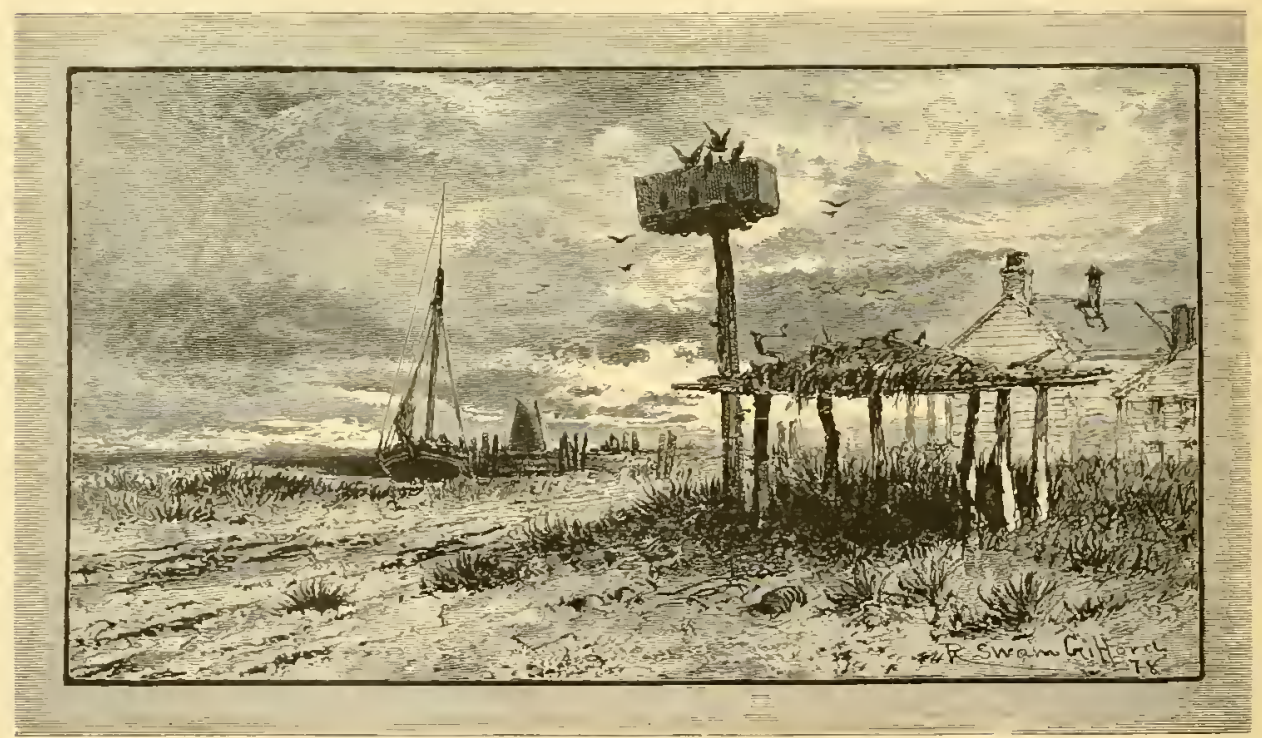




\title{
THE MICHIGAN GRAYLING.
}

\author{
BY THAII)EUS NORRIS.
}

AUTHOR OF "AMERICAN ANGLER'S BOOK."

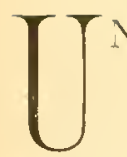

NTIL, within a few years, that portion of Michigan extending from the forty-fourth parallel to the Straits of Mackinaw, dotted with beautiful lakes and traversed by many a clear, winding river, was terra incognita to the fly-fisher; and although we were told years ago by explorers and adventurous anglers that trout in great numbers and of large size were taken in the waters of the northern portion of the peninsula, the grayling by its true name was unknown, and does not now form a subject for any of our angling authors. It was supposed that, except in the Arctic regions, it did not exist on our continent. About ten years ago, however, hunters, and those who were looking up timber lands, began to talk of a white-meated fish with all the game qualities of the trout, which they captured in streams of both water-sheds-east and west - as an adciition to their renison and "hard-tack." It was known to them as the "white trout," the " Crawford County trout," and under other" local names, until a specimen in alcohol was sent to Professor E. D. Cope, of the Philadelphia Academy of Natural Scienses, who described it in the proceedings of that institution in the year 1865 , and gave it the scientific name of Thymallus tricolor, the generic name arising from the fresh thyme-y smell of the fish when first taken from the water, the specific appellation having reference to its beautiful dorsal fin. And yet its discovery as a true srayling escaped the notice of nearly all of our fly-fishers: and to the few who might have meditated an expedition in search of it, its habitat was far off 
and then almost inaccessible. The following passage, however, from "American Fish Culture" (p. 196), by the present writer, and published by Porter \& Coates, in 1867, soon after Professor Cope described the fish, attracted the notice of Mr. J. V. Le Moyne, of Chicago.

"While on a trout-fishing excursion lately in the northern part of Pennsylvania, I met a very intelligent, though not a scientific person, who informed me that in exploring some timber lands on the Au Sable, in Michigan, he came across a new kind of trout which he had never seen before. From his description it was doubtless this new species of Thymallus. He said it readily took a bait of a piece of one of its fellows, a piece of meat being used to capture the first fish: and that it was very beautiful and of delicious Alavor."

The following summer, after consulting persons interested in timber lands, Mr. Le Noyne packed his "kit" and found his way by steamer to Little Traverse Bay, and thence by canoe through a series of lakes to the River Jordan, where he had great sport, not only with grayling, but with trout of good size, taking both from the same pool, and not unfrequently one of each on the same cast. I may here mention that the Jordan is one of the few streams of Michigan in which both are found. Trout are unknown in the Nanistee and Au Sable. My friend, Mr. 1). H. Fitzhugh, Jr., of Bay City, the year following, took them in the Rifle and went by a new railroad then being built to the Hersey and Muskegon, walking twenty miles of the distance. He had been waiting with much interest the extension of the Jackson, Lansing, and Saginaw Railroad northward, and in 1873 , when it crossed the Au Sable, he launched his boat high up on that lovely river. Since then the fame of the rare sporting qualities of this fish has spread among anglers, and they now come from many of our large towns and cities (especially those of the West) to camp on the banks of the Michigan rivers and enjoy the sport.

The European species ( T.vexillifer) is mentioned by all English authors on angling from the time of Dame Juliana Berners to the present. The opinion is advanced by some of them that it was introduced into England when under the religious sway of the see of Rome, as it is generally found in rivers near the ruins of old monas- 


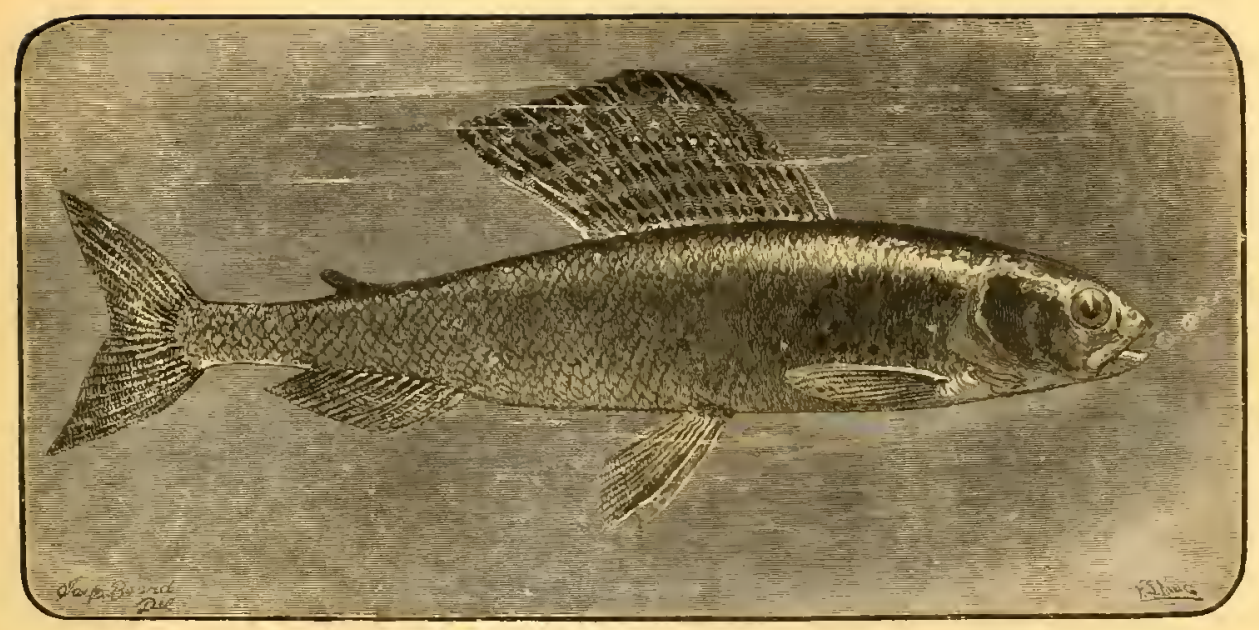



teries. Sir Humphrey l)avy, in his "Salmonia" (1828), wrote of it as inhabiting the Avon, the Ure, the Nye, and the Dee; and Hofland (1839), in addition to those, mentions the Trent, the I)ove, the I)erwent, the Wharfe, and a few other rivers. Sir Humphrey Davy also tells us that it is found in some of the streams of the Alpine valleys, and, he intimates, in some of the rivers of Sweden and Norway. A friend of the writer, who of late years has been in the habit of spending his summers in Bavaria, has had fair sport with grayling in the Isar and Traun, near Munich and Traunstein, as also in the Inn and Salza, and mentions the names of a few quiet English anglers who come annually in September to fish these rivers.

European waters, however, were probably never as prolific of grayling as those of Michigan; for trout. which feed largely on the young of all fish, are there found in the same streams. In Michigan rivers where grayling most abound there are no trout, and the fry of their own and other species are never found in their stomachs. The various orders of flies which lay their eggs in running water, and the larva of such flies, appear to be their only food.

Writers in sporting papers have recently claimed that grayling have also been found in the older States of the Union. If this be the fact, they are now extinct. They are said to exist in some few of the rivers of Wisconsin, which is quite probable, and also in Montana and Dakota. Dr. Richardson, in his "Famna Boreali-Americana," gives not only a glowing description of the exquisite beauty of Back's grayling ( $T$. signifer), but speaks with all the ardor of a true angler of its game qualities. The Esquimaux title. Hcalook powak, denoting wing-like fin, he says, alludes to its magnificent dorsal, which, as in the Michigan grayling, exceeds in size and beauty that of the European species.

Grayling, wherever found, are spring spawners, as also are the smelt and the capelin or spearling. All other genera of the salmon family spawn in autumn. The usual time with grayling, both here and in Europe, is the latter part of April and early in May. They do not push for the very sources of rivers, leaping falls and flapping sidewise over shallows to find some little rivulet as trout do, but deposit their ova in the parts of the stream where they are taken, or, if such portions are not of the proper temperature, they will sometimes seek the mouths of smaller and cooler affuents. The time of 
their spawning is limited to a few days or a week or so. Of the experts who have gone to the Au Sable to express the ova, fertilize it, and bring it East to introduce this fish into the Atlantic States. one found that they were not ready to spawn, and the next season, another, who went a week or so later, found that they had spawned. I have taken fry as long as my little finger on the first of September, which were the produce of eggs spawned in April. Those that came from ova of the preceding year were six inches long; at two years old, they are ten or twelve inches long; at three years old, they are thirteen to fifteen inches long; and at four years, sixteen or seventeen inches, and weigh from three-quarters of a pound to a pound and a quarter; each succeeding year adding proportionately less to their length and more to their girth. An abundance or deficiency of food, however, has much influence on their growth, while some are naturally more thrifty than others. Sir Humphrey Davy says: "Grayling hatched in June become in the same year, in September or October, nine or ten inches long, and weigh from half a pound to ten ounces, and the next year are from twelve to fifteen inches." On this point, as will be seen from the foregoing, I differ with him. 1 think he must have written from hearsay.

In Nichigan, in a day's fishing, the true-hearted angler returns to the water a great many more than he puts in his live-box. He will keep none under a half pound, and where the streams are so abundantly stocked, he will not begrudge their liberty to all under that weight. Our grayling are much more slender than the European species, but, if we credit English authors, do not attain as large a size. Three-fourths of a pound with us is a good average size, and one of a pound and a quarter is considered a large fish. I have hcard, however, of their being taken in the Jordan over three pounds. The grayling is a fish of more symmetrical proportions than the trout, although it has not the vermilion spots and bright colors over its body, but its head and mouth are much smaller, and with handsome, prominent eyes. Its habits also differ materially from those of the trout. It is never found in the strong, turbulent water at the head of a rift, but in the deeper portions of the smoothly gliding stream. It avoids a bottom of clay or the mosses so common to the beds of Michigan rivers, but is always found on gravel or sand. Its rise is straight up-sharp and sudden, and when its 
attention is once drawn to the artificial line, it does not turn back, as a trout does, on getting a sight of the angler, but in its eagerness disregards him entirely, and in running a river with the speed of the current, or even if the boat is poled along down stream, it frequently takes the fly within a few feet of the pole or the boat. Its play is quite as vigorous as that of the trout, and it leaps frequently above the surface of the water before it is sufficiently exhausted to be drawn in. There is this difference, however, between the two. The trout, like a certain denomination of Christians. scems to belicve in "final perseverance," and will kick and strugugle to the last, even as it is lifted in ; while the grayling, after you have sufficiently overcome its obstinate pluck to get its head above water. is taken in with pendent tail, as much as to say, "It's all up"; but as soon as it touches the floor of the boat, its flapping and floundering begin. If it takes a sheer across the current, with its large dorsal fin, it offers greater resistance than the trout. Where they are so numerous, one seldom uses the landing-net, for few escape by breaking away, and if they do, there are more to take hold at the next cast.

If in fishing with a whip of three flies the angler hooks a fish on either of his droppers, the stretcher fly as it sails around beneath is pretty sure of enticing another, and not unfrequently the disengaged dropper hooks a third fish. Sometimes, as I have sat on the cover of the live-box, I have looked down to see three of these bright fish, after 1 had exhausted them, all in a row, their dorsal fins erect and waving in the clear water like so many beautiful leaves of the coleus. Nor is the grayling in taking a fly as chary a fish as the trout. On a perfectly still water you may see the latter rising and taking in the minute natural flies, when the veriest artificial midge will not tempt it; but let even a light breeze spring up and a ripple appear on the surface, and then it cannot distinguish the natural from the artificial, and will take hold. The grayling, on the contrary, is the most eager, unsophisticated fish imaginable. When it sees anything bearing the most remote semblance of life, it "goes for it," even if the water is as smooth as a mirror.

The whole of Michigan south of the Straits of Mackinaw may certainly be called flat country. The only rising grounds to be 
found are a few sandy eminences, - they can scarcely be called hills, the formation of which we leave the geologist to account for. And yet the rivers abrading against these sand-hills occasionally cause precipitous bluffs (few of which exceed a hundred feet), or such an elevation as is known in a lumberman's parlance as a "roll-way."

There is a gradual but almost imperceptible elevation from Bay" City or Grand Rapids to the region where grayling are found. From the former to Grayling, where the railroad crosses the Au Sable, a distance of nearly a hundred miles, there is a rise of seven hundred feet, which gives the rivers an average current of about two and a half miles an hour. Wherever there is a contraction in the wiclth of the stream, however, especially around a bend, its velocity may be three, four, or even five miles, but on account of the absence of rocks in the bottom, it almost invariably flows smoothly. The strength of the current can only be seen where the ends of halfsunken logs or "sweepers" project above the surface, or when the canoeman turns his prow up-stream.

The grayling region on the Lake Huron water-shed has a top stratum of coarse white sand. On the streams flowing toward Lake Michigan. the sand is yellow, with more or less admixture of vegetable loam. The rains falling on these sandy plains and percolating through meet with a lower stratum of impervious clay, and thus form under-ground courses which crop out at the margin or in the beds of the streams and keep them at the temperature of spring water.

The eighth longitudinal line west from Washington may be considered the apex of the water-sheds, declining East and West, although the head-waters of streams occasionally interlock. By a short "carry," one can pass from the head-waters of the Manistee to those of the Au Sable. I have seen marks on both of these streams that gave evidence that surveyors did so forty years ago, and have no doubt that it was a route used by the Indians in crossing from Lake Michigan to Lake Huron.

The country, except on the barrens, furnishes a fine growth of white and yellow pine, as well as oak, beech, maple, and other hard woods. White cedars - the arbor vitæ of the East-invariably fringe the banks of rivers a few miles below their sources. which are generally in ponds or lakes. These trees appear to love 


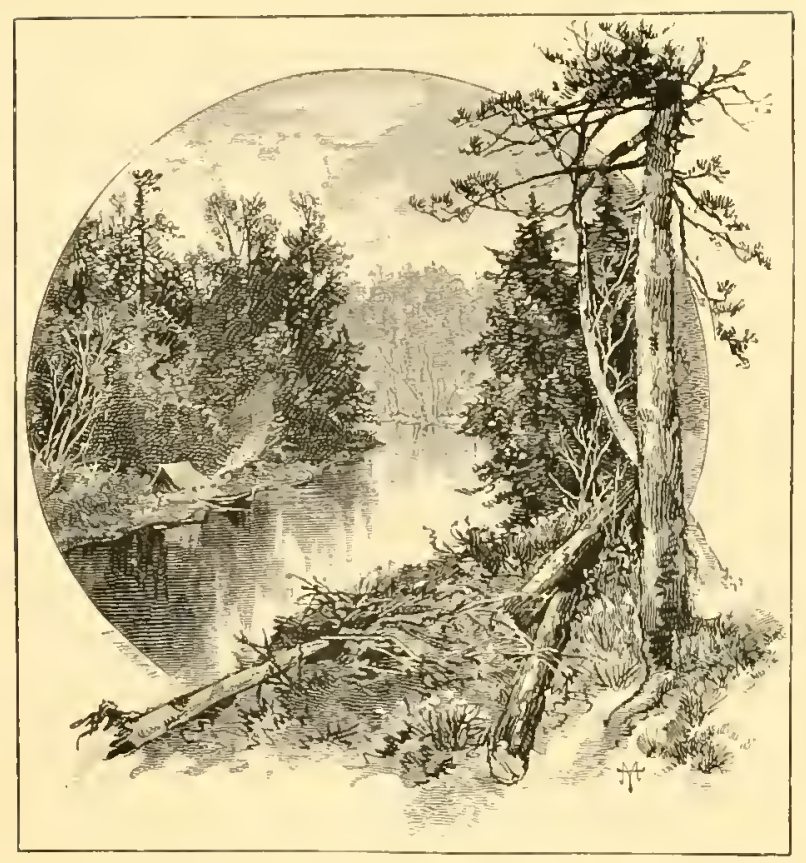

VIEW ON THE MANISTEE.

spring water, and do not appear until the stream has acquired that temperature. Growing on the banks of the streams, the current washes away the loose soil from their roots, which causes them to incline over and at last to fall into the water: and these are called "sweepers." These rivers, from the constant influx of spring water, never freeze, and owing to the slight water-shed and sandy top-soil are not subject to freshets, a spring rise of two feet being considered excessive. Such streams, here and in Europe, are the home of the grayling, for it loves water of a low, even temperature and a smooth. steady current.

The game-laws of Michigan recently enacted forbid the spearing and netting of grayling at all times, and do not admit of them being taken even with hook and line from January until June. These fish acquire condition soon after spawning, but are better in autumn and in season nearly all winter. So after the first of September the sportsman can unite shooting with fishing. Several summers ago, in August, while rumning the Iu Sable, we counted twelve deer and two bears. Is they were out of season, and my friend Fitzhugh was a stickler for the observance of the game-laws in every instance, we resisted the temptation to shoot them. 
The country I have described has, of course, none of that aweinspiring scencry we find on the shores of Lake Superior; but with its clear, ever-flowing, ever-winding rivers over white and yellow sands, with graceful cedars projecting at a sharp angle from the banks, and every bend of the stream opening a new view, it is novel and pleasing to one who has been shut up all winter in a crowded city. In rumning a grayling stream, the feeling is one of peace and quietude. There are no song-birds in those deep woods. One only hears the far-off falling of some old forest tree, or that weird sound caused by the rubbing of the branch of one tree against that of another, as they are swayed to and fro by the wind, and in the distance one can almost fancy that it is a human voice. Otherwise, all is as silent as death.

My first raid upon the grayling was in August, 1874, with Mr. Fitzhugh, of Bay City, on the Au Sable. We ran this river from Grayling, on the northern branch of the Jackson, Saginaw, and Lansing Railroad, to Thompson's, a distance of a hundred and sixty miles. From Thompson's, after loading our two boats on a stout two-horse wagon and occupying another with springs, we drove twenty-five miles to Tawas City, and then, after a few hours on a steamer, back to Bay City. There is no grayling-fishing at the station called Grayling, nor until one gets four or five miles down the stream where the cedars appear. From this as far as we ran it, - and there was yet sixty miles of it below Thompson's, - it is a beautiful stream, much prettier, I think, more rapid, and less obstructed with sweepers, than the Manistee. The distance by land is about seventy miles. On our second day, we killed and salted down-heads and tails off - a hundred and twenty pounds of fish, besides eating all we wanted. In one hanging rift close by the bank, as Len Iswel, my pusher, held on to the cedar boughs, 1 took at five casts fifteen fish, areraging three-quarters of a pound each. The following day, we fished along leisurely until we had our live-boxes, containing each sixty pounds, so full that the fish began to die. Then we passed over splendid pools in which we could see large schools of grayling on the bottom withoui casting a fly; for we would not destroy them in mere wantonness. In a few days, however, we came across occasional timber camps, when we commenced fishing again, and supplied all hands 


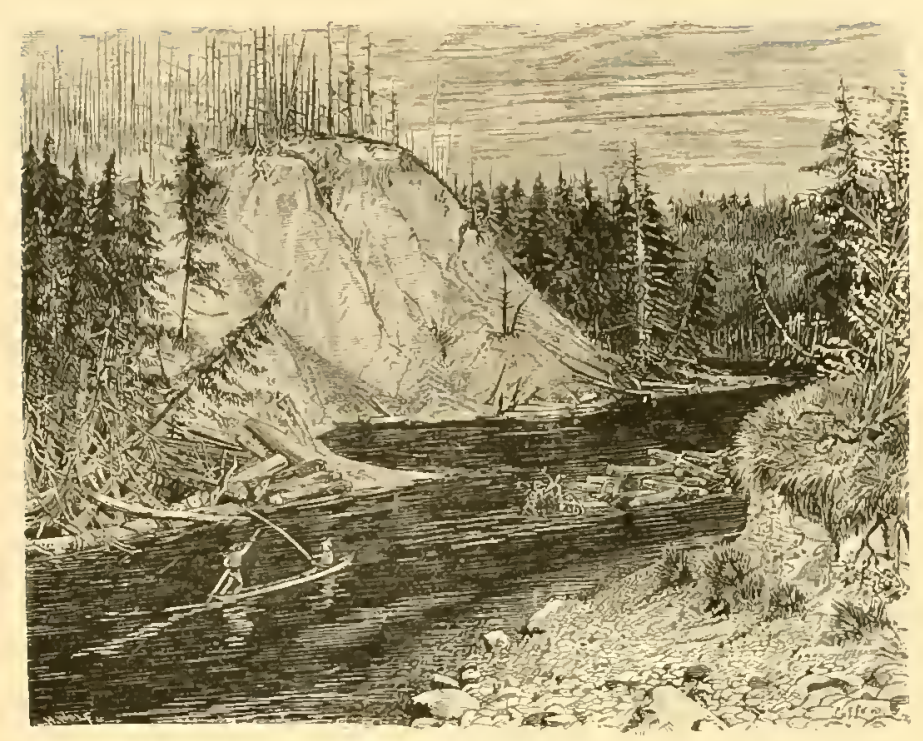

ON THE MINISTEE。

with fresh fish. One can leave Bay City by railroal in the morning and arrive at Grayling early enough in the afternoon to embark and drop down-stream seven or eight miles the same night. He should, however, engage boats and pushers beforehand.

There are two large branches, flowing almost as much as the main stream, that enter the Au Sable. The south-west comes in about forty-five miles below Grayling and the north branch sixty miles below. On this last stream there is a sluice dam. and when it is let off to float logs during the summer and autumn, the water is discolored somewhat, and the fish do not rise as well. One can get all the fishing he wants by running as far down as the south-west branch, which, as already stated, is forty-five miles by water, and is only twelve miles back to Grayling by land. He can engage a wagon at Grayling to come with ice on a stated day and haul back his boats, his luggage, and his fish. thus saving the labor of pushing back up-stream, which would occupy two days of incessant toil.

When I fished the Manistee several years ago, I went from Grayling with Mr. Fitzhugh and another friend, accompanied by our pushers, oier "the barrens," a distance of eight miles, to a camp established by I. F. Babbit, to fish with hook and line for 
the Bay City and Detroit markets. We made a permanent camp four miles below Babbit's, and fished five days, giving him threefourths of our fish, which he came for every day, and which (keeping none under a half pound) amounted to over five hundred pounds.

One of my most pleasant trips, however, was that of the latter part of August and early in September of the following year, when, in company with two young friends, I spent two weeks on the Manistee. We went by the Grand Rapids and Indiana Railroad to Mancelona, well up toward the Straits of Mackinaw. Here we loaded boats, stores, and camp equipage on a wagon drawn by a pair of stout horses, and journeyed eleven miles east to the heacl-waters of the main branch. Our trip was dashed with a spice of adventure and a good deal of hard work. W'e had struck the stream higher up than we expected. It was small, scarcely sufficient to float our boats, and still had the temperature it had acquired in the little lake which was its source. There were no cedars, which only appear when the streams have flowed far cnough from the ponds to feel the influence of spring water. On the morning of the second day, we came to the cedars and cold water, and with them the sweepers, which are cedars, as already described, which have been undermined by the current and have fallen into the water and always across the stream. We had three days and a half of hard chopping and hauling our boats over huge cedar logs, some of which had probably lain there for a century - for a cedar $\log$, if it remains in the water, never rots. On coming to some of these logs, we had to make a "carry," placing our luggage on their mossy covered trunks and pulling our empty boats over. We would then load up and go on to cut more sweepers and make more carries. At last, the stream widened and was free of sweepers, and we had magnificent fishing. The grayling were perfectly reckless and would take one's flies within ten feet of the boats. It was virgin water; no fly had heretofore been cast on it. After a day's sport, we came to the sweepers again, and had a day and a half more with them and half-sunken $\operatorname{logs}$ and a few carries. At two or three of these carries, the logs were over two feet through. Mosses had grown and spread on them until, as we saw by certain signs, bears used them as a highway. On one we found thrifty cedars growing at regular intervals from the parent trunk that were 


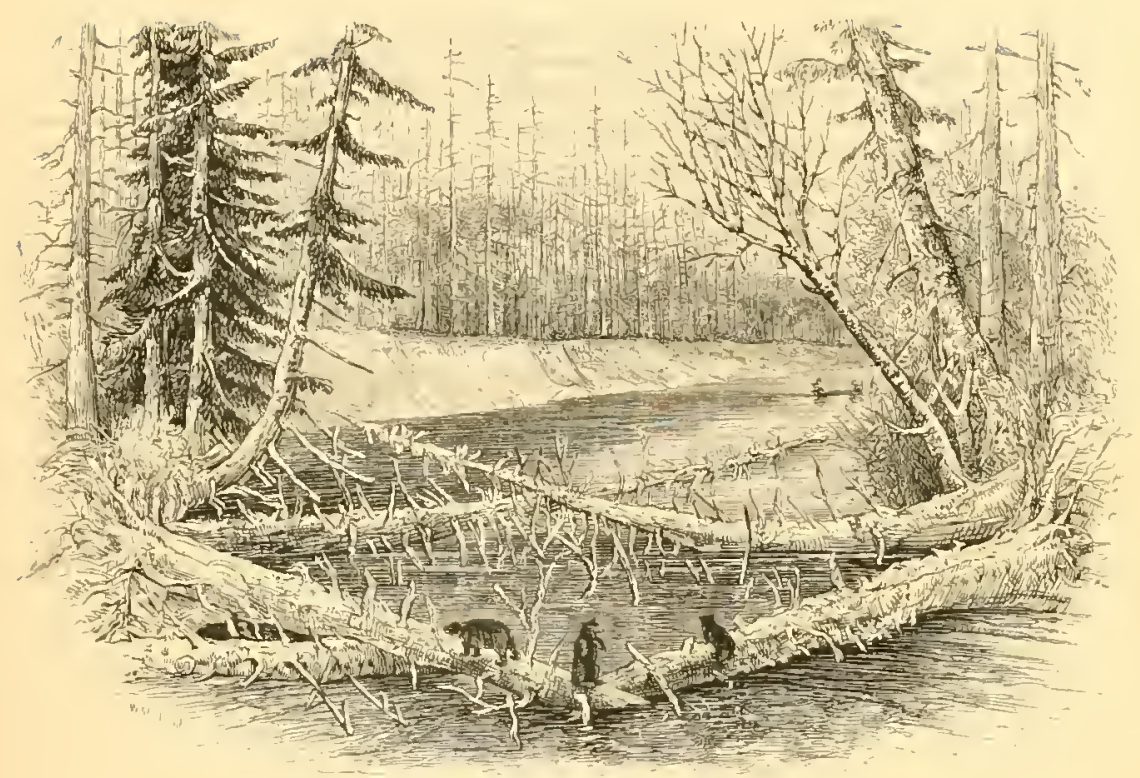

SWEELERS IN THE MANISTEE.

more than half a century old. Soon the stream increased so much in rolume, and was so wide, that a tree falling across could not obstruct the passage of our boats; and finally we came to open water again. And so we ran the stream down to $\mathrm{V}^{\mathrm{a}}$ alton Junction. a hundred and fifty miles by water, while it was scarce fifty on a bee-line.

The boat used on my first trip is worth description. It was built

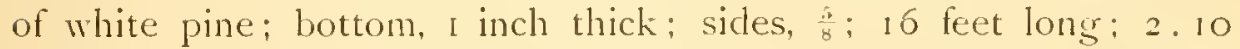
wide on top, 2.4 at bottom, and with a sheer of three inches on each side. The bottom was nearly level for eight feet in the center, with a sheer of five inches to the bow and seven inches to stern. The live-box was six feet from bow, extending back two feet. The sides were nailed to the bottom. Its weight was eighty pounds, and it carried two men - the angler and the pusher - with 200 pounds of luggage. With two coats of paint, it cost about fifteen dollars. The angler sits on the movable cover of the live-box, which is water-tight from other portions of the boat, and has holes bored in sides and bottom to admit of the circulation of the water to keep the fish alive, and as he captures his fish he slips them into holes on the right and left sides. An axe was always taken along to clear the river of fallen $\operatorname{logs}$ and sweepers. 
My customary tackle on these excursions is a twelve-foot rod of about eight and a half ounces: leaders eight feet long, and flies on hooks ranging from No. $;$ to No. 10 (O'Shaughnessy). I have found most of the flies used on Pennsylvania streams effective, and one can scarcely go amiss in his selection. One summer, 1 used for two weeks the same whip, viz.: "Professor" for the stretcher, "Silver Widow" for first, and "White-winged Coachman" for second dropper. The first is tied with guinea-fowl feather for wings, an amber or yellow-dyed hackle for legs, a yellow floss body wound with gold tinsel, and three sprigs of scarlet ibis for tail. The second has black wings, black hackle, and black body wound with silver tinsel. The third has white wings, red hackle, undyed, and body of peacock hurl.

As to stores. We found that for five men, including pushers, the following were about the right quantities for a two weeks' supply: 50 lbs. flour, I bushel potatoes, 25 lbs. of breakfast bacon, 12 lbs. butter, 1/2 peck of onions, with corn meal, tea, coffee, sugar, condensed milk, a jar of pickles, and a few cans of corn and tomatoes. Bread is a difficult thing to take or to keep in good condition. I would advise, therefore, the taking of a portable sheetiron stove, which, with a baker and all other appliances and conveniences, does not weigh over thirty-five pounds. With a box of yeast powder, hot rolls can be had at every meal.

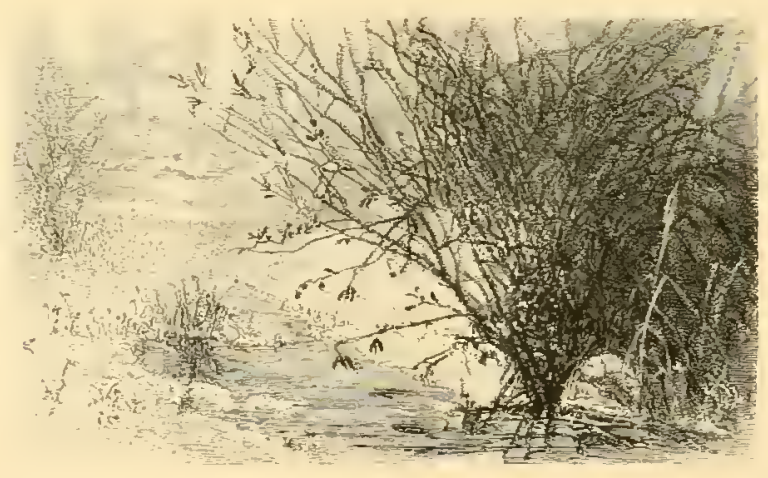




\section{SEA-TROUT FISHING. \\ BY.A. R. M I I ONOLGH.}

W

HAT is a sea-trout? I problem, to begin with, though quite a minor one, since naturalists have for some time past kept specimens waiting their leisure to decide whether he is a cadet of the noble salmon race or merely the chief of the familiar brook-trout tribe. Science inclines to the former view, upon certain slight but sure indications noted in fin-spines and grill-covers. The witness of guides and gaffers leads the same way, and the Indians all say that the habits of the sea-trout and the brook-trout differ, and that the contrast between the markings of the two kinds of fish, taken from the same pool, forbids the idea of their identity. Yet the testimony of many accomplished sportsmen affirms it. The gradual change of color in the same fish, as he ascends the stream, from plain silvery gray to deepest dotted bronze; his haunts at the lower end of pools, behind rocks, and among roots; his action in taking the fly with an upward leap, not downward from above, all these resemblances support the theory that the sea-trout is only an anadromous brook-trout. If the form and disposition of the spots are material, then new names of species need to be devised for the many varieties of California trout, some blotched with color like a snake's skin, others striped from gills to tail with a single vermilion streak. Indeed, the difference in color between the brook-trout and the sea-trout ranges within a far narrower scale than that between parr, grilse, and salmon. The question has already been before a jury, as so many questions involving facts of science do curiously drift under the sagacious ken of that palladium of our liberties so unfit to solve them. Certain poachers of the south shore of Long 
Island, charged with invading the close time for brook-trout in that lovely region of sea-seeking runlets, alleged in their defense the identity of the burden of their creels with the sea-trout, whose comings and goings are bound by no inland law. The jury, incompetent either to acquit or convict, had the good sense to disagree. And thus, until a final word of authority upon the contents of their alcohol-jars comes from the cabinet of the learned, this fish is still a fugitive from the juriscliction of science.

Careless of being classified so long as he can escape becoming a specimen, the sea-trout leisurely grows during his early years to an average weight of from two to two and a half pounds. They are often taken of much greater size. Among a hundred fish, some seven or eight will reach a weight of three pounds and upward. They are often caught weighing six or eight, and many more are found weighing between one and two pounds. It is a fair conclusion that the usual weight of the adult fish may be fixed at two pounds and a half. regarding the smaller ones as adolescents, and the larger as monsters; for the latter are dull and heavy in action. They take the fly with a surge, instead of a break, and drag more than they leap or rush when hooked, seeming unaware of either their strength or their danger until they are fairly netted. On the contrary, a two-pound fish is full of mettle and ruse-one would say of fire, in any other element. He spurns the water for the fly, tears the line whirring out, zigzags, leaps and darts, and yields some moments later than his heavier rival whose nose he has thrust aside to snatch the bait.

If Soyer could open his mouth on the subject, and bid his palate judge-Soyer, who, alas, has gone from the active to the passive state of cooking, if his epigram epitaph, "Soycz tranquillc," be true, or was it written for his wife? - he would murmur, amid grateful tears over the experiment, that a sea-trout is either younger than his prime or past it, unless two or two and a half pounds, neither more nor less, offer the judicious epicure the acme of firmness, pinky flake and sapid curd. Their vagrant habits forbid our learning where the greater part of their growth is gained or what its precise yearly rate of increase is. The way of a ship in the sea, confessed by the wise king one of the four mysteries, is a primer's lesson compared with the way of a fish that wanders through sea and river both. 


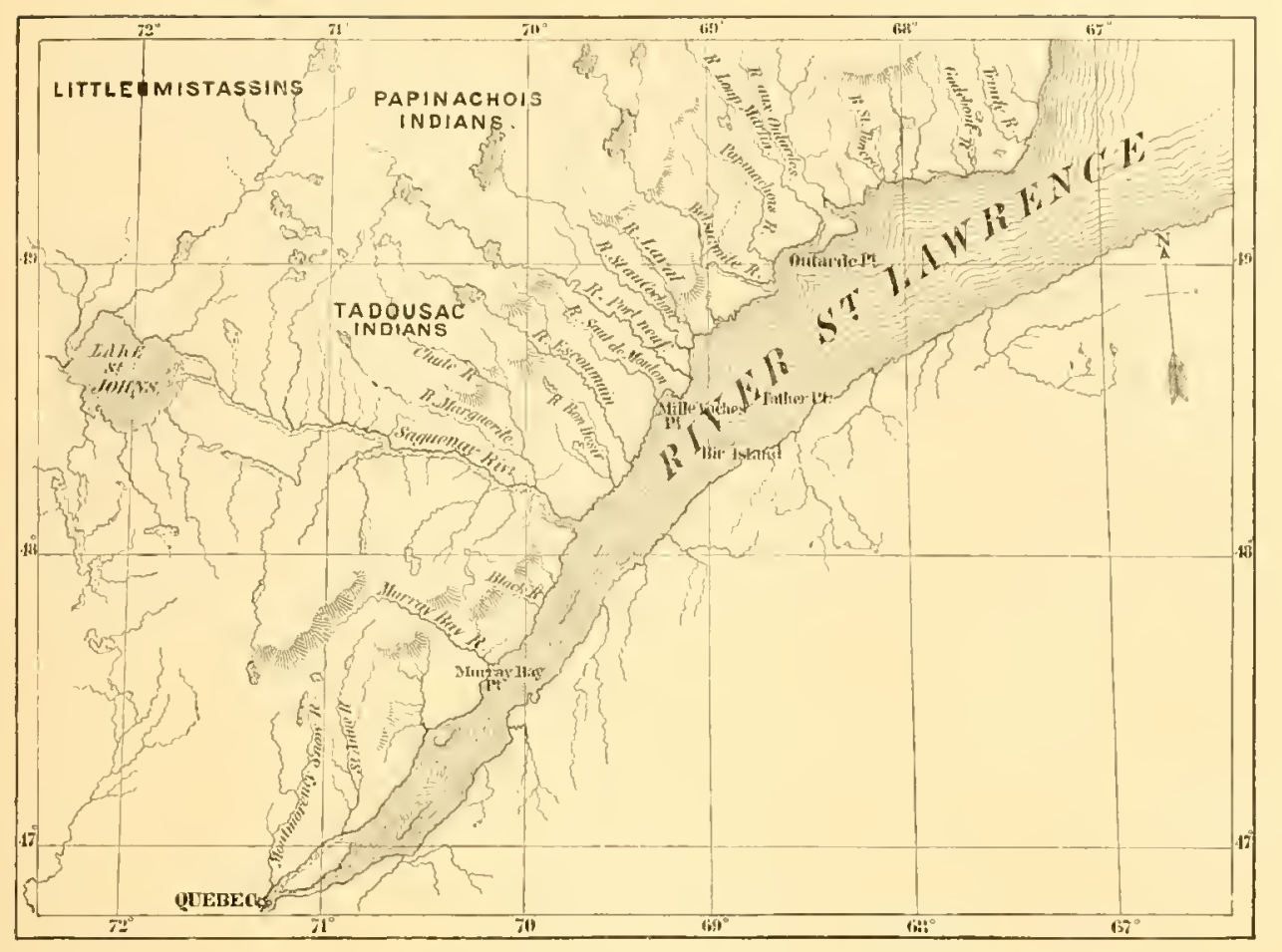

MAP OF SOME SE 1-TROUT WATERS.

Sea-trout are found in both hemispheres in the northern belt of the north temperate zone. Neither to Asia nor to South America are they known to resort. Their geographical distribution seems marked in longitude by the Norway border of Europe and the western coast of our own country. Their range northward is probably limited only by such conditions as exclude the possibility of life. In the late Polar expedition, Dr. Moss succeeded in capturing a small salmonoid inhabiting fresh-water lakes as far north as $82^{\circ} 40^{\prime}$. Along the whole coast of Labrador and the Dominion, and up the St. Lawrence River nearly to Quebec, they abound.

Nor is saltness of their medium essential to life, so long as they find an opportunity for migration to and from the depths. In Lake Superior and the streams flowing into it on the northern shore, they are plentiful at the usual seasons.

While in the sea, anadromous fishes are, of course, lost to observation; but it can hardly be supposed that they rove aimlessly through it, or resort to very great depths or very great 
distances from its shores. The annual return of many, if not all. of the survivors of those hatched in a particular river to the very nooks of the coast and tidal streams where their life as young fry began is undoubted. Extraordinary as so subtle an instinct seems, compared to our senses, with their limited relations to the world about us, it is not more wonderful than that which guides the returning flight of birds, through an element as trackless, to their original nests. The frequent experiments of Scotch experts with marked salmon, and lately those of our own fish commissioners with shad, prove that this recurring and unerring sense of locality is not an old-wives' fable, but a true discriminating and impelling heimaels.

Even when they "swim into our ken," the study of the ways of fish is perplexing and uncertain. Fur and feather do not elucle us as fin does. The naturalist can track a beast to his haunts, and finds him tangible and of the earth. Birds descend from their heights to nest and live within his view. Fish fleet like shadows through their mobile element, and much of the science regarding them must be as shifting and wavering as light in water, - much that goes with their vagrant and invisible existence must always remain within the sphere of conjecture. When, therefore, the return of migratory fish to their home rivers is spoken of, absolute precision as to times and ages is not intended. Some salmon are found in rivers, and the same is probably true of sea-trout, in every month of the year, at every stage of growth, both ascending and descending. But there is a general law that, at a fixed period and for the purpose of spawning, guides the great body of migratory fish up to the head-waters of the tidal streams out of which they originally came.

Along the Canadian coast, sea-trout begin to press in toward fresh water in the latter part of July. They enter the estuary of the St. Lawrence by myriads upon myriads, sending off detachments north and south as they move on until the main body is scattered into groups, of which those tending to the upper river make their appearance off the Saguenay during the first week in August. In the particular stream of which experience enables us to speak most definitely, their arrival is timed with singular punctuality for the $5^{\text {th }}$ or 6th of August. Often a pool that on one of those days held only 


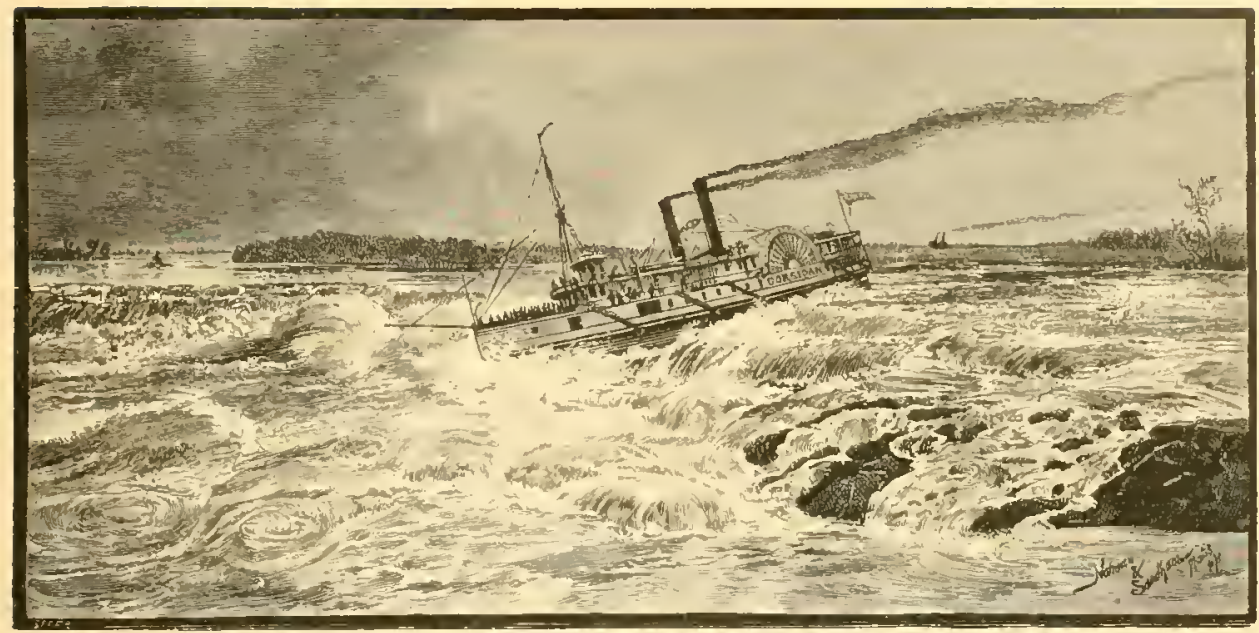

RUNNING THE, IACHINE RALIDS, ST, LAWLENCT: RIVER,

a lingering and indifferent salmon or two on their upward run would become filled during the following night with the vanguard of the advancing body of large sea-trout. In a general way, it may be said that the season for the latter begins when that for the former ends, though belated salmon are often intermingled for a time in the same pools with the first-comers among the sea-trout. I very backward season, or a dash of cold storm crossing the summer, as it sometimes does in those regions, may delay their approach to the shore for a few days, but not materially: For a time they hover about the out lets of the streams, haunting the reefs and passing out and in with the ebb and flow, seeming to grow gradually accustomed to the fresh water, till a higher tide helps to lift them over the bars and among the rocky passes of the rapids that abound in the smaller rivers. Very good sport may be had for a time in taking them at the mouths of the streams, from the long sand-spits past which some of these empty, or the slippery rocks and jagged reefs barring their discharge. At the distance of a far cast from the shore, their back fins show pointing above the surface of the incoming waters, whose breadth gives free space for long and vigorous runs. The guides and Indians will tell you - and experience proves them to be quite in the right - that the run of the fish is governed by the moon, and is greatest when she is full or new. At those periods they pursue their way up the stream in larger numbers, simply because the higher tides then prevailing aid them to pass the bars and rapids. 
Your guide's statement of fact is correct, while he errs, as many a wiser man has done, in attributing the effect to a primary instead of a secondary cause.

When once fairly in the current of fresh water, their movement up-stream is very rapid. Passionless and almost sexless as the mode of the muptials they are on their way to complete may seem to more highly organized beings, they drive with headlong eagerness through torrent and foam, toward the shining reaches and yravelly beds far up the river where their ova are to be deposited. The females come first, afterward the males, and the earliest runs of the fish always contain those of the largest size. For several days and nights they continue passing swiftly, seldom lying many hours in the same pool, never taking a backward stroke: then all at once there is a marked break in their streaming by, and the first run has gone on. Another one soon follows, and they persevere successively coming past till late in September, or even into October. All the fish of any one run are of nearly the same weight, and they continue decreasing in size with each successive run, until, as you descend the river, only an occasional straggler over one or one and a half pounds can be caught. On the California coast they, as well as the salmon, are at least a month later in entering the rivers, which remain during a great part of the summer too shallow and tepid to afford them a safe abode, until a heavy rain-fall comes.

These crowding refluent ranks are but a small proportion of those that quitted their native streams for the sea. Thinned as they are by voracious enemies there, and decimated again in shallower waters by man's destroying devices, the amazing fecundity of migratory fishes barely avails to maintain the annual supply. From some coasts these fish have wholly disappeared. The people of the U'nited States are more destructive in this respect than any other. They manage these things better in the Dominion. There, the importance of the fisheries as an object of commerce and a source of food, yielding for these interests as they did, for instance, in 1875 , over ten and a half millions of dollars, has attracted legislative protection, through measures which it would be difficult to apply generally or efficiently in our extended and democratic country. So far as the authority and resources of the fish commissioners of the different States extend, they are doing useful and honorable work which deserves the widest 


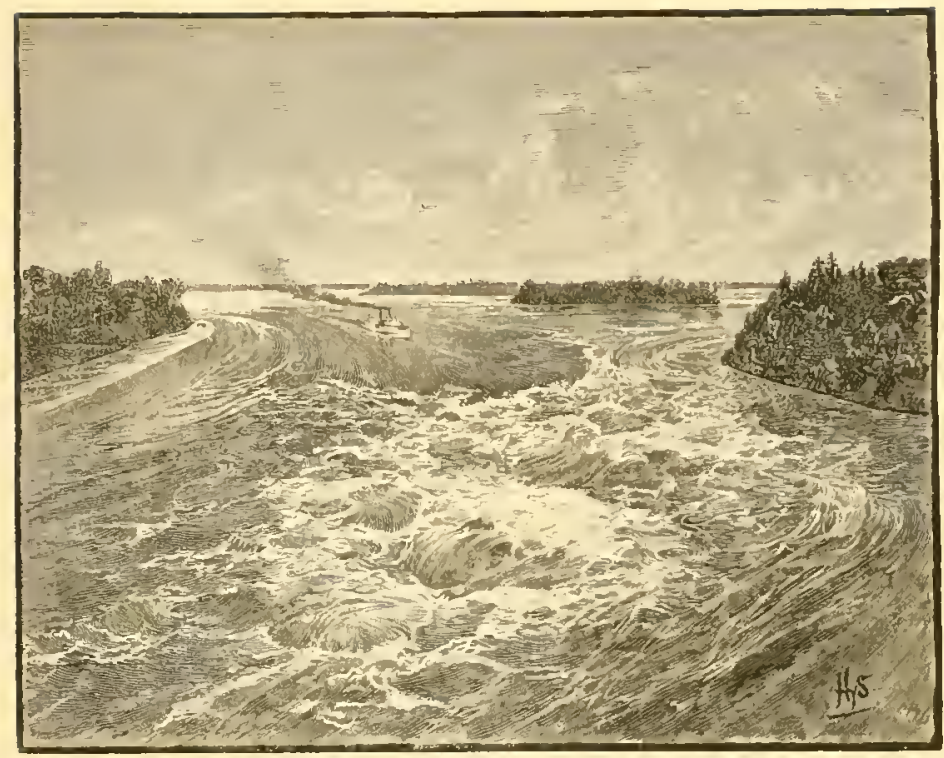

LONG SAULT RAPIDS.

public recognition and support. In Canada, all salmon-breeding rivers are leased, inspected, guarded, and yearly reported upon by a special commissioner in the Department of Marine and Fisheries. Salmon rivers are also sea-trout rivers, and good sea-trout fishing can only be obtained, except in streams too insignificant to be worth preserving, by taking either a lease of a salmon stream or a license from a lessee to fish one. There is little difficulty in making the latter arrangement, both because the seasons for the two varieties of fish are not concurrent and because a proprietor is only too glad to be aided in thinning out the sea-trout, which are very destructive to salmon ova and fry.

Along the course of the St. Lawrence between Quebec and the island of Anticosti some of the principal affluents on its north shore are the Murray Bay River, the Black, the numerous branches of the grand and far-reaching Saguenay, the two Bergeronnes, great and little, the Escoumaine, the Saut de Mouton, the Portneuf, the Saut au Cochon, the Laval, the Betsiamites, the Colombier, the River aux Outardes, the Godebout, Trinity River, the Pentecost, the Romaine, the Moisic, and the Mingan. Some of these are famous salmon rivers, held on long leases by. Canadians or by our own countrymen. - A few are obstructed at the outlet or not far above it by dams, 
affording, however, certain and excellent fishing for a short time at their mouths. Others, again, do not bear a high reputation as salmon rivers, owing to their having been either neglected or over-fished. One, the Betsiamite, or Bersimis, is reserved for the use of the Indians. It is a fine river, but so cruelly fished, netted, speared, and snared by its reckless proprietors that it has almost ceased to rank as a salmon-breeding water.

Many of these streams will long remain unvisited except by the most enterprising anglers, on account of their remoteness from the common lines of travel and the forbiclding uninhabited country through which they flow. The easiest access is still by the way of Quebec. As far as the village of Tadousac, at the mouth of the Saguenay, a daily steam line runs. But here all usual and comfortable ways of transportation end, and the solitary recesses beyond can be penetrated only by the aid of country carts or of small ressels. Taking into account the enforced delays of preparation, the forlorn condition of beasts, roads, and vehicles upon a land journey, and the accidents of winds, waves, and fogs, a visitor to any of these streams is hardly safe in counting upon less than seven or eight days' traveling between it and New York.

Whatever its soft Indian name may mean (if it be not rather Breton), Tadousac might well be called the place of rest. Within forty-eight hours from New York, one seems transported to one of the ends of the earth. All around it is vast and lonely. The great river stretches glimmering away to a shore seldom faintly seen. Behind, bare lofty crags shut it in, treeless and silent. A huge promontory bars it from the Saguenay, rolling black and cold as if drained from the eternal chasms of polar glaciers. The air comes thin and pure, the light falls sharp on the gray brows of the cliffs and the brown sand washed up by the bay. Most of those trim cottages dropped among the rocks belong to the best people in the province of Quebec, and a few to countrymen of our own, who long ago found out this retreat for cool, economical, northern lotus-eating. Such traces of human life are lost like dots in the great spaces. The silence is broken every hour by a restless little bell, tinkling from the gable of the oldest church on the continent. This is a pocketchapel, that could be set inside a town drawing-room, low-pitched, mossy, and winter-bitten, dark inside with two hundred years' censer-. 


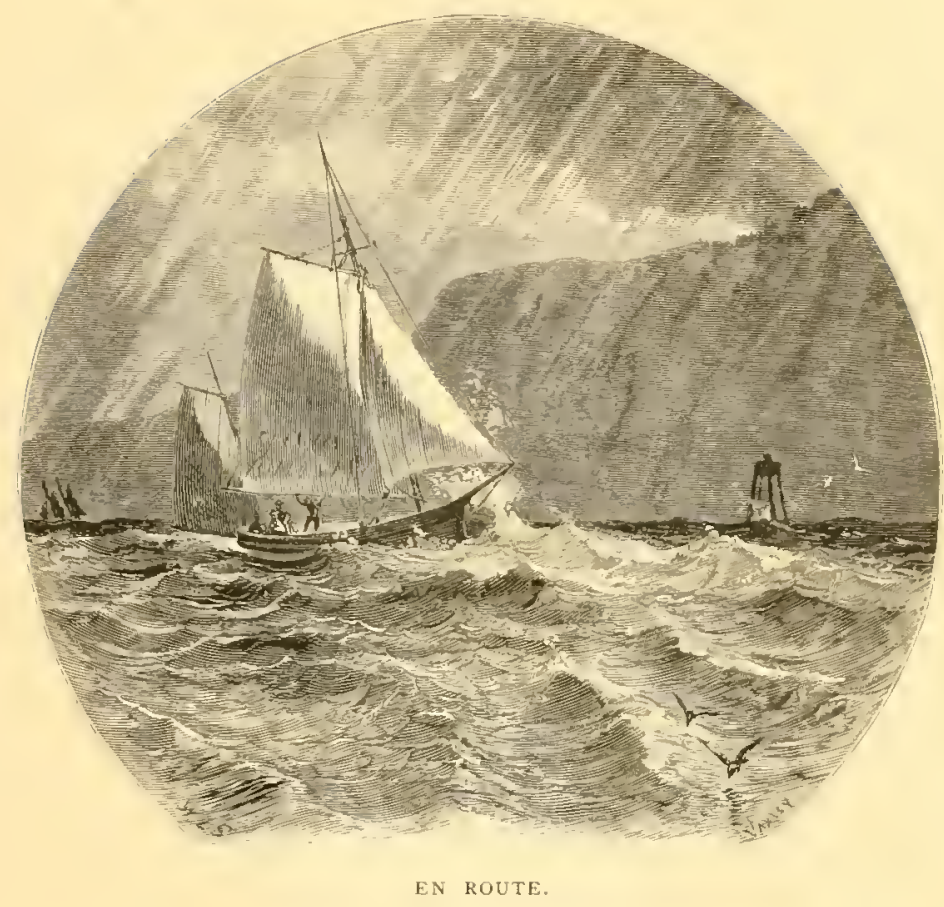

smoke-the homely shrine for the simple faith of a poor and kindly race. The hotel is everything that our sea-side caravansaries are not,--small, neat, quiet, with the host's hand for every wayfarer instead of being against him. Its neighborhood to the Saguenay attracts always a group of salmon-fishers, ready, for the stranger's benefit, with courtesy, information, and news from the streams. Everything, indeed, about the settlement is salmonoid. A short walk along the sands leads to a cluster of habitans' houses in a corner of the bay. Here, if the angler has taken due care for his arrangements in former years, his guides and skipper welcome him, and his impedimenta for the month's work are gathered. David, Gédéon, Edouard, Pierre Jacques, Fabian, with a dozen children, French and Indian mixture, meet him with hearty greeting. Poor Cyrille is missing. No paddle was more deft than his, no shot for a seal surer. Three years ago, in the St. John's, a treacherous whirlpool, boiling up at the foot of a rapid, wrenched the canoe out of his grip and sucked him with it to the bottom. The lot of these habitans is miserably hard and poor. The stony soil grudges a little grass or a handful of oats and potatoes. They make the rivers their farm, 
shooting seals on the jce, catching fish for salting, and hunting the porpoise. They are all wiry, agile fellows, temperate, docile, and good-natured. As guides, they are thoroughly faithful and expert, but a trifle lazy at times, and slow to learn anything beyond their range of habit. Part of them are of mixed race, part pure Canadian French, with a trace of gentle blood now and then, due to some irregular noble of the early rlays. Tadousac being the torminus a quo, beyond which nothing can be had, the traveler's first care is to examine his sporting chattels, accumulated there during years, and to find or set them all in order. If rats have gnawed the canvas of his tents, or the bed-sacking or bags, these are to be mended. The winter in a store-house may have dealt hardly with his canoes, that need perhaps bark patches or a thwart, and certainly new pitching. The tinker's art is among his guide's accomplishments, should the "battcric de cuisine" show signs of wear. Then the chaloupe is to be inspected as she lies aslant above low-tide mark on the sandsa seven or eight ton lighter-built craft, of some three feet draft, onemasted, with jigger astern, and stub bowsprit. Midships is a hold for ballast and cargo, forward a cabin built for dwarfs but holding berths, seats, and a table, and astern a clear space for handling sheets and helm, large enough for enjoyment of the evening pipe and the morning douche. All at last overhauled and stowed, the canoes triced up outside the shrouds and the special case of stores sorted for the cruise, which may last no one knows how long, we wait for a gentle south-west and the first of the ebb.

Opposite Tadousac, the St. Lawrence has a breadth of over twenty miles. Here the Saguenay, storming in, conquers the greater flood, as the Missouri does the Mississippi, and deepens the grandeur and wildness of its scenery. The southern bank is as picturesque and less rugged, but along the widening water we hug the northern shore, seldom stretching across far enough to see the outlines of the other break into distinct masses. Only below its junction with the Saguenay can the imperial character of this majestic river be felt. Crossing half a continent to meet the sea half way, it spreads like a sea itself, and tosses dangerous waves under a sudden gale. On the north it washes the base of spurs sent out by the great Laurentian range, whose iron-bound off-shoots frown down over the whole lower course of the river, retreating at points for a few miles, and 
opening everywhere among their recesses great breadths of a clayey soil. clotted with lakes, and channeled by rapid rivers. Some of these are fed by large sheets of water, and follow a course of over a hum-

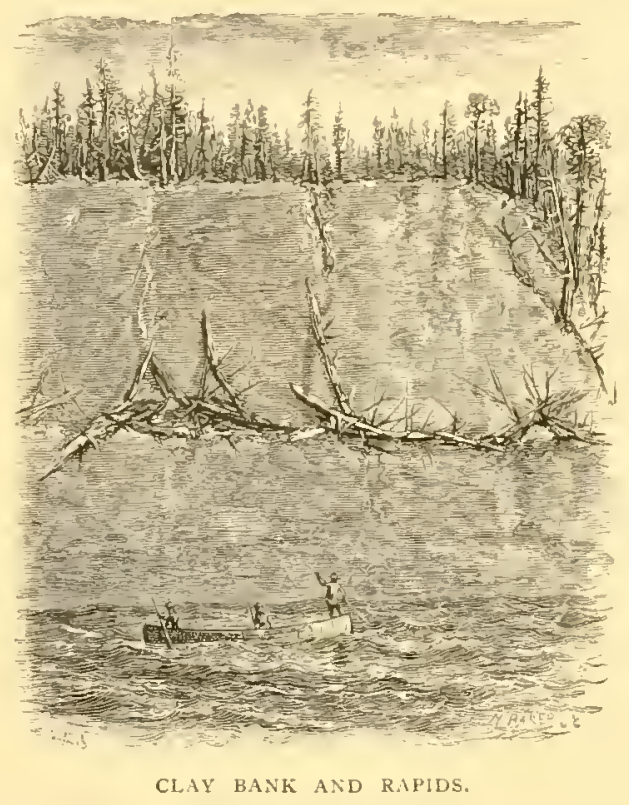

dred miles, while others run for less than a third that distance. Long, sandy capes jut into the river, and rocky islets fringe it, but for many unbroken leagues of its flow it laps the feet of the savage gray crags or chafes around granite blocks banded with red and purple. A fisherman's house under a cliff, a cluster of huts or a light-house where a stream pours in, and a single great saw-mill and lumber depot are the only inhabited spots along hundreds of miles in its course. The voyager making a port from curiosity or stress of weather gains a hearty welcome, giving in exchange his week-old news, fresh and strange to his hosts. The inmense expanse of the river, notwithstanding the steady commerce traversing it, is lonely as the sea- and often days pass without meeting a sail. With a fresh south-west breeze such as often prevails in August, the run has been made from Tadousac to the destination within twelve hours. Oftener, sailing with the morning ebb at nine, the afternoon of the next day has seen us at camp. One melancholy diary records four nights spent aboard with alternations of thick fog and baffling north-easter: our ressel, after a tossing struggle of endless $33 \mathrm{~A}$ 


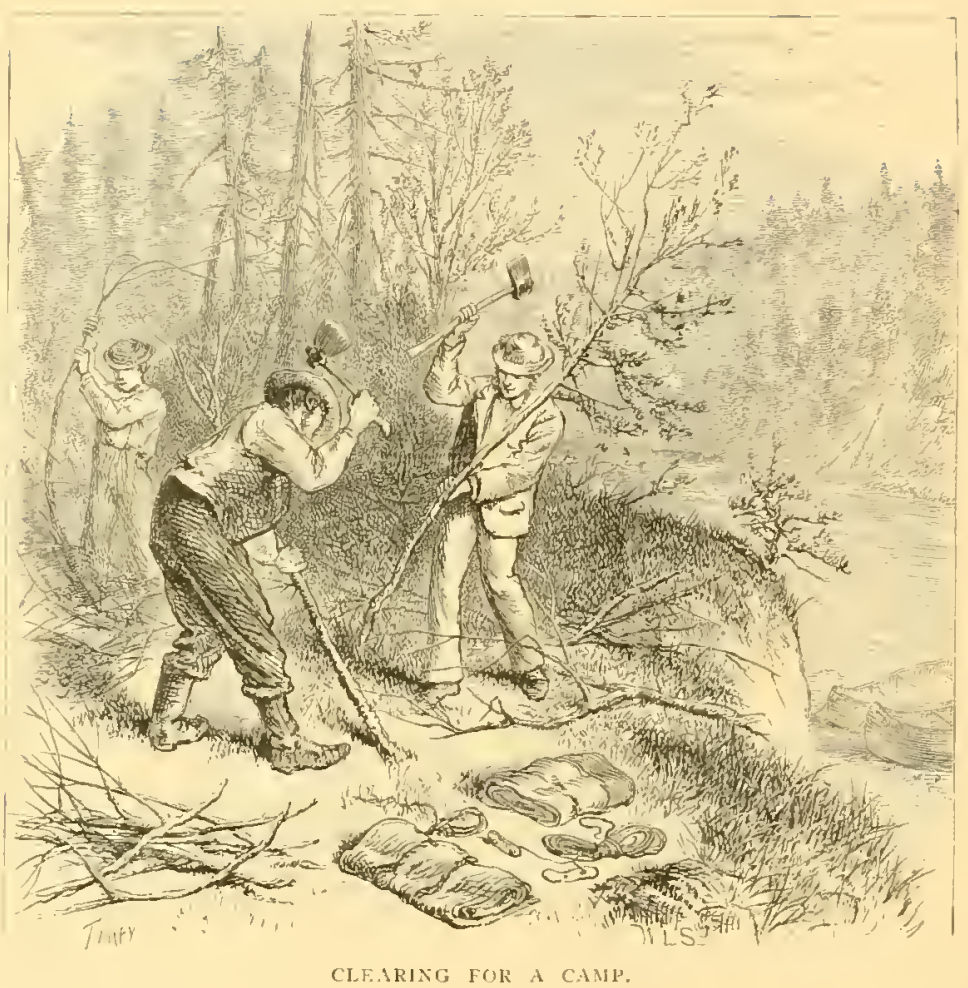

and hopeless tacks, turning tail to the blast each evening and bounding back for miles into some sheltered cove under the cliffs; and five days wasted in prematurely using up the stock of novels, counting wild ducks cutting the mist, listening for the blow of the grampus like escape steam, - gibors, the natives call him, - and watching the graceful roll of the white porpoises. After making the mouth of the strean, a favoring tide must be waited for, to carry our craft a couple of miles up its winding channel, in search of a good anchorage. It is safer to retain the chaloupe during all the angler's stay. If she is dismissed, there is no certainty of her arriving again within a week of the appointed day, and with the possibility of illness or accident in these solitudes, - though these are mishaps the sportsman never counts on, - it is well to have the means of immediate return at hand. Besides, the vessel serves as a convenient store-house, to be visited from up-stream for fresh supplies, and for relieving the camp of accumulating fish. Higher than the flow of the tide it is not possible to carry the chaloufo, and about 
this point she is moored and the canoes then unlashed, loaded with the tents and a day's rations, and headed against the current for a six miles tug to the lower camp.

With a sweep around the first point hiding the chaloupe, you take possession of the wilderness, or rather the wilderness of you. The sense of loneliness descends suddenly, oppressively, yet with a charm. Stretched along the bottom of the canoe, reclining against cushions of well-stuffed canvas sacks, with pipe alight, the quiet movement, the profound stillness, the lifeless aspect of nature, lull you into dreany delight. The river is not picturesque, in the usual senseits beauty is a stern beauty of its own. For some distance the rocks stretch along the bank, alternating with precipitous masses of clay, and sinking gradually into ranges of bowlders, then spreading out in pebbly beaches, where the first murmur of the rapids touches the ear from a distance. The hills are clothed with tall spruces, here descending rank on rank to the edge, there shattered and piled across gaps in the clay ramparts. Birches, some of noble height, are intermixed, and at the rim stout alders thrust their snaky branches in. At some points the shore falls level, sweeping back for a tract covered with bushes and such forest trees as the climate spares. But the pervading effect is somber, the prevailing color gloomy. Grays of the rocks, bluish browns of the clay, and the mournful hue of the spruce shadow the water, which struggrles in vain with its crisp breaks of white foam to brighten their reflections. Under the trees the color of the stream is dull olive, paling into brownish-yellow in the open reaches, but with no tone of the brandy tint that often stains waters flowing from spruce forests. While the tide holds, the rapids are drowned, but a mile or two up they begin to show their teeth and sound their dash. Shifting the paddle for the setting-pole, we work through the first of these, and glide into a still stretch of deep water covering great scattered rocks. In such pools salmon lie on their way up, but the trout prefer smaller and less smooth ones. From the break of the current among the surface rocks it can easily be seen what the height of the water in the river is, - whether the stream is so shrunken as to need tediously careful treatment, or so swollen that the turbid wave cheats both fish and fisher, or at that happy, just medium in which the latter will go most safely and the former most in danger. The guide slackens his stroke 
now and then, peering over the side to catch a glimpse of trout flitting like a shade through the depths if they have yet begun their wandering up, and often is able to say that they are moving in numbers - as often says it when none are seen. In his goodnature and eagerness to make it pleasant, this dear guide sees many things that are invisible, counts much more game than is caught, and never permits the puniest trout to be hooked without shouting "quel sammon!" Now and then whirling around a point, the river races down on us with the fierceness of a torrent, tossing in waves along a clay escarpment towering fifty feet, which it has cut down square and sheer as if with a razor. The rocks and pebbles are all shot off to the other bank, where the passenger may walk and wade while David gives the canoe rope, and plashes as he tows her alongside in the shallows. It is usual to refrain from casting the line on the way up, not only for the sake of avoiding delays - but, since the camp looks down on the choicest pool in all the river, why take the edge from the rapture of landing the best the first? As we ascend, the rapids grow more frequent - twenty have been counted from tide to camp, and all the number not told. Nore level spaces and denser trees succeed, the channel breaks up in places with islets of rock: and at last, rounding a curve, one of these lifts its feathery point of willows, Mavid reverses his pole to hush the clang of the iron shoe on the stones, a few strong thrusts force the boat up against the rush of the narrowing outlet, and she touches the bank at the foot of the Homer Pool. Before anything is unloaded, the angler springs out, rigs a cast, and hurrying to the head of the pool, drops his first fly. That moment is crowded with the expectation of the whole past year. Two of us once so landed and so stood, and four large fish for each were raised and netted before the men had cleared the canoes of their load. But that year there was much grass in the place, and the multitudes of mosquitoes sat on it, being in number about a million, each having also compressed twelve months' expectation into that moment. The thirst for blood on our side was soon satisfied, while the insects, far from taking off their keen edge, grew industrious in putting it on.

At this point, the stream, spreading out to a hundred and fifty feet in width, wheels to the right, striking a turtle-shaped rock nearly flush with the surface which splits it in two, hollowing on the near 


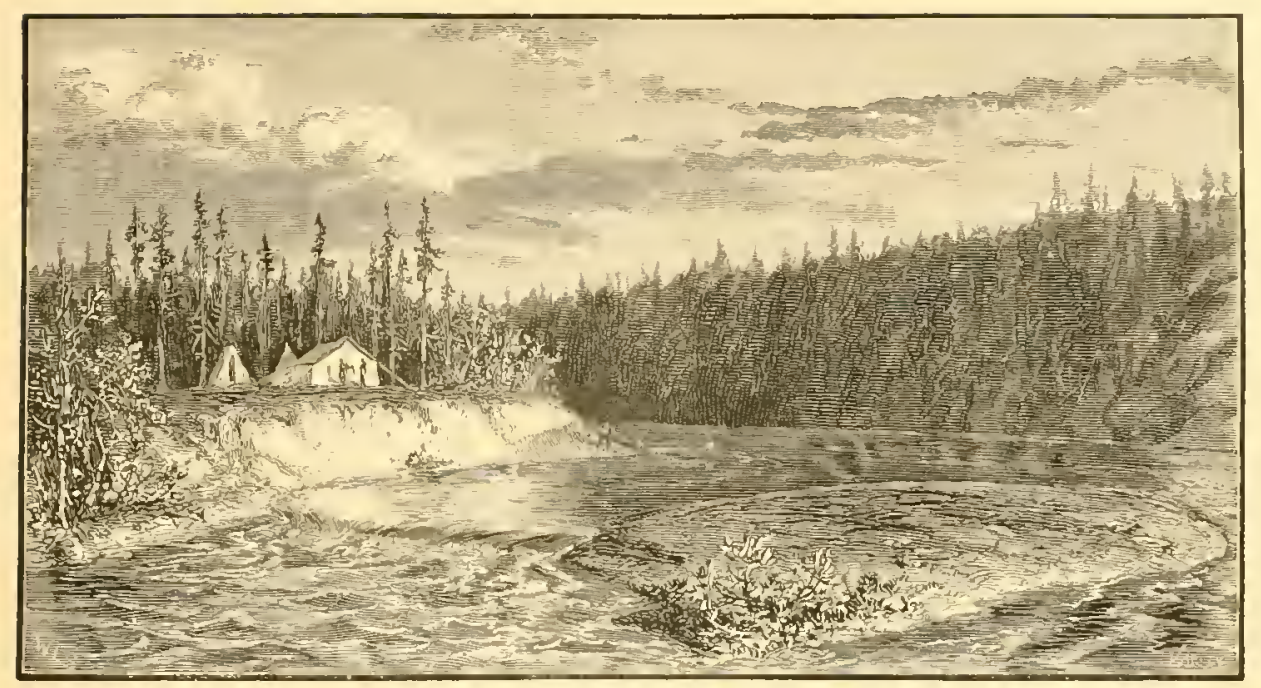

THE HONE CAMP.

side a deep pool, the breadth of a fair cast, and some sixty feet long. The farther side of this depression is a shelving wall, full of crevices and nooks, and the camp side a grassy bank four or five feet high, fringed at either end with bushes. Into the pool, above the turn, dashes a pretty run of swift water, three feet deep, with excellent wading ground. This little promontory is the only cleared spot on the stream. The trees were felled more than twenty years agro by an English baronet, who encamped with a retinue on this plateau, and has left traditions of famous sport. His forest lodge was chosen with the eye of a Nimrod, whose other eye must have been a landscape painter's. This basin is very seldom empty of trout. Last season, eleven fish weighing seventeen pounds were taken from it within an hour before breakfast by one rod, and the whole yield of the pool during the four days for which it was vexed only with a few casts at morning and evening was seventy-two fish.

A description of the peculiarities of a lodge in this vast wilderness, and of the obstacles to penetrating it and the devices for surmounting them, will probably not interest woodsmen, who are familiar with them all. But the greater part of readers have rather vague notions of a camp, a canoe, or a rapid; and to them a rough sketch of these features of a life in the woods may be interesting.

We "build our light town of canvas" with the precision of Roman camp-pitching. Removed from the bank so far that no backward- 
sailing fly may be arrested by its roof, one wall-tent rises near the shelter of the shrubs, and another opposite, if the party consists of two or more persons. Between them are planted the table and chairs, which were sketched out rather than finished by rough carpentry of adze and auger many summers ago and have wintered often in these thickets. Farther back, at the edge of the trees, stands an A tent for the men, and another to cover the provisions, with a space for the camp-fire between. Such a canvas house, with its outside fly stretched over, gives perfect shelter from heavy rains, and has nothing to fear except from sudden gusts that may rip out the tentpins. Its inside furnishing is simple but complete. First, the bedstead demands the attention due to arrangements for inviting tired nature's sweet restorer during nine good hours out of the twenty-four. Four stout crotches, kept apart by cross-pieces, and sunk deep in the ground, lift, at a height of two feet above it, two poles run through the broad hems of a canvas sacking, which may be double and stuffed with hemlock twigs. They give a springy support to buffalo robes and blankets. The upper one of these is to be doubled down its length, and a wide sheet, folded in the same way, laid between. An air-pillow and pillow-case complete a bed as trim as any ever spread by a neat-handed Hibernian Phillis. On the other side of the tent a neat wardrobe, with ample ventilation, is built up with similar rods on taller crotches. The dress needed is of thick woolen throughout, though at some noon hours in the brief intense summer of that region light clothes are comfortable. A few nights of last season were too hot for sleep-a rare experience. The mercury ranges usually between $40^{\circ}$ and $74^{\circ}$, but toward the end of August, and especially while aboard ship, the air is constantly chilly. Next, a sideboard rises against the rear tent-pole, piled up of empty boxes, the upper one of which holds the library,-pegs being set in the pole for thermometer, spring-balance, and lookingglass, if you will. The wine-cellar and spirit-vault are established outside the tent, under the fly. Add a block candlestick, strew the ground thickly with sapin covered by an India-rubber cloth for carpet, and one is better lodged than many a tenant of a log-cabin. Next day after arriving, the guides go down again with all the canoes to bring a fortnight's stores from the chaloupe. This burden loads their light craft so deep that care and skill are needed to twist 
through the rapids; and it will be late in the afternoon before the ring of their iron-shod poles against the stones, heard in measured cadence half a mile off, gives the signal of their return.

The time of their absence may be improred to review tackle and perfect it for serious work. The prudent angler will take at least three rods. Two of these should not be very light, for they may be called on, as has happened, to handle a salmon. In any case, the fish are so plentiful that it is not worth while to waste time over the smaller ones, and the most useful rod is one stiff enough to snub a pound trout, and bring him promptly to net. $A$ duplicate reel and line are, of course, provided. As to flies, the indifference of sea-trout about kind, when they are in the humor to take any, almost warrants the belief of some anglers that they leap in mere sport at whatever chances to be floating. It is true they will take incredible combinations, as if color-blind and blind to form. But experiments on their caprice are not safe. If their desire is to be tempted, that may most surely be done with three insects, adapted to proper places and seasons. One need not go beyond the range of a red-bodied fly with blue tip and wood-duck wings for ordinary use, a small all-gray fly for low water in bright light, and a yellowish fly, green-striped and winged with curlew feather, for a fine cast under alders after the patriarchs. By all means make your own flies, or learn to do so, for the sake of practicing a delicate art and amusing some idle hours on the stream. Resides, one's own handiwork is stronger than that of most shops, and with a pocket-book full of material, it wili be easy to replace a loss, by no means infrequent, caused by the tipping of a canoe.

Wading drawers of India-rubber, reaching well above the waist, are indispensable: and the foot that is shod with anything but a nail-studded sole will surely bring its wearer to great grief when it touches the treacherous clay. Nuch of the bottom is of this greasy stuff, looking like stone, but as slippery as glass, and unsafe for any foot-gear whatever. In some runs, the river-bed is pebbly, but usually strewed with large stones, and the current is so swift as to render a knee-deep stand unsteady.

The day's work in camp follows quite a regular routine. About six. the light wakes you-the guide never will. A dip in the pool or a bucket dash at the brink tones the nerves for a firm touch of the 
rod, while the reel sings its morning song over a brace of fish caught for breakfast, which the cook-guide is preparing. This need be nothing more substantial than ham and eggs, of which a week's supply can be kept (unless, indeed, a fondu is prepared, which the guide can be taught to compose very well), fish-balls, - and J)avid is an adept at these,- the trout, broiled on a wire gridiron, buttered toast or Boston crackers grilled, and marmalade, with tea or coffee. For a change, a partridge-chick can now and then be knocked over, or a squirrel or rabbit tried. After that comes the chef-d'a'ure of our wood-cook-crepss! These are thin rice cakes, fried crisp in a pan, and eaten with maple sugar. Do not grudge the men a good hour over their own breakfast. This month is sunshine in their dull year, and such plain fare sybaritic to them. And a pipe in this air, lit with a wood ember, is so doubly delicious that it needs no patience to prolong it awhile. About nine, the canoe floats off, bearing you sitting flat in the bottom, and the guide upright astern, either to the lower pools to fish from the boat, or to the upper water where landing and wading are more convenient. The fish will rise at almost any hour of the day, and in any weather,-rather more languidly from noon till three, under bright sky; rather more actively at early morning and after four. Where the water has gathered smoothness again after passing a rapid, it begins to deepen and converge to a point. Just there, in ten or fifteen feet depth, among the rocks forming a sort of dam, where the outlet of the pool breaks over in a glassy curve, the large trout love to lie, watching for insects swept down. Your fly follows the swirl, swimming swifter, till, just as it nears the rock at the very cleft of the fall, there is a surge, a tug, and the fish darts up-stream. The large ones seldom break the surface. Turn the rod at once with the reel uppermost, and do not check him tiil he tries to move down again, and then only gently. If he can be held away from the brink, - and it is not often, with care, that he slips over it,- - from four to seven minutes should suffice to bring him to net; though if he be fresh run from tide and over three pounds, twice that time may be needed. It is well to search the neighborhood of the bushes, too, before descending more than half-way down the pool, or of any great rocks scattered on the bottom.

While the fisherman is busy, the guide left at home has been cleaning and curing the catch of the day before. No fish are wasted. 


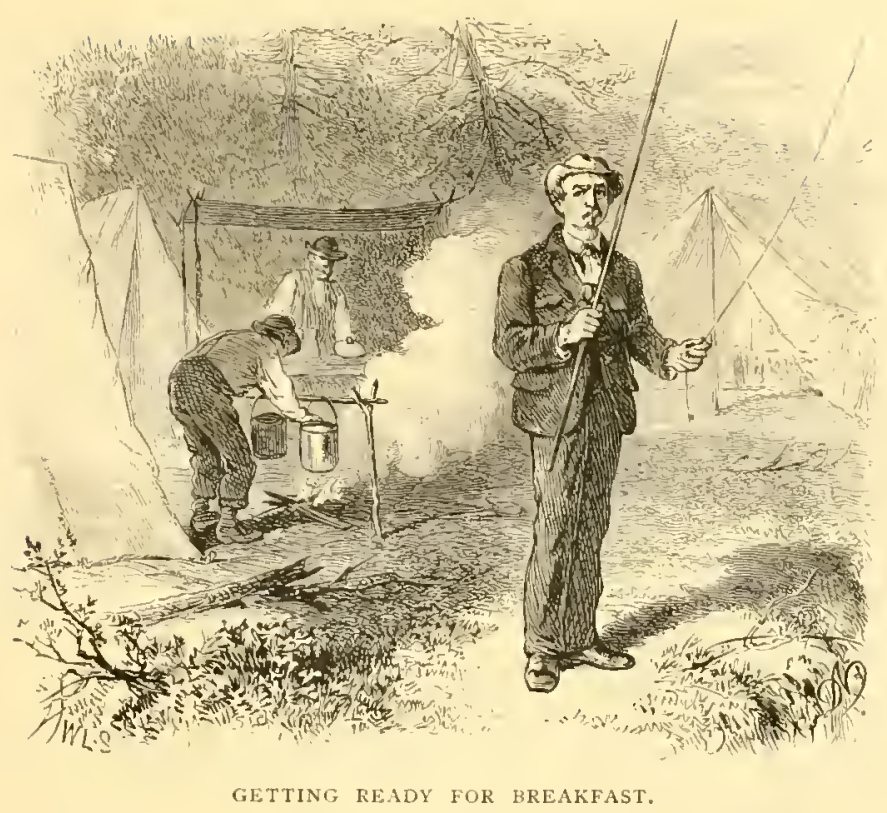

Coarse salt and barrels always make part of the chaloupi's freight, and the trout not eaten are packed and carried to Tadousac, as an important and welcome addition to the winter's stores for these poor fellows' families. When a larger trout than usual is netted, he is greeted with the cry. "C"cst bon pour lo baril." The return from the chase must be so timed that the rapids may be passed before dark. Immediately on landing, every fish caught is faithfully weighed (none being small enough to reject) and entered on the score. Usually, dinner is at six, the morning's carte being varied only with one of three or four kinds of preserved soup, baked or fried potatoes, boiled rice, sherry and Bordeaux, cheese, raisins, coffee, and a chasse. If you ask the best way of cooking the fishthose over two pounds weight deserve the pot; the flavor and juices of smaller ones above a pound will be kept unwasted by roasting them under the coals; and as to those below a pound, since in this region not St. Anthony, but probably St. Lawrence, is their patron, let them follow his fate and grill on the gridiron. None are small enough to spoil by frying; but our cordon, with a little superintendence, is quite equal to a stew in claret. After dinner, the platcau is large enough for a quarter-deck promenade of thirty steps to and fro, till, finishing the second cigar, you look up about nine to see the 


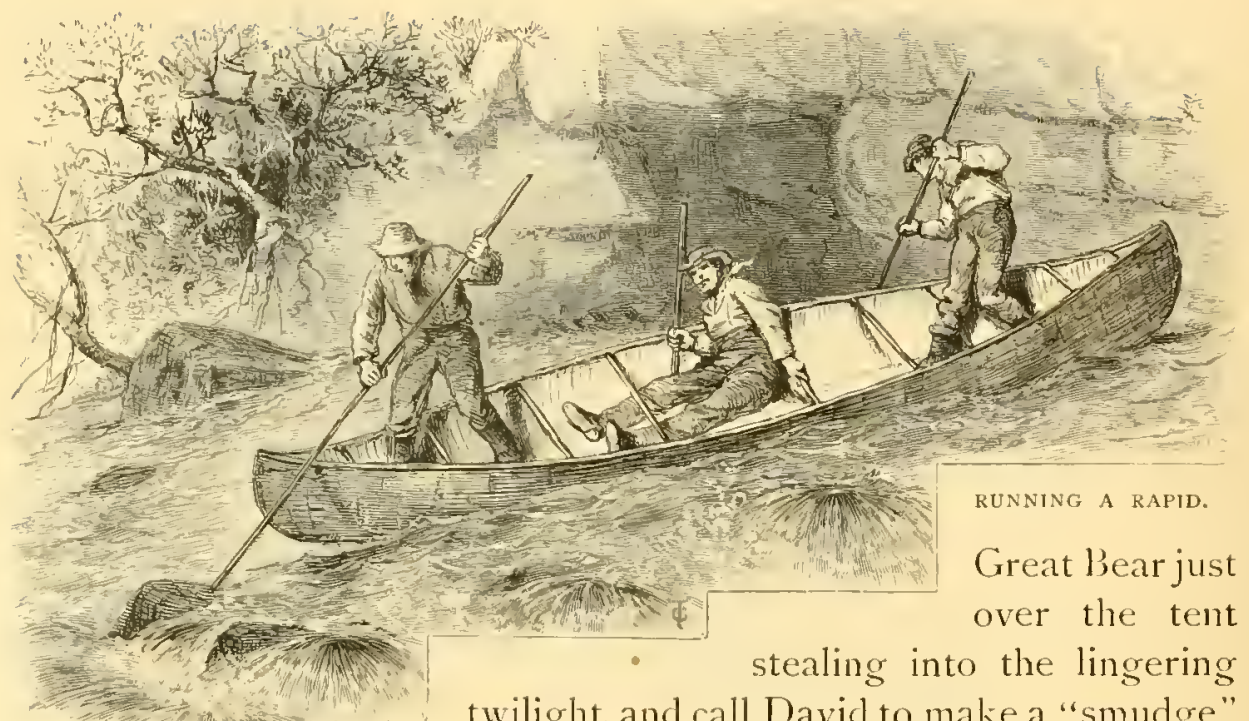

twilight, and call David to make a "smudge" inside the canvas that may completely clear it of mosquitoes, and to tie down the flaps, shutting you in for the night. On Sundays, the stream runs undisturbed. Reading, journalizing, and repairs of many kinds fill the time. Last summer, the Government guardian, an old acquaintance, chanced to arrive on Saturday night, and camped near us,- perhaps needlessly suspicious of a breach of Sunday close-time.

His business at this season was to examine and clear the portages, several of which are blazed along the river-side at points made impassable for canoes by the roughness or sudden fall of the rapids. The rapids vary greatly as to depth, height, and length. Some cover a rod of slightly broken water with small stones; some race for a quarter of a mile in surges over clay bottom, scooped and beaten as hard as rock, while others toss and dash on a sharp descent for twice that space out and in among a maze of granite bowlders. Up and down these last, and around some steep falls, the canoe must, of course, be coaxed with a line, the guide either wading and steadying her or stumbling alongside ashore. Running a rapid is really piloting, for the natural fall, the lay of the rocks, and the best water between them, remain always nearly the same. Many a jagged old sunken lump or bowlder-head just above the surface, worn glassy smooth, with long weeds streaming like hair from it, looks familiar to the angler year after year. Most of the rapids may be waded 
across at very low water, but with consiclerable risk, on account of the irregular, slippery foothold and the tearing current. The ascent or descent of a rapid is exciting, even without the trifle of danger it brings. The whispering ripple of the water deepens into an angry rush as you approach. It the head or foot the pitch looks much sharper than it really is, the eye taking in the foreshortened incline. Jown among crowded clusters of rocks, now seen, now swept under, the flood comes bounding, coiling, and shattered. Every epithet in Southey's particularly foolish piece of nursery drivel, the "Cataract of Lodore," might find reality and echo here.

In this sort of surf, half stone, half water, a common wooden boat would be bumped to pieces in five minutes. The only thing that can float in it, the birch canoe, is one of those marvels of clever adaptation that look like genius. Such a canoe is really nothing but a basket with pointed ends and stiffened sides. You sit, float, and toss in her as you would in a basket, and without most watchful perpendicularity and tiresome tension of nerves in balance, you tip out of her as you would out of a basket. She is a mere single skin of bark sewed together with deer-sinews,

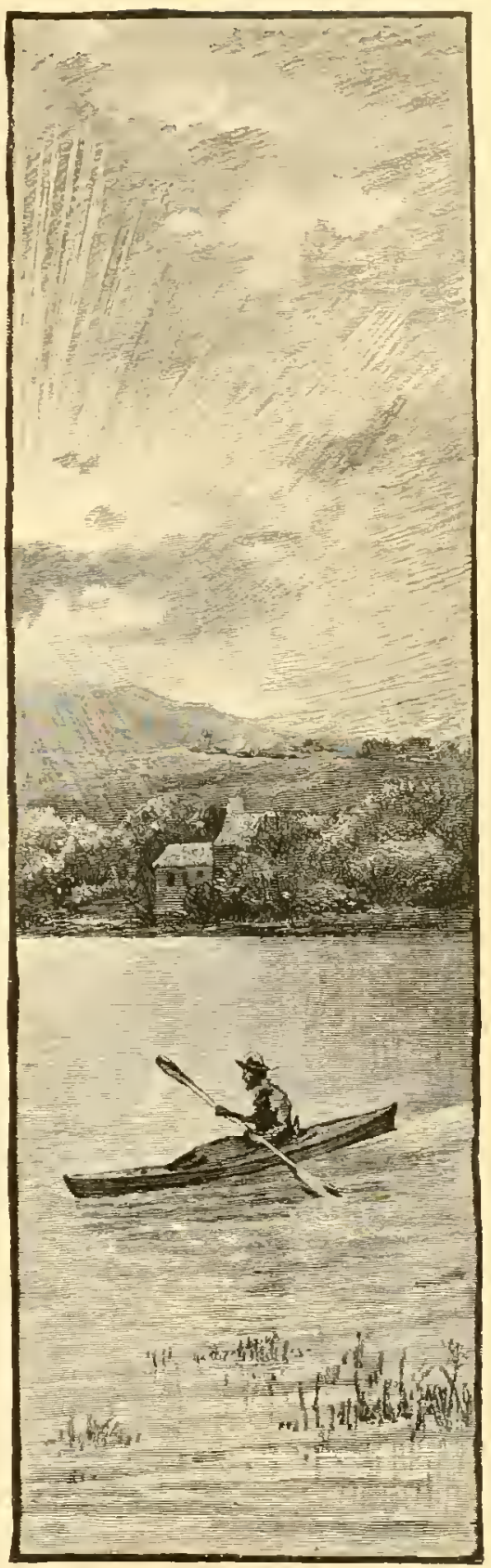

PADDLING. rimmed with slight ash or birch strips, and connected across at top by five slender thwarts, or "bords," modeled in all her lines so that the deepest point is along the middle bottom, and she turns in the 
water every way as on a pivot. The draught, with two men aboard, is three to four inches. Buoyant, of elastic frame, unsteady to the lightest touch, endways or sideways, she answers to shillful control like a sentient thing, and throws a clumsy rider like a mustang. With her light grace and delicate color, she is the lady of watercraft. The skill of these canoe-men is wonderful, only gained by long practice from early chilthood. Nearing the foot of the rapid, while yet in still water, the guide drops the paddle, stands erect with his setting-pole in the extreme stern, his boy in the same attitude at the point of the bow, and studies the eddies and stones intently. In a moment she is swung alongside a rock, her peak thrust just around it across the stream; then, with a mighty drive from the poles, she darts diagonally through the torrent and whirls her tail downstrean, under the lee of another rock a few feet higher up. She is again held, hugging the granite by main force, and edging forward till the beat of the water boiling up astern of her center helps to lift her on, and with another powerful send she shoots across upward again to the next covering point. She threads her intricate way among the bowlders by repetition of these zigzag dashes, sometimes missing the aim and crashing back against a rock, sometimes beaten aside by the pole slipping on the bottom, with the guide's eye quick at every turn, and his muscles steadily braced. The men's pose, alertness, and strength form a study. At times she must be thrust up by sheer power against the dead rush of the torrent, gaining inch by inch. David's cries to his boy rise above the noise of the water- "Poussc! arrête! lance l'cau! hale l'cau! autre bord! pousse, poussc au loin!" Accidents occur, but seldom from miscalculation. If a pole should snap while the stress of the flood beats on her, the canoe may be whirled broadside on, and capsized. Then there is a rolling and tumbling among the rocks, struggling for a footing, sometimes with hard bruises, - or if near the foot of the rapid, one may be swept into deep water and must keep a clutch on the point of the canoe till she drifts into shallows. Except in the larger rivers, there is not much danger of drowning. The guides prefer ascending to going down a rapid, as the risk of the canoe getting beyond their control is much less when the water drives against her in sight. They are very cautious, too, to avoid straining or bruising the boat. "You act as if this canoe belonged to you," David would reproach his boy at a careless movement. 
Well handled, a good birch may last for four years; or she may be banged into uselessness by an inexpert in one season of low water. The red bark is stouter and more durable than the smoother yellow.

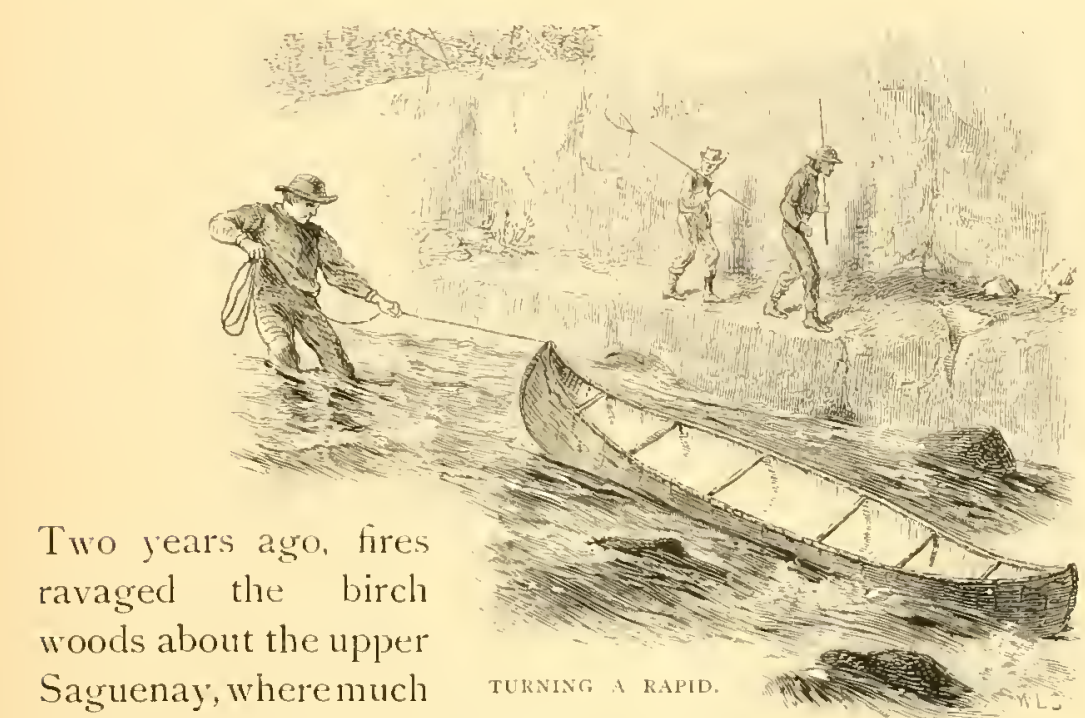

of the material is obtained, and forced

the Indians to seek their bark at great distances, increasing the price of their work. A new canoe of the size used in these streams costs with equipment from eighteen to twenty-two dollars. These are eighteen feet long, three and a quarter across, and fifteen inches deep, weighing about forty pounds. They are Montaignie canoes, built by Indians of the north shore. The larger ones, used in the St. John's and the greater rivers, will carry nine men or a freight of nearly a ton. They are made by the Micmacs of the south shore, and have higher peaks and flatter bottoms, with less roll than the former.

After eight or ten clays spent at the home camp, all the pools within range having been several times whipped over, and the run of large trout sensibly slackens. At a point seven miles higher up (measured through its crooks), the river rests, after its earlier wanderings for seventy miles through untrodden forests, and expands into a basin, between two and three miles across in either direction, deep set among craggy hills. Through this lake, and to the far regions beyond, all the fish, salmon and trout, pursue their pilgrimage. Just opposite the home camp a well-marked portage 
opens, cutting off the bends, and bearing straight over a mountain and through dense woods to the lake by a rough course of three miles. Sunday, a leisure-day, is usually chosen for this march, and most of the hours of it are required to make the carry and settle the new camp. At one trip, the men carry

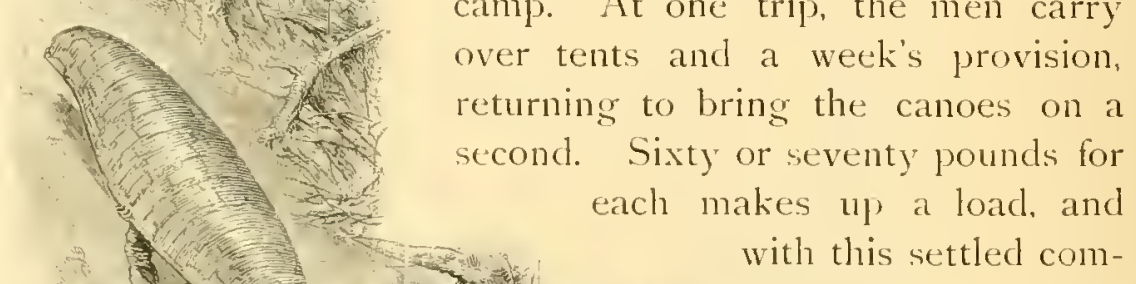

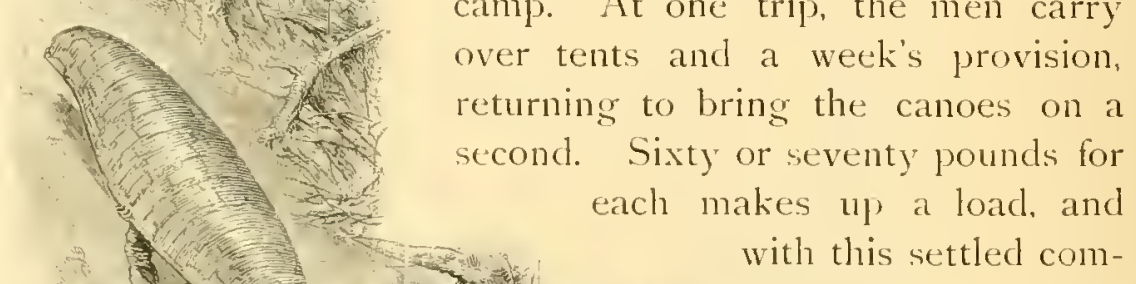

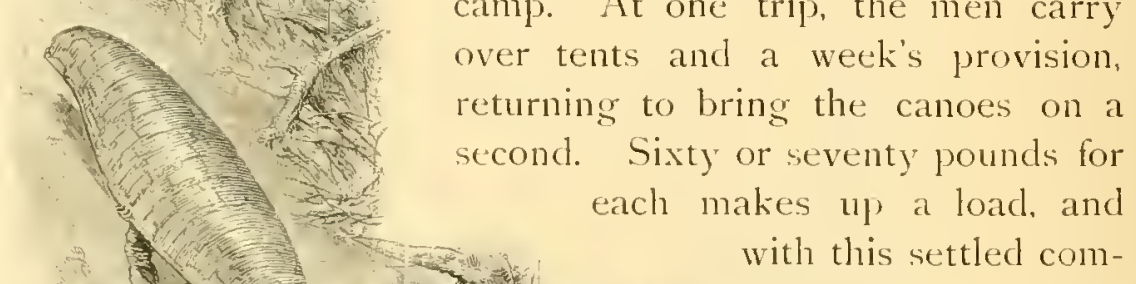

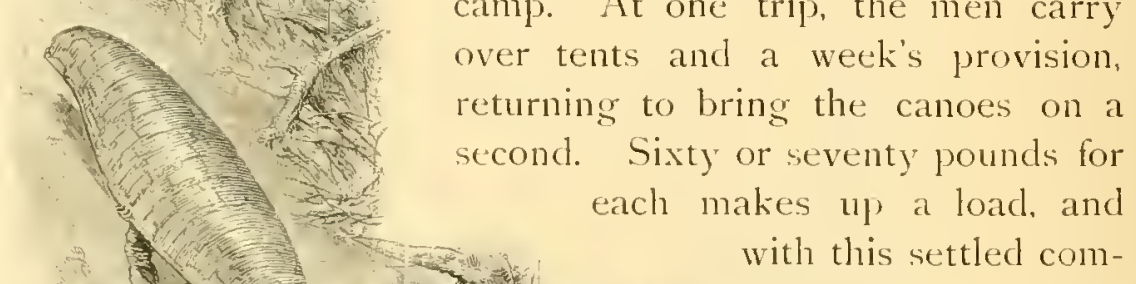
ders, and steadied by a broad strap passing over the forchead, so as to leave the arms quite free, they climb the steep hillcrest, often cutting steps in the wet clay, and press pactly on the shoul-

through the woods at a quick gait, making the distance within two hours. Portaging the canoes is much more difficult and delicate work. They are turned over, hoisted on the head, and carried poised with the two hands at the edges, a little forward of the middle, giving the bearer at a distance among the trees the look of an ungainly twolegged elephant. For a time, axe and knife must be depended on for tools, sapin for beds, and birch-bark for furniture. As we go on, the thicket grows denser and the solitude deepens. Very little animal life disturbs it. A few squirrels, and a partridge with her brood will . chirp and flutter; at the lake, we shall see swooping fish-hawks and hear the kingfisher's metallic cry. Occasionally, in these woods, as on 
the stream, a fresh bear's track is crossed, but the silence here is seldom broken except by the ceaseless under-song of the mosquito's hum-

"The horns of Elltand faintly blowing."

This minim of insects must have a word. Since fishing began, he and his stinging kin have been the angler's pest. Herodotus thinks him worthy of mention and describes the Egyptians' levice for protection against him, - that of spreading a net over a shaded cleft in the rocks, through the meshes of which he will not pass unless the sun shines in. The Sicilian fisherman of to-day contrives precisely the same refuge from his attack. But after the experience of many years on many streams, the assertion is conficlently made, that all masquerading in veils, helmets, goggles, and capes, brings mere vexation and impediment, and that the most effective and least troublesome protection is gained by rubbing every exposed surface thoroughly and often with a mixture of three parts of sweet oil and one part of oil of pennyroyal.

At the lake it is always cold. The sunsets over its rugged shores doubled in the crimson water, the frequent aurora flashing and streaming across the whole breadth of sky, and the clear stars looking down on a mirror as still, touch the feeling like beauty wasted, since so rarely seen, if nature knows any waste.

A variation of sport may be enjoyed here, if one condescends to capture the great pickerel abounding in the lake, either by casting a spoon with a stout rod among the lily-pads, or by lazily letting ten fathoms of line trail from the canoe while the guide paddles slowly, till one of these pond-sharks, striking, gorges the gaudy bait, and is hauled up alongside and knocked in his grim head with a short club. A couple of hours of this rude sport yielded to one line a hundred and twenty-two pounds, the largest fish weighing eight. This is merely justice pursuing murder, since the pickerel is a destroying terror to trout and salmon. They lurk in shoals around the outlet, to seize the fish passing up and wage havoc among them for a mile down the stream. Escaping these waylayers, the fish have still many miles to run before reaching the spawning-grounds. The intervening water above the lake is too free from rapids to afford good fishing until a tributary is reached, too far away to be attainable in the few days remaining. Pointing the flotilla peaks 
south out of the lake, we turn our backs upon nothing between it and Hudson's Straits, except the dreary solitudes of Labrador, with a few peaceable Indian tribes scattered through them. In its fall of two hundred feet through seven miles, between the outlet and the home camp, the river breaks into magnificent pools, drained by sharp, rough rapids, with long intervening stretches of deep-water lurking-places (even so late) for salmon. Many of them of large size are passed lying at the bottom motionless, as if cased in ice, or heard breaking at night. A small one now and then absorbs the

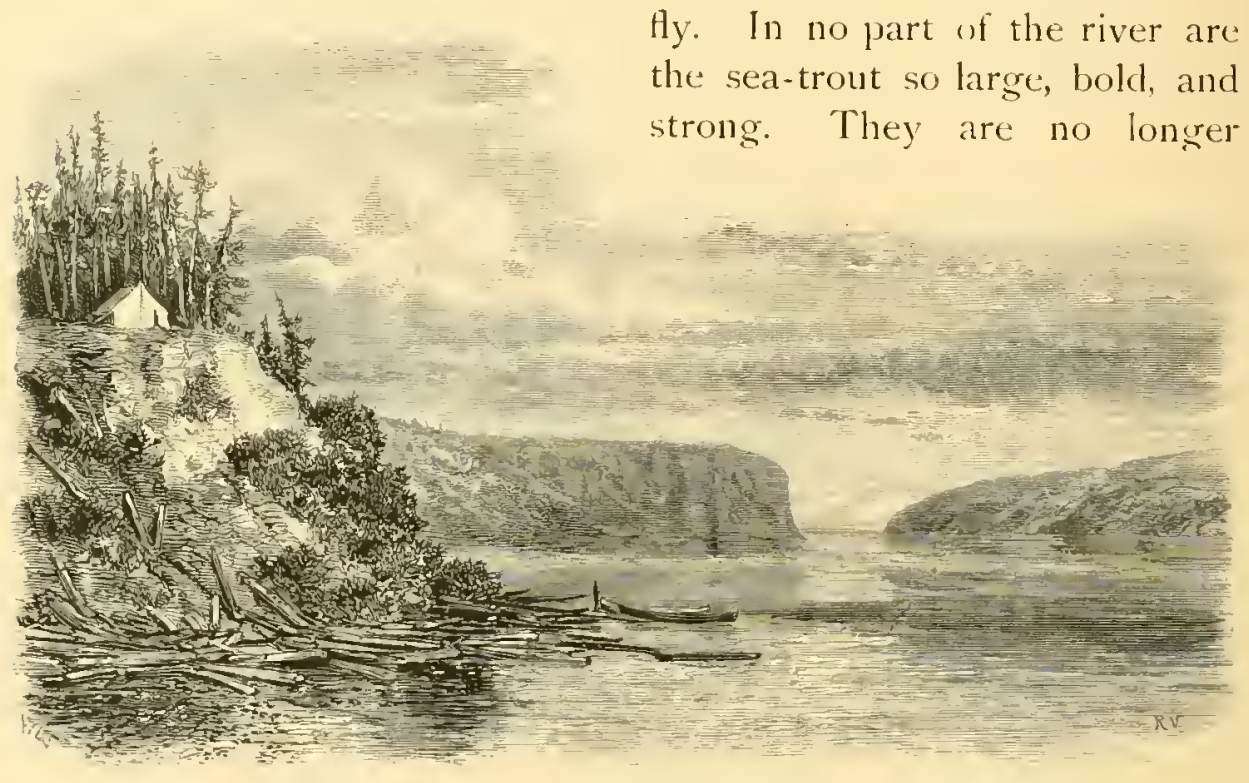

THE LAKE CAMP.

the gray trout that sailed in with the tide. Their color is rich and high beyond description,--backs a glittering bronze, shot with gold, and crooked, dark streaks; bellies like pearl, and fins a fan of strong crimson, purple, and black spines. Their dazzling vermilion spots "bicl the rash gazer wipe his eye." As a new puzzle for naturalists, some of the largest taken blush all exquisite rose wherever white usually shines. The beginning of the fishing and the verge of the pirate-pickerel's range is marked by a grand bald crag, towering four hundred feet, and sinking sheer into water, christened the Palisade Pool, where very large trout usually lie. The next few miles are a favorite preserve, always stocked in the season with a succession of splendid fish. The banks, still thickly 


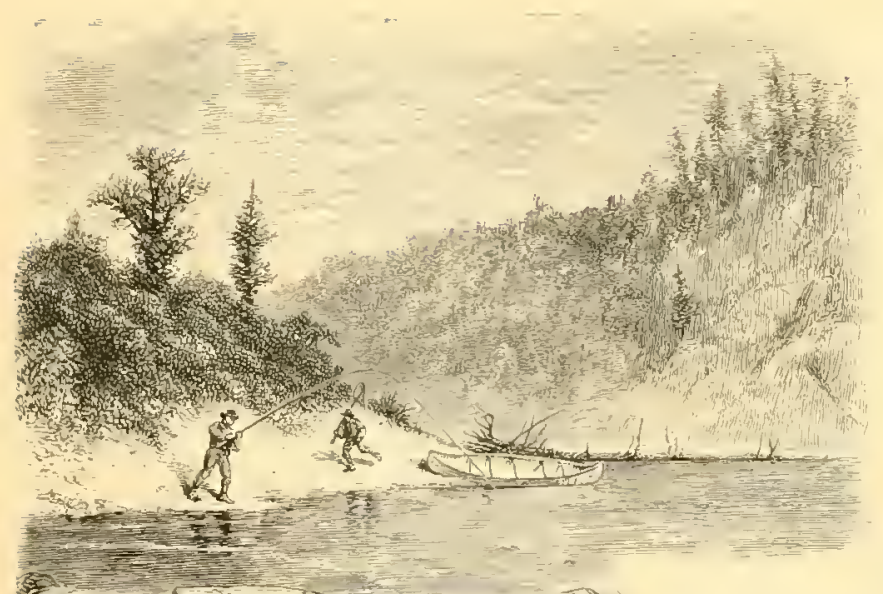

wooded with larch, spruce, sycamole, and small shrubs, show less of clay than those lower down, and more of pebbly ledge and short sandy beaches, so that fishing afloat is exchanged for wading, which insures a longer.

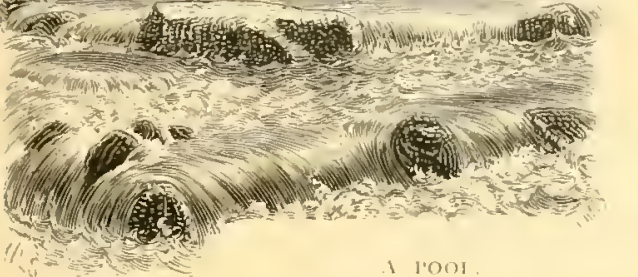

truer cast, and more ease in landing the fish. The long summer days of a week may be filled with excitement in whipping this range of twenty or thirty pools. So satisfactory is the work, indeed, that they are usually gone over several times on successive days from a new camp established near half-way down to the great fall, which separates them from the lower range of water accessible from the original camp. This is pitched near a curve, just below which the river receives two or three cool streamlets into a circular basin, parted from its main course by a little stony tongue, fringed with bushes, and about thirty yards across. This spring pool is a favorite resting-place for trout on the way up, and they have been seen literally paving its sandy floor, though its clearness and exposure to the sun render them very shy. From this pool, one hundred and six fish were taken by one rod in three days, thirteen of which weighed over three pounds, and the largest five.

Sunshine seldom interferes seriously with the sport in this region. Days of sullen, cold rain come on, leaving only an hour or two for work outside the tent. Sudden thunder-gusts break over us while afloat, driving us to the shelter of thick épinettes (dry spruces). or even to a pent-house under the canoe, turned bottom up, and propped on sticks. Sometimes a strange cloud of thin mist fills the valley, that seems to tingle with electricity, and is pungent with the smell of ozone. So sensitive the nerves become to that mysteriously 


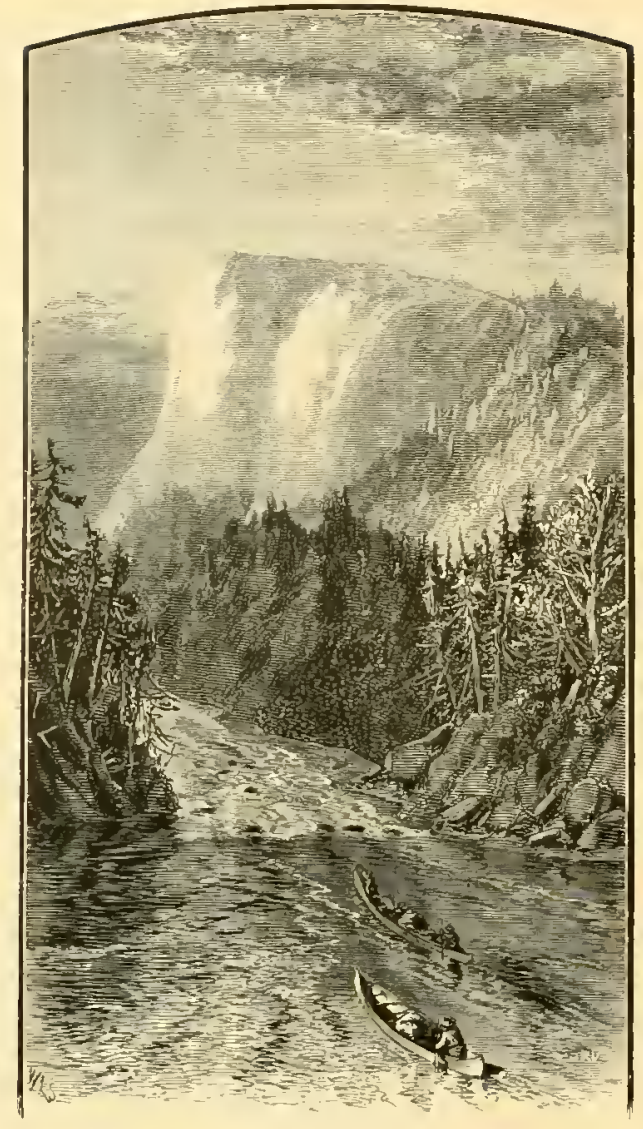

THE OUTLET

charged vapor, that one glances at the twig-tips, almost expecting to see them lit with St. Elmo's fire, like yard-arms at sea in an electric storm. Only some seasons, however, and some days in each, are free from one of the two extremes of too much or too little rain. Last summer, for instance, the weather continued so hot and dry, and the stream ran so low, that for long stretches not a fish was to be found at all in the pools, all having resorted to the mouths of little inlets, where they hung clustered like a swarm of bees. Down from the middle camp, the canoes go deeply loaded with tents and fish, dipping only now and then into an inviting pool, and taking some hours to reach a great rapid which seizes the river at the opening of a gorge and hurls it furiously along half a mile of tangled rocks, to plunge it over a steep, picturesque fall thirty feet high. Down this rapid the guides will slowly, cautiously pole or lead the 
canoes, sending the passenger to scramble along a rough path among the cliffs, from which he looks down on their clwindled, strusgling figures, and faintly hears their shouts. They meet again at the fall, round which, of course, the canoes are portaged, or slid down through a side chute, and we have passed the portal of the upper stream, and bid it farewell.

Three days of the best work for one rod in the upper waters, noted on the score in separate years, are: 37 fish of 79 pounds, 41 fish of $83 \mathrm{r} / 2$ pounds, 39 fish of $86 \frac{1}{2}$ pounds.

If the day of coming down to the home pool has been properly timed, its evening will be prolonged over the camp-fire to watch the full moon rise above a clump of pointed spruces fronting the tent. She brings the promise of a new run of fish, filling the pools after their week's rest, with occasional fine trout among them, lingering behind the seniors on their way up. A sweet sense of civilization attends the return from the deeper forests to bed and board, and the camp seems even neat and spacious after rougher quarters. The black flies are gone, and the mosquitoes only weakly wicked. Sometimes at morning frost sprinkles the ground, the days grow cooler, and the nights cold, till we sympathize with the man of old who cried, "Aha! I am warm; I have seen the fire," and enjoy the mere animal pleasure of heat. The men turn and resalt their fish, stowed in broad troughs of hemlock bark. The smell attracts small animals, and sometimes there is an alarm in camp that a bear has snuffed them out, and running out with the gun in the chilly night air, you catch sight of a lyn making off with one in his mouth. The sport is still fine; the fish, though not quite of the size of those earlier, rising and running with a dash. But the stores are dwindling, the canoes get leaky in spite of pitching, and the weather turns windy and changeable. The dull boom of the fog-gun from the light-house island-thirty miles off on the south shore of the great river-rolls oftener up the valley with a warning that autumn mists are gathering and autumn storms brewing. There steals on a sense of having been a month without telegrams or letters, and suddenly some morning you say "enough," and order the flotilla down to the chaloupe with everything not needed for one day more. Next day, after an early breakfast, we strike tents, pitch the table and chairs into the bushes to save them from spring floods, pack the canoes with what 
remains to make an ample load, and cast one longing, lingering fly behind before pushing into the current. The catch is always very good on the way down in point of numbers, but is apt to reduce the score as to average of weight. It is not always possible to fish or even to pause. Tiwo seasons ago, the river was very full on entering it, and after a week's difficult fishing, it rose steadily, with heavy showers, till its olive surface turned café-au-lait color, and rolled bank-full, effacing rocks and rapids alike. Down the middle, it tossed in waves over the sunken bowlders. A canoe would quickly have foundered there, and we were forced to drift along the margin, with the aid of branches, fairly washed out of the valley by the torrent. The kingfisher screams along the sands as we pass; perhaps a beaver pokes his nose cautiously out among alder roots: or a disturbed owl floats silently off into the woods. At length, after leisurely and regretfully dropping down for hours, the chaloupe's thin mast points above the next turn, and the quickened paddles cut the tide-water, driving the canoes alongside to take possession if she is found all right.

She may be found in quite a different condition. Some seasons aso, the men had left her the previous night hauled out into a little bay, and anchored on so bad a bottom that when she grounded with the falling ticle a rock started one of the planks below her quarter. and she lay stern under, half full of water, when we boarded her. Fishing out her cargo, and drying on the rocks what remained unspoiled, was a tedious waste of time; but when lightened and pumped out, her planking sprang into place and was easily secured. The voyage back oftenest consumes two days and nights against a down-stream wind, sometimes strong enough to raise an uncomfortable sea in making the port tack while the tide ebbs, and to drive us to some anchorage till it turns. Good and honest fellows as the guides are, there is, perhaps, the slightest possible disposition on the skipper's part to lengthen the cruise for his chartered craft by a half day or more, so that it is usually early morning when she works slowly up with sweeps against the edges of the powerful Saguenay current and rounds the point into Tadousac Bay. The summer birds have flown from the cottages and hotel- - the house seems only waiting our return to put out the fire in its hospitable stove and close its doors for the season. The steamer leaves L:Anse à 


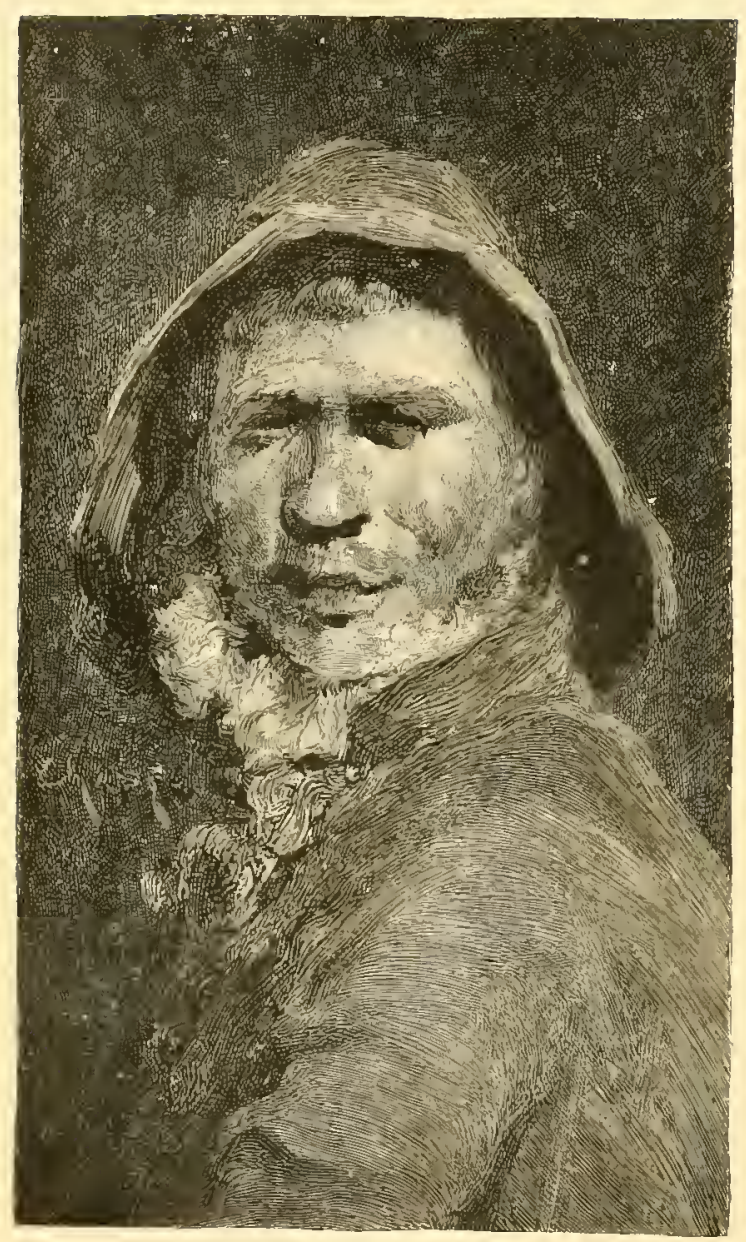

UUK SKIPPER.

l'Eau for Quebec late in the afternoon, yiving time for a substantial civilized dinner off other service than tin and for settling the accounts of the cruise.

The usual charge for canoe-men is a dollar and a half a day, in gold, and for the chaloupc, with its owner's services, two dollars. A liberal rule for calculation in laying in supplies at Quebec is to allow thirty cents for each ration, on the basis of two served to every man of the party each day for ordinary stores, with an addition for wine and spirits shipped, and for what the Germans call delicutessen, from which a quart of lime juice should by no means be 
omitted. The average cost of the month's excursion in each of four years-once with three in the party, once with two, and twice alone - has been from three hundred and seventy to four hundred dollars, including the sum paid for license to use the stream, as for salmonfishing. It results, therefore, that with respect to region, route,

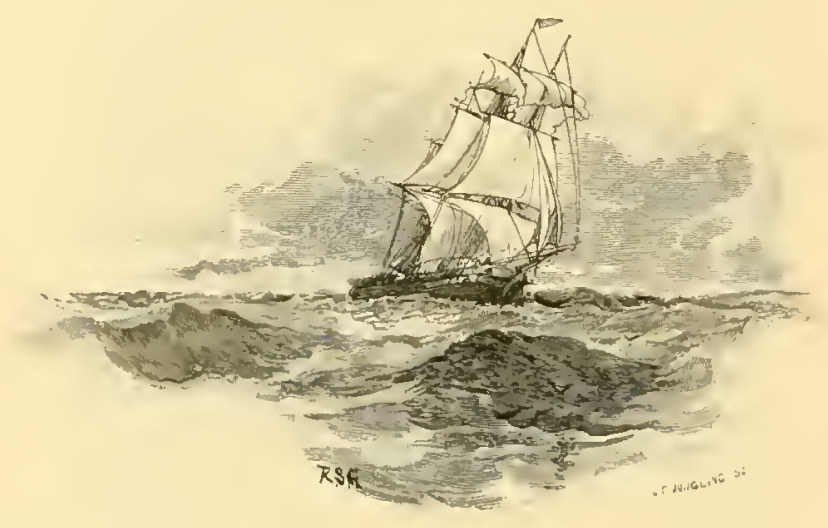

HOMEW.IRD BOUND.

equipment, and expense, - as to all things indeed excepting season, tackle, and size of fish,- there is little difference between salmonfishing and sea-trout fishing: and the angler who can choose his month will, of course, prefer the former. If forced to content himself with the minor sport, he will find that health and experience are no less essential to its enjoyment, and that the charms of Nature, impartially kind to all enthusiastic wooers who seek her wilderness shrine, will more than compensate for its comparative tameness. The following instances may prove that his record, if modest, is not likely to be insignificant; even though it might not provoke Mistress Quickly's comment-

"I'll warrant you, he's an infinitive thing on the score."

\begin{tabular}{|c|c|c|c|c|c|c|}
\hline Years. & Rods. & Days. & No. of fish. & Weight. & Average. & Over 3 lbs. \\
\hline I 872. & . 3 & 17 & 1017 & I 20.4 lbs. & I lb. 3 oz. & 92 \\
\hline 1877. & . 2 & I 3 & 222 & 274 & I " $31 / 2$ " & 7 \\
\hline I $\$_{75}$. & - I & 10 & 282 & $399 "$ & $1 " 61 / 2 "$ & I 4 \\
\hline 1876 & . I & 23 & 389 & $5^{60}$ & I : 7 & 26 \\
\hline
\end{tabular}




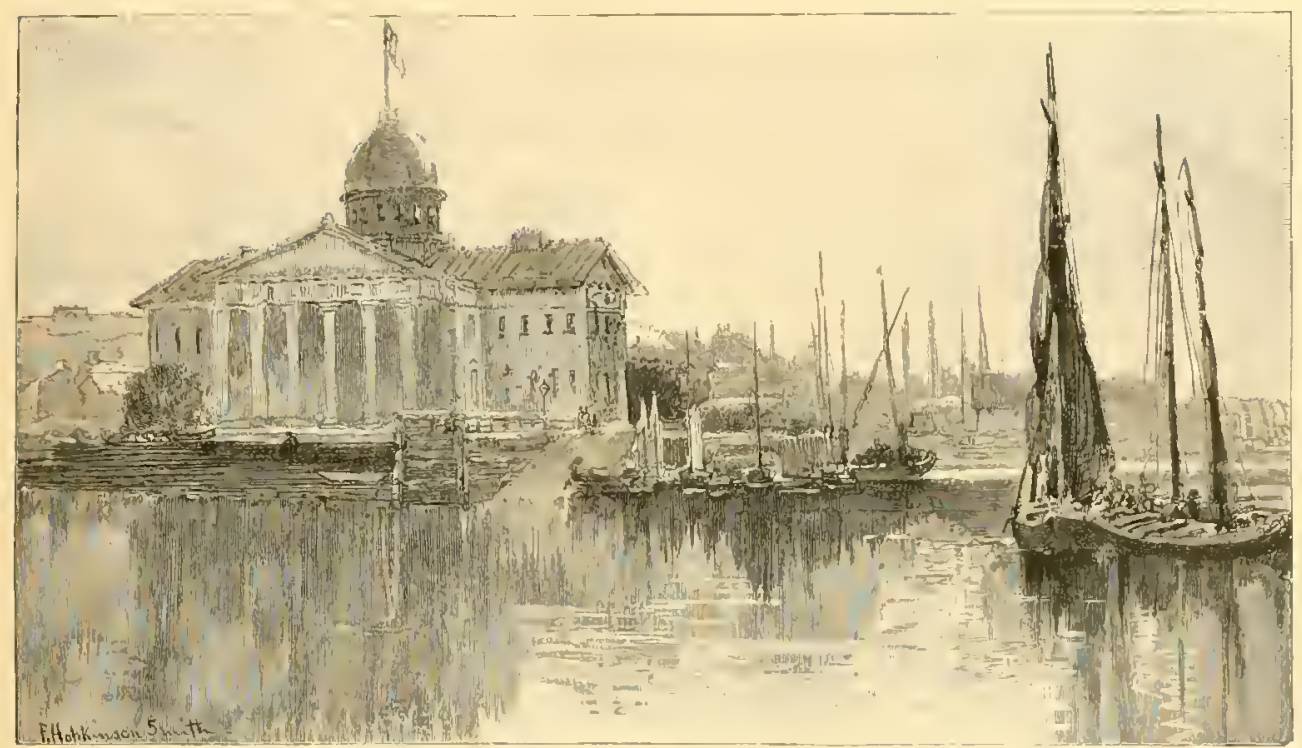

THE CUSTUM-HOUSE, QLEBEC.

When the angler, recounting these captives of his steel, pictures again each bright scene and hour of his summer's recreation, it will not be the least of his pleasures to remember that its fruits are aiding to make the cheerless life of his guides more enclurable, in the long winter while those dark forests bow beneath the weight of snows, and the stiffening river shivers through all its depths under the blasts storming down those stern Laurentian valley's.

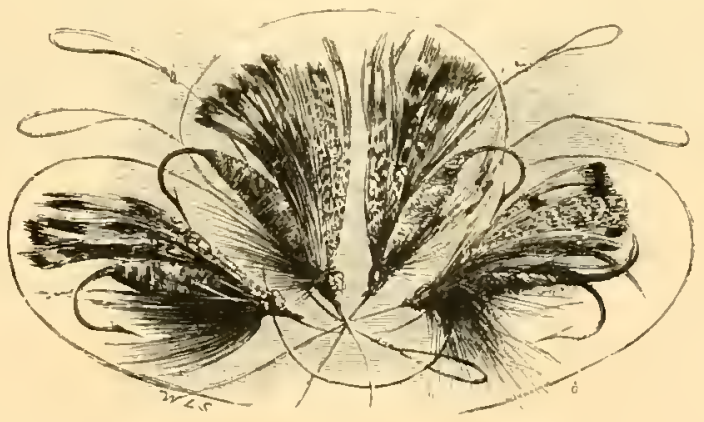




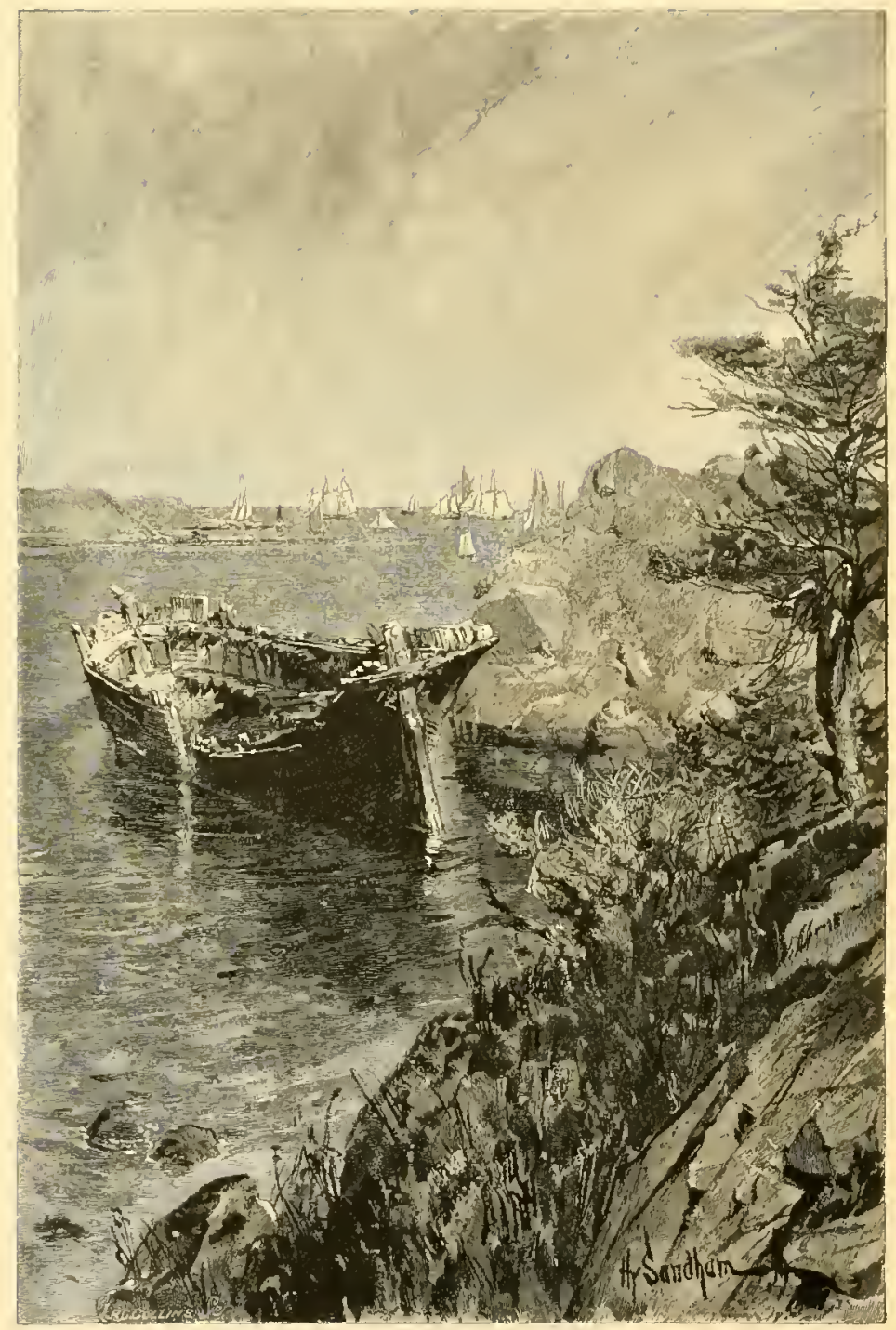




\title{
THE HALCYON IN CANADA.
}

\author{
Br JUHN BURRUUGHS.
}

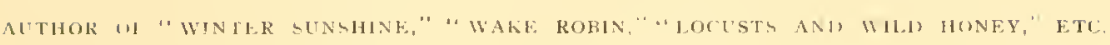

T

HHi halcyon, or kingfisher, is a grood guide when you go to the woods. He will not insure smooth water or fair weather, but he knows every stream and lake like a book, and will take you to the wildest and most unfrequented places. Follow his rattle, and you shall see the source of every trout and salmon stream on the continent. You shall see the Lake of II oods, and far-off Ithabaska and Abbitibbe, and the unknown streams that flow into Hudson's Bay, and many others. His time is the time of the trout, too, namely, from April to September. He makes his subterranean nest in the bank of some favorite stream, and then goes on long excursions up and down and over woods and mountains to all the waters within reach, always fishing alone, the true angler that he is, his fellow keeping far ahead or behind or taking the other branch. He loves the sound of a water-fall, and will sit a long time on a dry limb overhanging the pool below it, and, forgetting his occupation, brood upon his own memories and fancies.

The past season, my friend and I took a hint from him, and when the dog-star began to blaze, set out for Canada, making a big detour to touch at salt water and to take New York and Boston on our way.

The latter city was new to me, and we paused there and angled a couple of days, and caught an editor, a philosopher, and a poet, and might have caught more if we had had a mind to, for these waters are full of 'em, and big ones, too. 
Coming from the mountainous regions of the Hudson, we saw little in the way of scenery that arrested our attention until we beheld the St. Lawrence, though one gets glimpses now and then as he is whirled along through New Hampshire and Vermont that make him wish for a fuller view. It is always a pleasure to bring to pass the geography of one's boyhood; 'tis like the fulfilling of a dream; hence it was with partial eyes that I looked upon the Merrimac, the Connecticut, and the Passumpsic,-dusky, squaw-colored streans, whose names I had learned so long ago. The traveler opens his eyes a little wider when he reaches Lake Nemphremagog, especially if he have the luck to see it under such a sunset as we did, its burnished surface glowing like molten gold. This lake is an immense trough that accommodates both sides of the fence, though the larger and longer part of it by far is in Canada. Its western shore is bold and picturesque, being skirted by a detachment of the Green Mountains, the main range of which is seen careering along the horizon far to the south-west; to the east and north, whither the railroad takes you, the country is flat and monotonous.

The first peculiarity one notices about the farms in this northern country is the close proximity of the house and barn, in most cases the two buildings touching at some point,-an arrangement doubtless prompted by the deep snows and severe cold of this latitude. The typical Canadian dwelling-house is also presently met with on entering the Dominion, - a low, modest structure of hewn spruce logs, with a steep roof (containing two or more dormer windows) that ends in a smart curve, a hint taken from the Chinese pagoda. Even in the more costly brick or stone houses in the towns and vicinity this style is adhered to. It is so universal that one wonders if the reason of it also be not in the climate, the outward curve of the roof shooting the sliding snow farther away from the dwelling. It affords a wide projection, in many cases covering a veranda, and in all cases protecting the doors and windows without interfering with the light. In the better class of clap-boarded houses, the finish beneath the projecting eaves is also a sweeping curve, opposing and bracing that of the roof. A two-story country house or a Mansard roof, I do not remember to have seen in Canada; but in places they have become so enamored of the white of the snow that they even whitewash the roofs of their buildings, giving a cluster 


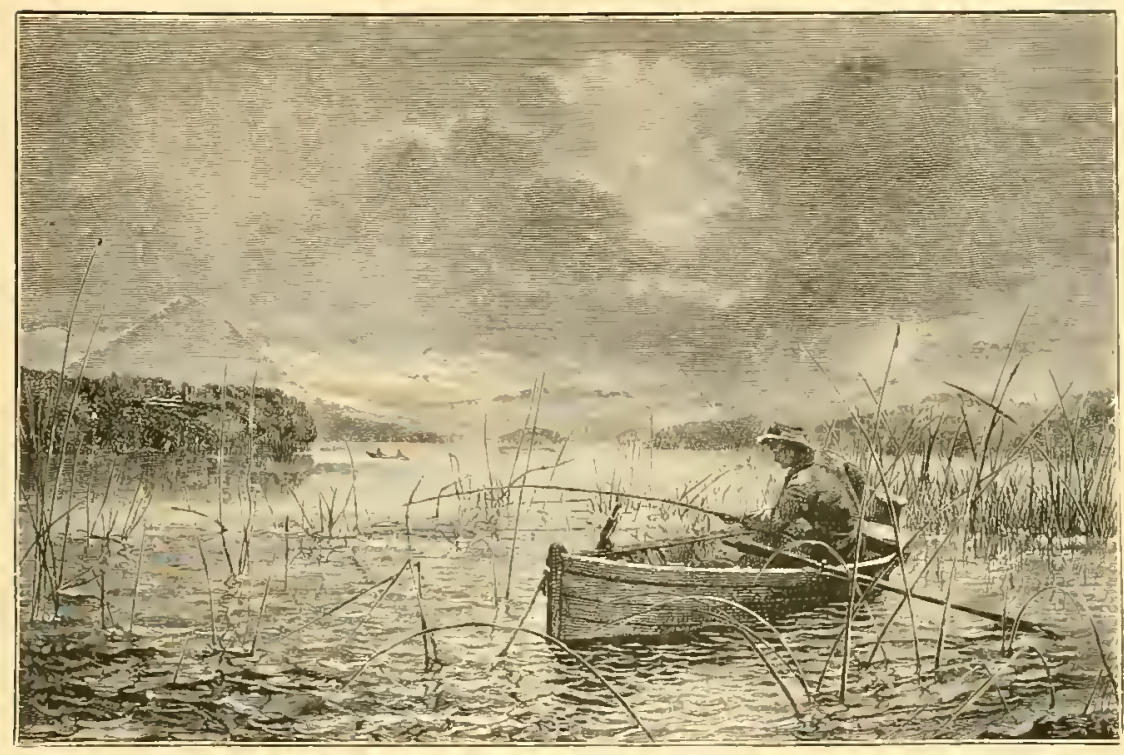

LAKE MEMPHREMAGOG.

of them the impression, at a distance, of an encampment of great tents.

As we neared Point Levi, opposite Quebec, we got our first view of the St. lawrence. "Iliad of rivers!" exclaimed my friend. "I et unsung!" The Hudson must take a back seat now, and a good ways back. One of the two or three great water-courses of the globe is before you. No other river. I imagine, carries such a volume of pure cold water to the sea. Nearly all its feeders are trout and salmon streams, and what an airing and what a bleaching it gets on its course. Its history, its antecedents, are unparalleled. The great lakes are its camping-grounds; here its hosts repose under the sun and stars in areas like that of states and kingdoms, and it is its waters that shake the earth at Niagara. Where it receives the Saguenay it is twenty miles wide, and when it debouches into the Gulf it is a hundred. Incleed, it is a chain of Homeric sublimities from beginning to end. The great cataract is a fit sequel to the great lakes; the spirit that is born in vast and tempestuous Superior takes its full glut of power in that fearful chasm. If paradise is hinted in the Thousand Islands, hell is unveiled in that pit of terrors.

Its last escapade is the great rapids above Montreal, down which the steamer shoots with its breathless passengers, after which, inhaling and exhaling its mighty tides, it flows calmly to the sea. 


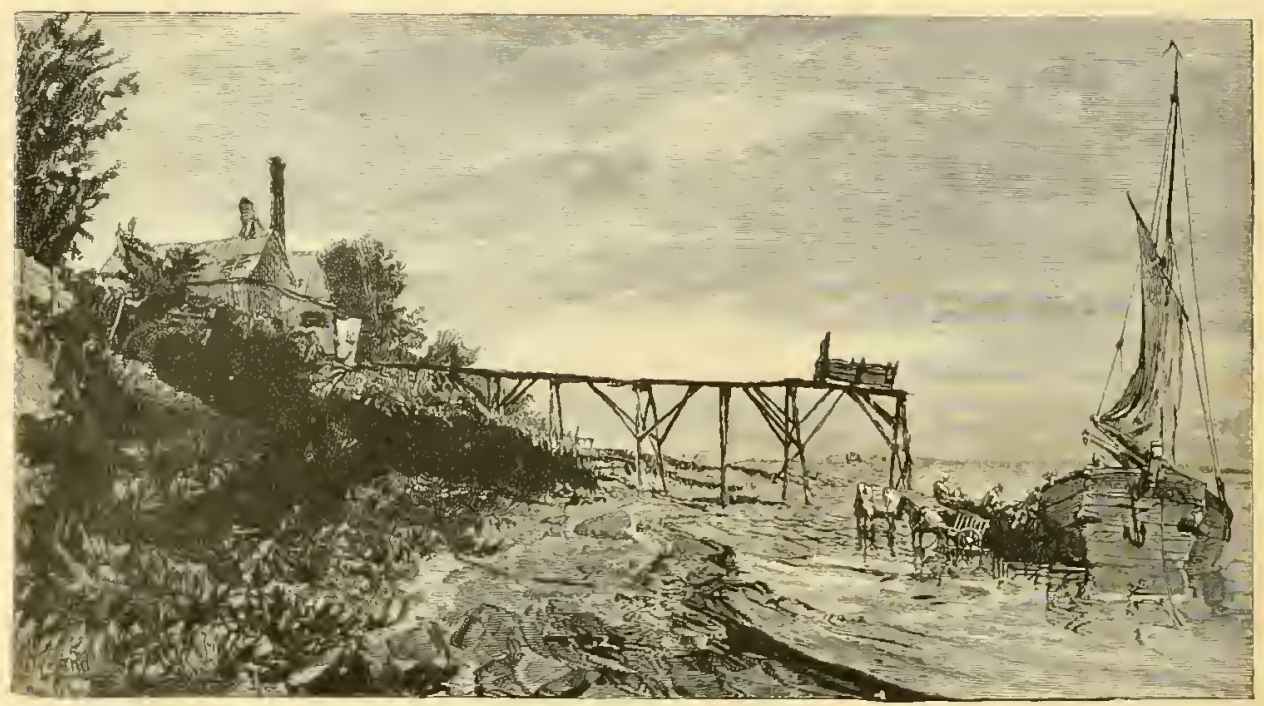

ON THE ST. LAWRENCE, NEAR MONTRE.AL,

The St. Lawrence is the type of nearly all the Canadian rivers, which are strung with lakes and rapids and cataracts, and are full of peril and adventure.

Here we reach the olclest part of the continent, geologists tell us, and here we encounter a fragment of the Old World civilization. Quebec presents the anomaly of a medixval European city in the midst of the American landscape. This air, this sky, these clouds, these trees, the look of these fields, are what we have always known; but these houses, and streets, and vehicles, and language, and physiognomy, are strange. As I walked upon the grand terrace, I saw the robin and kingbird and song-sparrow, and there in the tree, by Wolfe Monument. our summer warbler was at home. I presently saw, also, that our Republican crow was a British subject, and that he behaved here more like his European brother than he does in the States, being less wild and suspicious. On the Plains of Abraham, excellent timothy grass was growing and cattle were grazing. We found a path through the meadow, and, with the exception of a very abundant weed with a blue flower, saw nothing new or strange, - nothing but the steep, tin roofs of the city and its frowning wall and citadel. Sweeping around the far southern horizon, we could catch glimpses of mountains that were evidently in Maine or New Hampshire, while twelve or fifteen miles to the north the 
Laurentian ranges, dark and formidable, arrested the eye. Quebec, or the walled part of it, is situated on a point of land shaped not unlike the human foot, looking north-east, the higher and bolder side being next the river, with the main part of the town on the northern slope toward the St. Charles. Its toes are well down in the mud where this stream joins the St. Lawrence, while the citadel is high on the instep and commands the whole field. 'The grand Battery is a little

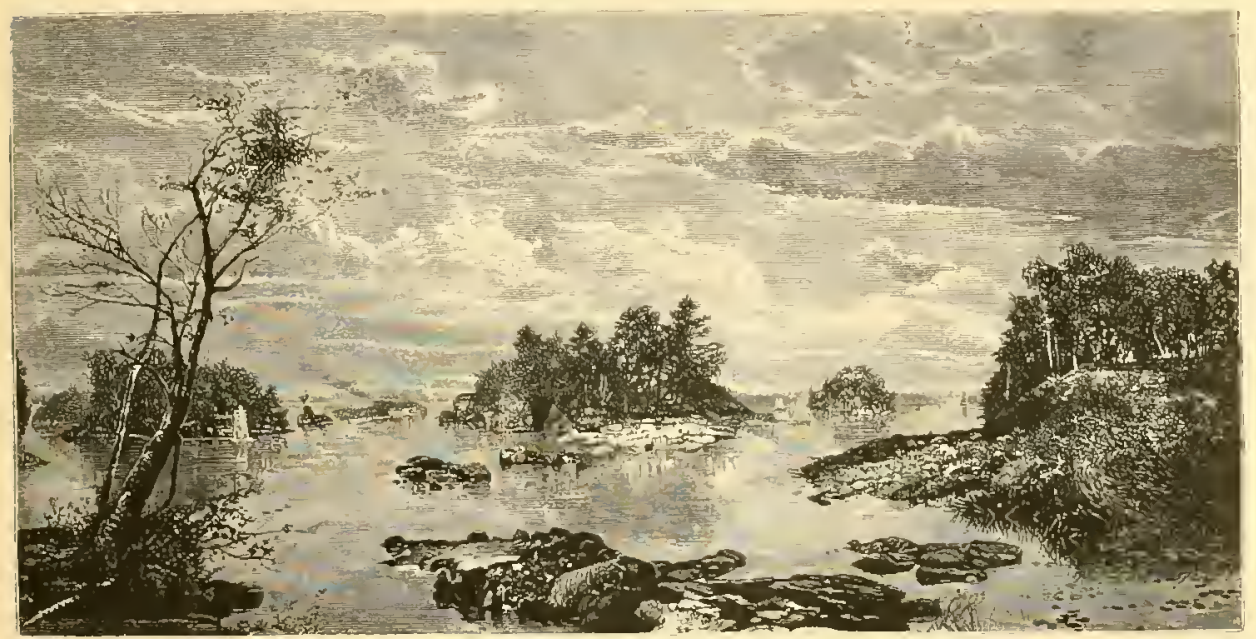

IN THE THOUSAND ISIAADS.

below, on the brink of the instep, so to speak, and the promenacler looks down several hundred feet into the tops of the chimneys of this part of the lower town and upon the great river sweeping by northeastward like another Amazon. The heel of our misshapen foot extends indefinitely toward Montreal. Upon it, on a level with the citadel, are the Plains of Abrahan. It was up its high, almost perpendicular, sides that Wolfe clambered with his army, and stond in the rear of his enemy one pleasant September morning over a hundred years ago.

To the north and north-east of Quebec, and in full view from the upper parts of the city, lies a rich belt of agricultural country, sloping gently toward the river, and running parallel with it for many miles, called the Beauport slopes. The division of the land into uniform parallelograms, as in France, was a marked feature, and is so throughout the Dominion. A road ran through the midst of it lined with trees, and leading to the falls of the Montmorency. I imagine 


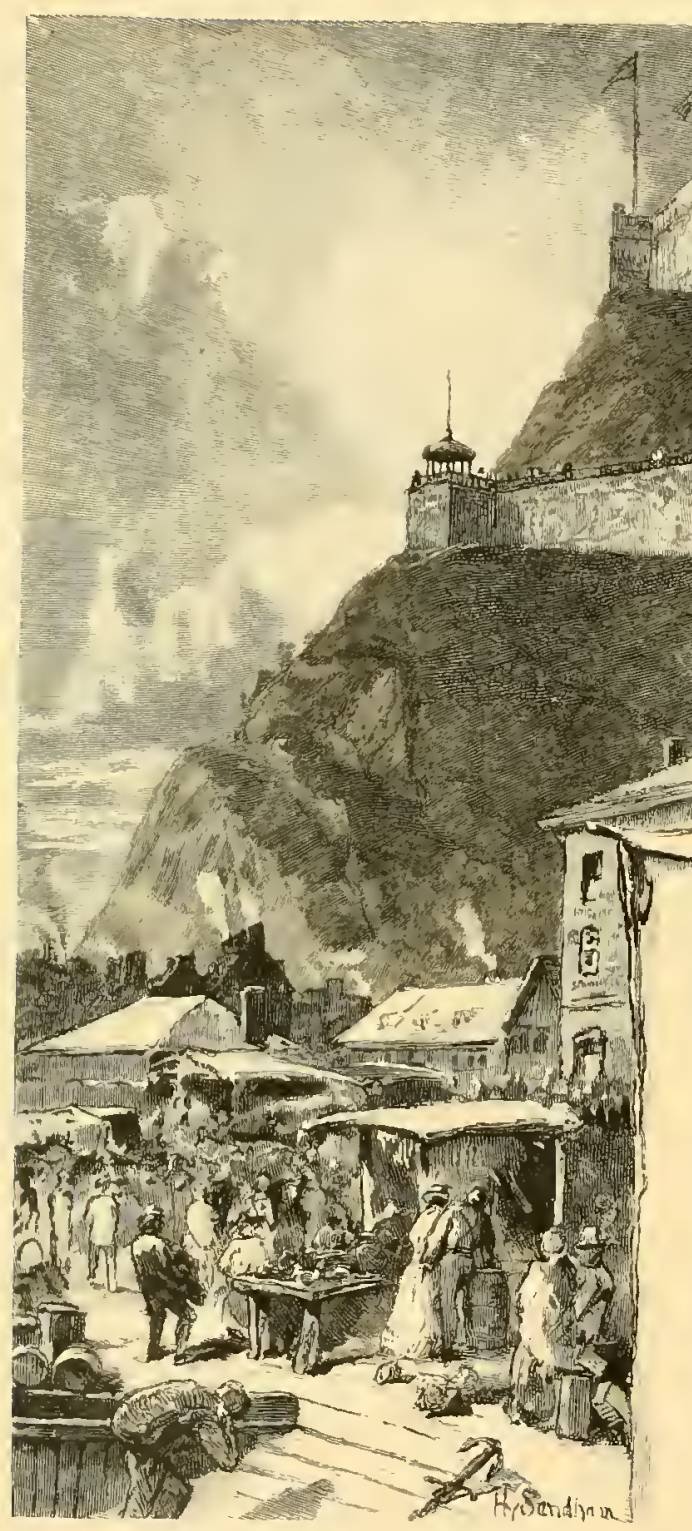

THE CITADEL AT QUEBEC.

that this section is the garden of Quebec. Beyond it rose the mountains. Our eyes looked wistfully toward them, for we had decided to penetrate the Canadian woods in that direction.

One hundred and twentyfive miles from Quebec, as the loon flies, almost due north, over unbroken spruce forests, lies Lake St. John, the cradle of the terrible Saguenay. On the map, it looks like a great cuttle-fish, with its numerous arms and tentacula reaching out in all directions into the wilds. It is a large, oval body of water, thirty miles in its greatest diameter. The season here, owing to a sharp northern sweep of the isothermal lines, is two or three weeks earlier than at Quebec. The soil is warm and fertile, and there is a thrifty, growing settlement here, with valuable agricultural 
produce, but no market nearer than Quebec, two hundred and fifty miles distant by water, with a hard, tedious land journey besides. In winter, the settlement can have little or no communication with the outside world.

To relieve this isolated colony and encourage further development of the St. John region, the Canadian Government is building a wagon-road through the wilderness from Quebec lirectly to the lake, thus economizing half the distance, as the road when completed will form with the old route, the Saguenay or St. Lawrence, one side of an equilateral triangle. A railroad was projected a few years ago over nearly the same ground, and the contract to build it given to an enterprising Vankee, who pocketed a part of the money and has never been heard of since. The road runs for one hundred miles through an unbroken wilderness, and opens up scores of streams and lakes abounding with trout, into which, until the road-makers fished them, no white man had ever cast a hook.

It was a good prospect, and we resolved to commit ourselves to the St. Joln road. The services of a young fellow, whom by reason of his impracticable French name we called Joe, was secured, and after a delay of twenty-four hours we were packed upon a Canadian buckboard, with hard-tack in one bag and oats in another, and the journey began. It was Sunday, and we held up our heads more conficlently when we got beyond the throng of well-dressed church-goers. For ten miles, we had a good stone road and rattled along it at a lively pace. In about half that distance we came to a large brick church, where we began to see the rural population, or habitans. They came mostly in two-wheeled vehicles, some of the carts quite fancy, in which the young fellows rode complacently beside their girls. The two-wheeler predominates in Canada and is of all styles and sizes. After we left the stone road, we began to encounter the hills that are preliminary to the mountains. The farms looked like the wilder and poorer parts of Maine or New Hampshire. While Joe was getting a supply of hay of a farmer to take into the woods for his horse, I walked through a field in quest of wild strawberries. The season for them was past, it being the 2oth of July, and I found barely enough to make me think that the strawberry here is far less pungent and high-flavored than with us. 


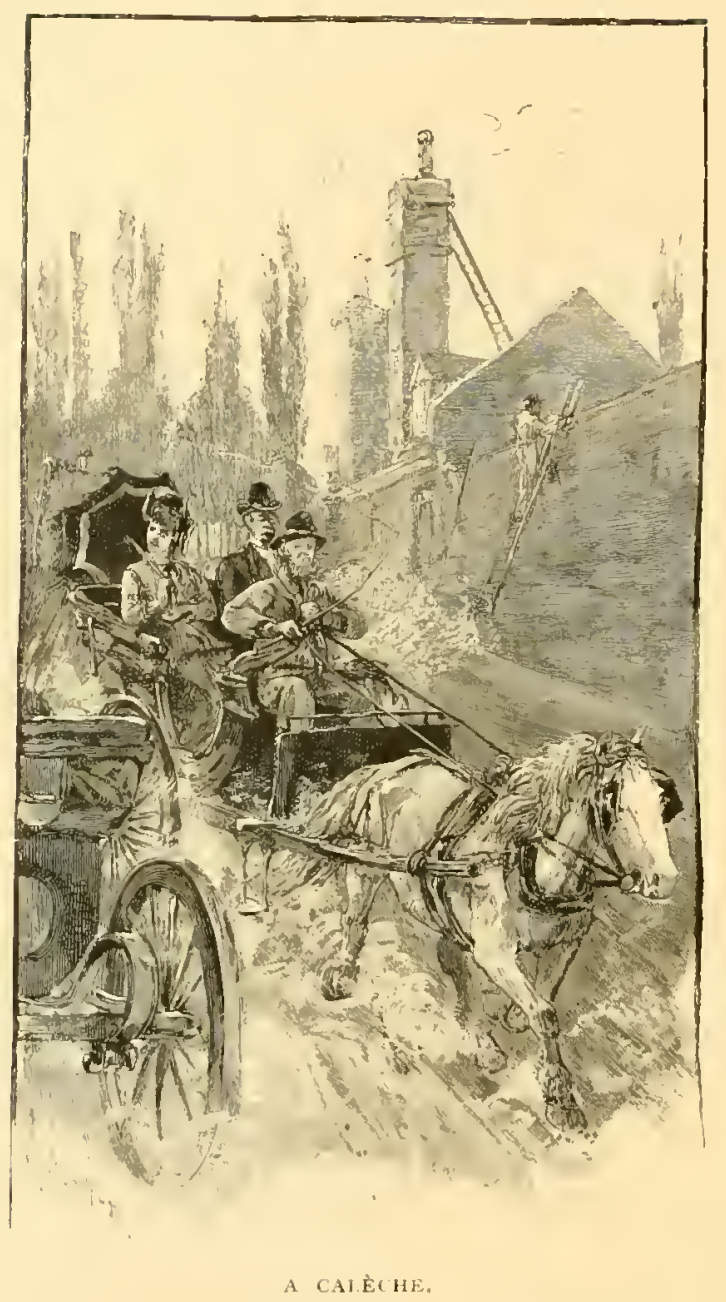

The cattle in the fields and by the road-side looked very small and delicate, the effect, no loubt, of the severe climate. We saw many rude implements of agriculture,-such as wooden plows shod with iron. We passed several parties of men, women, and children from Quebec, picnicking in the "bush." Here it was little more than a "bush"; but while in Canada, we never heard the woods designated by any other term. I noticed, also, that when a distance of a few miles or of a fraction of a mile is to be designated, the French Canadian does not use the term miles, but says it's so many acres through or to the next place. 
This fondness for the "bush" at this season seems quite a marked feature in the social life of the average Quebecer, and is one of the original French traits that holds its own among them. Parties leave the city in carts and wayons by midnight, or earlier, and drive out as far as they can the remainder of the night, in order to pass the whole Sunday in the woods, despite the mosquitoes and black flies. Those we saw seemed a decent, harmless set, whose idea of a grooct time was to be in the open air, and as far into the "bush" as possible.

The post-road, as the new St. John's road is also called, begins twenty miles from Quebec at Stoneham, the farthest settlement. Five miles into the forest upon the new road is the hamlet of La Chance (pronounced La Shaunce), the last house till you reach the lake, one hundred and twenty miles distant. Our destination the first night was La Chance's: this would enable us to reach the Jacques Cartier River, forty miles farther, where we proposed to encamp, in the afternoon of the next day. We were now fairly among the mountains, and the sun was well down behind the trees when we entered upon the post-road. It proved to be a wide, wellbuilt highway, grass-grown, but in good condition. After an hour's travel we began to see signs of a clearing, and about six o'clock drew up in front of the long, low, log habitation of La Chance. Their hearth-stone was outdoor at this season, and its smoke rose through the still atmosphere in a frail column toward the sky. The family was gathered here, and welcomed us cordially as we drew up, the master shaking us by the hand as if we were old friends. His English was very poor, and our French was poorer: but with Joe as a bridge between us, communication on a pitch was kept up. His wife could speak no English; but here true French politeness and graciousness was a language we could readily understand. Our supper was grot ready from our own supplies, while we sat or stood in the open air about the fire. The clearing comprised fifty or sixty acres of rough land in the bottom of a narrow valley, and bore indifferent crops of oats, barley, potatoes, and timothy grass. The latter was just in bloom, being a month or more later than with us. The primitive woods, mostly of birch, with a sprinkling of spruce, put a high cavernous wall about the scene. How sweetly the birds sang, their notes seeming to have unusual strength and volume in 3.5 .1 


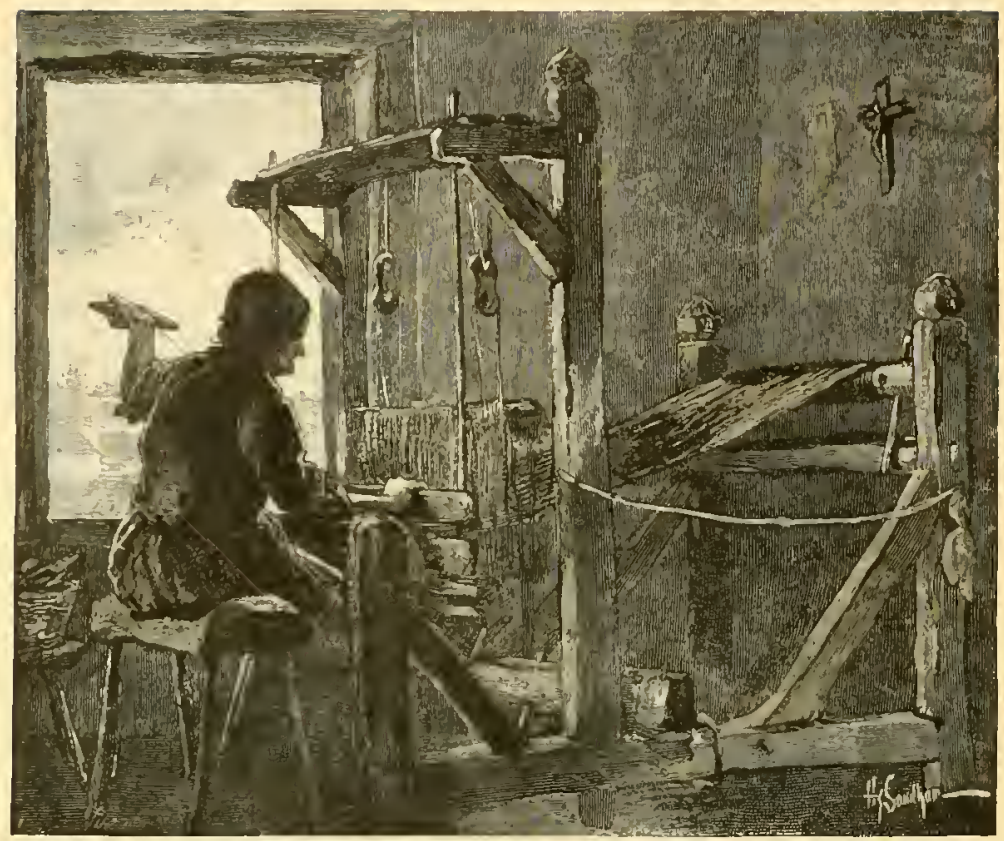

a Canadian interior.

this forest-bound opening! The principal singer was the whitethroated sparrow, which we heard and saw everywhere on the route. He is called here la sifflcu-- the whistler, and very delightful his whistle was. From the forest came the evening hym of a thrush, the olive-backed, perhaps, - like, but less clear and full than, the veerie's.

In the evening, we sat about the fire in rude home-made chairs, and had such broken and disjointed talk as we could manage. Our host had lived in Quebec, and been a school-teacher there; he had wielded the birch until he lost his health, when he came here and the birches rave it back to him. He was now hearty and well, and had a family of six or seven children about him.

We were given a good bed that night, and fared better than we expected. About one c'clock, I was awakened by suppressed voices outside the window. Who could it be? Had a band of brigands surrounded the house? As our outfit and supplies had not been removed from the wagon in front of the door, I got up, and, lifting one corner of the window paper, peeped out. I saw in the dim moonlight four or five men engaged in low conversation. Presently, one 
of the men advanced to the door and began to rap and call the name of our host. Then I knew their errand was not hostile; but the weird effect of that regular alternate rapping and calling ran through my dream all the rest of the night, Rat-tat, tat, tat._La Chance. Rattat, tat,- La Chance, five or six times repeated, before La Chance heard and responded. Then the door opened and they came in, when it was jabber, jabber, jabber in the next room till I fell asleep.

In the morning, to my inquiry as to who the travelers were and what they wanted, La Chance said they were old acquaintances going a-fishing and had stopped to have a little talk.

Breakfast was served early and we were upon the road before the sun. Then began a forty-mile ride through a dense Canadian spruce forest over the drift and bowlders of the paleozoic age. Up to this point, the scenery had been quite familiar,-not much unlike that of the Catskills, - but now there was a change; the birches disappeared, except now and then a slender white or paper birch, and spruce everywhere prevailed. A narrow belt on each side of the road had been blasted by fire, and the dry, white stems of the trees stood stark and stiff. The road ran pretty straight, skirting the mountains and treading the valleys, and hour after hour the dark, silent woods wheeled past us. Swarms of black flies-those insect wolves--waylaid us, and hung to us till a smart spurt of the horse, where the road favored, left them behind. But a species of large horse-fly, black and vicious, it was not so easy to get rid of When they alighted upon the horse, we would demolish them with the whip or with our felt hats, a proceeding the horse soon came to understand and appreciate. The white and gray Laurentian bowlders lay along the road-side. The soil seemed as if made up of decayed and pulverized rock, and doubtless contained very little vegretable matter. It is so barren that it will never repay clearing and cultivating.

Our course was an up-grade toward the highlands that separate the water-shed of St. John Lake from that of the St. Lawrence; and as we proceeded, the spruce became smaller and smaller till the trees were seldom more than eight or ten inches in diameter. Nearly all of them terminated in a dense tuft at the top, beneath which the stem would be bare for several feet, giving them the appearance, my friend said, as they stood sharply defined along the 
crests of the mountains, of cannon-swabs. Endless, interminable successions of these cannon-swabs, each just like its fellow, came and went, came and went, all day. Sometimes we could see the road a mile or two ahead, and it was as lonely and solitary as a path in the desert. Periods of talk and song and jollity were succeeded by long stretches of silence. A buckboard upon such a road does not conduce to a continuous flow of animal spirits. A good brace for the foot and a good hold for the hand is one's main lookout much of the time. We walked up the stceper hills, one of them nearly a mile long, then clung grimly to the board during the rapid descent of the other side.

We occasionally saw a solitary pigeon-in every instance a cock - leading a forlorn life in the wood, a hermit of his kind, or, more probably; a rejected and superfluous male. We came upon two or three broods of spruce-grouse in the road, so tame that one could have knocked them over with poles. We passed many beautiful lakes; among others, the Two Sisters, one on each side of the road. At noon, we paused at a lake in a deep valley, and fed the horse and had lunch. I was not long in gretting ready my fishing-tackle, and upon a raft made of two logs pinned together floated out upon the lake and quickly took all the trout we wanted.

Early in the afternoon, we entered upon what is called La Grand Brulure, or Great Burning, and to the desolation of living woods succeeded the greater clesolation of a blighted forest. All the mountains and valleys, as far as the eye could see, had been swept by the fire, and the bleached and ghostly skeletons of the trees alone met the gaze. The fire had come over from the Saguenay, a hundred or more miles to the east, seven or eight years before, and had consumed or blasted everything in its way. We saw the skull of a moose said to have perished in the fire. For three hours we rode through this valley and shadow of death. In the midst of it, where the trees had nearly all disappeared, and where the ground was covered with coarse, wild grass, we came upon the Morancy River, a placid yellow stream, twenty or twenty-five yards wide, abounding with trout. We walked a short distance along its banks and peered curiously into its waters. The mountains on either hand had been burned by the fire until in places their great granite bones were bare and white. 
At another point, we were within ear-shot for a mile or more of a brawling stream in the valley below us, and now and then caught a glimpse of foaming rapids or cascades through the dense spruce,a trout stream that probably no man had ever fished, as it would be quite impossible to to so in such a maze and tangle of wood.

We neither met nor passed nor saw any travelers until late in the afternoon, when we descried, far ahead, a man on horseback. It was a welcome relief. It was like a sail at sea. When be saw us, he drew rein and awaited our approach. He, too, had probably tired of the solitude and desolation of the road. He proved to be a young Canadian going to join the gang of workmen at the farther end of the road.

About four o'clock, we passed another small lake, and in a few moments more drew up at the bridge over the Jacques Cartier River, and our forty-mile ricle was finished. There was a stable here that had been used by the road-builders and was now used by the teams that hauled in their supplies. This would do for the horse; a snug log shanty, built by an old trapper and hunter for use in the winter, a hundred yards below the bridge, amid the spruces on the bank of the river, when rebedded and refurnished, would do for us. The river at this point was a swift, black stream from thirty to forty feet wide, with a strength and a bound like a moose. It was not shrunken and emaciated, like similar streams in a cleared country, but full, copious, and strong. Indeed, one can hardly realize how the lesser watercourses have suffered by the denuding of the land of its forest covering, until he goes into the primitive woods and sees how bounding and athletic they are there. They are literally well fed, and their measure of life is full. In fact, a trout brook is as much a thing of the woods as a moose or deer and will not thrive well in the open country.

Three miles above our camp was Great Lake Jacques Cartier, the source of the river, a sheet of water nine miles long and from one to three wide; fifty rods below was Little Lake Jacques Cartier, an irregular body about two miles across. Stretching away on every hand, bristling on the mountains and darkling in the valleys, was the illimitable spruce woods. The moss in them covered the ground nearly knee-deep, and lay like newly fallen snow, hiding rocks and logs, filling depressions, and muffling the foot. When it was dry, one could find a most delightful couch anywhere. 
The spruce seems to have colored the water, which is a dark amber color, but entirely sweet and pure. There needed no better proof of the latter fact than the trout with which it abounded and their clear and vivid tints. In its lower portions, near the St. Lawrence, the Jacques Cartier River is a salmon stream; but these fish have never been found as near its source as we were, though there is no apparent reason why they should not be.

There is, perhaps, no moment in the life of an angler fraught with so much eagerness and impatience as when he first finds himself upon the bank of a new and long-sought stream. When I was a boy and used to go a-fishing, I could seldon restrain my eagerness after I arrived in sight of the brook or pond, and must needs run the rest of the way. Then the delay in rigging my tackle was a trial my patience was never quite equal to. After I had made a few casts, or had caught one fish, I could pause and adjust my line properly. I found some remnant of the old enthusiasm still in me when 1 sprang from the buckboard that afternoon and saw the strange river rushing by. I would have given something if my tackle had been rigged so that I could have tried on the instant the temper of the trout that had just broken the surface within easy reach of the shore. But 1 had anticipated this moment coming along, and had surreptitiously undone my rod-case and got my reel out of my bag, and was therefore a few moments ahead of my companion in making the first cast. The trout rose readily; and, almost too soon, we had more than enough for dinner, though no "rod-smashers" had been seen or felt. Our experience the next morning and during the day, and the next morning in the lake, in the rapids, in the pools, was about the same; there was a surfeit of trout eight or ten inches long, though we rarely kept any under ten; but the big fish were lazy and would not rise: they were in the deepest water, and did not like to get up.

The third day, in the afternoon, we had our first and only thorough sensation in the shape of a big trout. It came none too soon. The interest had begun to flag. But one big fish a week will do. It is a pinnacle of delight in the angler's experience that he may well be three days in working up to, and, once reached, it is three days down to the old humdrum level again. At least, it is with me. It was a dull, rainy day; the fog rested low upon the mountains, and the time hung heavily upon our hands. About three o'clock, the rain 
slackened and we emerged from our den, Joe going to look after his horse, which had eaten but little since coming into the woods, the poor creature was so disturbed by the loneliness and the black flies; I to make preparations for dinner, while my companion lazily took his rod and stepped to the edge of the big pool in front of the camp. At the first introductory cast, and when his fly was not fifteen feet from him upon the water, there was a lunge and a strike, and apparently the fisherman had hooked a bowlder. I was standing a few yards below, engaged in washing out the coffee-pail, when I heard him call out:

"I have got him now!"

"Yes, I see you have," said I, noticing his bending pole and moveless line; "when I am through, I will help you get loose."

"No; but l'm not joking," said he: "I have got a big fish."

I looked up again, but saw no reason to change my impression, and kept on with my work.

It is proper to say that my companion was a novice at fly-fishing, he never having cast a fly till upon this trip.

Again he called out to me; but, deceived by his coolness and nonchalant tones, and by the lethargy of the fish, I gave little heed. I knew very well that if I had struck a fish that held me down in that way, I should have been going through a regular war-dance on that circle of bowlder-tops, and should have scared the game into activity, if the hook had failed to wake him up. But as the farce continued, I drew near.

"Does that look like a stone or a $\log$ ?" said my friend, pointing to his quivering line, slowly cutting the current up toward the center of the pool.

My skepticism vanished in an instant, and I could hardly keep my place on the top of the rock.

"I can feel him breathe," said the now warming fisherman; " just feel of that pole."

I put my eager hand upon the butt, and could easily imagine I felt the throb or pant of something alive down there in the black depths. But whatever it was moved about like a turtle. My companion was praying to hear his reel spin, but it gave out now and then only a few hesitating clicks. Still, the situation was excitingly dramatic, and we were all actors. I rushed for the landing-net, but 
being unable to find it, shouted desperately for Joe, who came hurrying back, excited before he had learned what the matter was. The net had been left at the lake below and must be had with the greatest dispatch. In the meantime, 1 skipped about from bowlder to bowlder as the fish worked this way or that about the pool, peering into the water to catch a glimpse of him, for he had begun to yield a little to the steady strain that was kept upon him. Presently l saw a shadowy, unsubstantial something just emerge from the black depths, then vanish. Then 1 saw it again, and this time the huge proportions of the fish were faintly outlined by the white facings of his fins. The sketch lasted but a twinkling; it was only a flitting shadow upon a darker background, but it gave me the profoundest lke Walton thrill I ever experienced. I had been a fisher from my earliest boyhood; l came from a race of fishers; trout streams gurgled about the roots of the family tree, and there was a long accumulated and transmitted tendency and desire in me that that sight gratified. I did not wish the pole in my own hands; there was quite enough electricity overflowing from it and filling the air for me. The fish yielded more and more to the relentless pole, till in about fifteen minutes from the time he was struck, he came to the surface, then made a little whirlpool where he disappeared again. But presently he was up a second time and lashing the water into foam as the angler led him toward the rock upon which I was perched, net in hand. As I reached toward him, down he went again, and, taking another circle of the pool, came up still more exhausted, when, between his paroxysms, 1 carefully ran the net over him and lifted him ashore, amid, it is needless to say, the wildest enthusiasm of the spectators. The congratulatory laughter of the loons down on the lake showed how even the outsiders sympathized. Much larger trout have been taken in these waters and in others. but this fish would have swallowed any three we had ever before caught.

"What does he weigh?" was the natural inquiry of each; and we took turns "hefting" him. But gravity was less potent to us just then than usual, and the fish seemed astonishingly light.

"Four pounds," we said; but Joe said more. So we improvised a scale. A long strip of board was balanced across a stick, and our groceries served as weights. A four-pound package of sugar kicked 
the beam quickly; a pound of coffee was added; still it went up; then a pound of tea, and still the fish had a little the best of it. But we called it six pounds, not to drive too sharp a bargain with fortune, and was more than satisfied. Such a beautiful creature! marked in every respect like a trout of six inches. We feasted our eyes upon him for half an hour. We stretched him upon the ground and admired him; we laid him across a log and withdrew a few paces and admired him; we hung him against the shanty and turned our heads from side to side as women do when they are selecting dressgoods, the better to take in the full force of the effect.

He graced the board, or stump, that afternoon and was the sweetest fish we had taken. The flesh was a deep salmon color and very rich. We had before discovered that there were two varieties of trout in these waters, irrespective of size, - the red-fleshed and the white-fleshed,-and that the former were best.

This success gave an impetus to our sport that carried us through the rest of the week finely. We had demonstrated that there were big trout here, and that they would rise to a fly. Henceforth, big fish were looked to as a possible result of every excursion. To me, especially, the desire to at least match my companion, who had been my pupil in the art, was keen and constant. We built a raft of logs, and upon it I floated out upon the lake, whipping its waters right and left, morning, noon, and night. Nany fine trout came to my hand, and were released because they did not fill the bill.

The lake became my favorite resort, while my companion preferred rather the shore or the long, still pool above. where there was a rude make-shift of a boat, made of common box-boards.

Upon the lake, you had the wildness and solitude at arms-length and could better take their look and measure. You became something apart from them; you emerged and had a vantage-ground like that of a mountain peak, and could contemplate them at your ease. Seated upon my raft, and slowly carried by the current or drifted by the breeze, 1 had many a long, silent look into the face of the wilderness, and found the communion good. I was alone with the spirit of the forest-bound lakes and felt its presence and magnetism. I played hide-and-seek with it about the nooks and corners, and lay in wait for it upon a little island, crowned with a clump of trees, that was moored just to one side the current near the head of the lake. 
Indeed, there is no depth of solitude that the mind does not endow with some human interest. As in a dead silence the ear is filled with its own murmur, so amid these aboriginal scenes one's feelings and sympathies become external to him, as it were, and he holds converse with them. Then a lake is the ear as well as the eye of a forest. It is the place to go to listen and ascertain what sounds are abroad in the air. They all run quickly thither and report. If any creature had called in the forest for miles about I should have heard it. At times, I could hear the distant roar of water off beyond the outlet of the lake. The sound of the vagrant winds purring here and there in the tops of the spruces reached my ear. $A$ breeze would come slowly down the mountain, then strike the lake, and I could see its footsteps approaching, by the changed appearance of the water. How slowly the winds move at times, sauntering like one on a Sunday walk! A breeze always enlivens the fish; a dead cahm, and all pennants sink; your activity with your fly is ill-timed, and you soon take the hint and stop. Becalmed upon my raft, 1 observed, as I have often done before, that the life of nature ebbs and flows, comes and departs, in these wilderness scenes; one moment her stage is thronged and the next quite deserted. Then there is a wonderful unity of movement in the two elements, air and water. When there is much going on in one, there is quite sure to be much going on in the other. You have been casting, perhaps, for an hour with scarcely a jump or any sign of life anywhere about you, when presently the breeze freshens, and the trout begin to respond, and then of a sudden all the performers rush in; ducks come sweeping by, loons laugh and wheel overhead, then approach the water on a long, gentle incline, plowing deeper and deeper into its surface until their momentum is arrested or converted into foam; the fish-hawk screams, the bald eagle goes flapping by, and your eyes and hands are full. Then the tide ebbs, and both fish and fowl are gone.

Patiently whipping the waters of the lake from my rude float, I became an object of great interest to the loons. I had never seen these birds before in their proper habitat, and the interest was mutual. When they had paused on the Hudson during their spring and fall migrations, 1 had pursued them in my boat to try to get near them. Now the case was reversed; I was the interloper now, and they would come out and study me. Sometimes 
six or eight of them would be swimming about watching my movements, but they were wary and made a wide circle. One day, one of their number volunteered to make a thorough reconnoissance. I saw him leave his comrades and swim straight toward me. He came, bringing first one eye to bear upon me, then the other. When about half the distance was passed over, he began to waver and hesitate. 'To encourage him l stopped casting, and taking off my hat, began to wave it slowly to and fro, as in the act of fanning myself. This started him again, - this was a new trait in the creature that he must scrutinize more closely: On he came, till all his markings were distinctly scen. With one hand I pulled a little revolver from my hip pocket, and when the loon was about fifty yards distant and had begun to sidle around me, I fired. At the flash I saw two webbed feet twinkle in the air, and the loon was gone! Lead could not have gone down so quickly. The bullet cut across the circles where he disappeared. In a few moments he re-appeared a couple of hundred yards away. "Ha-ha-ha-a-a," said he ; "ha-ha-ha-a-a" and "ha-ha-ha-aa," said his comrades, who had been looking on: and "ha-ha-ha-a-a," said we all, echo included. He approached a second time, but not so closely, and when I began to creep back toward the shore with my heavy craft, pawing the water first upon one side, then the other, he followed, and with ironical laughter witnessed my efforts to stem the current at the head of the lake. I confess it was enough to make a more solemn bird than the loon laugh; but it was no fun for me, and generally required my last pound of steam.

The loons flew back and forth from one lake to the other, and their voices were about the only notable wild sounds to be heard.

One afternoon, quite unexpectedly, I struck my big fish, in the head of the lake. I was first advised of his approacl by two or three trout jumping clear from the water to get out of his lordship's way. The water was not deep just there, and he swam so near the surface that his enormous back cut through. With a swirl he swept my fly under and turned. My hook was too near home, and my rod too near a perpendicular, to strike well. More than that, my presence of mind came near being unhorsed by the sudden apparition of the fish. If I could have had a moment's notice, or if I had not seen the monster, I should have fared better and the 
fish worse. I struck, but not with enough decision, and before I could reel up, my empty hook came back. The trout had carried it in his jaws till the frand was detected and then spat it out. He came a second time, and made a grand commotion in the water, but not in my nerves, for I was ready then, but failed to take the fly and so to get his weight and beauty in these pages. As my luck failed me at the last, I will place my loss at the full extent of the law, and claim that nothing less than a ten-pounder was spirited away from my hand that day. I might not have saved him, netless as I was upon my cumbrous raft; but I should at least have had the glory of the fight and the consolation of the fairly vanquished.

These trout are not properly lake-trout, but the common brooktrout (S. Fontanalis). The largest ones are taken with live bait through the ice in winter. The Indians and the habitans bring them out of the wood from here and from Snow Lake on their toboggans, from two and a half to three feet long. They have kinks and ways of their own. About half a mile above camp, we discovered a deep oral bay to one side the main current of the river, that evidently abounded in big fish. Here they disported themselves. It was a favorite feeding-ground, and late every afternoon the fish rose all about it, making those big ripples the angler delights to see. A trout, when he comes to the surface, starts a ring about his own length in diameter; most of the rings in the pool, when the eye caught them, were like barrel-hoops, but the haughty trout ignored all our best efforts; not one rise did we gret. We were told of this pool on our return to Quebec, and that other anglers had a similar experience there. But occasionally some old fisherman, like a great advocate who loves a difficult case, would set his wits to work and bring into camp an enormous trout taken there.

I had been told in Quebec that I would not see a bird in the woods, not a feather of any kind. But I knew I should, though they were not numerous. I saw and heard a bird nearly every day on the tops of the trees about, that 1 think was one of the cross-bills. The kingfisher was there ahead of us with his loud clicking reel. The osprey was there, too, and 1 saw him abusing the bald eagle, who had probably just robbed him of a fish. The yellow-rumped warbler I saw, and one of the kinglets was leading its lisping brood about through the spruces. In every opening, the white-throated sparrow 


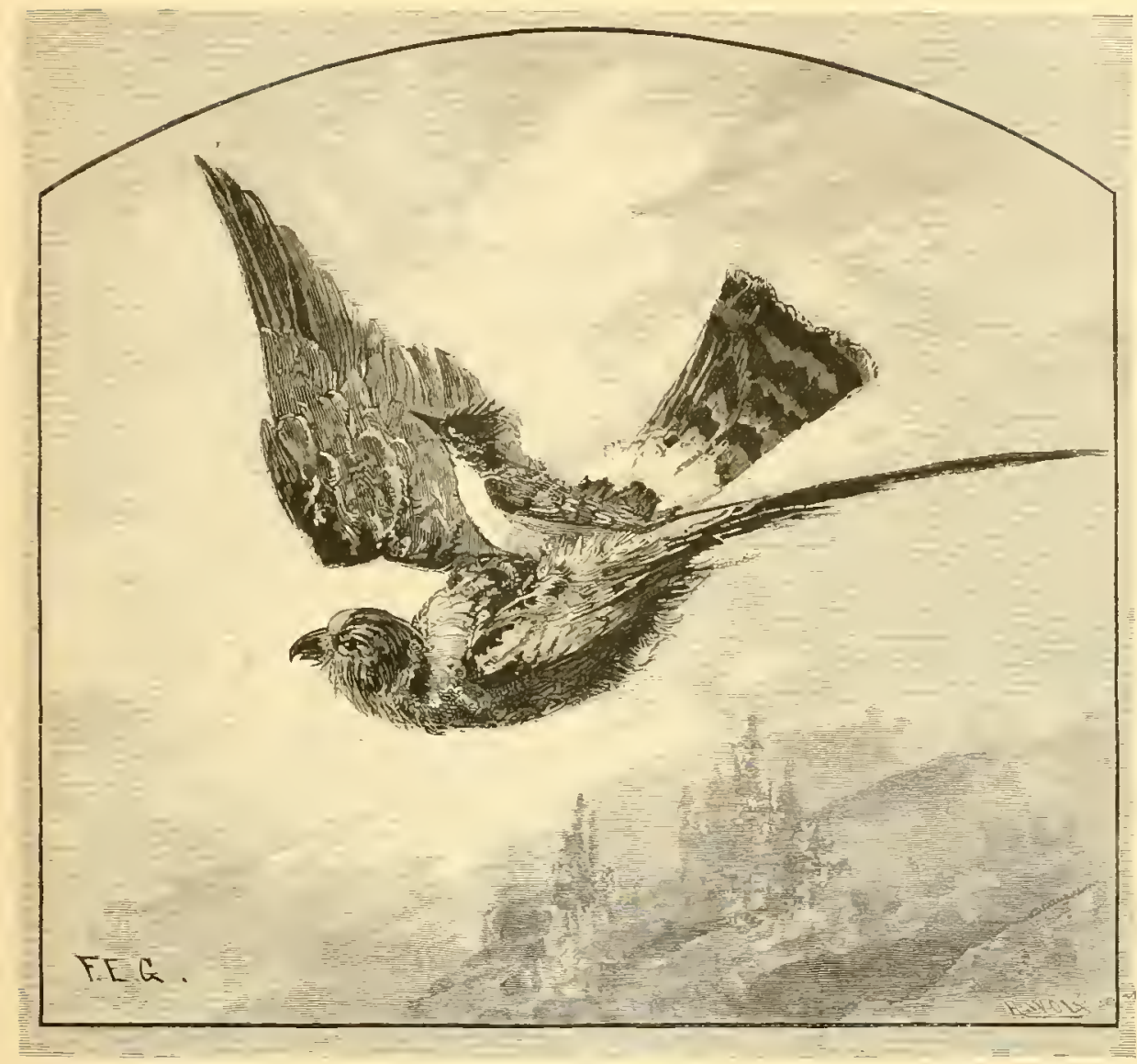

HAWK AND KINGBIRD.

abounded, striking up his clear, sweet whistle at times so loud and sudden that one's momentary impression was that some farm-boy was approaching or was secreted there behind the logs. Many times, amid those primitive solitudes, I was quite startled by the human tone and quality of this whistle. It is little more than a beginning: the bird never seems to finish the strain suggested. The Canada jay was there also, very busy about some important private matter.

One lowery morning as I was standing in camp, I saw a lot of ducks borne swiftly down by the current around the bend in the river a few rods above. They saw me at the same instant and turned toward the shore. On hastening up there, I found the old bird rapidly leading her nearly grown brood through the woods, as 36 
if to go around our camp. As I pursued them, they ran squawking with outstretched stubby wings, scattering right and left, and seeking a hiding-place under the logs and débris. 1 captured one and carried it into camp. It was just what Joe wanted; it would make a valuable decoy. So he kept it in a box, fed it upon oats, and took it out of the woods with him.

We found the camp we had appropriated was a favorite stoppingplace of the carmen who hauled in supplies for the gang of two hundred road-builders. One rainy day, near night-fall, no less than eight carts drew up at the old stable, and the rain-soaked drivers, after picketing and feeding their horses, came down to our fire. We were away, and Joe met us on our return with the unwelcome news. We kept open house so far as the fire was concerned; but our roof was a narrow one at the best, and one or two leaky spots made it still narrower.

"We shall probably sleep out-of-doors to-night," said my companion, "unless we are a match for this posse of rough teamsters."

But the men proved to be much more peaceably disposed than the same class at home; they apologized for intruding, pleading the inclemency of the weather, and were quite willing, with our permission, to take up with pot-luck about the fire and leave us the shanty. They dried their clothes upon poles and logs, and had their fun and their bantering amid it all. An Irishman among them did about the only growling; he invited himself into our quarters, and before morning had Joe's blanket about him in addition to his own.

On Friday, we made an excursion to Great Lake Jacques Cartier, paddling and poling up the river in the rude box-boat. It was a bright, still morning after the rain, and everything had a new, fresh appearance. Expectation was ever on tiptoe, as each turn in the river opened a new prospect before us. How wild and shaggy and silent it was! What fascinating pools, what tempting stretches of trout-haunted water! Now and then we would catch a glimpse of long black shadows starting away from the boat and shooting through the sunlit depths; but no sound or motion on shore was heard or seen. Near the lake we came to a long, shallow rapid, when we pulled off our shoes and stockings, and, with our trowsers rolled up above our knees, towed the boat up it, wincing and cringing amid the sharp, slippery stones. With benumbed feet and legs, we reached 


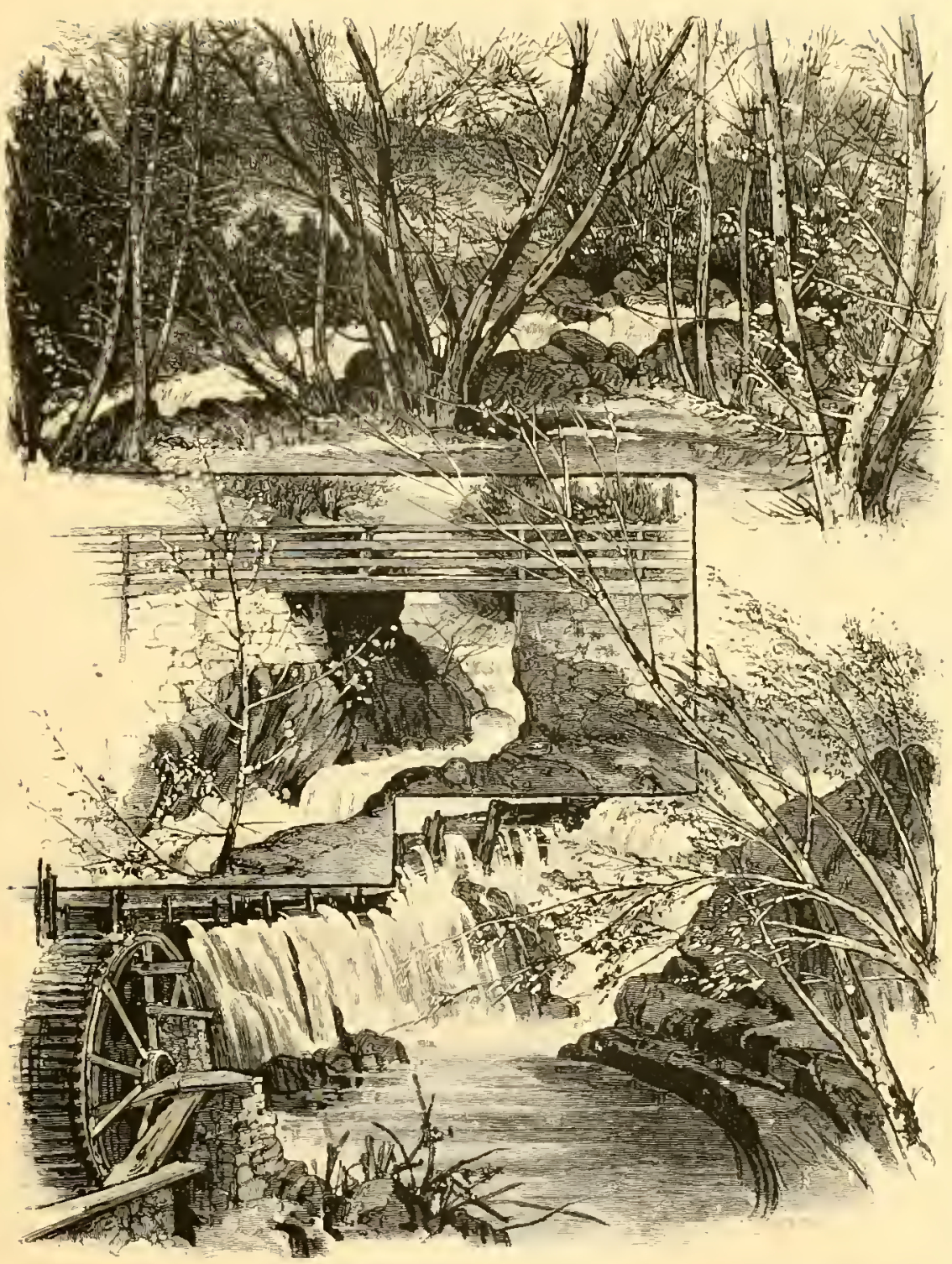

ON I HE WAY TU THE RIVER.

the still water that forms the stem of the lake, and presently saw the arms of the wilderness open and the long, deep-blue expanse in their embrace. $\mathrm{IT}^{\top} \mathrm{e}$ rested and bathed, and gladdened our eyes with the singularly beautiful prospect. Thé shadows of summer clonds were slowly creeping up and down the sides of the mountains that hemmed it in. On the far eastern shore, near the head, banks of what was 


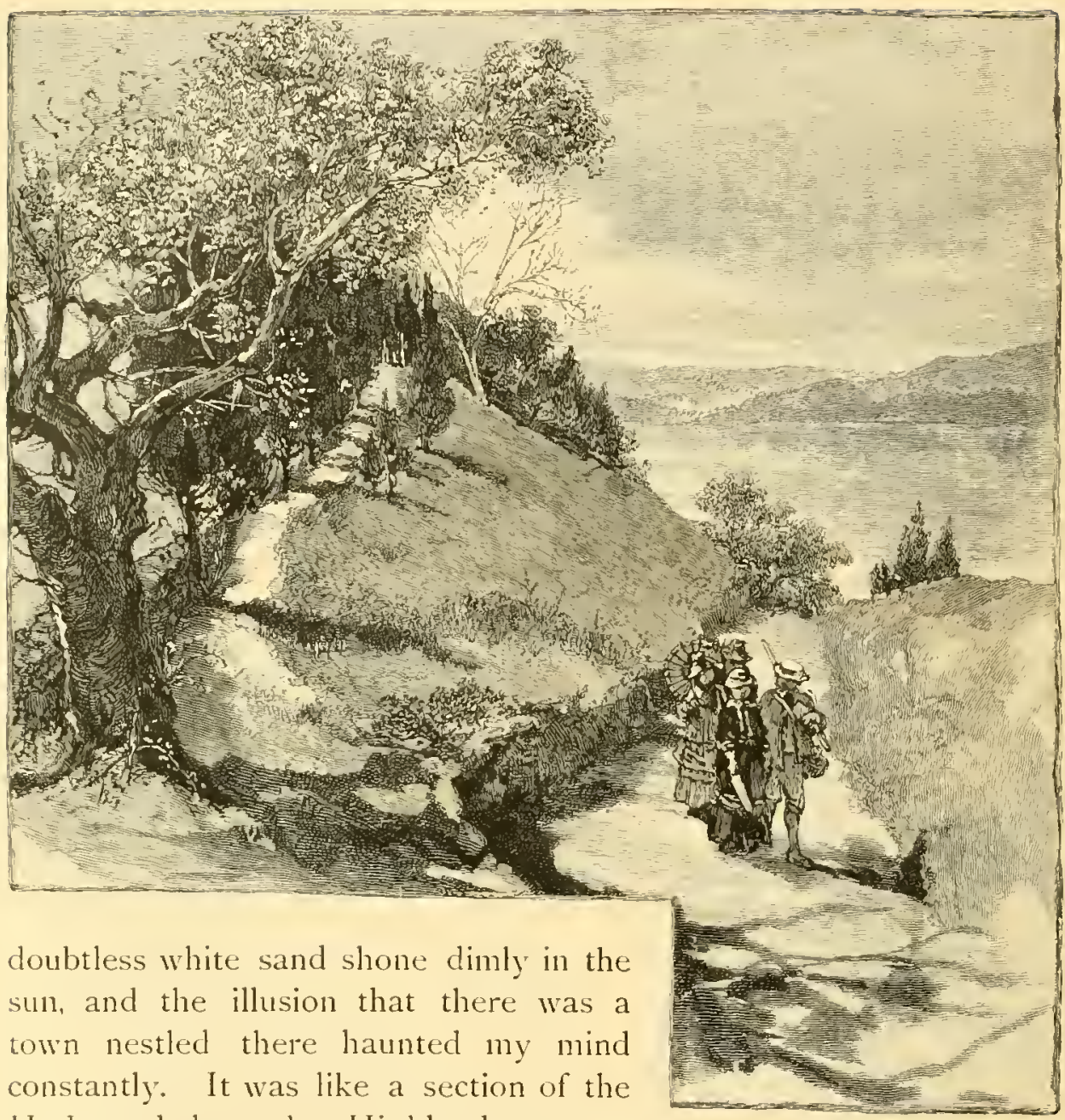

Huctson below the Highlands, except that these waters were bluer and colder,

and these shores darker than even Sir Hendrick first looked upon; but surely, one felt, a steamer will round that point presently, or a sail drift into view! We paddled a mile or more up the east shore, then across to the west, and found such pleasure in simply gazing upon the scene that our rods were quite neglected. We did some casting after awhile, but raised no fish of any consequence till we were in the outlet again, when they responded so freely that the "disgust of trout" was soon upon us.

At the rapids, on our return, as I was standing to my knees in the swift, cold current and casting into a deep hole behind a huge 
bowlder that rose four or five feet above the water amich-stream, two trout, one of them a large one, took my flies; and fincling the fish and the current united too strong for my tackle, 1 sought to gain the top of the bowlder, in which attempt I got wet to my middle and lost my fish. After I had gained the rock, I could not get away again with my clothes on without swimming ; which, to say nothing of wet garments the rest of the way home, I did not like to do amid those rocks and swift currents; so, after a vain attempt to communicate with my companion above the roar of the water, 1 removed my clothing, left them together with my tackle upon the rock, and by a strong effort stemmed the current and reached the shore. The boat was a hundred yards above, and when I arrived there my teeth were chattering with the cold, my feet were numb with bruises, and the black flies were making the blood stream down my back. We hastened back with the boat, and by wading out into the current again and holding it by a long rope, it swung around with my companion aboard, and was held in the eddy behind the rock. I clambered up, got my clothes on, and we were soon shooting downstream toward home; but the winter of discontent that shrouded onehalf of me made sad inroads upon the placid feeling of a day well spent that enveloped the other, all the way to camp.

That night something carried off all our fish, - doubtless a fisher or lynx, as Joe had seen an animal of some kind about camp that day.

I must not forget the two red squirrels that frequented the camp during our stay, and that were so tame they would approach within a few feet of us and take the pieces of bread or fish tossed to them.

When a particularly fine piece of hard-tack was secured, they would spin off to their den with it somewhere near by.

Caribou abound in these woods, but we saw only their tracks; and of bears, which are said to be plentiful, we saw no signs.

Saturday morning, we packed up our traps and started on our return, and found that the other side of the spruce-trees and the vista of the lonely road going south were about the same as coming north. But we understood the road better and the buckboard better, and our load was lighter, hence the distance was easier accomplished.

I saw a solitary robin by the road-side, and wondered what could have brought this social and half-domesticated birct so far $36 \mathrm{~A}$ 
into these wilds. In La Grand Brulure, a hermit-thrush perched upon a dry tree in a swampy place and sang most divinely. IVe paused to listen to his clear, silvery strain, poured out without stint upon that unlistening solitude. I was half persuaded I had heard him before on first entering the woods.

We nooned again at No Man's Inn, on the banks of a trout lake, and fared well and had no reckoning to pay. Late in the afternoon, we saw a lonely pedestrian laboring up a hill far ahead of us. When he heard us coming he leaned his back against the bank, and was lighting his pipe as we passed. He was an old man, an lrishman, and looked tired. He had come from the farther end of the road, fifty miles distant, and had thirty yet before him to reach town. He looked the dismay he evidently felt, when, in answer to his inquiry, we told him it was yet ten miles to the first louse, La Chance's. But there was a roof nearer than that, where he doubtless passed the night, for he did not claim hospitality at the cabin of La Chance. We arrived there betimes, but found the "spare bed" assigned to other guests; so we were comfortably lodged upon the haymow. One of the boys lighted us up with a candle, and made level places for us upon the hay.

La Chance was one of the game wardens or constables appointed by the Government to see the game laws enforced. Joe had not felt entirely at his ease about the duck he was surreptitiously taking to town, and when, by its "quack," "quack," it called upon La Chance for protection, he responded at once. Joe was obliged to liberate it then and there, and to hear the law read and expounded, and be threatened till he turned pale besides. It was evident that they follow the Home Government in the absurd practice of enforcing their laws in Canada. La Chance said he was under oath not to wink at or permit any violation of the law. and seemed to think that made a difference.

We were off early in the morning, and before we had gone two miles met a party from Quebec who must have been driving nearly all night to give the black flies an early breakfast. Before long, a slow rain set in: we saw another party who had taken refuge in a house in a grove. When the rain had become so brisk that we began to think of seeking shelter ourselves, we passed a party of young men and boys - sixteen of then - in a cart turning back to 
town, water-soaked and heary (for the poor horse had all it could pull), but merry and good-natured. We paused awhile at the farmhouse where we had got our hay on going out, were treated to a drink of milk and some wild red cherries, and when the rain slackened drove on, and by ten o'clock saw the city, eight miles distant, with the sun shining upon its steep, tinned roofs.

The next morning, we set out per steamer for the Saguenay, and entered upon the second phase of our travels, but with less relish than we could have wished. Scenery-hunting is the least satisfying pursuit I have ever engaged in. What one sees in his necessary travels, or doing his work, or going a-fishing, seems worth while; but the famous view you go out in cold blood to admire is quite apt to elude you. Nature loves to enter a door another hand has opened; a mountain view, or a water-fall, I have noticed, never looks better than when one has just been warmed up by the capture of a big trout. If we had been bound for some salmon-stream up the Saguenay, we should perhaps have possessed that generous and receptive frame of mind - that open house of the heart - which makes one "eligible to any sood fortune," and the grand scenery would have come in as fit sauce to the salmon. An adventure, a bit of experience of some kind, is what one wants when he goes forth to admire woods and waters, - something to create a draught and make the embers of thought and feeling brighten. Nature, like certain wary game, is best taken by seeming to pass by her, intent on other matters.

But without any such errand, or occupation, or indirection, we managed to extract considerable satisfaction from the view of the lower St. Lawrence and the Saguenay.

We had not paid the customary visit to the falls of the Montmorency, but we shall see them after all, for before we are a league from Quebec they come into view on the left. A dark glen or chasm there at the end of the Beaufort Slopes seems suddenly to have put on a long white apron. By intently gazing, one can see the motion and falling of the water, though it is six or seven miles away. There is no sign of the river above or below but this trembling white curtain of foam and spray.

It was very sultry when we left Quebec, but about noon we struck much clearer and cooler air, and soon after ran into an im- 
mense wave or puff of fog that came drifting up the river and set all the fog-guns booming along shore. We were soon through it into clear, crisp space, with room enough for any eye to range in. On the south, the shores of the great river appear low and uninteresting, but on the north, they are bold and striking enough to make it uphigh, scarred, unpeopled mountain ranges the whole way. The points of interest to the eye in the broad expanse of water were the white porpoises that kept rolling, rolling in the distance all day. They came up like the perimeter of a great wheel, that turns slowly and then disappears. From mid-forenoon we could see far ahead an immense column of yellow smoke rising up and flattening out upon the sky and stretching away beyond the horizon. Its form was that of some aquatic plant that shoots a stem up, through the water and spreads its broad leaf upon the surface. This smoky lily-pad must have reached nearly to Maine. It proved to be in the Indian country, in the mountains beyond the mouth of the Saguenay, and must have represented an immense clestruction of forest timber.

The steamer is two hours crossing the St. Lawrence from Rivière du Loup to Tadousac. The Saguenay pushes a broad sweep of dark-blue water down into its mightier brother, that is sharply defined from the deck of the steamer. The two rivers seem to touch, but not to blend, so proud and haughty is this chieftain from the north. On the mountains above Tadousac one could see banks of sand left by the ancient seas. Naked rock and sterile sand are all the Tadousacker has to make his garden of, so far as I observed. Indeed, there is no soil along the Saguenay until you get to Ha-ha Bay, and then there is not much, and poor quality at that.

What the ancient fires did not burn, the ancient seas have washed away. I overheard an English resident say to a Yankee tourist. "You will think you are approaching the end of the world up here." It certainly did suggest something apocryphal or antimundane - a segment of the moon or of a cleft asteroid, matter dead or wrecked. The world-builders must have had their foundry up in this neighborhood, and the bed of this river was doubtless the channel through which the molten granite flowed. Some mischief-loving god has let in the sea while things were yet red-hot, and there has been a time here. But the channel still seems filled with water from the mid-Atlantic, cold and blue-black, and in places between seven 
and eight thousand feet deep (one and a half miles). In fact, the enormous depth of the Saguenay is one of the wonders of physical geography. It is as great a marvel in its way as Niagara.

The ascent of the river is made by night, and the traveler finds himself in Ha-ha Bay in the morning. The steamer lies here several hours before starting on her return trip, and takes in large quantities of white birch wood, as she does also at Tadousac. The chief product of the country seemed to be huckleberries, of which large quantities are shipped to Quebec in rude board boxes, holding about a peck each. Little girls came aboard or lingered about the landing with cornucopias of birch-bark filled with red raspberries; five cents for about half a pint was the usual price. The village of St. Alphonse, where the steamer tarries, is a cluster of small, humble dwellings, dominated, like all Canadian villages. by an immense church. Lsually the church will hold all the houses in the village; pile them all up and they would hardly equal it in size; it is the one conspicuous object, and is seen afar; and on the various lines of travel one sees many more priests than laymen. They apiear to be about the only class that stir about and have a good time. Many of the houses were covered with birch-bark, - the canoe birch — held to its place by perpendicular strips of board or split poles.

A man with a horse and a buckboard persuaded us to give him twenty-five cents each to take us two miles up the St. Alphonse River to see the salmon jump. There is a high saw-mill dam there, which every salmon in his upward journey tries his hand at leaping. A race-way has been constructed around the dam for their benefit, which, it seems, they do not use till they have repeatedly tried to scale the dam. The day before our visit three dead fish were found in the pool below, killed by too much jumping. Those we saw had the jump about all taken out of them ; several did not get more than half their length out of the water, and occasionally only an impotent nose would protrude from the foam. One fish made a leap of three or four feet and landed on an apron of the dam and tumbled helplessly back; he shot up like a bird and rolled back like a clod. This was the only view of salmon, the buck of the rivers, we had on our journey.

It was a bright and flawless midsummer day that we sailed down the Saguenay, and nothing was wanting but a good excuse for being 
there. The river was as lonely as the St. John's road; not a sail or a smoke-stack the whole sixty-five miles. The scenery culminates at Cape Eternity, where the rocks rise sheer from the water to a height of eighteen hundred feet. This view dwarfed everything I had ever before seen. There is perhaps nothing this side the Yosemite chasm that equals it, and, emptied of its water, this chasm would far surpass that famous canon, as the river here is a mile and a quarter deep. The bald eagle nests in the niches in the precipice, secure from any intrusion. Immense blocks of the rock had fallen out, leaving areas of shadow and clinging, overhanging masses that were a terror and fascination to the eye. There was a great fall a few years ago, just as the steamer had passed from under and blown her whistle to wake the echoes. The echo came back, and with it a part of the mountain that astonished more than it delighted the lookers-on. The pilot took us close around the base of the precipice that we might fully inspect it. And here my eyes played me a trick the like of which they had never done before. One of the boys of the steamer brought to the forward deck his hands full of stones, that the curious ones among the passengers might try how easy it was to throw one ashore. "Any girl ought to do it," I said to myself, after a man had tried and had failed to clear half the distance. Seizing a stone, I cast it with vigor and confidence, and as much expected to see it smite the rock as I expected to live. "It is a good while getting there," I mused, as I watched its course. Down, down it went; there, it will ring upon the granite in half a breath; no, down-into the water, a little more than half-way! "Has my arm lost its cunning?" I said, and tried again and again, but with like result. The eye was completely at fault. There was a new standard of size before it to which it failed to adjust itself. The rock is so enormous and towers so above you that you get the impression it is much nearer than it actually is. When the eye is full it says, "Here we are," and the hand is ready to prove the fact; but in this case there is an astonishing discrepancy between what the eye reports and what the hand finds out.

Cape Trinity, the wife of this Colossus, stands across a chasm through which flows a small tributary of the Saguenay, and is a head or two shorter, as becomes a wife, and less rugged and broken in outline. 
From Rivière du Loup, where we passed the night and ate our first "Tommy-cods," our thread of travel makes a big loop around New Brunswick to St. John, thence out and down through Maine to Boston, - a thread upon which many delightful excursions and reminiscences might be strung. We traversed the whole of the valley of the Metapedia, and passed the doors of many famous salmon streams and rivers, and heard everywhere the talk they inspire; one could not take a nap in the car for the excitement of the big fish stories he was obligred to overhear.

The Metapedia is a most enticing-looking stream; its waters are as colorless as melted snow; I could easily have seen the salmon in it as we shot along, if they had come out from their hiding-places. It was the first white-water stream we had seen since leaving the Catskills; for all the Canadian streams are black or brown, either from the iron in the soil or from the leechings of the spruce swamps. But in New Brunswick we saw only these clear, silver-shod streams; I imagined they had a different ring or tone also. The Metapedia is deficient in good pools in its lower portions; its limpid waters flowing with a tranquil murmur over its wide, evenly paved bed for miles at a stretch. The salmon pass over these shallows by night and rest in the pools by day. The Restigouche, which it joins, and which is a famous salmon-stream and the father of famous salmon-streams, is of the same complexion and a delight to look upon. There is a noted pool where the two join. and one can sit upon the railroad bridge and count the noble fish in the lucid depths below. The valley here is fertile, and has a cultivated, well-kept look.

We passed the Jacquet, the Belledune, the Nepissisquit, the Miramichi ("happy retreat") in the night, and have only their birdcall names to report. 


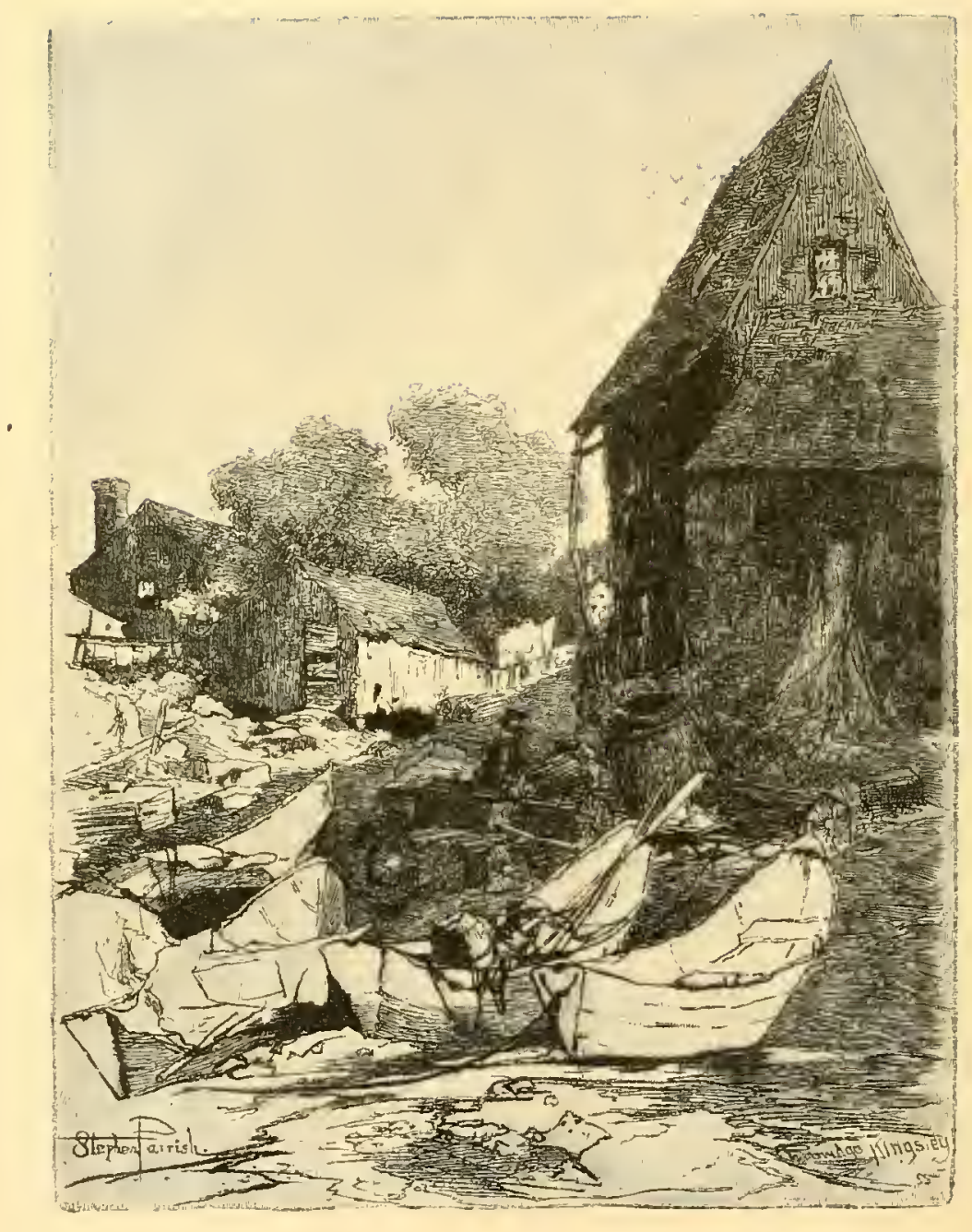




\section{AMONG THE THOUSAND ISLANISS. \\ HY HOIIART PYLE.}

T

HE terrific combat between Manabozho, the Indian hero, better known as the Hiawatha of Longfellow, and his father, the West Wind, was doubtless suggested to the first narrator of that memorable event by the lakes of northern New York upon the one hand, and those of the St. Lawrence chain upon the other, as marking the cavities from which those Titans might be supposed to have plucked the masses of rock they hurled at each other, the falling fragments of which formed that peculiar geological phenomenon known as the Thousand Islands, scattered through the St. Lawrence for a hundred miles or so of its course.

These islands, about eighteen hundred in number, siretching throughout that broad portion of the upper St. Lawrence extending from Lake Ontario to the Long Sault, are of all sizes and of all kinds; some not more than a yard or so in extent, and some covering many acres; some bare, rocky, and desolate; some thickly covered with a scraggy growth of scrub pines and hemlocks; some shaded with considerable forests of timber trees, and some cultivated here and there, producing such slight sustenance as the inhabitants can wring from an unfruitful soil.

In the old Indian days, this beautiful extent of the river from Clayton to Alexandria Bay, embracing an extent of sixteen miles, widening almost to a lake and crowded with a perfect maze of islands, went by the name of Manatoana, or Garden of the Great Spirit; and, indeed, in the time of Nature's undisputed empire, when the larger islands were covered with thick growths of pine, hemlock, white birch, and maple; when the wild deer swam from woody islet 
to woody islet, and each little lily-padded bay, nestling in among the hills and bluffs of the islands, teemed with water-fowl undisturbed by the report of a gun, it was worthy, to the semi-poetical mind of the Indian, to be an abode of Him who created all nature, and who had made this lovely region as an especial dwelling-place for himself. Even so late as fifty years ago, before the great tumultcreating steam-boats had disturbed these solitudes, the islands were the favorite retreat of deer: catamounts wailed in the tangled depths of the night-woods, and each cool nook and corner teemed with wild life.

Now, however, the inexorably rotating kaleidoscope of time has shaken away the savage scenes of old, never to be repeated, and new ones appear to the eye of the present. No longer in Alexan-

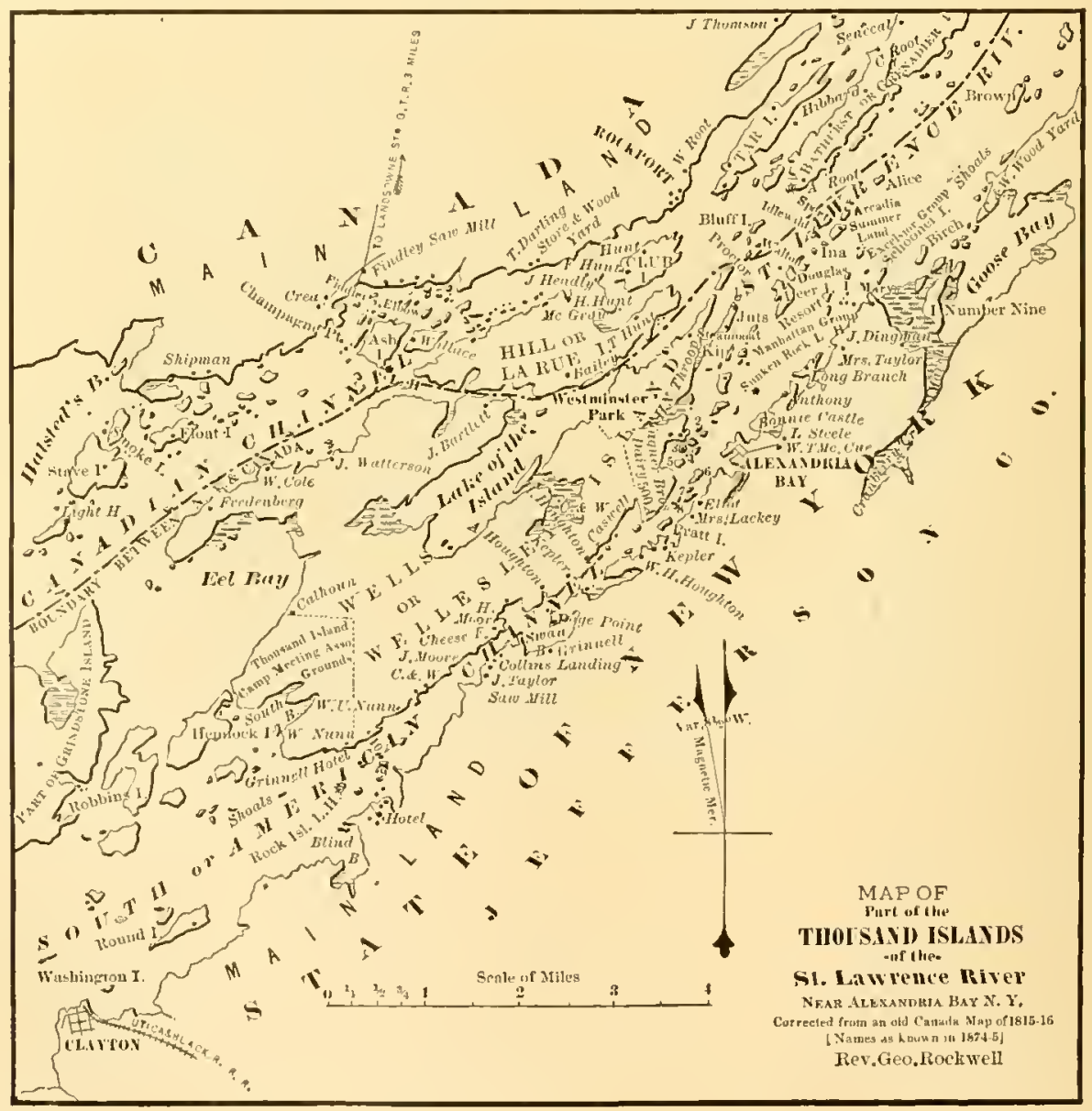


dria Bay-fortunately still beautiful-does Nature reign in silent majesty, for the constant flutter and bustle of the life and gayety of a summer resort have superseded her. But although Alexandria liay is in this continual tumult of life, for some fortunate and almost unaccountable reason, the Thousand Islands are not in the least. tinctured with the blase air of an ordinary watering-place, nor are they likely to become so. There are hundreds-thousands of places, rugged and solitary, among which a boat can glide, while its occupant lies gloriously inclolent, doing nothing, but reveling in the realization of life; little hays, almost land-locked, where the resinous odors of hemlock and pine fill the nostrils, and the whispers of nature's unseen life serves but to make the solitude more perceptible. Sometimes the vociferous cawing of crows sounds through the hol-

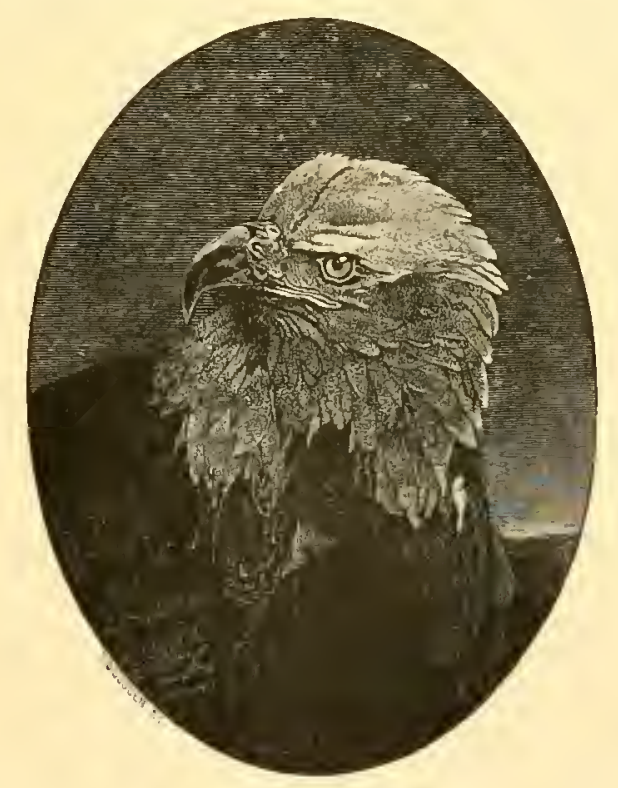

low woods, or a solitary eagle lifts from his perch on the top of a stark and dead pine and sails majestically across the blue arch of the sky. Such scenes occur in a beautiful sheet of water called the Lake of the Isle, lying placidly and balmily in the lap of the piney hills of Wells Island, reflecting their rugged crests in its glassy surface, dotted here and there by tiny islands.

In the stillest bays are spots that seem to lie in a Rip Van Winkle sleep, where one would scarcely be surprised to see an Indian 


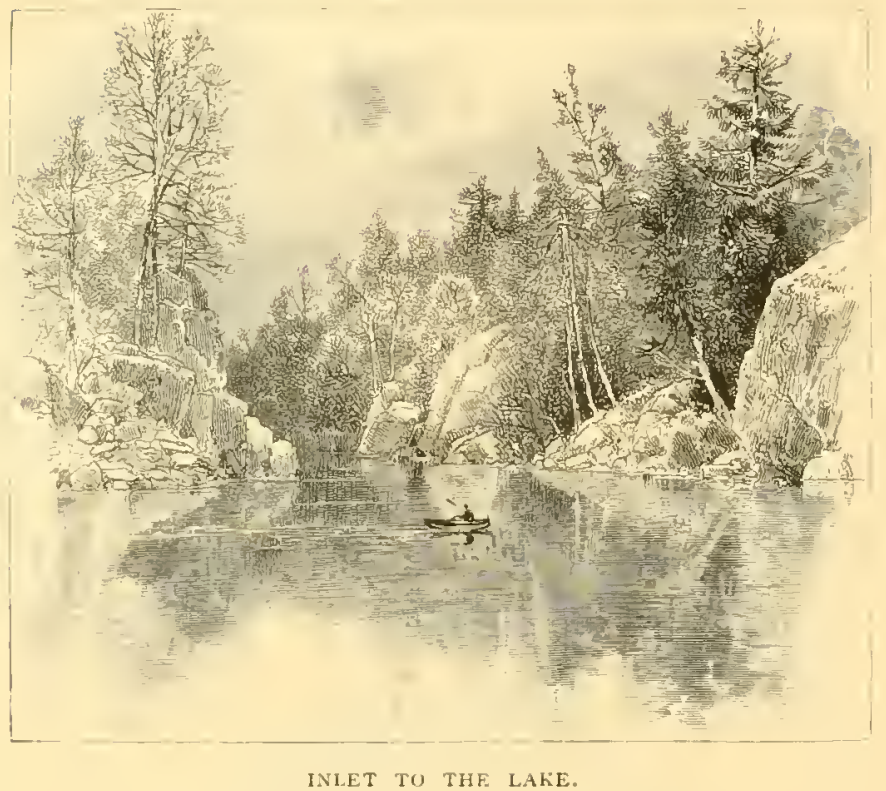

canoe shoot from beneath the hemlocks of the shore into the open, freighted with a Natty Bumpo or a Chingachgook, breaking the placid surface of the water into slowly widening ripples. In such a spot, one evening, after a day spent in sketching, when paddling our boat about in an indolent, aimless way, looking down through the crystal clearness of the water to the jungle of weeds below, now frightening a pickerel from his haunt or startling a brood of wood-ducks from among the rushes and arrowheads, we found ourselves belated. As the sun set in a blaze of crimson and gold, two boatmen rowing homeward passed darkly along the glassy surface that caught the blazing light of the sky, and across the water came, in measured rhythm with the dip of their oars, the tune of a quaint, old, half-melancholy Methodist hymn that they sang. We listened as the song trailed after them until they turned into the inlet behind the dusky woods and were lost to view. From such romantic and secluded scenes one can watch the bustle and hurry of life as serenely as though one were the inhabitant of another planet.

About a quarter of a mile back of the Thousand Island House is a spring of mineral water strongly tinctured with iron, clear as a diamond of the first water and cold as ice. A little creek, a perfect conservatory of aquatic and amphibious plants, winding in and out 


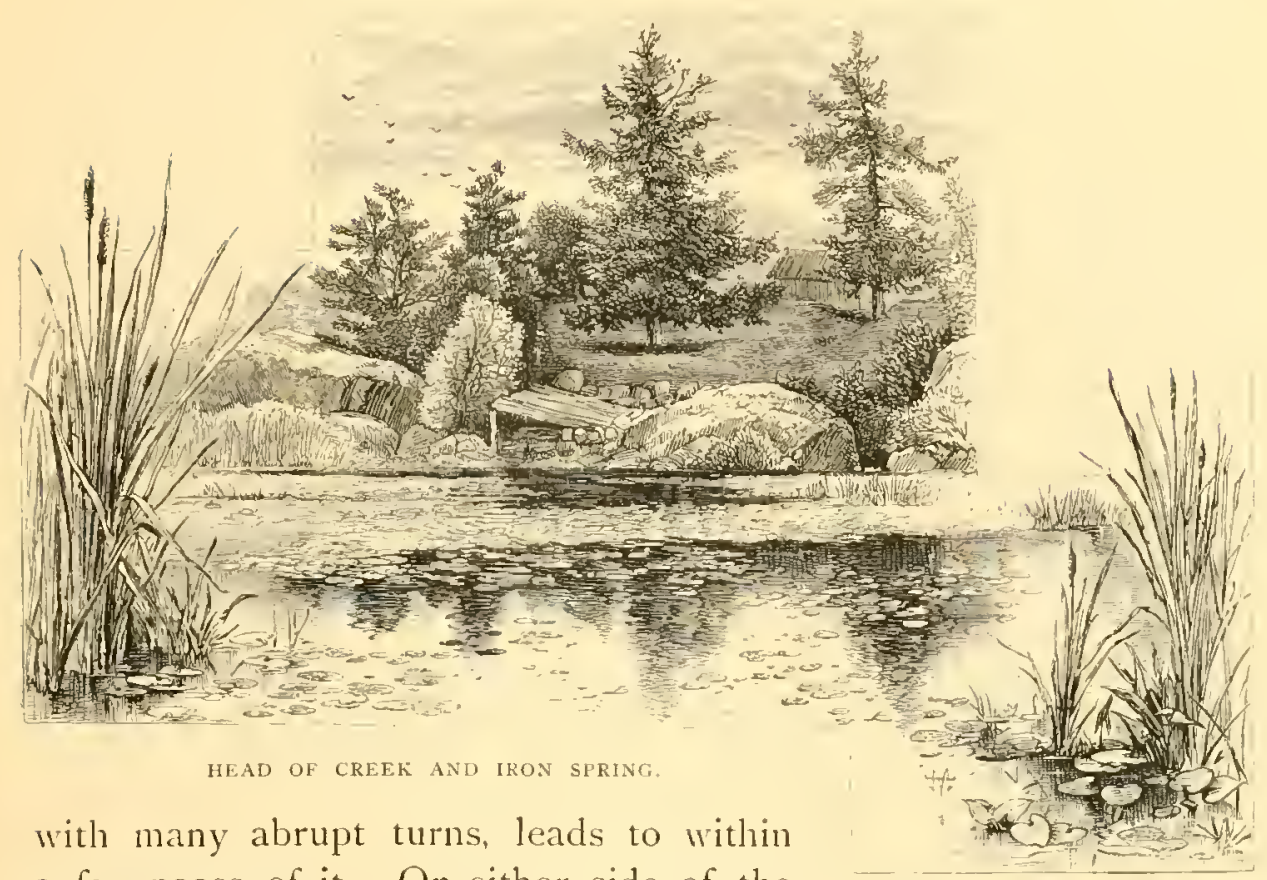

a few paces of it. On either side of the open water of its channel is an almost tropical tangle and profusion of vegetation; water-lilies, white as driven snow, with hearts of gold, reposing on their glossy, cool green pads; yellowdocks, arrowheads with purple clusters of tiny flowers, giant bulrushes, cat-tails and ferns, - all in a bewildering tangle of verdure, at times almost impassable. A rude wooden bridge spans it at one place, so close to the water that the boatman is obliged to bend nearly double in passing under it. Here one may occasionally see a chubby urchin angling in the glassy water for small pickerel or rock bass. The bottom of the creek is matted, and in some places fairly choked, with an exuberance of water-grasses of all descriptions.

Perhaps one of the best and easiest ways of becoming thoroughly acquainted with the various views, some of them extremely beautiful, that the islands present, is by means of a little steam-yacht which runs in daily trips around Wells Island. Starting from Alexandria Bay, she steams up the river among the group of islands lying there, past cottages and camping-tents nestling among the cool green shadows of the trees; past shallow hily-padded bays, at whose edge stands, sentinel-like, an ancient log-cabin or dilapidated barn; past a camp-meeting ground at the upper extremity of 


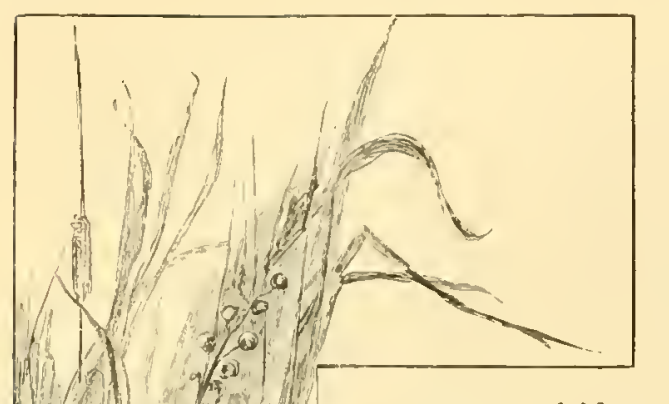

Wells Island, the so-called Thousand Island Park; and finally, taking a sudden turn, she seems to direct her course against an abrupt shore. As she advances, however, a little inlet gradually opens to view; a few rods further and the land seems to shift and change like a dissolving view, while the little craft glides into a narrow channel between two abrupt islands, the banks on either hand being shaded by overhanging pines and hemlocks. The channel, not more than six or seven feet deep, is thickly covered along the bottom with the usual tangle of waving watergrasses and weeds, long ribbons of eel-grass, feathery Carolina weed, and other varieties, purple, green, and brown. Now and then a startled pickerel darts from under the bows of the steamer, or a solitary heron flops heavily away from among the water-lilies along the bank. On past a shallow sheet of water, Eel Bay, where an occasional fisherman with his assistant may be seen; past the white towers of a stumpy light-house, perched upon the corner of a little island and defined against the dark green of the pines at its back; on, at last, into the Canadian channel. Here a bewildering maze of beautiful islands, north, south, east, and west, rises upon every hand. At times, the channel seems a lake surrounded by an amphitheater of thickly wooded hills and bluffs, with no outlet but that through which the boat has just entered; proceeding onward, it dissolves into a long channel, contracts into an abrupt inlet, or widens to an open bay. Further on is that sudden variation in the course of the channel known to all St. Lawrence voyagers and boatmen as the "Fiddler's Elbow." As the boat enters this portion of the channel, it seems to be directed by the helmsman point blank into an island. At the very moment, however, when a few rods of further progress in that 
direction would dash the boat against the rocks, she makes a sudden deviation to the left, another to the right, and lo! the Canadian channel lies before her a good mile and three-quarters broad, and Grenadier Light-house lifts in the far distance. After passing a number of curious Canadian lumber stations, perched high on the steep bank, the boat rounds the lower end of WTells Island, directs her course among the little isles on the American side, and finally stops at Alexandria Bay.

The islands in the Canadian channel of this part of the river are chiefly in possession of the Government of the Dominion. Among them are some of the most interesting of the whole group. Old Bluff raises his rugged front from a hundred feet of water to eighty feet of bare, perpendicular rock, his forehead closely matted with a thick growth of scrub pines. Through the center of the island runs a valley, almost a gorge, in which stands an uninhabited frame shanty for the accommodation of visitors. It is a rough, unfinished structure of the coarsest deal, but it looks picturesque and romantic enough, shaded and almost hidden as it is by maples and white birch. From the top of the high bluff, fronting down the river, a magnificent view is obtained of the islands lying beneath, both in the American and Canadian channels. Here the artist sat perched upon the sheer edge of the bluff, sketching diligently, in full riew of the natives for a mile around, and rastly to their astonishment.

"Hulloa, Cap!" came faintly up from below. He looked down: a cockle-shell of a melon-boat was tossing on the waves below.

"Be ye needin' a watermillin?"

He thought not, unless the anxious fruit-vender would carry it up the hill at the rear of the bluff. While engaged in this colloquy, the artist's sketch-book slipped from his hand and landed after many gyrations about half-way down the face of the cliff. Two of the party were obliged to go below in a boat, one of them climbing the rocks to secure the lost book, while a third remained above to direct their movements.

One of the most curious of the American islands stands a short distance above Alexandria Bay, - a cubical block of granite having almost the appearance of being carved by human hands, rejoicing in the not very savory name of The Devil's Oven, its summit giving 


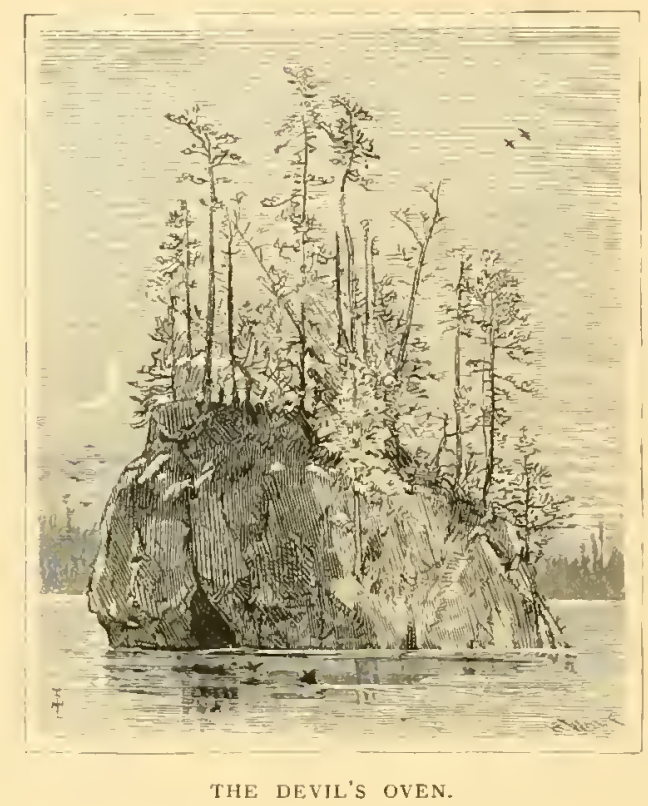

sustenance to a few gaunt cedars, and its sides perforated by an almost circular opening which at a distance does bear some resemblance to a grigantic baker's oven.

The upper extremity of Carleton's Island, some twenty-eight miles above Alexandria Bay, narrows into a contracted promontory of land ending in an abrupt bluff fifty or sixty feet high. Here, perched aloft, perceptible to all passers-by along the river, and distinctly visible for miles around, stand a number of toppling and half-ruined chimneys. Like so many sentinels standing solemnfaced, waiting for the blessed time of rest that will relieve them from duty, they watch over the ruins of an old French fort, so old that its history has been lost in the mists of the past. Attracted by that romantic glamour that hangs in the very air of the antiquated and dilapidated ruin, we were induced to pay it a visit, to the mild wonder of the natives, who seemed to look upon the artist as a species of harmless lunatic. So interested were we with the timeworn remains that a brief visit developed into a three days' stay.

The early history of the place is amost entirely lost, insomuch that it is supposed by some to be the ruin of old Fort Frontenac. It was, so far as existing data go to prove, commanded by the French about the year 1760 ; then fell into the hands of the English with the 


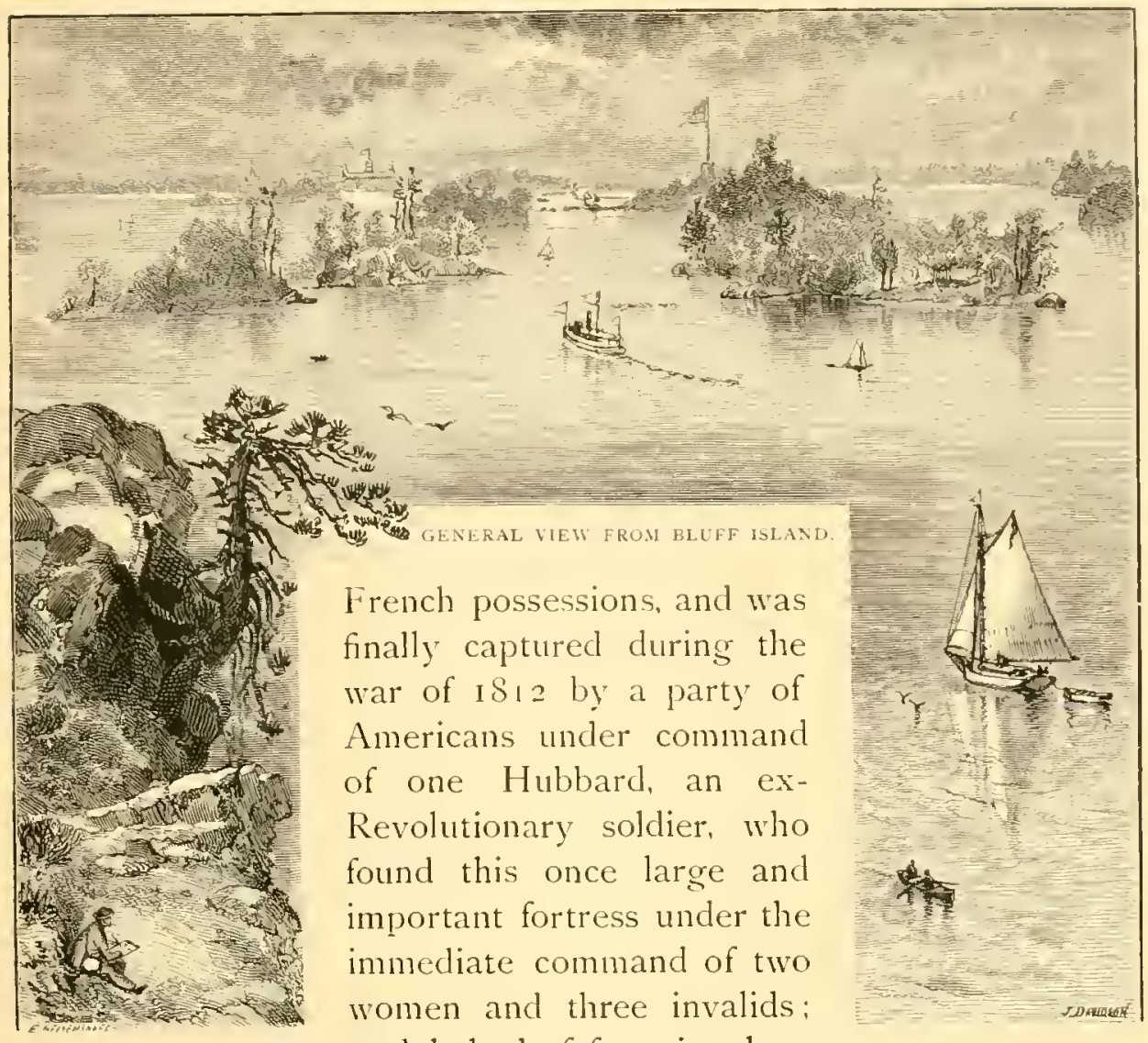
an Ichabod of forts, its glory

had departed. The women and invalids were valorously attacked, and after a slight resistance they capitulated; the poor old fort, as if to accelerate its already progressing ruin, was fired, and the Americans with their prisoners retired to the main-land, where they were received with salutes, cheers, and the music of the Cape Vincent band,-one fife and a drum.

Since that day the fort has never been rebuilt, but has been allowed gradually to crumble away into ruin, producing, as fruit of its semi-mythical history, a rich crop of romantic stories and legends. An antiquated well, dug through the solid Trenton limestone to the level of the lake, has been converted by the vivid imaginations of the natives into a receptacle of the doubloons which the French upon evacuating the fort are said to have thrown therein, with the brass cannons on top of them: though why they threw their doubloons 


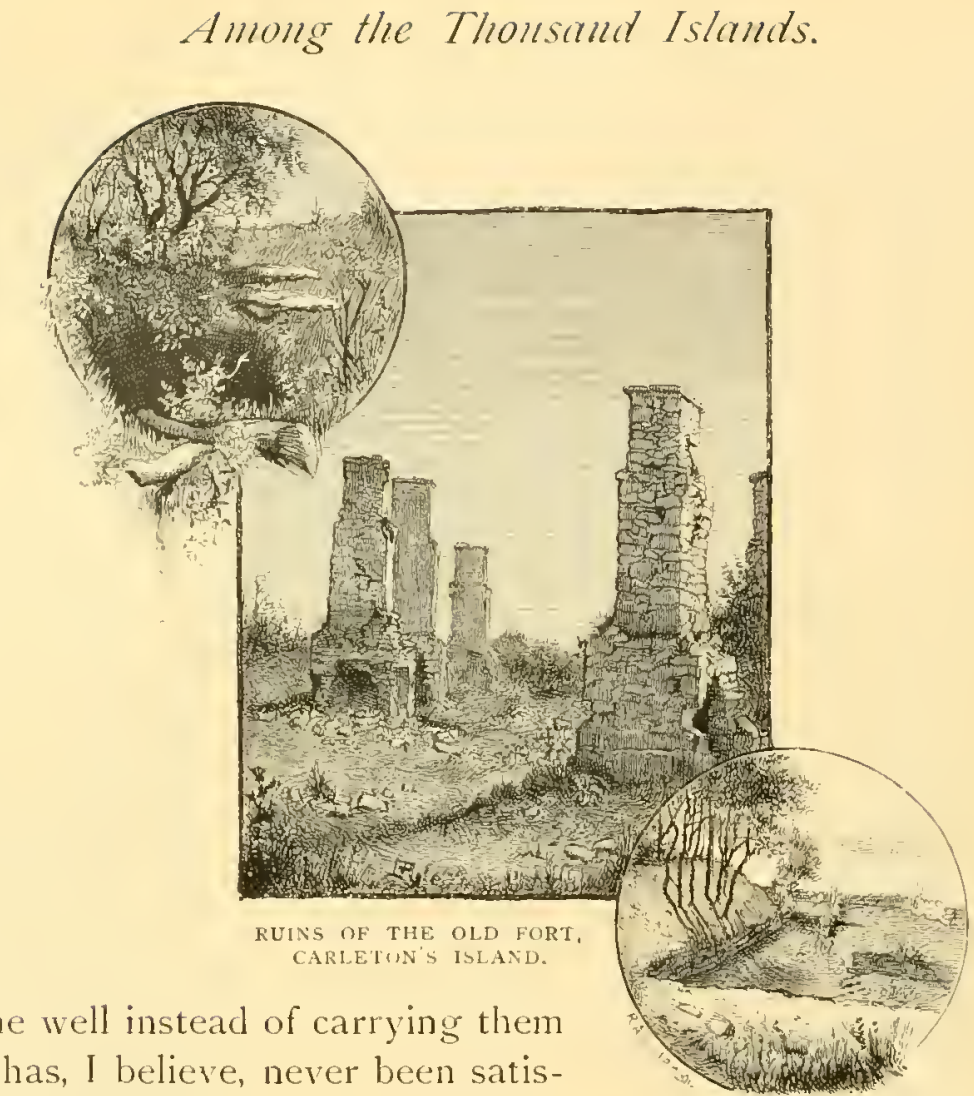

into the well instead of carrying them away, has, I believe, never been satisfactorily explained.

Upon either side, and immediately in front of the bluff upon which the old fort stands, is a pretty little bay, which once doubtless afforded pleasant and easy anchorage for the vessels that lay under its protecting guns. An innocent lumber craft, sunk many years ago in this harbor, has been, through the medium of the romantic atmosphere that hangs about the place, converted into an audacious smuggler that, blown ashore here, sank with a fabulous amount of moneys, silks, laces, and Canadian brandies hidden beneath the lumber.

Without doubt, the place was once of considerahle importance. The fortress has been built in the most elaborate manner after the system of Vauban, and exhibits a skill of the very highest order in the art of constructing defenses. The fortifications in the rear are semicircular in form; the trench, four feet deep and twenty broad, is cut through the solid Trenton limestone; the glacis, which is approached by a gradual elevation, being constructed of the same material to the height of four feet. Directly on the river-firont it is 
naturally impregnable, and at the precipitous side was probably defended merely by a stockade.

Numbers of graves lie in a flat field immediately back of the fort, many of which have been excavated by relic-seekers in search of French buttons or shoe and knee buckles. A number of ghost-like rose-bushes standing starkly here and there, long since past the lusty age of flower-bearing, probably marked out paths through this cemetery in the wilderness. Back in the island, in a copse, are the remains of an 1 ndian burying-ground, where numbers of stone arrowheads, tomahawks, etc., have been picked up at different times; and to the right of the fortress, immediately upon the bluff overlooking the Canadian Channel, are still older graves, where, it is said, as the bluff slowly wears away, an occasional grinning skull or grisly bone is exposed to the long excluded light of heaven.

In this vicinity, numbers of excellent old-fashioned wrought nails are constantly being plowed up or otherwise collected, some buildings being almost completely joined with them.

While here, we had an excellent opportunity of gaining a practical knowledge of the daily life of the island farmers, being obliged to lodge for a time at a little farm-house that nestled beneath the brow of the old fortification, like a swallow's nest in a cannon's mouth.

The proprietor did not seem overzealous to accommodate us; for what sane man, of his own free choice, would sit day after day in the broiling sun sketching the old chimneys? The bill of fare of our supper with the farm hands consisted of stewed potatoes, bread and butter, and pie, with the addition of scalding tea. The tea was perhaps rather lacking in the titillating taste of the herb itself, but any weakness in that direction was fully compensated for by the thickness of the bread and the solidity of the pie. After this repast, we were solemnly shown to our apartment immediately above the kitchen, dining and reception room, and in consequence intensely hot on this midsummer's night. Our sleeping chamber was evidently the room of state, hung with wonderful wall-paper, the floor pierced by the arm of a stove-pipe from the room below. Here stood the wash-stand, without the usual accompaniments of ewer, basin, and looking-glass; and our couches,-one a trundle-bed, and the other a gigantic four-poster of antiquated date. The stove-pipe 


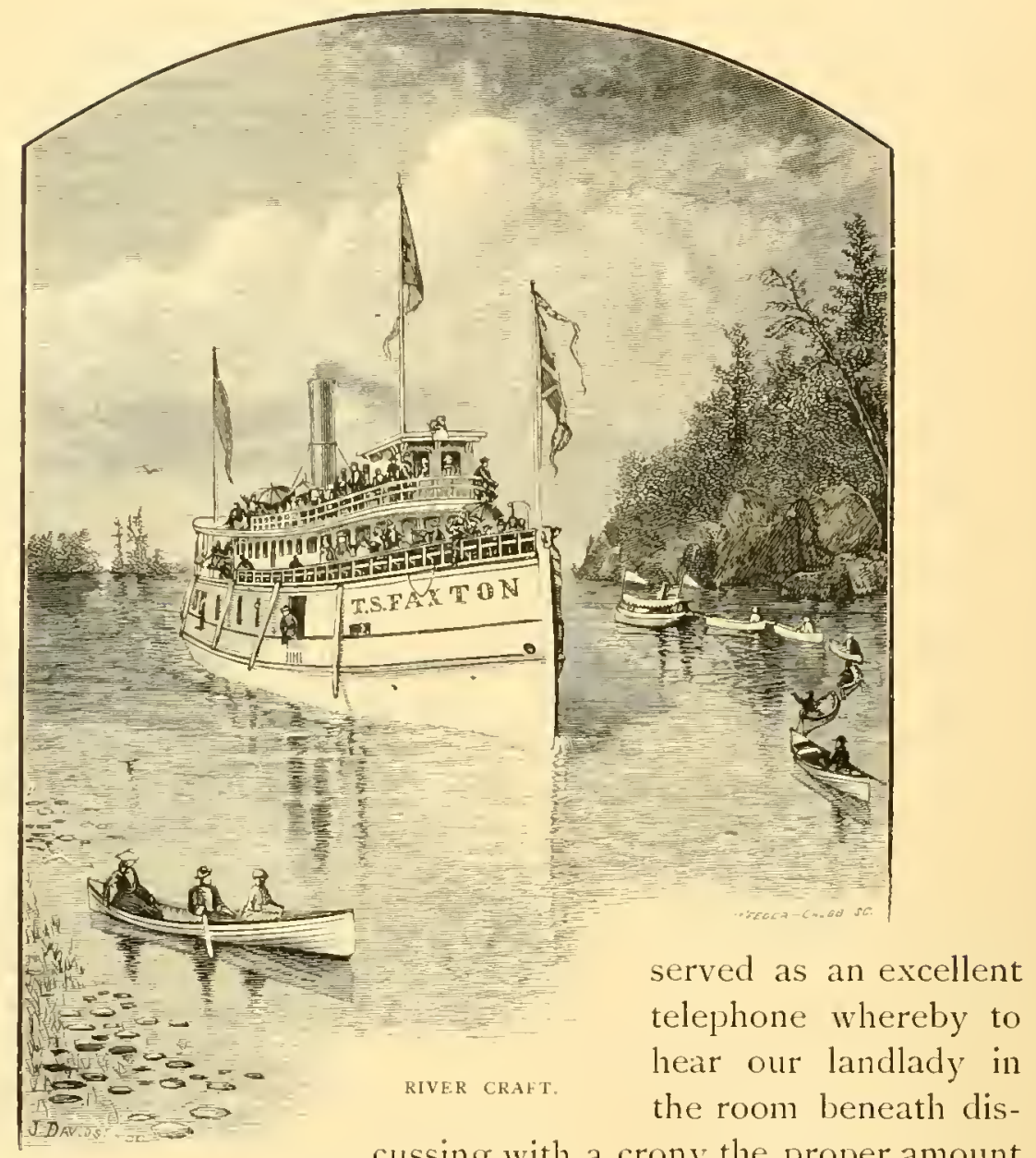

cussing with a crony the proper amount of board to charge her guests. "IVell," said the crony, "I've a feller a-stayen with me; I'm a-goin' to charge him two dollars a week, and "- in a cletermined tone- "I'm a-goin' to git it, too!" Modern luxuries should always be paid for at whatever price.

On some of the islands and along the main-land one sometimes comes upon an antiquated group of Lombardy poplars, almost invariably standing in the vicinity of some equally antiquated log-cabin or farm-house. The poplar is the ancient sign of hospitality, and in the old country was generally planted near an inn or hostelry: These trees doubtless were brought to this country by the old voyagers, and served as a landmark by which many a traveler or sailor on the St. Lawrence, making the long journey from Montreal to Toronto, 
hailed the vicinity of Christian help and assistance indicated by these darkly colored trees.

Behind Lower Grenadier Island, and three or four miles from Alexandria Bay, upon the Canadian main-land, are a number of excavations with remains of chimneys which we were puzzled for a long time to account for. They were certainly under-ground dwellings, but what was their use we could not satisfactorily explain. At length, we met a fisherman who told us he recollected hearing from his grandmother that in the "English war" British troops were quartered there during the winter. Whether the English war was that of $\delta_{1} \mathbf{2}$ or the Revolution, we could not discover; probably the war of older date may be referred to, as in many instances trees of considerable size have grown up in the midst of the excavations.

Of late years, perhaps, no event caused such a stir of excitement in this region as the so-called Patriot war in 1838 . - a revolt of certain Canadians dissatisfied with the government of Sir Francis Bond Head, then governor-general of Canada, - which was joined by a number of American agitators ever ripe for any disturbance. The first center of operations of these so-called patriots was Navy Island, in the middle of the Niagara River, where they congregated, employing the little steam-ressel Caroline in carrying arms and munitions of war to that point. At length the steamer was captured by some Canadians, fired, and run over the falls of Niagara. Considerable indignation was excited in the United States by this destruction of the property of American citizens, particularly along the border, where indignation meetings were held, and secret societies called "Hunter's Lodges" were formed, with pass-words, secret signals, and all due attendant mysteries, the express purpose of which was revenge upon the Canadian Government. The agitators were deceived by these signs into imagining that events were now ripe for a general border war, in which they hoped to free Canada from the rule of Great Britain.

It was a wild, insane affair altogether, and after some time consumed in petty threats of attack, finally reached a climax in the burning of the Canadian steamer Sir Robcrt Peel-one of the finest vessels upon the St. Lawrence. The most prominent actor in this affair was Bill Johnston, - a name familiar to every one around this region, - whose career forms a series of romantic adventures, 
deeds, and escapes,-followed by his final capture, - which would fill a novel. Indeed, we understand that a novel has been written by a Canadian Frenchman on this theme, though we have not had the good fortune to find any one who has read it. The burning of the steamer Pecl, which occurred on the 29th of May, $18_{3} 8$, remains, however, an act of inexcusable and stupid incendiarism, answering no conceivable good purpose.

For some time there had been mutterings among certain of the societies, and for a few days previous to the occurrence something mysterious was felt to be in progress. The night of the 29 th was tark and rainy. About eleven o'clock, the I'cel, then on her way from Prescott to Toronto, stopped at McDonald's Wharf, on the south side of Wellesley-now Wells-Island, for the purpose of replenishing her almost exhausted stock of wood. The passengers were all asleep in the cabin, and the crew busily engaged in their occupation, when a body of men, twenty in number, disguised as Indians and with blackened faces, yelling tumultuously and shouting. "Remember the Caroline!" ran quickly down the bank, armed with muskets and bayonets, led by a tall, strongly built man, in a red shirt-Bill Johnston himself. In a moment they overpowered the unsuspecting crew, while on board all was tumult and terror. Some of the ladies fainted, and several of the passengers fled to the shore through the rain, clad only in their night-clothes. A short opportunity was allowed for the passengers and crew to carry their baggage to the shore, but by far the greater part was lost when the vessel was subsequently burned.

Toward morning, the Pecl was drawn off from the wharf, and after being run upon a point of shoal about thirty yards below, was set on fire and abandoned. For some time the flames blazed aloft, illuminating the shores for miles around; but about dawn in the morning she once more got adrift, and finally sank in about seventy feet of water. It was nominally the intention of the captors of the steamer to convert her into a gun-boat and use her against the Canadian Government; but upon finding that she was firmly aground and resisted all their efforts to get her free, they fired her to prevent her recapture. By some it is asserted that the vessel was deliberately robbed and then burned to prevent detection and throw an air of patriotism over the crime of the perpetrators. 


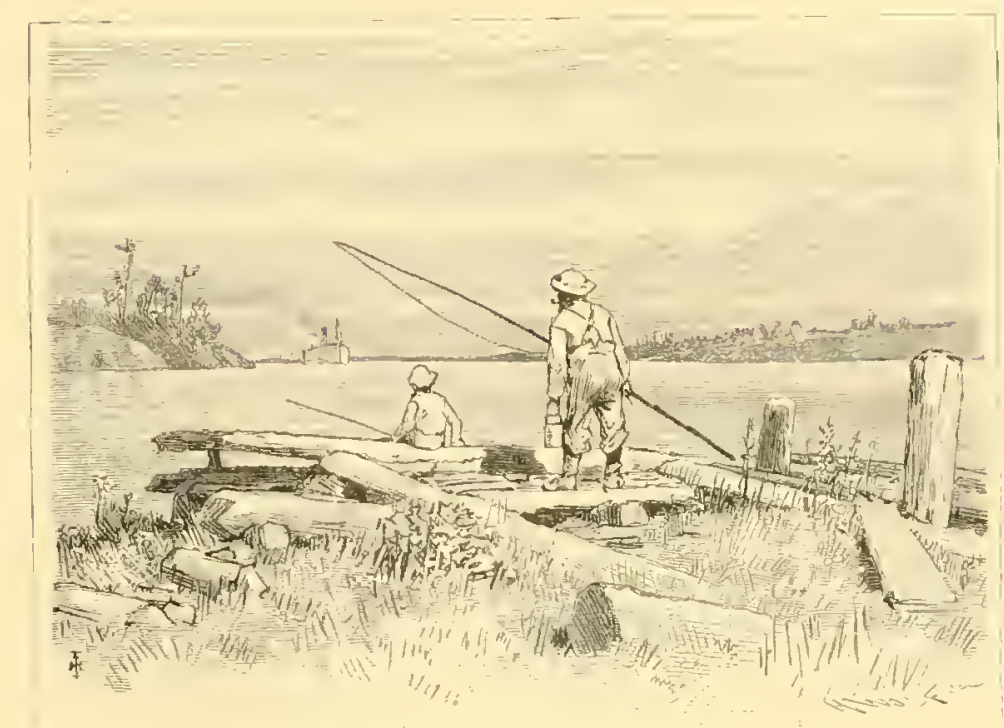

DOCK WHERE THE STEAMER "PEEL" WAS BLRNED.

Johnston was originally a British subject, but turned renegade, serving as a spy in the war of I $_{12}$, in which capacity he is said to have robbed the mails to gain intelligence. He hated his native country with all the bitterness which a renegade alone is capable of feeling. He was one of the earliest agitators upon the American side of the border, and was the one who instigated the destruction of the Pecl. A reward was offered by the government of each country for his apprehension, - so he was compelled to take to the islands for safety. Here he continued for several months, though with numbers of hair-breadth escapes, in which he was assisted by his daughter, who seems to have been a noble girl, and who is still living at Clayton. Many stories are told of remarkable acts performed by him,-- of his choking up the inlet of the Lake of the Isle with rocks, so as to prevent vessels of any size entering that sheet of water; of his having a skiff in which he could outspeed any ordinary sailing craft, and which he carried bodily across necks of land when his enemies were in pursuit of him, and of his hiding in all manner of out-of-the-way spots, once especially in the Devil's Oven, previously described, to which his daughter, who alone was in his confidence, disguised as a boy, carried provisions. He was finally captured and sent to Albany, where, after suffering a slight penalty 
for his offense, he was subsequently released, although he was always very careful to keep out of the clutch of the indignant Canadians. His son, John Johnston, still resides at Clayton, and from him, after some pressure, a part of this information as to his father's adventures was extracted.

There is a certain breath of life about the northern United States and the neighboring region of Canada suggestive even in midsummer of hard winters,- - of long months when the face of the St. Lawrence is as adamant; of snow lying four feet deep all winter without intermission; an indescribable reminder of that season when a huge wood fire roars in the capacious fire-place, and when the bellowing wind dashes hissing snow wreaths in among the tossing and writhing pines and hemlocks. There is a rugged look about the landscape, as though Nature, not daring to expend her strength in the labor of growing,- save in little secret nooks here and there, - merely rested to gain fresh strength for her yearly tussle with grim winter. The inhabitants-generally fishermen-are an honest, rough, weather-beaten set, truthful, - with the exception of legends of buried treasure, or perchance wonderful stories of an eighty-pound muskallonge or two,-kincl-hearted and hospitable. The fisherman is quaint in dialect, curious in manners, with the invariable story of the huge fish which he almost caught-and didn't. "Be ye a-goin' to skitch to-day?" inquires he, patronizingly, as he leans over the rail of the slip and looks down into the boat, where the artist is making some preparations. "Ye hadn't oughter lose so much time from fishin'." Or, "Where be ye ter dinner (take luncheon) to-day?" An island where it is customary to take picnic dinners is usually denominated a "dinnerin'-place."

Sometimes, rowing home at night, one passes by the blazing fire of a camping party, twinkling in the gloom of some thickly wooded islet. Around the fire move the dark forms of the boatmen or cook, preparing the evening meal. To one side, the campers themselves lie stretched at ease, smoking, or talking over the day's sport.

One of the great features of enjoyment to the casual visitor to the Thousand Islands consists in occasional picnic dinners- not the ordinary picnic dinner, where a table-cloth is spread upon the ground, and cold meats and sundries upon the table-cloth; where 


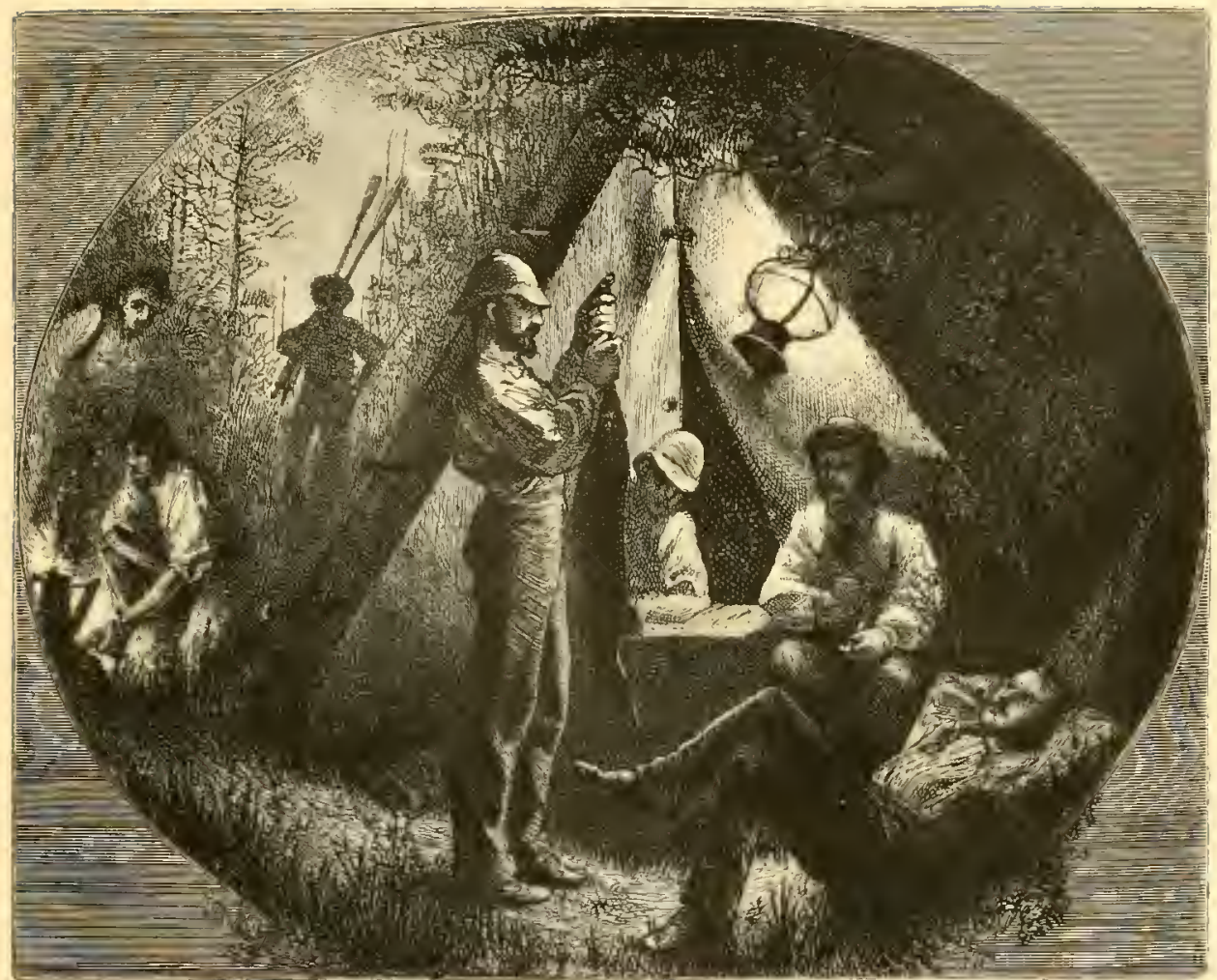

CAMPING OUT.

long-legged spiders or centipedes career across the viands or drop into one's cup of lukewarm coffee; but dinners as luxurious in their bill of fare as any of the hotels can afford, combined with all the unfettered gayety incident to such an al fresco meal. A day's fishing is nominally the backbone of the expedition, around which the day's pleasure is actually built. We will suppose that the party of a dozen ladies and gentlemen is formed, and the day planned for the expedition arrived, - a clear, sunny one, with not a ripple stirring the glassy surface of the stream. Six boats are hired, a gentleman and lady going in each, under the superintendence of a fisherman, which fisherman, if he should happen to be George Campbell, one of the Patterson Brothers, McCue, or some such competent hand, may afford his lucky party a day's sport that of itself would fully satisfy the expectations of most people. Perhaps, if the fishing-ground be distant. a steam yacht is engaged, the boats, stretching in a long line, are taken in tow, and off the jolly party starts, with flags flying merrily. 


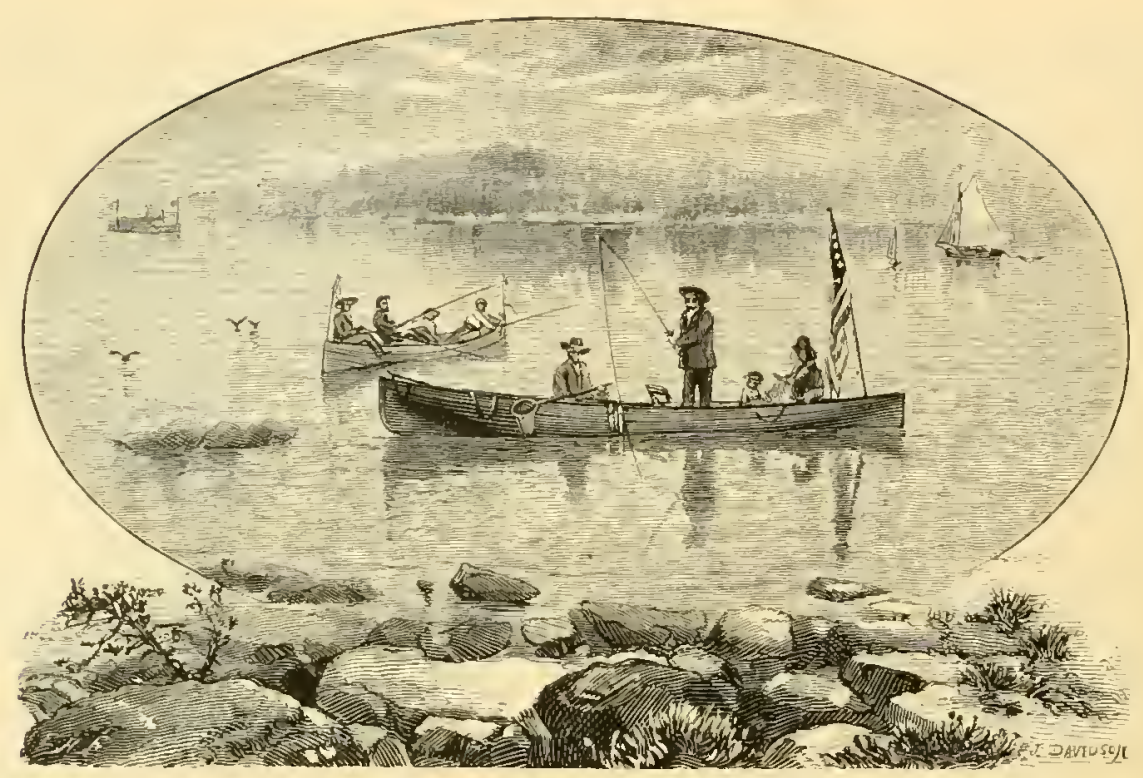

A FISHING PARTY.

At length, the desired spot is reached and the sport begins, each party fishing as if their lives depended upon it, and all internally praying that, if a monster pickerel or muskallonge is caught, - of which there may be about one chance in five hundred,- they may be the particular ones selected by Fortune as the catchers thereof. But whether such a capture is made or not, the fishing is sure to be fine, and so exciting that the dinner hour approaches without notice until, warned by the shrill whistle of the little steam-yacht, the boats wend their way from all quarters to the "dinnerin'-place."

The luncheon, mind you, is not made up according to the simple bill of fare presented at the desk of the hotel, composed of mere necessaries, such as eggs, bread and butter, coffee, and fat pork; but, under the supervision of Isaac, the overseer of the luncheon-room at the Thousand Island House, it crops out in various "extras" and "sundries," in the shape of a tender chicken or two, juicy steak and chops, green corn, tomatoes, and the like. The fishermenexcellent cooks, deft and cleanly-perform the task of preparing the meal with wonderful dispatch, and in a short time a royal repast is laid before the hungry anglers, whose appetites, whetted by healthful exercise and invigorating air, do ample justice to the feast. After dinner, while the fishermen are packing away the dishes and other 
et ceteras, the ladies retire for a short nap and the gentlemen for a social cigar; then, as evening approaches, back to the hotel, there to doff the flannel shirts and fishing-dresses, and once more to assume society clothes and manners.

Many, however, prefer solitary sport, or with a company of two or three grentlemen only; and by starting in the early morning, long trips can be made, far down below Grenadier Island. 'There, in the more shallow portions of the river, striped with long beds of water-grasses, green and purple, undisturbed by the turmoil and commotion of passing steam-boats, the indolent pickerel lies tranquilly in the secluded tangle of his own especial retreat; or huge black bass, reaching sometimes to the weight of five or six pounds, stand guard along the edge of the grass, waiting for some unwary minnow or perch to pass. At rare intervals are spots where the savage muskallonge, the tiger of fresh-

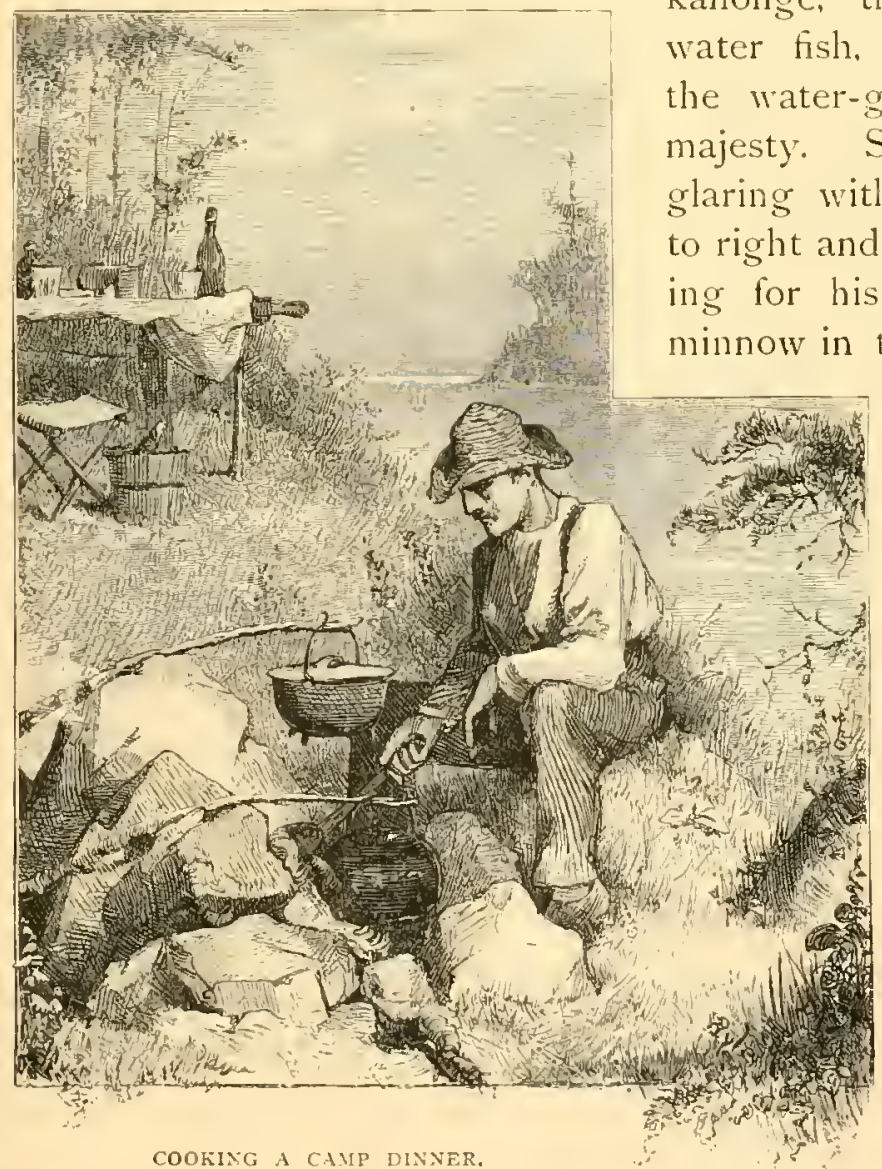
water fish, lies hidden among the water-grasses in solitary majesty. Sluggishly he lies, glaring with his savage eyes to right and left of him, watching for his prey. He sees a minnow in the distance, apparently twitching and wriggling in a very eccentric course ; a moment the monarch poises himself, with waving fins, then, a sudden sweep of his majestic tail, and he darts like a thunder-bolt upon his intended victin. The next moment the sharp agrony of the 


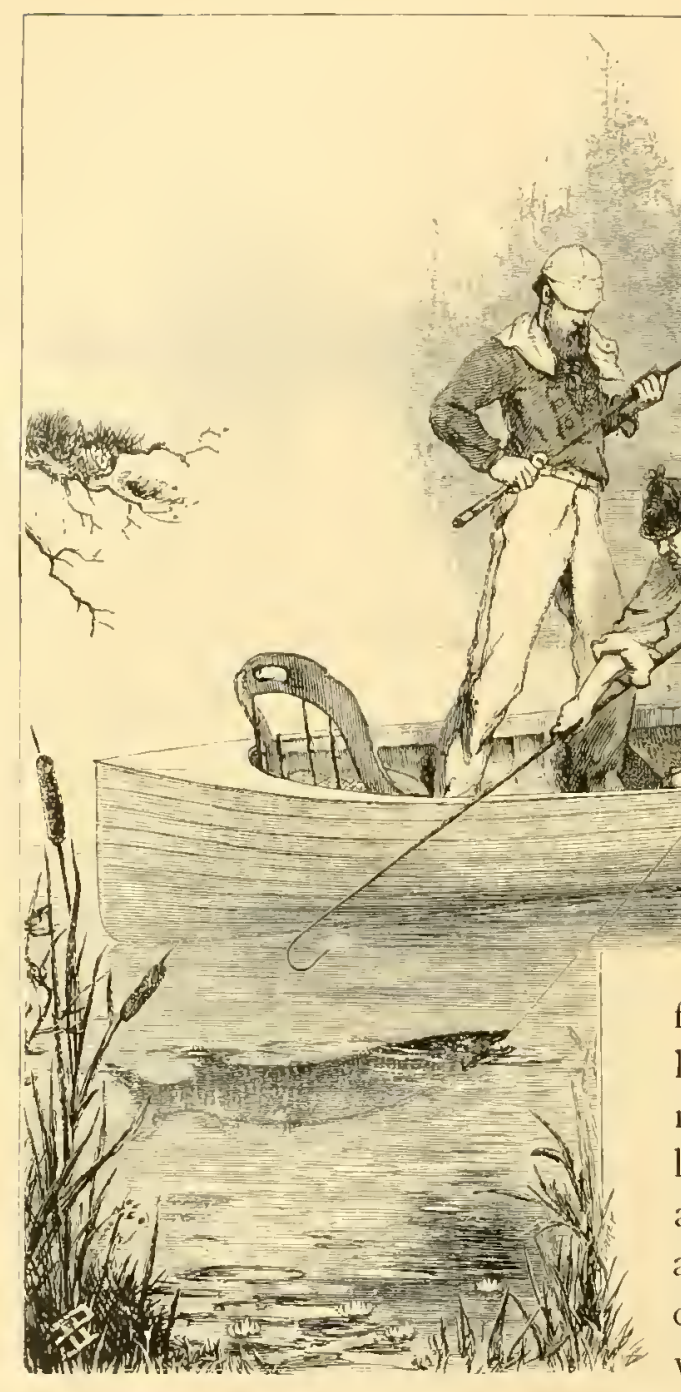

CATCHING A MUSKALLONGE. fisherman's hook is in his throat. For a moment he lies in motionless astonishment; then, as he feels the line tighten and discovers he is indeed caught, he struggles with rage, making the water eddy and swirl with

the sweeps of his powerful tail, and causing the rod to bend almost double. This way and that he darts, mad with rage and pain, while the line hisses as it spins from the reel; but in vain; in spite of all his endeavors, he feels the tightening line drawing him nearer and nearer to the surface. Again and again he is brought to the side of the boat only to dart away once more, until at last, sullen, exhausted, and conquered, he lies motionless in the water beside the victorious fisherman's skiff. A moment more and the gaff strikes his side and he is landed safely in the botton of the boat. 


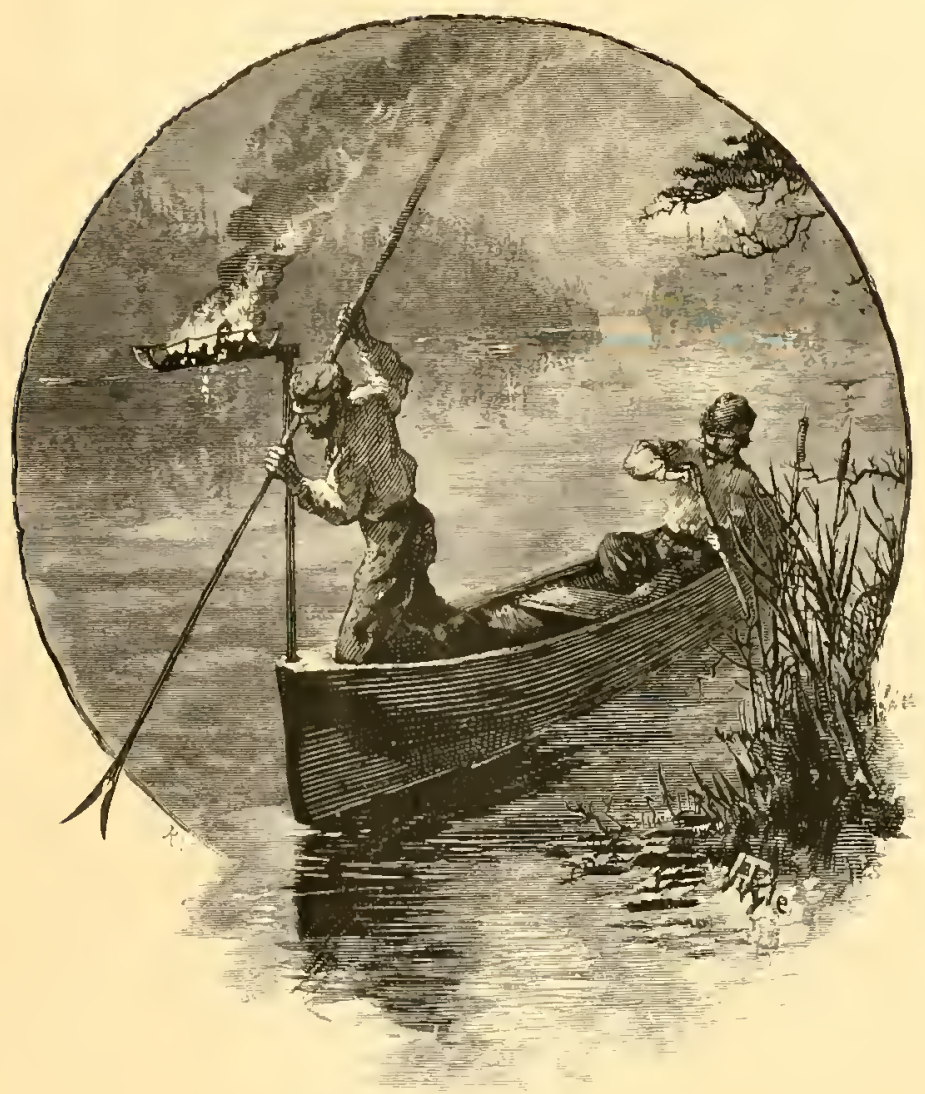

SPI:ARING; EELS IN EEL BAY.

"Hurrah! a twenty-pounder 1"

In the early spring, when the shallows of Eel Bay or other sheets of water of the same kind become free from ice, the water, not being deep, becomes warm much more quickly than elsewhere, and here the half-frozen fish congregate in great quantities. The professional fisherman in the bow of the boat holds a spear, in shape like a trident, but with an alternate sharp iron prong between each barbed shaft, the whole fixed upon a long, firm handle. Immediately upon seeing a fish, he darts this gig at him, fixing the barb so effectually in his victim that to strike is to capture him. The weapon used is called a jaw-spear, from its peculiar form, being a jaw-shaped piece of wood, with a sharp iron barb firmly fixed in the angle, against which the eels are forced and pinned fast until they are safely landed in the boat. Eel-spearing is generally pur- 
sued at night, not only because the water is usually more quiet then than during the day-time, but also because the light of the blazing pine chunks in the "jack" or open brazier fixed in the bow of the skiff makes objects on the bottom more apparent by contrast with the surrounding gloom.

It is a picturesque sight to see the swarthy forms of the fishermen, lit up in the circumscribed circle of light, looking like phantoms or demons - the one in the bow bending eagerly forward, holding the spear and watching the bottom keenly for his victim; the one in the stern silently packling the boat across the motionless water, not a sound breaking the stillness of night but the tremulous "Ho-o-o-o" of the screech-owl or the crackling of pine chunks in the jack. Suddenly the figure in the prow poises himself for a moment, drives his spear forward through the water with a splash, then draws it back with the wriggling victim gleaming in the blazing light of the pine.

In June there is fly-fishing, and fine sport it is to cast a fly so adroitly as to tempt a plump bass in the seclusion of his rocky retreat beneath the overhanging birches along the bank, and fine sport to land him, too; for the bass, lusty and strong through good living and pure water, will battle with the sportsman as vigrorously as ever did dappled trout, struck in the pools of Maine.

Toward summer, the fish become more sluggish and refuse to strike at a fly, and then "still fishing," with live minnows for bait, or the less skillful sport of "trolling" take the place of fly-fishing. Of trolling, little is to be said. The lines are merely trolled from the stern of the boat; and if the fish bites, unless it be an extraordinary large one, nothing is required but to haul him in, hand over hand, and land hin finally, without any skillful handling, in the bottom of the boat.

With still fishing, however, more skill is required. As a sport it occupies the intermediate point between trolling and fly-fishing, and, should very light rods be used, a great deal of sport may be obtained in playing and landing the fish. Nearly all the boatmen, upon the least encouragement, will recount stupendous stories of eighty-pound muskallonge, forty-pound pickerel, or eight-pound bass. The largest fish that I could find reliable record of as having been caught and landed were a muskallonge fifty-one pounds, a pickerel twentyseven, and a black bass six and a quarter. 
Numbers of ducks of different varieties frequent the bays and inlets of the Thousand Islands in the spring and autumn, and quantities of ruffed yrouse are found upon the main-land, so that the shooting is said to be excellent in its season. While we were there, two or three deer were said to have come from the main-land to Wells Island, where they were diligently hunted, but, so far as we heard, without success.

The most interesting part of the development of this region as a watering-place is that which relates to the settlement of the islands by private residents. The islands have not been held at too high a price, and a multitude of men have bought them and built houses upon them for summer use. Some of these are little more than shelters or "shooting-boxes"; some are comfortable houses: and several are expensive and very splendid and showy places, so that a passenger on a river steamer, making his first trip down the stream, will find much of picturesque interest in glimpses of the architecture which greet him on every hand. There is no chance for fighting over boundary lines, and some of the lots with a liquid fence are so small that their owners can throw a fly from their front door-step to the bass they can plainly see in the clear water which is never disturbed by a freshet.

There are summer hotels at Clayton and other points along the shore, but Alexandria Bay is the grand center of the summer life. Of course, the Lake Ontario and St. Lawrence boats from all parts touch here, and there is a daily line between Ogdensburg and Alexandria Bay. Here are the great hotels, and here is the multitude. The village contains about five hundred people, with two churchesa Methodist and a Dutch Reformed Presbyterian. The latter is a mission church, and was founded by the late Rev. Dr. Bethune, who was a famous fisherman in his day, and who, in his summer recreations on the river, did not forget to fish for men. The Methodists have established the "Thousand Island Park," several miles above, where they come in great numbers every year for recreation and a camp-meeting. They have a fine dock and quite a number of private residences. Westminster Park is a new enterprise. An association has purchased five or six hundred acres of Wells Island, nearly opposite to the village of Alexandria Bay, and the enterprise is now in the full tide of development. Fourteen miles of road have 
been laid out, five of which are already graded. A dock has been built more than a thousand feet long; and hundreds of building lots have been thrown into the market. Under the influence of this great influx of visitors, the fishing is quite likely to suffer; but the pure water and the pure air that sweep down the mighty channel are enough for the drinking and the breathing of a continent.

Pleasant are the recollections of the place of which some aspects are recorded here; pleasant for all reasons; pleasant as a center of watering-place life; pleasant for hours of fishing under the skillful guidance of George Campbell; and doubly pleasant, delightful, for hours of silent, solitary communion with Nature in tranquil bays and spicy cedar woods, - communion sometimes as uninterrupted as though we belonged to a different sphere from this earthly one of hurry and bustle; a place of legend and romance, of old associations-an unfailing fountain of interest both in itself and its inhabitants.

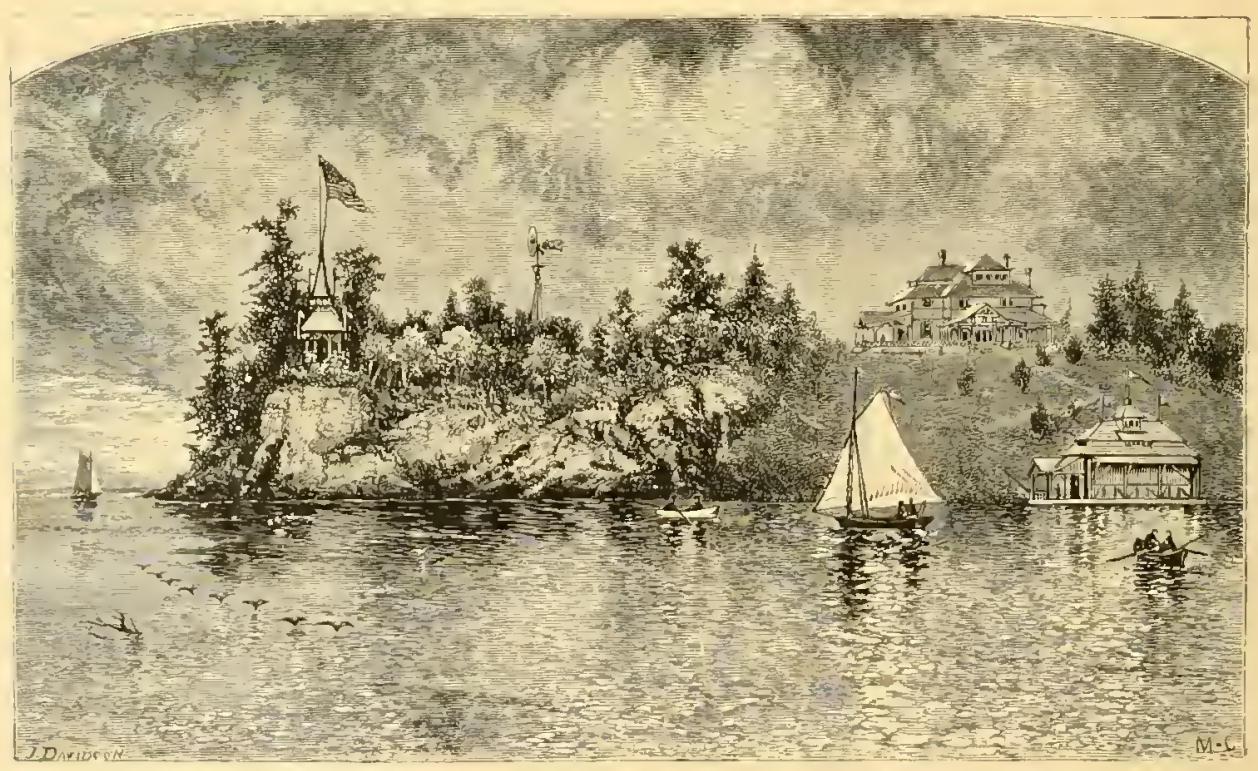

BONNIE CASTLE. OWNED BY THE LATE DR, J. G. HOLLAND. 


\section{THE SPLIT BAMBOO ROD.*}

ITS HISTORY, ETC.

T

HE "split bamboo"- "rent and glued bamboo"-rod has been generally supposed to be an American invention. The first split bamboo rod 1 ever saw or heard of was made by $\mathrm{Wm}$. Blacker, 54 Dean street, Soho, London, and to order, for James Stevens, an old and well-known angler, of Hoboken. N. J. This was in 1852 , and it was given to me for repairs and alterations in that year. I am certain of the date, as I made a rod for Mr. Stevens on his visit to the London Exhibition in I 85 I. I have the records of both dates, taken at the time, so that no mistake can be made. The rod is still in the possession of the family of Mr. Stevens.

The first attempt to give the history of the split bamboo rod in this country, that $I$ have been able to find, is as follows: A. G. Wilkinson. Esq. of Washington, D. C., in an article in "Scribner's Magazine" (now "The Century") for October, i876, on "Salmon Fishing," page 774 , says:

"I have taken not a little pains to get as far as possible a correct history of this somewhat remarkable invention."

Mr. Wilkinson gives the year I 866 as the one in which Mr. Phillippi, a gunmaker of Easton, Pa., made a glued-up split bamboo rod in three sections, or part of one. He was followed by Mrr. Green and Mr. Murphy.

* Through the courtesy of the editor of "The American Angler," we are permitted to republish the following articles giving the history of the split bamboo rod. 
Dr. Henshall, in his "Book of the Black Bass," pp. 201-203. under the caption of "Origin of the Split Bamboo Rod," says :

"For though purely an American invention as now construcled, the idea or principle is really of English origin."

The 1)octor then gives the date of the first split bamboo rod made in this country, by Samuel Phillippi, as about I $\delta_{4} S$; but all dates are from memory, and I believe the date given by Mr. Wilkinson is the nearer approach to the correct one. Mr. Phillippi never made a complete rod of split bamboo, only a tip and joint to a threepieced rod, the butt of ash, and the joint and tip made in three sections. Mr. Phillippi died about 1878 .

Mr. Murphy, of Newark, N. J., in an article by Mr. B. Phillips, on the origin of the split bamboo, published in the New York "Times," gives the date as $1 \delta_{4} 8$ when Mr. Phillippi used the natural bamboo, and subsequently made a joint of bamboo.

The next date given is about is6o, when Mr. E. A. Green, of Newark, N. J., made the first complete split bamboo rod. This date cannot be far astray, for Mr. Green made (that is, glued up) for the trade a few ; and I find my record, made at the time, to be Sept. 6. I 863 . These rods were made in four sections. Mr. Thaddeus Norris, of Philadelphia, is mentioned in connection with the invention, but he never claimed it. In I 863 or I 864 . Mr. Murphy, an acquaintance of Mr. Green, commenced to manufacture split bamboo rods for the tracle; these were in four sections.

The first rods constructed in si $x$ sections that were put into the market were made by Mr. H. L. Leonard, of Bangor, Me. This was about is $\$ 0$, and Dr. A. H. Fowler soon followed; Mr. Murphy, however, claims to have made one some time before.

The first split bamboo rod that I made myself was in June, I $\$ 69$. It was put together in four sections; made not of Calcutta bamboo, but of Chinese, which is much harder, more homogeneous, and more difficult to obtain than the former.

I have thus traced the record of the split bamboo rod on this side of the "herring pond," and now will look into its history on the other side.

Thomas Aldred, of London, claims, and I have never seen it disputed, to be the inventor of the three-section glued-up bamboo 
rod. The date under which Mr. Aldred claims, I have never been able to find. It was, however, previous to the Crystal Palace Exhibition in 1851 . There were three exhibitors in the Exhibition at the Crystal Palace at London in 1851, viz.: Ainge \& Aldred, J. Bernard, and J. K. Farlow. The rods exhibited were all of three longitudinal sections, the whole length of the cane, and not in sections between the knots and glued. Ange \& Aldred also exhibited the same rod at the Exhibition in 1853 at New York.

The first record I have been able to find of the construction of the split bamboo rod is in Ephemera's (Edward Fitzgibbon) "Handbook of Angling," second edition, page 255. London, 1848 , where he recommends a tip for a salmon rod to be made of bamboo cane rent longitudinally in to three wedge-shaped pieces, then glued together and reduced to the proper tapering thickness, ringed and whipped with unusual care and neatness. He adds: "I have changed my opinion with respect to rods made entirely of rent cane or any other wood rent. Their defects will always more than counterbalance their merits."

I have not been able to see a copy of the first edition of Ephemera's book, which was published in I844, in which he had evidently recommended the rent and glued rod, the book not being in the Lenos or Astor library or in any private library that I know of.

I now quote from Blacker's "Fly Making and Angling," London, I 855 , page 82 :

.. The rent and glued-up bamboo cane rods, which I turn out to the greatest perfection, are very valuable, as they are very light and powerful, and throw the line with great facility."

The first edition of this book, published in I $S_{42}$, I have also not been able to consult. The author was a practical rod-maker, and made the split bamboo rod 1 refer to in the beginning of this article.

In $1 S_{5} 6$ there was published in London an edition of Walton's "Complete Angler," edited by Edward Jesse, with notes and papers on fishing-tackle by the publisher, Henry G. Bohn. On page 325. in the article on rods, he says:

"The split or glued-up rod is difficult to make well, and very expensive. It is made of three pieces of split cane. which some say should have the bark inside, some outside, nicely rounded." 
In January, $185 \%$, the third edition of "The Practical Angler," by W. C. Stewart, was published in Edinburgh. On pagre 33, Mr. Stewart, in speaking of rods, says:

"The strength of bamboo lies in the skin, and in order to turn this to best account, rod-makers lay two or three strips together so as to form a complete skin all around. Rods are sometimes made entirely of bamboo, but they possess no advantage over those in common use to compensate for the additional expense, a twelve-foot rod of this material costing $E_{3}$ to $£+$."

At that time, bamboo rods were all made in three sections, with the enamel on the outside. I know that Mr. Wilkinson says the rods made by Alfred \& Sons were put together with the enamel on the inside; but 1 think this must be a mistake, unless he means that the enamel was on one side of the longitudinal section extending from the apex to the base of the triangle, and when glued is from center to circumference. But put the outside of the bamboo on the side of the triangle or apex, then the enamel is all gone, no matter in what number of sections the rod be made.

On the whole subject of enamel, there is much misunderstanding. No split bamboo rod ever was, is, or can be made with the enamel intact, no matter what number of sections or form of its construction, for the following reasons:

Calcutta bamboo (Bambusa arundinacea), which is the bamboo used for making rods, is one of the most useful and important of the grass family, and consists of a culm or cylinder (except at the nodes or joints, which are about ten to fifteen inches apart) and a solid at the nodes, with a projection on the outside of one-fiftieth to onethirtieth of an inch all around, except at the axil, where the branches grow on alternate sides. This projection has to be taken off in making the rod; then going through the thickness of the enamel from five to eight times, for the space of from one to two inches at each node, of which there are three in each of the six sections (which is the best number of sections from which a split bamboo rod can be made). These nodes being the weakest spot in the bamboo, in gluing up the sections they are never put on a line with one another, but one is moved up, say, two inches; the next down two inches, so as to make six less weak spots in the circumference of the joint and eighteen in each joint. 
All the Calcutta bamboo imported into this country or England is burned, before being exported, with a red-hot iron of elliptic form and from one-half to three-quarters of an inch wide, which destroys the strongest fiber immediately in contact with the enamel, and loosens the latter, so that, by estimate, about one-fifth of the enamel comes off in the working. As you cannot retain it all on the rod, it is just as strong if all the enamel is taken off; in fact, the enamel, or silex, on the outsicle of the bamboo only stiffens, but does not strengthen it. Glass is melted silex, and no one would think a rod was strengthened by giving it a coat of silex varnish.

It will be seen from the foregoing that in $18_{4} 8$ Ephemera's "Hand-book on Angling," second edition, mentions the complete threesection split bamboo rod as being in use in England, and that the first edition of this book, published in 1844 , has reference to the same rod. In 1851 , rods of similar make were exhibited at the Crystal Palace by three manufacturers, and two other writers on angling mention these rods in their books, published in 1855 and I 856 . The earliest date of manufacture in America of the complete split bamboo rod is that of 1860 , when Mr. Green, of Newark, N. J.. made a few rods of this character.

Willam Mitciele.

Since reading the interesting and valuable article by $m y$ old friend, Mr. William Mitchell, * * * I have consulted a modest angling library (which has always been at his service, as he well knows), and found that it contains both the works which he was desirous of seeing.

The first edition of the "Hand-book of Angling." by "Ephemera" (Edward Fitzgibbon), was published in 1847 , not 1844 , and it was owing to this mistake as to date, no doubt, that it was not to be found "in the Lenox or Astor library, or in any private library."

Blacker's first edition ( $18_{42}$ ) I clismiss from the discussion, as it contains no allusion to the construction of split bamboo, or to any kind of rod, in fact, but is devoted to the "Art of angling and complete system of fly-making and dyeing of colors."

Mr. Fitzgibbon, in the first edition of his work, pp. $278 \mathrm{ct} s c q$., in speaking of the construction of a salmon rod, says that he consulted 
a "Mr. Little, of 15 Fetter Lane, rod-maker to His Royal Highness, Prince Albert," who described the process of making the top and middle joints thus:

"They are to be made from the stoutest pieces of bamboo cane, called ' jungle, and brought from India. The pieces should be large and straight, so that you can rend them well through knots and all. Each joint should consist of three rent pieces, split like the foot of a portable garden chair. and afterwarl glued together, knot opposite to knot, or imperfect grain opposite to imperfect grain, but the best part opposite to that which may be knotty or imperfect, so as to equalize defectiveness and goodness. The natural badness of the cane you counteract by art, and none save a clever workman can do it. The butt of a salmon rod should be macle of plank ash or ground ash, though many goor judges prefer willow or red deal, as being much lighter, and where lightness is required the whole rod may le made of cane. The few makers that have as yet attempted solid cane or glued-up rods have generally placed the bark or hardest part of the cane inside in gluing, and then reduced the joints down on the outsicle to the usual tapering shape. Give me, however, the workman who glues the splices with the bark outside, and then gives his rod a true and correct action, allowing the three different barks to be seen visibly on the outside after he has rounded the whole.

"If the pieces are skillfully ghed together they will require no reducing, except at the comers, to bring the rod from the three-square to the round shape. I am prepared to prove that there are not more than three men in London capable of making, perfectly, rods of solid cane, rent. glued, and then correctly finished with the bark lying on the outside."

\section{Mr. Fitzgibbon goes on to say:}

"In my opinion, rods made entirely of lancewood are the worst; and those made entirely of rent and glued jungle cane are the best. They must be most carefully fashioned, and no maker can turn them out without charging a high price. I am also of opinion that they will last longer than any other sort of rod, and are far less liable to warping. I have a high opinion of their elasticity, and $\mathrm{Mr}$. Bowness, fishing-tackle maker, of No. 12 Bellyard, lemple Bar, showed me once a trout fly-rod, made in this, my favorite way, that had been for many years in use [the italics are mineL. D. A.] and was still straight as a wand. I never saw a better single-handed rod."

Allowing a reasonable construction to the expression, "for many years," this would seem to show that rods of "rent and jungle cane" were made as far back as i $830-40$.

It would be interesting to know what led to the sudden change of opinion as to the merits of such rods of "Ephemera"; that is to say, within the space of a twelvemonth - the period which elapsed between the dates of publication of the first and second editions of his book. As a not absolute disbeliever in bamboo rods, I, for one at least, confess to a good deal of curiosity upon this point.

Lawrence D. Alexander. 
ON THE INVENTION OF THLE RELL.

BY ALFREIS M. MAYER.

TuE first mention of the reel I have been able to find is the following passage taken from Barker's "Art of Angling," London, I 651 .

"Within two foot of the bottom of the rod there was a hole made for to put in a wind, to turn with a barrell to gather up his line, and loose at his pleasure."

In the second edition of this work, 1657 , the author says:

"You must have your wincler within two foot of the bottom, to goe on your rod made in this manner, with a spring, that you may put it on as low as you please."

In lzaak Walton's "Compleat Angler," London, I655, p. I 89, second edition, in Chap. VIl., containing "Observations of the Salmon, with Directions how to Fish for Him," is this passage:

"Note also, that many use to fish for a Salmon with a ring of wire on the top of their rod, through which the line may run to as great a length as is neerlful when he is hooked. And to that end, some use a wheel about the middle of their rod, or near their hand, which is to be observerl better by seeing one of them than by a large demonstration of words."

But it appears from the directions how to angle given in this work that neither Walton nor Cotton made use of the reel. Also, the passage just quoted, which mentions the reel, does not exist in the first edition of the "Compleat Angler," published in 1653 .

Among the objects composing the frontispiece to "The Experienc'd Angler; or, Angling Improved," by Col. Robert Venables, London, I662, is a good representation of a reel or winch. In this work occur the following directions as to the use of the reel:

"The next way of angling is with a troll for the Pike, which is very delightful; you may buy your troll ready made. therefore I shall not trouble myself to describe it, only let it have a winch to wind it withall, * * * * * * and then you may certainly conclude he hath pouched your bait, and rangeth abroad no more; then with your troll wind up your line. till you think you have it almost straight: then with a sharp jerk hook him, and make your pleasure to your content.

The Salmon takes the artificial fly very well; but you must use a troll, as for the Pike, or he, being a strong fish, will hazard your line, except you give him length." 
Juliana Berners, in her "Treatyse of Fysshynge with an Angle," printed in 1496 , does not speak of the reel.

ON TIE ORIGIN OF TIIE ARTIFICIAL FLY AND THE SILK-WORM GUT.

BY ALFRED M. MAYER.

"Who has not seen the scarus rise,

Decoy'd and caught by fraudful flies?"

MARTIAL, A. T. 43-104.

TIIE earliest explicit account of the use of the artificial fly is by Elian, a Latin author of the early part of the third century. In his "De Naturâ Animalium," a work originally written in Greek, we read:

"I have heard of a Macedonian way of catching fish, and it is this: Between Beroca and 'Thessalonica runs a river called the Astracus, and in it there are fish with spotted (or speckled) skins: what the natives of the country call them you had lietter ask the Macedonians. These fish feed on a fly which is peculiar to the country, and which hovers over the river. It is not like flies found elsewhere, nor does it resemble a wasp in appearance, nor in shaje would one justly describe it as a midge or a bee; it imitates the color of the wasl, and it hums like a lee. The natives call it Hippouros. As these flies seek their food over the water, they do not escape the observation of the fish swimming below. When, then, a fish observes a fly hovering ahove, it swins quickly up, fearing to agitate the river, lest it should scare away its prey; then coming up by its shadow. it opens its jaws and gulps down the fly, like a wolf carrying off a sheep from the flock or an eagle a goose from the farm-yard. Having lone this, it withdraws under the rippling water. Now, though the fishermen know of this, they do not use these flies at all for bait for the fish; for if a man's hand touch them, they lose their color, their wings decay, and they become unfit for food for the fish. For this reason, they have nothing to do with them, hating them for their bad character; but they have planned a snare for the fish, and get the better of them by their fisherman's craft. They fasten red (crimson-red) wool round a hook, and fit on to the wool two feathers, which grow under a cock's wattles, and which in color are like wax. Their rod is six feet long, and the line is of the same length. Then they throw their snare, and the fish, attracted and maddened by the color, comes up, thinking, from the pretty sight, to get a dainty mouthful. When, however, it opens its jaws, it is caught by the hook, and enjoys a bitter repast - a captive."

Subsequent to Elian's time, fly-fishing is not mentioned by any author till Dame Juliana Berners, in 1496, writes of it as a mode of angling well known, for she introduces the subject abruptly, as follows : 
"Thyse ben the xij flyes wyth whyche ye shall angle to ye trought \& grayllyng: and lubbe lyke as ye shall now here me tell."

She then describes "the donne flye, a nother doone flye, the stone flye, the yelowe flye, the black louper, the donne cutte, the maure flye, the taudy flye, the waspe flyc, the shell flye, and the drake flye," and gives the months to which they are especially adapted. An idea of her description is given in the following:

"In the begynnynge of Maye, a good flye, the body of roddyd wull \& lappid abowte wyth blacke sylke: the wynges of the drake \& of the redde capons hakyll."

Dr. Bethune says: "The twelve flies in the Berner's Treatise are the substratum of the mystery Colton has built up wisely and correctly."

"James Saunders, in his 'Compleat Fisherman,' London, 1724 , is the first angling author who mentions silk-worm gut (pp. 91-92); but Pepys, in his diary, says (March 1 8, 1667): "This day Mr. Cæsar told me a pretty "experiment of his angling with a minikin, a gutt-string varnished over, which keeps it from swelling, and is beyond any hair for strength and smalness. The secret I like mightily' (Vol. III., p. 171, Edition I 828). A writer in the "Field" (Jan. 2, 1864), on the subject of silk-worm gut, says: "About three months since, Mr. Geo. Bowness, of Bellyard, shewed me an advertisement of his grandfather's, date i 760 , announcing that the nero article, silk-worm gut, is to be had there. This pretty nearly fixes the date of its introduction into the tackle trade." "-From Bibliotheca Piscatoria.

RELATION BETWEEN THE WEAGIT AND LENGTII OF BROOK-TROUT.

By W. Hridgsox Ellis.

Two summers ago I formed one of a little party of anglers who spent the first three weeks of July and the first week of August on the north shore of Lake Superior. While there we made a number of careful observations of the weight and length of the trout we caught. The result of these observations I have collected in a table, showing the average weight corresponding to each inch in length from thirteen to twenty-three inches, the number of observations from which each average was determined, and also the corresponding weights calculated on the assumption that the weight varies as the cube of the length.

Two conclusions may be drawn from these observations: First, that under similar conditions all trout have the same shape. Secondly, that they grow symmetrically; that is, a five pounder is the same 
shape as a pounder. It is unnecessary to add that these conclusions can only be true under similar conditions. We cannot compare wellfed trout with half-starved ones, nor trout full of spawn with those not in that condition. Nor have we any right to suppose that figures deduced from observation on Lake Superior trout will apply to those caught elsewhere.

The growth of a trout takes place in three dimensions-length, breadth, and thickness; and if the growth is symmetrical, each of these dimensions will increase in the same proportion. Thus, if one fish is twice as long as another, he will also be twice as thick and twice as deep. He will, therefore, be cight times as heavy. In other words, the weight varies as the cube of the length.

If, then, we divide the cube of the length of a trout by the cube of the length of a pound trout, we shall, if the trout grows symmetrically, obtain the weight of that trout in pounds.

We see by the table that the length of a pound trout is thirteen inches, but as this number is only founded on one observation, it will not do to base our calculations upon it.

IVe can, however, from the length of a four-pound, three-and-a half-pound, three-pound, and two-and-a-half pound trout, calculate what the length of a pound trout ought to be. We find that the numbers obtained from all these four starting points agree exactly; and hence we obtain the number 13.17 inches as the length of a pound trout. The cube of 13.17 is 2286; and hence, if $w=$ the weight in pounds, and $l$-the length in inches, of any trout:

$$
z^{\prime}=\frac{k}{2286}
$$

The correspondence between the numbers calculated by this method and those found by observation is rendered still more striking, if we express them graphically, by representing the length on a horizontal scale, and drawing at each inch a perpendicular proportion to the weight.

The result will be a regular curve, almost coincident with that obtained from the formula given above.

Our trout were almost all caught in the lake, off rocky points, and at the mouths of small streams. They were in excellent condition. The average weight of our whole catch was two and a half pounds. 
Curve showing the relation between the length and weight of brook-trout.

The continuous heavy line represents the results of observation.

The dotted line shows where the theoretical curve liffers from that obtained by observation.

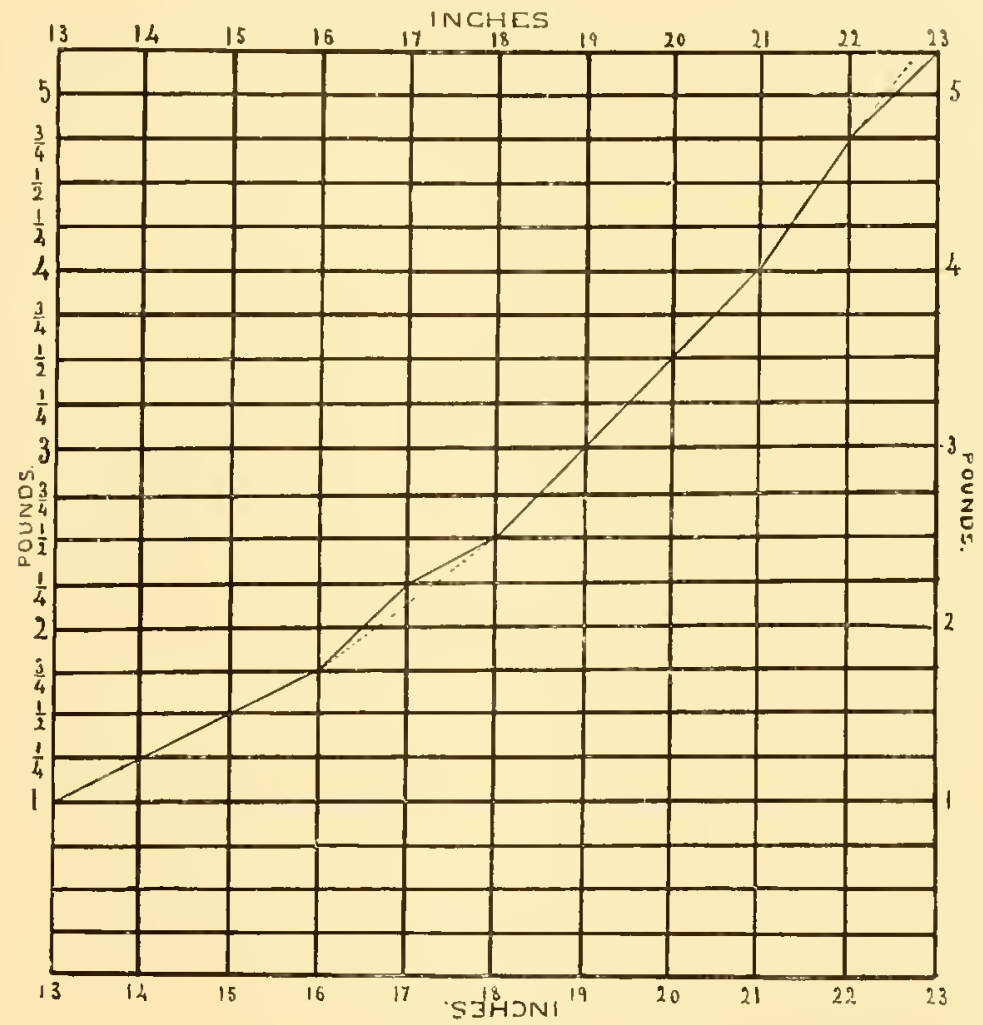

Calculated from for-

Length in inches. Number of observations.

Observed average weight in lbs.

mula $l_{3}$

$z^{\prime}=\frac{3}{2286}$.

$5 \frac{1}{4} \quad 5.32$

$43 / 4$... 4.65

+ . . 4.05

$31 / 2 \ldots 3.50$

3 ... 3.00

$2 \mathrm{I} / 2 \quad . \quad . \quad 2.55$

$21 / 4 \quad \ldots .2 .15$

$13 / 4 \quad . \quad . \quad 1.79$

$1 \mathrm{I} / 2 \quad \ldots \quad 1.48$

I I/4 . . . I.20

.96 
The foregoing article by Mr. W. Hodgson Ellis, of the School of Practical Science, Toronto, Canada, is here reprinted by permission of the author and the editor of "The American Angler," in which journal it was first published.

Mr. Ellis has put to the tests of measure and weight the opinions which Sir Humphrey Davy thus gives expression to in his "Salmonia; or, Days of Fly Fishing." Edit., Lond., $1 S_{5}$ I, p. 32.

Poieres. - This great fish that Ornither has just caught must be nearly of the weight I assigned to him.

Halieus.-Oh, no! he is, I think, above 5 lbs., but not 6 lbs.; but we can form a more correct opinion by measuring him, which I can easily do, the butt of my rod being a measure. He measures, from nose to fork, a very little less than twenty-four inches, and consequently, upon the scale which is appropriate to well-fed trout, should weigh 5 lbs. Io oz, - which, within an ounce, 1 doubt not, is his weight.

Physicus._Oh! I see you take the mathematical law, that similar solids are to each other in the triplicate ratio of one of their dimensions.

HALIFus.-You are right.

Physicus.-But I think you are below the mark, for this appears to me to be an extraordinarily thick fish.

HaLieus.- He is a well-fed fish, but in proportion not so thick as my model, which was a fish of seventeen inches by nine inches, and weighed 2 lbs.; this is my standard solid. We will try him. Ho! Mrs. B., bring your scales and weigh this fish. There, you see, he weighs $5 \mathrm{lb}$. 101/2 oz.

The following relations I found to exist between the length and weight of trout caught in the head-waters of the Androscoggin and Dead Rivers in Franklin County, Maine:

Length.
$83 / 4$ inches . . . . . $1 / 4$ pound.
I I "

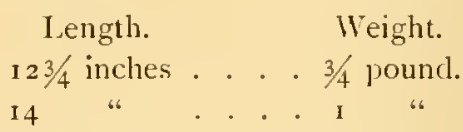

The relations are the results of many measures and weighings, and will serve to supply the length and weight of trout smaller than those given in Mr. Ellis's table.

It appears that the Lake Superior trout are stouter than those of the Maine waters above named, for I have found from many measures that a Maine brork-trout of one pound weight measures exactly fourteen inches from tip of nose to middle of end of caudle fin. Mr. Ellis gives 13.17 inches for the length of a 
pound trout. In applying his formula to the trout of Maine, it should read:

$$
w=\frac{l^{3}}{27+4}{ }^{*}
$$

Sir Humphrey Davy's statement, that an English trout (Salmo fario) i 7 inches long weighs $2 \mathrm{lbs}$., agrees to $1 / 4 \mathrm{lb}$. with the weight of an American brook-trout (Saliclinus fontinalis) 17 inches in length, as given in Mr. Ellis's table. If we take the weight of this sized trout as given by the theoretic curve of Mr. Ellis's diagram, it will differ only $2 \mathrm{oz}$. from the weight of Sir Humphrey Davy's 17 inch fish.

If a stick be notched at distances from one of its ends equal to those corresponding to the lengths of trout of from $\mathrm{r} / 4 \mathrm{lb}$. to $5 \mathrm{lbs}$. in weight, it might serve the double purpose of a club wherewith mercifully to kill the trout as soon as caught by giving him a blow back of the head, and to serve as a standard of measures wherewith our "brother of the angle" may obtain the weight of his fish, and thereby put a bridle on his imagination, and make of himself a truthful man when he speaketh of the great weights of fish caught in certain waters.-[EDITOR.]

* This law will not hold good for Maine trout over five or six pounds in weight, for after they have reached that weight they do not grow symmetrically, but become obese. In a letter from Mr. Ellis, referring to the trout whose weight and length are given in the above table, he says: "Our trout were beautiful, symmetrical fellows, and in capital condition."

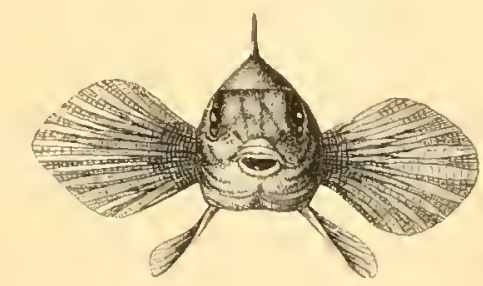




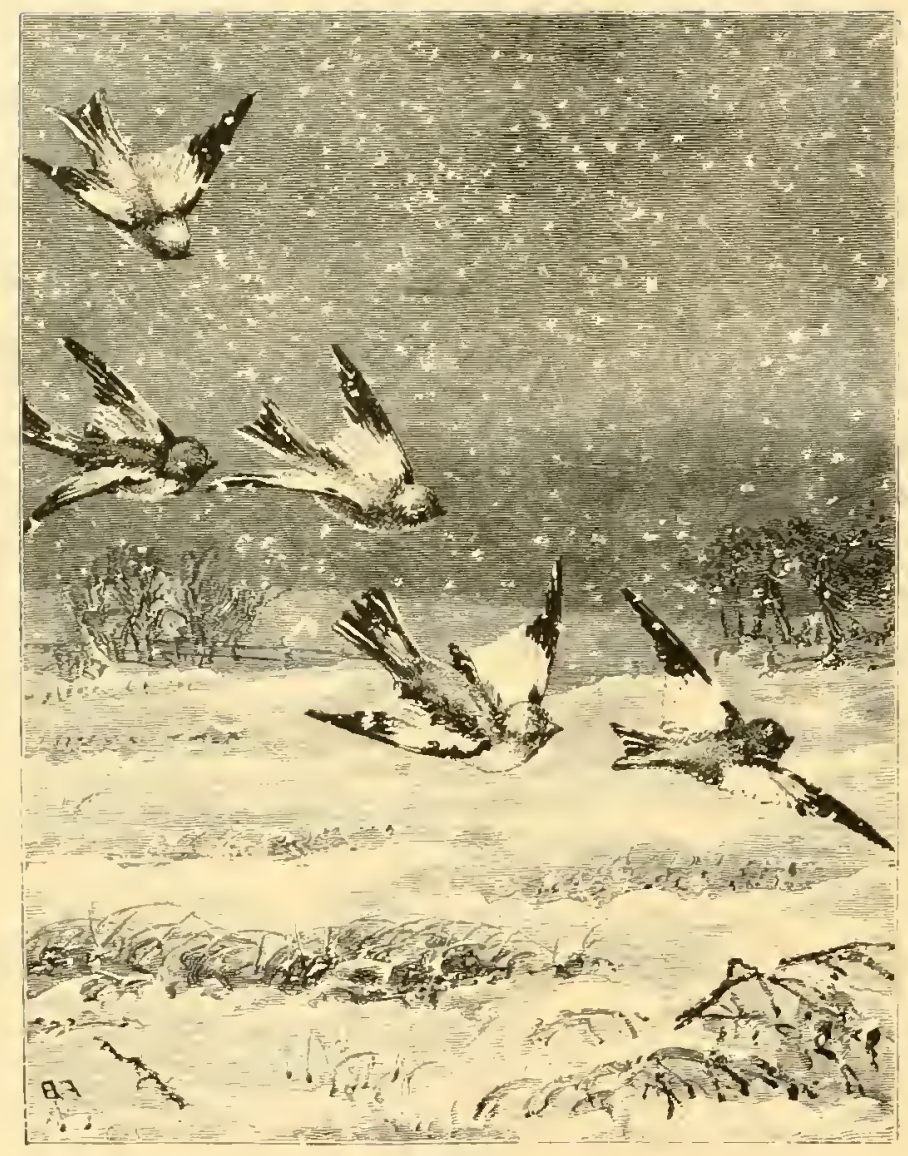




\section{FEATHERED GAME}


Together lit us beat this ample field, Try what the open, siluat the covert rictal.

-Pope. 


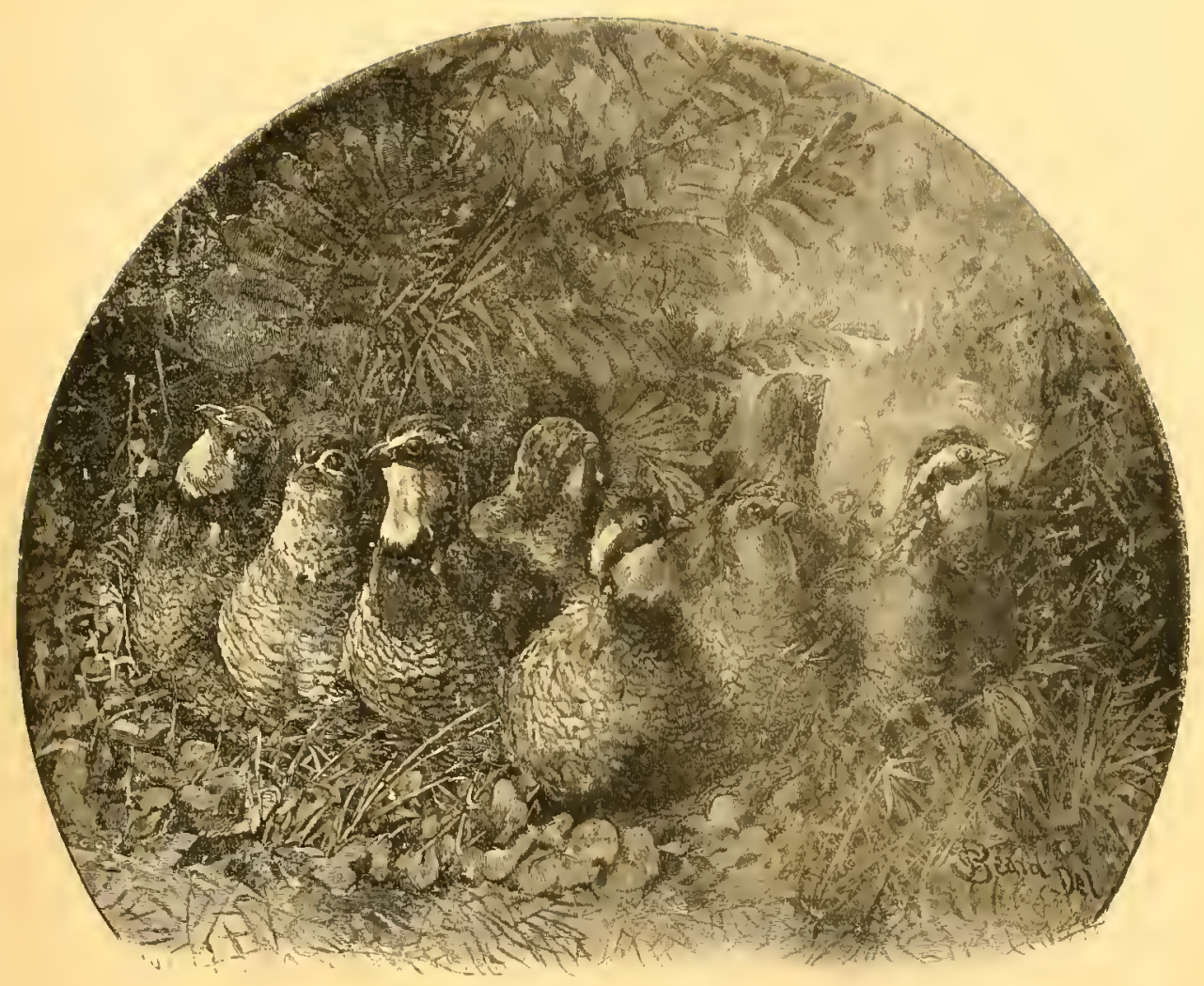





\title{
SOME AMERICAN SPORTING DOGS.
}

\author{
BY WILLIAM M. TILESTON.
}

$\mathrm{T}^{\circ}$

O IVRITE of sporting dogs, or, in other parlance, of dogs used for field-work, without mentioning the fox-hound, would be like representing the play of "Hamlet" with the melancholy Dane himself omitted. Yet 1 an fain to confess that this noble dog is the one with which 1 am least familiar. Certainly, 1 have heard his deep-toned voice while following the trail of a deer in northern woods, but he was only a degenerate scion of a noble race. I have followed another, still more degenerate, when the light snow showed the tracks of poor bunny where she wandered through the swamp in search of bud or berry for her morning meal. But the true fox-hound, without a cross, and bred with care, is a ram canis, at least in the northern States. And yet the fox-hound - certainly if we judge by the proclivities of the original settlers of different regions - was probably the first dog introduced into this country. It is not likely that the Pilgrim Fathers were given to the sports of the field; and yet what glorious shooting there must have been in the old commonweath when the Mayflower first dropped her anchor. How the ruffed grouse must have bred in the deep pine-woods! How the snipe must have swarmed in the meadows! and the woodcock in the swamps! And the deer, undisturbed by the sound of fire-arms or the bay of hound, how they must have increased and multiplied!

But whatever the Roundheads did, the Cavaliers who went to Virginia certainly carried their amusements with them, though tradition says not whether John Smith had dogs with him, or if the gentle Sir Walter discovered the nicotian weed through the medium of 
a sharp-nosed hound. Still, the fox-hound was introduced into Virginia at a very early day, and in that State, and perhaps in one or two others, he is to be found, and is still bred in comparative purity, - not that I would infer that pure-bred hounds are not to be seen elsewhere. Individuals are occasionally to be met with, and in the pack of Mr. Joe Donahue, who hunts near Hackensack, are to be found some fine specimens. Nor is it of any use for the most ardent fox-hunter of to-day to import dogs from England. It was not until the latter part of the seventeenth century that fox-hunting and the breeding of fox-hounds were pursued systematically in Great Britain, and it was probably in the middle of the succeeding century that the sport was brought across the water. It is a well-known fact that foxhunting was a fashionable amusement in Virginia long prior to the Revolution, and it is not improbable that the old style of Spanish pointer, then fashionable in England, shortly followed the

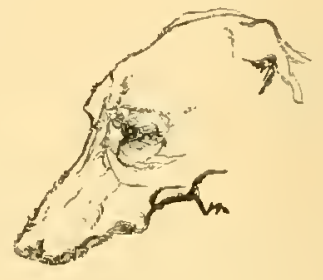

DEEK-HOUND. fox-hound. To fox-hunting, however, we must give the first place as a sport followed with the aid of a dog, and in spite of vicissitudes and tribulations of every kind, the southern gentleman still follows his pack, and enjoys the chase with the same zest as his forefathers. The

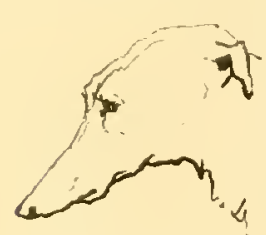

GREYHOUNI) fox-hound of to-day in America, however, is a very different animal from the hound now fashionable in England, and the choicest draft from the Quorn or the Pytchley would be found almost useless in a country so thickly timbered and with such high railfences as ours. In the earlier days of the colonies, the hounds then imported were much better suited to the needs of the sportsmen. A slow dog, such as was fashionable in the days of Squire Western, before hunting came to more closely resemble steeple-chasing (as it does now). was the dog which found favor with our Virginia grentlemen, and whose characteristics have been since adhered to. Not but that speed is desirable in a hound, but in our country it would be difficult, if not impossible, to follow him; and the introduction into the pack of one $\log$ such as is now used in England would most probably result in spoiling the sport.

Whatever may have been the quality of the first hounds imported, some of the bluest blood of the English kennels was subsequently 


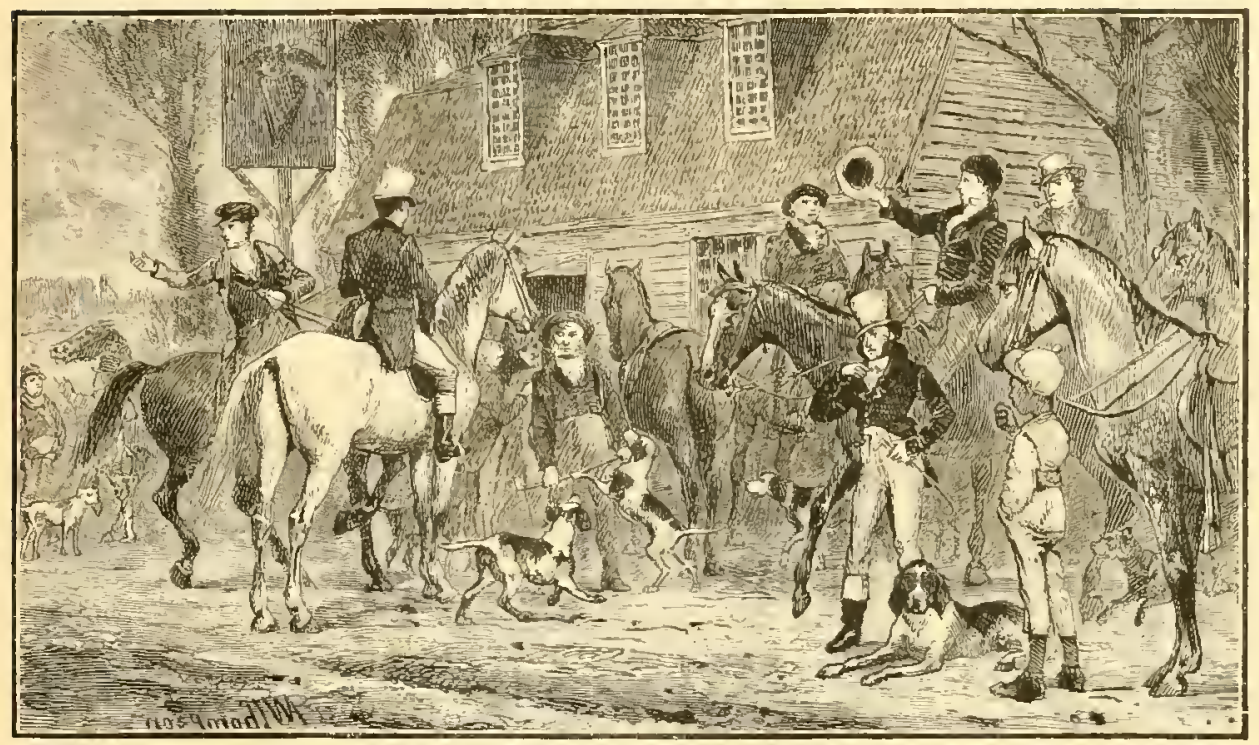

THE MEET AT THE "HARP AND E.GGE," NEAR PHLADELPHIA, I823.

crossed with it. In 1825 , Robert Oliver, the merchant prince of Baltimore, imported some celebrated black, white and tan hounds from Ireland, whose descendants are still highly prized. Subsequently, Commodore Stockton was presented by Sir Harry Goodricke, master of the Quorn, with several couples from that pack, some of whom were given to the late Mr. John S. Skinner, of Baltimore, who sent them to Wade Hampton, Esq., - father of the sentleman at present bearing that name, - who used them for hunting cleer in the neighborhood of the White Sulphur Springs, Ia. Afterward they went to his estate in South Carolina, where their blood has been mixed with that of the older strains until probably none of it remains in its purity. Fox-hunting, however, was not entirely confined to the Southern States, as will be seen by the following notice, which appeared in the "United States Ciazette," published in Philadelphia, on October 29, $18_{23}$ :

TO GENTLEMEN SPOR'TSMEN-A FINE RED FOX (LATELY caught) to be started from the house of Mr. James Greenham, sign of the Harp and Eagle, near the Upper Ferry, Schuylkill Bridge, on Friday, the 3 tst inst., at half-past one o'clock, P. M. Gentlemen sportsmen desirous of attending said chase will be thankfully received, and are particularly requested to bring their dogs, as this is for no benefit, any more than hoping said sportsmen will put their mites toward paying the cost of this advertisement. 
The fox appears to have been only a "bagman," and the hounds a scrub pack selected for the occasion. I have been writing now only of the hound as he is used in fox-hunting; in almost every section of the country where deer are found the fox-hound is used for hunting them. Here speed is most desirable, as the hunter does not expect to follow his dogs, but takes his station by some run-way or pond where the deer is almost sure to pass. Great strength is also a capital quality, as a buck at bay is no mean antagonist, and a first-class deer-hound should not only possess the intelligence but the ability to catch a deer by the hind leg and throw him.

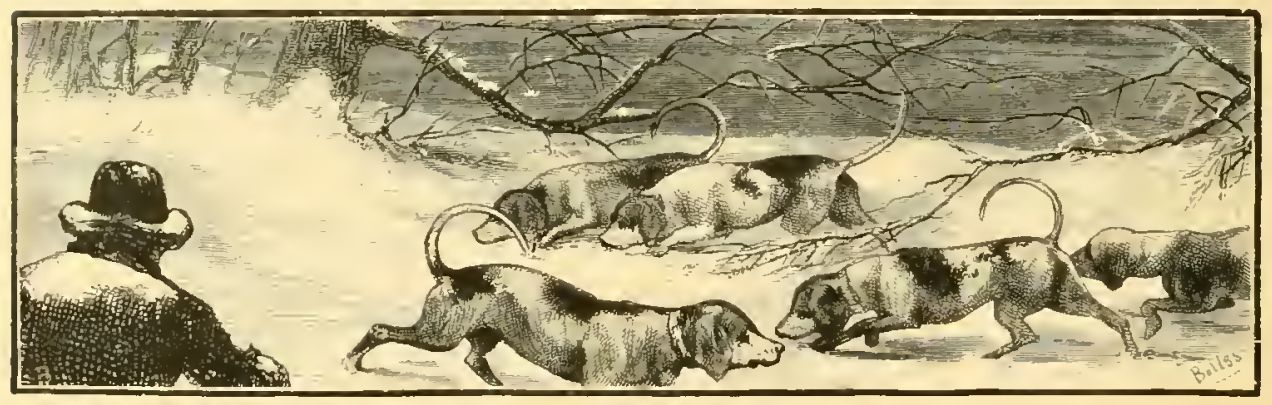

RABBIT-HUNTING WITH BEAGLES.

Fox-hounds, generally mongrels, are also used for hunting rabbits (hares) in this country; but a much more valuable dog for this purpose, and one which is fast coming in demand, is the little beagle, a miniature fox-hound, being from ten to twelve inches only in height at the shoulder. Merry workers they are, and to see a pack of them working on the scent of a hare (for we have no true rabbits, wild, in this country) is worth going miles to see. I am astonished that some gentlemen do not get together a pack of beagles. They can be followed on foot, and there are numbers of places within an hour or two's ride of New York where hares can be found in ample quantities for sport. Somewhat similar to the beagle, in size at least, although they differ in having crooked fore-legs, is the dachshund, a dog of German extraction. (John Phonix said of some one bred in a like manner, that his father was a Dutchman and his mother a duchess.) Dr. Twaddell, of Philadelphia, has some of pure breed, the finest in this country.

As a rule, however, nowadays, when one speaks of a sporting dog, he is generally supposed to refer to a dog used in connection 


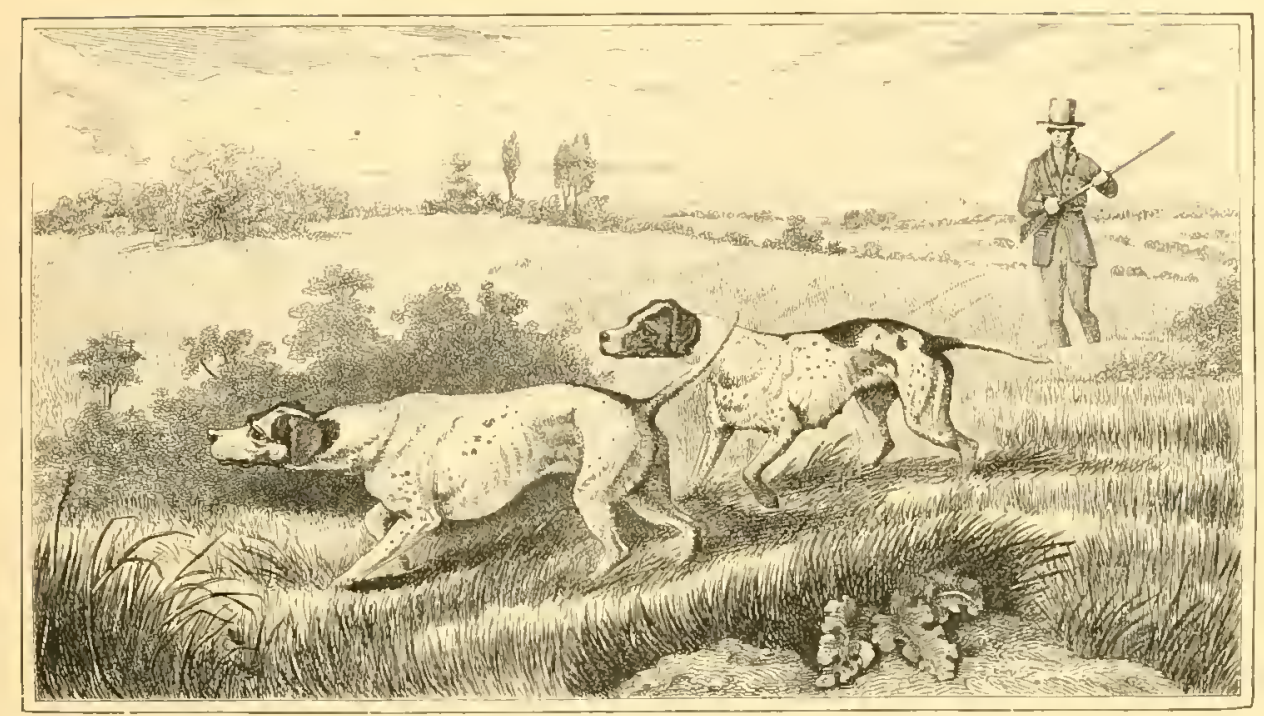

POINTERS OF FIFTY YEARS AGU, FROM AN OLD PRINT.

with a gun; and it is more particularly with those varieties that I feel at home, and regarding which I propose to write; premising that I am addressing the general reader as well as those young sportsmen who for lack of time and opportunity have yet to learn their A, B, C's in dog matters. The interest in dogs, particularly those used in shooting, has of late so increased that scores of wouldbe critics and authorities have sprung up. Without pretending to the eruclition of those professors in canine lore, my object is to impart to the class first mentioned such information, the result of my own experience, as will aid them, not only in deciding what description of $\operatorname{dog}$ may best suit their purposes, but also in keeping their dogs in health and right condition. To further assist my endeavors, I have selected for illustration such dogs as are types of their various classes, and who have attained celebrity on the showbench and in the field. Those who are not in the habit of reading the sporting literature of the day - and I mean by this the literature provided for the sportsman, not the sporting man-would be surprised were they made aware of the amount of paper spoiled and ink spilled in the wordy warfare which has been carried on for two or three years past, relative to the merits and demerits of various strains. Nor is the discussion confined to strains alone. I find myself at the outset called upon to decide, or at least so to describe 
that the reader can decide for himself, upon the relative merits of the two principal varieties of the dogs over which we shoot our game: namely, the setters and the pointers.

If our country were more circumscribed in its limits; were our shooting confined, say, to the States of New York, New Jersey, and Pennsylvania, the question would be one easily solved; for, if we except snipe-shooting on the meadows, most of our gumning is done in coverts: filled, perhaps, with low growing underbrush or thick and tangled vines and briers. It is true that quails feed in the stubble, and the bevies are usually first flushed in the open, but they immediately seek the recesses of swamp or wood, where they must be followed and routed singly if the bag is to be filled. The woodcock, the king of our game birds, haunts, in summer particularly, only the densest cover, where, by some little stream or marshy thicket, he finds in the yielding ooze and soft earth the worms and larva which form his diet. It therefore stands to reason that the dog for our purpose would be one like the setter, whose thick coat of hair would enable him to withstand the attacks of briers and brush, and all the effects of wet and cold; whose feet, provided by nature with tufts of hair between the toes, carry him without injury over the sharp fints of the mountain-side, where the ruffed grouse (partridge) loves to bask among the old logs and dead trees.

But our country is not all briery thicket or rough mountain-side. At the West there is the "boundless prairie," the home of the pinnated grouse, or "chicken"; where "cat" or "bull "briers are not found, and where wading is comparatively unknown. Here the sleek-coated pointer is in his element; for "chicken"-shooting in most States begins in August, and the heavy-coated setter suffers from the heat and want of water, while the pointer with his close hair hunts on, asking only for an occasional lap of water, until the day's work is done. In many places also the Canada thistle abounds, the burrs of which become so entangled in the coat of the setter as to cause him perfect misery. I have quite recently known of several instances of dogs positively refusing to work until the burrs were removed. In all such places the pointer is undoubtedly the best dog to shoot over. But all sportsmen do not go to the prairies in August, nor is the pinnated grouse the only game bird to be found there. In the latter part of September the ducks and snipe begin to 


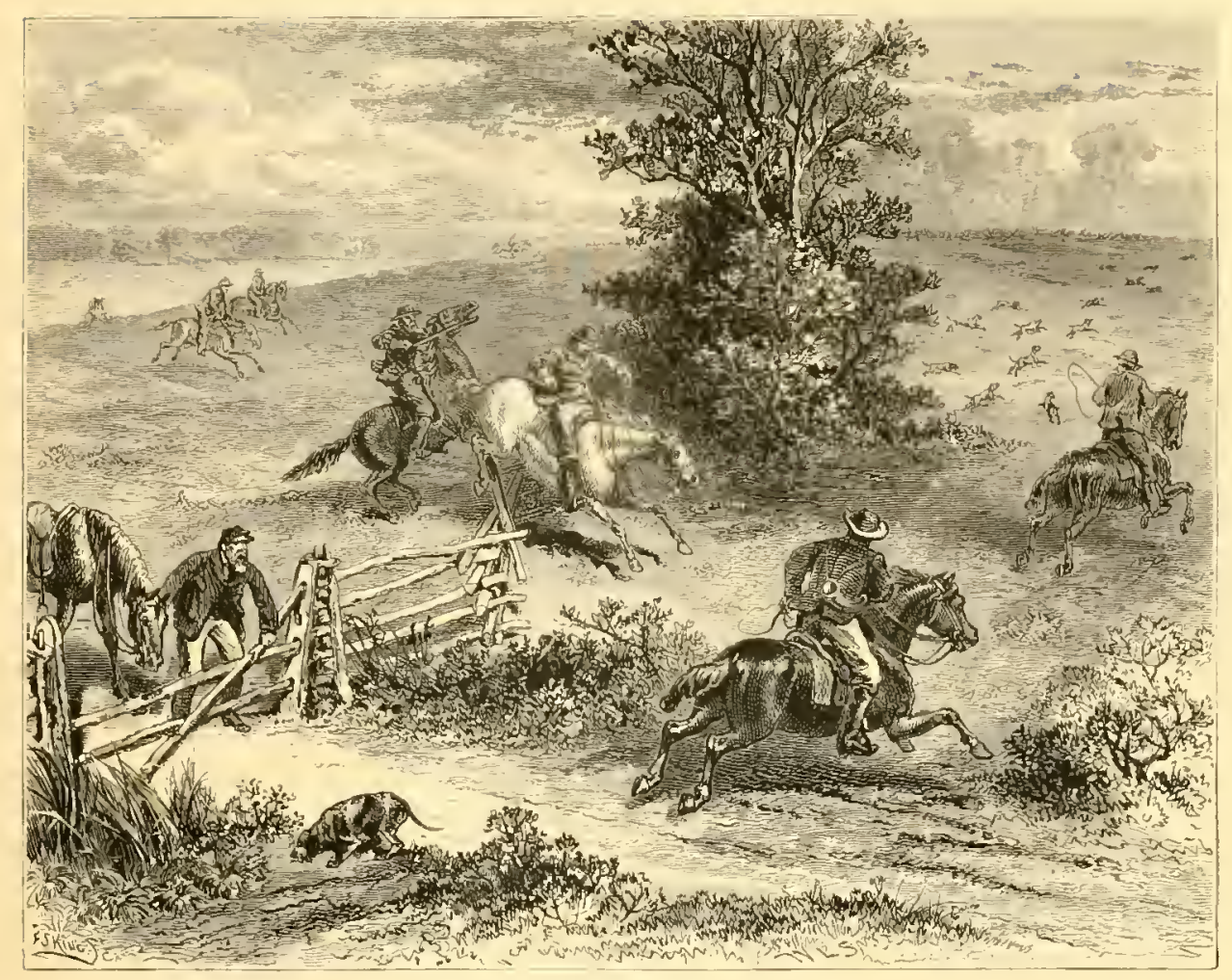

FOX-HUNTING IN THE SOUTH.

arrive on their annual southern migration; and then we have not only the cold weather which makes the setter comfortable in his thicker jacket, but we must go into the wet lands to find snipe, and the ponds or lakes for ducks. Here the setter undeniably has the advantage; for although the pointer will go into the water if ordered, or, if highly bred, into the most tangled thicket, his shivering and shaking discomfort in the one instance, and his lacerated and bleeding skin in the other, make him an object of compassion to a consiclerate master, and militate against the pleasures of the hunt. But the question is by no means, as yet, decided against the pointer. There is another thing in his favor which is well worthy of consideration before we arrive at a conclusion, and that is the comparative ease with which he is broken, and his excellent quality of retaining his education when once it has been fully perfected. Indeed, so much am I impressed with the value of that quality, that I should almost be tempted, in spite of a strong penchant for the setter, to suggest to 
a friend who would shoot but occasionally, and desired to break his own dogs, to choose a pointer in preference. But to those who are skillful in handling dogs, and who are so situated as to be able to keep their dogs in work during the shooting season, there can scarcely be a doubt that the setter is the better dog. Certainly he is the choice

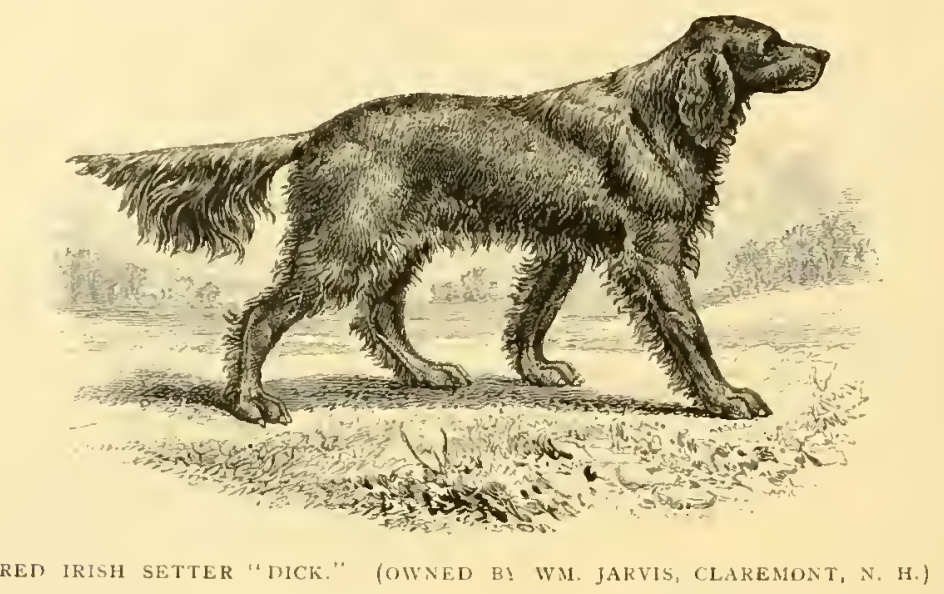

of the larger number of sportsmen, although it must be admitted that fashion prevails here as everywhere, and the setter is the fashionable dog of the day. Of course, in both setters and pointers there are exceptions to the general rules 1 have given, and individuals of either variety are to be found possessing the best qualities attributed to both.

Leaving the question of superiority, let us look at the different breeds and strains of both setters and pointers to which the choice must be narrowed down. There are now in this country two public tests for sporting dogs at which their qualities may be decided,bench-shows and field trials. At bench-shows dogs are exhibited in raised pens or boxes, and being taken before a duly appointed and presumably competent person, are judged by a certain standard for each variety, which I shall presently mention. This test, of course, is similar to one which a race-horse would pass in his box, and although it might be an indication, through form, of speed, endurance, and intelligence, it would be no index of the possession of those two great requisites, "nose," or scenting power, and "stanchness," without the former of which the most highly bred dog would be as valueless as the most worthless cur. At field trials dogs are 


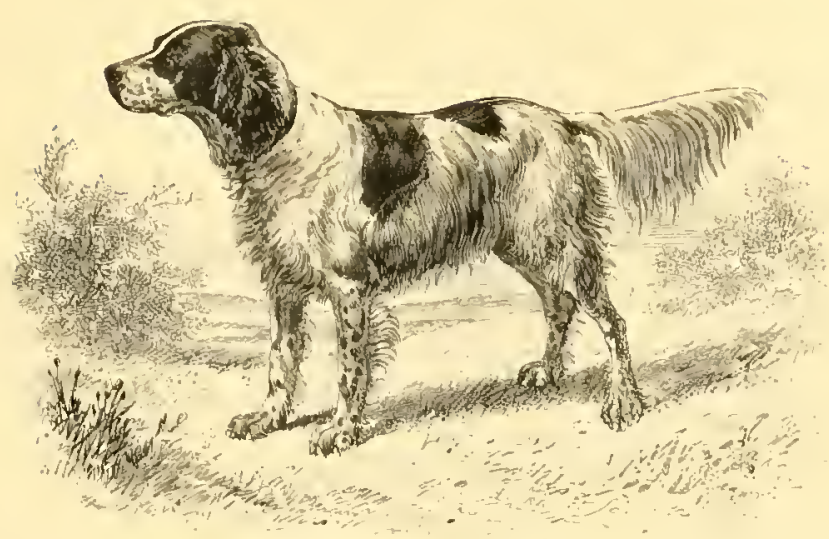

BLACK AND WHITE SETTER "GLY MANNERING," WINNER OF THE STUTT SPECIAI. PRI2E FOR BEST "NATIVE ENGI.ISH" SETTER AT THE CENTENNIAL BENCH-SHOW. (OWNED BY DUDLEY OLCUTT, OF ALBANY, N.Y.)

pitted against each other on their game, and judgment given through a certain scale of merits and demerits: they are awarded points for pointing their birds, for stanchness, pace, style, backing, and retrieving; or, deprived of them, for flushing birds, for backing, or for refusing to drop to shot or wing. It is obvious, however, that in the limited time allowed for a "trial," that the best dog might not always have the same opportunities to show his qualities as one his inferior. Still, when the rules shall have been perfected, the field trial will be a satisfactory test of the qualities of a dog for the purposes required.

Setters are divided into three classes, the English, Irish, and Gordon; these being usually divided again, at bench-shows, into native and imported classes. It is principally over the English setters - and the term is supposed to include those of every color but red, which would indicate lrish blood, and black-and-tan, which is the color of the Gordons - that the fight has been carried on, one side claiming that the native $\log$ - that is, one whose pedigree could not be traced directly to some imported celebrity - was a mongrel, and the other maintaining with equal persistency that the "blue blood," or imported dogs, were utterly unfit for our work, and that the careful but in many instances "in and in" breeding had resulted in deterioration. Of course both sides were, to a certain extent, right ; but, as is usual in violent partisanship, overeagerness had carried the matter beyond solid argument, and the outsider was left as much as ever in the dark. It must be admitted that, until 
the inauguration of bench-shows, breeding in this country, as a rule, was conducted in a most careless and slipshod manner, yet 1 believe we had strains of dogs, as well as individuals, which, even allowing each the benefit of its own ground and training, were fully equal, certainly as field performers, to any across the water. That we

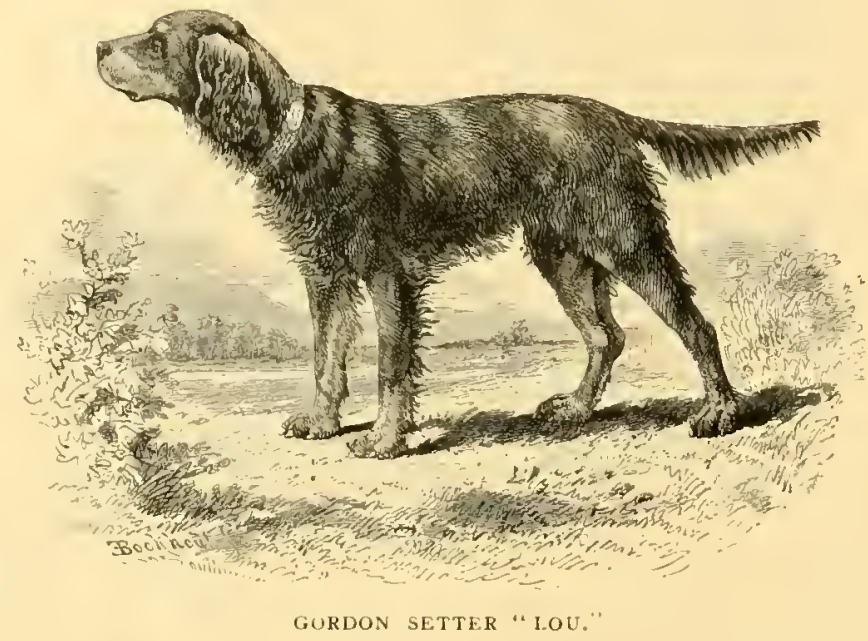

would have continued to possess them I very much doubt. Careless breeding, with no regard to the selection of the fittest, and no attention to pedigrees, combined with the fact that there are ten men today who shoot over dogs to where there was one twenty-five years ago, would soon have worn out the stock, had it not been renewed and regenerated with imported blood. There is no comparison between the amount of work demanded of our dogs and that required in England. Here, the average sportsman owns but one dog, and that one is expected to work from morning until night, day in and day out; while across the water no one thinks of going to the moors without at least half a dozen dogs, which are worked alternately in braces. Nor are their dogs taught or allowed to retrieve. A curlycoated retriever follows at the keeper's heels and brings in the dead, - British sportsmen having a theory that fetching dead birds injures the dog's scenting powers. The crossing of these "blue bloods" with the best of our natives is the true theory of breeding by which we will perpetuate the best qualities of both. Unfortunately, however, if a dog comes with a long pedigree from a widely advertised English kennel he is bred too indiscriminately without regard to his 


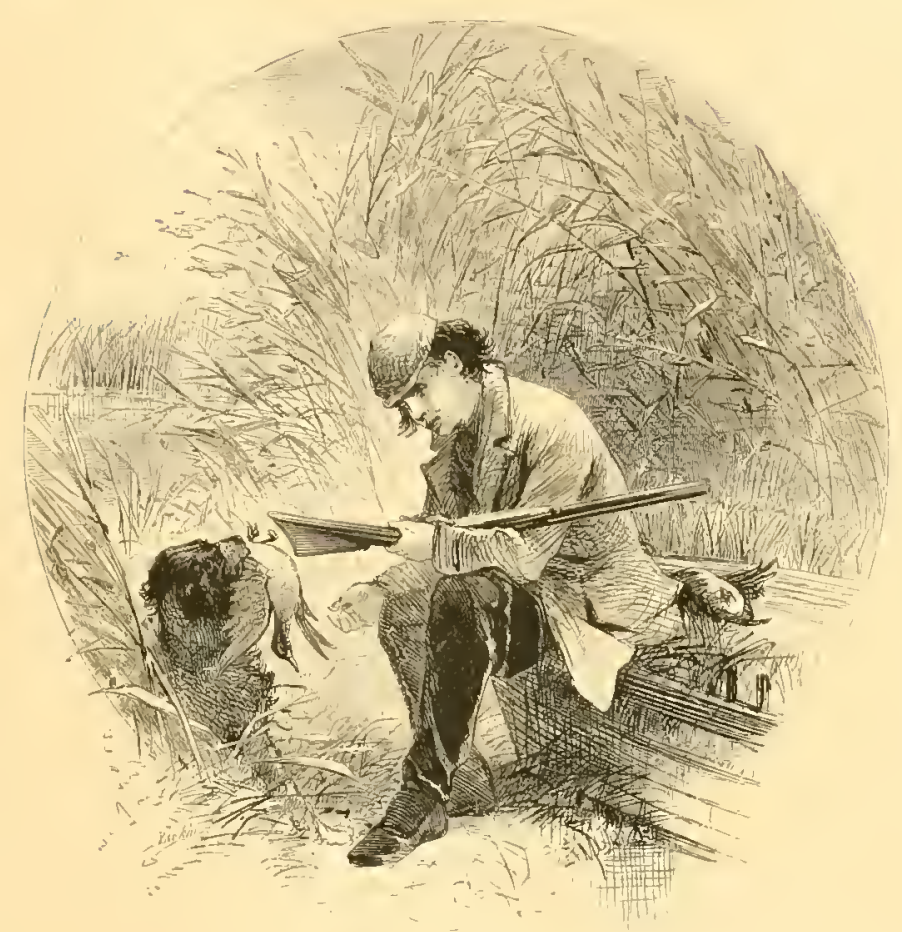

RETRIEVING.

qualifications for begetting good offspring, and much disappointment is the result. "Imported" is the magic word which covers a multitude of imperfections. Fortunately, very many dogs of well-known excellence have come to this country, and now that the matter has been fully discussed and a proper impetus given, our breeds are rapidly improving, and I believe it is an admitted fact that we have field dogs whose superiors are not to be found. As a specimen of the high-bred dog from imported stock, I have chosen "Guy Mannering," bred by Charles H. Raymond, Esq., of Morris Plains, N. J. This dog is the produce of "Pride of the Border" and "Fairy," - a pair of celebrated Laveracks, imported by Mr. Raymond from the kennels of the gentleman whose name is given to the strain, and who las bred them in purity for more than fifty years.

The setters known as the native English (a misnomer, as native American would be more proper) are generally, in color, orange and white, lemon and white, black and white, red and white, liver-colored and white, or all black; although they are to be found of a liver and 
tan or, in fact, of almost any known combinations of the colors mentioned except those of orange and lemon and black. The points by which they are judged in this country-perfection in these points is supposed to make the acme of a dog-are as follows:

"Head long, and somewhat narrow, with a fair distance from the eye to the end of the nose, which should not be snipy or ant-eater like; skull a little prominent; ears set on low and flat, not thrown back; the least stop just above or across the eyes; jaws level, with a little fullness of lip just at the back of the mouth; eye large but not protruding, with a quick appearance; neck thin and deep at setting-in on chest, moderately long and slightly arched, with no appearance of throatiness; shoulder-blades long and well receding at the points, with a flatness of shoulder-sides not noticed in any other dog; narrow at shoulder-point, but great muscular development in the shoulderblades and fore-arms; chest very deep, not over narrow between the fore-legs. Forelegs strong and muscular in the fore-arm; leg straight, with a slight, elastic-like appearance; foot moderately round, but oftener flat; back wide, deeply ribbed, lowering slightly from the shoulder to the hip; loins wide and very muscular; stifles full and well developed; hock well bent; stern [tail] carried almost level with the back, a moderate length, well flagged from the root, wearing off to nothing at tip of stern; coat wavy or straight, fine and silky, free from curl, especially on hind-quarters."

The Irish setter is a dog now fast coming into fashion with us. He is wiry and enduring, but headstrong, requiring a deal of work to keep him in command. When well bred they are remarkably handsome $\operatorname{logs}$, as will be seen from the portrait of Mr. Jarvis's "Dick." His bench-show points are as follows:

"Head narrow, widening a little in the forehead, skull slightly arched; ears a fair length, slightly folded, hanging straight, set well back in the head, and moderately feathered; eye hazel or lrownish, with a sensible and loving look, not prominent ; nose dark flesh-color, or black; chest but moderately wide, with great depth; back straight, but slightly receding to the hip, with good loins and well-bent stifles; stern carried slightly up, not much flagged, but slightly; coat inclined to be harsh, not soft and silky, smooth or wavy, and thick, but not too long; color a deep mahogany-red, but not any black; white, however, is allowable in some Irish breeds on chest and legs and neck."

The Gordon setter, in spite of a well-known English authority, from whom indeed we have received our points for judging, docs possess the "gro-ahead qualities now required." How any one who has shot over well-bred Gordons can make such an assertion, I am at a loss to imagine. Those that I have seen in the field have been dogs of remarkable endurance, and the rich beauty of their silky blackand-tan coats, and their affectionate dispositions, are unsurpassed 
by any other breed. "Idstone" says he has seen better setters of the black-and-tan than of any other breed. Their heads are a little heavier than the English setters, they have more flew, are deeper in

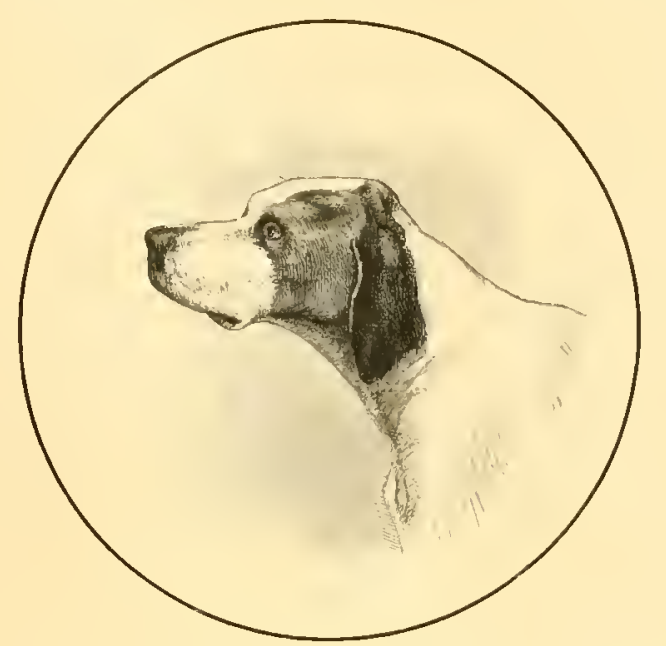

HEAD OF POINTER "SENSATION." (OWNED BY WESTMINSTER KENNEL, CLUB, NEW-YORK CITY.)

chest and body, with more bone; otherwise their points vary but little. Much, however, depends upon their coats, which must be a glossy black with a slight wave allowed, but no suspicion of a curl, and the tan with which they are marked should be of the richest red. Before leaving the setters, a word as to their origin may not be out of place. Mlost authorities claim that the setter was known in England long before the pointer was introduced, he being a direct descendant of the spaniel. In fact, they are spoken of as "setting spaniels," being used, before the introduction of fowling-pieces, to aid in securing game by first finding the birds and then "setting" or pointing in that position while the net was passed over dog and birds together. In time, after the introduction of the pointer, they came to point their game in the same manner, although even now we occasionally find a setter that drops or crouches to the ground immediately upon scenting his birds.

Although the colors of pointers at the present day are quite as varied as those of setters, there is but little doubt that the color of the old Spanish pointers, from whom they are all descended, was a liver and white. Color is quite a matter of fancy, but I confess to a preference for orange and white in the setter, and lemon and white 
in the pointer. But whatever the color, the good points of this dog are to be seen almost at a glance, from his build and the shortness of his coat. The fashionable pointer of the present day is a very different animal from his heavy, lumbering ancestor. Nany years agro, a cross of fox-hound was introduced, and to that we are indebted

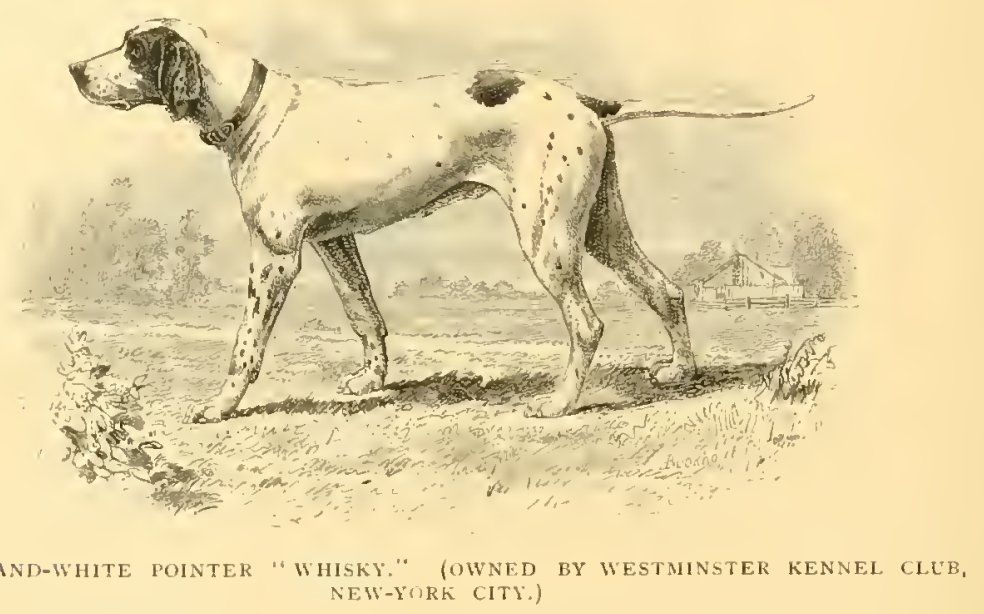

for the lighter-framed, more elegant animal we now possess, and probably also for the variations in color from the old orthodox liver, or liver and white. "Idstone" says that the pointer should be modeled to a great extent after the fox-hound, but that his head should be finer, his nose square, the upper lip slightly in excess of the lower, the corners of the mouth well flewed. The forehead should be raised but not round; it should be depressed in the center, almost forming a ridge $[i . c$, the furrow down the middle of the head separates it into two slightly rounded halves]. There should be a well-pronounced "stop" between the eyes; the ears should be thin, flexible and silky, of moderate size, set rather far back, but lying close to the head. The nasal bone should be depressed in the center, and should turn upward slightly. The head of "Sensation," in the cut on the preceding page, conforms more closely to these conditions than that of any other $\operatorname{dog} I$ have seen. The other proportions by which the pointer is judged in this country are as follows :

"Body rather inclined to be long, but not much so, thickening from the head to the set-in of the shoulders no looseness of the throat-skin, shoulders narrow at the meeting 


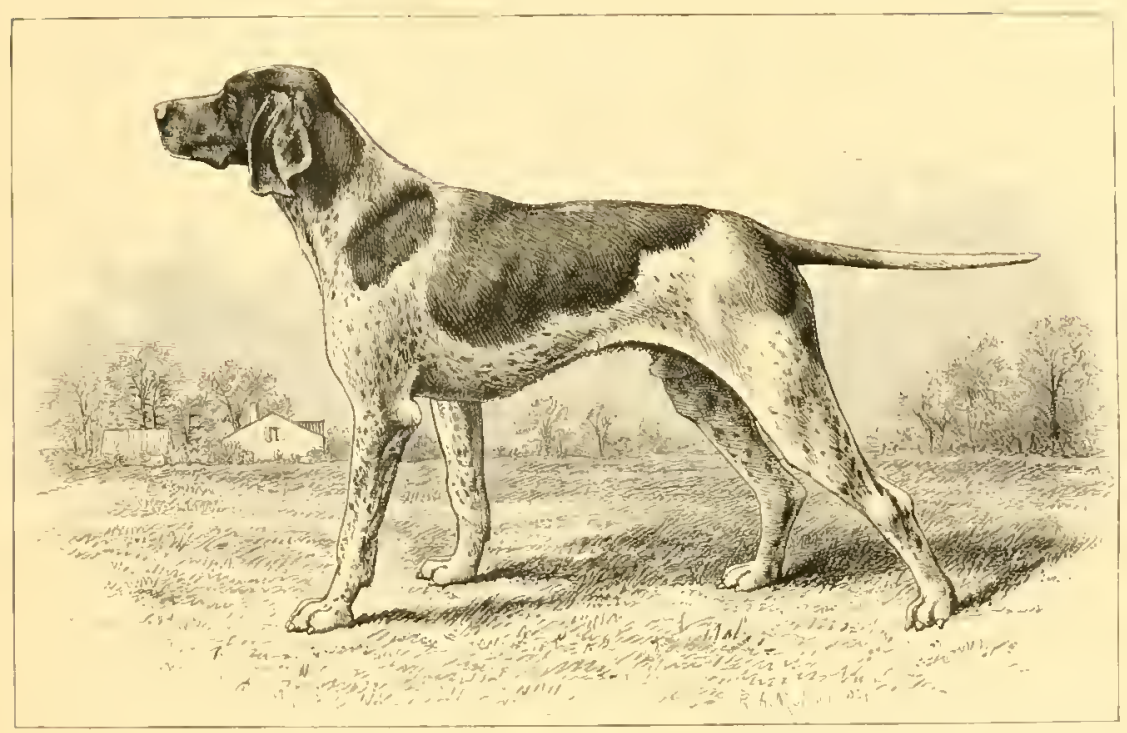

LIVER-AND-WHITE POINTER "RANGER" (OWNED BY S. B, DILLY, LIKE CITY, MINN.)

of the blade-bones, with a great amount of muscle, long in the blades, set slanting, with arm of the leg strong and coming away straight, and elbow neither out nor in; the legs not great, heavy-boned, but with a great amount of muscle; leg jressed straight to the foot, well rounded and symmetrical, with foot well rounded, that is, the fore-legs and feet; chest moderately deep, not over-wide, but sufficiently wide and deep to give plenty of breathing room; back level, wide in loins; deeply ribbed, and with nibs carried well back; hips wide and full of muscle, not straight in the bock, but moderately bent; stifles full and well developed; the stern nearly straight, going off tapering to the point, set in level with the back, carried straight, not above the level of back; symmetry and general appearance racy; and much beauty of form appears to the eye of a real pointer breeder and fancier."

At our bench-shows, pointers are divided into two classes, those weighing under, and those over, fifty pounds. It is difficult to name the period when pointers were first brought to this country. I have traced some as far back as 1810 , when a gentleman from Sheffield, England, brought a brace to Bucks County, Pennsylvania, where the "bird-dogs" were objects of great curiosity: I know of no one at the present day who has bred them more carefully or for a longer time than Mr. Frecterick Schuchard, of New York. For high courage, keen nose, and most perfect stanchness. I know of no pointer the superior of Mr. Dilly's "Ranger," - a dog who is worked on the prairies almost every day of the season, and of whom it is said by his admirers, "he never flushed a bird." 


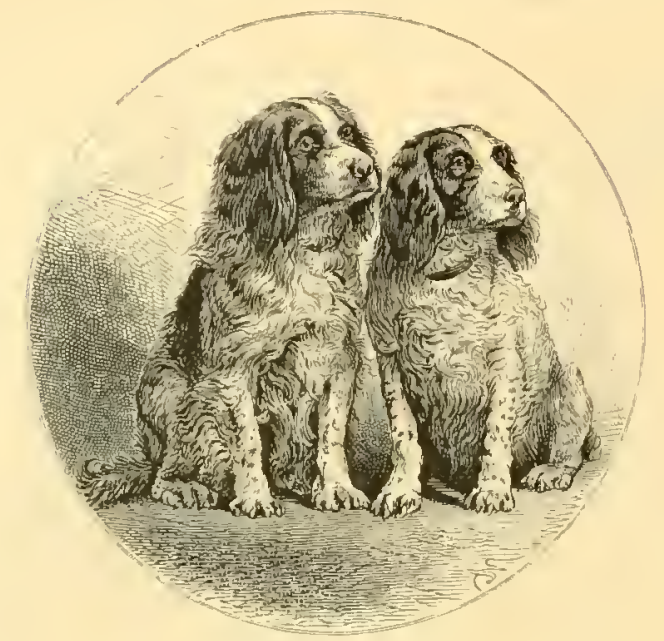

COCKER SPANIELS "SNIP" AND "JULIET." (OWNED BY S. J. BESTUR, HARTFORD, CONN.)

There is a dog which is destined to become a great favorite in this country, and I doubt not that we have a much larger sphere for his usefulness than they have in England. This is the little cocker spaniel. He is a merry, active worker, not pointing his birds, but giving tongue when he strikes the scent, which he follows until the bird is flushed. In our thick, almost impenetrable covers, particularly where woodcock are shot, in summer, the cocker is especially valuable, as he can make his way under briers and into places where a larger dog could not penetrate. In such shooting the dog is almost always out of sight of his master, and a stanch setter or pointer might be lost on his point; whereas, the cocker, by giving tongue, apprises the gunner, not only of his own whereabouts. but also of the presence of grame. Could I countenance such an unsportsman-like proceeding as shooting a bird while sitting, 1 might say that they would be useful for treeing ruffed grouse instead of the mongrels now used; but their real value is in woodcock shooting. The illustration of Mr. Bestor's fine imported dogrs sufficiently describes their general appearance. There is another variety of spaniel, the clumber, which is deservedly popular in England, as possessing all the advantages in cover shooting of the cocker, but hunts mute. They are rare even on the other side, and the only pure specimens I have seen in this country are those imported by Mr. Jonathan Thorne, Jr.. of Duchess County, in this State. As spaniels are not expected to point their game, they should be broken to range close, never more than twenty 
or thirty yards away from the gun, and always to "come to heel" or "down charge" at the report.

The dogs to which 1 have hitherto referred are those used almost exclusively for upland shooting, for although setters, or even pointers, if taught, will retrieve from water, yet when one is to follow

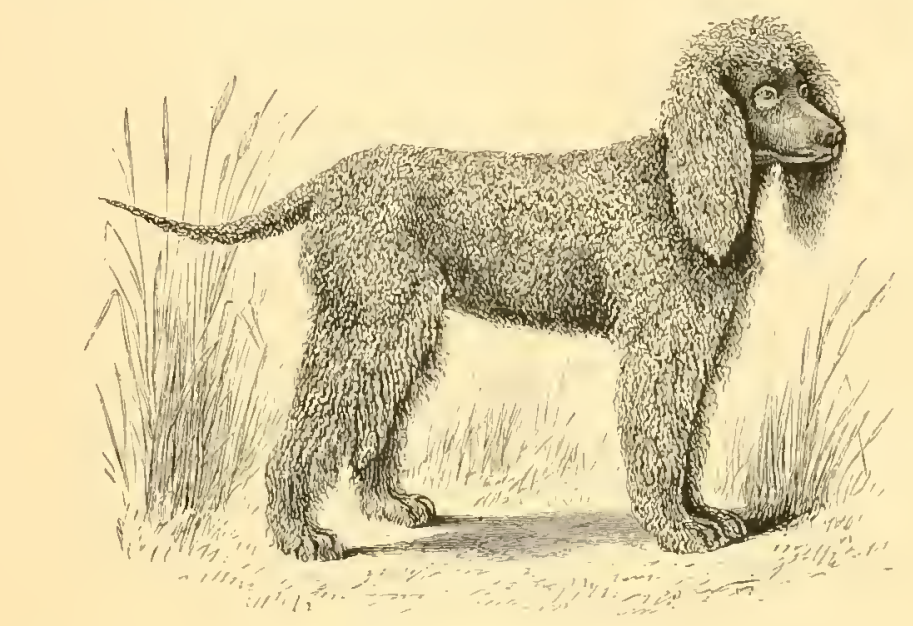

IRISH WATER-SPANIEL "SINBAD.

(OWNED BY J. H. WHITMAY, CHICAG(), H.L.)

duck-shooting to any great extent, whether on western lakes or on the waters of Chesapeake Bay or Currituck Sound, it is much better to be provided with a dog particularly adapted for the purpose. In fact, I once almost ruined several good setters in California by allowing them to retrieve constantly from water, the result being that all were afflicted with canker of the ear. At the present writing, my Gordon, "Lou," is displaying symptoms of the same complaint - the result, I believe, of unlimited swimming and diving last summer in the waters of the Great South Bay.* The pure Irish water-spaniel is rarely met with in this country. Mr. J. H. Whitman, of Chicago, a portrait of whose "Sinbad" is given, probably has the finest

* As canker of the ear is a very common disease, always indicaterl by the dog shaking his head and scratching at his ears, I would mention here that it can be easily cured by the following lotion :- Coulard's extract and wine of opium, of each one-half ounce; sulphate of zinc, one-half dram; water, seven ounces; mix. The ear should first be cleansed thoroughly with suap and warm water, and a little of the lotion injected twice a ilay.

N. B.-Since the foregoing was written, "Lou" has been entirely cured by this remerly. 
kennel of them. At the West, where much of the duck and goose shooting is done where the mud is deep and the wild rice is heavy, a dog of great strength and determination is required to bring in, not only the dead, but the many wounded birds which otherwise would be lost. The water-spaniel does all this, and withal is as docile, obedient, and intelligent as a French poodle. The head should be crowned with a well-defined top-knot, coming down in a peak on the forehead; the body should be covered with small crisp curls; the tail should be round and without feather, and the whole dog a dark liver-color.

The Chesapeake Bay dog, of which there are now three accepted types, is a dog of which even more is expected. He must have strength to breast the heaviest seas and bring in a goose; he must fight his way through broken ice, and if he meets a piece too large to scramble over he must dive under it. Several families in Maryland have had in their possession for many generations what each claims to be the genuine Chesapeake Bay dog, and at the late bench-show in Baltimore a compromise was made, and a classification agreed upon, by which each of the types is hereafter to be recognized. These are to be, first, the otter dog, of a tawny sedge in color; with very short hair; second, the curly-haired dog, redbrown in color, and third, the straight-haired dog of the same color. The dogrs at two years old should weigh not less than eighty pounds.

Now that I have described to the best of my ability, and within the space allotted to me, the different varieties of our sporting dogs, the reader must decide upon their merits for himself. Nor can I go into the subject of training dogs for field-work, for I believe, in the first place, that good dog-breakers are born, and not made; and secondly, not only would it be taking up too much space, but instructions, if they are of any value, are to be found in the works of recognized and much better authorities. I believe, moreover, that to a great extent, those sportsmen who are even capable of properly handling their dogs in the field after they are broken, are in the possession of a gift, I might almost call it genius, the secrets of which are patience and self-control. No one who has made his dogs his constant companions can have failed to be struck with the almost luman intelligence they sometimes display, and a man who wishes to control his dogs must first control himself. I have known an old, stanch 


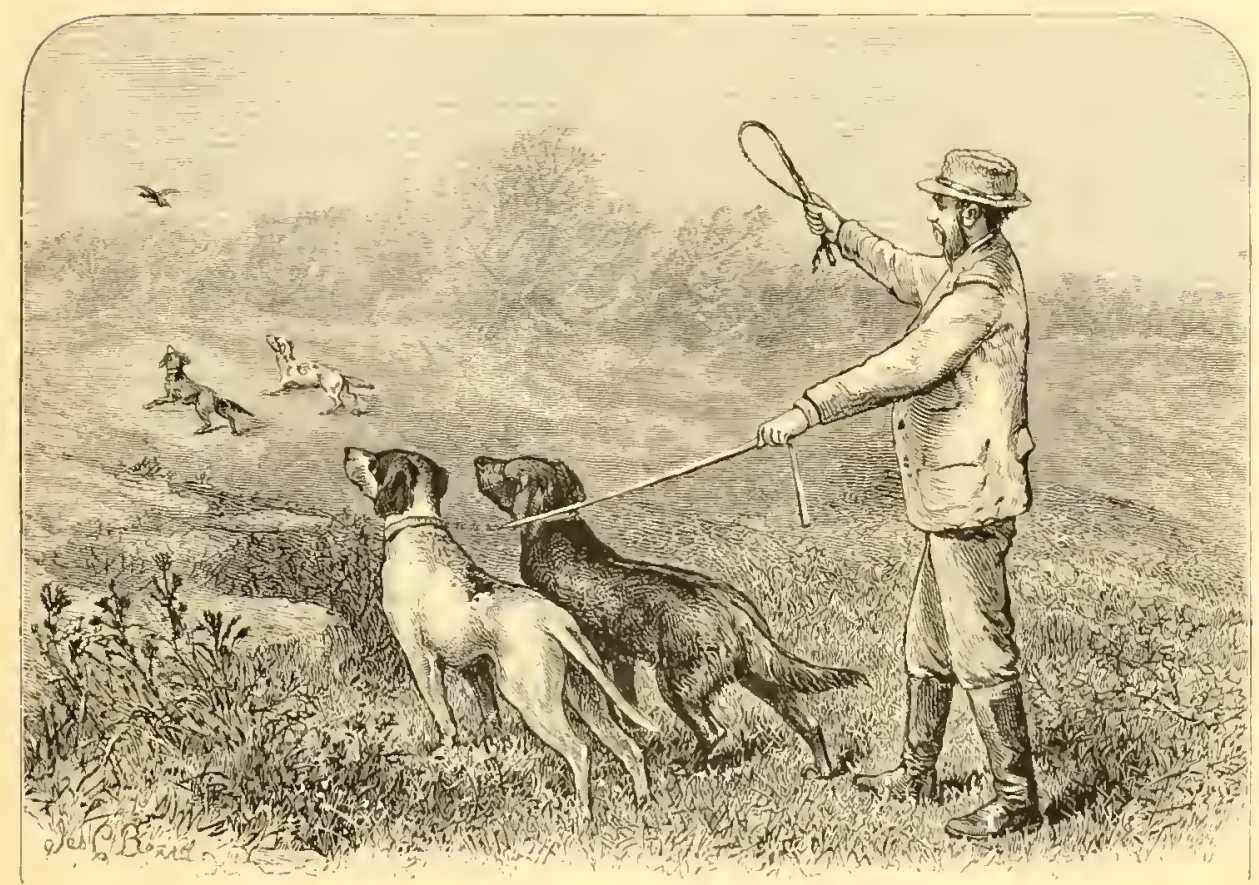

BREAKING YOUNG DOGS.

dogr to be loaned by his owner to some friends for a day's shooting. After working faithfully and finding hird after bird which they failed to kill, the old fellow dropped his tail in disgust and started for home, abandoning his share of the sport rather than witness their want of skill. The most successful men in the field are those who possess the greatest command over themselves; not abusing their dogs for the slightest fault, although using the whip judiciously: for dog nature is very like human nature, - some will do wrong from mere willfulness, and are only to be controlled by a strong hand. That dogs, when regularly shot over, enjoy the sport, is beyond question, and sometimes the mere putting on of a shooting-coat will drive them wild with excitement. And what sight is there more beautiful than that of a well-broken dog at work in the field-the instinct which teaches the wolf or the fox to hunt for his prey, toned down, or rather developed, by education to be subservient to the will of man, and accessory to his sport! You approach a fence, and, having crossed, call to your dog to do the same; for a dog should never, in theory at least, be allowed to enter a field or leave one before you. It is in the autumn, and in the woods the frost-painted 
leaves are carpeting the ground, while in the open the golden stubble is being burned by the early frosts. Perhaps it is a buckwheat or rye field where the quail, as active gleaners, still find enough of the scattered grain to afford them subsistence without going to the swamps for buds or skunk-cabbage seeds. Here they have been feeding in the early morning, and have sone to the hedge or that strip of dried grass for their noonday siesta. At the command "hie on," or "hold up," your dog starts on a gallop, - up wind if possible, - head up, to catch the scent which may be drifting across the stubble-tops, his stern —as his tail is technically called-whipping his sides. He crosses and recrosses the field, and presently comes to where the birds have been feeding. In an instant he stops, perhaps half turning to where the faint scent still lingers; but only for an instant, for the scent is cold; but with head to the ground and stern excitedly whipping his flanks, he either "roads" the birds, or, taking another cast, the wind brings him the hot scent of the bevy. Half crouching, he advances until his instinct and the strong scent from the birds tell him he can go no closer, when he stops, with tail extended stiffy, perhaps one fore-foot lifted as though ready for another step, with head rigid in the direction of the birds, and a few flecks of foam dotting his quivering nostrils. Look at him! Was ever a more perfect statue carved? Take your time; he'll stand perhaps for hours if the birds do not move. Now walk up to him; touch him if you will, and still the iron-like rigidity. Now step forward. Never let your dog flush the birds if you can help it. As you pass him, the bevy rise with that sharp, quick "whir-ir-r-r" which so thrills the sportsman as frequently to cause him to shoot too quick and wildly. Be cool. Select two of the outside birds, never shoot at the bunch,- - and, covering them carefully, fire. Your dog drops to the ground or the "lown charge" as the birds rise, and remains so until you have reloaded and ordered him first to "hold up" and then to "seek dead." Give your dog time. Even if you fancy you have marked the spot where the bird fell to an inch, he may be many yards away. The dog knows how to look for him, and will cast around until he catches the scent, and will road him until the wounded bird stops, when he will point him again.

I have said that your dog dropped when the birds rose. No young dog can be considered properly broken unless he drops "to wing" 


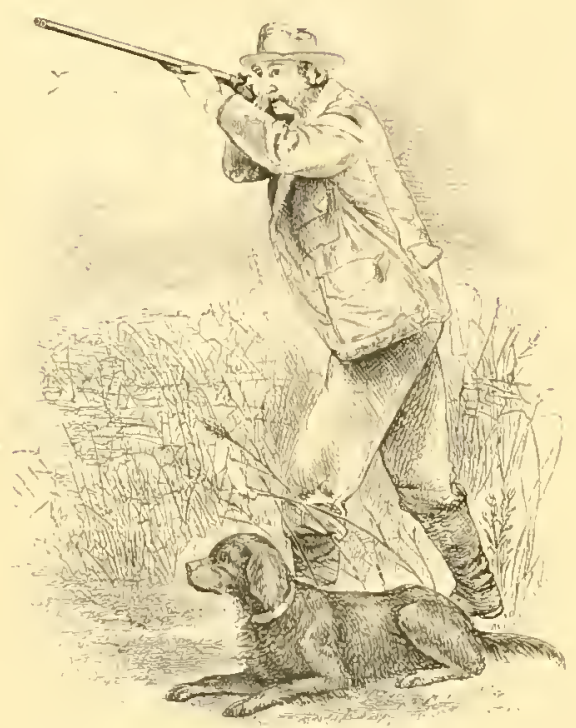

DOWN CHARGE!

and "to shot"; that is, when a bird rises, and when the gun is fired, and with young logs the latter at least should always be insisted upon. As they grow older and stancher, I should be satisfied if they came to heel when I fired. There are times when it is positive cruelty to compel a dog to drop to shot. particularly in the case of pointers on wet snipe meadows. It is the English custom not to break dogs until they are a year old. We begin much earlier, and a puppy is generally sent to the breaker at six months. I think much should depend upon the disposition of the dog. If possible, you should house or yard-break your logs; that is, teach them to drop or " charge" at command, to come in, to obey the whistle, to stop, and, if possible, to retrieve, before sending them to the breaker. Many prefer puppies born in the fall, as in the spring they can be broken on snipe, and some shooting can be had over them in the fall. . I believe, however, that fall puppies are much more difficult to rear, from the fact of their being likely to be exposed to cold and wet; in winter, too, they can get no grass, the corrective provided by nature for all canine ills, and one which should always be within their reach.

The puppy should also be accustomed to the report of fire-arms, 


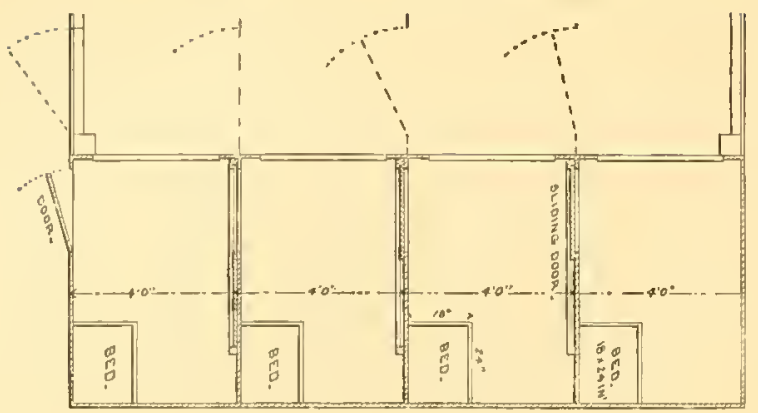

GROUND PLAN OF KENNEL.

as nothing is more discouraging to a sportsman than to find himself in possession of a "gun-shy" dog. This is to be done by taking him to the field, perhaps with an old dog, and by using at first small charges of powcler, fired only when he is at a little distance, and perhaps killing some small birds, — the great point being to associate the noise in his mind with some pleasure. Or it is not a bad idea to fire a lightly charged gun near the kennel just before feeding; but these extra precautions need only be taken where timidity is anticipated. Gun-shyness is supposed to be hereditary, but I am inclined to think that where puppies are handled judiciously at first, and not startled by an unexpected report, perhaps directly over them, but little trouble is to be apprehended. Too little attention is paid to the care and diet of dogs. They are left chained to their kennels for days at a time without exercise and without change of bedding, until they become afflicted with mange or covered with vermin. A simple and efficacious remedy for mange is prepared as follows: Take two ounces basilicon ointment, half ounce flour of sulphur, and sufficient spirits of turpentine to make of the proper consistency. Wash the dog thoroughly with carbolic soap, and rub the ointment into the skin. A few drops of Fowler's solution of arsenic is of

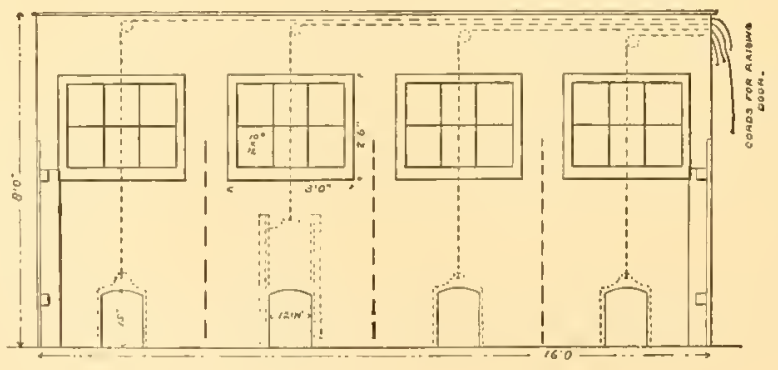

FRONT ELEVATION OF KENNEL. 
service in extreme cases. Where but one dog is kept, the scraps from the table should be ample for him; but where food must be prepared, there is nothing better than oat or corn meal thoroughly boiled in water, in which some coarse meat-such as a neck of beef or shin-bone-has been cooked almost to shreds, the meat. being chopped fine and mixed with the mush. The dogs should never be fed more than twice a day. But the great cause of death among dogs is distemper, and the more finely and carefully they are bred, the more susceptible they appear to be to its effects. Dogs of almost any age are liable to be attacked, and if they escape with life, may be left with chorea or St. Vitus's dance. In fact, in this

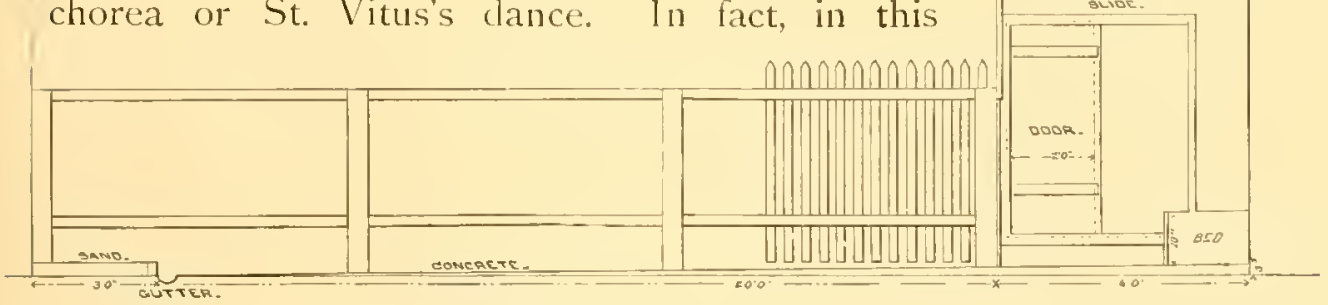

SIDE VIEW OF KENNEL.

respect distemper is not unlike measles, which often leaves a patient with some other disorder. Frequent post-mortems have revealed the fact that distemper in some of its forms very much resembles pneumonia, and, as in that disease, a certain amount of stimulation is necessary. The symptoms are, a thick, mattery discharge from the eyes and nose, with a dry, husky cough and a straining, as though a bone were lodged in the throat; a hot, dry nose, and general listlessness, with, later, a weakness of the hindquarters. Fits, in puppies particularly, are frequently present, but the symptoms vary somewhat, although the above are unmistakable. There are many remedies advocated for distemper, but 1 believe there is none more generally successful than that suggested by Dr. Webb, which consists of a course of calomel and quinine, commencing with a dose of the former, varying from ten to twenty grains, according to the size of the $\operatorname{dog}$, and followed by doses of five to ten grains of quinine daily, reducing the dose as the dog improves. When taken promptly in hand, and the dog is kept in a warm, dry place, the disease generally yields to this vigorous treatment. Cleanliness is the great source of health, and when more 


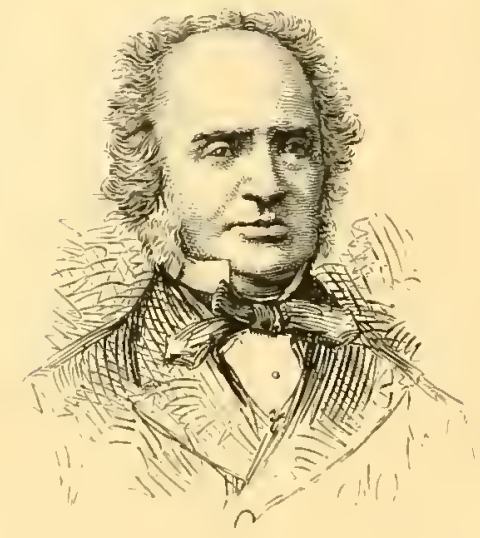

EDWARD I.AVERACK, ESQ., THE OLDEST BREEDER OF SETTERS IN FNGLAND.

than one dog is kept, a regular kennel and yard shoukl be prepared. A capital idea of their arrangement can be had from these plans, which are copied from those of Mr. Jesse Starr, Jr., of Camden, N. J. Further instruction on the subjects here treated of will be found in such exhaustive works as Dinks, Mayhew, and Hutchinson, or "Stonehenge," or "Idstone"; or, in America, Mr. Arnold Burges's "American Kennel and Sporting Field." Mr. Edward Laverack the oldest breeder in England, has written a work devoted to the discussion of the setter alone, in which are many valuable hints to the breeder and breaker.

No dogs possess greater intelligence or more excellent dispositions than those used by sportsmen, and where careful education has developed them to a high degree, they are fitted in every respect to be the trusted and beloved companions of man.

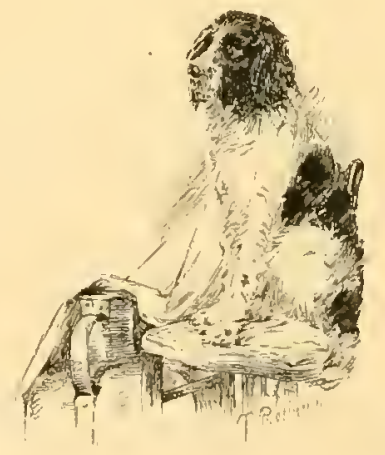




\title{
NORTH AMERICAN GROUSE.
}

\author{
$\mathrm{BY}$ CH $\backslash \mathrm{RI}, \mathrm{ES}$ E. WHITEHEAD.
}

W

HERE is the hill-side climber whose heart has not leaped at the burst of the ruffed grouse?

Autumn leaves are golden; the woodland carpet is sodden, and damp with dew and frost: the dank odors of decay and the aromatic balsam bring reveries to the mind; the patch of sunshine through the opening glade warms the body; a listless thought of some by-gone face is fixing your eye; your hand lingers on the polished trunk of the white-birch tree by which you are steadying yourself to swing over the lichened bowlder that bars your way, when whir, whir, whir-r, whir-r-r, whir-r-r-r from your very feet bursts out the cock-bird. The bright leaves fly in spangles, the sharp twigs crackle, and the leafy boughs spatter to his beating wings, as, swerving to the right and left, he dashes away through bush and open glade, and over the ravine, and out of sight, leaving the spectator with a flush on his brow and a prickle in his back, with his mouth half open, looking the way he went. No lady's bird is he. His retreat is the roughest hill-side, where rock and ravine make walking difficult and noisy, or swamps, where fallen trees and moss cover the ground knee-deep, and hemlock and spruce afford covert and buds for food. Sometimes in pairs they are found wandering away through the open woods in search of insects or beech-nuts; and again they will travel along the edges of grain-fields that adjoin swamp-land, to glean the wheat. When snows are deep, they visit old orchards and pick the ungleaned apples; and if the winter is severe they can live on spruce-buds or laurel-berries, - thus making the taste of their winter flesh bitter or even poisonous. 
The ruffed grouse lives abundantly from New Brunswick to the prairies of the West, from Canada to the Southern States,-keeping in the South to the high or mountainous lands. It is the most noble and alert of all the grouse family. The shape of its body and the pose of its head indicate robustness, both in walking and flying, and wonderful quickness in observation. Its small crested head turns with constant vigilance, and its full brown eye

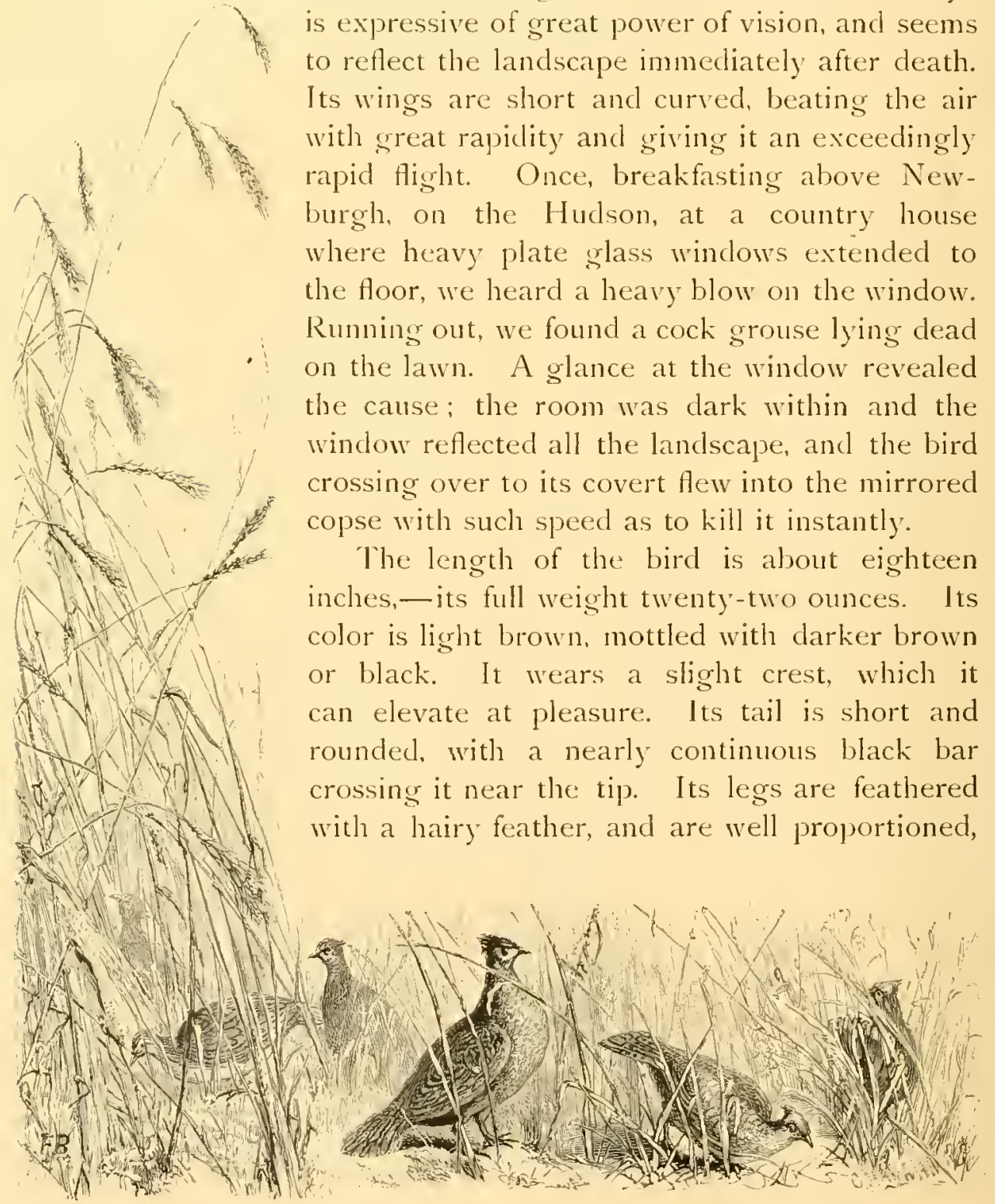


so that the bird stands high and runs with speed and endurance. It wears a ruff on its neck, made by the elongation of a half dozen glossy black feathers on each side of the neck, which it can elevate or depress at pleasure, and from which it takes its name of ruffed grouse. These feathers, as well as its other exterior feathers, are dark brown or chestnut, or ashy gray, varying much with individuals in different localities, those in countries farthest north and east beng the darkest and most ashy. In the western birds, the color is more rufous. These differences of color have induced some writers to note three varieties of ruffed grouse; but it would seem as if these differences of color are produced by local causes, for we often find the same bird on the Pacific coast having a marked variety of color. Authors have named one variety as the Sabine's grouse of Oregon, and another as the Arctic ruffed grouse of the Arctic regions. In that beautiful monograph of the "Tetraonidx," by Elliott, we find illustrations of both these so called varieties. Without intending to dispute their existence, a reference to the description of the Arctic grouse will show from what slight variations a new variety is named. That author specifies the marks that distinguish it as a different variety from the ruffed grouse, and mentions as the principal mark its size, it being one-third smaller; claiming also that the black band on the end of the tail is not continuous, but skips the three middle feathers. After reading this description, the writer looked over a game-bag of ruffed grouse killed in the northern part of the State of New York, containing twenty rufous-colored and ashen grouse of many shades: in two instances the band was scarcely visible in the middle feathers, and in three instances it did not exist. The diminished size in the Arctic region would be an effect of nature generally recosnizech

In the breeding season, the cocks select some fallen tree and, strutting up and down, beat with their wings, making a muffled drumming sound that can be heard for half a mile. The beat is at irregular intervals, beginning slowly and measuredly, and gradually. increasing in quickness, until it ends in a roll. If the bird happens to find a dry, well-placed $\log$, his tattoo of welcome can be heard a mile, and is one of the pleasantest of woodland sounds. It has the same accelerated pace, and is about the same duration as the call of the raccoon, and is only heard in the day-time, as the raccoon's 


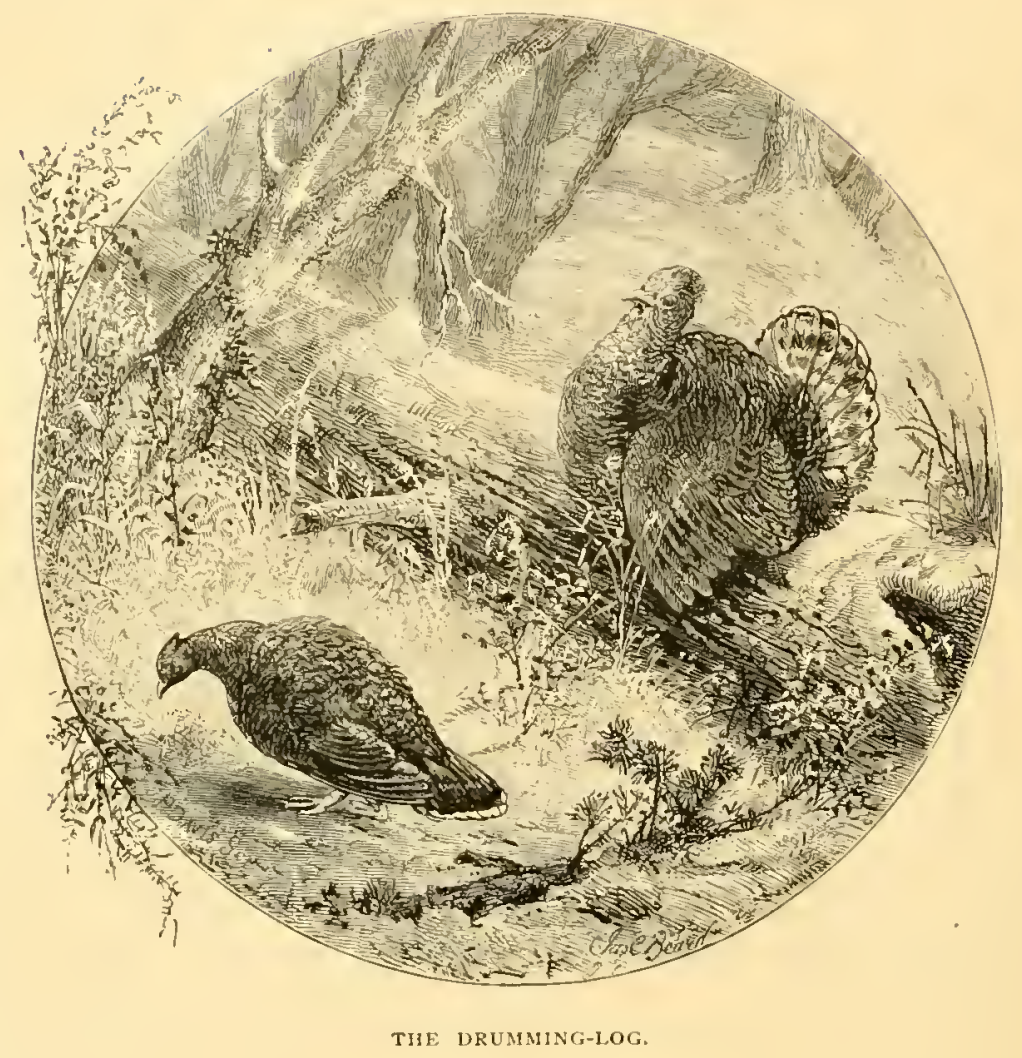

is only heard at night. Usually the same cock continues to use the same $\log$, but he will sound his call from any other place as well, the noise being produced by the blow of the wing against the body. When its mate hears the drumming, she slowly approaches, and, coquettishly picking at seeds she does not want, comes within sight of the drumming-log. A snail is on the May-apple plant right before her; she pecks at it three times before hitting it, and then scratches negligently at imaginary seeds. The cock raises his ruff till it looks like Queen Elizabeth's; the yellow skin beneath flushes with pride; he spreads his tail like a fan; he thrums his guitar, clucks an introductory welcome or two, and launches himself out and flies to his bride. If, however, another cock hears the drumming, he feels insulted at the sound on what he considers his own domain. He flies to the drumming-log and dashes at the brave drummer, 
and the one who is inferior in courage and strength yields his place to the bolder, and retires cliscomfited.

After the two birds have come together, the hen builds a hasty nest on the ground with twigs and grasses, laying in it from ten to twelve eggs, of a yellow-brown color, which are hatched in June, the young bircs attaining their growth by the first $\square$ of October, unless, as it often happens, floods

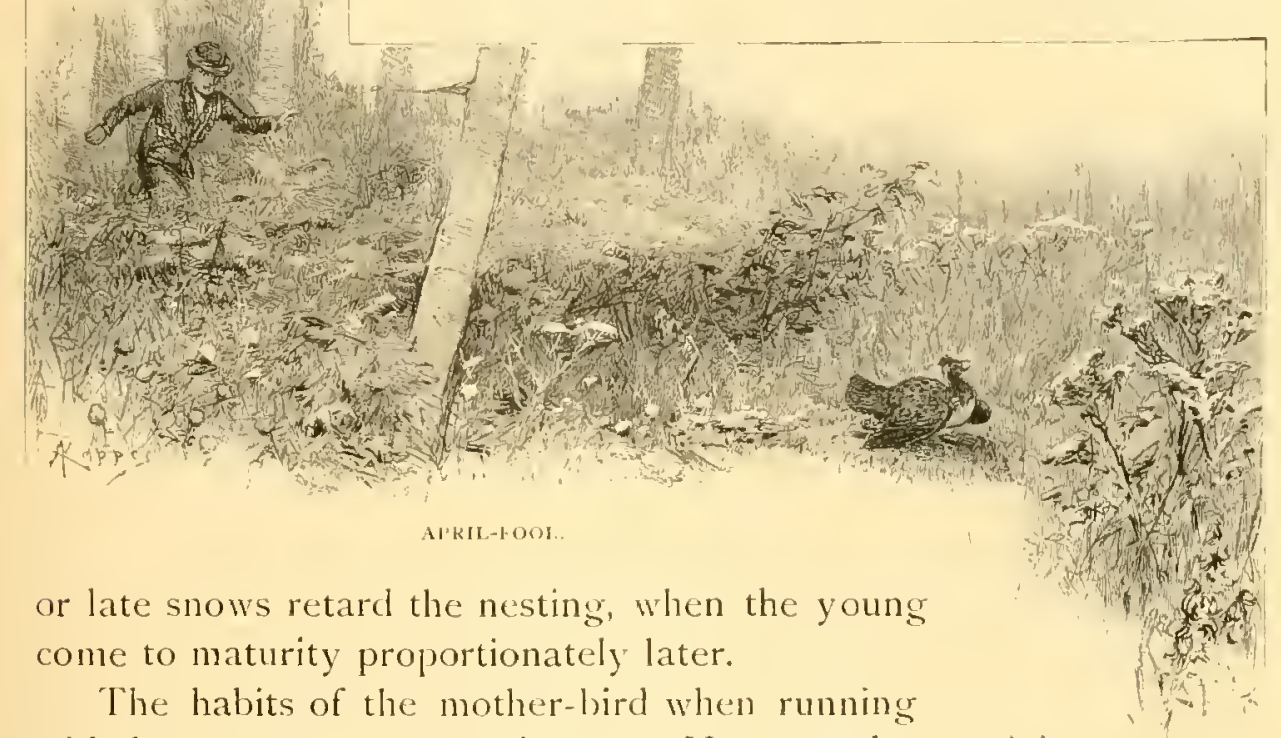
with her young are conspicuous. Her ceaseless activity, her boldness in danger, her sagacity in finding food, her ability in controlling the dimity little chicks confided to her charge, perpetually challenge admiration. With a warning cluck which the young understand perfectly, she flies away, and they run under the brown and scattered leaves, lying so still and so matched in color that no one can detect them, and when hidden they will not move unless they are touched. Or if the passer comes suddenly upon the brood, the mother's distressed cluck, her fluttered wings, and her tumbling on the ground irresistibly draw you to her. She gradually flutters along, uttering lamentable cries, and when you are about to place your hand on her back she skates away through the forest glade, uttering a note which we can easily translate into "April-fool."

This bird is the friend of the country boy. It has many a time made him jump as it burst out of the way-side bushes, and bird and 


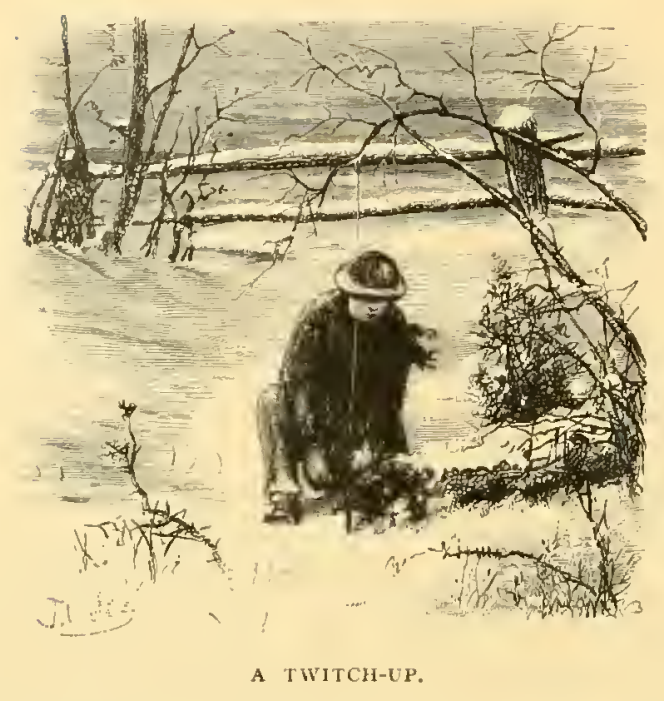

boy perpetually match their wits against each other,--the one in trapping and the other in avoiding being trapped. Naster Barefoot finds a drumming-log, and at once whips out his jack-knife and, bending down a neighboring hickory sapling, sets a twitch-up, with a slip-noose at the end, made of a string pulled out of one of his capacious pockets. The twitch-up being well watched, is sure to catch the bird or drive it away. As Barefoot grows older, he learns to set running snares of horse-hair or silk in the paths in the woods, and he will walk miles to attend them when he is too sick to go half a mile to school. At length, he grows to be a young man, "some farmer, some poacher," making a precarious living by selling game he has trapped or shot in season and out, and killing more birds than all the minks, owls, and foxes in the country side.

There is a curious habit in the ruffed grouse of taking to the trees when pursued by a small dog, and when a number of them flit into one tree, they will sit and be shot at until they are all successively killed, providing, always, that the lowest is killed first, and the dog keeps up his barking. For this chase a little red $\log$ is preferred, and doubtless the birds are accustomed thus to save themselves when pursued by foxes, and they see no difference in their canine pursuer, and are more in fear of him than of the gun, whose character they do not know so well. 


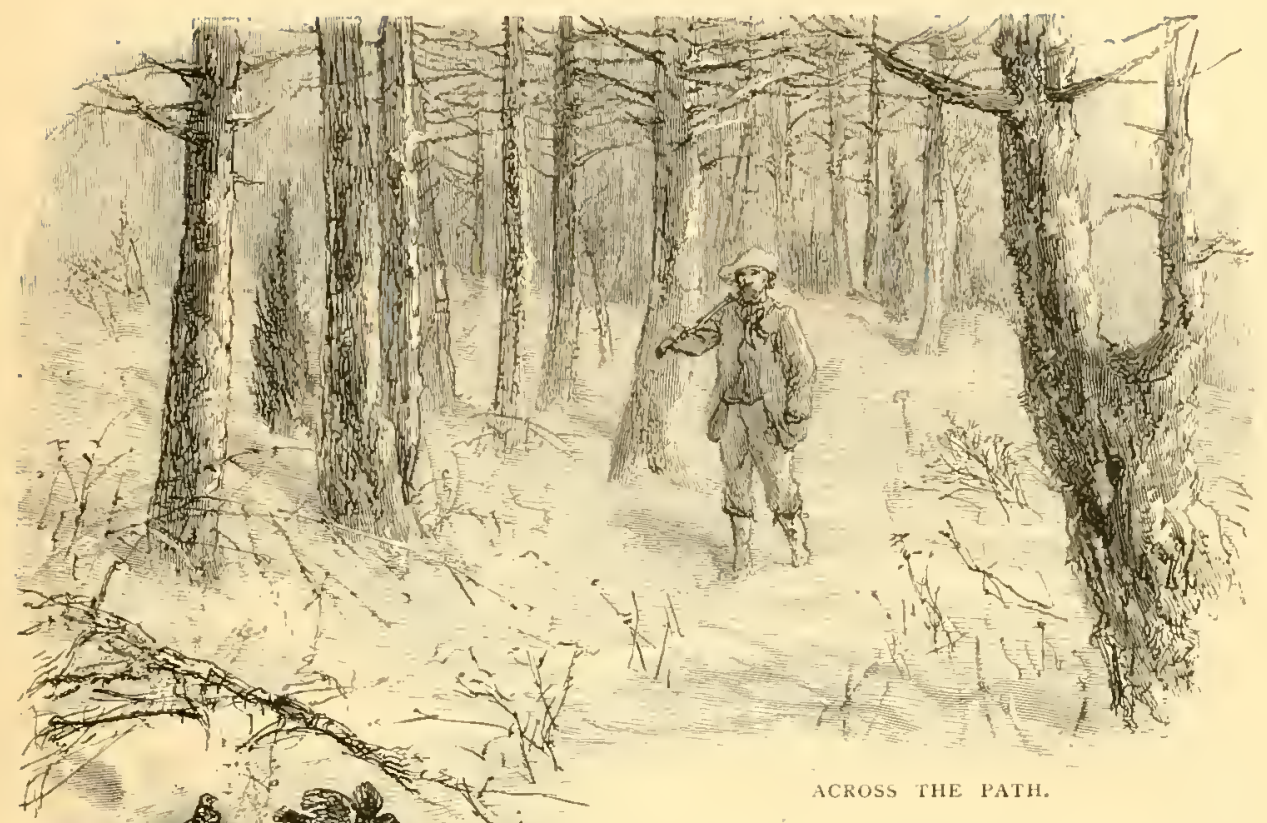

The ruffed grouse partakes of the sturdy nature of the woods he frequents. He is a real Northerner, and gleaned his living with the Puritan among the rocks and scaurs of New England. Too proud to migrate, he battled with the storms of the "stern and rock-bound coast," and when winter snows fell heavily, and the searching wind penetrated even the tangle of the spruce-swamp, he would find a lee on the ground, and suffer himself to be snowed under, and quietly wait under his white blanket till the tempest ceased. Sometimes he dashes out before the plodding woodman, all covered with snowflakes, leaving his little shelter plainly visible in the drift.

The true shooting season of this bird begins in the brisk and golden autumn. The sportsman following him needs an active step and a wondrous quick eye and hand to secure him. No bird that flies is oftener missed. He rarely lies to a dog. A careful pointer will show signs of game, and commence trailing him, for the scent is strong; but he bursts away well ahead of the dog, generally flying in a straight line. An experienced sportsman will take the shot, no matter how long, and carefully noting the line of flight, will flush him again, and again fire at him. After a few salutes of this kind, 
he seeks to avoid the exposure by hiding. Then the sportsman, following close after his dog, keeping always ready for a shot, may see the dog halt sharp, pointing to a thicket of briers and cut brush, then recalling the runs which he had made before the previous points, will step forward slowly, — slowly, - with his head high in air and eyes intent; a pause,- his foot is up for another step, when the bird rushes out again, scattering the brush with his quick wings, and whirling off the saffron leaves from the white birch. Never mind the aim, - the gun comes up to the line of flight, the sharp report awakens the echoes of the hills, and the pride of the woodland falls to the ground. Brave old bird, he died in the prime of life! No base snare shall choke him; no horned owl or stealthy mink shall pick his bones; but, roasted before a hickory fire, he will be served hot as the second course to a gentle meal, and have his virtues told by hunters who honor his name and worth, as they tell stories of the chase, or carol snatches of Thoreau's songs in the autumn night.

"Shot of the wood from thy ambush low,

Bolt off the dry leaves flying;

With a whirring spring like an Indian bow,

Thou speedest when the year is lying;

And thy neat gray form darts whirling past,

So silent all as thou fliest fast,

Snapping a leaf from the copses red,-

Our native bird on the woodland bred.

"And thy whirring wings I hear,

When the colored ice is warming

The twigs of the forest sere;

When the northern wind, a-storming,

Draws cold as death round the Irish hut,

That lifts its blue smoke in the railway cut,

And the hardy chopper sits dreaming at home,

And thou and I are alone in the storm."

The spruce grouse, or Canada grouse, is smaller than the ruffed grouse, its length being about sixteen inches, and its full weight sixteen ounces. Its range seems to be north of the latitude of the Mohawk River, in the State of New York, and extending through all of Canada and to Baffin's Bay. 


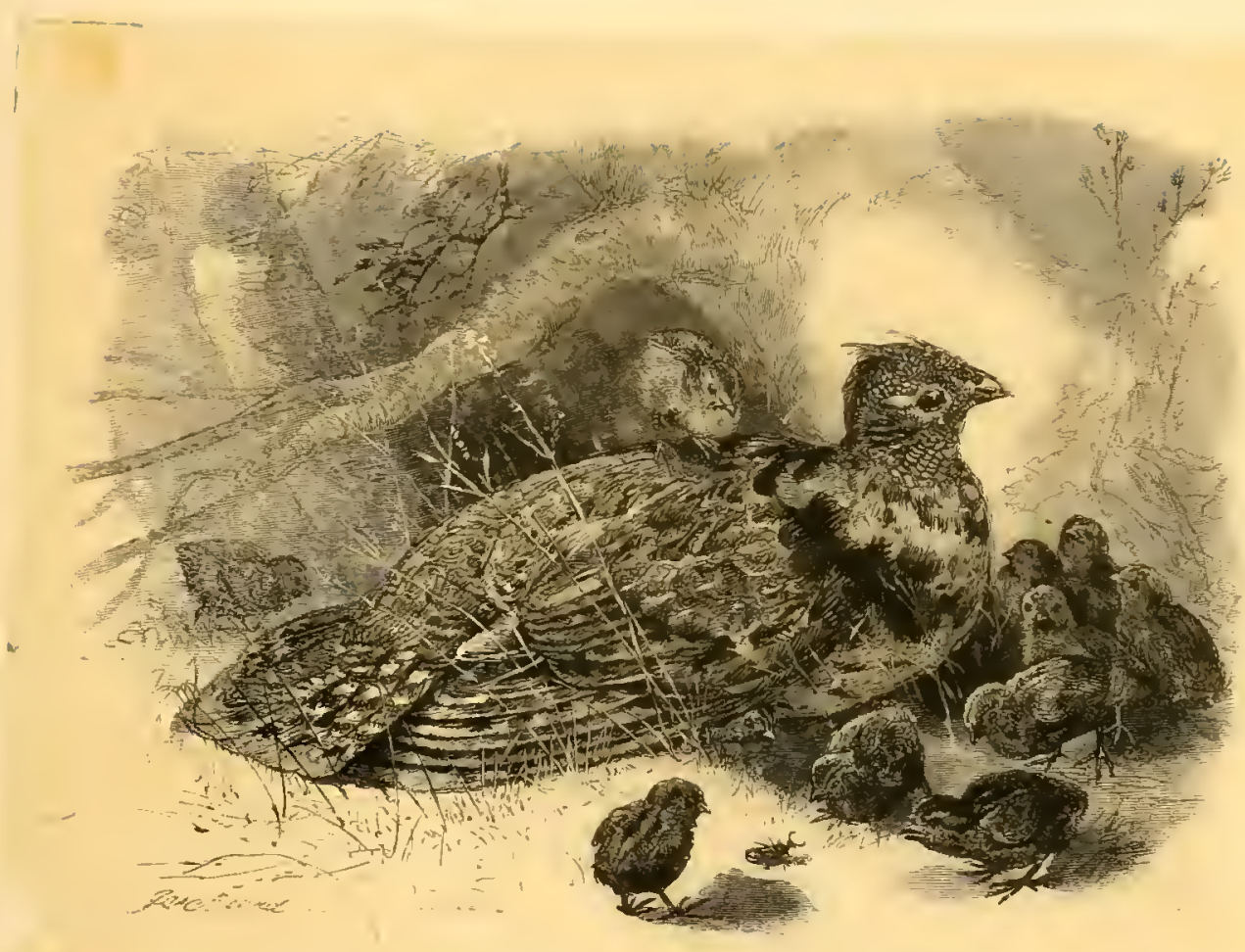



The color of the cock is dark brown or gray interspersed with black, each feather having three cross-bars of a still darker gray. On its breast is a large angular or crescent patch of black, the point of the angle coming up the neck. Its throat is black directly under the bill, and is mottled further down by little white feathers, and still larger white feathers patch its breast.* Its legs are feathered, but its toes are bare, as are all of this genus. The hen is quieter in color, mottled all over in red and brown. It has the habit of its race of making a drumming noise with its wings, but seems to do it by repeated blows on its own body, and sometimes makes this noise when in the air. Some authors note another bird, called Franklin grouse, which is a variety of this one. The tail feathers being carried out wide to the ends, and the upper and under tail coverts being tipped with white. These variations, when unaccompanied by any difference of structure or habits, seem to be of no importance to the ordinary reader or to the sportsman.

The spruce grouse makes its nest on the ground, generally sheltered by some low evergreen bush, and lays fifteen to twenty buff or fawn-colored eggs, spotted with brown. Often, when one is fishing from a canoe in some of the narrow brooks in Maine or Canada, a brood of these birds will be seen threading their way among the bushes or, if the weather is hot. coming to the water to drink, so gentle in their remoteness from man that they scarcely notice the passing boat. At times like these, they make use of a little piping cluck that is most gentle and familiar, by which the old bird calls the young ones of the flock to her whenever she finds any attractive food in the rotten wood or among the fallen mast. Again, they may be seen among the upper branches of the tallest spruce, picking the winter buds, and at their great elevation looking as small as snowbirds. When pursued, they take quickly to the trees, and seem to feel secure in their elevation, and are then easily shot. In the coldest winter, when the caribou hunter is making his camp in the evening forest, when the deep snow creaks under his snow-shoe. and the thermometer sinks to thirty degrees below zero in the still air, some

* All the male birds of this species which 1 have shot during the latter part of September, in the woods of north-western Maine, had around the eye a characteristic broad oval band of bare flesh of a bright deep orange-color. In the females this colored band is narrower, and borders only the upper half of the eye.-EDitor. 


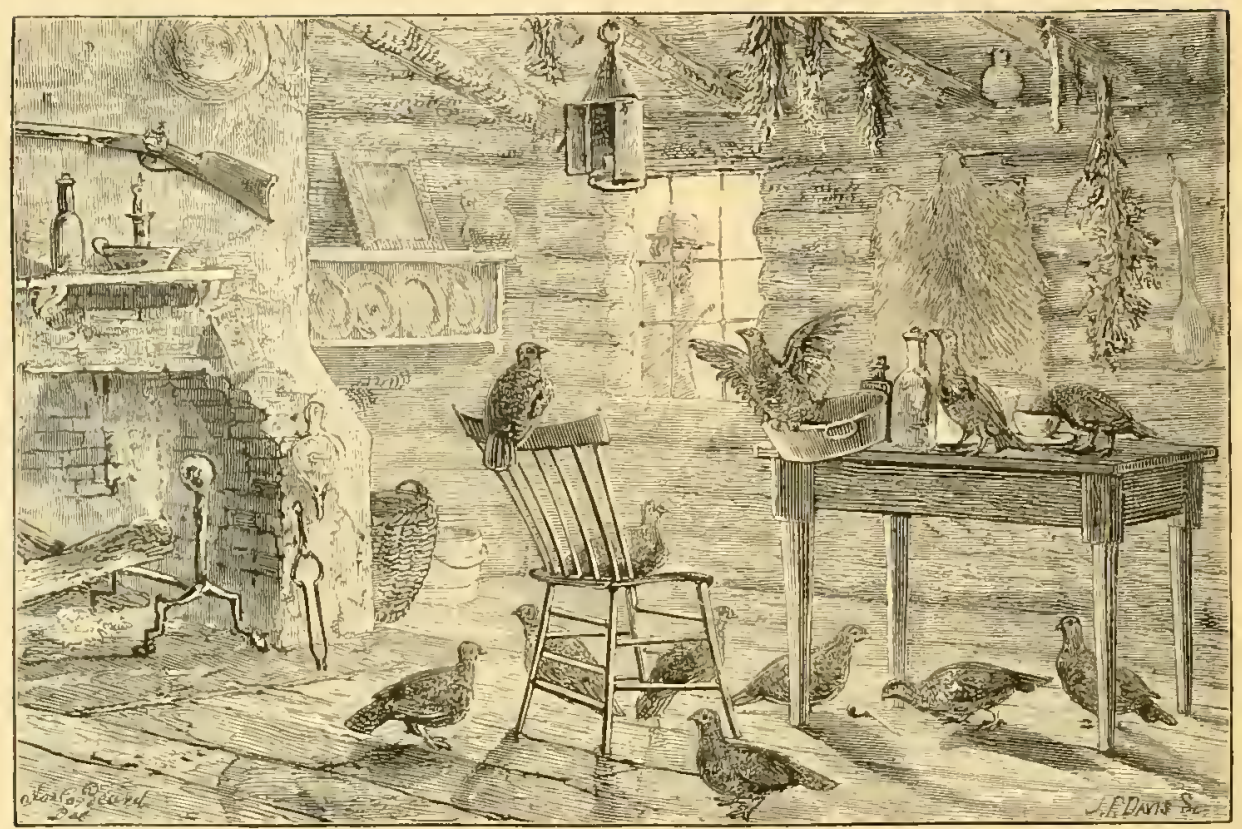

MAKING THEMSEIVES AT HOME.

of these yraceful birds will come running over the snow, familiar in the desolation, and contented and secure in their winter home, proving how apt for their position in life God's creatures are everywhere made. Once, returning to our $\log$ hut after an absence of several days on an exploring tour, we peered through the opening that was left for the window, and saw a brood of these glossy birds pecking about the floor and foraging on the remains of our feast. They crept into the empty flour-barrel, and pried into the tin meat-cans, and one old cock flitted upon the table and perched on the edge of a tin pan. His weight upset the dish, which clattered upon the floor, when the gay foragers, scared by the din, whirled out of the open door like "a swarm of golden bees," taking refuge in the neighboring hemlocks. They were not disturbed by us, for such gentle spirits bring good luck to the hunter's camp. Like the little gray wood-mouse that comes out of the logs and gathers the evening crumbs, they lend a certain domestic charm to the loncly hut that makes the solitary woodsman feel he is not alone.

The pinnated grouse, or prairie-fowl, is in numbers and use the most conspicuous of the American grouse. Its range is over all the open prairie-land of the North American continent, extending even 
to the Pacific, although the change of the climate there has produced some changes of plumage, which cause its identity to be cloubted. It is a larger bird than the ruffed grouse, its flesh being dark, while that is of a white or pink color. Its plumage is light brown, nearly uniformly barred on the breast, and spotted on the back with a darker brown. Formerly it existed on the plains of Long Island, New Jersey, and Maryland, but ceaseless hunting has destroyed it in all States east of Indiana.

It makes a nest of grass in the open prairie, laying ten or twelve eggs of a light color, spotted with irregular brown spots, and hatches in June; and generally the young are seven-eighths grown by the fifteenth of August, when the laws of most of the Western States permit the shooting of them. In Illinois, lowa, and Wisconsin it is not unusual for a sportsman to kill sixty in a day, at the opening of the season. In winter, when the snows compel them to come near the woods and the wheat-stacks for food, they are trapped in great numbers, packed in barrels, and sent to the cities of the Eastern States, and even to London. It is not unusual for shippers to send a hundred barrels of this game in a single consignment to New-York. It is this wholesale trapping and exportation which is exterminating the species. When the bird is young, it remains in its original covey, and when disturbed, scatters in the tall prairie-grass, and can then be flushed over the dogr, one at a time, so that the sportsman is thus often able to secure the whole covey. Later, several coveys unite in a pack, and by frosty weather several small packs unite, forming a pack of fifty to a hundred birds. Then they keep on the wide range of the open prairie. and become wary and watchful, and cannot be approached. The hunter must be content to take an occasional long shot as the pack is flying over him from one point to another. In these flights the fowl sometimes continue in the air ten miles, and

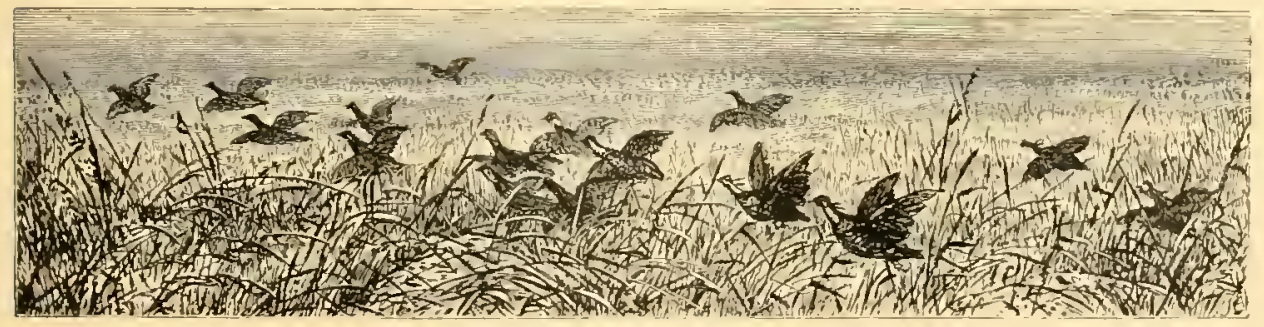

FLUSHING A COVEY OF PINNATED GROUSE. 


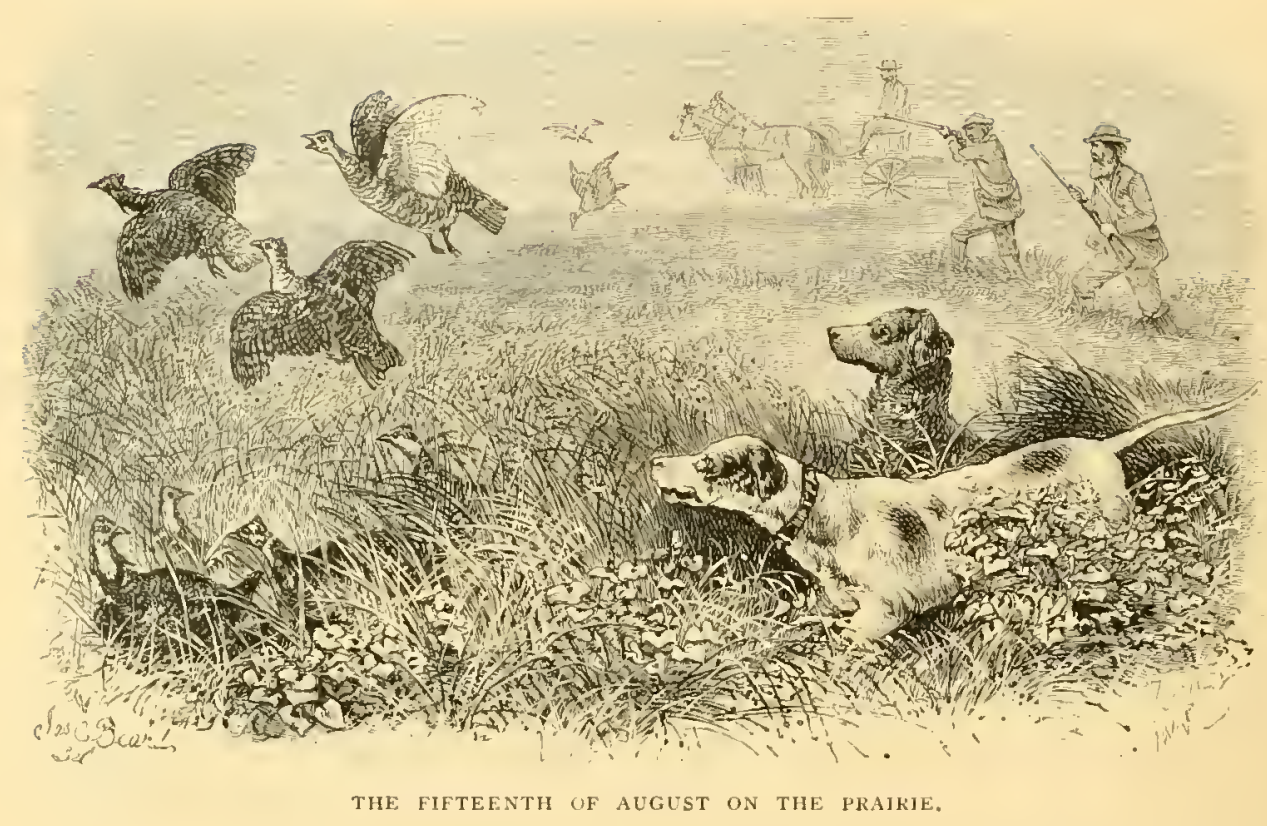

distance all pursuit. Still, there are now and then some late autumn days when the warm sunshine recalls the summer, and when, in the sheltered sloughs of the prairie, protected by low hills and rank grass, a covey will lie close, too indolent to fly away, and will rouse themselves one by one before the pointer. These are halcyon moments. The sportsman's nerves, braced by weeks of autumn shooting, are strong and steady, and every grouse that springs into the air falls with a thud to the ground, after the ringing shot. Every bird is a full-grown one, and the gillie-boy staggers under his load.

The true manner of shooting prairie-fowl is to drive over the prairie in a light wagon, letting the dogs range far and wide on either side. A well trained dog will range at times a half mile from the wagon, his bright colors and rapid motion rendering him conspicuous on the prairie. When he scents the birds he will come to a point so suddenly that at times his inertia, when attempting to halt, will swing him half around. He stands as if he saw.a ghost. The wagon drives near to him, the other dogs coming up and backing him. The sportsmen then alight and take their shots. Rarely the whole covey is flushed together, and frequently the old birds lie until the last, and while the sportsman is loading his gun 
will dash away, uttering their guick repeated cry of "Cluk-cluk-clukcluk," and looking back over their wings at the sportsman, who watches their flight and marks them down half a mile away. Is one goes to retrieve the dead birds still another and another will rise, and it is only until one has been carefully over the field that he feels secure that all the birds are up. The driver in the meantime, from his wagon, has marked the several birds down. The game that is secured is placed in the wagon, and with renewed hearts the sportsmen push on after the fugitives.

A pointer $\operatorname{dog}$ is considered the best dog for this pursuit, as his endurance and speed are great and he stands the heat without needing water better than setters. And no one who has not tramped all day with game through the prairie-grass can appreciate the relief it is to have the wagron always at hand to carry the game and luncheon and also, at times, the weary sportsman.

Often prairie-fowl meet their fate by coming in contact with the telegraph wires, and the trackmen on the railroads constantly find them with broken necks lying along the track.

As the coyote or prairie-wolf has disappeared, prairic-fowl have greatly increased in numbers. This restless and hungry marauder destroys innumerable nests and sitting birds. The writer was once watching a coyote from behind a prairie-knoll and saw him creep to windward cautiously and then jump on some prey. On going to the spot the wolf fled, leaving the feathers of a prairie-hen and her broken eggs to mark his wastefulness.

If the public would enforce the laws against trapping the birds in winter, they would greatly increase. But it requires the extinction of a valuable bird to teach the average American the importance of

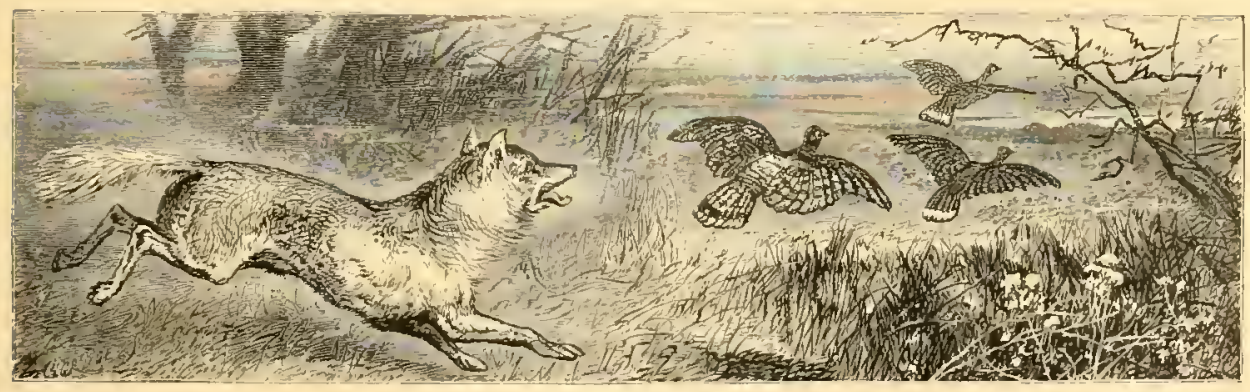

THE COIOTE HUNTING. 
its preservation. The trapper and dealer care nothing for the sport. They look only at the present money profit and leave future generations to take care of themselves. The true sportsman shoots only as much as he can use, and takes a pride in the existence and security and abundance of the bird he admires.

The other great source of destruction to the prairie-fowl arises from a habit of the IV estern farmers burning most of the prairie land in the autumn, and rescring small patches to burn in the spring, so that fall grazing will grow on the spring burnings. All the grouse in a county finding the great expanse of the prairie burnt over will nest in these patches of brown unburnt grass. The farmer then burns this grass in June, destroying every nest therein. No persuasion can induce him to forego this habit, as the fall grass is of more pleasure to him than the birds. The only remedy is for those interested in the race of birds to go over the country late in the fall and burn off all these remaining patches, thus forcing the grouse to nest on the burned prairie.

The pinnated yrouse has the power of inflating the two yellow sacks which he carries on the sides of his neck, and during the mating season the cocks are often seen strutting and swelling in mimic grandeur, with expanded wings and tail, and making a thrumming noise with their wings, striving to please by their grandiose ways. At these times they are pugnacious, and two cocks never meet without a battle. They flit up in the air several feet striking at each other with wings and feet until one yields the place of honor to the other and departs - a disappointed bird, to lead the life of a celibate.

One autumn day, watching for ducks while ensconced on a muskrat house in the great Mendocio marsh, which extends back many miles from the Mississippi River opposite Clinton, I noticed some objects moving on the summit of a knoll. By careful watching I discovered they were prairie-fowl, and, moved by curiosity, carefully approached them. As I drew near I discovered fifteen prairie-fowl apparently dancing a minuet. They were scattered about on the short turf, twenty yards apart, nodding their heads at one another, and presently two would run out and perform the figure which in a country dance is known as "cross over and back to places," all the while uttering a soft note of "coo-cooe"-the last syllable being 


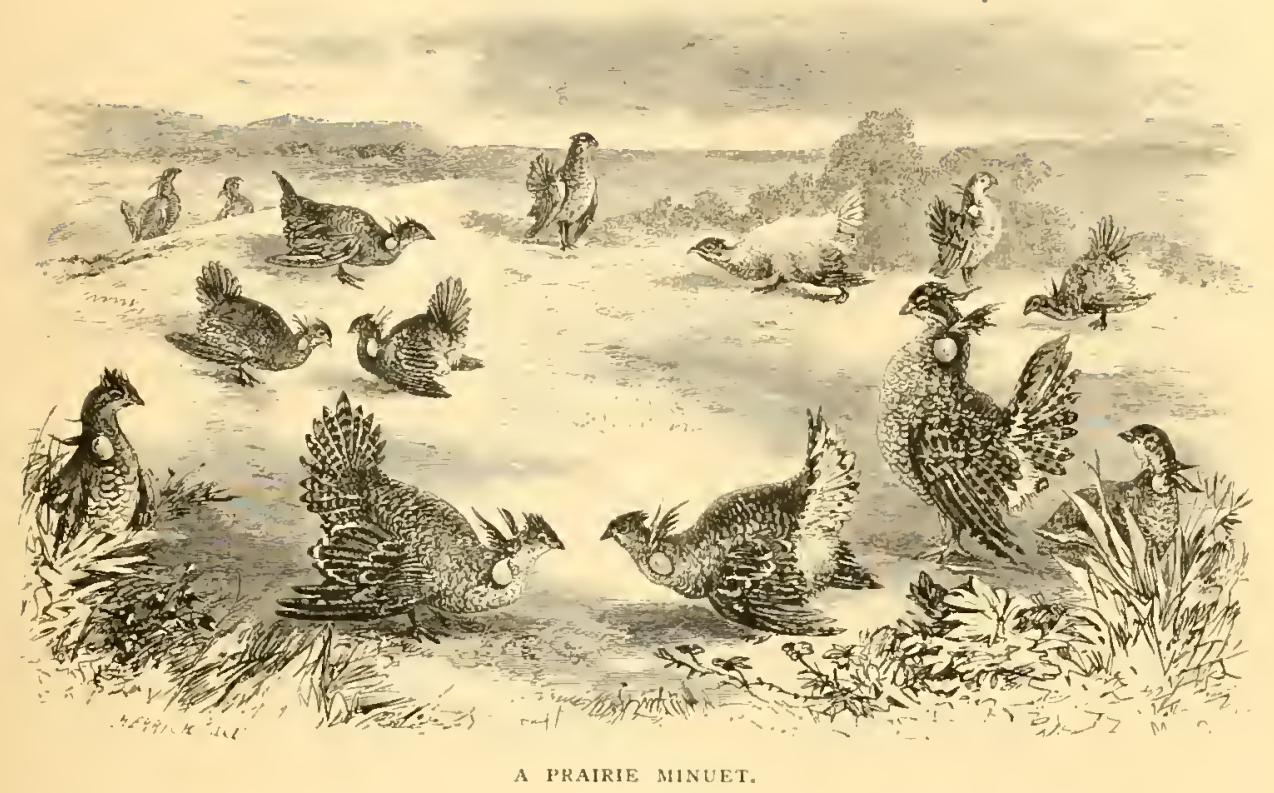

much elongated. Then would follow "salute your partners" and "dos à dos." This scene of merriment was sustained for half an hour and until a shot from a neighboring gun caused the birds to run into the tall cover of the reeds. The bright sunshine of autumn and the conspicuous group of native birds impressed the scene vividly on the spectator's mind. A neighboring farmer to whom the circumstance was mentioned said:

"Yes, them same birds skye around there mostly every day."

The other varieties of prairie grouse inclulge in the same kind of amusement.

The pin-tail, or sharp-tail, grouse is a close connection of the prairie-fowl, but without the gular sac; and, like that bird, it inhabits the open prairie land, nesting in the same manner, feeding on the same food, and often found associating with him. Its size is the same, but its color much lighter, and instead of the dark-brown bars on its breast, it carries little spots of a $V$ shape, of a light, ashy brown. Its name is derived from the two middle feathers in its tail extending beyond the others, thus forming a long, pointed tail.

It is claimed that there are two varieties of the sharp-tail grouse -one in the Arctic north, and one in the central territories of the 
continent, each with a slight variation,-the northern one having a black instead of a brown-colored back. If this is so, the writer has never seen the Arctic variety. The beautifully marked one with which we are familiar is common in Kansas, Nebraska, and Dakota; and on the Platte River we have seen it rise, with its whirring fight and lighter and ashier hue, from among a pack of pinnated grouse. Its flesh is lighter in color than that of the prairie-fowl, and more delicate in flavor.

'There is a curious habit of this bird; but whether connected with its mating instincts, or only with its love for social amusement, it is difficult to answer. It has a little ball-room all of its own, and, like that of the country girls of Italy, it is under the open sky. A circle of ground on the prairie is adopted, and by beating of wings and tramping it is cleared of grass for twenty feet around; and there, morning and evening, the party assembles and pirouettes and courtesies as in the olden time. By twos and fours they advance, and bow their heads, and drop their wings; then recede and advance again, and turn on their toes, swelling their feathers and clucking with gentle hilarity. Many cocks join in the dance, but there is no attempt at unseemly battle. It is gentleness all, and the hall is surrounded by rustling grass and golden asters. 'The hunters call such a spot, as they pass it, "chickens' stamping-ground." We have already noted the same habit in the prairie-fowl. The only difference between the two birds in this amusement seems to be that the prairie-fowl runs over a larger area of ground, usually selecting some bare knoll covered with scant, short grass.

The sharp-tail grouse is feathered not only to the toes, but to the first joint of the toes, as is the Rocky Mountain grouse; while the ruffed grouse is slightly feathered to the toes, and the pinnated grouse is scarcely feathered to the toes. The true ptarmigan wears abundant feathers down to his toe-nails.

Is the miner rides over the bare plains that form the approaches to the Rocky Mlountains, with the vivid sunshine reflected from barren earth and red hills, with the glare of noon blinking the eye, and the dust of the dry sage-bush, pulverized by the horse's tread, smarting the nostril, there suddenly flits out from the bush a large bird, looking at first glance like a bustard. It stands as high as a turkey- 


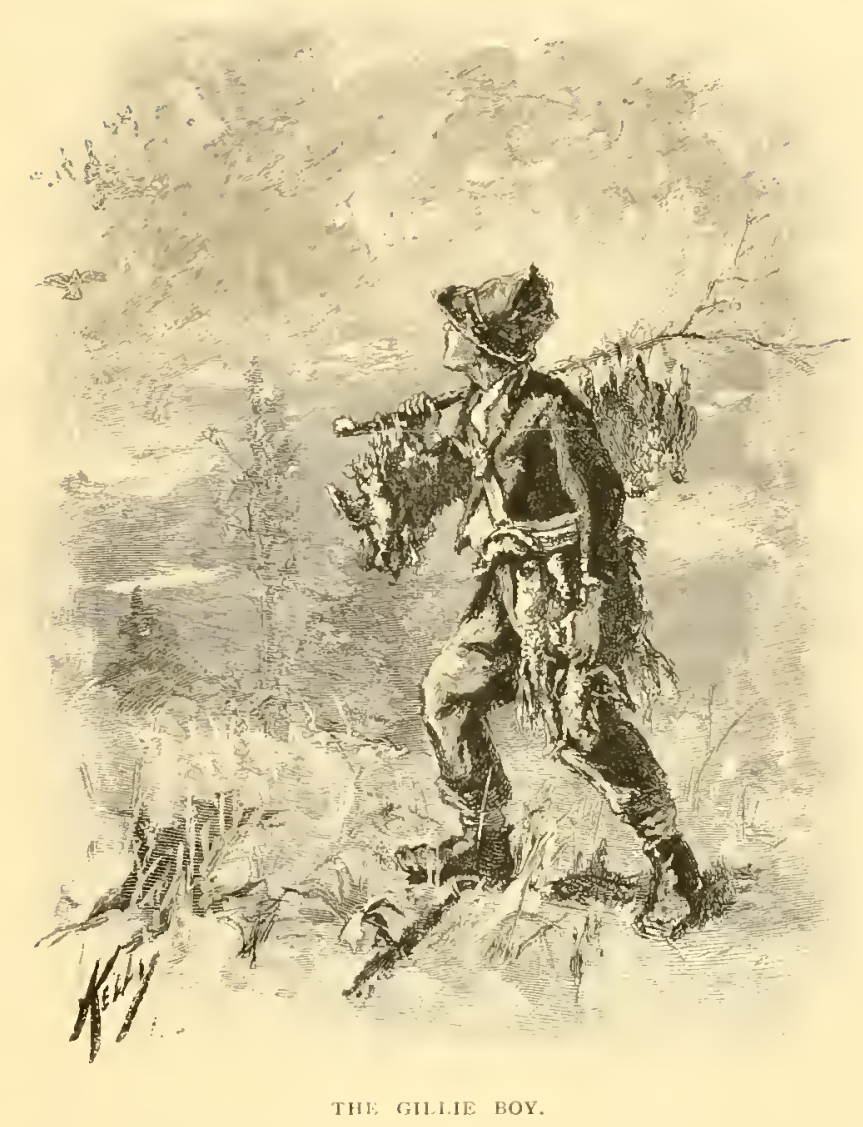

hen, and after a short flight will light on the stony ground, and turn to watch the passer-by. This is the Cock-of-the-plains, or Sagehen. Some learned folks have given it a curious Latin title; but as most sportsmen prefer shooting to studying Latin, they will best recognize the homely name the bird is known by in its own country. The color is a light ashy gray, marked by the overlapping feathers of a darker gray. It is the largest of the American grouse, being thirty inches in length, and is distinguishable in plumage by its pheasant-shaped tail of long, pointed feathers. These feathers are spiny and hard in texture, having the appearance of being worn off, and leaving the quill part projecting. This is noticeably so with the tail, the quill of the feather extending beyond the web. If the stranger follows the bird after lighting for the first time, it rises again and takes a free flight beyond some sheltering knoll. If it is 
not pursued, it squats upon the ground or under some bush until the danger is past, its predominating color corresponding so much with the ground that it often escapes notice. When walking, it has a slow and hesitating march. Its location is over the whole of the great plains lying east of the Rocky Mountains, wherever the sage-bush or artemisia grows. This is its frequent food, and it gives a pungency to its white flesh which renders it distasteful even to the hungry trapper. It has the saffron-colored side-pouches on the neck, similar to the ruffed grouse, and its habits of swelling these glands and strutting and thrumming with its wings are similar to those of the prairie-hen. It builds its nest on the ground of the desert, giving but little care to its preparation, and lays from twelve to sixteen eggs, dark brown in color, and spotted with irregular chocolate spots, more abundant at the larger than the smaller end. How its nest ever escapes the ravages of the coyote, that jackal of the plains, is a wonder. If it were not for the coyote, the number of this grouse would be ten times what it is now. lts flight is that of all its family, - a succession of quick short beats, which at rising makes the rushing sound that so bothers the nervous sportsman, and then a long sail with extended wings, to be followed again by the five or six short beats of the wing. As it rises, it gives forth its note of "Cluck-cluck-cluck!" repeated very rapidly, like the common hen. No disappointment is greater to the inexperienced and hungry hunter than to bring down one of these noble birds and, after spending an hour in its cooking, to find that it tastes like tansy bitters, with the bitters left out. We once had a "poetical cuss," as the teamsters called him, in a hunting party in Wyoming Territory. He quoted with great empliasis, on first meeting this bird, Hogg's lines:

\footnotetext{
"Birl of the wilderness,

Blithesome ancl cumberless,

Gay be thy matin o'er moorland and lea!

Emblem of happiness,

Blest le thy dwelling-place,-

Oh, to abicle in the desert with thee!"
}

We had sage-hen for supper that night. The next morning, when one rose before his horse while on the march, he was heard to call out : 


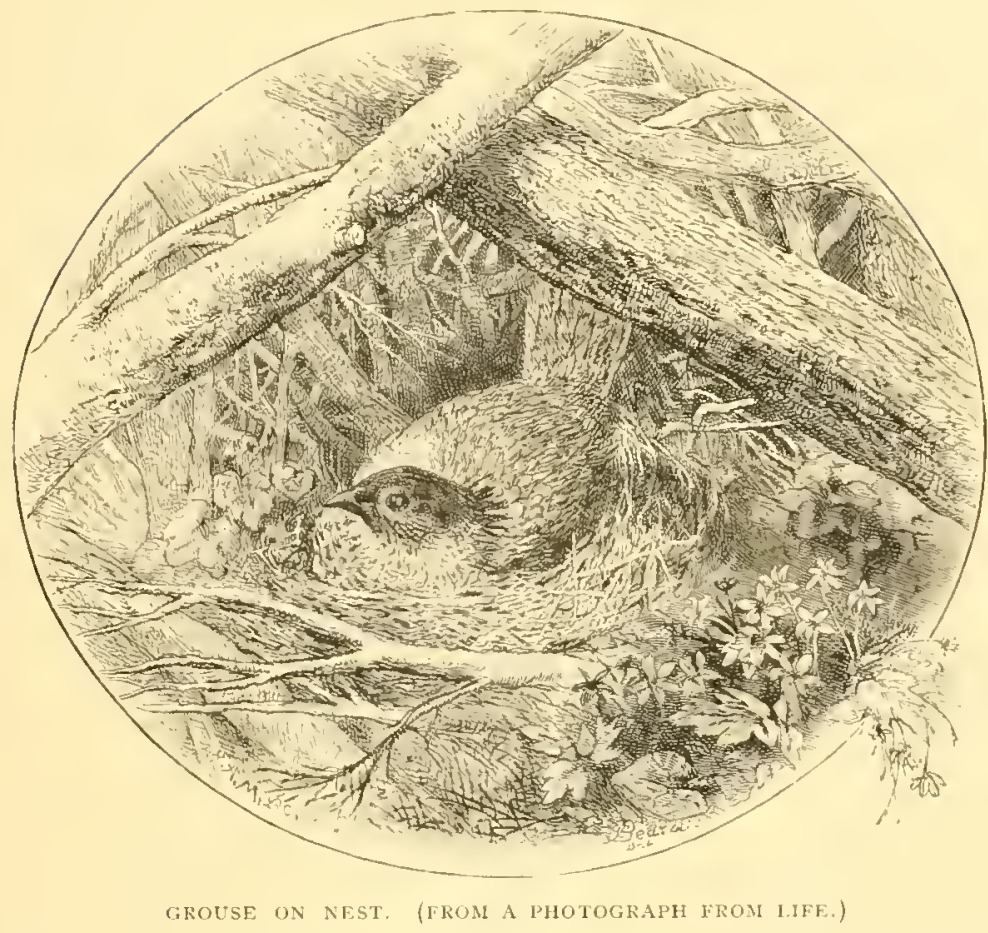

"Git out, you quinine brute! You're only fit for a prescription!"

Yet, for all his astringency, we love to see the sage-hen on the sultry march, bursting out from the bracken, starting the jackass-rabbit from its form, and awakening the landscape with his free flight.

The dusky grouse is found in the Rocky Mountains and the various spurs of highlands that are connected therewith.

It is a marvelously graceful bird, often quite black, or blue-black, and flecked here and there with little pencilings of white feathers, looking as though crystals of new snow had fallen upon it. These seem to be the tips of white feathers just coming to the surface of the black. Sometimes the bird is dusky, or of a dark slate color, marked with white, and always bearing that distinguishing mark of the grouse family, - the bright-colored streak over the eye-which, in this bird, is scarlet. Its tail is rounded, and ornamented with the band of a darker hue that most of the grouse family possess. It has the gular sac on the side of the neck, and its cry in the spring-time is like the blowing several times suddenly into an empty bottle. 
The hunter pursuing game over the ridges of the Rocky Mountains and among the dead timber that the Indians kill by their annual fires, finds this bird flitting out of the young shoots and sitting on the low branches of the neighboring trees. Its little head turns from sicle to side as it examines the stranger, - a movement accompanied by the nod of the pigeon, rendering it very difficult to shoot off its head with a pistol, though sometimes it allows several shots to be taken before flying.

Its proper colors, its most graceful shape, and its apparent tameness rendered it exceedingly attractive. Its flesh is constantly in camp, and every hunter, as he comes in at night, will have one or two slung to his saddle, as its white flesh is greatly preferred to the continued diet of elk's meat and venison. It has the peculiarity noted in that of the black game of Scotland, of having two colors of flesh on its breast, one being darker than the other. The habit it has of flitting to the lower branches of the trees on the slightest noise being heard is explained by the presence of the ever-prowling coyote.

This bird inhabits all the mountain-lands to the Pacific Ocean. In the Cascade Mountains they are abundant, inder the name of the blue grouse, and frequent the heavy pine or redwood timber. Another variety is spoken of as the Richardson grouse, varying only in a tail-marking. In the fall of the year, the blue grouse leaves the lower strata of vegetation, where it is liable to be buried in the snows, and where it has to dispute its occupancy with many stronger neighbors, and betakes itself to the upper plane of the pine-tree tops. There, two hundred feet or more from ground, it finds ample shelter in the dense, perpetual verdure, and unlimited supply of buds for food, and safety even from the eyes of man. No retreat could be so absolutely secure, - nothing but the lightning and the tempest can reach it; and its morning crow heralds the day while yet the trunk of the tree and the humbler birds that live near it are wrapped in darkness. When winter is passed, and little sprouts come forth out of the ground, the grouse descends to its old resorts and builds its nest, and shuffles in the sandy bank as it did the summer before. This is a true bird of the mountain, and has the resinous odor of the woods in its flesh. It reminds one of its noble congener of Scotland,- the black cock,- 
and of all his wild way's and glossy plumage, and the long days on the heather, and of the moorlands at Dumfries, and of the old song :

\author{
"And if up a bonnic black cock should spring, \\ To whustle him down wi' a slug in his wing, \\ And strap him on to my lunsie string, \\ Right seldom would I fail."
}

May his mountain fastnesses protect him from extermination for future ages, so that other explorers may be charmed as we have been, amid sterility, weariness, and hunger, by his beauty of form and delicacy of flesh!

We have thus told our tale of the North American grouse. The distinctive features of the genus are the bare and bright-colored patch over the eye, a short, curved bill, with the nostril covered with feathers, and a hairy leg, with bare toes. Our story is not a bookstory, or a compilation, - it is out of the head, it may be somewhat out of the heart. It does not claim to be learned, and its writer will not dispute about a feather; but all of the birds named are old friends, and he dare not caricature them.

There is another genus of this same Tetraonida family,- the genus Lagopus, or hair-foot. These have the toes, as well as the legs, covered with feathers. This gentis includes, in North America, the ptarmigan, the white-tail ptarmigan, and an Arctic ptarmigan called the rock ptarmigan. Their habitat seems to be the whole Arctic zone. They form the chief delicacy of the Arctic explorer, and hang plentifully in the larders of the posts of the Hudson's Bay Fur Company. When the winter is severe, they come down into the Canadas; and one winter a hunting friend on the Saguenay - good luck to him!- - sent us a barrelful. Such friends are above all price.

The white ptarmigan is all white, save the outer feather on each side of the tail, which outer feather is black. The white-tailed ptarmigan is as immaculate as snow, including all the tail-feathers. The remarkable feature of these birds is that they change the colors of their dress to suit the varying year, as does a fashionable lady, only the birds vary the style by dressing white in winter and brown in summer. This is one of those prudent plans of Dame Nature to preserve a race. On the spotless plains of winter, a brown bird would be a conspicuous object to every fox and snowy owl; so he is 
draped in snowy white, and squats unnoticed on the drift. In the summer foliage his whiteness would allure each passing hawk, but the brown, mottled color of his summer dress matches well the bracken and the lichen, and he thus escapes observation. This same care Nature bestows on the snow-bird and the great northern hare, both of which frequent the snowy plains.

But a summer evening is not long enough to write the story of their lives. To obtain a technical knowledge of the varieties of grouse or ptarmigan, one may study Wilson, or Audubon, or that comprehensive work on ornithology, entitled " North American Birds, by Baird, Brewer, and Ridgway."

To appreciate the beauty and learn the ways and manners of the birds of which we are writing, one must love them, and with Agassiz, "wander away and away with Nature, the dear old nurse, who sang to him night and day the rhymes of the universe." One must watch these birds in their own homes-among the roughness of primeval nature and amid the aroma of the balsam and the keen air of the frosty October-hear them beat their muffled drums and challenge all comers to their tournaments; and it's a dull, cold heart that will not throb in unison with their defiance, and love the hill-side the better for their music.

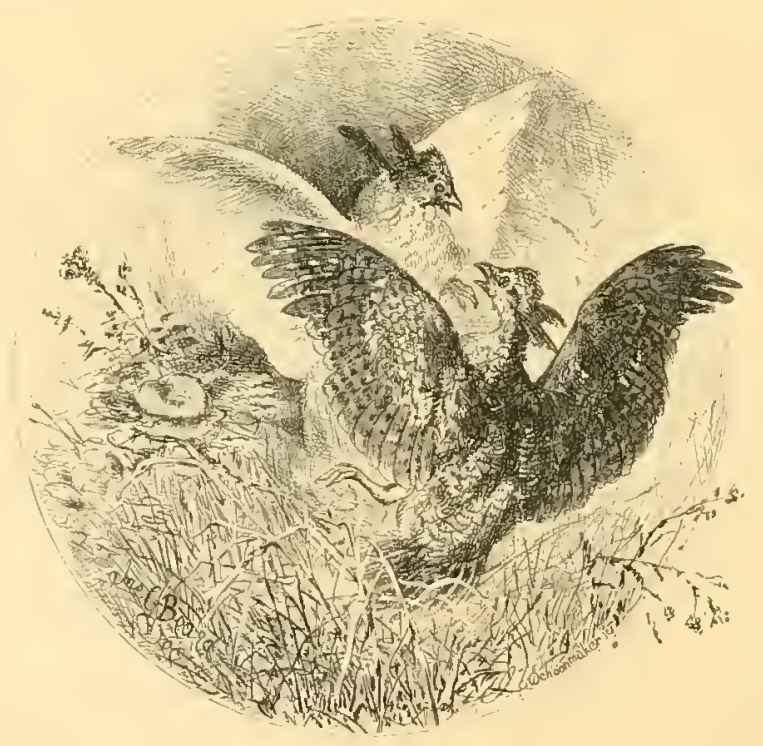




\title{
BOB WHITE, THE GAME BIRD OF AMERICA.
}

\author{
BY ALFRED M. MAVER.
}

$0^{\prime}$

$F$ all the game birds of America, none is so endeared to the lover of country life or better appreciated by the sportsman than little Bob. White. He may be found from southern Maine and Canada to the Gulf, and from the Atlantic to the high central plains, and he is known by various names. In the North and East, he is called Quail; in the South and IVest, he is Partridge; while everywhere he is known as Bob White. Let us then call him as he calls himself, and we will not be berated for our ignorance of natural history. In fact, he is neither quail nor partridge; but to our mind he seems more akin to the latter than to the former of his European cousins. The quail of Europe is a smaller and more dumpy bird than our little friend. His flesh is dark and loaded with fat. His plumage is dull and his aspect plebeian. He does not form into coveys, but flocks at the periods of his migrations, when he flies at night, and in the company of countless numbers, during the month of April crosses the Mediterranean to the European shores and islands, returning to Africa in the autumn.*

* "The quails assemble at the approach of autumn, to cross the Black Sea over to the southern coast. The order of this emigration is invariable. Towarl the end of August the quails, in a body, choose one of those fine days when the wind, blowing from the north at sunset, promises them a fine night; they take their departure about seven in the evening, and finish a journey of fifty leagues by break of day,-a wonderful distance for a short-winged bird, and one that is generally fat and sluggish of flight.

"Such prodigious quantities have appeared on the western coasts of the kingdom of Naples, in the vicinity of Nettuno, that one hundred thousand have in one day been taken within the space of four or five miles."-Daniel's "Rural Sports." 
He is a polygamous, pugnacious, selfish little Arab, and lacks entirely that gallant bearing and affectionate nature which are marked characteristics of the American bird. A wretched husband, he abandons his wives and young to their fate at the waning of the honeymoon: and his selfish manners are inherited by his chicks, who "are hardly full grown when they separate, or, if kept together, fight obstinately, and their quarrels are terminated only by their mutual destruction." It belies both the appearance and character of Bob White to call him after such a mean-looking, disreputable bird as the European quail.

The common European gray partridge differs somewhat in form from our bird, which in this particular resembles more closely the red-legged partridge of Europe; but what is said of the habits of Bob White applies equally well to the European partridge. The latter weighs twice as much as Bob White, but he has not Bob's sturdy, rapid, and often long-continued flight. Like our bird, his flesh is white; he forms into coveys; is monogamous, and keeps with his wife and brood till the following spring. He is not migratory or nocturnal in his habits. His wings are similar in form to those of our bird, having the third quill-feather the longest, which is a characteristic of the partridges, and distinguishes them from the quails, which have the first quill-feather the longest.

It is true that Bob White is sometimes partly migratory in his habits. It is said that he has "a running season" in October, when, joining a pack, he leaves the region of his birth and travels on foot in a southerly and easterly direction till he reaches the borders of streams and bays, where he may remain till November, when he returns to his former haunts. During his travels it would be useless to hunt him, for he then runs with great rapidity before the dog, and will not take wing.

The European partridge and Bob White differ in their call-notes and in their longevity. Daniel, in his superb "Rural Sports," London, 1812 , states: "It is said, the partridge, if unmolested, lives from fifteen to seventeen years; others dispute this computation, and maintain that they live seven years, and give over laying in the sixth, and are in full vigor when two years old." Dr. Elisha T. Lewis, in his "American Sportsman," Philadelphia, 1857 , says that the average duration of Bob White's life is three to five years; but 


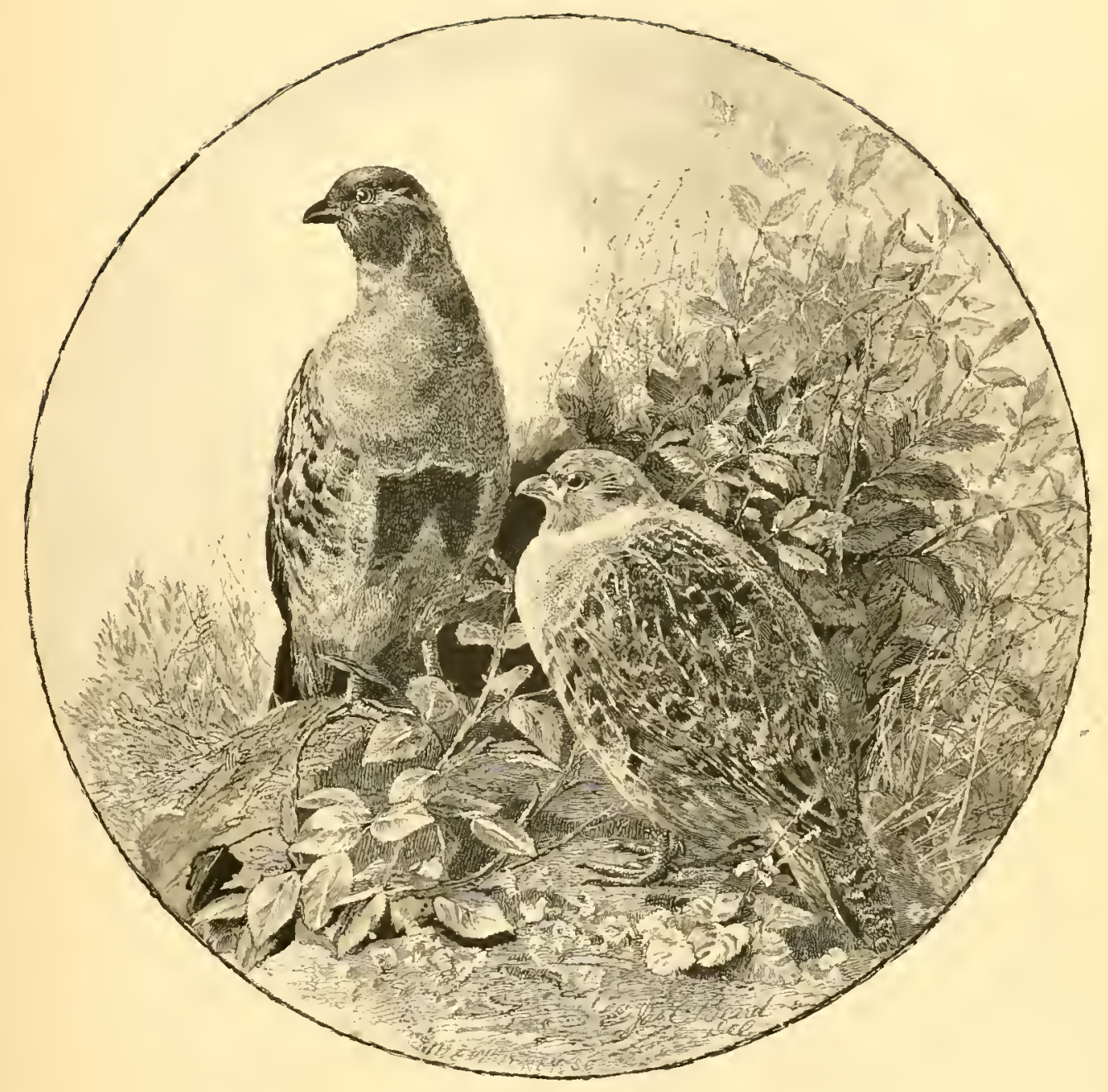

FUROPEAN GRAY PARTRIDGIS (PERDIX CINEREA), MALE AND FEMAIE. 



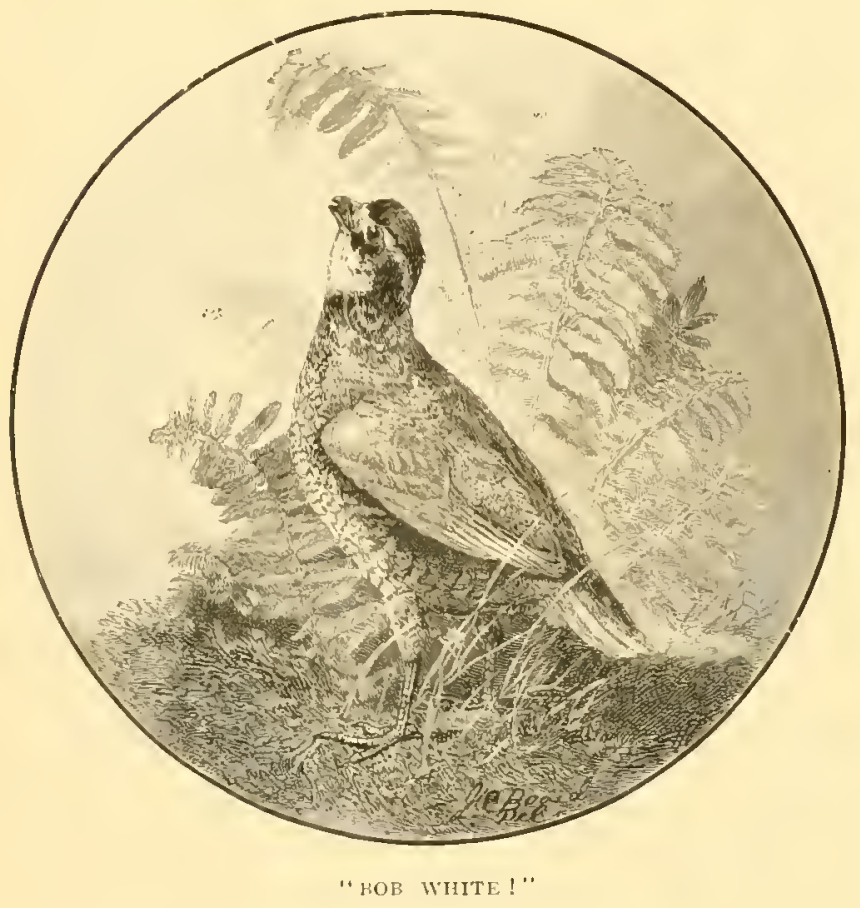

neither of these authors states how these facts were ascertained. Our distinguished ornithologist, Dr. Cones, classes Bob White among the partridges, and says:

" (our partridges [viz., Bob White, the Mountain, Valley, and Massena quails, etc.] may be distinguished among American Gallime by the foregoing characters, but not from those of the Old World; and it is highly improbable that, as a group, they are separable from all the forms of the latter by any decided peculiarities. I find that the principal supposed character, namely, a toothing of the under mandible, is very faintly indicated in some forms, and entirely wanting in others. Pending final issue, however, it is expedient to recognize the group, so strictly limited geographically, if not otherwise. * * * In habits, they agree more or less completely with the well-known Bol White: head completely feathered, and usually crested, the crest frequently assuming a remarkable shape; nasal fosse not filled with feathers, the nostrils covered with a naked scale, tarsi and toes naked, the latter scarcely or not fringecl."

If, however, many of our friends should persist - as they certainly will -in calling Bob White a quail, then they should call a brood of these birds a bo'y : while a coney should designate a brood, if they call him a Virginia partridge. The plumage differs so much with latitude that some naturalists have made out three species-the 


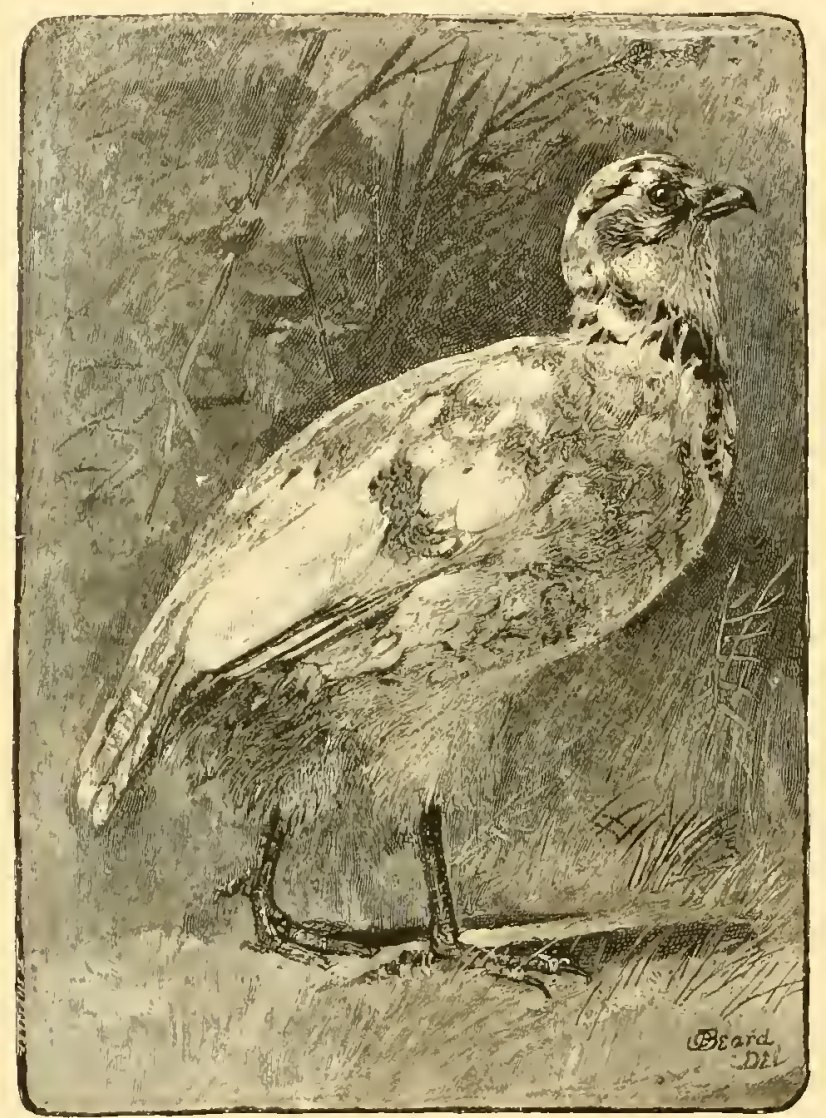

WHITE BUB WHTE, (FROM THE COILFCTION OF ALERER M, MAYER)

Orty'x Tirginianus, the O. Floridanus, and the O. Texamus. The male of the Floridanus is about the size of the female Iirginianus. Its bill is longer and jet black: its colors are darker and its black markings are heavier. The Tiramus is of the size of the Floridanus; the colors are paler, the prevailing shade being rather gray than brown: upper part much variegated with tawny. Sometimes Bob White dons a coat which is nearly white. One of these colorless birds is shown in the above engraving. He was shot in the month of November, by Mr. Charles Hallock, near Berlin, in Worcester County, Maryland.

If, after a day of successful shooting over a considerable area, the sportsman will count the number of cock and hen birds which have falien to his aim, he will find the former always outnumbering the latter. The exact ratio I do not know. I have but once separated 
them; then, in a bag of forty, 1 found twenty-four cocks to sixteen hens. According to the European naturalist, Ray, the European partridge hatches one-third more males than females.

The average weight of Bob IVhite varies considerably with the nature of his feeding-ground, the weather preceding the time when he is shot, and the age of the bird. Probably six and three-quarter ounces is a fair average weight. In Southern Maryland, I have shot a few cock-birds which weighed eight ounces and one-quarter, and one even as high in weight as eight ounces and three-quarters. lifty birds shot in the middle of North Carolina, last December, averaged seven ounces. Those bircts were cocks and hens, old and young, just as they came to bag in the field. Mr. Frank Schley says: "I have often killed a bag of birds along the Monocacy and Potomac bottoms in Maryland, in the month of December, that would average eight ounces." 1)r. Lewis, in his "American Sportsman," gives a record of ten braces of birds shot in the neighborhood of Mount Holly, New Jersey, that averaged eight ounces.

While the woodcock and Wilson's snipe are fated to disappear as civilization robs them of their restricted feeding-grounds, Bob White. if protected by the enforcement of judicious game laws, will thrive in the midst of cultivated lands, and will continue to test the gamecraft and marksmanship of future generations. He is destined to remain the game bird of America, and he is worthy of it; for there is none more impetuous in his flight, none that has such extended range in his feeding-grounds and coverts, none that demands of the gunner more knowledge of his habits in order to find him, and none that tests so well the training of a dog and the eye and nerve of the sportsman. We should be thankful that he, with the black bass, will be spared in the relentless action of that artificial selection which is slowly but surely taking from us the woodcock, the snipe, the grouse, and the wild trout.

Unlike the grouse and the European quail, our little American is a faithful husband and devoted father. To find Bob in Mormon practices is rare. Should he, however, discover that his gallant bearing and spruce attire have made him doubly beloved, he will show impartial devotion to his two spouses. From a fence-rail overhead, with his two wives on their nests, not two feet apart, he will gladden both their little hearts with his love-song. 
But this gallant and affectionate bird is naturally a monogamist. He selects his mate and makes his courtship in the spring, soon after the snow and frost have gone, when the willows have turned yellow, while the frogs are piping in the marsh' and the Wilson's snipe is drumming above the meadows. If the wintry storm should come back, the mates will re-assemble in a covey, and keep each other warm o' nights, and huddle on the sunny slopes during the day.

In the month of Nay they build their simple nest, formed of a slight depression in the ground, lined with dried leaves and soft grasses. This nest may be found under a tussock of grass, beneath a small bush, in the brier-grown corner of a worm-fence, at the foot of an old stump, alongside a $\log$, or often in the open fields of wheat or clover. The nest is sometimes closed above with stubble mingled with the grass tussock or briers, and provided with a side entrance; but the nest is as often found open above as closed.

In this nest the hen-bird lays from one dozen to two dozen eggs of a pure, brilliant white. While the hen is laying, and during her time of nesting, the cock is the happiest of husbands. Filled with joy and pride, he sits on the low bough of a neighboring tree, or perches on the fence-rail quite near his spouse, whom he never wearies of telling that he is "Bob White-your Bob White," in

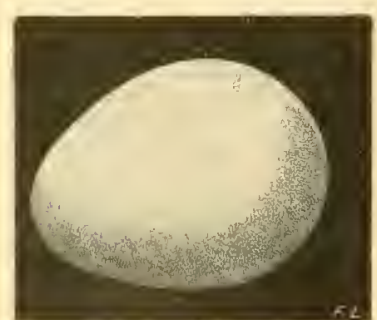

BOB TWHITE EGG (FULL, SIZE). (FROM THE COLLECTION OF A. B. BAILEY.) such a brilliant, happy voice that the farmer stops his work and the children leave their play to listen to him, and they are happier for having heard him.

In from three to four weeks the little downy young leave the egg, and even with pieces of egg-shell yet sticking on their backs they go off with their parents to be taught to search for food. They feed on the seeds of various grasses, weeds, and cereals, and on berries; and they return a hundred-fold the bounty of their landlord, by destroying for his benefit not only countless numbers of destructive insects, but quantities of weed-seed, one to two gills of which the adult birds can stow away in their little crops during a day's feeding. If rain should come on, or the cold wind blow, the mother calls her younglings under her wings, where they nestle safe from the chilling storm. When night comes on, she and her spouse take their 


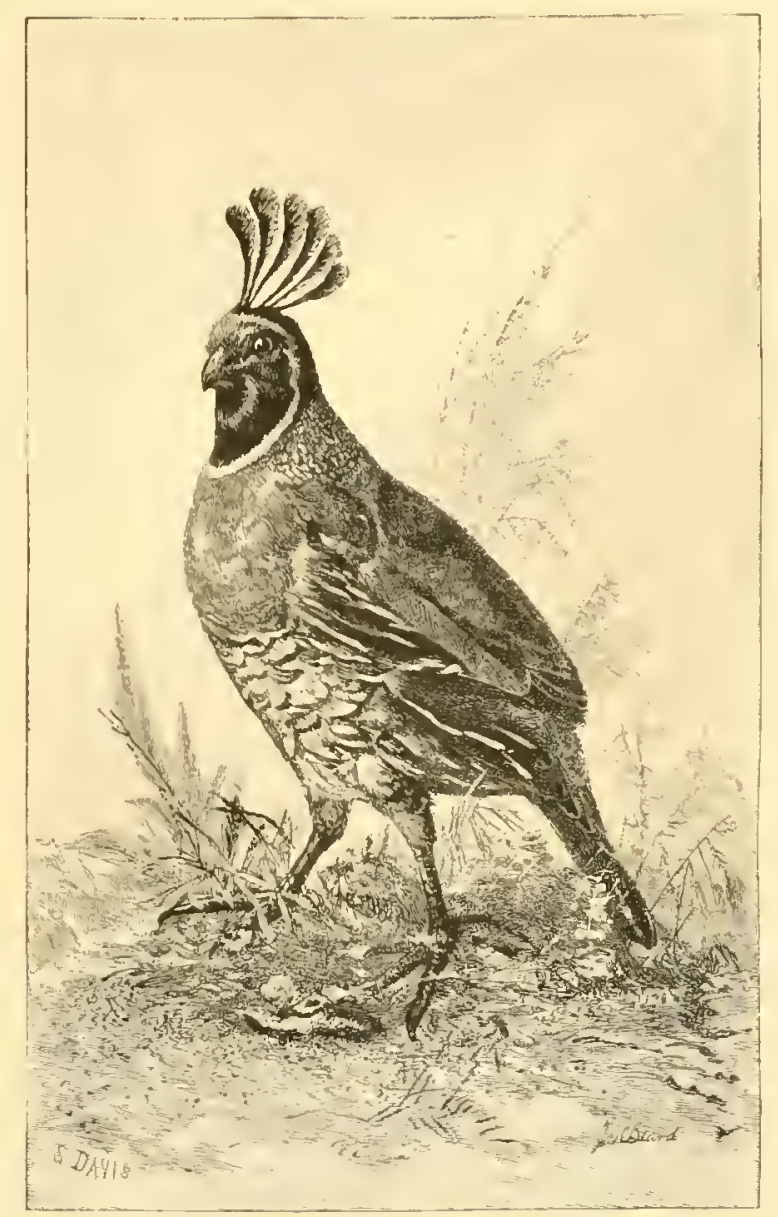

CALIFORNIA VALLEY PARTRIDGE OR QUAIL. (LOPHORTYX CALIFORNICLS.)

little ones to some place removed from the thicket, where prowl the fox and the weasel. Soon after being hatched, the young, in running, assist themselves with their tiny wings, and when two weeks old they take wing with a flutter that is very amusing to those familiar with the startling whir of the old birds. When too large to gather under the mother, they take their flight at night-fall from the stubble or grain-field where they have been feeding, and thus, breaking the scent, drop down in a compact cloud into some open space under a bush or tussock, and cozily huddling up to one another, form a little circle with their heads outward. Thus nestled, they see on all sides, and can spring at a moment from their bed to evade any foe that may steal on them in the night or at the early dawn. If the 
ground be covered with snow or hoar frost, or the weather be wet or blustering, they may remain huddled together all day, or may not venture to feed till late in the forenoon. But if they are greeted with the sunrise and good weather, they cheep a good-morning to one another in soft, cheerful voices, and go at once to their feedinggrounds, where they regale themselves on the wheat of the stubbles, the buckwheat, the seeds of grasses, and the rag-weed, and on the berries of the haw, the gum, and the chicken-grape. About ten or eleven o'clock they retire to the sunny side of a covert, and they do not venture forth again till three or four in the afternoon, when they agrain seek their food till sundown and bed-time.

In October and November, the sportsman often "springs" coveys containing birds too small to be shot; sometimes half the covey will be in this condition, the other half full-grown birds. This fact may be accounted for thus: The eggs and the young are often destroyed by the wet and cold of the early summer, or by beasts and birds of prey. If this calamity should overtake them, the hen again goes to laying, and this second brood is retarded by the time lost between the first and second nestings. When birds of two sizes are found in the same covey, it seems to show that the parents have raised two broods; and this. I think, happens oftener to the south than to the north of the James River,- the summer of our middle and northern States being generally too short for the raising of two broods. Baird says: "They have two broods in a season, the second in August"; while Audubon states that "in Texas, the Floridas, and as far eastward as the neighborhood of Charleston, in South Carolina, it breeds twice in the year. first in May, and again in September."

The cock-bird shares with the hen the duties and restraints of incubation. If his spouse should desire another brood, he will take charge of the half-grown young while she makes her second nesting. When the second brood appears, it runs with the first, and they form together one happy family, and remain with their parents till the following spring, in the pairing season, when the old family ties are severed.

The devotion of the parents to their unfledged young, and the real affection which the members of a family have for one another up to the time of their separation in the spring, have been so touchingly described by two of the most gifted of our writers on field 
sports, that I must here quote them; especially as the writings of $W$. P. Hawes ("J. Cypress, Jr.") are now rarely met with. He says:

"If you would see the purest, the sincerest, the most affecting picty of a parent's love, startle a famity of young quails and watch the conduct of the mother. She will not leave you. No, not she. But she will fall at your feet, uttering a noise which none but a distressed mother can make, and she will run, and flutter, and seem to try to be caught, and cheat your outstretched hand, and affect to be wing-broken and wounded, and yet have just strength to cumble along, until she has drawn you, fatigued, a safe distance from her threatened children and the hopes of her young heart; and then she will mount, whirring with glad strength, and away through the maze of trees you had not seen before, like a close-shot bullet, fly to her skulking infants. Listen, now! Do you hear those three half-plaintive notes, quickly and clearly poured out? She is calling the boys and girls together. She sings not now 'Bob White!' nor 'Ah! Bob White!' That is her husband's love-call, or his trumpet-blast of defiance. But she calis sweetly and softly for her lost children. Hear them 'Peep! peep! peep!' at the welcome voice of their mother's love! 'They are coming together. Soon the whole family will meet again. It is a foul sin to disturb them; but retread your devious way, and let her hear your coming footsteps breaking down the briers as you renew the danger. She is quiet. Not a word is passed between the fearful fugitives. Now, if you have the heart to do it, lie low, keep still, and imitate the call of the hen-quail. Oh, mother, mother! How your heart would die if you could witness the deception! The little ones raise up their trembling heads and catch comfort and imagined safety from the sound. 'Peep! peep!' 'They are coming to you, straining their little eyes and clustering together, and, answering, seem to say: "Where is she? Mother! mother! We are here!'”

\section{The following is by Henry William Herbert ("Frank For- rester"):}

"Unlike the young broods of the woolcock, which are mute, save the twitter with which they rise, the bevies of quail appear to be attached to each other by tender affection. If dispersed by accidental causes, either in the pursuit of their food, or from being flushed by some casual intruder, so soon as their first alarm has passed over, they begin calling to each other with a small, plaintive note, quite different from the amorous whistle of the male bird and from their merry, lay-break cheeping, and each one running toward the sound, and repeating it at intervals, they soon collect themselves together into one happy little family.

"If, however, the ruthless sportsman has been among them with his well-trained setier and unerring gun, so that death has sorely thinned their numbers, they will protract their little call for their lost comrades even to night-fall; and in such cases - I know not if it be fancy on my part - there has often seemed to me to be an unusual degree of melancholy in their wailing whistie.

"Once this struck me especially. I had found a small bevy of thirteen birds in an orchard, close to the house in which I was passing a portion of the autumn, and in a very few minutes killed twelve of them, for they lay hard in the tedded clover, and it 
was perfectly open shooting. The thirteenth and last bird, rising with two others which I killed right and left, flew but a short distance and dropped among some sumacs in the corner of a rail fence. I could have shot him certainly enough, but some undefined feeling induced me to call my dog to heel, and spare his little life; yet afterward I almos! regretted what I certainly intended at the time for mercy. For day after day, so long as I remained in the country, I heard his sad call from morn till dewy eve, crying for his departed friends, and full, apjarently, of memory, which is, alas! but too often another name for sorrow.

"It is a singular proof how strong is the passion for the chase and the love of pursuit implanted by nature in the heart of man, that however much, when not influenced by the direct heat of sport, we deprecate the killing of these little birds and pity the individual sufferers, the moment lhe dog points and the bev'y springs, or the propitious morning promises good sport, all the compunction is forgotten in the eagerness and emulation which are natural to our race."

Bob White schools the wing-shot as severely as the wily trout tries the angler. Like the trout, he has habits which we must be acquainted with in order to find him, and when found we ourselves may be found-wanting. Am 1 not a convicted boaster? Was it not only yesterday when I to myself said proudly "I'm a crackshot"?

\footnotetext{
"Deeply hast sunk the lesson thou hast given,
}

And shall not soon depart."

It requires much experience to divine the whereabouts of Bob White. If the weather be fair, start early, for the birds will be on their feeding-grounds at sunrise, and will be found in the fields of stubble, or in the midst of the rag-weed, and along the brier-fringed ditches; and do not forget the field of buckwheat, for they are especially fond of it. About ten or eleven they will cease feeding, and will seek the sunny side of some covert near a stream, where they will quench their thirst after their morning meal. Here they will dust and preen themselves, and take their noonday siesta. The birds will generally remain here till three or four hours after midday, and, closely huddled as they are, they are difficult for the dog to find.

The sportsman, if wise, will now follow the example of the birds, and seeking the quiet of some sheltered sunny nook, will take his lunch and rest himself and his dogs. How well we remember that pleasant spring-side, with the dogs stretched before us to catch the warm rays of the sun, their eyes furtively glancing at us, waiting for 


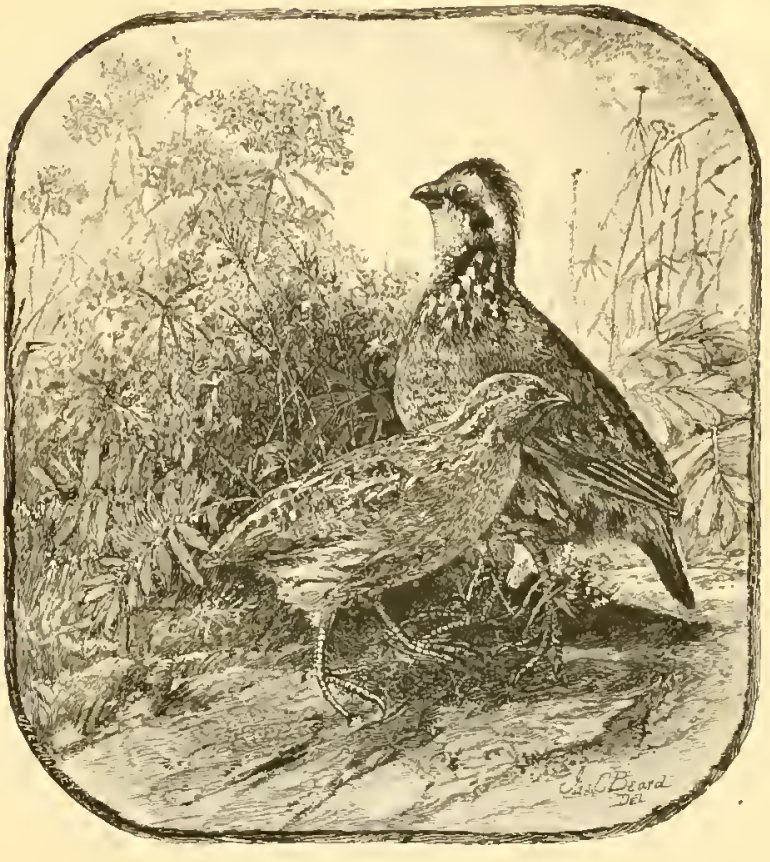

BUB WHITE AND EUROPEAN QUAIL.

their share of the lunch; the fragrant cigar, with pleasant jokes at our bad shots and untimely tumble, the generous admiration of our companions' skill, and talk about the wonderful working of the dogs. "What a picture! When that dog suddenly stopped at the end of his bound over that hillock, and with a hare in his mouth backed the Laverack bitch drawing on to a covey which she found just as he was retrieving!" "Y'es! and don't you remember, on t'other side of those woods, when she froze to the top of that stone fence when, in the act of leaping it, she winded a covey not twenty feet off on the other side?" * "Yes, good dogs! you have deserved well of us!" "So here's a glass of sherry to their long lives in happy huntinggrounds, and success to the day!" and we are off on a tramp of a halfdozen miles, which will bring to bag another score of birds and take us to the blazing hickory and bountiful country dinner of our cheery host.

If the weather is very dry, do not seek the birds on the uplands, for Bob White, though no hydropathist, likes the vicinity of water. But if your hunt occurs after a rainy spell, go to the upland stubblefields, and work your dogs along the border of the driest and sunniest of the coverts.

* Two real incidents which happened under the eye of the author. 


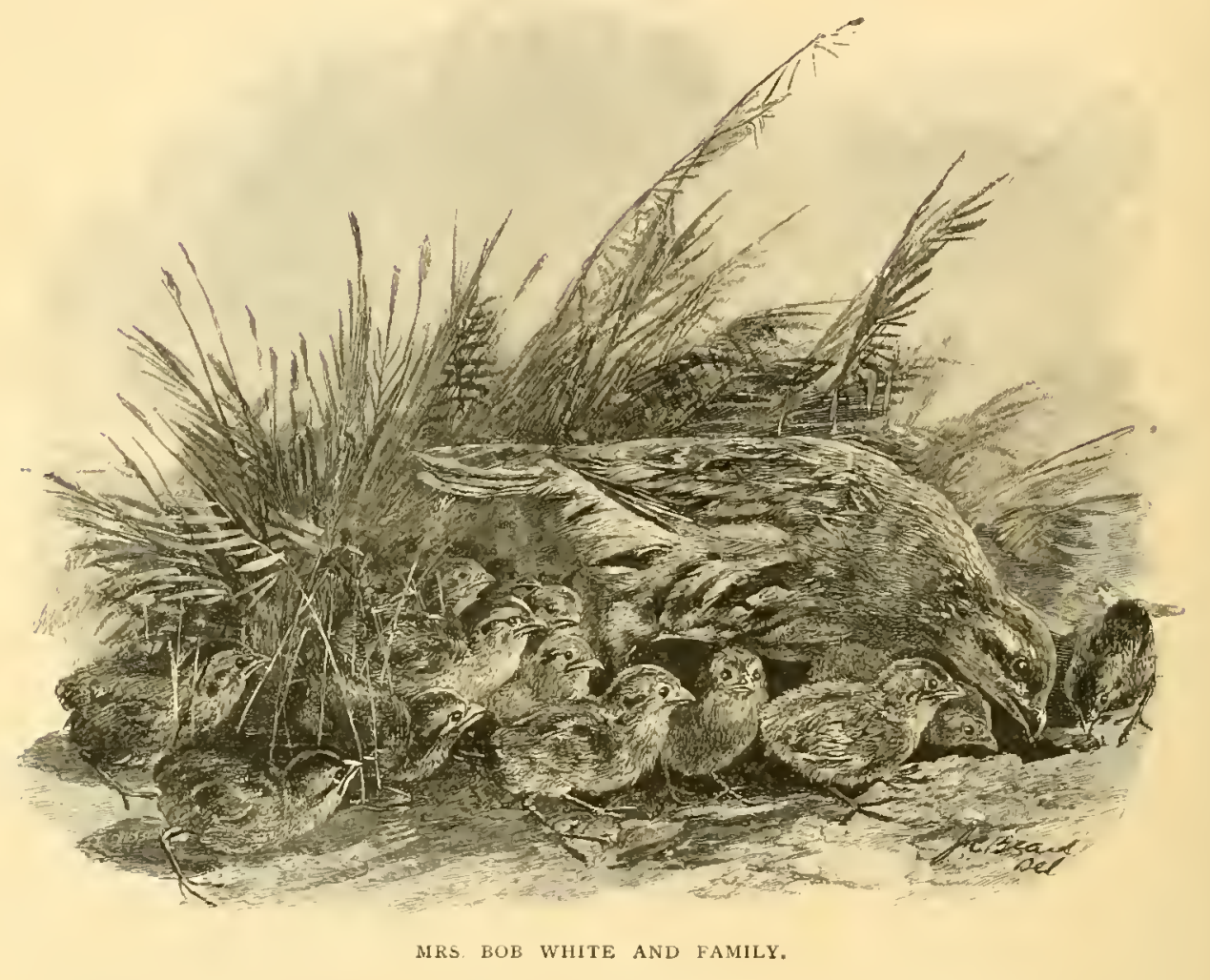

If it is windy and cold, the birds will be found in covert along the sumny lee slopes of the valleys, in the tall rag-weed and briers of the hollows, and on the sunny borders of the woods and hedge-rows. They will not now lie well to the dog, and when flushed will go like bullets into the deepest thickets. Should you hope to prevent this by getting them in between you and the dogs, you may often be mistaken, for in all likelihood they will spring over your head like sparks from under a blacksmith's hammer. The shooting is now difficult, for you will have to turn rapidly on your heel as the bird passes over you, and drop your aim just under him while he is only momentarily in sight.

If you had a fair day yesterday, but after a long spell of wet weather, and you returned home last night in a clear, cold, quiet air, you may expect to see the sunshine of to-morrow sparkling in the hoar-frost which covers the ground and all the herbage. Tarry at home till the sun has nearly melted the ice off the meadows, for you 
will get nothing but wet legs by tramping the fields while the ground is iced and while the birds are yet huddled and have not spread their scent.

When the dogs are seeking the coveys, let them range widely. When they stand the covey, do not exhaust yourself with haste in reaching them, but approach leisurely and quietly. When the covey springs be very quick, but very, a'ery steady, and do not fire till you are sure of your aim. Renember that it is your left arm and wrist that direct your gun; so grasp it well forward on the fore-end, and not near the breech, as some do. You will thus be able to give your gun that quick and firm motion which is indispensable to skill in "snap-shooting"; and all shooting at Bob White is of that character.

If it is your first shot of the season, and you are not gifted with a very steady nerve, you will do well to charge your gun with but one cartridge. By loing so, it is probable that a bird will drop to your first shot. If you had had two shots, you might have been too anxious for two birds, and thus have lost both. After two or three successes with a single barrel, try "a clouble" over the next point.

Always flush the birds yourself, for a dog "hied on" to flush may do so of his own accord when you are out of gunshot. At the springing of the corey, the dog must "down charge." or "drop to shot," and in either case hold his charge till ordered to "hold up" or to "seek dead." If he "break shot," he will often cause you great vexation in the loss of shots by his flushing birds which did not spring with their fellows, but which now get up in rapid succession, and before you have had time to reload. But a good retriever has his greatest pleasure in fetching a dead bird, and the intense satisfaction this act gives to him often causes him to lose his head and rush in on the report of the gun. The dropping to shot and retaining charge is one of the prime requisites in a dog, and is as difficult to teach a good retriever as it is essential to the true enjoyment of sport.

If the dog is unsteady, and apt to "break shot," do not load if you have fired only one barrel, for, in so doing, other birds may rise just as you have opened your gun or are handling a cartridge.

After the covey has been scattered, give your dog but little range. Keep your eye well on him as you approach the ground where you or your gillie has marked the birds. Be ready, if he be rash when $43^{A}$ 


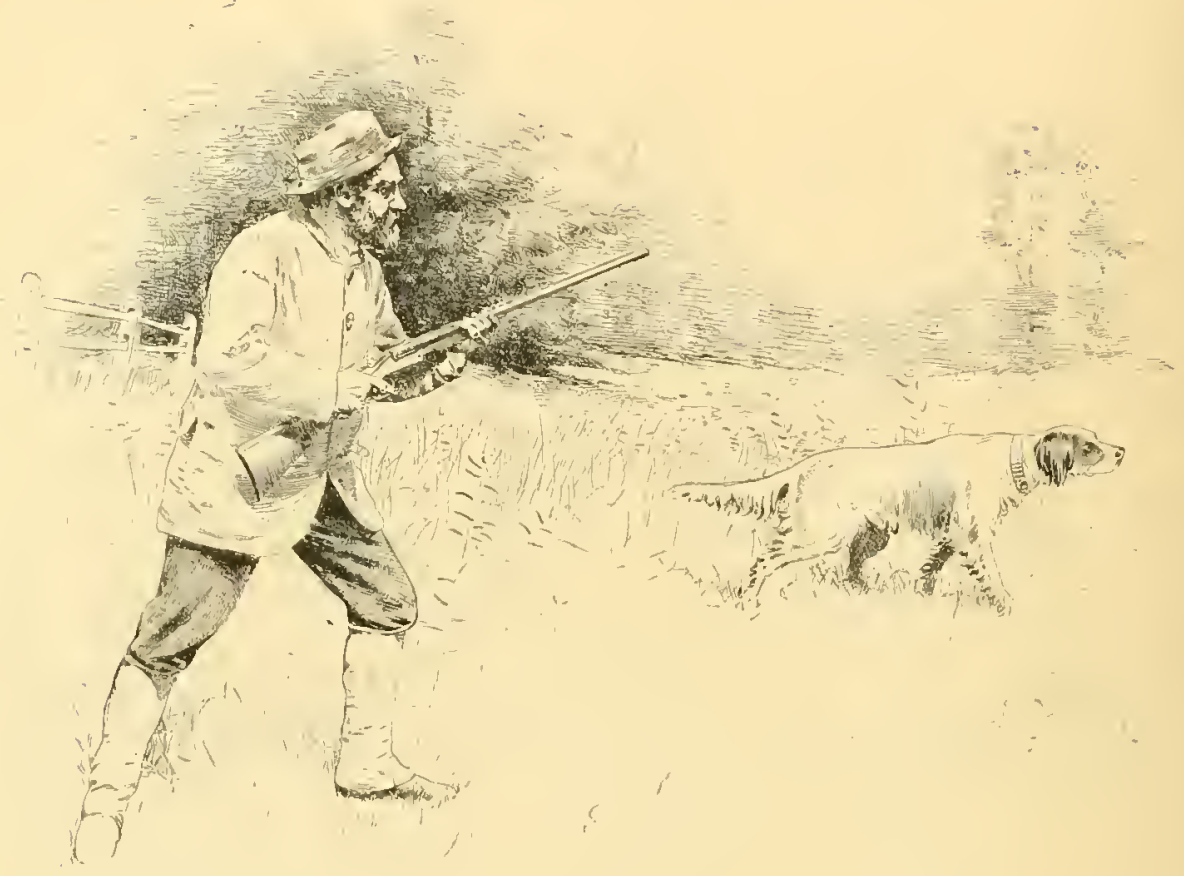

he "winds" the birds, to chide him, in a voice just sufficient to be heard. Stcady, there! To-ho!

Above all things, do not gret excited and gain in voice as you lose in temper. Take it leisurely, be quiet and cool, if you would enjoy the sport and kill cleanly. By all means, train your dog, if possible, to hunt without shouting to him. A short, quick whistle should call his attention. Then give him the order he waits for by waves of the hand: forward for "on "; a wave to the right or left, as you may desire him to quarter; while the upraised arm, with the palm of your hand toward him, should bring to "to-ho." Or, two short whistles may be often better for the same order, while one much prolonged should bring him to "heel." A dog that with head well up winds his birds and is stanch on a covey, that will drop to shot and retain his charge till ordered to retrieve, and will receive and obey your orders from the whistle and the motions of your arm and hand, is a dog indeed.

After the covey has been flushed and shot at and the birds have been well scattered, the real enjoyment in Bob White shooting 
begins. One may now have single and double shots over all kinds of ground and at birds taking every conceivable direction of flight. But often, the best of markers will be baffled in finding the birds whose flight he has carefully noted after the springing of the covey. The following incident is typical of the experience of all sportsmen: A large covey was once flushed and shot at, three birds falling to our fire. My friend and I watched the other birds as they flew across a swale, where we sprung them, and we saw them sail with extended wings over a large field on the valley slope, into which they dropped after a few flutters of their wings. On our approach to the field, the dogs quartered it, but they did not come to a stand. One dog flushed a bird on which he came suddenly, and he at once "charged." We found the dogs useless, and calling them to "heel," we walked slowly into the sedge. When we were about in the center of the field, the birds began to rise successively and singly in all directions - in front, on our side, and sometimes behind us, giving us delightful shots. Similar experiences recurring so often have made some sportsmen suppose that Bob White has a voluntary power of retaining his scent, and thus in time of danger eludes the dogs. But this well-known occurrence can be explained otherwise. Often when the friglitened birds alight, they do not run, but instantly crouch with their wings closely pressed against their bodies, so as to squeeze themselves into the smallest compass. This act, no doubt, causes a diminution in the emission of their effluvia. But if the birds have run after alighting, the dogs will surely find them, provided they do not run rapidly and to great distances, in which case the dogs are baffied by the multiplicity of scents; and especially will this be so if the dog gets on the trail of a bird which doubles like a hare on its track.

This haffling of a dog on ground containing a recently scattered covey shows that time should be allowed for the birds to recover from their confusion and begin to run together before you "hie on "the dogs to find them. If you are familiar with the country, and can remember the lanclmarks, the proper method is to flush two or three coveys, and then begin to hunt the scattered birds of the respective coveys in the order in which you flushed them.

To become a successful shot at Bob White, the sportsman should bear in mind that Bob, immediately after he has sprung, flies with a velocity which probably exceeds that of any other bird; and also that, 
unless fairly hit, he can carry off a number of pellets. When a covey springs, it rises at a considerable angle with the ground. Hence, in shooting at a bird in a flushed covey, the sportsman of unsteady nerve and sluggish muscles is apt to undershoot, the bird rising with such velocity that by the time the gunner has brought his gun into position the bird has passed above his line of sight. As a rule, I think that about one second generally elapses between the instant of springing of the bird and the moment of fire. This interval gives the bird time to gain a moderately horizontal line of flight, and allows the sportsman to get a fair aim.

In shooting at an incoming bird, let him be out of sight, and just below the rib of your gun at the moment of firing. At a bird going overhead, wait till he has passed well over; then shoot under him. At straightaway shots, hold a little high, so that you just catch a glimpse of the bird over your barrels.

In shooting at cross shots, it should be understood that the velocity of an ounce of No. 8 shot driven with three drams of powder is near to 900 feet per second. In that second a Bob White, if under full headway, will go 88 feet, if we estimate the velocity of his flight so low as only a mile a minute. If he is flying directly across your line of sight and thirty yards off, the shot will take one-tenth of a second to reach that distance, and in onetenth of a second the bird has gone over eight and eight-tenths feet. So, if we should fire a snap-shot directly at a cross-flying bird thirty yards distant, the center of the cloud of shot'would fall about nine feet behind him, and he would pass by unscathed. To kill him "clean," you must hold nine feet ahead of him. To some sportsmen nine feet may seem a great distance to "hold ahead" on a cross-flying bird thirty yards away, but not to those who have noticed attentively the relations of the line of their aim to the position of the bird at the wery moment they hear the report of their gun. Also, estimations of distances in the air beside a small and quickly moving object are very unreliable, and often when the sportsman thinks he has fired only one foot ahead of a bird he has really held ahead three feet. Let some one suspend horizontally in the air an unfamiliar object that must be distant from fence-rails and other things whose dimensions you know, and then guess its length. You will, after a few trials, be satisfied that the estimation of actual lengths at thirty yards is very fallacious. 
Bob White is a tough and hardy little fellow, and the true sportsman, always a lumane man, will remember this and endeavor to kill him outright. Often a bird will fly two or three hundred yards, though mortally wouncled. It is the duty of all sportsmen to watch carefully the flight of the birds he has shot at, and his experience of the nature of their flight will tell him if the bird has been struck. If he concludes that he has been, then it is his bounden duty to bring that bird to bag, and that right quickly.

The extraordinary vitality of this vigorous bird was once forcibly impressed on me. A covey was flushed at about one hundred yards from the edge of a wood. Only a few of the birds flew to the woods. One of them, going at a tremendous velocity, crossed my position at a distance of about forty yards. Holding my gun at what 1 judged was the proper distance ahead of him, I firect. This was the only shot fired at the birds making for the wood.

"Sam," said I to our negro gillic, "I think I hit that bird."

"No, sah," said Sam; "I tink not, sah. He's a-gwine to whah he forgit he lef' suffin, sah!"

Sam is a good marker, and has carefully watched the flight of hundreds of birds shot at. Y'et I could not entirely satisfy myself that the bird was not fairly hit, though he kept straight on in his vigorous flight. A sprained foot prevented rapid walking, and my companion entered the wood, with the dogs, before me. As I struck the edge of the woods I heard the report of his gun, and, after proceeding about one hundred yards, I heard a second shot, and in another instant a bird tumbled through the air and fell about a dozen feet in advance of me. I called out:

"I have them both!"

"Both what?" said he. "I only shot one bird, and the other flew away from your direction and I missed him clcan."

The bird my friend shot lay with his head toward me; the other, a large cock, lay on his back with his bill pointing toward the other bird, and not more than a foot from him. Both birds were warm. The large cock was the one I had fired at. He was struck fairly in the head and chest, and yet he had pitched into the woods and gone altogether nearly two hundred yards before he succumbed to his death-wounds.

Rules for shooting are of value, and directions founded on theory may serve to inform the beginner why he misses, and 
thus show him the way to improvement in his marksmanship; but no matter how well we may know how the shooting should be done, to do it is an art which can be attained only by the assiduous cultivation and development of certain peculiar natural gifts.

A beginner who, out of three shots, can bring one Bob White to bag, need not be discouraged or ashamed; with sufficient practice, he may one day kill one out of two birds fired at. The sportsman who does not select his shots (and no man really a sportsman can do that), but takes his chances in the open and in covert on all birds which offer a probability of success to his skill, and who, the season through, brings to his bag three out of five birds fired at, is an accomplished sportsman. If he can make three successful shots out of four, he is a phenomenal marksman.

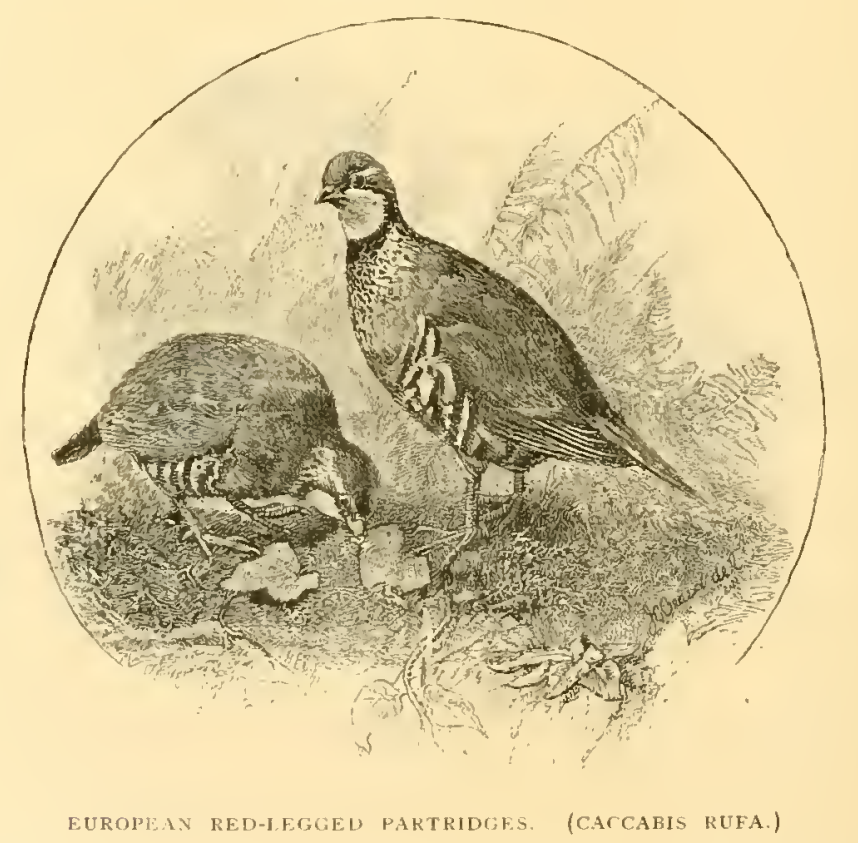

Last season, I shot with the best wing-shot I ever hunted with. At my request, this gentleman, Mr. H. K. B. Davis, of Philadelphia, has written for me the following statement, which, coming from one who has had such unusual opportunities in hunting Bob White, in North Carolina, cannot fail to be of interest to all sportsmen:

"I find, on referring to my record containing the number of coveys found and the number of birds killed, that the average is but little over three birds brought to bag 
from each covey flushed. When it is remembered that the usual number of birds found in a covey runs from ten to eighteen, it will give some idea of the difficulties to be overcome, and the large proportion of lirds that escape even with good shooting, as the same record shows that seventy-three out of every hundred birds shot at were brought to bag. This record, extendling over four years and running "up into the thousands of birds killed, gives very reliable data to base calculations upon.

"The dogs 1 hunted with 1 have every reason to believe are above the average in speed, endurance, and scenting powers; so there is only one conclusion to arrive at, and that is that these birds are exceedingly difficult both to find and to kill.

"There are many opinions as to the proper method of shooting on the wing. Some hold that 'snap-shooting' is the only way to shoot successfully. Sinap-shooting is generally understood to consist in putting the gun to the shoulder and firing the instant it is in position; making the allowance to the right, left, under, or above, as the case may require, before raising the gun; just as you point your finger, instinctively, to any object without having to sight along it. Others are just as sure that no one ever shot decently unless he followed the bird with the sight on the gun and covered it before firing. Some, again, insist that you must swing your gun along with the course of the bird after pulling the trigger. In my opinion, every one who has shot very much acquires a style peculiar to himself, and depending on his temperament and the kinds of birds he has had the most practice on.

"It may be well to give a few hints as to the necessary allowance to be made in taking ain at a bird flying so rapidly as Bob White. The most difficult shot is a bird coming directly toward you, and flying about twenty feet above the ground. I have been quite successful in this shot, by holding directly at the bird until he is within range, and then, just as I touch the trigger, I raise the muzzle of the gum about six inches. I would only advise trying this shot where there is more than one bird, and you want to use the second barrel. When there is only one incoming bird, wait until he passes over you, and then by shooting under him, more or less, according to the speed and elevation at which he is flying, you will be pretty sure to kill.

"In cross shots, at thirty yards and over, hold above the line of flight and from six to nine feet ahead of the birl. This may seem entirely too much, but I have frecuently shot Bob White when flying parallel to a rail-fence, when I aimed the full length of the rail ahead of him, this being nearly twelve feet."

The shooting of Bob White demands such quick action in handling the gun, and such long tramps to discover his retreats, that I would advise light guns for his pursuit. A pound more in weight will be felt in the afternoon of a long day's hunt, and the rapidity and ease with which a light and short gun can be handled makes it very efficient in snap-shooting in covert. A twelve-gauge sevenpound gun, of twenty-eight-inch barrels, carrying one ounce of No. 8 shot and three drams of powder, or a sixteen-guage of six pound's weight and twenty-six-inch barrels, charged with seven-eighths of an ounce of shot and two and three-quarter drams of powder, is to 
my liking in this most enjoyable of field sports; in which occupation may next season find you, my sportsman reader, who, though now weary and city-worn. will then forget your uncertain triumphs and petty vexations, when,

"Full of the expected sport, your heart beats high As, with impatient steps, you haste to reach The stubbles, where the scattered grain affords A sweet repast to the yet heedless game.

Near yonder hedge-row, where high grass and ferns The secret hollow shade, your pointers stand.

How beautiful they look! With outstretched tails, With heads immovable and eyes fast fixed; One fore-leg raised and bert, the other firm, Advanced forward, presses on the ground!"

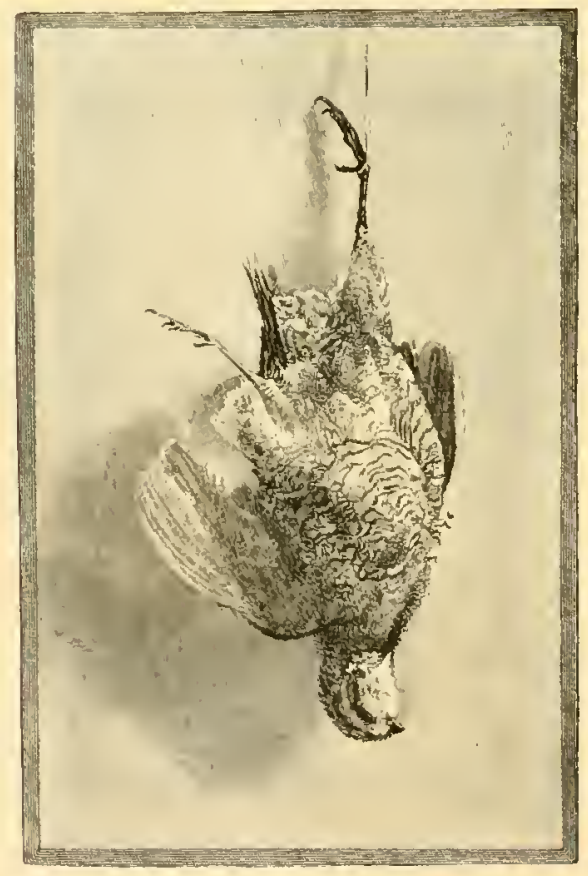




\section{THE AMERICAN WOODCOCK.}

By GEOR(iE BIRI) GRINNELL, PH. D.

T

HERE is a little russet-coated bird, dear to the heart of every sportsman, whose name is Philohclir minor. He is found in Canada and in Florida, in Maine and in Kansas, but the high, dry plains of the Rocky Mountain regrion limit the extension of his range westward, for he is a bird that loves moisture and cool, dark thickets.

The woodcock is not often seen, and is quite contented to be overlooked. He has no brilliant song to catch the ear, no gaudy plumes to attract the eye, nor does he perform graceful evolutions high in air in the broad glare of day. He is truly a modest fowl, and, except at night, or during the twilight of morning or evening, he does not willingly venture into situations where he can be viewed by the casual wanderer through field or wood. One who desires to make his acquaintance must penetrate into the depths of the most tangled swamps to find him at home. Even here, during the day, he is usually half asleep. Not so drowsy, however, as to be unaware of the approach of an intrucler. The soft rustling of the leaves, the occasional snapping of a dry twig, and the sound of the heavy footfall rouse him from his doze or his day-dream. He moves sideways bereath the spreading leaves of a tuft of skunk-cabbage and, with head turned on one side and great eyes spread to their widest, watches for the approaching form. Once in a while something may cause him to take the alarm, and dart away before it is within sight; but usually he lies close, - and when he rises, it is near at hand. He springs from the ground, uttering a shrill, twittering whistle, and twists about in his upward flight to dodge the branches which spread 
in a net-work above him, until he has topped the undergrowth, and then darts off in a straight line for fifty or a hundred yards, to plunge once more into his beloved cover.

In some parts of Canada the woodcock is known as a "bogsucker," while in the sea-board counties of Virginia he is a "night partridge" or a "pewee," and again, in portions of North Carolina, a "night peck."

As compared with his European cousin of the same name, the American woodcock is a small bird, weighing only from five to nine ounces. He is eleven or twelve inches in length, and of this the bill occupies from two and one-half to three inches. The plumage below is rich russet-brown, paling, on the upper breast, sides of the neck, and forehead, to ashen-gray. The crown is black with two or three cross-ines of tawny, and the back is curiously mottled with tawny, ash-gray and black, the latter predominating. The tail feathers are black, barred with tawny, their tips smoky-gray on the upper side and snow-white beneath. The legs and feet are pale flesh-color, the bill dark horn-color at the tip, becoming paler at the base, and the large, soft, humid eyes are brown.

The group of birds to which the woodcock and his near relative, the so-called "English" snipe belong, have a number of curious anatomical features, which have a direct relation to their mode of life. In most of the species the eye is very large, and placed high up and far back on the head, and the external opening of the ear is directly beneath, instead of behind it; the brain is tilted up, so to speak, and hence its base looks forward, instead of downward, as is usually the case with birds. The bill is soft and swollen at the tip, and is abundantly supplied with nerves, thus becoming a very delicate organ of touch. The birds are nocturnal or crepuscular in habit, and secure their food by probing and feeling for it in the soft ground. But they do not always, even if their brains are one quarter turned round, fall an easy prey to their human enemies.

The woodcock is almost the first of our migrants to return in the spring, and soon after his arrival, which is usually in March, he makes his presence known to those who understand where and when to listen for him, by the curious night song with which he wooes his mate. On warm, moonlight evenings he takes his flight high in air, and when far above the earth utters at frequent intervals 


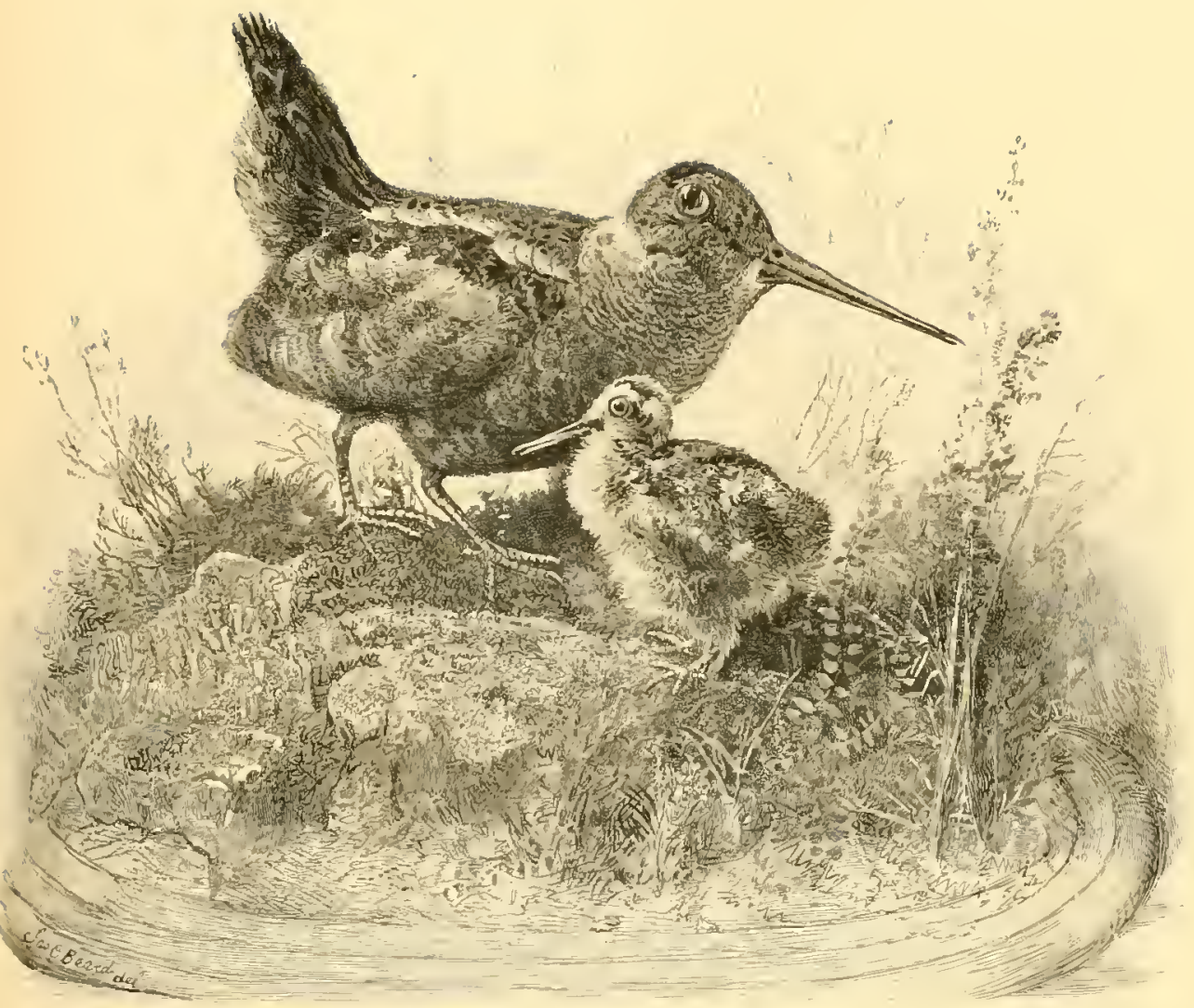

WOODCOCK AND YOUNG.

(DRAVN BY JAMES C. BEARD, AFTER SPLCIMENS MOUNTED BY W. T, HORNADAY.) 

a single note, somewhat like the ordinary call of the night-hawk. This he continues for some time, and then suddenly pitches downward from his height, and drops into cover. Here the female is waiting for him, and about her he struts, with head thrown back, wings trailing, and tail spread, - a parody on the turkey-cock of the farmyard. The nest is a rude structure of dead leaves and grass, and is usually placed under a fence, or by a log in some thick swamp, or perhaps on a tussock or bit of high ground in some alder run. The eggs are generally four in number, and are of a dull cream color marked with large spots of bright brown. As soon as the young emerge from the egr, they leave the nest and follow the mother. Thenceforward their development is rapid, and young birds have been found well able to fly by April 10. Two broods are usually reared in the Niddle States. A curious habit of the woodcock. which, though well attested, is as yet but little understood, is its practice of carrying its young from place to place, apparently to avoid danger. Exactly how the mother bird does this is, owing to imperfect observation, as yet a question, but the weight of evidence groes to show that she holds it clasped between her thighs, as a rider does his horse, and does not carry it in her weak and slender claws. She will sometimes thus transport her young for a hundred yards or more, and if pursued will even make a second flight with it.

By the last of July in favorable seasons the young of the second hatching are quite fit to look out for themselves, and early in August the woodcock disappear; that is to say, can no longer be found by those who search for them. In September they collect once more in their accustomed haunts, and they are fat, in good plumage, and fit for the gun.

Formerly it was legal all over the country to kill this species during the month of July, at which time many of the young were barely able to.fly, and when, after a late spring, some of the mother birds were still brooding the eggs of their second hatching. This practice, although often shown to be most pernicious, is still permitted in some States, but is universally condemned by the better class of sportsmen.

The coming together in September of the birds which have been mysteriously hidden away, no one knows where, is often loosely spoken of as "the first flight," or, in other words, is regarded as the 
beginning of the southward migration. It is, however, nothing more than a collecting in favorite food localities of the "home birds"those which have spent the summer, or been reared, in the neighborhood.

The first true migratory movement of the woodcock usually follows a sharp frost early in October. The birds are not gregarious, and for the most part move singly; though two, three, and even four have been seen flying together, and sometimes six or eight may be started in succession from a single small picce of cover. The migration is performed during the night; though in dull, cloudy weather there is some movement in the day-time. Their flight is low over the fields, and sometimes half a clozen will pass by in an hour. This low flight is swift and the birds are often killed by flying against telegraph wires, and sometimes dash themselves against buildings.

In New York and New Jersey, the woodcock may almost be considered as resident, for in mild winters a few birds are to be found late in December and early in February. The bird does not seem especially to dread the cold, but the freezing up of the ground cuts off the supply of food, and so obliges it to move southward. Often, however, in the coldest weather, an old fat bird may be found about some warm spring hole, where the ground never freezes; and here, if undisturbed, it may remain all through the winter.

The principal food of woodcock is the earth-worm, though they also devour many insects which are to be found in the damp situations which they affect, and have been seen to catch butterflies. The " angle-worm," however, is the main reliance of this species, and the number of those which a single bird will devour in a given time is astonishing. Audubon says that a woodcock will clevour in a single night more than its own weight in worms, and some experiments on this point, recently made on a captive bird, entirely confirm the observations of the great naturalist. This specimen was apparently a male, and weighed, at the time of its capture, five ounces. His cage was two feet long and one deep, and had been fitted up for him by covering the bottom with long, dry moss, except in one end, where there was a box of wet earth, eight inches square and three deep. The bird was fed altogether on earth-worms, and these were buried, a few at a time, in the mud. From the first, this woodcock manifested very little fear of man; and it was but a short time 


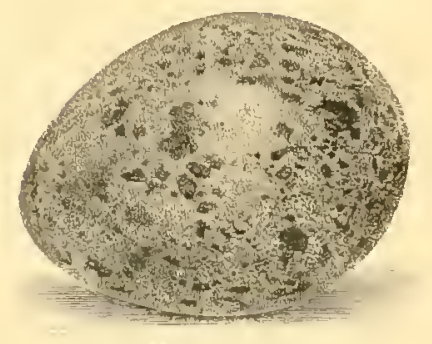

EGG OF WOODCOCK

before he so well understood what the opening of his cage door meant, that at the approach of his owner he would run to his "feeding-ground" in anticipation of the meal. So eager was he that it was necessary to push him away to the other end of the cage while the worms were being buried. As soon as he was permitted he woukl run to the mud and "bore" for the worms. This was a very interesting proceeding. He would push the point of his bill into the earth at an angle of about eighty degrees, and by two or three deliberate thrusts bury it to the base. While doing this the left foot was slightly advanced, and the body somewhat inclined forward. When the bill was wholly buried, he stood for a few seconds perfectly still, as if listening. Perhaps he was doingr so; but it seems more probable that he was waiting to see if he could perceive any movement in the earth near his bill. If none was felt he would withdraw his probe and thrust it in again a little further on. If, however, he detected any movement, the beak was hastily withdrawn, rapidly plunged in again in a slightly different direction, and the unfortunate worm was brought to the surface and devoured with evident satisfaction. When the supply of worms was exhausted the bird carefully cleansed the mud from his bill by means of his feet and, after giving himself a shake or two, retired to the farthest corner of his cage, buried his long beak among the feathers of his back and set tled himself for a quiet after-dinner nap. Sometimes he would thrust his bill down among the moss once or twice, and then walking to his water-dish would wash it by slowly moving his head from side to side. Ifter he had been confined for over a month, the worms fed to the bird during twenty-four consecutive hours were counted and weighed, and he was found to have eaten two hundred worms, weighing five and one-quarter ounces. At the end of this 
time he was still eager for food. Somewhat later he had increased one ounce in weight, and he now ate in twenty-four hours no less than eight ounces of worms.

If it were worth while to have a special gun for woodcock shooting, it should weigh not more than seven pounds, with 28 -inch barrels, and be of 12 or 16 gauge; but the one used for quail will answer every purpose. The charge should be three drams powder and an ounce of 12 shot. As, however, quail and ruffed grouse are almost sure to be started during a day's tramp after woodcock in the autumn, a more general charge, three and a half drams powder and an ounce of 10 shot is better. The dog is a most important auxiliary in woodcock shooting. A very few sportsmen employ cocker or field spaniels, which are trained to range close to the gun, and to give tongue as soon as they strike the scent, thus warning the shooter of the proximity of the bird, and preparing him for its possible rising. liut most men use the setter or pointer. A good woodcock dog should work close: that is, within sight of the gun. Often where the undergrowth is very thick, it becomes necessary to attach a bell to the (log's collar, so that if he pass out of sight for, a few moments, his whereabouts may still be known by the sound.

Late in November you will still find a few birds, and at this time they will all be lusty and strong of wing, and will test your skill. Cross the meadows then, and go down into the swamp, working along near the edge, where the underbrush is not too thick, and the soil under the leaves, as you can see in the cattle-tracks, is rich and black. Just beyond you on the left, a steep hill-side rises sharply from the edge of the swamp, its surface overgrown with low cedars, sumacs, and bayberry bushes. The old dog comes out of the swamp and turns toward the slope and, as he crosses before you, glances back inquiringly. He knows the hill-side, and understands as well as you do, that a cock is usually to be found on that warm southern exposure, at this time of the year. No need to wave the hand or use any elaborate signal to tell him to work up among the cedars and through the brush. A little sidewise movement of the head, and he is breasting the steep ascent, and rustling among the twigs and over the crisp leaves, while you walk along a cowpath at the foot of the slope. If there be a bird there, it will be sure to fly toward the swamp, and must, therefore, cross in front of you. For a few moments you hear the $\log$ as he works along 
above you; then the sound ceases and, as you pause to listen for it, there comes to the ear that shrill whistle, so like the midsummer twitter of the kingbird, that warns you to "mark cock." You see a brown flash among the green cedars, and the bird darts out to plunge into the swamp; but as he sees you, he turns sharply and fies down the path, straight away. You have plenty of time; bring up your gun deliberately, cover the bird and, when it is about thirty yards distant, fire, and it is yours. It the report of the gum your dog appears on the bank above, pauses a moment until you have slipped another cartridge into the gun. and then dashes off toward where the bird lies. I word steadies him as he approaches it, and after quartering once or twice, the scent reaches his nostrils. He feels for it, then pauses, and at command steps forward, gently takes the bird in his mouth, and trots slowly toward you, expressing as much pride and satisfaction in his face and in his slowly wagging tail as if he had captured the prize without any assistance of yours. On again, along the border of the swamp, sometimes stooping low to pass beneath the tangled underbrush, or forcing your way through the thick alders, making the dead stems crack and fly, or passing through a spot free from low shrubs, where the tall, gray trunks of the hardwood trees stand far apart, and the footfall is scarcely heard on the damp, dead leaves. For some time the dog works quictly ahead of you, manifesting none of the signs which would lead you to suspect that birds were near: but as you approach a little arm of the swamp which runs up a narrow ravine, the merry action of the setter's tail warns you to be prepared for the point. Yes, there where the wind has swept aside the leaves, exposing the black mud beneath, you see in it dozens of little round holes which tell you that the long bill has been at work here. Suddenly he stops and stands quite still, except that the tip of his tail moves a little from side to side. Is you step up to him, he moves on again, very slowly and cautiously, and then suddenly stops and remains motionless. It is a pretty picture, and one that the sportsman never tires of watching and admiring. The dog's forefoot is raised in the act of stepping, his tail is straight and rigid, head a little above the line of the back and slightly turned to one side, ears a little pricked. Walk up beside him and look at his face, and you will see, what his attitude already indicates, that he is laboring under strong excitement. His nose is perhaps within a few inches of the bird, 
and the scent is strong. You can see his eyes roll as he looks over the ground before him. His forehead is knotted into a frown, which shows how thoroughly in earnest he is. If you did not care about getting the shot, you might take the dog up by the tail and the back of the neck and throw him down to the ground without his relaxing a muscle. He would remain in exactly the position he had when he touched the earth again This is an experiment which one may easily make when out quail-shooting, and it is interesting to see how completely the knowledge of the presence of game overcomes the will-power of the animal. He will not make a movement after he has established his point. You may put the raised forefoot on the ground, and lift the other one, or may raise a hindfoot-cverything remains just as you placed it.

But your bird does not usually lie long enough for any of these operations to be gone through with. He is likely to fly up, from beneath the dog's nose, so close to you that you cannot shoot without running the risk of either missing altogether, or else blowing him to fragments, and will then, perhaps, dart behind a thick cedar, or twist into some alders, through which you can hardly see to shoot.

The "alder runs," so numerous throughout the New England States, are most satisfactory places to work for woodcock. These are usually the channels of little brooks, a few feet below the greneral level of the open meadows through which they pass. The ground is too damp to be successfully cultivated, and the farmer gives it up to the black alder, which attains a height of from fifteen to twenty feet. Beneath these, in the wet, springy soil, the skunk-cabbage (Symplocarpus), a variety of ferns, and many other moisture-loving plants grow in wild luxuriance. These "runs," or swales, are often so narrow that the best way to hunt them, if two are shooting together, is for one to take each side and let the dog work between them. The birds, when started, will either show themselves above the alders or, what is more likely, will break out on one side or the other, and fly forward along the edge of the bushes, giving a perfectly open shot, and one which not even a tyro ought to miss. In working out such places the bell should be put on the dog, for it is often so dark beneath the thick growth that it is difficult to see him. Should he come to a point and the bird decline to rise, a heavy stick or stone thrown into the bushes, just in front of him, will often flush it. 


\section{SNIPE-SHOOTING.}

BY GEORGE BIRD GRINNELL, PH。D.

T

HE Wilson's snipe is, in lhabits and appearance, very unlike his near relative the woodcock. While the latter is a rather heavily built, thick-set bird,-stocky, so to speak, - the snipe is much more slim and elegant in form. It is much smaller, too, weighing only about four ounces. It very closely resembles the jack snipe of Europe, - whence its usual appellation, "English," of which it is, according to the present views of ornithologists, only a variety (Gallinago media Wilsoni). In length it almost equals its cousin, already referred to, measuring from nine to eleven inches. The crown of the head is black, with a median stripe of cream color, the neck speckled with brown and gray, back variegated with black, reddish brown, and tawny, the latter forming longitudinal stripes on the inner long feathers of the shoulders. The tail is barred with black, white, and chestnut brown, the sides are waved with dusky, and the lower breast and belly are white. The bill is dark, and the feet and legs are pale greenish.

This species has a very wide distribution, and is found throughout the whole continent. It only insists on moist feeding-grounds, and so may be taken on the borders of streams and about the sloughs of the IVestern plains, around the edges of the alkaline lakes of the great central plateau of the Rocky Mountains, and in the marshes and along the river bottoms of California, as well as in the East and the Mississippi valley.

It passes the winter in the Gulf States, where at that season it is extremely abundant, and begins its northward migration early in February. By the last of that month it has reached the marshes of 
North Carolina, and sometimes Virginia ; and it usually makes its appearance in New Jersey and New York about the last of March or the first of April, though the date of its arrival depends almost entirely on the weather, and the consequent condition of its feedinggrounds. As long as the meadows are ice-bound it is useless to look for snipe; but as soon as the frost has come out of the ground, especially if the last thaw be followed by a soft, warm rain, the shooter may, with some prospect of success, visit the little spots of wet land, or the more extensive marshes, where his experience of former years tells him that the birds are likely to be found. At this time of the year they do not tarry long: but the places of those which pass on are at once filled by later comers, who are in turn replaced by others, so that snipe are usually found in greater or less abundance until after the first of May.

This species does not ordinarily breed with us in any considerable numbers, most of the birds passing the season of reproduction north of the United States line. Still, many rear their broods in the State of Mlaine, and their nests have been found in Connecticut, New York, Pennsylvania, and even further south. The nest is built on the high ground near some wet meadow, - or sometimes on a dry one if a tiny brook murmurs through the grass near at hand, - and is even of slighter construction than that of the woodcock, being little more than a depression in the ground lined with a few blades of grass. Four pointed eggs are laid in this, yellowish-olive in color. thickly spotted with black and dark umber. The young leave the nest as soon as they are hatched and follow the mother, or, as the naturalists would say, they are præcocial.

The snipe is essentially a bird of the open, and is rarely found in cover. Occasionally in the spring, when a late fall of snow occurs after the birds have come on, covering for a day or two the meadows where they feed, they may be found in alder or willow swamps near their usual haunts, probing the mud about the warm springs where the snow has melted; but as soon as the ground is again bare they leave such retreats and at once repair to the open. Sometimes, too, when persistently pursued on the marshes, they will take refuge among woods or even in dry and dusty corn-fields, but will only remain there for a few hours.

The favorite feeding-grounds of the snipe are fresh meadows. where the ground is always moist and the soil rich. One can tell as 


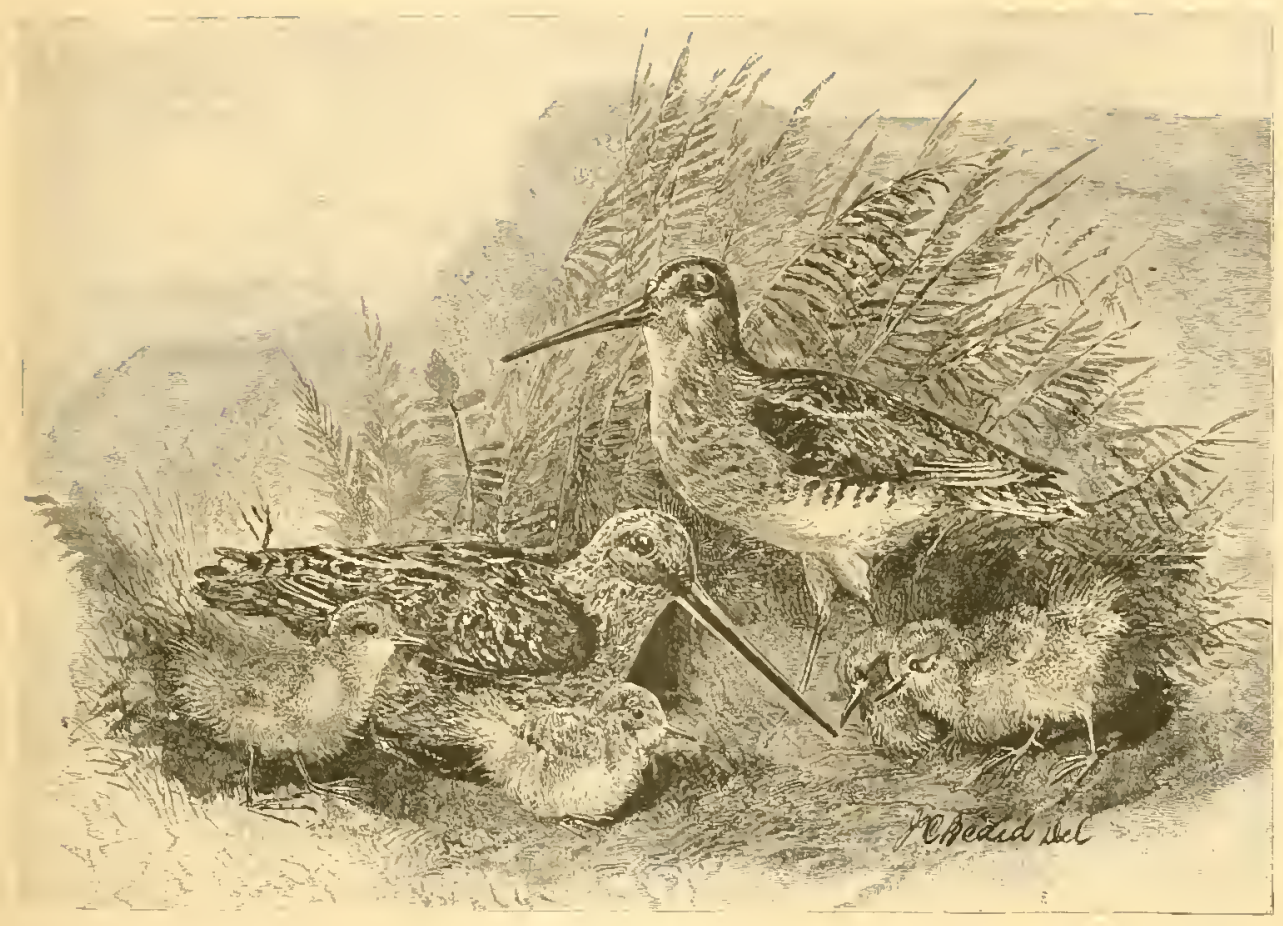

A WILSON'S MIPE FAMILY.

(DRAWN BY JAMES C. BFARD FROM SPECINLENS IN THE CUILECTION GF DR, E, B, WHITINGHAM, MOINTED RY DAVII, D. DICKERSON.) 

soon as he steps on the meadow whether the birds have recently been here; for in the cattle paths or in jlaces where the hogs have been rooting, or on the bare side of a tussock where no grass grows, the soil will be perforated by numerous tiny holes, showing where the bill has been inserted in the mud in the search for food. The presence of high grasses or reeds may sometimes keep the birds away from marshes to which they would resort in numbers if it were not for the luxuriance of the vegetation. They do not like to alight among such thich cover, and besides, they cannot easily get at the ground. It is therefore customary, in the early spring before their arrival, to burn over such tracts, and places that have been treated iin this way are favorite resorts for the travelers.

At present the Wilson's snipe is shot at all times and seasons, and has no protection under the law. The result of this unwise destruction is clearly seen in the greatly diminished numbers of the birds which anmully visit our more accessible meadows. If a female snipe, killed in April or May, be dissected, she will be found to contain egos in an advanced stage of development, varying in size from a marble to an egro nearly ready for exchusion. Many of the birds are paired long before they leave us in spring. They certainly should not be shot at this season, just as they are about to rear their young. Snipe-shooting in autumn is much more satisfactory, and the birds appear to be more numerous than in the spring, because at this season their feeding-grounds are more contracted, and they concentrate on the meadows that are always wet, and about ponds and marshes which have margins of black mud, in which they delight to bore. The prospect of finding them is thus much better than when they are dispersed over a much greater area.

The main body of the snipe leave us by the latter part of November, but a few prolong their stay into December, lingering as long as their feeding-grounds remain open. As with the woodcock, the cold is only indirectly the cause of their departure: the impossibility of their longer obtaining food being the immediate motive which drives them south. On the Laramie plains, where in winter the temperature falls sometimes to $-30^{\circ}$, and even $-40^{\circ}$. Fahrenheit, a few snipe are to be found throughout the winter, about certain warm springs which never freeze.

Few of our birds are so poor in local names as this one, for it is almost everywhere known either as the "English" or the "jack" 
snipe. Along the New England coast, however, it has an appellation which is rather curious. Is the bird arrives about the same time as the shad, and is found on the meadows along the rivers where the nets are hauled, the fishermen, when drawing their seines at night, often start it from its moist resting-place, and hear its sharp cry as it flies away through the darkness. They do not know the cause of the sound, and from the association they have dubbed its author the "shad spirit."

The snipe is either a bircl of weak mind, deplorably vacillating in character, or else he is much more shrewd and profound than any one thinks. At all events, he is notorious among sportsmen for two characteristics, denoting either high intelligence or lamentable indecision.

Most birds when they rise from the ground appear to have some definite idea of the direcrion in which they wish to go, and having started in a particular line of hight, keep to it, unless turned by some alarming apparition before them. Not so with the snipe, however. He springs from the ground uttering his curious squeaking cry, darts a few yards one way, changes his mind, and turns almost at right angles to his original course; then he appears to think he has made a mistake, and once more alters his direction, and so twists off, "angling" across the meadow until he is safely out of gunshot. He then either rises high in the air and swings about for awhile, looking for a desirable spot to alight, or else settles down into a straight, swift course, which he keeps up until his fright is over or he has come to a spot which is to his liking, when he throws himself to the earth, and with a peculiar toss of his wings checks his progress and alights. The eccentric zigzag flight of this species is very puzzling to many sportsmen; and some who are capital shots at other birds appear never to be able to calculate the movements of the snipe. The secret of success in killing these birds consists, we believe, in great quickness, - that is, in wasting no time in an attempt to follow their flight, but in pulling the trigger at the moment the gun is on the object. The peculiar cry which is uttered at short intervals during its flight is sometimes extremely irritating. especially after one has missed with both barrels. What appeared when first heard to be only an expression of fright, or a call of warning to its companions, sounds to the disappointed shooter, as it comes back to him 
more and more faintly from the distance, very much like a note of derision.

The other characteristic for which the snipe is noted is the eccentricity and irregularity of its arrival and stay with us during the migrations. That snipe are "uncertain birds" is a proposition which has universal acceptance among those who shoot over the wet meadows. As a rule, more dependence is to be placed on their coming in the fall than in the spring. But even in autumn they cannot be counted upon. Sometimes they arrive singly. or a few at a time, and those which are killed to-day are at once replaced by others; or again, for a week or two at a time, the meadows may be worked over without starting a bird, and then all at once they will be found in great numbers, and will then as suddenly and as completely disappear. A piece of ground which at evening affords splendid sport may be visited at clawn next day, and it will be found that the birds which were there have all cleparted. Happy is the man, therefore, who finds the snipe plenty, and he is wise who shall take advantage of the present opportunity. The advice, Carpe dicm, applies with more force to snipe-shooting than it does to a good many others of the affairs of life.

As early as the last of August, an occasional snipe may be found on the meaclows; but it is not until the latter part of September that the migrants begin to arrive in any numbers. They are now in good order-often very fat - and are lazy, and lie well to a dog, if the weather is right. The pleasantest time to shoot them is during the warm days of October and November.

At such a time the bircts are loath to rise. and will permit the dog to approach quite close to them before taking wing. On dark, cloudy days, on the other hand, especially if the wind be high, there is no such thing as getting a point on them, for they will rise at a distance of thirty or forty yards, and often the flight of the first one and his sharp skcap, skeap will be the signal for tevery snipe on the meadow to rise into the air and circle around for five or ten minutes before pitching down again. In such weather as this, the only chance of getting within shot of them is to work down the wind, - thus reversing the usual order of things in shooting.-and to keep the flog close in. Snipe always rise against the wind, and, by adrancing on them with it at your back, they 
are forced to fly toward you for some little distance, thus giving you an opportunity to get a shot at them at fair range.

Where birds are scarce, a good dog is invaluable, because of the amount of laborious walking that he saves the shooter; but there are times and places where a $\log$ is very much in the way. Such are some of our western snipe grounds, marshes where these birds are sometimes so abundant that they rise from the ground a clozen at a time, and where, perhaps for hours, the sound of their bleating cry is heard almost continually. Under such circumstances, a dog is only an annoyance; for the ground is so foiled by the scent of the many birds that have run over it that the poor animal is confused, and is constantly false-pointing and wasting his master's time. Here the only use to which the dog can be put is that of retrieving. There are some cunning old dogs that, when they find such a condition of things existing, will come in to heel without orders, and pay no further attention to the birds which are rising around them, only occupying themselves with the securing of those that may be shot.

This bird does not give forth a strong scent. and as it is often very little clisposed to lie well, a dog of unusual keenness of nose, as well as caution and steadiness, is required in its pursuit. A very faint scent should be enough to cause hin to stop until his master has come up to him, and he should then draw on very carefully until, if it will wait, he can locate his bird. There are days, to be sure, when snipe will permit the dog to get his nose within a few inches of them, but this is the exception rather than the rule.

It is always a convenience, however, to have a retriever with one while snipe-shooting, for without considerable practice it is not easy to mark down the dead bird so accurately that you can walk direct to it. This becomes especially difficult when several birds rise together, or nearly so, and you shoot first one and then another, and then perhaps try to mark down the remainder of the whisp. You have a general idea of the direction in which the first one fell, and are sure that the second dropped close by a certain little bunch of grass; but when, after having strained your eyes after the living and marked them down, you turn your attention to the dead, you are likely to find yourself somewhat perplexed. You see now that there 
are a dozen little bunches of grass near where the second bird fell, any one of which may be that by which you marked him; and as for the first, you feel very hopeless about being able to go within twenty yards of where it dropped. So you may lose half an hour of valuable time in searching for the dead. Practice in marking and a quick eye will, after awhile, enable you to retrieve your own birds successfully. Is a matter of fact, there is always something-a bunch of grass, a bit of drift stuff, a flower, a leaf, or a weed stalk - near your bird which is unlike anything else close to it; and you must see this object. whatever it is, and renember it, in the instant's glance that you have. Of course, some bircls will be lost, - that is inevitable; but it is wonderful to see how, by practice. the memory and the eye can be trained in a matter of this kind.

The snipe, although often very wary, appears to be quite devoid of that cunning which distinguishes so many of our game birds. When wounded, it rarely attempts to hide, but either runs off quietly in a straight course, or, if only wing-tipped, springs again and acrain into the air in its attempts to fly, and constantly utters its singular squeak of fright.

There is one feature of snipe-shooting which makes it very attractive, and this is that you have your dog constantly within sight; you can see all his graceful movements and enjoy his intelligent efforts to find the birds, - to locate without flushing them. To our notion, more than half the pleasure of field shooting of any description is derived from seeing the dog work, and this can be done better on the open snipe meadows than under almost any other circumstances. Beating for snipe, however, is usually, from the nature of the ground, very laborious work. The walking is often through mud and water up to the knees, or perhaps one is obliged to pick his way through an unusually soft marsh, springing from tussock to tussock, with every prospect of tumbling now and then from those unsteady resting places into mire of unknown depth. This mode of progression requires some muscular exertion and constant attention; and besides this, the dog must be constantly watched, and unexpected birds. which he may have passed by, must be shot at and marked down.

It is therefore esscntial that the snipe-shooter should carry no extra weight. His gum should be light, and his cartridges need 
not hold more than an ounce of No. 12 shot; for this bird is easily killed, and, as it is so small, and often rises at a considerable distance, it is important that as many of the leaden pellets as possible should be sent after it. Rubber boots reaching to the hip are, of course, necessary, and the clothing should be gray or brown in color,-inconspicuotis, at all events. The places in which the snipe are found are often resorted to by some species of our ducks as well. The little pools and creeks, which are sure to be found in extensive snipe marshes, furnish food for the blue and green winged teal, the black duck, mallard, baldpate, and woodduck. It will therefore be advisable for one who is about to visit such grounds to put in his pocket half a dozen cartridges, loaded with three and a half drams of powder and an ounce of No. 8 shot; for although No. 12 may prove effective against the ducks at short range, it is well to be prepared for longer shots.

As between woodcock and English snipe, the preference would be given with but few dissenting voices to the larger bird. Snipeshooting, from the erratic movements of the bird, is something that cannot be depended on, while, if the conditions of weather and feeding-grounds are favorable, one may count with some certainty at the proper season on having sport with the woodcock. As regards delicacy of flavor, there is nothing to choose between the two. For birds so nearly related they are wonderfully unlike in appearance and habits, and the snipe is certainly much better able to take care of himself than his rusty-coated cousin.

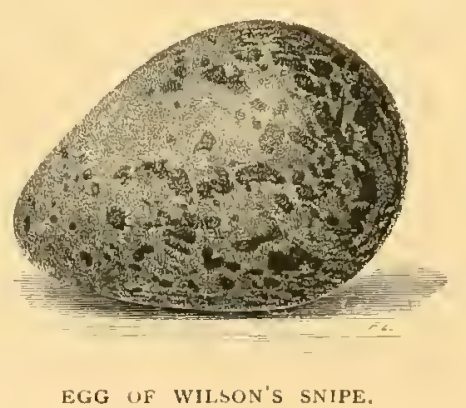




\section{FIELD SPORTS IN MINNESOTA.}

BY CHARLES A. ZIM MERMAN.

THE fall of ${ } S_{77}$ will long be remembered by the people of Minnesota as the time when the destructive locust took his farewell meal from their wheat-fields. Fields that might have yielded from three to five bushels of wheat per acre were not gleaned at all, but left to be plowed over in the fall. To such fields as these the wild fowl, for which the State is noted, resorted undisturbed, and geese, brant, cranes, and ducks fairly reveled in their bounty.

It may well be imagined that news of this state of affairs sent numerous hunting parties out along the two lines of railroad that penetrate the afflicted region, viz., the Sioux City and St. Paul, and the St. Paul and Pacific roads. During the last week in September of that year, the writer found himself with a party of three friends $c n$ route by the second-named road for a few days' stay among the wild fowl in Kandiyohi County. With every possible convenience for camping out, the outfit comprised also a portable Bond boat, and a full complement of decoy-ducks, together with a dozen or more goose-decoys, all of our own manufacture. W- our "Senior," brought along his retrieving setter and constant companion, "Prince." B-_ our "Junior," from Lake City, Mlinnesota, exhibited with pardonable pricte his "Royal Fan," a dark liver-and-white pointer, the first-prize winner in her class at the New York Bench Show of 1877. "Turk," a dark-brown Irish water-spaniel, accompanied his master J_- the most tireless hunter of the party. "Fuller" and "Occie," a matched pair of black-and-white setters, were the property of the writer, and with those before mentioned comprised the dogs of the party. 
A run of six hours brought us to Swede Grove, where we left the cars and were met by Mr. William Wilcox, alias "Bill," a wellto-do farmer and an ardent sportsman. His two-horse team and wagon furnished us transportation to his house.

"l'n glad you've come," said Bill, as we drove up briskly to the open door of his roomy divelling; "for the sand-hill cranes have been goin' for what little corn the plaguey 'hoppers left standin', and 'pears to me, gentlemen, with such guns as you have got along, you might make it right lively for 'em."

"Yes," chimed in his wife; "you can hear them even now, gentlemen. The noise is gettin' unbearable; and if you'll step up here on the porch, you can see them plain."

We assured her, while taking a look at the large birds, as they covered the field like a flock of sheep, that nothing would please us better than an immediate attack; but even as we debated on a plan of assault, the cranes, to the number of several hundred, as if they scented danger, took wing and with discordant cries circled about until they attained a certain altitude, when they left in the direction of Big Marsh.

I had long desired to make the closer acquaintance of these birds, incited a little, too, by many a failure to stalk them. On the sly, for fear of being laughed at by my companions, I had brought along three crane-decoys, neatly cut out of card-board and painted light gray, in fair imitation of the sand-hill crane. Here, at once, was the opportunity to make a test of their merit. So, leaving the rest of the party at a favorable moment, I took my way to the corn-field, where all was now quiet. The ground had been beaten hard in places by the busy feet of the marauding cranes, and corn-stalks lay here and there, as the hungry birds had wantonly tossed them. It did not take long to select a convenient "shock" for a "blind," or ambush, and I returned to the house filled with anticipations of the coming sport. Upon the floor of Bill's cozy sitting-room, surrounded by his children, who regarded my movements with open-mouthed attention, I proceeded with some diffidence to unwrap the package of decoys. Presently the crane counterfeits stood disclosed, and a ripple of merriment went round the circle, ending in a perfect roar upon the entrance of my friends, who relentlessly joined in.

"If you think, mister," said one of the plow-boys, after the merriment had somewhat subsided that, "you can fool a crane with 


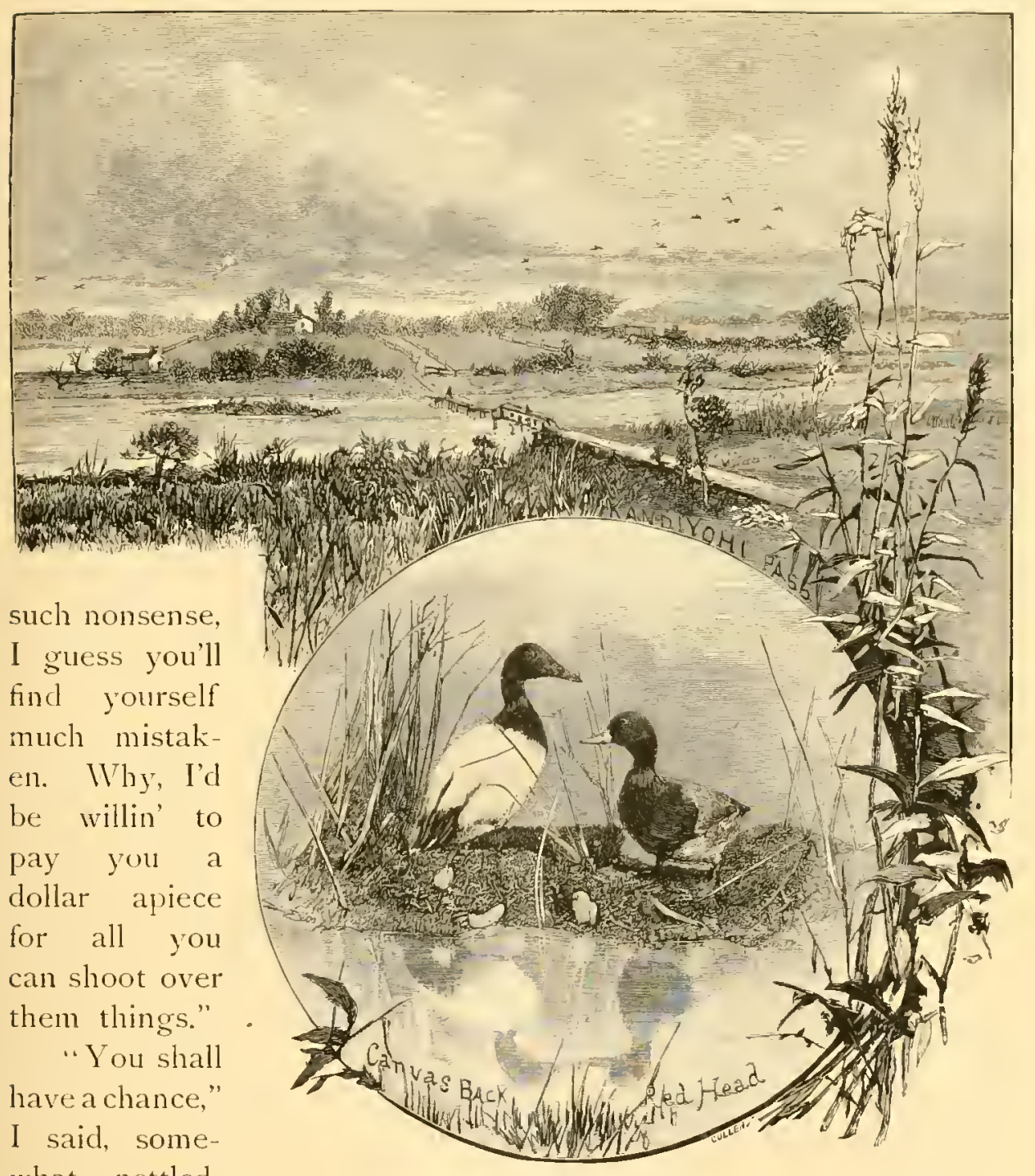

what nettled.

"When you ride out to your plowing in the morning, come to my stand, and you may have an opportunity to invest your small change."

When at last it was light enough to distinguish objects about me, I had been at my post in the corn-field a full hour, almost breathless with expectation. What if the cranes should fail to come, and I be compelled to return to the house empty-handed and face my more fortunate companions, the distant report of whose guns had been repeatedly borne to me from the direction 
of Crow River and Wilcox Pass? Worse than this would be the triumph of the knight of the plowshare. For the sixth time, certainly, I walked off a little distance and took a survey of my ambush, about which the three "base libels" were so naturally grouped as to give me quite a start when my eyes fell suddenly upon them. The smoke curled lazily upward from the farm-house chimney, and lost itself in a veil of mist which slowly ascended from the lake on the right of the house. Now, the upper edge of the cloud mist took on a rosy hue, due to the first warm rays of the sun, which seemed to be rising from an early morning bath in Wilcox Lake. The varying beauties of the veil of mist were duplicated by reflection in the still water beneath. The beauty of the scene made me quite forget my disappointment.

There is considerable activity now among Bill's barn-yard fowls, and I can even see his little folks scampering about the yard. A gentle breeze has ruffled the surface of the lake and carried away eversy trace of the fog which made the sunrise so beautiful. My slender decoys feel the influence of the wind, and nod in a ludicrous, if not most natural, manner. But in another minute I am scampering back to my blind, for in the clear sky above Big Marsh I have discovered a flock of cranes winging their way in a direct line for this field. Stepping quickly into my blind, I grasp my trusty gun, and somewhat nervously await their approach. Though scarcely considered fast flyers, they are not long in traversing the intervening space, and presently are circling about over me, evidently scanning the ground closely. Of course, when directly overhead, the decoys are invisible to them, but are again clearly seen when they have swung off at an angle. A little more maneuvering, and they seem to conclude there is no enemy about, for they set their wings, and, with long legs awkwardly dangling in the air, come on slowly, preparing to alight. Almost before I am aware of it they are upon me,-one, indeed, so near that, were I to fire now, he would be fearfully mangled. The leader of the flock offers a tempting shot at thirty-five yards; him I give the contents of my right barrel, and he doubles up instantly over my sight. Not wasting an instant, in the hope of making a "right and left." I "cut away" again at the now thoroughly alarmed flock, and one more of the immense birds comes to the ground. Too elated with my success 


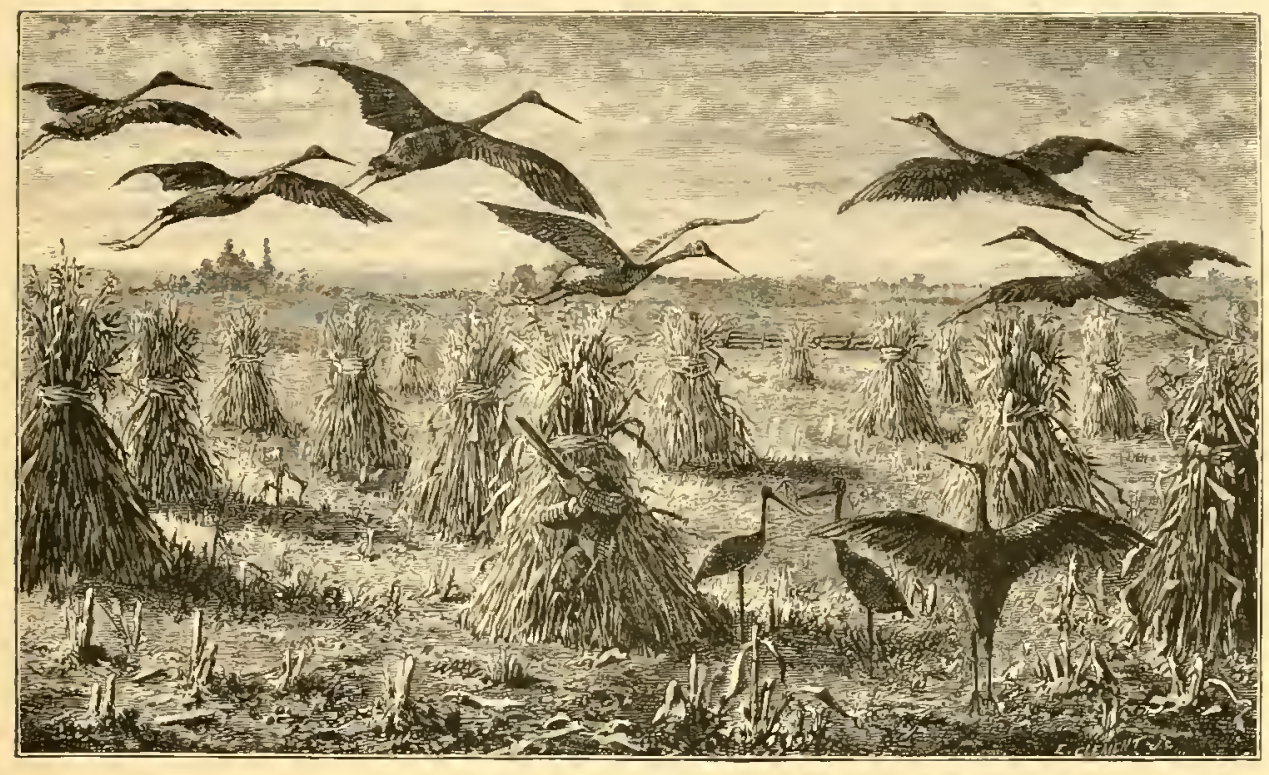

A CLOSE SHOT.

to exercise patience, or even to think of caution, I do not pause to reload, but, dropping my gun, run rapidly to bag. The first is found dead within forty yards: giving him only a glance, I pass on to the other, which is not less than sixty yards from the blind. The old fellow seems dead enough, and without much ado I stoop to pick him up, when he astonishes me by instantly rising to his feet, with every feather ruffed and his long wings beating the air. His ugly, sharp bill is extended, and emits a hissing noise, and altogether he is a very unpleasant-looking bird. For a full minute we gaze at each other, at least one of the two at a loss what to do next. It is becoming more and more evident to me that 1 do not care so much for him now as I did a short time ago. We are yet eying each other as I catch the sound of voices mingled with the confused tramp of horses, and feel certain that the plow-boys are approaching. Not caring to appear in a ricliculous light, above all others to these men, I determined to put an end to the scene, and accordingly make a quick attempt to seize the crane by the neck. This he successfully dodges, and in a twinkling wounds me in the wrist. Altogether out of patience, I make a bold dart for my gun, when to my astonishment the irate crane gives pursuit. At this moment the farm hands come 
into full view, and $I$ offer them the spectacle of the "city hunter," as they are pleased to style me, running away from a crane! The rest of the scene must be imagined. I do not attempt a settlement with the tormenters, but after finishing my enemy with a vengeful charge at close range, return to $m y$ blind, where I have the satisfaction of knocking over three more cranes before the summons to breakfast comes booming over the stubble.

My companions hang up in Bill's cool cellar thirty-one mallards, mostly green-heads. My adventure with the crane is freely discussed over juicy crane-steak sliced from the breast, which, together with good coffee and some of Mrs. Wilcox's best griddlecakes smothered in cream and white sugar, constituted a breakfast heartily enjoyed by all. After allowing me to be well teased, our host puts a somewhat more serious color upon the matter by assuring us that it was rather a dangerous proceeding to face a wounded crane, which, like the heron, always strikes for the eye. Once, to his knowledge, the bill penetrated through the eye of an Indian, producing instant death.

Twenty-eight miles or more lie between us and Kandiyohi, where we intend camping, and there is no alternative but instant cleparture after breakfast. By nine o'clock we are waving our adieus to the Wilcox fanily; whose worthy head accompanies us as driver, friend, and companion. Our outfit, none of the smallest, is snugly stowed away. The day is exceedingly pleasant, and the entire party is in the very best of spirits. The rolling prairie road offers no hinderance, and we jog on at a fair pace. The neat appearance of the farm-houses and their immediate surroundings shows plainly the thrift of the owners, who are mostly Swedes or Norwegians. A likely looking prairie bordering a stubble causes us to tie up the duck retrievers, Turk and Prince, and cast off Royal Fan and two setters; this is done with the hope of finding a brood of grouse, or (as they are called in this State) prairie-chickens.

Fan led off at a round pace and quartered her ground thoroughly, showing beautiful style and action with thorough training. B_- her proud owner, from his seat in the wagon, controlled her movements by the "call" and by the motion of the hand. I could not help wishing that Macdona might see her now, and behold in her superb action and style a confirmation of his 
judgment of her on the bench. Not much behind her, in either pace or style, were the two black-and-white setters, as with heads well up they dashed over the prairie; ranging in perfect accord with each other, yet entirely independent, they cast furtive and anxious glances in Fan's direction, evidently fearful lest she should secure a "point" before them or they lose an opportunity to "back."

Now Fan is slackening her pace, and is investigating a narrow strip of corn, which from neglect has become lodgred. E_-'s quick eye has detected the presence of game by the change in Fan's pace and manner. The two setters are down wind from her about forty yards distant, and are evidently scenting the same birds, for they come trotting up with their black noses high in the air, and with the peculiar elastic step seen only under these circumstances. Fan, in the meantime, proceeds with more caution, the scent becoming stronger: a moment or two of suspense on our part and the little beauty comes to a stand. ITe prepare to jump out, guns in hand, but desist as she makes a few steps in advance, every motion indicating her intense and increasing excitement. Presently, she is rigid! The setters have approached within a few yards, and the instant she makes her final stand become rigid also, backing her point stanchly. The trio form a picture no sportsman could fail to regard with pleasure: Fan is erect, yet exhibiting the characteristic point looked for in her species (not much does it resemble in its intensity of action the vacillation of a "puppy point"); her two companions, who seem to have attained an unnatural length, appear to be crouching for a spring, their usually kind faces showing lines and wrinkles indicative of strong excitement. "Are you all ready?" is B's question when we have ranged ourselves in position back of the dogs. Even as he speaks he makes one step forward, and a cock grouse flushes before him. He throws his gun quickly to his face: with the sharp report the bird drops into the corn, and a long stream of feathers drift down the wind, their number showing his perfect aim. Fan drops to "wing," instantly followed by Fuller and his mate. A step forward by our party and a pair flushing before $11-$ gives him an opportunity for a right-and-left, which he fully improves. Still the dogs maintain their recumbent attitudes, though it is easy to see their growing impatience. Another pair has bit the dust in response to a quick double from my gun, and poor J_- who seems to be 
fated, for so far not a bird has flushed to him, is becoming tired of the monotony of the thing. Then $\mathrm{B}-$ and $\mathrm{W}-$ each bring down another bird. When $\mathrm{B}-$ and $\mathrm{IV}-$ each bring down another bird, his impatience finds vent in words: "This is downright murder, gentlemen," said he; "you don't give the birds half a chance. A man," he added, "that could miss a chicken flushed in such easy range ought not to hunt in the company of sportsmen."

He had scarcely finished speaking when the old hen grouse of the brood whirred up under his very feet. Somewhat startled thereat, and before she had flown five yards, he fired all too quickly, scoring a clean miss. An exclamation escaped him at the result, and he at once sought her with his second barrel; his first had turned her a trifle from her course, and she presented now a side-shot at thirty yards. Any one of us could then have cut her down easily, but we preferred not to, and stood with guns in the position of ready, awaiting the result of his second. Bang! went the gun; on flew the bird. She was now fairly ours, and, though fifty yards away, succumbed instantly to the closely blended triple report from our pieces.

Like a man, the good-natured fellow faced our music and, taking off his hat, made us three, who stood laughing heartily, a most profound bow, at the same time remarking:

"I acknowledge the corn: it is not quite so easy as it appears to be," although he added, by way of retaliation, "I an quite certain even I could have stopped her ladyship with a treble dose!"

At the word "Fetch!" the eager dogs "seek dead," and in a twinkling come trotting proudly back each with a bird, on being relieved of which they are again sent in with a like result. Not much do these birds resemble the puny little ones bagged on the fifteenth of August, for they are full grown, hardy and strong, and very swift of wing. No. 7 shot, backed by a good charge of powder, has done the work. September grouse seldom lie so close as did this brood, every one of which lay safely bagged before us.

The three dogs, having had barely a taste of sport, show much unwillingness to take up again their position back of the wagon; but it is now the duck retrievers' turn, for we are about to enter a section of country thickly interspersed with small lakes or ponds, here called sloughs (pronounced slews). Turk and Prince, having work before them, are set free, and soon testify their appreciation 


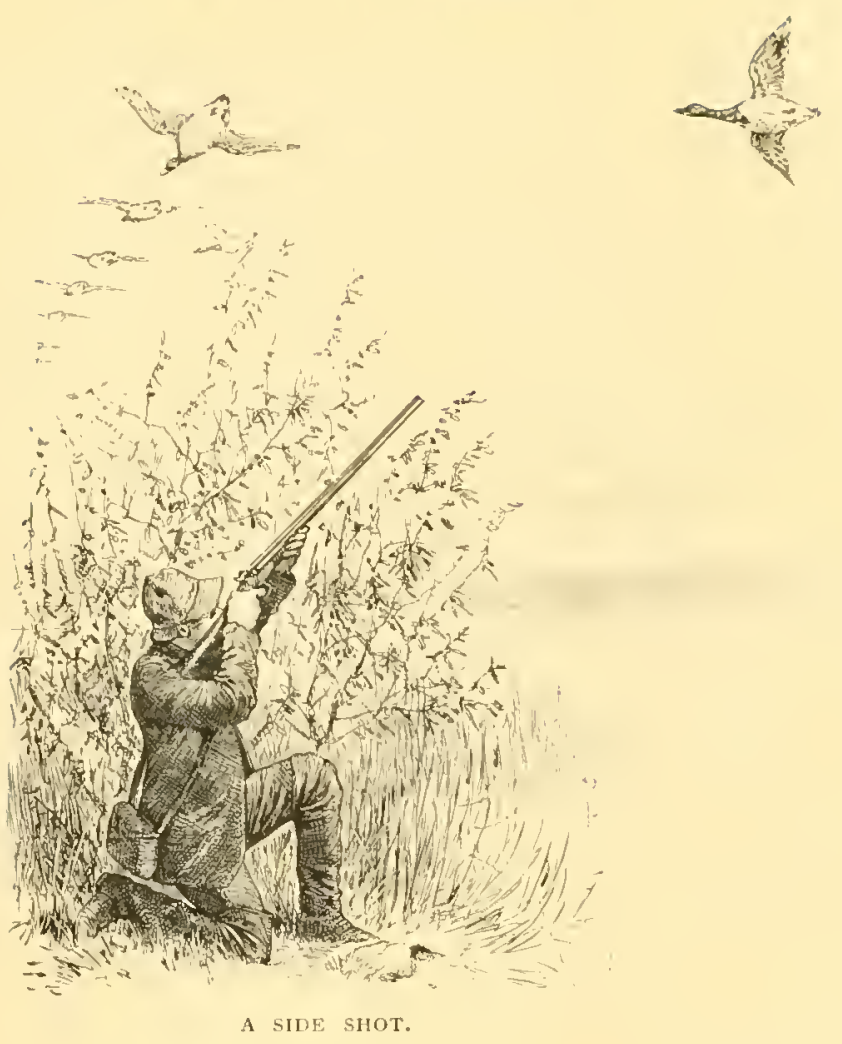

by eccentric gambols. The two setters and Fan would delight in retrieving ducks, but are not very often indulged; the example of the average "duck dog," as he dashes in at the crack of the gun, is apt to have a demoralizing effect upon the steadiest of pointers and setters, and they are tempted to "break shot" at all times, which would be disastrous on almost any game other than ducks.

Mallards, widgeons, and sprig-tails lelight in those small grassy ponds, which are generally thickly grown with wild rice, reeds, and rushes. A musk-rat house here and there furnishes sumning opportunities, and also enables them to mount guard. While Bill is securing his team to a convenient fence, we are planning an assault on one of these sloughs, which the little prairie-knoll ahead of us hides from our view. We employ the usual tactics, by surrounding it. each one approaching it from a different direction in deep silence, though we are not able from the shore to discover a feather. IThen every one is posted in as good cover as possible, Bill, according to previous arrangement, fires a random shot from his "pin-fire" over 
the water. In an instant, with a quacking and a terrible fluttering, the well-concealed ducks spring into the air, and make a break in the direction of one of the large lakes. This will bring them over J_ and I watch them nearing the fatal stand. Now the barrel of his gun points upward from the clump of reeds in which he is con-

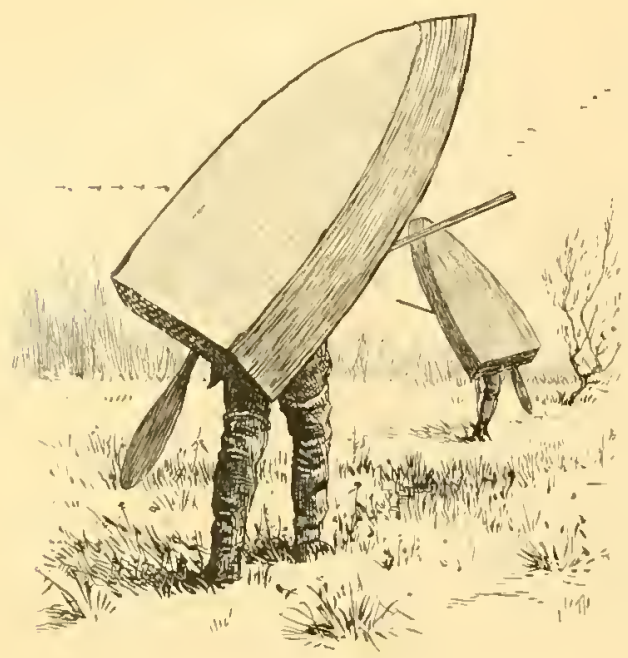

BONDED GOUDS IN TRANSIT, cealed, and two birds topple over almost before the double report of his piece has drifted across the puddle. This reception has startled the flock, and in considerable disorder they turn only to be met by a similar reception from $\mathrm{IV}-$. Again are they repulsed and seek a new direction, which brings them over my stand, but such a height have they attained that only one drops dead to my gun. But Bill is the champion, for he stops three ducks with one barrel of his gun, having had time to exchange his finer shot for "No. I," which tells with good effect at such long range. B-alone has not soiled his gun, but by working the dogs has succeeded in bagging most of the ducks killed. Fuller and Occie are sent over the hill after those knocked down by Wilcox, and we are once more on our way.

To me there is not much real sport in this style of shooting. though the game is large and fine; it lacks the excitement of the "pass" shooting, and many birds are lost by falling in to the matted reeds and grass, where the dogs have great trouble finding them; the incessant popping of the guns also has a tendency to divert their attention from the careful search necessary to find skulking wounded ducks. These sloughs or ponds occur very frequently upon the St. Paul and Pacific and Sioux City and St. Paul railroads, and under proper guidance a party of four or five will take heavy tribute from each as they go along. For this kind of shooting, a Bond boat offers superior advantages: çomposed of sheet-iron sides and a wooden 


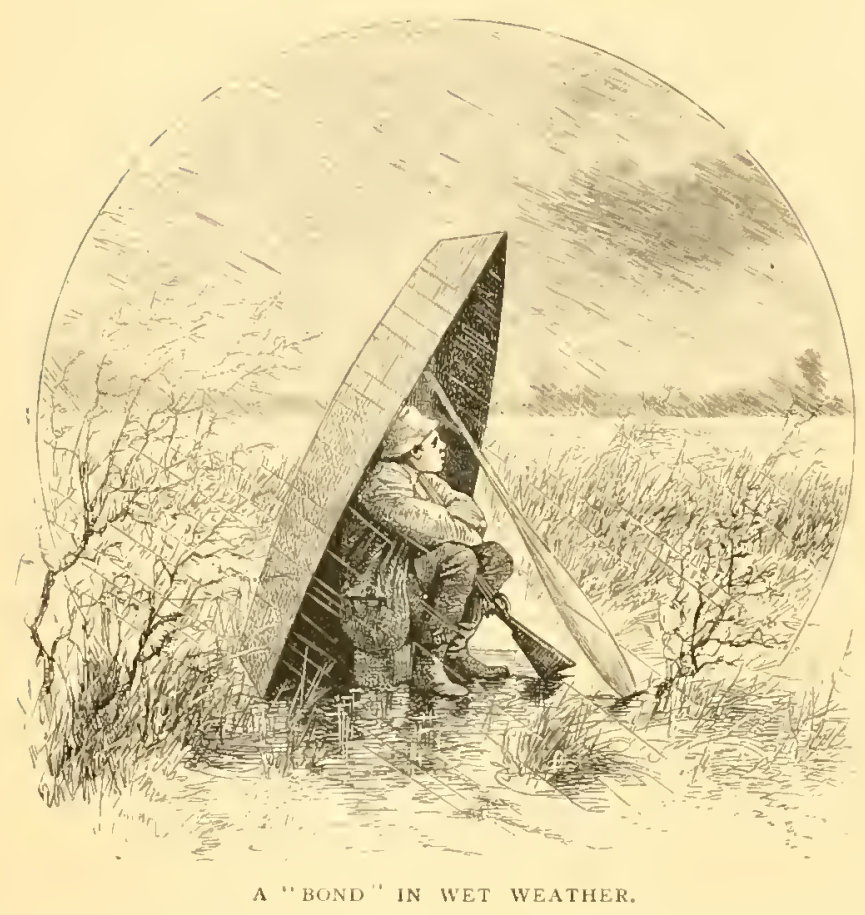

bottom, it is made in two water-tight compartments, besides an airchamber, to prevent sinking in case of an upset; it is of trifling weight, and easily transported. Two sportsmen, by each shouldering one-half of the boat, can make portage after portage, shooting out one pond and then carrying to another, no great distance ever intervening. These boats in transit upon a hunter's back have a most ludicrous aspect, and dull indeed must be he who cannot extract much humor out of the novel spectacle. Should a rainstorm arise, one of the compartments of the boat set up on encl makes a very good shelter. The inadvertent kicking away of the supporting paddle to your novel roof will certainly justify the laugh sure to be indulged in by your more careful companion; but, unlike the turtle which you so closely resemble as you look out from under your temporary shell, you can crawl out of it.

It was quite late, with frequent stopping on our route from one cause or another, when our destination was reached. IVe were well used to camping-out, and our tent was very soon in position and in readiness for the straw bedding hauled from a neighboring stack. This was at once stuffed into a wide, empty tick, brought along for 
that purpose, and we had a bed fit for a king, and one on which no tired hunter can long remain awake.

A coach candle in an improvised socket, fastened to the inside of the tent-pole, sufficiently illuminated the interior, and enabled us to get in readiness for the morning's work. "Chicken shells" were taken out, and suitable ones for duck-shooting substituted; no one forgetting to place a few loaded with "dbl. B" shot in a certain pocket of the Holabird shooting-coat; these last for a stray goose or two which has been known to fly over this pass more than once, in the memory of our mess.

Such an inviting bed as we had before us could not long remain untried, and one by one our party turned in. The full moon flooded our tent with a subdued light and brightly illuminated our surroundings. Through the tent-openings could be seen one arm of Little Kandiyohi and the two peninsulas, joined by a rickety bridge of hewn timber, which formed this well-known pass, and over which we are to have a "flight" in the morning twilight.

$1 \mathrm{am}$ quite certain that I have not been unconscious for more than fifteen minutes, when I am rudely awakened by a severe thump in the side, which I am half inclined to return with interest, until I see that my friends are up and dressed. The candle is burning, and a bright fire roars and crackles in the stove, diffusing an agreeable warmth throughout the tent.

All of us are decidedly sleepy, and we should perhaps be still in bed, were our inclinations strictly followed, and we show less impatience to face the keen morning air than do our dogs, whom Bill has set free on his way to feed the team. The moon has long since disappeared, and inky darkness has succeeded, and we feel our way along as we go down to our stands upon the peninsula. The air, for a September morning, is quite chilly, and in spite of the cup of hot coffee and plenty of wrappings, I am soon all of a tremble, and cannot help contrasting this with the warm and cozy bed out of which we had lately crept. I feel much pity for my two faithful dogs, who are lying crouched at my feet, impatient for the word to plunge into the dark and chilly current for a duck. Some are already passing over, as we know by the sound of wings swiftly cutting the air. By rubbing the phosphorus of a match, the dial of my watch is rendered visible, and it is some satisfaction to know that 


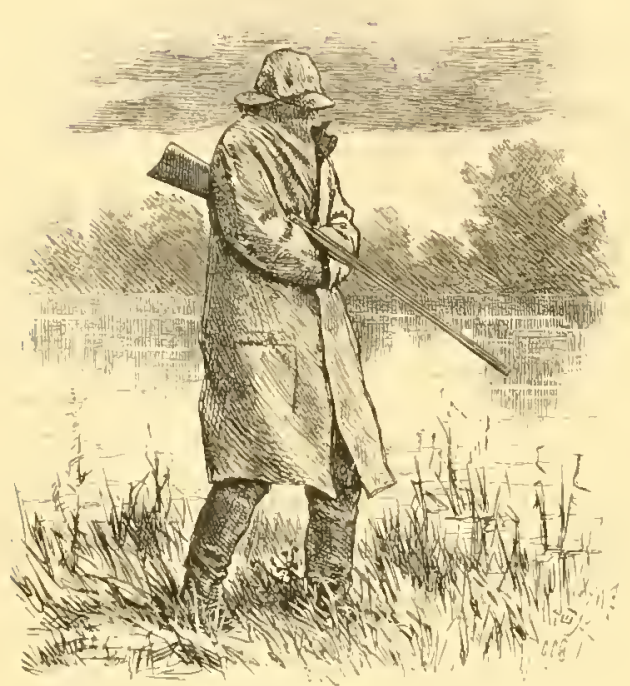

A COLD MORNING.

it is nearly five oclock and dawn is at hand. In a few minutes we shall be able to discern objects overhead, and by exercising skill and judgment, or "bull-head luck," as an old veteran of the pass calls it, a little execution may be clone.

I now proceed to take off my gloves and my " gum coat," which had been donned for warmth, and to fill the pockets of my "Holabird" with shells, which are in this instance loaded with five drams of Dupont's ducking powder, and one and a quarter ounces of No. 6 shot, for the early flight. Shells loaded with Nos. 4 and 5 shot are used later in the day, when the ducks begin to "climb" as they cross. The icy-cold gun-barrels strike a chill to my bare hands, but my pulse has gained a number of beats in the last few minutes, a pleasant thrill of excitement pervades me, and 1 an fast warming up to the work. Standing in a regular skirmish line, about thirty yards apart, in the position of "ready," with guns in hand, and both the hammers raised, we strain our eyes to catch a glimpse of the game that is streaming over, but the veil of darkness prevents our seeing. Who will draw first blood? More than once have our guns been quickly thrown to our faces and our fingers rested on the triggers, but none of us has acquired the art of shooting "by ear," and slowly and reluctantly we lower them again. But 
now from our junior's stand a blinding flash shoots up into the air at an acute angle, accompanied by a deafening crash, which rolls like a burst of thunder along the surface of the lake, until it is echoed back by the heavy belt of timber in a faint but perfect imitation. The sound that interests us most, however, is the plunge of the retrievers in to the lake and the splashing in front of my friend's blind as one or more victims flutter upon the surface of the water.

A bunch of four or five swiftly moving. shadowy objects now draw my fire, and before the echo of $m y$ double shot has fairly died away, J_ and $\mathrm{W}$ — have each made their first shots of the morning, and with good effect. Prince is now climbing the bank close by with a fine drake canvas-back, one of the two killed by the first gun of the morning. My two setters are swimming a race neck and neck for first choice on a pair that fell to my fire. As for Turk, he is absolutely cliving for a wounded duck which has so far managed to elude his gaping jaws. At each fresh failure to secure it, Turk gives a yelp of rage, but finally manages to seize the duck by one wing and makes for the shore. The slight hold he has obtained allows the duck to flutter vigorously, filling its captor's eyes with water, much to his disgust.

But the sport in the air eclipses in interest that in the lake, and at W__'s sharp "Nark! east!!" every one goes down behind his blind, out of sight of an approaching flock of red-heads. They come on, unconscious of impending trouble, not over two yards above the surface of the water. Their first hint of danger is taken from seeing the dogs, which are swimming for shore, and they make an extraordinary effort to mount high in the air. This gives us a splendid opportunity, for from our point of sight they appear to stand still, and a volley at this instant gives the dogs more work to do. Our second barrels are put in with telling effect, and the badly demoralized flock now presents a far different appearance from that of a few moments before. The Bond boat is now used to recover the birds that fell on the west side of the peninsula, and that would drift away before the dogs could attend to them.

A momentary lull in the flight gives an opportunity to look about us and count our spoils. My friends have seventeen ducks between them, while my own string shows six-three canvas-backs, 


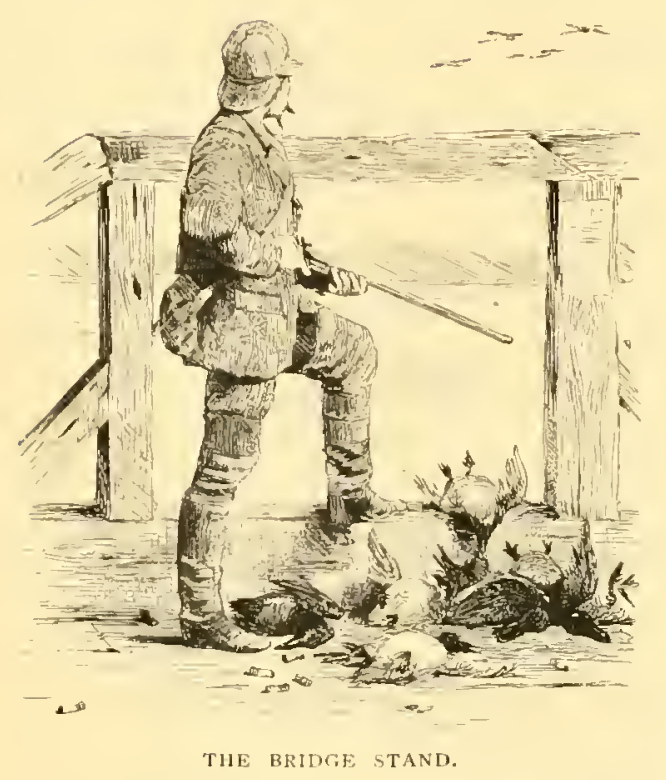

all drakes but one, two red-heads, and a widgeon - not very bad luck, certainly, and the flight is not half over.

The canvas-backs are handled with a degree of satisfaction that even the green-head and more gaudy mallard fail to inspire. To use the words of the lamented "Frank Forrester": "This is the royalty of ducks. No other water-fowl to him is equal, or second, or in any way comparable." While it is not unusual for a novice to mistake the red-head for the canvas-back, which it is true they resemble, the difference is yet quite marked. The attention once carefully drawn to the head of the latter, no red-head can ever again be mistaken for it. Aside from the color of the bill, which in the case of the latter is light blue and in the other black, the length and shape of both heacl and bill differ greatly.

Suddenly we hear the steady honking of an approaching flock of wild geese, which have left Kandiyohi Lake, and are flying up the narrows toward us on their way to the fields. A bird'seye view of our party at this moment would have been most amusing, for every one of us seemed struck with a sudden and ardent desire to lay hands on something, and that in a most incredibly 
short space of time. Each of us had one or more shells for just such an emergency as the present. To find and substitute these shells quickly, and without alarming the rapidly approaching geese, is the occasion of our frantic efforts. Those of us who had started out that cool morning enveloped in at least three coats apiece, and had laid them aside from time to time in as many different places, were in trouble indeed. W- had left his goose ammunition in his shell-pouch by the blind, but having walked away a few rods while his dog was pilfering my ducks, he was now making for the coveted shells on all fours, so as not to be visible, with a celerity that would have astonished the many friends of this usually dignified gentleman.

Three of the lhuge birds are now heading for my blind, and the rest of the flock veer off in the direction of my comrades. My two expectant setters are already crouching for a spring, when the shell, which I have with some difficulty found, and which I am placing with some nervous trepidation into the opened breech of my gun, begins to stick; in the haste and

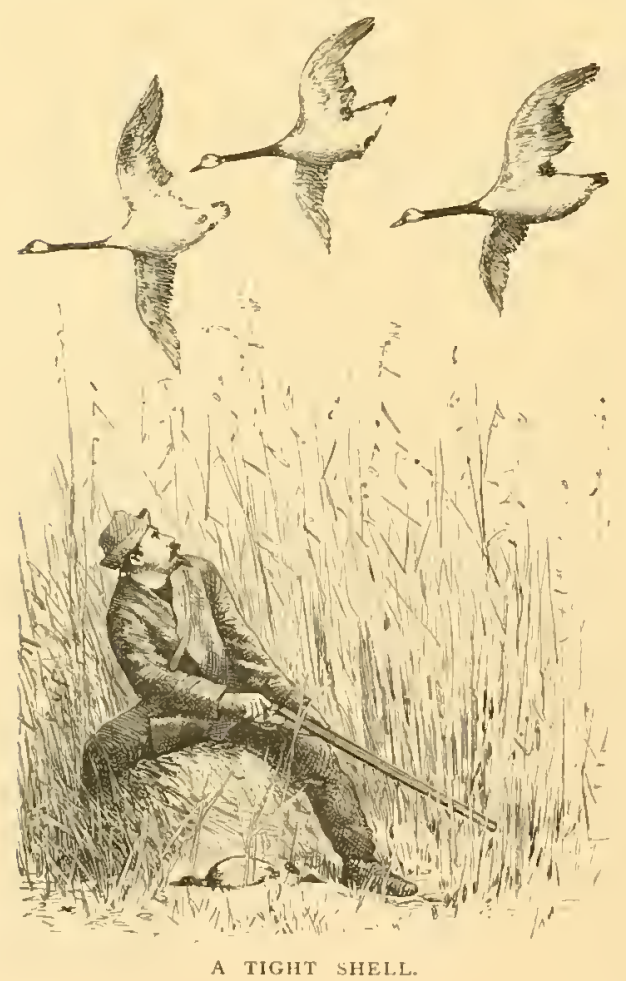
excitement, I bear hard upon it, but it does not budge a particle. I then attempt to extract the shell; but no, it sticks as if it had always been there. Though I struggle like a madman in my efforts to dislodge it, I can make no impression, and have the mortification of beholding the geese sail over a rod or two above me, near enough, in fact, to have used even my No. 6 shot with deadly effect. "Bang! bang!" comes a volley from my right, and two of the "old honkers" tumble headlong into the lake, displacing at least a barrel of water as they strike the surface.

The main flight having passed over, and out of which we 
have taken fair toll, we are favored with more "singles" than flocks; the shooting is consequently more interesting,

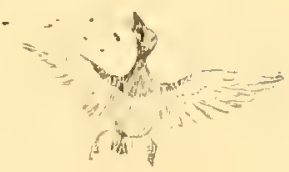
because more difficult. Clean misses at these swift-flying birds are frequent. It seems at times next to an impossibility to swing the gun rapidly enough to cover and avoid shooting behind. Shooting into flocks "for general results," without singling out a bird, may be excusable in a Sunday "pothunter," or in a novice anxious to give a new Scott, Purdy, or Parker a good airing; but in a true sportsman - never. High or long shots should seldom be attempted here, as misses beyond fifty or sixty yards are common, and scores of birds are struck whose wounds prove fatal only after long suffering.

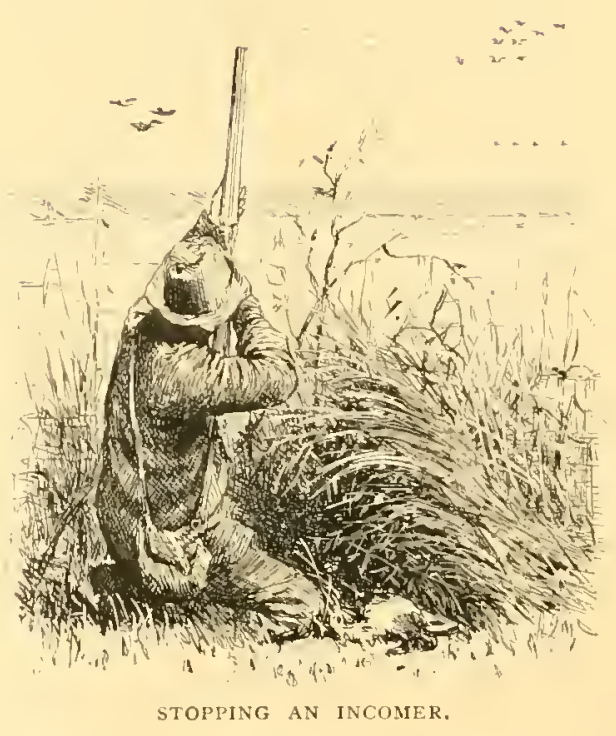

Side shots are most deadly; but proper allowance must be made for distance and speed of flight. Opportunities for double shots occur continually, and to make them it is often necessary to use the first barrel of the gun on an incoming bird, and the second will then, in all probability, be a side or quartering shot.

To stop an "incomer," raise the gun carefully in the line of his flight; move quickly ahead of the duck, when you judge him to be in range; and, when you lose sight of head and bill over your gun, pull instantly. The flight of a duck is ordinarily at the rate of about sixty miles an hour; but when accelerated by fear, or a brisk wind, or both, it is nearly double, and must be experimented upon to be fully appreciated. To become a good "pass shot," some of the requisites are: to be able to judge distances quickly and accurately; to be able to cover well the moving bird, and not to check the motion 
of the gun at the moment of discharge. Most sportsmen flinch at that supreme moment, and unless the habit is entirely overcome, they cannot expect ever to become good wing shots. The "chokeboring" of guns, in limited use long ago, has only very recently come into favor and rather more general use. Upon the pass or

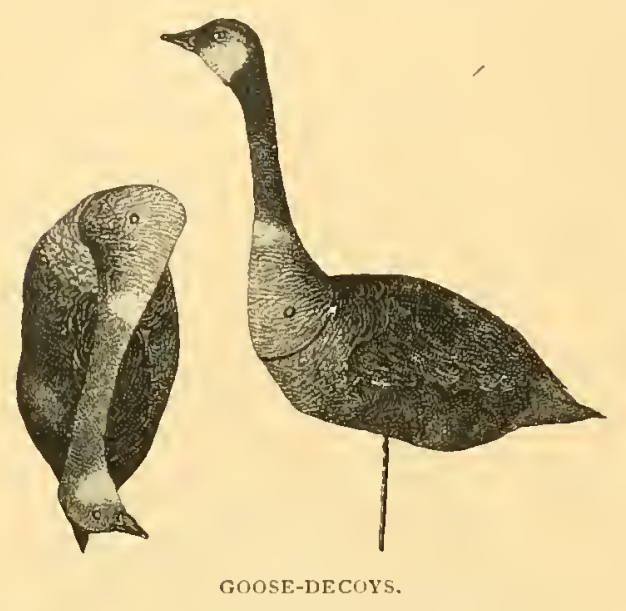
elsewhere, it adds at least onefourth more distance to the killing range of the gun. This is done by the effect it has upon the "pattern" made by the shot, causing the gun to throw a greater number of shot pellets into a given circle than can be done by the cylinder or straight bore. One barrel of the duckhunter's gun should surely be bored in this way.

Kandiyohi was once famous for its black-duck flights; but of late they seem to have abandoned it, and more mallards, red-heads, and canvas-backs are found here. Vallisneria, often miscalled wild celery ( 1 say miscalled, because it bears no resemblance in taste to the common celery), is beginning to grow thickly in places, in addition to the wild rice, and may account for this fact.

It was in this vicinity that the pair of canvas-backs were killed by that veteran sportsman, General H. H. Sibley,-well known to the readers of the old "Spirit of the Times" under the nom de plume of "Hal-a-Dakotah," - and by him sent to his friend "Frank Forrester," thereby settling a controversy between the two gentlemen, and proving conclusively - what Forrester had before denied - that the true Tallisncria is found away from the sea-coast.

To have anything like sport in the pursuit of the common wild goose (Bemicla Canadensis), the ordinary methods of hunting water-fowl hardly answer here; besides, the lakes they frequent are not large enough to justify the use of the bay-shooting tactics from sink-boats, and from blinds near the water. These birds are exceedingly wary when upon the fields, and are very seldom bagged by stalking. In their watchfulness they have but one rival, and he an 


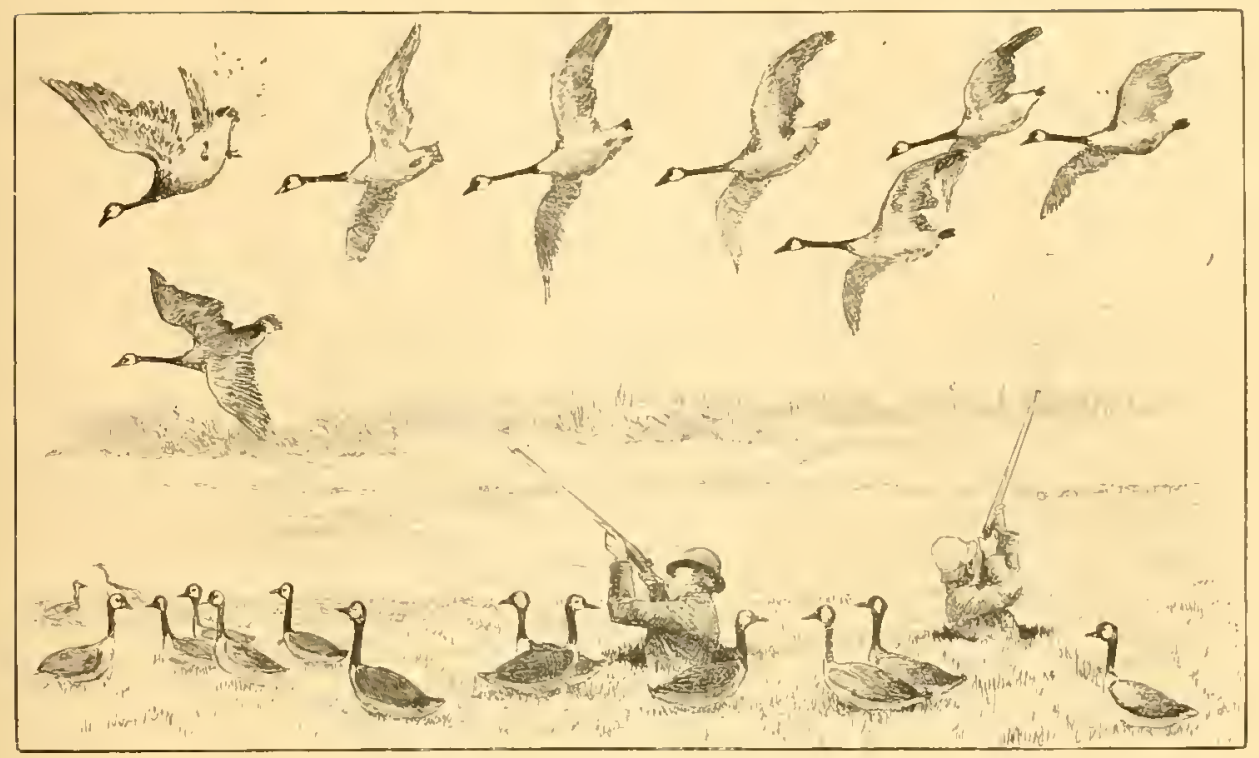

GOOSE-SHOOTING FROM STUBBLE.

effective ally, in the sand-hill crane, which often feeds in their midst, thus adding to the difficulty of approach within effective range. The difficult problem of their successful capture was at last solved for us by Colonel Sam Doughty; of Lake City, Minn., who introduced shooting over decoys from pits dug in the stubble or new breaking, where it has been ascertained geese are in the habit of feeding. The decoys are of the simplest construction and greatest portability, being merely flat forms in good outline painted in initation of the wild goose; these, when seen at right angles to their flat surfaces, at ordinary shot-gun range and beyond, are well calculated to deceive not alone his gooseship but even amateur sportsmen.*

Two flights a day are made by the geese from the large lakes in search of food: one taking place at daybreak in the morning and lasting perhaps an hour, and the other at four o'clock in the afternoon, occupying about the same length of time. On these flights they are often accompanied by the snow-goose (Anser-hyporborcus) and the white-fronted goose (Ansor Gambclii), which are here called respectively white and black brant, though they do not much

* Ex-Governor A will never forget how natural was the look of Major C_- 's decoys on that memorable day near Kirkhoven, when. after crawling a long distance. he emptied his gun in riddiling them. They had been left after the early morning flight by their owner, who witnessed the incident from afar. 


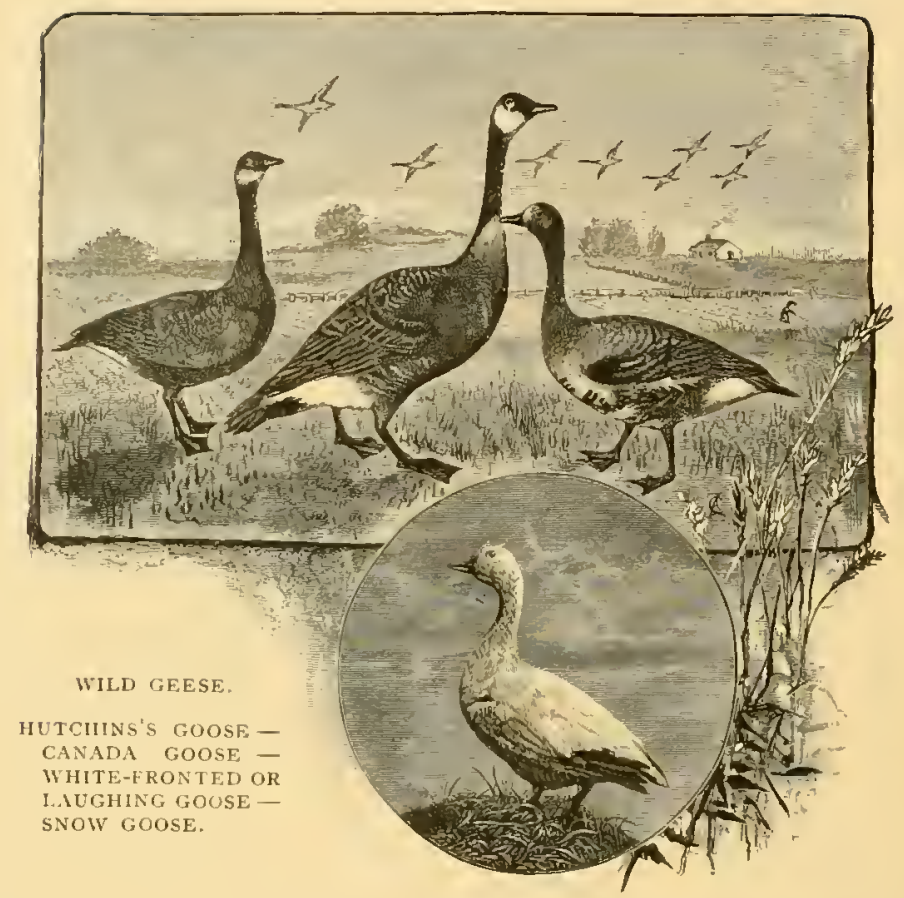

resemble the true brant of the sea-coast (Branta hemida),* which may be found occasionally in the midst of flocks of the other kinds, yet are by no means common.

From about the latitude of Kandiyohi County to the Red River of the north, the different species of the wild goose hold high revel and, upon the approach of the cold weather, may be seen in countless thousands massing for the southern flight. An early morning drive along the wheat-fields which they frequent will disclose them feeding either upon stubble or breaking. They must be allowed to depart not only unmolested, but of their own accord, when an examination of the feeding-ground is carefully made, and the pits may then at once be sunk. If there are two shooters, as many pits are necessary, and they are best circular in form, about thirty inches in diameter and forty inches in depth. The earth of the excavation may be partially utilized in constructing a slight embankment around the edges of the pit. The surface of the soil about the pit-openings must be manipulated until it accords in appearance with the natural surroundings. The pits may be near enough to permit of a whispered conversation between the occupants when the game is ap-

* Branta bernicle (Linn.) on the Pacific coast is the variety nigricans. 
proaching. The decoys, to the number of a dozen or more, being flat, must be placed at such angles that when viewed from any point of the compass a few apparently solid geese are seen.

In the air, with no intervening object to correct the eye, geese appear very large, and consequently nearer than they actually are, and one is exposed to the temptation of firing too soon: therefore, the hole should be "worked" by a veteran at the business, who will command "Fire!" in due time.

Under the guidance of our junior, B-, an old hand at this kind of work, our party bagged, in four times "setting " out, twentyone Canada, four white-fronted and three snow geese.

The decoy-ducks were put to good use in the lakes about our camp, and as the best of decoy shooting begins here after eight o'clock in the morning, and ends near three in the afternoon, no time is lost that could be better employed on the pass or on the stubble. There is a satisfaction in shooting over decoys that is not found in any other style of shooting, since by the exercise of judgment in placing the decoys and boat, the ducks may be forced to present whatever kind of shots you most desire.

Our bag for the week's trip was: Geese, thirty-one; cranes, five; pinnated grouse, fourteen; canvas-backs, seventeen; mallards and other ducks, one hundred and ten; Wilson's snipe and golden plover, twenty-eight.

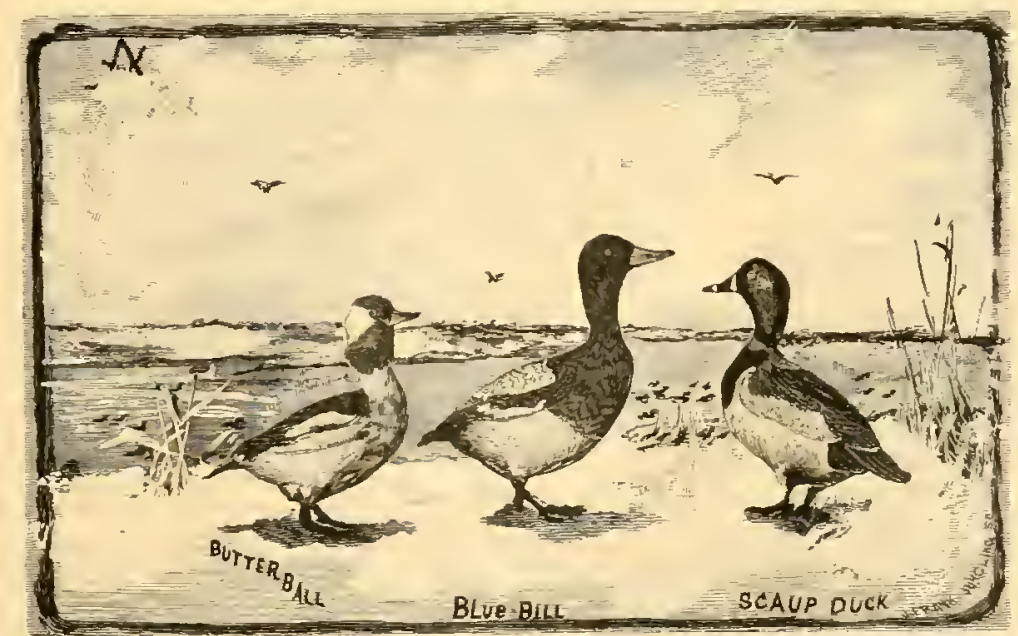

$46 \mathrm{~A}$ 


\section{CANVAS-BACK AND TERRAPIN.}

Br W. MACKAY LAFFAN.

T

HE Chesapeake has conferred upon Baltimore the title of the "gastronomic capital" of the country. The fish, the game, and the reptiles of its generous waters, and the traditions of the Maryland kitchen, have made Baltimore a Mecca toward which the eyes of all American bon-vivants are turned with a veneration that dyspepsia cannot impair. Places have their dishes and exult in them. New England points with pride to an unsullied record of pumpkin-pies. New Orleans has its pompano, and boasts it much as Greenwich does its white-bait. In San Francisco, you win the confidence of the Californian by praising his little coppery oysters and saying that they remind you of "Ostend penn'orths" or Dublin's Burton-Bindins, and that, after all, the true taste of the "natives" is only acquired in waters where there is an excess of copper in suspension. At Norfolk, the sacred dish that is offered upon the altar of hospitality is the hog-fish. The modest New Yorker, in the acerbity of the lenten season, asks his foreign friend if he ever saw anything like "our shad." In Albany, you partake of "beef" sliced from a Hudson River sturgeon, - a fish of which cutlets from the shoulders are served in San Francisco to excellent purpose as filcts de sole. Chicago has been heard to speak of white-fish. In Calcutta one inwardly consumes with curry. Bird's-nest soup, made from the gelatinous and insipid secretion of the sea-swallow, is the dish of honor at Shanghai. But Baltimore rests not its reputation upon the precarious tenure of a single dish; it sits in complacent contemplation of the unrivaled variety of its local market and calmly forbids comparison. While the Chesapeake continues to give it its 
terrapins, its canvas-backs, its oysters and its fish, this may be done with safety; and among the pleasantest recollections that a stranger may have shall be those of a Maryland kitchen in the "season." Visitors from the mother-country seldom overlook it, and they have

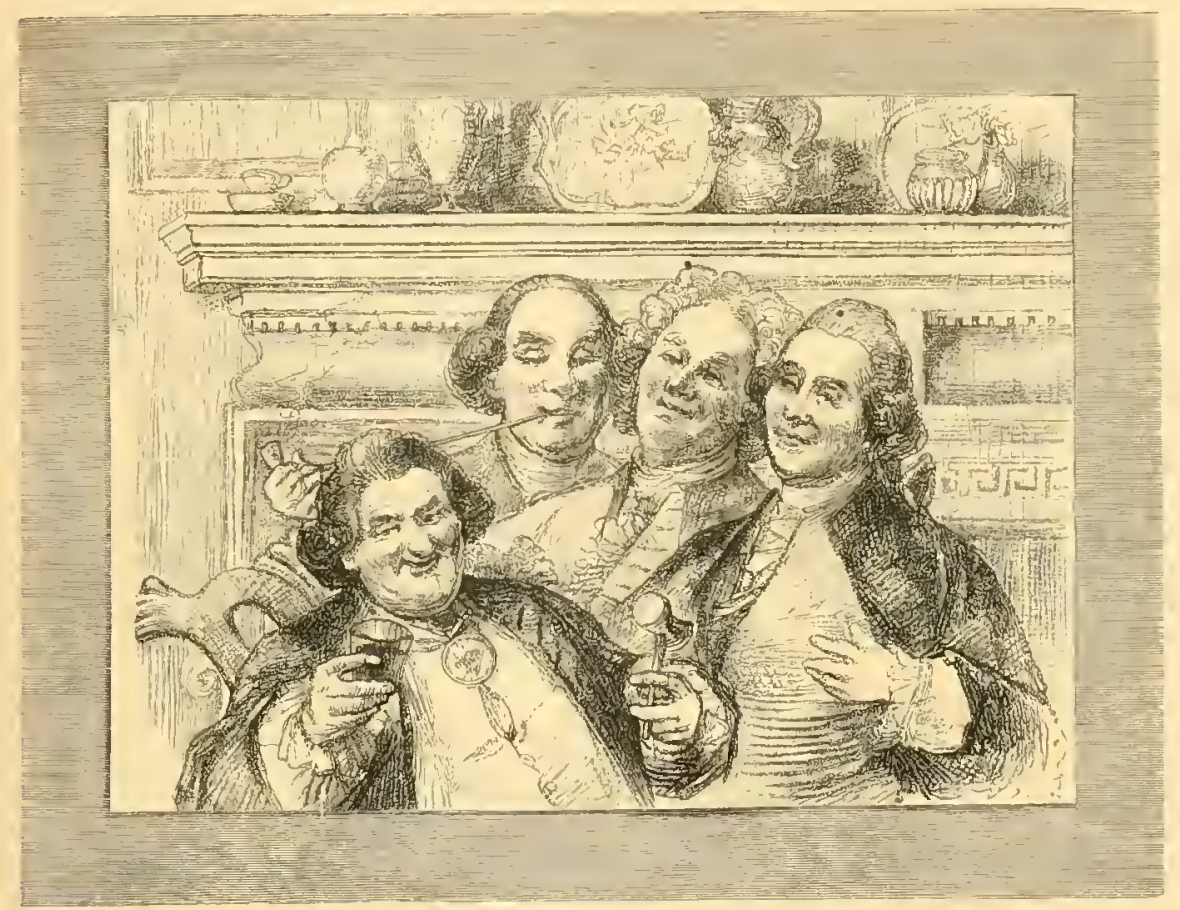

AT THE CLUB IN COLONIAL DAYS.

recorded their sentiments ever since the old colonial days. In these days of rapid transit, it were strange if our transatlantic cousins did not know more about it; and Liverpool receives many a crate of canvas-backs, many a barrel of choice oysters, and many a can of terrapin, cumningly packed in Baltimore. There have recently been dinners given in London and Paris at which every article of food upon the table came from America.

The shores within reach of Baltimore are of considerable extent and are for the most part owned by wealthy citizens. In winter they are known as "ducking-shores," in summer as "fishing-shores." Some are leased to "clubs," just as trout and salmon rivers are in England and Scotland and Norway, but a majority are private property and are carefully guarded. The ducks of the Chesapeake are the same birds that are seen in Hudson's Bay and on the northern 
lakes. They follow the edge of the winter along the Atlantic coast, and the water they prefer to feed in is that in which ice is about to form or from which it has just disappeared. Nowhere are they so

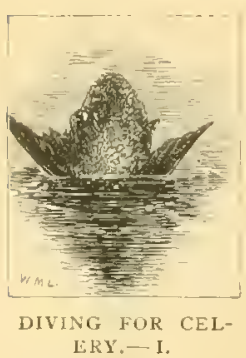

LRY FOR CEL good for the table as in the Chesapeake. Elsewhere they are tough or fishy; but the great vegetable beds of its shallows, and the quantity of wild celery that they contain, impart to their flesh its greatest delicacy and best flavor. In the matter of variety, they are known as canvas-backs, red-heads, bald-pates, blackheads and mallards. There are numbers of smaller ducks with arbitrary names depending apparently very much upon the locality and its peculiar ornithological bent. In the way of larger birds there are swans and geese. Their numbers are inconceivable, but they are very wild and hard to approach. Both, for the table, are as fine in their way as any game bird that flies.

There are various ways of shooting the ducks of the Chesapeake and its broad affluent, the Susquehanna. Genthemen for the most part shoot from "blinds" and use decoys; while market gunners use the "sink-boat" or the "night reflector." "Blinds" are

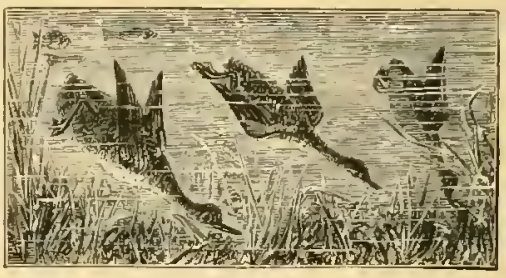

DIVING FOR CELERY.-II.

any sort of artificial concealment placed at an advantageous point upon the shore. They generally consist of a seat in a sort of box, or shelter, some four feet deep, and capable of containing three or four persons and a couple of dogs. They are thoroughly covered up with pine branches and young pine-trees and communicate with the shore by a path similarly sheltered. The water in front is comparatively shallow, and, if it contain beds of wild celery on the bottom, is sure to be a feeding-ground for the ducks. About thirty yards from the "blind" are anchored a fleet of perhaps a hundred and fifty decoys. They are wooden ducks roughly carved and painted, but devised with a strict regard for variety and sex. At a little distance they are calculated to deceive any eye, and they certainly have a great deal of weight in determining the action of a passing flock, or "bunch," of ducks. The sink-boat is in reality a floating blind. It is nothing more than an anchored box, or coffin, with hinged flaps to keep the water from invading it. The gunner 


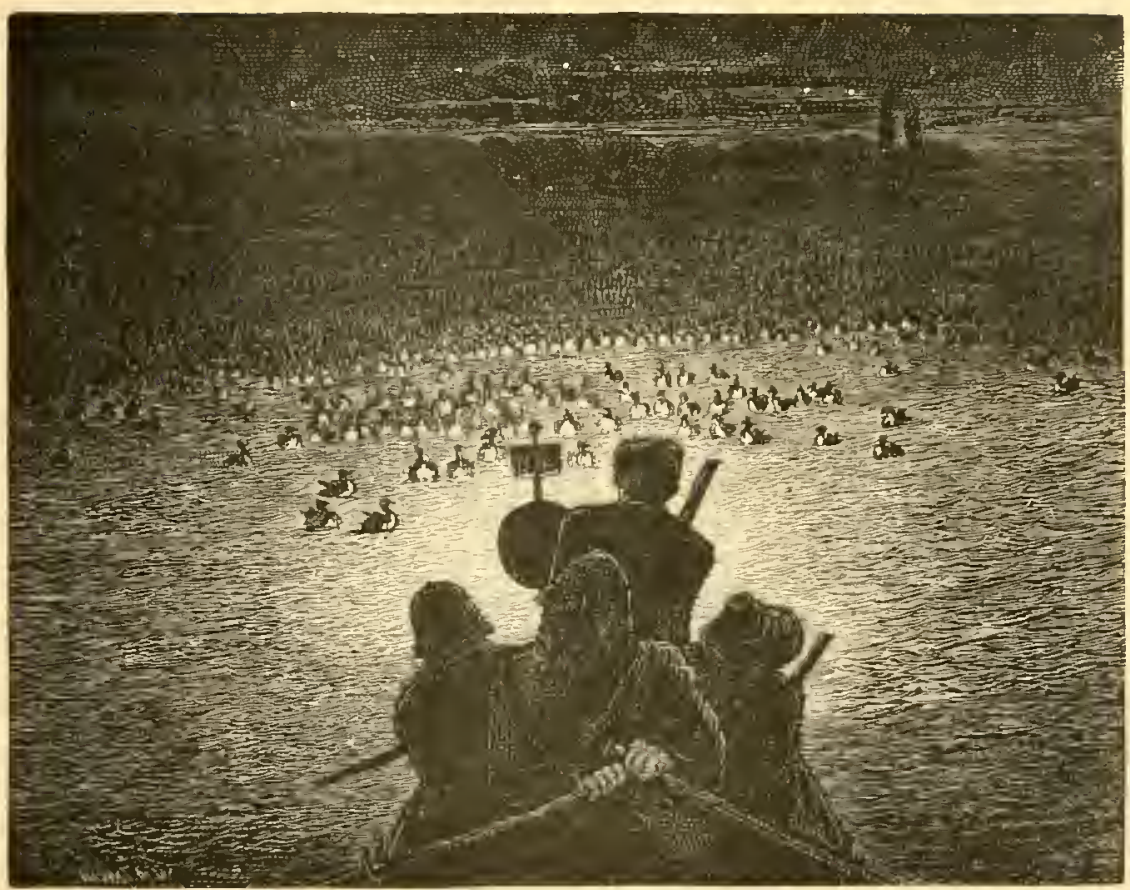

THE NEFARIOUS POT-HUNTER.

lies on his back in it, completely out of sight, and around it are placed the decoys. It is extremely tiresome work, but very destructive to the birds. They float down the stream when shot and are picked up from a boat stationed below. It is a wholesale murdering sort of thing and has little "sport" about it. The "night reflector" is quite as bad. It consists of a large reflector behind a common naphtha lamp and mounted upon the bow of a boat. The latter is rowed out into the stream, where the ducks are "bedded" for the night, and the birds, fascinated by the light, swim to it from every side and bob against the boat in helpless confusion. The number of birds secured depends only on the caliber of the gun. From twenty to thirty ducks to each shot fired is a common experience. The hunter who uses one of these reflectors may succeed in getting into half a dozen "beds" in a night. Another thing he sometimes succeeds in is getting a charge of shot in his body from some indignant sportsman on shore. If a rifle is handy and any one chances to be up and about at the hour, no hesitation is felt at having a crack at the "pot-hunter's" nefarious light.

Accepting an invitation for a day's duck-shooting at B.'s gave 


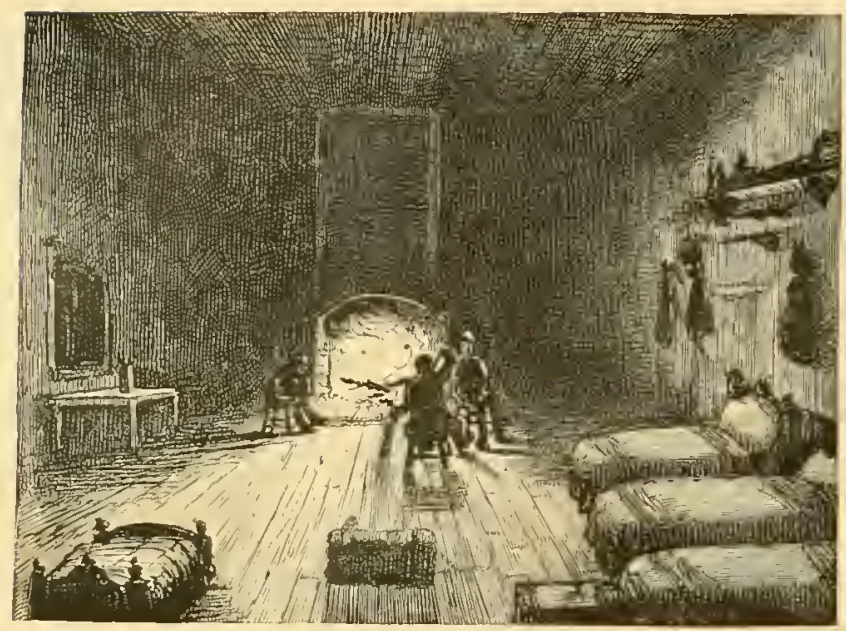

UUR QUARTERS.

me a personal experience of one of the best "shores" in Maryland. Seated in a good, serviceable wagon, our party of three left Baltimore in the afternoon, and a brisk trot of two hours and a half over roads for the most part in excellent condition brought us to the ducking-shore on Bush River. The last mile or so was through the "woods" over a comparatively new road with water on each side of it, the surrounding ground being evidently in a marshy condition. The undergrowth was very thick and young, as if it were taking the place of a forest recently destroyed by fire. There were, however, plenty of tall gum-trees, chestnuts, and pines, and it was, as B. enthusiastically described it, while pointing to the track of an animal in the road, a splendid spot for 'coons and 'possums. We drew out shortly into a clearing, on the other side of which was a house and some out-buildings, the only habitation in sight or within a considerable distance. The barking of innumerable dogs welcomed our approach, and as we pulled up in front of the door, the river, about four hundred yards in width, came into view just in the rear. It was evidently the establishment of a plain. comfortable farmer, whose guardianship of the ducking and fishing doubtless greatly diminished the annual rental to the owner. Our "traps" were soon inside and the horses stabled. We had one large room containing six small and well-kept beds, and at one end a capacious fire-place, on which a great pile of hickory logs was burning and diffusing a genial glow and the not disagreeable odor of a wood fire. On the ceiling were 
fishing-rods, nets, and tackle of every description; while around the walls were gun-racks, clothing, and hunting paraphernalia in profusion. At seven o'clock, a substantial and well-cooked dinner or supper was served in the adjoining kitchen, to which our farmer sat down with us. The conversation related chiefly to some recent incidents of 'coon-hunting, and a discussion as to the probable direction of the wind in the morning. Apprehensions of a north-west wind were expressed, but the general idea was that it would blow up from the south-west with snow or rain, in which case the ducks would be plentiful. After half an hour spent in selecting guns, filling cartridgebelts and satchels, and in other preparations, we turned in at nine o'clock, and, although the hour was somewhat unusual to me, I slept soundly. At three o'clock, our farmer came in and called us and lit the lamp. Breakfast - beefsteak, rashers of bacon, eggs, and coffee - was already sputtering and crackling in the kitchen. A hasty dowse of water with an eighth of an inch of ice on its surface, and a liberal "nip" of whisky, - the latter insisted upon for sanitary reasons of obscure origin but evidently great weight, - and we sat down. Either there was something in the air or the spirits were at the bottom of it, but at any rate the heavy supper of the previous evening seemed entirely forgotten, and the quantity of breakfast consumed was amazing. We were out in the sharp, frosty air and

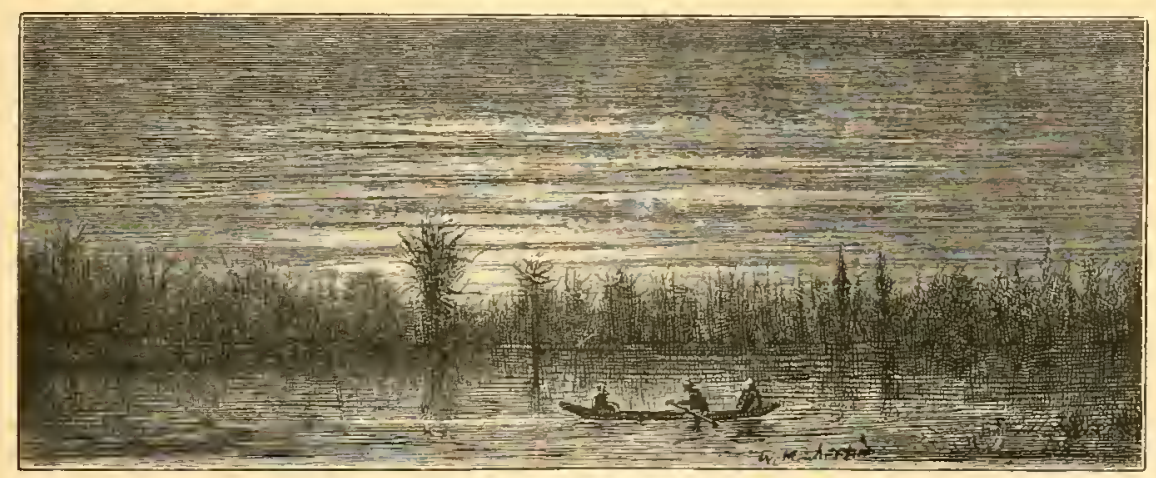

ROWING DOWN TO TUE BLIND, $4.30 \mathrm{~A}$. M.

bright moonlight at a quarter to four o'clock, excellently fortified to meet the demands of the day and the rigor of the weather.

It was but a few yards from the house to the water, and we had a row of a mile and a half to the "blind." We grot into a grood, steady, flat-bottomed boat, in which two dogs, whom no one had 


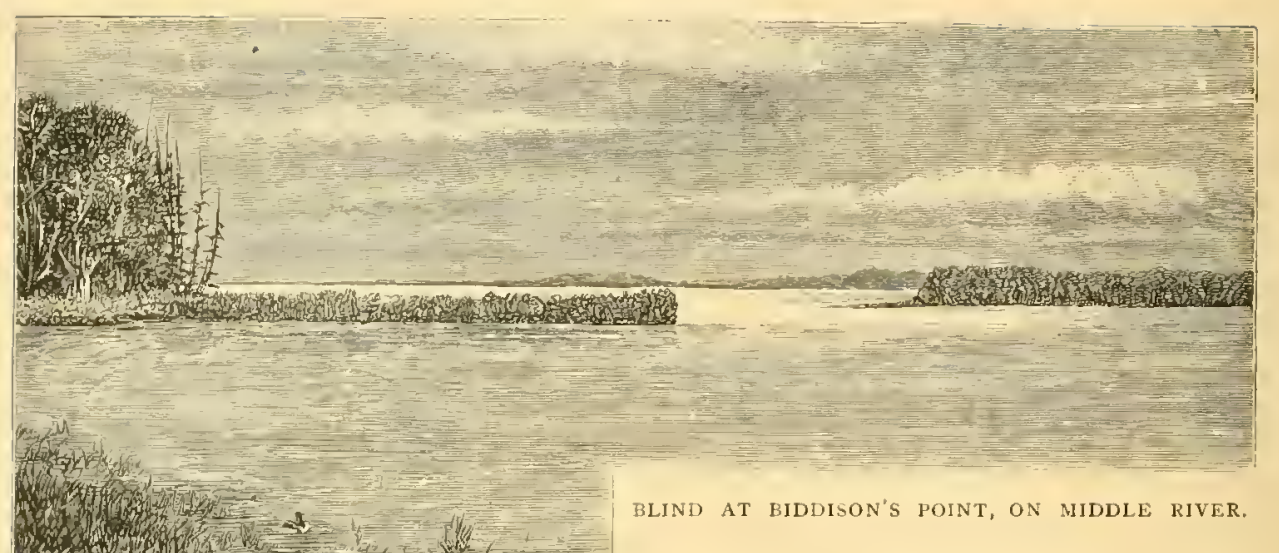

called, took their places in perfunctory and solemn fashion, and we shoved off, while about a dozen hounds and yard-dogs howled a muffled and anxious adieu from the bank. The moon hung low near the tree-tops, the river was dark, and its outlines black and mysterious. About a quarter of an inch of ice had formed, and as we crashed steadily through it, odd and fantastic echoes came from the gloomy and silent shores. As we reached the broader water nearer the mouth of the creek the ice disappeared, but the surface was calm and nowhere gave back a reflection of the moon. N. was in the bow and $I$ in the stern, our host, B., rowing in the middle. Suddenly he stopped, seized his gun and loaded it. M. did the same; I was too mystified to understand the proceeding, and was content to wonder and look on, peering around in the gloom to find the occasion, and seeing nothing but the impenetrable shadows and the undefined depths of the dark shore.

"Hist!" said B. "There is where they are," and taking his gun between his knees, he pulled a few strong, quiet strokes again. In a moment there was a most astonishing and startling noise, and I saw, about five hundred yards to the right, a long line of bright silver break upon the water. Thousands of ducks that had made a great "bed" in the creek during the night had been startled and were taking wing simultaneously, and the noise made by their splashing as they rose was tremendous. Presently, as the last duck 
lifted into the air, it ceased, and all was as silent as before. Not a duck could be seen; but my two friends had their guns cocked and were apparently listening intently. In a minute I heard a curious, whistling sound. It grew louder and seemed to approach, but 1 could see nothing whatever. As I looked, both my companions brought up their guns and fired both barrels almost simultantously overhead.

"Hush !" said 13. "Listen carefully. Mark one! Mark two! Mark three!"

I heard the splashes, and as the birds, falling, broke the water, it faintly caught up the moonlight, and we could see three ducks struggling not one hundred yards off; at the same moment both dogs, without an order from any one, disappeared overboard.

"How did you know where to fire?" I asked.

"You are not used to it yet," replied B. "When you are, you'll see ducks easily enough on the darkest night."

The ducks, on rising, had wheeled around, making a semicircle of half a mile, and, as my friends' experience led them to expect, had come directly down the river. There were thousands of them in the air, and the whistling sound was made by their wings. In the meantime, both dogs came up to the side to be taken in. Each had a red-head in his mouth; the third bird having died, could not be detected in the darkness, and was abandoned.

A further pull of some ten minutes brought us to the blind, inside of which we found Joe, the darkey who had put out the decoys during the night. He was fast asleep in the straw, though the thermometer was below freezing-point. He took our boat and rowed it away out of sight around the nearest point, and then returning, lay down by the dogs and went to sleep again. We seated ourselves to wait for day-break and ducks, and I endeavored to persuade myself that I was not cold. My companions spoke in hushed ecstasy of the south-west wind that blew up the river as the moon went down. It struck me as the coldest wind I had ever known, and I drew my hands up my sleeves and made a manful effort to keep my teeth from chattering. A gray light stole across the eastern sky, and I began to see the canards riding at anchor in front of our blind. I was undeniably cold, and it was all I could do to keep from confessing to myself that I felt miserable. Besides, my companions had 


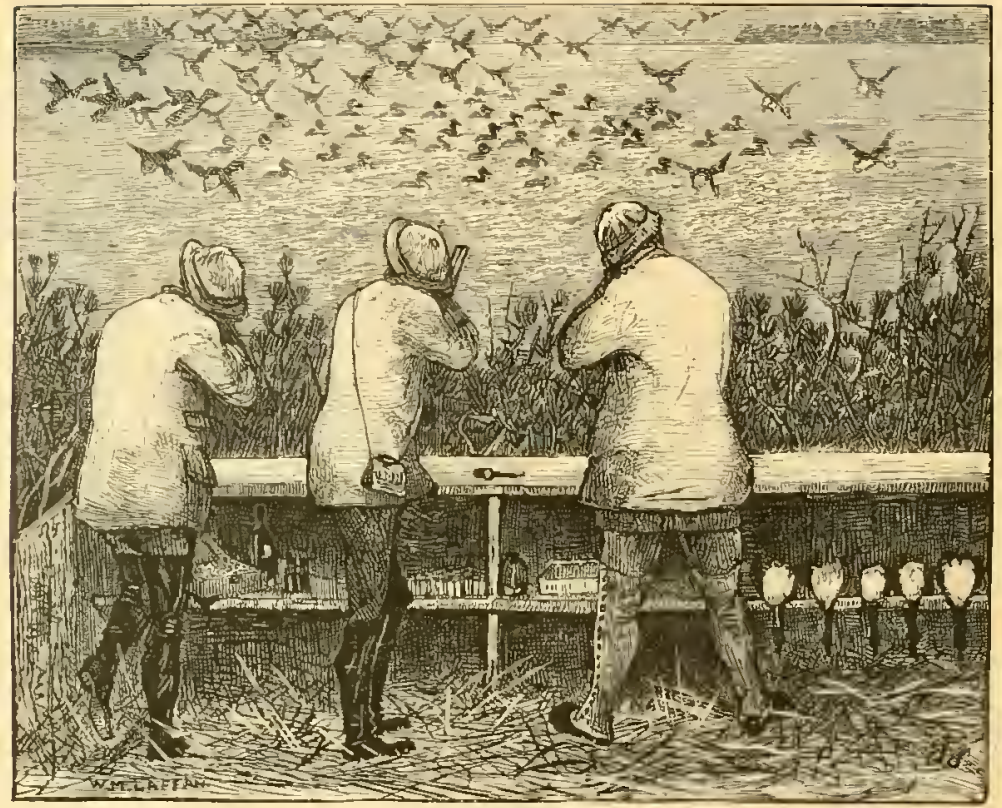

OVER THE DECOYS.

been whispering dismal experiences of whole days in blinds without a solitary shot, and I began to despise the whole business. The blind became a dry-goods box in a bush, and the decoys an unblushing and unworthy device, and I could have readily proclaimed the whole thing unsportsmanlike and disgraceful, had there been a spark of encouragement in the demeanor of even sleepy Joe. The gray light grew brighter, and a blue, hazy "smoke" seemed to creep up the river as day dawned over the cold water. Presently, we heard a shrilly, feeble whistle, precisely such as the young puddle-duck of the barn-yard makes in his earliest vocal efforts. "Bald-pates!" saic B.; and overhead, far out of reach, we saw four ducks. "There'll be lots of them now," said B. "They are coming up the river before the wind. H'sh! mark, mark, now quiet everybody!" Right out of the blue smoke, coming directly toward our blind, came not less than two hundred black-heads. On they came, straight toward the decoys. Within a hundred yards of our noses, the leader swerved, and out they all went. not one coming within gunshot. Before 1 could give way to my disappointment. B. gave his warning again. "Nark, mark, a bunch of canvas-backs!" and from the same direction, flying within a foot or two of the water, came some twenty ducks. They saw the decoy flock, turned in, and in a monent 
more were hovering within a few inches of the wooden heads. All three stood up, and as the ducks hung fluttering, six barrels were poured into them, and one, two, four, six, eight, and another- noyes-no-yes-nine ducks tumbled into the water, and splashed and floundered around in their death agonies. While it would be impossible for me to swear that I had hit one, I had an abiding consciousness that at least four of the birds were mine, and I became wholly oblivious of the temperature. "Mark again!" said the keensighted and watchful B. "Mark single duck coming right in. Now, sir, take him, he's your first choice! Now, sir!*** Good, sir, by gracious!" I had tumbled that single duck over like a professor. To say that I was delighted will not do.' I was excited; I was wild, and I began to mark invisible ducks myself. "Good sport?" said B. "Gorgeous!" said I. " Yes," said B.; " it generally drives a man crazy, the first day of good shooting he gets, and then we have to take him up here in the woods and tie him to a tree till he calms down, and is fit to be allowed back in the blind." I did not think I was so excited, but I soothed myself. But by this time it was almost sunrise, and we could see ducks coming up the river in countless numbers. Presently, a largre flock left the middle of the stream and swept out about half a mile below into a broad bay. At first, it seemed as if they would "bed" there, but they turned and headed for the blind. We crouched low, and scarcely dared to breathe lest they should swerve out into the stream again. On they came like a whirlwind, and were fluttering and splashing on the decoys as we rose and fired six barrels into the thickest part of them. Not less than twenty canvas-backs and red-heads fell, and, as some, only disabled, tried to swim away, a few more shots made sure of them.

" Mark, gemmen, mark!" said Joe, holding down the dogs, and "whir" came a flock of bald-pates right over us from behind. B., who shoots from his left shoulder, had his gun up in an instant and fired both barrets overhead, and two large, heavy birds fell wounded outside the line of the decoys. Neither M. nor myself had been quick enough. "Now, Joe, said B., "out with you; quick!" Joe let go the dogs and dived under the blind, and in a moment more was paddling out and picking up duck after duck with his little canoe. Here came in the office of the dogs, whose wonderful instinct and training and perfect experience constitute one of the most astonish- 


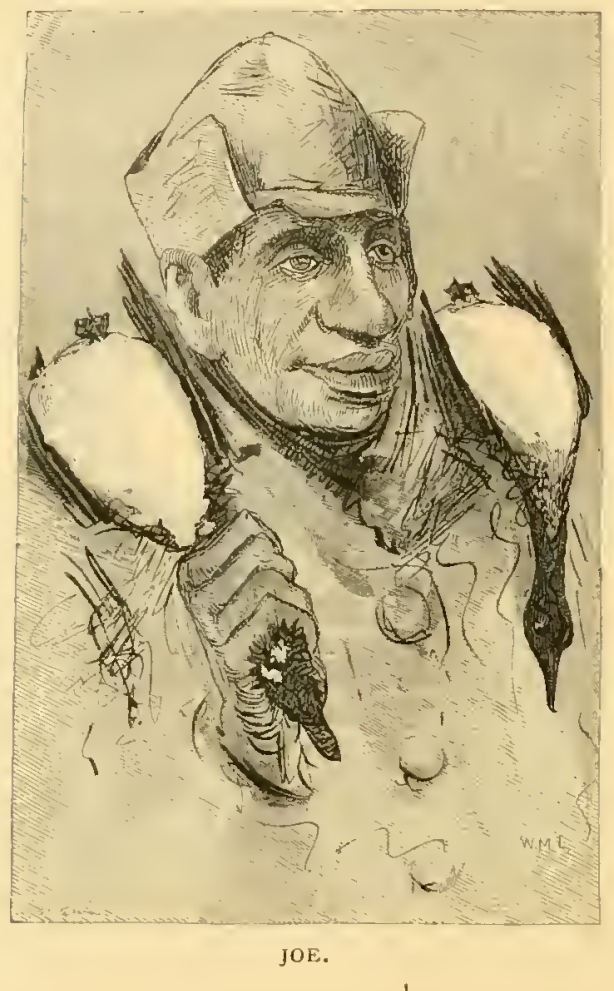

ing examples of animal intelligence that one may see. They were not, in appearance, dogs that would attract any special attention. They belonged to the breed known as Chesapeake-duck-dogs, and they certainly showed that retrieving ducks was their vocation. They went out straight through some thirty birds, in and around the decoys, toward the two bald-pates, which, only slightly disabled, were swimming rapidly away. Each dog selected his bird and went for it steadily. As the dog drew near, down went the duck. The dog stopped, and, as it were, stood up in the water, turning slowly around in a circle looking for the duck to re-appear. The moment it came up he went for it again. This time he got nearer. The same thing was repeated, the dog each time waiting patiently for the duck's re-appearance, and each time getting nearer and nearer to it. Finally, with a sudden dash and a partial dive, each dog seized his duck, and turning, swam to shore with it. They would not trouble themselves with the ducks that Joe could secure, but selected those that required their particular attention, swimming after each not less than a quarter of a mile. When a shot is fired and a duck falls, a 
dog trained as these were will. unless forbidden, leave the blind immediately and secure the bird. If no duck falls the dog lies down again, invariably using his own judgment as to the result of the shot. He will never stir without express orders, if he thinks the shot has been ineffectual. The breed is peculiar to these waters. It is adlapted to the cold water, and has been cultivated for years, and is greatly prized by the sportsmen of Naryland.

As much interest is now taken in this remarkalsle breed of dogs, we will give a few quotations about it, taken from "The Dog and the Sportsman," by 'T. S. Skinner, former editor of the "Turf Register," etc., Philadelphia, i $S_{45}$. In this book, the first published in this country on the dog, game, and the gim,- and now quite scarce,is the first account of the origin of this breed. These quotations will put the reader in possession of the ancient histony of the Chesapeake liay dog-[EDitor|.

"As to this stock, besides the liest of them being still red or black, there are other reasons for assuming that those most esteemed have descended from, and still partake distinctly of, the blood and trats of a pair of these colors, brought directly, male and female, from Newfoundland to Maryland, nearly forty years ago. Of that importation, we are glad to have it in our power to jreserve the following authentic memoir, furnished, at our instance, ly the importer himself, a gentleman who possesses, as all his friends know, an instinctive fondness for goorl dogs and good deet's:

\section{“ BaLtimore, MarylaxD, January 7, i $S_{+5}$.}

"My" Dear Sir: In the fall of $1807 \mathrm{l}$ was on board of the ship, Canton, belonging to my uncle, the late Hugh Thompson, of Baltimore, when we fell in, at sea, near the termination of a very beavy equinoctial gale, with an linglish brig in a sinking condition, and took off the crew. The brig was loaled with cod-fish, and was bound to Poole, in England, from Newfoundland. I boarded her, in command of a boat from the Canton, which was sent to take off the English crew, the brig's own boats having been all swept away, and her crew in a state of intoxication. 1 found on board of her two Newfoundland pups, male and female, which $\mathrm{f}$ sared, and subsequently, on landing the English crew at Norfolk, our own destination being Baltimore, l purchased these two pups of the English captain for a guinea apiece. Being bound again to sea. I gave the dog-pup, which was called Sailor, to Mr. John Mlercer, of West River, and the slut-pup, which was called Canton, to 1)r. James Stewart, of Sparrow's Point. The history which the English captain gave me of these puls was, that the owner of his brig was extensively engaged in the Newfoundland trade, and had directed his correspondent to select and send him a pair of pups of the most approved Newfoundland breed, but of different families, and that the pair I purchased of him were selected under this order. The dog was of a dingy red color and the shut black. They were not large; their hair was short, but very thick coated; they had dew-ciaws. lboth attained great reputation as water-dogs. They were most sagacious in everything, particularly in all duties connected with duck-shoting. Governor Lloyd exchanged a 
merino ram for the dog, at the tine of the merino fever, when such rams were selling for many hundred dollars, and took him over to his estate on the eastern shore of Maryland, where his progeny were well known for many years after, and may still be known there and on the western shore as the Sailor bred. 'The slut remained at Sparrow's Point till her death, and her progeny were and are still well known through Patajsco Neck, on the Gunpowder, and up the bay, amongst the duck-shooters, as unsurpasserl for their purposes. I have heard both Hoctor Stewart and Mr. Mercer relate most extraordinary instances of the sagacity and performance of both dog and slut, and would refer you to their friends for such particulars as I am unable, at this clistance of time, to recollect with sufficient accuracy to repeat.

$$
\begin{aligned}
& \text { "'Yours, in haste, } \\
& \text { ". George Law.' }
\end{aligned}
$$

"On inquiry, since the date of the above, of Mr. Mercer and of Dr. J. Stewart, it is ascertained of the former, who owned Sailor, that he was of fine size and figure-lofty in his carriage, and built for strength and activity; remarkably muscular and broad across the hips and breast; head large, but not out of proportion; muzzle rather larger than is common with that race of log; his color a dingy red, with some white on the face and breast; his coat short and smooth, but uncommonly thick, and more like a coarse fur than hair; tail full, with long hair, and always carried very high. His eyes were very peculiar; they were so light as to have almost an unnatural appearance, something resembling what is termed a zcall eye in a horse; and it is remarkable that in a visit which I made to the eastern shore, nearly twenty years after he was sent there, in a slool, which had been sent expressly for him, to West River, by Governor Lloyd, I saw many of his descendants who were marked with this peculiarity.'

"Does it not secm to be a characteristic of the best water-dogs that, like the eagle and the owl, the lion and the cat, and other birds and beasts of prey whose condition and habits require extraordinary powers of vision, as does the dog when swimming in pursuit of dicks at a great distance, that they should have eyes of a yellow or, at least, of an uncommon, not black, color?

* * * "Were old Vamell (the trusted servant and duck-shooter of that venerable and high-spirited patriot, Doctor I. Stewart) still alive, he could relate many most extraordinary feats performed by Canton at Sparrow's Point. She surpassed her species generally in unrivaled devotion to the water and to the sport of ducking, as carried on by the old Doctor's colored man, Varnell, with his murderous swizel gun!' Her patience and endurance of fatigue seemed almost incredible, and her performances would be best illustrated by taking down, from the old l)octor and others, who remember them, the facts of her fights with wounded swans, after pursuing them in the water for miles. Also her extraordinary pursuit of wounded ducks, amongst rotten and floating ice, and sometimes in fogs and darkness. On one occasion, she brought out 22 or 23 ducks, all killed or wounded by Varnell at a single shot. A good deal of time was lust in pursuing these wounded clucks, and at the close of this pursuit, it being then dark, Varnell gave up the slut as lost, so many hours had she been engaged in loringing out her game; but after Varnell had sorrowfully turned his face homeward, she overtook him with one or two ducks in her mouth; and the old Doctor remembers hearing Varnell say, that at one time, when she was most 


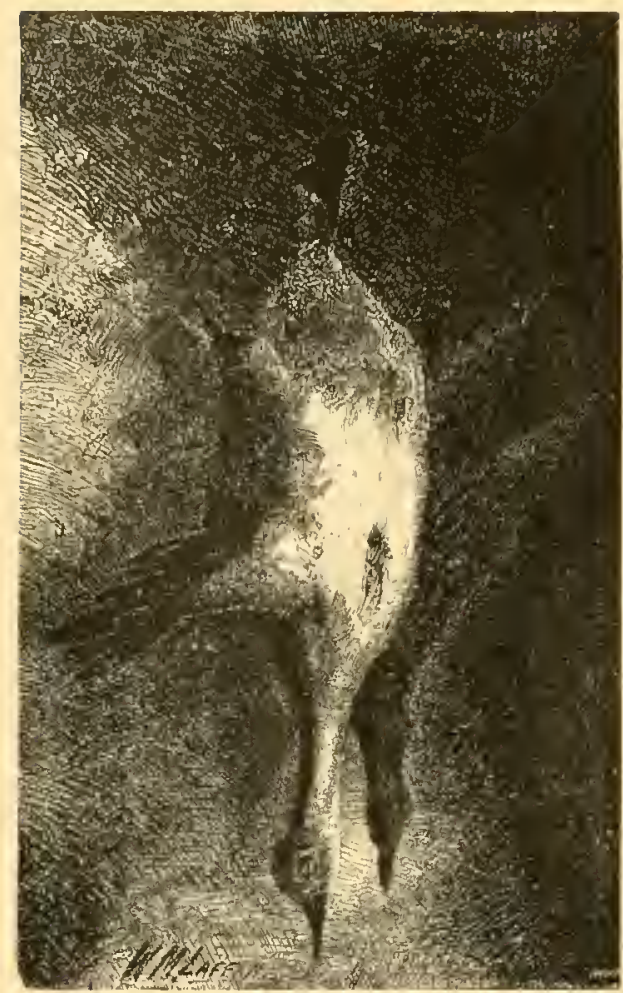

INTERRLPTED PILGRIMS.

fatigued, she climbed on a cake of floating ice, and after resting herself on it, she renewed her pursuit of the ducks.

* * * In their descendants, even to the present remote generation, the fine qualities of the original pair are conspicuously preserved, in sjite of occasional stains of inferior blood. * * * There is one now (Leo) at Naxwell's Point, on the Gunpowiler River, in Maryland, a descendant of Sailor, through a slut pup of his, who deserves to be named as a noble sprecimen of his tribe. * * * Leo stands in height from zo to 22 inches; black, with a small white spot on his breast, and a little white on each foot; his eyes, again, yellow! IIis form is something after the model of the setter, without his feathery tail, or the smooth one of the pointer: not so deep in the chest as the setter, but romuler in his loody, and larger in the neck, with his ears smaller and more set up, and the tips of them turning down. His hair not exactly long, yet further from being short; with a woolly under-jacket to protect his skin from the water, for he has often to make his way through the ice. Such is the fersonnel of Leo-a

" "Whose honest heart is still his master"s own,

Who labors, fights, lives, breathes for him alone.

"Many anecrotes might le related in proof of his reasoning powers: but we have room only to add, in general terms, that he comes fully' up to the line of his 
duty. Of how few bipecls can we say as much? When ducks are passing over, he takes his stand with his master, his fore-feet resting on the blind, and, still as a mouse, he watches not the gun, nor anything but the game as it approaches; and listenng to hear the shot strike, the moment a duck is seen to falter in its flight as it falls, the good dog plunges in the river like a ball from a cannon, and, from whatever distance, brings the luck and lays it at the feet of his master. He has been known to bring out as many as three at a time, and has the sagacity, when some are only crippled and in danger of being lost, to give to them first a finishing grip, leaving such as are stone deal to be secured at leisure. When a duck dives to escape him, it is curious to see how he will stand erect, head and shoulders out of water, watching in all directions for its re-appearance. Such are the offices, such the achievements, of the high-brech water-dog of the Chesapeake Bay and the noble estuaries that commingle in its bosom.

"Three types of the Chesapreake Bay dog are now recognized: (1.) The Otter breed: color, tawny sedge; hair, very short. (2.) The Red Winchester: hair, long. (3.) The red-brown, with a curly coat. A white spot on the breast is not unusual in the three types.

"Measurements: From fore-toe to top of back, 25 inches; from tip of nose to base of head, ro inches; girth of body back of fore-leg, 33 inches; breast, 9 inches; around fore-feet, 6 inches; around fore-arm below shoulder, 7 inches; between eyes, 2 If inches; length of ears, 5 inches; from base of head to root of tail, 35 inches; tail, 6 inches; around the muzzle below eyes, ro inches."

By nine o'clock we had ninety-six fine ducks in our blind, and a very handsome and imposing looking lot of game, indeed, they made. After that hour the ducks ceased "trading," as flying from one point to another is termed, and began to form great beds of countless thousands out in the open water. As far as the eye could reach, the middle of the stream and the broad water of the river below were covered with them. There were literally acres of duchs of all kinds; but "trading" was at an end, and shooting, except of an occasional single or stray duck, was temporarily suspended.

" W'ell," said B., "I suppose, now, you'd like to see some duchtolling?"

"I'd like to be told," I replied, "what tolling is."

B. declined to explain, and said the only way to find out was to see it for oneself. It was determined to go over to Cold Spring, and as a walk of half a mile across one of these peninsulas will take one from one estuary to another, we shouldered our guns and were soon in sight of it. It was just such another sheet of water as we had left, with woods growing thickly down to a sandy shore. IVe 
walked leisurely over, and Joe, having gone to his calin for a young spaniel in his keeping, overtook us. Cold Spring was full of ducks, but they were all "bedded" far out from the shore. We made for a sheltered cove, and were shortly crawling on our hands and knees through the calamus and dry, yellow-tufted marsh-grass, which made a good cover almost to the water's edge. Joe left the dogs with us, and, going back into the woods, presently returned with his hat full of chips from the stump of a tree that had been felled. The ducks were swimming slowly up before the wind, and it seemed possible that a large body of them might pass within a few hundred yards of where we were. The two dogs, Rollo and Jim, lay down close behind us, and Joe, tying flat behind a thick tuft a few yards to our right, and about fifteen feet from the water's edge, had his hat full of chips and held the young spaniel beside him. All remained perfectly quiet and watched the dicks. After nearly three-quarters of an hour's patient waiting, we saw a large body of ducks gradually drifting in toward our cove. They were between three and four hundred yards away, when B. saicl:

"Try them now, Joe! Now, boys, be ready, and don't move a muscle until I say fire!"

Then Joe commenced tolling the ducks. He threw a chip into the water, and let his dog go. The spaniel skipped eagerly in with unbounded manifestations of delight. 1 thought it for a moment a great piece of carelessness on Joe's part. But in went another chip just at the shallow edge, and the spaniel entered into the fun with the greatest zest imaginable. Joe kept on throwing his chips, first to the right and then to the left, and the more he threw, the more gayly the dog played. For twenty minutes I watched this mysterious and seemingly purposeless performance, but presently, looking toward the ducks. I noticed that a few coots had left the main body and had headed toward the dog. Even at that distance, 1 could see that they were attracted by his actions. They were soon followed by other coots, and, after a minute or two, a few large ducks came out from the bed and joined them. Others followed these, and then there were successive defections of rapidly increasing numbers. Several ducks stood up in the water by the aid of their wings, sustained themselves a moment, and, sitting down, swam rapidly around in involved circles, betraying the greatest excitement. And 


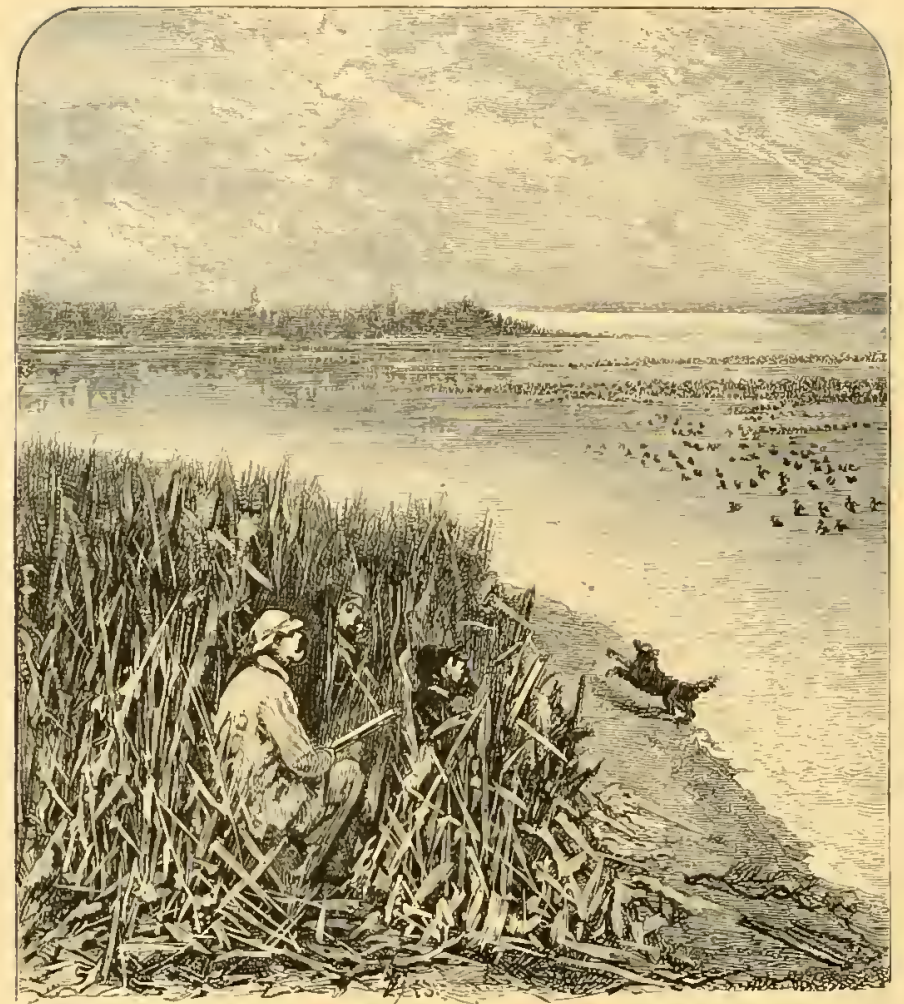

A TOIL OF DUCKS CUMING IN.

still the dog played, and played, and gamboled in graceful fashion after Joe's chips. By this time the ducks were not over two hundred yards away, and, taking heart of their numbers, were approaching rapidly, showing in all their actions the liveliest curiosity. It was an astonishing and most interesting spectacle to see them marshaling about, to see long lines stand up out of the water, to note their fatuous excitement, and the fidelity with which the dog kept to his deceitful antics, never breaking the spell by a fatal bark or a disturbing movement. The more wildly he played, the more erratic grew the actions of the ducks. They deployed from right to left, retreated and advanced, whirled in companies, and crossed and recrossed one another. Stragglers hurried up from the rear, and bunches from the main bed came fluttering and pushing through to the front to sce what it was all about. By this time the nearest skirmishers were not a hundred yards off, and as Joe threw the chips to right or left and the dog wheeled after them, so would the ducks immediately wheel from side to side. On they came until 
some were about thirty yards away. These held back, while the ungovernable curiosity of those behind made them push forward until the dog had a closely packed audience of over a thousand ducks gathered in front of him.

"Fire!" said B., and the spectacle ended in havoc and slaughter. We gave them the first barrel sitting, and, as they rose, the second.

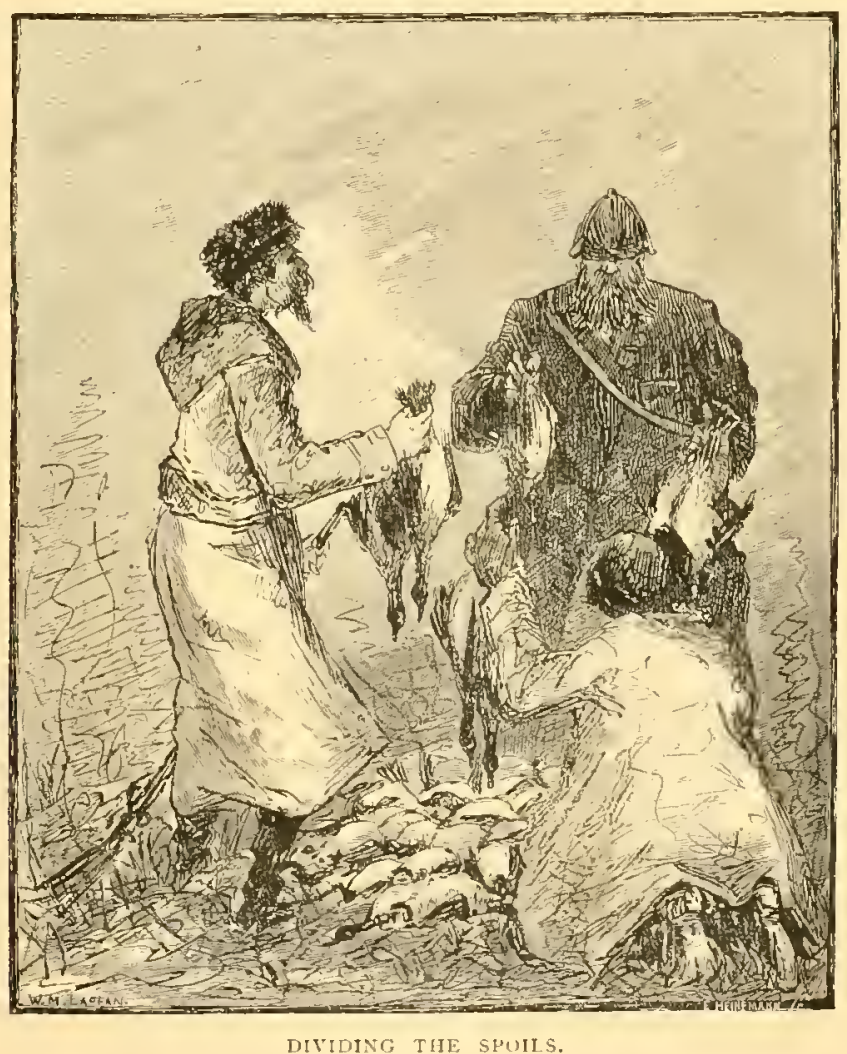

We got thirty-nine canvas-backs and red-heads and some half dozen coots.

Another way of "tolling" ducks, said to be very effectual, is with a gorgeous yellow-and-red handana handkerchief, waved above the grass and rushes on a stick. Ducks will walk right up on shore to examine it and pay the penalty of their curiosity. The canvas-back has the bump of inquisitiveness more largely developed than any other wild variety. 
J. S. Skinner, in "The Dog and the Sportsman," Phila., I 845 , gives the following account of the origin of this singular method of decoying ducks-[Enrtok]:

"More than forty years ago ( 1805 ), this curious mode of getting ducks is said to have had its commencement near Havre de Grace, Maryland.

"Tradition says the discovery was made by a sportsman who, patiently waiting for a bocly of ducks to feed within gun-shot (as was then the only chance of getting a shot at them on the water), saw them suddenly raise their heads and swim directly for the shore. On looking for the cause of this strange maneuver, he found they were decoyed by a red fox playing on the shore.

"In active, sprightly dog is generally selected for this service. *** The only act neressary is to keep your dog in constant motion; a red color is best. and a long bushy tail of great advantage.

"The canvas-back and red-heads are the best to tole, and they appear to be differently operated on. The former comes to the dog with head erect. sitting high on the water, and when near you has, if I may use the expression, a kind of idiotic look in the eye, whereas the latter are more sunk in the water, and appear unconscious of their approach to the shore."

Upon the table the canvas-back makes a royal dish, though few can distinguish between it and the red-head when both are in season. Only those very familiar with the birds can tell which is which when alive, and, when served, it becomes almost an impossibility. The celery flavor is more marked in the canvas-back in the best of the season. It is seldom served precisely as it should be anywhere out of Maryland. If allowed to remain in the oven five minutes too long it is unfit for the table. A great deal also depends upon the carving. A good, quick oren will cook a full-sized duck in twentytwo minutes. It should never remain in orer twenty-five. After a duck is picked and drawn, it should be simply wiped dry. Water should never touch it, and it should be fairly seasoned before going to the fire.* When done, the birds should be placed in pairs in hot, dry dishes. There is no need to prepare a gravy: immediately they are cut they will fill the dish with the richest gravy that ever was tasted. One canvas-back to each "cover" is considered a fair allow-

* "P. S. How to Cook a Canvas-13ack.-Take it as soon after the "leaden messenger' brings it down as possible, even while it is yet warm, if it can be so, and cook it in a 'tin kitchen,' turning and basting it frequently with a gravy composed in the bottom of the oven with a little water and a grain of salt and its own drippings. The fire should be a bisk one (hickory the best), so that it may be done 'to a turn' in twenty-five or, at most, thirty minutes. Serve it up immediately in its own gravy, with 
ance at a Maryland table, but when the bird is only an incident of the dinner or supper, of course half a bird is sufficient for each person. Slicing the bird is unheard of. The two-pronged fork is inserted diagonally astride the breast-bone, and the knife lays half of the bird on each side, leaving the "carcass" on the fork between. The triangle of meat an inch thick comprised between the leg and

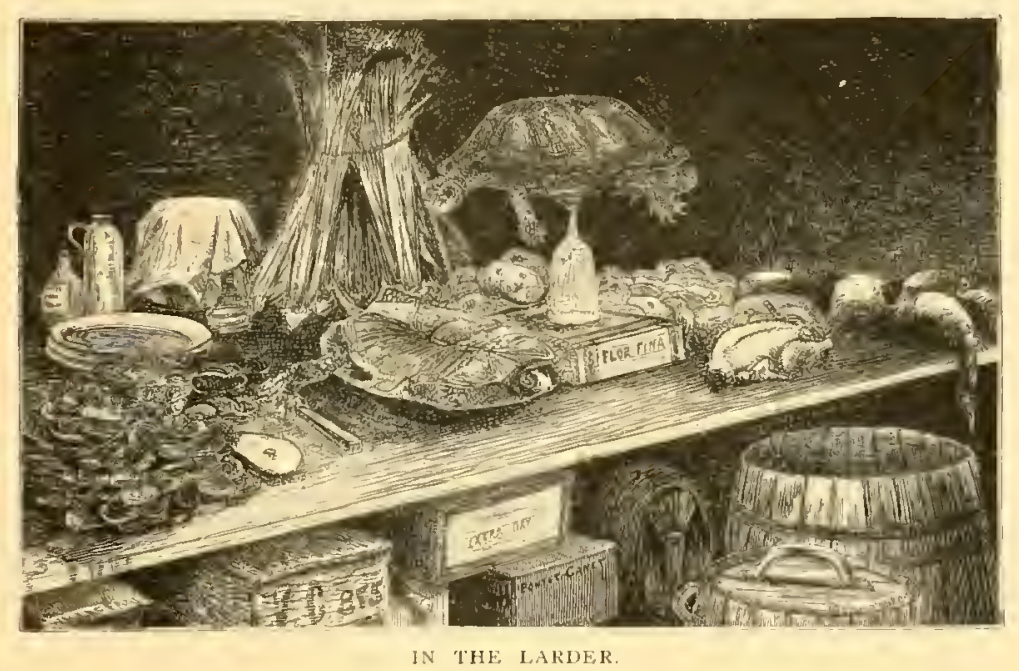

the wing, with its apex at the back and its base at the breast, is considered the most delicious morsel of meat that exists. The canvasback in Maryland is served with large hominy fried in cakes, celery, and a dry champagne, or a bottle of Burgundy that is Burgundy.

Terrapin, in the order of dishes, preceles the duck at the table. In Baltimore, it is a great lenten dish, devout and wealthy Catholics finding that it greatly facilitates the observance of the "regulations." It is singular that it should appear to be exempt from the church prohibition, for when on the table it would be hard to define

a dish of nice, wel] boiled (and then fried) milk-white hominy; and then, if it may so happen, with Cadwallader's old 'butler' at your elbow. If such fare do not

"'Raze out the written troubles of the brain.'

And dispose the partaker to love his neighbor as himself,

And thank l'rovidence for all its bounties,

"Oh, hear him to some distant shore,

some solitary cell,

Where none but savage monsters roar,

Where love ne'er deigns to rwell."

[From "The Dog and the Sportsman," by .J. S. Skinner, Philadelphia, 1 $S_{45}$. ] 
it as anything but very positive meat. It is certainly quite as much meat as a broiled leg of a frog. Terrapins are worth from $\$ 25$ to $\$ 36$ a dozen during the season. A dozen terrapins consists of twelve "diamond-backs," no one of which measures less than seven inches in length on the under shell. A seven-inch terrapin is called a "count-

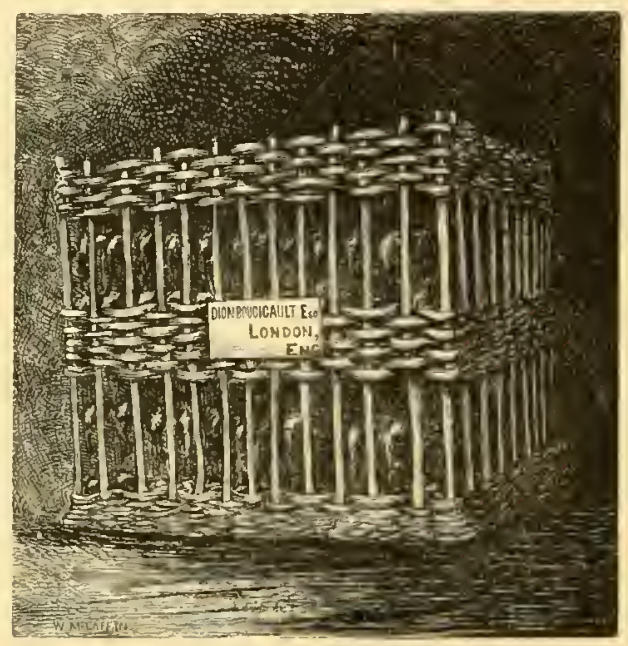

POSTHUMOUS MIGRATION.

terrapin," and anything smaller is not counted. The largest known do not exceed ten inches in length and eight pounds in weight; and such are extremely rare. The seven-inch terrapin averages four pounds in weight. "Sliders," the common river turtles of almost all the rivers of the region, grow to a much larger size. They sell at from $\$ 6$ to $\$ 9$ a dozen, and are largely used by hotels and restaurants, where they are retailed at $\$ 1$ and $\$ 1.25$ a dish as genuine diamond-back terrapin. It is next to impossible to get a genuine dish of terrapin at a public house. The one or two people controlling the trade say they sell almost exclusively for private tables.

Terrapin are caught all the way from Savannah and Charleston to the Patapsco River, at Baltimore, but the genuine diamond-back belongs only to the upper Chesapeake and its tributaries. The majority of the slicters are brought to Baltimore from the James River. The terrapin-catchers make from $\$ 5$ to $\$ 50$ per week, and they find the reptile, or "bird," as the bon wizunt calls it, by probing the mud in the shallows with sticks. The terrapin is dormant, and 


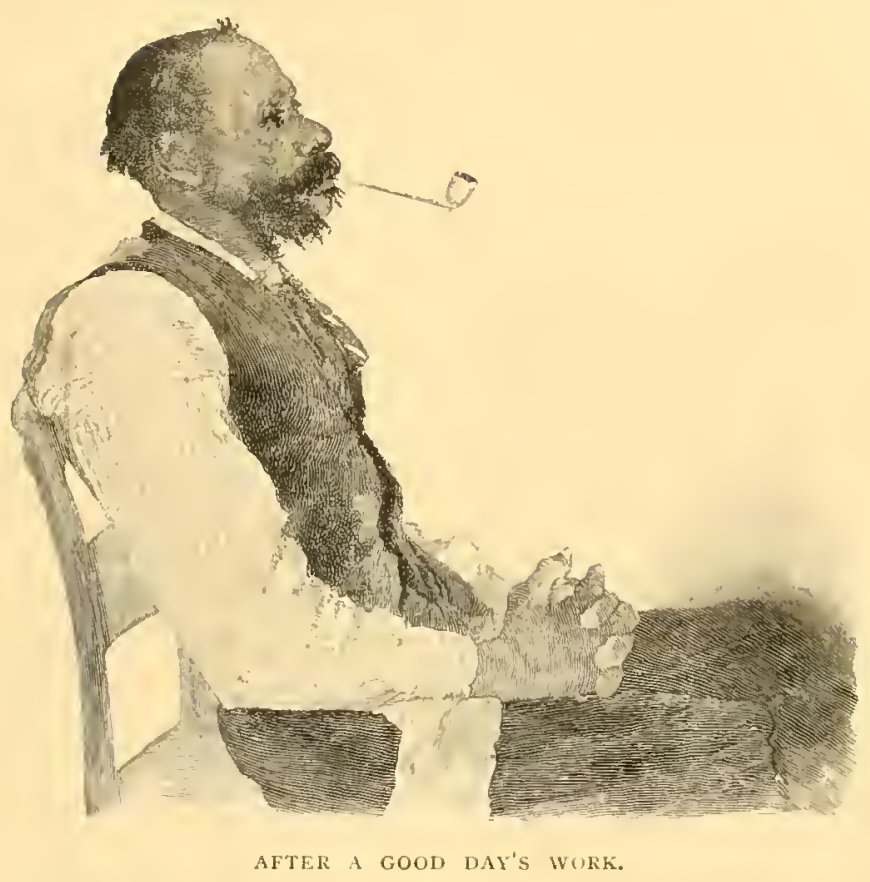

when found is easily secured. A four-pound terrapin taken about September ${ }_{1} 5^{\text {th }}$ will exist prosperously in a dark, cool place, without food or drink, until April 15 th, and (the dealers say) will gain two ounces in weight. After that time it gets lively and active, and will take hold of a finger with great effusion and effectiveness. The male terrapin is known as a "bull" and the female as a "cow." The latter is much more highly prized, and generally contains about thirty eggs. No dish of terrapin is thought complete without being garnished with these. It is sad to be compelled to state that the sinful restaurateur and hotel man betakes him to the egg of the pigeon. wherewith to set off his counterfeit presentment of a noble reptile.

Thirty years ago, the largest dealer in Baltimore had hard work to dispose of the terrapin he received at $\$ 6$ a dozen. The product, he tells me, is about the same, year in and year out. He sells as many now as he did then. But okd people on the eastern peninsula bring to mind when of a warm day the terrapins, basking in shoals on the surface of the water, were caught in seines and fed to the pirs. That day, however, is of the past. and it is doubtful if this valuable article of food is not gradually becoming extinct. The negroes who 
make a business of sending them to market complain of their increasing rarity, and nothing but the high price has stimulated them to keep up the supply.

The negroes are credited with having been the first to bring the virtues of the terrapin to notice. They cooked, and still cook it, by placing it alive among the hot coals or in an oven. When it is sufficiently cooked, the under shell is easily removed with a knife, and the contents are then eaten from the inverted upper shell, nothing being removed but the gall-sac. There are many, particularly epicures of

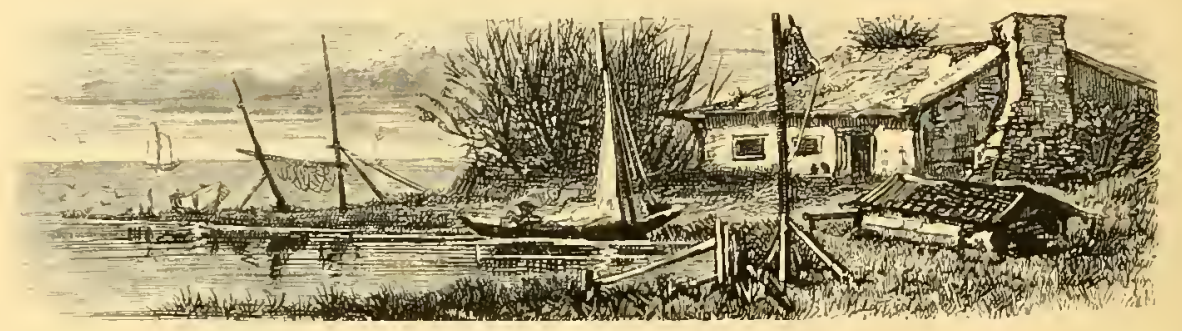

A TERRAPIN HUNTER'S HOME.

long experience with the terrapin, who maintain that this is the true way to cook it. One noted for his knowledge of Maryland dishes invariably cooks his terrapin as follows: He places a "count," alive, on its back in an old-fashioned ten-plate stove, roasts it until the under shell is easily detached, removes the gall, adds a little butter, salt, and a glass of good sherry or madeira, and then eats it, with a sense as of a Mussulman discounting the delights of the seventh heaven. He has never met Mr. Bergh.

Baltimore consumes most of the terrapins caught. Large numbers are shipped to New York. Delmonico is a good customer of the Baltimore market, and Scoggins's game and terrapin dépôt is seldom without a box or two addressed to the New York restaurant. With all due respect for a New York cuisinc, neither the terrapin nor the canvas-back is ever the same when eaten away from, so to speak, its native heath. There is an indefinable halo of originality about Maryland cookery, wholly independent of the process just delicately alluded to in connection with terrapin, that obtains nowhere else. A Maryland dinner is simplicity itself. but it would tax" the capacity of the "best men" of a New York club.

Washington eats more fish than any other city in the Inited States in proportion to its population, but Baltimore probably eats 
more good things generally. There is a sort of refined barbarism about such a monu as that of a plain winter dinner in Maryland that would doubtless vex Mr. Felix Deliée and his confrères of that august fraternity; the cordons bleus of New lork. Here it is, without any of the "illusions" in which a lrench artist would so like to enshroud it: "Four small oysters from Lynhaven Bay (once opened, they would never again be inclosed in the self-same shell); terrapin à la Maryland: canvas-lack ducks; a small salad of crab and lettuce. Vegetables:-baked lrish potatoes; fried hominy cakes, and plain celery." If this shall have been attended by adventitious circumstances, it will put the artificialities of refined cookery of the exalted order entirely to the blush.

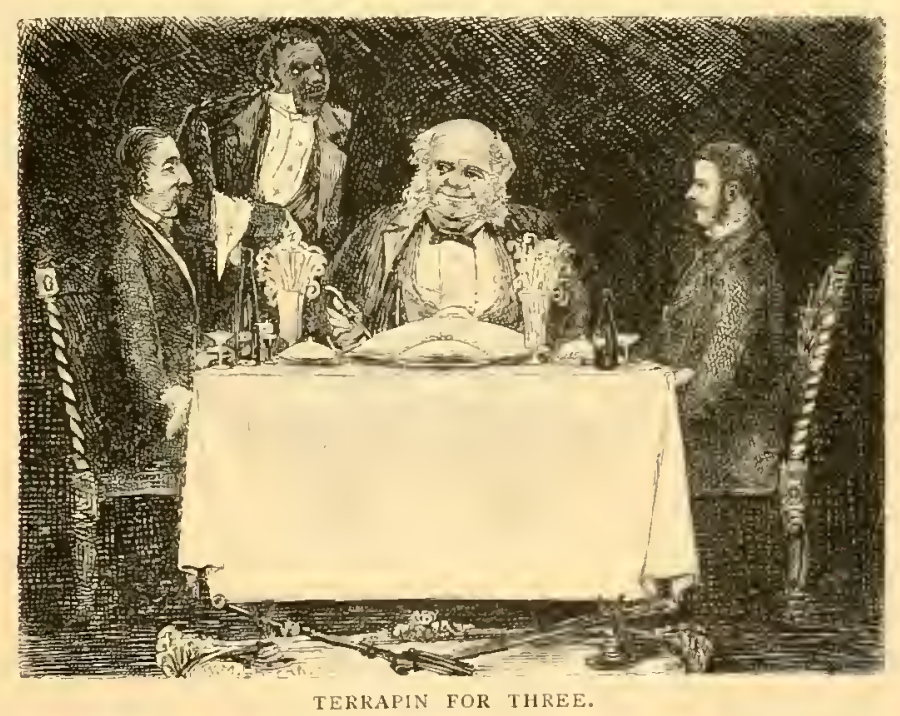




\title{
A DAI WITH THE RAILS.
}

\author{
BI A LFREI) M. MAYER.
}

\begin{abstract}
COON after the Christmas holidays, sport with dog and gun ceases. and has become a matter for reveries before the evening fire, where scene after scene comes and goes with the involun. tary action of the mind, as it recalls those happy days of sport with congenial and manly friends. What a refreshment the mind thus takes to itself! What a respite are these reveries from the weariness of routine and the emptiness and heartlessness of conventional life! The pleasures of the sportsman do not end with his sport, no more than the murmurs of the rivulet we heard last summer in the depths of the forests cease to soothe us because now silenced in the death of winter.
\end{abstract}

With the cool evenings of September the sportsman is reminded of the approaching fall, and bethinks himself of what he can do to satisfy his longing for his favorite pastime. He recollects that now the wild oats are turning yellow and their ripened heads are waving over the marshes and borders of our tidal rivers. Here the Soras, or Carolina rails, are fattening into delicious morsels. It is true the sport is tame compared with shooting bob white or woodcock over "Billy's" sure and steady point; but the gun has not been handled for eight months, and our friend thinks the practice will be an easy introduction to his November shooting; and then his boy, who can already hold his gun pretty well on clay pigeons, wishes to try his Christmas gift on real birds, and what can be better for his first lesson in wing-shooting than a day with the rails among the high, waving water-oats? He will surely bring many birds to bag, and he will ever remember in after-life the pricle and pleasure he had 
when, on reaching home, with beaming face he hastened to present his mother with his first bag of real game.

When they reached the tavern on the border of the river, they were greeted with the honest laugh of the innkeeper and hearty shakes of the hands by the "pushers," who rose from their seat on the veranda to welcome the grentleman so well known to them; for he had spent many seasons in shooting over these marshes. Ifter much talk about the time of hish water, the various places where rail were most likely to be abundant, and the successes of those sportsmen who had just left for home, two pushers were engaged to be in readiness soon after dinner, for the shooting-ground selected (if ground it may be called) was over three miles distant. The pushers came soon after the youth had unpacked the guns and cartridges, had donned his shooting-jacket, and had got his father's "traps" in shape to be handily carried to the boats. I strongly suspect that these preparations had so fired the imagination of the youngster with anticipated sport that he had not had so much real pleasure in a twelvemonth. He met the pushers as they reached the river-bank. The two boats he there saw were flatbottomed, pointed at the bow, with a broad stern in which was a roomy seat for the pusher to stand on while he plied his "gaff." This is the name given to the pushing-pole, from twelve to fifteen feet long, and fashioned at one end somewhat like the gaff to which is fastened "the head" of the mainsail of a sloop. In one of the boats was another form of gaff, whose end was more like a large gun-stock. Both gaffs were quite broad, so that in crossing small spaces of open and deep water the pusher can use them quite effectively as paddles.

In the bow of each boat was a grood-sized basket, covered with a canvas flap, and holding a large cigar-box containing a hundred or more of cartridges. This box was tied with its upper edge nearly in a line with the top of the basket. This arrangement left the bottom and nearly all of the space in the basket free for the birds: and the canvas cover shielded these from the sun and the cartridges from the wet.

Before starting, the father instructed his son to take a score or so of cartridges and put them in the roomy right-hand pocket of his shooting-jacket, explaining that they would thus be in the most 
convenient position in loading; for, on opening the gun, the right hand unlocks the breech-action while the left holds the gun with a grasp around the barrels and fore-end. Thus the right hand is free to extract the exploded shells and to take the cartridges from the pocket and slip them into the breech chambers without it being necessary to relieve the left hand's grasp on the gun. Also, as soon as the gun is loaded, the left hand is in position to bring the gun to the shoulder for aim and fire. Miuch of the success of rail-shooting depends on the rapidity with which the gunner can take advantage of shots presented by numbers of birds rising in rapid succession.

In the bottom of the boats were several blocks of wood painted white. The uses of these the young sportsman soon found out.

Before starting, they wrapped around the calf of their right legs several folds of thick flannel. This was to act as a sort of buffer to rest against the edge of the seat just forward of midship, before which they were to stand in shooting. The calf of the right leg rested against it, with the left leg placed well forward, but all without any stiffness of posture. When the boat is shoved forward by the pusher, it moves through the resisting oats with a sort of jerk, and the calf of the right leg of the gunner is thrown at each push back against the edge of the seat which braces him. The wearing of the flannel, though not absolutely necessary, and by some probably regarded as effeminate, will add greatly to the comfort of a day's shooting, in the course of which the leg receives a great many rubs and thumps.

During the trip to the shooting-grounds, the pusher, who was now also guardian and instructor to the son of an old patron, laid down various precepts which the youngster was to follow in railshooting, interspersed with many interesting anecdotes illustrating the curious habits of these interesting little birds. He told his pupil that he must stand at ease, with his legs not too stiff, so that he should preserve an upright position; and that he must keep his feet steadily in one position while he was ready with his gun to shoot; that he must be quick with his gun, for a bird would often rise at twenty yards or more away and merely flit up, and then drop down in the oats; but that he must let a bird get off some dis- 


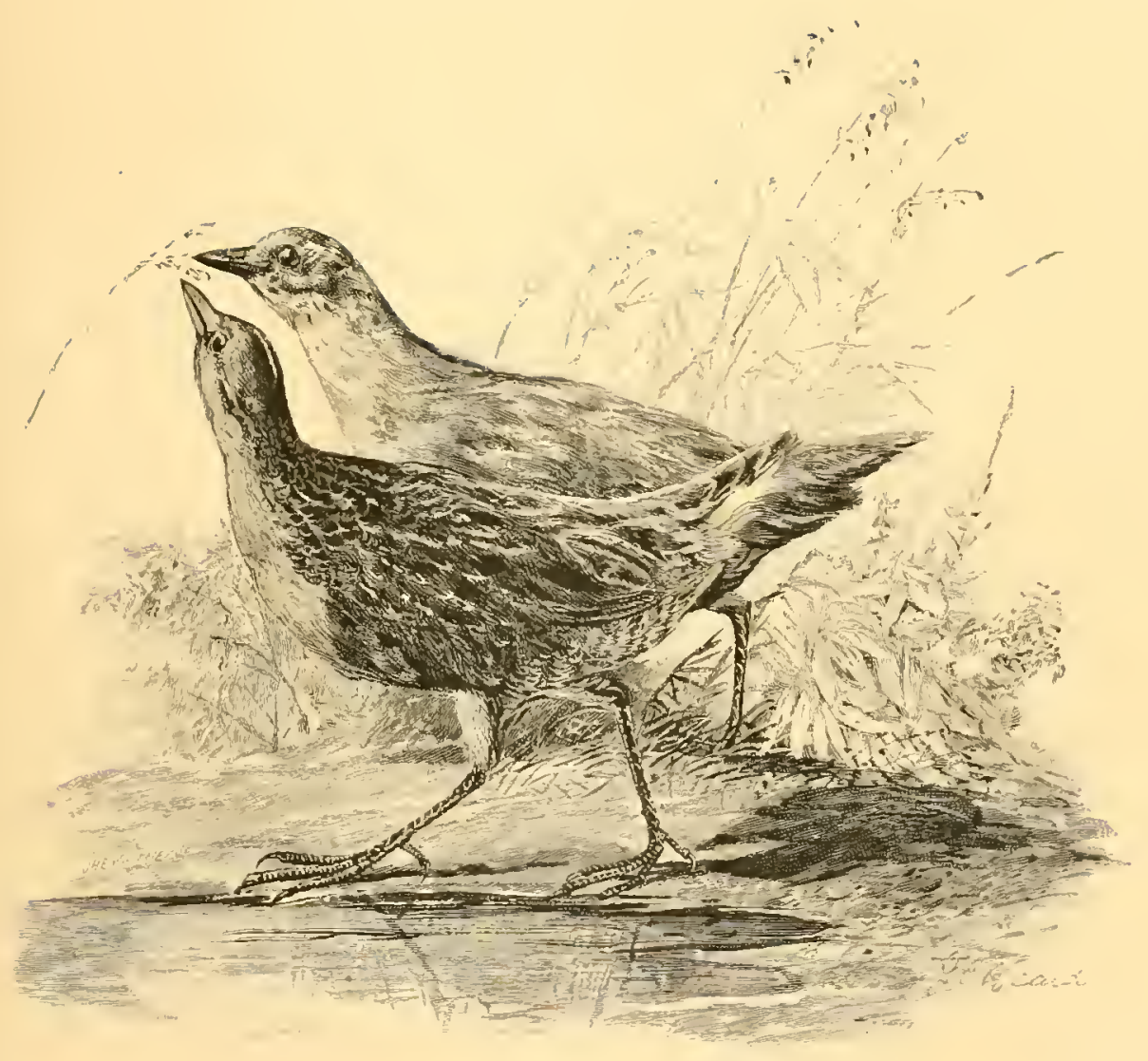

MALE ANT FIMALE RAIL.

DRAWY BY JAMES C. BEARD. 

tance if he was flushed quite near the boat, for otherwise his shot would blow him to pieces.

Arriving at the edge of the marsh, the pushers shipped their oars, and, plunging the broad butts of their gaffs into the mud, with strong and skillful arms they sent the boats into the midst of the water-oats.

As they entered the oats, the youth stood up in the boat, and was gazing with that steady, wide-awake, and all-around look so well known to those who have watched a sportsman in the act of flushing a bird. He held his gun with the muzzle pointing upward. His left hand was well forward on the fore-end, with the forefinger of his right under the trigger-guard. The pusher at once took in the pose, and saw that his father had been schooling him. The next instant a thrill was sent through the young sportsman as two birds sprung from the oats - one directly in front of him, the other on his left quarter. The first he fired at instantly and blew to pieces. In his haste to get the other, he shifted his left foot, tilted the boat, and then shot under the bird. The old pusher here stopped his boat, and, leaning on his gaff, said:

" Well! that's a good lesson. I had no idee you'd 'a' shewn off the good p'ints I give you so soon. I tell you ag'in to give the near bird time before shootin', and when you take a side shot don't take a step in dancin'. But the bird's 'a count,' so I'll jist find his head to show your father that you killed your first bird."

They had not gone over twenty yards farther when three rails sprung up. The first that caught the boy's eye was the one which, with a rather rapid rate, went to the right. This he fired at and missed. The other bird flew to the left, and this one he killed cleanly. The pusher "marked" and "boated" this bird, and then went for the bird first shot at. Though he had accurately marked him down, he failed to flush him on approaching the spot. The pusher said the rail had gone under the water and was no doubt quite near, clinging to a submerged stalk with his beak just above water, and that it was useless to try to flush him. for he would allow the boat to go over him before he would take wing. He said the rails often acted in this manner after they had been flushed and shot at, or when they had been slightly wounded. Sometimes, however, even when they had not been already flushed, they would remain perfectly 


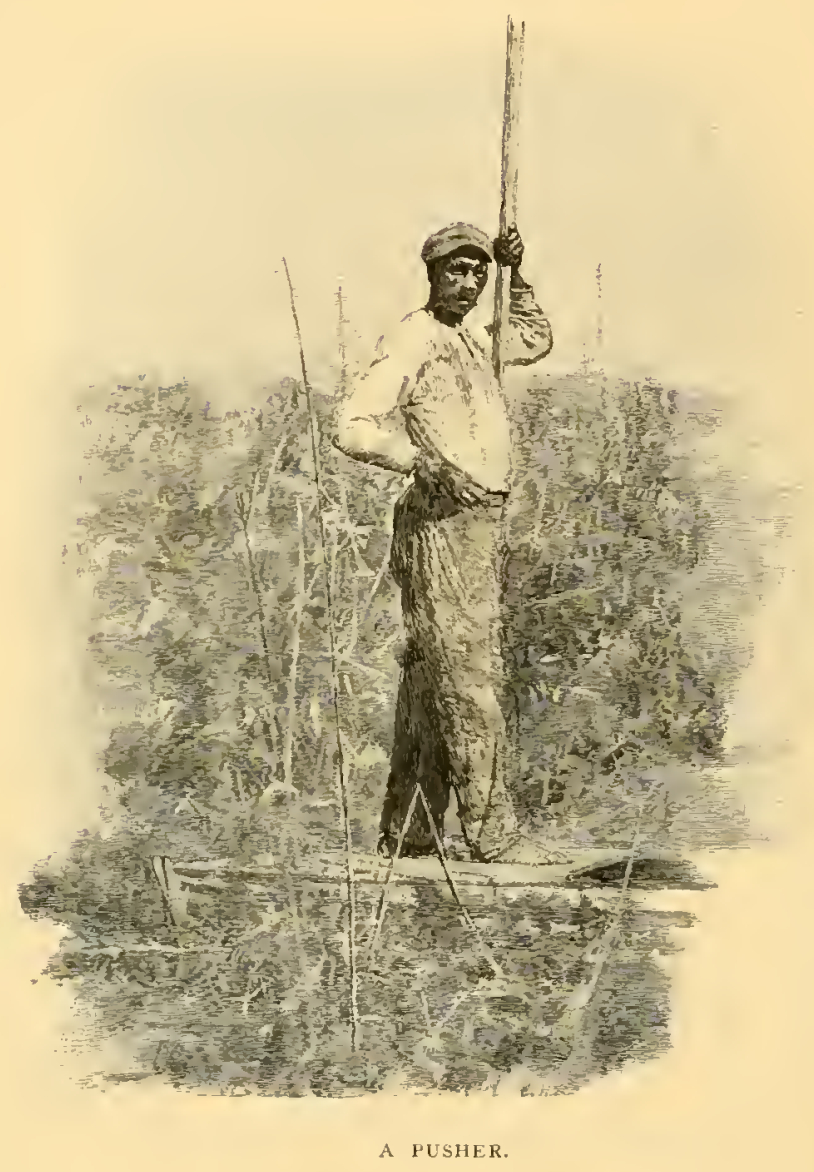

quiet till the boat had approached near them, and then would quickly swim to one side, in case the water was not too thickly studded with oat-stalks.

The next shots were at a flock of reed-birds, which rose in a compact cloud not twelve yards from the gunner. As he had been forewarned of their presence by the pusher, he was on his guard, and so reserved his fire till the birds were twenty yards distant, when, in quick succession, he emptied both barrels at them. The flock did not seem much diminished by his shots. and he was much surprised when, shortly afterward, the pusher and he had gathered in more than thirty birds - a dainty dinner. The pusher could not help expressing his surprise at the want of delight in the youth at such a record for his two shots, but gave a merry 
chuckle, with "A chip of the old block," when the boy told him that he had rather kill one bird flying swiftly across than bring fifty to bag out of a flock.

"Mark! teal," said the pusher, as he caught sight of three bluewinged teal coming swiftly down the river.

The youth had just time to charge his grun with a cartridge of No. 4 shot, which he took out of his left-hand pocket, and to bring his gun to bear on the teal as they passed him on the left at about forty yards distant. Bang! and with quickened wings they passed unscathed.

"Why, I held directly on that rear bird," said the crest-fallen youth.

"If," said the pusher, "you had held directly on the leacter, you might have killed the bird you fired at. You must hold two yards ahead of those birds flying across at that distance. Now sit down, and I'll take you to the other shore; but remember, it is there not sheltered from the wind as in this cove, among these hills and high trees, and the birds will fly faster, and it may be that, when the wind catches them, some of them will twist as they go, in a way like snipe."

And so it happened; the rail rising wildly and speeding away with astonishing rapidity for a bird generally so sluggish in flight. Here the youth met with many disappointments; but he was young and ambitious, and it does not take long for an intelligent youth to profit by failures - in the pursuit of pleasure.

"I've the knack of it now."

"Good shot!" said the pusher, as the youngster cleanly hilled a cross-flying bird at thirty yards.

"Yes, I held over a foot ahead of him."

"That's right. I)id you see the other bird scud across the river? Who would have thought that was a rail? You see how an easterly wind can make then gro."

"I suppose," said the boy, "that's the way they fly when the first frost chills them, and they all leave between sunset and sunrise. Father says they migrate in the fall to great distances, going even beyond the southern borders of our country, to the IV est Indies, and that they have been known to alight on ships when over a hundred miles distant from the nearest land." 


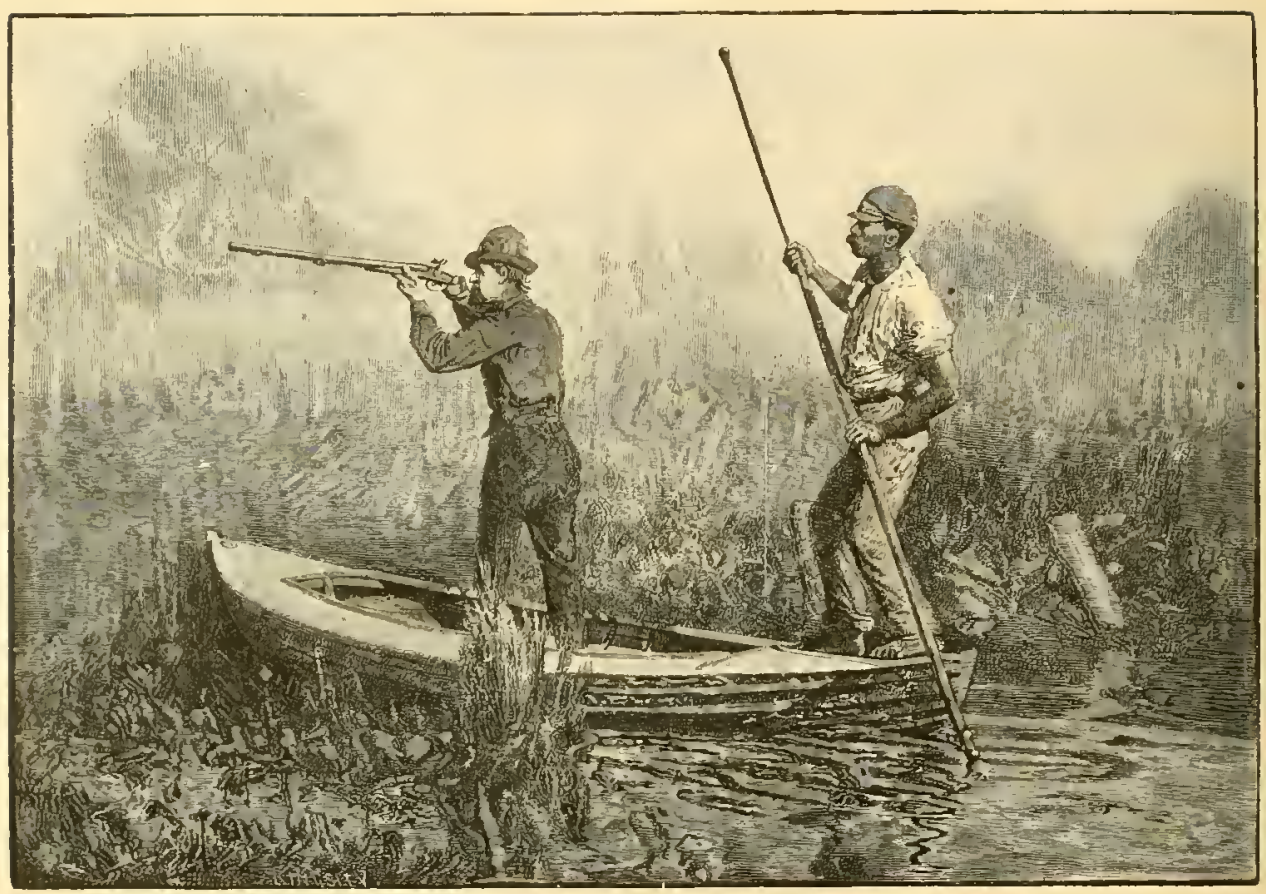

RAIL-SIIOOTING.

With varying successes and failures, the youth shot till the tide had fallen so low that the birds had enough near ground to retreat to when the boat approached them and they would not take wing.

And thus ended the boy's first lesson in the marshes. To say he was prouch, notwithstanding his lost teal, would do him injustice. He thought more of how happy he was to know that hereafter he could be a companion to his father when he ran away from the confusion and cares of the city for three or four days' relaxation in the brown autumn fields, or when he left in summer for two or three weeks' sojourn in the depths of the northern woods.

On entering the oats, the father's boat had taken a different direction from that of his son's, till they were separated by fifty yards or more. Thus no danger could ensue should the youngster, in the heat of sport, shoot toward his father. As a further precauttion against danger, the youth's gun, a 16 -gauge $6 \mathrm{lb}$. breechloader, was charged with only 2 drachms of powder and 3/4 Oz. of No. I 2 shot, the finest made, except "dust-shot." His father shot a $12-$ gauge gun, loaded with $21 / 2$ drachms of powder and I ounce of No. Io shot. He also had in his boat another gun of Io-gauge, charged 
with + drachms of powder and $1 / 1+$ ounces of No. 4 shot, in reserve, in case a flock of teals shoukl spring up before him or fly overhead as they "traded" up or down the river. He had not gone far into the oats before the rail began to spring up above the tops of the oats, and then flutter away with drooping legs. Two rose in front of him, and he quickly cut them down. He had no sooner reloaded, when three birds rose, two of which fell to his aim. The pusher now threw two of his painted blocks to the spot where the first two fell, and pushed for the brace which had just tumbled. These were soon found, and he then sought his blocks on the right, and, finding these, he soon picked up the two rails quite near them.

Thus, without a miss, the father killed 29 birds; the zoth he lost by the boat taking a rapid jerk forward in water rather free of oats just as he discharged his gun. The result of his day's sport was 105 Carolina rails, brought to boat with 116 shots. He missed six birds, and the pusher failed to find five others which he killed. He also brought to bag five teals, three coots, and one king-rail.

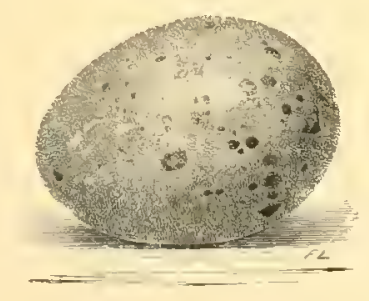

EGG OF TIE CIROLINA RAIL. 


\title{
WILD TURKEY-SHOOTING.
}

\author{
BY JAMES GORDON.
}

T

HE wild turkey, Meleagris Galloparo, the noblest species of American game birds, is common throughout the South and West, and yet is so wild that its habits are but little known. The writer, although an experienced hunter, finds each year something new to learn concerning its peculiarities.

Our wild turkey takes little care in the preparation of a nest. I have often found them sitting on the bare ground in exposed positions. Yet they are very tenacious when sitting, and will allow a man to approach quite near before they will leave their eggs. It is generally believed that our domestic turkey owes its origin to our common wild turkey, M. Gabloparo. Even the great ornithologist Auclubon falls into this error. Our domestic turkey is derived from the wild turkey of Mexico, Mcleagris Mexicana, which is a coarser fowl than the wild turkey of America; but it is easily tamed, while the American turkey, like the Indian, is untameable. They can, indeed, be made quite grentle, when hatched by a barn-yard fowl and fed from the hand, but such is their propensity to ramble that they ultimately stray off and become wild again.

If you have never seen a wild turkey, do not take his plebeian cousin of the barn-yard for a model, for they are very unlike. His voice is as different as the crow of the game-cock from the Shanghai. The domestic turkey's grobble is coarse and disagreeable, while the gobble of the wild turkey is as shrill and clear as the note of a cavalry bugle. When heard at early dawn in the still forest, it is singularly sharp and piercing. It seems to strike upon the senses rather than upon the ear, penetrating the nerves of the hunter with a thrill of 
pleasurable emotion. If you will come to the South and accompany me some morning in the spring, which is the gobbling season, we will seek his haunts. If there is a large creek bottom near, we will look for him there. We reach the foot of the hills at dawn; daylight is beginning to appear in the east, and the stars are facling from sight. Now, if there is one in hearing, we will make him gobble; this we do by imitating the hoot of the barred owl. Instantly a clear, rolling gobble responds,- - good-a, good-a, good-a, good-a. good,"- - others reply, and for a mile above and below is heard the refrain.

To which one shall we go? We hoot again, and listen intently to the reply; then, selecting the fattest, proceed in his direction. You ask how we know which is the fattest? Not a difficult task at all for an experienced sportsman; the more shrill and sharp the grobble, the more fat there is on his breast; when the breast-sponge is not covered with fat, the gobble is hoarse and flabby. We stop occasionally to be sure of our course, as we slip forward as rapidly and noiselessly as possible. When near enough to hear his strut, we pause to listen. The woods, that before seemed so still, are now alive with noises. The whip-poor-wili is wailing its plaintive song, and every bird, that was sleeping so quictly a few minutes ago, is now fussing around with the morning greetings to his drowsy mate. Concealed by the foliage of a wide beech, we peer through the misty shadows, and behold him standing on the limb of a lofty cypress. We watch him suck the air to inflate his windbag, then hear him emit a pulmonic puff and drum, and he immediately lowers his tail and wings. Many think the strut of the turkey-cock is made by scraping the tips of his flight feathers. This is a mistake; he merely touches the ground with the tips of his wings. The strut is made by forcing the air out of the windbag. He has selected his position in the cypress, because cypress brakes are always surrounded by water. which protects him from the approach of the wild-cat and coon. as they prowl about during the night; besides, anything wading in water makes a noise, and the turkey is a light sleeper. Be cautious, too, how you walk, for around these marshy sloughs the sliny moccasin and deadly cotton-mouth lie in their coils ready to strike their envenomed fangs into the foot of the intruder. Sometimes the turkey can be shot on his roost, and many are killed in this way, especially by hunters, who watch them fly up to roost, and 
shoot them by moonlight. Not being afraid of cattle, they are easily approached after dark by a man with a cow-bell tied on his arm. It is now broad daylight, and as we are as near as we can get without frightening him, let us conceal ourselves until he flies down. He is roosting low; a fat gobbler does not like to fly high.

Now he alights on the ground, and stands like a bronze statue looking for some lurking foe. We now take our yelper, and give a few sharp yelps; he hears the call, and, spreading his tail like a fan, drops his gray flight feathers until they tip the earth, struts and grobbles. He is coming leisurely and cautiously toward us; now a hen yelps on the other side, and he pauses between the two calls, then struts and gobbles again. The hen is impatient for the caresses of her gallant. and runs to him; the others gather around, and with his harem he wanders off to his feeding-grounds, regardless of the seductive calls of the hen left behind. We hear him gobbling in the distance, and follow very cautiously, taking advantage of every thicket to screen our approach.

VTe call again, and hear in reply, instead of a gobble, a bungling attempt at a hen-call, made by some backwoodsman. The gobbler had detected the fraud and left. Fearing we might be mistaken for a turkey and shot at, as once happened to the writer, we approach the woodsman, and while talking with him hear the gobbler a long way off, and immediately set out after him, our well-trained pointer creeping at our heels. The morning has passed, and the turkeys have left the bottoms and sought the ridges, where the leaves have been burnt off by the farmers that the grass may grow early for pasturage. In the burnt woods it is difficult to approach very near, as all the undergrowth is destroyed; and this is the place he selects to spend his nooning, where he can pick the tender grass and gather bugs and grasshoppers with no fear of being surprised. The hens, one by one, have stolen off to their nests, and now he only gobbles at long intervals, but will continue strutting occasionally all day. Getting his location, we slip carefully around a ridge, and reaching a point without being seen, near enough to be heard by him, give a cluck and gulp like a hen that has just left her nest. Having caught the note of a hen in the morning, we imitate her voice. This is one of the perfections in the art of turkey-calling: no two leaves of the forest are alike, nor are any two voices of birds or men alike. 
A very delicate ear, trained to catch the sounds of the roods, can detect the slightest peculiarity in the note of a turkey-hen; and as the sobbler catches the familiar sound, he gobbles, but remains standing erect as a statue of patience. He has been deceived by hunters before, but this call was so like one of his wives that, in spite of his suspicious nature, he almost resolves to go to her; but still he stands and listens. A less experienced hunter would call again; but we remain quiet a long time. Patience is the great secret in the art of turkey-hunting. He becomes impatient, and gobbles. Still no answer. 'Then a low, seductive call, as much as to say, very coquettishly, it is immaterial, Sir linight, whether you come or not. He has located the call, and decides to wo to it. A young gobbler has joined him who dares not strut in his presence, but precedes the old cock, who struts leisurely behind, using the young gobbler as a guard in front. They are still approaching very cautiously. In the meantime, the hunter is stretched on his back, with his head and shoulders resting against the foot of a giant oak, his gun on his knees, and his dog crouched low beside him. They are now close enough for a shot. A novice would have shot at the foremost; the skilled hunter aims at the head of the hindmost. For two reasons: first, he is the largest; second, it will leave the remaining turkey nearer for the second barrel. At the crack of the gun, the old bird falls flopping to earth in a death struggle, with a load of No. 6 shot in his head. The other runs off as fast as his legs can carry him. He has not even time to rise and fiy, before the other barrel, loaded with B. Bs, cuts him down.

Let us go again in the afternoon, and see if we can find a gobbler on his feeding-grounds. N'e try our callers, but hear no answer. W'e then call fast and loud, like a hen that had returned from her nest among the hills and, finding no company in the bottom, feels lonesome. A long silence follows; we are tempted to call again, but experience has taught us that too much calling at this hour will excite suspicion. Presently we hear the puff and drum of the strut. and we know he has heard our call, and is looking for us. Now he passes within short range. Do not move; before you could raise your gun he would dart behind a tree and be off like a shot. He is passing a tree; now, while he is behind it, place you gun in position. He steps out, you fire at his head, and the white turban sinks to 
earth. The sun is now low on the horizon; let us go down by the cypress breaks: perhaps we can roost one. Again we are quietly seated. and in a little while hear the flopping of wings; they are flying up to roost. We might now slip under the roost and shoot; but this is unsportsmanlike; so we will quietly retire, and return in the morning and try our skill in calling a gobbler down. There are many ways of hunting turkeys. I have sometimes used a tame gobbler as a decoy. The wild gobblers, when they hear the strut and gobble of a strange turkey, will come forward to give battle to the intruder. Then they are hunted with logs. A gobbler can be run down and caught with hounds; he is a heavy bird, and after two or three flights cannot rise to fly again. After the spring season is past, the gobblers cease gobbling and wander about alone, or in small flocks, until after the young broods are large enough to take care of themselves; then they gather together in large flocks as the fall comes on. At this season, they are hunted with dogs. A well-trained pointer who runs silently on the track and dashes in and scatters the flock with a quick bark is the best for this service. After the flock is scattered, the hunter conceals himself, and in a little while they will begin to call together. If it is in the early fall, they make a note like pci, pce, pce. As they grow older, the call is coarser. They are easily called up and killed at this season. Even a novice may deceive a young turkey that has never been hunted. The instruments used for turkey-calls are various; the wing-bone of a turkey is the most primitive instrument, or the vibration of a leaf placed against the lips. I use a hollow tube or a block with a piece of wire scraped against a whet-stone.

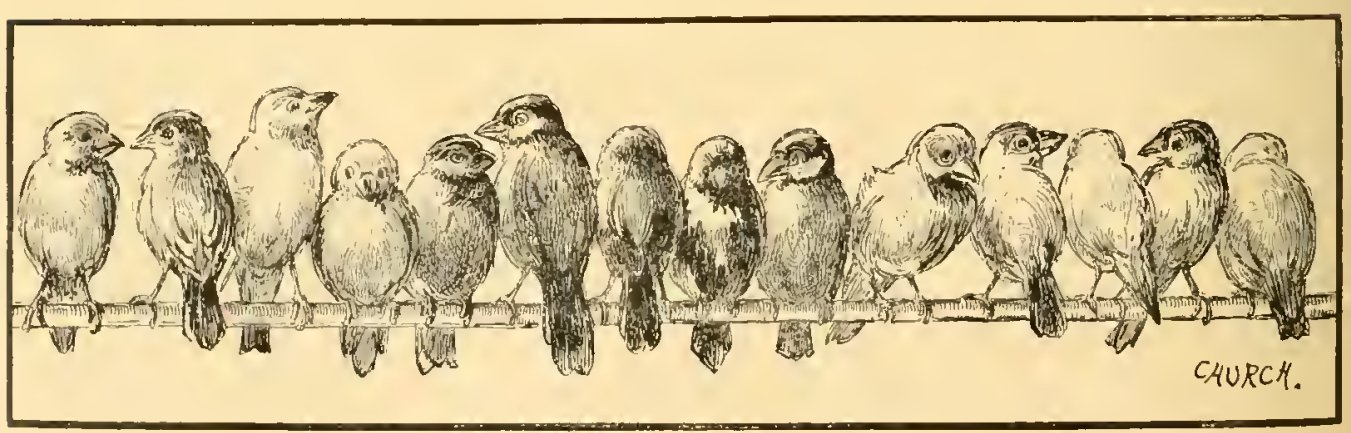




\title{
THE SHOT-GUN.
}

\author{
BY ALFRED M. MAYER.
}

W

HEN the great amount of energy pent up in gumpowder had become generally known in Europe, during the fourteenth century, men began to exercise their minds in the invention of cannon and hand-arms that could withstand and direct this tremendous force. It is quite interesting to find that the cannons of the fourteenth century were breech-loaders. In the sixteenth century both breech-loaders and muzze-loaders were in general use.

Hand fire-arms were also used in the fourteenth century. They were called bombardes. The bombarde was simply a barrel fixed to a stock, and fired from the shoulder. Later, this arm was supplanted by the hand-culverin, a rather heavy arm weighing from ten to fifty pounds. Its bore was about three-fourths of an inch. It was fired from a forked rest. Two men were required to use the piece; one to hold and aim it, the other to apply the fire to the touch-hole and to help to carry and load it. During the fifteenth century these arms appear to have been extensively used, for at the battle of Norat, 1476 , the Swiss were armed with 6000 culverins.

The gun retained the form of the culverin till the early part of the sixteenth century, when the Spaniards invented the arquebus. This gun had a longer barrel and smaller bore than the culverin. In the forepart of the stock was hinged the "serpentine," which carried a slow-match. The latter was lighted at a match burning on the top of the barrel, and then, on depressing the neck of the serpentine by pulling (what was the counterpart of) the trigger, the powder was set fire to in the side flash-pan. Later, the serpentine was divided into two parts, the lower part forming a trigger, the upper a 


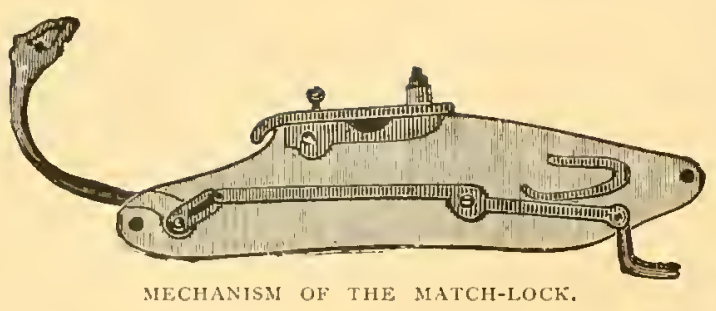

hammer which was sent forward by a spring on pulling the trigger. This, the match-lock, is the first and the simplest of gun locks.

In 515 , a notable improvement in fire-arms was made at Nuremburg in the invention of the wheel-lock, by which fire was obtained by the friction of fint against pyrites, a method of procuring fire which Europeans had used since prehistoric times. A steel wheel. B, with a grooved and roughened edge, was set in rapid rotation by the action of a spring coiled in its interior. This wheel was wound up by a key turning the axis C. The piece of pyrites, E, carried in the hammer, 1), was thrown onto the rotating wheel when the trigger was pulled. The friction of these substances caused a strean of sparks to fly into the flashpan. The wheel-lock greatly increased the rapidity of fire, especially at game which unexpectedly came in sight; it also allowed the marksman to use freely both hands in aiming and firing his piece.

With the improvement of the wheel-lock, the gun began to supplant the long-bow and cross-bow among European sportsmen. The invention of "hail-shot," about 155 o, added to the popularity of the gun (which now first became a shot-gun) by giving. greater success to the sportsman when shooting at moving game. But the longbow and the arbalest by no means disappeared from the hands of sportsmen or from the armies of Europe. The bow had its peculiar advantage over the shot-gun as a hunting arm in being noiseless, and its inexpensiveness placed it within the reach of all who were privileged to carry arms. Besides, in those days, the art of shooting on the wing was unknown: and at still game, the arrow launched from the long-bow of a skillful archer was probably as effective as the wheel-lock gun. The killing range of the arrows of the long-bow, their accuracy of flight, and the rapidity with which they could be discharged, gave the long-bow the glory of holding 
its own against fire-arms long after their introduction into armies of Europe. It is stated that an English archer could pierce any armor at two hundred yards distant, except that made of Milan or the best Spanish plate; and the ancient accounts of men in armor having been shot through is confirmed by breast and back plates, in European museums, perforated with arrow-holes. Indeed, so well did the English appreciate the peculiar excellence of the long-bow as a military arm, that it retained a place in their army even as late as 1627.

The wheel-lock hunting arm received improvements in workmanship and in matters of detail, but remained essentially the same for a century, when, in 1630 , the flint-lock was invented in Spain. To Spanish artisans are also due great advances in the manufacture of gun-barrels, in which art they continued to improve so much that those of their best artisan, Nicholas Biz, of Madrid, sold as high as two hurrdrech clollars.

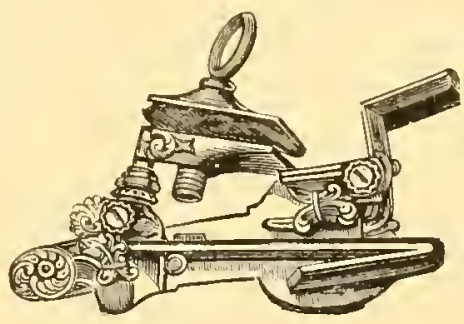

SPANISH FLINT-LOCK.

The flint-lock fowling-piece held its own during two centuries, during which period it was gradually improved in all its parts, - in the texture and chambering of the barrels, in the locks, and in the general proportions of the gun,- till it reached the zenith of its excellence, about 1815, "when," says Mr. W. IV. Greener ("The Gun and its Development"), "the renowned Joseph Manton-the king of gin-makers-had so improved and adcled to its mechanism as to make a first-rate sporting gun veritably an engine; for it is from that word that the term 'gun' is derived. The various improvements to effect self-priming and to render the flash-pan water-tight greatly added to the mechanical parts, and a pair of the best pattern flintlocks, well made and finished, were well worth the seven pounds paid for their manufacture. Nanton's latest improvement in fintlocks was the gravitating stop, which rendered it impossible for the cock to fall upor the hammer whilst loading the gun. The use of them was, however, superseded by detonating guns, to which Manton also devoted a portion of his time. This wonderful maker appears to have lect the fashion in everything relating to fire-arms; and his pattern locks, stocks, and furniture were minutely copied by 


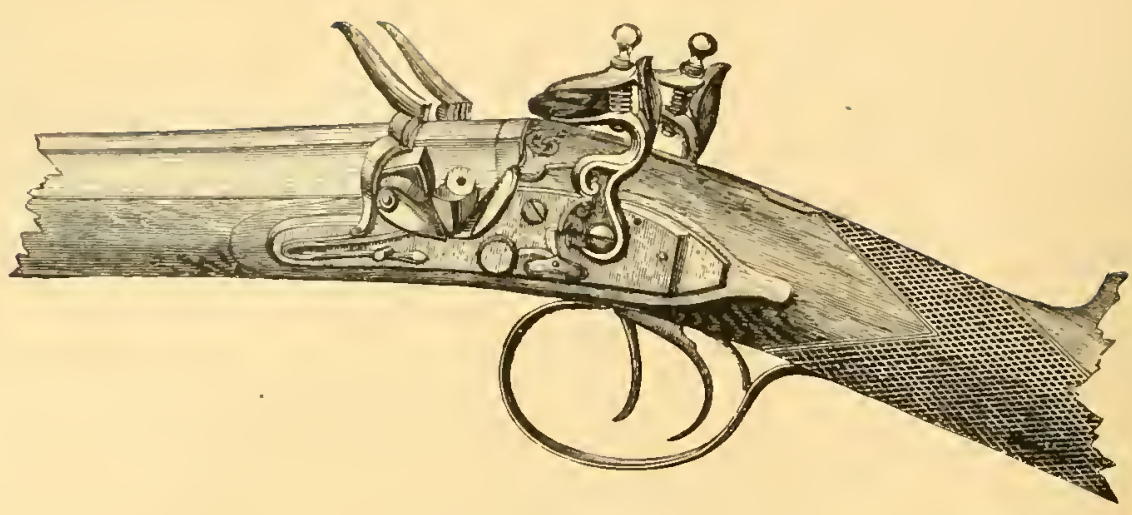

MANTON FIINT-LACK.

gun-makers of less note. We give an illustration of the Manton fowling-piece, showing his well-known pattern hammers and cocks, the water-tight flash-pan, and his gravitating stops. Joseph Manton, although he received the extraordinarily high price of seventy guineas for his best guns, failed several times, and died poor. This is accounted for partly by the losses he sustained in lawsuits respecting his patents. He was buried in Kensington Cemetery, and a monument bearing his epitaph, composed by Colonel Hawker, gives the date of his death-29th June, 1835 , aged sixty-nine-and eulogizes his work as a practical gun-maker and inventor."

Between 1807 and $18_{25}$, several inventors endeavored to replace the uncertain and slow fire of the flint-lock by the surer and quicker ignition given by the explosion of a fulminate. Several devices, such as "detonating tubes "placed in the touch-hole and armed with fulminate, fulminate placed in the bottom of the cartridge and exploded by the perforation of a needle, and fulminate inclosed between paper or metallic foil, were tried, till the well-known nipple and copper cap was devised about 1818 , an invention which is claimed by Colonel Hawker, who showed this plan first to Joseph Manton.

In s $_{3} 6$, Lefaucheux, of Paris, invented his pin-fire cartridge and his breech-loader. I place the cartridge first, for breech-loaders, too numerous and varied to mention, had been invented before; but the modern breech-loader owes its hearty approval of sportsmen to the admirable invention of the Lefaucheux cartridge, with its stout. unyielding flanged base, without which, or its equivalent in the Pottet central-pin cartridge of 1856 , the breech-loader would never have had the extensive use it now deservedly enjoys. 
The Lefaucheux gun is shown below. In the left-hand barrel is a cartridge, the-pin of which fits in a recess cut in the top of the breech. This pin is struck by the hammer and driven into the fulminate held in the bottom of a little brass cup in the center of the base of the cartridge. When the gun is closed, the barrels fit close to the "standing-breech." When the lever, shown under the "breech-action," is turned till it comes in line with the axis of the gun,

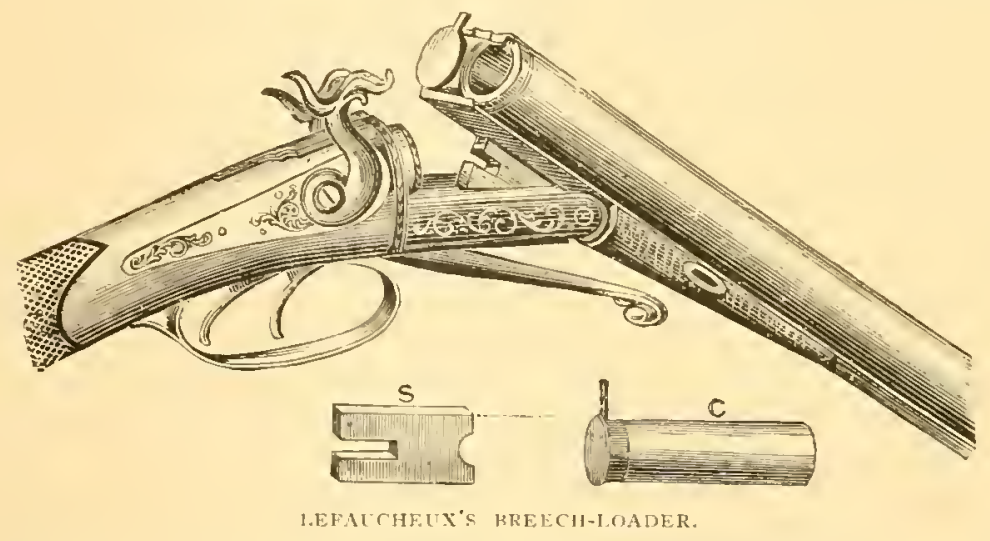

it throws a bolt into the "lump "attached to the underside of the barrels, and thus locks the breech-end of the barrels to the breech-action The lump and the slot into which the bolt fit are shown separately at S.

The down-drop action of the barrels on opening the gun, and the mode of securing them to the breech-action by a bolt working in a lump fixed to the underside of the barrels, seen in Lefaucheux's first breech-loader, has been universally adopted by gunmakers since his gun appeared in 1836 . It has been greatly improved in the details of mechanism, but the general plan remains the same. The weakness in the locking of his barrels to the breech-action was soon found out, and has been remedied by numerous plans in which double and even triple bolts, further removed than his from the hinge-joint, have been used.

The mechanisms invented for opening and for locking breechloaders are so numerous, and the majority of them accomplished the object so perfectly, that one cannot fail to get a trustworthy gun if ordered of any maker of established reputation. In selecting as types two breech-loaders, one with hammers, the other hammerless, to illustrate our remarks on the gun, we wish it distinctly understood that thereby we do not intend to convey the impression that we judge 


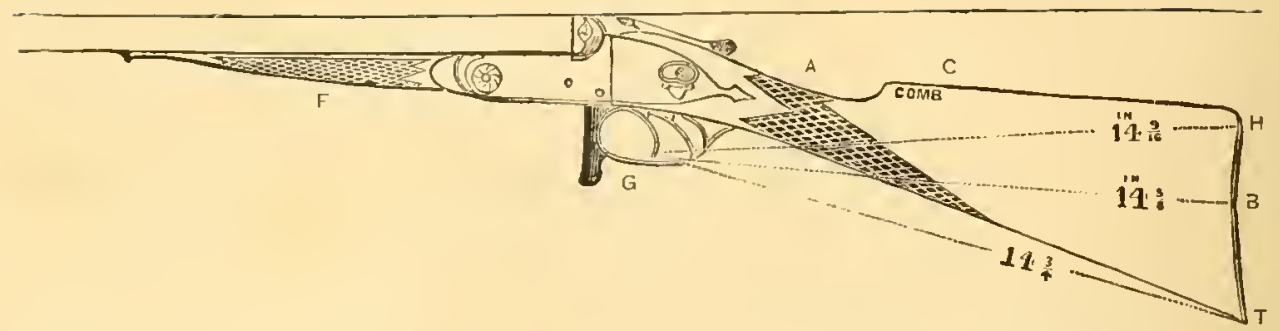

these superior in all respects to those of other makers. 'Two had to be selected out of the numerous types now offered to sportsmen, and in doing so, we have selected two with which we have had much experience and which are undoubtedly excellent.

Before proceeding to describe the modern breech-loading shotgun, it is essential that the general reader be conversant with the names of the various parts of the gun, including the separate pieces composing the lock.

The names of the parts of the stock are, $A$, the hand; $B$, the butt; $H$, the heel; $\mathrm{T}$, the toe of the butt; $\mathrm{C}$, the comb; $\mathrm{F}$, the fore-end; and $G$, the trigger-guard.

The barrels are attached to the breech-action, the name given to the whole piece of iron X, Y, Z. This is screwed firmly to the stock. The perpendicular part of this $\_$shaped piece is called the break-off, because in muzzle-loaders the barrels could be separated from the rest of the gun at that place. The face of the break-off, against which the breech-end of the barrels tightly fits, is called the standingbreech, or false-breech. The barrels rotate on the breech-action around the hinge-joint, V. The lumps I, and L, firmly dovetailed

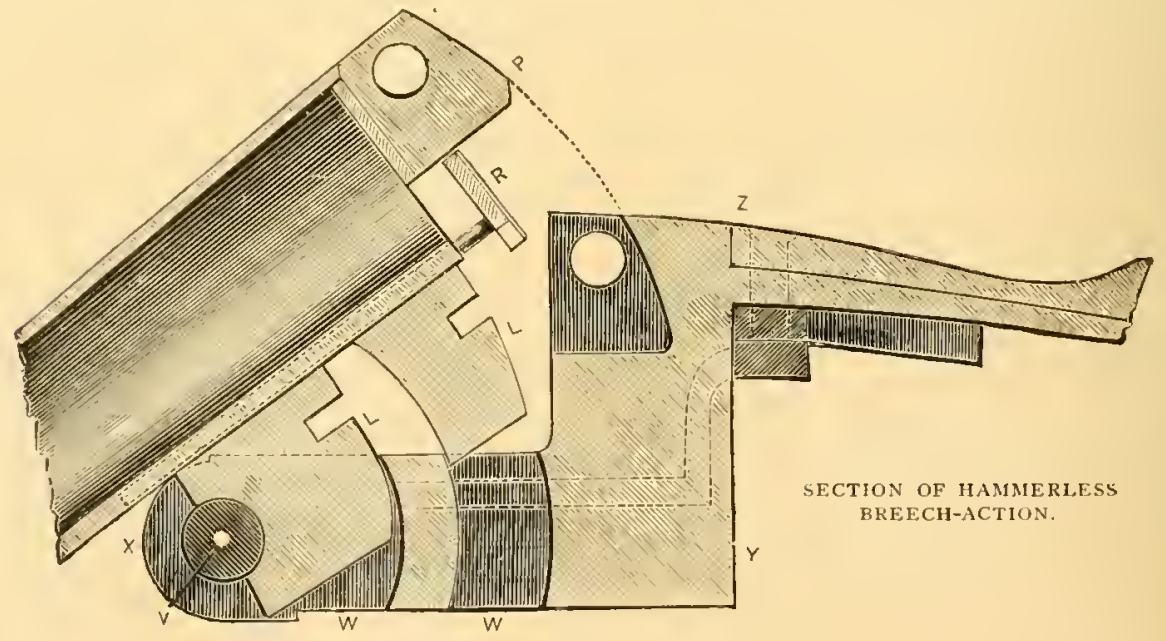


between the barrels, have their surfaces wrought to portions of cylin ders whose common center is the center of the hinge-joint. These cylindrical surfaces fit closely in the corresponding slots $\mathrm{W}$, IV cut in the breech-action. The cartridge-extractor is shown at $R$. It is worked by a cam attached to the fore-end. When the grun is opened, or "broken," this cam presses forward the rod of the extractor, and pushes out the cartridges sufficiently to allow the fingers to remove them. $P$ is the extension-rib which fits in a recess cut in the breakoff. When the gun is closed, bolts enter the slots $\mathrm{S}, \mathrm{S}^{\mathrm{T}}$ and the hole in the extension-rib, and firmly and securely lock the barrels to the breech-action. To unlock and open the gun, the top-lever, L. is pressed from left to right; this draws the bolts and the grun opens.

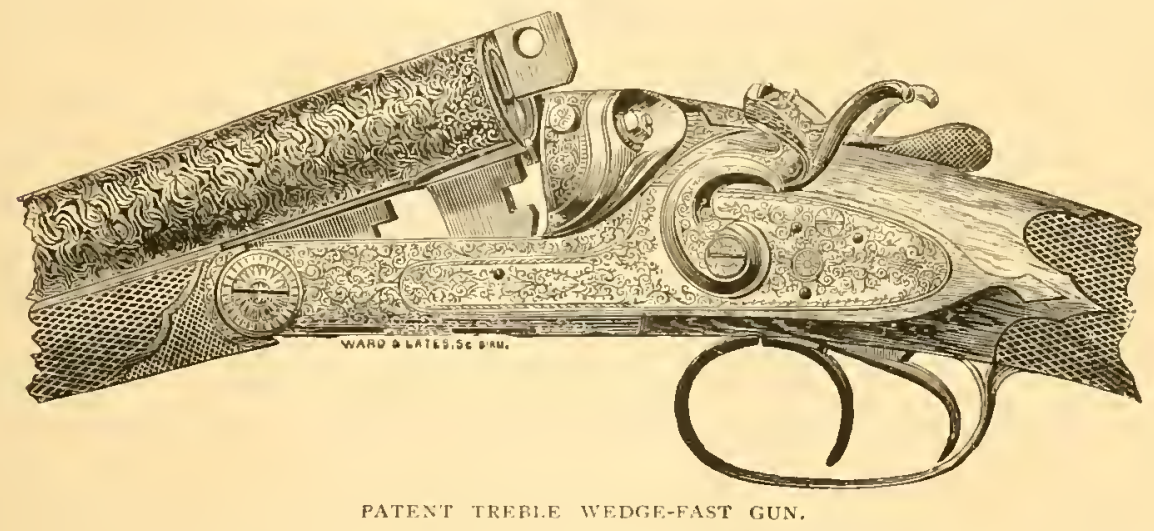

This engraving shows the appearance of one of Mr. W. W. Greener's guns when opened. The breech-action and locking gear jist described are those of one of these guns.

The parts of an ordinary bar-lock are shown on page 772. Warren's "Shooting, Boating, and Fishing" (Scribner and Sons, I87 I). The longer leg of the mainspring, $S$, has a hook or claw at its end which rests on the pin of the swivel, shown linked to the right of the tumbler, 2. The action of this swivel is to increase instead of diminishing the force of the spring as it unbends on the descent of the hammer, 3. The interposition of the swivel between the tumbler and mainspring causes the latter to act with increasing leverage on the tumbler as the spring unbends. This increasing leverage will be apparent to any one who will compare the pressure of the thumb on the hammer when it is just lifted with what it is just before the hammer catches at full cock. In the tumbler are cut two notches, 


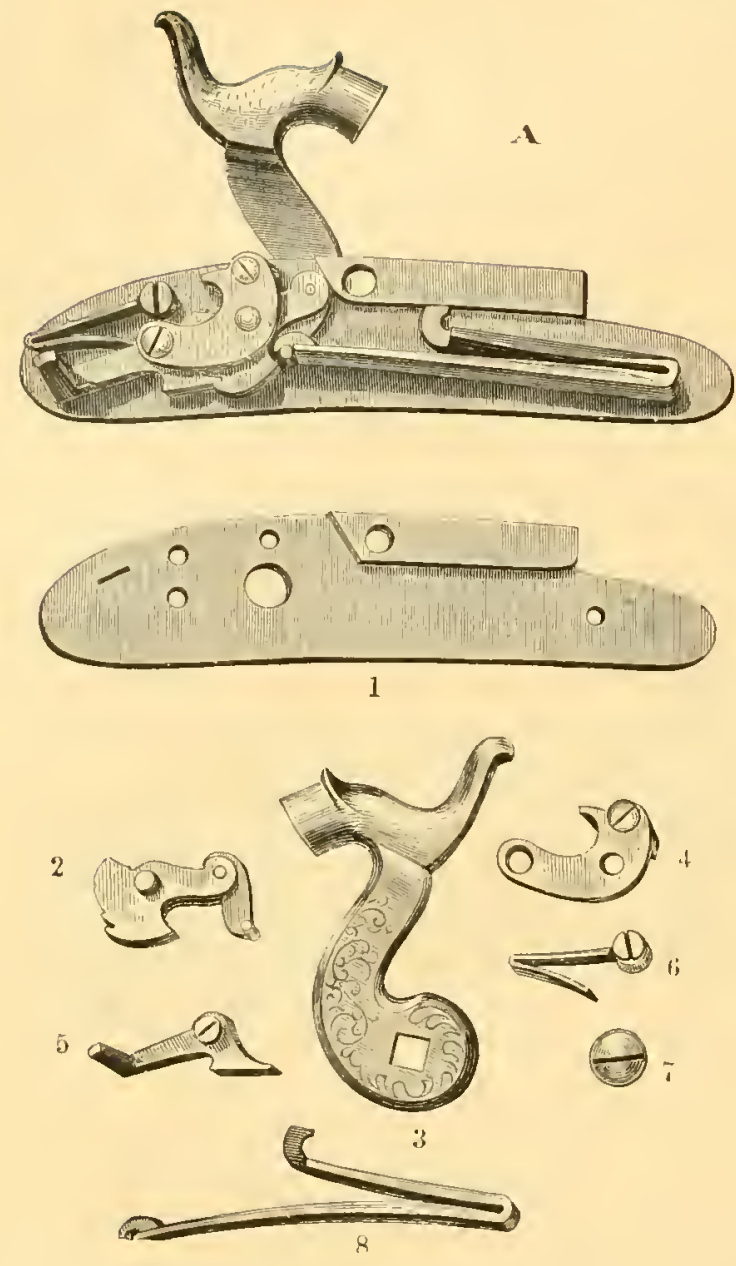

called bents. Une of these, into which the sear, 5, falls when the hammer is at half-cock, is so deep and of such form that a pull on the trigger cannot force the sear out of it. The other is shallower, and so shaped that a pull on the trigger - generally of about four pounds - will disengage the sear and cause the hammer to strike on the striking or firing pins. The tumbler and sear work between the lockplate, I, and the bridle, 4 , which is screwed to the lockplate. The sear-spring, 6 , constantly presses the end of the sear against the tumbler. The tumbler has a journal which goes through the lock-plate, and to a square shoulder on this journal is secured the hammer by a screw, 7 .

In improvement was made in the above lock in 1869 by Mr. Stanton, of Wolvernanpton, England. His lock is known as the rebounding lock, the peculiarity of which is that after the hammer has struck the striking-pin it flies back to half-cock. This is accomplished by having the upper leg of the mainspring free, and extending it so that it reaches under a projection on the tumbler. This projection falls on the upper leg of the mainspring just before the hammer strikes the firing-pin, and the projection of the tumbler thus forces the upper ley of the spring downward so far that the hammer reaches and strikes the firing-pin; but the next instant this portion of the spring throws up the projection on the tumbler, and thus brings the hammer to about one-eighth of an inch above the cap or firing-pin. 


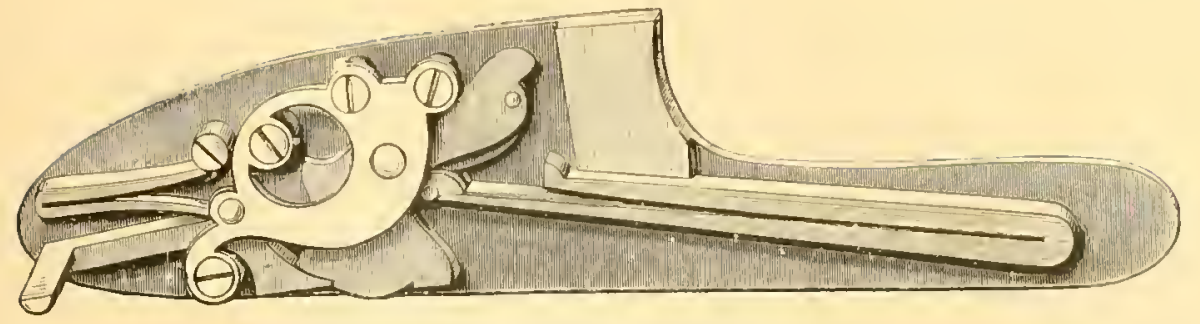

STANTON'S REBOUNDING LOCK, COCKEI-TUI.I, SIZE.

In this position of the hammer the sear is just clear of the halfcock bent, so that if the hammer is pressed forward the sear closes in this bent and prevents its further motion toward the cap. No sportsman should think of buying a gun not furnished with these rebounding locks, which have so mich diminished the risk of accidents. The peculiar points in the construction of this lock which we have described will be understood with the aid of the above engraving from "The Modern Sportsman's Gun and Rifle," by S. H. Walsh.

If the sportsman understands the construction of the locks of his gun, he can readily take them apart, clean and oil them, and put them together. He is sometimes required to do this after his gun has beein exposed to the wet; especially after he has been shooting on the shores of bay and estuaries, where he is often exposed for hours to the spray of salt water.

To Take Apart i Lock-(1) Take off the locks by unscrewing the side-pin which holds them together and binds them to the breechaction and stock. (2) Pull the hammer to full-cock, then clamp tightly the legs of the mainspring in a spring-cramp. (3) Relieve the sear from the bent and push the hammer forward; the mainspring will now come off in the jaws of the cramp. (4) Unscrew the bricle-pins and take off the bridle. (5) Take off the sear and then the sear-spring. (6) Take out the screw which holds the hammer on the tumbler, and, putting a brass punch on the arm or journal of the tumbler, knock the latter free of the hammer.

To Put the Parts or a Lock Together.-(1) Put on sear-spring. (2) Put on the tumbler. (3) Cramp the sear-spring, and then put on the sear so that it goes into the half-cock bent on the tumbler. (4) Screw bridle to lock-plate. (5) Take the mainspring in the cramp and hook it on to the swivel, and force the stud on mainspring into its hole in the lock-plate; then press mainspring down quite close to $49 \mathrm{~A}$ 


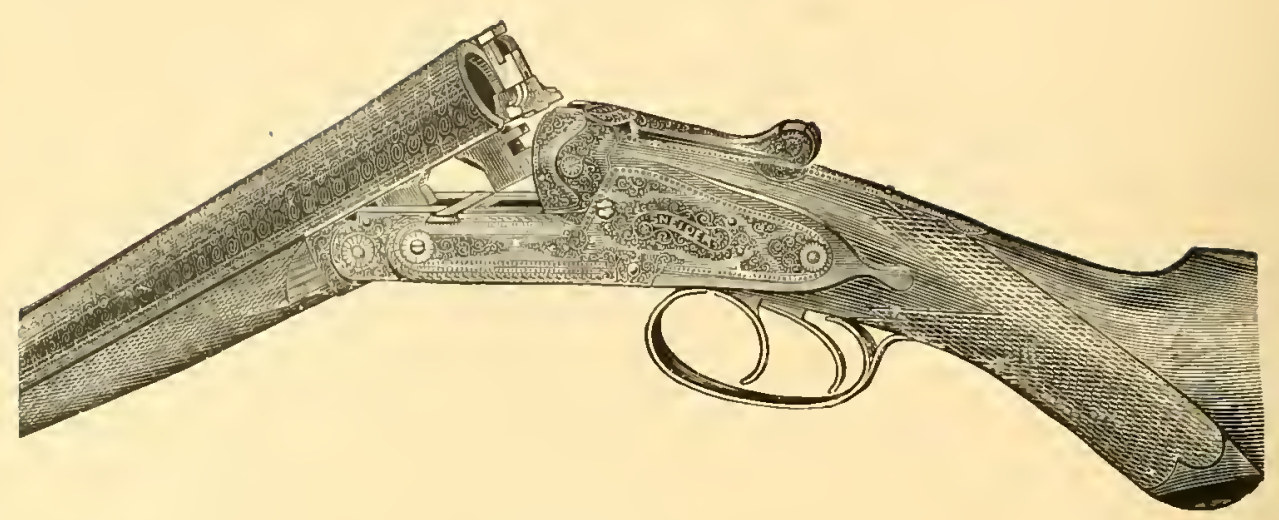

HAWMERLESS GUN

lock-plate. Now, on removing the spring-cramp, the lock is ready to have the hammer placed on the tumbler. (6) To do this, place the lock on a wooden block, and drive the hammer on to the square shoulder of the journal of the tumbler; then put in the screw that binds the hammer firmly to the tumbler.

We have given a description of a breech-loader with hammers in referring to Mr. WV. W. Greener's table-bolt and extension-rib gun. As type of hammerless guns, we select this of Mlr. Sneider, of Baltimore.

The accompanying figures and appended descriptions will show clearly the peculiarities of this gun. The safety action is excellent. By the forward rotation of the milled wheel in the end of the top lever, a bolt is put on the sears and holds them so effectually that no pull on the trigger or jar to the gun can set them free of the catches in the hammer-carrier, and there is no necessity of setting free the sears till the instant of firing. The gun is held "ready" with the index-finger under the guard and the ball of the thumb on the safetywheel. At the moment the bird rises the gun is thrown against the shoulder, and with this motion the thumb can naturally rotate the safety-wheel backward and take off the lock on the sears. This movement is soon acquired by the sportsman, and when it becomes

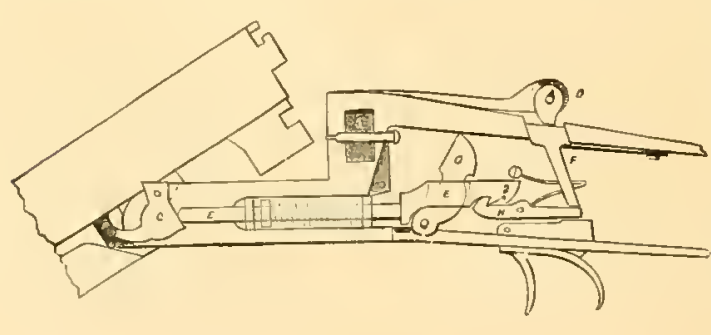
automatic to him it adds greatly to his assurance of safety from accidents.

This represents the breech and part of the fore-end of the Sneider hammerless gun ; also the lock with lock-plate 
removed. The operations of the various parts are as follows: When the gun is opened to load, the pushing lever, $\mathrm{Q}$, is forced by the camshaped surface, $\mathrm{P}$, in fore-end, against the hammer-carrier, E, pushing it backward against the hammer, $G$, and bringing it to full-cock, where it is held by the interlocking of the hooks on the hammer-carrier, E, and sear, H. By pulling the trigger, the sear is pressed upward, thereby releasing the hammer-carrier, $\mathrm{E}$, which is driven forward by the mainspring, taking with it the hammer, $\mathrm{I}$, and exploding the cartridge.

To set the gun at safety, press forward the button, D, on the end of lever, which, pushing the bolt, F, against arm of the sear, causes a rigid interlocking of the two hooks. This is a positive locking, and prevents all danger of the gun jarring off, which is possible if the safety-bolt only presses against the triggers. On the hammercarrier, $E$, is a nut, $I$, for regulating the tension of the mainspring, $K$. To let the hammers down from full-cock, open the gun and hold back both triggers while closing.

The slot in hammer-carrier, $\mathrm{E}$, is shaped in such a way that when the hammer is forced down upon the strikers to explode the charge there is room left behind the shoukler of the hammer to allow it to go back again from the striker, relieving the same instantly from contact with the cartridge, thus making a rebounding hammer at once simple and effective. Although, from the secure and positive locking of the hammer-carrier, $\mathrm{E}$, and the sear, $\mathrm{H}$, there is no danger of jarring off, even when the safety-bolt is not in place, yet the lock is provided with an extra catch, 2, which will assist the fall of the hammer before striking the firing-pin, if by any means the jarring off of the hammer should occur.

At 1 , in the figure, is seen a gas-chamber which communicates with the holes of the firing-pins. If any gas should blow back it will go into this gas-chamber, and thence escape by vent-holes in the standing-breech, and not go into the locks. This action of the gases on the locks has been one of the objections to hammerless guns.

The cut on page 776 shows Sneider's double-grip top-lever gun, with all its parts, cut in half, and the gun ready for insertion of cartridge.

The top-grip, B, inserted from above, is held from below by nut, E; the lower grip, C, inserted from below, rests against the solid breech, the square hole in $C$ receiving the square shank of $B$, so that when $\mathrm{B}$ is turned, $\mathrm{C}$ must turn also. The interlocking of the upper- 


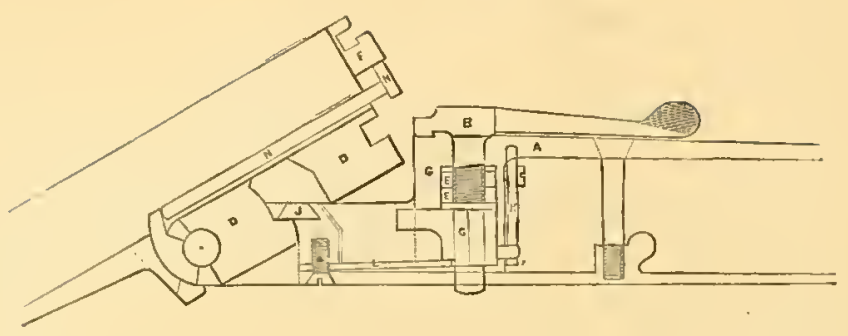

grip, B, with the lug, F, prevents any and all springing of the barrels and breech at this point. Any wear on B can be taken up by tightening nut, E, without altering the position of $\mathrm{C}$; and any wear on $\mathrm{C}$, by screwing downward the second nut, $\mathrm{E}$, on shank of $\mathrm{B}$, without altering position of $\mathrm{B}$. To prevent the nut, $\mathrm{E}$, from getting loose, a steel washer with a tongue fits between it and the face of the breech. Thus, with the two pieces $\mathrm{B}$ and $\mathrm{C}$ and the nuts $\mathrm{E} \mathrm{E}$ is formed a perfect double-grip action, allowing compensation for wear, requiring nothing further, if strength alone is considered. To keep the grips and the hug, F, and hook, D, from wearing by continual contact, stop $L$ enters into a notch on the underside of grip, C, when the gun is opened, holding the grip out of the way until the barrels are brought home, when $\mathrm{L}$ is depressed by lower lug. $\mathrm{D}$, and the grips allowed to swing into their locking position. The gun is made self-closing by the spring, $\mathbf{K}$, bearing against a stud on $\mathrm{C}$, bringing the grips home when released from the hold of $L$. The strain on the hinge when the barrels drop is entirely obviated by the shoulder-lug, D, coming in contact with check, J. This check works exactly like the bolt which holds the front stock to the barrels. Wear on hinge is taken up by compensating hinge-bolt.

Mr. Sneider claims for this action: That with four pieces, B, E, E, C, a perfect double-grip gun is formed; that, without affecting the strength of the action, it is made self-closing, by spring, $\mathrm{K}$, and the movement, and consequently the wear upon the parts lessened exactly onc-half by the introduction of stop, $L$; that the strain on the hinge-bolt is entirely overcome by check, J; and that means of compensation is supplied at every point where wear can occur in a breech-loader-on $\mathrm{B}$ by nut $\mathrm{E}$, on $\mathrm{C}$ by nut, and on hinge-bolt by

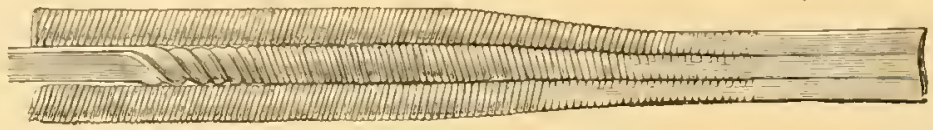

THREF-TWIST RARRF, 


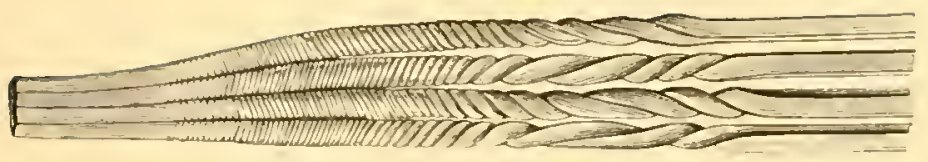

FOLR-TWIST BIRRFI

compensating bolt, and that this compensation can be made at any one of these points without affecting the position of the other pieces.

GUA-BARRL1s.- It is needless, in a work of the general character of this one, to go into a lengthy description of the details of the processes employed in making gun-barrels; but a general account of the operations in their manufacture may be of interest to the sportsman, in serving to give clearer ideas on the differences in the texture of the twist, Damascus, and laminated steel barrels which are now used. The twist barrel is often called stub-twist, from the stubs of horseshoe nails out of which these barrels were first made. These stubs and other "scraps" are welded together, drawn into bars, then heated, and while one end is in a notch, or clamp. the other end of the rod is attached to the axis of a crank and twisted. At present, these rods are made of selected iron, the supply and quality of stubs having fallen off. These twisted rods are now beaten into flat bars and then wrapped around a mandrel, and their edges are welded together. This forms the twist barrel.

The Damascus barrel is formed by taking nearly equal proportions of refined iron and steel bars. These are placed in piles, or "fagroted," and then heated and thoroughly welded together. The bar thus formed is cut into equal lengths, again "fagoted," welcled under a trip-hammer, drawn into narrow rods, and these are then twisted. To make the best 1)amascus barrel, three of these twisted rods are placed alongside of each other, and forged into a ribbon of the dimensions of cross-section of one-half inch by seven-sixteenths for the breech-end of the barrel, and one-half by threc-sixteenths of an inch for the muzzle-end. This ribbon is now wrapped around a mandrel, and its convolutions are firmly welded tosether at a white heat by hammering the ribbon on the mandrel while placed in a semi-cylindrical groove. Another portion is added to that just

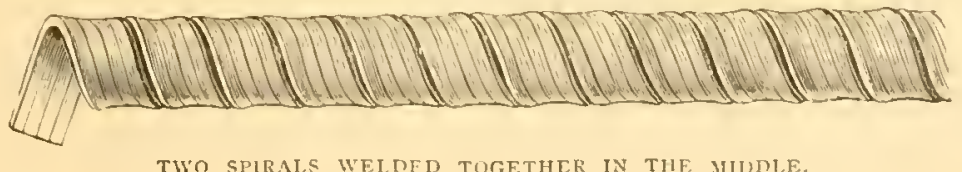

TWO SPIRALE WEIDFD TOSETHER IN THE MHMI.F. 
formed by "jumping" and hammering till the length of the barrel is completed.

Laminated steel barrels are formed of ribbons composed of six parts of steel to four of iron, and the only difference between laminated steel-and Damascus barrels is that the ribbons composing the former are made of rods less twisted; but the ribbons are subjected to more hammering when on the mandrel, in order to get greater condensation and firm welding of the fibers of the two metals.

The Pruing of GuN-barkels. - The law in England requires gun-barrels, whether of domestic or foreign make, to be subjected to proof before they can be offered for sale when part of a gun. The barrels are subjected to two proofs. The first is called provisional, the second definitive proof. There are two companies in England authorized by law to prove gun-barrels. The one at London is called the London Gunmakers Company; the other, at Birmingham, is the Birmingham Guardians. The tests are precisely the same at both places. Barrels to be subjected to provisional proof are bored and ground, and plugs are screwed into their breeches. In these plugs the touch-hole is drilled. In the following table are given the charges used in provisional and definitive proofs of the gauges of guns given in thic first column. I have added a column of usual loads for these guns with which to compare the charges used in the proof-house:

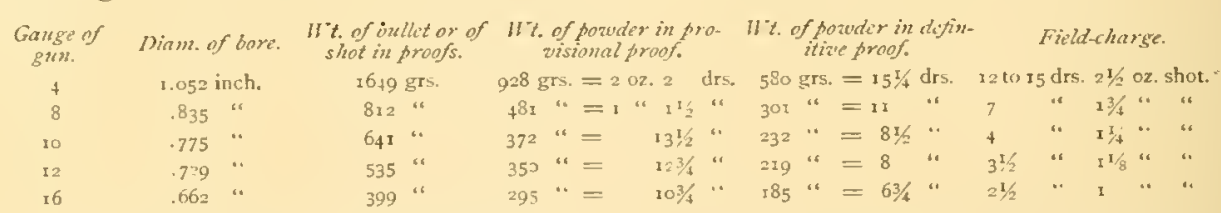

Over the charge of powder used in either proof is rammed a cork wad. Over this is placed the bullet, which is also covered with a cork wad. In testing choke-bored barrels, the bullet is replaced by the same weight of shot of No. 6, English. In the definitive proof, the barrels have to be presented to the company in a finished state and attached to their breech-loading actions. It is prohibited by law to reduce the weight of these barrels, after the company has stamped them to show that they have received the provisional and definitive proofs. The stamps used by the London Gunmakers Company on

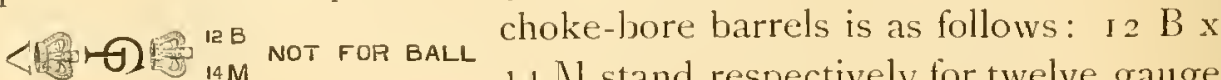
at breech, fourteen gauge at muzzle. 
This stamp is that used by the Guardians of the Birmingham l'roofhouse:

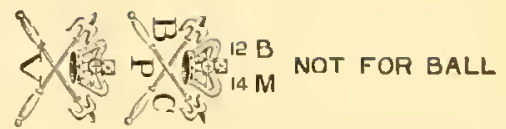

An examination of the table shows that the charge of powder used in provisional proof is about $3^{1 / 3}$ times the average field charge, and in definitive proof it is about $21 / 3$ times the field charge. The ball, or charge of shot, has very little more weight than the average charge used by the sportsman.

Belgium is the only country, besides England, whose laws require the proving of gun-barrels. At the Liege proof-house, each breechloader is proved thrice. First, the barrels are tested, then the barrels and breech-action, and finally the finished gun. The proof charges for a twelve-gauge gun are a bullet, or a charge of shot weighing 34 grammes. Twenty-two grammes of powder are used in the first proof, 5 grammes in the second, and 7 grammes in the third proof.

The following are the Belgium proof-marks: $(\mathrm{EC}) \&$

To 'Test the Straightress of the Bore of a Gun-rarkel.The barrels of high-priced guns are not always straight. They may have been so before they were soldered together and ribbed, but these operations often draw and bend the barrels. The straightness of a barrel can be readily tested by any purchaser in the following manner: Take a thin card-board wad of the gauge of the gun, and with a pair of dividers get its center. Perforate this center with a pinhole. Place the muzzle of the gun on the Aoor, and push the wad from the breech till it reaches the floor at the muzzle-end of the gun. Now point the barrel toward the bright sky or at the porcelain shade of a lamp. Place the breech of the barrel quite close to the eye and look at the brightly illuminated pinhole. You will see this hole in the axis of the barrel. Around $\mathrm{it}$, as a center, you will observe three or four bright rings. If the barrel be straight these rings will be perfectly concentric, with the pinhole for their common center. If the barrel be bent, say to the left, then the circles will appear as, if slid to the left of the central pinhole; the direction in which the circles appear displaced corresponds to the direction in which the barrel is bent.

The above is a severe test, and there are few barrels that will stand it. A similar test, though less searching, may be applied by merely placing the breech very close to the eye and looking through 
the barrel directed to the bright sky, when you will observe the opening of the muzzle and, surrounding it, three or four bright, broad rings, which will all be concentric with the bright circle of the muzzle if the barrel be straight.*

A study of the accompanying carefully drawn diagram will show how these circles are produced by the reflections of the light of the pinhole from? the sides of the barrels.

Gunmakers use a method of testing called " shad-

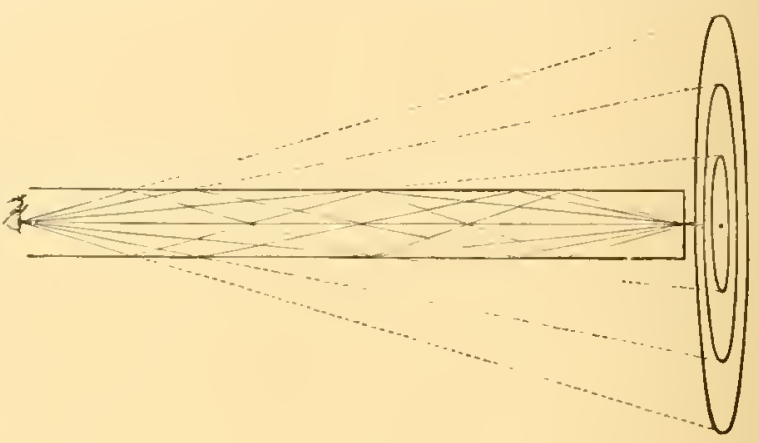
ing," which is applied by holding the breech a few inches from the eye and looking through the barrel at the top of a window-sash and seeing if its image has straight edges as it appears reflected along the sides of the interior of the barrels.

The choke of a gun, and the dimensions of any part of the bore, may be examined by long-legged calipers supplied with a spring and an index-gauge; or, by well oiling the interior of the barrel and then taking a plaster cast of it, on which measures can be made with a pair of vernier calipers.

ChOKL-BORED BARRELS. - It is not possible to state who was the first inventor of choke-boring. It is probable that one or another of the different modes of boring, which differ from that producing a plain cylinder, has been used from time to time during the past one hundred years; but it is certain that our countryman, Joseph W. Long, first called public attention to the excellence of the system of choke-boring. From this country the knowledge of its merits went to England, and now choke-boring is practiced by gunsmiths throughout the world.

* The reader may anuse himself with a few experiments which will make clear to him the philosophy of these methods of testing gun-barrels. Take two or three glass tubes about one-half inch in bore and eighteen inches long. One of these tubes should be as straight as can be selected at the glassware dealers. The other should appear evidently bent or curved. Cover the outside of these tubes with black varnish or cloth, so as to exclude the light. Close one end of each tube with a circle of card-board with a pinhole in its center. On looking through the tubes, you will sce the circles concentric with the pinhole in the straight tube and eccentric in the curved ones. 
Is far back as 1787, M. Magné de Marolles, in "La Chasse au Fusil," gave an account of choke-boring. But he did not commend the system, which he thought, if advantageous, would greatly increase the recoil of the gun. Colonel Hawker, in "Instructions to Young Sportsmen," London, $1 \$ 14$, had very strong opinions against chokebores. We next find mention of choke-boring in 1835 , in Deyeux's "Le Vieux Chasseur."

Mr. Long, in his "American Wild-Fowl Shooting," N. Y.. is79, gives the invention of a really successful mode of choke-boring to Jeremiah. Smith, of Rhode Island, who discovered its merits in 1827. From him it was learned by Nathaniel Whitman, of Mansfield, Mass., and the method was practiced by Joseph Tonks, of Boston, who, in I 870 , made such a remarkably close shooting gun for Mr. Long that he informed his brother sportsmen of its remarkable power. and these choke-bores of Tonks came rapidly in favor with duck-shooters. In 1872 , he explained this mode of boring to a gunsmith named Johnson, of Monmouth, Ill., who subsequently rebored to a choke the guns of many sportsmen. In 1872 , Robert M. Faburn took out a patent for an expanding-bit, which gave to barrels a relief near the muzzle, producing what is known as the "jug," or "tulip choke." But Faburn's mode of boring was not that practiced by Tonks; the latter, Mr. Long says, bored his barrel a true cylinder from the breech to where the construction began near the muzzle. This is the mode of boring which MIr. Greener has claimed as his invention, and he no doubt invented it, but many years subsequent to Mr. Tonks's practice of it. Mr. Long states that Tonks's choke-boring doubled the closeness of pattern on the target at forty yards and increased its killing range by twenty-five yards.

The choke-bore now almost universally adopted by gunmakers is as follows: Taking a twelve-gauge gun as an example. the construction of the bore from the front of the breech-chamber to within one and a half inch of the muzzle amounts to about $\frac{1}{10}$ th of an inch. At one and a half inch from the muzzle begins a sharp contraction which, in the length of one inch, equals ingoth of an inch. The last half inch of the bore is a true cylinder.

The guns usually used by sportsmen are of $4,8,10,12$, and 16 gauges. The charges of powder and shot with which these different gauges are loaded are as follows:

The four-bore gun is a single 44 -inch barrel gun, weighing about 
20 lbs. This gun is used in "point shooting" at ducks on the Chesapeake. It is charged with from 12 to 15 drams of powder, similar to Hazard's No. 5 or to Dupont's No. 1, and with $2 \frac{1}{2}$ ozs. of shot.

An eight-bore double-barrel gun weighs about $15 \mathrm{lbs}$, and is charged with 7 to 8 drams of powcler and with I $5 / 8$ to I $3 / 4 \mathrm{oz}$. of shot. The powder used in this gun is similar in quality and texture to that used in the No. 4 gauge.

A ten-bore gun weighs about 10 lbs., and its load is from 4 to 5 drams of powder and about $\mathrm{I} 1 / 4 \mathrm{oz}$. of shot. In this gauge, and in the twelve-bore, I have found that the best powder is one similar to Hazard's No. 4 duck-shooting powcler.

I twelve-bore carries a charge of from 3 to $3 \frac{3}{4}$ drams of powder, and from I oz. to $1 \frac{1}{4} \mathrm{Oz}$. of shot.

The sixteen-gauge is loaded with from 2 to 3 drams of powder, and with 3 oz. to $1 \mathrm{oz}$. of shot. In this gange of gun, use a powder like "Hazard's No. 4" or "Mupont's choke-bore" powder.

The charges of powder and shot which will give the best shooting of a given gun must be determined by the sportsman himself. The load depends on the weight of the gun, on the length and texture of the barrels, and on the manner in which these are bored.

To get the charge best suited to a gun, use the smallest quantity of shot that will give the desired closeness of pattern, driven with the largest charge of powder which, together with the load of shot, will give a recoil which will not produce any disagreeable effects on the shoulder, head, or eyes of the shooter. You will then have obtained the three conditions essential to the best shooting of this particular gun, viz.: First, such closeness of pattern that the game does not escape between the pellets; secondly, a high velocity in the shot, giving penetration and range*; and, thirdly, comfort to the shooter. To show how different guns of the same gauge may vary in their charge in order to produce accord in the above-named three conditions, we will cite experience with three twelve-gauge guns in our possession. They are of different weights, differ in the lengths of barrels, and they are bored differently. In order to get the conditions 1 have mentioned, one of them in the closest accord has to be charged with $3^{1 / 2}$ drams of powder and $11 / 8 \mathrm{oz}$. of shot;

* The great advantage of the choke-bore is, that from the closeness with which it throws shot, the charge of the latter may be much reduced, when compared with the charge the cylinder-bore requires to give the same closeness of pattern. 
the second, with $3 \frac{1}{4}$ drams of powder and 1 $1 / 8$ oz. of shot; and the third, with 3 drams of powder and $1 \mathrm{oz}$. of shot. The last gun gives the best results in the field.

The recoil of a gun is greater than one on first thought would suppose. If a twelve-gauge gun of $7 / 2 \mathrm{lbs}$. weight is held against the shoulder with a pressure of So lbs., it will, when discharged with a load of $3 \frac{1}{4}$ drams of powder and $1 \frac{1}{8} \quad 0 z$ of shot, give a blow of 30 lbs. to the shooter. A 16 -gauge gun, with $23 / 4$ drams of powder and $1 \mathrm{oz}$. of shot, will have a recoil of 20 lbs. above the So lbs. of pressure against the shoulder; while a 20 -gauge, charged with $2 / / 4$ drams of powder and $7 / 8$ of an oz. of shot, will give a push of 15 lbs. above the So lbs. of pressure against the shoulder. Often the recoil is such that, though not noticed after only a few shots, separated by considerable intervals, it becomes disagreeable, and even painful, to the shoulder, and especially to the head and eyes, after many shots have been made in rapid succession; therefore the sportsman, in adjusting his load for recoil, should consider whether he is to shoot only occasionally, as in the greater portion of the shooting over dogs, or whether he is to make a great many shots in rapid succession, as in shooting bay-snipe, rails, or, sometimes, in duck-shooting.

Whether the 10, 12, or 16 gauge is the best for upland shooting depends on the endurance and weight of the sportsman, on the distances at which shots are offered, and whether these are in the open or in covert. Taking the best performance of each of these gauges, the advantages of penetration, pattern, and range lie with the larger gauge. A I2-bore, taking all in all, is, in our opinion, the best for shooting over dogs, either in the open or in covert. Whether it shall have both barrels full-choked, or one barrel full-choked and the other either cylinder-bore or modified choke, and whether the barrels shall be long or short, depends on the kind of "shot" the sportsman is. In these matters he must, as in selecting the charges for his gun, decide from his experience what best suits him. To lay down laws on these matters to which all sportsmen should conform is evidently absurd. If a sportsman is slight of build and of moderate powers of endurance, let him select a light i 2 -gauge gun of 7 lbs. weight or a 16 -gauge of $6 \mathrm{lbs}$. If his favorite sport is shooting Bob White and woodcock, and he can afford only one gun, then let him get a I6-gauge, of weight from 6 to $6 \mathrm{y} / 2 \mathrm{lbs}$., with barrels of 26 inches in 
length. Let his first barrel be cylinder-bore and his second either a modified or full choke, and he will not go far astray.

In deciding whether he shall have a barrel full-choke, modifiedchoke, or cylinder, he should remember that a i a-gauge full-choked gun will put 200 pellets of No. 7 Tatham shot in a target 30 inches in diameter at 40 yards distant, while a cylinder barrel of same gauge will, in similar circumstances, put in 120 to 130 ; and also that the smaller gauges of 16 and 20 generally throw their shot sufficiently close and regular without any choke, or, at least, with very little. Indeed this, I infer, is the reason why these small bores were in such great repute among upland shooters before the introduction of choke-bored barrels.

The difference between carrying the weight of a $7 \frac{\pi}{2}$ or a $6 \mathrm{lb}$. gun, while trifling to some men, is to others the difference between weariness and cheerfulness.

Relative Weights of rile same Measure of Different Sizes of Silot. - The amounts of powder and shot in the charges of guns are not weighed but measured. From time to time, discussions have arisen among sportsmen as to the relative weights of the same measure of different sizes of shot, and the subject is of sufficient importance to demand a careful examination. To get the weight of an ounce measure of each size of shot, I weighed, in an accurate balance, 50 measures-full of the given sized shot, and divided the weight by 50 . The measure used is known as Dixon's, and is the one generally used by sportsmen. The shot used was of the American standard sizes, made by Tatham Brothers, to whom we are indebted for their courtesy in furnishing us with sizes made with new and carefully graduated sieves.

\begin{tabular}{|c|c|c|c|c|c|c|c|c|}
\hline No. of shot. & & Diam. & of pellet. & & $\begin{array}{c}\text { No. of pellets to } \\
\text { I oz. of }+371 / 2 \\
\text { grains. }\end{array}$ & & $\begin{array}{l}\text { 1t. in grains of } \\
\text { I oz. of Dixon's } \\
\text { measure. }\end{array}$ & $\begin{array}{l}\text { Excess of } \\
\text { wi. of meas } \\
\text { ured oz. over } \\
4371 / 2 \text { grs. }\end{array}$ \\
\hline I & & 0.16 & inch. & & 71 & & $447 \cdot I$ & 9.8 \\
\hline 2 & . & 0.15 & $"$ & . & 86 & & 459.0 & 21.5 \\
\hline 3 & . & 0.14 & "“ & . & 106 & & 455.5 & 18.0 \\
\hline 4 & & 0.13 & ." & . & 132 & & 467.7 & 30.2 \\
\hline 5 & & 0.12 & .* & . . & I68 & & +64.3 & 26.8 \\
\hline 6 & & 0.11 & .. & . . & 218 & & 470.4 & $3^{2.9}$ \\
\hline 7 & & 0.10 & ." & . . & $29 \mathrm{I}$ & & 479.2 & 41.7 \\
\hline 8 & & 0.09 & "6 & . . & 399 & & 477.7 & 40.2 \\
\hline 9 & & 0.08 & "6 & & $56 S$ & & 482.4 & 44.9 \\
\hline I0 & & 0.07 & .. & & 848 & & 487.5 & 50.0 \\
\hline II & & 0.06 & .. & . & I 346 & & +89.5 & 52.0 \\
\hline 12 & & 0.05 & $"$ & . & 2326 & & +91.3 & 53.8 \\
\hline
\end{tabular}




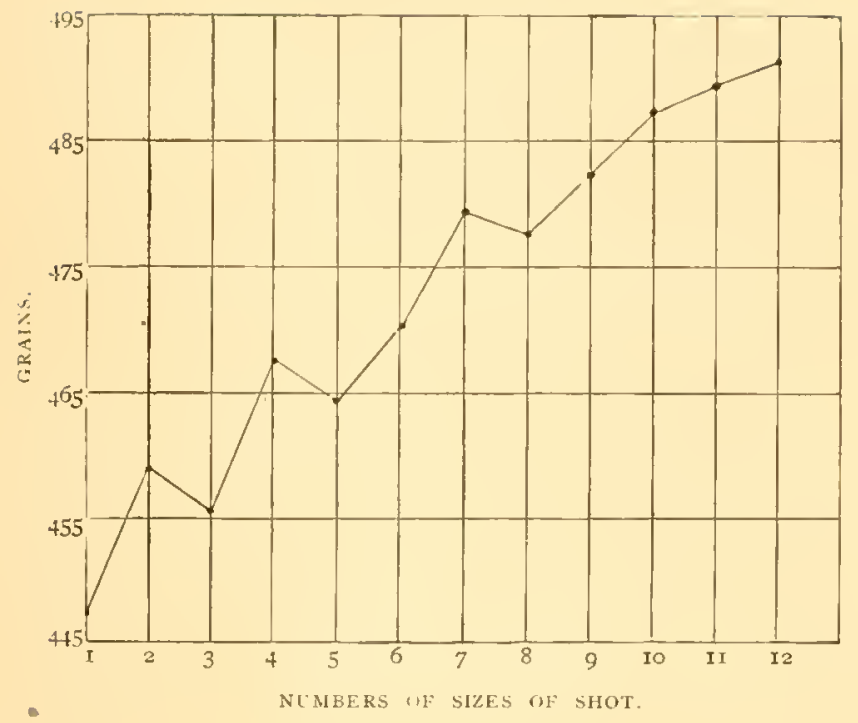

In the above diagram are shown at a glance the relations between the I oz. measure full of shot of different sizes and their respective weights. The sizes of shot are given on the horizontal line and the weight on the left-hand vertical line. Each division of the vertical scale equals one grain in weight. It will be observed that the weight of the ounce measure full of shot increases with the smallness of the pellet. The irregularities from a smooth curve observed belonging to shot of the sizes $3,5,8$, and 11 , are due to the fact that the diameters of the pellets of these sizes are such that they do not chamber in the measure as closely as those of the other sizes.

This is at once seen in making the comparison of the chambering in the bottom of the measure of one layer of 2 and 3,4 and 5 , or 7 and 8 .

This particular shot-measure gives too much weight for all the sizes. A measure of No. I shot is about 10 grains in excess of the ounce of $437 \mathrm{I} / 2$ grains, while a measure of No. 12 is 54 grains too heavy. The difference in the weights of a measure full of No. I and No. 12 is 44 grains; in other words, a measure of No. 12 shot weighs a little more than $\frac{x}{10}$ of an ounce more than a measure of No. I, while the difference in weight of a measure of No. 7 and No. 12 shot equals about $\frac{1}{36}$ of an ounce. 
Experiments on the Vlilocities of Charges of Various sized Silot Discharge1) from Guns of Twelve and Ten Gauge, with Apreications of these Experinents to tile Art of Shooting ON THE WING. - In the year I 880 , I made very many experiments on the velocity of fowling-piece shot that may be of interest to the sportsman, as they have given facts which lie at the foundation of the theory of shooting on the wing. The knowledge of these facts, while they may serve to guide the experienced sportsman in his shooting, will not make a crack shot, no more than an elaborate description of how to play on the violin will make a violinist. Practice alone will make a good marksman. The knowledge of the facts relating to the velocity of shot will, however, often serve to explain to the sportsman the causes of his failures to bring down birds on the wing, and may call his attention to defects in his style of shooting that practice may correct.

Description of tile Chronoscope used $1 \mathrm{~N}$ TIIE Experiments ON tile Velocity of Shot, and a Determination of the Magnitude of THE ERROR IN ITS RESULTS. - The chronoscope used in these experiments is very simple. It consists of a metal cylinder turning on an axle on which is cut a screw. This screw moves in a stationary nut, and this arrangement gives the cylinder a lateral motion when it is revolved on its axle. The cylinder is covered with fine printing paper, which is then smoked with burning camphor. A tuning-fork is screwed into one end of a thick piece of wood. The other end of this piece of wood is hinged to a base. To the end of one of the prongs of the fork is cemented with shellac a small, triangular piece of foil. The fork is vibrated by a bow, and then the hinged board is brought down against a stop so adjusted that the point of the foil on the fork just touches the smoked paper. On now turning the cylinder, a wavy trace will be written on it by the vibrations of the fork.

To determine the number of vibrations made in one second by the fork, a good clock, accurately rated, sent at each second an electric spark from an induction coil out of the tracing-point and through the paper. Thus the sinuous traces of the fork were punctured by electric sparks. The number of waves of the fork's trace contained between two of these punctures is the number of vibrations made by the fork in one second. A multitude of experiments showed that the range of the determination of the number 
of vibrations per second of the fork was very small, and the means of several such measures did not vary from one another by more than one-tenth of a vibration, or, expressed in time, the variation did not surpass the $\frac{1}{2560}$ th of a second. This fact showed that the chronoscope, so far as its records were concerned, was sufficiently constant and accurate for measures on the velocity of projectiles.

The effect of temperature on the vibratory period of the fork had been determined in a previous research. It amounts to an increase of .oooo45 of the periodic time of the fork's vibration for an increase of I deg. Fahr. in the temperature of the fork.

The guns used in the experiments had rebounding locks. The primary current of an induction-coil passed through a break-piece fixed under the rebounding hammer, so that at the instant the cartridge was exploded the electric current was broken and then immediately formed again. The current which passed through this break-piece was led by a wire to an upright piece of tin plate whose front surface leaned against a thick copper wire. Another wire led from the tin plate (which stood in a shallow trough of mercury) back to the battery. One terminal of the secondary coil of the inductorium is connected with the axis of the metal cylinder, the other terminal with the foot of the fork.

This chronoscope is worked as follows: One person vibrates the fork with a bow, and then brings the pointed foil down on the smoked paper and rotates the cylinder. While the fork is marking its sinuous trace he cries "fire," and the other person discharges the gun at the tin plate. At the instant the cartridge explodes, a minute spark issues from the tracing-point of the fork and cuts a small hole through the blackened paper in the sinuous trace of the fork; and when the tin plate is knocked over by the shot, another similar spark flies from the tracing-point.

We know the distance between the breech of the gun and the tin plate: the number of flexures in the trace of the fork contained between the two spark-holes gives the time the shot took to go over the known distance, whence the velocity of the shot per second is readily computed.

The fork used in these experiments made about 256 vibrations, or flexures, in the trace in one second; so, if there should appear 32 flexures between the two spark-holes, the record would give $\frac{3}{2} \frac{3}{6}$ ths, or one-eighth of a second for the time of flight of the shot from the 
gun to the distant target. Two guns were used in these experiments, one of 12 the other of 10 gauge. They were "full chokebored," and were choked exactly alike. They were made by the Colt Arms Manufacturing Co., of Hartford, Ct.

The following tables give the results of our experiments:

1. 10 Colt gun. 5 drs. Curtis \& Harrey 11 I. 12 Colt gum. $3^{\mathrm{T}} 4$ drs. Curtis \& Harpowder, $1 \frac{1 / 4}{4}$ oz. shot.

vey powder, 1 ! 8 oz. of shot.

Size of Shot. Tel. jo yds. Tel. 10 yds. tiel. 50 yits.

No. I buck . 1153 . 1067 . - -

$\mathrm{FF} \cdot 11+7 \cdot 1132 \cdot-$

$\mathrm{BP} \cdot .1146 .1126$.

No. 3. . 1066 . 1015.928

No.6... гог2. . $96_{3} .859$

No. 8. . $995 \cdot .880 \cdot 775$

No. 10.. 908. $.903 \cdot .716$

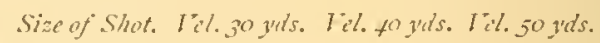

No. :luck. - . - . . - -

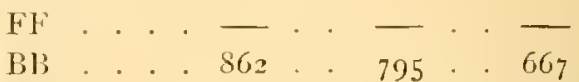

No. 3. . 844. . 754.696

No. 6. . 825 . 739 . 600

No. S. . 816. . 749.607

No.10. . 796 . 680 . 610

11. Io Colt gun, + drs. Curtis \& Harvey powder, I 1/4 oz. shot.

IV. I 2 Colt gun, 4 irs. Curtis \& Harvey powrler, $11 / 40 z$ of shot.

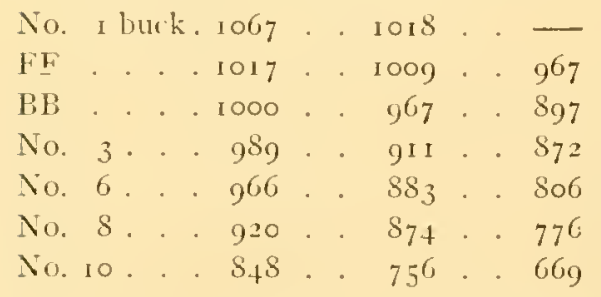

No. 8. . 847 . 722 . 671

No.10. . $748 \cdot .657 \cdot 59^{6}$

Each measure of velocity given in these tables is the mean value obtained from several experiments, varying in number from three to six. The headings, "velocity 30,40 , and 50 yards," mean that the numbers under them give the average velucities of the fiight of shot over these distances, and not the velocities at 30,40 , and 50 yards from the gun.

It will be observed that the shot used were Nos. 10, 8, 6, 3, BB, FF, and No. 1 buckshot. They were so selected because a pellet of any number in the above series weighs very nearly double the preceding one. Thus, a pellet of No. 8 weighs double one of No. 10. a pellet of No. 6 weighs double one of No. S, and so on. These relations of weight among the pellets were obtained so that I could readily reach the relations existing between the velocity of gunshot and the weight. of the pellet. The shot used was kintly furnished me by Tatham \& Bros., of New York, who used carefully gauged sieves in their manufacture. The powder used was 
Curtis \& Harvey's Diamond Grain No.6. The powder and shot in each cartridge fired had been carefully weighed out in an accurate balance.

A glance at the tables at once shows the rapid increase in the velocity of gunshot from No. 10 up to No. 3. With the heavier pellets the increase in velocity is less marked. Thus the table

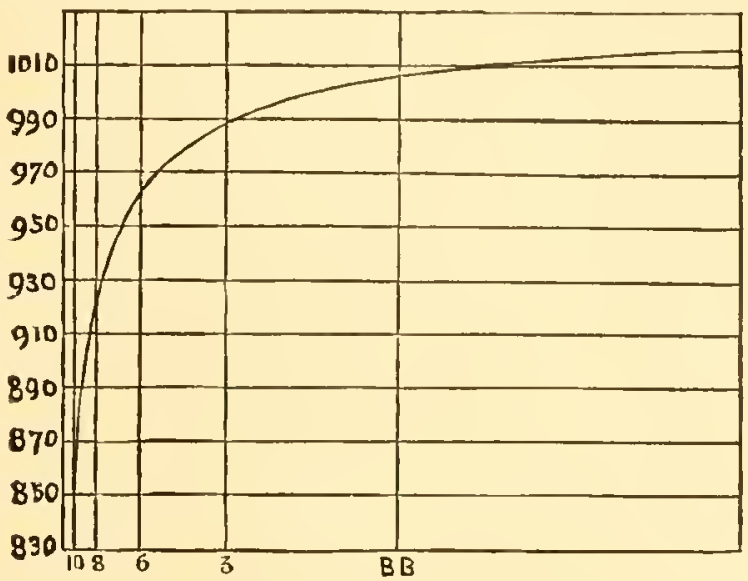

headed "Io Colt gun, 4 drs. Curtis \& Harvey, 1 1/4 oz. shot" shows that No. 8 shot has 72 feet per second velocity over No. Io shot, and No. 6 has 46 feet over No. 8, while No. 3 has only 23 feet over No. 6, and BB shot gains only i f feet over No. 3 .

The relations between velocity and weight of pellet shown in this table may be taken as a type of all the experiments, and I have graphically shown their relations in the accompanying curve.

The divisions on the scale, measured from the bottom line upward, give the velocity per second of the pellets. One unit on this scale equals 20 feet of flight of a pellet, and a unit of the scale, measured from right to left on the diagram, equals one unit of weight of pellet. The weight of a pellet of No. Io shot is here taken as the unit of weight. The numbers of the shot are written under the horizontal line; the velocities on the vertical line. When the curve intersects these lines, we find the velocity given on the vertical scale corresponding to the number or weight of shot given on the horizontal line of the diagram.

So far as the experiments with these two special guns show, there is no doubt a great superiority in the 10 over the 12 gauge gun, when each is loaded with the same weight of powder and shot. 
Thus, with the same charge of powcler and shot, + drs. powder and $\mathrm{I}_{\mathrm{H}} \mathrm{Oz}$. shot, fired from the 10 -gauge, gives a velocity of $100 \mathrm{feet}$ per second more than that given by the 12 -gauge. This fact is conclusively shown in the comparison of the figures in the two tables headed " 10 Colt gun, 4 drs. C. \& I. powder, and $1{ }^{\text {It }}$ Oz. shot" and "I 2 Colt gun. 4 drs. C. \& H. powder, and $1{ }^{1}+$ Oz. shot." The difference in velocity was in favor of the so-gauge in each of the sixty separate experiments, which were made to get the numbers (contained in the above-mentioned tables) on the lines of No. 8 and No. so shot.

With No. 10 shot the mean velocity given by the 10 -gauge gun over the first 30 yards is 8.8 feet. With the same charge in the 12 -gauge the velocity is 748 feet, showng a clifference of 100 feet in favor of the 10-gauge. With No. 8 shot the difference amounts to 72 feet. The average difference in favor of the 1 o-gauge in the flight of shot Nos. 8 and 10 over 40 yards amounts to 1 1o feet.

If we assume, as we certainly may without grave error, that the penetration of shot varies as the square of its velocity, these experiments will give the relative penetrations of the 10 to the I g gauge about as 9 is to $\%$. These experiments show that the recent movement in favor of small-bore guns is one in the wrong direction. It appears that a 10-gauge gun, if of about $8 \mathrm{lbs}$. weight, would be the best fowling-piece for upland shooting.

That the 10-gauge shows such superiority over the 12 may be accounted for by the fact that the same charge occupies less length in a 10 than it does in a 12 bore, and hence there are fewer pellets in contact with the barrel of the former than of the latter to oppose by their friction the projectile force of the powder; and secondly, the powder in a 10 -gange is exploded nearer the center of its volume, and thus does not have so much chance of blasting before it the unburnt powder contained in the portion of the charge removed from the point of ignition.

I also venture to predict that with the same weight of barrels the 10-gauge will not heat as much as the 12, because the motion of the shot, lost by the greater resistance it opposes in a 12 -gauge cartridge, must appear in the form of heat.

The third fact which these experiments show is that with $1 / 3 \mathrm{oz}$. of shot and 3.4 drs. of powder an average velocity is obtained which requires $4 \mathrm{drs}$. of powder to give $1 / \frac{1}{4} \mathrm{oz}$. of shot a velocity equal to that given by $3^{1 / 4}$ drs. to $1 \frac{1}{1 / 8} \mathrm{oz}$. Now, + drs. of powder, if not fired from 
a gun weighing at least 9 Ibs., and from a good, strong, muscular shoulder, is disagreeable. The effect on the body, and especially on the brain, is neither conclucive to pleasant nor to yood shooting. The number of pellets in a charge of $1{ }^{1}+6 z$. of No. 8 shot is 499 . In a charge of $1 \% 8$ oz. of the same shot there are $4+9$, therefore only 50 pellets more in a charge of $1 y_{+}^{\mathrm{y}} \mathrm{Oz}$. than in a charge of $1^{\mathrm{I}} 8 \mathrm{oz}$; and surely the want of the 50 will not cause a good shot to miss his bird with 4.49 pellets, nor will the addition of the 50 grive a bad shot any more chance of bringing his bird to hay with his 499 peliets.

There are two styles of shooting on the wing. (one is called "snap-shooting," where the shooter; on selecting the bird which he wishes to bag, quickly brings the gun to his shoulder and, at the instant it is in place, fires. If the bird is a cross-shot, he determines, at the moment of fire, the distance to which he should direct his gun ahead of its flght, this distance depending on the velocity of the bird's flight and on his distance from it. This manner of shooring is practiced the more generally by upland gunners in shooting quail. grouse, and woodcock.

The other style of shootng may be designated as "the swingshot," in which the gunner swings his gun ahead of the cross flight of the bird till he attains the proper distance ahead of it, and then fires: but he keeps his gun moving, with a regular angular velocity; till after its discharge. This method of shooting is certainly the only one which has been found successful in the shooting of hay fowl, as ducks, brant, and wild getese. There are sportsmen who will contend that they merely follow the bird with the gun, and discharge it while it is pointing directly at the bird. I once put this opinion to the test in the following manner: Four willets came over the decoys, flying in line with a good speed. With my grun I followed the leading bird coolly and accurately, and kept the sun moving regularly after its discharge. Instead of killing the bird aimed at, the third from the leader dropped clead.

To give a rule applicable to all sunners, for the clistance at which a gun should be held ahead of a bird in the "swing-shot," is not possible. Some sportsmen follow a bird, and then, after reaching before it the proper distance. suddenly stop the angular motion of the gum, and then fire. Others, after following the bird a short distance, give a quick, lateral motion to the gun, and then fire. Others, 
again, bring the gun, with a lateral motion, ahead of the bird, and keep the gun moving till their experience decides the proper distance ahead of its flight, and then fire while the gun is keeping its previous regular angular velocity.

For the simple illustration of the bearing of these experiments on the art of shooting on the wing, 1 will suppose that, at the moment of fire, the gun is stationary; in other words, that we are firing "snap shots." If the bird has a velocity across the line of sight of 30 miles an hour (i. c., $44 \mathrm{ft}$. per sec.), and we are using charges in a 12 -gauge gun of $3 \frac{1}{4}$ drs. of Curtis \& Harvey powder and 1 1/8 0\%. of shot, we shall have to shoot about 5 feet ahead of the bird if it is flying at a distance of 30 yards; at 7 feet ahead, if at a distance of 40 yards, and 11 feet ahead of the bird, if at a distance of 50 yards.

These distances ahead, for cross-shots at birds flying at the rate of 30 miles an hour, may appear out of all reason with the experiences of many sportsmen; but a few simple experiments will convince them that they grenerally hold farther ahead of a cross-flying bird than they are aware. In the grass of a level field drive two twigs, far removed from fence-rails or any familiar object with which can be compared the distance separating the twigrs; then bring your friend up to 40 yards distance of the twigs and ask him if he would hold alsead, by the distance separating the twigs, at a cross-flying duck groing over the twigs. He will, in all probability, tell you, "Certainly, the twigs are only about is inches apart." Similar experiments made with rough sticks and branches suspended in the air at various distances have convinced me that it is very difficult to judge accurately of the actual distance you hold ahead of hirds, especially when they are flying over water or in the open.

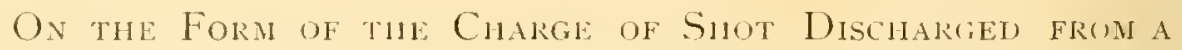
Gux.- Does the shot clischarged from a gun progress through the air in the form of a cylinder, a sphere, or in the shape of a spindle? We have made experiments which show that the cloud of shot as it passes through the air changes its shape as it goes from the muzzle to a distance, and that its general form is egg or spindle shaped. We regret that the experiments on this interesting and quite important subjec of investigation have not been brought to the com- 
pletion we desire before their publication. It may, however, interest our readers to know how one can see the form of the cloud of shot as it rushes through the air at the rate of 800 or more of feet in a second. It is viewed in the following manner: A disk of about 6 inches in diameter, formed of thin black paper, has cut in it one or more narrow, radical slits. The disk is set in rapid rotation, by means of clock-work, and the top of the disk rotates in a direction opposed to that of the charge of shot. On looking through the slit at a point on white background while the charge of shot is passing, one gets an instantaneous glance at the passing shot, which is of such short duration that all the shot appear stationary in the line of sight. By changing the position of the apparatus and the point at which you view the passing cloud of shot, you obtain views of its form at various distances from the gun.

In our experiments on the velocity of shot, the numbers given are those which refer to the pellets which first struck the target. A cross-flying bird shot at must be struck successively by pellets as it passes, and the killing power of a gun evidently depends on the form of the cloud of shot which it projects and high velocities given to the pellets forming the cloud of shot.

OX THE FITTNG of THE: GUN TO THE SHOCTEk- There are two dimensions of a gun which must conform to the shooter, in order that he may shont successfully and comfortably. These are the length of the stock, measured from the middle of the buttplate to the front trigger, and the "drop" of the stock, or the distance from the upper edge of the toe of the butt to a straight edgre laid on the rib of the gun and extending to the end of the butt. If the purchaser will try the fit of several yuns of lifferent lengths and drop of stock in the following manner, he may select one which will exactly suit him: Stand in front of a mirror placed flat against a wall. Throw the gun into position to aim at your right eye. If you now see your eye just above the rib, and also the upper surface of the rib of the gun, you may conclude-if the gun always comes into this position-that it fits you. That customers may select the grun best adapted to their use, sun dealers should have on hand one with a stock whose length and drop could be altered by means of screws or clamps. 
Haninlig of Gins in the Field. Always carry your gun pointing upward, and never, under any circumstances, hold your gun in any other position, except at the moment of bringing it into position to fire. Some sportsmen carry the gun pointing downward, and bring it into position at the shoulder by elevating the muzzle. This is not the proper way to bring a gun into position to get a rapid and sure aim; and also, it is evidently danserous to sweep the muzzle of a gun from the ground upward just as you are about to take aim and to pull the trigger. Many accidents have occurred to fellowsportsmen and to dogs by the finger inadvertently touching the trigger as the barrel is lifted into position. If the barrel is carried pointing upward and then cropped to the line of aim, the stock at the same time describes an arc upward, and falls naturally and easily into position inside of the shoulder. Leep your trigger finger uncier the guard till your gun is in position to fire.

Before jumping ditches or climbing over fences, put your hammers at half-cock. If carrying a hammerless gun, throw the safety-catch into action, then grasp you gun firmly in the right hand and hold it in a vertical position. In going through thick covert of briers, vines, or brush, put your hand over the hammers.

II ithdraw the cartridges as soon as you bave decided to shoot no more that day. If you carry a hammerless gun, lct no one touch it till you have drawn the cartridges.

Boys and persons learning to shoot should not be allowed to carry in the ficld a loaded gun in the company of sportsmen till they have satisfied the sportsmen that they will carry their arms in a manner that will insure, as far as possible, freedom from accident to themselves and to their companions.

CARE of Cuns. - N lways clean your gun after the day's shooting. Tow, crash, or hannel are good materials to wipe out the barrels with. If the air is dry and the powder is caked, a little moisture should be used on the wiper. Then dry the barrels thoroughly with dry wipes; then oil a soft iron brush, or ooo sand-pajer backed with flannel, and get the lead out of the barrels; then wipe them dry and oil them and the outside of breech-action, locks, and stock. Before you put the barrels in the gun-case, close up the breech and muzzle with plugs made of flannel or cork saturated with purified sperm oil. If 
your shooting has been in salt air, give your gun - after cleaning it a thick coating of purified lard oil, such as is used in the light-houses, for this is the best lubricant to prevent the corrosive action of salt air.

The honey-combing of gun-barrels is caused by the residue, left by the exploded powder, setting up a galvanic action between the iron and steel composing l lamascus and laminated steel barrels, or between the different grades of iron forming twist barrels. This fact I have proved by the following experiments:

A piece of "low-carbon" steel and a piece of soft iron were placed each in a separate vessel, containing a very dilute solution of sulphuric acid, or a solution of the residue from gun-barrels. It was found that each metal was acted on and corroded. But on placing the bars of iron and steel in the same ressel of dilute acid, and bringing in contact their upper ends which were outside the acid, it was observed that the iron now dissolved rapidly, while the steel was barely acted on. Moreover, on connecting the ends of the steel and iron bars with a galvanometer, we olserved that an electric current was in action, and that the soft iron held the same relation to the steel as the zinc plate in a battery holds to the plate of copper, platinum, or carbon. (On placing pieces of laminated and I) amascus barrels in the dilute acid, they became honey-combed after a lew days by the corrosion of the soft iron of the barrels, and reproduced the exact appearance of barrels honey-combed by ordinary use.

This honey-combing is therefore produced by a want of homogeneity in the material composing the barrels; and as it occurs even when the greatest care is taken to clean the barrels after each day's shooting, it appears that it can only be prevented by forming gunbarrels out of some substance which has the same structure and composition throughout all its mass - such as decarbonized steel or pure cast-steel. If aluminum could be obtained cheaply, it would make the best of barrels. Bulk for bulk, this metal weighs only onethird of steel, and there would be no difficulty in making the barrels thick enough to have sufficient strength. Aluminum bronze might be tried as a material for gun-barrels. 


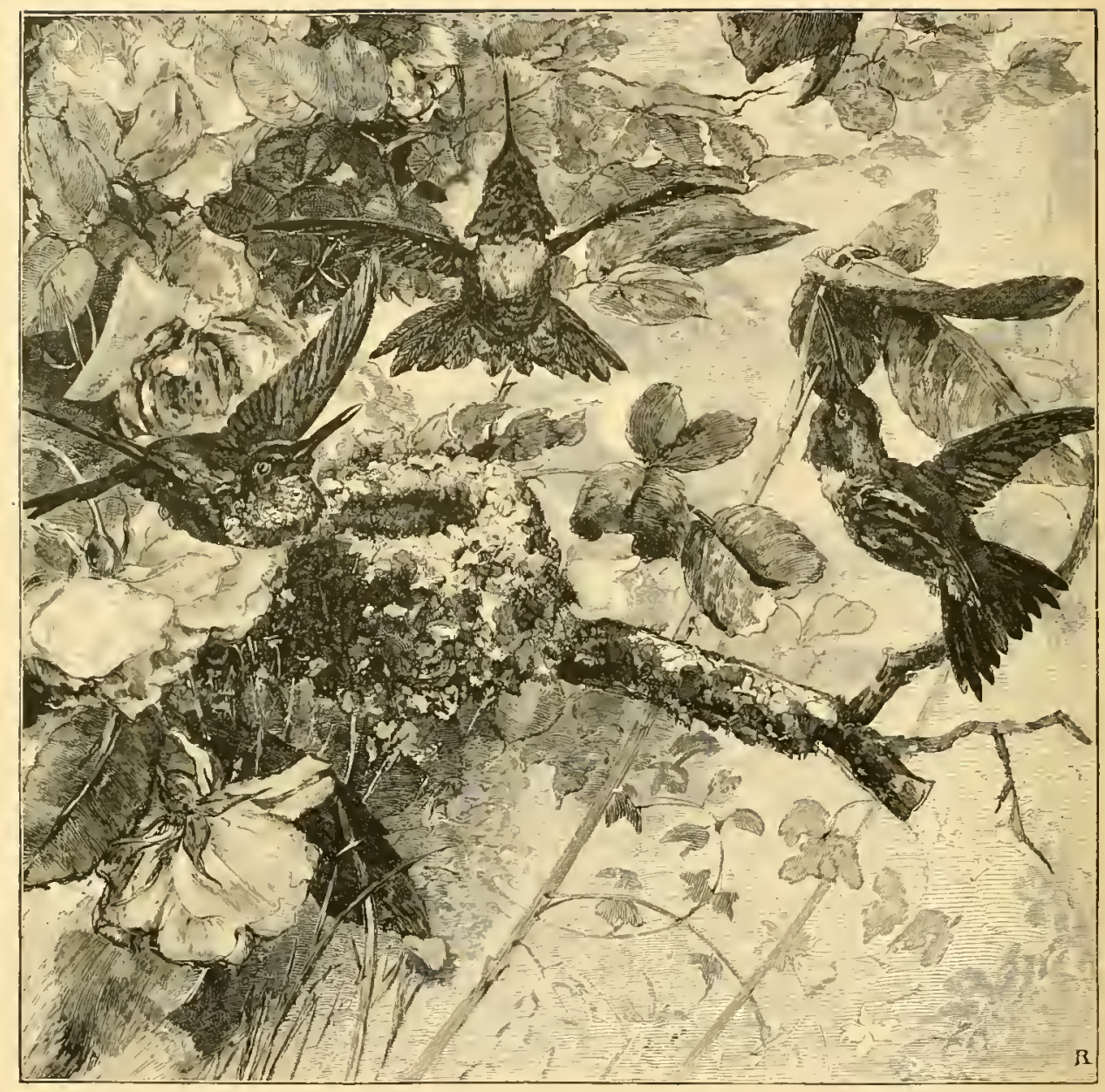




\section{OUT OF DOORS}


If I could put my woonds in song,

Ant tell what's there enjoyed.

All men would to my Eavilons lirong,

And leare the cities void.

- Emerson. 


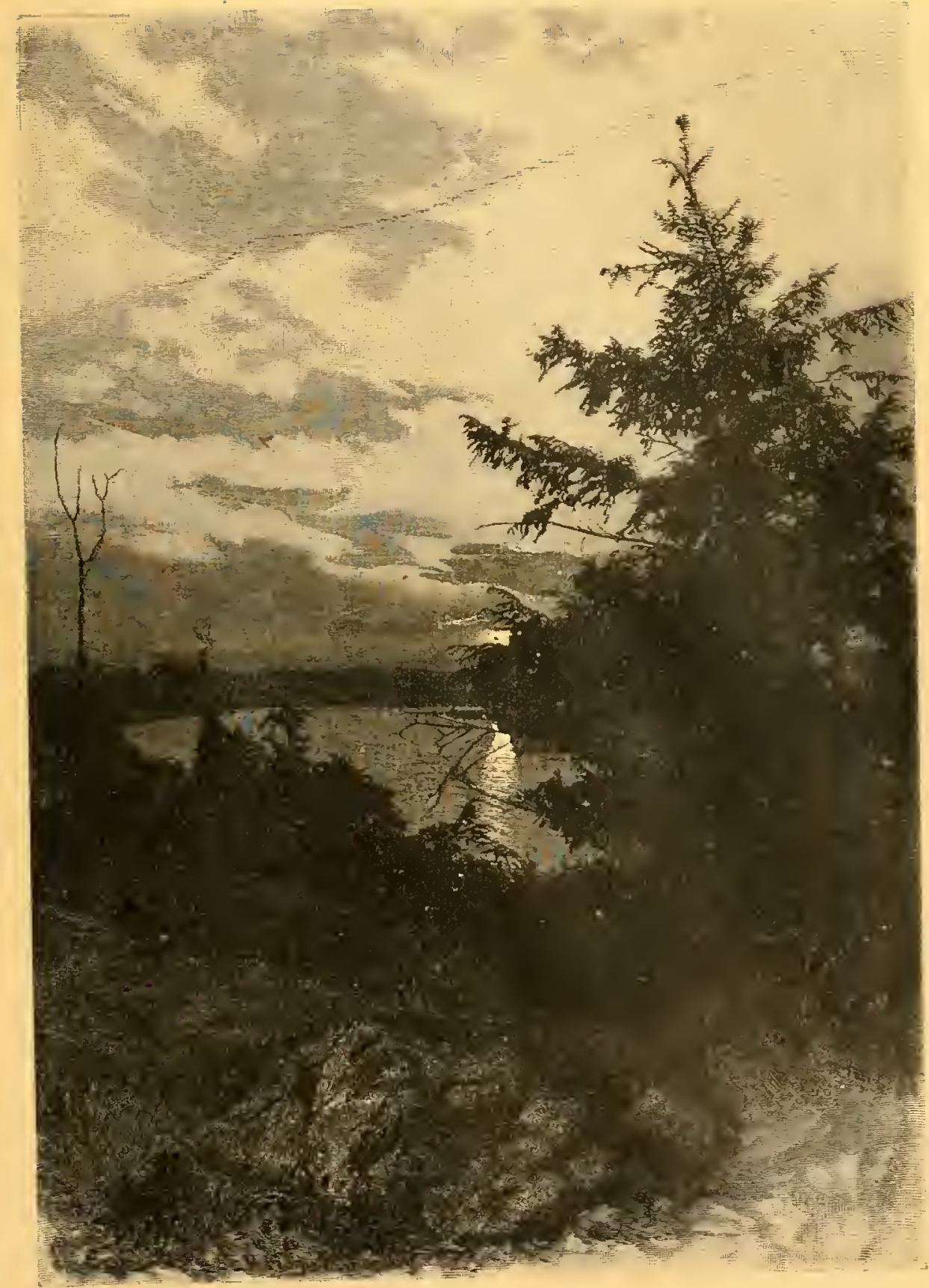





\title{
CAMPS AND TRAMPS ABULT KTAADN.
}

\author{
Bi ARBOR ILEX.
}

ПНАT noble mountain K̇taadn,* towering grand and peculiar out of the vast and undulating forest of northern Naine, its lofty head a pyramid with rayged apex as of a volcano, its ever luminous face looking serenely southward and mirrored in a hundred lakes, its huge body lying leagues along to the north and plowed into gorges by the glaciers of xons, - Ktaadn and its retinue of magnificent domes, sole representatives of the primal continent, - all these have been sung by the poet and portrayed by the painter.

Imagine that you are fifty miles from any railway, twenty-five from the nearest highway, and thirteen from a practicable footing for any apparatus of transportation other than human legs; that you have come to stay a month; that your party, some of whom are not strong, is to be wholesomely and plentifully fed, and protected against rain, frost, and probably snow; that the forest affords no other habitation or subsistence to you than to the wild animals about you; that game is uncertain, and fish, while large enough, indeed, to delight the sportsman, are not plentiful enough to insure subsistence;-fancy this, and you will indeed have come short of a lumberman's idea of roughing it; but you will have put yourself in a puzzle over two propositions - 1st, as the woods provide little, much must be carried in; $2 \mathrm{~d}$, as little can be carried in, the woods must furnish much. The resultant of these opposed ideas may be expressed by

* The orthography - Ktaadn - is not that of the maps; the Maine State College people, who ought to be allowed to name their own mountains, insist upon "Ktahdin." But those eminent authorities, Thoreau, and J. Hammond Trumbull,- the latter our best expert in Indian nomenclature,-prescribe the spelling here adoptecl. 
the following formula:-skill $\times$ pork + blankets --success. Skill, in the form of experienced and strong guides, transports itself and the other necessaries; pork means heat and tissue in the smallest compass; warm and water-proof clothing are obviously indispensable. Hard-breacl, tea, sugar, and a few lemons (anti-scorbutic) are indispensable: beans, wheat flour, and baking powders, potatoes, rice, and a few raisins (a little sweet is so sweet in the woods), should be taken where transportation is not too difficult. Indian meal, canned meats and vegetables, and butter, furnish the means of occasional luxuries. With regard to spirits, rum is probably the best adapted, and, while a little is necessary in case of exhaustion or chill, and often has a hygienic importance, it is a very serious mistake, as the hardy humbermen well know, to use it as a stimulant before exertion, or freely at any time.

The natural essentials of a permanent camp are, Ist, convenient proximity to water: $2 \mathrm{~d}$, a forest to shield the works from the sun, and the tents and the fire especially from heavy winds: $3 \mathrm{~d}$, a level bit of ground having as dry a nature as may be, and some natural drainage. The artificial essentials are, a camp-fire and a tent for the party and another for the guides. To this may be added a tent to be used for putting supplies out of the rain, and also for putting them out of sight. The working drawings and the night view so fully illustrate the arrangement and construction of our camp that little other description is required. Fig. 1 is a cross section through the center of tents and camp-fire. Fig. 2 is a ground plan and a horizontal section of the surrounding trees. Permanent tents are "logged" a foot or two high on three sides, and the ends are covered with thin boards split from white cedar logs, or with birch-bark or boughs. The roof is a piece of heavy cotton cloth soaked in brine to protect it against the sparks of the camp-fire, and

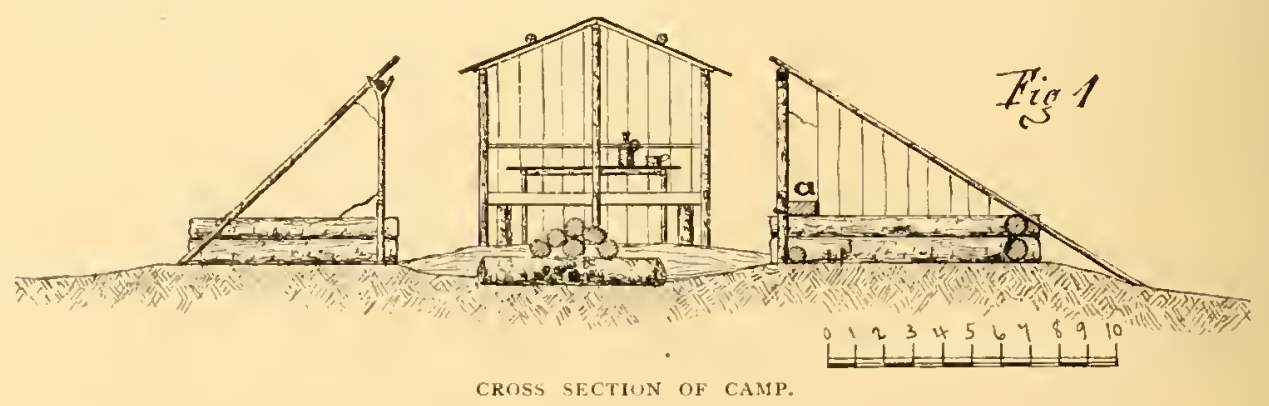




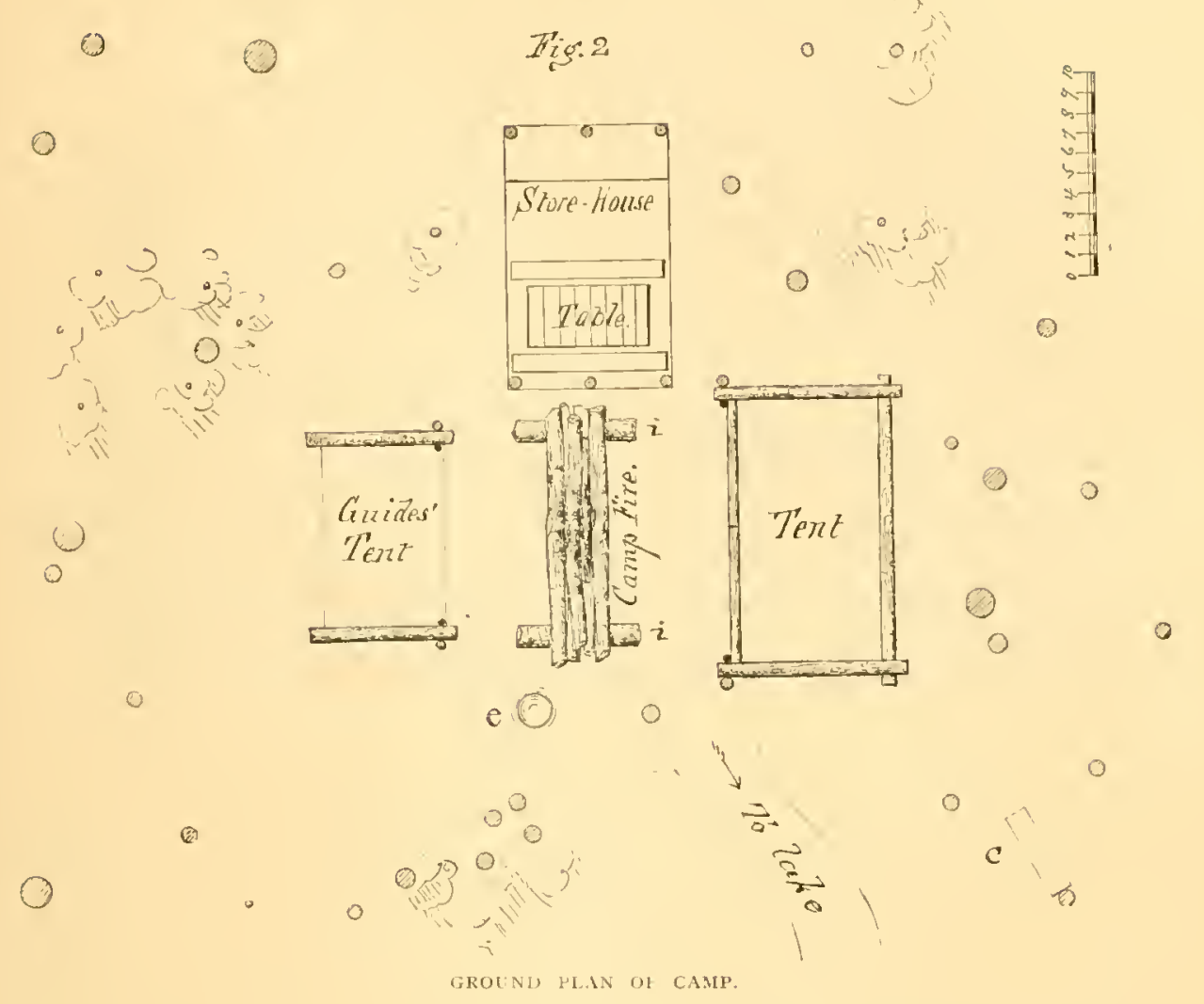

supported on poles. The front is quite open to the fire, not to speak of the rain. The ground forming the floor is smoothed off and covered thickly with small boughs of evergreen; upon these the rubber and woolen blankets which form the beds are laid. The "I)eacon's seat," a, Fig. 1, answers almost every other purpose of clomestic furniture. Our store-house and dining-room was constructed of round sticks, roofed and covered at one end with white cedar "splints." The wash-stand was at c; the bean-hole, e, will be further referred to. The camp-fire is laid on two "hand-chuicks," i, i, or on two suitable stones, and consists of logs from four to fourteen inches in diameter and eight to fourteen feet long. Three-quarters of a cord of wood are burned per day. Lying in a three-sided tent, wrapped in blankets and water-proofs, with one's feet a length off from such a fire, is protection against any sort of bad weather, and yet it realizes every advantage of being out-of-doors. A temporary tent may consist of a mere cloth or of boughs laid upon inclined 


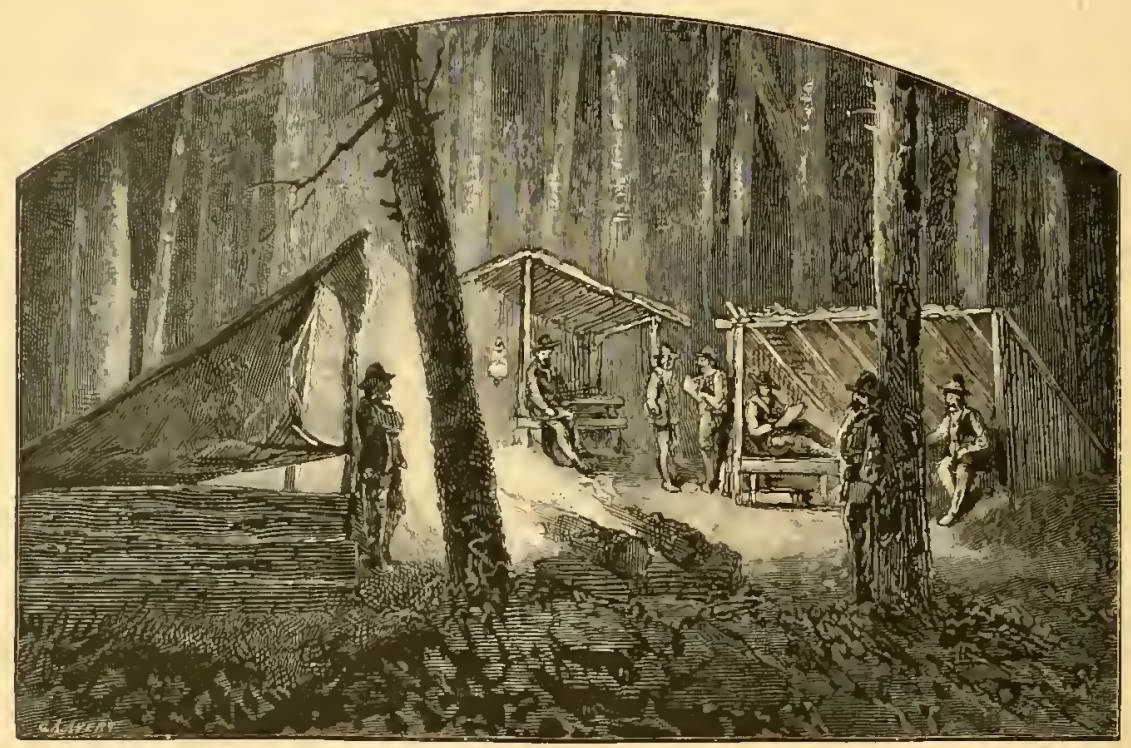

NIGHT VIEW OF THE CAMP.

poles, or it may be logged or otherwise reënforced according to the weather. Smaller parties sometimes prefer the "A" tent. Wrorks like ours may be built from standing trees, in a day or two, by three expert guides. Our camp was placed some thirty rods from Ktaadn Lake, and a good path was cut to it through the underwood.

We are a party of six excursionists and five gruides. Four of us are artists, whom we will call I)on Cathedra, Don Gifaro, Herr Rubens, and M. De IVoods. Two of us are professional men,- M. La Rose and myself, Mr. Arbor llex.

At 7 1'. 1., September th, we boarded an Eastern Railroad sleeping-car at Boston. We breakfasted in Bangor and dined in the village of Nattewamkeas, on the European and North American Railway, fifty-eight miles further, where we met our chief guide and bought our heavy supplies. Wedged with our impedimenta into two dvagons, we jogged twenty-five miles to the northward, and slept in the outlying settlement of Sherman. On the bright morning of the 6 th we and our roughing bagsage were packed into a four-horse, springless wagon, with the running grear of a sun-carriage and the side-grating of a bear-cage. The significance of this construction soon became obvious. Upon driving some half-dozen miles to the eastward, we suddenly rose upon 
a crést where Ktaadn and its retinue of lesser mountains burst upon our view, - a revelation of grandeur and beauty all the more impressive because the previous scenery had been so tame. At noon, away out beyond the precincts of permanent habitation, we had our first out-of-door dinner. Our sportsmen cast in Swift Brook for trout without success - it was a bad time of year: but a slice of pork toasted on a forked stick, a piece of hard-tack, and a cup of milkless tea were, thus early in our quest of healthy appetites, more palatable than a ragout at I)elmonico's. The excursionists, excepting myself, walked on; two guides and I stuck (with difficulty) to the wagon, upon a road consisting of a slit cut through a dense forest, over a tract of stumps, mud, thinly corduroyed swamps, and granite bowlders. The forest was broken only by " the farm" or "Hunt's," where hay and vegetables were raised in the early lumbering days, now a temporary habitation. Here, on the east branch of the Penobscot, 1 found our party fishing without success, but canoeing with great satisfaction. This whole territory, except a few tracts, was burned over forty years ago; some of the new growth is already good timber, and here and there a dead monarch stretches his huge form across our path.

A canoe ride two miles up the east branch was to me as delightful as it was novel. Our stalwart guide fairly lifted our larger "birch" with its four passengers over the shallower rapids. A short tramp through the forest brought us before sundown to our first encampment on the "lower crossing" of the Wasatiquoik, twelve miles from Sherman.

Next morning, the 7 th, we witnessed the construction, in two hours, of a sled or "jumper," by means of an axe and a two-inch auger. At ten o'clock the baggage was bound to two jumpers and started off by four horses, our party of eleven, on foot, forming advance and rear guards. So we tramped over hill and occasional

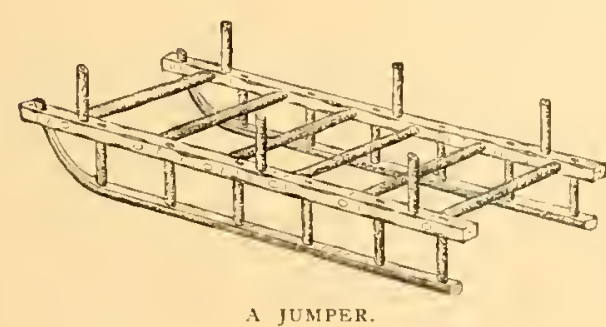

$51 \mathrm{~A}$ swamp, up the Wasatiquoik valley, stopping as much time as moving, occasionally holding the craft from capsizing, and prying her over falien trees, stumps, and rocks. Much of the surface of the country is a mass of granite bowlders of 


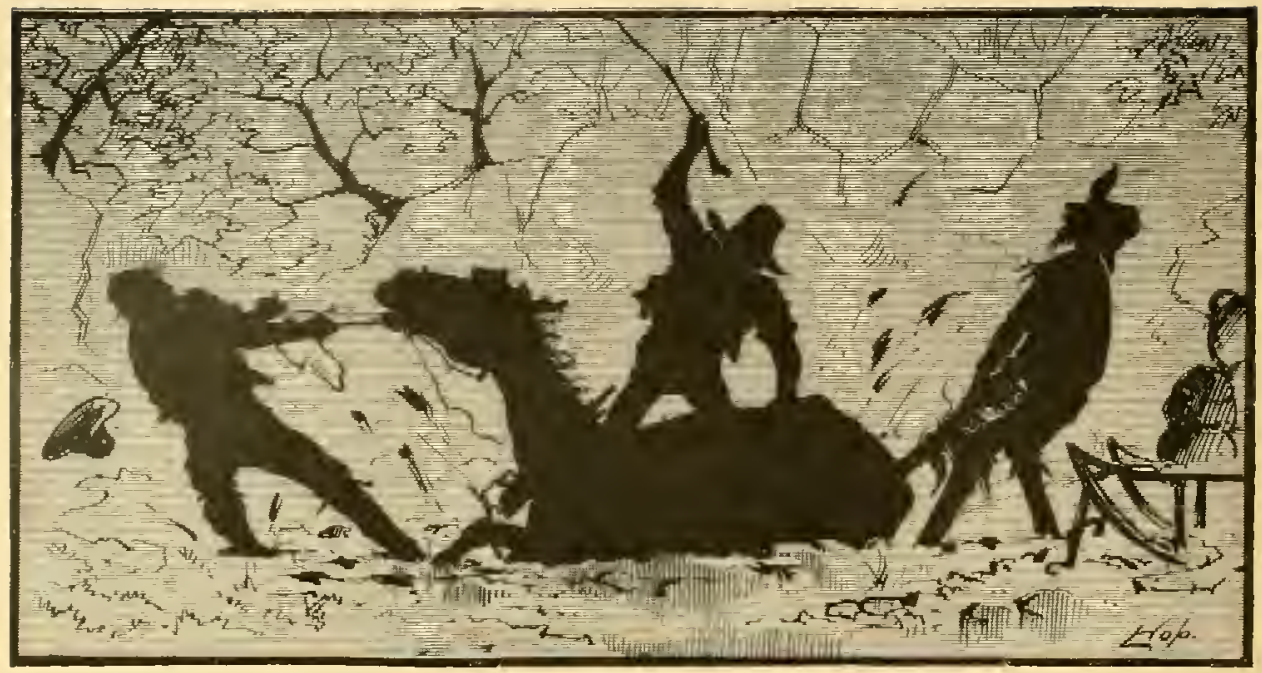

THE MISSING LINK.

every size. Where disintegrated stone and vegetable mold have accumulated for ages, the road is practicable for wagons; but on slopes, where the filling has washed out, it is amazing to see a horse get over it at all, especially when he has to drag soft wooden sledrunners over the serrated edges of big stones.

The rest of the road presented still steeper pitches, deeper bogs, and more entanglingly strewn rocks. One of our horses, a straggling, raw-boned "missing link," afforcled us no little tugging and plenty of amusement, in our fruitless efforts to keep him right side up and his various members comparatively collected together. Along toward evening he quite abandoned the transportation business, flinging himself in wild gymnastics, and finally he slid off the side of a corduroy and sank up to his middle in the muck. After we had tugged at him for half an hour, during which time he maintained a strict neutrality, we convinced him, by means of a birch rod, that he must take a hand in the encounter, whereupon he roused up and floundered out. We waded the "upper crossing" of the IVasatiquoik at dusk, having traveled eight miles; the advance guard had already prepared a camp.

Next morning we got a fair start, and by noon had made the remaining five miles to Ktaadn Lake, which we should have done the day before. After we had pried our unfortunate horse out of several holes in the first mile of road, and the other one had shown 
symptoms of collapse, we abandoned the jumper and sent the team back. Meanwhile, one horse of the other jumper having distributed most of his shoes and gone out of service, his companion dragged the vehicle alone up many steep pitches, and was only dismissed, with our blessing, when the jumper had left its starboard runner on a rock. So we had a chance to find out how wonderfully easier it is to walk light over bad roads than to lug twenty pounds of baggage. The guides spent the afternoon in "backing" in our wraps and a day's provisions. We dineil by the dam at the foot of the little lake,-one of the many difficult but unremunerative works built a few years ago to "drive" logs, - and got into a temporary camp for the night.

The bean-hole, that principal base in camp topography, is made large enough to take in an iron pot; and when the hole is heated to a cherry-red by a big internal fire, and when the pot is filled with parboiled, yellow-eyed beans and a cube of pork with fat and lean in proper strata, and when the pot is set in the hole for the night and covered with coals, then begins a beneficent tissue-making alchemy which transmutes the humbler food into ambrosia fit for Mlount Ktaadn, if not for Mount Olympus.

The fishing along shore now began to abound chiefly in chub, and Don Gifaro, the epicure, was beginning contemptuously to dub this ever-ready-for-breakfast fish as "Ktaadn trout," while at the same time Don Gifaro, the sportsman, was silently determining where the real "fish" lay. All in good time, an ancient and dilapidated raft was discovered, and as soon mounted by the Don, De Woods, and La Rose, who poled and paddled it with no end of work to the previously determined spot. After an hour's fishing, La Rose's bare hands taking the place of a landing-net, they returned laden with trout; seven fish weighed over ten pounds, and one was a three-pounder, twenty inches long. Meanwhile, a guide had shot a brace of partridges, and our style of living was rapidly assuming the Madison Square type. 1 give all concerned the benefit of two experiences I acquired this day: first, don't lay a trout in a frying-pan of red-hot fat with your fingers; second. when you do, get a distinguished artist to paint them with white lead and turpentine; it prejudices one against a warm tone in art, though the ultimate repose of the composition is charming. 


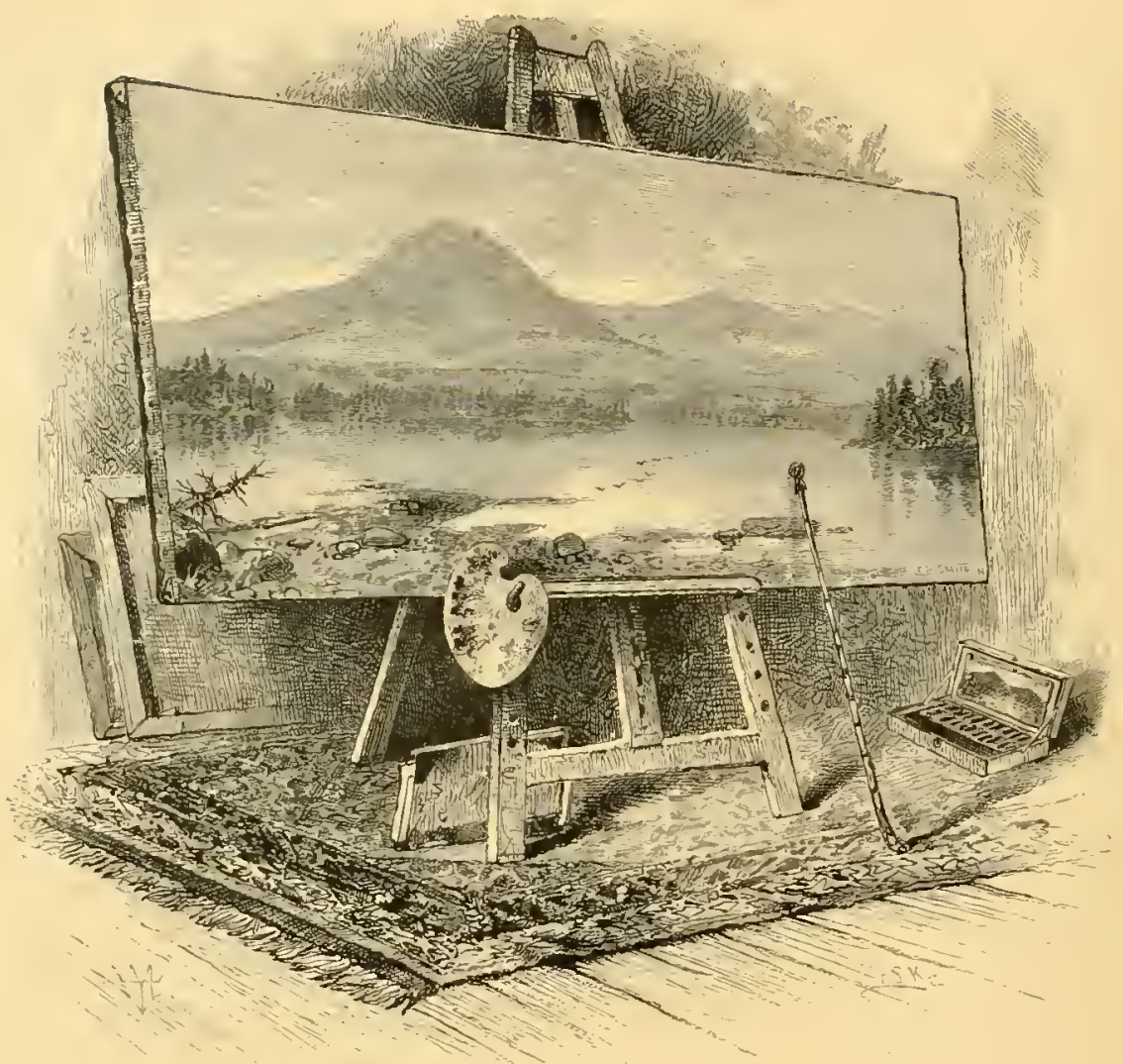

KTAADN, FROM THE SOUTH SHORE (1) THE, LAKL:

The mountain was now growing in our sight, and our artists were already making finished pencil studies and catching the everchanging tints. Few views of mountains in any country exceed that from the southern shore of Lake Ktaadn, in combined grandeur and beauty, - the great pyramid, ten miles away on the left, ever changing in the varying moisture of air and shadow of cloud, brilliant anct rosy in early sunshine while twilight still broods over the valley; each rock-ril, and rift searched out by the full blaze of mid-day, opalescent in the mistier air of afternoon, and then a harmonious mass of blended purple and blue outlined against the sunset and mirrored in the lake; its foreground a densely wooded plain of dark evergreens, broken here and there on the margin by tangled underwood of every hue of green, already richly flecked with autumnal color. In front, on the near opposite shore, abruptly rises Mount Turner, 
its flanks dense with primeval hard-woods, the green interspersed with daily deepening red and yellow, and its summit a thicket of evergreens. Twenty miles away on the right, and most beautiful of all, the Traveler, - a flattened dome, rising higher than the loftiest peak of the Catskills, grand and symmetrical indeed, but lovely, as I see it far away in the soft, rosy sunset, when Ktaadn has put on the darker robes of evening. Such appears to be the view from our camp-shore; but as I look over my shoulder at the canvas of my companion, I realize how inadequately it can be described in words.

Our life, pleasant as was its routine by day, was not mere

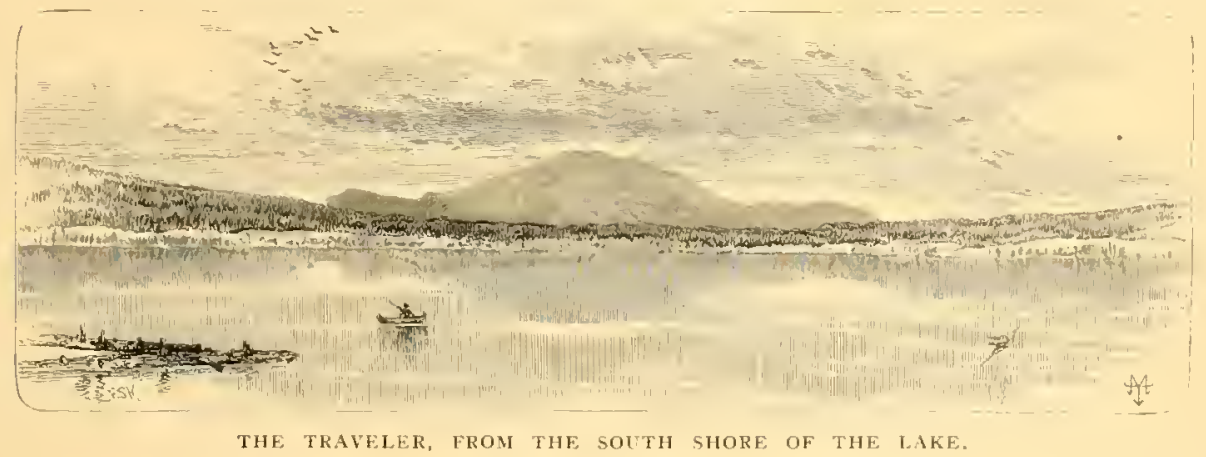

sketching, fishing, and tramping. The evening meal, with its liberal fare and its rousing appetites, its jokes and its relation of the day's experiences, and then the lying at ease before the glowing campfire, with its pipes and punch and stories, and the dropping off of one and another in sweet, healthful sleep, without the formality of "retiring"-these are scenes of which the memories will last like those of Ktaadn itself.

On the bright, clear morning of the $1+$ th, Don Cathedra, Rubens, and De Woods, with two guides bearing supplies, penetrated the trackless wilderness of Mount Turner, - a tangling and difficult progress through primeval forests, to gain what the Don had imagined to be the grandest view of Ktaadn. While the rest of us were consoling ourselves for our loneliness, about dark, with a rice pudding composed of two raisins to one grain of rice, and a ravishing sauce, - a thoughtful study by La Rose. - up rose De Woods in our midst, pale as an apparition. He had preceded and lost his party, ascended a peak of Turner, and being without provisions, descended 


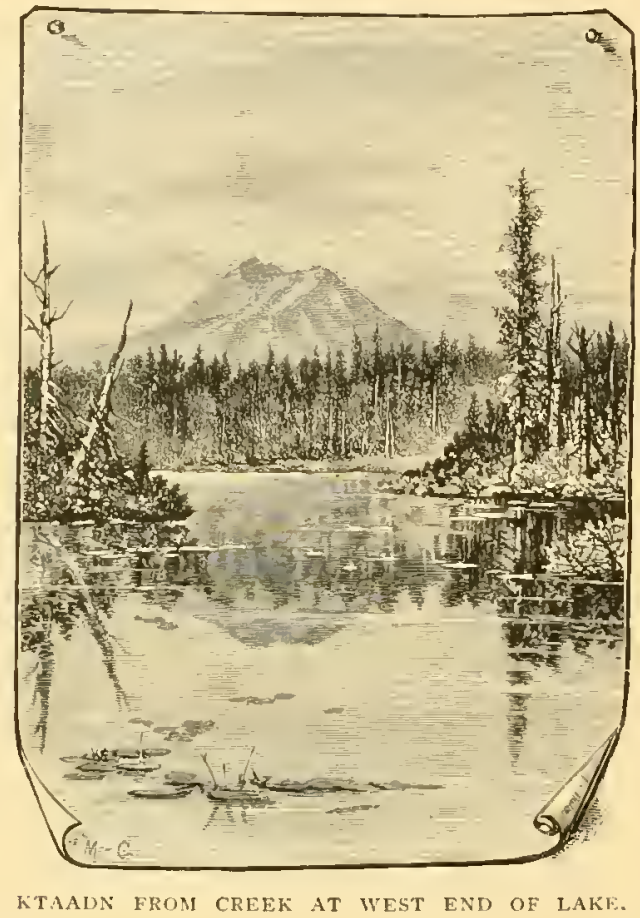

after four o'clock and waded a mile of lake to escape the entangling thicket of the margin.

The sunrise of the next day was like opening the book of Revelations. While everything was lying asleep in misty twilight, suddenly the lurking leaden clouds in the west blushed as the east flung them its salute across the sea, and wreathed themselves in rosy garlands upon the brow of the monarch. And then the monarch awoke, and rose up in the mirage, and bathed himself in the yellow light, till his crest was transmuted into gold, and his breast into leagues of pink coral, while every glory of the rainbow rolled down his gorgeous flanks as morning broke upon the plain.

The Mount Turner party returned next day, and told their stories over the evening camp-fire,-stories of hard struggles over wind-falls and through tangled underwood, of a few spoonfuls of water apiece on the mountain top, and of compensation for their troubles in the rare beauty of a primeval forest, - singular growths, dead trunks tumbled picturesquely together by the wind, great trees wreathing their roots around big bowlders cushioned all over with mosses, and little rivulets running out below, all variegated with the glistening white birch 


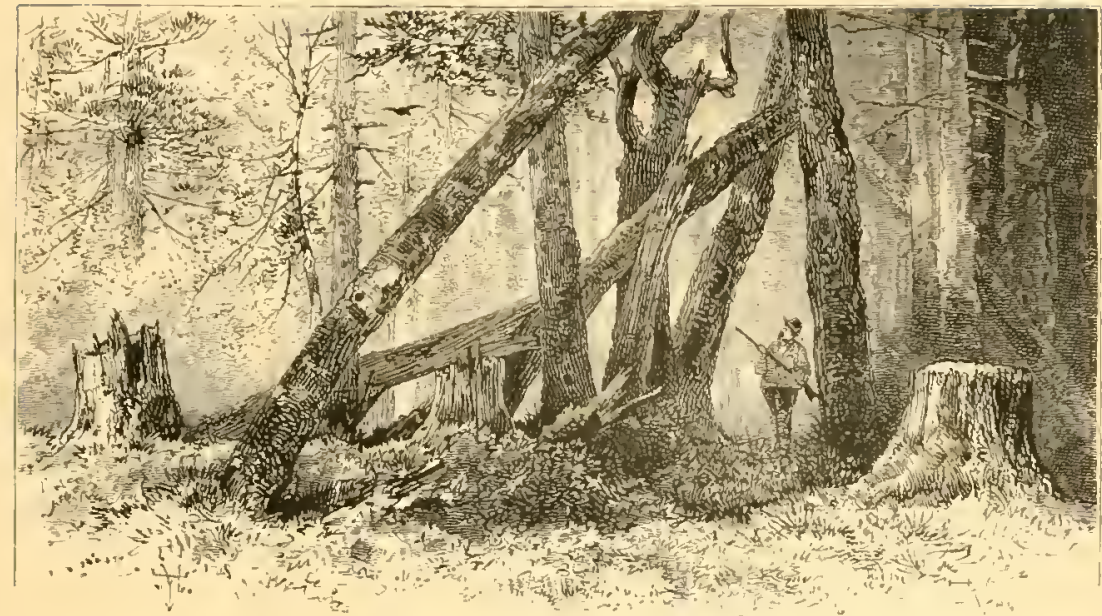

WOOD INTERIOR ON WOUNT TLKNER.

and the great bronzed and many-tinted leaves of the moose-wood. The Ion pronounced the view of Ktaadn "grand, but not pictorial." When rallied about getting lost, De IToods simply told the story of the Indian found wandering to and fro in the wilderness, against whom a similar charge was made. "Lost!" growled he: "Indian no lost, Indian here: wigwam lost."

On the morning of the I 6 th, Don Cathedra and 1, with two guides, started toward the Great Basin, lying in the mountain in rear of the pyramid. Two other guides had preceded us, with provisions for the whole party; they were to return the same lay, and to go up with the others in the morning. I started earlier, not expecting to be able to make the whole ten difficult miles in one day; but after various halts, we reached the Basin at 5 r. x. and pitched our camp. Being too tired to sleep, I lay for hours in this solemn amphitheater, watching the moon-lit clouds drift over its ragged summit, but not yet appreciating its vastness and its awful grandeur, for the night was singularly mild, and there was no sound but the soft sighing of the wind in the evergreens, as an occasional current circled around the Basin. I was yet to hear the sounds and see the sights of that great gulf.

The first half of our journey was throuch a comparatively level country, over the remains of an old humbering road. While there was much good walking, there were occasional swamps over which the footing of stumps and slippery logs was made still more precari- 
ous by a low growth of shrubs which quite concealed it. Getting over these places brought a stress upon the temper as well as upon muscle and nerve. The remainder of the way to the Basin was chiefly a line of spotted trees, which gradually led up the lower flanks of the mountain, but wound in detail over steep pitches and through tangled thickets. There were occasional "wind-falls," which were difficult to penetrate or to get around, and where the blazed line was easily lost; and there were rocky stream-beds to be climbed on all fours. A point two miles from the Basin reveals a magnificent view, both of the mountain and of Ktaadn Lake and its surrounding hills. Much of the forest has been harmed by neither fire nor axe, and is full of beautiful pictures.

The body of Ktaadn extends, in bulk, some ten miles to the north of the pyramid. Its east side is gouged out in two enormous chasms - the Great Basin and the North Basin, the depth of which does not appear to the beholder from Ktaadn Lake. The Great Basin is a horse-shoe shaped gorge, some three miles in longest diameter and above a mile deep. Its floor is a plateau, a thousand feet above the general plain, embracing a forest and a little lake. The less precipitous northern lobe is divided from the southern by a "horseback." The southern lobe of the Great Basin, not visible from Ktaadn Lake, is an amphitheater a mile in diameter. Its formation is not only magnificent, but surprising, in that it occupies the whole interior of the pyramid. The huge head of Ktaadn is hollow, but its hollowness only adds to its pictorial effect. It is the twofold wonder of our eastern scenery;- - our grandest mountain inclosing our grandest gorge,-and so associating in one harmonious whole the effects of Sierra peaks with those of Colorado cañons.

At the foot of our camp is the little Basin Lake, a thousand feet long and half that width,- cold, clear, and azoic as the granite cliffs that rise out of its shore. Around it lie drift bowlders of every age, and huge rocks, split from the mountain, like monolithic houses tumbled together by an earthquake. Over the smaller débris manycolored foliage creeps up into the rifts, and towering above and beyond is the ragged granite precipice half a mile in sheer altitude. On such a grand scale is everything here that distances are deceptive. What was apparently a mere belt of trees on the opposite shore is a forest more than half a mile deep, through which we followed up a picturesque stream-bed to the foot of the cliffs. 


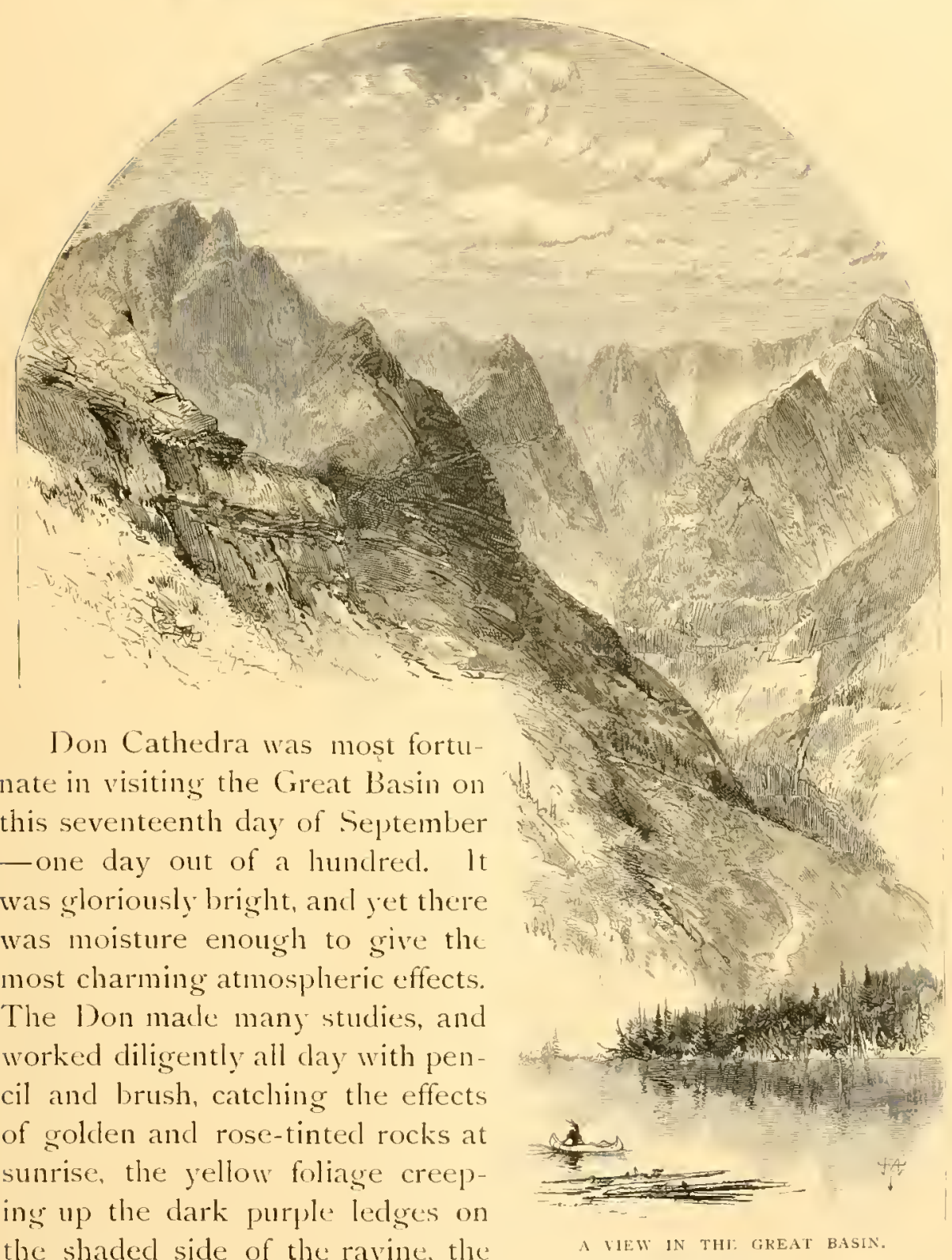

dim line in the atmosphere between the light and the shadow falling diagonally down the eastern cliff, the wild and ragged slides and stream-beds on the illuminated west slope the picturesque foreground of autumn-tinted hard-woods and dark cvergreens reflected in the lake- that wonderful association of grandeur in mass, with exquisite beauty in detail, sụch as one can rarely see among all our 
Appalachian mountains. In the midst of our musings, suddenly an avalanche came tearing down the precipice-enormous rocks bounding from ledge to ledge, bursting and scattering as they struck, throwing out white clouds like cannon smoke, and finally lost in the crashing forest below. The long time occupied in the descent gave evidence of the enormous height of the precipice.

But the afternoon brought a rapid change of scene. As the party from lake Kitaadn came straggling in, a storm - which can be so quickly brewed on a mountain-top-had no sooner thrown its shadow upon us than its substance followed in wind and rain, driving us into the little temporary tent while the guides were preparing a better one. During the intervals in the storm, our united exertions resulted, before dark, in a logged tent, well shielded and floored with boughs. We supped, and packed our supplies and ourselves into night-quarters during a drizzling rain, choked and blinded every few minutes by clouds of smoke, which the eddying wind flung in every direction, and secretly brooding, every one, over the probability that the equinoctial had caught us in that meteorological whirlpool, Ktaadn Basin.

At midnight, Pomola, the deity of this domain, who had so sweetly beguiled us into his den, gave us a taste of his wrath. Being at the tempestuous corner of the tent, I was roused from my dreams by a ripping and a snapping of things in general, and awoke to find the roof gone, the protecting boughs blown over, a torrent of rain pouring upon us, and the last embers of the camp-fire nearly extinguished. The guides' tent had quite disappeared in the gust. But before the general eye had perceived the situation, the ever-ready John had pulled back and fastened down our flapping roof, and given an impetus to the fire. Then there was a general re-adjustment in the tent; the edges of underlying rubber cloths were propped up so that water would not run in, and overlying wraps were ridged so that rain would run off. Always excepting that old campaigner, I) on Gifaro - he wasted no time by waking up and fooling around in the dark. I got hold of the tea, and slept with it the rest of the night under my water-proofs, and somebody else did the same with the sugar.

Ascending the mountain was the prescribed work of the next day, and we made an early start. It soon became so warm that we 


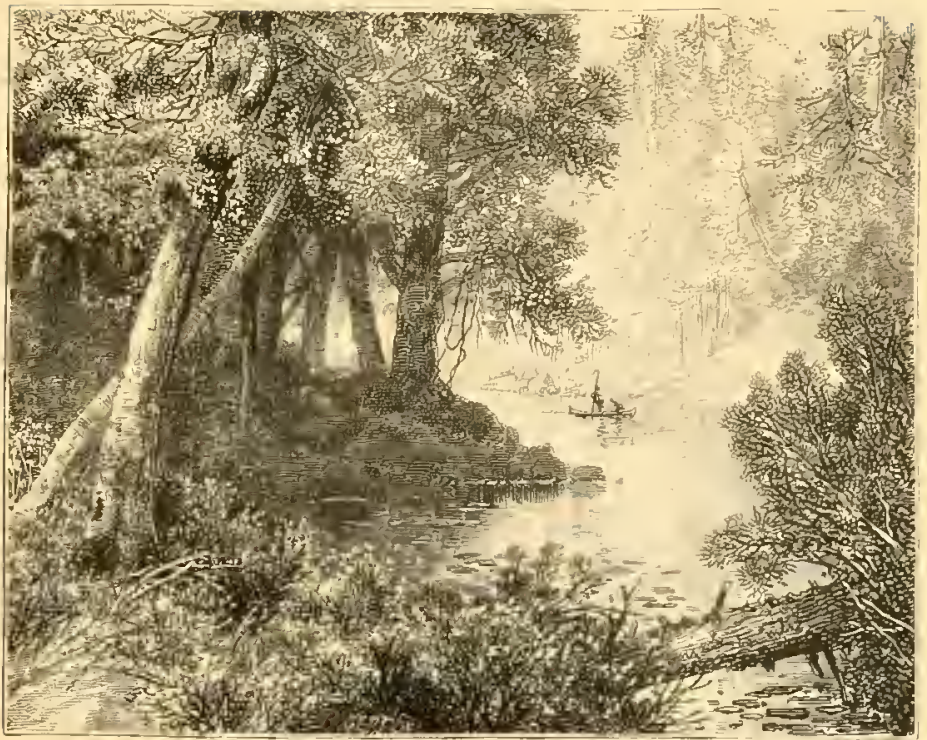

EAST BRANCH OF THE PENUBSCOT.

strapped our coats and waistcoats about our waists (the best way to carry weight, as John Gilpin knew), and scrambled up a dry streambed, over every form and size of rocky impediment, till we reached a "slicle," which 1 supposed might conform to the angle of repose; but the unscientific way in which Ktaadn rocks will arrange themselves, overhanging rather than receding, I leave succeeding tramps to account for. It was a hard and exhausting scale, but by no means a harmful one, when there were plenty of rests. IVe ascended a slide in the north lobe of the Great Basin, - the lowest part of the mountain, and yet so high that lichens were the largest growths,and there we found what is called the table-land, but which is, in fact, a gradual slope toward the west. Here Don Cathedra and his guide left us to explore the comparatively undiscovered North Basin, and we proceeded up a gradual but rugged incline, now through entangling shrubs, now over patches of huge rocks tumbled together, until we at last reached the summit of Ktaadn.

I have seen many stretches of splendid landscape from many mountain tops, but to my thinking the view from the top of Ktaadn is the most remarkable and the most beautiful I have ever seen. It was, on this peculiarly bright day, a panorama of exceeding splendor. The groundwork of the whole visible landscape is a vast wooded plain, broken in the rear of Ktaadn by a few bold and picturesque 
hills, bounded on the south-western horizon by the grand group of the White Mountains, and interspersed everywhere with innumerable shining lakes-Moosehead in the far distance, Chesuncook, a river expansion, Millinocket with its hundred islands; and on the other side, our own little Ktaadn l,ake, and Mount Turner and the Traveler looking so small from our towering height.

The night of the zoth was a memorable one. Don Gifaro, Rubens, and De Woods were to leave us next morning, and we sat up talking over our adventures, and promising ourselves many happy returns, till the unprecedentedly late hour of ten o'clock.

The remaining days of our camping, although we could not get used to the vacant seats, were full of pleasant incidents. La Rose kept our table loaded with splendid fish, and Don Cathedra and I sketched from morning till night, producing some of our finest studies. The I on manipulated the brush and the palette, to be sure, but as I held the umbrella and generally supervised the work. I feel justified in the foregoing use of the pronoun. The aspects of the mountain were now surprisingly various and beautiful. Our equinoctial storm was chiefly a wind storm. One day it drove the Great Basin all full of clouds, and they poured out of the apex like stean out of a volcano: and when they were luridly lighted by the setting sun, the scene was extremely wild and gorgeous.

And so, day after day, the mountain and the forest grew more beautiful. But the end must come; and on the 25 th, with great reluctance, we broke camp and started back to Sherman cn route for home.

Our supplies for 11 men ( 6 excursionists and 5 guides) 16 days, and 5 men 5 days, $=1$ man, 201 days, were:

\begin{tabular}{|c|c|c|}
\hline Mess pork & . I 15 & pound \\
\hline Hard bread & - 80 & ". \\
\hline Crackers. & i 6 & .* \\
\hline Sugar (granulated) & so & .. \\
\hline Wheat flour & 70 & .. \\
\hline Indian meal & . 25 & .. \\
\hline Beans . . . & . 65 & .. \\
\hline Potatoes. & .180 & .. \\
\hline Ham & 15 & .. \\
\hline Onions & & . \\
\hline
\end{tabular}

Total

\begin{tabular}{|c|c|c|}
\hline Rice . & 5 & pounds. \\
\hline Butter & . & " \\
\hline Raisins & 5 & . \\
\hline Bread powders & 3 & . \\
\hline Tea. . & 9 & .• \\
\hline Canned meat & 7 & .. \\
\hline Lemons . & 8 & .. \\
\hline Sundry preserves, etc & . 5 & $\therefore$ \\
\hline Fish, mostly tròt (estimated & .100 & .. \\
\hline Game & & .* \\
\hline
\end{tabular}

313 pounds. 
This gives, say, four pounds of raw food per day per man. There was, of course, a large percentage of waste in its preparation and in its transportation from camp to camp. The cost of this raw food (excluding, of course, fish, same, and transportation) was sixty-five dollars, or thirty-two and one-third cents per man per day. Our bill of fare has included the obvious simple and the following compound dishes:

Crackers, dampened and fried in pork fat, with onions (bisyuc à la Ile $\left.\mathrm{r}^{-}\right)$: fried cakes, of various mixtures of wheat and corn meal; Indian plum-pudding (cauchcmar); rice-pudding. with raisins: raisin-pudding, with rice ( $c x^{2}$-cathedra); baked pork and beans; canned meats warmed up with potatoes and cracker crumbs; eel-pie; partridge-soup and stew; duck-stew, and sauces of sugar, butter, and rum. As the guides were so constantly employed in arranging new camps and transporting supplies, they had no time to seek large game, although we saw both moose and caribou.

The necessary camp utensils (some of which most guides have on hand) for our number and our style of living are: An iron pot with overlapping cover, a tin tea-pot, two frying-pans, four tin pails, two of them having covers and removable wire legs (parboiling ressels), the whole to pack in a nest; a nest of four deep tin dishes or pans, the largest fifteen inches and the smallest ten inches in diameter, to be used as mixing vessels and platters; a tin baker, say $16 \times 12 x ;$ inches; a dozen of each of the following: tin pint cups, tin dinner plates, and cheap tea-spoons, knives and forks; three larger cooking spoons of different sizes, two butcherknives, two tin wash-basins, a salt-box, a pepper-box, and a wire gridiron. We did not have a camp-stove, which would have been a great convenience. The half of a stout barrel is good to keep pork in, and will also hold fish, game, etc., in separate birch-bark vessels. A birch-bark lined hole in the earth is a good store-room for meat. There should be plenty of dish-cloths and towels, and five pounds of bar soap. A can of kerosene and a student-lamp may be readily taken; a dozen candles are convenient, although the camp-fire furnishes the necessary illumination. No work nor amusement requiring a good light is attempted after dark. The matches should be distributed among the party, and each person should carry a few in a corked metal case. Some nails and tacks of assorted sizes prove 


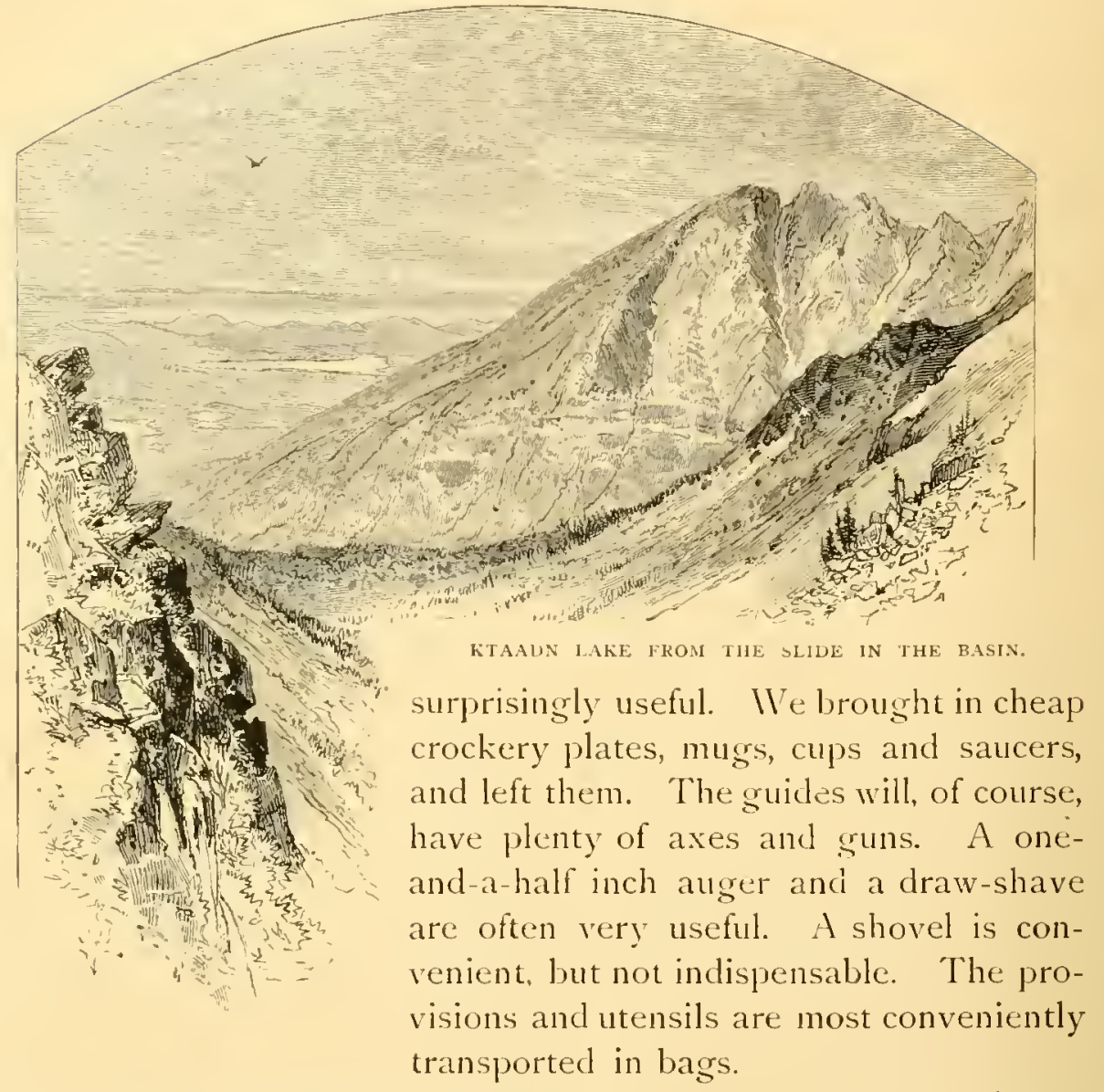

It is a great mistake to take other than stout clothing. Adaptation of clothing to the great variations of temperature may be readily made by "doubling up." The rubber cloth should be permanently lined with the half of one blanket to lie on, the other half of the blanket and the sides of the rubber cloth forming a cover. The foot of this bed should be made, by means of straps and buckles, into a bag, so that the occupant may roll about, bed and all, without pulling the clothes off or getting them wet when it rains. This bag of bedding, rolled into a bundle. forms its own water-proof case. The clothing is transported in a rubber bagr, made like a mail-bag, and having an inside flap. To this outfit each person will add the implements of his specialty. A few quires of heary paper, hoth for wrapping and for preserving leaves, are of use to all. Pencils, pocket-knives, and such indispen- 
sables, should be taken in duplicate. Climbing mountains and tumbling through thickets is pocket-picking business. The party should have a good field-glass, an aneroid barometer for measuring heights, and a pocket-compass.

The cost of the expedition (sixteen days in the woods) to each excursionist was $\$ \$ \$ S O .83$.

The railway transportation was 47 per cent. of the whole expense. The distance from New York to Ktaadn by our route is exactly 600 miles.

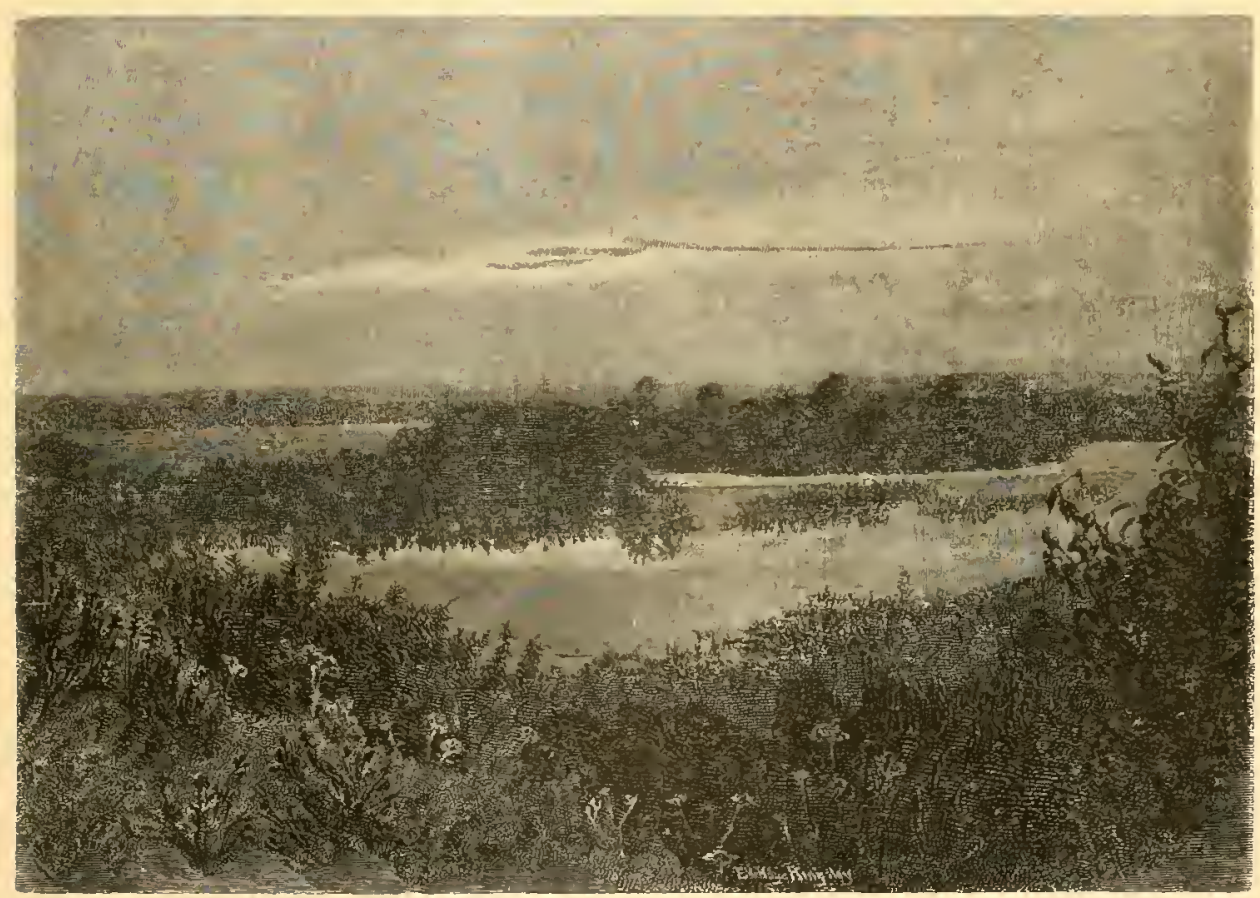




\section{HON I KILLED A BEAR.}

BY CHARLES DUDLEY WARNER,

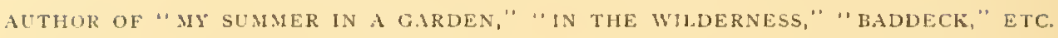

S O many conflicting accounts have appeared about my casual encounter with an \dirondack bear last summer, that in justice to the public, to myself, and to the bear, it is necessary to make a plain statement of the facts. Besides, it is so seldom 1 have occa sion to kill a bear that the celebration of the exploit may be excused.

The encounter was unpremeditated on both sides. I was not hunting for a bear, and I have no reason to suppose that a bear was looking for me. The fact is that we were both out blackberrying, and met by chance, - the usual way. There is among the Adirondack visitors always a great deal of conversation about bears, - a general expression of the wish to see one in the woods, and much speculation as to how a person would act if he or sine chanced to meet one. But bears are scarce and timid and appear only to a favored few.

It was a warm day in August, just the sort of day when an adventure of any kind seemed impossible. But it occurred to the housekeepers at our cottage - there were four of them - to send me to the clearing, on the mountain back of the house, to pick blackberries. It was rather a series of small clearings, running up into the forest, much overgrown with bushes and briers, and not unromantic. Cows pastured there, penetrating through the leafy passages from one opening to another, and browsing among the bushes. I was kindly furnished with a six-quart pail, and told not to be gone long.

Not from any predatory instinct, but to save appearances, I took a gun. It adds to the manly aspect of a person with a tin pail if he also carries a gun. It was possible 1 might start up a partridge; though how I was to hit him, if he started up instead of standing 
still, puzzled me. Nany people use a shot-gun for partridges. I prefer the rifle: it makes a clean job of death, and does not prematurely stuff the bird with globules of lead. The rifle was a Sharp's, carrying a ball-cartridge (ten to the pound), an excellent weapon belonging to a friend of mine, who had intended, for a good many years back, to kill a deer with it. He could hit a tree with it - if the wind did not blow, and the atmosphere was just right, and the tree was not too far off-nearly every time. Of course, the tree must have some size. Needless to say that 1 was at that time no sportsman. Years ago, I killed a robin under the most humiliating circumstances. The bird was in a low cherry-tree. I loaded a big shot-gun pretty full, crept up uncler the tree, rested the gun on the fence, with the muzzle more than ten feet from the bird, shut both eyes, and pulled the trigger. When I got up to see what had happened, the robin was scattered about under the tree in more than a thousand pieces, no one of which was big enough to enable a naturalist to decide from it to what species it belonged. This disgusted me with the life of a sportsman. I mention the inciclent to show that, although I went blackberrying armed, there was not much inequality between me and the bear.

In this blackberry-patch bears had been seen. The summer before, our colored cook, accompanied by a little girl of the vicinage, was picking berries there one day, when a bear came out of the woods and walked toward then. The girl took to her heels and escaped. Aunt Chloe was paralyzed with terror. Instead of attempting to run, she sat down on the ground where she was standing, and began to weep and scream, giving herself up for lost. The bear was bewildered by this conduct. He approached and looked at her; he walked around and surveyed her. Probably he had never seen a colored person before, and did not know whether she would agree with him; at any rate, after watching her a few moments, he turned about and went in to the forest. This is an authentic instance of the delicate consideration of a bear, and is much more remarkable than the forbearance toward the African slave of the well-known lion, because the bear had no thorn in his foot.

When I had climbed the hill, I set up my rifle against a tree, and began picking berries, lured on from bush to bush by the black gleam of fruit (that always promises more in the distance than it 
realizes when you reach it), penetrating farther and farther, through leaf-shaded cow-paths flecked with sunlight, into clearing after clearing. 1 could hear on all sides the tinkle of bells, the cracking of sticks, and the stamping of cattle that were taking refuge in the thicket from the flies. Occasionally, as I broke through a covert. I encountered a meek cow, who stared at me stupidly for a second and then shambled off into the brush. I became accustomed to this dumb society, and picked on in silence, attributing all the wood-noises to the cattle, thinking nothing of any real bear. In point of fact, however, I was thinking all the time of a nice romantic bear, and, as I picked, was composing a story about a generous she-bear who had lost her cub, and who seized a small girl in this very wood, carried her tenderly off to a cave, and brought her up on bear's milk and honey. When the girl got big enough to run away, moved by her inherited instincts, she escaped, and came into the valley to her father's house (this part of the story was to be worked out, so that the child would know her father by some family resemblance, and have some language in which to address him), and told him where the bear lived. The father took his gun, and, guided by the unfeeling daughter, went into the woods and shot the bear, who never made any resistance, and only, when dying, turned reproachful eyes upon her murderer. The moral of the tale was to be kindness to animals.

I was in the midst of this tale, when I happened to look some rods away to the other edge of the clearing, and there was a bear! He was standing on his hind-legs, and doing just what I was doing, - picking blackberries. With one paw he bent down the bush, while with the other he clawed the berries into his mouth,- -green ones and all. To say that I was astonished is inside the mark. I suddenly discovered that I didn't want to see a bear, after all. At about the same moment, the bear saw me, stopped eating berries, and regarded me with a glad surprise. It is all very well to imagine what you would do under such circumstances. Probably you would'nt do it: I didn't. The bear dropped down on his forefeet and came slowly toward me. Climbing a tree was of no use, with so good a climber in the rear. If I started to run, I had no doubt the bear would give chase; and although a bear cannot run down-hill as fast as he can run up-hill, yet I felt that he could get over this rough, brush-tangled ground faster than I could. 
The bear was approaching. It suddenly occurred to me how 1 could divert his mind until l could fall back upon my military base. My pail was nearly full of excellent berries, - much better than the bear could pick himself. I put the pail on the ground, and slowly backed away from it, keeping my eye, as beast-tamers do, on the bear. The ruse succeeded.

The bear came up to the berries and stopped. Not accustomed to eat out of a pail, he tipped it over, and nosed about in the fruit, "gorming" (if there is such a word) it down, mixed with leaves and dirt, like a pig. The bear is a worse feeder than the piy. Whenever he disturbs a maple-sugar camp in the spring, he always upsets the buckets of syrup, and tramples around in the sticky sweets, wasting more than he eats. The bear's manners are thoroughly disagreeable.

As soon as my enemy's head was down, 'I started and ran. Somewhat out of breath, and shaky, I reached my faithful rifle. It was not a moment too soon. I heard the bear crashing through the brush after me. Enraged at my duplicity, he was now coming on with blood in his eye. I felt that the time of one of us was probably short. The rapidity of thought at such moments of peril is well known. I thought an octavo volume, had it illustrated and published, sold fifty thousand copies, and went to Europe on the proceeds, while that bear was loping across the clearing. As I was cocking the gun, I made a hasty and unsatisfactory review of my whole life. I noted that even in such a compulsory review, it is almost impossible to think of any good thing you have done. The sins come out uncommonly strong. I recollected a newspaper subscription 1 had delayed paying years and years ago, until both editor and newspaper were dead, and which now never could be paid to all eternity.

The bear was coming on.

I tried to remember what I had read about encounters with bears. I couldn't recall an instance in which a man had run away from a bear in the woods and escaped, although I recalled plenty where the bear had run from the man and got off. 1 tried to think what is the best way to kill a bear with a gun, when you are not near enough to club him with the stock. Ny first thought was to fire at his head; to plant the ball between his eyes; but this is a dangerous experiment. The bear's brain is very small; and, unless you hit that, the bear does not mind a bullet in his head; that is, not 
at the time. I remembered that the instant death of the bear would follow a bullet planted just back of his fore-leg and sent into his heart. This spot is also difficult to reach, unless the bear stands off, side toward you, like a target. I finally determined to fire at him generally.

The bear was coming on.

The contest seemed to me very different from anything at Creedmoor. I had carefully read the reports of the shooting there; but it was not easy to apply the experience I had thus acquired. I hesitated whether I had better fire lying on my stomach or.lying on my back and resting the gun on my toes. But in neither position, I reflected, could I see the bear until he was upon me. The range was too short, and the bear wouldn't wait for me to examine the thermometer, and note the direction of the wind. Trial of the Creedmoor method, therefore, had to be abandoned, and I bitterly regretted that 1 had not read more accounts of off-hand shooting.

For the bear was coming on.

I tried to fix my last thoughts upon my family. As my family is small this was not difficult. Dread of displeasing my wife or hurting her feelings was uppermost in my mind. What would be her anxiety as hour after hour passed on, and 1 did not return? What would the rest of the househoid think, as the afternoon passed and no blackberries came? What would be my wife's mortification when the news was brought that her husband, had been eaten by a bear? I cannot imayine anything more ignominious than to have a husband eaten by a bear. And this was not my only anxiety. The mind at such times is not under control. With the gravest fears the most whimsical ideas will occur. I looked beyond the mourning friends, and thought what kind of an epitaph they would be compelled to put upon the stone. Something like this:

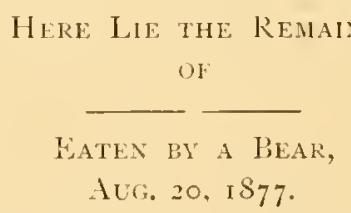

It is a very unheroic and even disagreeable epitaph. That "eaten by a bear" is intolerable. It is grotesque. And then I thought what an inadequate language the English is for compact expression. It would not answer to put upon the stone simply "eaten"; for that is indefinite, and requires explanation; it might 
mean eaten by a cannibal. This difficulty could not occur in the German, where cssen signifies the act of feeding by a man, and fressen by a beast. How simple the thing would be in German:

HIER IJIEGT

HUCHWOHLGEBURLN

HERK — -

Gefressen,

IUG. 20,1877 .

That explains itself. The well-born one was eaten by a beast, and presumably by a bear. - an animal that has a bad reputation since the days of Elisha.

The bear was coming on; he had, in fact, come on. I judged that he could see the whites of my eyes. All my subsequent reflections were confused. I raised the gun, covered the bear's breast with the sight, and let drive. Then I turned, and ran like a deer. I did not hear the bear pursuing. I looked back. The bear had stopjed. He was lying down. I then remembered that the best thing to do after having fired your gun is to reload it. I slipped in a charge, keeping my eyes on the bear. He never stirred. I walked back suspiciously: There was a quiver in the hind legs, but no other motion. Still, he might be shamming; bears often sham. To make sure, I approached and put a ball into his head. He dicln't mind it now; he minded nothing. Death had come to him with a merciful suddenness. He was calm in death. In order that he might remain so. I blew his brains out, and then started for home. I had killed a bear!

Notwithstanding my excitement, \& managed to saunter into the house with an unconcerned air. There was a chorus of voices:

"Where are your blackberries?"

"Why were you gone so long?"

"Where's your pail?"

"I left the pail."

"Left the pail! What for?"

"A bear wanted it."

"Oh, nonsense!"

"Well, the last I saw of it a bear had it."

"Oh, come! you really didn't see a bear?"

"Yes, but I did really see a real bear."

"Did he run?"

"Yes; he ran after me." 
" 1 don't believe a word of it. What did you do?"

"Oh, nothing particular - except kill the bear."

Cries of "Gammon!" "Don't believe it !"

"Where's the bear?"

"If you want to see the bear you must go up into the woods. I couldn't bring him down alone."

Having satisfied the household that something extraordinary had occurred, and excited the posthumous fear of some of them for my own safety, I went down into the valley to get help. The great bearhunter, who keeps one of the summer boarding-houses, received my story with a smile of incredulity; and the incredulity spread to the other inhabitants and to the boarders as soon as the story was known. However, as I insisted in all soberness, and offered to lead them to the bear, a party of forty or fifty people at last started off with me to bring the bear in. Nobody believed there was any bear in the case; but everybody who could get a gun carried one; and we went into the woods armed with guns, pistols, pitchforks, and sticks, against all contingencies or surprises, - a crowd made up mostly of scoffers and jeerers.

But when I led the way to the fatal spot, and pointed out the bear lying peacefully wrapped in his own skin, something like terror seized the boarders and genuine excitement the natives. It was a no-mistake bear, by George! and the hero of the fightwell. I will not insist upon that. But what a procession that was, carrying the bear home! and what a congregation was speedily gathered in the valley to see the bear! Our best preacher up there never drew anything like it on Sunday.

And 1 must say that my particular friends, who were sportsmen, behaved very well, on the whole. They didn't deny that it was a bear, although they said it was small for a bear. Mr. Deane, who is equally good with a rifle and a rod, admitted that it was a very fair shot. He is probably the best salmon-fisher in the United States, and he is an equally good hunter. I suppose there is no person in America who is more desirous to kill a moose than he.

But he needlessly remarked, after he had examined the wound in the bear, that he had seen that kind of a shot made by a cow's horn.

This sort of talk affected me not. When I went to sleep that night my last delicious thought was: "I've killed a bear." 


\title{
A FIGHT WITH A TROUT.
}

\author{
Bi CHARLES I U I) L F WARNER,
}

ALTHUR OF "MY SUMMER IN A GARLEA," "IN THE WHDERNESS," " BADDECK, ' FTC.

T

ROUT-FISHING in the Adirondacks would be a more attractive pastime than it is, but for the popular notion of its danger. The trout is a retiring and harmless animal, except when he is aroused and forced into a combat; and then his agility, fierceness, and vindictiveness become apparent. No one who has studied the excellent pictures representing men in an open boat, exposed to the assaults of long, enraged trout fying at them through the open air with open mouth, ever ventures with his rod upon the lonely lakes of the forest without a certain terror, or ever reads of the exploits of daring fishermen without a feeling of admiration for their heroism. Most of their adventures are thrilling, and all of them are, in narration, more or less unjust to the trout; in fact, the object of them seems to be to exhibit, at the expense of the trout, the shrewdness, the skill, and the muscular power of the sportsman. Ny own simple story has few of these recommendations.

We had built our bark camp one summer, and were staying on one of the popular lakes of the Saranac region. It would be a very pretty region, if it were not so flat, if the margins of the lakes had not been flooded by dams at the outlets, - which have killed the trees, and left a rim of ghastly dead-wood, like the swamps of the under-world pictured by Dorés bizarre pencil, - and if the pianos at the hotels were in tune. It would be an excellent sporting region also (for there is water enough), if the fish commissioners would stock the waters, and if previous hunters had 
not pulled all the hair and skin off from the deers' tails. Formerly, sportsmen had a habit of catching the deer by the tails, and of being dragged in mere wantonness round and round the shores. It is well known that if you seize a deer by this "holt," the skin will slip off like the peel from a banana. This reprehensible practice was carried so far that the traveler is now hourly pained by the sight of peeled-tailed deer mournfully sneaking about the wood.

IVe had been hearing for weeks of a small lake in the heart of the virgin forest, some ten miles from our camp, which was alive with trout, unsophisticated, hungry trout; the inlet to it was described as stiff with them. In my imagination, I saw them lying there in ranks and rows, each a foot long, three tiers deep, a solid mass. The lake had never been visited, except by stray sable-hunters in the winter, and was known as the Lnknown Pond. I determined to explore it, fully expecting, however, that it would prove to be a delusion, as such mysterious haunts of the trout usually are. Confiding my purpose to Luke, we secretly made our preparations, and stole away from the shanty one morning at day-break. Each of us carried a boat, a pair of blankets, a sack of bread, pork, and maple sugar; while 1 had my case of rods, creel, and book of flies, and Luke had an axe and the kitchen utensils. We think nothing of loads of this sort in the woods.

Five miles through a tamarack swamp brought us to the inlet of Unknown Pond, upon which we embarked our fleet, and paddled down its vagrant waters. They were at first sluggish, winding among triste fir-trees, but gradually developed a strong current. At the end of three miles, a loud roar ahead warned us that we were approaching rapids, falls, and cascades. We paused. The danger was unknown. TVe had our choice of shouldering our loads and making a ditour through the woods, or of "shooting the rapids." Naturally, we chose the more dangerous course. Shooting the rapids has often been described, and I will not repeat the description here. It is needless to say that I drove my frail bark through the boiling rapids, over the successive water-falls, amid rocks and vicious eddies, and landed half a mile below, with whitened hair and a boat half full of water; and that the guide was upset, and boat, contents, and man were strewn along the shore.

After this common experience we went quickly on our journey. 
and, a couple of hours before sundown, reached the lake. If I live to my dying day I never shall forget its appearance. The lake is almost an exact circle, about a quarter of a mile in diameter. The forest about it was untouched by axe and unkilled by artificial fooding. The azure water had a perfect setting of evergreens, in which all the shades of the fir, the balsam, the pine, and the spruce were perfectly blended; and at intervals, on the shore in the emerald rim, blazed the ruby of the cardinal-flower. It was at once evident that the unruffled waters had never been vexed by the keel of a boat. But what chiefly attracted my attention and amused me was the boiling of the water, bubbling and breaking, as if the lake were a vast kettle, with a fire underneath. A tyro would have been astonished at this common phenomenon; but sportsmen will at once understand me when I say that the water boiled with the breaking trout. I studied the surface for some time to see upon what sort of flies they were feeding, in order to suit iny cast to their appetites; but they seemed to be at play rather than feeding, leaping high in the air in graceful curves, and tumbling about each other as we see them in the Adirondack pictures.

It is well known that no person who regards his reputation will ever kill a trout with anything but a fly. It requires some training on the part of the trout to take to this method. The uncultivated, unsophiscated trout in unfrequented waters prefers the bait; and the rural people, whose sole object in going a-fishing appears to be to catch fish, indulge them in their primitive taste for the worm. No sportsman, however, will use anything but a fly, except he happens to be alone.

While Luke launched my boat, and arranged his seat in the stern. I prepared my rod and line. The rod is a bamboo, weighing seven ounces, which has to be spliced with a winding of silk thread every time it is used. This is a tedious process; but by fastening the joints in this way, a uniform spring is secured in the rod. No one devoted to high art would think of using a socket-joint. My line was forty yards of untwisted silk upon a multiplying reel. The "leader" (I am very particular about my leaders) had been made to order from a domestic animal with which I had been acquainted. The fisherman requires as grood a catgut as the violinist. The interior of the house-cat, it is well known, is exceedingly sensitive; but it may not be so well known that the reason why some cats leave 
the room in distress when a piano-forte is played is because the two instruments are not in the same key, and the vilmations of the chords of the one are in discord with the catgut of the other. On six feet of this superior article 1 fixed three artificial flies,---a simple brown hackle, a gray body, with scarlet wings, and one of my own invention, which 1 thought would be new to the most experienced flycatcher. The trout-fly does not resemble any known species of insect. It is a "conventionalized" creation, as we say of ornamentation. The theory is that, fly-fishing being a high art, the fly must not be a tame imitation of nature, but an artistic suggestion of it. It requires an artist to construct one, and not every bungler can take a bit of red flannel, a peacock's feather, a flash of tinsel thread, a cock's plume, a section of a hen's wing, and fabricate a tiny object that will not look like any fly, but still will suggest the universal conventional fly.

I took my stand in the center of the tipsy boat; and Luke shoved off, and slowly paddled toward some lily-pads, while I began casting, unlimbering my tools, as it were. The fish had all disappeared. I got out, perhaps, fifty feet of line, with no response, and gradually: increased it to one hundred. It is not difficult to learn to cast; but it is difficult to learn not to snap off the flies at every throw. Of this, however, we will not speak. I continued casting for some moments, until I became satisfied that there had been a miscalculation. Either the trout were too green to know what I was at, or they were dissatisfied with my offers. I reeled in and changed the flies (that is, the fly that was not snapped off). After studying the color of the sky, of the water, and of the foliage, and the moderated light of the afternoon, I put on a series of beguilers, all of a subdued brilliancy, in harmony with the approach of evening. At the second cast, which was a short one, I saw a splash where the leader fell, and gave an excited jerk. The next instant I perceived the game, and did not need the unfeigned "dam" of Luke to convince me that I had snatched his felt hat from his head and deposited it among the lilies. Discouraged by this, we whirled about, and paddled over to the inlet, where a little ripple was visible in the tinted light. At the very first cast 1 saw that the hour had come. Three trout leaped into the air. The danger of this maneuver all fishermen understand. It is one of the commonest in the woods; three heavy trout taking hold at once, rushing in different directions, smash the tackle into 
flinders. I evaded this catch and threw again. I recall the moment. A hermit-thrush, on the tip of a balsam, uttered his long, liquid, evening note. Happening to look over my shoulder, I saw the peak of Narcy gleam rosy in the sky ( 1 can't help it that Marcy is fifty miles off, and cannot be seen from this region: these incidental touches are always used). The hundred feet of silk swished threugh the air, and the tail-fly fell as lightly on the water as a three-cent piece (which no slamming will give the weight of a ten) drops upcn the contribution-plate. Instantly there was a rush, a swirl. I struck, and "Got him, by-_!" never mind what Luke said I got him by. "Out on a fly," continued that irrevent gruide; but I told him to back water and make for the center of the lake. The trout, as soon as he felt the prick of the hook, was off like a shot, and took out the whole of the line with a rapidity that made it smoke. "Give him the butt!" shouted Luke. It is the usual remark in such an emergency. I gave him the butt : and recognizing the fact and my spirit, the trout at once sank to the bottom and sulked. It is the most dangerous mood of a trout: for you cannot tell what he will do next. We reeled up a little, and waited five minutes for him to reflect. A tightening of the line enraged him, and he soon developed his tactics. Coming to the surface, he made straight for the boat faster than I could reel in. and evidently with hostile intentions. "Look out for him !" cried Luke, as he came flying in the air. I evaded him by dropping flat in the bottom of the boat; and when I picked my traps up, he was spinning across the lake as if he had a new idea; but the line was still fast. He did not run far. I gave him the butt again; a thing he seemed to hate, even as a gift. In a moment the evil-minded fish, lashing the water in his rage, was coming back again, making straight for the boat as before. Luke. who was used to these encounters, having read of them in the writings of travelers he had accompanied, raised his paddle in selfdefense. The trout left the water about ten feet from the boat, and came directly at me with fiery eyes, his speckled sides flashing like a meteor. I dodgred as he whisked by with a vicious slap of his bifurcated tail, and nearly upset the boat. The line was of course slack; and the danger was that he would entangle it about me and carry away a leg. This was evidently his game, but I entangled it. and only lost a breast-button or two by the swiftly-moving string. The 
trout plunged into the water with a hissing sound, and went away again with all the line on the reel. Nore butt; more indignation on the part of the captive. The contest had now been going on for half an hour, and I was getting exhausted. We had been back and forth across the lake and round and round the lake. What I feared was that the trout would start up the inlet and wreck us in the bushes. But he had a new fancy, and began the execution of a maneuver which I had never read of. Instead of coming straight toward me, he took a large circle, swimming rapidly, and gradually contracting his orbit. I reeled in, and kept my eye on him. Round and round he went, narrowing his circle. I began to suspect the game; which was to twist my head off. When he had reduced the radius of his circle to about twenty-five feet, he struck a tremendous pace through the water. It would be false modesty in a sportsman to say that I was not equal to the occasion. Instead of turning round with him, as he expected. I stepped to the bow, braced myself, and let the boat swing. Round went the fish, and round we went like a top. I saw a line of Mount Marcys all round the horizon; the rosy tint in the west made a broad band of pink along the sky above the treetops; the evening-star was a perfect circle of light, a hoop of gold in the heavens. We whirled and reeled, and reeled and whirled. I was willing to give the malicious beast butt and line and all, if he would only go the other way for a change.

When I came to myself Luke was gaffing the trout at the boatside. After we had got him in and dressed him he weighed threequarters of a pound. Fish always lose by being "got in and dressed." It is best to weigh them while they are in the water. The only really large one I ever caught got away with my leader when I first struck him. He weighed ten pounds.

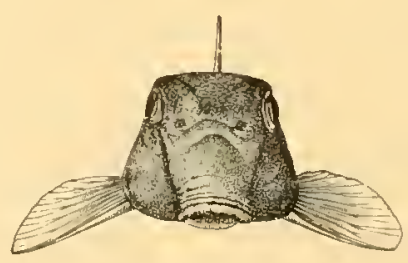




\title{
HOW TO MOLNT A BIRD.
}

BrFREISRIC A. LUC'AS,

FX-PRESIDENT OF THE SUCIETY WF AMERICAN TAXIDEKMISTS.

\begin{abstract}
CHOULI) you become the prey of a desire to mount some pretty songster, quaint owl, or swift-winged game bird that has fallen W a victim to your skill, it is hoped that a careful perusal of this chapter will enable you to do so. First, however, experiment with a bird or two that you do not particularly care for before essaying your skill on one that you prize. In selecting a bird for your first trial, choose one of moderate size and comparatively tough skin. The robin, cow bunting, crow blackbird, and bob white are all pretty good subjects, while woodpeckers, cuckoos, and very large or very small birds are to be shunned until you have acquired some little experience. When you have acquired skill by practice, you will find among young birds and mammals some of the prettiest and quaintest subjects for your art. When setting out with the intention or expectation of securing birds for mounting, take with you a newspaper or two, a little cotton batting, and a pair of forceps. As soon as a bird is shot, plug the vent, nostrils, and mouth with cotton; also, treat any large shot-holes in the same manner, and transfer the bird, head downward, to a paper cornucopia of such length that you may twist together the open end without damaging the tail. If there is blood on the plumage, do not attempt to remove it until reaching home. The best thing in which to carry birds is a fish-basket, as in that they are not bent out of shape. Do not skin the bird as soon as it is shot, but wait a little


while, until the blood has coagulated. Before commencing operations, study the bird carefully; note where the wings lie when folded, mark how far forward and how low down are the knees, and, above all, notice the length of the bird. A very good plan is to gently stretch a bird to its utmost, and to make a mark at the tip of its bill and at the end of its tail, for future reference. Anything over this is, of course, wrong, and there are but few positions wherein this limit would be

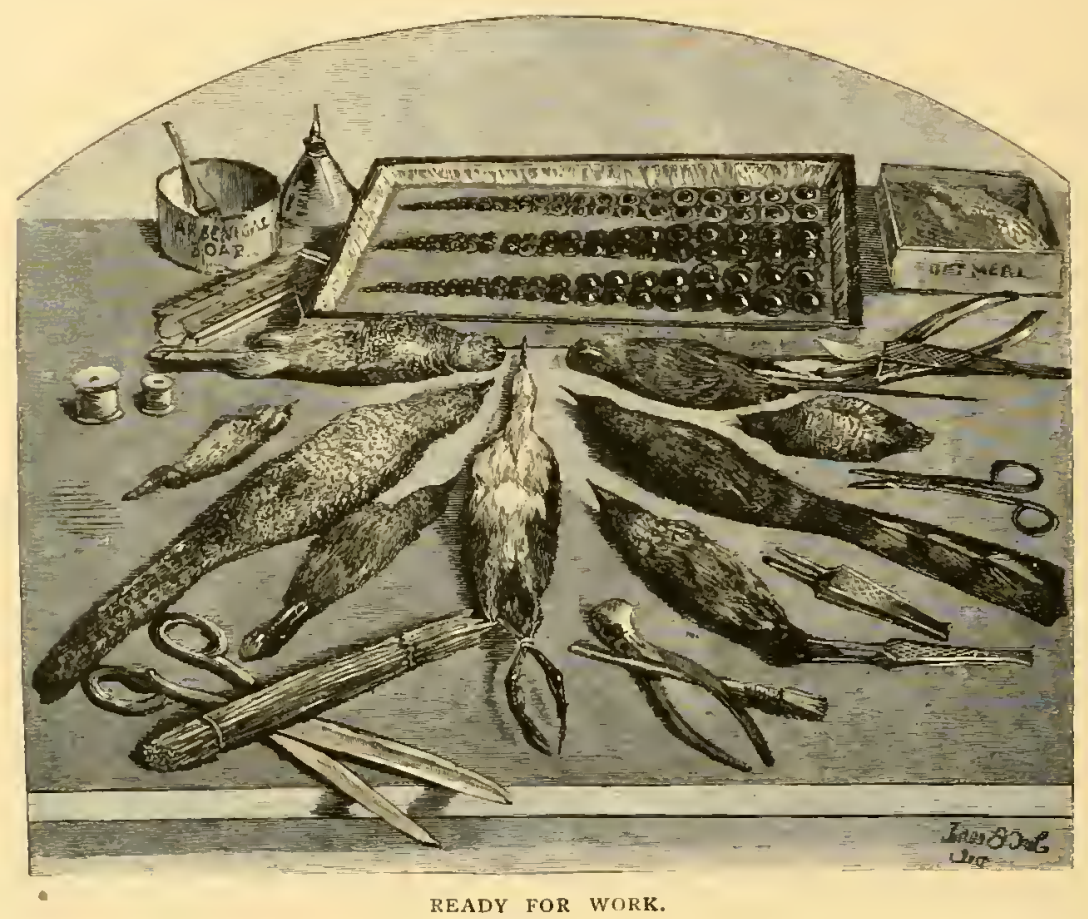

reached. For skinning purposes, you need a scalpel or other small knife, a pair of sharp-pointed scissors, a knitting-needle, and a pair of small spring forceps; also, a dish of plaster-of-paris,-white corn meal may be used instead, - and either powdered arsenic or arsenical soap.* Cotton batting, of course, is included among the necessities.

* Which of these two may be the better is open to discussion, but I prefer to use the soap. Powdered arsenic, mixed with half its weight of powdered alum, is easily obtained, and rloes not soil the feathers if it comes in contact with them. On the contrary, it is not so penetrating as the soap, does not stick to the skin when it is at all dry. and at times dries the skin too rapidly. Arsenical soap is penetrating, keeps the skin moist, and acts as a lubricant when you are inserting the neck or turning the legs. Its one disadvantage is that you must use it carefully in order not to soil the feathers. 


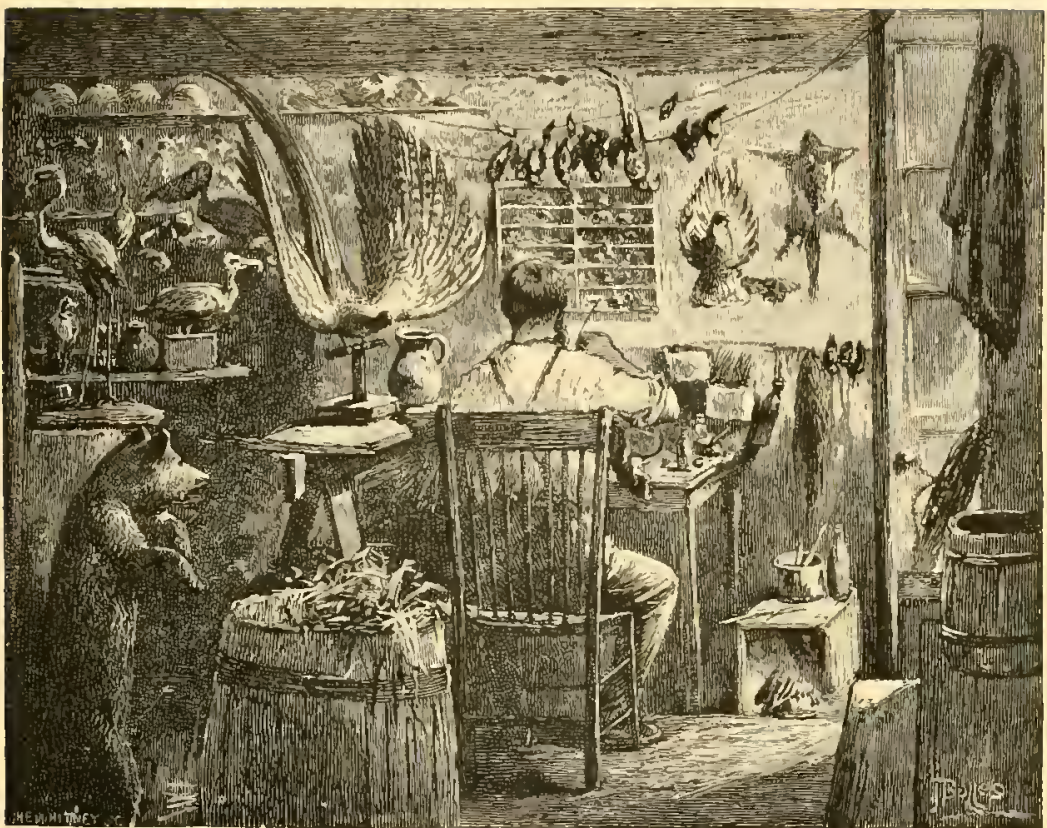

A TAXIDERMIST'S SANCTUM.

First cleanse off any blood stains by washing carefully with tepid water and drying with plaster of paris.* Be careful that you allow no plaster to "set" on the feathers, but keep them constantly moving, changing the plaster now and then, until quite dry. Renew the plugrs of cotton in the vent, mouth, and nostrils, placing a little plaster in the throat before introducing the cotton, and also putting a pinch on each eye. Now lay the bird on its back, part the feathers on the under side down the center, and make a cut from near the upper end of the breast-bone to the vent, ending in it. Take care in doing this not to cut through the thin walls of the abdominal cavity; but if you are unlucky enough to do this, apply cotton and plaster liberally. Catch one edge of the cut skin with the forceps or finger tips, and work the butt of the scalpel between the skin and body so as to

* In this connection I give two recipes, which will be found useful. Bent tail and wing feathers may be straightened by dipping in hot water; or, better yet, by holding them in a jet of steam — only in doing this beware of steaming the skin, or it will shrink. To remove grease, wash with turpentine and dry with plaster. One drawback in using plaster is the difficulty of removing all traces of it ; but by gently beating and dusting this can be accomplished. 
push off the skin. From time to time put on a little plaster, to absorb the moisture from the body and to prevent the feathers from sticking to it. Work down until you reach the knee, when you push up the ley from without, insert the point of the scissors or scalpel under the bend, and cut through the joint. Continue to push up the leg and work down the skin until it is skinned as far down as possible. You will find the finger nails most useful for this purpose. Sever the tendons low down and tear off the muscles. Draw the leg back smoothly and skin the opposite one. Work the skin well away from the sides of the body and down to the base of the tail. Cut across the lower bowel, and, working the point of the scissors carefully under the lower part of the backbone, divide it just above the roots of the tail feathers. A bird's skin is very thin just at this particular point. The operation above described requires much care, and at first occasionally results in de-tailing the bird. Work the skin cautiously away from the lower part of the back, not pulling it, but pushing it gently or cutting carefully at its junction with the body. You may find it convenient at this stage to hang the bird from a look suspended over your work-table; but after a little practice this will be necessary only with large birds. The skin will now peel easily from the body until the shoulder joint is reached, when, if the bird is small, you cut through the arm bone half way between shoulder and elbow, or, if the bird is large, disjoint it.* As soon as the wings are cut loose, the skin comes easily away from the neck, and from now onward it will be necessary to support the skin, as otherwise its weight, especially in a good-sized bird, would be apt to stretch the neck. You now come to the base of the skull, and here you will meet with more or less trouble, for generally it is hard to get the head through the neck. In fact, some birds, such as ducks, woochpeckers, and the like, have such large heads that it is impossible to skin them through the neck. In such cases, sever the neck close to the skull, and, turning the skin right side out, make a cut along the top and back of the head. Through this opening the skull may be readily skinned out. Usually, however, you can coax away the skin until the ears are reached, or, rather, the delicate membrane lining

* The arm bone must also be left entire if you wish to mount the bird with spread wings. 


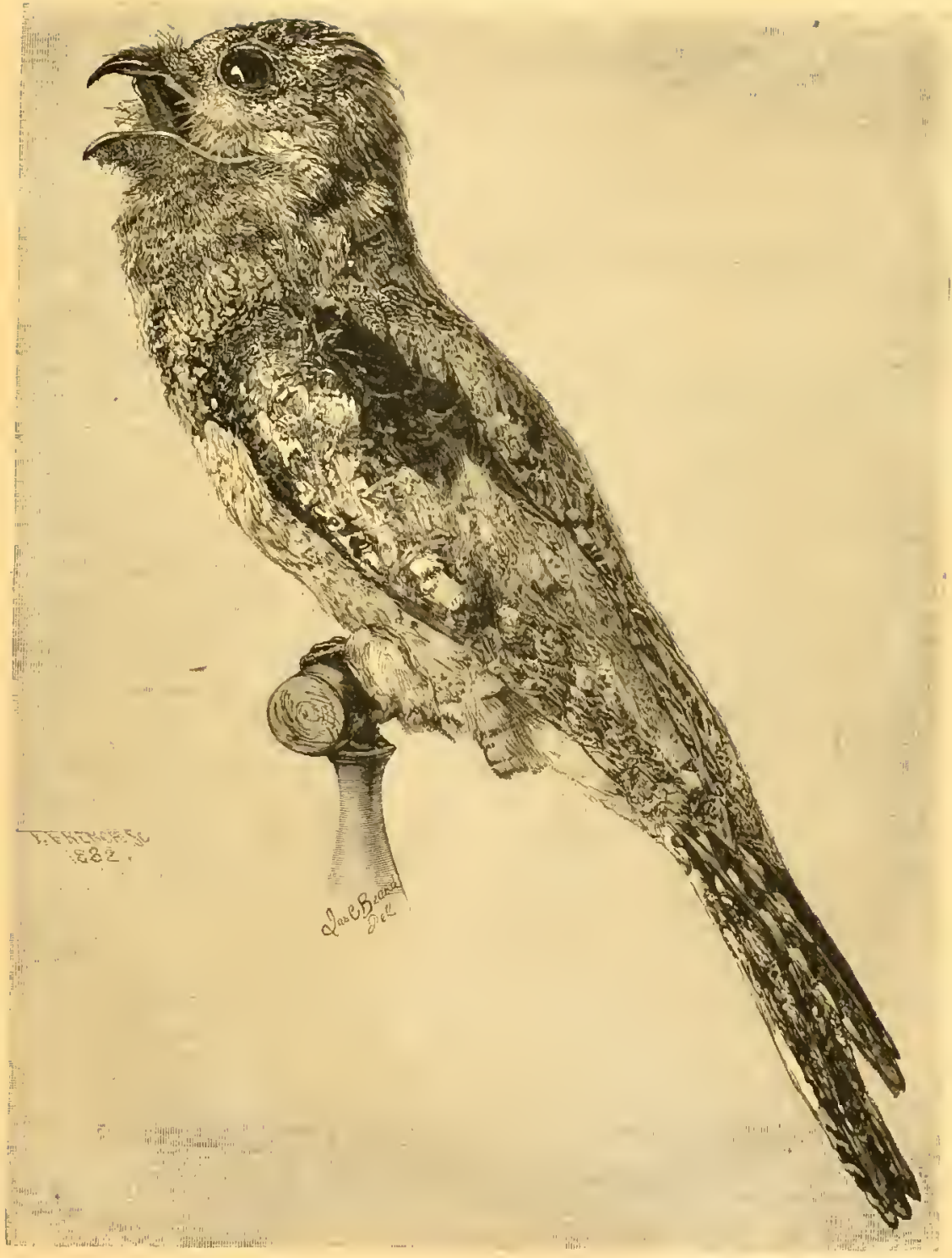





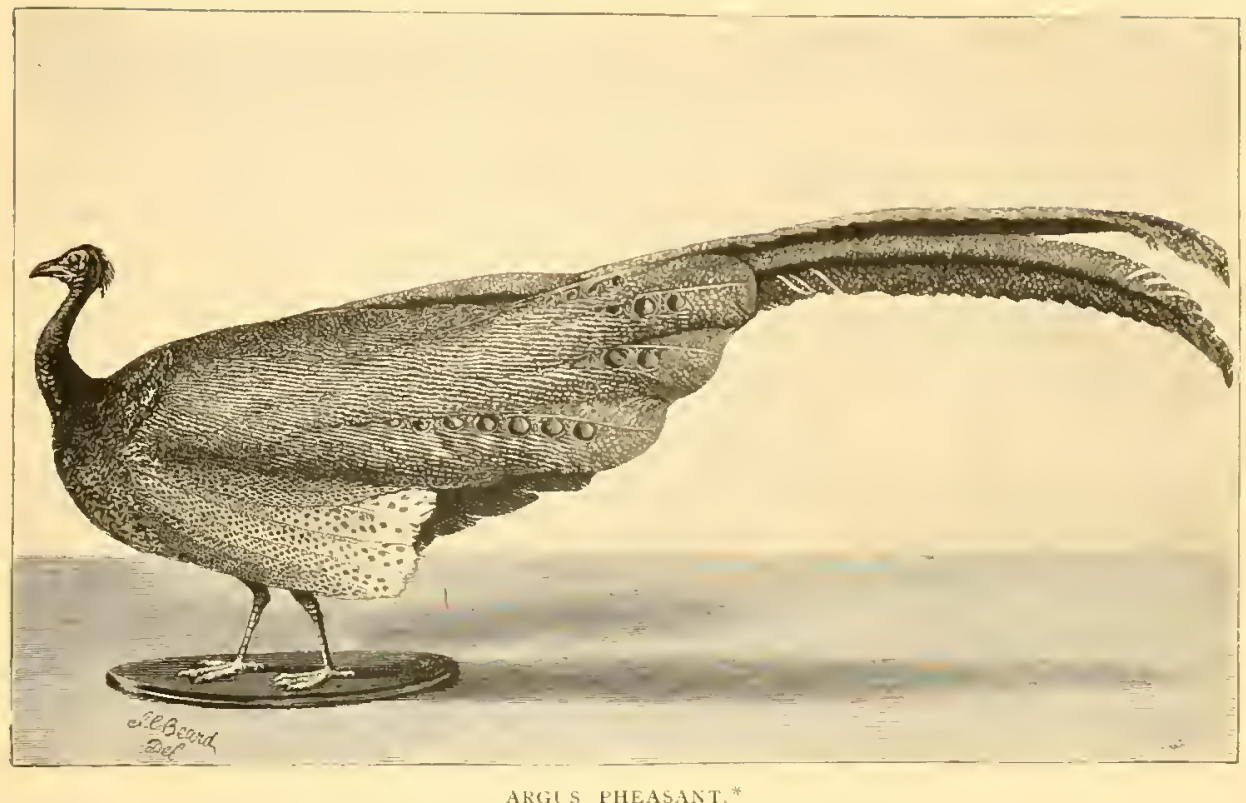

the passage. Cut through this, as near the skull as possible, inserting the scalpel point under the front portion, and picking it out. Having done this, you come almost immediately to the eyes, and here it requires careful cutting to detach the skin without injury to the eyelid. Be careful also not to cut into the eyeball, and thus let the inclosed fluid out on the feathers. Skin well down to the base of the bill; if you do not, the place where you left off will be marked by an unsightly ridge in the mounted bird. Take out the eyes, cut off the base and under part of the skull, and most of the brain, together with the tongue, will come away with the neck. Scrape the meat from the jaw, and all is done save skinning the wings. It may be allowable in small birds to skin the wings to the wrists, detaching the secondaries from the bone; iut although it saves a little time, I would not recommend it. The better way is to remove the muscle on the fore-arm with forceps. after having worked down the skin as far as possible on the front edge of the wings. Poison the skull thoroughly, and put a little cotton in the eye-sockets, - enough to fill, but not distend them, - also bringing a thin flap

* 'This illustration and the following were all drawn from specimens of the taxidermist's work. 
down over the angle of the jaw. Now work back the skin until you can catch the tip of the bill, and, holding on by it, gently push back the skin with the finger tips until the bird is right side out again. Now poison the body thoroughly, either by shoveling in the dry arsenic and working it into every cranny of the neck, wings, and legs, or by pasting on arsenical soap.*

Get plenty of preservative on the roots of the tail, first removing the oil glands. Of course, the bird now looks a little mussy, but that is soon remedied. With the forceps or knitting-needle raise the feathers near the roots and let them drop into place. See that the wings and legs are not twisted. Insert the needle in the eye, run it between the skull and skin, and work the latter a little forward, for the chances are that the skin has been dragged backward in re-turning. your bird is now skinned and lies before you ready for mounting, and for this you need certain materials and tools. The materials are: excelsiort for bodies, fine tow for necks and legs, and annealed iron wire of various sizes. Fine hay (rowen) or coarse tow makes grood bodies where excelsior is not obtainable, and cotton may be used as a very poor substitute for tow. The necessary tools are: flat, round, and cutting pliers, a flat file, awls, a pair of eight-inch spring stuffing forceps, needles, thread, and pins. There are many other tools you will find handy; and among these I would strongly recommend a jeweler's vise having a hole running lengthwise through the handle. This is a most serviceable instrument for wiring birds' legs. Also, make yourself a few little pushers, by flattening one end of a wire six or eight inches long and filing a few notches in it. Bend the opposite end into a ring. Cut and straighten wires for the legs and body, making them amply long to allow for clinching and selecting wires for the legs sufficiently large to firmly support the finished bird. Sharpen both ends of the body wire and one end of the leg wires. The first step is to unite the wing bones with a thread, so that they are a little closer than they were originally. Fasten the thread to the bone toward the elbow, and not at the

* My own method of applying the soap is as follows: After getting the skin right side out, I poison the neck and wings. When the false body is inserted, I turn down the skin a little and poison all around it, and finally I poison the legs just after they have been wired and wrapped. Thus I lessen all chances of smearing the feathers.

$\dagger$ Excelsior is fine wood shavings, and can be obtained at any upholsterer's. 


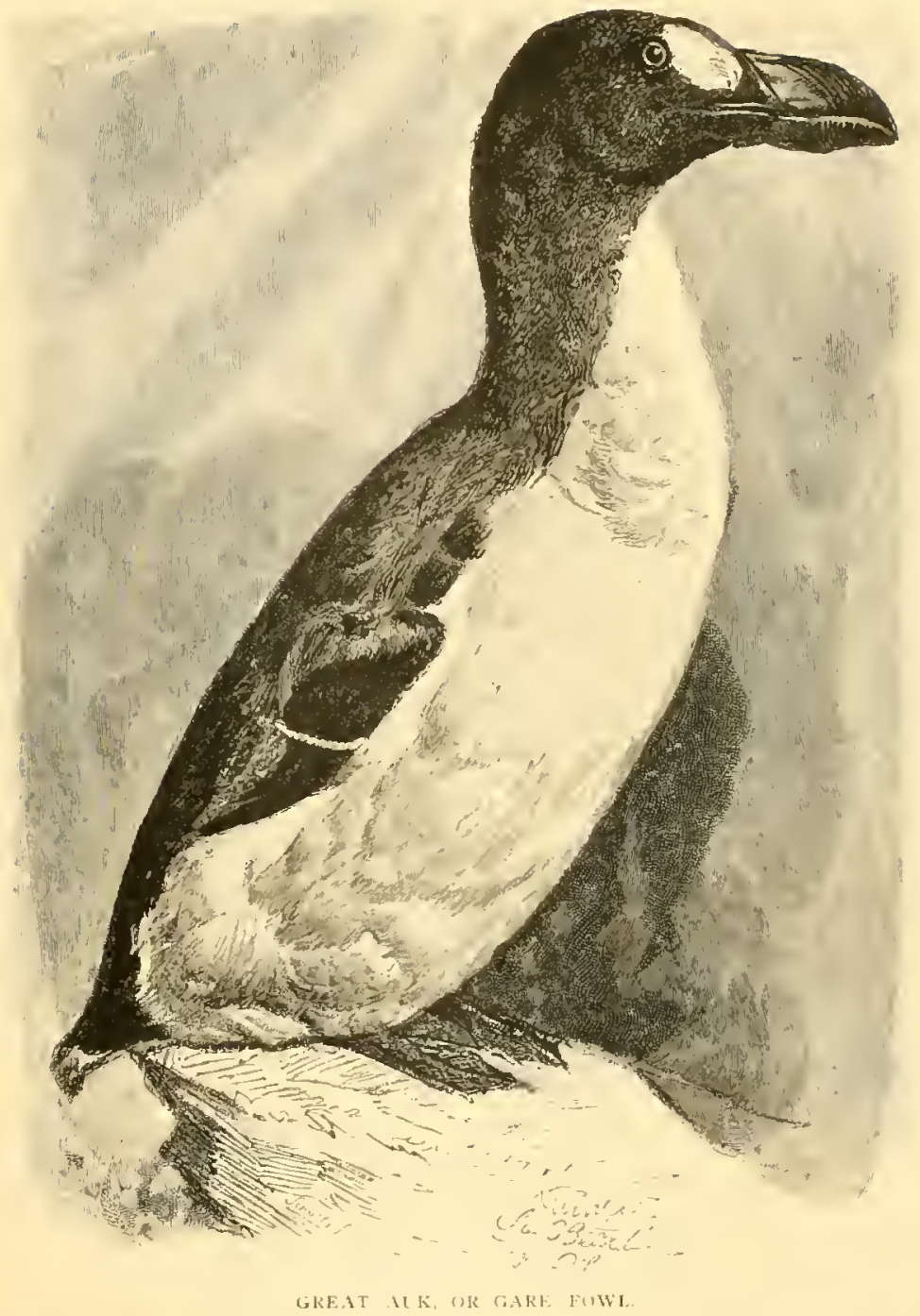

upper, or free, extremity. If a bircl is to be mounted with spread wings, the first move is to wire them, by entering a wire from the inside just under the elbow, running it along over the lower bone of the fore-arm, and continuing it on the under side clear to the tip of the wing, there bringing it out. Simple as a description of this operation appears, it is rather difficult to perform, and you must proceed slowly and carefully. Secure the wire to the upper arm bone just above the elbow, and again near its free extremity, and wind a very little tow around both. The wings are fastened to the body 


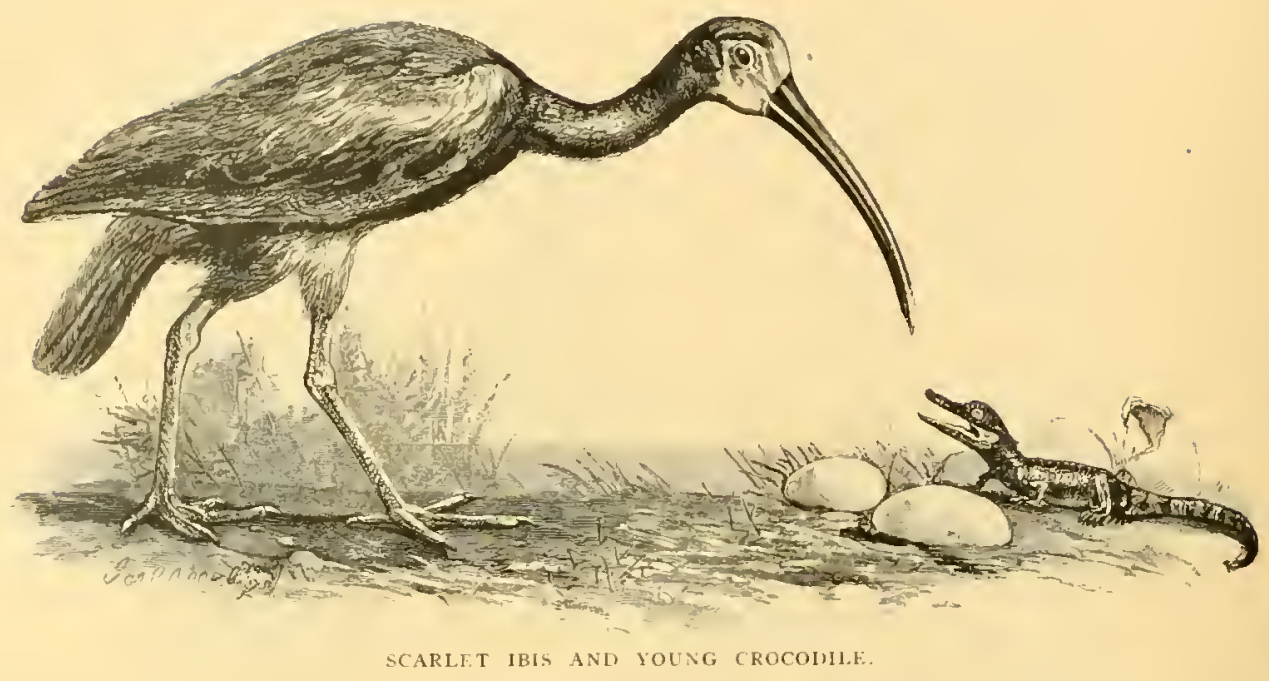

in precisely the same manner as are the legs,- - hereafter to bc described,- only, of course, the wing wires must be clinched first. Avoid the common mistake of starting the wings from the sides of the body, and place them well up on the back.

Now, with the body of the bird lying before you, proceed to make one of excelsior to replace it. Note well the general shape of the natural body, but do not imagine that it is necessary to accurately copy it. Your work is to be externally and not internally correct, and what is wanted is the easiest and best method to make it fair to look upon. In ducks and water-birds grenerally the body is flattened from above downward; in waders it is flattened sidewise; while in most others it is rather rounded. Mold the excelsior between the palms of your hands, and wind it tightly with fine twine or stout thread, adding a little material here and there to bring about the desired shape. Let the finished body be smooth, a trifle narrower on the back than on the breast, and let it be a little more pointed at the tail than the original. Above all things, make it firm and hard, for on the solidity of the body depends the stability of the bird and its

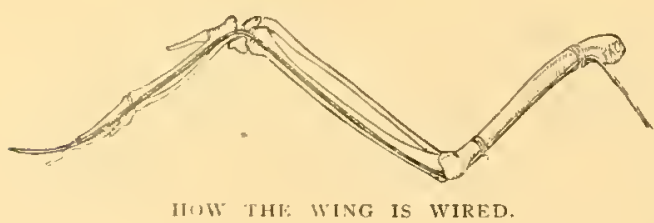
ability to undergo without finching the twists and pulls it must undergo in posing. Try it in the skin, and if it does not fit, make any required alterations. 
Take the body wire, bend it like a U, with one long and one short leg, and thrust them through the body from the posterior end so that the long wire may come out a little above the center; twist the two ends togrether for a turn or two, and cut off the shorter end. Holding the body in your right hand, you twist around the pro-

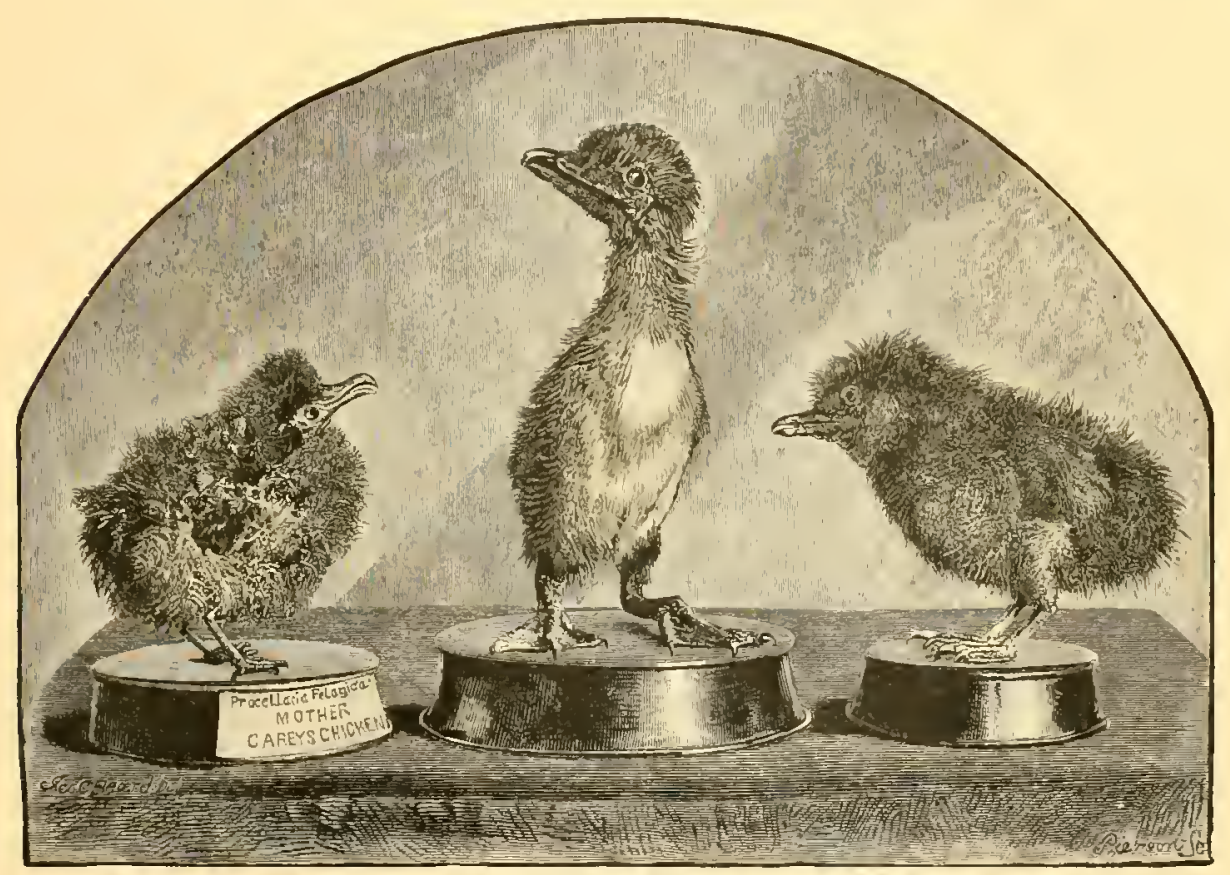

YOUNG WATEREOWI.

jecting wire enough fine tow to form the neck. A little practice will give you the knack of doing this so that the neck will be hard and smooth. It should be a trifle larger-not longer - than the original, because the feathers will lie a little closer in the mounted than in the living bird, and yet their necks must be of the same size outwardly.*

If there is the slightest danger of the tow becoming loose, secure it by wrapping with fine thread; in fact, if you do this always, you will be saved much inconvenience and loss of temper. If your wire

* Herons and some other birds have flattened necks, which are made in the following manner: Wind a small neck on the body wire as above directed, and make a second roll on a separate and smaller wire. Uniting these two, you have a flat neck. which imitates the muscles and the wind-pipe. 
is sufficiently long, it will project beyond the tow neck from one to three inches, according to the size of the bird. Insert this in the neck of the skin, and carefully work the body up into the skin and the skin down over the body, bringing the wire out through the crown of the head, or a little in front of it. Be careful when you do this that the skin on top of the head is not drawn backward; for if this happens, the wire will hold it there and an unnatural look be the result. You will find a perverse tendency of the wire, especially in long-necked birds, to come out through the side of the neck. Work the neck up into the skin until it meets the base of the skull, adjust the feathers a little, and proceed with the legs. Insert the wire in the sole of the foot, and with a twisting motion force it slowly up the back of the leg, past the heel,- - too often called knee, - until the point has entered what was the fleshy part of the leg. Then turn the leg inside out so that the wire may not catch the skin, and pull it through with a pair of pliers. The chances are ten to one that, for the first few times, the leg wire will insist on catching in the heel-joint or coming through the skin just above it; but we will suppose that the leg has been safely wired and that the wire projects for a short distance above the bone. The muscles of the leg are to be replaced by fine tow - cotton will do for small birds, but not at all for large ones - wound on smoothly until the leg nicely fits the skin.

Observe that a bird's leg has a most graceful taper, like that of an Indian club, and that it does not start abruptly from the bone. In turning back the skin, be sure that you do not get a twist in the leg, a very common and vexatious occurrence. If a bird is to be made walking, one leg must be wired from above downward, the wire being made to follow along the middle toe and brought out at the first joint. Many taxidermists do not deem it worth while to wrap the legs of small birds, but I do it to the very smallest; if it does nothing more, it at least prevents the wire from coming in contact with the skin and possibly rusting through. Having made the legs, the next step is to secure them to the body, and this is done by thrusting the wires through it, bending them back, and finally clinching the points on the sides from which they started. Three points should be specially looked after: first, that the legs are solidly attached; sec ond, that they are not too high up,-i. $c_{\text {. }}$ too near the back,-and, third, that they are well forward. Mlost amateurs, and not a few pro- 
fessionals, bring a bird's knees altogether too near his tail, the result being a very awkward-looking creature. As a rule, a bird's heels come about opposite the base of the tail. Mll birds of prey have the knees very free,-outside the body, as it were. - while just the reverse is true of swimmers and divers. Bend the legs backward,

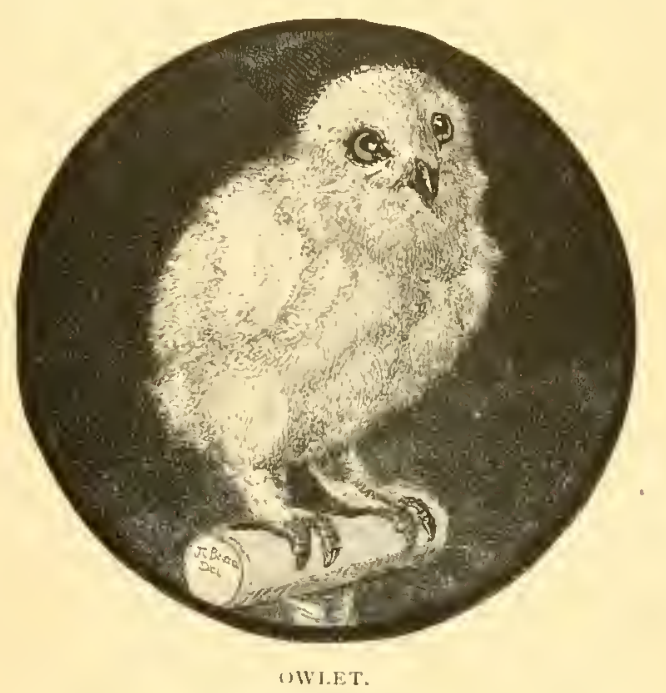

see that they are of the same length, and adjust the feathers a little. ivith the long forceps and pushers, work some finely cut tow smoothly around the base of the skull and top of the neck. I have never seen this advised, and yet it is a very necessary proceeding in order to secure the best results. It is of special importance in mounting owls, in order to impart that roundness of the heacl so characteristic of those birds. You may also put a little filling in the upper throat. Turn the bird face downward, and with the thumb and finger lift up and work together the skin on the upper part of the shoulders and lower part of the neck, at the same time working the wings toward each other. It is well to repeat this operation from time to time, as a little attention here does much to prevent the bare spots on the sides of the neck from showing in the finished specimen. Bend a sharp-pointed wire into a $\mathbf{T}$-shape, the point being on the upright portion, and run it through the base of the tail, just below the central feathers and well into the body. In doing this, be careful not to get the wire between the feathers; for if you do, nothing can induce the tail to spread evenly. In a living bird, the tail feathers are moved 


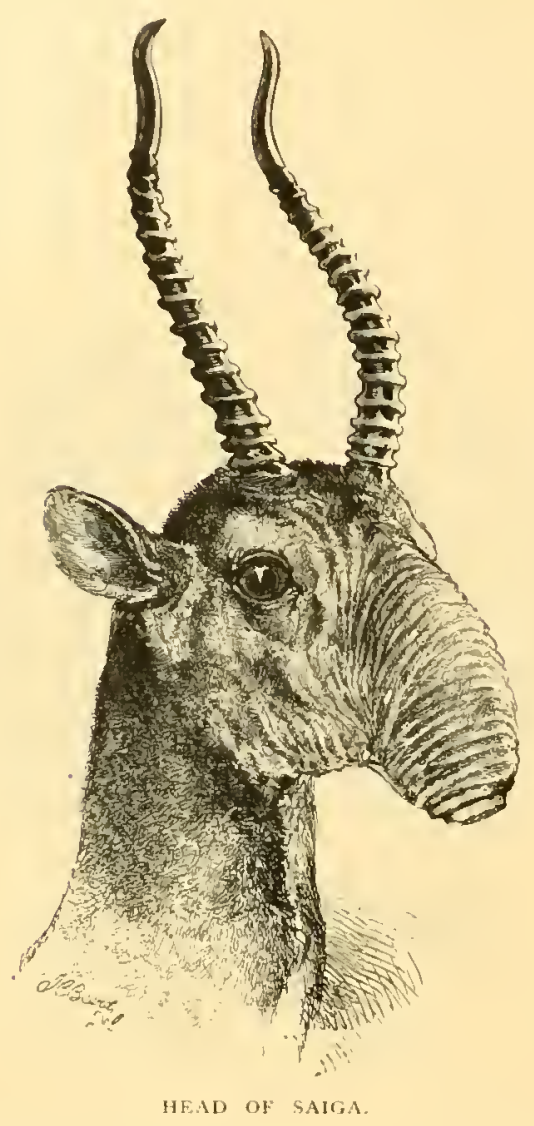

together, no one more than another; and it must be your aim to secure this beautiful uniformity. Now begin at the lower part of the opening and sew up the cut, inserting a little filling - cut tow-from time to time in such places as may want it. You will very likely need some around the base of the tail, and assuredly some around and above the knees, to imitate the thighs and join the legs smoothly to the body. Possibly there will be some wanted on the breast; although this will not be the case if you have made the body correctly. Do not be surprised if in sewing up the opening you cannot quite make the edges of the cut meet. The skin - especially of thinskinned birds - dries and shrinks here very rapidly, and nature has kindly provided birds with feathers which conceal many of the shortcomings of the taxidermist. But in ducks and other birds with thick skins and short, dense feathers you must make both sides meet. Apparently, the bird is now nearly finished, but in reality it is very far 
from completion. Your bird may be well wired, correctly put together, and smoothly filled, but if it is not placed in a proper attitude, all goes for naught. True, very much depends on all this preliminary work, and it needs to be thoroughly well done in order to make the mounted bird a success; but from now onward, every touch tells.

1) ress the feathers a little with your small forceps, catching them low down, raising them and letting them fall into place, or pulling them gently into position here and there as occasion may demand. Adjust the legs, bringing the heels a little nearer together than are the knees, while at the same time you put them at the proper distance from the body. In ordinary positions of perching birds, very little of the leg shows above the heel, while the heels themselves are brought near the body. The reverse of this is true in running and wading birds. A great deal, too, depends on having the proper angle between the tibia and tarsus, and you will soon discover that there is much power of expression in a bird's feet and legs. A very common

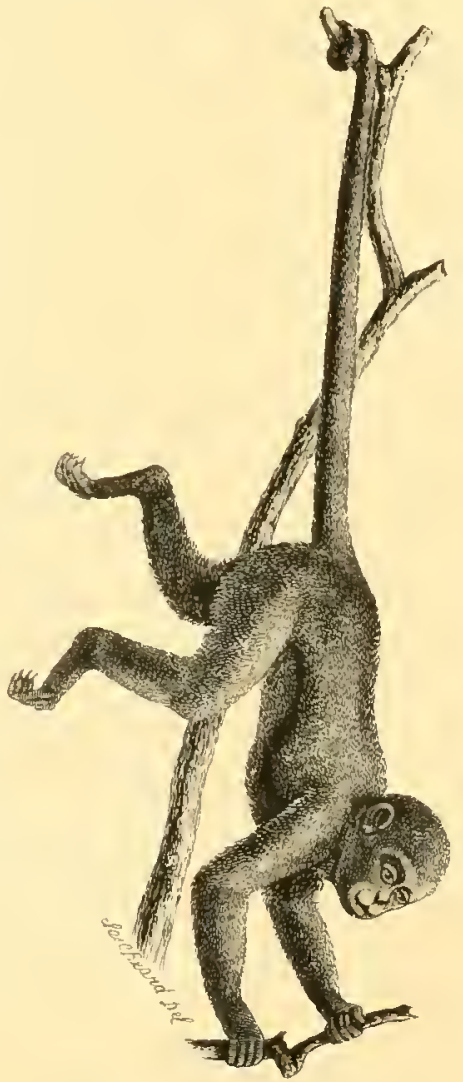

A SOUTH AMERICAN MONKEY. mistake is that of making small birds stand too upright. Notice the sparrows as they hop about the street, or observe your pet canary, and you will see how a bird's legs should be placed. In parrots, the heel is usually below the line of the foot; and the owl shows his relationship with the parrot by bringing his heels so far backward and downward that only the feet project beyond the long, fluffy feathers of the breast. Nany swimming birds, on the contrary, hold their legs almost as straight as sticks, the gull being an extreme case. When you are in doubt regarding a given point, consult a living bird and you will get much valuable information, not seldom some that is quite at variance with your pet theories. Having placed the feet, it is time to transfer the bird to a temporary 
perch; and be sure that the base to this is solid, and that the crossbar is securely nailed on, so that you may twist your bird about without pulling your perch to pieces or tipping it over. If on standing the bird upright you find that the back is not round enough, or the breast too flat, or that you have omitted to put any filling in the

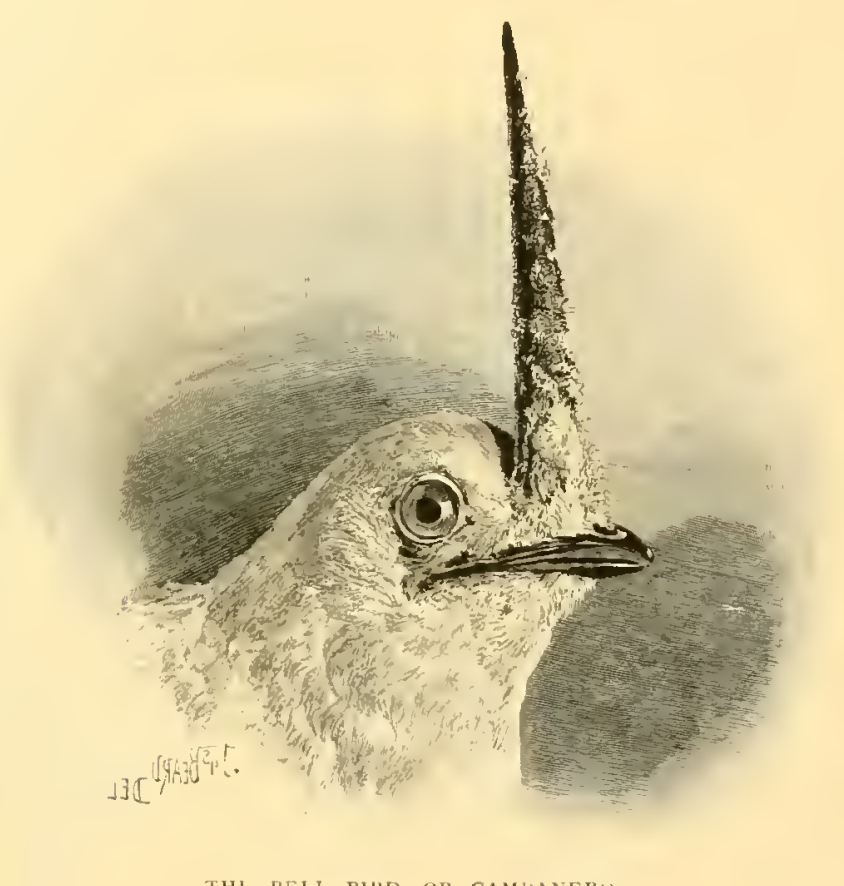

THL BELL BIRD, OR CAMYANERW

sides, - and these mistakes frequently occur, - now is the time to remedy the deficiency. Make an incision, lengthwise of the body, under the wing, and with your little pushers introduce enough cut tow to fill the vacancy. At first the pushers will go awry and the tow roll into balls or work into the wrong place; but draw liberally on your stock of patience, and with a little practice all will gro well. It is usually unnecessary to sew up the cut under the wing, as it is quite hidden; but if the bird be a good-sized one, a stitch or two may not be amiss. Bearing in mind the fact that a bird's neck is not straight, but a double curve like the letter S, you imitate this shape as follows: Bend the head and neck forward, and grasp the bird by the back with your left hand, the tip of the forefinger resting against the base of the neck. With the right hand press the head and upper neck back- 


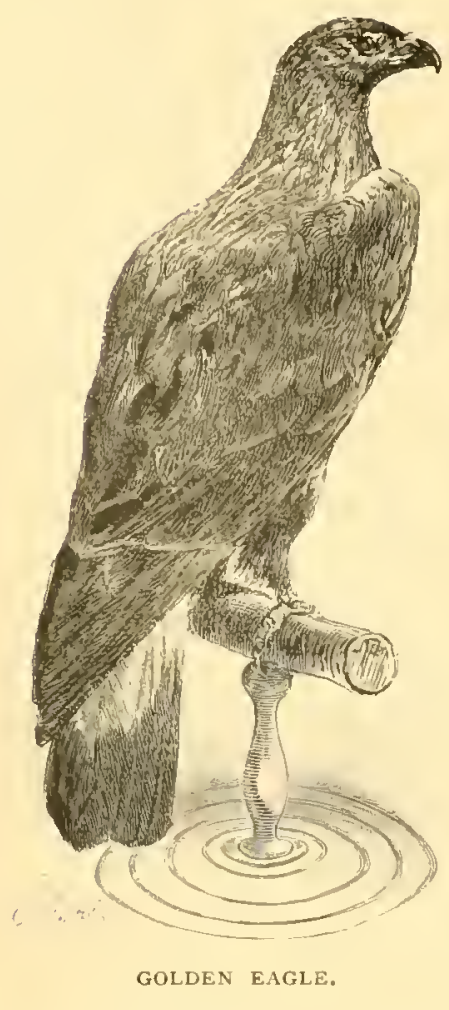

ward, and the lower curve is made. In shaping the upper part of the neck, the mistake is frequently made of crooking the neck itself too much, whereas it should be curved but little, the effect being produced by bending the head sharply downward. If these instructions seem somewhat prolix, believe me they are not too much so, for a common fault of works in taxidermy is that they are deficient in detail and fail to draw attention to the little points whereon hinges the success of the completed work. Now see if the eyes are in the same plane, and not one higher than the other, and look to it that the center of gravity is all right. Your bird should look as if he were resting on perch or pedestal, and not as if he would pitch forward were the wires removed. Having settled these two points satisfactorily, proceed with the wings, the first step being to get their tips even. Living birds often carry their wings in a very slovenly manner, but they rarely have their tips out of line. The frequency with which one wing will insist on coming out wrong is more remarkable than amusing; and it occasionally requires the outlay of 
considerable time to induce them to look equally well. The scapularies, or feathers on the shoulders, are often troublesome and require coaxing into place. A very handy tool for this purpose is a darningneedle fastened in a short handle, or you may sharpen one end of your knitting-needle.

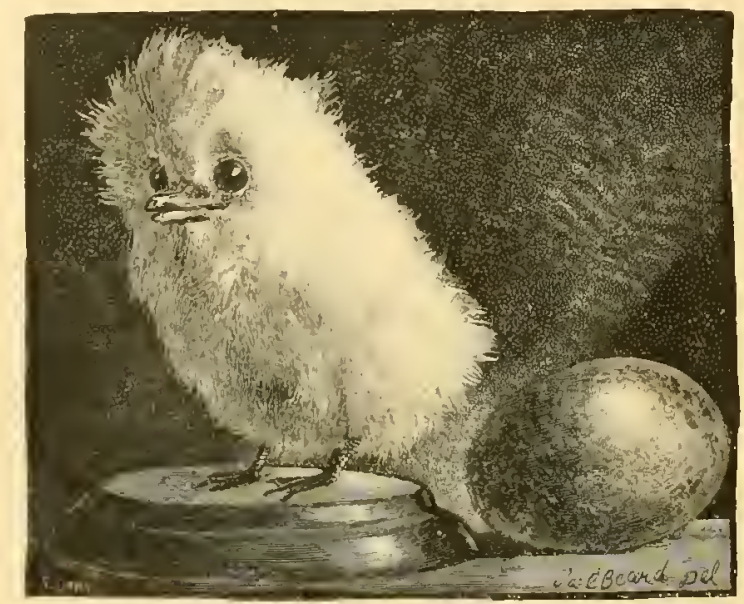

A L.1TTLE STRANGER FROM THE TROPICS.

This you thrust into the roots of the feathers, and with a combined lifting and twisting motion bring them where they belong. Trouble with the scapularies often arises from one of two causes, which I mention in order that you may guard against them. The first is too much filling in the back, or between the wing bones and the skin. The second is filling worked into and distending the bare spot that runs from the sides of the neck down over the wings. The wings are secured to the body with from one to three wires, according to the size of the bird and the amount of pains you wish to take. The first wire-and this is never onitted-runs slightly downward and backward through the wrist or bend of the wing; the second is inserted between the bones of the fore-arm near the elbow, and points forward; while the third you enter near the tuft of feathers known as the spurious wing, and direct upward. Beware of running a wire between the roots of the primaries; for if they are thus wedged apart, nothing but changing the wire will induce them to lie as they should. Next arrange the tail feathers, which may be done in several ways, the easiest and least satisfactory of which is to reverse the manner 


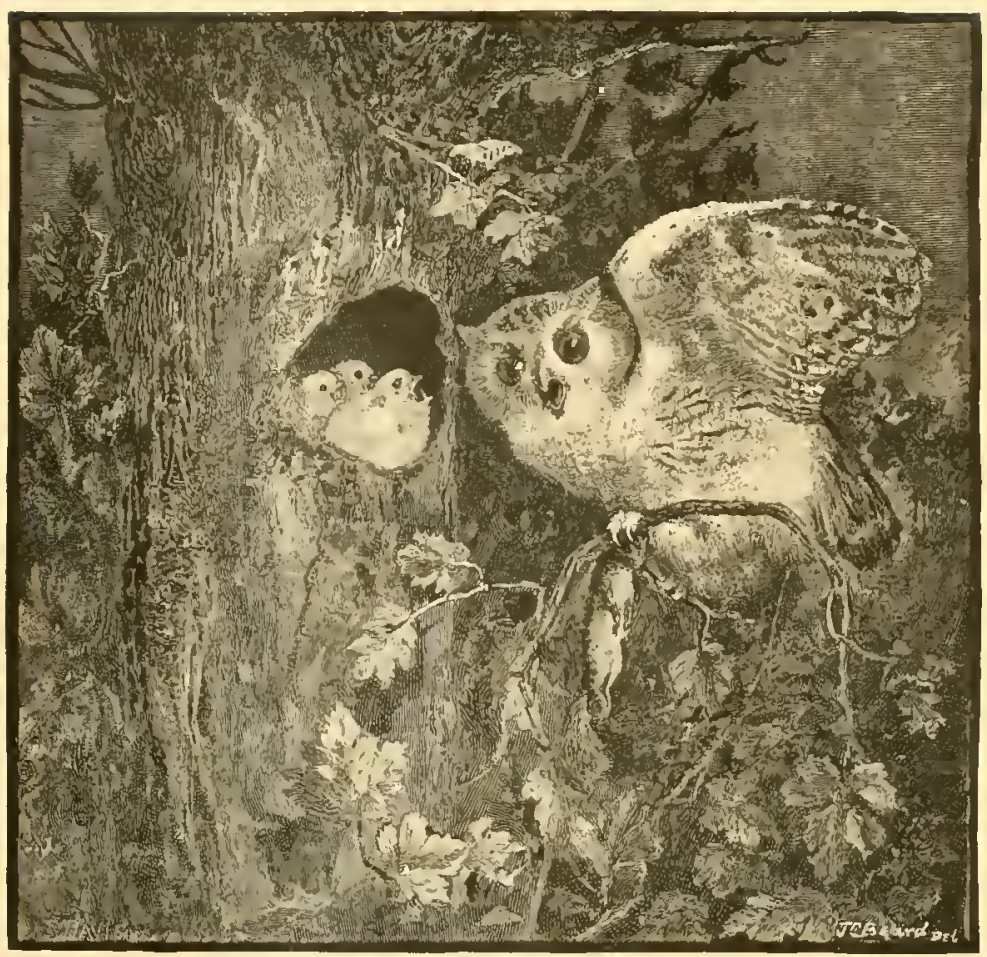

A FAMILY OF SCREECH OWLS.

in which they naturally lic, so that they lap under from the outermost feather. The best plan is to place a piece of cardboard above and another below the tail, and secure them tightly together with pins, thus holding every feather securely. For acry large birds with widespread tails it will be necessary to run a wire through all the quills near the base of the tail - a tedious and aggravating operation, but one which is sure to hold. Whichever plan is adopted, remember what was said previously - that the feathers of the tail are always equidistant. Insert a little filling in the upper part of the throat if it needs it, but be careful not to get too much there, which, by the way, is a very common fault. Tie the bill together by running a thread through the nostrils and around the lower mandible, or run a pin into the skull from below in such manner as to secure it. And now, after a careful inspection and final dressing with the light forceps, the bird is ready to be wound; and on the manner in which this is done depends much of the bird's smoothness and general good looks. If the winding is slovenly and careless, it will undo a great 


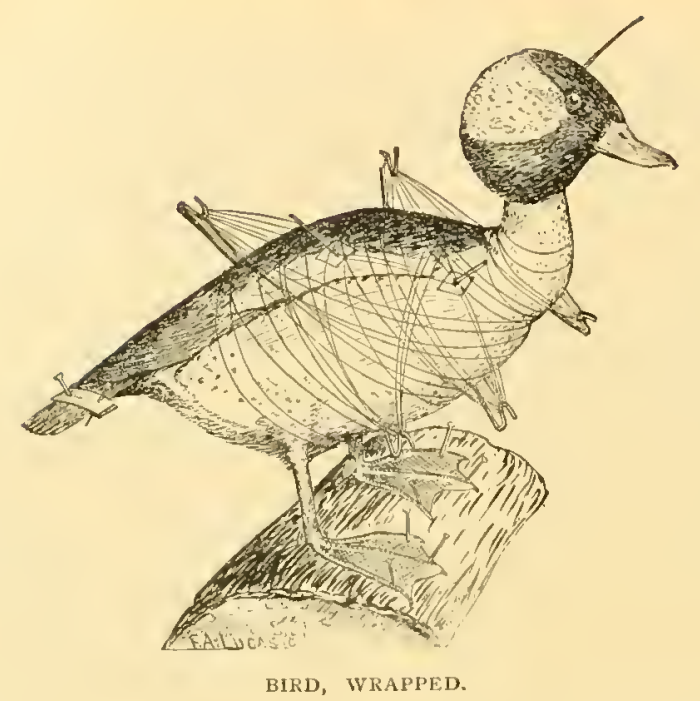

deal of previous good work; if neat and careful, it will greatly enhance it. Place small, square pieces of paper over the wires which fasten the wings, and make ready from six to ten long pins or sharpened wires. If pins are used, tie a bit of coarse, waxed thread around them about a quarter of an inch below the heads, and leave the ends sticking out for about the same distance. If wires are used, bend the unsharpened end into a $U$ shape. Place from three to five wires in line along the back and as many more along the breast, and use soft, light thread for winding. Begin by making a few turns quite around the bird in order to secure all feathers, and then proceed systematically, first with one wing then with the other, then with the back and breast. Let the thread lie lightly on such places as are smooth and in place, and gently press down any spots which are too high. Never try to produce a depression by a single turn of the thread, but use several at minute intervals. The use of the bend in the wires and the thread around the pins is this: it keeps the thread from touching the plumage where pressure would be injurious. Thus, by winding around and back from the upper series of wires, you can secure the breast and sides without bearing down any of the feathers on the back, and vice icrsâ. I have dwelt at length on this winding process, because there are but few who seem to realize its importance or go about it in a systematic manner.*

* It is but just that credit should be given to Mr. F. S. Webster for this method of winding, a still more detailed account of which, written by him, appeared in the Report of the Society of American Taxidermists for 188I-82. 
Do not put in the eyes until the hird is thoroughly dry; the reason for this being that you run the risk of disturbing the feathers of the fresh skin in setting them, or that the shrinkage of the skin may leave them bulging out of their sockets. A little cotton moistened in warm water and placed in the orbits will soon relax them. lmbed the eyes in putty, or stick them in with mucilage, the former method being my own preference. Press them well in, and with the point of a needle carefully adjust the cyelids. If the eyclid has become stretched, catch it up with a fine thread behind the eye. Now cut off the wrapping, pull out the wires in the back and breast, and cut off those in the head, tail, and wings, and your specimen is ready to transfer to its final support. This may be a neatly turned stand,-a twig fastened to a neat base or macle to hang against the wall, or a section of a tree-trunk. Gnarled and water-worn roots form excellent pedestals for owls, ducks, and herons. Rough cork, just as it comes off the trce, makes excellent rock-work, with the addition of a little paint and a few lichens. () course you will wish to make some groups of birds, but when you do so, strive to avoid a mere heterogeneous gathering, and endeavor to find some excuse for calling the birds together, or to make a group that shall form a harmonious picture; and in every case try to catch the spirit of the bird as well as its outward aspect.

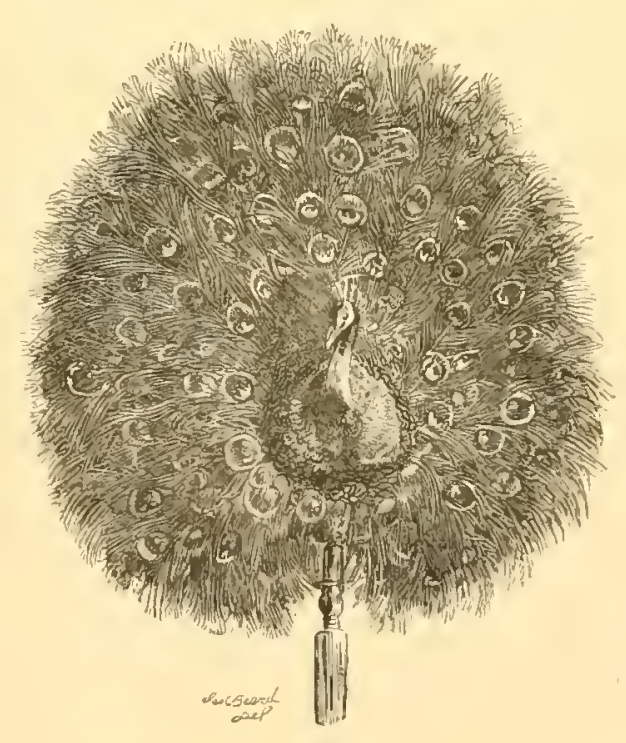


BOII-SIHOOTING.

\author{
By MAURICE THOMPSON.
}

AUTHOR OF "THE WITCHERY OF ARCHERY," ETC.

M

ANY nations and tribes of men have been famous for their archery. The Parthians, Carduchians, Scythians, and Persians are mentioned by the old writers as mighty bowmen. Some of the Imerican Indians are very expert, though by no means graceful or powerful archers. Much has been spoken and printed of the wonderful effect of Indian arrows at long range. It is all imagination. The best Sioux, Navajo, or Comanche archer would rarely be able to hit a man at eighty yards. But the yeomen of "Merrie Englande" were the world's most excellent archers. No doubt they, too, have been favorably misrepresented by loving historians. We should not be slow to forgive those who doubt the difficult feats in the story of Robin Hood. He never did hit a willow wand three hundred or two hundred yards, three shots in succession; nevertheless, those bowmen who followed the old lords of England in the days of Crécy and Agincourt, and Flodden Field and Bannockburn and Neville's Cross, were crack shots, and sent their shafts with such force that it took the best Spanish mail to withstand them. No doubt Robin Hood performed a good deal of fancy shooting; but that he "told" every rivet and joint of a knight's armor at long range with his arrow-points is a pretty tough story for an archer to believe. For one, however, I gladly accept the stories of Robin's poaching proclivities, and the great havoc he made with the game wherever he close to hunt.

Taking wild game has nearly ceased to be reckoned among the means of gaining a livelihood, and has fallen, or risen, as one may view it, to the level of a sport or means of recreation from the 
exhaustion and depression consequent to the civilized methods of self-destruction called busincss.

I wish by this paper to show that if the long-bow were atopted as the sporting weapon of the world, game would increase everywhere, while expert sportsmen would get all that they could desire from their favorite pastime, as regards both mental and physical recreation and a goodly weight in the game-bag. I speak confidently on this subject, having fifteen years of happy experience in archery to draw from.

I was yet in my teens when I was taught the use of the long-bow by Thomas Williams, a sort of hermit, whose cabin stood in the midst of a vast pine forest that bordered my father's plantation in the beautiful Cherokee country of North Georgia. My brother and 1 had, in a boyish way, been practicing archery for some years before Williams gave us lessons; Dut, though we had of our own efforts become expert in the making and use of our weapons, we found, to our chagrin, that before we could dare call ourselves bowmen all we had learned must go for naught, and an art must be mastered, the difficulties of which at first seemed insurmountable. Nilliams was a better archer than either of us can ever hope to be; but he was ashamed for any man to see him out with his bow and quiver.

Before entering upon the subject of using the bow and arrows, let us examine the weapons and their necessary accompaniments, so that we may clearly understand the few technicalities connected with a discussion of archery.

Figure $\mathrm{I}$ of the diagram on the opposite page is a good representation of a long-bow after the best English model. It is six feet from tip to tip, as it lies unstrung, and is made of lemon-wood, lance-wood, or yew. Figure 2 shows the weapon strung ready for use, which shortens it three or three and a half inches. This bow is the kind I have used for years. It has a plush handle and horn nock-tips. Its wood is yellow as gold, straight-grained, waxy in appearance, heavy. springy as steel and flexible as whalebone. It was made by Philip Highfield, London. The string is of the best white henup, slack twisted, stiffly waxed, and whipped with silk at the ends and mictule. By referring to the detail drawings and examining the cross-section and representation of the nocks and the handle, any one possessed of ordinary mechanical skill can, from a well-seasoned billet of common 
mulberry or sassafras wood, make an excellent bow with which to begin practice.

The two arrows represented in the figure are those used for hunting purposes. The best target arrows. for use in the game of archery, are for sale by all dealers in sporting implements. (Ask for the bestfooted, whole nock, Highfield arrows, $\$ 9.00$ per dozen.) But your hunting arrows cannot be procured in the market. No manufacturer makes them. You must first know what you want, then stand by some good workman till he has satisfied you. The barbed shaft in the illustration I have made as follows: twenty-eight inches long, of hickory, perfectly straight, even, and smooth, a little less than one-third of an inch in diameter, well-seasoned and oiled. The thin, flat, barbed head is set in a slit sawed for it, and fastened by fine brass wire, as shown in the detail drawings on the next

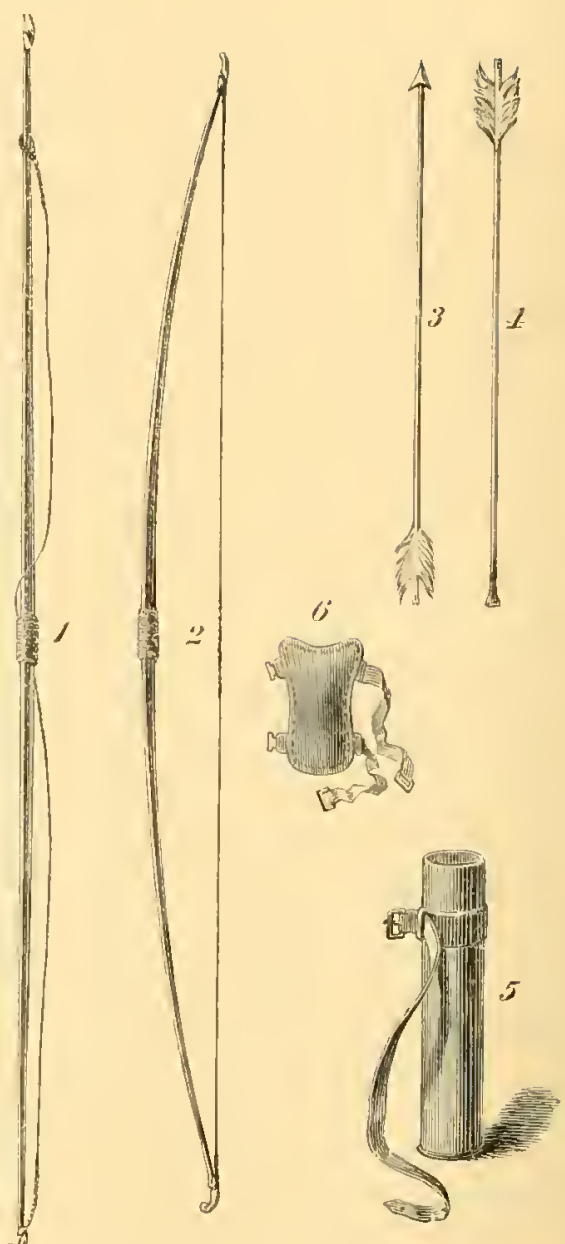
page. The feathering is a most 3. BARBED ARROW ; + RLUNTARROW; 5 . QUVER important and difficult thing to ac-

complish, and upon this depends largely the value of your arrow. After you have set the head in one end of your shaft and cut a deep. safe nock in the other, glue three strips of feather on, three inches from the nock and four inches long. running toward the head, so arranged as to stand at an angle of one hundred and twenty degrees to one another, and slightly spiral, so as to give a turning motion to the arrow as it flies. The blunt arrows used for shooting small game, and wild-wood birds not game, of the size of a pheasant, or smaller, are made precisely as above, excepting that a ferrule of pewter or harder metal is substituted for the barbed point. The shaft must be 


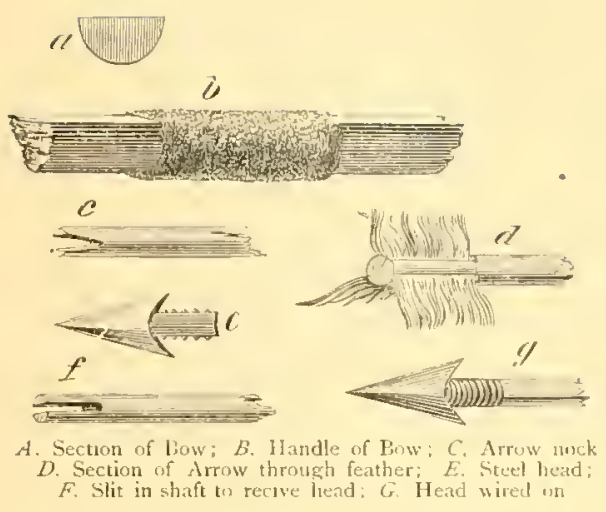

exactly straight, smooth, and even, as already stated. The slightest inecpuality or crook will spoil the chance of accurate shooting. A sord quiver is made of stiff harness leather, circular, three and a half inches in diameter, eighteen inches deep, and decorated to suit your fancy. It is worn attached to a belt passing around the waist or slung diagonally to the shoul-

der. Shooting-gloves I never use, and cannot recommend. A brace. or wrist-guard, may or may not be necessary, according to the conformation of the joints. It is a stiff piece of smooth leather curved to fit over the left lore-arm and wrist, and made to fasten with elastic straps, as shown in Figure 6.

Now, to string your bow. Observe, first, that the handle is a little nearer to one nock than to the other. The longer end of the bow is the upper one in shooting. To string the weapon, fasten the cord well in the lower end nock. so that the loop made at the other end of the cord shall pass around the bow about three or four inches, or less, from the upper nock, - the variation in this distance to regulate the amount of tension. Now, place the lower end of the bow in the hollow of your right foot planted firmly on the ground; clasp the handle of your weapon with your right hand; place the heel of your left palm on the upper end and back of the bow, just below the stringloop; draw the bow toward you with your right and push it from you with your left hand. This will bend the bow. Now slip the loop up into the nock with

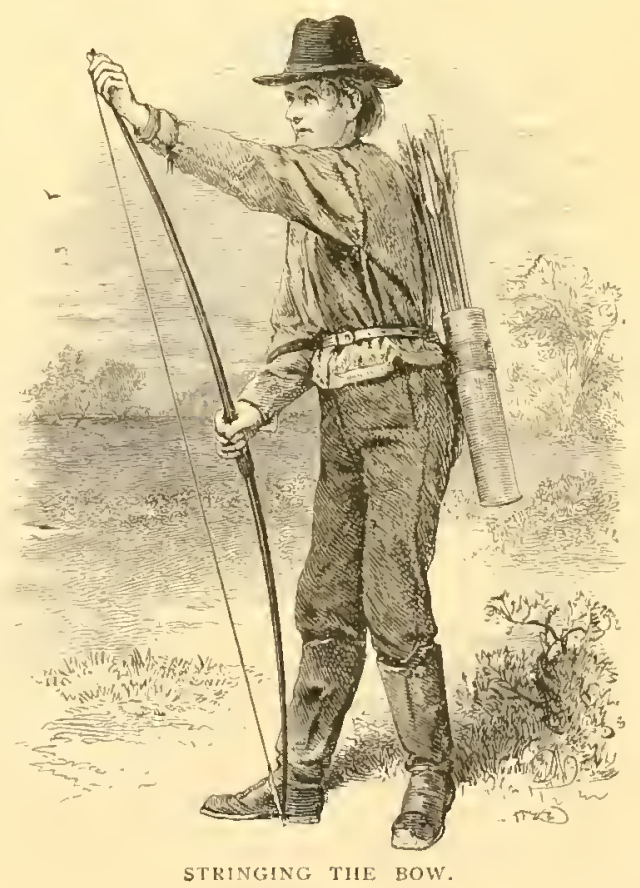




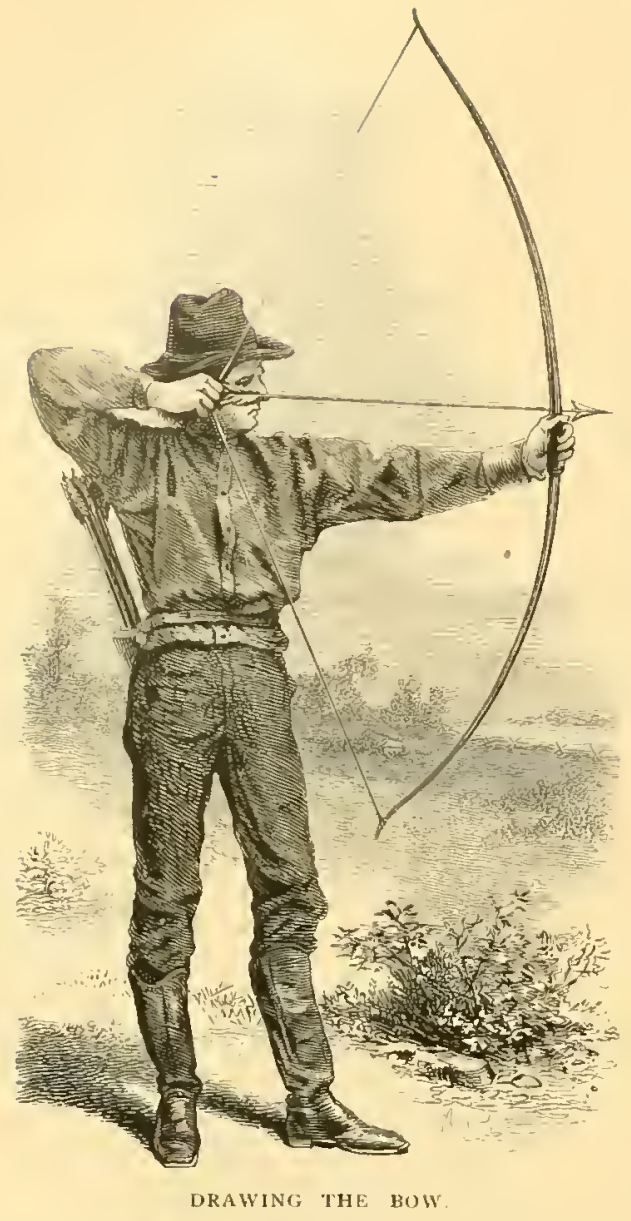

the thumb and forefinger of the left hand. Your bow is strung. and the cord stands about five or six inches from the handle. The accompanying cut shows the archer in the act of shooting. 'The arrow' rests on the left hand. and is drawn to the head. The nock end of the shaft is held between the first and second fingers of the right hand and upon the string, which is drawn to the right ear by all the fingers being hooked stiffly over it. The relcase must be smart and clear, giving the arrow a strong, even flight.

Archery as a game needs but few words of description. Two targets of straw, faced with canvas, upon which are painted four concentric rings and a bull's-eye, are placed at any lesired distance apart, facing each other. The competing archers stand by one target and shoot three arrows each at the other target, then walk forward and reverse the direction of their shots. By this method the exercise of shooting is combined with that of walking. The score is kept as follows: bull's-eye, 9 ; first ring, 7 ; second ring, 5 ; third ring, 3 ; fourth, or outermost ring, $\mathrm{I}$.

Archery clubs of from seven to fifteen members, both ladies and gentlemen, could be formed all over the country more easily, at less expense, and with far better results than cricket croquet, or baseball clubs. The rules governing such organizations should be few and simple, not unlike those of rifle clubs. Prizes could be offered and medals of championship adopted. Once brought into public notice and fairly established, no sport or game would be half so popular or permanent. It has in it all the elements of desirable 
pastime and recreation. The physical exercise is better than foncins. boxing, or lifting; it has every feature of an exciting competitive: game, is attended with no danger, and "shows off" the human form to the very best advantage. - all its poses being those of srace, easc, and power combined

From the earliest days of successful archery in England, green has been the bowman's favorite color, and all his metal decorations have been of silver. Clubs have, therefore, senerally chosen a uniform in which leaf green is the prevailing color, and their badges and medals have been wrought of silver, - a ring, a crescent, or a richly chased arrow being the commonest device.

In giving directions how to shoot, I cannot hope to improve on the simple language of the old disciple of the bow, Roger Ascham, who, in 1545 , wrote a little book on the subject of archery, entitled "Toxophilus," in which he saly:

" The first point is, when a man should shoot, to take such footing and standing as shall be both comely to the eye and profitable to his use. setting his countenance and all other parts of his body after such a behavior and port, that both all his strength may be employed to his own most at'vantage and his shot made and handled to other men's pleasure and delight. A man must not go too hastily to it, for that is rashness, nor yet make too much to do ahout it, for that is curiosity; the one foot must not stand too far from the other. lest he stoop too much, which is unseemly, nor yel too near together, lest he stand too straight 11 , for so at man shall neither use his strength well, nor yet stand steadfastly. The mean betwixt both must be kept, a thing more pleasant to behold when it is done, than easy to be taught how it should be done."

A little care at first will save you a great deal of trouble and annoyance. I! hen you begin to shoot, learn at once to stand firmly on your feet, the left slightly advanced, the head easily poised, the upper portion of the body gently inclined forward, and the shoulders neither lifted nor drooped. Hold the bow vertically with the left hand, the arm extended straight. Nock the arrow well on the string, draw with all the fingers of your right hand, till you feel your right ear, fix your eyes steadily on the target, and let fly. The shaft will sing through the air with a sound peculiarly musical, and hit with a force that will surprise you, even though at first you use a bow of but forty pounds' weight, $i . c^{\prime}$. one which requires a draft of but forty pounds to draw a 28 -inch arrow to the head.

Forty yards from target to target is a long enough range to begin practice with, and it might well be not over half that length. 
In fact, though many of the English clubs scorn to shoot less than a hundred yards, my experience goes that fifty or sixty paces measure about the longest certain range for the average archer. using a bow of not over fifty-five pounds' weight. Few ladies are able to use a bow stronger than thirty-five or forty pounds, and it requires a man of the strongest muscle to draw a ninety-pound one. I recommend a bow under rather than over your strength, for accurate, easy shooting.

If you begin your practice for the purpose of learning to shoot wild game by "field and flood," you must not use a target at all. One who is trained to aim at a large, graduated target, either with gun or bow, can rarely shoot well at game. The reason

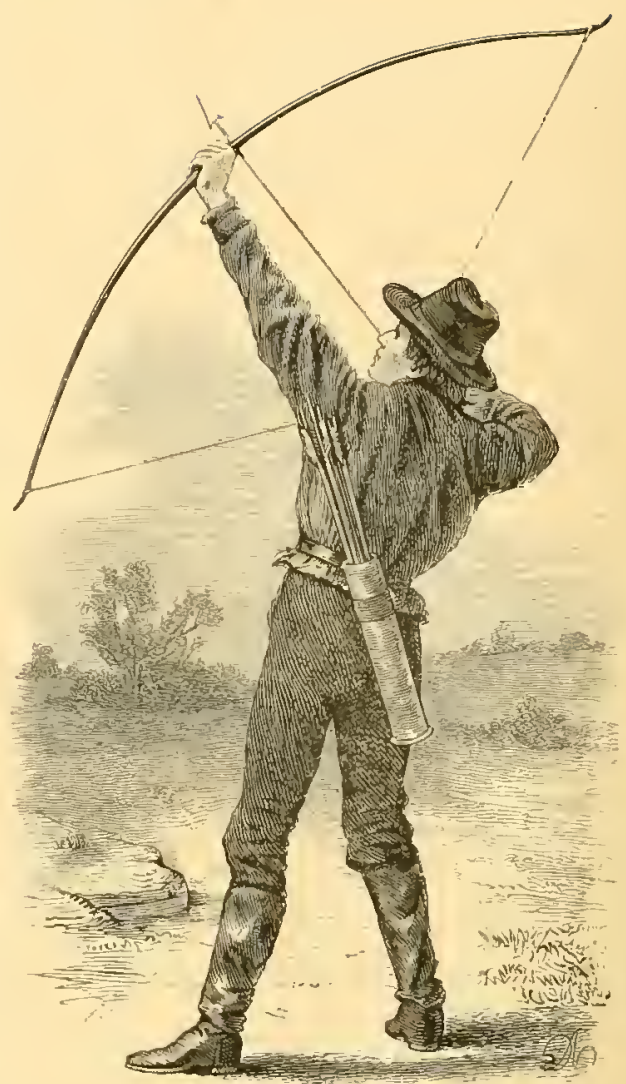

IIMING; IIIGH is that in target shooting at a fixed distance he gets used to a certain size, color, and condition of background. and when he gets into the woods and lifts his bow to draw on a bird or a hare, his accustomed rings and dark background are not there. His vision is blurred, he draws waveringly, and shoots indifferently. A black rubber ball four inclies in diameter, suspended in micl-air by a string fastened to the low limb of an apple-tree, makes a first-rate substitute for a bird, and a small bag of straw, placed flat on the ground and shot at at about twenty-five yards, makes good hare practice. You will soon learn the great advantage of not using the same distance all the time, as in the game of archery.

Your first practice on wild things should be carefully done, choosing the tamest and least wary of birds, in order that you may make short shots and observe how near you come to hitting your mark. You must not think of game till you have shown your ability to hit 


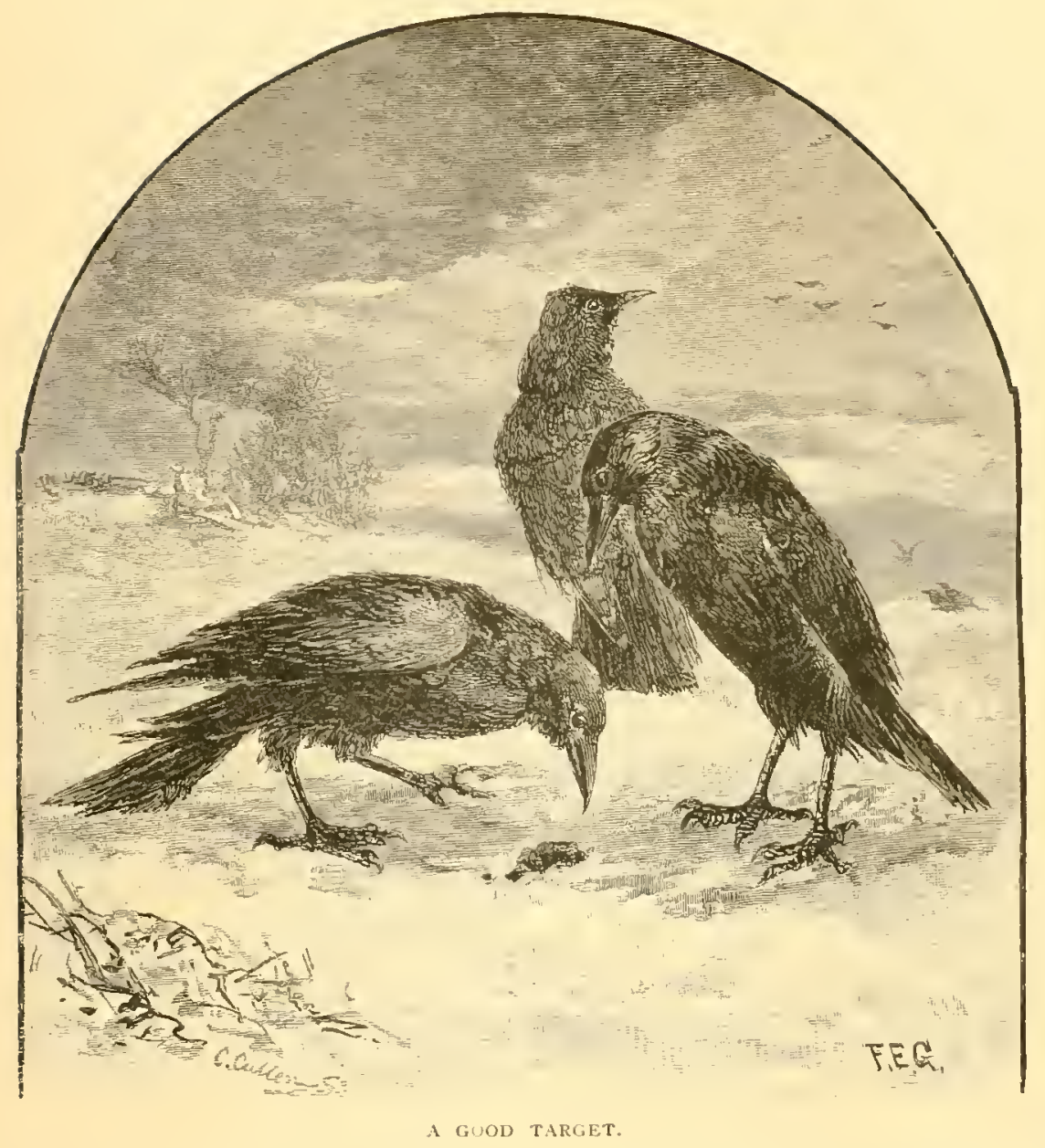

a woodpecker or meadow-lark at twenty paces - not every shot, nor once in five, or in twenty, even; but you must get well used to shooting at these birds and to hitting one occasionally before you can approach a hare or a quail with any degree of calmness. You need not fear that woodpecker-shooting will prove poor sport. Some of my happiest bouts in the woods have owed all their charm to the excitement of chasing an ivory-bill, a red-head, or a speckled "sapsucker" from tree to tree, whacking away at him whenever he got still, watching the flight of my arrow as it whisked past him or struck close by him with a ringing rap like the blow of a hammer, till at last I plumped him over, stringing him half-way down my shaft. 
Three things are requisite to bird-shooting with the bow. First, you must know how to measure distance with the eye accurately and quickly; secondly, you must be quick and noiseless in your movements; thirdly, you must draw uniformly, that is, put the same power on every shot, no matter how near or far the bird may be. When you begin to shoot in the woods, after considerable experience and success at target practice, you will discover that to be a good shot is not the half of what it takes to make you a tolerable bird-slayer. some of the finest shots you will ever make will be misses, and some of the poorest will be center hits.

You will never be a good shot till all the operations of archery are performed as naturally and almost as involuntarily as your breathing. A meadow-lark shows his yellow breast in a bunch of clover blossoms thirty yards ahead - you pause instantly, throw up your bow quickly, gracefully, draw an arrow to the head, let go sharply - all with as little effort and with precisely the same half voluntary, half mechanical accuracy with which you take so many steps in walking. Your arrow flies with a keen hiss straight to the mark and knocks the bird over and over amid a cloud of gold feathers and clover leaves. When you can do this one time out of five, you may begin to call yourself an archer and look about for game. But even then I will wager you a grood bow you miss your first hare, though you may find him crouched in his form not twenty feet from your nose. In fact, while a hare is a good large target, he is very difficult to hit before one has learned by experience just how to aim at him.

In still-hunting you will generally find him in his form, his body and neck elongated, his ears flat, his chin resting on his fore-feet: he is fast asleep with his round eyes open. He looks larger by half than he really is, which is apt to cause you to aim indifferently and shoot carelessly. You draw with great deliberation and let drive. Whack goes your arrow through the grass in which he lies, but to your utter amazement up springs the frightened hare and scuds away like a bit of gray paper before a gust of wind. You do not get another shot at him. He hunts his hole. Upon examination you find that you have overshot him, and your arrow will be sticking in the ground just beyond his form, and slanting back across it toward you. This is your first and most important lesson in hare-shooting. Hereafter you will aim low. Yes, too low entirely; for your next hare gets 


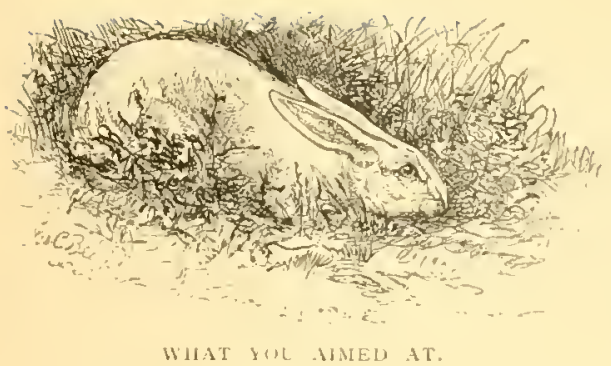

WUAT YQL MALEU AT.

out of his form before you sec him. and after a few long, lazy bounds, squats on his haunches and waits for you to shoot at him. You aim low and let fly and have the chasrin to see your arrow strike full ten feet short! The hare resolves himself into an ecstasy of billowy ambulation, outrunning the other by several seconds on the mile, and you are left pensively leaning on your bow, longing for a shot-gun! The third time is the charm, maylip, and you bowl your game over in fine style. A week or two of daily practice in good hare-cover will get you well up toward successful shooting at this game; then you will be ready

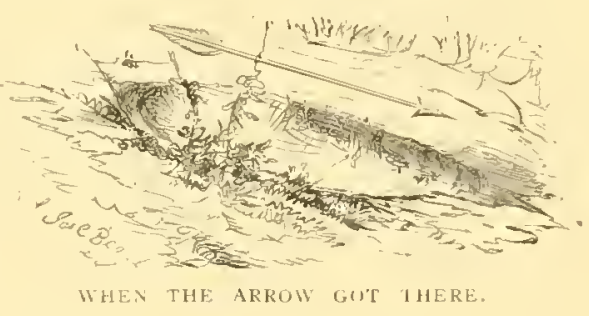
for quail and pheasant. These birds are so similar in their habits that to know one is to be pretty well acquainted with the other. You hunt them on damp, cloudy days with a very small clog, to escape which they fly up and alight on the lower limbs of trees and hedge shrubs or the stakes of worm fences. This gives you rare sport, and shot by shot you knock lown your birds.

Thus you gradually advance in the science and art of archery till you become a "crack shot," able to match any ordinary rifleman at forty yards. I can now leave you and proceed to give some notes on a few of the many hunting-grounds I have shot over with the long-bow. But first a word about the dress of a wild-wood archer. Your angler has his suit, your gunner has his: why may not the archer affect a peculiar garb? He cloes. It consists of low-legged jack-boots, corduroy breeches, a green-checked hickory shirt, and a broad-brimmed, light, soft felt hat. If the weather is chilly or cold, a heavy flannel shirt may be worn under the hickory, or a closefitting jacket may be put on over it. The main object is to keep your clothes down to the minimum in weight, and at the same time have no skirts or lappels to hinder your shooting.

Florida was the first grand hunting-ground visited by my brother and mysclf. After a year or two of training under Williains and a 
great deal of hunting among the hills and along the fine streams of North Georgia had made real archers of us, we spent three winters there shooting over some of the finest water and land region for sporting to be found in the world. My note-books are full of incidents, some of which are fresh to me as I read them over. But I cannot do more here than pick out two or three of the most striking. The reader must not expect to get even a glimpse of the dark side. One does not care to write or read about failures, disappointments, vexatious delays, worrying accidents, and ill-luck generally, - these things come frequently to every sportsman. Some days he can find no game; some days he finds everything and can hit nothing; sometimes he breaks a bow, sometimes he loses all his arrows. The successful day, the "brilliant shot," the exciting chase ending in capture, the long-range hit when I expected to miss-these are all down in my field-books, along with rough drawings of the birds, curious plants, strange insects, notable trees, and whatever happened to strike me as worth future thought.

Our party in Florida consisted of three,-Will and myself and Cæsar-an inky, midnight black man, who acted as cook, washerman, boatman, everything except sportsman. Casar was a source of amusement to us. In fact, his face was so comically dull and heavy, and yet so plashed over with evidences of a keen sense and keener love of the ludicrous, that a single contortion of its outlines was enough to make one laugh.

We camped once for a week on Lower Indian River, and it was there that I made a shot of which I have some hesitancy in

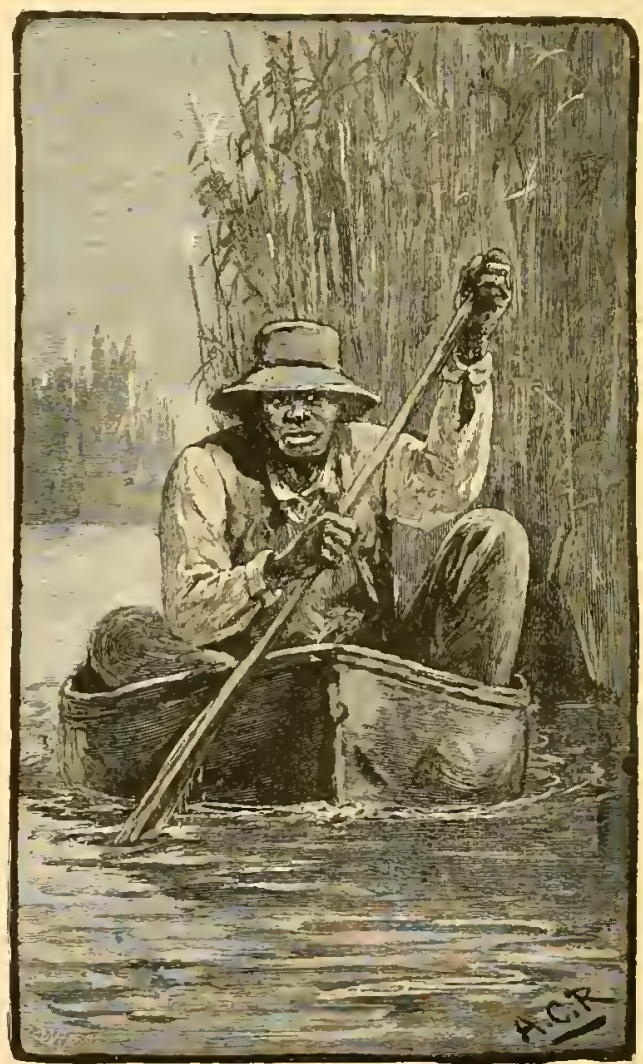

CÆSAR. 
speaking, so sure am 1 that its history must appear apocryphal, and I have no means of proving its truth. Our tent was pitched in a clump of palmetto trees, on a low jut of shore overlooking the frith of a lagoon of the river. A visiting party, composed of Mr. Willis Lloyd Parker and friends, of London, England, had just left us, making us a parting present of five bottles of pale sherry; so we planned to have a quiet dinner to the memory of our guests. Will was to go down the

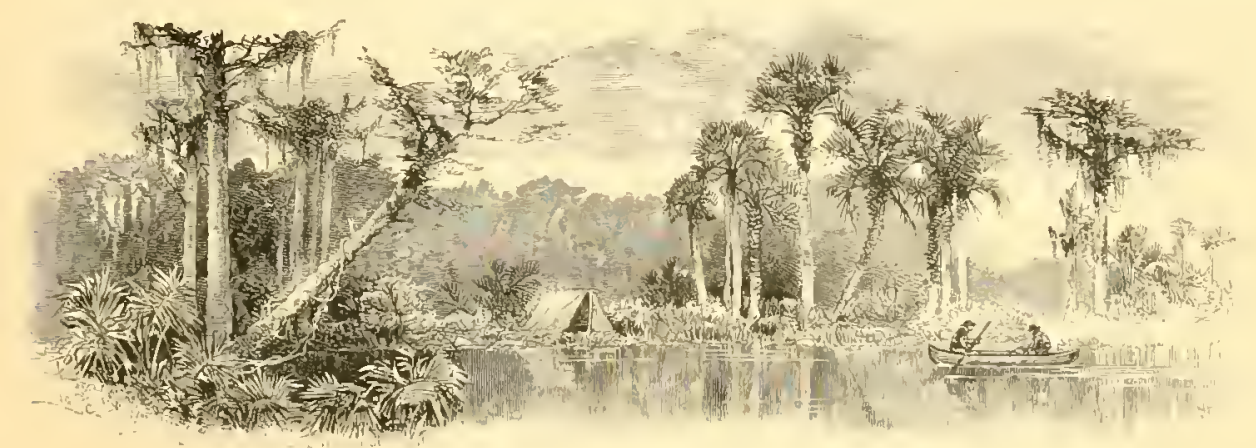

OUR CAMP ON INDIAN KIVER,

river for wild-fowl, while I pushed up the lagoon in a canoe, hoping to get a young turkey or two from a flock I had seen a few days before on a sort of island. Casar remained at the tent to take care of things. An hour of leisurely pulling over a still dead sheet of dark water brought me to where the lagoon forks at a sharp angle, flowing on either side of a densely wooded tongue of land, to where, a mile away, a barely perceptible shallow slough runs across from prong to prong, thus making a triangular island, barely separated from the main-land by this slough, over which deer or turkey could easily pass at low tide. I had caught sight of a late-hatched brood of turkey just at twilight one evening as I was passing this point, but they turned and ran into a thicket, and I did not care to follow them with only a few minutes of day-time to spare. I had come prepared for them now, and, looking about for a landing-place, I drew the canoe into a reëntrant angle of the shore, and secured it just as the sun of a semi-tropical winter day made glorious all the points of the flat verdurous landscape. Strapping on my quiver and stringing my bow, I plunged into the marshy wood where vines, moss, low-hanging boughs, tufts of palmetto and saw-palm made progress at times a matter of great labor, and attended with so much noise 


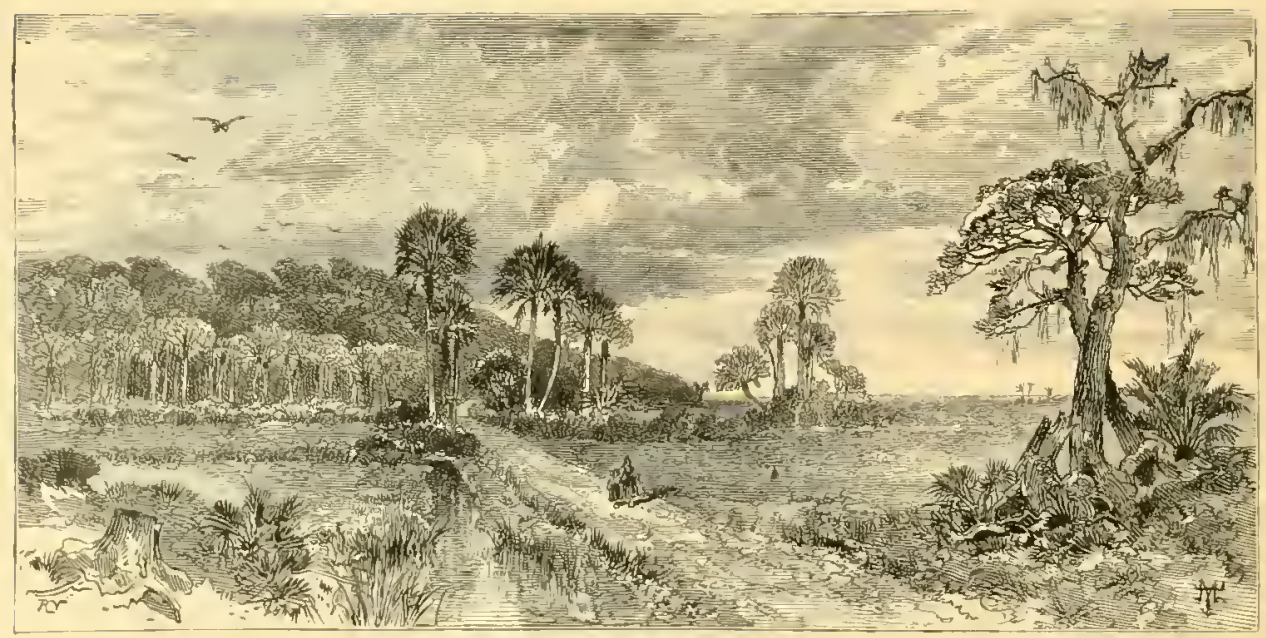

ON THE EDGE OF THE WUODS.

that such a thing as getting near a turkey was impossible. Farther in, however, a broad glade or meadow of low, coarse grass opened before me, on the opposite rim of which l saw the birds skulking quietly along far beyond bow-shot. The only feasible method of approach was to slip around the edge of the glade just inside the fringe of cover. To do this involved time and patient toil, but your archer is used to such tedious strategy. lioot by foot, rod by rod, stealthily as a cat, I made my way, till at length I came to a break in the cover, to pass which would be sure to expose me to the birds. They were fully one hundred and fifty yards away, moving slowly, close together, in a direction "quartering" to me. A few more steps, and they would be in the jungle. I must have a shot. My only chance was to risk the luck of a long-range flight at them. so 1 braced myself for a steady pull, elevated my bow-arm, drew to my ear, and let go a shaft. At the sound of the recoil of my weapon, the turkeys stopped, lifted their heads, and began that sharp cry of "Pit_pit!" so well known to sportsmen. Meantime, my arrow went singing through the elongated parabola of its flight. I watched it with that fixed eagerness which always attends a moment of intense suspense. A little breeze was blowing, but it did not seem to affect the course of the shaft. Swiftly it swept down, and I saw the feathers shatter out from the back of one of the turkeys, which tried to rise, but could not. It was a "solid hit," as we term it, and the bird was done for. The others of the flock took rapidly to wing, and soon 


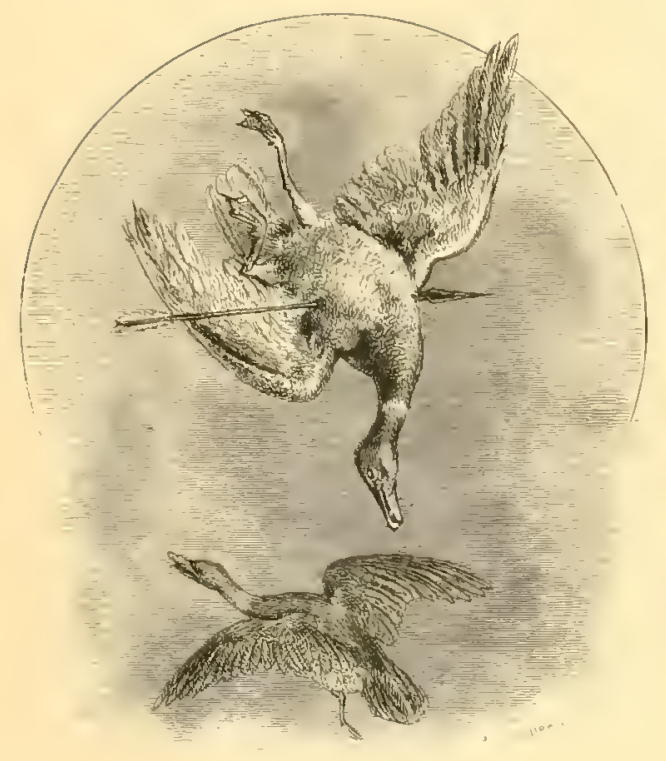

A SUCCESSFUI, 4 HOT.

curved into cover. This is the longrest successful bow-shot we have recorded. It must be noted, however, that I did not shoot at any particular bird, but at the flock, and of course "much good luck" was a strong element in influencing the result.*

On approaching my turkey, I found it pierced through the spine and lungs, quite dead. I spent an hour or two after this beating about the island, but saw no more of the flock. Three deer got up before me, and in following them I passed around an arm of the lagoon. Before I was aware of it, I had betangled myself in a jungle, from which it took me two hours more to extricate myself, and it was two o'clock when I reached my canue. Feeling pretty hungry, I did not dally much in returning to the tent. When I reached it, however, Cæasar was not there, and no preparations for dinner were visible. I lay down to smoke and rest. In a few minutes IVill came in, tired too; but Casar could not be heard from, though we called him in no gentle way. Finally, we had to make a fire and prepare the dinner ourselves. We roasted the turkey, which, being only about half-grown, cooked easily, and Will made some excellent coffee. We had sailor's biscuit, some pickles, onions, canned fruit, and then the wine; but when we came to look for the last-named article, not a bottle could be found! O Casar, what unfeeling treachery! We understood the matter now, and a little search discovered him lying under a palmetto-tree, sleeping the sleep of the very drunk. By his side were all the bottles, two of

* While on the subject of long shots, 1 must give to Captain H. H. Talbott, of our Crawfordsville (Indiana) Archery Club, the credlit of one of the fairest and finest, which was made in the presence of several witnesses. He hit a golden-winged woodpecker, a bird not quite so large as a dove, at a measured distance of seventy-nine yards. This, of course, is a better recorl than mine alove given. 


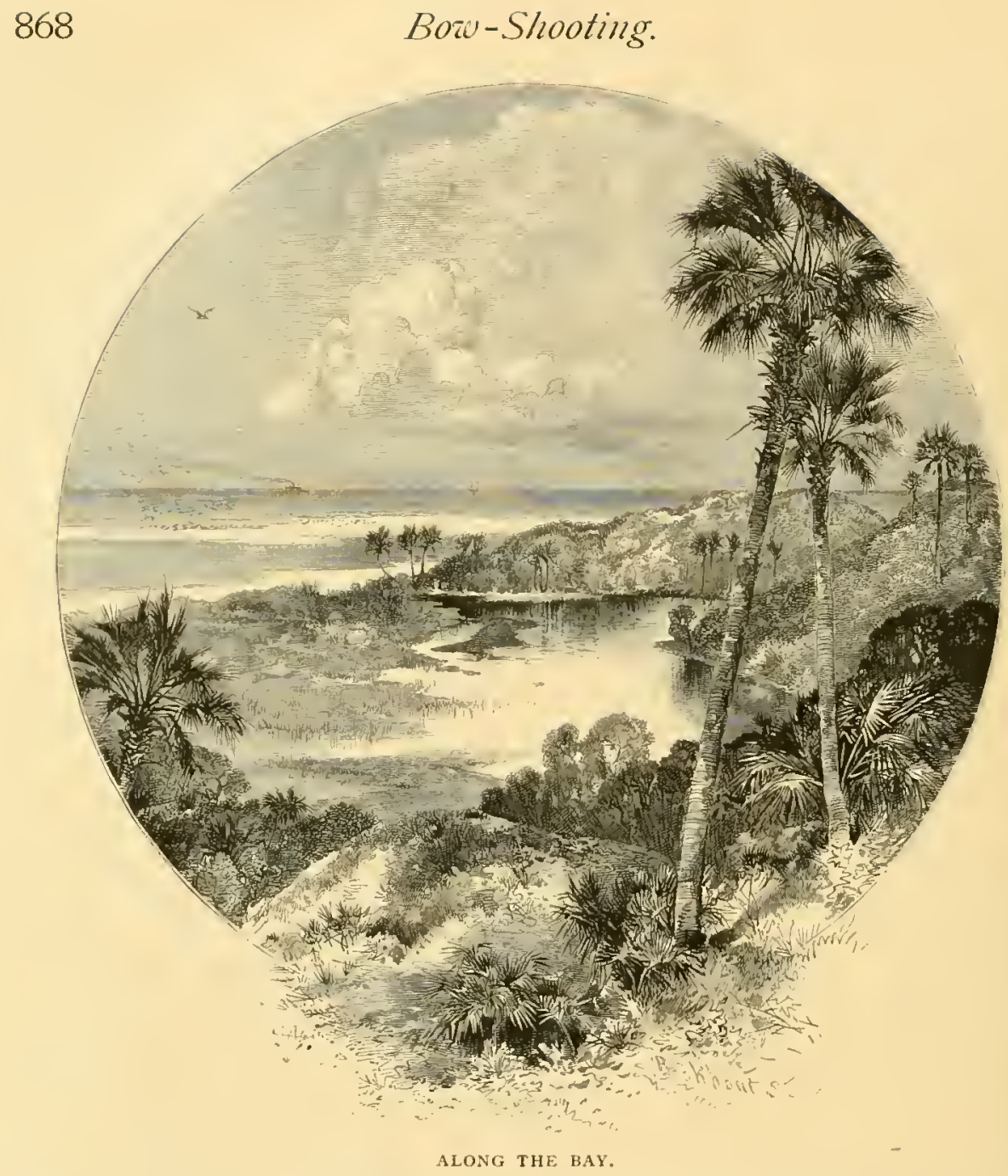

them nearly empty! We threatened to trounce him roundly when he got sober; but that great black, appealing face repelled our anger, and we forgave him.

I caunot think of camp life in Florida without longing to talk and write glowingly of it, but this paper must be a "practical" one. I am sure of this, however: no man ever went to Florida with a shotgun and found such sport, such exercise, such exhilarating pastime and recreation, as he could have found had he been an accomplished archer. Much of our time there was spent heron-shooting, and every sportsman knows what a wary, wild, almost unapproachable bird the heron is. Let me here say that woodcraft is probably the most important and most difficult part of all an archer's training. To be a successful hunter with the bow, you must know perfectly all the 
habits of your game; you must be stealthy and sly as an Indian, not the least excitable, patient, watchful, storing up in your memory every item of experience; and, above all, you must be keen-sighted and steady of hand. For to get within good bow-shot of your game is of the first value, and scarcely second to this is the power of instantly centering all your faculties in the act of shooting.

To show how a perfectly trained archer manages his approach to very wary game under circumstances of extreme difficulty, let me describe how Will worked his way to within forty yards of a snowy heron. The great white bird was sitting on the top of an old cypress-stump about twenty yards out in a shallow pond, and we were lying on a green tussock six hundred yards away. We had been talking about the great difficulty of getting a shot at him, and finally one of us remarked that it would be evidence of the very highest skill if a hunter should show himself able to outwit that old heron, and get within fair shooting distance of him. Finally, Will determined to try his luck, on condition that he should be considered champion if he succeeded.

The ground between us and the pond in which the cypress-stump stood was covered with thin, stiff grass, about knee high, with here and there tall tufts of broad-leaved aquatic weeds growing around little puddles of water. Will's method of procedure was to lie down in the grass, and snake himself along from one of these tufts to another, which would have been rapid enough and quite easy had the tufts been anything like in a row leading toward the bird; but this was not the case. Sometimes a space had to be passed, in full view of the heron, where nothing but the thin grass offered any cover. Here Will's patience and skill were put to strongest test. Lying flat in the grass, face downward, he drew himself forward inch by inch (so slowly that his motion was hardly discernible), till a weedtuft would hide him fron the game, then he would slip rapidly up to the tuft and repeat the process of slow, painful progress to another. Cæsar and I watched alternately the archer and the bird. Now and then the latter would stretch out its wings and shake them a little, or lift up its head to the full extent of its long neck; but the movements were not those of fright. As Will neared his game, his motions became still more slow and careful. He zigzagged back and forth from tuft to tuft, gaining only a few feet of distance for many yards 


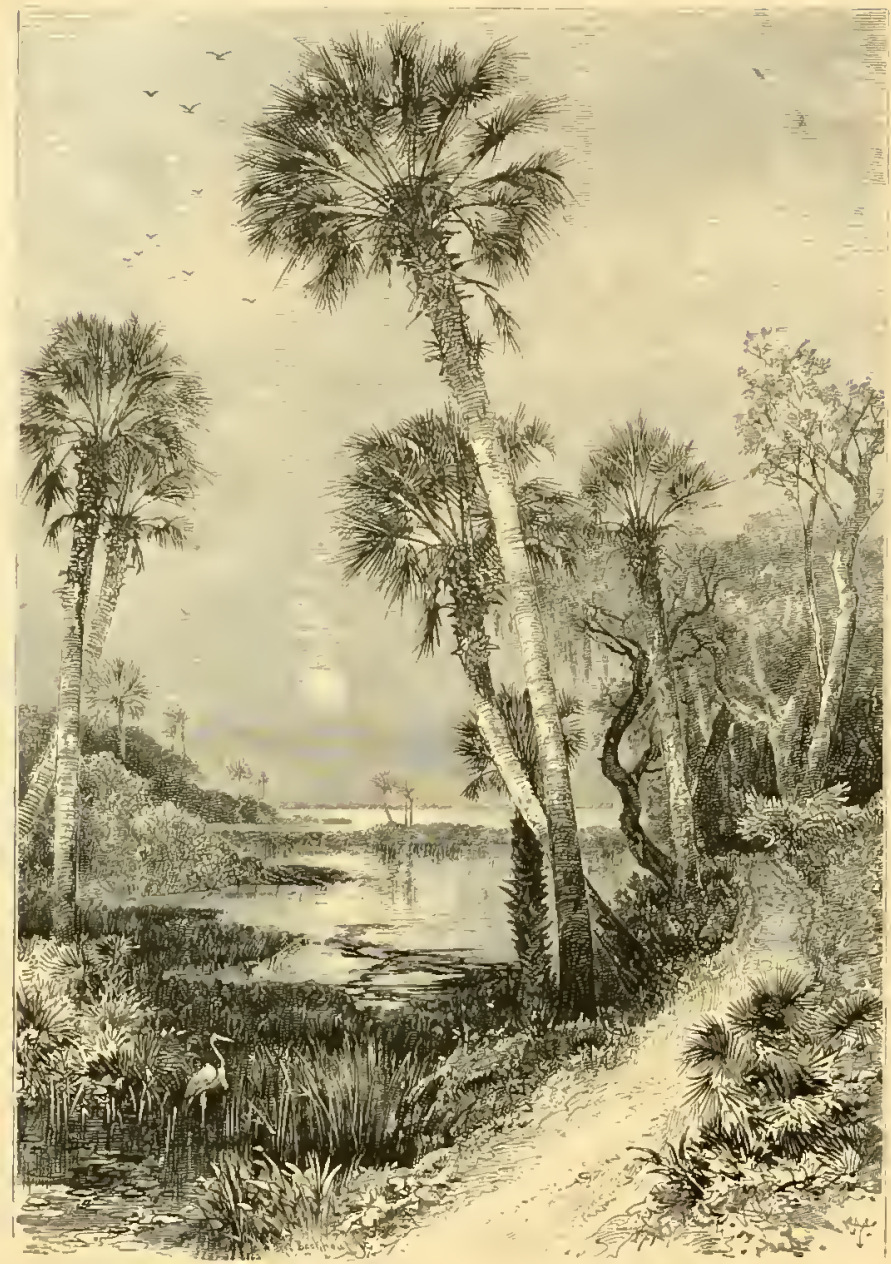

THE HAUNT OF THE HERON.

of creeping. But he was getting the space quite narrow between him and the heron. Presently it only remained for him to reach another tuft. Line by line he seemed to move, scarcely faster than the hand of a clock, and at last we saw him draw himself up behind the tall weeds. For a few moments he rubbed his arms to relieve them of their weariness, then he slipped an arrow from his quiver, nocked it on the string, and moved to one side of the tuft to get a view of his bird. I was watching his movements through a good glass, and I felt my nerves tingle with the excitement of expectancy. All at once he drew and shot. Down came the heron impaled on the shaft, his great wings spread out and his long neck doubled under him! Cæsar and I leaped to our feet and yelled with delight. 
Shooting fish might seem to be poor sport, but in the clear spring-streams of North Georgia we have had sone lively work and right royal fun killing bass (" trout," the people call then there) with the bow and arrow. Will was the first to attempt this, and after two hours' sport he brought in a string of five re six bass, one of them weighing over four pounds. They were certainly the most toothsome fish 1 ever ate, their flavor being equal to the famed pompano, while their flesh seemed firmer and juicier. After this, "trout" shooting became a favorite change with us when tired of other sport or when other game did not offer. No disciple of lzaak Walton need fly into a passion at this, for in the clear spring-streams of North Georgia no bass would ever take either fly or minnow for me, thumgh in the rivers and brooks they are lively enough game for the hook. In the Oothcaloga, a small mill-stream near Calhoun, I caught a string of sixteen pounds in less than two hours, but in the Cranetah and Bir Spring streams they will not rise or strike at all.

It is a long step from Florida to the Kankakee region of Illinois and Indiana; but there are times when the sportsman may take the step with profit to himself. In the spring and fall, this region is one of the finest grounds for mallard, teal, wood-duck, and greese, to be found in the L'nited States. I need not say to a sportsman that the mallard is a king's own bird for the table. The canvas-back does not surpass it. I have shot corn-fed mallards whose flesh was as sweet as that of a young quail, and at the same time as choiceflavored as that of the woodcock. A favorite way of shooting these birds, and geese also, with the bow, is for the archer to conceal himself at a point over which a flock will fly when disturbed, and send an assistant to go by a wicle circuit round the game and drive it over. I have seen eight or ten birds taken in this way during the course of two hours' shooting. But the best sport is had by slipping along the shores of the ponds and streams and getting single shots by strategy. In the Kankakee lagoons one may shoot all day at buffle-heads, wood-duck, teal, scaup-duck, and mallard without getting out of sight of his camp. On the flat prairies bordering this river plover are plentiful, and no bird offers a better mark for an arrow. It is somewhat difficult to hit, but the sport is exciting on account of the fact that on the smooth. level meadow of the prairie 
you can mark just how near you come to killing each bird; and oftentimes a miss, when your arrow fairly lifts the back-feathers of the game or "tips" its tail or beak, gives you as much pleasure as if you had bowled it over. The peculiarly lively skip and jump taken by a plover when an arrow-head strikes into the ground beside it is enough to make any healthy man laugh in spite of himself. Of course, when shooting at game so small,

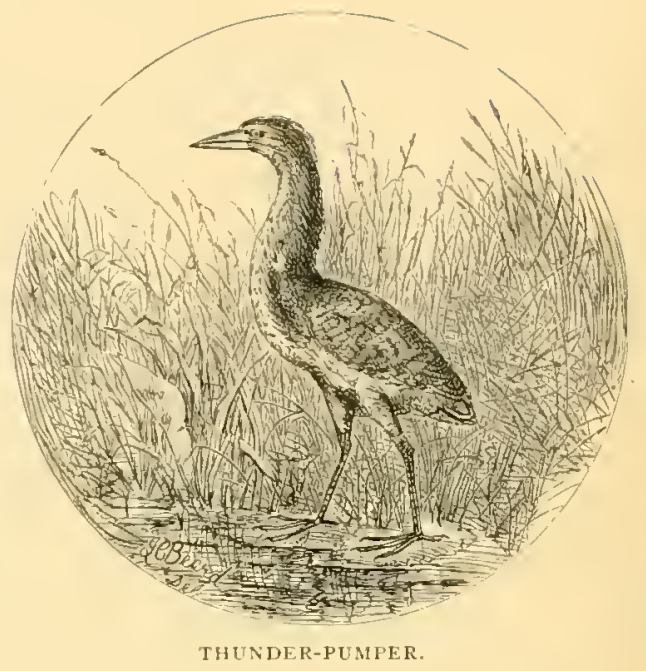
you must be content to miss five times as often as you hit; indeed, to kill once out of five shots would be excellent archery. I have had some days of rare sport when my score showed over forty shots to each bird I bagged.

A kind of bittern or night-heron haunts the prairie sloughs in the Kankakee region, and often, for lack of better game, I have knocked them over for their wing-feathers, which make excellent trimmings for light arrows. The natives call these bitterns by the very appropriate, if not euphonious, name of "thunder-pumper."

It is rather remarkable that the archer is subjected to the criticism of everybody who sees him. A grave man, who boasted of having served many years in the Hoosier senate, once gave me a long lecture on the folly and childishness of "playing with bows 'n arrers"; but he would sit all day beside a mill-pond, fishing for " goggleeyes" and sun-perch, without dreaming of childishness. A Kankakee herder, with a cast of countenance decidedly hangdog, ventured to set his big cur on Will, because he went among some cattle to shoot at a prairie-hen; but a well directed blunt shaft settled the dog. which ran yelling back to its irate master. I well remember an old curmudgeon whom we ran across in a Florida woods. He carried a flint-locked rifle, nearly six feet long, and wore what, some twenty years before, had been a beaver tile. He helped himself to an enormous quid of smoking fine-cut, and forthwith began to ply us with questions about our weapons. We very patiently explained our 


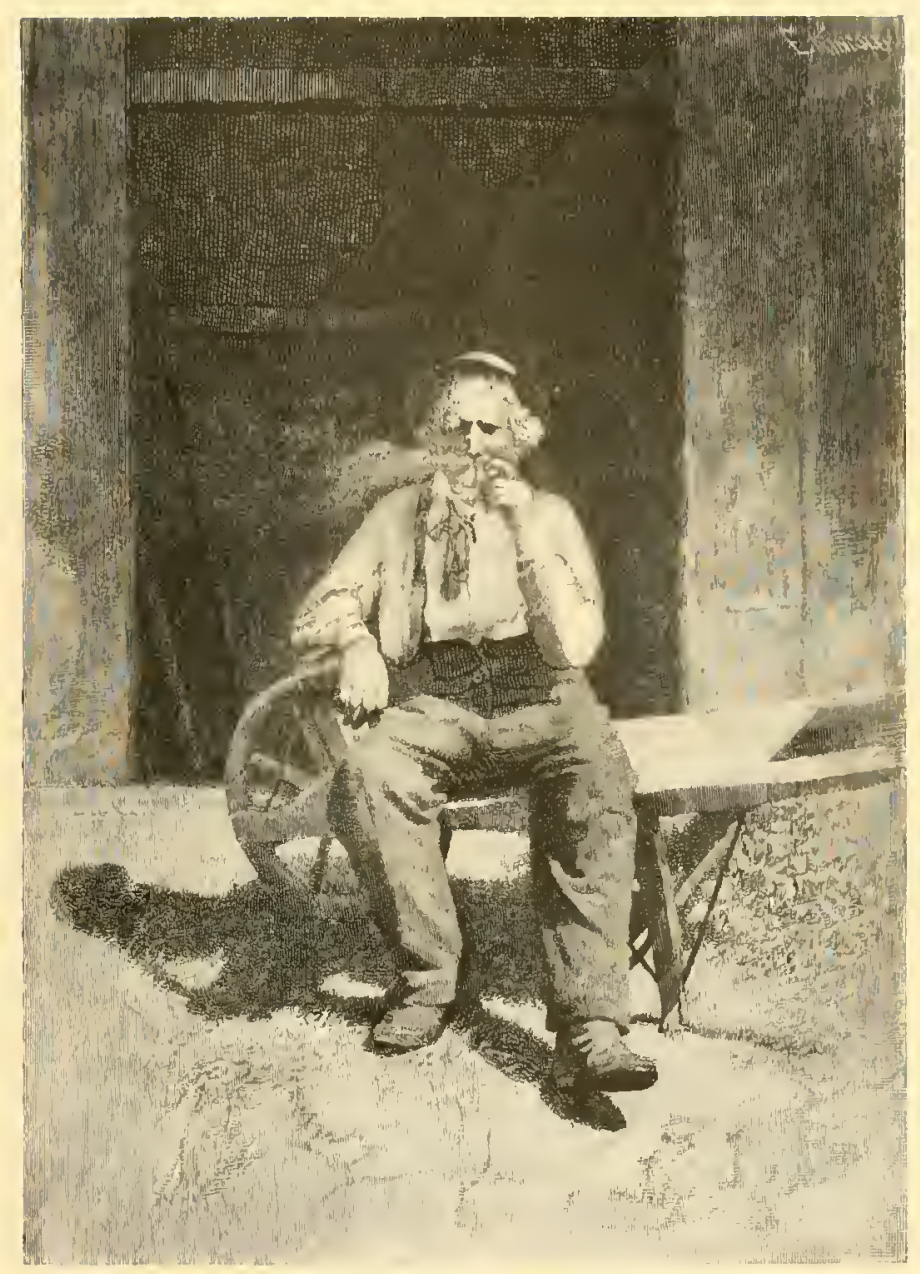

A STAID ULD FARMER.

method of shooting and how our arrows were made, the use of our quivers, and so on, till he seemed satisfied, and stood for a moment as if plunged in deep meditation. Then he turned abruptly away and left us, muttering as he did so, "Ye couldn't gi me a thousand o' them ere bows!"

Sometimes we have been followed for a half-day at a time by a staid old farmer, to watch us shoot. His delight at our success was as unbounded as his amazement was profound.

Wood-duck shooting is the bowman's richest sport, and the bird itself is the most royal of game in everything but size. The little streams of the Middle and Western States, especially those of Indiana 
and Illinois, teem with wood-duck in their season, which is from the first of September to about the tenth of November, when they fly south. These small streams mostly flow through a wooded country, between low bluffs fringed with papaw and hazel thickets, and overshadowed by giant oak and plane trees. Acorns are constantly dropping into the clear water, giving the ducks all the food they desire; but should this source chance to fail, the wheat-stacks and corn-shocks of the farmer are hard by, and to them they make daily excursions. Under cover of the bluffs or the hazel and papaw thickets, the archer has easy work approaching his bircls, and generally gets within short range of them before he shoots. If you can keep the shot-gunners away, three or four miles of a well stocked stream will afford two archers plenty of sport for a whole season. Hunting them with the bow does not drive the birds off to other haunts; but the sound of a gun soon depopulates a stream, whether any duck be killed or not. The little rivulet I am now hunting along is so shallow that $l$ can wacle it at any point, and its average width is not over fifteen yards. No gunners have been on it this season-i.c., within a mile or two of my cabin, each way. The ducks are plentifully distributed along my beat, and seem very fat. I am having grand luck.

Yesterday, I found an old, dead, scraggy plane-tree, so full of knot-holes and deserted woodpecker holes that it looked like a dry honey-comb, and it was literally crammed with flying squirrels. I spent an hour pounding on the old shell and shooting at the little animals when they came out of the holes. Anything that flies, swims, climbs, or runs is game for the archer. He shoots at everything, from a tomtit to a hawk or an eagle, from a flyingsquirrel or ground-squirrel to a deer. He is out for sport, and means to have it.

To close this paper, a few plain rules for bow-shooting will be of value to those who may be tempted to try it.

The first thing is to secure good weapons. A poor bow and slipshod arrows are worse than none.

For target practice, a fifty-pound lemon-wood bow, six feet long, and best-footed Highfield arrows, twenty-eight inches long, are what is needed. A hunting-bow should be ten or fifteen pounds heavier. 


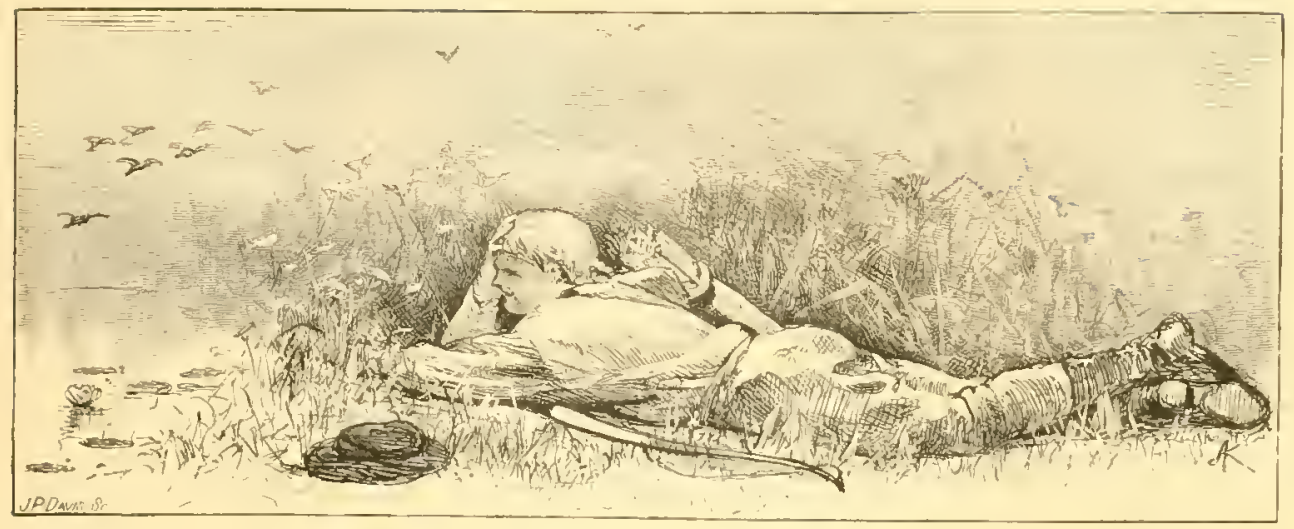

WAITIG FOR A SIIOT.

All your weapons and accouterments must be kept dry and well oiled. Dampness and archery do not ayree.

Never allow yourself to make a careless shot at anything. Strive for excellence at every effort.

Never try to take aim when shooting, but fix your eyes steadily on the mark, and guide your arrow by your sense of dimetion.

Squeese the bow-handle with the left hand. You cannot hold it too fast. Draw quickly and evenly. Let go without "bobbling" or tremor.

Do not allow the sight of game to put you all in a quiver. You cannot shoot well when excited.

I do not decry angling and gunning, except that the latter is too destructive of game. I am an enthusiastic "disciple of the rod," but whenever I cast a fly or troll a minnow my long-bow is near at hand and a well filled quiver at my side. You cannot combine gunning and angling on account of the weight of the gun and accouterments, and still more because the noise of fire-arms is sure to render timid fish sullen. I have known the bass in a well stocked pool utterly to refuse the most tempting bait through an entire day, for nothing more than a pistol-shot fired close by. The twang of a bowstring seems to frighten nothing. It was the old first note of music made by Apollo.

I will here endeavor to set forth the whole "code of practice" of archery as I follow it:

To MAKF a Goun Buw.-Take a good, clear billet split from mulberry, sassafras, Southern cedar, black locust, ash, or apple-tree, 
giving preference to the woods in the order named. Let the billet be from five to seven feet long, according to the desired length of the bow. Now with great care shave the piece down to a uniform size for its whole length, say nearly circular, and two and a half inches in diameter. Lay the piece away to dry in the shade for two months, taking care that no hint of moisture ever reaches it. When it is thoroughly seasoned, finish as follows: First, mark the exact center of the billet, and from this point in the direction of what is to be the lower end of the bow lay off a space of five inches for the handle. From each extremity of the handle taper the bow to the ends, each of which must be a shade larger than the tip of the archer's third finger. Now dress the handle and body of the bow down till by trying it you find it nearly of the proper strength, then flatten the back a little the whole length of the bow, glue a bit of green plush round the handle, and your bow is ready for the horn tips, which are the ends of cow-horns bored out to fit over the bow's ends and nocked or notched as seen in the detail drawings on a previous page. The hole bored in the horn to receive the tip of the bow should be deep enough to let the wood pass in to slightly above the nock. To make the horn work easily, boil it in water for an hour or two. A bow of six feet in length and of sixty pounds drawing power will throw a good arrow two hundred and twenty-five yards. Of course, the reader knows at once that his bow must be suited to his muscular force and to the experience he has had in archery. Fifty pounds drawing weight is about right for an ordinary man to begin with. The length of the bow should be two or three inches in excess of the archer's height. A lady's bow may be from twenty-eight to forty pounds strong. I have somewhere seen it stated that her majesty Queen Victoria in her younger days greatly enjoyed archery, and gloried in her ability to brace and draw a fifty-five pound bow.

To Make a Good Bowstring. - Take silk or flax harness-thread of the best quality and twist a string of about one-seventh of an inch in diameter, waxing it well during the process of twisting with shoemaker's wax or bees-wax. Fasten one end of this string tightly into the nock of the lower end of the bow. With the other end of the string form a neat, firm loop (not a slip-noose) around the other end of the bow, two and a half or three inches below the nock. Your weapon is now ready to string, or "brace," as the old archers had it. 
To Make a GuOl) Arkow.-Make the shaft as directed in the previous article; peel off the skin or outer covering of the broad sicte of a groose-feather with the vane or plume on the skin, or rather peet three feathers thus and glue the strips on the shaft as therein described. These vanes may, if necessary, be held to their places till the glue is hard by a wrapping of fine thread. The nock must be deep and smooth, and large enough to receive the string freely. The heads of target-shafts can be made by any smith. They consist of light, pointed iron or steel thimbles made to fit over the ends of the arrows; or you can make excellent heads by boring out bits of pointed horn and using them in the place of the steel heads. The steel points for the shafts used in hunting large game I have already described. By referring to the detail cuts there given any good blacksmith can make them. They should not weigh over a halfounce. A good arrow-head for bird-shooting is made by pouring melted hard pewter over the end of the shaft and keeping it to its place, till cooled, by a cup of stiff writing-paper. To do this, cut a shoulder one inch or less from the extremity of the shaft, and slightly lessen the wood for that distance; then roll the paper round the shaft, and tie it so as to leave room for the pewter to fill in round the shoulder between the wood and the paper. This will form a smooth, bright ferrule. Some sharp spiral notches cut in the wood where the pewter goes will serve to hold it firmly to its place when it cools. Ladies' arrows may be from, twenty-three to twenty-seven inches long, and highly colored with gilt and gay paints to suit the taste or whim of the archer.

How to Shoot. - Your bow being first strung or braced, hold it horizontally before you, $i . c$., with the bow at right angles with your body, your left hand firmly grasping the handle; slip an arrow under the string and over the bow at the right edge of your left hand and touching the left forefinger knuckle; place the arrow-nock well on the string; turn the palm of your right hand up, placing the first three fingers thereof under the string, hooking their tips round it with the arrow between the first and second, and the thumb extended along the shaft near the nock. Now, keeping all holds thus, turn the bow till it stands vertically before you, your arrow resting against and above your left forefinger knuckles; turn your left side to the target, fix your eye steadily on the center of the bull's-eye, draw the string 
back till your right thumb touches the upper tip of your right ear; squeeze the bow-handle powerfully with the left hand, steady! let drive! Now, if you have paid good heed to the above directions and have been sure to keep the arrow-nock well on the string, you have made a pretty shot. Do not attempt to take aim. The only way to become a good bow-shot is to learn to guide your shaft by feeling, $i . \varepsilon$., by your sense of direction and distance Your eyes must be glued, so to speak, upon the target. This is the one great rule of archery.

\section{Miscellaneous.}

No home-made bows or target-arrows can half-way equal those beautiful weapons made by Philip Highfield, of London, England; Messrs. Peck and Snyder, of New York City, are Mr. Highfield's American agents. A letter addressed to them will procure for its writer a catalogue and numbered price-list of archery goods. In purchasing a bow ask for a " gentleman's (or lady's) lemon-wood bow, horn-tipped, plush-handled," stating desired length and strength. I would advise the reader to begin with a rather weak bow.

For target-arrows order "gentleman's (or lady's) whole-nocked, best-footed, Highfield target-arrows," naming length.

Targets, made of plaited straw and faced with canvas, may be had of any size from one foot to four feet in diameter. Each archery club will need at least two targets.

The best shooting gloves are of kid or lisle thread, with closefitting gauntlet-bands covering the whole fore-arm, thus serving as both glove and arm-guard. I cannot recommend the finger-tips sold as shooting gloves by the dealers.

To form a club, let any number from six to thirty gentlemen and ladies associate themselves by a constitution and by-laws taking some appropriate name, and electing their officers, such as masterbowman, secretary, and treasurer. I prefer the title of master-bowman to that of president, and suggest that societies do not cumber their organizations with too many officers. The master-bowman is, of course, the leader or chief of his band. He settles all disputes between his followers arising on the field or in the hall. The secretary and treasurer fill the same places, respectively, that are filled by like officers in other associations or companies. At each shooting, 
the archer who makes the highest number or score is entitled to the honorary title of captain of numbers or captain of the target. A silver arrow, a small silver bugle-horn, or some other appropriate prize, may be offered. An old Spanish yew bow of English make would be a happy choice.

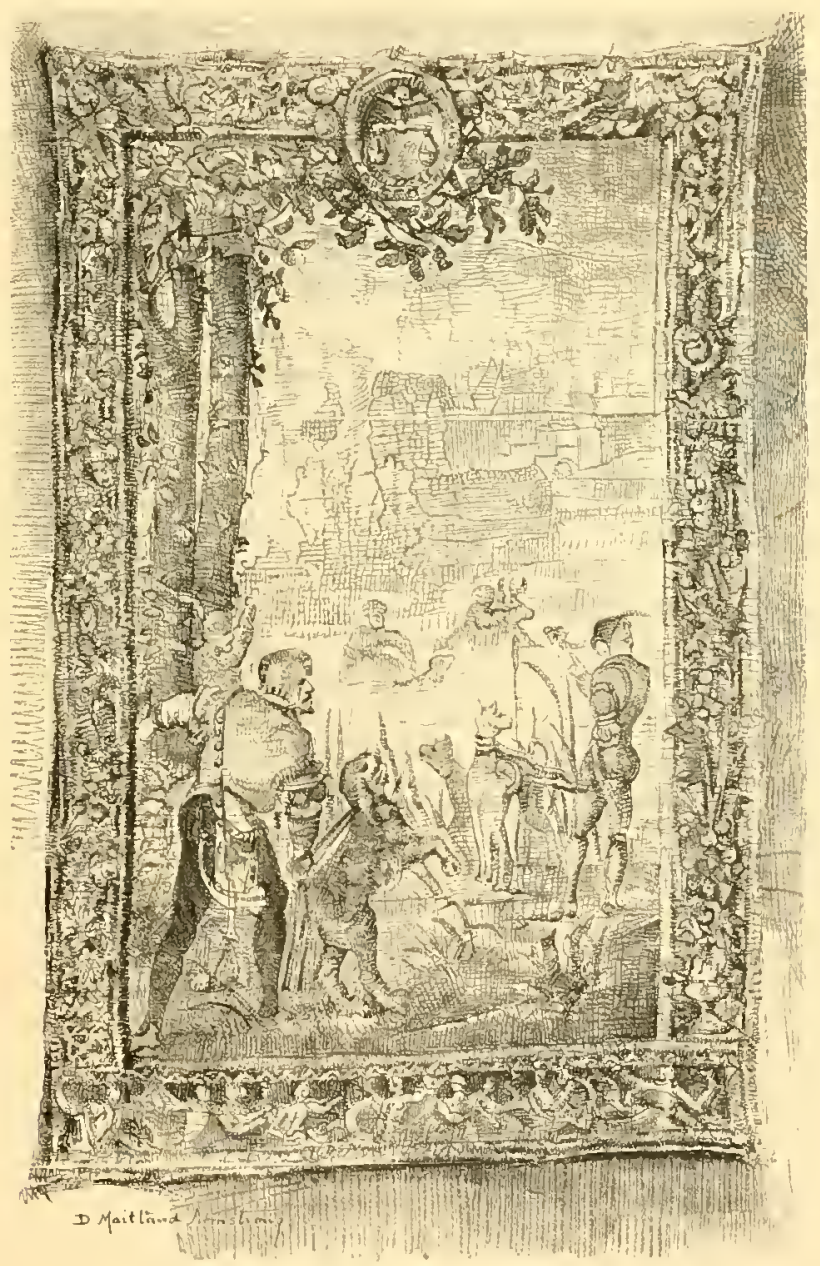




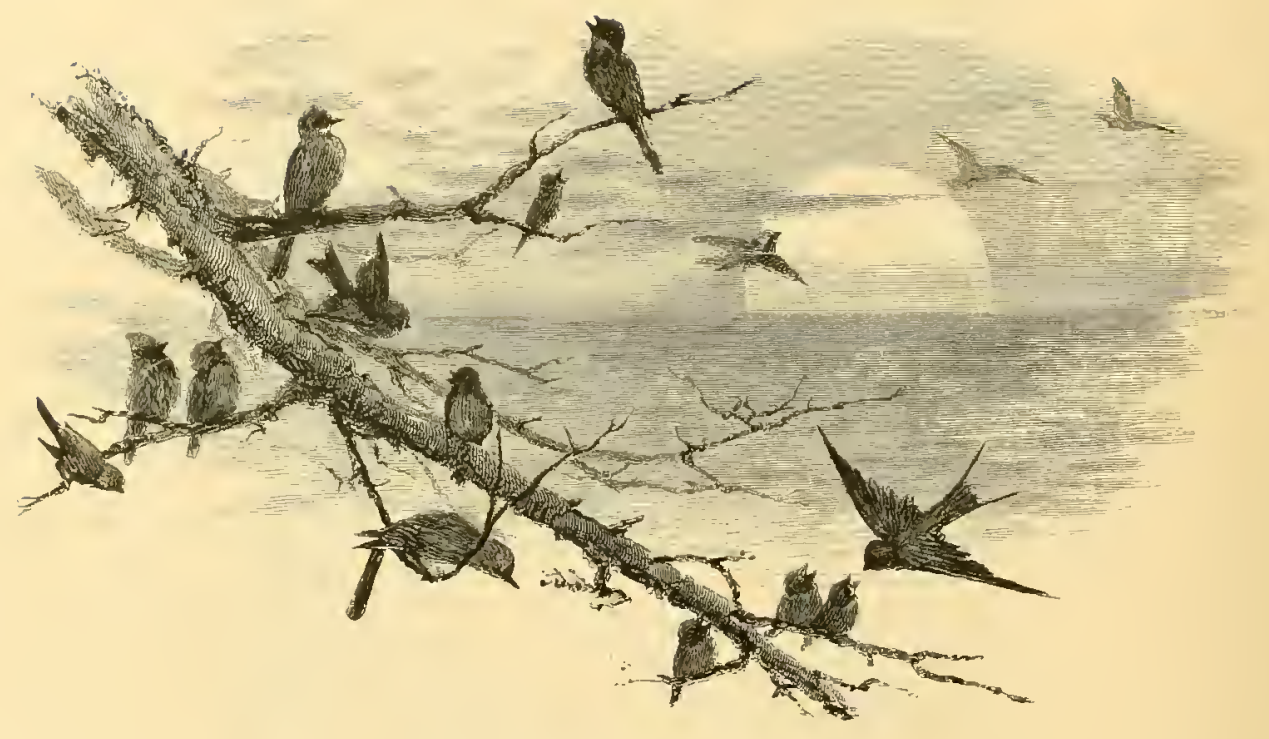




\section{THE BLUI!-GLN. \\ BY ALFRED II. II A Y ER.}

I

$\mathrm{N}$ studying the development of the modern gun and rifle, ${ }^{*}$ it is very interesting to see how nearly all the parts and functions of these arms are foreshadowed in the blow-gun, a weapon admirably aclapted to the nceds of the hunter in the country where it is cmployed. This arm, like many other weapons used by savages, is found in use among tribes of different races inhabiting countries far removed from one another. The blow-gun is the sporting-arm of the Dyaks of Borneo, and of the Indians inhabiting South America between the Amazon and the Orinoco rivers. It was also used by the Choctaws of the lower Mississippi. Bossu, in his "Travels in Louisiana, 1756," says: "They (the Choctaws) are very expert in shooting with an instrument made of reeds about seven feet long, into which they put a little arrow feathered with the wool of a thistle; and in aiming at an object they blow into the tube, and often hit the aim, and frequently kill little birds with it."

The four different types of blow-guns used by savages are alike in general form and method of use. 1 will give an account of the blow-gun used by the Macoushies of Guiana, and called by them the fucuna. These Indians are the most expert of all the savages in the manufacture of the blow-gun. They also have the secret of the preparation of the death-dealing wourali poison with which their blow-gun arrows are tipped. A neighboring tribe, called Warus, . 2 the best canoe-makers, and they exchange canoes and paddles for the blow-guns and wourali of the Macoushies.

The Nacoushie blow-gun is made of two reeds, one within the other. The inner reed is called the ourah, and it is the use of this 
inner barrel which makes the Macoushie gun superior to all others. The ourah is only found on the sandstone ridge of the upper Orinoco. It grows to a height of fifteen feet without a joint. The diameter of the reed is only half an inch, while its thickness is not more than twice that of a playing-card. Its interior is by nature highly polished and is of a regular bore, contracting slightly from one end to the other. But this reed cannot be used alone, for it is fragile, and the thinness of its walls allows it to bend when held away from the vertical position; so it is incased in another tube made of a species of palm. A rod of this, having the proper diameter, is cut and steeped in water, which allows its interior pulp to be taken out. Into this tube, called the somourah, is slipped the ourah reed, and the savage gummaker has a wonderful skill in straightening the axis of his gun-barrel, and neatly fitting it to the interior of the samourah, where it is firmly fixed in place by the black kurumanni wax. The samourah is then scraped down to the proper thickness and polished.

The mouth-end, or breech, of the gun is bound with a string made of silk-grass. The muzzle is slid through a hole in the saucershaped piece of actero nut, and the space between the interior of the nut and the tube is filled with kurumanni wax. This nut forms a ferrule to the tube and also serves as the front sight of the gun. The rear sight is ingeniously formed of two of the lower incisors of a rodent called the acouchi. These teeth are cemented to the tube with wax, with their convex sides upward. In the space between these teeth the wax is depressed, so as to form a rear sight similar to the open sight of a rifle, at about two feet distant from the mouthpiece. This tube, though very strong, is quite light. It is eleven feet long, and it weighs only one pound and a half.

The arrows propelled by this gun are about the size of knittingneedles. They are formed of the leaf-ribs of the coucourite palm. The Indian forms the shafts of his arrows and points them by drawing these leaf-ribs between the sharp-edged teeth of the pirai fish. On one end of the arrow is wound a pear-shaped mass of wild cotton and fastened there with a fiber of silk-grass. The arrows are woven together, so that they may be coiled on a reel, and safely carried in a water-proof quiver.

The Indians of Guiana also use a very ingenious arrow. In 
this the ball of cotton is replaced by a piece of thin bark wrapped into a cone, which the puff of air expands and causes it to fit the tube tightly without windage. Here is the first inception of the Minié-ball. Longer pieces of the same bark are fixed along the sides of the shaft, and these wings are twisted, so that the arrow in its flight must rotate on its axis. Here we have the counterpart of the rotating rifle-ball.

The bore of all the blow-guns that I have examined is slightly conical, tapering about four millimeters in bore from mouth-piece to muzzle. Here we have the first choke-bores. It may be said that they did not intend them to be such, for nature thus macte the hollow of their reeds. This is true; but nevertheless their guns are choked, and the arrows are always propelted toward the end having the smaller diameter of bore.

In the blow-gun, or sumpitan, of the Dyaks, * the analogy of the blow-gun to modern ams is carried yet further in the appearance of the bayonet. The sumpitan is armed at its muzzle with a spear-head, which is bound to the side of the end of the tube so as not to interfere with the flight of the arrow. This spear is supposed to serve also for a front sight.

The reader who is fond of tracing the analogues of our modern arms, tools, and customs in the weapons, implements, and habits of savages will be pleased to have found in the blow-gun the elements of our most approved modern fire-arms. The blow-gun uses the expansive force of a gas in propelling a projectile. It is of necessity a breech-loader. It is choke-bored. It has rear and front sights. It throws a projectile which, like the rifle-ball, rotates around its axis in its flight, and like the Minié-ball, expands at its base so as to fit closely the barrel through which it is propelled; and lastly, it carries at its muzzle the equivalent of a bayonet.

The wourali poison with which the arrows are tipped is made by the conjurers of the tribe, and the secret of its preparation is handed down from father to son. This, together with the fact that all the neighboring tribes purchase this poison of the Macoushies, in whose interest it is to keep the composition a secret, throws some

* For an account of the sumpitan, see "The Head-Hunlers of Borneo," by Carl Bock, London, r88 r. 
doubt over the information which travelers have obtained of its composition. Our knowledge of its ingredients is due mainly to Watterton,* who spent much time among the natives of Guiana. From them he received the information that the ingredients of the poison were the wourali vine (which is nearly allied to the strychnus toxifera which furnishes the nux vomica from which strychnine is made), the bitter root of the hyarri plant, the glutinous juices expressed from the stems of two bulbous plants; two kinds of ants, one a huge black one, whose venomous sting often causes a fever, the other a small red insect, whose sting is like the thrust of a red-hot needle: and lastly, the poison-bags of the labarri and couanacouchi snakes. Boiling water is poured over the scrapings of the wourali and hyarri woods, which are placed in a colander resting on an earthen pot. Into the decoction which flows into the pot the Indian now squeezes the gelatinous juice of the bulbous plant, and then adds the serpents' poison and the ants. This mixture is simmered down to the consistence of molasses. The pot is then tightly closed with leaves and a skin, and always kept in a dry place.

"The act of preparing the poison," says Mr. Watterton, "is not considered as a common one; the savage may shape his bow, fasten the barb on the point of his arrow, and make his other implements of destruction, either lying in his hammock or in the midst of his family; but if he has to prepare the wourali poison, many precautions are supposed to be necessary.

"The women and young girls are not allowed to be present, lest the Yabahou, or evil spirit, should do them harm. The shed under which it has been boiled is pronounced polluted, and abandoned ever after. He who makes the poison must eat nothing that morning, and must continue fasting as long as the operation lasts. The pot in which it is boiled must be a new one, and must never have held anything before, otherwise the poison would be deficient in strength; add to this that the operator must take particular care not to expose himself to the vapor which arises from it while on the fire.

"Though this and other precautions are taken. such as frequently" washing the face and hands, still, the Indians think that it affects the

* "Wanderings in South America, the North-west of the United States, and the Antilles, in the years I812. I8I6, I820. and I82 I." By Charles Watterton, Esq. London, Macmillan \& Co., I879. 
health; and the operator either is, or, what is more probable, supposes himself to be, sick for some days after.

"Thus it appears that the making the wourali poison is considered as a gloomy and mysterious operation, and it would seem that they imagine it affects others as well as him who boils it; for an Indian agreed one evening to make some for me, but the next morning he declined having anything to do with it, alleging that his wife was with child!"

To shoot the blow-gun, the Indian rests his left elbow against his hip and grasps the tube with the palm of his hand upward; then, with the palm of the right hand downward, he grasps the tube near the mouth-piece. This manner of holding his gun is similar to a method, though a bad one, of aiming with a rifle.

The birds and animals at which he shoots are generally in the tops of the highest trees, often out of reach of any ordirrary shotgun; but the Indian rarely faits to bring them down. Throwing his body backward, the gun rises till it has the proper elevation, when, with a quick expiration of his lungs, the arrow leaves the tube with a pop like that made by a cork quickly taken out of a small bottle.

"It is natural," says Watterton, "to imagine that when a slight wound only is inflicted the game will make its escape. Far otherwise. The wourali poison almost instantaneously mixes with blood or water; so that if you wet your finger, and dash it along the poisoned arrow in the quickest manner possible, you are sure to carry off some of the poison. Though three minutes generally elapse before the convulsions come on in the wounded bird, still a stupor evidently takes place sooner, and this stupor manifests itself by an apparent unwillingness in the bird to move. This was very visibie in a dying forl.

"Having procured a healthy, full-grown one, a short piece of a poisoned blow-pipe arrow was broken off and run up into its thigh, as near as possible betwixt the skin and the flesh, in order that it might not be incommoded by the wound. For the first minute it walked about, but walked very slowly, and did not appear the least agitated. During the second minute it stood still, and began to peck the ground; and ere half another had elapsed. it frequently opened and shut its mouth. The tail had now dropped, and the wings almost touched the ground. By the termination of the third 
minute, it had sat down, scarce able to support its head, which nodded, and then recovered itself, and then nodded again, lower and lower every time, like that of a weary traveler slumbering in an erect position; the eyes alternately open and shut. The fourth minu, brought on convulsions, and life and the fifth terminated together.

"The flesh of the game is not in the least injured by the poison nor does it appear to corrupt sooner than that killed by the gun or knife. The body of this fowl was kept for sixteen hours, in a climate damp and rainy, and within seven degrees of the equator; at the end of which time it had contracted no bad smell whatever, and there were no symptoms of putrefaction, saving that just around the wound the flesh appeared somewhat discolored. * * * * *

"With a quiver of poisoned arrows slung over his shoulder, and with his blow-pipe in his hand, in the same position as a soldier carries his musket, see the Macoushi Indian advancing toward the forest in quest of powises, maroudis, waracabas, and other feathered game.

"These generally sit high up in the tall and tufted trees, but still are not out of the Indian's reach; for his blow-pipe, at its greatest elevation, will send an arrow three hundred feet. Silent as midnight, he steals under them, and so cautiously does he tread the ground that the fallen leaves rustle not beneath his feet. His ears are open to the least sound, while his eye, keen as that of the lynx, is employed in finding out the game in the thickest shade. Often he imitates their cry, and decoys them from tree to tree till they are within range of his tube. Then, taking a poisoned arrow from his quiver, he puts it in the blow-pipe and collects his breath for the fatal puff. Silent and swift the arrow flies, and seldom fails to pierce the object at which it is sent. Sometimes the wounded bird remains in the same tree where it was shot, and in three minutes falls down at the Indian's feet. Should he take wing, his flight is of short duration, and the Indian, following the direction he has gone, is sure to find him dead.

"The Indian, on his return home, carefully suspends his blowpipe from the top of his spiral roof, seldom placing it in an oblique position, lest it should receive a cast." 
INDEX 



\section{N DEX.}

Alce Amerianns. See Moose.

Alexander, Lawrence 1)., Paper by. The sylit-Bamboo Rorl, 6o1.

Antelope, 3 or, 303 .

Antilocanta dincriana Ord. See Antelope.

"Arbor llex." Paver by.

Camps and Tramps about Ktaann, Sor.

Bamboo Rod, The split, 408, +11, 597.

Bass, Black, 379, 396, 451,591, 594, 87 I.

Bass, Stripecl, $4+9$.

Bear, How I killed a, 8zo.

Bear-hunting in the South, $6_{5}$.

Bear, The Black, $49,176,820$.

Birch Bark, 182, 252, 519, 527. 520, 569 .

Bison Americamus. See liuffalo.

Bird, Jlow to mount a, $8_{33}$.

Black-tail I leer, $130,149,258,301$.

Blow-( sun, The, 881 .

Blue Fish, 452, 455 .

Bobbing, 393 .

Bol, White, 620,663 .

Bond Boats, 7 I4.

Bow-shooting, 854 .

Bream and Bass, In the Haunts of, 396 .

Butfialo Hunting, ror.

Burroushs, John, Paper by.

The Halcyon in Canada, 5+1.

Calls, ITood, 161, I 78, 190, 194, 196, 200, $214,763,764$.

Camp, 168, 182, 185, 1 $87,216,240,261$, $327,360,+21,432,+33 \cdot+46,521,715$, $730,802,817$.

Callarla, 54, 154, 182, 187,208, for, 473 , $507,5+1,573$.

Canoe, $18+527$

Canvas-back and Terrapin, 726.

Curiacus Columbinnus. See Black-tail Deer.

Cariacus Macrotis. See Mule-1)eer.

Cariacus Marrotis Califormitus, 149.

Carterts Tirginianus. See Tirginia Deer.

Caribou, I $30,140,188,199,205,208,565$.

Caton, John Dean, I 33, 1 35, 149, 243.

Cervide, 'The North Americall, I 29.

Corius dlces. See Moose.

Comus Canadensis. See Elk.

Corrus Rangifer. See Caribou.

Cerans Tarandus, See Caribou.

Chumming, $+5^{2}, 4^{6}$.

1)eer, Family. See Cervidx.

1)eer-hunting on the Au Sable, 233 .

Dogs, 40, 60, 66, 70, 74, 82, 152, 204, 242 , $254,270,312,318,322,615,645,653$, $675,676,692,701,705,710,731,736$, $7+0$.
I)ogs, Some American Sporting, 615.

Ducks, 68, 561, 595, 620,707, 710, 714, $718,722,725,726,871$.

1) unraven, Earl of, l'aper by.

Moose-hunting in Canarla, r 82 .

litk, $130,14+, 2+3$.

Ellis IV. Hodgson, laper by.

Weight and 1,ength of Prook-'Trout, 605.

Endicott, Francis, Paper ly.

Striped Bass, $4+9$.

Eskimo, I 29, 314.

Fish-Hooks, $337,364,3^{8} 3,38_{4}, 406,506$, 523.

Fish-Hook, The Primitive, 337, 539.

Fly, Artificial, and Silk-worm Gut, 6o.4. See, also, Fish-hooks.

lox-hunting, 53, 79,616.

Gillinago media ITilsoni. See snipe.

Geese, Wild, 68, $719,722,724$.

Goat, Rocky Mountain, 300.

Gorlon, James, Papers by.

Bear-hunting in the South, $6_{5}$.

Wild Turkey-shooting, 760.

Cirayling, The Michigan, 493.

Cirimell, (seorge Bird, Papers by.

The North American Cervidie, I 29.

The Antelope, 303 .

'The American Woodcock, 685 .

Snipe-shooting, 695 .

(irouse, 595, 620, 639, 710 .

Gun, (See Shot-Gun, The.) 74, 84, I 15 , $261,275,480,68_{3}, 692,703,717,722$, 751,758 .

Halcyon in Canada, The, 541 .

Henshall, James A., Paper hy. Black Bass Fishing, 379.

Horns of Deer, 132, 140, 1 $11,1+4,147$, $149,156,158,210,211,244,259,260$, 304.327.

Indian Hunters, 50, 56, 58, 126, I 28, 159 , $160,165,19^{1}, 214,257,287,299,3^{13}$, +73 .

Killing Fish, 389,427 .

Ktaach, Camps and 'Tramps about, 8оr.

Labrax Lineatus. See Bass, Striped.

Laffan, IV. Mackay, Papers by. Deer-hunting on the Au Sable, 233. Canvas-back and Terrapin, 726 .

Lucas, Frederic A., Paper by. How to mount a Bird, 833 .

Macdonough, A. R.. Paper by. Sea-Trout Fishing, 507. 
Mayer, Alfred M., Papers by. The Prehistoric Hunter, 29. On the Invention of the Reel, $60_{3}$. Artificial Fily and Silk-worm Gut, 604. Weight and Length of Brook-Trout, 608 . Bob IVhite, $66_{3}$.

A Day with the Rails, $75^{\circ}$.

The Shot-ciun, 765.

The Blow-Gun, 881.

Melagris Galloparo. See Turkey.

Wicropterus. See Black Bass.

Mills, J. Harrison, Paper by.

Hunting the Mule-1)eer in Colorado, 257.

Minnesota, Field Sports in, 705.

Mirchell, William, Pajer by.

The Split-Pamboo Rod, 597.

Mississippi, 65

Moose, $130,136,154,182,208$.

Muir, John, Paper by.

The IVild Sheep of the Sierra, 280.

Mule-Deer, 130, 147, 257, 301.

Inskallonge, 591, 592 .

Musk-Ox Hunt, A, 312.

New England, 54, 79, I 54, 209, 351, +49, $45^{6}, 5+2,802,828$.

Norris, Thaddeus, Paper by.

The Michigan Grayling, 493.

Oribos Moschatus. See Musk-Ox.

Oits Montana. See Sheep, Wild.

Partridge. See Bob White.

Phillips, Barnet, Paper by.

The Primitive Fish-lrook, 337.

Philuhcla Minor. See Woodcock.

Phocent Communis. See Porpoise.

Pickerel, 531, 578, 591 .

Porpoise-shooting, 473 .

Portage, $183,530$.

Prairie Fowl. See Cirouse.

Prehistoric Hunter, The, 29, 339.

Prong-horn. See Antelope.

Ptarmigan. See Grouse.

Pyle, Howard, Paper by.

Among the Thousand Islands, 573.

Quail. See Bob White.

Quebec, 40 I, 417, 433, 539, 544, 546.

Rails, A Day with the, $75^{\circ}$.

Rangeley I akes, Trout-fishing in the, 351 .

Ranifer Gronlandicus. See Caribou.

Reel, On the Invention of the, $60_{3}$

Reindeer. See Caribou.

Robinson, Rowland E., Paper by.

Fox-Hunting in New England, 79.

Rock Fish. See Bass, Striped.

Rods, $3^{8} 3 \cdot 3^{85}, 406,410,506,523,597$.
Sage Hen. See Grouse.

Salmon, 368, 401, 569, 57 1.

Salmon Rivers, 401, 405, 511,513 .

Salmo Fontinalis. See Trout.

Salmo Salar. See Salmon.

Schwatka, Frederick, Paper by.

A Musk-Ox I1unt, 313 .

Sea Trout, 434,507 .

Seymour, Filward, Paper by.

Trout-fishing in the Rangeley Lakes, 351.

Sheep, IIild, 263,280 .

Shot. See Shot-Giun.

Shot-Gun, The, $76_{5}$.

Skittering, 394.

Snipe, 620, 695 .

Striped Bass, 449.

Taxidermy, 833 .

Terrapin, 745

Tetritonidie. See Grouse.

Thompson, Maurice, Papers by.

In the the Haunts of Bream and Bass (l'oem), $39^{6}$.

Bow-shooting, 854 .

Thousand Islands, Among the, 545, 573 .

Thymallus tricolor. See Grayling.

Tileston, William MI., Paper by.

Some American Sporting Dogs, 6 i 5.

Traps, 61, 644.

Trolling, 393, 594.

Trout, 18 I, 35 I, 45 I, 462, 494, 554, 559, $565,807,827$.

Trout, Weight and Length of, 605 .

Trout, A Fight with a, 827 .

Trout, Sea, 507.

Turkey-shooting, Wilk, $760,866$.

Ursus Americanus. See Bear.

Iulpes Fulius. See Fox.

Vircinia Deer, I 30, I 51, 209, 243, 259.

Wallace, Lew, Paper by.

A Buffalo Hunt in N. Mexico, Ios.

Ward, Charles C., Papers by.

The Black Bear, 49.

Moose-hunting, I 54 .

Caribou-hunting, 208.

Porpoise-shooting, 473 .

Warner, Charles Dudley, Papers by.

How 1 killed a Bear, 820 .

A Fight with a Trout, 827 .

Whitehead, Charles E., Paper by.

North American Grouse, 639.

Wilkinson, A. G., Paper by.

Salmon-fishing, $40 \mathbf{r}$.

IVoodcock, 620,685 .

Zimmerman, Charles A., Paper by. Field Sports in Minnesota, 705. 











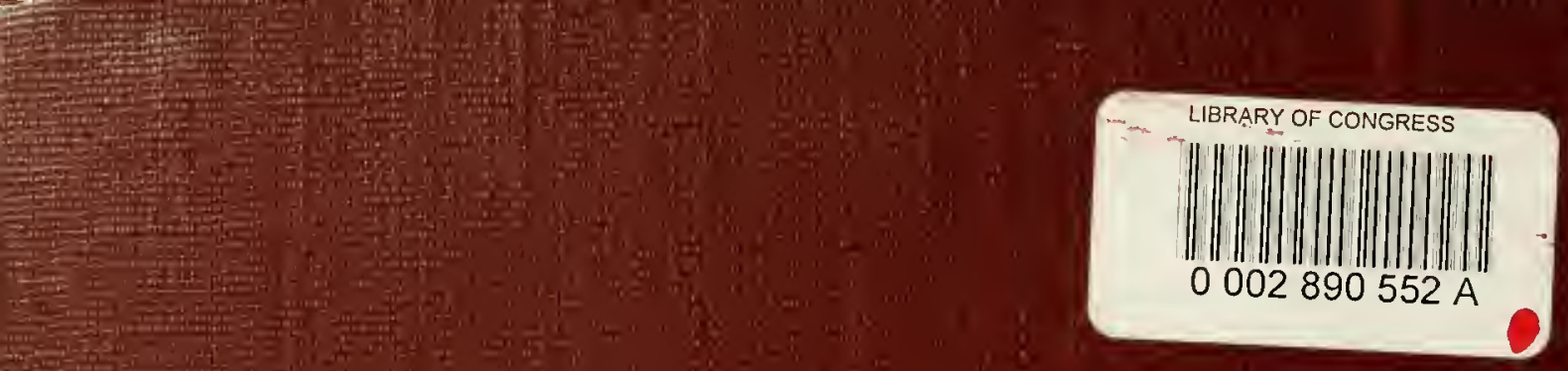

